\title{
ground \\ Potential Contaminant Pathways from Hydraulically Fractured Shale to Aquifers
}

by Tom Myers

\begin{abstract}
Hydraulic fracturing of deep shale beds to develop natural gas has caused concern regarding the potential for various forms of water pollution. Two potential pathways - advective transport through bulk media and preferential flow through fractures-could allow the transport of contaminants from the fractured shale to aquifers. There is substantial geologic evidence that natural vertical flow drives contaminants, mostly brine, to near the surface from deep evaporite sources. Interpretative modeling shows that advective transport could require up to tens of thousands of years to move contaminants to the surface, but also that fracking the shale could reduce that transport time to tens or hundreds of years. Conductive faults or fracture zones, as found throughout the Marcellus shale region, could reduce the travel time further. Injection of up to $15,000,000 \mathrm{~L}$ of fluid into the shale generates high pressure at the well, which decreases with distance from the well and with time after injection as the fluid advects through the shale. The advection displaces native fluids, mostly brine, and fractures the bulk media widening existing fractures. Simulated pressure returns to pre-injection levels in about $300 \mathrm{~d}$. The overall system requires from 3 to 6 years to reach a new equilibrium reflecting the significant changes caused by fracking the shale, which could allow advective transport to aquifers in less than 10 years. The rapid expansion of hydraulic fracturing requires that monitoring systems be employed to track the movement of contaminants and that gas wells have a reasonable offset from faults.
\end{abstract}

\section{Introduction}

The use of natural gas (NG) in the United States has been increasing, with $53 \%$ of new electricity generating capacity between 2007 and 2030 projected to be with NGfired plants (EIA 2009). Unconventional sources account for a significant proportion of the new NG available to the plants. A specific unconventional source has been deep shale-bed NG, including the Marcellus shale primarily in New York, Pennsylvania, Ohio, and West Virginia (Soeder 2010), which has seen over 4000 wells developed between 2009 and 2010 in Pennsylvania (Figure 1). Unconventional shale-bed NG differs from conventional

Hydrologic Consultant, 6320 Walnut Creek Road, Reno, NV 89523; (775) 530-1483; fax: (775) 530-1483; tom_ myers@charter.net

Received August 2011, accepted February 2012.

(C) 2012, The Author(s)

Ground Water (C) 2012, National Ground Water Association.

doi: 10.1111/j.1745-6584.2012.00933.x sources in that the host-formation permeability is so low that gas does not naturally flow in timeframes suitable for development. Hydraulic fracturing (fracking, the industry term for the operation; Kramer 2011) loosens the formation to release the gas and provide pathways for it to move to a well.

Fracking injects up to 17 million liters of fluid consisting of water and additives, including benzene at concentrations up to $560 \mathrm{ppm}$ (Jehn 2011), at pressures up to $69,000 \mathrm{kPa}$ (PADEP 2011) into low permeability shale to force open and connect the fractures. This is often done using horizontal drilling through the middle of the shale with wells more than a kilometer long. The amount of injected fluid that returns to the ground surface after fracking ranges from $9 \%$ to $34 \%$ of the injected fluid (Alleman 2011; NYDEC 2009), although some would be formation water.

Many agency reports and legal citations (DiGiulio et al. 2011; PADEP 2009; ODNR 2008) and peerreviewed articles (Osborn et al. 2011; White and Mathes 


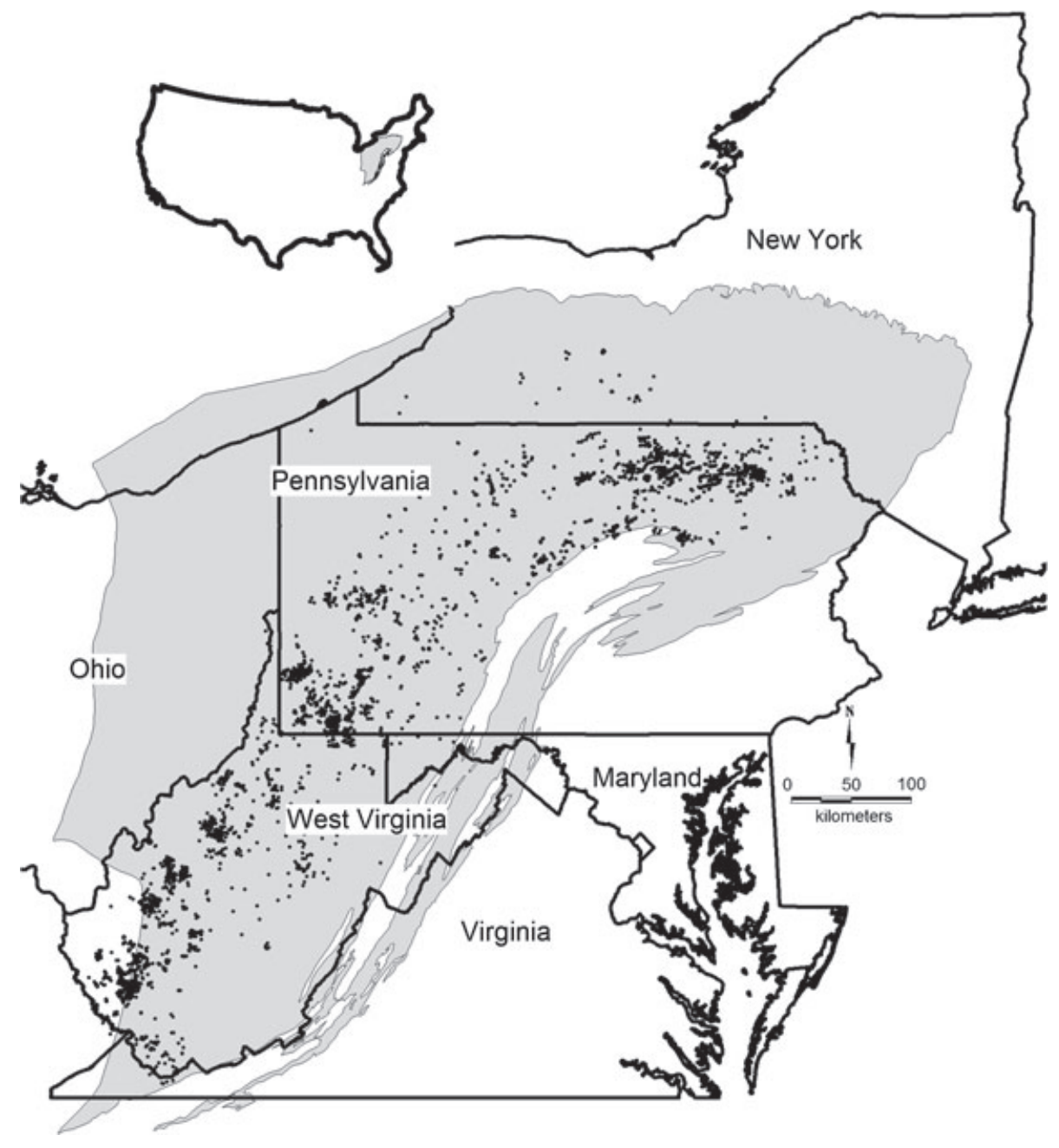

Figure 1. Location of Marcellus shale in the northeastern United States. Location of Marcellus wells (dots) drilled from July 2009 to June 2010 and total Marcellus shale wells in New York and West Virginia. There are 4064 wells shown in Pennsylvania, 48 wells in New York, and 1421 wells in West Virginia. Faulting in the area is documented by PBTGS (2001), Isachsen and McKendree (1977), and WVGES (2011, 2010a, 2010b).

2006) have found more gas in water wells near areas being developed for unconventional $\mathrm{NG}$, documenting the source can be difficult. One reason for the difficulty is the different sources; thermogenic gas is formed by compression and heat at depth and bacteriogenic gas is formed by bacteria breaking down organic material (Schoell 1980). The source can be distinguished based on both $\mathrm{C}$ and $\mathrm{H}$ isotopes and the ratio of methane to higher chain gases (Osborn and McIntosh 2010; Breen et al. 2007). Thermogenic gas can reach aquifers only by leaking from the well bore or by seeping vertically from the source. In either case, the gas must flow through potentially very thick sequences of sedimentary rock to reach the aquifers. Many studies which have found thermogenic gas in water wells found more gas near fracture zones (DiGiulio et al. 2011; Osborn et al. 2011; Breen et al. 2007), suggesting that fractures are pathways for gas transport.

A pathway for gas would also be a pathway for fluids and contaminants to advect from the fractured shale to the surface, although the transport time would be longer. Fracking fluid has been found in aquifers (DiGiulio et al.
2011; EPA 1987), although the exact source and pathways had not been determined. With the increasing development of unconventional NG sources, the risk to aquifers could be increasing. With so little data concerning the movement of contaminants along pathways from depth, either from wellbores or from deep formations, to aquifers, conceptual analyses are an alternative means to consider the risks.

The intent of this study is to characterize the risk factors associated with vertical contaminant transport from the shale to near-surface aquifers through natural pathways. I consider first the potential pathways for contaminant transport through bedrock and the necessary conditions for such transport to occur. Second, I estimate contaminant travel times through the potential pathways, with a bound on these estimates based on formation hydrologic parameters, using interpretative MODFLOW2000 (Harbaugh et al. 2000) computations. The modeling does not, and cannot, account for all of the complexities of the geology, which could either increase or decrease the travel times compared to those considered herein. The article also does not include improperly abandoned 
boreholes which could cause rapid transport in addition to natural pathways.

\section{Method of Analysis}

Using the Marcellus shale region of southern New York (Figure 1), I consider several potential scenarios of transport from shale, $1500 \mathrm{~m}$ below ground surface (bgs) to the surface, beginning with pre-development steady state conditions to establish a baseline and then scenarios considering transport after fracking has potentially caused contaminants to reach formations above the shale. To develop the conceptual models and MODFLOW-2000 simulations, it is necessary first to consider the hydrogeology of the shale and the details of hydraulic fracturing, including details of how fracking changes the shale hydrogeologic properties.

\section{Hydrogeology of Marcellus Shale}

Shale is a mudstone, a sedimentary rock consisting primarily of clay- and silt-sized particles. It forms through the deposition of fine particles in a low energy environment, such as a lake- or seabed. The Marcellus shale formed in very deep offshore conditions during Devonian time (Harper 1999) where only the finest particles had remained suspended. The depth to the Marcellus shale varies to as much as $3000 \mathrm{~m}$ in parts of Pennsylvania, and averages about $1500 \mathrm{~m}$ in southern New York (Soeder 2010). Between the shale and the ground surface are layers of sedimentary rock, including sandstone, siltstone, and shale (NYDEC 2009).

Marcellus shale has very low natural intrinsic permeability, on the order of $10^{-16}$ Darcies (Kwon et al. 2004a, 2004b; Neuzil 1986, 1994). Schulze-Makuch et al. (1999) described Devonian shale of the Appalachian Basin, of which the Marcellus is a major part, as containing "coaly organic material and appear either gray or black" and being "composed mainly of tiny quartz grains $<0.005 \mathrm{~mm}$ diameter with sheets of thin clay flakes." Median particle size is $0.0069 \pm 0.00141 \mathrm{~mm}$ with a grain size distribution of $<2 \%$ sand, $73 \%$ silt, and $25 \%$ clay. Primary pores are typically $5 \times 10^{-5} \mathrm{~mm}$ in diameter, matrix porosity is typically $1 \%$ to $4.5 \%$ and fracture porosity is typically 7.8\% to 9\% (Schulze-Makuch et al. 1999 and references therein).

Porous flow in unfractured shale is negligible due to the low bulk media permeability, but at larger scales fractures control and may allow significant flow. The Marcellus shale is fractured by faulting and contains synclines and anticlines that cause tension cracks (Engelder et al. 2009; Nickelsen 1986). It is sufficiently fractured in some places to support water wells just 6 to $10 \mathrm{~km}$ from where it is being developed for NG at $2000 \mathrm{~m} \mathrm{bgs}$ (Loyd and Carswell 1981). Conductivity scale dependency (SchulzeMakuch et al. 1999) may be described as follows:

$$
K=C v^{m}
$$

$K$ is hydraulic conductivity $(\mathrm{m} / \mathrm{s}), C$ is the intercept of a $\log$-log plot of observed $K$ to scale (the $K$ at a sample volume of $\left.1 \mathrm{~m}^{3}\right), v$ is sample volume $\left(\mathrm{m}^{3}\right)$, and $m$ is a scaling exponent determined with $\log$-log regression; for Devonian shale, $C$ equals $10^{-14.3}$, representing the intercept, and $m$ equals 1.08 (Schulze-Makuch et al. 1999). The very low intercept value is a statistical but not geologic outlier because it corresponds with very low permeability values and demonstrates the importance of fracture flow in the system (Schulze-Makuch et al. 1999). Most of their 89 samples were small because the deep shale is not easily tested at a field-scale and no groundwater models have been calibrated for flow through the Marcellus shale. Considering a 1-km square area with $30-\mathrm{m}$ thickness, the $\mathrm{Kh}$ would equal $5.96 \times 10^{-7} \mathrm{~m} / \mathrm{s}$ $(0.0515 \mathrm{~m} / \mathrm{d})$. This effective $K$ is low and the shale would be an aquitard, but a leaky one.

\section{Contaminant Pathways from Shale to the Surface}

Thermogenic NG found in near-surface water wells (Osborn et al. 2011; Breen et al. 2007) demonstrates the potential for vertical transport of gas from depth. Osborn et al. (2011) found systematic circumstantial evidence for higher methane concentrations in wells within $1 \mathrm{~km}$ of Marcellus shale gas wells. Potential pathways include advective transport through sedimentary rock, fractures and faults, and abandoned wells or open boreholes. Gas movement through fractures depends on fracture width (Etiope and Martinelli 2002) and is a primary concern for many projects, including carbon sequestration (Annunziatellis et al. 2008) and NG storage (Breen et al. 2007). Open boreholes and improperly sealed water and gas wells can be highly conductive pathways among aquifers (Lacombe et al. 1995; Silliman and Higgins 1990).

Pathways for gas suggest pathways for fluids and contaminants, if there is a gradient. Vertical hydraulic gradients of a up to a few percent, or about $30 \mathrm{~m}$ over $1500 \mathrm{~m}$, exist throughout the Marcellus shale region as may be seen in various geothermal developments in New York (TAL 1981). Brine more than a thousand meters above their evaporite source (Dresel and Rose 2010) is evidence of upward movement from depth to the surface. The Marcellus shale, with salinity as high as $350,000 \mathrm{mg} / \mathrm{L}$ (Soeder 2010; NYDEC 2009), may be a primary brine source. Relatively uniform brine concentrations over large areas (Williams et al. 1998) suggest widespread advective transport. The transition from brine to freshwater suggests a long-term equilibrium between the upward movement of brine and downward movement of freshwater. Faults, which occur throughout the Marcellus shale region (Figure 1) (Gold 1999), could provide pathways (Konikow 2011; Caine et al. 1996) for more concentrated advective and dispersive transport. Brine concentrating in faults or anticline zones reflects potential preferential pathways (Wunsch 2011; Dresel and Rose 2010; Williams 2010; Williams et al. 1998).

In addition to the natural gradient, buoyancy would provide an additional initial upward push. At TDS equal to $350,000 \mathrm{mg} / \mathrm{L}$, the density at $25{ }^{\circ} \mathrm{C}$ is approximately 
$1290 \mathrm{~kg} / \mathrm{m}^{3}$, or more than $29 \%$ higher than freshwater. The upward force would equal the difference in weight between the injected fluid and displaced brine. As an example, if 10,000,000 $\mathrm{L}$ does not return to the surface as flowback (Jehn 2011), the difference in mass between the volume of fracking fluid and displaced brine is approximately $3,000,000 \mathrm{~kg}$, which would cause an initial upward force. The density difference would dissipate as the salt concentration in the fracking fluid increases due to diffusion across the boundary between the fluid and the brine.

In just Pennsylvania, more than 180,000 wells had been drilled prior to any requirement for documenting their location (Davies 2011), therefore the location of many wells is unknown and some have probably been improperly abandoned. These pathways connect aquifers through otherwise continuous aquitards; overpressurization of lower aquifers due to injection near the well pathway could cause rapid transport to higher aquifers (Lacombe et al. 1995). In the short fracking period, the region that is overpressurized remains relatively close to the gas well (see modeling analysis below), therefore it should be possible for the driller to locate nearby abandoned wells that could be affected by fracking. This article does not consider the potential contamination although unlocated abandoned wells of all types must be considered a potential and possibly faster source for contamination due to fracking.

\section{Effect of Hydraulic Fracturing on Shale}

Fracking increases the permeability of the targeted shale to make extraction of NG economically efficient (Engelder et al. 2009; Arthur et al. 2008). Fracking creates fracture pathways with up to 9.2 million square meters of surface area in the shale accessible to a horizontal well (King 2010; King et al. 2008) and connects natural fractures (Engelder et al. 2009; King et al. 2008). No post-fracking studies that documented hydrologic properties were found while researching this article (there is a lack of information about pre- and postfracking properties; Schweitzer and Bilgesu 2009), but it is reasonable to assume the $K$ increases significantly because of the newly created and widened fractures.

Fully developed shale typically has wells spaced at about 300-m intervals (Edwards and Weisset 2011; Soeder 2010). Up to eight wells may be drilled from a single well pad (NYDEC 2009; Arthur et al. 2008), although not in a perfect spoke pattern. Reducing by half the effective spacing did not enhance overall productivity (Edwards and Weisset 2011) which indicates that 300-m spacing creates sufficient overlap among fractured zones to assure adequate gas drainage. The properties controlling groundwater flow would therefore be affected over a large area, not just at a single horizontal well or set of wells emanating from a single well pad.

Fracking is not intended to affect surrounding formations, but shale properties vary over short ranges (King 2010; Boyer et al. 2006) and out-of-formation fracking is not uncommon. In the Marcellus shale, out-of-formation fracks have been documented $500 \mathrm{~m}$ above the top of the shale (Fisher and Warpinski 2011). These fractures could contact higher conductivity sandstone, natural fractures, or unplugged abandoned wells above the target shale. Also, fluids could reach surrounding formations just because of the volume injected into the shale, which must displace natural fluid, such as the existing brine in the shale.

\section{Analysis of Potential Transport along Pathways}

Fracking could cause contaminants to reach overlying formations either by fracking out of formation, connecting fractures in the shale to overlying bedrock, or by simple displacement of fluids from the shale into the overburden. Advective transport, considered as simple particle velocity, will manifest if there is a significant vertical component to the regional hydraulic gradient.

Numerical modeling, completed with the MODF LOW-2000 code (Harbaugh et al. 2000), provides flexibility to consider potential conceptual flow scenarios, but should be considered interpretative (Hill and Tiedeman 2007). The simulation considers the rate of vertical transport of contaminants to near the surface for the different conceptual models, based on an expected, simplified, realistic range of hydrogeologic aquifer parameters.

MODFLOW-2000 is a versatile numerical modeling code, but there is insufficient data regarding the geology and water chemistry between aquifers and the deep shale, such as salinity profiles or data concerning mixing of the brine with fracking fluid, to best use its capabilities. As more data becomes available, it may be useful to consider simulating the added upward force caused by the brine by using the SEAWAT-2000 module (Langevin et al. 2003).

Vertical flow would be perpendicular to the general tendency for sedimentary layers to have higher horizontal than vertical conductivity. Fractures and improperly abandoned wells would provide pathways for much quicker vertical transport than general advective transport. This article considers the fractures as vertical columns with model cells having much higher conductivity than the surrounding bedrock. The cell discretization is fine, so the simulated width of the fracture zones is realistic. Dual porosity modeling (Shoemaker et al. 2008) is not justified because turbulent vertical flow through the fractures is unlikely, except possibly during the actual fracking that causes out-of-formation fractures, a scenario not simulated here. MODFLOW-2000 has a module, MNW (Halford and Hanson 2002), that could simulate rapid transport through open bore holes. MNW should be used in situations where open boreholes or improperly abandoned wells are known or postulated to exist.

The thickness of the formations and fault would affect the simulation, but much less than the several-order-ofmagnitude variation possible in the shale properties. The overburden and shale thickness were set equal to 1500 and $30 \mathrm{~m}$, respectively, similar to that observed in southern New York. The estimated travel times are proportional for thicker or thinner sections. The overburden could be predominantly sandstone, with sections of shale, mudstone, and limestone. The vertical fault is assumed 
to be 6-m thick. The fault is an attempt at considering fracture flow, but the simulation treats the 6-m wide fault zone as homogeneous, which could underestimate the real transport rate in fracture-controlled systems which could be highly affected by dispersion. The simulation also ignores diffusion between the fracture and the adjacent shale matrix (Konikow 2011).

There are five conceptual models of flow and transport of natural and post-fracking transport from the level of the Marcellus shale to the near-surface to consider herein:

1. The natural upward advective flow due to a head drop of $30 \mathrm{~m}$ from below the Marcellus shale to the ground surface, considering the variability in both shale and overburden $K$. This is a steady state solution for upward advection through a $30-\mathrm{m}$ thick shale zone and 1500-m overburden. Table 1 shows the chosen $K$ values for shale and sandstone.

2. Same as number 1, but with a vertical fracture connecting the shale with the surface, created using a high-conductivity zone in a row of cells extending through all from above the shale to the surface. This emulates the conceptual model postulated for flow into the alluvial aquifers near stream channels, the location of which may be controlled by faults (Williams et al. 1998). The fault $K$ varies from 10 to 1000 times the surrounding bulk sandstone $K\left(K_{\mathrm{ss}}\right)$.

3. This scenario tests the effect of extensive fracturing in the Marcellus shale by increasing the shale $K$ $\left(K_{\mathrm{sh}}\right)$ from 10 to 1000 times its native value over an extensive area. This transient solution starts with initial conditions being a steady state solution from scenario 1 . The $K_{\mathrm{sh}}$ increases from 10 to 1000 times at the beginning of the simulation, to represent the relatively instantaneous change on the regional shale hydrogeology imposed by the fracking. The simulation estimates both the changes in flux and the time for the system to reach equilibrium.

4. As number 3, considering the effect of the same changes in shale properties but with a fault as in number 2 .

5. This scenario simulates the actual injection of 13 to 17 million liters of fluid in $5 \mathrm{~d}$ into fractured shale from a horizontal well with and without a fault.

\section{Model Setup}

The model domain was 150 rows and columns spaced at $3 \mathrm{~m}$ to form a $450-\mathrm{m}$ square (Figure 2) with 50 layers bounded with no flow boundaries. The 30-m thick shale was divided into 10 equal thickness layers from layer 40 to 49 . The overburden layer thickness varied from $3 \mathrm{~m}$ just above the shale to layer $34,6 \mathrm{~m}$ from layer 33 to 29 , $9 \mathrm{~m}$ from layer 28 to $26,18 \mathrm{~m}$ in layer $25,30 \mathrm{~m}$ from layer 24 to $17,60 \mathrm{~m}$ from layer 16 to $6,90 \mathrm{~m}$ from layer 5 to 3 , and $100 \mathrm{~m}$ in layers 2 and 1 . A 6-m wide column from layer 39 to the surface is added for some scenarios in the center two rows to simulate a higher $K$ fault.
Table 1

Sandstone (ss) and Shale (sh) Conductivity (K) $(\mathrm{m} / \mathrm{d})$ and the Steady State Flux $\left(\mathrm{m}^{3} / \mathrm{d}\right)$ for Model 1 Scenarios

\begin{tabular}{|c|c|c|}
\hline Flux & $\boldsymbol{K}_{\mathrm{ss}}$ & $\boldsymbol{K}_{\mathrm{sh}}$ \\
\hline 1.7 & 0.1 & 0.00001 \\
\hline 1.8 & 0.5 & 0.00001 \\
\hline 1.9 & 1 & 0.00001 \\
\hline 1.9 & 5 & 0.00001 \\
\hline 2.0 & 10 & 0.00001 \\
\hline 2.0 & 50 & 0.00001 \\
\hline 2.0 & 100 & 0.00001 \\
\hline 1.7 & 0.1 & 0.00001 \\
\hline 9.5 & 0.1 & 0.00005 \\
\hline 19.0 & 0.1 & 0.0001 \\
\hline 81.2 & 0.1 & 0.0005 \\
\hline 135.9 & 0.1 & 0.001 \\
\hline 291.5 & 0.1 & 0.005 \\
\hline 340.9 & 0.1 & 0.01 \\
\hline 394.3 & 0.1 & 0.05 \\
\hline 401.8 & 0.1 & 0.1 \\
\hline 409.2 & 0.1 & 0.5 \\
\hline 40.7 & 0.001 & 0.1 \\
\hline 186.0 & 0.005 & 0.1 \\
\hline 339.1 & 0.01 & 0.1 \\
\hline 988.3 & 0.05 & 0.1 \\
\hline 1297.3 & 0.1 & 0.1 \\
\hline 1748.0 & 0.5 & 0.1 \\
\hline 1826.1 & 1 & 0.1 \\
\hline 1902.8 & 5 & 0.1 \\
\hline 1915.4 & 10 & 0.1 \\
\hline 338.3 & 0.1 & 0.01 \\
\hline 984.1 & 0.5 & 0.01 \\
\hline 1292.5 & 1 & 0.01 \\
\hline 1731.5 & 5 & 0.01 \\
\hline 1816.0 & 10 & 0.01 \\
\hline 17.4 & 1 & 0.0001 \\
\hline 86.3 & 1 & 0.0005 \\
\hline 176.7 & 1 & 0.001 \\
\hline 775.1 & 1 & 0.005 \\
\hline 1292.5 & 1 & 0.01 \\
\hline 2746.8 & 1 & 0.05 \\
\hline 3183.2 & 1 & 0.1 \\
\hline 3650.5 & 1 & 0.5 \\
\hline 3719.9 & 1 & 1 \\
\hline
\end{tabular}

The model simulated vertical flow between constant head boundaries in layers 50 and 1, as a source and sink, so that the overburden and shale properties control the flow. The head in layers 50 and 1 was 1580 and $1550 \mathrm{~m}$, respectively, to create a gradient of 0.019 over the profile. Varying the gradient would have much less effect on transport than changing $K$ over several orders of magnitude and was therefore not done.

Scenario 5 simulates injection using a WELL boundary in layer 44, essentially the middle of the shale, from columns 25 to 125 (Figure 2). It injects 15 million liters over one 5 -d stress period, or $3030 \mathrm{~m}^{3} / \mathrm{d}$ into 101 model cells at the WELL. The modeled $K_{\text {sh }}$ was changed to its 


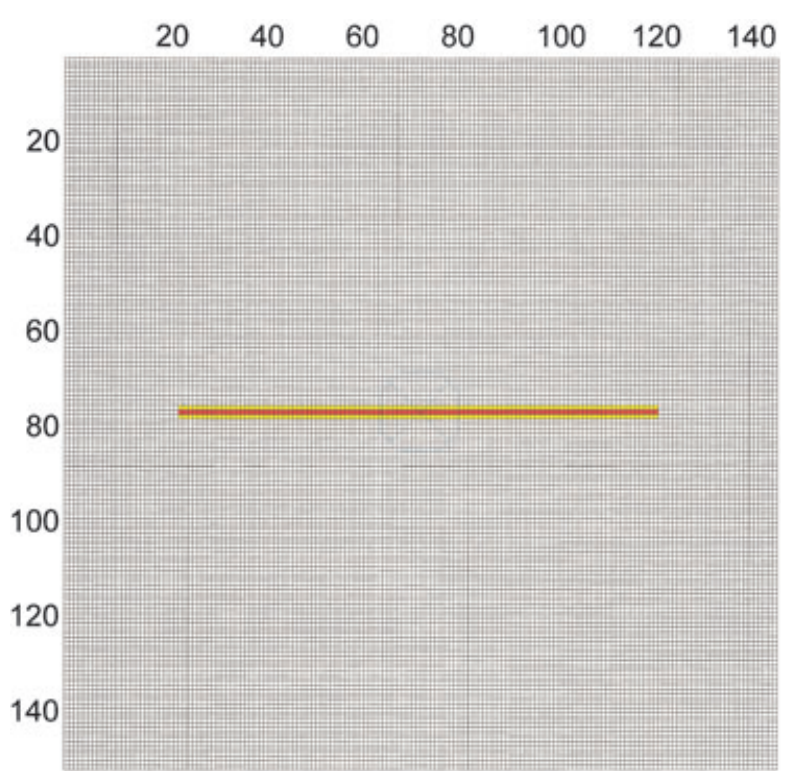

Figure 2. Model grid through layer 44 showing the horizontal injection WELL (red) and DRAIN cells (yellow) used to simulate flowback. There is only one monitoring well because the off-center well is not used in layer 44.

assumed fracked value at the beginning of the simulation. Simulating high rate injection generates very high heads in the model domain, similar to that found simulating oil discharging from the well in the Deepwater Horizon crisis (Hsieh 2011) and water quality changes caused by underground coal gasification (Contractor and El-Didy 1989). DRAIN boundaries on both sides of the WELL simulated return flow for $60 \mathrm{~d}$ after the completion of (Figure 2), after which the DRAIN was deactivated. The $60 \mathrm{~d}$ were broken into four stress periods, 1, 3, 6, and $50 \mathrm{~d}$ long, to simulate the changing heads and flow rates. DRAIN conductance was calibrated so that $20 \%$ of the injected volume returned within $60 \mathrm{~d}$ to emulate standard industry practice (Alleman 2011; NYDEC 2009). Recovery, continuing relaxation of the head at the well and the adjustment of the head distribution around the domain, occurred during the sixth period which lasted for $36,500 \mathrm{~d}$.

There is no literature guidance to a preferred value for fractured shale storage coefficient, so I estimated $S$ with a sensitivity analysis using scenario 3 . With fractured $K_{\text {sh }}$ equal to $0.001 \mathrm{~m} / \mathrm{d}$, two orders of magnitude higher than the in situ value, the time to equilibrium resulting from simulation tests of three fractured shale storage coefficients, $10^{-3}, 10^{-5}$, and $10^{-7} / \mathrm{m}$, varied twofold (Figure 3). The slowest time to equilibrium was for $S=$ $10^{-3} / \mathrm{m}$ (Figure 3), which was chosen for the transient simulations because more water would be stored in the shale and flow above the shale would change the least.

\section{Results}

\section{Scenario 1}

Table 1 shows the conductivity and flux values for various scenarios. The steady state travel time

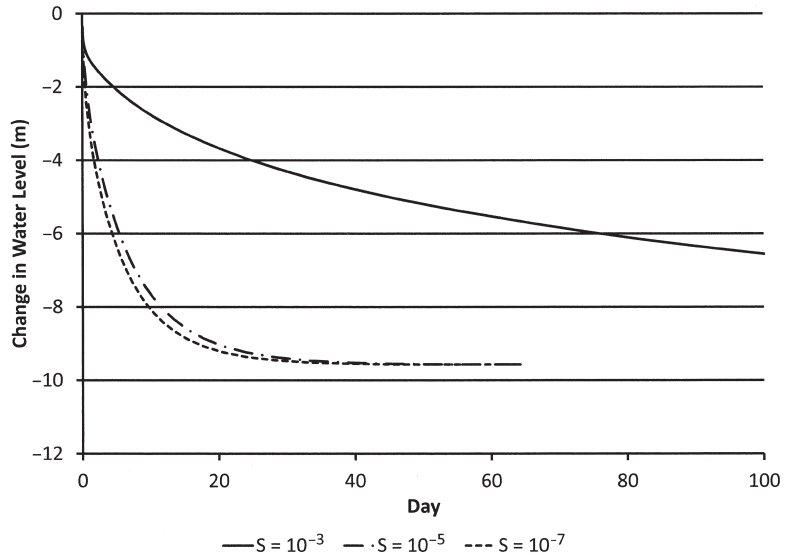

Figure 3. Sensitivity of the modeled head response to the storage coefficient used in the fractured shale for model layer 39 just above the shale.

for a particle through $1500 \mathrm{~m}$ of sandstone and shale equilibrates with one of the formations controlling the advection (Figure 4). For example, when the $K_{\text {sh }}$ equals $1 \times 10^{-5} \mathrm{~m} / \mathrm{d}$, transport time does not vary with $K_{\mathrm{ss}}$. For $K_{\text {ss }}$ at $0.1 \mathrm{~m} / \mathrm{d}$, transport time for varying $K_{\text {sh }}$ ranges from 40,000 to 160 years. The lower travel time estimate is for $K_{\text {sh }}$ similar to that found by Schulze-Makuch et al. (1999). The shortest simulated transport time of about 20 years results from both the sandstone and shale $K$ equaling $1 \mathrm{~m} / \mathrm{d}$. Other sensitivity scenarios emphasize the control exhibited by one of the media (Figure 4). If $K_{\mathrm{sh}}$ is low, travel time is very long and not sensitive to $K_{\mathrm{ss}}$.

\section{Scenario 2}

The addition of a fault with $K$ one to two orders of magnitude more conductive than the surrounding sandstone increased the particle travel rate by about 10 times (compare Figure 5 with Figure 4). The fault $K$ controlled the transport rate for $K_{\mathrm{sh}}$ less than $0.01 \mathrm{~m} / \mathrm{d}$. A highly

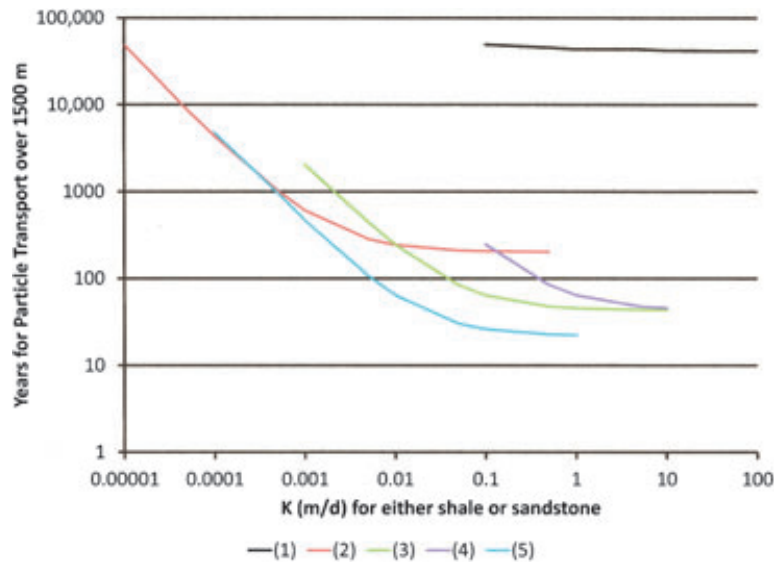

Figure 4. Sensitivity of particle transport time over $1500 \mathrm{~m}$ for varying shale and sandstone vertical $K$. Effective porosity equals 0.1 . (1) - varying $K_{\mathrm{ss}}, K_{\mathrm{sh}}=$ $10^{-5} \mathrm{~m} / \mathrm{d}$; (2) - varying $K_{\mathrm{ss}}, K_{\mathrm{sh}}=0.1 \mathrm{~m} / \mathrm{d}$; (3)-varying $K_{\mathrm{ss}}, K_{\mathrm{sh}}=0.1 \mathrm{~m} / \mathrm{d}$; (4)-varying $K_{\mathrm{ss}}, K_{\mathrm{sh}}=0.01 \mathrm{~m} / \mathrm{d}$; and (5)—varying $K_{\mathrm{ss}}, K_{\mathrm{sh}}=1.0 \mathrm{~m} / \mathrm{d}$. 


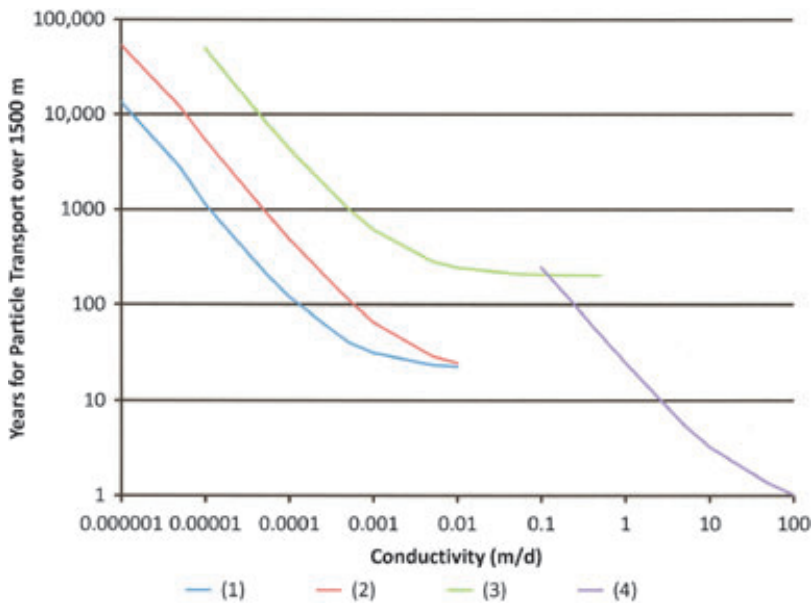

Figure 5. Variability of transport through various scenarios of changing the $K$ for the fault or shale. Effective porosity equals 0.1. (1)-varying $K_{\mathrm{sh}}, K_{\mathrm{sh}}=0.01 \mathrm{~m} / \mathrm{d}$; (2) - varying $K_{\mathrm{sh}}, K_{\mathrm{sh}}=0.1 \mathrm{~m} / \mathrm{d}$; (3) - no fault; (4)-varying $K$ fault, $K_{\mathrm{sh}}=0.1 \mathrm{~m} / \mathrm{d}, K_{\mathrm{sh}}=0.01 \mathrm{~m} / \mathrm{d}$. Unless specified, the vertical fault has $K=1 \mathrm{~m} / \mathrm{d}$ for variable $K_{\mathrm{sh}}$.

conductive fault could transport fluids to the surface in as little as a year for $K_{\text {sh }}$ equal to $0.01 \mathrm{~m} / \mathrm{d}$ (Figure 5). However, a fault did not significantly change the overall model flux, so with fault values are not shown in Table 1.

\section{Scenarios 3 and 4}

Scenarios 3 and 4 estimate the time to establish a new equilibrium once the $K_{\mathrm{sh}}$ changes, due to fracking, between values specified in scenarios 1 and 2. Equilibrium times vary by model layer as the changes propagate through the domain, and flux rate for the simulated changes imposed on natural background conditions. The fracking-induced changes cause a significant decrease in the head drop across the shale and the time for adjustment of the potentiometric surface to a new steady state depends on the new shale properties.

The time to equilibrium for one scenario 3 simulation, $K_{\text {sh }}$ changing from $10^{-5}$ to $10^{-2} \mathrm{~m} / \mathrm{d}$ with $K_{\text {ss }}$ equal to $0.1 \mathrm{~m} / \mathrm{d}$, varied from 5.5 to 6.5 years, depending on model layer (Figure 6). Near the shale (layers 39 and 40), the potentiometric surface increased from 23 to $25 \mathrm{~m}$ reflecting the decreased head drop across the shale. One hundred meters higher, in layer 20, the potentiometric surface increased about $20 \mathrm{~m}$. Simulation of scenario 4 , with a fault with $K=1 \mathrm{~m} / \mathrm{d}$, decreased the time to equilibrium to from 3 to 6 years within the fault zone, depending on model layer (Figure 6). Highly fractured sandstone would allow more vertical transport, but advective flow would also increase so that the base $K_{\text {ss }}$ would control the overall rate.

The flux across the upper boundary changed within 100 years for scenario 3 from 1.7 to $345 \mathrm{~m}^{3} / \mathrm{d}$, or 0.000008 to $0.0017 \mathrm{~m} / \mathrm{d}$, reflecting control by $K_{\mathrm{ss}}$. There is little difference in the equilibrium fluxes between scenario 3 and 4 indicating that the fault primarily affects the time to equilibrium rather than the long-term flow rate.

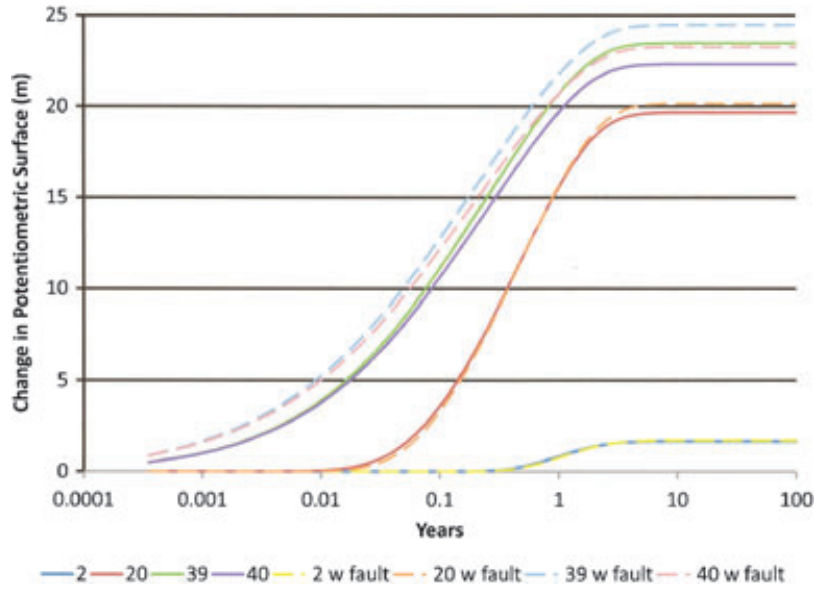

Figure 6. Monitoring well water levels for specified model layers due to fracking of the shale; monitor well in the center of the domain, including in the fault, $K$ of the shale changes from 0.00001 to $0.01 \mathrm{~m} / \mathrm{d}$ at the beginning of the simulation.

\section{Scenario 5: Simulation of Injection}

The injection scenarios simulate 15 million liters entering the domain at the horizontal well and the subsequent potentiometric surface and flux changes throughout. The highest potentiometric surface increases (highest injection pressure) occurred at the end of injection (Figure 7), with a $2400 \mathrm{~m}$ increase at the horizontal well. The simulated peak pressure both decreased and occurred longer after the cessation of injection with distance from the well (Figures 7 and 8). The pressure at the well returned to within $4 \mathrm{~m}$ of pre-injection levels in about $300 \mathrm{~d}$ (Figure 7). After injection ceases, the peak pressure simulated further from the well occurs longer from the time of cessation, which indicates there is a pressure divide beyond which fluid continues to flow away from the well bore while within which the fluid flows toward the well bore. The simulated head returned to near pre-injection levels slower with distance from the well (Figure 7), with levels at the edge of the shale (layer 40) and in the near-shale sandstone (layer 39) requiring several hundred days to recover. After recovering from injection, the potentiometric surface above the shale increased in response to flux through the shale adjusting to the change in shale properties (Figure 8), as simulated in scenario 3. The scenario required about $6000 \mathrm{~d}$ (16 years) for the potentiometric surface to stabilize at new, higher, levels (Figure 8). Removing the fault from the simulation had little effect on the time to stabilization, and is not shown.

Prior to injection, the steady flux for in situ shale $\left(K_{\mathrm{sh}}=10^{-5} \mathrm{~m} / \mathrm{d}\right.$ ) was generally less than $2 \mathrm{~m}^{3} / \mathrm{d}$ and varied little with $K_{\mathrm{ss}}$ (Figure 4). Once the shale was fractured, the sandstone controlled the flux which ranges from 38 to $135 \mathrm{~m}^{3} / \mathrm{d}$ as $K_{\mathrm{ss}}$ ranges from 0.01 to $0.1 \mathrm{~m} / \mathrm{d}$ (Figure 9), resulting in particle travel times of 2390 and 616 years, respectively. More conductive shale would allow faster transport (Figure 4). Adding a fault to the scenario with $K_{\mathrm{ss}}$ equal to $0.01 \mathrm{~m} / \mathrm{d}$ increased the flux to approximately $63 \mathrm{~m}^{3} / \mathrm{d}$ and decreased the particle travel 


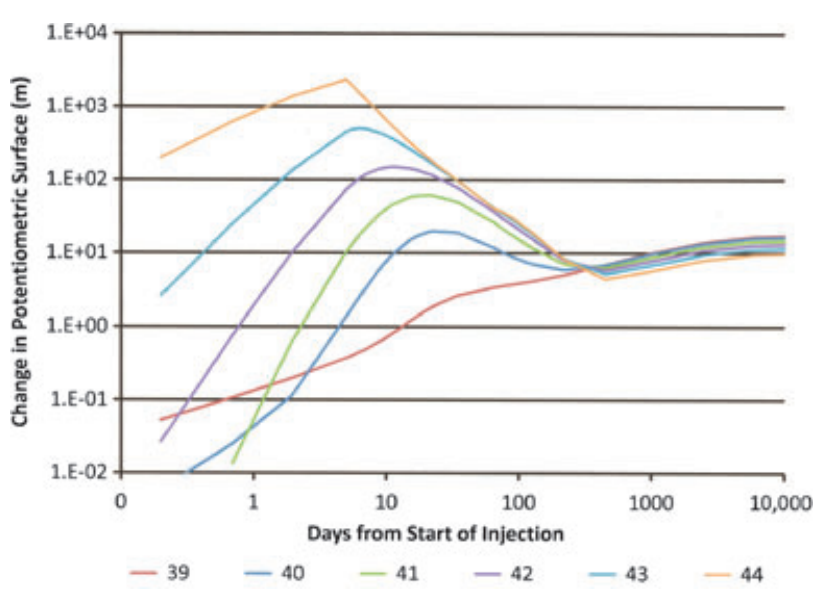

Figure 7. Simulated potentiometric surface changes by layer for specified injection and media properties. The monitoring point is in the center of the domain. Fault is included. $K_{\mathrm{sh}}=$ $0.01 \mathrm{~m} / \mathrm{d}, K_{\mathrm{sh}}=0.001 \mathrm{~m} / \mathrm{d} . S$ (fractured shale) $=0.001 / \mathrm{m}$, $S(\mathrm{ss})=0.0001 / \mathrm{m}$.

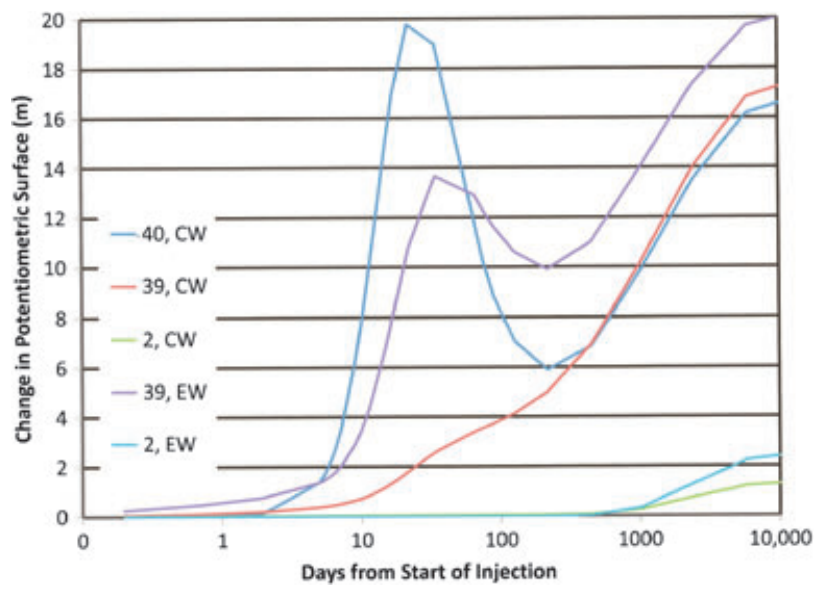

Figure 8. Simulated potentiometric surface changes for layers within the shale and sandstone. $\mathrm{CW}$ is center monitoring well and EW is east monitoring well, about $120 \mathrm{~m}$ from the centerline. Fault is included. The line for layer 2, CW plots beneath the line for layer 2, EW. $K_{\mathrm{ss}}=$ $0.01 \mathrm{~m} / \mathrm{d}, K_{\mathrm{sh}}=0.001 \mathrm{~m} / \mathrm{d}, S$ (fractured shale) $=0.001 / \mathrm{m}$, $S(\mathrm{ss})=0.0001 / \mathrm{m}$.

time to 31 years. Approximately, $36 \mathrm{~m}^{3} / \mathrm{d}$ flowed through the fault (Figure 9). The fault properties control the particle travel time, especially if the fault $K$ is two or more orders of magnitude higher than the sandstone.

Simulated flowback varied little with $K_{\text {sh }}$ because it had been calibrated to be $20 \%$ of the injection volume. A lower storage coefficient or higher $K$ would allow the injected fluid to move further from the well, which would lead to less flowback.

Vertical flux through the overall section with a fault varies significantly with time, due to the adjustments in potentiometric surface. One day after injection, vertical flux exceeds significantly the pre-injection flux about $200 \mathrm{~m}$ above the shale (Figure 10). After $600 \mathrm{~d}$, the vertical flux near the shale is about $68 \mathrm{~m}^{3} / \mathrm{d}$ and in

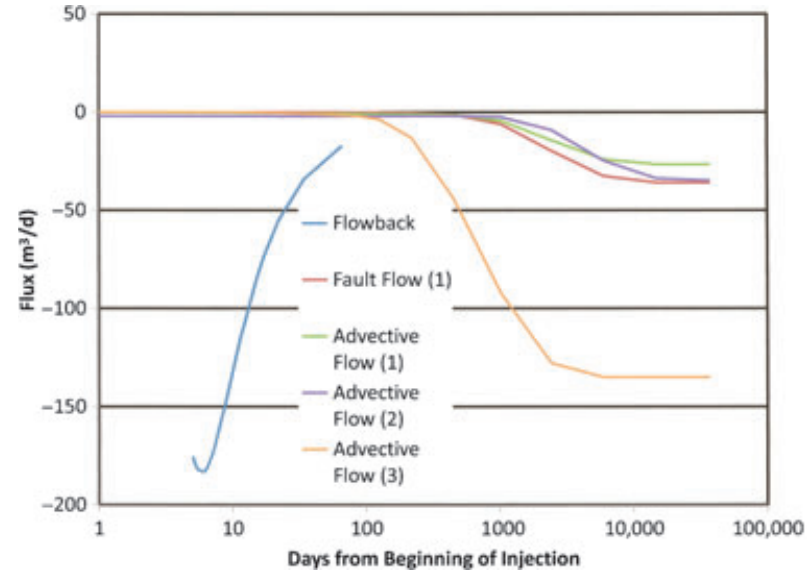

Figure 9. Comparison of flux for three scenarios. Flowback is the same for all scenarios. (1): Kss $=0.01 \mathrm{~m} / \mathrm{d}$, Ksh $=$ $0.001 \mathrm{~m} / \mathrm{d}$, Fault $\mathrm{K}=1 \mathrm{~m} / \mathrm{d}$; (2): Kss $=0.01 \mathrm{~m} / \mathrm{d}$, Ksh $=$ $0.001 \mathrm{~m} / \mathrm{d}$, no fault; (3) Kss $=0.1 \mathrm{~m} / \mathrm{d}, \mathrm{Ksh}=0.001 \mathrm{~m} / \mathrm{d}$, no fault.

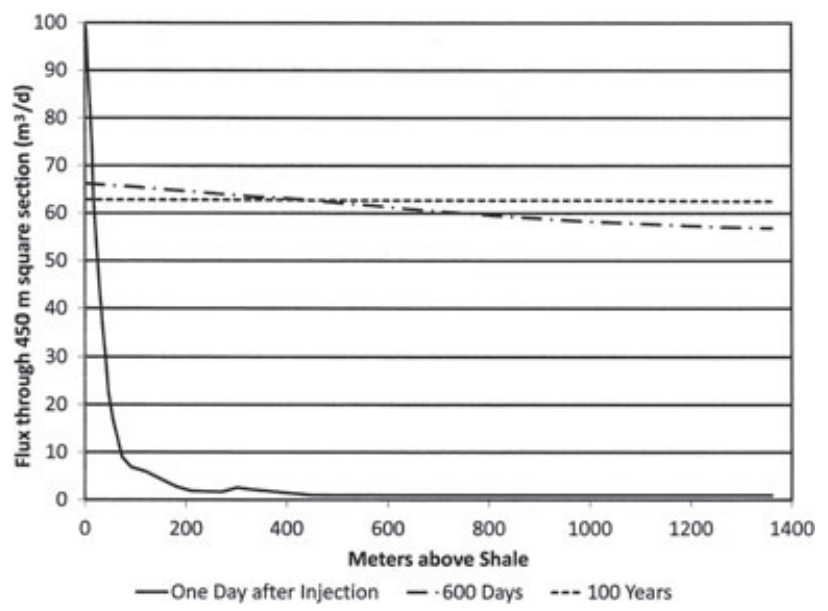

Figure 10. Upward flux across the domain section as a function of distance above the top of the shale layer. Cross section is $202,500 \mathrm{~m}^{2}$.

layer 2 about $58 \mathrm{~m}^{3} / \mathrm{d}$; it approaches steady state through all sections after 100 years with flux equaling about $62.6 \mathrm{~m}^{3} / \mathrm{d}$. The 100 -year flux is $61.5 \mathrm{~m}^{3} / \mathrm{d}$ higher than the pre-injection flux because of the changed shale properties.

\section{Discussion}

The interpretative modeling completed herein has revealed several facts about fracking. First, MODFLOW can be coded to adequately simulate fracking. Simulated pressures are high, but velocities even near the well do not violate the assumptions for Darcian flow. Second, injection for $5 \mathrm{~d}$ causes extremely high pressure within the shale. The pressure decreases with distance from the well. The time to maximum pressure away from the well lags the time of maximum pressure at the well. The pressure drops back to close to its pre-injection level 
at the well within $300 \mathrm{~d}$, indicating the injection affects the flow for significantly longer periods than just during the fracking operation. Although the times may vary based on media properties, the difference would be at most a month or so, based on the various combinations of properties simulated. The system transitions within 6 years due to changes in the shale properties. The equilibrium transport rate would transition from a system requiring thousands of years to one requiring less than 100 years within less than 10 years.

Third, most of the injected water in the simulation flows vertically rather than horizontally through the shale. This reflects the higher $K_{\mathrm{ss}} 20 \mathrm{~m}$ above the well and the no flow boundary within $225 \mathrm{~m}$ laterally from the well, which emulates in situ shale properties that would manifest at some distance in the shale.

Fourth, the interpretative model accurately and realistically simulates long-term steady state flow conditions, with an upward flow that would advect whatever conservative constituents exist at depth. Using low, unfractured $K$ values, the transport simulation may correspond with advective transport over geologic time although there are conditions for which it would occur much more quickly (Figure 4). If the $K_{\mathrm{sh}}$ is $0.01 \mathrm{~m} / \mathrm{d}$, transport could occur on the order of a few hundreds of years. Faults through the overburden could speed the transport time considerably. Reasonable scenarios presented herein suggest the travel time could be decreased further by an order of magnitude.

Fifth, fracking increases the $K_{\mathrm{sh}}$ by several orders of magnitude. Out-of-formation fracking (Fisher and Warpinski 2011) would increase the $K$ in the overburden, thereby changing the regional hydrogeology. Vertical flow could change over broad areas if the expected density of wells in the Marcellus shale region (NYDEC 2009) actually occurs.

Sixth, if newly fractured shale or out-of-formation fractures come close to contacting fault fracture zones, contaminants could reach surface areas in tens of years, or less. Faults can decrease the simulated particle travel time several orders of magnitude.

\section{Conclusion}

Fracking can release fluids and contaminants from the shale either by changing the shale and overburden hydrogeology or simply by the injected fluid forcing other fluids out of the shale. The complexities of contaminant transport from hydraulically fractured shale to nearsurface aquifers render estimates uncertain, but a range of interpretative simulations suggest that transport times could be decreased from geologic time scales to as few as tens of years. Preferential flow through natural fractures fracking-induced fractures could further decrease the travel times to as little as just a few years.

There is no data to verify either the pre- or post-fracking properties of the shale. The evidence for potential vertical contaminant flow is strong, but there are also almost no monitoring systems that would detect contaminant transport as considered herein. Several improvements could be made.

- Prior to hydraulic fracturing operations, the subsurface should be mapped for the presence of faults and measurement of their properties.

- A reasonable setback distance from the fracking to the faults should be established. The setback distance should be based on a reasonable risk analysis of fracking increasing the pressures within the fault.

- The properties of the shale should be verified, postfracking, to assess how the hydrogeology will change.

- A system of deep and shallow monitoring wells and piezometers should be established in areas expecting significant development, before that development begins (Williams 2010).

\section{Acknowledgments}

This research was funded by the Park Foundation and Catskill Mountainkeepers. The author thanks Anthony Ingraffea, Paul Rubin, Evan Hansen, two anonymous reviews, and the journal editor for helpful comments on this article.

\section{References}

Alleman, D. 2011. Water used for hydraulic fracturing: Amounts, sources, reuse, and disposal. In Hydraulic Fracturing of the Marcellus Shale, National Groundwater Association short course. Baltimore, Maryland.

Annunziatellis, A., S.E. Beaubien, S. Bigi, G. Ciotoli, M. Coltella, and S. Lombardi. 2008. Gas migration along fault systems and through the vadose zone in the Latera calder (central Italy): Implications for $\mathrm{CO}_{2}$ geological storage. International Journal of Greenhouse Gas Control 2; 353-372. DOI: 10.1016/j.ijggc.2008.02.003.

Arthur, J.D., B. Bohm, and M. Layne. 2008. Hydraulic Fracturing Consideration for Natural Gas Wells of the Marcellus Shale. Cincinnati, Ohio: Ground Water Protection Council.

Boyer, C., J. Kieschnick, R. Suarez-Rivera, R.E. Lewis, and G. Waters. 2006. Producing gas from its source. Oilfields Review 18, no. 3: 36-49.

Breen, K.J., K. Revesz, F.J. Baldassare, and S.D. McAuley. 2007. Natural gases in ground water near Tioga Junction, Tioga County, north-central Pennsylvania-Occurrence and use of isotopes to determine origins. Scientific Investigations Report Series 2007-5085. Reston, Virginia: U.S Geological Survey.

Caine, J.S., J.P. Evans, and C.B. Forster. 1996. Fault zone architecture and permeability structure. Geology 24, no. 11: $1025-1028$

Contractor, D.N., and S.M.A. El-Didy. 1989. Field application of a finite-element water-quality model to a coal seam with UCG burns. Journal of Hydrology 109: 57-64.

Davies, R.J. 2011. Methane contamination of drinking water caused by hydraulic fracturing remains unproven. Proceedings of the National Academy of Sciences USA 108: E871.

DiGiulio, D.C., R.T. Wilkin, C. Miller, and G. Oberly. 2011. DRAFT: Investigation of Ground Water Contamination near Pavillion, Wyoming. Ada, Oklahoma: U.S. Environmental Protection Agency, Office of Research and Development.

Dresel, P.E., and A.W. Rose. 2010. Chemistry and origin of oil and gas well brines in western Pennsylvania. 4th ser., OpenFile Report OFOG 10-01.0, 48. Harrisburg: Pennsylvania Geological Survey. 
Edward, K.L., and S. Weisset. 2011. Marcellus shale hydraulic fracturing and optimal well spacing to maximize recovery and control costs. Paper 140463 in SPE Hydraulic Fracturing Technology Conference, January 24-26, 2011, The Woodlands, Texas.

Energy Information Administration (EIA). 2009. Annual Energy Outlook with Projections to 2030. Washington, D.C.: U.S. Department of Energy. http://www.eia.doe.gov/oiaf/aeo/ (accessed May 23, 2011).

Engelder, T., G.G. Lash, and R.S. Uzcategui. 2009. Joint sets that enhance production from Middle and Upper Devonian gas shales of the Appalachian Basin. AAPG Bulletin 93, no. 7: $857-889$.

Environmental Protection Agency (EPA). 1987. Report to congress, management of wastes from the exploration, development, and production of crude oil, natural gas, and geothermal energy, volume 1 of 3 , oil and gas. Washington, DC: EPA.

Etiope, G., and G. Martinelli. 2002. Migration of carrier and trace gases in the geosphere: an overview. Physics of the Earth and Planetary Interiors 129: 3-4.

Fisher, K., and N. Warpinski. 2011. Hydraulic fracture-height growth: real data. Paper SPE 145949 presented at the Annual Technical Conference and Exhibition, Denver, Colorado. DOI: 10.2118/145949-MS.

Gold, D. 1999. Lineaments and their interregional relationships. In The Geology of Pennsylvania, ed. C.H. Schultz, 307-313. Harrisburg: Pennsylvania Department of Conservation and Natural Resources.

Halford, K.J., and R.T. Hanson. 2002. User guide for the drawdown-limited, multi-node well (MNW) package for the U.S. Geological Survey's modular three-dimensional finitedifference ground-water flow model, Versions MODFLOW96 and MODFLOW-2000, 33. Open-File Report 02-293. Sacramento, California: U.S. Geological Survey.

Harbaugh, A.W., E.R. Banta, M.C. Hill, and M.G. McDonald. 2000. Modflow-2000, the U.S. Geological Survey modular ground-water model-User guide to modularization, concepts and the ground-water flow process. Open-File Report 00-92. Reston, Virginia: U.S. Geological Survey.

Harper, J.A. 1999. Devonian. In The Geology of Pennsylvania, ed. C.H. Schultz, 108-127. Harrisburg: Pennsylvania Department of Conservation and Natural Resources.

Hill, M.C., and C.R. Tiedeman. 2007. Effective Groundwater Model Calibration: With Analysis of Data, Sensitivities, Predictions, and Uncertainty. Hoboken, New Jersey: John Wiley and Sons.

Hsieh, P.A. 2011. Application of MODFLOW for oil reservoir simulation during the Deepwater Horizon crisis. Ground Water 49, no. 3: 319-323. DOI: 10.1111/j.17456584.2011.00813.x.

Isachsen, Y.W., and W. McKendree. 1977. Preliminary Brittle Structure Map of New York, Map and Chart Series No. 31. Albany, New York: New York State Museum.

Jehn, P. 2011. Well and water testing-What to look for and when to look for it. In Groundwater and Hydraulic Fracturing of the Marcellus Shale, National Groundwater Association short course. Baltimore, Maryland.

King, G. 2010. Thirty years of gas shale fracturing: What have we learned? Paper SPE 133456 presented at the SPE Annual Technical Conference and Exhibition, September 19-22, 2010, Florence, Italy.

King, G.E., L. Haile, J. Shuss, and T.A. Dobkins. 2008. Increasing fracture path complexity and controlling downward fracture growth in the Barnett shale. Paper 119896 presented at the SPE Shale Gas Production Conference, November 16-18, 2008, Fort Worth, Texas.

Konikow, L.F. 2011. The secret to successful solute-transport modeling. Ground Water 49, no. 2: 144-159. DOI: 10.1111/j.1745-6584.2010.00764x.
Kramer, D. 2011. Shale-gas extraction faces growing public and regulatory challenges. Physics Today 64, no. 7: 23-25.

Kwon, O., A.K. Kronenberg, A.F. Gangi, B. Johnson, and B.E. Herbert. 2004a. Permeability of illite-bearing shale: 1. Anisotropy and effects of clay content and loading. Journal of Geophysical Research 109: B10205. DOI: 10.1029/2004/JB003052.

Kwon, O., B.E. Herbert, and A.K. Kronenberg. 2004b. Permeability of illite-bearing shale: 2 . Influence of fluid chemistry on flow and functionally connected pores. Journal of Geophysical Research 109: B10206. DOI:10.1029/2004JB00 3055 .

Lacombe, S., E.A. Sudickey, S.K. Frape, and A.J.A. Unger. 1995. Influence of leak boreholes on cross-formational groundwater flow and contaminant transport. Water Resources Research 31, no. 8: 1871-1882.

Langevin, C.D., W.B. Shoemaker, and W. Guo. 2003. MODF LOW-2000, the U.S. Geological Survey modular groundwater model-Documentation of the SEAWAT-2000 version with the variable-density flow process (VDF) and the integrated MT3DMS transport process (IMT), 43 p. OpenFile Report 03-426. Tallahassee, Florida: U.S. Geological Survey.

Loyd, O.B., and L.D. Carswell. 1981. Groundwater resources of the Williamsport region, Lycoming County, Pennsylvania. Water Resources Report 51. Pennsylvania: Department of Environmental Resources.

Neuzil, C.E. 1994. How permeable are clays and shales? Water Resources Research 30, no. 2: 145-150.

Neuzil, C.E. 1986. Groundwater flow in low-permeability environments. Water Resources Research 22, no. 8: 1163-1195.

New York State Department of Environmental Conservation (NYDEC). 2009. Draft Supplemental Generic Environmental Impact Statement on the Oil, Gas and Solution Mining Regulatory Program-Well Permit Issuance for Horizontal Drilling and High-Volume Hydraulic Fracturing to Develop the Marcellus Shale and Other Low-Permeability Gas Reservoirs. Albany, New York: State Department of Environmental Conservation.

Nickelsen, R.P. 1986. Cleavage duplexes in the Marcellus Shale of the Appalachian foreland. Journal of Structural Geology 8, no. 3/4: 361-371.

Ohio Department of Natural Resources (ODNR). 2008. Report on the Investigation of the Natural Gas Invasion of Aquifers in Bainbridge Township of Geauga County, Ohio. ODNR, Division of Mineral Resources Management.

Osborn, S.G., A. Vengosh, N.R. Warner, and R.B. Jackson 2011. Methane contamination of drinking water accompanying gas-well drilling and hydraulic fracturing. Proceedings of the National Academy of Sciences 108, no. 20 $8172-8176$

Osborn, S.G., and J.C. McIntosh. 2010. Chemical and isotopic tracers of the contribution of microbial gas in Devonian organic-rich shales and reservoir sandstones, northern Appalachian Basin. Applied Geochemistry 25, no. 3: 456-471.

Pennsylvania Bureau of Topographic and Geologic Survey (PBTGS). 2001. Bedrock Geology of Pennsylvania (Digital Files). Harrisburg, Pennsylvania: PA Department of Conservation and Natural Resources.

Pennsylvania Department of Environmental Protection (PADEP) 2011. Marcellus Shale. http://www.dep.state.pa.us/dep/ deputate/minres/oilgas/new_forms/marcellus/marcellus.htm (accessed June 1, 2011).

Pennsylvania Department of Environmental Protection (PADEP). 2009. Notice of Violation, Re: Gas Migration Investigation, Dimock Township, Susquehanna County, Letter from S. C. Lobins, Regional Manager, Oil and Gas Management, to Mr. Thomas Liberatore, Cabot Oil and Gas Corporation. February 27, 2009. 4 pp., PADEP, Meadville, Pennsylvania. 
Schoell, M. 1980. The hydrogen and carbon isotopic composition of methane from natural gases of various origins. Geochemica et Cosmochiica Act 44, no. 5: 649-661.

Schulze-Makuch, D., D.A. Carlson, D.S. Cherkauer, and P. Malik. 1999. Scale dependence of hydraulic conductivity in heterogeneous media. Ground Water 37, no. 6: 904-919.

Schweitzer, R., and H.I. Bilgesu. 2009. The role of economics on well and fracture design completions of Marcellus Shale wells. Paper 125975 in SPE Eastern Regional Meeting, September 23-25, 2009, Charleston, West Virginia.

Shoemaker, W.B., E.L. Kuniansky, S. Birk, S. Bauer, and E.D. Swain. 2008. Documentation of a conduit flow process (CFP) for MODFLOW-2005. U.S. Geological Survey techniques and methods, Book 6, chapter A24, 50 p. Reston, Virgina: U.S. Geological Survey.

Silliman, S., and D. Higgins. 1990. An analytical solution for steady-state flow between aquifers through an open well. Ground Water 28, no. 2: 184-190.

Soeder, D.J. 2010. The Marcellus shale: Resources and reservations. EOS 91, no. 32: 277-278.

T.A.L. Research and Development (TAL). 1981. Geology, drill holes, and geothermal energy potential of the basal Cambrian rock units of the Appalachian Basin of New York State. In Prepared for New York State Energy Research and Development Authority, $54 \mathrm{p}$.

West Virginia Geological and Economic Survey (WVGES). 2011. Completed Wells-Marcellus Shale, West Virginia. Morgantown, West Virginia: WVGES.
West Virginia Geological and Economic Survey (WVGES). 2010a. Structural Geologic Map (Faults)-Topo of the Onondaga Limestone or Equivalent, West Virginia. Morgantown, West Virginia: WVGES.

West Virginia Geological and Economic Survey (WVGES). 2010b. Structural Geologic Map (Folds)-Topo of the Onondaga Limestone or Equivalent, West Virginia. Morgantown, West Virginia: WVGES.

White, J.S., and M.V. Mathes. 2006. Dissolved-gas concentration in ground water in West Virginia, 8. Data Series 156. Reston, Virginia: U.S. Geological Survey.

Williams, J.H. 2010. Evaluation of well logs for determining the presence of freshwater, saltwater, and gas above the Marcellus shale in Chemung, Tioga, and Broome Counties, New York. Scientific Investigations Report 2010-5224, 27. Reston, Virginia: U.S. Geological Survey.

Williams, J.H., L.E. Taylor, and D.J. Low. 1998. Hydrogeology and groundwater quality of the Glaciated Valleys of Bradford, Tioga, and Potter Counties, Pennsylvania. Water Resource Report 68. Pennsylvania Dept of Conservation and Natural Resources and U.S. Geological Survey.

Wunsch, D. 2011. Hydrogeology and hydrogeochemistry of aquifers overlying the Marcellus shale. In Groundwater and Hydraulic Fracturing of the Marcellus Shale, National Groundwater Association short course. Baltimore, Maryland. 


\title{
Methane contamination of drinking water accompanying gas-well drilling and hydraulic fracturing
}

\author{
Stephen G. Osborn ${ }^{\mathrm{a}}$, Avner Vengosh ${ }^{\mathrm{b}}$, Nathaniel R. Warner ${ }^{\mathrm{b}}$, and Robert B. Jackson ${ }^{\mathrm{a}, \mathrm{b}, \mathrm{c}, 1}$ \\ ${ }^{a}$ Center on Global Change, Nicholas School of the Environment, bivision of Earth and Ocean Sciences, Nicholas School of the Environment, and \\ 'Biology Department, Duke University, Durham, NC 27708
}

Edited* by William H. Schlesinger, Cary Institute of Ecosystem Studies, Millbrook, NY, and approved April 14, 2011 (received for review January 13, 2011 )

\begin{abstract}
Directional drilling and hydraulic-fracturing technologies are dramatically increasing natural-gas extraction. In aquifers overlying the Marcellus and Utica shale formations of northeastern Pennsylvania and upstate New York, we document systematic evidence for methane contamination of drinking water associated with shalegas extraction. In active gas-extraction areas (one or more gas wells within $1 \mathrm{~km}$ ), average and maximum methane concentrations in drinking-water wells increased with proximity to the nearest gas well and were 19.2 and $64 \mathrm{mg} \mathrm{CH}_{4} \mathrm{~L}^{-1}(n=26)$, a potential explosion hazard; in contrast, dissolved methane samples in neighboring nonextraction sites (no gas wells within $1 \mathrm{~km}$ ) within similar geologic formations and hydrogeologic regimes averaged only $1.1 \mathrm{mg} \mathrm{L}^{-1}(P<0.05 ; n=34)$. Average $\delta^{13} \mathrm{C}_{-} \mathrm{CH}_{4}$ values of dissolved methane in shallow groundwater were significantly less negative for active than for nonactive sites $(-37 \pm 7 \%$ and $-54 \pm 11 \%$, respectively; $P<0.0001)$. These $\delta^{13} \mathrm{C}_{-} \mathrm{CH}_{4}$ data, coupled with the ratios of methane-to-higher-chain hydrocarbons, and $\delta^{2} \mathrm{H}-\mathrm{CH}_{4}$ values, are consistent with deeper thermogenic methane sources such as the Marcellus and Utica shales at the active sites and matched gas geochemistry from gas wells nearby. In contrast, lower-concentration samples from shallow groundwater at nonactive sites had isotopic signatures reflecting a more biogenic or mixed biogenic/ thermogenic methane source. We found no evidence for contamination of drinking-water samples with deep saline brines or fracturing fluids. We conclude that greater stewardship, data, andpossibly-regulation are needed to ensure the sustainable future of shale-gas extraction and to improve public confidence in its use.
\end{abstract}

groundwater | organic-rich shale | isotopes | formation waters | water chemistry

ncreases in natural-gas extraction are being driven by rising energy demands, mandates for cleaner burning fuels, and the economics of energy use (1-5). Directional drilling and hydraulic-fracturing technologies are allowing expanded natural-gas extraction from organic-rich shales in the United States and elsewhere $(2,3)$. Accompanying the benefits of such extraction $(6,7)$ are public concerns about drinking-water contamination from drilling and hydraulic fracturing that are ubiquitous but lack a strong scientific foundation. In this paper, we evaluate the potential impacts associated with gas-well drilling and fracturing on shallow groundwater systems of the Catskill and Lockhaven formations that overlie the Marcellus Shale in Pennsylvania and the Genesee Group that overlies the Utica Shale in New York (Figs. 1 and 2 and Fig. S1). Our results show evidence for methane contamination of shallow drinking-water systems in at least three areas of the region and suggest important environmental risks accompanying shale-gas exploration worldwide.

The drilling of organic-rich shales, typically of Upper Devonian to Ordovician age, in Pennsylvania, New York, and elsewhere in the Appalachian Basin is spreading rapidly, raising concerns for impacts on water resources $(8,9)$. In Susquehanna County, Pennsylvania alone, approved gas-well permits in the Marcellus formation increased 27-fold from 2007 to 2009 (10).

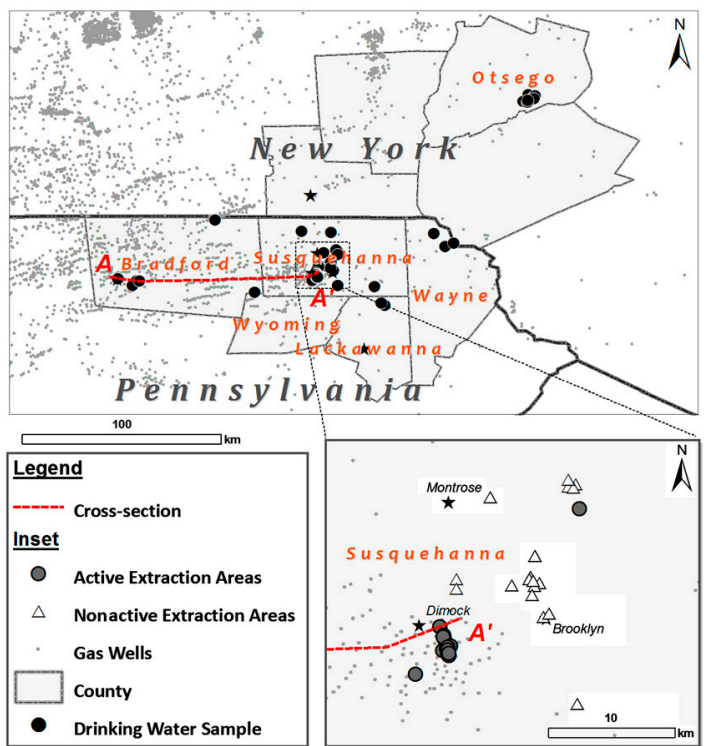

Fig. 1. Map of drilling operations and well-water sampling locations in Pennsylvania and New York. The star represents the location of Binghamton, New York. (Inset) A close-up in Susquehanna County, Pennsylvania, showing areas of active (closed circles) or nonactive (open triangles) extraction. A drinking-water well is classified as being in an active extraction area if a gas well is within $1 \mathrm{~km}$ (see Methods). Note that drilling has already spread to the area around Brooklyn, Pennsylvania, primarily a nonactive location at the time of our sampling (see inset). The stars in the inset represent the towns of Dimock, Brooklyn, and Montrose, Pennsylvania.

Concerns for impacts to groundwater resources are based on (i) fluid (water and gas) flow and discharge to shallow aquifers due to the high pressure of the injected fracturing fluids in the gas wells (10); (ii) the toxicity and radioactivity of produced water from a mixture of fracturing fluids and deep saline formation waters that may discharge to the environment (11); (iii) the potential explosion and asphyxiation hazard of natural gas; and (iv) the large number of private wells in rural areas that rely on shallow groundwater for household and agricultural use-up to one million wells in Pennsylvania alone-that are typically unregulated and untested $(8,9,12)$. In this study, we analyzed groundwater from 68 private water wells from 36- to $190-\mathrm{m}$ deep in

Author contributions: S.G.O., A.V., and R.B.J. designed research; S.G.O. and N.R.W. performed research; A.V. contributed new reagents/analytic tools; S.G.O., A.V., N.R.W. and R.B.J. analyzed data; and S.G.O., A.V., N.R.W., and R.B.J. wrote the paper.

The authors declare no conflict of interest.

*This Direct Submission article had a prearranged editor.

Freely available online through the PNAS open access option.

${ }^{1}$ To whom correspondence should be addressed. E-mail: jackson@duke.edu.

This article contains supporting information online at www.pnas.org/lookup/suppl/ doi:10.1073/pnas.1100682108/-/DCSupplemental. 


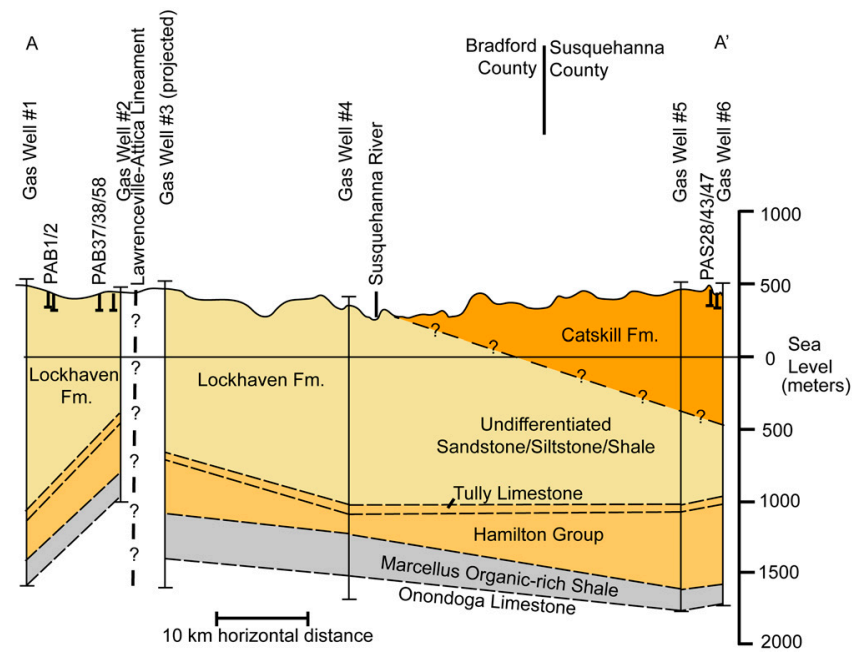

Fig. 2. Geologic cross-section of Bradford and western Susquehanna Counties created from gas-well log data provided by the Pennsylvania Department of Conservation and Natural Resources. The approximate location of the Lawrenceville-Attica Lineament is taken from Alexander et al. (34). The Ordovician Utica organic-rich shale (not depicted in the figure) underlies the Middle Devonian Marcellus at approximately 3,500 m below the ground surface.

northeast Pennsylvania (Catskill and Lockhaven formations) and upstate New York (Genesee formation) (see Figs. 1 and 2 and SI Text), including measurements of dissolved salts, water isotopes $\left({ }^{18} \mathrm{O}\right.$ and ${ }^{2} \mathrm{H}$ ), and isotopes of dissolved constituents (carbon, boron, and radium). Of the 68 wells, 60 were also analyzed for dissolved-gas concentrations of methane and higher-chain hydrocarbons and for carbon and hydrogen isotope ratios of methane. Although dissolved methane in drinking water is not currently classified as a health hazard for ingestion, it is an asphyxiant in enclosed spaces and an explosion and fire hazard (8). This study seeks to evaluate the potential impact of gas drilling and hydraulic fracturing on shallow groundwater quality by comparing areas that are currently exploited for gas (defined as active-one or more gas wells within $1 \mathrm{~km}$ ) to those that are not currently associated with gas drilling (nonactive; no gas wells within $1 \mathrm{~km}$ ), many of which are slated for drilling in the near future.

\section{Results and Discussion}

Methane concentrations were detected generally in 51 of 60 drinking-water wells (85\%) across the region, regardless of gas industry operations, but concentrations were substantially higher closer to natural-gas wells (Fig. 3). Methane concentrations were 17-times higher on average $\left(19.2 \mathrm{mg} \mathrm{CH}_{4} \mathrm{~L}^{-1}\right)$ in shallow wells from active drilling and extraction areas than in wells from nonactive areas $\left(1.1 \mathrm{mg} \mathrm{L}^{-1}\right.$ on average; $P<0.05$; Fig. 3 and Table 1). The average methane concentration in shallow groundwater in active drilling areas fell within the defined action level (10-28 $\mathrm{mg} \mathrm{L}^{-1}$ ) for hazard mitigation recommended by the US Office of the Interior (13), and our maximum observed value of $64 \mathrm{mg} \mathrm{L}^{-1}$ is well above this hazard level (Fig. 3). Understanding the origin of this methane, whether it is shallower biogenic or deeper thermogenic gas, is therefore important for identifying the source of contamination in shallow groundwater systems.

The $\delta^{13} \mathrm{C}-\mathrm{CH}_{4}$ and $\delta^{2} \mathrm{H}-\mathrm{CH}_{4}$ values and the ratio of methane to higher-chain hydrocarbons (ethane, propane, and butane) can typically be used to differentiate shallower, biologically derived methane from deeper physically derived thermogenic methane (14). Values of $\delta^{13} \mathrm{C}-\mathrm{CH}_{4}$ less negative than approximately $-50 \%$ are indicative of deeper thermogenic methane, whereas values more negative than $-64 \%$ are strongly indicative of microbial methane (14). Likewise, $\delta^{2} \mathrm{H}-\mathrm{CH}_{4}$ values more negative than about $-175 \%$, particularly when combined with low $\delta^{13} \mathrm{C}-\mathrm{CH}_{4}$ values, often represent a purer biogenic methane origin (14).

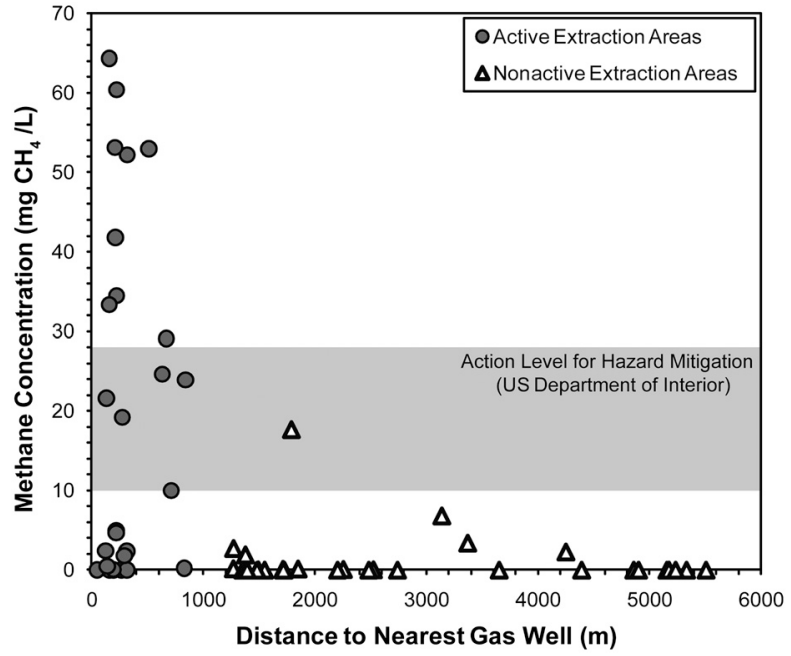

Fig. 3. Methane concentrations (milligrams of $\mathrm{CH}_{4} \mathrm{~L}^{-1}$ ) as a function of distance to the nearest gas well from active (closed circles) and nonactive (open triangles) drilling areas. Note that the distance estimate is an upper limit and does not take into account the direction or extent of horizontal drilling underground, which would decrease the estimated distances to some extraction activities. The precise locations of natural-gas wells were obtained from the Pennsylvania Department of Environmental Protection and Pennsylvania Spatial Data Access databases (ref. 35; accessed Sept. 24, 2010).

The average $\delta^{13} \mathrm{C}-\mathrm{CH}_{4}$ value in shallow groundwater in active drilling areas was $-37 \pm 7 \%$, consistent with a deeper thermogenic methane source. In contrast, groundwater from nonactive areas in the same aquifers had much lower methane concentrations and significantly lower $\delta^{13} \mathrm{C}-\mathrm{CH}_{4}$ values (average of $-54 \pm$ $11 \%$; $P<0.0001$; Fig. 4 and Table 1$)$. Both our $\delta^{13} \mathrm{C}-\mathrm{CH}_{4}$ data and $\delta^{2} \mathrm{H}-\mathrm{CH}_{4}$ data (see Fig. S2) are consistent with a deeper thermogenic methane source at the active sites and a more biogenic or mixed methane source for the lower-concentration samples from nonactive sites (based on the definition of Schoell, ref. 14).

Because ethane and propane are generally not coproduced during microbial methanogenesis, the presence of higher-chain hydrocarbons at relatively low methane-to-ethane ratios (less than approximately 100) is often used as another indicator of deeper thermogenic gas $(14,15)$. Ethane and other higher-chain hydrocarbons were detected in only 3 of 34 drinking-water wells from nonactive drilling sites. In contrast, ethane was detected in 21 of 26 drinking-water wells in active drilling sites. Additionally, propane and butane were detected $(>0.001 \mathrm{~mol} \%)$ in eight and two well samples, respectively, from active drilling areas but in no wells from nonactive areas.

Further evidence for the difference between methane from water wells near active drilling sites and neighboring nonactive sites is the relationship of methane concentration to $\delta^{13} \mathrm{C}-\mathrm{CH}_{4}$ values (Fig. $4 A$ ) and the ratios of methane to higher-chain hydro-

Table 1. Mean values \pm standard deviation of methane concentrations (as milligrams of $\mathrm{CH}_{4} \mathrm{~L}^{-1}$ ) and carbon isotope composition in methane in shallow groundwater $\delta^{13} \mathrm{C}_{-} \mathrm{CH}_{4}$ sorted by aquifers and proximity to gas wells (active vs. nonactive)

\begin{tabular}{lcc} 
Water source, $n$ & milligrams $\mathrm{CH}_{4} \mathrm{~L}^{-1}$ & $\delta^{13} \mathrm{C}^{-\mathrm{CH}_{4}, \% o}$ \\
\hline Nonactive Catskill, 5 & $1.9 \pm 6.3$ & $-52.5 \pm 7.5$ \\
Active Catskill, 13 & $26.8 \pm 30.3$ & $-33.5 \pm 3.5$ \\
Nonactive Genesee, 8 & $1.5 \pm 3.0$ & $-57.5 \pm 9.5$ \\
Active Genesee, 1 & 0.3 & -34.1 \\
Active Lockhaven, 7 & $50.4 \pm 36.1$ & $-40.7 \pm 6.7$ \\
Total active wells, 21 & 19.2 & $-37 \pm 7$ \\
Total nonactive wells, 13 & 1.1 & $-54 \pm 11$ \\
\hline
\end{tabular}

The variable $n$ refers to the number of samples. 


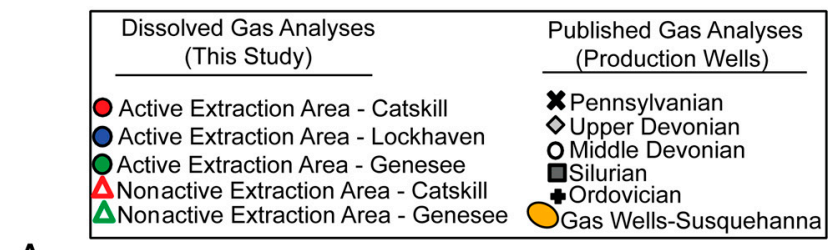

A

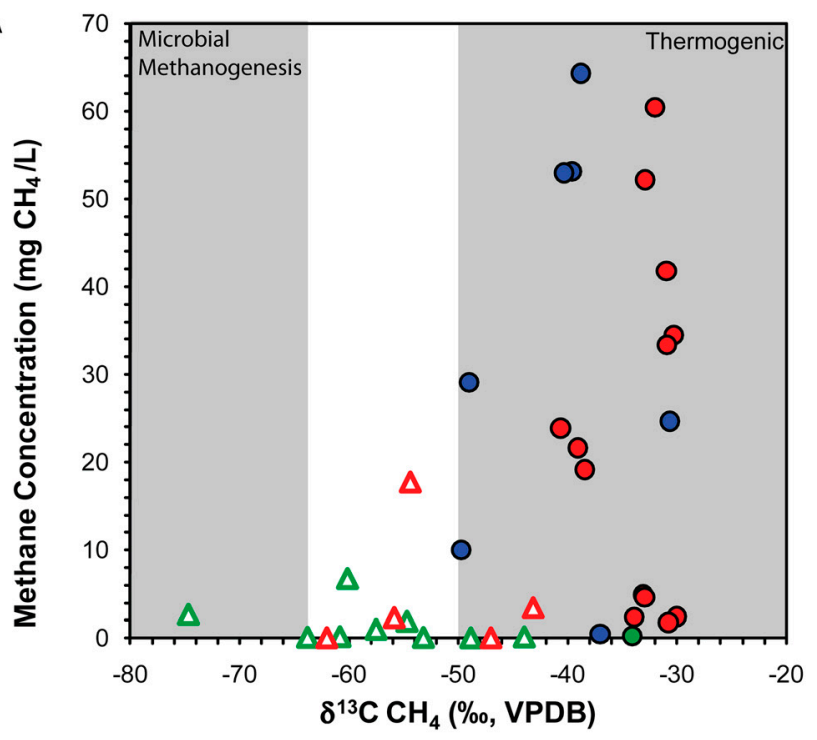

B

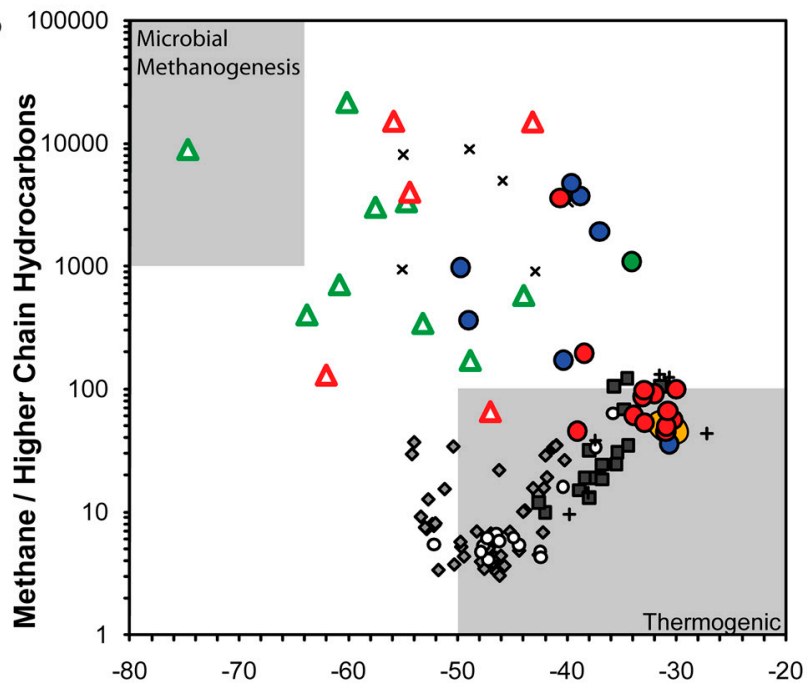

Fig. 4. (A) Methane concentrations in groundwater versus the carbon isotope values of methane. The nonactive and active data depicted in Fig. 3 are subdivided based on the host aquifer to illustrate that the methane concentrations and $\delta^{13} \mathrm{C}$ values increase with proximity to natural-gas well drilling regardless of aquifer formation. Gray areas represent the typical range of thermogenic and biogenic methane taken from Osborn and Mcintosh (18). VPDB, Vienna Pee Dee belemnite. (B) Bernard plot (15) of the ratio of methane to higher-chain hydrocarbons versus the $\delta^{13} \mathrm{C}$ of methane. The smaller symbols in grayscale are from published gas-well samples from gas production across the region (16-18). These data generally plot along a trajectory related to reservoir age and thermal maturity (Upper Devonian through Ordovician; see text for additional details). The gas-well data in the orange ovals are from gas wells in our study area in Susquehanna County, Pennsylvania (data from Pennsylvania Department of Environmental Protection). Gray areas represent typical ranges of thermogenic and biogenic methane (data from Osborn and Mclntosh, ref. 18).

carbons versus $\delta^{13} \mathrm{C}^{-\mathrm{CH}_{4}}$ (Fig. $4 B$ ). Methane concentrations not only increased in proximity to gas wells (Fig. 3), the accompanying $\delta^{13} \mathrm{C}_{-} \mathrm{CH}_{4}$ values also reflected an increasingly thermogenic methane source (Fig. 4A).
Using a Bernard plot (15) for analysis (Fig. $4 B$ ), the enriched $\delta^{13} \mathrm{C}^{-\mathrm{CH}_{4}}$ (approximately $>-50 \%$ ) values accompanied by low ratios of methane to higher-chain hydrocarbons (less than approximately 100) in drinking-water wells also suggest that dissolved gas is more thermogenic at active than at nonactive sites (Fig. $4 B$ ). For instance, 12 dissolved-gas samples at active drilling sites fell along a regional gas trajectory that increases with reservoir age and thermal maturity of organic matter, with samples from Susquehanna County, Pennsylvania specifically matching natural-gas geochemistry from local gas wells (Fig. $4 B$, orange oval). These 12 samples and local natural-gas samples are consistent with gas sourced from thermally mature organic matter of Middle Devonian and older depositional ages often found in Marcellus Shale from approximately 2,000 $\mathrm{m}$ below the surface in the northern Appalachian Basin (14-19) (Fig. 4B). In contrast, none of the methane samples from nonactive drilling areas fell upon this trajectory (Fig. $4 B$ ); eight dissolved-gas samples in Fig. $4 B$ from active drilling areas and all of the values from nonactive areas may instead be interpreted as mixed biogenic/ thermogenic gas (18) or, as Laughrey and Baldassare (17) proposed for their Pennsylvanian gas data (Fig. $4 B$ ), the early migration of wet thermogenic gases with low- $\delta{ }^{13} \mathrm{C}^{-} \mathrm{CH}_{4}$ values and high methane-to-higher-chain hydrocarbon ratios. One data point from a nonactive area in New York fell squarely in the parameters of a strictly biogenic source as defined by Schoell (14) (Fig. $4 B$, upper-left corner).

Carbon isotopes of dissolved inorganic carbon $\left(\delta^{13} \mathrm{C}\right.$-DIC $>$ $+10 \% 0$ ) and the positive correlation of $\delta^{2} \mathrm{H}$ of water and $\delta^{2} \mathrm{H}$ of methane have been used as strong indicators of microbial methane, further constraining the source of methane in shallow groundwater (depth less than $550 \mathrm{~m})(18,20)$. Our $\delta^{13} \mathrm{C}$-DIC values were fairly negative and show no association with the $\delta^{13} \mathrm{C}^{-\mathrm{CH}_{4}}$ values (Fig. S3), which is not what would be expected if methanogenesis were occurring locally in the shallow aquifers. Instead, the $\delta^{13} \mathrm{C}$-DIC values from the shallow aquifers plot within a narrow range typical for shallow recharge waters, with the dissolution of $\mathrm{CO}_{2}$ produced by respiration as water passes downward through the soil critical zone. Importantly, these values do not indicate extensive microbial methanogenesis or sulfate reduction. The data do suggest gas-phase transport of methane upward to the shallow groundwater zones sampled for this study $(<190 \mathrm{~m})$ and dissolution into shallow recharge waters locally. Additionally, there was no positive correlation between the $\delta^{2} \mathrm{H}$ values of methane and $\delta^{2} \mathrm{H}$ of water (Fig. S4), indicating that microbial methane derived in this shallow zone is negligible. Overall, the combined gas and formation-water results indicate that thermogenic gas from thermally mature organic matter of Middle Devonian and older depositional ages is the most likely source of the high methane concentrations observed in the shallow water wells from active extraction sites.

A different potential source of shallow groundwater contamination associated with gas drilling and hydraulic fracturing is the introduction of hypersaline formation brines and/or fracturing fluids. The average depth range of drinking-water wells in northeastern Pennsylvania is from 60 to $90 \mathrm{~m}$ (12), making the average vertical separation between drinking-water wells and the Marcellus Shale in our study area between approximately 900 and 1,800 m (Fig. 2). The research area, however, is located in tectonically active areas with mapped faults, earthquakes, and lineament features (Fig. 2 and Fig. S1). The Marcellus formation also contains two major sets of joints (21) that could be conduits for directed pressurized fluid flow. Typical fracturing activities in the Marcellus involve the injection of approximately 13-19 million liters of water per well (22) at pressures of up to $69,000 \mathrm{kPa}$. The majority of this fracturing water typically stays underground and could in principle displace deep formation water upward into shallow aquifers. Such deep formation waters often have high concentrations of total dissolved solids $>250,000 \mathrm{mg} \mathrm{L}^{-1}$, trace 
toxic elements, (18), and naturally occurring radioactive materials, with activities as high as 16,000 picocuries per liter ( $1 \mathrm{pCi} \mathrm{L}{ }^{-1}=0.037$ becquerels per liter) for ${ }^{226} \mathrm{Ra}$ compared to a drinking-water standard of $5 \mathrm{pCi} \mathrm{L}^{-1}$ for combined ${ }^{226} \mathrm{Ra}$ and ${ }^{226} \mathrm{Ra}(23)$.

We evaluated the hydrochemistry of our 68 drinking-water wells and compared these data to historical data of 124 wells in the Catskill and Lockhaven aquifers $(24,25)$. We used three types of indicators for potential mixing with brines and/or saline fracturing fluids: ( $i$ ) major inorganic chemicals; (ii) stable isotope signatures of water $\left(\delta^{18} \mathrm{O}, \delta^{2} \mathrm{H}\right)$; and (iii) isotopes of dissolved constituents $\left(\delta^{13} \mathrm{C}\right.$-DIC, $\delta^{11} \mathrm{~B}$, and $\left.{ }^{226} \mathrm{Ra}\right)$. Based on our data (Table 2), we found no evidence for contamination of the shallow wells near active drilling sites from deep brines and/or fracturing fluids. All of the $\mathrm{Na}^{+}, \mathrm{Cl}^{-}, \mathrm{Ca}^{2+}$, and DIC concentrations in wells from active drilling areas were consistent with the baseline historical data, and none of the shallow wells from active drilling areas had either chloride concentrations $>60 \mathrm{mg} \mathrm{L}^{-1}$ or Na-Ca$\mathrm{Cl}$ compositions that mirrored deeper formation waters (Table 2). Furthermore, the mean isotopic values of $\delta^{18} \mathrm{O}, \delta^{2} \mathrm{H}, \delta^{13} \mathrm{C}$-DIC, $\delta^{11} \mathrm{~B}$, and ${ }^{226} \mathrm{Ra}$ in active and nonactive areas were indistinguishable. The ${ }^{226} \mathrm{Ra}$ values were consistent with available historical data (25), and the composition of $\delta^{18} \mathrm{O}$ and $\delta^{2} \mathrm{H}$ in the well-water appeared to be of modern meteoric origin for Pennsylvania (26) (Table 2 and Fig. S5). In sum, the geochemical and isotopic features for water we measured in the shallow wells from both active and nonactive areas are consistent with historical data and inconsistent with contamination from mixing Marcellus Shale formation water or saline fracturing fluids (Table 2).

There are at least three possible mechanisms for fluid migration into the shallow drinking-water aquifers that could help explain the increased methane concentrations we observed near gas wells (Fig. 3). The first is physical displacement of gas-rich deep solutions from the target formation. Given the lithostatic and hydrostatic pressures for 1-2 km of overlying geological strata, and our results that appear to rule out the rapid movement of deep brines to near the surface, we believe that this mechanism is unlikely. A second mechanism is leaky gas-well casings (e.g., refs. 27 and 28). Such leaks could occur at hundreds of meters underground, with methane passing laterally and vertically through fracture systems. The third mechanism is that the process of hydraulic fracturing generates new fractures or enlarges existing ones above the target shale formation, increasing the connec- tivity of the fracture system. The reduced pressure following the fracturing activities could release methane in solution, leading to methane exsolving rapidly from solution (29), allowing methane gas to potentially migrate upward through the fracture system.

Methane migration through the 1- to 2-km-thick geological formations that overlie the Marcellus and Utica shales is less likely as a mechanism for methane contamination than leaky well casings, but might be possible due to both the extensive fracture systems reported for these formations and the many older, uncased wells drilled and abandoned over the last century and a half in Pennsylvania and New York. The hydraulic conductivity in the overlying Catskill and Lockhaven aquifers is controlled by a secondary fracture system (30), with several major faults and lineaments in the research area (Fig. 2 and Fig. S1). Consequently, the high methane concentrations with distinct positive $\delta^{13} \mathrm{C}-\mathrm{CH}_{4}$ and $\delta^{2} \mathrm{H}-\mathrm{CH}_{4}$ values in the shallow groundwater from active areas could in principle reflect the transport of a deep methane source associated with gas drilling and hydraulic-fracturing activities. In contrast, the low-level methane migration to the surface groundwater aquifers, as observed in the nonactive areas, is likely a natural phenomenon (e.g., ref. 31). Previous studies have shown that naturally occurring methane in shallow aquifers is typically associated with a relatively strong biogenic signature indicated by depleted $\delta^{13} \mathrm{C}-\mathrm{CH}_{4}$ and $\delta^{2} \mathrm{H}-\mathrm{CH}_{4}$ compositions (32) coupled with high ratios of methane to higher-chain hydrocarbons (33), as we observed in Fig. $4 B$. Several models have been developed to explain the relatively common phenomenon of rapid vertical transport of gases $\left(\mathrm{Rn}, \mathrm{CH}_{4}\right.$, and $\left.\mathrm{CO}_{2}\right)$ from depth to the surface (e.g., ref. 31), including pressure-driven continuous gas-phase flow through dry or water-saturated fractures and density-driven buoyancy of gas microbubbles in aquifers and water-filled fractures (31). More research is needed across this and other regions to determine the mechanism(s) controlling the higher methane concentrations we observed.

Based on our groundwater results and the litigious nature of shale-gas extraction, we believe that long-term, coordinated sampling and monitoring of industry and private homeowners is needed. Compared to other forms of fossil-fuel extraction, hydraulic fracturing is relatively poorly regulated at the federal level. Fracturing wastes are not regulated as a hazardous waste under the Resource Conservation and Recovery Act, fracturing wells are not covered under the Safe Drinking Water Act, and only recently has the Environmental Protection Agency asked fracturing

Table 2. Comparisons of selected major ions and isotopic results in drinking-water wells from this study to data available on the same formations (Catskill and Lockhaven) in previous studies $(24,25)$ and to underlying brines throughout the Appalachian Basin $(18)$

\begin{tabular}{|c|c|c|c|c|c|c|c|}
\hline & \multicolumn{2}{|c|}{ Active } & \multicolumn{2}{|c|}{ Nonactive } & \multicolumn{2}{|c|}{ Previous studies (background) } & \multirow[b]{2}{*}{$\begin{array}{c}\text { Appalachian brines } \\
\qquad \begin{array}{c}(18,23) \\
N=21\end{array}\end{array}$} \\
\hline & $\begin{array}{l}\text { Lockhaven } \\
\text { formation } \\
\quad N=8\end{array}$ & $\begin{array}{c}\text { Catskill } \\
\text { formation } \\
N=25\end{array}$ & $\begin{array}{c}\text { Catskill } \\
\text { formation } \\
N=22\end{array}$ & $\begin{array}{c}\text { Genesee } \\
\text { group } \\
N=12\end{array}$ & $\begin{array}{c}\text { Lockhaven } \\
\text { formation (25) } \\
\qquad N=45\end{array}$ & $\begin{array}{c}\text { Catskill formation } \\
\qquad \begin{array}{c}(24) \\
N=79\end{array}\end{array}$ & \\
\hline $\begin{array}{l}\text { Alkalinity as } \mathrm{HCO}_{3}^{-} \text {, } \\
\mathrm{mg} \mathrm{L}^{-1} \\
\mathrm{mM}\end{array}$ & $\begin{array}{l}285 \pm 36 \\
{[4.7 \pm 0.6]}\end{array}$ & $\begin{array}{l}157 \pm 56 \\
{[2.6 \pm 0.9]}\end{array}$ & $\begin{array}{l}127 \pm 53 \\
{[2.1 \pm 0.9]}\end{array}$ & $\begin{array}{l}158 \pm 56 \\
{[2.6 \pm 0.9]}\end{array}$ & $\begin{array}{l}209 \pm 77 \\
{[3.4 \pm 1.3]}\end{array}$ & $\begin{array}{l}133 \pm 61 \\
{[2.2 \pm 1.0]}\end{array}$ & $\begin{array}{c}150 \pm 171 \\
{[2.5 \pm 2.8]}\end{array}$ \\
\hline Sodium, mg L ${ }^{-1}$ & $87 \pm 22$ & $23 \pm 30$ & $17 \pm 25$ & $29 \pm 23$ & $100 \pm 312$ & $21 \pm 37$ & $33,000 \pm 11,000$ \\
\hline Chloride, $\mathrm{mg} \mathrm{L}^{-1}$ & $25 \pm 17$ & $11 \pm 12$ & $17 \pm 40$ & $9 \pm 19$ & $132 \pm 550$ & $13 \pm 42$ & $92,000 \pm 32,000$ \\
\hline Calcium, mg L ${ }^{-1}$ & $22 \pm 12$ & $31 \pm 13$ & $27 \pm 9$ & $26 \pm 5$ & $49 \pm 39$ & $29 \pm 11$ & $16,000 \pm 7,000$ \\
\hline Boron, $\mu \mathrm{g} \mathrm{L}^{-1}$ & $412 \pm 156$ & $93 \pm 167$ & $42 \pm 93$ & $200 \pm 130$ & NA & NA & $3,700 \pm 3,500$ \\
\hline$\delta^{11} \mathrm{~B} \%$ & $27 \pm 4$ & $22 \pm 6$ & $23 \pm 6$ & $26 \pm 6$ & NA & NA & $39 \pm 6$ \\
\hline${ }^{226} \mathrm{Ra}, p \mathrm{Ci} \mathrm{L}{ }^{-1}$ & $0.24 \pm 0.2$ & $0.16 \pm 0.15$ & $0.17 \pm 0.14$ & $0.2 \pm 0.15$ & $0.56 \pm 0.74$ & NA & $6,600 \pm 5,600$ \\
\hline$\delta^{2} \mathrm{H}, \%$, VSMOW & $-66 \pm 5$ & $-64 \pm 3$ & $-68 \pm 6$ & $-76 \pm 5$ & NA & NA & $-41 \pm 6$ \\
\hline$\delta^{18} \mathrm{O}, \%$, VSMOW & $-10 \pm 1$ & $-10 \pm 0.5$ & $-11 \pm 1$ & $-12 \pm 1$ & NA & NA & $-5 \pm 1$ \\
\hline
\end{tabular}

Some data for the active Genesee Group and nonactive Lockhaven Formation are not included because of insufficient sample sizes (NA). Values represent means \pm 1 standard deviation. NA, not available.

$N$ values for $\delta^{11} \mathrm{~B} \%$ analysis are $8,10,3,6$, and 5 for active Lockhaven, active Catskill, nonactive Genesee, nonactive Catskill, and brine, respectively. $N$ values for ${ }^{226} \mathrm{Ra}$ are $6,7,3,10,5$, and 13 for active Lockhaven, active Catskill, nonactive Genesee, nonactive Catskill, background Lockhaven, and brine, respectively. $\delta^{11} \mathrm{~B} \%$ normalized to National Institute of Standards and Technology Standard Reference Material $951 . \delta^{2} \mathrm{H}$ and $\delta^{18} \mathrm{O}$ normalized to Vienna Standard Mean Ocean Water (VSMOW). 
firms to voluntarily report a list of the constituents in the fracturing fluids based on the Emergency Planning and Community Right-to-Know Act. More research is also needed on the mechanism of methane contamination, the potential health consequences of methane, and establishment of baseline methane data in other locations. We believe that systematic and independent data on groundwater quality, including dissolved-gas concentrations and isotopic compositions, should be collected before drilling operations begin in a region, as is already done in some states. Ideally, these data should be made available for public analysis, recognizing the privacy concerns that accompany this issue. Such baseline data would improve environmental safety, scientific knowledge, and public confidence. Similarly, long-term monitoring of groundwater and surface methane emissions during and after extraction would clarify the extent of problems and help identify the mechanisms behind them. Greater stewardship, knowledge, and-possibly-regulation are needed to ensure the sustainable future of shale-gas extraction.

1. Pacala S, Socolow R (2004) Stabilization wedges: Solving the climate problem for the next 50 years with current technologies. Science 305:968-972.

2. Tour JM, Kittrell C, Colvin VL (2010) Green carbon as a bridge to renewable energy. Nature Mater 9:871-874

3. Kerr RA (2010) Natural gas from shale bursts onto the scene. Science 328:1624-1626

4. Raupach MR, et al. (2007) Global and regional drivers of accelerating $\mathrm{CO}_{2}$ emissions. Proc Natl Acad Sci USA 104:10288-10293.

5. US Energy Information Administration (2010) Annual Energy Outlook 2010 with Projections to 2035 (US Energy Information Administration, Washington, DC), DOE/EIA0383; http://www.eia.doe.gov/oiaf/aeo/pdf/0383(2010).pdf.

6. US Environmental Protection Agency (2011) Hydraulic Fracturing. (US Environmental Protection Agency, Washington, DC), http://water.epa.gov/type/groundwater/uic/ class2/hydraulicfracturing/.

7. Kargbo DM, Wilhelm RG, Campbell DJ (2010) Natural gas plays in the Marcellus shale: Challenges and potential opportunities. Environ Sci Technol 44:5679-5684.

8. Revesz KM, Breen KJ, Baldassare AJ, Burruss RC (2010) Carbon and hydrogen isotopic evidence for the origin of combustible gases in water supply wells in north-central Pennsylvania. Appl Geochem 25:1845-1859.

9. Zoback M, Kitasei S, Copithorne B Addressing the environmental risks from shale gas development. Worldwatch Institute Briefing Paper 1 (Worldwatch Inst, Washington, DC), http://blogs.worldwatch.org/revolt/wp-content/uploads/2010/07/EnvironmentalRisks-Paper-July-2010-FOR-PRINT.pdf.

10. Pennsylvania Department of Environmental Protection, Bureau of Oil and Gas Management (2010) 2009 Year End Workload Report. (Pennsylvania Dept of Environmental Protection, Bureau of Oil and Gas Management, Harrisburg, PA), http://www. dep.state.pa.us/dep/deputate/minres/oilgas/2009\%20Year\%20End\%20Report-WEBSITE. pdf.

11. Colborn T, Kwiatkowski C, Schultz K, Bachran M (2010) Natural gas operations from a public health perspective. Hum Ecol Risk Assess, in press.

12. Pennsylvania Department of Environmental Protection (2011) Private Water Wells in Pennsylvania. (Pennsylvania Dept of Environmental Protection, Harrisburg, PA), http://www.dep.state.pa.us/dep/deputate/watermgt/wc/Subjects/SrceProt/well/.

13. Eltschlager KK, Hawkins JW, Ehler WC, Baldassare F (2001) Technical Measures for the Investigation and Mitigation of Fugitive Methane Hazards in Areas of Coal Mining (US Dept of the Interior, Office of Surface Mining Reclamation and Enforcement, Pittsburgh).

14. Schoell M (1980) The hydrogen and carbon isotopic composition of methane from natural gases of various origins. Geochim Cosmochim Acta 44:649-661.

15. Bernard BB (1978) Light hydrocarbons in marine sediments. PhD Dissertation (Texas A\&M Univ, College Station, TX)

16. Jenden PD, Drazan DJ, Kaplan IR (1993) Mixing of thermogenic natural gases in northern Appalachian Basin. Am Assoc Pet Geol Bull 77:980-998.

17. Laughrey CD, Baldassare FJ (1998) Geochemistry and origin of some natural gases in the Plateau Province Central Appalachian Basin, Pennsylvania and Ohio. Am Assoc Pet Geol Bull 82:317-335.

18. Osborn SG, McIntosh JC (2010) Chemical and isotopic tracers of the contribution of microbial gas in Devonian organic-rich shales and reservoir sandstones, northern Appalachian Basin. App/ Geochem 25:456-471.

19. Repetski JE, Ryder RT, Harper JA, Trippi MH (2006) Thermal maturity patterns in the Ordovician and Devonian of Pennsylvania using conodont color alteration index (CAI) and vitrinite reflectance (\%Ro). Northeastern Geology Environmental Sciences 28:266-294.

\section{Methods}

A total of 68 drinking-water samples were collected in Pennsylvania and New York from bedrock aquifers (Lockhaven, 8; Catskill, 47; and Genesee, 13) that overlie the Marcellus or Utica shale formations (Fig. S1). Wells were purged to remove stagnant water, then monitored for $\mathrm{pH}$, electrical conductance, and temperature until stable values were recorded. Samples were collected "upstream" of any treatment systems, as close to the water well as possible, and preserved in accordance with procedures detailed in SI Methods. Dissolved-gas samples were analyzed at Isotech Laboratories and water chemical and isotope $(\mathrm{O}, \mathrm{H}, \mathrm{B}, \mathrm{C}, \mathrm{Ra})$ compositions were measured at Duke University (see SI Methods for analytical details).

ACKNOWLEDGMENTS. We thank Rebecca Roter, Peggy Maloof, and many others who allowed us to sample their water wells; Laura Ruhl and Tewodros Rango for coordination and field assistance; Nicolas Cassar for thoughtful suggestions on the research; and Kaiguang Zhao and Rose Merola for help with figures. Jon Karr and the Duke Environmental Isotope Laboratory performed analyses of $\delta^{18} \mathrm{O}, \delta^{2} \mathrm{H}$, and $\delta^{13} \mathrm{C}$ of groundwater samples. William Chameides, Lincoln Pratson, William Schlesinger, the Jackson Lab, and two anonymous reviewers provided helpful suggestions on the manuscript and research. We gratefully acknowledge financial support from Fred and Alice Stanback to the Nicholas School of the Environment and from the Duke Center on Global Change.

20. Martini AM, et al. (1998) Genetic and temporal relations between formation waters and biogenic methane: Upper Devonian Antrim Shale, Michigan Basin, USA. Geochim Cosmochim Acta 62:1699-1720.

21. Engelder T, Lash GG, Uzcategui RS (2009) Joint sets that enhance production from Middle and Upper Devonian gas shales of the Appalachian Basin. Am Assoc Pet Geol Bull 93:857-889.

22. Pennsylvania Department of Environmental Protection (2011) (Pennsylvania Dept of Environmental Protection, Harrisburg, PA), Marcellus Shale, http://www.dep.state. pa.us/dep/deputate/minres/oilgas/new_forms/marcellus/marcellus.htm.

23. New York State Department of Health, Bureau of Environmental Radiation Protection (2009) (New York State Dept of Health, Troy, NY), Comments, July 21, 2009, Supplemental Generic Environmental Statement on the Oil and Gas Regulatory Program Well Permit Issuance for Horizontal Drilling and Hydraulic-Fracturing to Develop the Marcellus Shale and other Low Permeability Gas Reservoirs; http://www. riverkeeper.org/wp-content/uploads/2010/01/Riverkeeper-DSGEIS-Comments-Appendix3-NYSDOH-Environmental-Radiation-Memo.pdf.

24. Taylor LE (1984) Groundwater Resources of the Upper Susquehanna River Basin, Pennsylvania: Water Resources Report 58. (Pennsylvania Dept of Environmental ResourcesOffice of Parks and Forestry-Bureau of Topographic and Geologic Survey, Harrisburg PA) 139.

25. Williams JH, Taylor L, Low D (1998) Hydrogeology and Groundwater Quality of the Glaciated Valleys of Bradford, Tioga, and Potter Counties, Pennsylvania: Water Resources Report 68. (Commonwealth of Pennsylvania Dept of Conservation and Natural Resources, Harrisburg, PA) p 89.

26. Kendall C, Coplan TB (2001) Distribution of oxygen-18 and deuterium in river waters across the United States. Hydrol Processes 15:1363-1393.

27. Van Stempvoort D, Maathuis H, Jaworski E, Mayer B, Rich K (2005) Oxidation of fugitive methane in groundwater linked to bacterial sulfate reduction. Ground Water 43:187-199.

28. Taylor SW, Sherwood Lollar B, Wassenaar LI (2000) Bacteriogenic ethane in nearsurface aquifers: Implications for leaking hydrocarbon well bores. Environ Sci Technol 34:4727-4732.

29. Cramer B, Schlomer S, Poelchau HS (2002) Uplift-related hydrocarbon accumulations: the release of natural gas from groundwater. 196 (Geological Society Special Publications, London), 447-455.

30. Geyer AR, Wilshusen JP (1982) Engineering characteristics of the rocks of Pennsylvania environmental geology supplement to the state geologic map, 1982 Pennsylvania Geological Survey. (Dept of Environmental Resources, Office of Resources Management, Harrisburg, PA)

31. Etiope G, Martinelli G (2002) Migration of carrier and trace gases in the geosphere: An overview. Phys Earth Planet Inter 129:185-204.

32. Aravena R, Wassenaar LI (1993) Dissolved organic carbon and methane in a regional confined aquifer, southern Ontario, Canada: Carbon isotope evidence for associated subsurface sources. App/ Geochem 8:483-493.

33. Coleman DD, Liu C, Riley KM (1988) Microbial methane in the shallow Paleozoic sediments and glacial deposits of the Illinois, USA. Chem Geol 71:23-40.

34. Alexander SS, Cakir R, Doden AG, Gold DP, Root SI (2005) Basement depth and related geospatial database for Pennsylvania: Pennsylvania Geological Survey, 4th ser., OpenFile General Geology Report 05-01.0. (Pennsylvania Dept of Conservation and Natural Resources, Middletown, PA), http://www.dcnr.state.pa.us/topogeo/openfile.

35. Pennsylvania Spatial Data Access (PASDA) Online mapping, data access wizard, oil and gas locations. (Pennsylvania Dept of Environmental Protection, Harrisburg, PA) http://www.pasda.psu.edu/uci/SearchResults.aspx?searchType=mapservice\&condition= OR\&entry=PASDA 
Report to Congress

\section{Management of Wastes from the Exploration, Development, and Production of Crude Oil, Natural Gas, and Geothermal Energy}

\section{Volume 1 of 3 \\ Oil and Gas}
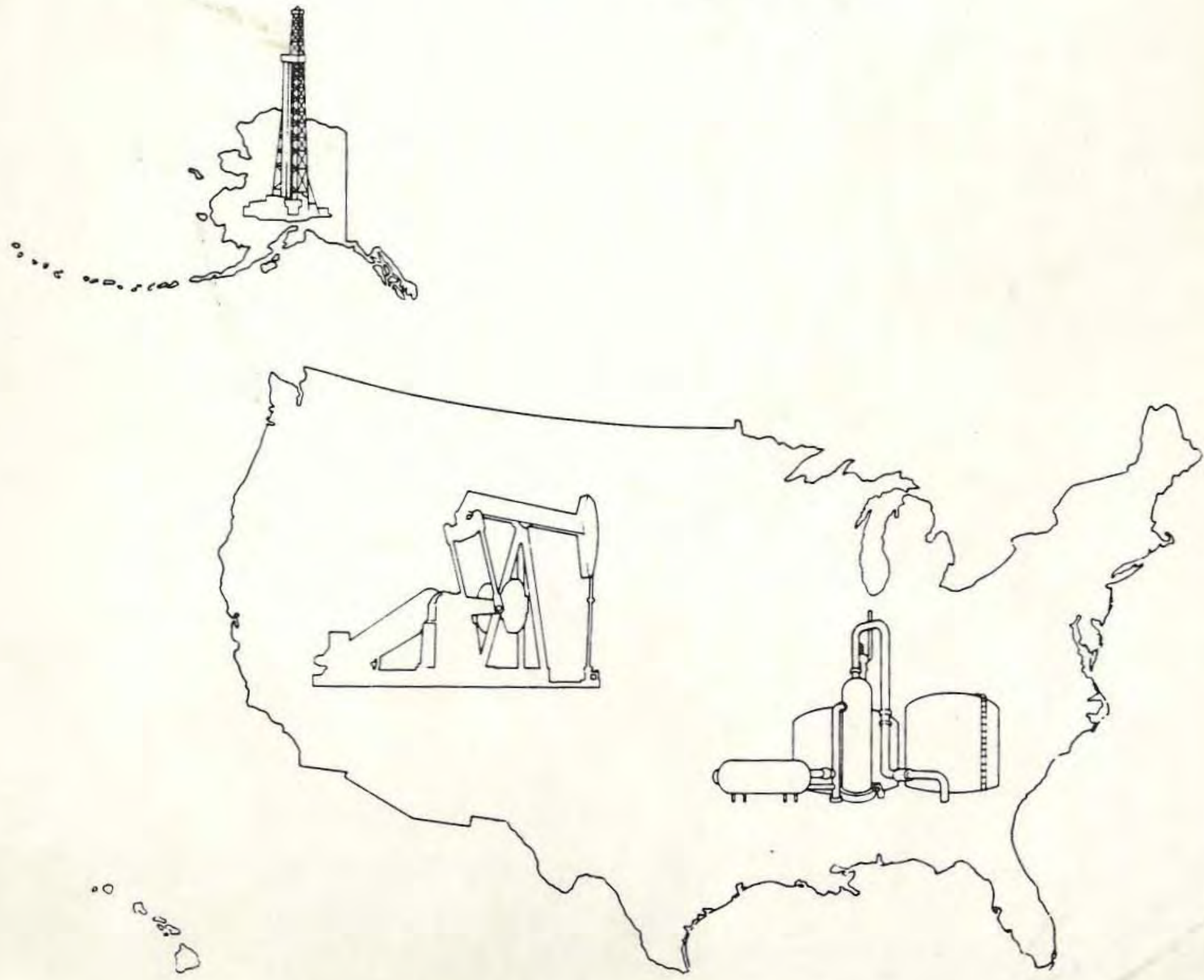


\title{
Report to Congress
}

\author{
MANAgement OF WASTES FROM THE \\ Exploration, Development, and Production \\ of Crude Oil, Natural Gas, and Geothermal Energy
}

VOLUME 1 OF 3

OIL AND GAS

UNITED STATES ENVIRONMENTAL PROTECTION AGENCY

Office of Solid Haste and Emergency Response

Washington, D.C. 20460

December 1987 
Chapter I - INTRODUCTION

Statutory Requirements and General Purpose..................I-1

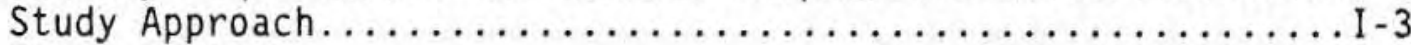

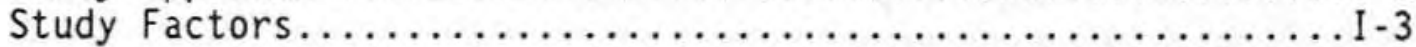

Chapter II - OVERVIEW OF THE INDUSTRY

Description of the $0 i 1$ and Gas Industry....................

Exploration and Development...........................

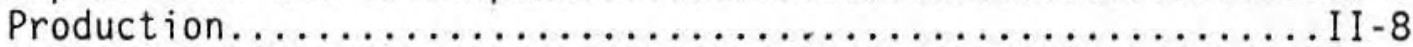

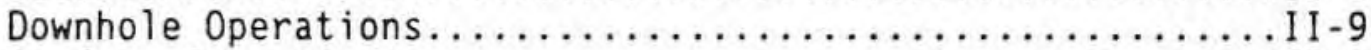

Surface Operations.............................

Definition of Exempt Wastes...............................

Scope of the Exemption...............................

Waste Volume Estimation Methodology....................11-19

Estimating Volumes of Drilling Fluids and

Cuttings ........................ 19

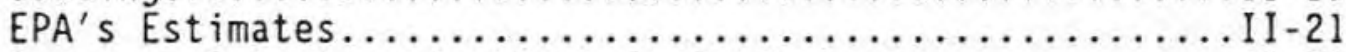

American Petroleum Institute's Estimates.............II-23

Estimating Volumes of Produced Water................... II-24

EPA's Estimates................................

API's Estimates.................................

Waste Volume Estimates.............................

Characterization of Wastes..........................

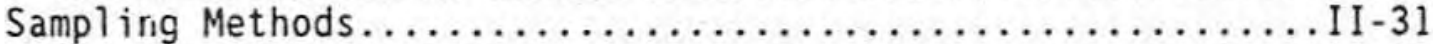

EPA Sampling Procedures..............................

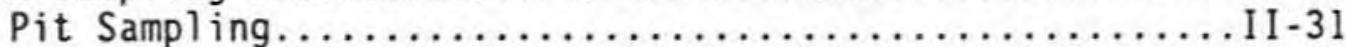

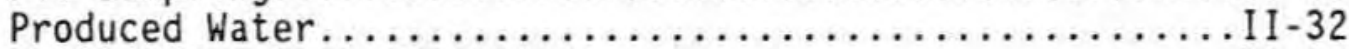

Central Treatment Facilities........................

API Sampling Methods...............................

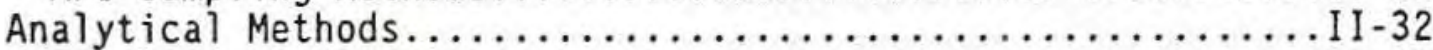

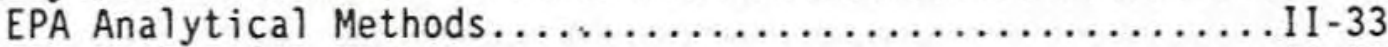

API Analytical Methods...............................

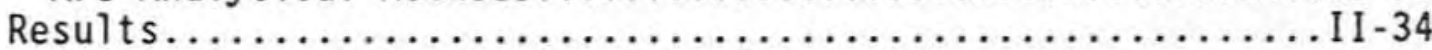

Chemical Constituents Found by EPA in $0 \mathrm{il}$ and Gas.........II-34

Comparison to Constituerits of Potential Concern

Identified in the Risk Analysis.................... II-36 
Chapter II - Continued Page

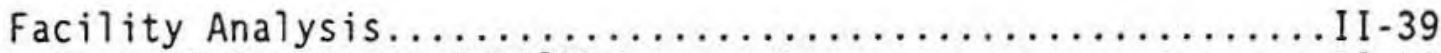

Central Treatment Facility..........................II-40

Central Pit Facility................................

Drilling Facilities................................

Production Facility.............................

Waste Characterization Issues...........................

Toxicity Characteristic Leaching Procedure (TCLP)..........II-41

Solubility and Mobility of Constituents.................. II-43

Phototoxic Effect of Polycyclic Aromatic

Hydrocarbons (PAH) ........................ 44

$\mathrm{pH}$ and 0 ther RCRA Characteristics......................

Use of Constituents of Concern.........................

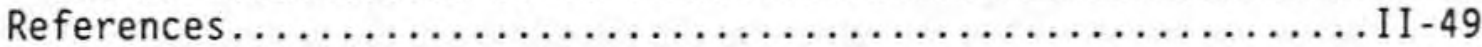

Chapter III - CURRENT AND ALTERNATIVE WASTE MANAGEMENT PRACTICES

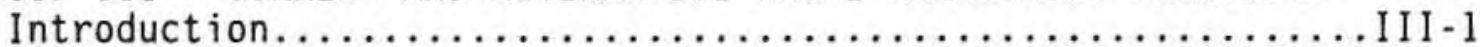

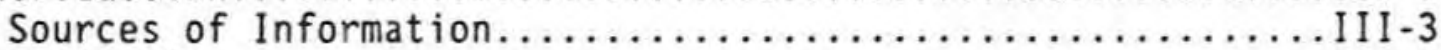

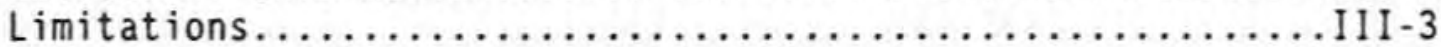

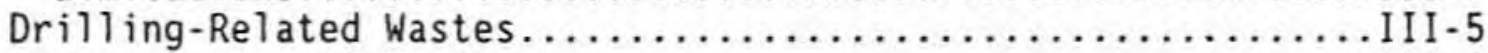

Description of Waste................................

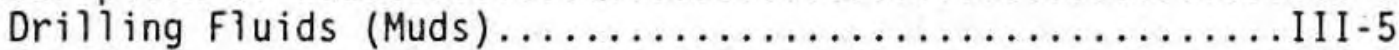

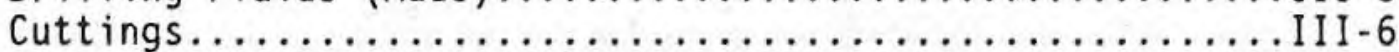

Waste Chemicals..................................

Fracturing and Acidizing Fluids......................

Completion and Workover Fluids.......................

Rigwash and Other Miscellaneous Wastes..................III-13

Onsite Drilling Waste Management Methods..................III-13

Reserve Pits..................................III-14

Annular Disposal of Pumpable Drilling Wastes..............III-18

Drilling Waste Sol idification........................III-20

Treatment and Discharge of Liquid Wastes to Land

or Surface Water.....................................

Closed Cycle Systems..................................

Disposal of Drilling Wastes on the North Slope of

Alaska.........................................

Offsite Waste Management Methods....................... III-27

Centralized Disposal Pits............................ III-27

Centralized Treatment Facilities.......................... 
Chapter III - Continued Page

Commercial Landfarming....................... II -30

Reconditioning and Reuse of Drilling Media..............III-32

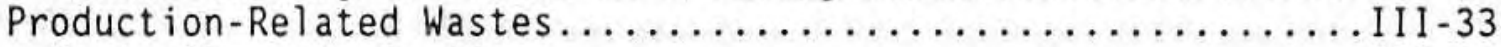

Waste Characterization.......................... II -33

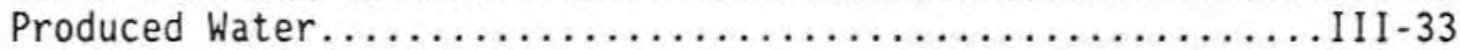

Low-Volume Production Wastes........................ II 34

Onsite Management Methods...........................

Subsurface Injection........................... II 35

Evaporation and Percolation Pits................... II -44

Discharge of Produced Waters to Surface Water

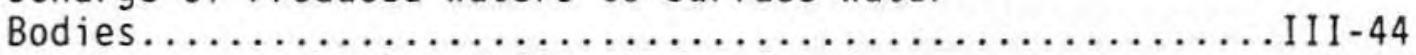

Other Production-Related Pits............................ 45

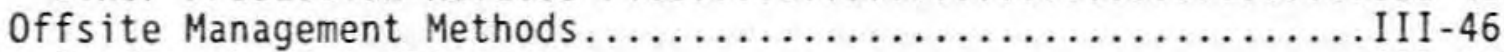

Road or Land Applications................................. 46

Well Plugging and Abandonment........................ II -47

References................................... II -49

\section{Chapter IV - DAMAGE CASES}

Introduction .........................

Purpose of Damage Case Review........................

Methodology for Gathering Damage Case Information............ IV-2

Information Categories..............................

Sources and Contacts..................................

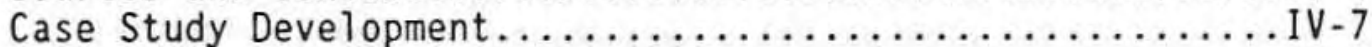

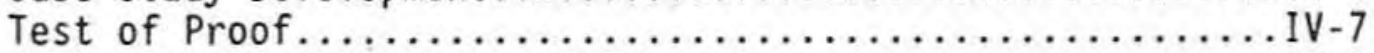

Review by State Groups and Other Sources................

Limitations of the Methodology and Its Results...............

Schedule for Collection of Damage Case Information.......... IV-9

Limited Number of $0 i 1$ - and Gas-Producing States

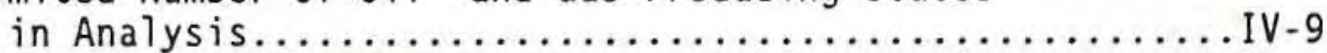

Difficulty in Obtaining a Representative Sample............. 10

Organization of this Presentation......................

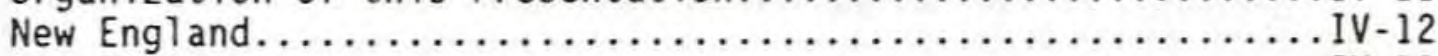

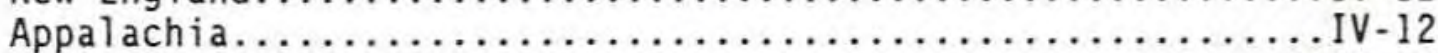

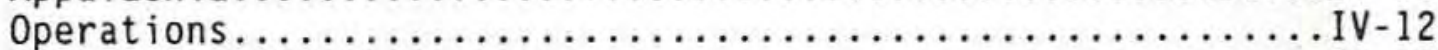

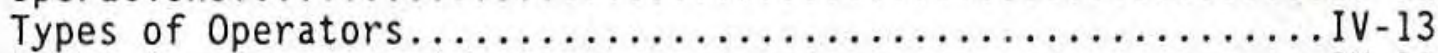

Major Issues............................ 


\section{TABLE OF CONTENTS (continued)}

Chapter IV - (Continued) Page

Contamination of Ground Water from Reserve Pits...........IV-13

Illegal Disposal of 0il Field Wastes in Ohio...............

Contamination of Ground Water from Annular Disposal

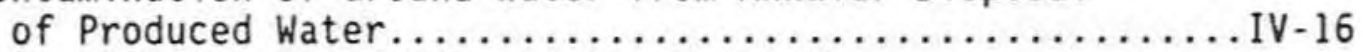

Illegal Disposal of $0 i 1$ and Gas Waste in

West Virginia.......................... 17

Illegal Disposal of 0 il Field Waste in

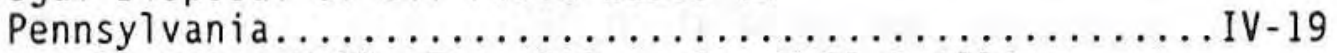

Damage to Water Wells From 0 il or Gas Well Drilling

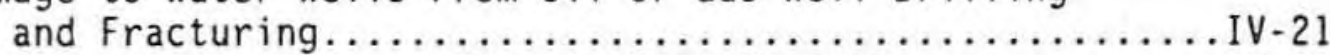

Problems with Landspreading in West Virginia............

Problems with Enhanced 0 il Recovery (EOR) and

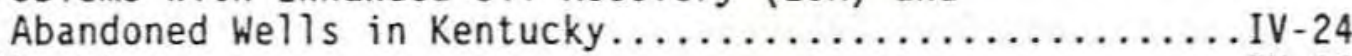

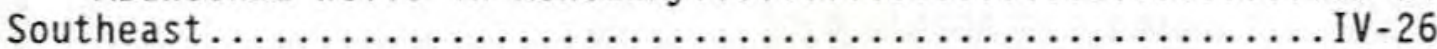

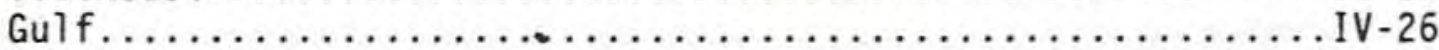

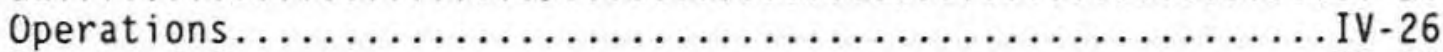

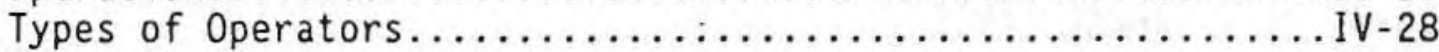

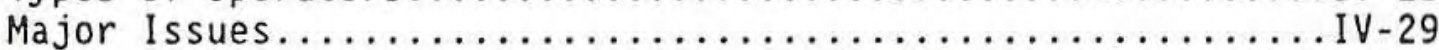

Ground Water Contamination from Unlined Produced

Water Disposal Pits and Reserve Pits................. 29

Allowable Discharge of Drilling Mud Into.Gulf Coast

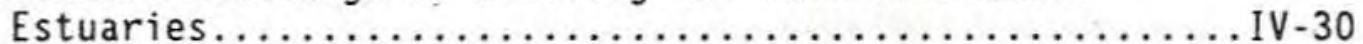

Illegal Disposal of Oil Field Waste in the Louisiana

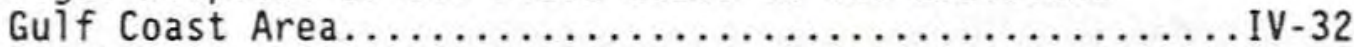

Illegal Disposal of 0 il Field Waste in Arkansas........... IV-35

Improperly Operated Injection Wells..................

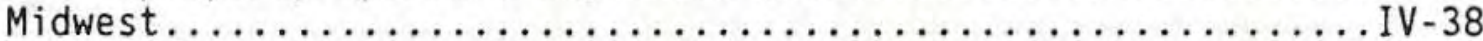

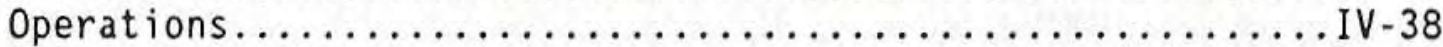

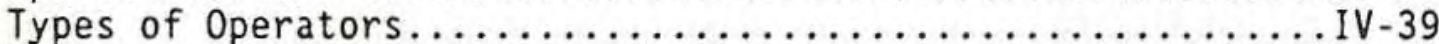

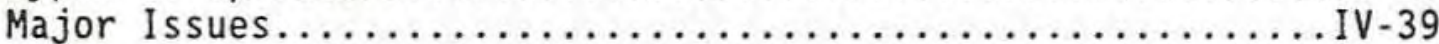

Groundwater Contamination in Michigan................ IV-39

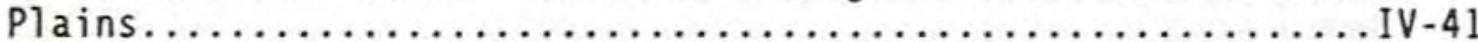

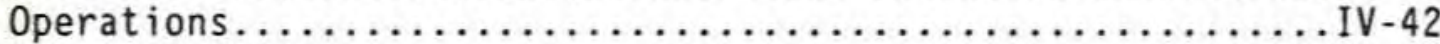

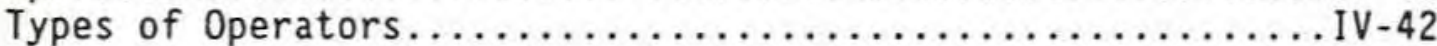

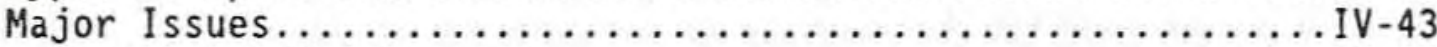

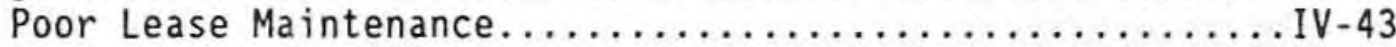

Unl ined Reserve Pits............................. 45 
Chapter IV - Continued Page

Problems with Injection Wells $\ldots \ldots \ldots \ldots \ldots \ldots \ldots \ldots \ldots \ldots \ldots \ldots \ldots$ IV -46

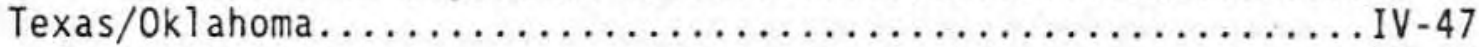

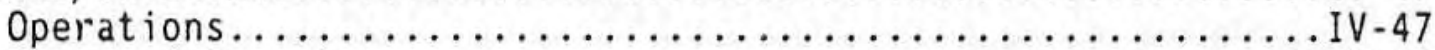

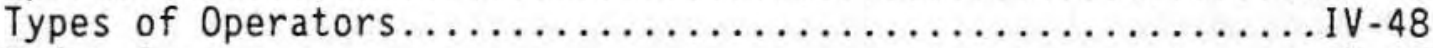

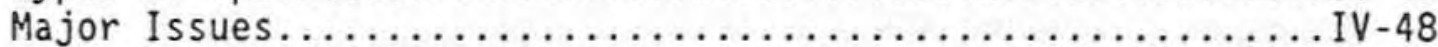

Discharge of Produced Water and Drilling Mud into Bays and Estuaries of the Texas Gulf Coast................. Leaching of Reserve Pit Constituents into Ground Water.... IV-52 Chloride Contamination of Ground Water from Operation of Injection Wells.............................. IV 53

Illegal Disposal of $0 i 1$ and Gas Wastes................. IV-54

Northern Mountain....................................

Operations..........................................

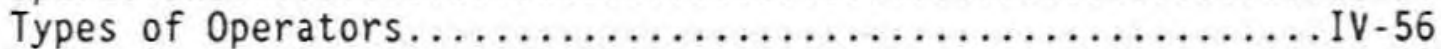

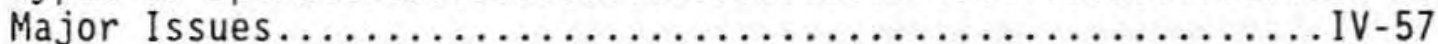

Illegal Disposal of $0 i 1$ and Gas Wastes..................

Reclamation Problems........................... 58

Discharge of Produced Water into Surface Streams........... IV-59

Southern Mountain..................................... 60

Operations.......................................

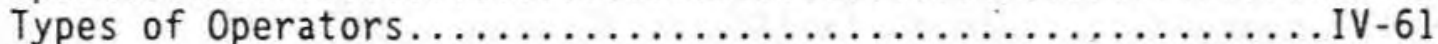

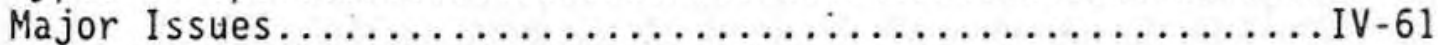

Produced Water Pit and 0il Field Waste Pit Contents

Leaching into Ground Water....................... 61

Damage to Ground Water from Inadequately Maintained

Injection Wells.................................. 65

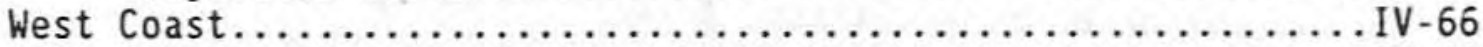

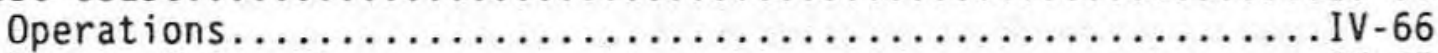

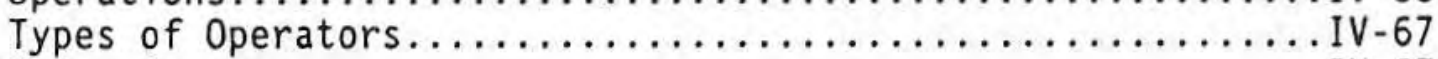

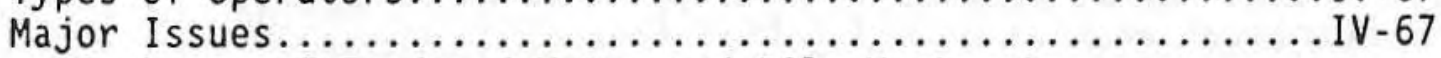

Discharge of Produced Water and 0ily wastes to

Ephemeral Streams............................... 67

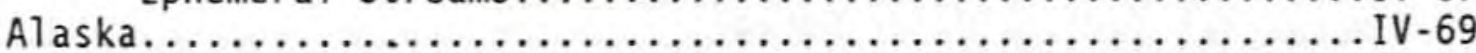

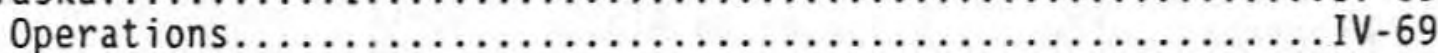

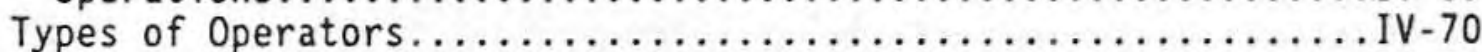

Major Issues......................................

Reserve Pits, North Slope........................ 


\section{TABLE OF CONTENTS (cont inued)}

Chapter IV - Continued $\quad \underline{\text { Page }}$

Waste Disposal on the North Slope................ IV-73

Disposal of Drilling Wastes, Kenai Peninsula.............. IV-74

Miscellaneous Issues............................. IV

Improper Abandoned and Improperly Plugged Wells............ IV-76

Contamination of Ground Water with Hydrocarbons............. IV-79

0 il Spills in the Arctic............................ 80

Chapter V - RISK MODELING

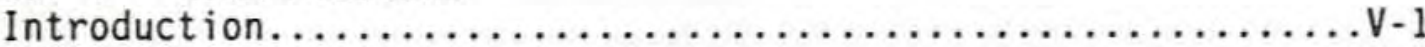

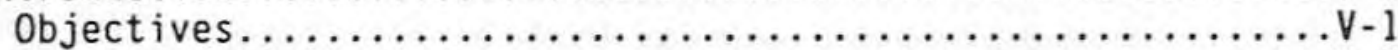

Scope and Limitations..........................

Quantitative Risk Assessment Methodology.................

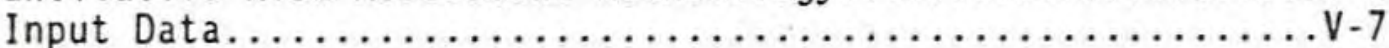

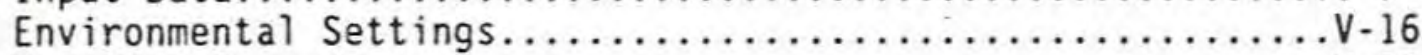

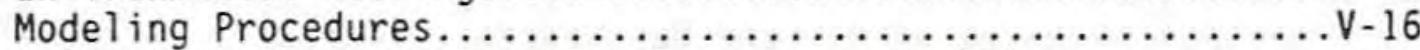

Quantitative Risk Modeling Results: Human Health............

Onsite Reserve Pits -. Drilling Wastes.................. V-23

Nationally Weighted Risk Distributions................

Zone-Weighted Risk Distributions.................

Evaluation of Major Factors Affecting Health Risk........V-29

Underground Injection -. Produced Fluids............... 34

Nationally Weighted Risk Distribution................

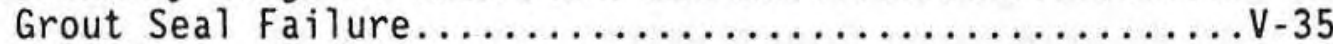

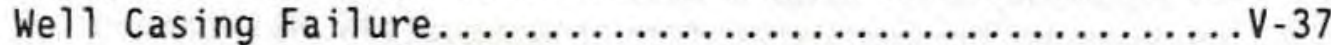

Zone-Weighted Risk Distributions..................

Evaluation of Major Factors Affecting Health Risk........V-41

Direct Discharge of Produced Water to Surface Streams.......V-44

Potentially Exposed Population...................... -45

Quantitative Risk Modeling Results: Resource Damage......... V-50

Potential Ground-Water Damage -. Drilling Wastes............ V-51

Potential Ground-Water Damage .. Produced Water............ V-53

Potential Surface Water Damage...................... V-54

Assessment of Waste Disposal on Alaska's North Slope......... -55

Locations of $0 i l$ and Gas Activities in Relation to

Environments of Special Interest....................

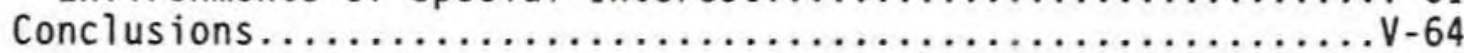

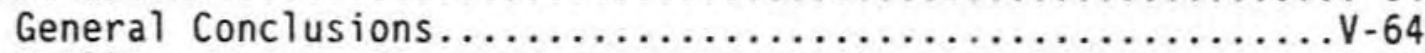

Drilling Wastes Disposed of in Onsite Reserve Pits........V-65

Produced Fluid Wastes Disposed of in Injection Wells.......V-67 


\section{TABLE OF CONTENTS (continued)}

Chapter V - Continued $\quad \underline{\text { Page }}$

Stripper Well-Produced Fluid Wastes Discharged

Directly into Surface Water....................... 69

Drilling and Production Wastes Disposed of on Alaska's

North Slope.................................. 69

Locations of 0 il and Gas Activities in Relation to

Environments of Special Interest....................

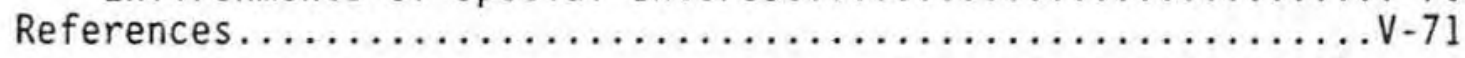

Chapter VI - COSTS AND ECONOMIC IMPACTS OF ALTERNATIVE

WASTE MANAGEMENT PRACTICES

Overview of the Cost and Economic Impact Analysis............ VI-1

Cost of Basel ine and Alternative Waste Management

Practices................................... 3

Identification of Waste Management Practices.............VI-3

Cost of Waste Management Practices.................... VI-6

Waste Management Scenarios and Applicable Waste

Management Practices............................. 14

Basel ine Scenario..................................

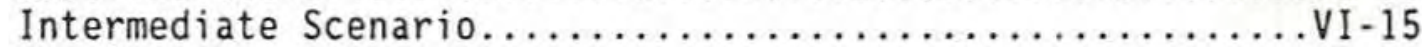

The Subtitle $C$ Scenario................................

The Subtitle $C-1$ Scenario............................

Summary of Waste Management Scenarios..................

Cost and Impact of the Waste Management Scenarios for

Typical New $0 i 1$ and Gas Projects...................... 18

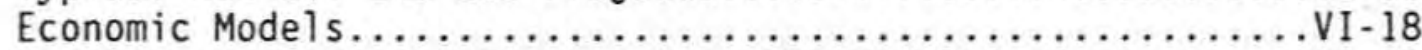

Quantities of Wastes Generated by the Model Projects.......VI-21

Model Project Waste Management Costs................... II-21

Impact of Waste Management Costs on Representative

Projects...................................... 25

Regional and National-Level Compliance Costs of the

Waste Management Scenarios.........................

Closure Analysis for Existing Wells........................

Intermediate and Long-Term Effects of the Waste

Management Scenarios............................... 35

Production Effects of Compliance Costs................. VI-35

Additional Impacts of Compliance Costs................ II-37

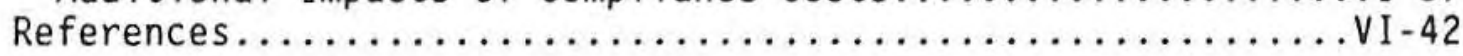

Chapter VII - CURRENT REGULATORY PROGRAMS

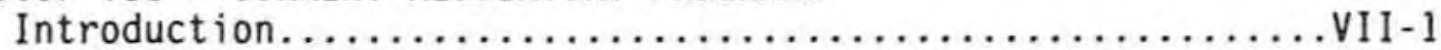

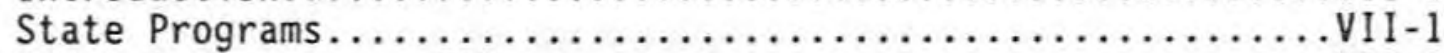

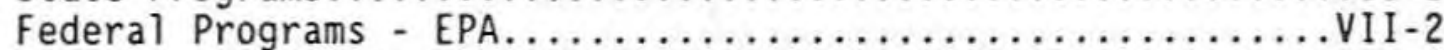

Underground Injection Control...................... VII-2

Effluent Limitations Guidelines....................VII-4 
Chapter VII - Continued Page

Summary of Major Regulatory Activity Related to Onshore $0 i 1$ and Gas..........................

Onshore Segment Subcategories......................

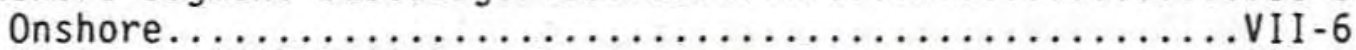

Stripper $(0 i 1$ Wells)............................ 6

Coastal..................................

Wildl ife and Agriculture Use......................

Federal Programs - Bureau of Land Management...............

Introduction. ........................ 8

Regulatory Agencies........................

Rules and Regulations........................

Drilling............................... 10

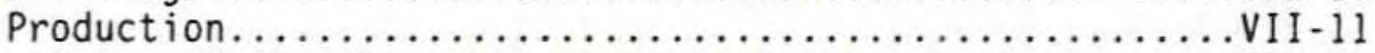

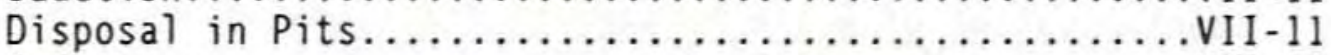

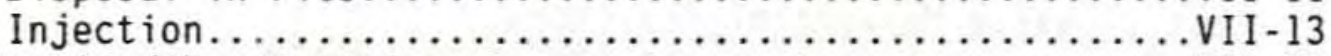

Plugging/Abandonment............................ 13

Implementation of State and Federal Programs............... VII-14

References..............................

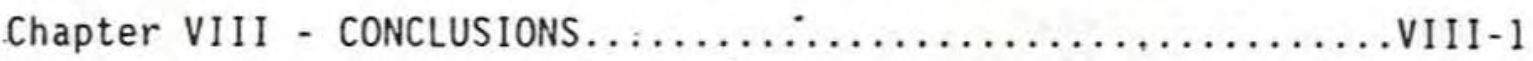

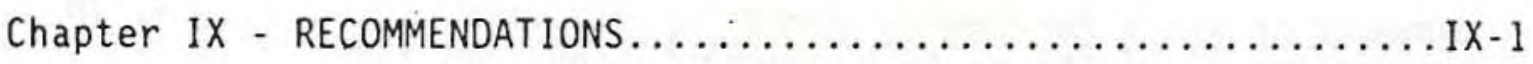




\section{LIST OF TABLES}

$\underline{\text { Table }}$

Page

II-1 Partial List of Exempt and Nonexempt Wastes.............II-20

II-2 Estimated U.S. Drill ing Waste Volumes, 1985.............II-27

II-3 Estimated U.S. Produced Water Volumes, $1985 \ldots \ldots \ldots \ldots \ldots$ II-29

II-4 Constituents of Concern Found in Waste Streams

Sampled by EPA and API........................ II 37

II-5 EPA Samples Containing Constituents of Concern............II-38

II-6 pH Values for Exploration, Development, and Production

Wastes (EPA Samples)........................... II-46

II-7 Comparison of Potential Constituents of Concern that

Were Modeled in Chapter V........................ II-48

III-1 States with Major 0il Production Used as Primary

References in This Study.........................III-4

III-2 Characterization of $0 i 1$ and Gas Drilling Fluids..........III-7

IV-1 Types of Damage of Concern to This Study............... IV-3

IV-2 List of States from Which Case Information Was

Assembled...................................

IV-3 Sources of Information Used in Developing Damage Cases...IV-6

$V-1$ Model Constituents and Concentrations...............

$V-2$ Toxicity Parameters and Effects Thresholds...............

V-3 Drilling Pit Waste (Waste-Based) Management Practices.....V-14

V-4 Produced Water Waste Management Practices.............. V-15

V-5 Values and Sources for Environmental Setting Variables....V-17

V-6 Definition of Best-Estimate and Conservative Release

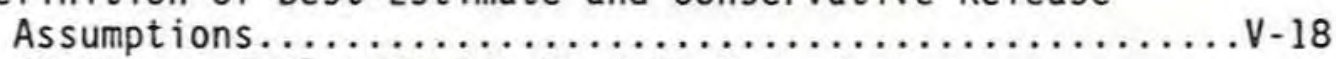

V-7 Definition of Flow Fields Used in Groundwater

Transport Modeling............................ 22

V-8 Surface Water Flow Rates at Which Concentrations of Waste Stream Constituents in the Mixing Zone Will Exceed Reference Levels.........................

V-9 Population Potentially Exposed Through Private Drinking Water Wells at Sample Drilling and Production Areas.....V-48

V-10 Population Potentially Exposed Through Public Water Supplies at Sample Drilling and Production Areas........V-49

V-11 Surface Water Flow Rates at Which Concentrations of Waste Stream Constituents in the Mixing Zone Will Exceed Aquatic Effects and Resource Damage Thresholds...V-56 


\section{LIST OF TABLES (cont inued)}

Table

Page

VI-1 Summary of Baseline Disposal Practices................

VI-2 Summary of Engineering Design Elements for Baseline and Alternative Waste Management Practices..............

VI-3 Unit Costs of Drilling Waste Disposal Options, by Zone....VI-12

VI-4 Unit Costs of Underground Injection of Produced Water,

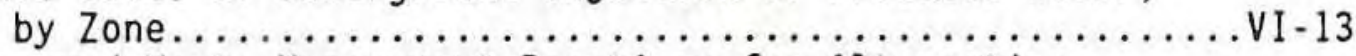

VI-5 Assumed Waste Management Practices for Alternative Waste Management Scenarios.......................... 19

VI-6 Economic Parameters of Model Projects for U.S.

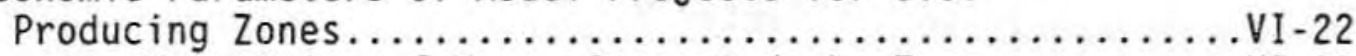

VI-7 Average Quantities of Waste Generated, by Zone........... VI-23

VI-8 Weighted Average Regional Costs of Drilling Waste Management for Model Projects Under Alternative Waste Management Scenarios....................... 26

VI-9 Weighted Average Unit Costs of Produced Water Management for Model Projects Under Alternative Waste Management Scenarios........................ 27

VI-10 Impact of Waste Management Costs on Model Projects: Comparisons of After-Tax Internal Rate of Return........VI-28

VI-11 Impact of Waste Management Costs on Model Projects: Increase in Total cost of Production..................

VI-12 Annual Regional and National RCRA Compliance Costs of Alternative Waste Management Scenarios.........VI-31

VI-13 Distribution of 011 Production Across Existing

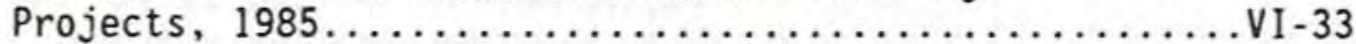

VI-14 Impact of Waste Management Cost on Existing Production....VI-34

VI-15 Long-Term Impacts on Production of Cost Increases Under Waste Management Scenarios.................... 38

VI-16 Effect of Domestic Production Decline on Selected Economic Parameters in the Year 2000............... 39

VII-1 Reserve Pit Design, Construction, and Operation........VII-15 VII-2 Reserve Pit Closure/Waste Removal.................. VII-20 VII-3 Produced Water Pit Design and Construction.............. II-24 VII-4 Produced Water Surface Discharge Limits............... VII-26 VII-5 Produced Water Injection Well Construction............... VII-28 VII-6 Well Abandonment/Plugging.................... VII-7 State Enforcement Matrix........................... VII -8

BLM Enforcement Matrix........................ 


\section{LIST OF FIGURES}

Figure

$\underline{\text { Page }}$

I-1 $0 i 1$ and Gas Production Zones....................

II-1 Typical Rotary Drilling Rig........................

II-2 Typical Production Operation, Showing Separation of

$0 \mathrm{il}$, Gas, and Water.............................11

II-3 Average Water Production with Dissolved/Associated Gas...II-12

II-4 0il Production with High 0 il/Water Ratio Without

Significant Dissolved Associated Gas................II-13

III-1 Annular Disposal of Waste Drilling Fluid..............III-19

III-2 Typical Produced Water Disposal Design.................III-37

III-3 Annular Disposal Outside Production Casing.............III-38

III-4 Pollution of a Freshwater Aquifer Through

Improperly Abandoned Wells...................... II I-48

V-1 Overview of Quantitative Risk Assessment Methodology......V-6

V-2 Overview of Modeling Scenarios Considered in the Quantitative Risk Assessment.....................

V-3 Nationally Weighted Distribution of Health Risk Estimates............................. 25

V-4 Weighted vs. Unweighted Distribution of Cancer Risk Estimates............................... 27

V-5 Health Risk Estimates (Unweighted) as a Function of Size and Distance............................ 32

V-6 Health Risk Estimates (Unweighted) as a Function of Ground-Water Type........................... 33

V-7 Nationally Weighted Distribution of Health Risk

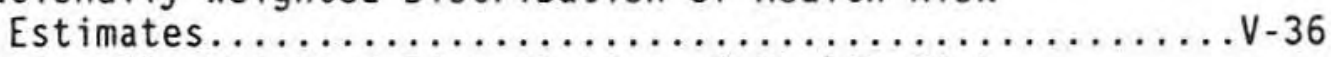

V-8 Nationally Weighted Distribution of Health Risk

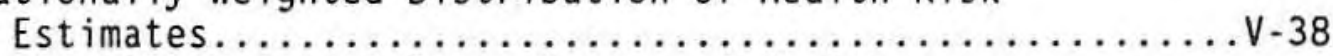

V-9 Nationally Weighted Distribution of Health Risk Estimates.................................. 39

$V-10$ Health Risk Estimates (Unweighted) as a Function of Ground-Water Type................................. 


\section{LIST OF EXHIBITS}

Exhibit

$\underline{\text { Page }}$

Exhibit 1 Section $8002(\mathrm{~m})$ Resource Conservation and

Recovery Act as amended by PL $96-482 \ldots \ldots \ldots \ldots \ldots$ I-13 


\section{CHAPTER I}

\section{INTRODUCTION}

\section{STATUTORY REQUIREMENTS AND GENERAL PURPOSE}

Under Section 3001 (b)(2)(A) of the 1980 Amendments to the Resource Conservation and Recovery Act (RCRA), Congress temporarily exempted several types of solid wastes from regulation as hazardous wastes, pending further study by the Environmental Protection Agency (EPA). ${ }^{1}$ Among the categories of wastes exempted were "drilling fluids, produced waters, and other wastes associated with the exploration, development, or production of crude oil or natural gas or geothermal energy." Section $8002(\mathrm{~m})$ of the Amendments requires the Administrator to study these wastes and submit a final report to Congress. This report responds to those requirements. Because of the many inherent differences between the oil and gas industry and the geothermal energy industry, the report is submitted in three volumes. Volume 1 (this volume) covers the oil and gas industry; Volume 2 covers the geothermal energy industry; Volume 3 covers State regulatory summaries for the oil and gas industry and includes a glossary of terms. This report discusses wastes generated only by the onshore segment of the oil and gas industry.

The original deadline for this study was October 1982. EPA failed to meet that deadline, and in August 1985 the Alaska Center for the Environment sued the Agency for its failure to conduct the study.

1 EPA is also required to make regulatory determinations affecting the 011 and gas and geothermal energy industries under several other major statutes. These include designing appropriate eff luent limitations guidelines under the Clean Water Act, determining emissions standards under the Clean Air Act, and implementing the requirements of the underground injection control program under the Safe Drinking Water Act. 
EPA entered into a consent order, obligating it to submit the final Report to Congress on or before August 31, 1987. In April 1987, this schedule was modified and the deadline for submittal of the final Report to Congress was extended to December 31, 1987.

Following submission of the current study, and after public hearings and opportunity for comment, the Administrator of EPA must determine either to promulgate regulations under the hazardous waste management provisions of RCRA (Subtitle C) or to declare that such regulations are unwarranted. Any regulations would not take effect unless authorized by an act of Congress.

This does not mean that the recommendations of this report are limited to a narrow choice between application of full Subtitle $C$ regulation and continuation of the current exemption. Section 8002 (m) specifically requires the Administrator to propose recommendations for "[both] Federal and non-Federal actions" to prevent or substantially mitigate any adverse effects associated with management of wastes from these industries. EPA interprets this statement as a directive to consider the practical and pruderit means available to avert health or environmental damage associated with the improper management of oil, gas, or geothermal wastes. The Agency has identified a wide range of possible actions, including voluntary programs, cooperative work with States to modify their programs, and Federal action outside of RCRA Subtitle C, such as RCRA Subtitle D, the existing Underground Injection Control Program under the Safe Drinking Water Act, or the National Pollution Discharge Elimination System under the Clean Water Act.

In this light, EPA emphasizes that the recommendations presented here do not constitute a regulatory determination. Such a determination cannot be made until the public has had an opportunity to review and comment on this report (i.e., the determination cannot be made until June 1988). Furthermore, the Agency is, in several important areas, presenting optional approaches involving further research and consultation with the States and other affected parties. 


\section{STUDY APPROACH}

The study factors are listed in the various paragraphs of Section $8002(\mathrm{~m})$, which is quoted in its entirety as Exhibit 1 (page I-13). For clarity, the Agency has designed this report to respond specifically to each study factor within separate chapters or sections of chapters. It is important to note that although every study factor has been weighed in arriving at the conclusions and recommendations of this report, no single study factor has a determining influence on the conclusions and recommendations.

The study factors are defined in the paragraphs below, which also introduce the methodologies used to analyze each study area with respect to the oil and gas industry. More detailed methodological discussions can be found later in this report and in the supporting documentation and appendices.

\section{STUDY FACTORS}

The principal study factors of concern to Congress are listed in subparagraphs (A) through (G) of Section $8002(\mathrm{~m})(1)$ (see Exhibit 1). The introductory and concluding paragraphs of the Section, however, also contain directives to the Agency on the content of this study. This work has therefore been organized to respond to the following comprehensive interpretation of the $8002(\mathrm{~m})$ study factors.

\section{Study Factor 1 - Defining Exempt Wastes}

RCRA describes the exempt wastes in broad terms, referring to "drilling fluids, produced waters, and other wastes associated with the exploration, development, or production of crude $0 i 1$ or natural gas or geothermal energy." The Agency, therefore, relied to the extent possible on the legislative history of the amendments, which provides guidance on the definition of other wastes. The tentative scope of the exemption is discussed in Chapter II of this volume. 
Study Factor 2 - Specifying the Sources and Volumes of Exempt Wastes

In response to Section $8002(\mathrm{~m})(1)(A)$, EPA has developed estimates of the sources and volumes of all exempt wastes. The estimates are presented in Chapter II, "Overview of the Industry."

Comprehensive information on the volumes of exempt wastes from oil and gas operations is not routinely collected nationwide; however, estimates of total volumes produced can be made through a variety of approaches.

With respect to drilling muds and related wastes, two methods for estiunating volumes are presented. The first, developed early in the study by EPA, estimates drilling wastes as a function of the size of reserve pits. The second method is based on a survey conducted by the American Petroleum Institute (API) on production of drilling muds and completion fluids, cuttings, and other associated wastes discharged to reserve pits. Both methods and their results are included in Chapter II.

Similarly, EPA and API developed independent estimates of produced water volumes. EPA's first estimates were based on a survey of the injection, production, and hauling reports of State agencies; API's were based on its own survey of production operations. Again, this report presents the results of both methodologies.

\section{Study Factor 3 - Characterizing Wastes}

Section $8002(\mathrm{~m})$ does not directly call for a laboratory analysis of the exempted wastes, but the Agency considers such a review to be a necessary and appropriate element of this study. Analysis of the principal high-volume wastes (i.e., drilling fluids and produced waters) can help to indicate whether any of the wastes may be hazardous under the 
definitions of RCRA Subtitle $C$. Wastes were examined with regard to whether they exhibited any of the hazardous characteristics defined under 40 CFR 261 of RCRA, including extraction procedure toxicity, ignitability, corrosivity, and reactivity. Also, a compositional analysis was performed for the purpose of determining if hazardous constituents were present in the wastes at concentrations exceeding accepted health-based limits.

EPA therefore conducted a national screening type program that sampled facilities to compile relevant data on waste characteristics. Sites were selected at random in cooperation with State regulatory agencies, based on a division of the United States into zones (see Figure I-1). Samples were subjected to extensive analysis, and the results were subjected to rigorous quality control procedures prior to their publication in January 1987. Simultaneously, using a different sampling methodology, API sampled the same sites and wastes covered by the EPA-sponsored survey. Chapter II of this report, "Overview of the Industry," presents a summary of results of both programs.

\section{Study Factor 4 - Describing Current Disposal Practices}

Section $8002(m)(1)(B)$ calls for an analysis of current disposal practices for exempted wastes. Chapter III, "Current and Alternative Waste Management Practices," summarizes EPA's review, which was based on a number of sources. Besides reviewing the technical literature, EPA sent representatives to regulatory agencies of the major oil- and gas-producing States to discuss current waste management technologies with State representatives. In addition, early drafts of this study's characterizations of such technologies were reviewed by State and industry representatives. 


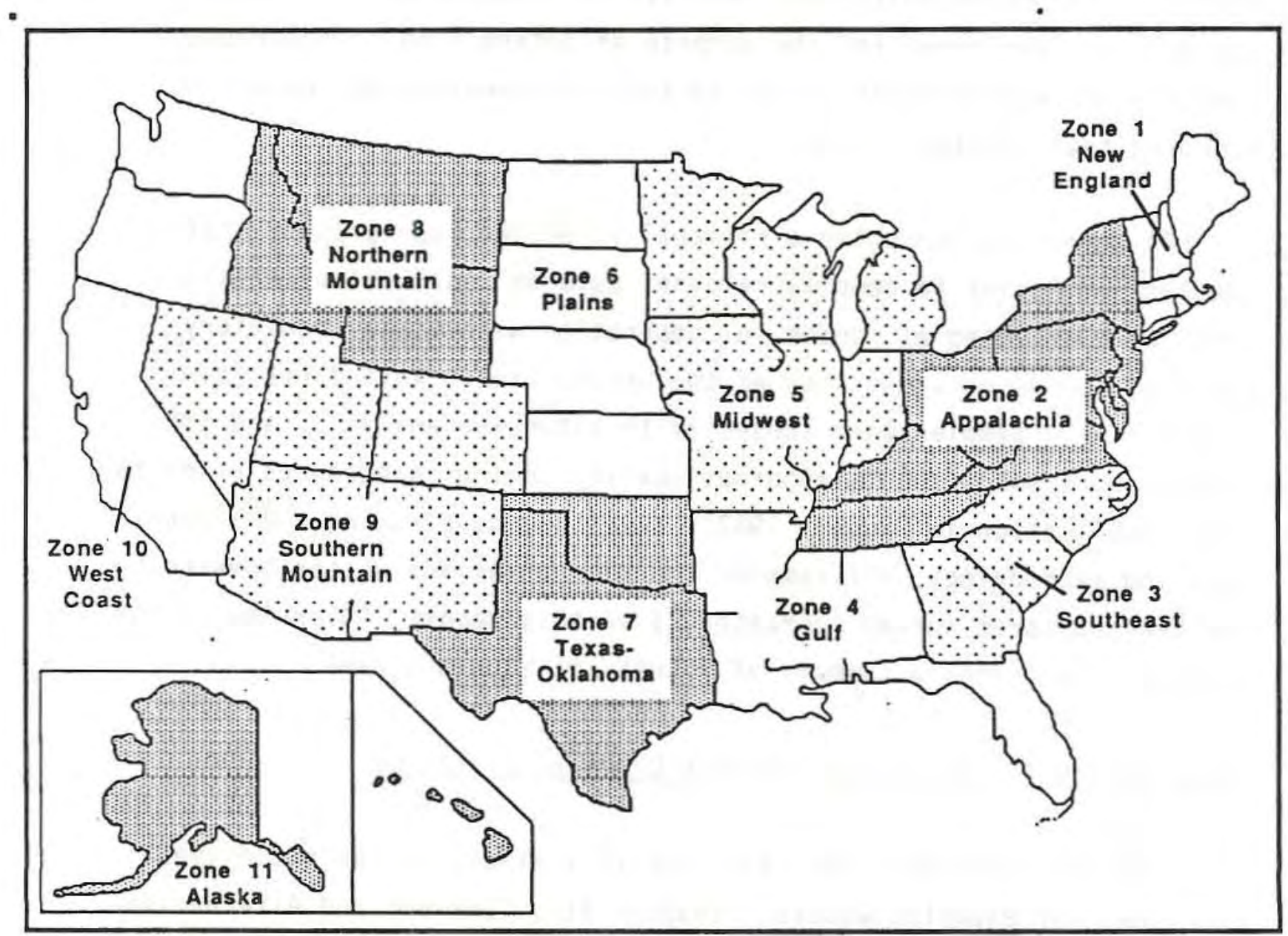

Figure 1-1

Oil and Gas Production Zones

Divisions of the United States

Used for the

RCRA Section 8002(m) Study of OII and Gas Wastes 
The Agency intentionally has not compiled an exhaustive review of waste management technologies used by the oil and gas industry. As stressed throughout this volume, conditions and methods vary widely from State to State and operation to operation. Rather, the Agency has described the principal and common methods of managing field-generated wastes and has discussed these practices in general and qualitative terms in relation to their effectiveness in protecting human health and the environment.

Study Factor 5 - Documenting Evidence of Damage to Human Health and the Environment Caused by Manaqement of $0 \mathrm{il}$ and Gas Wastes

Section $8002(m)(1)(D)$ requires EPA to analyze "documented cases" of health and environmental damage related to surface runoff or leachate. Although EPA has followed this instruction, paragraph (1) of the section also refers to "adverse effects of such wastes [i.e., exempted wastes, not necessarily only runoff and leachate] on humans, water, air, health, welfare, and natural resources...."

Chapter IV, "Damage Cases," summarizes EPA's effort to collect documented evidence of harm to human health, the environment, or valuable resources. Cases were accepted for presentation in this report only if, prior to commencement of field work, they met the standards of the test of proof, defined as (1) a scientific study, (2) an administrative finding of damage under State or other applicable authority, or (3) determination of damage by a court. Many cases met more than one such test of proof.

A number of issues of interpretation have been raised that must be clarified at the outset. First, in the Agency's opinion, the case study approach, such as that called for by Section $8002(\mathrm{~m})$, is intended only to define the nature and range of known damages, not to estimate the frequency or extent of damages associated with typical operations. The 
results presented here should not be interpreted as having statistical significance. The number of cases reported in each category bears no statistically significant relationship to the actual types and distribution of damages that may or may not exist across the United States.

Second, the total number of cases bears no implied or intended relationship to the total extent of damage from oil or gas operations caused at present or in the past.

Third, Section 8002 (m)(1)(D) makes no mention of defining relationships between documented damages and violations of State or other Federal regulations. As a practical necessity, EPA has in fact relied heavily on State enforcement and complaint files in gathering documentation for this section of the report. ${ }^{2}$ Consequently, a large proportion of cases reported here involve violations of State regulations. However, the fact that the majority of cases presented here involve State enforcement actions implies nothing, positive or negative, about the success of state programs in enforcing their requirements on industry.

Study Factor 6 . Assessing Potential Danger to Human Health or the Environment from the Wastes

Section $8002(m)(1)(C)$ requires analysis of the potential dangers of surface runoff and leachate. These potential effects can involve all types of damages over a long period of time and are not necessarily limited to the categories of damages for which documentation is currently available.

2 Other sources have included evidence submitted by private citizens or supplied by attorneys in response to inquiries from EPA researchers 
Several methods of estimating potential damages are available, and EPA has combined two approaches in responding to this study factor in Chapter V, "Risk Modeling." The first has been to use quantitative risk assessment modeling techniques developed for use elsewhere in the RCRA program. The second has been to apply more qualitative methods, based on traditional environmental assessment techniques.

The goal of both the quantitative and the qualitative risk assessments has been to define the most important factors in causing or averting human health risk and environmental risk from field operations. For the quantitative evaluation, EPA has adapted the EPA Liner Location Model, which was built to evaluate the impacts of land disposal of hazardous wastes, for use in analyzing drilling and production conditions. Since oil and gas operations are in many ways significantly different from land disposal of hazardous wastes, all revisions to the Liner Location Model and assumptions made in its present application have been extensively documented and are summarized in Chapter $V$. The procedures of traditional environmental assessment needed no modification to be applied.

As is true in the damage case work, the results of the modeling analysis have no statistical significance in terms of either the pattern or the extent of damages projected. The Agency modeled a subset of prototype situations, designed to roughly represent significant variations in conditions across the country. The results are very useful for characterizing the interactions of technological, geological, and climatic differences as they influence the potential for damages.

Study Factor 7 - Reviewing the Adequacy of Government and Private Measures to Prevent and/or Mitigate any Adverse Effects

Section 8002 (m)(1) requires that the report's conclusions of any adverse effects associated with current management of exempted wastes 
include consideration of the "adequacy of means and measures currently employed by the oil and gas industry, Government agencies, and others" to dispose of or recycle wastes or to prevent or mitigate those adverse effects.

Neither the damage case assessment nor the risk assessment provided statistically representative data on the extent of damages, making it impossible to compare damages in any quantitative way to the presence and effectiveness of control efforts. The Agency's response to this requirement is therefore based on a qualitative assessment of all the materials gathered during the course of assembling the report and on a review of State regulatory programs presented in Chapter VII, "Current Regulatory Programs." Chapter VII reviews the elements of programs and highlights possible inconsistencies, lack of specificity, potential problems in implementation, or gaps in coverage. Interpretation of the adequacy of these control efforts is presented in Chapter VIII, "Conclusions."

Study Factor 8 - Defining Alternatives to Current Waste Management Practices

Section 8002 (m)(1) requires EPA to analyze alternatives to current disposal methods. EPA's discussion in response to this study factor is incorporated in Chapter III, "Current and Alternative Waste Management Practices."

Chapter III merges the concepts of current and alternative waste management practices. It does not single out particular technologies as potential substitutes for current practices because of the wide variation in practices among States and among different types of operations. Furthermore, waste management technology in this field is fairly simple. At least for the major high-volume waste streams, no significant, field-proven, newly invented technologies that can be considered "innovative" or "emerging" are in the research or development stage. 
Practices that are routine in one location may be considered innovative or alternative elsewhere. On the other hand, virtually every waste management practice that exists can be considered "current" in one specific situation or another.

This does not mean that improvements are not possible: in some cases, currently available technologies may not be properly selected, implemented, or maintained. Near-term improvements in waste management in these industries will likely be based largely on more effective use of what is already available.

\section{Study Factor 9 - Estimating the Costs of Alternative Practices}

Subparagraph (F) calls for analysis of costs of alternative practices. The first several sections of Chapter VI, "Costs and Economic Impacts of Alternative Waste Management Practices, "present the Agency's analysis of this study factor.

For the purposes of this report, EPA based its cost estimates on 21 prototypical regional projects, defined so as to capture significant differences between major and independent companies and between stripper operations and other projects. The study evaluates costs of waste disposal only for the two principal high-volume waste streams of concern, drilling fluids and produced waters, employing as its baseline the use of unlined reserve pits located at the drill site and the disposal of produced waters in injection wells permitted under the Federal Underground Injection Control Program and located off site.

The study then developed two alternative scenarios that varied the incremental costs of waste management control technology, applied them to each prototype project, and modeled the cost impacts of each. The 
first scenario imposes a set of requirements typical of full subtitle C management rules; the second represents a less stringent and extensive range of requirements based, in essence, on uniform nationwide use of the most up-to-date and effective controls now being applied by any of the States. Model results indicate cumulative annual costs, at the project level, of each of the more stringent control scenarios.

\section{Study Factor 10 . Estimating the Economic Impacts on Industry of} Alternative Practices

In response to the requirements of subparagraph (G), the final two sections of Chapter VI present the Agency's analysis of the potential economic impacts of nationwide imposition of the two control scenarios analyzed at the project level.

Both the cost and the economic impact predicted in this report are admittedly large. Many significant variations influence the economics of this industry and make it difficult to generalize about impacts on either the project or the national level. In particular, the price of oil itself greatly affects both levels. Fluctuations in the price of oil over the period during which this study was prepared have had a profound influence on project economics, making it difficult to draw conclusions about the current or future impacts of modified waste management practices.

Nevertheless, the Agency believes that the analysis presented here is a reasonable response to Congress's directives, and that the results, while they cannot be exact, accurately reflect the general impacts that might be expected if environmental control requirements were made more stringent. 
EXHIBIT 1:

Section $8002(\mathrm{~m})$ Resource Conservation and Recovery Act as anended by PL 96-482

"(m) Drilling Fluids, Produced Waters, and Other Wastes Associated with the Extraction. Development, or Production of Crude 0,1 or Natural Gas or Geothermal Energy, - (1) The Administrator shall conduct a detailed and comprehensive study and submit a report on the adverse effects, if any, of drilling fluids, produced waters, and other wastes associated with the exploration, development, or production of crude oil or natural gas or geothermal energy on human health and the environment, including. but not limited to the effects of such wastes on humans, water, air, health, welfare, and natural resources and on the adequacy of means and measures currently employed by the 011 and gas and geothermal drilling and production industry, Government agencies, and others to dispose of and utilize such wastes and to prevent or substantialiy mitigate such adverse effects. Such study shall include an analysis of-

"(A) the sources and volume of discarded material generated per year from such wastes:

"(B) present disposal practices:

"(C) potential danger to human health and the environment from the surface runoff or leachate:

"(D) documented cases which prove or have caused danger to human health and the environnent from surface runoff or leachate;

"(E) alternatives to current disposal methods:

"(F) the cost of such alternatives: and

"(G) the impact of those alternatives on the exploration for. and development and production of, crude oil and natural gas or geothermal energy.

In furtherance of this study, the Administrator shall, as he deems appropriate, review studies and other actions of other. Federal agencies concerning such wastes with a view toward avoiding duplication of effort and the need to expedite such study. The Administrator shall publish a report of such and shall include appropriate findings and recomendations for Federal and non-Federal actions concerning such effects.

"(2) The Administrator shall complete the research and study and submit the report required under paragraph (1) not later than twenty-four months from the date of enactment of the Solid Waste Disposal Act Amendments of 1980. Upon completion of the study, the Administrator shall prepare a summary of the findings of the study, a plan for research, development, and demonstration respecting the findings of the study, and shall submit the findings and the study, along with any recormendations resulting from such study. to the Comittee on Environment and Public Works of the United States Senate and the Comittee on Interstate and Foreign Comerce of the United states House of Representatives.

"(3) There are authorized to be appropriations not to exceed $\$ 1,000,000$ to carry out the provisions of this subsection. 


\section{.}

.

. 


\section{CHAPTER II \\ OVERVIEW OF THE INDUSTRY}

\section{DESCRIPTION OF THE OIL AND GAS INDUSTRY}

The oil and gas industry explores for, develops, and produces petroleum resources. In 1985 there were approximately 842,000 producing 0 il and gas wells in this country, distributed throughout 38 States. They produced 8.4 million barrels ${ }^{1}$ of $0 i 1,1.6$ million barrels of natural gas 1 iquids, and 44 billion cubic feet of natural gas daily. The American Petroleum Institute estimates domestic reserves at 28.4 billion barrels of oil, 7.9 billion barrels of natural gas 1 iquids, and 193 trillion cubic feet of gas. Petroleum exploration, development, and production industries employed approximately 421,000 people in $1985 .^{2}$

The industry is as varied as it is large. Some aspects of exploration, development, and production can change markedly from region to region and State to State. Well depths range from as little as 30 to 50 feet in some areas to over 30,000 feet in areas such as the Anadarko Basin of Oklahoma. Pennsylvania has been producing oil for 120 years; Alaska for only.15. Maryland has approximately 14 producing wells; Texas has 269,000 and completed another 25,721 in 1985 alone. Production from a single well can vary from a high of about 11,500 barrels per day (the 1985 average for wells on the Alaska North Slope) to less than 10 barrels per day for many thousands of "stripper" wells located in Appalachia and

\footnotetext{
1 Crude oil production has traditionally been expressed in barrels. A barrel is equivalent to $5.61 \mathrm{ft}^{3}, 0.158 \mathrm{~m}^{3}$, or 42 U.S. gallons.

2 These numbers, provided to EPA by the Bureau of Land Management (ELM), are generally accepted.
} 
the more developed portions of the rest of the country. ${ }^{3}$ Overall, 70 percent of all U.S. oil wells are strippers, operating on the margins of profitability. Together, however, these strippers contribute 14 percent of total U.S. production--a number that appears small, yet is roughly the equivalent of the immense Prudhoe Bay field in Alaska.

Such statistics make it clear that a short discussion such as this cannot provide a comprehensive or fully accurate description of this industry. The purpose of this chapter is simply to present the terminology used in the rest of this report ${ }^{4}$ and to provide an overview of typical exploration, development, and production methods. With this as introduction, the chapter then defines which oil and gas wastes EPA considers to be exempt within the scope of RCRA Section 8002; estimates the volumes of exempt wastes generated by onshore $0 i 1$ and gas operations; and presents the results of sample surveys conducted by EPA and the American Petroleum Institute to characterize the content of exempt oil and gas wastes.

\section{Exploration and Development}

Although geological and geophysical studies provide information concerning potential accumulations of petroleum, the only method that can confirm the presence of petroleum is exploratory drilling. The majority of exploratory wells are "dry" and must be plugged and abandoned. When an exploratory well does discover a commercial deposit, however, many development wells are typically needed to extract oil or gas from that reservoir.

\footnotetext{
3 The definition of "stripper" well may vary from State to State. For example, North Dakota defines a stripper as a well that produces 10 barrels per day or less at 6,000 feet or less; 11 to 15 barrels per day from a depth of 6,001 feet to 10,000 feet: and 16 to 20 barrels per day for wells that are 10,000 feet deep.

4 A glossary of terms is also provided in Volume 3.
} 
Exploratory and development wells are mechanically similar and generate similar wastes up to the point of production. In order to bring a field into production, however, development wells generate wastes associated with well completion and stimulation; these processes are discussed below. From 1981 to 1985, exploration and development drilling combined averaged 73,000 wells per year (API 1986). Drilling activity declined in 1986 and by mid-1987 rebounded over 1986 levels.

In the early part of the century, cable-tool drilling was the predominant method of well drilling. The up-and-down motion of a chisel-like bit, suspended by a cable, causes it to chip away the rock, which must be periodically removed with a bailer. Although an efficient technique, cable-tool drilling is limited to use in shallow, low-pressure reservoirs. Today, cable-tool drilling is used on a very limited basis in the United States, having been replaced almost entirely by rotary drilling.

Rotary drilling provides a safe method for controlling high-pressure 0 il/gas/water flows and allows for the simultaneous drilling of the well and removal of cuttings, making it possible to drill wells over 30,000 feet deep. Figure II-1 illustrates the process. The rotary motion provided by mechanisms on the drill rig floor turns a drill pipe or stem, thereby causing a bit on the end of the pipe to gouge and chip away the rock at the bottom of the hole. The bit itself generally has three cone-shaped wheels tipped with hardened teeth and is weighted into place by thick-walled collars. Well casing is periodically cemented into the hole, providing a uniform and stable conduit for the drill stem as it drills deeper into the hole. The casing also seals off freshwater aquifers, high-pressure zones, and other troublesome formations.

Most rotary drilling operations employ a circulation system using a water-or oil-based fluid, called "mud" because of its appearance. The 


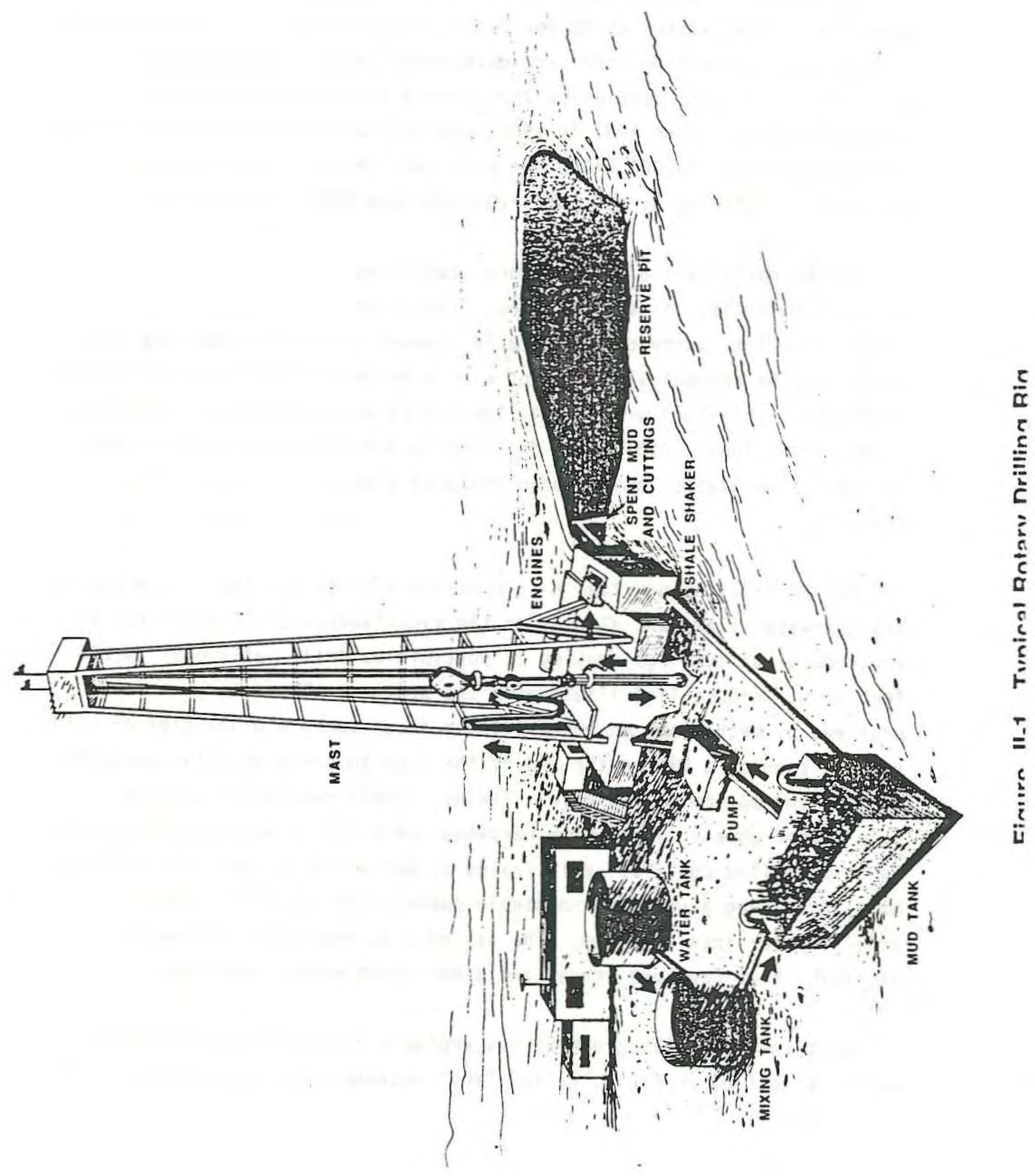


mud is pumped down the hollow drill pipe and across the face of the bit to provide lubrication and remove cuttings. The mud and cuttings are then pumped back up through the annular space between the drill pipe and the walls of the hole or casing. Mud is generally mixed with a weighting agent such as barite, and other mud additives, thus helping it serve several other important functions: (1) stabilizing the wellbore and preventing cave-ins, (2) counterbalancing any high-pressure 0il, gas, or water zones in the formations being drilled, and (3) providing a medium to alleviate problems "downhole" (such as stuck pipe or lost circulation).

Cuttings are removed at the surface by shale shakers, desanders, and desilters; they are then deposited in the reserve pit excavated or constructed next to the rig. The reclaimed drilling mud is then recirculated back to the well. The type and extent of solids control equipment used influences how well the cuttings can be separated from the drilling fluid, and hence influences the volume of mud discharged versus how much is recirculated. Drilling mud must be disposed of when excess mud is collected, when changing downhole conditions require a whole new mud formulation, or when the well is abandoned. The reserve pit is generally used for this purpose. (Reserve pits serve multiple waste management functions. See discussion in Chapter III.) If the well is a dry hole, the drilling mud may be disposed of downhole upon abandonment.

The formation of a drilling mud for a particular job depends on types of geologic formations encountered, economics, availability, problems encountered downhole, and well data collection practices. Water-based drilling muds predominate in the United States. Colloidal materials, primarily bentonitic clay, and weighting materials, such as barite, are common constituents. Numerous chemical additives are available to give the mud precise properties to facilitate the drilling of the well; they include acids and bases, salts, corrosion inhibitors, viscosifiers, 
dispersants, fluid loss reducers, lost circulation materials, flocculants, surfactants, biocides, and lubricants. (See also Table III-2.)

0il-based drilling fluids account for approximately 3 to 10 percent of the total volume of drilling fluids used nationwide. The oil base may consist of crude 0il, refined oil (usually fuel oil or diesel), or mineral oil. 0il-based drilling fluid provides lubrication in directionally drilled holes, high-temperature stability in very deep holes, and protection during drilling through water-sensitive formations.

In areas where high-pressure or water-bearing formations are not anticipated, air drilling is considerably faster and less expensive than drilling with water- or oil-based fluids. (Air drilling cannot be used in deep wells.) In this process, compressed air takes the place of mud, cooling the bit and lifting the cuttings back to the surface. Water is injected into the return line for dust suppression, creating a slurry that must be disposed of. In the United States, air drilling is most commonly used in the Appalachian Basin, in southeastern Kansas/northeastern OKlahoma, and in the Four Corners area of the Southwest. Other low-density drilling fluids are used in special situations. Gases other than air, usually nitrogen, are sometimes useful. These may be dispersed with liquids or solids, creating wastes in the form of mist, foam, emulsion, suspension, or gel.

Potential producing zones are commonly measured and analyzed (logged) during drilling, a process that typically generates no waste. If hydrocarbons appear to be present, a drill stem test can tell much about their characteristics. When the test is completed, formation fluids collected in the drill pipe must be disposed of.

If tests show that cominercial quantities of $0 i 1$ and gas are present, the well must be prepared for production or "completed." "Cased hole" 
completions are the most common type. First, production casing is run into the hole and cemented permanently in place. Then one or more strings of production tubing are set in the hole, productive intervals are isolated with packers, and surface equipment is installed. Actual completion involves the use of a gun or explosive charge that perforates the production casing and begins the flow of petroleum into the well.

During these completion operations, drilling fluid in the well may be modified or replaced by specialized fluids to control flow from the formation. A typical completion fluid consists of a brine solution modified with petroleum products, resins, polymers, and other chemical additives. When the well is produced initially, the completion fluid may be reclaimed or treated as a waste product that must be disposed of. For long-term corrosion protection, a packer fluid is placed into the casing/tubing annulus. Solids-free diesel oil, crude oil, produced water, or specially treated drilling fluid are preferred packer fluids.

Following well completion, oil or gas in the surrounding formations frequently is not under sufficient pressure to flow freely into the well and be removed. The formation may be impacted with indigenous material, the area directly surrounding the borehole may have become packed with cuttings, or the formation may have inherent low permeability.

Operators use a variety of stimulation techniques to correct these conditions and increase oil flow. Acidizing introduces acid into the production formation, dissolving formation matrix and thereby enlarging existing channels in carbonate-bearing rock. Hydraulic fracturing involves pumping specialized fluids carrying sand, glass beads, or similar materials into the production formation under high pressure; this creates fractures in the rock that remain propped open by the sand, beads, or similar materials when pressure is released. 
Other specialized fluids may be pumped down a production well to enhance its yield; these can include corrosion inhibitors, surfactants, friction reducers, complexing agents, and cleanup additives. Although the formation may retain some of these fluids, most are returned to the surface when the well is initially produced or are slowly released over time. These fluids may require disposal, independent of disposal associated with produced water.

Drilling operations have the potential to create air pollution from several sources. The actual drilling equipment itself is typically run by large diesel engines that tend to emit significant quantities of particulates, sulfur oxides, and oxides of nitrogen, which are subject to regulation under the Clean Air Act. The particulates emitted may contain heavy metals as well as polycyclic organic matter (POMs). Particulariy for deep wells, which require the most power to drill, and in large fields where several drilling operations may be in progress at the same time, cumulative diesel emissions can be important. 0il-fired turbines are also used as a source of power on newer drilling rigs. Other sources of air pollution include volatilization of light organic compounds from reserve pits and other holding pits that may be in use during drilling; these are exempt wastes. These light organics can be volatilized from recovered hydrocarbons or from solvents or other chemicals used in the production process for cleaning, fracturing, or well completion. The volume of volatile organic compounds is insignificant in comparison to diesel engine emissions.

\section{Production}

Production operations generally include all activities associated with the recovery of petroleum from geologic formations. They can be divided into activities associated with downhole operations and activities associated with surface operations. Downhole operations include primary, secondary, and tertiary recovery methods; well workovers; and well stimulation activities. Activities associated with 
surface operations include 0 il/gas/water separation, fluid treatment, and disposal of produced water. Each of these terms is discussed briefly below.

\section{Downhole Operations}

Primary recovery refers to the initial production of oil or gas from a reservoir using natural pressure or artificial lift methods, such as surface or subsurface pumps and gas lift, to bring it out of the formation and to the surface. Most reservoirs are capable of producing oil and gas by primary recovery methods alone, but this ability declines over the life of the well. Eventually, virtually all wells must employ some form of secondary recovery, typically involving injection of gas or liquid into the reservoir to maintain pressure within the producing formation. Waterflooding is the most frequently employed secondary recovery method. It involves injecting treated fresh water, seawater, or produced water into the formation through a separate well or wells.

Tertiary recovery refers to the recovery of the last portion of the oil that can be economically produced. Chemical, physical, and thermal methods are available and may be used in combination. Chemical methods involve injection of fluids containing substances such as surfactants and polymers. Miscible oil recovery involves injection of gases, such as carbon dioxide and natural gas, which combine with the oil. Thermal recovery methods include steam injection and in situ combustion (or "fire flooding"). When oil eventually reaches a production well, injected gases or fluids from secondary and tertiary recovery operations may be dissolved or carried in formation oil or water, or simply mixed with them; their removal is discussed below in conjunction with surface production operations.

Workovers, another aspect of downhole production operations, are designed to restore or increase production from wells whose flows are 
inhibited by downhole mechanical failures or blockages, such as sand or paraffin deposits. Fluids circulated into the well for this purpose must be compatible with the formation and must not adversely affect permeability. They are similar to completion fluids, described earlier. When the well is put back into production, the workover fluid may be reclaimed or disposed of.

Other chemicals may be periodically or continuously pumped down a production well to inhibit corrosion, reduce friction, or simply keep the well flowing. For example, methanol may be pumped down a gas well to keep it from becoming plugged with ice.

\section{Surface Operations}

Surface production operations generally include gathering of the produced fluids (oil, gas, gas liquids, and water) from a well or group of wells and separation and treatment of the fluids. See

Figures II-2, II-3, and II-4. As producing reservoirs are depleted, their water/oil ratios may increase steeply. New wells may produce little if any water; stripper wells may vary greatly in the volume of water they produce. Some may produce more than 100 barrels of water for every barrel of oil, particularly if the wells are subject to waterflooding operations.

Virtually all of this water must be removed before the product can be transferred to a pipeline. (The maximum water content allowed is generally less than 1 percent.) The oil may also contain completion or workover fluids, stimulation fluids, or other chemicals (biocides, fungicides) used as an adjunct to production. Some oil/water mixtures may be easy to separate, but others may exist as fine emulsions that do 


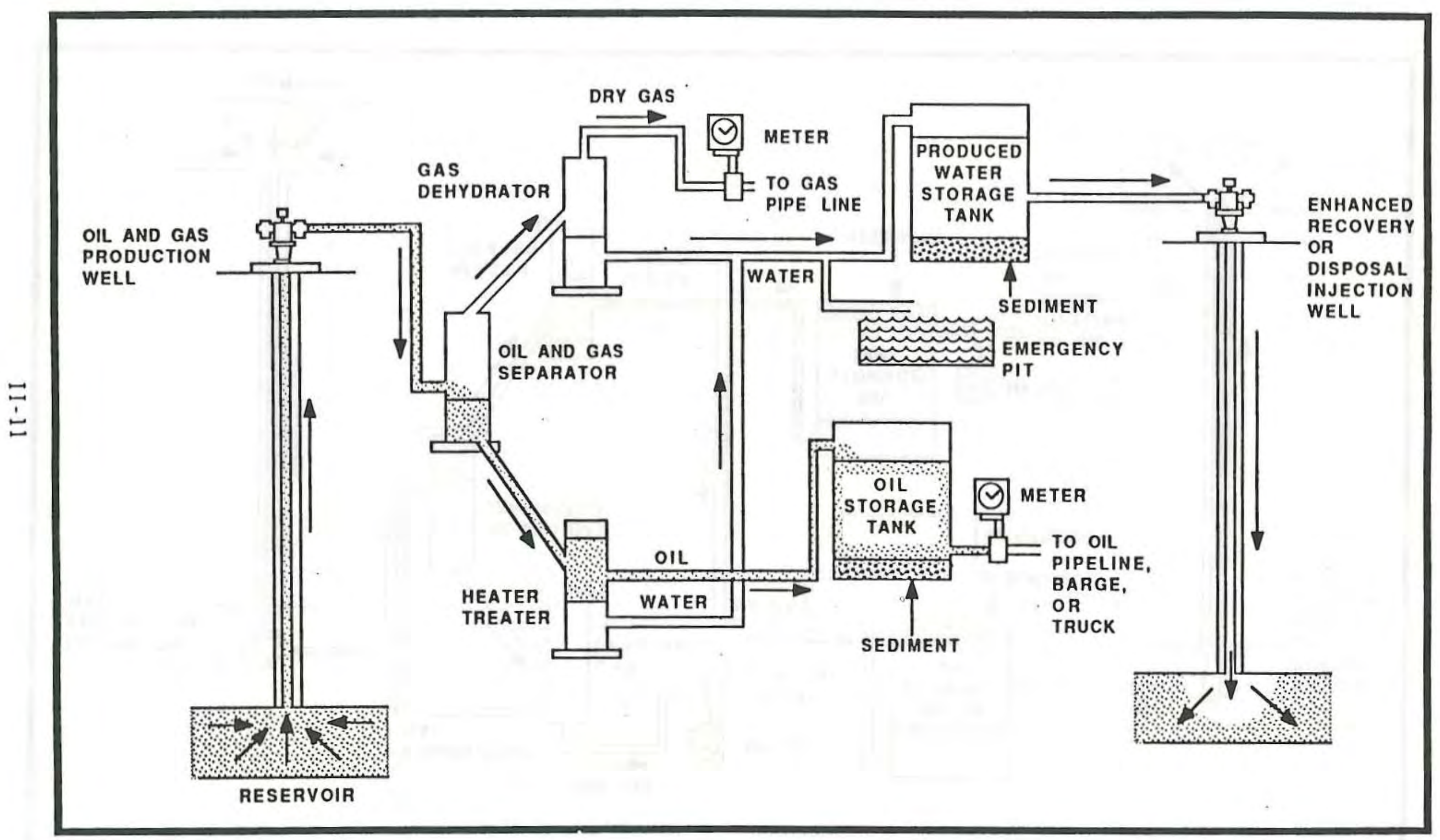

Figure II-2 Typical Production Operation, Showing Separation of Oil, Gas, and Water

Produced waters are not always injected as Indicated In this Ilgure. Produced water may be trucked to central treatment and disposal facilitles, discharged Into disposal plts, dlscharged to surface or coastal waters, or used for beneflclal or agrlcultural use. 


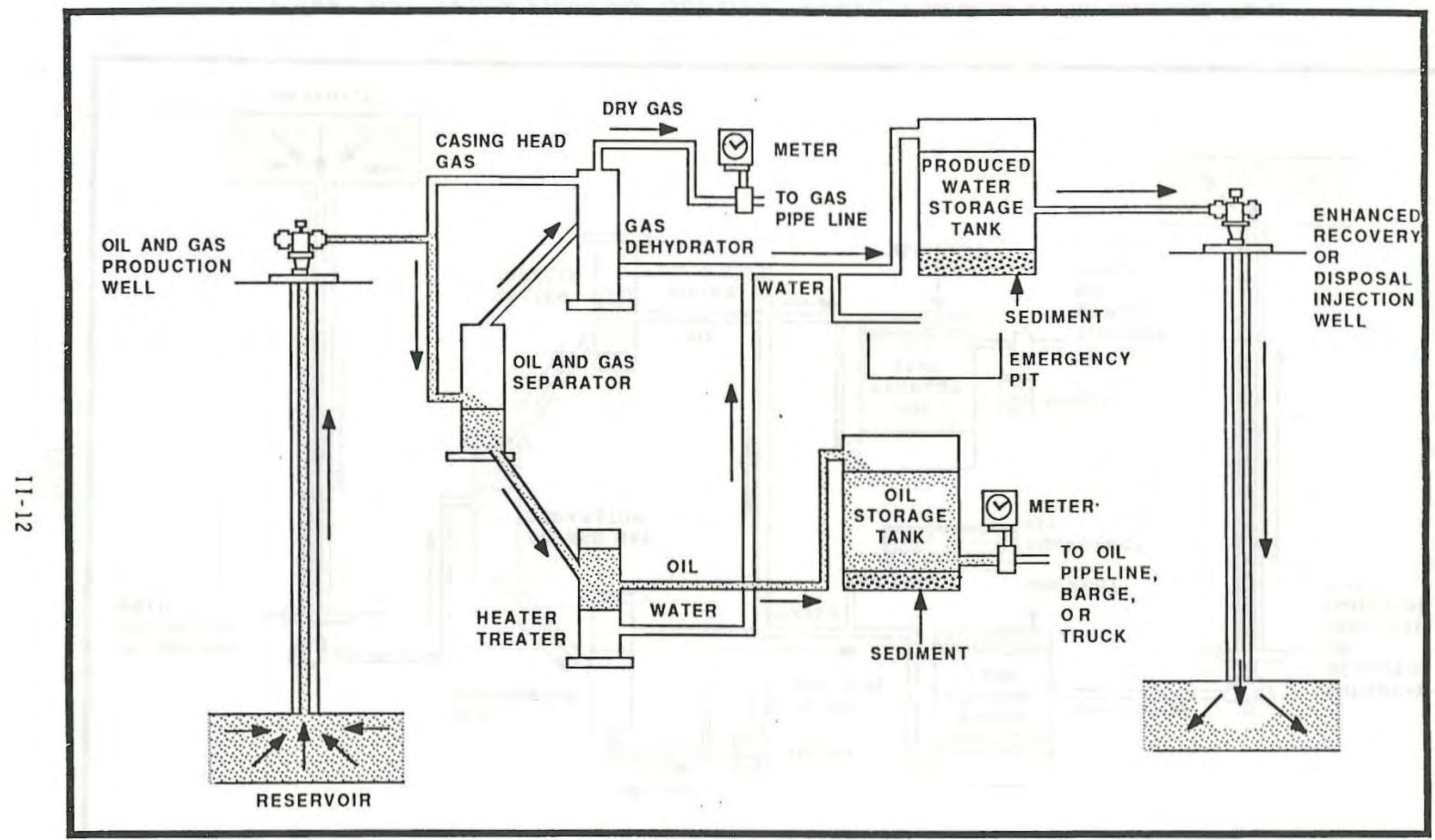

Figure II-3 Oil Production With Average $\mathrm{H}_{2} \mathrm{O}$ Production With Dissolved/Associated Gas

Produced waters are not always injected as indicated in this figure. Produced water may be trucked to central treatment and disposal facilities, discharged into disposal pits, discharged to surface or coastal waters, or used for beneficial or agricultural use. 


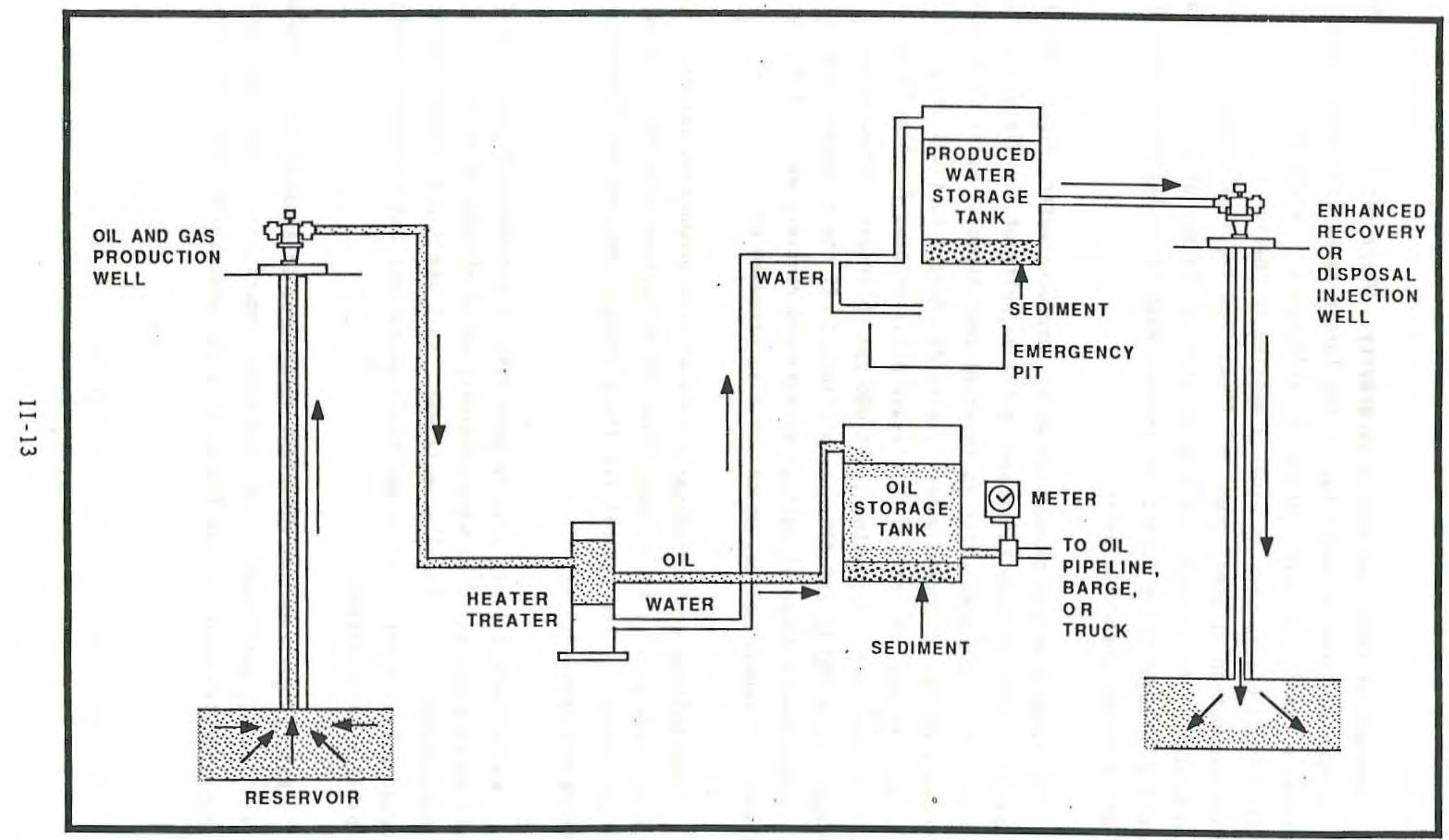

Figure II-4 High Oil/ $\mathrm{H}_{2} \mathrm{O}$ Ratio Without Significant Dissolved/Associated Gas

Produced waters are not always injected as indicated in this figure. Produced water may be trucked to central treatment and disposal facilities. discharaed into disposal pits, discharged to surface or coastal waters, or used for beneficial or agricultural use. 
not separate of their own accord by gravity. Where settling is possible, it is done in large or small tanks, the larger tanks affording longer residence time to increase separation efficiency. Where emulsions are difficult to break, heat is usually applied in "heater treaters." Whichever method is used, crude oil flows from the final separator to stock tanks. The sludges and liquids that settle out of the oil as tank bottoms throughout the separation process must be collected and discarded along with the separated water.

The largest volume production waste, produced water, flows from-the separators into storage tanks and in the majority of oil fields is highly saline. Most produced water is injected down disposal wells or enhanced recovery wells. Produced water is also discharged to tidal areas and surface streams, discharged to storage pits, or used for beneficial or agriculturai use. (Seawater is $35,000 \mathrm{ppm}$ chlorides. Produced water can range from 5,000 to $180,000 \mathrm{ppm}$ chlorides.) If the produced water is injected down a disposal well or an enhanced recover.y well, it may be treated to remove solids, which are also disposed of.

Tank bottoms are periodically removed from production vessels. Tank bottoms are usually hauled away from the production site for disposal. Occasionally, if the bottoms are fluid enough, they may be disposed of along with produced water.

Waste crude oil may also be generated at a production site. If crude oil becomes contaminated with chemicals or is skimmed from surface impoundments, it is usually reclaimed. Soil and gravel contaminated by crude oil as a result of normal field operations and occasional leaks and spills require disposal.

Natural gas requires different techniques to separate out crude oil, gas liquids, entrained solids, and other impurities. These separation processes can occur in the field, in a gas processing plant, or both, but 
more frequently occur at an offsite processing plant. Crude oil, gas liquids, some free water, and entrained solids can be removed in conventional separation vessels. More water may be removed by any of several dehydration processes, frequently through the use of glycol, a liquid dessicant, or various solid dessicants. Although these separation media can generally be regenerated and used again, they eventually lose their effectiveness and must be disposed of.

Both crude oil and natural gas may contain the highly toxic gas hydrogen sulfide, which is an exempt waste. (Eight hundred ppm in air is lethal to humans and represents an occupational hazard, but not an ambient air toxics threat to human health offsite.) At plants where hydrogen sulfide is removed from natural gas, sulfur dioxide $\left(\mathrm{SO}_{2}\right)$ release results. (EPA requires compliance with the National Ambient Air Quality Standards (NAAQS) for sulfur dioxide; DOI also has authority to regulate these emissions.) Sulfur is often recovered from the hydrogen sulfide $\left(\mathrm{H}_{2} \mathrm{~S}\right)$ as a commercial byproduct. $\mathrm{H}_{2} \mathrm{~S}$ dissolved in crude oil does not pose any danger, but when it is produced at the wellhead in gaseous form, it poses serious occupational risks through possible leaks or blowouts. These risks are also present later in the production process when the $\mathrm{H}_{2} \mathrm{~S}$ is separated out in various "sweetening" processes. The amine, iron sponge, and selexol processes are three examples of commercial processes for removing acid gases from natural gas. Each $\mathrm{H}_{2} \mathrm{~S}$ removal process results in spent or waste separation media, which must be disposed of. EPA did not sample hydrogen sulfide and sulphur dioxide emissions because of their relatively low volume and infrequency of occurrence.

Gaseous wastes are generated from a variety of other production-related operations. Volatile organic compounds may also be released from minute leaks in production equipment or from pressure vents on separators and storage tanks. When a gas well needs to be cleaned out, it may be produced wide open and vented directly to the atmosphere. 
Emissions from volatile organic compounds are exempt under Section $3001(b)(2)(A)$ of RCRA and represent a very low portion of national air emissions. Enhanced oil recovery steam generators may burn crude oil as fuel, thereby creating air emissions. These wastes are nonexempt.

\section{DEFINITION OF EXEMPT WASTES}

The following discussion presents EPA's tentative definition of the scope of the exemption.

\section{Scope of the Exemption}

The current statutory exemption originated in EPA's proposed hazardous waste regulations of December 18, 1978 (43 FR 58946). Proposed 40 CFR 250.46 contained standards for "special wastes"--reduced requirements for several types of wastes that are produced in large volume and that EPA believed may be lower in toxicity than other wastes regulated as hazardous wastes under RCRA. One of these categories of special wastes was "gas and oil drilling muds and oil production brines."

In the RCRA amendments of 1980 , Congress exempted most of these special wastes from the hazardous waste requirements of RCRA Subtitle $C$, pending further study by EPA. The oil and gas exemption, Section $3001(b)(2)(A)$, is directed at "drilling fluids, produced waters, and other wastes associated with the exploration, development, or production of crude oil or natural gas." The legislative history does not elaborate on the definition of drilling fluids or produced waters, but it does discuss "other wastes" as follows:

The term "other wastes associated" is specifically included to designate waste materials intrinsically derived from the primary field operations associated with the exploration, development, or production of crude oil and natural gas. It would cover such substances as: hydrocarbon bearing soil in and around related facilities; drill cuttings; and materials (such as hydrocarbons, 
water, sand and emulsion) produced from a well in conjunction with crude oil and natural gas and the accumulated material (such as hydrocarbons, water, sand, and emulsion) from production separators, fluid treating vessels, storage vessels, and production impoundments. (H.R. Rep No. 1444, 96th Cong., 2d Sess. at 32 (1980)).

The phrase "intrinsically derived from the primary field operations..." is intended to differentiate exploration, development, and production operations from transportation (from the point of custody transfer or of production separation and dehydration) and manufacturing operations.

In order to arrive at a clear working definition of the scope of the exemption under Section $8002(\mathrm{~m})$, EPA has used these statements in conjunction with the statutory language of RCRA as a basis for making the following assumptions about which oil and gas wastes should be included in the present study.

- Although the legislative history underlying. the oil and gas exemption is limited to "other wastes associated with the exploration development or production of crude oil or natural gas," the Agency believes that the rationale set forth in that history is equally applicable to produced waters and drilling fluids. Therefore, in developing criteria to define the scope of the Section 3001 (b) (2) exemption, the Agency has applied this legislative history to produced waters and drilling fluids.

- The potential exists for small volume nonexempt wastes to be mixed with exempt wastes, such as reserve pit contents. EPA believes it is desirable to avoid improper disposal of hazardous (nonexempt) wastes through dilution with nonhazardous exempt wastes. For example, unused pipe dope should not be disposed of in reserve pits. Some residual pipe dope, however, will enter the reserve pit as part of normal field operations; this residual pipe dope does not concern EPA. EPA is undecided as to the proper disposal method for some other waste streams, such as rigwash that often are disposed of in reserve pits.

Using these assumptions, the test of whether a particular waste qualifies under the exemption can be made in relation to the following three separate criteria. No one criterion can be used as a standard when defining specific waste streams that are exempt. These criteria are as follows. 
1. Exempt wastes must be associated with measures (1) to locate oil or gas deposits, (2) to remove oil or natural gas from the ground, or (3) to remove impurities from such substances, provided that the purification process is an integral part of primary field operations. ${ }^{5}$

2. Only waste streams intrinsic to the exploration for, or the development and production of, crude oil and natural gas are subject to exemption. Waste streams generated at oil and gas facilities that are not uniquely associated with the exploration, development, or production activities are not exempt. (Examples would include spent solvents from equipment cleanup or air emissions from diesel engines used to operate drilling rigs.)

Clearly those substances that are extracted from the ground or injected into the ground to facilitate the drilling, operation, or maintenance of a well or to enhance the recovery of oil and gas are considered to be uniquely associated with primary field operations. Additionally, the injection of materials into the pipeline at the wellhead which keep the lines from freezing or which serve as solvents to prevent paraffin accumulation is intrinsically associated with primary field operations. With regard to injection for enhanced recovery, the injected materials must function primarily to enhance recovery of oil and gas and must be recognized by the Agency as being appropriate for enhanced recovery. An example would be produced water. In this context, "primarily functions" means that the main reason for injecting the materials is to enhance recovery of oil and gas rather than to serve as a means for disposing of those materials.

3. Drilling fluids, produced waters, and other wastes intrinsically derived from primary field operations associated with the exploration, development, or production of crude oil, natural gas, or geothermal energy are subject to exemption. Primary field operations encompass production-related activities but not transportation or manufacturing activities. With respect to oil production, primary field operations encompass those activities occurring at or near the wellhead, but prior to the transport of oil from an individual field facility or a centrally located facility to a carrier (i.e., pipeline or trucking concern) for transport to a refinery or to a refiner. With respect to natural gas production, primary field operations are those activities occurring at or near the wellhead or at the gas plant but prior to that point at which the gas is transferred from an individual field facility, a centrally located facility, or a gas plant to a carrier for transport to market.

\footnotetext{
5 Thus, wastes associated with such processes as oil refining, petrochemical-related manufacturing. or electricity generation are not exempt because those processes do not occur at the primary field operations.
} 
Primary field operations may encompass the primary, secondary, and tertiary production of $0 i 1$ or gas. Wastes generated by the transportation process itself are not exempt because they are not intrinsically associated with primary field operations. An example would be pigging waste from pipeline pumping stations.

Transportation for the $0 i 1$ and gas industry may be for short or long distances. Wastes associated with manufacturing are not exempt because they are not associated with exploration, development, or production and hence are not intrinsically associated with primary field operations. Manufacturing (for the oil and gas industry) is defined as any activity occurring within a refinery or other manufacturing facility the purpose of which is to render the product commercially saleable.

Using these definitions, Table II-l presents definitions of exempted wastes as defined by EPA for the purposes of this study. Note that this is a partial list only. Although it includes all the major streams that EPA has considered in the preparation of this report, others may exist. In that case, the definitions listed above would be applied to determine their status under RCRA.

\section{Waste Volume Estimation Methodology}

Information concerning volumes of wastes from $0 i 1$ and gas exploration, development, and production operations is not routinely collected nationwide, making it necessary to develop methods for estimating these volumes by indirect methods in order to comply with the Section $8002(\mathrm{~m})$ requirement to present such estimates to Congress. For this study, estimates were compiled independently by EPA and by the American Petroleum Institute (API) using different methods. Both are discussed below.

\section{Estimating Volumes of Drilling Fluids and Cuttings}

EPA considered several different methodologies for determining volume estimates for produced water and drilling fluid. 
Table 11-1 Partial List of Exempt and Nonexempt Wastes

EXEMPT WASTES

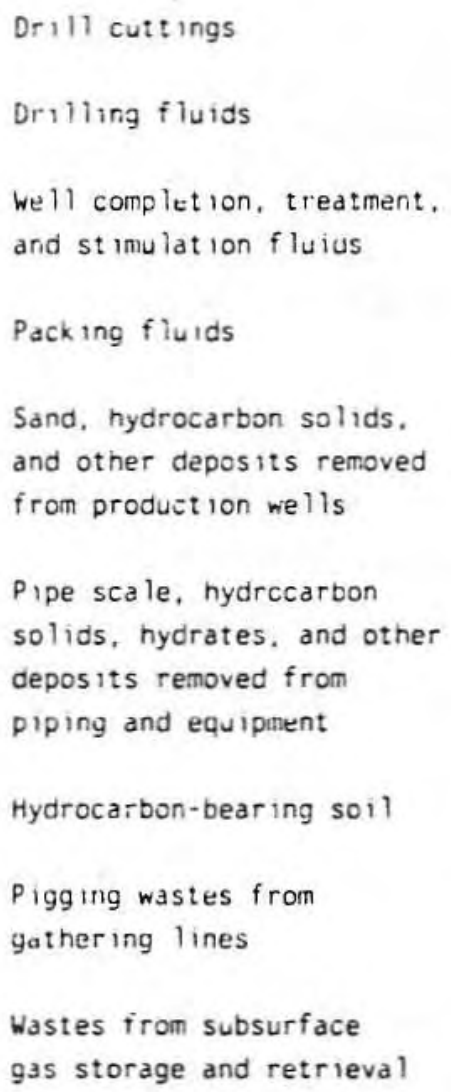

Waste lubricants, hydraulic fluids, motor 011 , and paint

Waste solvents from cleanup operations

Of $f$-specification and unused materials intended for disposal

Incinerator ash

Pigging wastes from transportation pipelines Tathle 1]-1

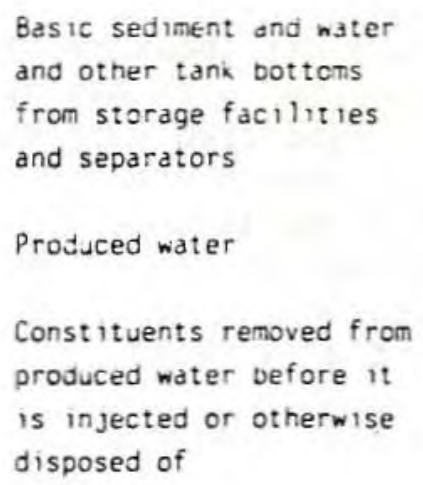

Accuinulated materials (such as hydrocarbons, solids. sand. and emulsion) from production separators, fluid-treating vessels. and product ion impoundments that are not mixed with separation or treatment media

Drilling muds from off shore operations

NONEXEMPT WASTES

Sanitary wastes, trash, and gray water

Gases, such as SOx, NOx, and particuldtes from gas turbines or other machinery

Drums (filled, partially filled, or cleaned) whose contents are not intended for use
Appropriate fluids injected downhole for secondary and tertiary recovery operations

Liquid hydrocarbons removed from the production stream but not from oil refining

Gases removed from the production stream. such as hydrogen sulfide, carbon dioxide, and volat 1 lized hydrocarbons

Materials ejected from a production well during the process known as blowing down a well

Waste crude oil from primary field operations

Light organics volatilized from recovered hydrocarbons or from solvents or other chemicals used for cleaning. fracturing, or well completion

Waste iron sponge, glycul, and other separation media

Filters

Spent catalysts

Wastes from truck- and druincleaning operations

Waste solvents from equipment ma intenance

Spills from pipelines or other transport methods 
EPA's estimates: For several regions of the country, estimates of volumes of drilling fluids and cuttings generated from well drilling operations are available on the basis of waste volume per foot of well drilled. Estimates range from 0.2 barrel/foot (provided by the West Virginia Dept. of Natural Resources) to 2.0 barrels/foot (provided by NL Baroid Co. for Cotton Valley formation wells in Panola County, Texas). EPA therefore considered the possibility of using this approach nationwide. If it were possible to generate such estinates for all areas of the country, including allowances for associated wastes such as completion fluids and waste cement, nationwide figures would then be comparatively easy to generate. They could be based on the total footage of all wells drilled in the U.S., a statistic that is readily available from API.

This method proved infeasible, however, because of a number of complex factors contributing to the calculation of waste-per-foot estimates that would be both comprehensive and valid for all areas of the country. For instance, the use of solids control equipment at drilling sites, which directly affects waste generation, is not standardized. In addition, EPA would have to differentiate among operations using various drilling fluids (oil-based, water-based, and gas-based fluids). These and other considerations caused the Agency to reject this method of estimating volumes of drilling-related wastes.

Another methodology would be to develop a formal model for estimating waste volumes based on all the factors influencing the volume of drilling waste produced. These factors would include total depth drilled, geologic formations encountered, drilling fluid used, solids control equipment used, drilling problems encountered, and so forth. Such a model could then be applied to a representative sample of wells drilled nationwide, yielding estimates that could then be extrapolated to produce nationwide volumes estimates. 
This method, too, was rejected as infeasible. It would have required access to data derived from the dril?er's logs and mud logs maintained at individual well sites, which would have been very difficult to acquire. Beyond this, other data and analytical needs for building such a model proved to be beyond the resources available for the project.

With these methodologies unavailable, EPA developed its estimates by equating the wastes generated from a drilling operation with the volume of the reserve pit constructed to service the well. Typically, each well is served by a single reserve pit, which is used primarily for either temporary or permanent disposal of drilling wastes. Based on field observations, EPA made the explicit assumption that reserve pits are sized to accept the wastes anticipated from the drilling operation. The Agency then collected information on pit sizes during the field sampling program in 1986 (discussed later in this chapter), from literature searches, and by extensive contact with State and Federal regulatory personnel.

EPA developed three generic pit sizes $(1,984-, 22,700-$, and 87,240-barrel capacity) to represent the range of existing pits and assigned each State a percent distribution for each pit size based on field observation and discussion with selected State and industry personnel. For example, from the data collected, Utah's drilling sites were characterized as having 35 percent small pits, 50 percent medium pits, and 15 percent large pits. Using these State-specific percent distributions, EPA was then able to readily calculate an estimate of annual drilling waste volumes per year for each State. Because Alaska's operations are generally larger than operations in the other oil- and gas-producing States, Alaska's generic pit sizes were different $(55,093-$ and 400,244-barrel capacity.) 
Although the EPA method is relatively simple, relying on a well site feature that is easily observable (namely, the reserve pit), the method does have several disadvantages. It does not explicitly account for waste volume increases and decreases due to evaporation, percolation, and rainwater collection. The three generic pit sizes may not adequately represent the wide range of pit sizes used for drilling, and they all assume that the total volume of each reserve pit, minus a nominal 2 feet of freeboard, will be used for wastes. Finally, the information collected to determine the percent distributions of pit sizes within States may not adequately characterize the industry, and adjusting the distribution would require gathering new information or taking a new survey. All of these uncertainties detract from the accuracy of a risk assessment or an economic impact analysis used to evaluate alternative waste management techniques.

The American Petroleum Institute's estimates: As the largest national oil trade organization, the API routinely gathers and analyzes many types of information on the $0 i 1$ and gas industry. In addition, in conducting its independent estimates of drilling waste volumes, API was able to conduct a direct survey of operators in 1985 to request waste volume data--a method that was unavailable to EPA because of time and funding limitations. API sent a questionnaire to a sample of operators nationwide, asking for estimated volume data for drilling muds and completion fluids, drill cuttings, and other associated wastes discharged to the reserve pit. Completed questionnaires were received for 693 individual wells describing drilling muds, completion fluids, and drill cuttings; 275 questionnaires also contained useful information concerning associated wastes. API segregated the sampled wells so that it could characterize drilling wastes within each of 11 sampling zones used in this study and within each of 4 depth classes. Since API maintains a data base on basic information on all wells drilled in the U.S., including location and depth, it was able to estimate a volume of wastes for the more than 65,000 wells drilled in 1985. The API survey does have 
several significant 1 imitations. Statistical representativeness of the survey is being analyzed by EPA. Respondents to the survey were primarily large oil companies. The survey was accompanied by a letter that may have influenced the responses. Also, EPA experience with operators indicates that they may underestimate reserve pit volumes.

Even though volumetric measurement and statistical analysis represent the preferred method for estimating drilling waste volumes, the way in which API's survey was conducted and the data were analyzed may have some drawbacks. Operators were asked to estimate large volumes of wastes, which are added slowly. to the reserve pit and are not measured. Because the sample size is small in comparison to the population, it is questionable whether the sample is an unbiased representation of the drilling industry.

\section{Estimating Volumes of Produced Water}

By far the largest volume production waste from $0 i 1$ and gas operations is produced water. Of all the wastes generated from 0 il and gas operations, produced water figures are reported with the most frequency because of the reporting requirements under the Underground Injection Control (UIC) and National Pollution Discharge Elimination System (NPDES) programs.

EPA's estimates: Because produced water figures are more readily available than drilling waste data, EPA conducted a survey of the State agencies of $33 \mathrm{oil-}$ and gas-producing States, requesting produced water data from injection reports, production reports, and hauling reports. For those States for which this information was not available, EPA derived estimates calculated from the oil/water ratio from surrounding States (this method used for four States) or derived estimates based on information provided by State representatives (this method used for six States). 
API's estimates: In addition to its survey of drilling wastes, API conducted a supplemental survey to determine total volumes of produced water on a State-by-State basis. API sent a produced water survey form to individual companies requesting 1985 crude $0 i 1$ and condensate volumes and produced water volumes and distribution. Fourteen operators in 23 States responded. Because most of the operators were active in more than one State, API was able to include a total of 170 different survey points. API then used these data to generate water-to-oil ratios (number of barrels of water produced with each barrel of oil) for each operator in each State. By extrapolation, the results of the survey yield an estimate of the total volume of produced water on a statewide basis; the statewide estimated produced water volume total is simply the product of the estimated State ratio (taken from this survey) and the known total oil production for the State. API reports this survey method to have a 95 percent confidence level for produced water volumes. No standard deviation was reported with this confidence level.

For most States, the figure generated by this method agrees closely with the figure arrived at by EPA in its survey of State agencies in 33 oil-producing States. For a few States, however, the EPA and API numbers are significantly different; Wyoming is an example. Since most of the respondents to the API survey were major companies, their production operations may not be truly representative of the industry as a whole. Also, the API method did not cover all of the States covered by EPA.

Neither method can be considered completely accurate, so judgment is needed to determine the best method to apply for each State. Because the Wyoming State agency responsible for oil and gas operations believes that the API number is greatly in error, the State number is used in this report. Also, since the API survey did not cover many of the States in the Appalachian Basin, the EPA numbers for all of the Appalachian Basin States are used here. In all other cases, however, the API-produced water volume numbers, which were derived in part from a field survey, are believed to be more accurate than EPA numbers and are therefore used in this report. 


\section{Waste Volume Estimates}

Drilling waste volumes for 1985, calculated by both the EPA and API methods, appear in Table II-2. Although the number of wells drilled for each State differs between the two methods, both methods fundamentally relied upon API data. The EPA method estimates that 2.44 billion barrels of waste were generated from the drilling of 64,508 wells, for an average of 37,902 barrels of waste per well. The API method estimates that 361 million barrels of waste were generated from the drilling of 69,734 wells, for an average of 5,183 barrels of waste per well. EPA has reviewed API's survey methodology and believes the API method is more reliable in predicting actual volumes generated. For the purposes of this report, EPA will use the API estimates for drilling waste volumes.

Produced water volumes for 1985, calculated by both the EPA and API methods, appear in Table II-3. The EPA method estimates 11.7 billion barrels of produced water. The API method estimates 20.9 billion barrels of produced water.

\section{CHARACTERIZATION OF WASTES}

In support of this study, EPA collected samples from oil and gas exploration, development, and production sites throughout the country and analyzed them to determine their chemical composition. The Agency designed the sampling plan to ensure that it would cover the country's wide range of geographic and geologic conditions and that it would randomly select individual sites for study within each area (USEPA 1987). One hundred one samples were collected from 49 sites in 26 different locations. Operations sampled included centralized treatment facilities, central disposal facilities, drilling operations, and production facilities. For a more detailed discussion of all aspects of EPA's sampling program, see USEPA 1987. 
Table II-2 Estimated U.S. Drilling Waste Volumes, 1985

\begin{tabular}{|c|c|c|c|c|}
\hline \multirow[b]{2}{*}{ State } & \multicolumn{2}{|c|}{ EPA method } & \multicolumn{2}{|c|}{ API method } \\
\hline & $\begin{array}{l}\text { Number of. } \\
\text { wells drilled }\end{array}$ & $\begin{array}{l}\text { Volume } \\
1,000 \text { bbl }\end{array}$ & $\begin{array}{l}\text { Number of } \\
\text { wells drilled }\end{array}$ & $\begin{array}{l}\text { Volume } \\
1,000 \text { bbl }\end{array}$ \\
\hline Al abama & 343 & 15,179 & 367 & 5,994 \\
\hline Alaska & 206 & 4,118 & 242 & 1,816 \\
\hline Arizona & 3 & 56 & 3 & 23 \\
\hline Arkansas & 975 & 43,147 & 1,034 & 8,470 \\
\hline Cal ifornia & 3,038 & 82,276 & 3,208 & 4,529 \\
\hline Colorado & 1,459 & 27,249 & 1,578 & 8,226 \\
\hline Florida & 21 & 929 & 21 & 1,068 \\
\hline Georgia & $\mathrm{NC}^{\mathrm{C}}$ & NC & 1 & 2 \\
\hline Idaho & NC & NC & 3 & 94 \\
\hline Illinois & 2,107 & 57,063 & 2,291 & 2,690 \\
\hline Indiana & 910 & 24,645 & 961 & 1,105 \\
\hline Iowa & NC & NC & 1 & 1 \\
\hline Kansas & 5,151 & 96,818 & 5,560 & 17,425 \\
\hline Kentucky & 2,141 & 8,683 & 2,482 & 4,874 \\
\hline Louisiana & 4,645 & 205,954 & 4,908 & 46,726 \\
\hline Maryland & 85 & 345 & 91 & 201 \\
\hline Michigan & 823 & 22,289 & 870 & 3,866 \\
\hline Mississippi & 568 & 25,136 & 594 & 14,653 \\
\hline Missouri & 22 & 596 & 23 & 18 \\
\hline Montana & 591 & 36,302 & 623 & 4,569 \\
\hline Nebraska & 261 & 4,906 & 282 & 761 \\
\hline Nevada & 34 & 1,070 & 36 & 335 \\
\hline New Mexico & 1,694 & 31,638 & 1,780 & 13,908 \\
\hline New York & 395 & 1,602 & 436 & 1,277 \\
\hline North Dakota & 485 & 9,116 & 514 & 4,804 \\
\hline Ohio & 3,413 & 13,842 & 3,818 & 8,139 \\
\hline Okl ahoma & 6,978 & 383,581 & 7,690 & 42,547 \\
\hline Oregon & 5 & 135 & 5 & 5 \\
\hline Pennsylvania & 2,466 & 10,001 & 2,836 & 8,130 \\
\hline
\end{tabular}


Table II-2 (cont inued)

\begin{tabular}{|c|c|c|c|c|}
\hline State & $\begin{array}{l}\text { EPA me } \\
\text { Number of } \\
\text { wells drilled }\end{array}$ & $\begin{array}{c}\text { od } \\
\text { Volume } \\
1,000 \mathrm{bbl}\end{array}$ & $\begin{array}{l}\text { API } \\
\text { Number of } \\
\text { wells drilled }\end{array}$ & $\begin{array}{l}\text { hod } \\
\text { Volume }{ }^{b} \\
1,000 \text { bbl }\end{array}$ \\
\hline $\begin{array}{l}\text { South Dakota } \\
\text { Tennessee } \\
\text { Texas } \\
\text { Utah } \\
\text { Virginia } \\
\text { Washington } \\
\text { West Virginia } \\
\text { Wyoming }\end{array}$ & $\begin{array}{r}44 \\
169 \\
22,538 \\
332 \\
85 \\
\mathrm{NC}^{\mathrm{C}} \\
1,188 \\
1,409^{d}\end{array}$ & $\begin{array}{r}827 \\
685 \\
1,238,914 \\
6,201 \\
345 \\
\mathrm{NC}^{\mathrm{C}} \\
4,818 \\
86,546^{\mathrm{d}}\end{array}$ & $\begin{array}{r}49 \\
228 \\
23,915 \\
364 \\
91 \\
4 \\
1,419 \\
1,497\end{array}$ & $\begin{array}{r}289 \\
795 \\
133,014 \\
4,412 \\
201 \\
15 \\
3,097 \\
13,528\end{array}$ \\
\hline U.S. Total & 64,499 & $2,444,667$ & 69,734 & 361,406 \\
\hline
\end{tabular}

a Based on total available reserve pit volume, assuming $2 \mathrm{ft}$ of freeboard (ref.). b Based on total volume of drilling muds, drill cuttings, completion fluids, circulated cement, formation testing fluids, and other water and solids. c Not calculated.

d EPA notes that for Wyoming, the State's numbers are 1,332 and 11,988,000, respectively. 
Table II-3 Estimated U.S. Produced Water Volumes, 1985

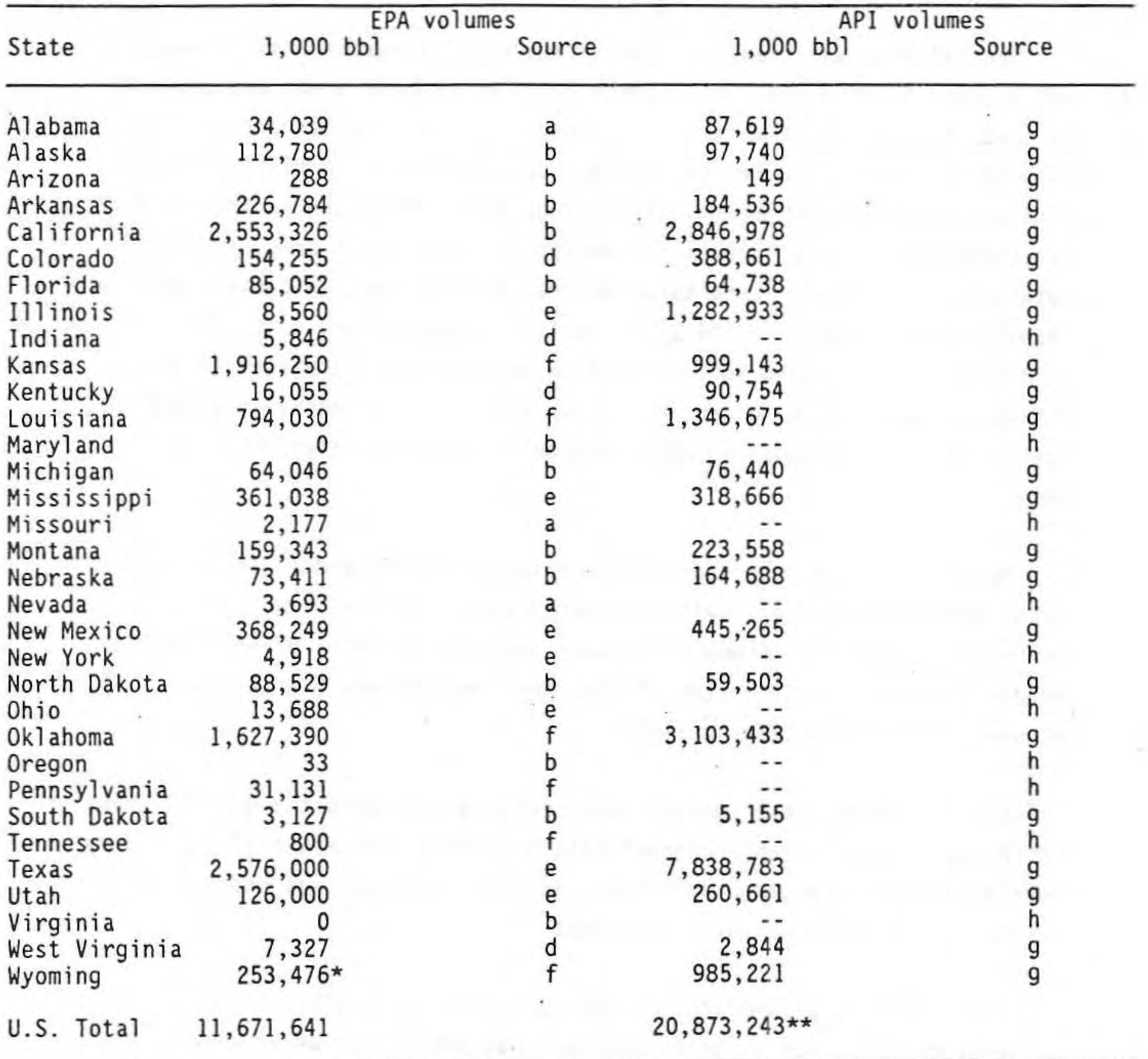

\footnotetext{
Sources: a. Injection Reports

b. Production Reports

c. Hauling Reports

d. Estimate calculated from water/oil ratio from surrounding States

e. Estimate calculated from water/oil ratio from other years for which data were available

f. Estimate calculated from information provided by State representative. See Table I-8, (Westec, 1987) to explain footnotes a-f

g. API industry survey

h. Not surveyed

* Wyoming states that $1,722,599,614$ barrels of produced water were generated in the State in 1985. For the work done in Chapter VI, the State's numbers were used.

** Includes only States surveyed.
} 
Central pits and treatment facilities receive wastes from numerous oil and gas field operations. Since large geographic areas are serviced by these facilities, the facilities tend to be very large; one pit in Oklahoma measured 15 acres and was as deep as 50 feet in places. Central pits are used for long-term waste storage and incorporate no treatment of pit contents. Typical operations accept drilling waste only, produced waters only, or both. Long-term, natural evaporation can concentrate the chemical constituents in the pit. Central treatment and disposal facilities are designed for reconditioning and treating wastes to allow for discharge or final disposal. Like central pits, central treatment facilities can accept drilling wastes only, produced water only, or both.

Reserve pits are used for onsite disposal of waste drilling fluids. These reserve pits are usually dewatered and backfilled. Waste byproducts present at production sites include saltwater brines (called produced waters), tank botton sludge, and "pigging wax," which can accumulate in the gathering lines.

Extracts from these samples were prepared both directly and following the proposed EPA Toxicity Characteristic Leaching Procedure (TCLP). They were analyzed for organic compounds, metals, classical wet chemistry parameters, and certain other analytes.

API conducted a sampling program concurrent with EPA's. API's universe of sites was slightly smaller than EPA's, but where they overlapped, the results have been compared. API's methodology was designed to be comparable to that used by EPA, but API's sampling and analytical methods, including quality assurance and quality control procedures, varied somewhat from EPA's. These dissimilarities can lead to different analytical results. For a more detailed discussion of all aspects of API's sampling program, see API 1987. 


\section{Sampling Methods}

Methods used by EPA and by API are discussed briefly below, with emphasis placed on EPA's program.

\section{EPA Sampling Procedures}

Pit sampling: All pit samples were composited grab samples. The EPA field team took two composited samples for each pit--one sludge sample and one supernatant sample. Where the pit did not contain a discrete liquid phase, only a sludge sample was taken. Sludge samples are defined by EPA for this report as tank bottoms, drilling muds, or other samples that contains a significant quantity of solids (normally greater than 1 percent). EPA also collected samples of drilling mud before it entered the reserve pit.

Each.pit was divided into four quadrants, with a sample taken from the center of each quadrant, using either a coring device or a dredge. The coring device was lined with Teflon or glass to avoid sample contamination. This device was preferred because of its ease of use and deeper penetration. The quadrant samples were then combined to make a single composite sample representative of that pit.

EPA took supernatant samples at each of the four quadrant centers before collecting the sludge samples, using a stainless steel liquid thief sampler that allows liquid to be retrieved from any depth. Samples were taken at four evenly spaced depths between the liquid surface and the sludge-supernatant interface. EPA followed the same procedure at each of the sampling points and combined the results into a single composite for each site.

To capture volatile organics, volatile organic analysis (VOA) vials were filled from the first liquid grab sample collected. All other 
sludge and liquid samples were composited and thoroughly mixed and had any foreign material such as stones and other visible trash removed prior to sending them to the laboratory for analysis (USEPA 1987).

Produced water: To sample produced water, EPA took either grab samples from process lines or composited samples from tanks. Composite samples were taken at four evenly spaced depths between the liquid surface and the bottom of the tank, using only one sampling point per tank. Storage tanks that were inaccessible from the top had to be sampled from a tap at the tank bottom or at a flow line exiting the tank. For each site location, EPA combined individual samples into a single container to create the total liquid sample for that location. EPA mixed all composited produced water samples thoroughly and removed visible trash prior to transport to the laboratory (USEPA 1987).

Central treatment facilities: Both liquid and sludge samples were taken at central treatment facilities. All were composited grab samples using the same techniques described above for pits, tanks, or process lines (USEPA 1987).

\section{API Sampling Methods}

The API team divided pits into six sections and sampled in an "S" curve pattern in each section. There were 30 to 60 sample locations depending upon the size of the pit. API's sampling device was a metal or PVC pipe, which was driven into the pit solids. When the pipe could not be used, a stoppered jar attached to a ridged pole was used. Reserve pit supernatant was sampled using weighted bottles or bottom filling devices. Produced waters were usually sampled from process pipes or valves. API did not sample central treatment facilities (API 1987).

\section{Analytical Methods}

As for sampling methods, analytical methods used by EPA and by API were somewhat different. Each is briefly discussed below. 


\section{EPA Analytical Methods}

EPA analyzed wastes for the RCRA characteristics in accordance with the Office of Solid Waste test methods manual (SW-846). In addition, since the Toxicity Characteristic Leaching Procedure (TCLP) has been proposed to be a RCRA test, EPA used that analytical procedure for certain wastes, as appropriate. EPA also used EPA methods 1624 and 1625 , isotope dilution methods for organics, which have been determined to be scientifically valid for this application.

EPA's survey analyzed 444 organic compounds, 68 inorganics, 19 conventional contaminants, and 3 RCRA characteristics for a total of 534 analytes. Analyses performed included gas and liquid chromatography, atomic absorption spectrometry and mass spectrometry, ultraviolet detection method, inductively coupled plasma spectrometry, and dioxin and furan analysis. All analyses followed standard EPA methodologies and protocols and included full. quality assurance/quality control (QA/QC) on certain tests (USEPA 1987).

Of these 534 analytes, 134 were detected in one or more samples. For about half of the sludge samples, extracts were taken using EPA's proposed Toxicity Characteristic Leaching Procedure (TCLP) and were analyzed for a subset of organics and metals. Samples from central pits and central treatment facilities were analyzed for $136 \mathrm{chlorinated} \mathrm{dioxins} \mathrm{and} \mathrm{furans}$ and 79 pesticides and herbicides (USEPA 1987).

\section{API Analytical Methods}

API analyzed for 125 organics, 29 metals, 15 conventional contaminants, and 2 RCRA characteristics for each sample. The same methods were used by API and EPA for analysis of metals and conventional 
pollutants with some minor variations. For organics analysis EPA used methods $1624 \mathrm{C}$ and $1625 \mathrm{C}$, while API used EPA methods 624 and 625 . While the two method types are comparable, method 1624 (and 1625C) may give a more accurate result because of less interference from the matrix and a lower detection limit than methods 624 and 625 . In addition, $Q A / Q C$ on API's program has not been verified by EPA. See USEPA 1987 for a discussion of EPA analytical methods.

\section{Results}

Chemical Constituents Found by EPA in $0 i 1$ and Gas Extraction Waste Streams

As previously stated, EPA collected a total of 101 samples from drilling sites, production sites, waste treatment facilities, and commercial waste storage and disposal facilities. Of these 101 samples, 42 were sludge samples and 59 were liquid samples (USEPA 1987).

Health-based numbers in milligrams per liter (mg/L) were tabulated for all constituents for which there are Agency-verified limits. These are either reference doses for noncarcinogens (Rfds) or risk-specific doses (RSDs) for carcinogens. RSDs were calculated, using the following risk levels: 10-6 for class $A$ (human carcinogen) and 10-5 for class $B$ (probable human carcinogen). Maximum contaminant limits (MCLs) were used, when available, then Rfds or RSDs. An MCL is an enforceable drinking water standard that is used by the Office of Solid Waste when ground water is a main exposure pathway.

Two multiples of the health-based limits (or MCLs) were calculated for comparison with the sample levels found in the wastes. Multiples of 100 were used to approximate the regulatory level set by the EP toxicity test (i.e., $100 \times$ the drinking water standards for some metals and 
pesticides). Multiples of 1,000 were used to approximate the concentration of a leachate which, as a first screen, is a threshold level of potential regulatory concern. Comparison of constituent levels found by direct analysis of waste with multiples of health-based numbers (or MCLs) can be used to approximate dispersion of this waste to surface waters. Comparison of constituent levels found by TCLP analys is of waste with multiples of health-based numbers (or MCLs) can be used to approximate dispersion of this waste to ground water.

For those polyaromatic hydrocarbons (PAHS) for which verified health-based numbers do not exist, limits were estimated by analogy with known toxicities of other PAHs. If structure activity analysis (SAR) indicated that the PAH had the potential to be carcinogenic, then it was assigned the same health-based number as benzo(a)pyrene, a potent carcinogen. If the SAR analysis yielded equivocal results, the PAH was assigned the limit given to indeno-(1,2,3-cd) pyrene, a PAH with possible carcinogenic potential. If the SAR indicated that the PAH was not likely to be carcinogenic, then it was assigned the same number as naphthalene, a noncarcinogen.

The analysis in this chapter does not account for the frequency of detection of constituents, or nonhuman health effects. Therefore, it provides a useful indication of the constituents deserving further study, but may not provide an accurate description of the constituents that have the potential to pose actual human health and environmental risks. Readers should refer to Chapter V, "Risk Modeling," for information on human health and environmental risks and should not draw any conclusions from the analysis presented in Chapter II about the level of risk posed by wastes from oil and gas wells.

EPA may further evaluate constituents that exceeded the health-based limit or MCL multiples to determine fate, transport, persistence, and toxicity in the environment. This evaluation may show that constituents 
designated as secondary in the following discussion may not, in fact, be of concern to EPA.

Although the Toxicity Characteristics Leaching Procedure (TCLP) was performed on the sludge samples, the only constituent in the leach exhibiting concentrations that exceeded the multiples previously described was benzene in production tank bottom sludge. All of the other chemical constituents that exceeded the multiples were from direct analysis of the waste.

\section{Constituents Present at Levels of Potential Concern}

Because of the limited number of samples in relation to the large universe of facilities from which the samples were drawn, results of the waste sampling program conducted for this study must be analyzed carefully. EPA is conducting a statistical analysis of these samples.

Table II-4 shows EPA and API chemical constituents that were present in $0 i l$ and gas extraction waste streams in amounts greater than. health-based limits multiplied by 1,000 (primary concern) and those constituents that occurred within the range of multiples of 100 and 1,000 (secondary concern). Benzene and arsenic, constituents of primary and secondary concern respectively, by this definition, were modeled in the risk assessment chapter (Chapter $V$ ). The table compares waste stream location and sample phase with the constituents found at that location and phase. Table II-5 shows the number of samples compared with the number of detects in EPA samples for each constituent of potential concern.

The list of constituents of potential concern is not final. EPA is currently evaluating the data collected at the central treatment facilities and central pits, and more chemical constituents of potential concern may result from this evaluation. Also, statistical analysis of the sampling data is continuing. 


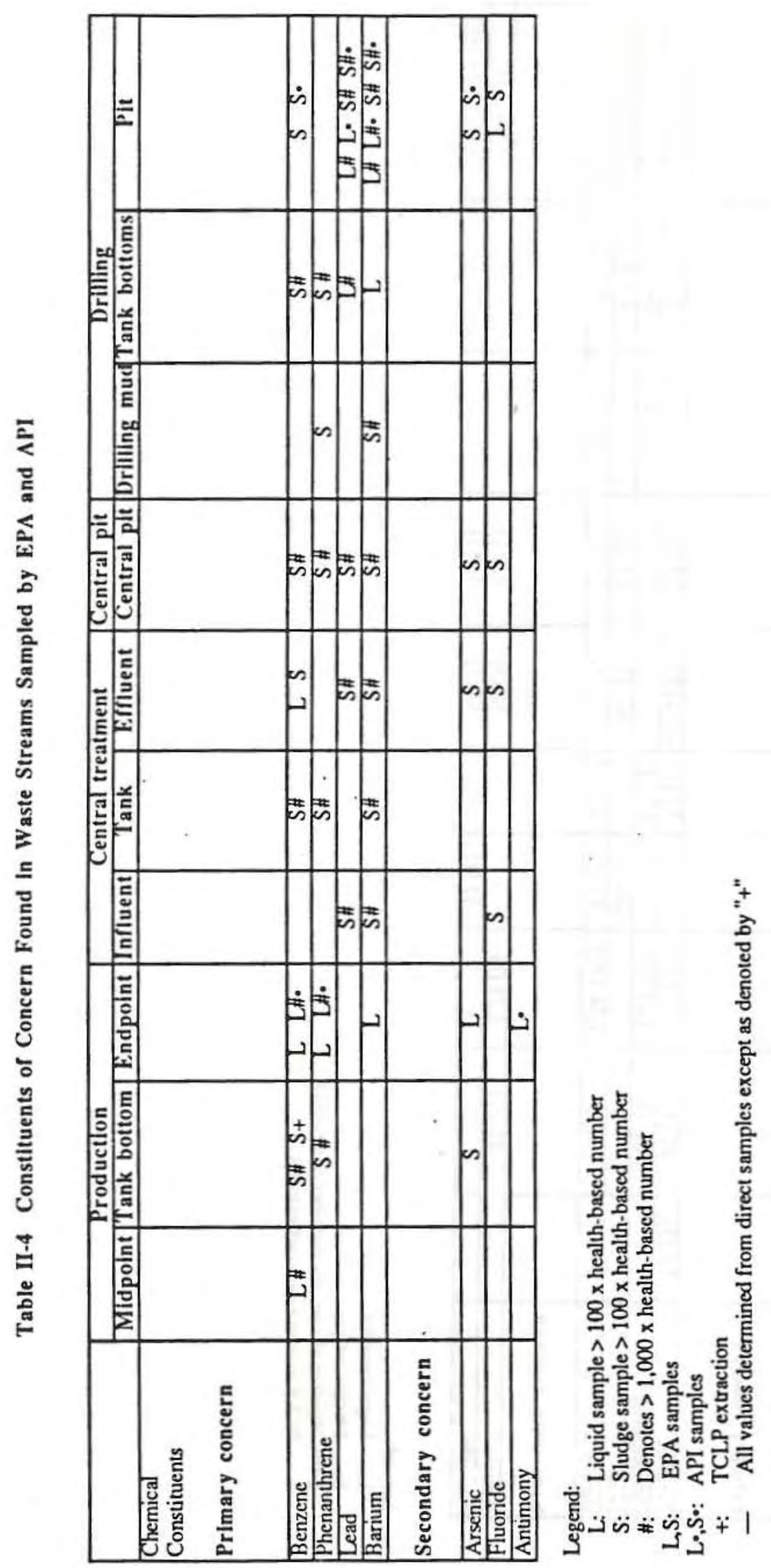




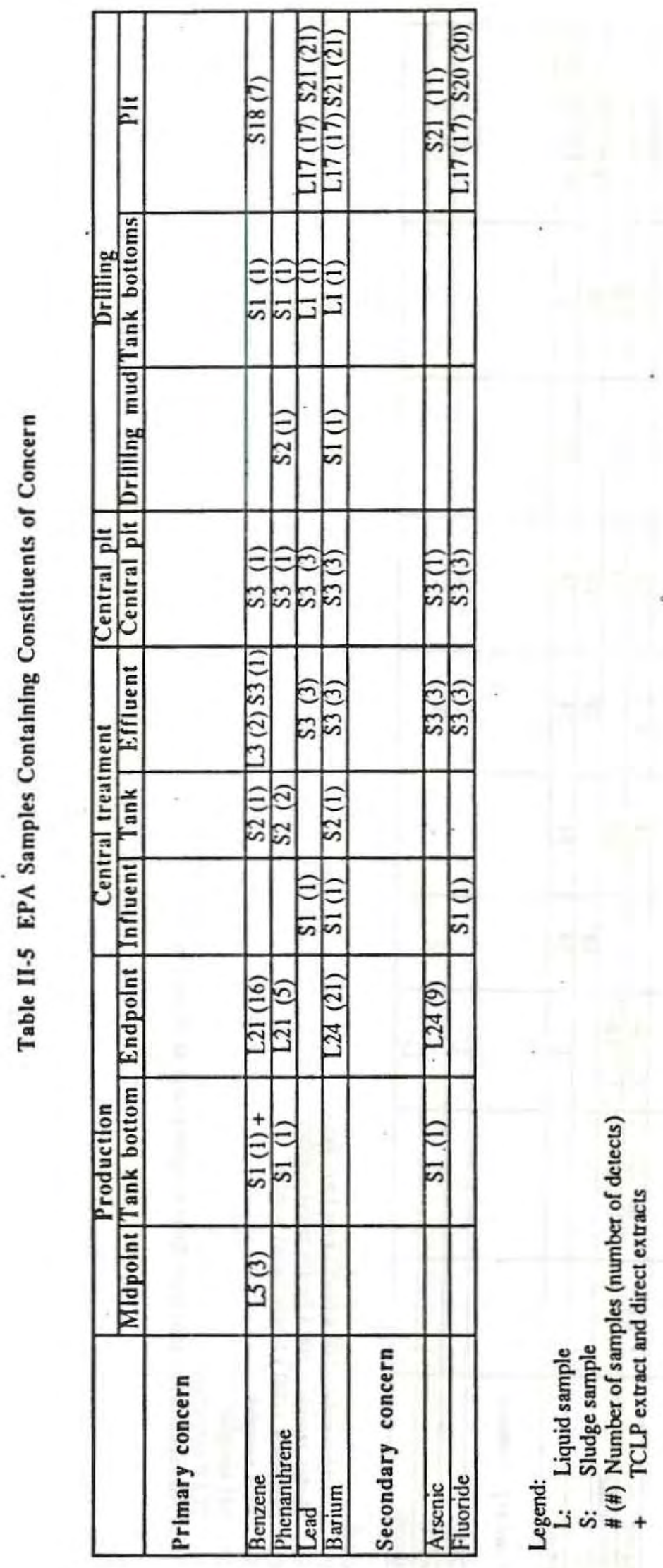


Comparison to Constituents of Potential Concern Identified in the Risk Arialysis

This report's risk assessment selected the chemical constituents that are most likely to dominate the human health and environmental risks associated with drilling wastes and produced water endpoints. Through this screening process, EPA selected arsenic, benzene, sodium, cadmium, chromium VI, boron, chloride, and total mobile ions as the constituents to model for risk assessment. ${ }^{\epsilon}$

The chemicals selected for the risk assessment modeling differ from the constituents of potential concern identified in this chapter's analysis for at least three reasons. First, the risk assessment screening accounted for constituent mobility by examining several factors in addition to solubility that affect mobility (e.g., soil/water partition coefficients) whereas, in Chapter II, constituents of potential concern were not selected on the basis of mobility in the environment. Second, certain constituents were selected for thie risk assessment modeling based on their potential to cause adverse environmental effects as opposed to human health effects; the Chapter II analysis considers mostly human health effects. Third, frequency of detection was considered in selecting constituents for the risk analysis but was not considered in the Chapter II analysis.

\section{Facility Analysis}

Constituents of potential concern were chosen on the basis of exceedances in liquid samples or TCLP extract. Certain sludge samples are listed in Tables II-4 and II-5, since these samples, through direct

\footnotetext{
6 Mobile ions modeled in the risk assessment include chloride, sodium, potassium, calcium. magnesium, and sulfate.
} 
chemical analysis, indicated the presence of constituents at levels exceeding the multiples previously described. One sludge sample analyzed by the TCLP method contained benzene in an amount above the level of potential concern. This sample is included in Tables II-4 and II-5. The sludge samples are shown for comparison with the liquid samples and TCLP extract and were not the basis for choice as a constituent of potential concern. Constituents found in the liquid samples or the TCLP extract in amounts greater than 100 times the health-based number are considered constituents of potential concern by EPA.

\section{Central Treatment Facility}

Benzene, the only constituent found in liquid samples at the central treatment facilities, was found in the effluent in amounts exceeding the level of potential concern.

\section{Central Pit Facility}

No constituent was found in the liquid phase in amounts exceeding the level of potential concern at central pit facilities.

\section{Drilling Facilities}

Lead and barium were found in amounts exceeding the level of potential concern in the liquid phase of the tank bottoms and the reserve pits that were sampled. Fluoride was found in amounts that exceeded 100 times the health-based number in reserve pit supernatant.

\section{Production Facility}

Benzene was present in amounts that exceeded the level of potential concern at the midpoint and the endpoint lccations. Exceedances of the 
level of potential concern that occurred only at the endpoint location were for phenanthrene, barium, arsenic, and antimony. Benzene was present in amounts exceeding the multiple of 1,000 in the TCLP leachate of one sample.

\section{WASTE CHARACTERIZATION ISSUES}

Toxicity Characteristic Leaching Procedure (TCLP)

The TCLP was designed to model a reasonable worst-case mismanagement scenario, that of co-disposal of industrial waste with municipal refuse or other types of biodegradable organic waste in a sanitary landfill. As a generic model of mismanagement, this scenario is appropriate for nonregulated wastes because those wastes may be sent to a municipal landfill. However, most waste from oil and gas exploration and production is not disposed of in a sanitary landfill, for which the test was designed. Therefore, the test may not reflect the true hazard of the waste when it is managed by other methods. However, if these wastes were to go to a sanitary landfill, EPA believes the TCLP would be an appropriate leach test to use.

For example, the TCLP as a tool for predicting the leachability of oily wastes placed in surface impoundments may actually overestimate that leachability. One reason for this overestimation involves the fact that the measurement of volatile compounds is conducted in a sealed system during extraction. Therefore, all volatile toxicants present in the waste are assumed to be available for leaching to ground water. None of the volatiles are assumed to be lost from the waste to the air. Since volatilization is a potentially significant, although as yet unquantified, route of loss from surface impoundments, the TCLP may overestimate the leaching potential of the waste. Another reason for overestimation is that the TCLP assumes that no degradation--either chemical, physical, or biological--will occur in the waste before the 
leachate actually leaves the impoundment. Given that leaching is not likely to begin until a finite time after disposal and will continue to occur over many years, the assumption of no change may tend to overestimate leachability.

Conversely, the TCLP may underestimate the leaching potential of petroleum wastes. One reason for this assumption is a procedural problem in the filtration step of the TCLP. The amount of mobile liquid phase that is present in these wastes and that may migrate and result in ground-water contamination is actually underestimated by the TCLP. The TCLP requires the waste to be separated into its mobile and residue solid phases by filtration. Some production wastes contain materials that may clog the filter, indicating that the waste contains little or no mobile fraction. In an actual disposal environment, however, the liquid may migrate. Thus, the TCLP may underestimate the leaching potential of these materials. Another reason for underestimation may be that the acetate extraction fluid used is not as aggressive as real world leaching fluid since other solubilizing species (e.g., detergents, solvents, humic species, chelating agents) may be present in leaching fluids in actual disposal units. The use of a citric acid extraction media for more aggressive leaching has been suggested.

Because the TCLP is a generic test that does not take site-specific factors into account, it may overestimate waste leachability in some cases and underestimate waste leachability in other cases. This is believed to be the case for wastes from oil and gas exploration and production.

The EPA has several projects underway to investigate and quant ify the leaching potential of oily matrices. These include using filter aids to prevent clogging of the filter, thus increasing filtration efficiency, and using column studies to quantitatively assess the degree to which oily materials move through the soil. These projects may result in a leach test more appropriate for oily waste. 
Solubility and Mobility of Constituents

Barium is usually found in drilling waste as barium sulfate (barite), which is practically insoluble in water (Considine 1974). Barium sulfate may be reduced to barium sulfide, which is water soluble. It is the relative insolubility of barium sulfate that greatly decreases its toxicity to humans; the more soluble and mobile barium sulfide is also much more toxic (Sax 1984). Barium sulfide formation from barium sulfate requires a moist anoxic environment.

The organic constituents present in the liquid samples in concentrations of potential concern were benzene and phenanthrene. Benzene was found in produced waters and effluent from central treatment facilities, and phenanthrene was found in produced waters.

An important cominingling effect that can increase the mobility of nonpolar organic solvents is the addition of small amounts of a more soluble organic solvent. This effect can significantly increase the extent to which normally insoluble materials are dissolved. This solubility enhancement is a log-linear effect. A linear increase in cosolvent concentration can lead to a logarithmic increase in solubility. This effect is also additive in terms of concentration. For instance, if a number of cosolvents exist in small concentrations, their total concentration may be enough to have a significant effect on nonpolar solvents with which the cosolvents come in contact (Nkedi-Kizza 1985, Woodburn et al. 1986). Common organic cosolvents are acetone, toluene, ethanol, and xylenes (Brown and Donnelly 1986).

Other factors that must be considered when evaluating the mobility of these inorganic and organic constituents in the environment are the use of surfactants at $0 i 1$ and gas drilling and production sites and the 
general corrosivity of produced waters. Surfactants can enhance the solubility of many constituents in these waters. Produced waters have been shown to corrode casing (see damage cases in Chapter IV).

Changes in $\mathrm{pH}$ in the environment of disposal can cause precipitation of compounds or elements in waste and this can decrease mobility in the environment. Also adsorption of waste components to soil particles will attenuate mobility. This is especially true of soils containing clay because of the greater surface area of clay-sized particles.

Phototoxic Effect of Polycyclic Aromatic Hydrocarbons (PAH)

New studies by Kagan et al. (1984), Allred and Giesy (1985), and Bowling et al. (1983) have shown that very low concentrations (ppb in some cases) of polycyclic aromatic hydrocarbon (PAH) are lethal to some forms of aquatic wildlife when they are introduced to sunlight after exposure to the PAHs. This is called the phototoxic effect.

In the study conducted by Allred and Giesy (1985), it was shown that anthracene toxicity to Daphnia pulex resulted from activation by solar radiation of material present on or within the animals and not in the water. It appeared that activation resulted from anthracene molecules and not anthracene degeneration products. Additionally, it was shown that wavelengths in the UV-A region ( 315 to $380 \mathrm{~nm}$ ) are primarily responsible for photo-induced anthracene toxicity.

It has been shown that PAHs are a typical component of some produced waters (Davani et al., 1986a). The practice of disposal of produced waters in unlined percolation pits is allowing PAHs and other constituents to migrate into and accumulate in soils (Eiceman et al., $1986 \mathrm{a}, 1986 \mathrm{~b})$. 
pH and Other RCRA Characteristics

of the RCRA parameters reactivity, ignitability, and corrosivity, no waste sample failed the first two. Reactivity was low and ignitability . averaged $200^{\circ} \mathrm{F}$ for all waste tested. On the average, corrosivity parameters were not exceeded, but one extreme did fail this RCRA test (See Table II-6). A solid waste is considered hazardous under RCRA if its aqueous phase has a pH less than or equal to 2 or greater than or equal to 12.5. As previously stated, a sludge sample is defined by EPA in this document as a sample containing a significant quantity of solids (normally greater than 1 percent).

Of the major waste types at oil and gas facilities, waste drilling muds and produced waters have an average neutral pH. Waste drilling fluid samples ranged from neutral values to very basic values, and produced waters ranged from neutral to acidic values. In most cases the sludge phase tends to be more basic than the liquid phases. An exception is the tank bottom waste at central treatment facilities, which has an average acidic value. Drilling waste tends to be basic in the liquid and sludge phases and failed the RCRA test for alkalinity in one extreme case. At production facilities the $\mathrm{pH}$ becomes more acidic from the midpoint location to the endpoint. This is probably due to the removal of hydrocarbons. This neutralizing effect of hydrocarbons is also shown by the neutral pH values of the production tank bottom waste. An interesting anomaly of Table II- 6 is the alkaline values of the influent and effluent of central treatment facilities compared to the acidic values of the tank bottoms at these facilities. Because central treatment facilities accept waste drilling fluids and produced waters, acidic constituents of produced waters may be accumulating in tank bottom sludges. The relative acidity of the produced waters is also indicated by casing failures, as shown by some of the damage cases in Chapter IV. 
Table II-6 pII Values for Exploration, Development and Production Wastes (EPA Samples)

\begin{tabular}{|c|c|c|c|c|c|c|c|c|c|c|}
\hline & & Midpoint & Tank bottom & Endpoint & Influent & Tank & Effluent & Central pit & Tank bottom & Pit \\
\hline & Production & & & & & & & & & $\cdot$ \\
\hline & Sludge & & $7.0 ; 7.0 ; 7.0$ & & & & & & & \\
\hline & Liquid & $6.4 ; 6.6 ; 8.0$ & & $2.7 ; 7.6 ; 8.1$ & & & & & & \\
\hline & & & & & & & & & & \\
\hline & Central treatment & & & & & & & & & \\
\hline & Sludge & & & & $8.8 ; 8.8 ; 8.8$ & $2.0 ; 3.9 ; 5.8$ & $5.7 ; 8.2 ; 10.0$ & & & \\
\hline$\Xi$ & Liquid & & & & $5.7 ; 6.5 ; 7.3$ & & $7.0 ; 8.2 ; 10.1$ & & & \\
\hline+ & Central pit & +5 & 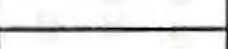 & 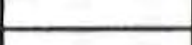 & 工 & - & {[} & & & \\
\hline & & & & & & & & & & \\
\hline & Sludge & & & & & & & $7.2 ; 8.0 ; 9.2$ & & \\
\hline & Liquid & & & & & & & $5.7 ; 7.5 ; 8.5$ & & \\
\hline & mritens & & & & & & & & & \\
\hline & Driming & & & & & & & & & \\
\hline & Sludge & & & & & & & & & $6.8 ; 9.0 ; 12.8$ \\
\hline & Liquid & & & & & & & & $7.1 ; 7$ & $6.5 ; 7.7$ \\
\hline
\end{tabular}

Legend:

\#;\#; \# - minimum; average; maximum 
Use of Constituents of Concern

The screening analysis conducted for the risk assessment identified arsenic, benzene, sodium, cadmium, chromium VI, boron, and chloride as the constituents that likely pose the greatest human health and environmental risks. The risk assessment's findings differ from this chapter's findings since this chapter's analysis did not consider the frequency of detection of constituents, mobility factors, or nonhuman health effects (see Table 11-7). Some constituents found in Table II-4 were in waste streams causing damages as documented in Chapter IV. 
Table II-7 Comparison of Potentlal Constituents of Concern That Were Modeled in Chapter V

\begin{tabular}{|lll|}
\hline \multicolumn{1}{|c|}{ Chemical } & $\begin{array}{c}\text { Chapter } \\
I^{*}\end{array}$ & \multicolumn{1}{c|}{$\begin{array}{c}\text { Reasons for not including in Chapter V } \\
\text { risk analysis }\end{array}$} \\
\hline Benzene & P Yes & N/A \\
Phenanthrene & P No & $\begin{array}{l}\text { Low frequency in drilling pit and produced water samples; } \\
\text { low ground-water mobility; relatively low concentration- } \\
\text { to-toxicity ratio; unverified reference dose used for } \\
\text { Chapter } 2 \text { analysis. }\end{array}$ \\
Lead & P No & Low ground-water mobility. \\
Barium & P No & Low ground-water mobility. \\
Arsenic & S Yes & N/A \\
Fluoride & S No & Relatively low concentration-to-toxicity ratio. \\
Antimony & S No & Low frequency in drilling pit and produced water samples.
\end{tabular}

- $\mathrm{P}=$ primary concern in Chapter II; $\mathrm{S}=$ secondary concern in Chapter II.

*. Yes = modeled in Chapter V analysis; no = not modeled in Chapter V analysis.

... Table summarizes primary reasons only; additional secondary reasons may also exist. 


\section{REFERENCES}

Allred. P. M., and Giesy, J. P. 1985. Solar radiation induced toxicity of anthracene to daphnia pulex. Environmental Toxicology Chem.

4: $219-226$.

API. 1986. American Petroleum Institute. Comments to the docket on the proposed toxicity characteristic leaching procedure (Doc.

\#F-86-TC-FFFFF). August 12, 1986.

- 1987. American Petroleum Institute. $0 i 1$ and gas industry

exploration and production wastes (Doc. \#471-01-09).

Baker, F.G., and Brendecke, C.M. 1983. Groundwater. 21: 317.

Bowling, J. W., Laversee, G. J., Landram, P. F., and Giesy, J. P. 1983. Acute mortality of anthracene contaminated fish exposed to sunlight. Aquatic Toxicology. 3: 79-90.

Brown, K.W., and Donnelly, K.C. 1986. The occurrence and concentration of organic chemicals in hazardous and municipal waste landfill leachate. In Press.

Considine, Douglas M., ed. 1974. Chemical and process technology encyclopedia. New York: McGraw Hill Inc.

Davani, B., Ingram, J., Gardea, J.L., Dodson, J.A., and Eiceman, G.A. 1986a. Hazardous organic compounds in liquid waste from disposal pits for production of natural gas. Int. J. Environ. Anal. Chem. 20 (1986): 205.

Davani, B., Gardea, J.S., Dodson, J.A., and Eiceman, G.A. 1986b. Organic compounds in soils and sediments from unlined waste disposal pits for natural gas production and processing. Water, Air and Soil Pollution. 27: 267-276.

Eiceman, G.A., Davani, B., and Ingram, J. 1986a. Depth profiles for hydrocarbons and PAH in soil beneath waste disposal pits from production of natural gas. Int. J. Environ. Anal. Chem. 20 (1986): 508.

Eiceman, G.A., McConnon, J.T., Zaman, M., Shuey, C., and Earp, D. $1986 \mathrm{~b}$. Hydrocarbons and aromatic hydrocarbons in groundwater surrounding an earthen waste disposal pit for produced water in the Duncan Oil Field of New Mexico. Int. J. Environ. Anal. Chem. 24 (1986): 143-162. 
Environmental Defense Fund. 1986. Comments of the Environmental Defense Fund on the June 13, 1986 proposed Toxicity Characteristic Leaching Procedure (Doc $\#$ F-86-TC-FFFFF). August $12,1986$.

Kagan, J., Kagan, P. A., and Buhse, H. E., Jr. 1984. Toxicity of alpha terthienyl and anthracene toward late embryonic stages of ranapieines. J. Chem. Ecol. 10: 1015-1122.

Nkedi-Kizza, P., et al. 1985. Influence of organic cosolvents on sorption of hydrophobic organic chemicals by soils. Fnviron. Sci. Technol. 19: 975-979.

Sax, N. Irving. 1984. Dangerous properties of industrial materials. New York: Nostrand Reinhold Company.

USEPA. 1987. U.S. Environmental Protection Agency. Technical report: exploration development and production of crude oil and natural gas; field sampling and analytical results (appendices $A-G$ ), EPA \#530-SW-87-005. (DoC. \# OGRN FFFF).

Woodburn, K. B., et al. 1986. Solvophobic approach for predicting sorption of hydrophobic organic chemicals on synthetic sorbents and soils. J. Contaminant Hydrology 1: 227-241. 


\section{CHAPTER III}

\section{CURRENT AND ALTERNATIVE WASTE MANAGEMENT PRACTICES}

\section{INTRODUCTION}

Managing wastes produced by the 0 il and gas industry is a large task. By the estimates gathered for this report, in 1985 over 361 million barrels of drilling muds and 20.9 billion barrels of produced water were disposed of in the 33 States that have significant exploration, development, and production activity. In that same year, there were 834,831 active $0 i 1$ and gas wells, of which about 70 percent (580,000 wells) were stripper operations.

The focus of this section is to review current waste management technologies employed for wastes at all phases of the explorationdevelopment-production cycle of the onshore oil and gas industry. It is convenient to divide wastes into two broad categories. The first category includes drilling muds, wellbore cuttings, and chemical additives related to the drilling and well completion process. These wastes tend to be managed together and may be in the form of liquids, sludges, or solids. The second broad category includes all wastes associated with $0 i l$ and gas production. Produced water is the major waste stream and is by far the highest volume waste associated with oil and gas production. Other production-related wastes include relatively small volumes of residual bactericides, fungicides, corrosion inhibitors, and other additives used to ensure efficient production; wastes from oil/gas/water separators and other onsite processing facilities; production tank bottoms; and scrubber bottoms. ${ }^{1}$

\footnotetext{
1 For the purpose of this chapter, all waste streams, whether exempt or nonexempt, are discussed.
} 
In addition to looking at these two general waste categories, it is also important to view waste management in relation to the sequence of operations that occurs in the life cycle of a typical well. The chronology involves both drilling and production--the two phases mentioned above--but it also can include "post-closure" events, such as seepage of native brines into fresh ground water from improperly plugged or unplugged abandoned wells or leaching of wastes from closed reserve pits.

Section $8002(\mathrm{~m})$ of RCRA requires EPA to consider both current and alternative technologies in carrying out the present study. Sharp distinctions between current and alternative technologies are difficult to make because of the wide variation in practices among States and among different types of operations. Furthermore, waste management technology in this field is fairly simple. At least for the major high-volume streams, there are no significant newly invented, field-proven technologies in the research or development stage that can be considered "innovative" or "emerging." Although practices that are routine in one location may be considered innovative or alternative elsewhere, virtually every waste management practice that exists can be considered "current" in one specific situation or another. This is because different climatological or geological settings may demand different management procedures, either for technical convenience in designing and running a facility or because environmental settings in a particular region may be unique. Depth to ground water, soil permeability, net evapotranspiration, and other site-specific factors can strongly influence the selection and design of waste management practices. Even where geographic and production variables are similar, States may impose quite different requirements on waste management, including different permitting conditions. 
Long-term improvements in waste management need not rely, however, purely on increasing the use of better existing technology. The Agency does foresee the possibility of significant technical improvements in future technologies and practices. Examples include incineration and other thermal treatment processes for drilling fluids; conservation, recycling, reuse, and other waste minimization techniques; and wet air oxidation and other proven technologies that have not yet been applied to oil and gas operations.

\section{Sources of Information}

The descriptions and interpretations presented here are based on State or Federal regulatory requirements, published technical information, observations gathered onsite during the waste sampling program, and interviews with State officials and private industry. Emphasis is placed on practices in 13 States that represent a cross-section of the petroleum extraction industry based on their current drilling activity, rank in production, and geographic distribution. (See Table III-1.)

\section{Limitations}

Data on the prevalence, environmental effectiveness, and enforcement of waste management requirements currently in effect in the petroleum-producing States are difficult to obtain. Published data are scarce and often outdated. Some of the State regulatory agencies that were interviewed for this study have only very limited statistical information on the volumes of wastes generated and on the relative use of the various methods of waste disposal within their jurisdiction. Time was not available to gather statistics from other States that have significant oil and gas activity. This lack of concrete data makes it difficult for EPA to complete a definitive assessment of available disposal options. EPA is collecting additional data on these topics. 
Table 111-1 States with Major Oil Production Used as Primary

References in This Study

Alaska
Arkansas
California
Colorado
Kansas
Louisiana
Michigan
New Mexico
Onio
Oklahoma
Texas
West Virginia
Wyoming

II I - 4 


\section{DRILLING-RELATED WASTES}

\section{Description of Waste}

Drilling wastes include a wide variety of materials, ranging in volume from the thousands of barrels of fluids ("muds") used to drill a well, to the hundreds of barrels of drill cuttings extracted from the borehole, to much smaller quantities of wastes associated with various additives and chemicals sometimes used to condition drilling fluids. A general description of each of these materials is presented in broad terms below.

\section{Drilling Fluids (Muds)}

The largest volume drilling-related wastes generated are the spent drilling fluids or muds. The composition of modern drilling fluids or muds can be quite complex and can vary widely, not only from one geographical area to another but also from one depth to another in a particular well as it is drilled.

Muds fall into two general categories: water-based muds, which can be made with fresh or saline water and are used for most types of drilling, and oil-based muds, which can be used when water-sensitive formations are drilled, when high temperatures are encountered, or when it is necessary to protect against severe drill string corrosion in hostile downhole environments. Drilling muds contain four essential parts: (1) liquids, either water or oil; (2) reactive solids, the viscosity- and density-building part of the system, often bentonite clays; (3) inert solids such as barite; and (4) additives to control the chemical, physical, and biological properties of the mud. These basic components perform various functions. For example, clays increase viscosity and 
density, barium sulfate (barite) acts as a weighting agent to maintain pressure in the well, and 1 ime and caustic soda increase pH and control viscosity. Additional conditioning materials include polymers, starches, lignitic material, and various other chemicals (Canter et al. 1984).

Table III-2 presents a partial list, by use category, of additives to drilling muds (Note: this table is based on data that may, in some cases, be outdated.)

\section{Cuttings}

Well cuttings include all solid materials produced from the geologic formations encountered during the drilling process that must be managed as part of the content of the waste drilling mud. Drill cuttings consist of rock fragments and other heavy materials that settle out by gravity in the reserve pit. Other materials, such as sodium chloride, are soluble in fresh water and can pose problems in waste disposal. Naturally occurring arsenic may also be encountered in significant concentrations in certain wells and in certain parts of the country and must be disposed of appropriately. (Written communication with Mr. Don Basko, Wyoming $0 i 1$ and Gas Conservation Commission.)

\section{Waste Chemicals}

In the course of drilling operations, chemicals may be disposed of by placing them in the well's reserve pit. These can include any substances deliberately added to the drilling mud for the various purposes mentioned above (see Table III-2). 
Table 111-2 Characterization of 011 and Gas Drilling Fluids

Source: Information in this table was taken from American Petroleum Institute (AP1) Bullet in 13F (1978). Drilling practices nave evolved significantly in some respects since its publication: the information presented below may therefore not be fully accurate or current.

Bases

Bases used in formulating drilling fluid are predominant ly fresh water, with minor use of saltwater or olls, including diesel and mineral oils. It is est imated that the industry used 30,000 tons of diesel 011 per year in drilling fluid in 1978. ${ }^{\text {a }}$

\section{Weight ing Agents}

Comnon weight ing agents found in drilling fluids are barite, calcium * carbonate, and galena $(P t S)^{b^{*}}$ Approximately $1,900,000$ tons of barite, 2.500 tons of calcium carbonate, and 50 tons of galena (the mineral form of lead) are used in drilling each year.

\section{Viscosifiers}

Viscosifiers found in drilling fluid include:

- Bentonite clays

- Attapulgite/seprolite

650.000 tons/year

- Asphalt/gilsonite

85,000 tons/year

- Asbestos

- Bio-polymers

a This figure included contributions from of fshore operations. According to API, use of diesel oil in drilling fluid has been substantially reduced in the past 10 years principally as a result of its restricted use in offshore operations.

b API states that galena is no longer used in drilling mud. 


\section{Dispersants}

Dispersants used in drilling fluid include:

- Cadmium, chromium, iron. and other metal lignosulfonates

65,000 tons/year

- Natural, causticized chromium and zinc lignite

50.000 tons/year

- Inorganic phosphates

1.500 tons/year

- Modified tannins

1.200 tons/year

Fluid Loss Reducers

Fluid loss reducers used in drilling fluid include:

- Starch/organic polymers

- Cellulosic polymers (CMC, HEC)

- Guar gum

- Acrylic polymers
15,000 tons/year 12,500 tons/year 100 tons/year 2.500 tons/year

Lost Circulation Materials

Lost circulation materials used comprise a variety of nontoxic substances including cellophane, cotton seed, rice hulls, ground Formica, ground leather, ground paper, ground pecan and walnut shells, mica, and wood and cane fibers. A total of 20,000 tons of these materials is used per year. 
Table 1II-2 (continued)

Surface Active Agents

Surface active agents (used as emu is ifiers, detergents, defoamants) include:

- Fatty acids, naphthenic acids, and soaps

- Organic sulfates/sulfonates

1,000 tons/year

- Aluminum stearate (quantity not available)

Lubricants

Lubricants used include:

- Vegetable oils 500 tons/year

- Graphite $<5$ tons/year

Flocculating Agents

The primary flocculating agents used in drilling are:

- Acrylic polymers 2,500 tons/year

Biocides

Biocides used in drilling include:

- Organic amines, amides, amine salts

- Aldehydes (paraformaldehyde) 500 tons/year

- Chlorinated phenols <1 ton/year

- Organosulfur compounds and (quantity not available) organometallics

Miscellaneous

Miscellaneous drilling fluid additives include:

- Ethoxylated a $\mid k y l$ phenois

1.800 tons/year

- Aaliphatic alcohols

$<10$ tons/year

- Aluminum anhydride derivatives

(quant it ies not and chrom alum available) 


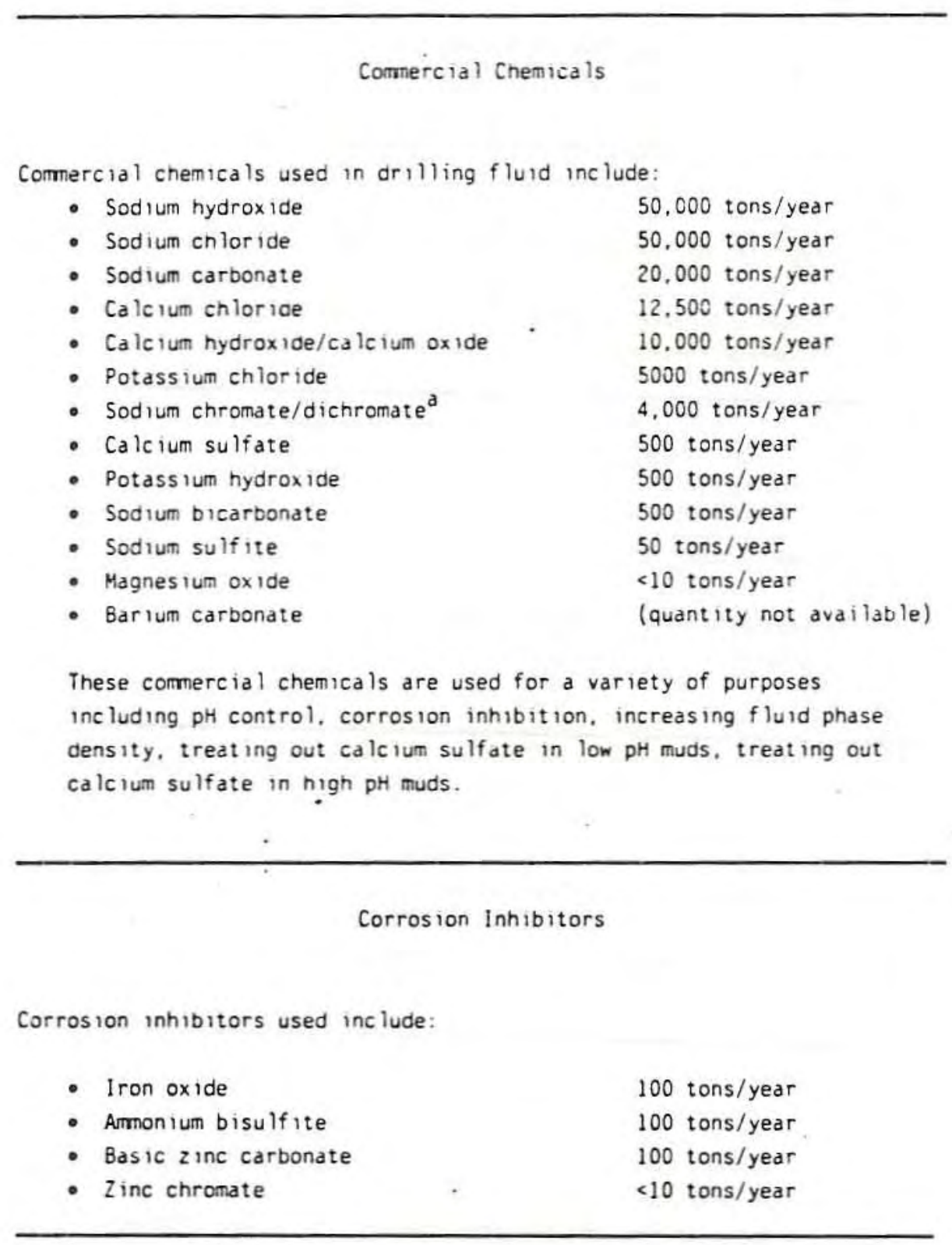

a API states that sodium chromate is no longer used in drilling mud. 
Fracturing and Acidizing Fluids

Fracturing and acidizing are processes commonly used to enlarge existing channels and open new ones to a wellbore for several purposes:

- To increase permeability of the production formation of a well;

- To increase the zone of influence of injected fluids used in enhanced recovery operations; and

- To increase the rate of injection of produced water and industrial waste material into disposal wells.

The process of "fracturing" involves breaking down the formation, often through the application of hydraulic pressure, followed by pumping mixtures of gelled carrying fluid and sand into the induced fractures to hold open the fissures in the rocks after the hydraulic pressure is released. Fracturing fluids can be oil-based or water-based. Additives are used to reduce the leak-off rate, to increase the amount of propping agent carried by the fluid, and to reduce pumping friction. Such additives may include corrosion inhibitors, surfactants, sequestering agents, and suspending agents. The volume of fracturing fluids used to stimulate a well can be significant. ${ }^{2}$ Closed systems, which do not involve reserve pits, are used very occasionally (see discussion. below). However, closed systems are widely used in California. Many oil and gas fields currently being developed contain low-permeability reservoirs that may require hydraulic fracturing for commercial production of oil or gas.

\footnotetext{
2 Mobile 0 il Co. recently set a well stimulation record (single stage) in a Wilcox formation well in Zapata County. Texas, by placing 6.3 million pounds of sand, using a fracturing fluid volume of $1.54 \mathrm{million}$ gallons (World 0il, January 1987).
} 
The process of "acidizing" is done by injecting acid into the target formation. The acid dissolves the rock, creating new channels to the wellbore and enhancing existing ones. The two basic types of acidizing treatments used are:

- Low-pressure acidizing: acidizing that avoids fracturing the formation and allows acid to work through the natural pores (matrix) of the formation.

- Acid fracturing: acidizing that utilizes high pressure and high volumes of fluids (acids) to fracture rock and to dissolve the matrix in the target formation.

The types of acids normally used include hydrochloric acid (in concentrations ranging from 15 to 28 percent in water), hydrochlorichydrofluoric acid mixtures ( 12 percent and 3 percent, respectively), and acetic acid. Factors influencing the selection of acid type include formation solubility, reaction time, reaction products effects, and the sludging and emulsion-forming properties of the crude oil. The products of spent acid are primarily carbon dioxide and water.

Spent fracturing and acidizing fluid may be discharged to a tank, to the reserve pit, or to a workover pit.

\section{Completion and Workover Fluids}

Completion and workover fluids are the fluids placed in the wellbore during completion or workover to control the flow of native formation fluids, such as water, oil, or gas. The base for these fluids is usually water. Various additives are used to control density, viscosity, and filtration rates; prevent gelling of the fluid; and reduce corrosion. They include a variety of salts, organic polymers, and corrosion inhibitors. 
When the completion or workover operation is completed, the fluids in the wellbore are discharged into a tank, the reserve pit, or a workover pit.

Rigwash and Other Miscellaneous Wastes

Rigwash materials are compounds used to clean decks and other rig equipment. They are mostly detergents but can include some organic solvents, such as degreasers.

Other miscellaneous wastes include pipe dope used to lubricate connections in pipes, sanitary sewage, trash, spilled diesel oil, and lubricating oil.

All of these materials may, in many operations, be disposed of in the reserve pit.

\section{ONSITE DRILLING WASTE MANAGEMENT METHODS}

Several waste management methods can be used to manage oil and gas drilling wastes onsite. The material presented below provides a separate discussion for reserve pits, landspreading, annular disposal, solidification of reserve pit wastes, treatment and disposal of liquid wastes to surface water, and closed treatment systems.

Several waste management methods may be employed at a particular site simultaneously. Issues associated with reserve pits are particularly complex because reserve pits are both an essential element of the drilling process and a method for accumulating, storing, and disposing of wastes. This section therefore begins with a general discussion of 
several aspects of reserve pits--design, construction, operation, and closure--and then continues with more specific discussions of the other technologies used to manage drilling wastes.

\section{Reserve Pits}

\section{Description}

Reserve pits, an essential design component in the great majority of well drilling operations, ${ }^{3}$ are used to accumulate, store, and, to a large extent, dispose of spent drilling fluids, cuttings, and associated drill site wastes generated during drilling, completion, and testing operations.

There is generally one reserve pit per well. In 1985, an estimated 70,000 reserve pits were constructed. In the past, reserve pits were used both to remove and dispose of drilled solids and cuttings and to store the active mud system prior to its being recycled to the well being drilled. As more advanced solids control and drilling fluid technology has become available, mud tanks have begun to replace the reserve pit as the storage and processing area for the active mud system, with the reserve pit being used to dispose of waste mud and cuttings. Reserve pits will, however, continue to be the principal method of drilling fluid storage and management.

A reserve pit is typically excavated directly adjacent to the site of the rig and associated drilling equipment. Pits should be excavated from undisturbed, stable subsoil so as to avoid pit wall failure. Where it is impossible to excavate below ground level, the pit berm (wall) is usually constructed as an earthen dam that prevents runoff of liquid into adjacent areas.

3 Closed systems, which do not involve reserve pits, are used very occasionally (see discussion below). However, closed systems are widely used in California. 
In addition to the components found in drilling mud, common constituents found in reserve pits include salts, $0 i 1$ and grease, and dissolved and/or suspended heavy metals. Sources of soluble salt contamination include formation waters, downhole salt layers, and drilling fluid additives. Sources of organic contamination include lubricating oil from equipment leaks, well pressure control equipment testing, heavy oil-based lubricants used to free stuck drill pipe, and, in some cases, oil-based muds used to drill and complete the target formation. ${ }^{4}$ Sources of potential heavy metal contamination include drilling fluid additives, drilled solids, weighting materials, pipe dope, and spilled chemicals (Rafferty 1985).

The reserve pit itself can be used for final disposal of all or part of the drilling wastes, with or without prior onsite treatment of wastes, or for temporary storage prior to offsite disposal. Reserve pits are most often used in combination with some other disposal techniques, the selection of which depends on waste type, geographical location of the site, climate, regulatory requirements, and (if appropriate) lease agreements with the landowner.

The major onsite waste disposal methods include:

- Evaporation of supernatant;

- Backfilling of the pit itself, burying the pit solids and drilled cuttings by using the pit walls as a source of material (the most common technique);

- Landspreading all or part of the pit contents onto the area immediately adjacent to the pit;

\footnotetext{
4 Charles A. Koch of the North Dakota Industrial Comission, Oil and Gas Division. states that "A cumpany would not normally change the entire drilling fluid for just the target zone. This change would add drastically to the cost of drilling."
} 
- Onsite treatment and discharge;

- Injecting or pumping all or part of the wastes into the well annulus; and

- Discharge to surface waters.

Another less common onsite management method is chemical solidification of the wastes.

Dewatering and burial of reserve pit contents (or, alternatively, landspreading the pit contents) are discussed here because they are usually an integral aspect of the design and operation of a reserve pit. The other techniques are discussed separately.

Dewatering of reserve pit wastes is usually accomplished through natural evaporation or skimming of pit liquids. Evaporation is used where climate permits. The benefits of evaporation may be overstated. In the arid $\mathrm{climate}$ of Utah, 93 percent of produced waters in an unlined pit percolated into the surrounding soil. Only 7 percent of the produced water evaporated (Davani et al. 1985). Alternatively, dewatering can be accomplished in areas of net precipitation by siphoning or pumping off free liquids. This is followed by disposal of the liquids by subsurface injection or by trucking them offsite to a disposal facility. Backfilling consists of burying the residual pit contents by pushing in the berms or pit walls, followed by compaction and leveling. Landspreading can involve spreading the excess muds that are squeezed out during the burial operation on surrounding soils; where waste quantities are large, landowners' permission is generally sought to disperse this material on land adjacent to the site. (This operation is different from commercial landfarming, which is discussed later.) 


\section{Environmental Performance}

Construction of reserve pits is technically simple and straightforward. They do not require intensive maintenance to ensure proper function, but they may, in certain circumstances, pose environmental hazards during their operational phase.

Pits are generally built or excavated into the surface soil zones or into unconsolidated sediments, both of which are commonly highly permeable. The pits are generally unlined, ${ }^{5}$ and, as a result, seepage of liquid and dissolved solids may occur through the pit sides and bottom into any shallow, unconfined freshwater aquifers that may be present. When pits are lined, materials used include plastic liners, compacted soil, or clay. Because reserve pits are used for temporary storage of drilling mud, any seepage of pit contents to ground water may be temporary, but it can in some cases be significant, continuing for decades (USEPA 1986).

Other routes of environmental exposure associated with reserve pits include rupture of pit berms and overflow of pit contents, with consequent discharge to land or surface water. This can happen in areas of high rainfall or where soil used for berm construction is particularly unconsolidated. In such situations, berms can become saturated and weakened, increasing the potential for failure. Leaching of pollutants after pit closure can also occur and may be a long-term problem especially in areas with highly permeable soils.

5 An AP1 study suggests that 37 percent of reserve pits are lined with a clay or synthet ic liner. 
Annular Disposal of Pumpable Drilling Wastes

\section{Description}

Annular disposal involves the pumping of waste drilling fluids down the annulus created between the surface and intermediate casing of a well (see Figure III-1). (Disposal of solids is accomplished by using burial, solidification, landfarming, or landspreading techniques.) Disposal down the surface casing in the absence of an intermediate casing is also considered annular disposal. Annular disposal of pumpable drilling wastes is significantly more costly than evaporation, dewatering, or land application and is generally used when the waste drilling fluid contains an objectionable level of a contaminant or contaminants (such as chlorides, metals, oil and grease, or acid) which, in turn, limits availability of conventional dewatering or land application of drilling wastes. However, for disposal in a "dry" hole, costs may be relatively low. No statistics are available on how frequently annular injection of drilling wastes is used.

\section{Environmental Performance}

The well's surface casing is intended to protect fresh ground-water zones during drilling and after annular injection. To avoid adverse impacts on ground water in the vicinity of the well after annular injection, it is important that surface casing be sound and properly cemented in place. There is no feasible way to test the surface casing for integrity without incurring significant expense.

Assuming the annulus is open and the surface casing has integrity, the critical implementation factor is the pressure at which the reserve 


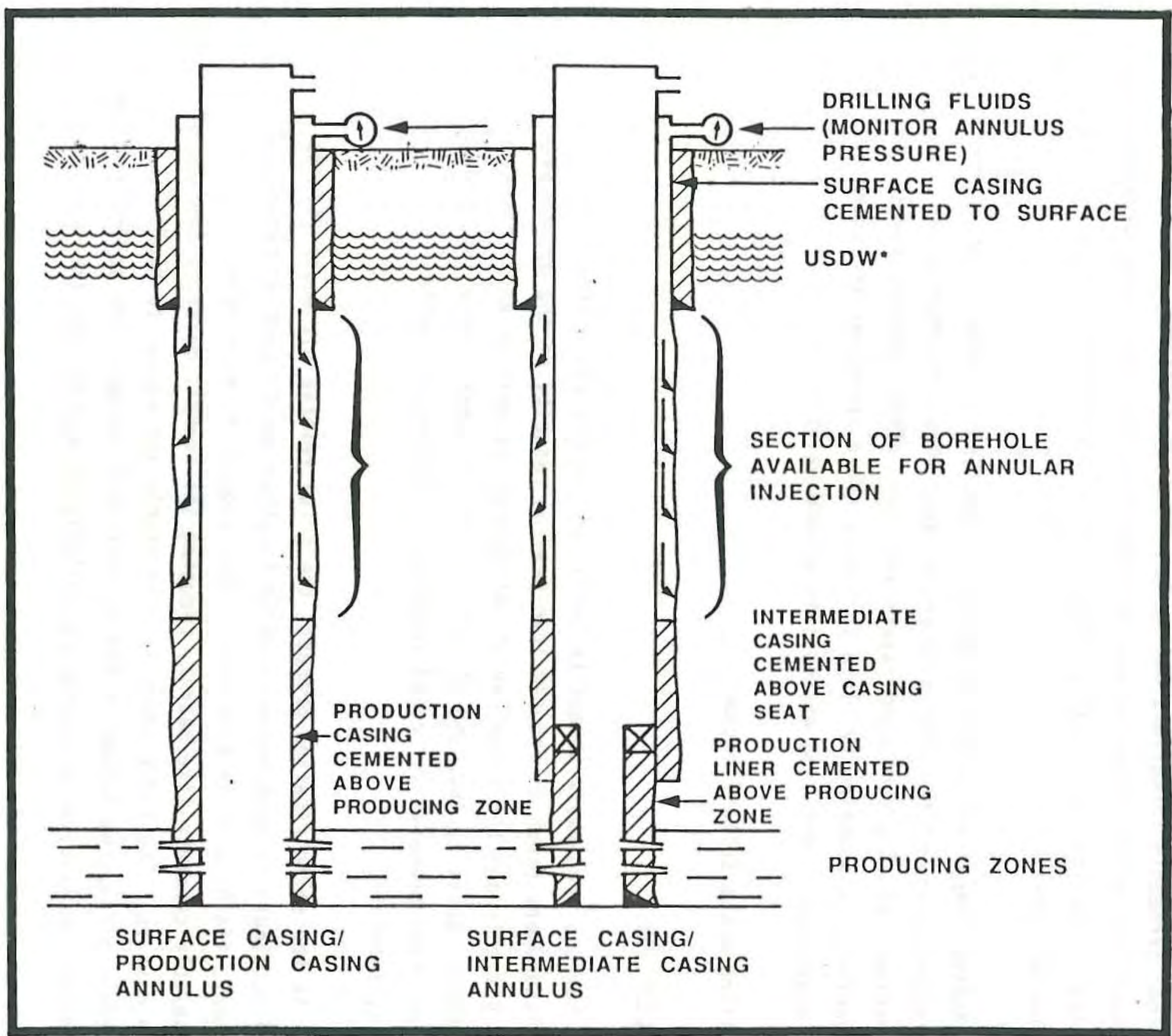

- UNDERGROUND SOURCE OF DRINKING WATER NOTE: NOT TO SCALE

Figure III-1 Annular Disposal of Waste Drilling Fluids 
pit contents are injected. The receiving strata are usually relatively shallow, permeable formations having low fracture pressures. If these pressures are exceeded during annular injection, the strata may develop vertical fractures, potentially allowing migration of drilling waste into freshwater zones.

Another important aspect of annular injection is identification and characterization of the confining shale layer above the receiving formation. Shallow confining layers are, very often, discontinuous. Any unidentified discontinuity close to the borehole increases the potential for migration of drilling wastes into ground water.

\section{Drilling Waste Solidification}

\section{Description}

Surface problems with onsite burial of reserve pit contents reported by landowners (such as reduced load-bearing capacity of the ground over the pit site and the formation of wet spots), as well as environmental problems caused by leaching of salts and toxic constituents into ground water, have prompted increased interest in reserve pit waste solidification.

In the solidification process, the total reserve pit waste (fluids and cuttings) is combined with solidification agents such as commercial cement, flash, or lime kiln dust. This process forms a relatively insoluble concrete-like matrix, reducing the overall moisture content of the mixture. The end product is more stable and easier to handle than reserve pit wastes buried in the conventional manner.. The solidification process can involve injecting the solidifying agents into the reserve pit 
or pumping the wastes into a mixing chamber near the pit. The waste does not have to be dewatered prior to treatment. Solidification can increase the weight and bulk of the treated waste, which may in some cases be a disadvantage of this method.

\section{Environmental Performance}

Solidification of reserve pit wastes offers a variety of environmental improvements over simple burial of wastes, with or without dewatering. By reducing the mobility of potentially hazardous materials, such as heavy metals, the process decreases the potential for contamination of ground water from leachate of unsolidified, buried reserve pit wastes. Bottom sludges, in which heavy metals largely accumulate, may continue to leach into ground water. (There are no data to establish whether the use of kiln dust would add harmful constituents to reserve pit waste. Addition of kiln dust would increase the volume of waste to be managed.)

Treatment and Discharge of Liquid Wastes to Land or Surface Water

\section{Description}

Discharge of waste drilling fluid to surface water is prohibited by EPA's zero discharge effluent guideline. However, in the Gulf Coast area, the liquid phase of waste drilling muds having low chloride concentrations is chemically treated for discharge to surface water. The treated aqueous phase (at an appropriate alkaline $\mathrm{pH}$ ) can then be 
discharged to land or surface water bodies. ${ }^{6}$ The addition of selected reagents to reserve pit liquids must achieve the necessary reactions to allow effective separation of the suspended solids prior to - dewatering of the sludge in the reserve pit.

Onsite treatment methods used prior to discharge are commercially available for reserve pit fluids as well as for solids. They are typically provided by mobile equipment brought to the drill site. These methods include $\mathrm{pH}$ adjustment, aeration, coagulation and flocculation, centrifugation, filtration, dissolved gas flotation, and reverse osmosis. All these methods, however, are more expensive than the more common approach of dewatering through evaporation and percolation. Usually, a treatment company employs a combination of these methods to treat the sludge and aqueous phases of reserve pit wastes.

\section{Environmental Performance}

Treatment and discharge of liquid wastes are used primarily. to shorten the time necessary to close a pit.

\section{Closed Cycle Systems}

\section{Description}

A closed cycle waste treatment system can be an alternative to the use of a reserve pit for onsite management and disposal of drilling

\footnotetext{
6 David Flannery states that his interpretation of EPA's effluent guidelines would preclude such a discharge. "On July 4, 1987, a petition was filed with EPA to revise the effluent guideline. If that petition is granted, stream discharges of drilling fluid and produced fluids would be allowed at least from operations in the Appalachian States."
} 
wastes. Essentially an adaptation of offshore systems for onshore use, closed systems have come into use relatively recently. Because of their high cost, they are used very rarely, usually only when operations are located at extremely delicate sites (such as a highly sensitive wildlife area), in special development areas (such as in the center of an urbanized area), or where the cost of land reclamation is considered excessive. They can also be used where limited availability of makeup water for drilling fluid makes control of drill cuttings by dilution infeasible.

Closed cycle systems are defined as systems in which mechanical solids control equipment (shakers, impact type sediment separation, mud cleaners, centrifuges, etc.) and collection equipment (roll-off boxes, vacuum trucks, barges, etc.) are used to minimize waste mud and cutting volumes to be disposed of onsite or offsite. This in turn maximizes the volume of drilling fluid returned to the active mud system. Benefits derived from the use of this equipment include the following (Hanson et a). 1986):

- A reduction in the amount of water or oil needed for mud maintenance;

- An increased rate of drill bit penetration because of better solids control;

- Lower mud maintenance costs;

- Reduced waste volumes to be disposed of; and

- Reduction in reserve pit size or total elimination of the reserve pit.

Closed cycle systems range from very complex to fairly simple. The degree of solids control used is based on the mud type and/or drilling program and the economics of waste transportation to offsite disposal 
facilities (particularly the dollars per barrel charges at these facilities versus the cost per day for additional solids control equipment rental). Closed systems at drill sites can be operated to have recirculation of the liquid phase, the solid phase, or both. In reality, there is no completely closed system for solids because drill cuttings are always produced and removed. The closed system for solids, or the mud recirculation system, can vary in design from site to site, but the system must have sufficient solids handling equipment to effectively remove the cuttings from muds to be reused.

Water removed from the mud and cuttings can be reused. It is possible to operate a separate closed system for water reuse onsite along with the mud recirculation system. As with mud recirculation systems, the design of a water recirculation system can vary from site to site, depending on the quality of water required for further use. This may include chemical treatment of the water.

\section{Environmental Performance}

Although closed systems offer many environmental advantages, their high cost seriously reduces their potential use, and the mud and cuttings must still ultimately be disposed of.

\section{Disposal of Drilling Wastes on the North Slope of Alaska--A Special} Case

The North Slope is an arctic desert consisting of a wet coastal plain underlain by up to 2,500 feet of permafrost, the upper foot or two of which thaws for about 2 months a year. The North Slope is considered to be a sensitive area because of the extremely short growing season of the tundra, the short food chain, and the lack of species diversity found in 
this area. Because of the area's severe climate, field practices for management of drilling media and resulting waste are different on the North Slope of Alaska from those found elsewhere in the country. In the Arctic, production pads are constructed above ground using gravel. This type of construction prevents melting of the permafrost. Reserve pits are constructed on the production pads using gravel and native soils for the pit walls; they become a permanent part of the production facility. Pits are constructed above and below grade.

Because production-related reserve pits on the North Slope are permanent, the contents of these pits must be disposed of periodically. This is done by pumping the aqueous phase of a pit onto the tundra. This pumping can take place after a pit has remained inactive for 1 year to allow for settling of solids and freeze-concentration of constituents; the aqueous phase is tested for effluent limits for various constituents established by the State of Alaska. The National Pollutant Discharge El imination System (NPDES) permit system does not cover these discharges. An alternative to pumping of the reserve pit liquids onto the tundra is to "road-spread" the liquid, using it as a dust control agent on the gravel roads connecting the production facilities. Prior to promulgation of new State regulations, no standards other than "no oil sheen" were established for water used for dust control. ADEC now requires that at the edge of the roads, any leachate, runoff, or dust must not cause a violation of the State water quality standards. Alaska is evaluating the need for setting. standards for the quality of fluids used to avoid undesirable impacts. Other North Slope disposal options for reserve pit liquids include disposal of the reserve pit liquids through annular injection or disposal in Class II wells. The majority of reserve pit 1 iquids are disposed of through discharge to the tundra.

Reserve pits on the North Slope are closed by dewatering the pit and filling it with gravel. The solids are frozen in place above grade and 
below grade. Freezing in place of solid waste is successful as long as hydrocarbon contamination of the pit contents is minimized. Hydrocarbon residue in the pit contents can prevent the solids from freezing completely. In above-grade structures thawing will occur in the brief summer. If the final waste surface is below the active thaw zone, the wastes will remain frozen year-round.

Disposal of produced waters on the North Slope is through subsurface injection. This practice does not vary significantly from subsurface injection of production wastes in the Lower 48 States, and a description of this practice can be found under "Production-Related Wastes" below.

\section{Environmental Performance}

Management of drilling media and associated waste can be problematic in the Arctic. Because of the severe climate, the reserve pits experience intense freeze-thaw cycles that can break down the stability of the pit walls, making them vulnerable to erosion. From time to time, reserve pits on the North Slope have breached, spilling untreated liquid and solid waste onto the surrounding tundra. Seepage of untreated reserve pit fluids through pit walls is also known to occur.

Controlled discharge of excess pit liquids is a State-approved practice on the North Slope; however, the long-term effects of discharging large quantities of liquid reserve pit waste on this sensitive environment are of concern to EPA, Alaska Department of Environmental Conservation (ADEC), and officials from other Federal agencies. The existing body of scientific evidence is insufficient to conclusively demonstrate whether or not there are impacts resulting from this practice. 


\section{OFFSITE WASTE MANAGEMENT METHODS}

Offsite waste management methods include the use of centralized disposal pits (centralized injection facilities, either privately or commercially operated, will be discussed under "subsurface injection" of production wastes), centralized treatment facilities, commercial landfarming, and reconditioning and reuse of drilling media.

\section{Centralized Disposal Pits}

\section{Description}

Centralized disposal pits are used in many States to store and dispose of reserve pit wastes. In some cases, large companies developing an extensive oil or gas field may operate centralized pits within the field for better environmental control and cost considerations. Most centralized pits are operated commercially, primarily for the use of smaller operators who cannot afford to construct properly designed and sited disposal pits for their own use. They serve the disposal needs for drilling or production wastes from multiple wells over a large geographical area. Centralized pits are typically used when storage and disposal of pit wastes onsite are undesirable because of the high chloride content of the wastes or because of some other factor that raises potential problems for the operators.' Wastes are generally transported to centralized disposal pits in vacuum trucks. These centralized pits are usually located within 25 miles of the field sites they serve.

7 Operators, for instance, may be required under their lease agreements with landowners not to dispose of their pit wastes onsite because of the potential for ground-water contamination. 
The number of commercial centralized pits in major oil-producing States may vary from a few dozen to a few hundred. The number of privately developed centralized pits is not known.

Technically, a centralized pit is identical in basic construction to a conventional reserve pit. It is an earthen impoundment, which can be lined or unlined and used to accumulate, store, and dispose of drilling fluids from drilling operations within a certain geographical area. Centralized pits tend to be considerably larger than single-well pits; surface areas can be as large as 15 acres, with depths as great as 50 feet. Usually no treatment of the pit contents is performed. Some centralized pits are used as separation pits, allowing for solids settling. The liquid recovered from this settling process may then be injected into disposal wells. Many centralized pits also have State requirements for oil skimming and reclamation.

\section{Environmental Performance}

Centralized pits are a storage and disposal operation; they usually perform no treatment of wastes.

Closure of centralized pits may pose adverse environmental impacts. In the past some pits have been abandoned without proper closure, sometimes because of the bankruptcy of the original operator. So far as EPA has been able to determine, only one State, Louisiana, has taken steps to avoid this eventuality; Louisiana requires operators to post a bond or irrevocable letter of credit (based on closing costs estimated in the facility $\mathrm{plan}$ ) and have at least $\$ 1$ million of liability insurance to cover operations of open pits. 
Centralized Treatment Facilities

\section{Description}

A centralized treatment facility for oil and gas drilling wastes is a process facility that accepts such wastes solely for the purpose of conditioning and treating wastes to allow for discharge or final disposal. Such facilities are distinct from centralized disposal pits, which do not treat drilling wastes as part of their storage and disposal functions. The use of such facilities may remove the burden of disposal of wastes from the operators in situations where State regulations have imposed stringent disposal requirements for burying reserve pit wastes onsite.

Centralized treatment may be an economically viable alternative to onsite waste disposal for special drilling fluids, such as oil-based muds, which cannot be disposed of in a more conventional manner. The removal, hauling, and treatment costs incurred by treatment at commercial sites will generally outweigh landspreading or onsite burial costs. A treatment facility can have a design capacity large enough to accept a great quantity of wastes from many drilling and/or production facilities.

Many different treatment technologies can potentially be applied to centralized treatment of $0 i l$ and gas drilling wastes. The actual method used at the particular facility would depend on a number of factors. One of these factors is type of waste. Currently, some facilities are designed to treat solids for $\mathrm{pH}$ adjustment, dewatering, and solidification (muds and cuttings), while others are designed to treat produced waters, completion fluids, and stimulation fluids. Some facilities can treat a combination of wastes. Other factors determining treatment method include facility capacity, discharge options and requirements, solid waste disposal options, and other relevant state or local requirements. 


\section{Environmental Performance}

Experience with centralized treatment is limited. Until recently, it was used only for treatment of offshore wastes. Its use in recent years for onshore wastes is commercially speculative, being principally a commercial response to the anticipated impacts of stricter state rules pertaining to oil and gas drilling and production waste. The operations have not been particularly successful as business ventures so far.

\section{Commercial Landfarming}

\section{Description}

Landfarming is a method for converting reserve pit waste material into soil-like material by bacteriological breakdown and through soil incorporation. The method can also be used to process production wastes, such as production tank bottoms, emergency pit cleanouts, and scrubber bottoms. Incorporation into soil uses dilution, biodegradation, chemical alteration, and metals adsorption mechanisms of soil and soil bacteria to reduce waste constituents to acceptable soil levels consistent with intended 1 and use.

Solid wastes are distributed over the land surface and mixed with soils by mechanical means. Frequent turning or disking of the soil is necessary to ensure uniform biodegradation. Waste-to-soil ratios are normally about $1: 4$ in order to restrict concentrations of certain pollutants in the mixture, particularly chlorides and oil (Tucker 1985). Liquids can be applied to the land surface by various types of irrigation including sprinkler, flood, and ridge and furrow. Detailed landfarming design procedures are discussed in the literature (Freeman and Deuel 1984). 
Landfarming methods have been applied to reserve pit wastes in commercial offsite operations. The technique provides both treatment and final disposition of salts, $0 i 1$ and grease, and solids. Landfarming may eventually produce large volumes of soil-like material that must be removed from the area to allow operations to continue.

Requirements for later reuse or disposal of this material must be determined separately.

\section{Environmental Performance}

Landfarming is generally done in areas large enough to incorporate the volume of waste to be treated. In commercial landfarming operations where the volume of materials treated within a given area is large, steps must be taken to ensure protection of surface and ground water. It is important, for instance, to minimize application of free liquids so as to reduce rapid transport of fluids through the soils.

The process is most suitable for the treatment of organics, especially the lighter fluid fractions that tend to distribute themselves quickly into the soil through the action of biodegradation. Heavy metals are also "treated" in the sense that they are adsorbed onto clay particles in the soil, presumably within a few feet of where they are applied; but the capacity of soils to accept metals is limited depending upon clay content. Similarly, the ability of the soil to accept chlorides and still sustain beneficial use is also limited.

Some States, such as OKlahoma and Kansas, prohibit the use of commercial landfarming of reserve pit wastes. Other States, such as Louisiana, allow reuse of certain materials treated at commercial landfarming facilities. Materials determined to meet certain criteria after treatment can be reused for applications such as daily sanitary 
landfill covering or roadbed construction. When reusing landfarmed material, it is important that such material not adversely affect any part of the food chain.

Reconditioning and Reuse of Drilling Media

\section{Description}

Reconditioning and reuse of drilling media are currently practiced in a few well-defined situations. The first such situation involves the reconditioning of oil-based muds. This is a universal practice because of the high cost of oil used in making up this type of drilling media. A second situation involves the reuse of reserve pit fluids as "spud" muds, the muds used in drilling the initial shallow portions of a well in which lightweight muds can be used. A third situation involves the increased reuse of drilling fluid at one well, using more efficient solids removal. Less mud is required for drilling a single well if efficient solids control is maintained. Another application for reuse of drilling media is in the plugging procedure for well abandonment. Pumpable portions of the reserve pit are transported by vacuum truck to the well being closed. The muds are placed in the wellbore to prevent contamination of possibly productive strata and freshwater aquifers from saltwater strata. The ability to reuse drilling media economically varies widely with the distance between drilling operations, frequency and continuity of the drilling schedule, and compatibility between muds and formations among drill sites.

\section{Environmental Performance}

The above discussion raises the possibility of minimization of drilling fluids as an approach to limiting any potential environmental impacts of drilling-related wastes. Experience in reconditioning and reusing spud muds and oil-based muds does not provide any estimate of 
specific benefits that might be associated with recycling or reuse of most conventional drilling muds. Benefits from mud recycling at the project level can be considerable. From a national perspective, benefits are unknown. The potential for at least some increased recycling and reuse appears to exist primarily through more efficient management of mud handling systems. Specific attempts to minimize the volume of muds used are discouraged, at present, by two factors: (1) drilling mud systems are operated by independent contractors, for whom sales of muds are a primary source of income, and (2) the central concern of all parties is successful drilling of the well, resulting in a general bias in favor of using virgin materials.

In spite of these economic disincentives, recent industry studies suggest that the benefits derived from decreasing the volume of drilling mud used to drill a single well are significant, resulting in mud cost reductions of as much as 30 percent (Amoco 1985).

\section{PRODUCTION-RELATED WASTES}

\section{Waste Characterization}

\section{Produced Water}

When oil and gas are extracted from hydrocarbon reservoirs, varying amounts of water often accompany the oil or gas being produced. This is known as produced water. Produced water may originate from the reservoir being produced or from waterflood treatment of the field (secondary recovery). The quantity of water produced is dependent upon the method of recovery, the nature of the formation being produced, and the length of time the field has been producing. Generally, the ratio of produced water to oil or gas increases over time as the well is produced.

Most produced water is strongly saline. Occasionally, chloride levels, and levels of other constituents, may be low enough (i.e., less 
than $500 \mathrm{ppm}$ chlorides) to allow the water to be used for beneficial purposes such as crop irrigation or livestock watering. More often, salinity levels are considerably higher, ranging from a few thousand parts per million to over $150,000 \mathrm{ppm}$. Seawater, by contrast, is typically about $35,000 \mathrm{ppm}$ chlorides. Produced water also tends to contain quantities of petroleum hydrocarbons (especially lower molecular weight compounds), higher molecular weight alkanes, polynuclear aromatic hydrocarbons, and metals. It may also contain residues of biocides and other additives used as production chemicals. These can include coagulants, corrosion inhibitors, cleaners, dispersants, emulsion breakers, paraffin control agents, reverse emulsion breakers, and scale inhibitors.

Radioactive materials, such as radium, have been found in some oil field produced waters. Ra-226 activity in filtered and unfiltered produced waters has been found to range between 16 and 395 picocuries/liter; Ra-228 activity may range from 170 to 570 picocuries/liter (USEPA 1985). The ground-water standard for the Maximum Contaminant Level (MCL) for combined Ra-226 and Ra-228 is 5 picocuries/liter ( 40 CFR, Part 257, Appendix 1). No study has been done to determine the percentage of produced water that contains radioactive materials.

\section{Low-Volume Production Wastes}

Low-volume production-related wastes include many of the chemical additives discussed above in relation to drilling (see Table III-2), as well as production tank bottoms and scrubber bottoms.

\section{Onsite Management Methods}

Onsite management methods for production wastes include subsurface injection, the use of evaporation and percolation pits, discharge of produced waters to surface water, and storage. 


\section{Subsurface Injection}

Description: Today, subsurface injection is the primary method for disposing of produced water from onshore operations, whether for enhanced oil recovery (EOR) or for final disposal. Nationally, an estimated 80 percent of all produced water is disposed of in injection wells permitted under EPA's Underground Injection Control (UIC) program under the authority of the Safe Drinking Water Act. ${ }^{B}$ In the major oil-producing States, it is estimated that over 90 percent of production wastes are disposed of by this method. Subsurface injection may be done at injection wells onsite, offsite, or at centralized facilities. The mechanical design and procedures are generally the same in all cases.

In enhanced recovery projects, produced water is generally reinjected into the same reservoir from which the water was initially produced. Where injection is used solely for disposal, produced water is injected into saltwater formations, the original formation, or older depleted producing formations. Certain physical criteria make a formation suitable for disposal, and other criteria make a formation acceptable to regulatory authorities for disposal.

The sequence of steps by which waste is placed in subsurface formations may include:

- Separation of free oil and grease from the produced water;

- Tank storage of the produced water;

- Filtration;

- Chemical treatment (coagulation, flocculation, and possibly pH adjustment); and, ultimately,

- Injection of the fluid either by pumps or by gravity flow.

8 API states that 80 to 90 percent of all produced water is injected in Class 11 wells. 
By regulation, injection for the purpose of disposal must take place below all formations containing underground sources of drinking water (USDWS). Figure III-2 displays a typical disposal well pumping into a zone located below the freshwater table (Templeton and Associates 1980). The type of well often preferred by State regulatory agencies is the well specifically drilled, cased, and completed to accept produced water and other oil and gas production wastes. Another type of disposal well is a converted production well, the more prevalent type of disposal and enhanced recovery well. An injection well's location and age and the composition of injected fluids are the important factors in determining the level of mechanical integrity and environmental protection the well can provide.

Although it is not a very widespread practice, some produced water is disposed of through the annulus of producing wells. In this method, produced water is injected through the annular space between the production casing and the production tubing (see Figure III-3).$^{9}$ Injection occurs using little or no pressure. The disposal zone is shallower than the producing zone in this case. Testing of annular disposal wells is involved and expensive.

One method of testing the mechanical integrity of the casing used for annular injection, without removing the tubing and packer, is through the use of radioactive tracers and sensing devices. This method involves the pumping of water spiked with a low-level radioactive tracer into the injection zone, followed by running a radioactivity-sensing logging tool through the tubing string. This procedure should detect any shallow casing leaks or any fluid migration between the casing and the borehole. Most State regulatory agencies discourage annular injection and allow the practice only in small-volume, low-pressure applications.

\footnotetext{
9 In the State of Ohio, produced water is gravity-fed into the annulus rather than being pumped.
} 


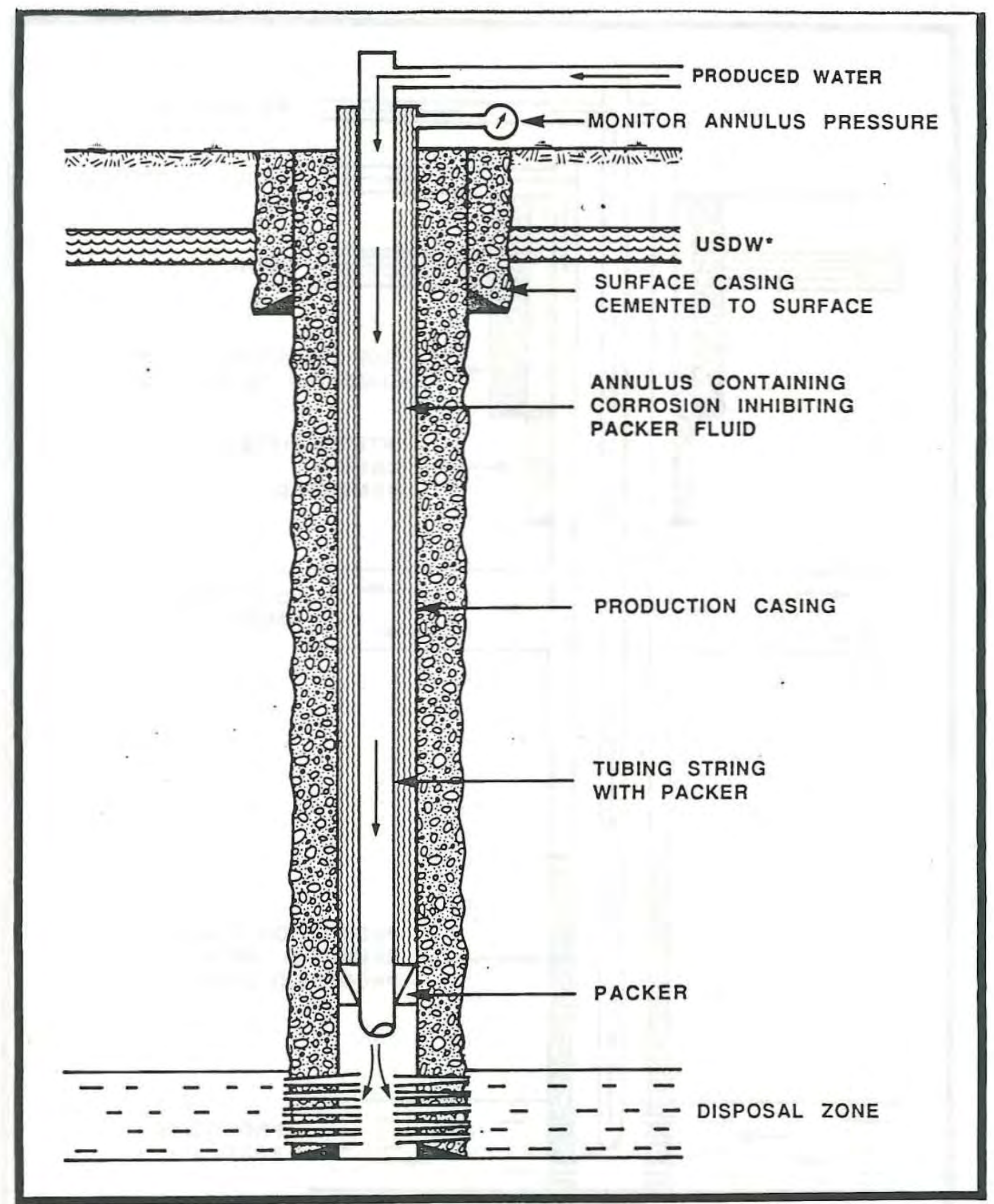

SOURCE: TEMPLETON, ELMER E., AND ASSOCIATES, ENVIRONMENTALLY ACCEPTABLE DISPOSAL OF SALT BRINES PRODUCED WITH OIL AND GAS, JANUARY, 1980.

- underground source of dRINKING water NOTE: NOT TO SCALE

Figure III-2 Typical Produced Water Disposal Well Design 


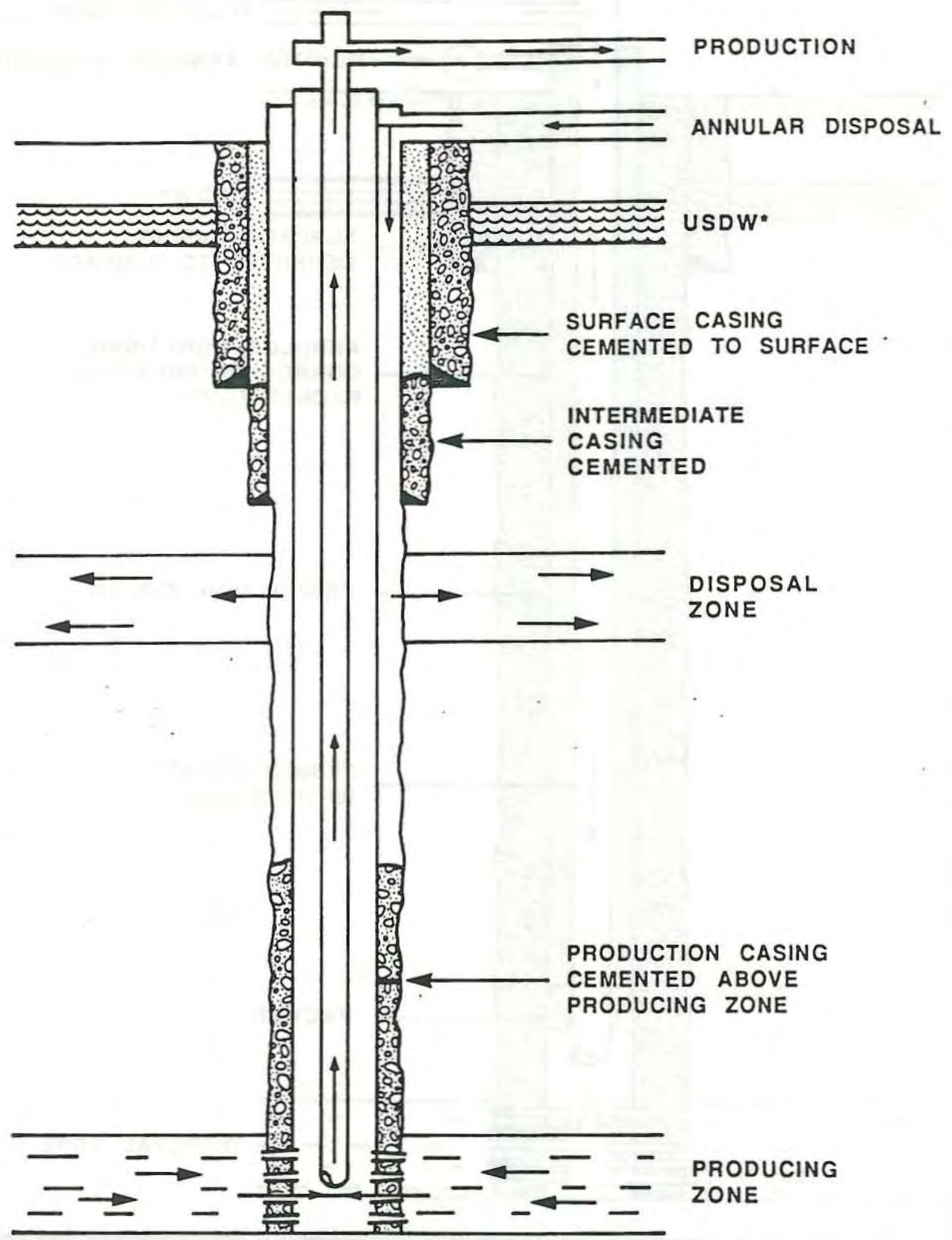

SOURCE: TEMPLETON, ELMER E., AND ASSOCIATES, ENVIRONMENTALLY ACCEPTABLE DISPOSAL OF SALT BRINES PRODUCED WITH OIL AND GAS, JANUARY, 1980.

- underground source of dRINKING water NOTE: NOT TO SCALE

Figure III-3 Annular Disposal Outside Production Casing 
Environmental performance: From the environmental standpoint, the primary issue with disposal of produced waters is the potential for chloride contamination of arable lands and fresh water. Other constituents in produced water may also affect the quality of ground water. Because of their high solubility in water, there is no practical way to immobilize chlorides chemically, as can be done with heavy metals and many other pollutants associated with oil and gas production.

Injection of produced water below all underground sources of drinking water is environmentally beneficial if proper safeguards exist to ensure that the salt water will reach a properly chosen disposal horizon, which is sufficiently isolated from usable aquifers. This can be accomplished by injecting water into played-out formations or as part of a waterflooding program to enhance recovery from a field. Problems to be avoided include overpressurization of the receiving formation, which could lead to the migration of the injected fluids or native formation fluids into fresh water via improperly completed or abandoned wells in the pressurized area. Another problem is leaking of injected fluids into freshwater zones through holes in the tubing and casing.

The UIC program attempts to prevent these potential problems. The EPA UIC program requires periodic mechanical integrity tests (MITs) to detect leaks in casing and ensure mechanical integrity of the injection well. Such testing can detect performance problems if it is conscientiously conducted on schedule. The Federal regulations require that mechanical integrity be tested for at least every 5 years. If leaks are detected or mechanical integrity cannot be established during the testing of the well, the response is generally to suspend disposal operations until the well is repaired or to plug and abandon the well if repair proves too costly or inefficient. The Federal regulations also require that whenever a new well or existing disposal well is permitted, a one-quarter mile radius around the well must be reviewed for the presence of manmade or natural conduits that could lead to injected fluids or native brines leaving the injection zone. In cases where 
improperly plugged or completed wells are found, the permit applicant must correct the problems or agree to 1 imit the injection pressure. Major factors influencing well failure include the design, construction, and age of the well itself (converted producing wells, being older, are more likely to fail a test for integrity than newly constructed Class II injection wells); the corrosivity of the injected fluid (which varies chiefly in chloride content); and the injection pressure (especially if wastes are injected at pressures above specified permit limits).

Design, construction, operation, and testing: There is considerable variation in the actual construction of Class II wells in operation nationwide because many wells in operation today were constructed prior to enactment of current programs and because current programs themselves may vary quite significantly. The legislation authorizing the UIC program directed EPA to provide broad flexibility in its regulations so as not to impede oil and gas production, and to impose only requirements that are essential to the protection of USDWs. Similarly, the Agency was required to approve State programs, for oil and gas wells whether or not they met EPA's regulations as long as they contained the minimum required by the Statute and were effective in protecting USDWs. For these reasons there is great variability in UIC requirements in both State-run and EPA-run programs. In general, requirements for new injection wells are quite extensive. Not every State, however, has required the full use of the "best available" technology. Furthermore, State requirements have evolved over time, and most injection wells operate with a lifetime permit. In practice, construction ranges from wells in which all USDWs are fully protected by two strings of casing and cementing, injection is through a tubing, and the injection zone is isolated by the packer and cement in the wellbore to shallow wells with one casing string, no packer, and little or no cement.

With respect to requirements for mechanical integrity testing of injection wells, Federal UIC requirements state that "an injection well 
has mechanical integrity if: (1) there is no significant leak in the casing, tubing or packer; and (2) there is no significant fluid movement into an underground source of drinking water through vertical channels adjacent to the injection well bore." Translation of these general requirements into specific tests varies across States.

In addition to initial pressure testing prior to operation of injection wells, States (including those that do not have primacy under the UIC program) also require monitoring or mechanical integrity tests of Class II injection wells at least once every 5 years. In lieu of such a casing pressure test, the operator may, each month, monitor or record the pressure in the casing/tubing annulus during actual injection and report the pressure on a yearly basis.

To date, about 70 percent of all Class 11 injection wells have been tested nationwide, though statistics vary across EPA Regions. Data on these tests available at the Federal level are not highly detailed. Although Federal legislation lists a number of specific monitoring requirements (such as monitoring of injection pressures, volumes, and nature of fluid being injected and 5-year tests for mechanical integrity), technical information such as injection pressure and waste characterization is not reported at the Federal level. (These data are often kept at the State level.) Until recently, Federal data on mechanical integrity tests listed only the number of wells passing and failing within each State, without any explanation of the type of failure or its environmental consequences.

For injection wells used to access underground hydrocarbon storage and enhanced recovery, a well may be monitored on a field or project basis rather than on an individual well basis by manifold monitoring, provided the owner or operator demonstrates that manifold monitoring is 
comparable to individual well monitoring. Manifold monitoring may be used in cases where facilities consist of more than one injection well and operate with a common manifold. Separate monitoring systems for each well are not required provided the owner or operator demonstrates that manifold monitoring is comparable to individual well monitoring.

Under the Federal UIC program, all ground water with less than 10,000 $\mathrm{mg} / \mathrm{L}$ total dissolved solids (TDS) is protected. Casing cemented to the surface is one barrier against contamination of USDWs. State programs vary in their requirements for casing and cementing. For example, Texas requires surface casing in strata with less than 3,000 ppm TDS; Louisiana, less than 1,500 ppm TDS; New Mexico, less than 5,000 ppm TDS. However, all wells must be designed to protect USDWs through a combination of surface casing, long string or intermediate casing, cementing, and geologic conditions.

Proximity to other wells and to protected aquifers: When a new injection well is drilled or an existing well is converted for injection, the area surrounding the site must be inspected to determine whether there are any wells of record that may be unplugged or inadequately plugged or any active wells that were improperly completed. The radius of concern includes that area within which underground pressures will be increased. All States have adopted at least the minimum Federal requirement of a one-quarter mile radius of review; however, the Agency is concerned that problems may still arise in instances where undocumented wells (such as dry holes) exist or where wells of record cannot be located.

States typically request information on the permit application about the proximity of the injection well to potable aquifers or to producing wells, other injection wells, or abandoned oil-or gas-producing wells 
within a one-quarter mile radius. In Oklahoma, for instance, additional restrictions are placed on UIC Class II wells within one-half mile of an active or reserve municipal water supply well unless the applicant can "prove by substantial evidence" that the injection well will not pollute a municipal water supply.

Although these requirements exist, it is important to recognize the following:

- Policy on review of nearby wells varies widely from State to State, and the injection well operator has had only a limited responsibility to identify possible channels of communication between the injection zone and freshwater zones.

- Many injection operations predate current regulations on the review of nearby wells and, because of "grandfather" clauses, are exempt.

Operation and maintenance: Incentives for compliance with applicable State or Federal UIC requirements will tend to vary according to whether. a well is used for enhanced recovery or purely for waste disposal. Wells used for both purposes may be converted production wells or wells constructed specifically as Class II wells.

In order for enhanced recovery to be successful, it is essential for operators to ensure that fluids are injected into a specific reservoir and that pressures within the producing zone are maintained by avoiding any communication between that zone and others. Operators therefore have a strong economic incentive to be scrupulous in operating and maintaining Class II wells used for enhanced recovery.

On the other hand, economic incentives for careful operation of disposal wells may not be as strong. The purpose here is to dispose of fluids. The nature of the receiving zone itself, although regulated by State or Federal rules, is not of fundamental importance to the well 
operator as long as the receiving formation is able to accept injected fluids. Wells used for disposal are often older, converted production wells and may be subject to more frequent failures.

\section{Evaporation and Percolation Pits}

Description: Evaporation and percolation pits (see discussion above under "Reserve Pits") are also used for produced water disposal. An evaporation pit is defined as a surface impoundment that is lined by a clay or synthetic liner. An evaporation/percolation pit is one that is unl ined.

Environmental performance: Evaporation of produced water can occur only under suitable climatic conditions, which limits the potential use of this practice to the more arid producing areas within the States. Percolation of produced water into soil has been allowed more often in areas where the ground water underlying the pit area is saline and is not suitable for use as irrigation water, livestock water, or drinking water. The use of evaporation and percolation pits has the potential to degrade usable ground water through seepage of produced water constituents into unconfined, freshwater aquifers underlying such pits. $^{10}$

\section{Discharqe of Produced Waters to Surface Water Bodies}

Description: Discharge of produced water to surface water bodies is generally done under the NPDES permit program. Under NPDES, discharges are permitted for (1) coastal or tidally influenced water, (2) agricultural and wildlife beneficial use, and (3) discharge of produced water from stripper oil wells to surface streams. Discharge under NPDES often occurs after the produced water is treated to control 
$\mathrm{pH}$ and minimize a variety of common pollutants, such as oil and grease, total dissolved solids, and sulfates. Typical treatment methods include simple oil and grease separation followed by a series of settling and skimming operations.

Environmental performance: Direct discharge of produced waters must meet State or Federal permit standards. Although pollutants such as total organic carbon are limited in these discharges, large volumes of discharges containing low levels of such pollutants may be damaging to aquatic communities. ${ }^{11}$

\section{Other Production-Related Pits}

Description: A wide variety of pits are used for ancillary storage and management of produced waters and other production-related wastes. These can include: ${ }^{12}$

1. Basic sediment pit: Pit used in conjunction with a tank battery for storage of basic sediment removed from a production vessel or from the bottom of an oil storage tank. (Also referred to as a burn pit.)

2. Brine pit: Pit used for storage of brine used to displace hydrocarbons from an underground hydrocarbon storage facility.

3. Collecting pit: Pit used for storage of produced water prior to disposal at a tidal disposal facility, or pit used for storage of produced water or other $0 i 1$. and gas wastes prior to disposal at a disposal well or fluid injection well. In some cases, one pit is both a collecting pit and a skimming pit.

4. Completion/workover pit: Pit used for storage or disposal of spent completion fluids, workover fluids, and drilling fluid; silt; debris; water; brine; oil; scum; paraffin; or other materials that have been cleaned out of the wellbore of a well being completed or worked over.

11 This phenomenon is documented in Chapter IV.

12 List adapted from Texas Railroad Commission Rule 8, amended March 5, 1984. 
5. Emergency produced water storage pit: Pit used for storage of produced water for a limited period of time. Use of the pit is necessitated by a temporary shutdown of a disposal well or fluid injection well and/or associated equipment, by temporary overflow of produced water storage tanks on a producing lease, or by a producing well loading up with formation fluids such that the well may die. Emergency produced water storage pits may sometimes be referred to as emergency pits or blowdown pits.

6. Flare pit: Pit that contains a flare and that is used for temporary storage of liquid hydrocarbons that are sent to the flare during equipment malfunction but are not burned. A flare pit is used in conjunction with a gasoline plant, natural gas processing plant, pressure maintenance or repressurizing plant, tank battery, or well.

7. Skimming pit: Pit used for skimming oil off produced water prior to disposal of produced water at a tidal disposal facility, disposal well, or fluid injection well.

8. Washout pit: Pit located at truck yard, tank yard, or disposal facility for storage or disposal of oil and gas waste residue washed out of trucks, mobile tanks, or skid-mounted tanks. ${ }^{13}$

The Wyoming $0 i l$ and Gas Conservation Commission would add pits that retain fluids for disposal by evaporation such as pits used for gas wells or pits used for dehydration facilities.

Environmental performance: All of these pits may cause adverse environmental impact if their contents leach, if they are improperly closed or abandoned, or if they are used for improper purposes. Although they are necessary and useful parts of the production process, they are subject to potential abuse. An example would be the use of an emergency pit for disposal (through percolation or evaporation) of produced water.

\section{Offsite Management Methods}

\section{Road or Land Applications}

Description: Untreated produced water is sometimes disposed of by application to roads as a deicing agent or for dust control.

\footnotetext{
13 The Alaska Department of Environmental Conservation questions whether pits described in Items 1,6 , and 8 should be exempt under RCRA.
} 
Environmental performance: Road or land application of produced waters may cause contamination of ground water through leaching of produced water constituents to unconfined freshwater aquifers. Many States do not allow road or land application of produced waters.

\section{Well Plugging and Abandonment}

There are an estimated 1,200,000 abandoned oil or gas wells in the United States.

To avoid degradation of ground water and surface water, it is vital that abandoned wells be properly plugged. Plugging involves the placement of cement over portions of a wellbore to permanently block or seal formations containing hydrocarbons or high-chloride waters (native brines). Lack of plugging or improper plugging of a well may allow native brines or injected wastes to migrate to freshwater aquifers or to come to the surface through the wellbore. The potential for this is highest where brines originate from a naturally pressurized formation such as the Coleman Junction formation found in West Texas. Figure III-4 illustrates the potential for freshwater contamination created by abandoned wells (IIlinois EPA 1978).

\section{Environmental Performance}

Proper well plugging is essential for protection of ground water and surface water in all oil and gas production areas. 


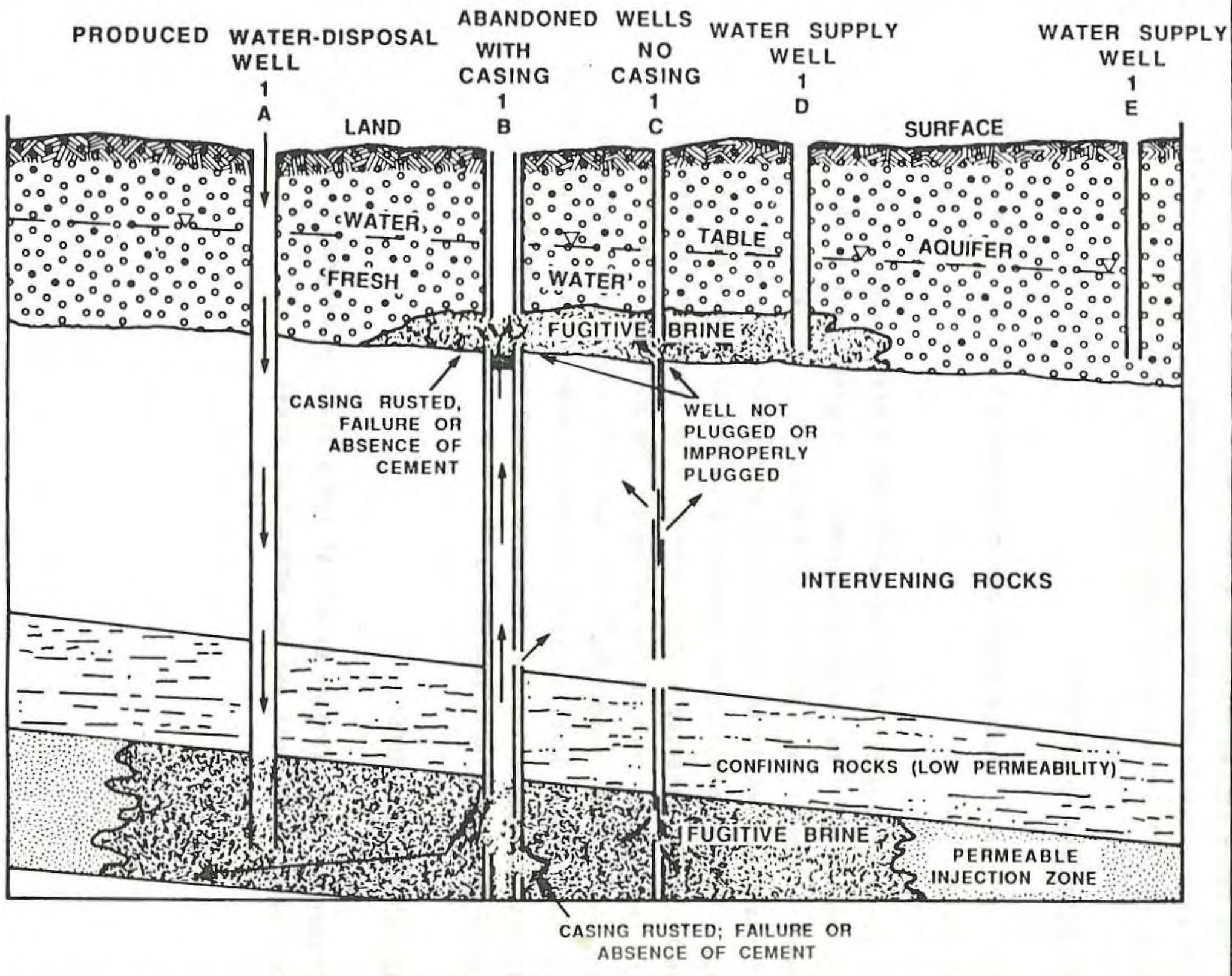

SOURCE: ILLINOIS EPA, ILLINOIS OIL FIELD BRINE DISPOSAL ASSESSMENT:

STAFF REPORT, NOVEMBER 1978.

NOTE: NOT TO SCALE

Figure III-4 Pollution of a Fresh Water Aquifer Through Improperly 


\section{REFERENCES}

Canter, L. W. 1985. Drilling waste disposal: environmental problems and issues. In Proceedings of a National Conference on Disposal of Drilling Wastes.

Canter, L.W., et al., 1984. Environmental implications of offsite drilling mud pits in Oklahoma. Report submitted to OKlahoma Corporation Commission, Oklahoma City, Oklahoma.

Cooper, R. V. 1985. Institutional management perspective of drilling waste disposal. In Proceedings of a National Conference on Disposal of Drilling Wastes.

Crabtree, A. F. 1985. Drilling mud and brine waste disposal in Michigan. Geological Survey Division of Michigan Department of Natural Resources.

Davani et al. 1986. Organic compounds in soils and sediments from unlined waste disposal pits for natural gas production and processing. Water, Air and Soil Pollution. No. 27. 1986.

Deeley, G. M. 1986. Attenuation of chemicals within waste fresh water drilling fluids. In Proceedings of a National Conference on Drilling Muds.

Deeley, G. M., and Canter, L. W. 1985. Chemical speciation of metals in nonstabilized and stabilized drilling muds. In Proceedings of a National Conference on Disposal of Drilling Wastes.

Freeman, B. D., and Deuel, L. E. 1984. Guidelines for closing drilling waste fluid pits in wetland and upland areas. 7 th Annual Energy Sources Technology Conference and Exhibition. New Orleans, Louisiana.

Hanson et al. 1986. A Review of mud and cuttings disposal for offshore and 1 and based operations. In Proceedings of a National Conference on Drilling Muds.

Illinois Environmental Protection Agency. 1978. Illinois oil field brine disposal assessment: staff report.

Lloyd, D. A. 1985. Drilling waste disposal in Alberta. In Proceedings of a National Conference on Drilling Muds.

McCaskill, C. 1985. Well annulus disposal of drilling waste. In Proceedings of a National Conference on Disposal of Drilling Wastes.

MoeCo Sump Treatment. 1984. Recommendations concerning the design and rehabilitation of drilling fluid containment reserve pits. 
Musser, D. T. 1985. In-place solidification of oil field drilling fluids. In Proceedings of a National Conference on Disposal of Drilling Wastes.

Rafferty, J. H. 1985. Recommended practices for the reduction of drill site waste. In Proceedings of a National Conference on Disposal of Drilling Wastes, University of Oklahoma Environmental and Ground Water Institute.

Templeton, E. E., and Associates. 1980. Environmentally acceptable disposal of salt brines produced with oil and qas. For the Ohio Water Development Authority.

Tucker, B. B. 1985. Soil application of drilling wastes. In Proceedings of a National Conference on Disposal of Drilling Wastes.

USEPA. 1979. U.S. Environmental Protection Agency. Cost of compliance, proposed Underground Injection Control Program. A. D. Little, Inc.

- 1985. U.S. Environmental Protection Agency. Proceedings of the Onshore 0 il and Gas Workshop, Michigan Meeting Report. Ventura, Calif.: VenVirotek Corporate Literature.

. 1986. U.S. Environmental Protection Agency. State/Federal 0il and Gas Western Workshop. California.

Wascom, C. D. 1986. 0ilfield pit regulations: a first for the Louisiana oil and gas industry. In Proceedings of a National Conference on Drilling Muds. 


\title{
CHAPTER IV
}

\section{DAMAGE CASES}

\section{INTRODUCTION}

\author{
Purpose of the Damage Case Review
}

The damage case study effort conducted for this report had two principal objectives:

\section{To Respond to the Requirements of Section $8002(\mathrm{~m})(\mathrm{C})$}

The primary objective was to respond to the requirements of Section $8002(\mathrm{~m})$ of RCRA, which require EPA to identify documented cases that prove or have caused danger to human health and the environment from surface runoff or leachate. In interpreting this passage, EPA has emphasized the importance of strict documentation of cases by establishing a test of proof (discussed below) that all cases were required to pass before they could be included in this report. In addition, EPA has emphasized development of recent cases that illustrate damages created by current practices under current State regulations. This has been complicated in some instances by recent revisions to regulatory requirements in some States. The majority of cases presented in this chapter ( 58 out of 61 ) occurred during the last 5 years. Historical damages that occurred under prior engineering practices or under previous regulatory regimes have been excluded unless such historical damages illustrate health or environmental problems that the Agency believes should be brought to the attention of Congress now. ${ }^{1}$ The overall objective is to present documented cases that show reasonably clear links of cause and effect between waste management practices and resulting damages, and to identify cases where damages have been most significant in terms of human health or environmental impacts.

1 The primary example of this is the problem of abandoned wells, discussed at length under

Miscellaneous Issues below. The abandoned well problem results for the most part from inadequate past plugging practices. Although plugging practices have since been improved under State regulations, associated danages to health and the environment are cont inuing. 
To Provide an Overview of the Nature of Damages Associated with $0 i 1$ and Gas Exploration, Development, or Production Activities

In the course of accumulating damage cases, EPA has acquired a significant amount of information that has provided helpful insights into the nature of damages.

Methodology for Gathering Damage Case Information

The methodology for identifying, collecting, and processing damage cases was originally presented in draft form in the Technical Report published on October 31,1986 . The methodology, which differs minimally from the draft, is outlined below.

\section{Information Categories}

The damage case effort attempted to collect and record several categories of information on each case. Initially, this information was organized into a data base from which portions of cases were drawn for use in the final report. Categories of information were as follows:

1. Characterization of specific damage types: For each case, the environmental medium involved was determined (ground water, surface water, or land), along with the type of incident and characterization of damage. Only cases with documented damage were included. Types of potential health or environmental damages of interest are shown on Table IV-1.

2. The size and location of the site: Sites were located by nearest town and by county. Where significant hydrogeological or other pertinent factors are known, they were included; however, this type of information has been difficult to gather for all cases.

3. The operating status of the facility or site: All pertinent factors relating to the site's status (active, inactive, in process of shutdown, etc.) have been noted. 


\section{Table IV-1 Types of Damage of Concern to This Study}

1. Human Health Effects (acute and chronic): While there are some instances where contamination has resulted in cases of acute adverse human health effects, such cases are difficult to document. Levels of pollution exposure caused by oil and gas operations are more likely to be in ranges associated with chronic carcinogenic and noncarcinogenic effects.

2. Environmental Effects: Impairment of natural ecosystems and habitats, including contaminating of soils, impairment of terrestrial or aquatic vegetation, or reduction of the quality of surface waters.

3. Effects on Wildlife: Impairment to terrestrial or aquatic fauna; types of damage may include reduction in species' presence or density, impairment of species' health or reproductive ability, or significant changes in ecological relationships among species.

4. Effects on Livestock: Morbidity or mortality of livestock, impairment in the marketability of livestock, or any other adverse economic or health-based impact on livestock.

5. Impairment of Other Natural Resources: Contamination of any current or potential source of drinking water, disruption or lasting impairment to agricultural lands or commercial crops, impairment of potential or actual industrial use of land, or reduction in current or potential use of land. 
4. Identification of the type and volume of waste involved: While the type of waste involved has been easy to define, volumes often have not.

5. Identification of waste management practices: For each incident, the waste management practices associated with the incident have been presented.

6. Identification of any pertinent requlations affecting the site:

State regulations in force across the oil-and gas-producing States are discussed at length in Appendix A. Since it would be unwieldy to attempt to discuss all pertinent regulations in relation to each site, each documented case includes a section on Compliance Issues that discusses significant regulatory issues associated with each incident as reported by sources or contacts. ${ }^{2}$ In some cases, interpretations were necessary.

7. Type of documentation available: All documentation available for each case was included to the extent possible. For a few cases, documentation is extensive.

For the purpose of this report, the data base was condensed and is presented in Appendix C.

\section{Sources and Contacts}

No attempt was made to compile a complete census of current damage cases. States from which cases were drawn are listed on Table IV-2. As evident from the table, resources did not permit gathering of cases from all States.

Within each of the States, every effort was made to contact all - available source categories listed in the Technical Report (see Table IV-3). Because time was extremely limited, the effort relied principally on information available through relevant State and local agencies and

2 All discussions have been reviewed by State officials and by any other sources or contacts who provided information on a case. 
Table IV-2 States From Which Case Information Was Assembled

1. Alaska

2. Arkansas

3. Califomia

4. Colorado

5. Kansas

6. Louisiana

7. Michigan

8. New Mexico

9. Ohio

10. Oklahoma

11. Pennsylvania

12. Texas

13. West Virginia

14. Wyoming 


\section{Table IV-3 Sources of Information}

\section{Used in Developing Damage Cases}

1. Relevant State or Local Agencies: including State environmental agencies; oil and gas regulatory agencies; State, regional, or local departments of health; and other agencies potentially knowledgeable about damages related to oil and gas operations.

2. EPA Regional Offices

3. Bureau of Land Management

4. Forest Service

5. Geological Survey

6. Professional or trade associations

7. Public interest or citizens' groups

8. Attorneys engaged in litigation 
on contacts provided through public interest or citizens' groups. In some instances, cases were developed through contacts with private attorneys directly engaged in litigation. Because these nongovernmental sources often provided information on incidents of which State agencies were unaware, such cases were sometimes undocumented at the State level. State agencies were, however, provided with review drafts of case write-ups. They, in turn, provided extensive additional information and comments.

\section{Case Study Development}

Virtually all of the data used here were gathered through direct contacts with agencies and individuals, or through followup to those contacts, rather than through secondary references. For each State, researchers first contacted all State agencies that play a significant role in the regulation of oil or gas operations and set up appointments for field visits. At the same time, contacts and appointments were made where possible with local citizens' groups and private attorneys in each State. Visits were made in the period between December 1986 and February 1987. During that time, researchers gathered actual documentation and made as many additional contacts as possible.

\section{Test of Proof}

All cases were classified according to whether they met one or more formal tests of proof, a classification that was to some extent judgmental. Three tests were used, and cases were considered to meet the documentation standards of $8002(\mathrm{~m})(\mathrm{C})$ if they met one or more of them. 
The tests were as follows:

1. Scientific investigation: A case could meet documentation standards if damages were found to exist as part of the findings of a scientific study. Such studies could be extensive formal investigations supporting litigation or a State enforcement action, or they could, in some instances, be the results of technical tests (such as monitoring of wells) if such tests (a) were conducted with State-approved quality control procedures, and (b) revealed contamination levels in excess of an applicable State or Federal standard or guideline (such as a drinking water standard or water quality criterion).

2. Administrative ruling: A case could meet documentation standards if damages were found to exist through a formal administrative finding, such as the conclusions of a site report by a field investigator, or through existence of an enforcement action that cited specific health or environmental damages.

3. Court decision: The third way in which a case could be accepted was if damages were found to exist through the ruling of a court or through an out-of-court settlement.

EPA considered the possibility of basing its damage case review solely on cases that have been tried in court and for which damage determinations have been made by jury or judicial decision. This approach was rejected for a variety of reasons. First and most important, EPA wanted wherever possible to base its damage case work on scientific evidence and on evidence developed by States as part of their own regulatory control programs. Since States are the most important entity in controlling the environmental impacts of this industry, the administrative damage determinations they make are of the utmost concern to EPA. Second, comparatively few cases are litigated, and many litigated cases, perhaps a majority; are settled out of court and their records sealed through agreements between plaintiffs and defendants. Third, as data collected for this report indicate, many litigated cases are major cases in which the plaintiff may be a corporation or a comparatively wealthy landowner with the resources necessary to develop 
the detailed evidence necessary to successfully litigate a private suit (see damage case LA 65 on pages IV-78 and IV-79). Private citizens rarely bring cases to court because court cases are expensive to conduct, and most of these cases are settled out of court.

\section{Review by State Groups and Other Sources}

All agencies, groups, and individuals who provided documentation or who have jurisdiction over the sites in any specific State were sent draft copies of the damage cases. Because of the tight schedule for development of the report, there was limited time available for damage case review. Their comments were incorporated to the extent possible; EPA determined which comments should be included.

\section{Limitations of the Methodology and Its Results}

\section{Schedule for Collection of Damage Case Information}

The time period over which the damage case study work occurred was short, covering portions of three consecutive months. In addition, much of the field research was arranged or conducted over the December 1986-January 1987 holiday period, when it was often difficult to make contacts with State agency representatives or private groups. To the extent that resources permitted, followup visits were made to fill gaps. Nevertheless, coverage of some States had to be omitted entirely, and coverage in others (particularly 0klahoma) was limited.

Limited Number of $0 i 1$ - and Gas-Producing States in Analysis

of the States originally intended to be covered as discussed in the Technical Report, several were omitted from coverage; however, States 
visited account for a significant percentage of U.S. oil and gas production (see Table IV-2).

\section{Difficulty in Obtaining a Representative Sample}

In general, case studies are used to gain familiarity with ranges of issues involved in a particular study topic, not to provide a statistical representation of damages. Therefore, although every attempt was made to produce representative cases of damages associated with oil and gas operations, this study does not assert that its cases are a statistically representative record of damages in each State. Even if an attempt had been made to create a statistically valid study set, such as by randomly selecting drilling operations for review, it would have been difficult for a number of practical reasons.

First, record keeping varies significantly among States. A few States, such as Ohio, have unusually complete and up-to-date central records of enforcement actions and complaints. More often, however, enforcement records are incomplete and/or distributed throughout regional offices within the State. Schedules were such that only a few offices, usually only the State's central offices, were visited by researchers. Furthermore, their ability to collect files at each office was limited by the time available on site (usually 1 day, but never more than 3 days) and by the ability of each State to spare staff time to assist in the research. The number of cases found at each office and the amount of material gathered were influenced strongly by these constraints.

Second, very often damage claims against oil and gas operators are settled out of court, and information on known damage cases has often been sealed through agreements between landowners and oil companies. 
This is typical practice, for instance, in Texas. In some cases, even the records of well-publicized damage incidents are almost entirely unavailable for review. In addition to concealing the nature and size of any settlement entered into between the parties, impoundment curtails access to scientific and administrative documentation of the incident.

A third general limitation in locating damage cases is that $0 i 1$ and gas activities in some parts of the country are in remote, sparsely populated, and unstudied areas. In these areas, no significant population is present to observe or suffer damages, and access to sites is physically difficult. To systematically document previously unreported damages associated with operations in more remote areas would have required an extensive original research project far beyond the resources available to this study.

\section{Organization of This Presentation}

As noted throughout this report; conditions affecting exploration, development, and production of oil and gas vary extensively from state to. State, and by regions within States. While it would be logical to discuss damage cases on a State-by-State basis, the following discussion is organized according to the zones defined for other purposes in this project. Within each zone the report presents one or more categories of damages that EPA has selected as fairly illustrative of practices and conditions within that zone, focusing principally on cases of damage associated with management of high-volume wastes (drilling fluids and produced waters). Wherever possible, State-specific issues are discussed as well. 
At the end of this chapter are a number of miscellaneous categories of damage cases that, although significant and well-documented, are associated either with management of lower volume exempt wastes or with types of damage not immediately related to management of wastes from current field operations. Such categories include damages caused by unplugged or improperly plugged abandoned wells.

\section{NEW ENGLAND}

The New England zone includes Maine, New Hampshire, Vermont, Massachusetts, Rhode Island, and Connecticut. No significant oil and gas are found in this zone, and no damage cases were collected.

\section{APPALACHIA}

The Appalachian zone includes Delaware, Kentucky, Maryland, New Jersey, New York, Ohio, Pennsylvania, Tennessee, Virginia, and West Virginia. Many of these States have minimal oil and gas production. Damage cases were collected from Ohio, West Virginia, and Pennsylvania.

\section{Operations}

$0 i 1$ and gas production in the Appalachian Basin tends to be marginal, and operations are often low-budget efforts. Funds for proper maintenance of production sites may be limited. Although the absolute amount of oil produced in the Appalachian zone is small in comparison with the rest of the country, the produced water-to-product ratios are typically very high and produced waters contain high concentrations of chlorides. ${ }^{3}$

3 David Flannery, on behalf of various oil and gas trade organizations, states that "... in absolute terms, the discharge of produced water from wells in the Appalachian states is sma 11." 
In West Virginia in $1985,1,839$ new wells were completed at an average depth of 4,270 feet. Only 18 exploratory wells were drilled in that year. In Pennsylvania 4,627 new wells were completed in 1985 to an average depth 2,287 feet; 59 exploratory wells were drilled in that year. Activity in Ohio is developmental rather than exploratory, with only 78 exploratory wells drilled in 1985 out of a total of 6,297 wells completed. The average depth of a new well in 1985 was 3,760 feet.

\section{Types of Operators}

0il and gas production in the Appalachian Basin is dominated by small operators, some well-established, some new to the industry. Major companies still hold leases in some areas. Since most extraction in this zone is economically marginal, many operators are susceptible to market fluctuations.

\section{Major Issues}

\section{Contamination of Ground Water from Reserve Pits}

Damage case incidents resulting from unlined reserve pits, with subsequent migration of contaminants into ground water, are found in the State of Ohio.

In 1982, drilling activities of an unnamed oil and gas company contaminated the well that served a house and barn owned by a Mr. Bean, who used the water for his dairy operations. Analysis done on the water well by the Ohto Department of Agriculture found high levels of barium, iron, sodium, and chlorides. (Barium is a common constituent of drilling mud.) Because the barium content of the water well exceeded State standards, Mr. Bean was forced to shut down his dairy operations. Milk produced at the Bean farm following contamination of the water well contained $0.63 \mathrm{mg} / \mathrm{L}$ of barium. Concentrations of chlorides, barium, iron, sodium, and other residues in the water well were above the U.S. EPA's Secondary Drinking Water Standards. Mr. Bean drilled a new well, which also became contaminated. As of September 1984, Mr. Bean's water 
well was still showing signs of contamination from the drilling-related wastes. It is not known whether $\mathrm{Mr}$. Bean was able to recover financially from the disruption of his dairy business. $(\mathrm{OH} 49)^{4}$

This case is a violation of current Ohio regulations regarding drilling mud and produced waters.

\section{Illegal Disposal of 0il Field Wastes in Ohio}

Illegal disposal of oil field wastes is a problem in Ohio, as elsewhere, but the State is making an aggressive effort to increase compliance with State waste disposal requirements and is trying to maintain complete and up-to-date records. The State has recently banned all saltwater disposal pits. A legislative initiative during the spring of 1987 attempted to overturn the ban. The attempt was unsuccessful.

The Miller Sand and Gravel Co. thougn an active producer of sand and gravel, has also served as an illegal disposal site for oil field wastes. An investigation by the Ohio Department of Natural Resources (DNR) found that the sand and gravel pits and the surroundirig swamp were contaminated with 011 and high-chloride produced waters. Ohio inspectors noted a flora $k^{\prime l l l ~ o f ~}$ unspecified size. Ohio Department of Health laboratory analysis of soil and liquid samples from the pits recorded chloride concentrations of $269,000 \mathrm{mg} / \mathrm{L}$. The -surrounding swamp chloride concentrations ranged from $303 \mathrm{mg} / \mathrm{L}$ (upstream from the pits) to $60,000 \mathrm{mg} / \mathrm{L}$ (area around the pits). This type of discharge is pronibited by State regulations. $(\mathrm{OH} 45)^{5}$

This discharge was a violation of State regulations.

4 References for case cited: Ohio EPA, Division of Public Water Supply, Northeast District Office, interoffice communication froin E. Mohr to M. Hilovsky describing test results on Mr. Bean's water we11, 7/21/86. Letters from E. Mohr, Ohio EPA, to Mr. Bean and Mr. Hart explaining water sampling results, 10/20/82. Letter from Miceli Dairy Products Co. to E. Mohr. Ohio EPA. explaining test results from Mr. Bean's milk and water well. Letters from E. Mohr, Ohio EPA, to Mr. Bean explaining water sampling results from tests completed on 10/7/82, 2/2/83, 10/25/83,6/15/84. $8 / 3 / 84$, and $9 / 17 / 84$. Generalized stratigraphic sequence of the rocks in the Upper Portion of the Grand River Basin.

5 References for case cited: Ohio EPA, Division of Wastewater Pollution Control, Northeast District Office, interoffice communication from E. Mohr to D. Hasbrauck. District Chief, concerning the results from sampling at the sand and gravel site. Ohio Department of Health. Environmental Sample Submission Reports from samples taken on $6 / 22 / 82$. 
Equity $0 i 1$ \& Gas Funds, Inc., operates Well \#1 on the Engle Lease, knox County. An Ohio DNR official inspected the site on April 5, 1985. There were no saltwater storage taniks on site to collect the high-chloride produced water that was being discharged from a plastic hose leading from the tank battery into a culvert that, in turn, emptied into a creek. The inspector took photos and samples. Both produced water and oil and grease levels were of sufficient magnitude to cause damage to flora and fauna, according to the not ice of violation filed by the State. The inspector noted that a large area of land along the culvert had been contaminated with oil and produced water. The suspension order indicated that the "..violations present an imminent danger to public health and safety and are likely to result in imediate and substantial damage to natural resources." The operator was required by the State to "...restore the disturbed land surface and remove the 011 from the stream in accordance with Section 1509.072 of Ohio Revised Statutes..." $(\mathrm{OH} 07)^{6}$

\section{This was an illegal discharge that violated Ohio regulations.}

\section{In another case:}

Zenith 011 \& Gas Co. operated Well $\approx 1$ in Hopewell Township. The Onio DNR issued a suspension order to Zenith in March of 1984 after State inspectors discovered produced water discharges onto the surrounding site from a breech in a produced water pit and pipe leading from the pit. A Notice of Violation had been issued in February 1984, but the violations were still in effect in March 1984. A State inspection of an adjacent site, also operated by Zenith 0 il \& Gas Co.. discovered a plastic hose extending from one of the tank batteries discharging high-chloride produced water into a breached pit and onto the site surface. Another tank was discharging produced hater from an open vaive directly onto the site surface. State inspectors also expressed concern about lead and mercury contamination from the discharge. Lead levels in the discharge were 2.5 times the accepted level for drinking water, and mercury levels were 925 times the acceptable levels for drinking water, according to results filed for the State by a private laboratory. The State issued a suspension order stating that the discharge was "...causing contamination and pollution..." to the surface and subsurface soil, and in order to remedy the problem the operator would have to restore the disturbed land. (Ohio no longer allows the use of produced water disposal pits.) $(\mathrm{OH} \mathrm{12})^{7}$

\section{This was an illegal discharge that violated Ohio regulations.}

6 References for case cited: The Columbus Water and Chemical Testing Lab, lab reports. Ohio Department of Natural Resources. Division of $0 i 1$ and Gas, Notice of Violation, 5/5/85

7 References for case cited: Ohio Department of Natural Resources, Division of $0 i 1$ and Gas, Suspension Order $\$ 84-07,3 / 22 / 84$. Muskingum County Complaint Form. Columbus Water and Chemical Testing Lab sampling report. 


\title{
Contamination of Ground Water from Annular Disposal of Produced Water
}

Ohio allows annular disposal of produced waters. This practice is not widely used elsewhere because of its potential for creating ground-water contamination. Produced water containing high levels of chlorides tends to corrode the single string of casing protecting ground water from contamination during annular disposal. Such corrosion creates holes in a well's casing that can allow migration of produced water into ground water. Under the Federal UIC program, Ohio requires operators of annular disposal wells to conduct radioactive tracer surveys to determine whether produced water is being deposited in the correct formations. Tracer surveys are more expensive than conventional mechanical integrity tests for underground injection wells, and only 2 percent of all tracer surveys were witnessed by DNR inspectors in 1985 .

\begin{abstract}
The Donofrio well was a production 011 well with an annular disposal hookup fed by a 100-bbl produced water storage tank. In December 1975, shortly after completion of the we 11, tests conducted by the Columbus Water and Chemical Testing Lab on the Donofrio residential water well showed chloride concentrations of $4.550 \mathrm{ppm}$. One month after the well contamination was reported, several springs on the Donof $r 10$ property showed contamination from high-chloride. produced water and oil, according to Ohio EPA inspections. On January 8, 1976, Ohio EPA investigated the site and reported evidence of 011 overflow from the Donofrio well production facility. lack of diking around storage tanks, and the presence of several produced water storage pits. In 1986, 11 years after the first report of contamination, a court order was issued to disconnect the annular disposal lines and to plug the well. The casing recovered from the well showed that its condition ranged from fair to very poor. The casing was covered with rust and scale, and six holes were found, ${ }^{8}(\mathrm{OH} 38)^{9}$
\end{abstract}

8 Comments in the Docket by David Flannery and American Petroleum Institute (API) pertain to $\mathrm{OH}$ 38. Mr. Flannery states that "...the water well involved in that case showed contamination levels which predated the comencement of annular disposal..." EPA believes this statement refers to bacterial contanination of the well discovered in 1974. (EPA notes that the damage case discusses chloride contamination of the water well, not bacterial contamination.)

9

References for case cited: Ohio Department of Natural Resources. Division of 011 and Gas, interoffice communication from M. Sharrock to S. Kell on the condition of the casing removed from the Donofrio well. Cormunication from Attorney General's Office, E.S. Post, discussing court order to plug the Donofrio we11. Perry County Common Pleas Court Case \$19262. Letter from R.M. Kimba11. Assistant Attorney General. to Scott Kell. Ohio Department of Natural Resources, presenting case sumary from 1974 to 1984 . Ohio Department of Health lab sampling reports from 1976 to 1985. Columbus water and Chemical Test ing Lab, sampling reports from 12/1/75, 7/27/84, and $8 / 3 / 84$. 
This well could not pass the current criteria for mechanical integrity under the UIC program.

An alternative to annular disposal of oil field waste is underground injection in Class II wells, using tubing and packer, but these Class II disposal wells are significantly more expensive than annular disposal operations.

\section{7 egal Disposal of $0 i 1$ and Gas Waste in West Virginia}

Environmental damage from illegal disposal of wastes associated with drilling and production is by far the most common type of problem in West Virginia. Results of illegal disposal include fish kills, vegetation kills, and death of livestock from drinking polluted water. Fluids illegally disposed of include $0 i 1$, produced waters of up to $180,000 \mathrm{ppm}$ chlorides, drilling fluids, and fracturing fluids that can have a $\mathrm{pH}$ of as low as 3.0 (highly acidic).

Illegal disposal in this State takes many forms, including draining of saltwater holding tanks into streams, breaching of reserve pits into streams, siphoning of pits into streams, or discharging of vacuum truck contents into fields or streams.

Enforcement is difficult both because of limited availability of State inspection and enforcement personnel and because of the remote location of many drill sites (see Table VII-7). Many illegal disposal incidents come to light through complaints from landowners or anonymous informers. 
Beginning in 1979. Allegheny Land and Mineral Company of West Virginia operated a gas we11. \#A-226, on the property of Ray and Charlotte Willey. The well was located in a corn field where cattle were fed in winter, and within 1,000 feet of the Willey's residence. The well was also adjacent to a stream known as the Beverlin Fork. Allegheny Land and Mineral operated another gas well above the residence known as the $\$ A-306$, also located on property owned by the Willeys. Allegheny Land and Mineral maintained open reserve pits and an open waste ditch, which ran into Beverlin Fork. The ditch served to dispose of produced water, 011, drip gas, detergents, fracturing fluids, and waste production chemicals. Employees of the company told the Willeys that fluids in the pits were safe for their livestock to drink.

The Willeys alleged that their cattle drank the fluid in the reserve pit and became poisoned, causing abortions, birth defects, weight loss, contaminated milk, and death. Hogs were also allegedly poisoned, resulting in infertility and pig still-births, according to the complaint filed in the curcuit court of Doddridge County, by the Willeys, against Allegheny Land and Mineral. The Willeys claimed that the soil on the farm was contaminated, causing a decrease in crop production and quality; that the ground water of the farm was contaminated, polluting the water well from which they dren their domestic water supply; and that the value of their real estate had been diminished as a result of these damages. Laboratory tests of soil and water from the property confirmed this contamination. The Willeys incurred laboratory expenses in having testing done on livestock. soil, and water. A judgment filed in the circuit court of Doddridge County was entered in 1983 where in the Hilleys were awarded a cash settlement in court for a total of $\$ 39.000$ plus interest and costs. 10 (wV 18) ${ }^{11}$

\section{This practice would violate current West Virginia regulations.}

On February 23, 1983. Tom Ancona, a fur trapper, filed a complaint concerning a fish kill on Stillwell Creek. A second complaint was also filed anonymously by an employee of Marietta Royalty Co. Ancona, accompanied by a State fisheries biologist, followed a trail consisting of dead fish, frogs, and salamanders up to a drill site operated by Marietta Royalty Co., according to the complaint filed with the West Virginia DNR. There they found a syphon hose draining the drilling waste pit into a tributary of Stillwell Creek. Acid levels at the pit measured a pH of 4.0, enough to shock and kill aquatic life, according to West Virginia District Fisheries Biologist Scott Morrison. Samples and photographs were taken by the DNR. No, dead aquatic life was found above the sample

10 West Virginia Department of Energy states that "...now the Division does not allow that type of practice, and would not let a landowner subvert the reclamation law."

11 References for case cited: Complaint form filed in circuit court of Doddridge County, West Virginia, "81-c-18. Judgment form filed in circuit court of Doddridge County. West Virginia. Water quality sumary of Ray Willey farm. Letter from $D$. J. Horvath to Ray Willey. Water analysis done by Mountain State Environmental Service. Veterinary report on cattle and hogs of Willey farm. Lab reports from National Veterinary Services Laboratories documenting abnormalities in Willey livestock. 
site. Marietta Royalty Co. was fined a total of $\$ 1,000$ plus $\$ 30$ in court costs. ${ }^{12}$ (WV 20) 13

This discharge was in direct violation of West Virginia regulations.

\section{Illegal Disposal of 0il Field Waste in Pennsylvania}

In Pennsylvania, disposing of oil and gas wastes into streams prior to 1985 violated the State's general water quality criteria, but the regulations were rarely enforced. In a study conducted by the U. S. Fish and Wildlife Service, stream degradation was found in relation to chronic discharges to streams from $0 i 1$ and gas operations:

\footnotetext{
The U.S. Fish and Wildife Service conducted a survey of several streams in Pennsylvania from 1982-85 to determine the impact on aquatic life over a period of years resulting from discharge of oil field wastes to streams. The area studied has a history of chronic discharges of wastes from $0 i l$ and gas operations. The discharges were primarily of produced water from product ion and enhanced recovery operations. The streams studied were Miami Run. South Branch of Cole Creek, Panther Run, Foster Brook, Lew is Run, and Pithule Creek. The study noted a decline downstream from discharges in all fish populations and populations of frogs, salamanders, and crayfish. $(P A 02)^{14}$
}

These discharges of produced waters are presently allowed only under the National Pollutant Discharge Elimination System (NPDES) permit system.

\footnotetext{
12 The West Virginia Department of Energy states that "This activity has now been regulated under West Virginia's general permit for drilling fluids. Under that permit there would have been no environmental damage."

13 References for case cited: Complaint Form \#6/170/83, West Virginia Department of Natural Resources, 2/25/83. West Virginia Department of Natural Resources Incident Report ing Sheet, $2 / 26 / 83$. Sketches of Marietta drill site. Complaint for Sumons or Warrant, $3 / 28 / 83$. Sumnons to Appear, 3/18/83. Marietta Royalty Prosecution Report. West Virginia Department of Natural Resources. Interoffice memorandum containing spill investigation details on Marietta Royalty incident.
}

14 References for case cited: U.S. Fish and Wildlife. Sumary of Data from Five Streams in Northwest Pennsylvania, 3/85. Background information on the streams selected for $f$ ish $t$ issue analysis, undated but after $10 / 23 / 85$. Tables 1 through 3 on point source discharge samples collected in the creeks included in this study. undated but after 10/30/84. 
The long-term environmental impacts of chronic, widespread illegal disposal include loss of aquatic life in surface streams and soil salt levels above those tolerated by native vegetation. In 1985, Pennsylvania established State standards concerning this type of discharge. Discharges are now permitted under the NPDES system.

The northwestern area of Pennsylvania was officially designated as a hazardous spill area (Clean Water Act, Section $311(k)$ ) by the U.S.EPA in 1985 because of the large number of oily waste discharges that have occurred there. Even though spills are accidental releases, and thus do not constitute wastes routinely associated with the extraction of $0 i 1$ and gas under the sense of the 3001 exemption, spills in this area of Pennsylvania appear to represent deliberate, routine, and continuing illegal disposal of waste oil.

Breaching of pits, opening of tank battery valves, and improper oil separation have resulted in an unusually high number of sites discharging oil directly to streams. The issue was originally brought to the attention of the State through a Federal investigation of the 500,000 acre Allegheny National Forest. That investigation discovered 500 separate spills. These discharges have affected stream quality, fish population, and other related aquatic life.

The U.S. EPA declared a four-county area (including Mckean, Warren, Venango, and Elk counties) a major spill area in the summer of 1985. The area is the oldest commercial oil-producing region in the world. Chronic low-level releases have occurred in the region since earliest production and cont inue to this day. EPA and other agencies (e.g.. U.S. Fish and Wildlife, Pennsylvania Fish and Game. Coast Guard) were concerned that cont inued discharge into the area's streams has already and will in the future have major environmental impact. The area is dotted with thousands of marginal stripper wells (producing a high ratio of produced water to oil), as well as thousands of abandoned wells and pits. In the Allegheny Reservoir itself, divers spotted 20 of 81 known improperly plugged or unplugged wells, 7 of which were leaking oily high-chloride produced water into the reservoir and have since been plugged. EPA is concerned that many others are also leaking native oily produced water. 
The Coast Guard (USCG) surveyed the forest for $011 \mathrm{sp} 11$ ls and produced water discharges, ident ifying those of particular danger to be cleaned immediately, by government if necessary. In the Allegheny Forest alone. USCG ident if ied over 500 sites where oil was leaking from wells, pits, pipelines, or storage tanks. In 59 cases, $0 i 1$ was being discharged directly into streams; 217 sites showed evidence of past discharges and were on the verge of discharging again into the Allegheny Reservoir. Illegal disposal of oil field wastes has had a detrimental effect on the environment: ". . there has been a lethal effect on trout streams and damage to timber and habitat for deer, bear and grouse," On Lewis Run, 52 discharge sites have been ident if ied and the stream supports little aquatic life. A linost all streams in the Allegheny forest nave suppressed fish population as a "... direct result of pollution from 011 and gas activity." (API notes that 011 and produced water leaks into streams are prohibited by State and Federal regulations. $)^{15} \quad(P A O 9)^{16}$

These leaks are prohibited by State and Federal regulations. However, discharges are allowed, by permit, under the NPDES program.

\section{Damage to Water Wells from 0 il or Gas Well Drilling and Fracturing}

In West Virginia, the minimum distance established for separating oil or gas wells from drinking water wells is 200 feet. Siting of oil or gas drill sites near domestic water wells is not uncommon. ${ }^{17}$ West. Virginia has no automatic provision requiring drillers to replace water wells lost in this way; owners must replace them at their own expense

15 Coments in the docket by API pertain to PA 09. API states that " $\ldots 1$ itigation is currently pending with respect to this case in which questions have been raised about the factual basis for government action in this case."

16 References for case cited: U.S. Geological Survey letter from Buckwalter to Rice concerning sampling of water in northern Pennsylvania, 10/27/86. Pennsylvania Department of Environmental Resources press release on analysis of water samples, undated but after $8 / 63$. $0 i 1$ and Water: When One of the By products of High-grade Oil Production is a Low-grade Allegheny National Forest. It's Time to Take a Hard Look at Our Priorities, by Jim Morrison. Pennsyivania Wildlife, Vo1. 8, No. 1. Pittsburgh Press, "Spoiling a Wilderness," 1/22/84; "011 Leaking into Streams at 300 Sites in Northwestern Area of the State," 1985. Warren Times. "Slick 1ssues Underscore Oil Cleanup in National Forest." 1986.

17 According to members of the Legal Aid Society of Charleston, West Virginia, landowners have little control over where oil and gas wells are sited. Although a provision exists for hearings to be held to question the siting of an 011 or gas well. this process is rarely used by private landowners for economic and other reasons. 
or sue the driller. Where there is contamination of a freshwater source, State regulations presume an oil or gas drilling site is responsible if one is located within 1,000 feet of the water source.

During the fracturing process, fractures can be produced, allowing migration of native brine, fracturing fluid, and hydrocarbons from the oil or gas well to a nearby water well. When this happens, the water well can be permanently damaged and a new well must be drilled or an alternative source of drinking water found.

In 1982, Kaiser Gas Co. drilled a gas well on the property of Mr. James Parsons. The well was fractured using a typical fracturing fluid or gel. The residual fracturing fluid migrated into Mr. Parson's water well (which was drilled to a depth of 416 feet), according to an analysis by the West Virginia Environmental Health Services Lab of well water samples taken from the property. Darik and light gelatinous material (fracturing fluid) was found, along with white fibers. (The gas well is located less than 1,000 feet from the water we11.) The chief of the laboratory advised that the water well was contaminated and unfit for domestic use, and that an aiternative source of domestic water had to be found. Analysis showed the water to contain high levels of fluoride, sodium, iron, and manganese. The water, according to DNR officials, had a hydrocarbon odor. Indicating the presence of gas. To date Mr. Parsons has not resumed use of the well as a domestic water source. (API states that this dainage resulted from a malfunct ion of the fracturing process. If the fractures are not limited to the producing formation, the $0 i 1$ and gas are lost from the reservoir and are unrecoverable.) ${ }^{18}$ (WV 17) 19

18 Comments in the Docket pertain to WV 17, by David Flannery and West Virginia Department of Energy. Mr. Flannery states that "...this is an area where water problems have been known to occur independent of 0 il and gas operations." EPA believes that the "problems" Mr. Flannery is referring to are the natural high level of fluoride, alkalinity, sodium, and total dissolved solids in the water. However, the constituents of concern found in this water well were the gelatinous material associated with the fracturing process, and hydrocarbons. West Virginia Department of Energy states that the WVDOE "...had no knowledge that the Pittsburg sand was a fresh water source." Also, WVDOE pointed out that WV Code 228-1-20"... requires an operator to cement a string of casing 30 feet below all fresh water zones." According to case study records, Kaiser Gas Co. did install a cement string of casing 30 feet below the Pittsburg sand, from which Mr. Parson drew his water.

19 References for case cited: Three lab reports containing analysis of water well. Letter from J. E. Rosencrance, Environmental Health Services Lab, to P. R. Merritt, Sanitarian, Jackson County, West Virginia. Letter from P. R. Merritt to J. E. Rosencrance requesting analysis. Letter from M. W. Lewis, Office of 011 and Gas, to James Parsons stating State cannot help in recovering expenses, and $\mathrm{Mr}$. Parsons must file civil suit to recover damages. Water well inspection report complaint. Sample report forms. 
There were no violations of West Virginia regulations in this case.

\author{
Damage cases involving drilling activity in proximity to residential \\ areas are known to have occurred in Pennsylvania:
}

\begin{abstract}
Civil suit was brought by 14 families living in the village of Belmar against a Meadville-based 011 drilling company. Norwesco Development Corparation, in June 1986. Norwesco had drilled more than 200 wells near Belmar, and residents of the village claimed that the activity had contaminated the ground water from which they drew their domestic water supply. The Pennsyivania Department of Environmental Resources and the Pennsylvania Fish Cormission cited Norwesco at least 19 times for violations of State regulations. Norwesco claimed it was not responsible for contamination of the ground water used by the village of Belmar. Norwesco suggested instead that the contamination was from old. long-abandoned wells. The Pennsyivania Department of Environmental Resources (DER) agreed with Belmar residents that the contamination was from the current drilling operations. Ground water in Belnar had been pristine prior to the drilling operation of Norwesco. All families relying on the ground water lost their domestic water supply. The water from the contaminated wells would "...burn your eyes in the shower, and your skin is so dry and itchy when you get out." Families had to buy bottled water for drinking and had to drive, in some cases. as far as $30 \mathrm{miles}$ to bathe. Not on ly were residents not atle to drink or bathe using the ground water: they could not use the water for washing clothes or household items without causing permanent stains. Plumbing fixtures were pitted by the high level of total dissolved solids and high chloride levels.

In early 1986, DER ordered Norwesco to provide Belmar with an alternative water supply that was equal in quality and quantity to what the Belmar residents lost when their wells were contaminated. In November 1986 Norwesco of fered a cash sett lement of $\$ 275,000$ to construct a new water system for the village and provided a temporary water supply. (PA $08)^{20}$
\end{abstract}

This case represents a violation of Pennsylvania regulations.

\title{
Problems with Landspreading in West Virginia
}

Landspreading of drilling muds containing up to $25,000 \mathrm{ppm}$ chlorides was allowed in West Virginia until November 1, 1987. The new limit is $12,500 \mathrm{ppm}$ chlorides. These concentrations of chlorides are considerably

20 References for case cited: Pittsburgh Press, "Franklin County Village Sees Hope after Bad Water Ordeal." 12/7/86. Morning News, "0il Drilling Firm Must Supply Water to Homes," 1/7/86; "village Residents Sue Drilling Company," 6/7/86. 
higher than concentrations permitted for landspreading in other States and are several times higher than native vegetation can tolerate. Landspreading of these high-chloride muds may result in damage to arable land. This waste drilling mud may kill surface vegetation where the mud is directly applied; salts in the wastes can leach into surrounding soil, affecting larger plants and trees. Leaching of chlorides into shallow ground water is also a potential problem associated with this practice.

In early 1986 Tower Drilling land-applied the contents of a reserve pit to an area 100 feet by 150 feet. All vegetation died in the area where pit contents were directly applied, and three trees adjecent to the land application area were dying allegedly because of the leaching of high levels of chlorides into the soil. A complaint was made by a private citizen to the West Virginia DNR. Samples taken by West Virginia DNR of the contaminated soil measured 18,000 ppm chlorides ${ }^{21}$ (WV 13$)^{22}$

Land applying reserve pit contents with more than $12,500 \mathrm{ppm}$ chlorides is now in violation of West Virginia regulations.

Problems with Enhanced 0 il Recovery (EOR) and Abandoned Wells in Kentucky

The Martha 0il Field, located in northeastern Kentucky, is situated on the border of Lawrence and Johnson counties and occupies an area in excess of 50 square miles. 011 production began in the early 1920s and secondary recovery operations or waterflooding commenced in 1955. Ashland Exploration, Inc., operated UIC-permitted injection wells in the area. Approximately 8,500 barrels of fresh water were being injected per day at an average pressure of 700 pounds per square inch.

21 Comments in the Docket by David Flannery and API pertain to WV 13. The statements by API and Mr. Flannery are identical. They state that it might not be "...possible to determine whether it was the chloride concentration alone which caused the vegetation stress." Also, they claim that the damage was short term and "...full recovery of vegetation was made." Neither commenter submitted supporting documentation.

22 References for case cited: West Virginia Department of Natural Resources complaint form $\# 6 / 131 / 86$. Analytical report on soil analysis of $k i 11$ area. 
Several field investigations were conducted by the U.S. Environmental Protection Agency, Region IV, to appraise the potential for and extent of contamination of ground-water resources. Field inspections revealed widespread contamination of underground sources of drinking water (USDWs).

From Apr 1129 through May 8, 1986, representatives of the U.S. EPA. Region IV, conducted a surface water investigation in the Blaine Creek watershed near Martha, Kentucky. The study was requested by the U.S. EPA Water Management Division to provide additional baseline information on stream water quality conditions in the Blaine Creek area. Blaine Creek and its tributaries have been severely impacted by 011 production activities conducted in the Martha fieid since the early 1900s. The Water Management Division issued an administrative order requiring that waterflooding of the 011-bearing strata cease by February 4, 1986, and a lso requiring that direct or indirect brine discharges to area streams cease by May 7, 1986.

For the study in 1986, 27 water chemistry sampling stations, 13 of which were also biological sampling stations, were established in the Blaine Creek watershed. Five streams in the study area were considered control stations. Blological sampling indicated that macroinvertebrates in the immediate Martha 011 field area were severely impacted. Many species were reduced or absent at all stations within the oil field. Blaine Creek stations downstream of the oil field, although impacted, showed gradual improvement in the benthic macroinvertebrates. Control stations exhitited the greatest diversity of benthic macroinvertebrate species. Water chemistry results for chlorides generally indicated elevated levels in the Martha oll field drainage area. Chloride values in the affected area of the oil field ranged from 440 to $5,900 \mathrm{mg} / \mathrm{L}$. Control station chloride values ranged from 3 to $42 \mathrm{mg} / \mathrm{L}$.

In May of 1987, EPA, Region IV, conducted another surface water investigation of the Blaine Creek watershed. The study was designed to document changes in water quality in the watershed 1 year following the cessation of oil production activities in the Martha oil field. By May of 1987, the major operator in the area, Ashland Exploration. Inc., had ceased operations. Some independently owned production wells were still in service at this time. Chloride levels, conductivity, and total dissolved solids levels had significantly decreased at study stations within the Martha oil field. Marked improvements were observed in the benthic invertebrate commity structures at stations within the Martha field. New species that are considered sensitive to water quality conditions were present in 1987 at most of the biological sampling stations, indicating that significant water quality improvements had occurred following cessation of 011 production activities in the Martha field. Chloride leve is in one stream in the Blaine Creek watershed decreased from $5,900 \mathrm{mg} / \mathrm{L}$ to $150 \mathrm{mg} / \mathrm{L} .23$

23 References for case cited: Martha 0il Field Water Quality Study, Martha, Kentucky. U.S. EPA, Athens, Georgia, May 1986. Martha Oil Field Water Quality Study, Martha, Kentucky, U.S. EPA, Athens, Georgia, May 1987. 
In response to EPA's notice of violations and other requirements, Ashland proposed to EPA that it would properly plug and abandon all existing injection wells, oil production wells, and water-supply wells and most gas production wells in the Martha field. EPA, Region IV, issued to Ashland an Order on Consent With Administrative Civil Penalty under the authority of Section 1423(9)(2) of the SDWA. Ashland has paid an administrative penalty of $\$ 125,000$ and will plug and abandon approximately 1,433 wells in compliance with EPA standards. If warranted, Ashland will provide alternative water supplies to private water well users whose supplies have been adversely affected by oil production activities.

\section{SOUTHEAST}

The Southeast zone includes North Carolina, South Carolina, and Georgia. There is little oil and gas activity in this zone. No field research was conducted to collect damage cases in this zone.

\section{GULF}

The Gulf zone includes Arkansas, Louisiana, Mississippi, Alabama, and Florida. Attention in the damage case effort was focused on Arkansas and Louisiana, the two major producers of the zone.

\section{Operations}

Operations in Arkansas are predominantly small to mid-sized operations in mature production areas. A significant percentage of 
production in this area comes from stripper wells, which produce large volumes of associated produced water containing high levels of chlorides. For Arkansas, most production occurs in the southern portion of the State.

The average depth of a new well drilled in Arkansas in 1985 was 4,148 feet. That year 121 exploratory wells were drilled and 1,055 new wells were completed.

Louisiana has two distinct production areas. The northern half of the State is dominated by marginal stripper production from shallow wells in mature fields. The southern half of Louisiana has experienced most of the State's development activity in the last decade. There has been heavy, capital-intensive development of the Gulf Coast area, where gas is the principal product. Wells tend to be of medium depth; operations are typically located in or near coastal wetland areas on barge platforms or small coastal islands. Operators dredge canals and estuaries to gain access to sites.

In this area, reserve pits are constructed out of the materials found on coastal islands, mainly from peat, which is highly permeable and susceptible to damage after exposure to reserve pit fluids. Reserve pits on barges are self-contained, but are allowed to be discharged in particular areas if levels of certain constituents in wastes are below specified limits. If certain constituents are found in concentrations above these limits in the waste, they must be injected or stored in pits (unlined) on coastal islands. 
For many operators in the Gulf Coast area, produced water is discharged directly to adjacent water bodies. Fields in this region have an average water/oil ratio of from $4: 1$ to $6: 1$. The Louisiana Department of Environmental Quality (DEQ) is now requiring that operators apply for permits for these discharges. At this writing, the Louisiana DEQ had received permit applications for approximately 750 to 800 discharge points. Results of field work done by the Louisiana DEQ, the Louisiana Geological Survey, and the Louisiana University Marine Consortium show that roughly 1.8 to 2.0 million barrels of produced water are discharged daily in this area. According to the Louisiana Geological Survey, many receiving water bodies contain fresh water, with some receiving water bodies 70 times fresher than the oil field discharges. The U.S. Fish and Wildlife Service has stated that it will aggressively oppose any permits for produced water discharges in the Louisiana wetlands of the Gulf Coast.

The average depth of a new well drilled in northern Louisiana in 1985 was 2,713 feet; along the Gulf Coast it was 10,150 feet. In the northern part of the State, 244 exploratory wells were drilled and 4,033 production wells were completed. In the southern part of the State, 215 exploratory wells were drilled and 1,414 production wells were completed.

\section{Types of Operators}

In Arkansas, operators are generally small to mid-sized independents, including some established operators and others new to the industry. Because production comes mostly from stripper wells, operators tend to be vulnerable to market fluctuations.

Northern Louisiana's operators, like those in Arkansas, tend to be small to mid-sized independents. They share the same economic vulnerabilities with their neighbors in Arkansas. In addition, however, 
Louisiana's more marginal operations may be particularly stressed by the new Rule 29B, which requires the closing out and elimination of all current and future onsite produced water disposal pits by 1989 . Estimated closing costs per pit are $\$ 20,000$.

Operators in southern Louisiana tend to be major companies and large independents. They are less susceptible to fluctuating market conditions in the short term. Projects in the south tend to be larger than those in the north and are located in more environmentally sensitive areas.

\section{Major Issues}

Ground-Water Contamination from Unlined Produced Water Disposal Pits and Reserve Pits

Unlined produced water disposal pits have been used in Louisiana for many years and are only now being phased out under Rule 29B. Past practice has, however, resulted in damages to ground water and danger to human health.

\footnotetext{
In 1982, suit was brought on behalf of Dudley Romero et al. against operators of an 011 waste comercial disposal facility. PAB $0,1 \mathrm{CO}$. The plaint iffs stated that their domestic water wells were contaminated by wastes dumped into open pits in the PAB 0 il Co. facility which were alleged to have migrated into the ground water, rendering the water wells unusable. $0 i 1$ field wastes are dumped into the waste pits for skimming and separation of oil. The pits are unlined. The PAB facility was operating prior to Louisiana's first comercial oil field waste facility regulations. After promulgation of new regulations, the facility cont inued to operate for 2 years in violation of the new regulations, after which $t$ ime the State shut down the facility.

The plaintiff's water wells are downgradient of the facility, drilled to depths of 300 to 500 feet. Problems with water wells date from 1979. Extensive analys is was performed by Soil Testing Engineers, Inc., and U.S. EPA, on the plaint iff's water wells adjacent to the site to determine the probability of the well contamination coming from the PAB 0 il Co. site. There was also analys is on surface soil contamination. Soil Testing
} 
Engineers, Inc., determined that it was possible for the wastes in the PAB 0 il Co. pits to reach and contaminate the Romeros' water wells. Surface sampling around the perimeter of the PAE 011 CO. Site found high concentrations of metals. Resistivity testing showed that plumes of chloride contamination in the water table lead from the pits to the water wells. Borings that determined the substrata makeup suggested that it would be possible for wastes to contaminate the Romero ground water witnin the time that the facility had been in operation if the integrity of the clay cap in the pit had been lost (as by deep excavation somewhere within it). The pit was 12 feet deep and within range to percolate into the water-bearing sandy soil.

The plaintifis complained of sickness, nausea, and dizziness, and a loss of cattle. The case was settled out of court. The plaint iffs received 5140,000 from PAB 0,1 Co. $(L A \quad 67)^{24}$

Unlined commercial disposal pits are now illegal in Louisiana.

The ground in this area is highly permeable, allowing pit contents to leach into soil and ground water. Waste constituents potentially leaching into ground water from unlined pits include arsenic, cadmium, chromium, copper, lead, nickel, zinc, and chlorides. There have been incidents illustrating the permeability of subsurface formations in this area. $^{25}$

Allowable Discharge of Drilling Mud into Gulf Coast Estuaries

Under existing Louisiana regulations, drilling muds from onshore operations may be discharged into estuaries of the Gulf of Mexico. The State issues permits for this practice on a case-by-case basis. These

24 References for case cited: Soil Testing Engineers, Inc.. Brine Study, Romero, et a 1., Abbeville. Louisiana, 10/19/82. U.S. EPA lab analysis of pits and wells, 10/22/81. Dateline, Louisiana: Fight ing Chemical Dumping, by Jason Berry, May-June, 1983.

25 A gas we 11 operated by Conoco, which had been plugged and abandoned, blew out be low the surface from December 11, 1985, to January 9, 1986. The blowout sent gas through fault zones and permeable formations to the land surface owned by Claude H. Gooch. The gas could be ignited by a match held to the ground. The gas was also determined to be a potential hazard to drinking water wells in the immediate area. 
estuaries are often valuable commercial fishing grounds. Since the muds can contain high levels of toxic metals, the possibility of

bioaccumulation of these metals in shellfish or finfish is of concern to EPA.

In 1954, the Glendale Drilling Co., under contract to Woods Petroleum, was drilling from a barge at the intersection of Taylor's Bayou and Cross Bayou. The operation was discharging drill cuttings and mud into the bayou within 1,300 feet of an active oyster harvesting area and State oyster seeding area. At the $t$ ime of discharge, oyster harvests were in progress. (It is State policy in Louisiana not to grant permits for the discharge of drill cuttings within 1,300 feet of an active oyster harvesting area. The Louisiana Department of Environmental Quality does not allow discharge of whole mud into estuaries.)

A State Water Pollution Control Division inspector noted that there were two separate discharges occurring from the barge and a low mound of mud was protruding from the surface of the water beneath one of the discharges. Woods Petroleum had a letter from the Louisiana Department of Environmental Quality authorizing them to discharge the drill cuttings and associated mud, but this permit would presumably not have been issued if it had been known that the drilling would occur near an oyster harvesting area. While no damage was noted at time of inspection, there was great concern expressed by the Louisiana Oyster Growers Association, the Louisiana Department of Wildife and Fisheries. Seafood Division, and some parts of the Department of Water Pollution Control Division of the Department of Environmental Quality. The concern of these groups stemed from the possibility. that the discharge of muds and cuttings with high . content of metals may have long-term impact on the adjacent comnercial oyster fields and the State oyster seed fields in nearby Junop Bay. In such a situation, metals can precipitate from the discharge, settling in progressively higher concentrations in the bayou sediments where the oysters mature. The bioaccumulation of these metals by the oysters can have an adverse impact on the oyster population and could also lead to human health problems if contaminated oysters are consumed.

The Department of Environmental Quality decided in this case to direct the oil company to stop the discharge of drill cuttings and muds into the bayou. In this instance, the Department of Environmental Quality ordered that a drill cutting barge be used to contain the remainder of the drill cuttings. The company was not ordered to clean up the mound of drill cuttings that it had already deposited in the bayou. (LA 20) 26

Activities in this case, though allowed by the State, are illegal according to State law.

26 References for case cited: Louisiana Department of Environmental Quality. Water Pollution Control Division. Office of Water Resources, internal memorandum, 6/3/85. 


\title{
Illegal Disposal of 0il Field Waste in the Louisiana Gulf Coast Area
}

\author{
The majority of damage cases collected in Louisiana involve illega? \\ disposal or inadequate facilities for containment of wastes generated by \\ operations on the Gulf Coast. For example:
}

\begin{abstract}
Two Louisiana Water Pollution Control inspectors surveyed a swamp adjacent to a KEDCO 011 Co. facility to assess flora damage recorded on a Notice of Violation issued to KEDCO on $3 / 13 / 81$. The Notice of Violation discussed produced water discharges into an adjacent canal that emptied into a cypress swamp from a pipe protruding from the pit levee. Analysis of a sample collected by a Mr. Mart in. the complainant, who expressed concern over the high-chloride produced water discharge into the canal he used to obtain water for his crawfish pond. showed salinity levels of $32,000 \mathrm{ppm}$ (seawater is $35,000 \mathrm{ppm}$ ).

On April 15, 1981, the Water Pollution Control inspectors made an effort to measure the extent of damage to the trees in the cypress swamp. After surveying the size of the swamp. they randomly selected a compass bearing and surveyed a transect measuring 200 feet by 20 feet through the swamp. They counted and then classified all trees in the area according to the degree of damage they had sustained. Inspectors found that "... an approximate total area of 4,088 acres of swamp was severely damaged." Within the randomly selected transect, they classified all trees according to the degree of damage. Out of a total of 105 trees. 73 percent were dead. 18 percent were stressed, and 9 percent were norma 1. The inspectors' report noted that although the transect ran through a heavily damaged area, there were other areas much more severely impacted. They therefore concluded, based upon data collected and firsthand observation, that the percentages of damaged trees recorded "... are a representative, if not conservative, est imate of damage over the entire affected area." In the opinion of the inspectors. the discharge of produced water had been occurring for some time. judging by the amount of damage sustained by the trees. KEDCO was fined $\$ 9.500$ by the State of Louisiana and paid $\$ 4,500$ in damages to the owner of the affected crawfish farm. (LA 45) 27
\end{abstract}

This discharge was in violation of Louisiana regulations.

27 References for case cited: Louisiana Cepartment of Natural Resources, Water Pollution Control Division, internal memo. Cormier and St. Pe to Givens, concerning damage evaluat ion of swamp near the KEDCO 011 Co. facility $6 / 24 / 81$. Not ice of Violation, Water Pollution Control Log $\# 2-8-81-21$. 
Most of the damage cases collected involved small operations run by independent companies. Some incidents, however, involved major oil companies:

Sun 011 Co. operates a site located in the Chacahoula Field. A Department of Natural Resources inspector noted a site configuration during an inspection $(6 / 25 / 62)$ of a tank battery surrounded by a pit levee and a pit ( 30 yards by 50 yards). The pit was discharging produced water into the adjacent swamp in two places, over a low part in the levee and from a pipe that had been put through the ring levee draining directly into the swamp. Produced water. 011, and grease were being discharged into the swamp. Chloride concentrations from samples taken by the inspectors ranged from 2.948 to $4.848 \mathrm{ppm}$, and 0.1 and grease concentrations measured 12.6 to $26.7 \mathrm{ppm}$. The inspector noted that the discharge into the swamp was the means by which the company drains the tank battery ring levee area. A notice of violation was issued to Sun 0 il by the Department of kitural Resources. (LA 15) 28

\section{This discharge was in violation of Louisiana regulations.}

\section{Some documented cases noted damage to agricultural crops:}

Dr. Wilma Subra documented damage to D.T. Caffery's sugar cane fields adjacent to a production site, which included a saltwater disposal we11. in St. Mary Parish. The operator was Sun 0 il. The documentation was collected between July of 1985 and November of 1986 and included reports of salt concentrations in soll at various locations in.the sugar cane fields. along with descriptions of accompanying damage. Dr. Subra noted that the sugar cane fieids had various areas that were barren and contained what appeared to be sludge. The production facility is upgradient from the sugar cane fields, and Dr. Subra surmised that produced water was discharged onto the soil surface from the facility and that a plume of salt contamination spread downgradient, thereby affecting 7.3 acres of sugar cane fields, over a period of a year and a half.

In July 1985, Or. Subra noted that the cane field, though in bad condition, was predominantly covered with sugar cane. There were, however, weeds or barren soil covering a portion of the site. The patch of weeds and barren soil matched the area of highest salt concentration. In the area where the topography suggested that brine concentrations would be lowest, the sugar cane appeared healthy. Subsequent field investigation and soil sampling conducted by Dr. Subra in November of 1986 found the field to be nearly barren, with practically no sugar cane growing.

28 References for case cited: Louisiana Department of Natural Resources, Water Pollution Control Division, internal memo from Cormier to Givens, $8 / 16 / 82$, concerning Sun $0 i 1$ Co. brine discharge, Chacahoula field. Log $\# 2-8-81-122$. Lab analysis, $7 / 2 / 82$. 
Dr. Subra measured concentrations of salts in the soil ranging from a low of $1,403 \mathrm{ppm}$ to $35,265 \mathrm{ppm}$ at the edge of the field adjacent to the oil operation. Sun has undertaken a reclamation project to restore the land. It is estimated that the project will take 2 to 3 years to complete. In the interim. Sun $0,1 \mathrm{Co}$. will pay the sugar cane farmer for loss of crops. 29 (LA 63$)^{30}$

The State of Louisiana has not taken any enforcement action in this case; it is unclear whether any State regulations were violated.

\author{
Most damage associated with illegal disposal involves disposal of \\ produced water containing high levels of chloride (brine). Illegal \\ disposal of other types of oil field waste also result in environmental \\ damage:
}

Chevco-Kengo Services. Inc. operates a centralized disposal facility near Abbeville. Louisiana. Produced water and other wastes are transported from surrounding product ion fields by vacuum truck to the facility. Complaints were filed by private citizens alleging that discharges from the facility were damaging crops of rice and crawfish, and that the facility represented a threat to the health of nearby residents. An inspection of the site by the Water Pollution Control Division of the Department of Natural Resources found that a truck washout pit was emptying oil field wastes into a roadside ditch flowing into nearby coulees.

Civil suit was brought by private citizens against Chevco-kengo Services, Inc., asking for a total of $\$ 4$ million in property damages, past and future crop loss, and exemplary damages. Lab analys is performed by the Department of Natural Resources of waste samples indicated high metals content of the wastes, especially in samples taken from the area near the facility and in the adjacent rice fields, indicating that the discharge of wastes from the facility was the source of damage to the surrounding land. The case is in litigation. ${ }^{31}$ (LA9O) $)^{32}$

The State did not issue a notice of violation in this case. However, this type of discharge is illegal.

29 API states that an accidental release occurred in this case. EPA records show this release lasted 2 years.

30 References for case cited: Documentation from Dr. Wilma Subra, including a series of maps documenting changes in the sugar cane over a period of $t$ ime, 12/86. Maps showing location of sampling and salt concentrations.

31 API states that these discharges were accidental.

32 References for case cited: Louisiana Department of Natural Resources, Water Pollut ion Control Division, internal memo, lab analysis, and photographs, 8/25/83. Letter from West land 0 il Development Corp. to Louisiana Department of Natural Resources, 4/15/83. 


\section{1 legal Disposal of 0 il Field Waste in Arkansas}

The majority of damage cases found in Arkansas relate to $i 11$ egal. dumping of produced water and oily waste from production units. Damages typically include pollution of surface streams and contamination of soil with high levels of chlorides and oil, documented or potential contamination of ground water with elevated levels of chlorides, and damage to vegetation (especially forest and timberland), from exposure to high levels of chlorides.

An 011 production unit operated by Mr. J. C. Langley was discharging 011 and produced water in large quantities onto the property of Mr. Melvin Dunn and Mr. W. C. Shaw. The oil and produced water discharge allegedly caused severe damage to the property, interfered with livestock on the property, and delayed construction of a planned lake. Mr. Dunn had spoken repeatedly with a company representative operating the facility concerning the 011 and produced water discharge. but no changes occurred in the operation of the facility. A complaint was made to Arkansas Department of Pollution Control and Ecology (ADPCE). the operator was informed of the situation. and the facility was brought into compliance. Mr. Dunn then hired a private attorney in order that remedial action be taken. It is not known whether the operator cleaned up the damaged property. ${ }^{33}$ (AR 07) $)^{34}$

This discharge was in violation of Arkansas regulations.

On September 20, 1984, an anonymous complaint was filed with ADPCE concerning the discharge of oil and produced water in and near Smackover Creek from production units operated by J. S. Beebe 0,1 Account. Upon investigation by ADPCE, it was found that saltwater was leaking from a salt water disposal well located on the site. Mr. Beebe wrote a letter stating his willingness to correct the situation. On November 16, 1984, the site was again investigated by ADPCE, and it was found that pits on location were being used as the primary disposal facility and were

33 API states that this incident constituted a spill and is therefore a non-RCRA issue.

34 References for case cited: Arkansas Department of Pollution Control and Ecology (ADPCE) Complaint form, \#EL 1721. 5/14/84. Letter from Michael Landers, attorney to Mr. Dunn. requesting investigation from Wayne Thomas concerning Langley violations, Letter from J. C. Langley to Wayne Thomas, ADPCE, denying responsibility for damages of Dunn and Shaw property, 6/5/84. Cert if ied letter from Wayne Thomas to J. C. Langley discussing violations of facility and required remedial actions, 5/30/87. Map of violation area, 5/29/84. ADPCE oil field waste survey document ing unreported oil spill on Langley unit, 5/25/84. Letter from Michae 1 Landers, attorney to ADPCE, discussing damage to property of Dunn and Shaw, 5/11/84. 
overflowing and leaking into Smackover Creek. The ADPCE issued a Notice of Violation (LIS 84-066) and noted that the pits were below the creek level and overflowed into the creek when heavy rains occurred. One pit was being siphoned over the pit wal1. while waste from another pit was flowing onto the ground through an open pipe. The floors and walls of the pits were saturated, allowing seepage of waste from the pits. ADPCE ordered Mr. Beebe to shut down production and clean up the site and fined him \$10.500. (AR 10) 35

These discharges were occurring in violation of Arkansas regulations.

The State of Arkansas has limited resources for inspecting disposal facilities associated with oil and gas production. (See Table VII-7.) Furthermore, the two State agencies responsible for regulating oil and gas operations (the Arkansas $0 i 1$ and Gas Commission (OGC) and the Arkansas Department of Pollution Control and Ecology (ADPCE)) have overlapping jurisdictions. In the next case, the landowner is the Arkansas Game and Fish Commission, which attempted to enforce a permit it issued to the operator for drilling activity on the Commission's land. As of summer 1987, no permit had been issued by either the OGC or the ADPCE.

In 1983 and again in 1985. James M. Roberson, an oil and gas operator, was given surface access by the Arhansas Game and Fish Comission for drilling in areas in the Sulphur River Wildlife Managenent Area (SRWMA), but was not issued a drilling permit by either of the State agencies that share jurisdiction over 011 and gas operations. Surface rights are owned by the Arkansas Game and Fish Comission. The Cormission attempted to write its own permits for this operation to protect the wildlife management area resources. Mr. Roberson repeatedly violated the requirements contained in these surface use permits, and the Commission also determined that he was in violation of general State and Federal regulations applicable to his operation in the absence of OGC or ADPCE permits. These violations led to release of oil and high-chloride produced water into the wet land areas of the Sulphur River and Mercer Bayou from a leaking saltwater disposal we 11 and 1 llegal produced water disposal pits maintained by the operator.

35 References for case cited: ADPCE complaint form \#EL 1792, 9/20/84, and 8/23/84. ADPCE inspection report. $9 / 5 / 84$. Letter from ADPCE to J. S. Beebe out lining first run of violations, $9 / 6 / 84$. Letter stating willingness to cooperate from Beebe to ADPCE, 9/14/84. ADPCE complaint form - $E L$ 1789. 9/19/84. ADPCE inspection report, 9/25 and 9/26/84. ADPCE complaint form \$EL 1822 . $11 / 16 / 84$. ADPCE Notice of Violation, Findings of Fact, Proposed Order and Civil Penalty Assessment. $11 / 21 / 84$. Map of area. Miscellaneous letters. 
011 and saltwater damage to the area was documented in a study conducted by Hugh A. Johnson, Ph.D., a professor of biology at Southern Arkansas University. His study mapped chloride levels around each well site and calculated the affected area. The highest chloride level recorded in the wetland was 9,000 ppm (native vegetation begins to be stressed from exposure to $250 \mathrm{ppm}$ chlorides). He found that significant areas around each well site had dead or stressed vegetation related to excessive chloride exposure. The Game and Fish Comission fears that continued discharges of produced water and 011 in this area will threaten the last remaining forest land in the Red River bottoms. ${ }^{36}$ (AR 04$)^{37}$

These discharges were in violation of State and Federal regulations.

Jurisdiction in the above case is unclear. Under a 1981 amendment to the State $0 i 1$ and Gas ACt, OGC was granted formal permit authority over oil and gas operations, but this authority is to be shared in certain situations with the ADPCE. Jurisdiction is to be shared where Underground Injection Control (UIC) wells are concerned, but is not clearly defined with respect to construction or management of reserve pits or disposal of drilling wastes. ADPCE has made attempts to clarify the situation by issuing informal letters of authorization to operators, but these are not universally recognized throughout the State. (A full discussion of this issue can be found in Chapter VII and in Appendix A.)

\footnotetext{
36 API states that the Arkansas Water and Air Pollution Act gives authority at several levels to require cleanup of these illegal activities and to prevent further occurrences. EPA believes that even though State and Federal Laws exist which prohibit this type of activity, no mechanism for enforcement is in place.

37 References for case cited: Letter from Steve Forsythe, Department of the Interior (DOI), to Pat Steveris. Army Corps of Engineers (ACE), stating that act ivities of Mr. Roberson have resulted in significant adverse environmental impacts and disruptions and that DOI recommends remedial action be taken. Chloride Analys is of Soil and Water Samples of Selected Sites in Miller County, Arkansas, by Hugh A. Johnson, Ph.D., 10/22/85. Letter to Pat Stevens, ACE, from Dick Whittington, EPA, discussing damages caused by Jimmy Roberson in Sulphur River Wildife Management Area (SRLMA) and recommending remedial action and denial of new permit application. 0 il and Gas well drilling permits dated 1983 and 1985 for Roberson activities. A number of letters and complaints addressing problems in SRWMA resulting from activities of James Roberson. Photographs. Maps.
} 
Improper operation of injection wells raises the potential for long-term damage to ground-water supplies, as the following case from Arkansas illustrates.

On September 19, 1984, Mr. James Tribble made a complaint to the Arkansas Department of Pollution Control and Ecology concerning salt water that was coming up out of the ground in his yard, killing his grass and threatening his water well. There are many 011 wells in the area. and water flooding is a common enhanced recovery method at these sites. Upon inspection of the wells nearest to his residence, it was discovered that the operator, J. C. Mclain, was inject ing salt water into an unpermitted well. The salt water was being injected into the casing. or. annulus, not into tubing. Injection into the unsound casing allegedly allowed migration into the freshwater zone. A produced water pit at the same site was near overflowing. State inspectors later noted in a followup inspection that the violations had been corrected. No fine was levied. (AR 12) 38

Operation of this well would now be in violation of UIC requirements.

\section{MIDWEST}

The Midwest zone includes the States of Michigan, Iowa, Indiana, Wisconsin, Illinois, and Missouri. Damage cases were collected in Michigan.

\section{Operations}

Michigan produces both $0 i 1$ and gas from limestone reef formations at sites scattered throughout the State at a depth of 4,000 to 6,000 feet.

38 References for case cited: ADPCE Complaint form, fEL 1790, 9/19/84. ADPCE inspection report, 9/20/84. Letter from ADPCE to Mr. J. C. MCLain describing violations and required corrective action, 9/21/84. ADPCE reinspection report, 10/11/84. 
$0 i l$ and gas development is relatively new in this area, and most production is primary (that is, as yet it involves no enhanced or secondary recovery methods, such as water flooding). Exploration in Michigan is possibly the most intense currently under way anywhere in the country. The average depth of new wells drilled in 1985 was 4,799 feet. In that year 863 wells were completed, of which 441 were exploration wells.

Types of Operators

Operators in Michigan include everything from small independent companies to the major oil companies.

\section{Major Issues}

Ground-Water Contamination in Michigan

All the damage cases gathered in Michigan are based on case studies written by the Michigan Geological Survey, which regulates oil and gas operations in the State. All of these cases deal with ground water contamination with chlorides. While the State has documented that damages have occurred in all cases, sources of damages are not always evident. Usually, several potential sources of contamination are listed for each case, and the plume of contamination is defined by using monitoring wells. Most of the cases involve disposal of produced waters.

In June 1983, a water well owned by Mrs. Geneva Brown was tested after she had filed a complaint to the Michigan Geological Survey. After responding, the Michigan Geological Survey found a chloride concentration of $490 \mathrm{ppm}$ in the water. Subsequent sampling from the water well of a neighbor. Mrs. Dodder, showed that her well measured $760 \mathrm{ppm}$ chloride in August. There are a total of 15 oil and gas wells in the area surrounding the contaminated water wells. Only five of the wells are still producing. recovering a combination of oil and produced water. The source of the pollution was evidently the H. E. Trope, Inc., crude oil separating facilities and brine storage tanks located upgradient from the contaminated water wells. Monitoring wells were installed to confirm the source of the contamination. St iff diagrams were used to confirm the similarity of the constituents of the formation brine and the chloride contamination of the 
affected water wells. Sample results located two plumes of chloride contamination ranging in concentration from 550 to 1,800 ppm that are traveling in a southeasterly direction downgradient from the produced water storage tanks and crude 011 separator facilities owned by H.E. Trope (MI 05$)^{39}$

Produced water spills from production facilities are covered by Michigan regulations.

Ground-water contamination in the State has also been caused by injection wells, as illustrated by the following case:

In April 1980, residents of Green Ridge Subdivision, located in Section 15. Laketon Township. Muskegon County. complained of bad-tasting water from their domestic water wells. Some wells sampled by the local health department revealed elevated chloride concentrations. Because of the proximity of the Laketon 011 Field, an investigation was started by the Michigan Geological Survey. The Laketon 0,1 Field consists of dry holes, producing 011 wells, and a produced water disposal well, the Harris 0,1 Corp. Lappo $\$ 1$. 0,1 wells produce a mixture of 011 and produced water. The produced water is separated and disposed of by gravity in the produced water disposal well and is then placed back in the producing formation. After reviewing monitoring well and electrical resistivity survey data, the Michigan Geological Survey concluded that the source of the . contamination was the Harris 011 Corp. Lappo \#1 produced water disposal well, which was being operated in violation of UIC regulations. (MI 06$)^{40}$

This disposal well was being operated in violation of State regulations.

Damage to ground water under a drill site can occur even where operators take special precautions for drilling near residential areas. An example follows:

References for case cited: Open file report. Michigan Department of Natural Resources, Investigation of Salt-Contaminated Groundwater in Cat Creek Oil Fieid, Hersey Township, conducted by D. W. Forstat, 1984. Appendix includes correspondence relating to investigation, area water well drilling logs, Stiff diagrams and water analysis, site monitor well drilling logs, and water sample analys is for samples used in the investigation.

40 References for case cited: Open file report. Michigan Departiment of Natural Resources, Invest igation of Salt-Contaminated Groundwater in Green Ridge Subdivision, Laketon Township. conducted by B. P. Shirey, 1980. Appendix includes correspondence relating to invest igation, area water well drilling logs. Stiff diagrams and water analysis, site monitor well drilling logs, and water sample analysis for samples used in the investigation. 
Drilling operations at the Burke Unit $\equiv 1$ caused the temporary chioride contamination of two comestic water weils and longer lasting chloride contamination of a third well closer to the drill site. The operation was carried out in accorcance with State regulations and special site restrictions required for urban areas, using rig engines equipped with mufflers, steel mud tanks for contalnment of drilling wastes, lining for earthen pits that may contain salt water, and the placement of a conductor casing to a depth of 120 feet to isolate the well from the freshwater zone beneath the rig.

The drilling location is underlain by permeable surface sand, with bedrock at a depth of less than 50 feet. Contamination of the ground water may have occurred when material flushed from the mud tanks remained in the lined pit for 13 days before removal. (The material contained high levels of cnlorides, and liners can leak.) According to the State report, this would have allowed for sufficient time for contaminants to migrate into the freshwater aquifer. A leak from the produced water storage tank was also reported by the operator to have occurred before the contamination was detected in the water wells. One shallow well was less than 100 feet directly east of the drill pit area and 100 to 150 feet southeast of the produced water leak site. Chloride concentrations in this well measured by the Michigan Geological Survey were found to range from 750 $(9 / 5 / 75)$ to $1.325(5 / 23 / 75) \mathrm{ppm}$. By late August, two of the wells had returned to normal, while the third we 11 still measured 28 times its original background concentration of chloride. (MI $04)^{41}$

In this case, damages resulted from practices that are not in violation of State regulations.

\section{PLAINS}

The Plains zone includes North Dakota, South Dakota, Nebraska, and Kansas. All of these States have $0 i 1$ and gas production, but for this study, Kansas was the only State visited for damage case collection. Discussion is limited to that State.

41 References for case cited: Open file report. Michigan Department of Natural Resources, Report on Ground-Water Contamination, Sullivan and Company, J.D. Burke No. 1, Pennf ie Id Township. conducted by J. R. Byerlay, 1976. Appendix includes correspondence relating to investigation, area water well drilling logs, Stiff diagrams and water analysis, site monitor well drilling logs, and water sample analysis for samples used in the investigation. 


\section{Operations}

$0 i 1$ and gas production in Kansas encompasses a wide geographical area and ranges from marginal oil production in the central and eastern portions of the State to significant gas production in the western portion of the State. Kansas is the home of one of the largest gas fields in the world, the Giant Hugoton field. Other major areas of oil production in Kansas include the Central Kansas Uplift area, better known as the "Kansas 0il Patch," the El Dorado Field in the east and south, and the Eastern Kansas Shoestring sandstone area. The Eastern Kansas Shoestring sandstone production area is composed mainly of marginal stripper operations. The overall ratio of produced water to oil in Kansas is about 40:1, but the ratio varies depending on economic conditions, which may force the higher water-to-oil ratio wells (i.e., those in the Mississippian and Arbuckle producing formations) to shut down.

The average depth of a new well drilled in Kansas in 1985 was 3,770 feet. In that year 6,025 new wells were completed. Of those, 1,694 were exploratory.

\section{Types of Operators}

Operators in Kansas include the full range from majors to small independents. The Hugoton area is dominated by majors and mid-sized to large independents. Spotty oil production in the northern half of eastern Kansas is dominated by small independent producers, and oil production is densely developed in the southern half. 
Major Issues

Poor Lease Maintenance

There are documented cases in Kansas of damage associated with inadequate lease maintenance and illegal operation of pits. These cases commonly result in contamination of soil and surface water with high levels of chlorides as well as long-term chloride contamination of ground water.

Temple 0,1 Company and Wayside Production Company operated a number of 011 production leases in Montgomery County. The leases were operated with 1 llegally maintained saltwater containment ponds, improperly abandoned reserve pits, unapproved emergency saltwater pits, and improperly abandoned saltwater pits. Numerous 011 and saltwater spills were recorded during operation of the sites. Documentation of these incidents started in 1977 when adjacent landowners began to complain about soil pollution. vegetation kills, fish kills, and pollution of freshwater streams due to 0,1 and saltwater runoff from these sites. The leases also contain a large number of abandoned, unplugged wells, which may pose a threat to ground water. ${ }^{42}$ Complaints were received by the Conservation Division, Kansas Department of Health and the Environment (KDHE). Montgomery County Sheriff, and Kansas Fish and Game Commission. A total of 39 violations on these leases were documented between 1983 and 1984 .

A sample taken by KDHE from a 4 1/2-foot test hole between a freshwater pond and a creek on one lease showed chloride concentrations of $65,500 \mathrm{ppm}$. Water samples taken from pits on other leases showed chloride concentrations ranging from 5,000 to $82,000 \mathrm{ppm}$.

The Kansas Corporation Comission (KCC) issued an administrative order in 1984, fining Temple and Wayside a total of $\$ 80,000$. Initially, $\$ 25,000$ was collected, and the operators could reapply for licenses to operate in Kansas in 36 months if they initiated adequate corrective measures. The case is currently in private litigation. The KCC found that no progress had been made towards bringing the leases into compliance and, therefore, reassessed the outstanding $\$ 55,000$ penalty. The KCC has since sought judical enforcenent of that penalty in the District Court, and a journal entry has been signed and was reviewed by the KCC and is now ready to be filed in District Court. Additionally. in a separate lawsuit between the landowners, the lessors, and the Temples regarding operation of the leases, the landowners were successful and the leases have reverted back to the landowners. The new operators are prevented from operat ing without KCC authority. (KS 01) 43

42 Comnents in the Docket by the Kansas Corporation Commission (Beatrice Stong) pertain to KS 01 . With regard to the abandoned wells, Kansas Corporation Comission states that these wells are "...cemented from top to bottom...", they have "... limited resource energy..." and the stat ic fluid level these reservoirs could sustain are "...well below the location of any drinking or usable water."

43 References for case cited: The Kansas Corporation Comission Court Order describing the evidence and charges against the Temple 0 il Co., 5/17/84. 
This case represents habitual violation of Kansas regulations.

On January 31, 1986, the Kansas Department of Health and the Environment (KDHE) inspected the Reitz lease in Mon:gomery County, operated by Marw in Harr of El Dorado. Arkansas. The lease included an unpermitted emergency pond containing water that had $56,500 \mathrm{ppm}$ chlorides. A large seeping area was observed by KDHE inspectors on the south side of the pond, allowing the flow of salt mater down the slope for about 30 feet. The company was not ified and was asied to apply for a permit and install a liner because the pond was constructed of sandy clay and sandstone. The operator was directed to immediately empty the pond and backf 111 it if a liner was not installed. On February 24, the lease was reinspected by KDHE and the emergency pond was still full and actively seeping. It appeared that the lease had been shut down by the operator. A "pond orcer" was issued by KDHE requiring the company to drain and backfill the pond. On April 29, the pond was still full and seeping.

Water samples taken from the pit by KDHE showed chloride concentrations of from 30,500 ppm $(4 / 29 / 86)$ to $56.500 \mathrm{ppm}(1 / 31 / 86)$. Seepage from the pit showed chloride concentrations of 17.500 ppm $(2 / 24 / 86)$. The Kansas Department of Health and the Environment stated that "...the use of the pond... has caused or is likely to cause pollution to the soil and the waters of the State." An administrative penalty of $\$ 500$ was assessed against the operator, and it was ordered that the pond be drained and backf, 11 led. $(K S O B)^{44}$

This activity is in violation of current Kansas regulations.

Such incidents are a recognized problem in Kansas. On May 13, 1987, the Kansas Corporation (KCC) added new lease maintenance rules to their oil and gas regulations. These new rules require permits for all pits, drilling and producing, and require emptying of emergency pits within 48 hours. Spills must now be reported in 24 hours. The question of concern is how stringently these rules can be enforced, in the light of the evident reluctance of some operators to comply. (See Table VII-7.)

44 References for case cited: Kansas Department of Health and Environment Order assessing civil penalty, in the matter of Marvin Harr, Case No, 86-E-77, 6/10/86. Pond Order issued by Kansas Department of Health and Environment, in the matter of Marvin Harr, Case No. 86-P0-008, $3 / 21 / 86$. 
Unlined Reserve Pits

Problems with unlined reserve pits are illustrated in the following cases.

Getween February 9 and 27, 1986, the Ell1ott $\# 1$ was drilled on the property of Mr. Lanrence Kcehling. The hutchinson Salt member, an underground formation, was penetrated during the drilling of Elliott $\# 1$. The drilling process dissolved between 100 and 200 cubic feet of salt. which was disposed of in the unlined reserve pit. The reserve pit lies 200 feet away from a well used by Mr. Koenling for his ranching operations. Within a few weeks of the drilling of the Elliott $: 1$. Mr. Koenling's nearby well began to pump water containing a saltwater drilling fluid.

Ground water on the koehling ranch has been contaminated with high levels of chlorides allegedly because of leaching of the reserve pit fluids into the ground water. Water samples taken from the Koehling livestock water well by the KCC Conservation Division showed a chloride concentration of $1650 \mathrm{mg} / \mathrm{L}$. Eackground concentrations of chlorides were in the range of 100 to $150 \mathrm{ppm}$. It is stated in a KCC report, dated November 1986, that further moveinent of the saltwater plume can be anticipated, thus polluting the Koehling donestic water well and the water well used by a farmstead over $1 \mathrm{mile}$ downstrean from the Koehling ranch. It is also stated in this $\mathrm{KCC}$ report that other wells drilled in the area using unlined reserve pits would nave similarly affected the grounawater.

The KCC now believes the source of ground-water contamination is not the reserve pit from the Elliott $\$ 1$. The $k C C$ has drilled two monitoring wells, one 10 feet from the edge of the reserve pit location and the other within 400 feet of the affected water well, between the affected well and the reserve pit. The monitoring well drilled 10 feet from the reserve pit site tested 60 ppm chlorides. (EPA notes that it is not known if this monitoring well was located upgradient from the reserve pit.) The monitoring well drilled between the affected well and the reserve pit tested $750 \mathrm{ppm}$ chlorides. (EPA notes that the level of chlorides in this monitoring well is more than twice the level of chlorides allowed under the EPA drinking water standards). The case is still open, pending further investigation. EPA believes that the evidence presented to date does not refute the earlier KCC report. which cited the reserve pit as the source of ground-water contamination, since the recent $\mathrm{KCC}$ report does not suggest an alternative source of contamination. (KS 05$)^{45}$

Unpermitted reserve pits are in violation of current Kansas regulations.

45 References for case cited: Sumnary Report, Koehling Water Well Pollution, 22-10-15W. KCC, Conservation Division. Jim Schoof, Chief Engineer, 11/86. 
$\mathrm{Mr}$. Leslie, a private lancowner in Kansas, suspected that chloride contamination of a natural spring occurred as a result of the presence of an abandoned reserve pit used when western Drilling Inc. arilled a well (Leslie $\$ 1$ ) at the Leslie Farm. Drilling in this area required penetration of the Hutchinson Salt member, during which 200 to 400 cubic feet of rock salt was dissolved and discharged into the reserve pit. The ground in the area consists of highly unconsolidated solis. which would allow for migration of pollutants into the ground water. Water at the top of the Leslie \#1 had a conductivity of 5,050 umnos. Conductivity of the spring water equaled 7.250 umhos. As noted by the KCC. "very saline water" was coming out of the springs. Conductivity of 2,000 umhos will damage soil, precluding growth of vegetation. No $f$ ines were levied in this case as there were no violations of State rules and regulations. The Leslies filed suit in civil court and won their case for a total of $\$ 11,000$ from the 011 and gas operator. ${ }^{46}$ (KS 03$)^{47}$

Current Kansas regulations call for a site-by-site evaluation to determine if liners for reserve pits are appropriate.

\section{Problems with Injection Wells}

Problems with injection wells can occur as a result of inadequate maintenance, as illustrated by the following case.

On July 12, 1981, the Kansas Department of Health and the Environment (KDHE) received a complaint from Albert Richneier. a landowner operating an irrigation well in the South Solomon River valley, His irrigation well had encountered salty water. An irrigation well belonging to an adjacent landowner. L. M. Paxson, had become salty in the fall of 1980. 011 has been produced in the area since 1952, and since 1962 secondary recovery by water flooding has been used. Upon investigation by the KDHE. it was discovered that the cause of the pollution was a saltwater injection well nearby, operated by Petro-Lewis. A casing profile caliper log was run by an operator-contractor under the direction of KDHE staff, which revealed numerous holes in the casing of the injection well. The producing formation, the Kansas City-Lansing, requires as much as 800 psi at the wellhead while injecting fluid to create a profitable enhanced 011 recovery project. To remediate the contamination, the alluvial aquifer was pumped, and the initial chloride concentration of $6,000 \mathrm{mg} / \mathrm{L}$ was lowered to 600 to $700 \mathrm{mg} / \mathrm{h}$ in a year's time. Chloride contamination in some areas was lowered from $10,000 \mathrm{mg} / \mathrm{L}$ to near background levels. However, a contamination problem continues in the Paxson we11, which shows chlorides in the range of $1,100 \mathrm{mg} / \mathrm{L}$ even though KDHE, through pumping, has tried to reduce the

46 API states that NDHE had authority over pits at this time. The KCC now requires permits for such pits.

47 Reference for case cited: Final Report. Gary Leslie Saltwater Pollution Problem, Kingman County, KCC Conservation Division, Jim Schoof. Chief Engineer, 9/86. Contains letters, memos, and analysis pertaining to the case. 
concentration. After attempts at repair. Petro-Lewis decided to plug the injection we $11^{48}(\mathrm{KS} 06)^{49}$

Operation of such a well would violate current Kansas and UIC regulations.

\section{TEXAS/OKLAHOMA}

The Texas/Oklahoma zone includes these two States, both of which are large producers of $0 i 1$ and gas. As of December 1986, Texas ranked as the number one producer in the U.S. among all oil-producing States. Because of scheduling constraints, research on this zone concentrated on Texas, and most of the damage cases collected come from that State.

\section{Operations}

0 il and gas operations in Texas and OKlahoma began in the 1860s and are among the most mature and extensively developed in the U.S. These two States include virtually all types of operations, from large-scale exploratory projects and enhanced recovery projects to marginal small-scale stripper operations. In fact, the Texas/0klahoma zone includes most of the country's stripper well production. Because of their maturity, many operations in the area generate significant quantities of associated produced water.

\footnotetext{
48 Comments in the Docket by the KCC (Bill Bryson) pertain to KS 06. KCC states that of the affected irrigation wells, one is "...back in service and the second is approaching near normal levels as it continues to be pumped." API states that Kansas received primacy for the UIC program in 1984 .
}

49 References for case cited: Richmeier Pollution Study, Kansas Department of Health and Environment. G. Blackburn and W. R. Bryson, 1983. 
Development of oil and gas reserves remains active. In 1985, some 9,176 new wells were completed in Oklahoma, 385 of which were exploration wells. In Texas in the same year, 25,721 wells were completed on shore, 3,973 of which were exploration wells. The average depth of wells in the two areas is comparable: Oklahoma, 4,752 feet; Texas, 4,877 feet.

Because the scale and character of operations varies so widely, cases of environmental damage from this zone are also varied and are not limited to any particular type of operation.

\section{Types of Operators}

Major operators are the principal players in exploration and development of deep frontiers and capital-intensive secondary and tertiary recovery projects. As elsewhere, the major companies have the best record of compliance with environmental requirements of all types; they are least likely to cut corners on operations, tend to use high-quality materials and methods when drilling, and are generally responsible in handling well abandonment obligations.

Smaller independent operators in the zone are more susceptible to fluctuating market conditions. They may lack sufficient capital to purchase first-quality materials and employ best available operating methods.

\section{Major Issues}

Discharge of Produced Water and Drilling Muds into Bays and Estuaries of the Texas Gulf Coast

Texas allows the discharge of produced water into tidally affected 


\section{estuaries and bays of the Gulf Coast from nearby onshore development. Cases in which permitted discharges have created damage include:}

In Texas, 011 and gas producers operating near the Gulf Coast are permitted to discharge produced water into surface streams if they are found to be tidally affected. Along with the produced water, residual production chemicals and organic constituents may be discharged. including lead, zinc, chromium, barium, and water-soluble polycyclic aromatic hydrocarbons (PAHs). PAHs are known to accumulate in sediment, producing liver and lip tumors in catfish and affecting mixed function oxidase systems of mammals, rendering a reduced immune response. In 1984, a study conducted by the U.S. Fish and Wildlife Service of sediment in Tabb's Bay, which receives discharged produced water as well as discharges from upstream industry (i.e.. discharges from ships in the Houston Ship Channel). indicates severe degradation of the environment by PAH contamination. Sediment was collected from within 100 yards of several tidal discharge points of 011 field produced water. Analytical results of these sediments indicated severe degradation of the environment by PAH contamination. The study noted that sediments contained no benthic fauna, and because of wave action, the contaminants were cont inuously resuspended, allowing chronic exposure of contaminants to the water column. It is concluded by the U.S. Fish and Wildife Service that shrimp, crabs, oysters, fish, and fish-eating birds in this location have the potential tc be heavily contaminated with PAHs. While these discharges have to be within Jexas Water Quality Standards, these standards are for conventional pollutants and do not consider the water soluble components of 011 that dre in produced water such as PAHS. ${ }^{50}(7 \times 55)^{51}$

50 NPDES permits have been applied for, but EPA has not issued permits for these discharges on the Gulf Coast. The Texas Rallroad Comission (TRC) issues permits for'these discharges. The TRC disagrees with the source of damage in this case.

51 References for case cited: Letter from U.S. Department of the Interior, Fish and Wildlife Service, signed by H. Dale Hall, to Railroad Comission of Texas, discussing degradation of Tabb's Bay because of discharge of produced water in upstream estuaries: includes lab analysis for polycyclic aromatic hydrocarbons in Tabb's Bay sediment samples. Texas Railroad Comission Proposal for Decision on Petronilla Creek case documenting that something other than produced water is killing aquatic organisms in the creek. (Roy Spears, Texas Parks and Wildlife, did LCSO study on sunfish and sheepshead minnows using produced water and Aranssas Bay water. Produced water diluted to proper salinity caused mortality of 50 percent. (Seawater contains 19,000 ppm chlorides.) 


\title{
These discharges are not in violation of existing regulations.
}

\begin{abstract}
Produced water discharges contain a high ratio of calcium ions to magnesium ions. This high ratio of calcium to magnesium has been found by Texas Parks and Wildilfe officials to be lethal to common At lantic croaker, even when total salinity levels are within tolerable limits. In a bioassay study conducted by Texas Parks and Wildlife, this fish was exposed to various ratios of calcium to magnesium, and it was found that in 96-hour LC50 studies, mortality was 50 percent when exposed to calcium-magnesium ratios of $6: 1$. the natural ratio being $1: 3$. Nearly all of 0 il field produced water discharges on f t le with the Army Corps of Engineers in Galveston contain ratios exceeding the $6: 1$ rat 10 , known to cause mortality in At lant ic croaker as established by the LC50 test. ${ }^{52}(\text { TX } 31)^{53}$
\end{abstract}

\section{These discharges are not in violation of current regulations.}

\author{
Until very recently, the Texas Railroad Commission (TRC) allowed \\ discharge of produced water into Petronilla Creek, parts of which are 20 \\ miles inland and not tidally affected.
}

For over 50 years, 011 operators (including Texaco and Amoco) have been allowed to discharge produced water into Petronilla Creek, a supposedly tidally influenced creek. Discharge areas were as much as $20 \mathrm{miles}$ inland and contained fresh water. In 1981, the pollution of Petronilla Creek from discharge of produced water became an issue when studies done by the Texas Parks and Wild life and Texas Department of Water Resources documented the severe degradation of the water and damage to native fish and vegetation. All freshwater species of fish and vegetation were dead because of exposure to toxic coristituents in discharge liquid. Portions of the creek were black or bright orange in color. Heavy 011 slicks and oily slime were observable along discharge areas.

Impacts were observed in Baffin Bay, into which the creek empties. Petronilla Creek is the on ly freshwater source for Baffin Bay. which is a nursery for many $f$ ish and shellfish in the Gulf of Mexico. Sediments in Baffin Bay show elevated levels of toxic constituents found in Petronilla Creek. For 5 years, the Texas Department of Water Resources and Texas Parks and Wildlife, a long with environmental groups., worked to have the discharges stopped. In 1981, a hearing was held by the Texas Rallroad Commission (TRC). The conclusion of the hearing was that discharge of the produced water plus disposal of other trash by the public was degrading Petronilla Creek. The TRC initiated a joint committee (Texas Department of Water Resources, Texas Parks and Wildife Department, and TRC) to establish the source of the trash, clean up

52 API comments in the Docket pertain to TX 31 . API states that models show that "...rapid mixing in Bay waters results in no pollution to Bay waters as a whole from calcium ions or from the ca lc ium-magnesium rat io."

53 References for case cited: Toxic Effects of Calcium on the At lantic Croaker: An Investigation of One Component of 0,1 Field Brine, by Kenneth N. Knudson and Charles E. Belaire, undated. 
trash from the creek, and conduct additional studies. After this work was completed, a second hearing was held in 1984. The creek was shown to contain high levels of chromium, barium, oil, grease, and EPA priority pollutants naphthalene and benzene. 0,11 operators stated that a no dumping order would put them out of business because 011 production in this area is marginal. In 1986. the TRC ordered a nalt to discharge of produced water into nontidal portions of Petronilla Creek. (TX 29) 54

Although discharges are now prohibited in this creek, they are allowed in other tidally affected areas.

Long-term environmental impacts associated with this type of discharge are unknown, because of limited documentation and analysis. Bioaccumulation of heavy metals in the food chain of estuaries could potentially affect human health through consumption of crabs, clams, and other foods harvested off the Texas Gulf Coast.

Alternatives to coastal discharge do exist. They include underground injection of produced water and use of produced water tanks. While the Texas Railroad Commission has not stopped the practice of coastal discharge, it is currently evaluating the need to preclude this type of discharge by collecting data from new applications, and it is seeking delegation of the NPDES program under the Federal Clean water Act. The TRC currently asks applicants for tidal discharge permits to analyze the produced water to be discharged for approximately 20 to 25 constituents.

54 References for case cited: The Effects of Brine Water Discharges on Petronilla Creek, Texas Parks and Wildlife Department, 1981. Texas Department of Water Resources interoffice memorandum documenting spills in Petronilla Creek from 1980 to 1983. The Inf luence of Oilfield Brine Water Discharges on Chemical and Biological Conditions in Petronilla Creek, by Frank Shipley. Texas Department of Water Resources, 1984. Letter from Dick Whittington, EPA, to Richard Lowerre, document ing absence of NPDES permits for discharge to Petronilla Creek. Final Order of TRC, banning discharge of produced water to Petronilla Creek, 6/23/86. Numerous letters, articles, legal documents, on Petronilla Creek case. 
Leaching of Reserve Pit Constituents into Ground Water

Leaching of reserve pit constituents into ground water and soil is a problem in the Texas/Oklahoma zone. Reserve pit liners are generally not required in Texas and $0 \mathrm{klahoma.} \mathrm{When} \mathrm{pits} \mathrm{are} \mathrm{constructed} \mathrm{in} \mathrm{permeable}$ soil without liners, a higher potential exists for migration of reserve pit constituents into ground water and soil. Although pollutant migration may not always occur during the active life of the reserve pit, problems can occur after closure when dewatered drilling mud begins to leach into the surrounding soil. Pollutants may include chlorides, sodium, barium, chromium, and arsenic.

On November 20, 1981, the Michigan-Wiscons in Pipe Line Company began drilling an oil and gas well on the property of Ralph and Judy Walker. Orilling was completed on March 27, 1982. Unlined reserve pits were used at the drill site. After 2 months of drilling, the water well used by the Halkers became polluted with elevated levels of chloride and barium ( 683 ppm and $1,750 \mathrm{ppb}$, respectively). The Walkers were forced to haul fresh water from Elk City for household use. The Walkers filed a complaint with the OK lahoma Corporation Commission (OCC), and an investigation was conducted. The Michigan-Wisconsin Pipe Line $C o$. was ordered to remove all drilling mud from the reserve pit.

In the end, the Walkers retained a private attorney and sued Michigan-Wiscons in for damages sustained because of migration of reserve pit fluids into the freshwater aquifer from which they drew their domestic water supply. The Halkers won their case and received an award of $\$ 50,000.55(0 K 08)^{56}$

Constructing a reserve pit over a fractured shale, as in this case, is a violation of OCC rules.

In 1973. Horizon 0,1 and Gas drilled an 017 well on the property of Dorothy Moore. As was the comnon practice, the reserve pit was dewatered, and the remaining mud was buried on site. In 1985-86, problems from the buried reserve pit waste began to appear. The reserve pit contents

55 API states that the OK lahoma Corporation Commission is in the process of developing regulations to prevent leaching of salt muds into ground water.

56 References for case cited: Pretrial Order, Ralph Gail Walker and Judy Walker vs. Michigan-Wiscons in Pipe Line Company and Big Chief Drilling Company, U.S. District Court, Western District of OKlahoma, \#CIV-82-1726-R. Direct Examination of Stephen G. MCL in, Ph. D. Direct Examination of Robert Hall. Direct Examination of Laurence Alatshuler. M. D. Lab results from Wa lker water well. 
were seeping into a nearby creek and pond. The surrounding soil had very high chloride content as established by Dr. Billy Tucker. an agronomist and soil scientist. Extensive erosion around the reserve pit became evident, a common problem with high-salinity soil. 0,1 slicks were visible in the adjacent creek and pond. An irrigation well on the property was tested by Dr. Tucker and was found to have 3000 ppm chlorides; however, no monitoring wells had been drilled to test the ground water prior to the drilling of the 011 well, and background levels of chlorides were not established. Dorothy Moore has filed civil suit against the operator for damages sustained during the 011 and gas drilling activity. The case is pending. 57 $\left(\begin{array}{ll}0 & 02\end{array}\right)^{58}$

Oklahoma performance standards prohibit leakage of reserve pits into ground water.

Chloride Contamination of Ground Water from Operation of Injection Wells

The Texas/0klahoma zone contains a large number of injection wells used both for disposal of produced water and for enhanced or tertiary recovery projects. This large number of injection wells increases the potential for injection well casing leaks and the possibility of ground water contamination.

The Devore $\$ 1$, a saltwater injection well located on the property of Verl and Virginia Hentges, was drilled in 1947 as an exploratory well. Shortly afterwards, it was permitted by the Ox lahoma Corporation Commission (OCC) as a saltwater injection well. The injection formation, the Layton, was known to be capable of accepting 80 barrels per hour at 150 psi. In 1984, George Kahn acquired the well and the OCC granted an exception to Rule 3-305, Operat ing Requirements for Enhanced Recovery Injection and Disposal Wells, and permitted the well to inject 2,000 barrels per day at 400 psi. Later in 1984. it appeared that there was saltwater migration from the intended injection zone of the Devore \#1 to the surface. 59 The Hentges alleged that the migrating salt water had polluted the ground water used on their ranch.

57 API comments in the Docket pertain to OK 02. API states that "...there is no evidence that there has been any seepage whatsoever into surface water." API states that there are no irrigation wells on Mrs. Moore's farm. Further, it states that erosion has been occurring for years and is the "...result of natural conditions coupled with the failure of Mrs. Moore to repair terraces to prevent or limit such erosion." API has not provided supporting documentation.

58 References for case cited: Extensive soil and water analysis results collected and interpreted by Dr. Billy Tucker, agronomist and soil scientist, Stillwater, Okla. Correspondence and conversation with Randall Wood, private attorney, Stack and Barnes, Ok lahoma City, Ok la.

59 Comnents by API in the Docket pertain to OK 06. API states that "...tests on the well pressure test and tracer logs indicate the injection well is not a source of salt water." API has not provided documentation with this statement. 
In addition, they alleged that the migrating salt water was finding its way to the surface and polluting Warren Creek, a freshwater stream used by downst ream residents for domest ic water. Salt water discharged to the surface had contaminated the soil and had caused vegetation $k i l l s$. A report by the $O C C$ concluded that "...the Devore $\# 1$ salt water disposal well operations are responsibie for the contaminant plume in the adjacent alluvium and streams." The OCC required that a workover be done on the we11. The workover was completed, and the operator cont inued to dispose of salt water in the well. The Hentges then sought private legal assistance and filed a lawsuit against George Kahn, the operator, for $\$ 300,000$ in actual damages and $\$ 3,000,000$ in punitive damages. The lawsuit is pending. scheduled for trial in October 1987.60 (OK 06$)^{61}$

Although at the time, the OCC permitted injection into the well at pressures that may have polluted the ground water, Oklahoma prohibits any contamination of drinking-water aquifers.

\section{Illegal Disposal of $0 i 1$ and Gas Wastes}

Illegal disposal of $0 i 1$ and gas exploration and production wastes is a common problem in the Texas/0klahoma zone. Illegal disposal can take many forms, including breaching of reserve pits, emptying of vacuum trucks into fields and ditches, and draining of produced water onto the land surface. Damage to surface soil, vegetation, and surface water may result as illustrated by the examples below.

On May 16, 1984, Esenjay Petroleum Co. had completed the L.W. Bing $\$ 1$ well at a depth of 9.900 feet and had hired T\&L Lease Service to clean up the drill site. During cleanup. the reserve pit, containing high-chromium drilling mud, was breached by T\&L Lease Service, allowing drilling mud to flow into a tributary of Hardy Sandy Creek. The drilling mud was up to 24 inches deep a long the north bank of Hardy Sandy. Drilling mud had been pushed into the trees and brush adjacent to the drill site. The spill was reported to the operator and the Texas Railroad Comission (TRC). The TRC ordered cleanup, which began on May 20.

60 APl states that the operator now believes old abandoned saltwater pits to be the source of contamination as the well now passes UIC tests.

61 References for case cited: Remedial Action Plan for Aquifer Restoration within Section 22. Township 21 North, Range 2 West. Noble County, Ok lahoma, by Stephen 6. McLin. Ph. D. Surface Pollution at the De Vore \#1 Saltwater Disposal Site, Ok lahoma Corporation Comission, 1986. District Court of Nobie County. Amended Petition, Verl E. Hentges and Virginia L. Hentges vs. George Kahn, \#C-84-110, 7/25/85. Lab analys is records of De Vore well from OK lahoma Corporation Comission and Southwell Labs. Communication with Alan DeVore. plaint iffs' attorney. 
Because of high levels of chromium contained in the drilling mud, warnings were issued by the Lavaca-Navidad River Authority to residents and lancowners downstream of the spill as it represented a possible health hazard to cattle watering from the affected streams. The River Authority also advised against eating the fish from the affected waters because of the high chromium levels in the drilling mud. $(T X 21)^{62}$

\section{This discharge was a violation of State and Federal regulations.}

On September 15, 1983. TXO Production Company began drilling its Dunn Lease We11 No. B2 in Live Oak County. On October 5, 1983, employees of TXO broke the reserve pit levee and began spreading drilling mud downhill from the site. towards the fence line of property owned by the Dunns. By October 9, the mud had entered the draw that flows into two stock tanks on the Dunn property. On November 24 and 25, dead fish were observed in the stock tank. On December 17 , Texas Parks and Wildife documented over $700 \mathrm{fish}$ killed in the stock tanks on the Dunn property. Despite repeated requests by the Dunns. TXO did not clean up the drilling mud and polluted water from the Dunn property.

Lab results from TRC and Texas Department of Health indicated that the spilled drilling mud was high in levels of arsenic, barium, chromium, lead, sulfates, other metals, and chlorides. In February 1984, the TRC stated that the stock tanks contained unacceptable levels of nitrogen, barium, chromium, and iron, and that the chemicals present were detrimental to both fish and livestock. (The Dunns water their cows at this same stock tank.) After further analysis, the TRC issued a memorandum stating that the fish had died because of a cold front moving through the area, in spite of the fact that the soll, sediment, and water in and around the stock pond contained harmful substances. Ult imately, TXO was $f$ ined $\$ 1,000$ by the TRC, and TXO paid the Dunns a cash settlement for damages sustained. ${ }^{63}(T \times 22)^{64}$

This activity was in violation of Texas regulations.

62 References for case cited: Memorandum from Lavaca-Navidad River Authority document ing events of Esenjay reserve pit discharge, 6/27/84, signed by J. Henry Neason. Letter to TRC from Lavaca-Navidad River Authority thanking the TRC for taking action on the Esenjay case, "Thanks to your enforcement actions, we are slowly educating the operators in this area on how to work within the law." Agreed Order, Texas Railroad Comission, \#2-83,043, 11/12/84, fining Esenjay $\$ 10,000$ for deliberate discharge of drilling muds. Letter from U.S. EPA to TRC inviting TRC to attend meeting with Esenjay Petroleum to discuss discharge of reserve pit into Hardy Sandy Creek, 6/1/84, signed by Thomas G. Giesberg. Texas Railroad Comission spill report on Esenjay operations, 5/18/84.

63 API states that the fish died from oxygen depletion of the water. The Texas Railroad Commission believes that the fish died from exposure to cold weather.

64 References for case cited: Texas Railroad Comission Mot ion to Expand Scope of Hearing, $\$ 2-82,919,6 / 29 / 84$. Texas Railroad Comission Agreed Order, $\$ 2-82,919,12 / 17 / 84$. Analysis by Texas Veterinary Medical Diagnostic Laboratory System on dead fish in Dunn stock tank. Water and soil sample analysis from the Texas Railroad Comission. Water and soil samples from the Texas Department of Health. Letter from Wendell Taylor. TRC, to Jerry Mullican, TRC, stat ing that the fish $k 111$ was the result of cold weather. $7 / 13 / 84$. Miscellaneous letters and memos. 


\section{NORTHERN MOUNTAIN}

The Northern zone includes Idaho, Montana, and Wyoming. Idaho has no commercial production of oil or gas. Montana has moderate oil and gas production. Wyoming has substantial oil and gas production and accounts for all the damage cases discussed in this section.

\section{Operations}

Significant volumes of both oil and gas are produced in Wyoming. Activities range from small, marginal operations to major capital- and energy-intensive projects. $0 i 1$ production comes both from mature fields producing high volumes of produced water and from newly discovered fields, where $0 i 1 /$ water ratios are still relatively low. Gas production comes from mature fields as well as from very large new discoveries.

Although the average new well drilled in Wyoming in 1985 was about 7,150 feet, exploration in the State can be into strata as deep as 25,000 feet. In 1985, 1,332 new wells were completed in Wyoming, of which 541 were exploratory.

\section{Types of Operators}

Because of the capital-intensive nature of secondary and tertiary recovery projects and large-scale drilling projects, many operations in the State are conducted by the major oil companies. These companies are likely to implement environmental controls properly during drilling and completion and are generally responsible in carrying out their well abandonment obligations. Independents also operate in Wyoming, producing 
a significant amount of $0 i 1$ and gas in the State. Independent operators may be more vulnerable to fluctuating market conditions and may be more likely to maintain profitability at the expense of environmental protection.

Major Issues

Illegal Disposal of 0 il and Gas Wastes

Wyoming Department of Environmental Quality officials believe that illegal disposal of wastes is the most pervasive environmental problem associated with oil and gas operations in Wyoming. Enforcement of State regulations is made difficult as resources are scarce and areas to be patrolled are large and remote. (See Table VII-7.)

Altex 0,1 Company and its predecessors have operated an 011 production field for several decades south of Rozet, Wyoming. (Altex purchased the property in 1984.) An access road runs through the area, which, according to Wyoming Department of -Environmental Quality (WDEQ). for years was used as a orainage for produced water from the oil field operations.

In August of 1985, an official with WDEQ collected soil samples from the road ditch to ascertain chloride levels because it had been observed that trees and vegetation along the road were dead or dying. WDEQ analysis of the samples showed chloride levels as high as $130,000 \mathrm{ppm}$. The road was chained off in October of 1985 to preclude any further illegal disposal of produced water. 65 (WY 03) 66

In early Octoher 1985. Cities Service 011 Company had completed drilling at a site northeast of Cheyenne on Highway 85. The drilling contractor, 28S 0,1 Construction Company. was suspected of illegally disposing of drilling fluids at a site over a mile away on the Pole Creek Ranch. An employee of $28 S$ had given an anonymous tip to a County detective. A stake-out of the

65 Comments in the Docket from the Wyoming 011 and Gas Conservation Comission (WOGCC) (Mr. Don Basko) pertain to WY 03 . WOGCC states that "...not all water from Altex 0 il producing wells... caused the contamination problem." Further, wOGCC states that "Illegal dumping, as well as a flow line break the previous winter. had caused a high level of chloride in the soil which probably contributed to the sagebrush and cottonwood trees dying."

66 References for case cited: Analysis of site by the Wyoming Department of Environmental Quality (WDEQ). Quality Division Laboratory, File $\$ 2352179,12 / 6 / 85$. Photographs of dead and dying cottonwood trees and sagebrush in and around site. Conversation with WDEQ off icials. 
illegal cperation was made with law enforcement and WDEQ personnel. Stake-out personnel took samples and photos of the reserve pit and the dump site. During the stake-out, vacuum trucks were witnessed draining reserve pit contents down a slope and into a small pond on the Pole Creek Ranch, After sufficient evidence had been gathered, arrests were made by Wyoming law enforcement personnel, and the trucks were impounded. The State sued Z\&S and won a total of $\$ 10.000$. (WY 01$)^{67}$

This activity was in violation of Wyoming regulations.

During the week of April 8. 1985, field personnel at the Byron/Garland field operated by Marathon 0,1 Company were cleaning up a storage yard used to store drums of $011 \mathrm{fie}$ ld chemicals. Drums containing discarded production chemicals were punctured by the field employees and allowed to drain into a ditch adjacent to the yard. Approximately 200 drums containing 420 gallons of fluid were drained into the trench. The chemicals were demulsifiers. reverse demulsifiers, scale and corrosion inhibitors, and surfactants. Broken transformers containing PCBs were leaking into soil in a nearby area. Upon discovery of the condition of the yard, Wyoming Department of Environmental Quality (WDEQ) ordered Marathon to begin cleanup procedures. At the request of the WDEQ. ground-water monitors were installed, and monitoring of nearby Arnoldus Lake was begun. The State filed a civil sult against Marathon and won a $\$ 5000$ fine and $\$ 3006$ in expenses for lab work. 60 (WY 05) 69

This activity was in direct violation of Wyoming regulations.

\section{Reclamation Problems}

Although Wyoming's mining industry has rules governing reclamation of sites, no such rules exist covering oil and gas operations. As a result, reclamation on privately owned land is often inadequate or entirely lacking, according to WDEQ officials. By contrast, reclamation on Federal lands is believed to be consistently more thorough, since Federal

67 References for case cited: WDEQ memorandum document ing chronology of events leading to arrest of 285 employees and owners. Lab analys is of reserve pit mud and effluent, and mud and effluent found at dump site. Consent decree from District Court of First Judicial District, Laramie County. Wyoming. docket $\$ 108-493$. The People of the State of Wyoming vs. Z8S Construction Company. Photographs of vacuum trucks dumping at Pole Creek Ranch.

API states that the operator, thinking the drums had to be empty before transport offsite. turned the drums upside down and drained 420 gallons of chemicals into the trench.

References for case cited: Sumnary of Byron-Garland case by Marathon employee J. C. Fowier. List of drums, contents, and field uses. Cross-section of disposal trench area. Several sets of lab analyses. Map of Garland field disposal yard. Newspaper articles on incident. District court consent decree. The People of the State of Wyoming vs. Marathon 011 Company. \#108-87. 
leases specify reclamation procedures to be used on specific sites. WDEQ officials state that this will be of growing concern as the State continues to be opened up to 0 il and gas development. ${ }^{70}$

WDEQ officials have photographs and letters from concerned landowners, regarding reclamation problems, but no developed cases. The Wyoming $0 i 1$ and Gas Conservation Commission submitted photographs documenting comparable reclamation on both Federal and private lands. The issue is at least partially related to drilling waste management, since improper reclamation of sites often involves inadequate dewatering of reserve pits before closure. As a result of this inadequate dewatering, reserve pit constituents, usually chlorides, are alleged to migrate up and out of the pit, making revegetation difficult. The potential also exists for migration of reserve pit constituents into ground water.

\section{Discharge of Produced Water into Surface Streams}

Because much of the produced water in Wyoming is relatively low in chlorides, several operations under the beneficial use provision of the Federal NPDES permit program are allowed to discharge produced water directly into dry stream beds or live streams. The practice of chronic discharge of low-level pollutants may be harmful to aquatic communities in these streams, since residual hydrocarbons contained in produced water appear to suppress species diversity in live streams.

A study was undertaken by the Columbia National Fisheries Research Laboratory of the U. S. Fish and Wildife Service to determine the effect of continuous discharge of low-level oil effluent into a stream and the resulting effect on the aquatic comunity in the stream. The discharges to the stream contained $5.6 \mathrm{mg} / \mathrm{L}$ total hydrocarbons. Total hydrocarbons in the receiving sediment were $979 \mathrm{mg} / \mathrm{L}$ to $2,515 \mathrm{mg} / \mathrm{L}$. During the study, samples were taken upstream 
and downstream from the discharge. Species diversity and comunity structure were studied. Water analysis was done on upstream and downstream samples. The study found a decrease in species diversity of the macrobenthos community (fish) cownstream from the discharge. further characterized by total elimination of some species and drastic alteration of community

structure. The study found that the downstream comunity was characterized by only one dominant species, while the upstream community was dominated by three species. Total hydrocarbon concentrations in water and sediment increased 40 to 55 fold downstream from the discharge of produced water. The authors of the study stated that "...based on our findings, the fisheries and aquatic resources would be protected if discharge of 011 into fresh water were regulated to prevent concentrations in receiving streams water and sediment that would alter structure of macroberithos communities." (WY 07$)^{71}$

These discharges are permitted under NPDES.

\section{SOUTHERN MOUNTAIN}

The Southern Mountain zone includes the States of Nevada, Utah, Arizona, Colorado, and New Mexico. All five States have some oil and gas production, but New Mexico's is the most significant. The discussion below is limited to New Mexico.

\section{Operations}

Although hydrocarbon production is scattered throughout New Mexico, most comes from two distinct areas within the State: the Permian Basin in the southeast corner and the San Juan Basin in the northwest corner.

Permian Basin production is primarily oil, and it is derived from several major fields. Numerous large capital-and energy-intensive enhanced recovery projects within the basin make extensive use of $\mathrm{CO}_{2}$ flooding. The area also contains some small fields in which production

\footnotetext{
71 References for case cited: Petroleum Hydrocarbon Concentrations in a Salmonid Stream Contaminated by Oil Field Discharge Water and Effects on the Macrobenthos Comnunity, by D.F. Hoodward and R.G. Riley, U.S. Department of the Interior, Fish and Wildlife Service. Columbia National Fisheries Research Laboratory. Jackson. Wyoming. 1980; submitted to Transactions of the American Fisheries Society.
} 
is derived from marginal stripper operations. This is a mature production area that is unlikely to see extensive exploration in the future. The Tucumcari Basin to the north of the Permian may, however, experience extensive future exploration if economic conditions are favorable.

The San Juan Basin is, for the most part, a large, mature field that produces primarily gas. Significant gas finds are still made, including many on Indian Reservation lands. As Indian lands are gradually opened to oil and gas development, exploration and development of the basin as a whole will continue and possibly increase.

Much of the State has yet to be explored for oil and gas. The average depth of new wells drilled in 1985 was 6,026 feet. The number of new wells drilled in 1985 was 1,734, of which 281 were exploratory.

\section{Types of Operators}

The capital- and energy-intensive enhanced recovery projects in the Permian Basin, as well as the exploratory activities under way around the State, are conducted by the major oil companies. Overall, however, the most numerous operators are small and medium-sized independents. Small independents dominate marginal stripper production in the Permian Basin. Production in the San Juan Basin is dominated by midsize independent operators.

\section{Major Issues}

Produced Water Pit and 0il Field Waste Pit Contents Leaching into Ground Water

New Mexico, unlike most other States, still permits the use of unlined pits for disposal of produced water. This practice has the potential for contamination of ground water. 
In July 1985, a study was undertaken in the Duncan Oil field in the San Juan Basin by faculty members in the Department of Chemistry at New Mexico State University, to analyze the potent ial for unlined produced water pit contents. Including hydrocarbons and aromatic hydrocarbons, to migrate into the ground water. The oil field is situated in a flood plain of the San Juan River. The site chosen for investigation by the study group was similar to at least 1,500 other nearby production sites in the flood plain. The study group aug test pits around the disposal pit on the chosen site. These test pits were placed abovegradient and downgradient of the disposal pit, at 25 - and 50 -meter intervals. A total of 9 test pits were dug to a depth of 2 meters, and soil and ground-water samples were obtained from each test pit. Upon analysis, the study group found volatile aromatic hydrocarbons were present in both the soil and water samples of test pits downgradient, demonstrating migration of unlined produced water pit contents into the ground water.

Environmental impact was summarized by the study group as contamination of shallow ground water with produced water pit contents due to leaching from an unlined produced water disposal pit. Benzene was found in concentrations of $0.10 \mathrm{ppb}$. New Mexico Water Quality Control Commission standard is $10 \mathrm{ppb}$. Concentrations of ethylbenzene, xylenes, and larger hydrocarbon molecules were found. No contamination was found in test pits placed abovegradient from the disposal pit. Physical signs of contamination were also present, downgradient from the disposal pit. including black, Oily staining of sands above the water table and black, oily film on the water itself. Hydrocarbon odor was also present. (NM 02) 72

It is now illegal to dispose of more than five barrels per day of produced water into unlined pits in this part of New Mexico.

As a result of this study, the use of unlined produced water pits was limited by the State to wells producing no more than five barrels per day of produced water. While this is a more stringent requirement than the previous rule, the potential for contamination of ground water with hydrocarbons and chlorides still exists. It is estimated by individuals familiar with the industry in the State that 20,000 unlined emergency

72 References for case cited: Hydrocarbons and Aromatic Hydrocarbons in Groundwater Surrounding an Earthen Waste Disposal Pit for Produced Water in the Duncan Oil Field of New Mexico, by G.A. Eiceman, J.T. McConnon, Masud Zaman, Chris Shuey, and Douglas Earp. 9/16/85. Polycyclic Aromat ic Hydrocarbons in Soil at Groundwater Level Near an Earthen Pit for Produced Water in the Duncan Oil Field, by B. Davani, K. Lindley, and G.A. Eiceman, 1986. New Mexico 0il Conservation Commission hearing to define vulnerable aquifers, coments on the hearing record by Intervenor Chris Shuey, Case No. 8224 . 


\title{
produced water disposal pits are still in existence in the San Juan Basin area of New Mexico. ${ }^{73}$
}

New Mexico has experienced problems that may be due to centralized oil field waste disposal facilities:

\begin{abstract}
Lee Acres "modified" landfill (meaning refuse is covered weekly instead of daily as is done in a "sanitary" lanafi11) is located $4.5 \mathrm{~m}$ les E-SE of Farmington. New Mexico. It is owned by the U.S. Bureau of Land Management (BLM). The landf 111 is approximately 60 acres in size and includes four unlined liquid-waste lagoons or pits, three of which were actively used. Since 1981. a variety of liquid wastes associated with the oil and gas industry have been disposed of in the lagoons. The predominant portion of liquid wastes disposed of in the lagoons was produced water, which is known to contain aromatic volatile organic compounds (VoCs). According to the New Mexico Department of Health and Environment, Environmental Improvement Division, 75 to 90 percent of the produced water disposed of in the lagoons originated from Federal and Indian 011 and gas leases managed by BLM. Water produced on these leases was hauled from as far away as Nageez 1, which is $40 \mathrm{~m}$ les from the Lee Acres site. Disposal of produced water in these unlined pits was, according to New Mexico State officials, in direct violation of BLM's rule NTL-2B. which prohibits, without prior approval, disposal of produced waters into unlined pits. originating on Federally owned leases. The Department of the Interior states that disposal in the lagoons was "...specifically authorized by the State of New Mexico for disposal of produced water." The State of New Mexico states that "There is no truth whatsoever to the assertion that the landfill lagoons were specifically authorized by the State of New Mexico for disposal of produced water." Use of the pits ceased on $4 / 19 / 85 ; 8,800$ cubic yards of waste were disposed of prior to closure.
\end{abstract}

New Mexico's Environmental Improvement Division (NMEID) asserts that leachate from the unlined waste lagoons that contain 011 and gas wastes has contributed to the contamination of several water wells in the Lee Acres housing subdivision located downgradient from the lagoons and downgradient from a refinery operated by Giant, located nearby. NME1D has on file a soil gas survey that documents extensive contamination with chlorinated VOCs at the landfill site. High levels of sodium, chlorides, lead, chromium, benzene, toluene, xylenes, chloroethane, and trichloroethylene were found in the waste lagoons. An electromagnetic terrain survey of the Lee Acres landf 111 site and surrounding area, conducted by NMEID. located a plume of contaminated ground water extending from the landfill. This plume runs into a plume of contamination known to exist, emanating from the refinery. The plumes have become mixed and are the source of

73 Governor Carruthers refutes this and states that "Unlined pits in fresh water areas in Southeast New Mexico were banned beginning in 1950, with a general prohibition adopted in 1967." EPA notes that New Mexico still permits unlined pits to be used for disposal of produced water if the pit does not receive more than five barrels of produced water per day. 
contamination of the ground water serving the Lee Acres housing subdivision. ${ }^{74}$ One domestic well was sampled extensively by NME1D and was found to contain extremely high levels of chlorides and elevated levels of chlorinated vocs, including trichloroethane. (Department of the Interior (DO1) states that it is unaware of any violations of New Mexico ground-water standards involved in this case. New Mexico states that State ground-water standards for chloride, total dissolved solids, benzene, xylenes, 1,1-dichloroethane, and ethylene dichloride have been violated as a result of the plume of contamination. In addition, the EPA Safe Drinking Wa:er Standard for trichloroethylene has been violated.) New Mexico State officials state that "The landf 111 appears to be the principal source of chloride, total dissolved solids and most chlorinated Vocs, while the refinery appears to be the principal source of aromatic VOCs and ethylene dichloride."

During the period after disposal operations ceased and before the site was closed, access to the lagoons was essentially unrestricted. While NMEID believes that it is possible that non-oil and gas wastes illegally disposed of during this period may have contributed to the documented contamination. the primary source of ground-water contamination appears to be from $0: 1$ and gas wastes.

The State has ordered BLM to provide public water to residents affected by the contamination, develop a ground-nater monitoring system, and investigate the types of drilling. drilling procedures, and well construction methods that generated the waste accepted by the landf 111 . BLM submitted a motion-to-stay the order so as to include Giant Refining Company and El Paso Natural Gas in cleanup operations. The motion was denied. The case went into litigation. According to State officials. "The State of New Mexico agreed to dismiss its lawsuit only after the Bureau of Land Management agreed to conduct a somewhat detalled hydrogeologic investigation in a reasonably expeditious period of time. The lawsuit was not dismissed because of lack of evidence of contamination emanat ing from the landf $111 . "$ The refinery company has completed an

74

In a letter dated $8 / 20 / 87$. Giant Refining Company states that "Benzene, toluene and xylenes are naturally occurring compounds in crude 011 , and are consequently in high concentrations in the produced water associated with that crude 011 . The only gasoline additive used by Giant that has been found in the water of a residential well is DCA (ethylene dichloride) which has also been found in the landf 111 plume." Giant also notes that the refinery leaks in the last 2 years resulted in less than 30,000 gallons of diesel being released rather than the 100,000 gallons stated by the Department of Interior in a letter to EPA of $8 / 11 / 87$. 
extensive hydrogeologic investigation and has implemented containment and cleanup measures. ${ }^{75}$ (NM 05) 76

\section{Current New Mexico regulations prohibit use of unlined commercial disposal pits.}

\section{Damage to Ground Water from Inadequately Maintained Injection Wells}

\section{As in other States, New Mexico has experienced problems with} injection wells.

A saltwater injection we11. the B0-3, operated by Texaco, is used for produced water disposal for the Moore-Devonian 0il field in southeastern New Mexico. Injection occurs at about 10,000 $\mathrm{ft}$. The Ogallala aquifer, overlying the oil production formation, is the sole source of potable ground water in much of southeastern New Mexico. Dr. Daniel B. Stephens, Associate Professor of Hydrology at the New Mexico Institute of Mining and Technology, concluded that injection well BO- 3 has contributed to a saltwater plume of contamination in the Ogallala aquifer. The plume is nearly $1 \mathrm{mile}$ long and contains chloride concentrations of up to $26,000 \mathrm{ppm}$.

A local rancher sustained damage to crops after irrigating with water contaminated by this saltwater plume. In 1973, an irrigation well was completed satisfactorily on the ranch of Mr. Paul Hamilion, and, in 1977, the well began producing water with chlorides of 1,200 ppm. Mr. Hamilton's crops were severely damaged, resulting in heavy economic losses, and his farm property was foreclosed on. There is no evidence of crop damage from irrigation prior to 1977. Mr. Hamilton initiated a private law suit against Texaco for damages sustained to his ranch. Texaco argued that the saltwater plume was the result of leachate of brines from unlined brine disposal pits, now banned in the area. Dr. Stephens proved that if old pits in the vicinity.

75 Comments in the Docket from BLM and the State of New Mexico pertain to NM 05. BLM states that the refinery upgradient from the subdivision is responsible for the contamination because of their "...extremely sloppy housekeeping practices..." which resulted in the loss of "...hundreds of thousands of gallons of refined product through leaks in their underground piping system." The Department of the Interior states that "There is, in fact. mounting evidence that the landfill and lagoons may have contributed little to the residential well contamination in the subdivisions." DOI states "...we strongly recommend that this case be deleted from the Damage Cases [Report to Congress]." "New Mexico states that "EID [Environmental Improvement Division] strongly believes that the Lee Acres Landfill has caused serious ground water contamination and is well worth inclusion in the 0,1 and Gas Damage Cases chapter of your [EPA] Report to Congress on 0 il, Gas and Geotherma 1 Wastes."

76 References for case cited: State of New Mexico Administrative Order No. 1005; contains water analysis for open pits, monitor wells, and impacted domestic wells. Motion-to-stay Order No. 1005. Denial of motion to stay. Newspaper articles. Southwest Research and Information Center, Response to Hearing before Water Quality Control Comission, 12/2/86. Letter to Dan Derkics. EPA. from Department of the Interior, refuting Lee Acres damage case, $8 / 11 / 87$. Letter to Dan Derkics, EPA, from NME1D, refuting Department of the Interior letter of $8 / 11 / 87$, dated $8 / 18 / 87$. Letter to Dan Derkics, EPA, from Giant Ref ining Company, $8 / 20 / 87$. 
previously used for saltwater disposal, had caused the contamination, high chloride levels would have been detected in the irrigation well prior to 1977 . Dr. Stephens also demonstrated that the BO-3 injection well had leaked some $20 \mathrm{~m}$ lllion gallons of brine into the fresh ground water. causing chloride contamination of the Ogallala aquifer from which Mr. Hamilton drew his irrigation water. Based on this evidence a jury awarded Mr. Hamilton a cash sett lement from Texaco for damages sustained botn by the leaking injection well and by the abandoned disposal pits. The well has had workovers and additional pressure tests since 1978 . The well is st 111 in operation. in compliance with UIC regulations. (NM 01$)^{77}$

Current UIC regulations require mechanical integrity testing every 5 years for all Class II wells.

The well in the above case was tested for mechanical integrity several times during the course of the trial, during which the plaintiff's hydrologist, after contacting the Texas Railroad Commission, discovered that this injection well would have been classed as a failed well using criteria established by the State of Texas for such tests. However, at the time, the well did not fail the test using criteria established by the State of New Mexico. Both States have primacy under the UIC program.

\section{WEST COAST}

The West Coast zone includes Washington, Oregon, and California. Of the three states, California has the most significant hydrocarbon production; Washington and Oregon have only minor oil and gas activity. Damage cases were collected only in California.

\section{Operations}

California has a diverse $0 i 1$ and gas industry, ranging from stripper production in very mature fields to deep exploration and large enhanced recovery operations. Southern California and the San Joaquin Valley are dominated by large capital- and energy-intensive enhanced recovery

\footnotetext{
77 References for case cited: Oil-Field Brine Contamination - A Case Study, Lea Co. New Mexico, from Selected Papers on Water Quality and Pollution in New Mexico - 1984; proceedings of a symposium. New Mexico Bureau of Mines and Resources.
} 
projects, while the coastal fields are experiencing active exploration. California's most mature production areas are in the lower San Joaquin Valley and the Sacramento Basin. The San Joaquin produces both oil and gas. The Sacramento Valley produces mostly gas.

The average depth of new wells drilled in California in 1985 was 4,176 feet. Some 3,413 new wells were completed in 1985, 166 of which were exploratory.

\section{Types of Operators}

Operators in California range from small independents to major producers. The majors dominate capital-and energy-intensive projects, such as coastal development and large enhanced recôvery projects. Independents tend to operate in the mature production areas dominated by stripper production.

Major Issues

Discharge of Produced Water and 0ily Wastes to Ephemeral Streams

In the San Joaquin Valley, the State has long allowed discharge of oily high-chloride produced water to ephemeral streams. After discharge to ephemeral streams, the produced water is diverted into central sumps for disposal through evaporation and percolation. Infiltration of produced water into aquifers is assumed to occur, but official opinion on its potential for damage is divided. Some officials take the position that the aquifers are naturally brackish and thus have no beneficial use for agriculture or human consumption. A report by the Water Resources Control Board, however, suggests that produced water may percolate into useable ground-water structures. 
For the purposes of this study conducted by Bean/Logan Consulting Geologists, ground water in the study area was categorized according to geotype and compared to produced water in sumps that came from production zones. Research was conducted on sumps in Cymric Valley. Mckittrick Valley, Midnay Valley. Elk Hills, Buena Vista Hills, and Buena Vista Valley production fields. While this recent research was not investigating ground-water dainages per se, the study suggests obvious potentid for damages relating to the ground water. The hydrogeologic analysis prepared for the California State Water Resources Control Board concludes that about 570,000 tons of salt from produced water were deposited in 1981 and that a total of $14.8 \mathrm{~m} 111$ ion tons have been deposited since 1900. The California Water Resources Bcard suspects that a portion of the salt has percolated into the ground water and has degraded it. In addition to suspected degradation of ground water. officers of the California Department of Fish and Game often find birds and anima is entrapped in the olly deposits in the affected ephemeral streams. Exposure to the oily deposits often proves to be fatal to these birds and animals. ${ }^{78}$ (CA 21) $)^{79}$

This is a permitted practice under current California regulations.

Aside from concerns over chronic degradation of ground water, this practice of discharge to ephemeral streams can cause damage to wildlife. The volume of wastes mixed with natural runoff sometimes exceeds the holding capacity of the ephemeral streams. The combined volume may then overflow the diversions to the sump areas and continue downstream, contaminating soil and endangering sensitive wildlife habitat. The oil and gas industry contends that it is rare for any wastes to pass the diversions set up to channel flow to the sumps, but the California Department of Fish and Game believes that it is a common occurrence.

Produced water from the Crocker Canyon area flows downstream to where it is diverted into Valley Waste Disposal's large unlined evaporation/percolation sumps for oil recovery (cooperatively operated by local 011 producers). In one instance, discovery by California $F$ ish and Game officials of a significant spill was made over a month after it occurred. According to the California State Water Quality Board, the incident was probably caused by heavy rainfall, as a consequence of which the volume of rain and waste exceeded the containment capacity of the disposal facility. The sumps became eroded, allowing oily waste to flow down the valley and into a wildiffe habitat occupied by several endangered species including blunt-nosed leopard lizards. San Joaquin kit foxes, and giant kangaroo rats.

\footnotetext{
78 API states that the California Regional Water Quality Board and EPA are present ly deciding whether to promulgate additional permit requirements under the Clean water Act and NPDES.

79 References for case cited: Lower Westside Water Quality Invest igation Kern County, and Lower Westside Water Quality Investigation Kern County: Supplementary Report, Bean/Logan Consult ing Geologists, 11/85; prepared for California State Hater Resources Control Board. Westside Groundhater Study. Michael R. Rector, Inc., 11/83; prepared for Hestern 0,1 and Gas Association.
} 
According to the State's report, there were 116 known wildlife losses including 11 giant kangaroo rats. The count of dead anima is was est imated at only 20 percent of the actual number of animals oestroyed because of the delay in finding the spill, allowing poisoned animals to leave the area before dying. Vegetation was covered with waste throughout the spill area. The California Department of Fish and Game does not believe this to be an isolated incident. The California Water Resources Control Board. during its investigation of the incident, noted "... deposits of older accumulated 011 , thereby indicating that the sane channel had been used for wastewater disposal conveyance in the past prior to the recent discharge. Cleanup activities conducted later revealed that bulldup of older oil was significant." The companies implicated in this incident were fined $\$ 100,000$ and were required to clean up the area. The companies denied responsibility for the discharge. (CA OB) ${ }^{80}$

This release was in violation of California regulations.

\section{ALASKA}

The Alaska zone includes Alaska and Hawail. Hawaii has no oil or gas production. Alaska is second only to Texas in oil production.

\section{Operations}

Alaska's oil operations are divided into two entirely separate areas, the Kenai Peninsula (including the western shore of Cook Inlet) and the North Slope. Because of the areas' remoteness and harsh climate, operations in both areas are highly capital-and energy-intensive. For the purposes of damage case development, and indeed for most other types of analysis, operations in these two areas are distinct. Types of damages identified in the two areas have little in common.

80

References for case cited: Report of $011 \mathrm{Sp} i 11$ in Buena Vista Valley, by Mike Glinzak, California Division of 0,1 and Gas (DOG), 3/6/86; map of site and photos accompany the report. Letters to Sun Exploration and Product ion Co. from DOG, $3 / 12$ and $3 / 31 / 86$. Newspaper artic les in Bakersfield Californian, 3/8/86, 3/11/86, and undated. California Water Quality Control Board, Administrative Civil Liability Complaint $\$ A C L-016,8 / 8 / 86$. California Water Quality Control Board. internal memoranda. Smith to Pfister concerning cleanup of site, 5/27/86; Smith to Nevins concerning description of damage and investigation, including map, 8/12/86. California Department of Fish and Game, Dead Endangered Species in a California Oil Spill, by Capt. E.A Simons and Lt. M. Ak in, undated. Fact Sheets: Buena Vista Creek 0il Spill, Kern County, 3/7/86, and Mamma Is Occurring on Elk Hills and Buena Vista Hills, undated. Letter from Lt. Ak in to EPA contractor, $2 / 24 / 87$. 
Activities on the Kenai Peninsula have been in progress since the late 1950s, and gas is the primary product. Production levels are modest as compared to those on the North Slope.

North Slope operations occur primarily in the Prudhoe Bay area, with some smaller fields located nearby. $0 i l$ is the primary product. Production has been under way since the trans-Alaska pipeline was completed in the mid 1970s. Much of the oil recovery in this area is now in the secondary phase, and enhanced recovery through water flooding is on the increase.

There were 100 wells drilled in the State in 1985, all of them on the North Slope. In 1985, one exploratory well was drilled in the National Petroleum Reserve - Alaska (NPRA) and two development wells were drilled on the Kenai Peninsula.

\section{Types of Operators}

There are no small, independent oil or gas operators in Alaska because of the high capital requirements for all activities in the region. Operators in the Kenai Peninsula include Union $0 i l$ of California and other major companies. Major producers on the North Slope are ARCO and Standard Alaska Production Company.

\section{Major Issues}

\section{Reserve Pits, North Slope}

Reserve pits on the North Slope are usually unlined and made of permeable native sands and gravels. Very large amounts of water flow in this area during breakup each spring in the phenomenon known as "sheet flow." Some of this water may unavoidably flow into and out of the reserve pits; however, the pits are designed to keep wastes in and keep 
surface waters out. Discharge of excess liquids from the pits directly onto the tundra is permitted under regulations of the Alaska Department of Environmental Conservation (ADEC) if discharge standards are met. (See summary on State rules and regulations.)

Through the processes of breakup and discharge, ADEC estimates that 100 million gallons of supernatant are pumped onto the tundra and roadways each year, ${ }^{81}$ potentially carrying with it reserve pit constituents such as chromium, barium, chlorides, and oil. Scientists who have studied the area believe this has the potential to lead to bioaccumulation of heavy metals and other contaminants in local wildlife, thus affecting the food chain. However, no published studies that demonstrate this possibility exist. Results from preliminary studies suggest that the possibility exists for adverse impact to Arctic wildlife because of discharge of reserve pit supernatant to the tundra:

In 1983, a study of the effects of reserve pit discharges on water quality and the macroinvertebrate comnunity of tundra ponds was undertaken by the U. S. Fish and Wildiife Service in the Prudhoe Bay 011 production area of the North Slope. Discharge to the tundra ponds is a common disposal method for reserve pit fluid in this area. The study shows a clear difference in water quality and biological measures among reserve pits. ponds receiving discharges from reserve pits (receiving ponds), distant ponds affected by discharges through surface water fiow, and control ponds not affected by discharges. Ponds directly receiving discharges had significantly greater concentrations of chromium. arsenic, cadnium, nickel, and barium than did control ponds, and distant ponds showed significant ly higher levels of chromium than did control ponds. Chromium levels in reserve pits and in ponds adjacent to drill sites may have exceeded EPA chronic toxicity criteria for protection of aquatic life. (AK O6) 82

These discharges were permitted by the State of Alaska. No NPDES permits have been issued for these discharges. New Alaska regulations have more stringent effluent limits.

81 Statement by Larry Dietrick to Carla Greathouse.

82 References for case cited: The Effects of Prudhoe Bay Reserve Pit Fluids on the Water Quality and Macroinvertebrates of Tundra Ponds, Dy Robin L. West and Elaine Snyder-Conn, Fairbanks Fish and Wildife Enhancement Office, U.S. Fish and Wildlife Service. Fairbanks, Alaska, $9 / 87$. 
In the sumer of 1985, a field method was developed by the U. S. Fish and Wildife Service to evaluate toxicity of reserve pit fluids discharged into tundra wet lands at Prudhoe Bay. Alaska. Results of the study document acute toxicity effects of reserve pit fluids on Daphnia. Acute toxicity in Dapnnia was observed after 95 hours of exoosure to liquid in five reserve pits. Daphnia exposed to ilquid in receiving ponds also had significantly higher death/imobilization than did Daphnia exposed to liquid in control ponds after 96 hours. At Drill Site 1, after 96 hours. 100 percent of the Daphnia introduced to the reserve pit had been immobilized or were dead, as comparea to a control pond which showed less than 5 percent immobilized or dead after 96 hours. At Drill Site 12, 80 percent of the Daphnia exposed to the reserve pit liquid were dead or imnobilized after 96 hours and less than 1 percent of Daphnia exposed to the control pond were dead or immobilized. ${ }^{83}(A K 07)^{84}$

In June 1985, five dr 111 sites and three control sites were chosen for studying the effects of drilling fluids and their discharge on fish and waterfowl habitat on the North Slope of Alaska. Bioaccumulation analys is was done on fish tissue using water samples collected from the reserve pits. Fecundity and growth were reduced in daphnids exposed for 42 days to liquid composed of 2.5 percent and 25 percent drilling fluid from the selected drill sites. Bioaccumulation of barium, titanium, iron, ccpper, and molybdenum was documented in fish exposed to drilling fluids for as littie as 96 hours. $(A K O B)^{85}$

Erosion of reserve pits and subsequent discharge of reserve pit contents to the tundra constitute another potential environmental problem on the North Slope. If exploration drilling pits are not closed out at the end of a drilling season, they may breach during "breakup." Reserve pit contaminants are then released directly to the tundra. (As described in Chapter III, production reserve pits are different from exploration reserve pits. Production reserve pits are designed to last for as long as 20 years.) A reserve pit wall may be poorly constructed or suffer structural damage during use; the wall may be breached by the hydrostatic head on the walls due to accumulation of precipitation and produced fluids. New exploration reserve pits are generally constructed below-grade. Flow of gravel during a pit breach can choke or cut off tundra streams, severely damaging or el iminating aquatic habitat.

83 API comments in the Docket pertain to AK 07 . API discusses the relevance of the Daphnia study to the damage cases.

84 References for case cited: An In Situ Acute Toxicity Test with Daphnia: A Promising Screening Tool for Field Biologists? by Elaine Snyder-Conn, U.S. Fish and Wildlife Service, Fish and Wildlife Enhancement, Fairbanks, Alaska, 1985.

85 References for case cited: Effects of 0il Drilling Fluids and Their Discharge on Fish and Waterfowl Habitat in Alaska, U.S. Fish and Wildlife Service, Columbia National Fishery Research Laboratory. Jackson Field Station, Jackson, Wyoming. February 1986. 
The Awuna Test We11 No. 1, which is 11,200 feet deep, is in the National Petroleum Reserve in Alaska (NPRA) and was a site selected for cleanup of the NPRA by the U.S. Geological Survey (USGS) in 1984. The site is in the northern foothills of the Brooks Range. The well was spud on February 29, 1980, and operations were completed on April 20,1981. A side of the reserve pit berm wasned out into the tundra during spring breakup, allowing reserve pit fluid to flow onto the tundra. As documented by the USGS cleanup team, high levels of chromium, oil, and grease have leached into the so11 downgradient from the pit. Chromium was found at 2.2 to $3.0 \mathrm{mg} / \mathrm{kg}$ dry weight. The high levels of 011 and grease may be from the use of Arct ic Pack ( 85 percent diesel fuel) at the well over the winter of 1980 . The cleanup team noted that the downslope soils were discolored and putrefied, particularly in the upper layers. The pad is located in a runoff area allowing for erosion of pad and pit into surrounding tundra. A vegetation kill area caused by reserve pit fluid exposure is approximately equal to half an acre. Areas of the drill pad may remain barren for many years because of contamination of soil with salt and hydrocarbons. The well site is in a caribou calving area. ${ }^{86}$ (AK 12) 87

This type of reserve pit construction is no longer permitted under current Alaska regulations.

\section{Waste Disposal on the North Slope}

\section{Inspection of oil and gas activities and enforcement of State} regulations on the North Slope is difficult, as illustrated by the following case:

North Slope Salvage. Inc. (NSS1) operated a salvage business in Prudhoe Bay during 1982 and 1983. During this time, NSSI accepted delivery of various discarded materials from oil production companies on the North Slope, including more than 14,000 fifty-five gallon drums, 900 of which were full or held more than residual amounts of oils and chemicals used in the development and recovery of oil. The drums were stockpiled and managed by NSSI in a manner that allowed the discharge of hazardous substances. While the NSSI site may have stored chemicals and wastes from other operations that supported 011 and gas exploration and production (e.g.. vehicle maintenance materials), such storage would have const ituted a very small percentage of NSSI's total inventory.

\section{6}

API states that exploratory reserve pits must now be closed 1 year after cessation of drilling operations. EPA notes that it is important to distinguish between exploratory and production reserve pits. Production reserve pits are permanent structures that remain open as long as the well or group of wells is producing. This may be as long as 20 years.

87 References for case cited: Final Wellsite Cleanup on National Petroleum Reserve Alaska, USGS, July 1986. 
The situation was discovered by the Alaska Department of Environmental Conservation (ADEC) in June 1983. At this $t$ ime, the State of Alaska requested Federal enforcement, but Federal action was never taken. An inadequate cleanup effort was mounted by NSS1 after confrontation by ADEC. To preclude further discharges of hazardous substances, ARCO and Sohio paid for the cleanup because they were the primary contributors to the site. Cleanup was completed on August 5 . 1983. after 58,000 gallons of chemicais and water were recovered. It is unknown how much of the hazardous substances was carried into the tundra. The discharge consisted of oil and a variety of organic substances known to be toxic. carcinogenic, mutagenic, or suspected of being carcinogenic or mutagenic. ${ }^{88}(A K 10)^{89}$

\title{
Disposal of Drilling Wastes, Kenai Peninsula
}

\author{
Disposal of drilling wastes is the principal practice leading to \\ potential environmental degradation on the Kenai Peninsula. The \\ following cases involve centralized facilities, both commercial and \\ privately run, for disposal of drilling wastes:
}

\begin{abstract}
Operators of the Sterling Special Waste Site have had a long history of substandard monitoring. having falled during 1977 and 1978 to carry out any well sampling and otherwise having perforined only irregular sampling. This was in violation of ADEC permit requirements to perform quarterly reports of water quality samples from the monitoring wells. An internal ADEC memo (L.G. Elphic to R.T. Whlliams. 2/25/76) noted “...we must not forget...that this is the State's first sanctioned hazardous waste site and as such must receive close observation during its initial operating period.".90

A permit for the site was reissued by ADEC in 1979 despite know ledge by ADEC of lack of effective ground-water monitoring. In July of 1980. ADEC Engineer R. Williams visited the site and filed a report noting that the "...operation appears completely out of control." Monitoring well samples were analyzed by ADEC at this time and were found to be in excess of drinking water standards for iron. lead, cadmium, copper. zinc, arsenic, phenol, and oil and grease. One private water well in the vacinity showed 0.4 ppb 1,1,1-trichloroethane. The Sterling School well showed $2.1 \mathrm{~g} / \mathrm{L}$ mercury. (Subsequent tests show mercury concentration be low detection 1 imits $-0.001 \mathrm{mg} / \mathrm{kg}$,) Both contamination incidents are alleged to be caused by the Sterling
\end{abstract}

88 A laska Department of Environmental Conservation (ADEC) states that this case "... is an example of how the 011 industry inappropriately considered the limits of the exemption [under RCRA Section 3001]."

89 References for case cited: Report on the Occurrence. Discovery, and Cleanup of an 0 il and Hazardous Substances Discharge at Lease Tract 57, Prudhoe Bay. Alaska, by Jeff Mach - ADEC, 1984. Letter to Dan Derkics, EPA, from Stan Hungerford, ADEC, 8/4/87.

90 The term "hazardous waste site" as used in this memo does not refer to a "RCRA Subt it le C hazardous waste site." 
Special Waste Site. Allegations are unconf irmed by the ADEC. (AK 03)

\section{Practices at the Sterling site were in violation of the permit.}

This case involves a 45-acre gravel pit on Poppy Lane on the Kenai Peninsula used since the 1970 s for disposal of wastes associated with gas development. The gravel pit contains barrels of unident if ied wastes, drilling muds, gas condensate, gas condensate-contaminated peat. abandoned equipment, and soll contaminated with diesel and chemicals. The property belongs to Union 0.1 Co.., which bought it around 1968. Dumping of wastes in this area is 11 legal; reports of last observed dumping were in October 1985, as witnessed by residents in the area.

In this case, there has been demonstrated contamination of adjacent water wells with organic compounds related to gas condensate (ADEC laboratory reports from October 1986 and earlier). Alleged health effects on residents of neighboring properties include nausea, diarrhea, rashes. and elevated levels of metals (chromium, copper) in blood in two residents. Property values have been effectively reduced to zero for residential resale. A fire on the site on July 8 . 1981, was attributed to combustion of petroleum-related products, and the fire department was unable to extinguish it. The fire was allegedly set by people illegally disposing of wastes in the pit. Fumes from organic liquids are noticeable in the breathing zone onsite. UNOCAL has been directed on several occasions to remove gas condensate in wastes from the site. Since June 19. 1972. disposal of wastes regulated as solid wastes has been illegal at this site. The case has been actively under review by the State since 1981. (AK 01) ( $^{92}$

91 References for case cited: Dames and Moore well monitoring report, showing elevated metals referenced above. October 1976. Dowling Rice \& Associates monitoring results, 1/15/80, and Mar Enterprises monitoring results, September 1980, provided by Walt Pederson, showing elevated levels of metals, oil, and greașe in ground water. Detalled letter from Eric Meyers to Glen Aikens, Deputy Comissioner, ADEC, recount ing permit history of site and failure to conduct proper monitoring, $1 / 22 / 82$. Test imony and transcripts from Walt Pederson on public forums complaining about damage to drinking water and mismanagement of site. Transcripts of waste logs of site from $9 / 1 / 79$ to $8 / 20 / 84$, indicating on ly $264,436 \mathrm{bbl}$ of muds received, during a period that should have generated much more waste. Letter from Howard Keiser to Union 011 . 12/7/81, indicat ing that "...drilling mud is being disposed of by methods other than at the Sterling Special Waste Site and by methods that could possibly cause contamination of the ground water."

92 References for case cited: Photos showing illegal dumping in progress, Field investigations. State of Alaska Individual Fire Report on "petroleum dump," 7/12/81. File memo on site visit by Howard Keiser. ADEC Environmental Field Officer, in response to a complaint by State Forestry Officer, 7/21/81. Memo from Howard Keiser to Bob Martin on his objections to grant ing a permit to Union $0 i 1$ for use of site as disposal site on basis of impairment of wildlife resources. $7 / 28 / 83$. Letter. ADEC to Union 011 , objecting to lack of cleanup of site despite not if ication by $A D E C$ on $10 / 3 / 84$. Analytical reports by $A D E C$ indicating gas condensate contamination on site, $8 / 14 / 84$. EPA Potential Hazardous Waste Site ldent ification, indicating cont inued dumping as of $8 / 10 / 85$. Citizens' complaint records. Blood test indicating elevated chromium for neighboring resident Jessica Black, 1/16/85. Letter to Mike Lucky of ADEC from Union 011 confirming cleanup steps, $2 / 12 / 85$. Memo by Carl Reller, ADEC ecologist, indicating presence of significant toxics on site, $8 / 14 / 85$. Minutes of Waste Disposal Comission meeting. $2 / 10 / 85$. ADEC analyt ic reports indicating gas condensate at site. 10/10/85. Letters from four different real estate firms in area confirming inability to sell residential property in Poppy Lane area. Letter from Bill Lamoreaux. $A D E C$, to J. Black and R. Sizemore referencing high selenium/chromium in the ground water in the area. Miscellaneous technical documents. EPA Potential Hazardous Waste Site Preliminary Assessment, 2/12/87. 
These activities are illegal under current Alaska regulations.

\section{MISCELLANEOUS ISSUES}

\section{Improperly Abandoned and Improperly Plugged Wells}

Degradation of ground water from improperly plugged and unplugged wells is known to occur in Kansas, Texas, and Louisiana. Improperly plugged and unplugged wells enable native brine to migrate up the wellbore and into freshwater aquifers. The damage sustained can be extensive.

Problems also occur when unidentified improperly plugged wells are present in areas being developed as secondary recovery projects. After the formation has been pressurized for secondary recovery, native brine can migrate up. unplugged or improperly plugged wells, potentially causing extensive ground-water contamination with chlorides.

In 1961. Gulf and its predecessors began secondary recovery operations in the East Gladys Unit in Sedgwick County, Kansas. During secondary recovery, water is pumped into a target formation at high pressure, enhancing $0 i 1$ production. This pumping of water pressurizes the formation. which can at $t$ imes result in brines being forced up to the surface through unplugged or improperly plugged abandoned wells. When Gulf began their secondary recovery in this area, it was with the knowledge that a number of abandoned wells existed and could lead to escape of salt water into fresh ground water.

Gerald Blood alleged that three improperly plugged wells in proximity to the Gladys unit were the source of fresh ground-water contamination on his property. Mr. Blood runs a peach orchard in the area. Apparently native brine had migrated from the nearby abandoned wells into the fresh ground water from which Mr. Blood draws water for domestic and irrigation purposes. Contamination of irrigation wells was first noted by Mr. Blood when, in 1970. one of his truck gardens was $k i l l e d$ by irrigation with salty water. Brine migration contaminated two more irrigation wells in the mid-1970s. By 1980, brine had contaminated the irrigation wells used to irrigate a whole section of Mr. Blood's land. By this $t$ ime, adjacent landowners also had contaminated wells. Mr. Blood lost a number of peach trees as a result of the contamination of his irrigation we11: he also lost the use of his domestic well. 
The Bloods sued Gulf $0 i l$ in civil court for damages sustained by their farm from chloride contamination of their irrigation and residential wells. The Bloods won their case and were awarded an undisclosed amount of money. ${ }^{93}$ (KS 14) 94

\title{
Current UIC regulations prohibit contamination of groundwater.
}

\section{The potential for environmental damage through ground-water} degradation is high, given the thousands of wells abandoned throughout the country prior to any State regulatory plugging requirements.

\begin{abstract}
In West Texas, thousands of $0 i 1$ and gas wells have been drilled over the last several decades, many of which were never properly plugged. There exists in the subsurface of this area a geologic formation known as the Coleman Junction, which contains extremely salty native brine and possesses natural artesian properties. Since this formation is relatively shallow, most $0 i l$ and gas wells penetrate this formation. If an abandoned well is not properly plugged, the brine contained in the Coleman Junction is under enough natural pressure to rise through the improperly plugged well and to the surface.

According to scient if ic data developed over several years, and presented by Mr. Ralph Hoelscher, the ground water in and around San Angelo. Texas, has been severely degraded by this seepage of native brine, and much of the agricultural land has absorbed enough salt as to be nonproductive. This situation has created a hardship for farmers in the area. The Texas Railroad Commission states that soil and ground water are contaminated with cnlorides because of terracing and fertilizing of the land. According to Mr. Hoelscher, a long-time farmer in the area, little or no fertilizer is used in local agriculture. $(T \times 11)^{95}$
\end{abstract}

Improper abandonment of oil and gas wells is prohibited in the State of Texas.

93 API states that damage in this case was brought about by "old injection practices."

94 References for case cited: U.S. District Court for the district of Kansas, Memorandum and Order, Blood vs, Gulf; Response to Defendants' Statement of Uncontroverted Facts; and Memorandum in Opposition to Motion for Summary Judgment. Means Laboratories, Inc., water sample results. Department of Health, District Office \#14, water samples results. Extensive miscellaneous memoranda, letters, analysis.

95 References for case cited: Hater analys is of Ralph Hoelscher's domestic we11. Soil Salinity Analysis, Texas Agricultural Extension Service - The Texas A\&M University System, Soil Testing Laboratory, Lubbock. Texas 79401. Photographs. Conversation with Wayne Farre11. San Angelo Health Department. Conversation with Ralph Hoelscher, resident and farmer. 


\section{CHAPTER V}

\section{RISK MODELING}

\section{INTRODUCTION}

This chapter summarizes the methods and results of a risk analysis of certain wastes associated with the onshore exploration, development, and production of crude $0 i l$ and natural gas. The risk analysis relies heavily on the information developed by EPA on the types, amounts, and characteristics of wastes generated (summarized in chapter II) and on vaste management practices (summarized in Chapter III). In addition, this quantitative modeling analysis was intended to complenient EPA's damage case assessment (Chapter IV). Because the scope of the model effort was limited, some of the types of damage cases reported in Chapter IV are not addressed here. On the other hand, the risk modeling of ground-water pathways covers the potential for certain more subtle or long-term risks that might not be evidenced in the contemporary damage case files. The methods and results of the risk analysis are documented in detail in a supporting EPA technical report (USEPA 1987a).

EPA's risk modeling study estimated releases of contaminants from selected oil and gas wastes into ground and surface waters, modeled fate and transport of these contaminants, and estimated potential exposures, health risks, and environmental impacts over a 200-year modeling period. The study was not designed to estimate absolute levels of national or regional risks, but rather to investigate and compare potential risks under a wide variety of conditions.

\section{Objectives}

The main objectives of the risk analysis were to (1) characterize and classify the major risk-influencing factors (e.g., waste types, waste 
management practices, environmental settings) associated with current operations at $0 i l$ and gas facilities; ${ }^{1}$ (2) estinate distributions of major risk-influencing factors across the population of oil and.gas facilities within various geographic zones; (3) evaluate these factors in terms of their relative effect on risks; and (4) develop, for different geographic zones of the U.S., initial quantitative estimates of the possible range of baseline health and environmental risks for the variety of existing conditions.

Scope and Limitations

The major portion of this risk study involved a predictive quantitative modeling analysis focusing on large-volume exempt wastes managed according to generally prevailing industry practices. EPA also examined (but did not attempt quantitative assessment of) the potential effects of oil and gas wastes on the North Slope of.A? aska, and reviewed the locations of $0 i l$ and gas activities relative to certain environments of special interest, including endangered species habitats, wetlands, and public lands.

Specifically, the quantitative risk modeling analysis estimated long-term human health and environmental risks associated with the disposal of drilling wastes in onsite reserve pits, the deep well injection of produced water, and the direct discharge of produced water from stripper wells to surface waters. These wastes and waste management practices encompass the major waste streams and the most common management practices within the scope of this report, but they are not necessarily those giving rise to the most severe or largest number of damage cases of the types presented in Chapter IV. For risk modeling purposes, EPA generally assumed full compliance with applicable current State and 1 References in this chapter to $0 i 1$ and gas facilities, sites, or activities refer to
exploration. developinent, and production operations. 
Federal regulations for the practices studied. Risks were not modeled for a wide variety of conditions or situations, either permitted or. illegal, that could give rise to damage incidents, such as waste spills, land application of pit or water wastes, discharge of produced salt water to evaporation/percolation pits, or migration of injected wastes through unplugged boreholes.

In this study, EPA analyzed the possible effects of selected waste streams and management practices by estimating risks for model scenarios. Model scenarios are defined as hypothetical (but realistic) combinations of variables representing waste streams, management practices, and environmental settings at oil and gas facilities. The scenarios used in this study were, to the extent possible, based on the range of conditions that exist at actual sites across the U.S. EPA developed and analyzed more than 3,000 model scenarios as part of this analysis.

EPA also estimated the geographic and waste practice frequencies of occurrence of the model scenarios to account for how well they represent actual industry conditions and to account for important variations in oil and gas operations across different geographic zones of the U.S. ${ }^{2}$ These frequencies were used to weight the model results, that is, to account for the fact that some scenarios represent more sites than others. However, even the weighted risk estimates should not be interpreted as absolute risks for real facilities because certain major risk-influencing factors were not modeled as variables and because the frequency of occurrence of failure/release modes and concentrations of toxic constituents were not available.

2 The 12 zones used in the risk assessment are identical to the zones used as part of EPA's waste sampling and analys is study (see Chapter 11), with one exception: zone 11 (Alaska) was divided into zone $11 \mathrm{~A}$ represent ing the North Slope and zone 118 represent ing the Cook Inlet-Kenai Peninsula area. 
A principal limitation of the risk analysis is that EPA had only a relatively small sample set of waste constituent concentration data for the waste streams under study. As a result, the Agency was unable to construct regional estimates of toxic constituent concentrations or a national frequency distribution of concentrations that could be directly related to other key geophysical or waste management variables in the study. Partly because of this data limitation, all model scenarios defined for this study were analyzed under two different sets of assumptions: a "best-estimate" ${ }^{3}$ set of assumptions and a "conservative" set of assumptions. The best-estimate and conservative sets of assumptions are distinguished by different waste constituent concentrations, different timing for releases of drilling waste and produced water, and, in some cases, different release rates (see the later sections on model scenarios and model procedures for more detail). The best-estimate assumptions represent a set of conditions which, in EPA's judgment, best characterize the industry as a whole, while the conservative assumptions define higher-risk (but not worst-case) conditions. It is important to clarify that the best-estimate and conservative assumptions are not necessarily based on a comprehensive statistical analysis of the frequency of occurrence or absolute range of conditions that exist across the industry; instead, they reflect EPA's best judgment of a reasonable range of conditions based on available data analyzed for this study.

Another major limitation of the study is the general absence of empirical information on the frequency, extent, and duration of waste releases from the oil and gas field management practices under consideration. As described below, this study used available engineering judgments regarding the nature of a variety of failure/release mechanisms for waste pits and injection wells, but no assumptions were made

3 As used here, the term best est imate is different from the stat istical concept of maximum likelihood (i.e., best) est imate. 
regarding the relative frequency or probability of occurrence of such failures.

Although EPA believes that the scenarios analyzed are realistic and representative, the risk modeling for both sets of scenarios incorporated certain assumptions that tend to overestimate risk values. For example, for the health risk estimates it was assumed that individuals ingest untreated contaminated water over a lifetime, even if contaminant concentrations were to exceed concentrations at which an odor or taste is detectab?e. In addition, ingested concentrations were assumed to equal the estimated center line (i.e., highest) concentration in the contaminant plume.

Other features of the study tend to result in underestimation of risk. For example, the analysis focuses on risks associated with drilling or production at single oil or gas wells, rather than on the risks associated with multiple wells clustered in a field, which could result in greater risks and impacts because of overlapping effects. Also, the analysis does not account for natural or other source background levels of chemical constituents which, when combined with the contamination levels from oil and gas activities, could result in increased risk levels.

\section{QUANTITATIVE RISK ASSESSMENT METHODOLOGY}

EPA conducted the quantitative risk assessment through a four-step process (see Figure V-1). The first three steps--collection of input data, specification of model scenarios, and development of modeling procedures--are described in the following subsections. The last step, estination of effects, is described in subsequent sections of this chapter that address the quantitative modeling results. 


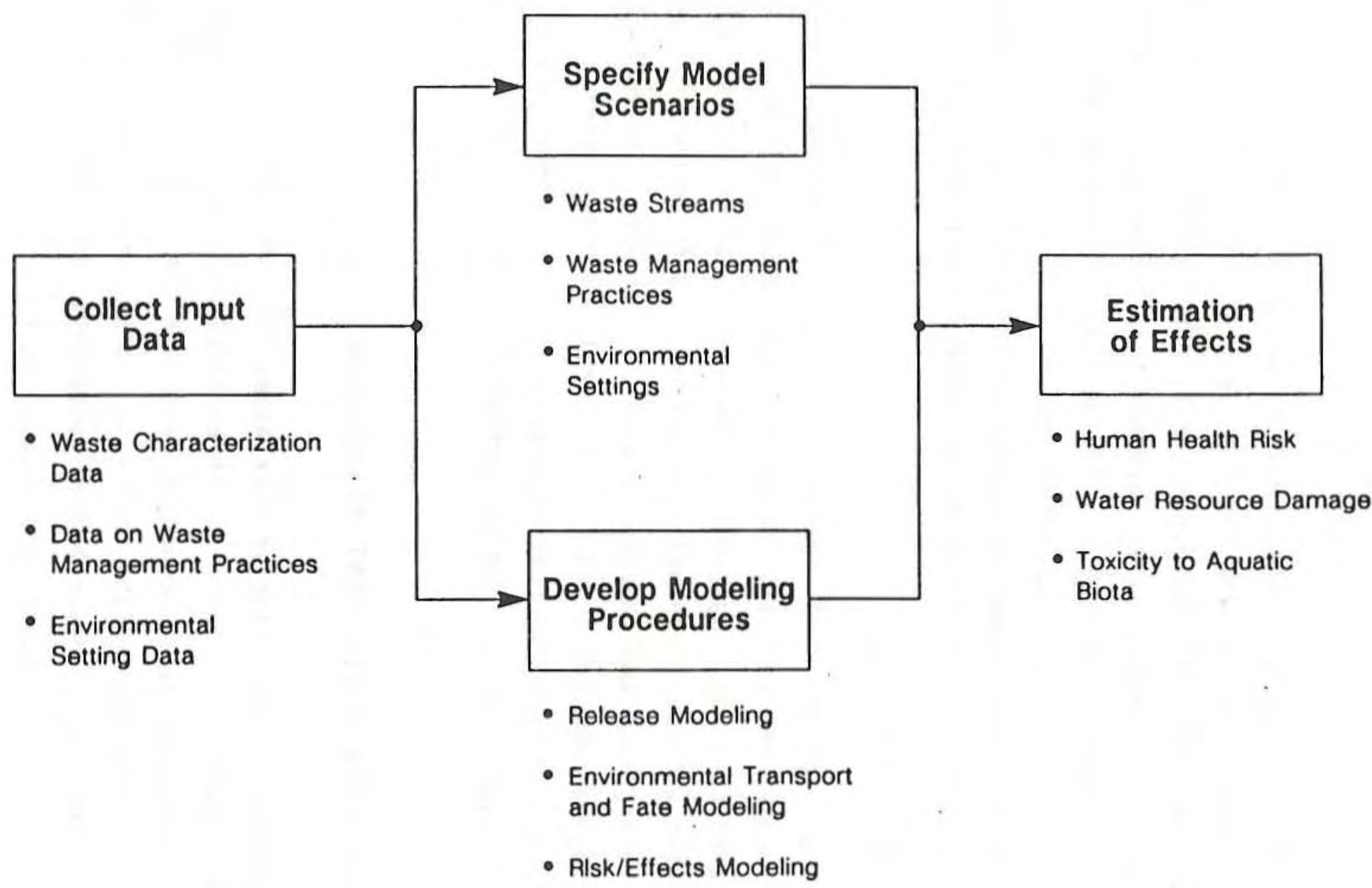

Figure V-1 Overview of Quantitative Risk Assessment Methodology 
Input Data

EPA collected three main categories of input data for the quantitative modeling: data on waste volumes and constituents, waste management practices, and environmental settings. Data on waste volumes were obtained from EPA's own research on sources and volumes of wastes, supplemented by the results of a survey of oil and gas facilities conducted by the American Petroleum Institute (API) (see Chapter II). Data on waste constituents were obtained from EPA's waste stream chemical analysis study. The results of EPA's research on current waste managenent practices, supplemented by API's studies (see Chapter III), were the basis for defining necessary input parameters concerning waste management practices. Data needed to characterize environmental settings were obtained from an analysis of conditions at 266 actual drilling and production locations sampled from areas with high levels of oil and gas activity (see USEPA 1987a, Chapter 3, for more detail on the sample selection and analytical methods).

\section{Model Scenarios}

The model scenarios in this analysis are unique combinations of the variables used to define waste streams, waste management practices, and environmental settings at oil and gas facilities. Although the model scenarios are hypothetical, they were designed to be:

- Representative of actual industry conditions (they were developed using actual industry data, to the extent available);

- Broad in scope, covering prevalent industry characteristics but not necessarily all sets of conditions that occur in the industry; and

- Sensitive to major differences in environmental conditions (such as rainfall, depth to ground water, and ground-water flow rate) across various geographic zones of the U.S. 
As illustrated in Figure V-2, EPA decided to focus the quantitative analysis on the human health and environmental risks associated with three types of environmental releases: leaching of drilling waste chemical constituents from onsite reserve pits to ground water below the pits (drilling sites); release of produced water chemical constituents from underground injection wells to surface aquifers ${ }^{4}$ (production sites); and direct discharge of produced water chemical constituents to streams and rivers (stripper well production sites).

\section{Chemical Constituents}

EPA used its waste sampling and analysis data (described in Chapter II) to characterize drilling wastes and produced water for quantitative risk modeling. Based on the available data, EPA could not develop separate waste stream characterizations for various geographic zones; one set of waste characteristics was used to represent the nation. The model drilling waste represents only water-based drilling muds (not oil-based muds or wastes from air drilling), which are by far the most prevalent drililing mud type. Also, the model drilling waste does not represent one specific process waste, but rather the combined wastes associated with well drilling that generally are disposed of in reserve pits.

For both drilling wastes and produced water, EPA used a systematic methodology to select the chemical constituents of waste streams likely to dominate risk estimates (see USEPA 1987a, Chapter 3, for a detailed description of this methodology). The major factors considered in the chemical selection process were (1) median and maximum concentrations in

\footnotetext{
4 For the purpose of this report, a surface aquifer is defined as the geologic unit nearest the land surface that transmits sufficient quantities of ground water to be used as a source of drinking water. It is distinguished from aquifers at greater depths, which may be the injection zone for an underground injection well or are too deep to be generally used as a drinking water source.
} 

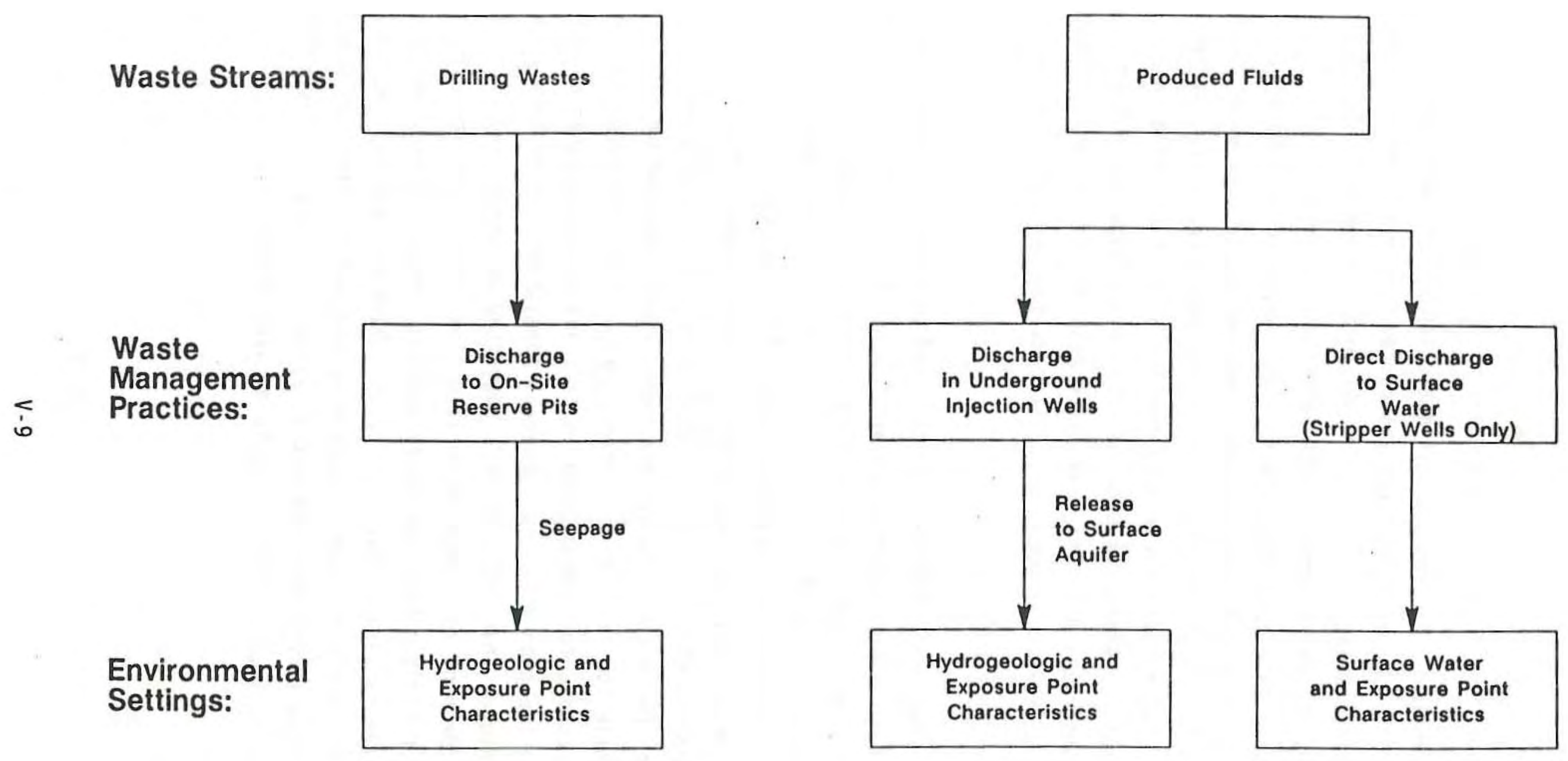

Figure V-2 Overview of Modeling Scenarios Considered in the Quantitative Risk Assessment 
the waste samples; (2) frequency of detection in the waste samples; (3) mobility in ground water; and (4) concentrations at which human health effects, aquatic toxicity, or resource damage start to occur. Through this screening process, EPA selected six chemicals for each waste type that were likely to dominate risk estimates in the scenarios modeled. For each selected chemical, two concentrations were determined from the waste characterization data. The 50th percentile (median) was used to set constituent concentrations for a "best-estimate" waste characterization, while the 90 th percentile was used for a "conservative" waste characterization. The selected chemicals and concentrations, shown in Table $V-1$, served as model waste streams for the quantitative risk analysis.

Of the chemicals selected, arsenic and benzene were modeled as potential carcinogens. Both substances are rated as Group A in EPA's weight-of-evidence ratirig system (i.e., sufficient evidence of carcinogenicity in humans). Sone scientists, however, believe that arsenic may not be carcinogenic and may be a necessary element at low levels. Sodium, cadmium, and chromium VI were modeled for noncarcinogenic effects. The critical (i.e., most sensitive) health effects for these constituents are hypertension for sodium and liver and kidney damage for cadmium and chromium VI. It is emphasized that the effect threshold for sodium used in this analysis was based on potential effects in the high-risk (not general) population. (The level used is slightly higher than EPA's $20 \mathrm{mg} / \mathrm{L}$ suggested guidance level for drinking water.) The high-risk population is defined to include individuals with a genetic predisposition for hypertension, pregnant women, and hypertensive patients. Finally, boron, chloride, sodium, cadmium, chromium VI, and total mobile ions were modeled for their potential aquatic toxicity and resource damage effects. Table $V-2$ lists the cancer potency factors and effects thresholds used in the study. 
Table V-1 Model Const ituents and Concentrations ${ }^{a}$

\begin{tabular}{|c|c|c|}
\hline \multirow[b]{2}{*}{$\begin{array}{l}\text { Produced water } \\
\text { constituents }\end{array}$} & \multicolumn{2}{|c|}{ Concentrations } \\
\hline & $\begin{array}{l}\text { Median } \\
(\mathrm{mg} / \mathrm{L})\end{array}$ & $\begin{array}{l}\text { Upper } 90 \% \\
\left(m_{y} ; L\right)\end{array}$ \\
\hline Arsenic & 0.02 & 1.7 \\
\hline Benzerie & 0.47 & 2.9 \\
\hline Boron & 9.9 & 120 \\
\hline Sodium & 9,400 & 67,000 \\
\hline Chloride & 7,300 & 35,000 \\
\hline Mobile ions ${ }^{b}$ & 23,000 & 110,000 \\
\hline
\end{tabular}

\begin{tabular}{|c|c|c|c|c|c|c|}
\hline \multirow{5}{*}{$\begin{array}{l}\text { Drilling waste } \\
\text { (water-based) } \\
\text { constituents }\end{array}$} & \multicolumn{6}{|c|}{ Concentrations } \\
\hline & \multicolumn{2}{|c|}{ Pit liquids } & \multicolumn{2}{|c|}{ p,t solids/TCLP ${ }^{C}$} & \multicolumn{2}{|c|}{ Pit solids'direct } \\
\hline & Median & Upper $90 \%$ & Median & Upper $90 \%$ & Median & Upper 90\% \\
\hline & \multirow{2}{*}{\multicolumn{2}{|c|}{$(\mathrm{mg} / \mathrm{L})$}} & \multirow{2}{*}{\multicolumn{2}{|c|}{ (mg/L) }} & \multirow{2}{*}{\multicolumn{2}{|c|}{$(\mathrm{mg} / \mathrm{kg})$}} \\
\hline & & & & & & \\
\hline Arsenic & 0.0 & 0.16 & 0.0 & $0.002^{d}$ & 0. & 0.010 \\
\hline Cadmium & 0.056 & 1.4 & 0.011 & 0.29 & 2. & 5.4 \\
\hline Sodium & 6.700 & 44,000 & $1,200^{\mathrm{e}}$ & $4.400^{e}$ & 8.500 & 59,000 \\
\hline Chloride & 3.500 & 39.000 & $2.000^{f}$ & $11.000^{f}$ & 17.000 & 88,000 \\
\hline Chromium VI & 0.43 & 290 & 0 & 0.78 & 22 & 190 \\
\hline Mobile ions ${ }^{b}$ & 17,000 & 95,000 & 4.000 & 16.000 & 100.000 & 250.000 \\
\hline
\end{tabular}

ATe median constituent concentrations from the relevant sumples in the EPA waste sampling/ analys is study were used for a "best-estimate" waste characterization, and the 90th percentile concentrations were used for a "conservative" waste characterization (data source: USEPA 1987b).

Mobile ions include chloride, sodium, potassium, calcium. magnesium, and sulfate.

${ }^{C_{T C L P}}=$ toxicity characteristic leaching procedure.

Upper 90th percentile arsenic values est imated based on detection 1 imit.

epreliminary examinations indicate that the sodium TCLP values may overestimate the actual leachable sodium concentrations in reserve pit sainples. The accuracy of these concentrations is the subject of an ongoing evaluation.

${ }^{f}$ Chloride TCLP values are est unated based on sodium data. 
Table V-2 Toxicity Parameters and Effects Thresholds ${ }^{\text {a }}$

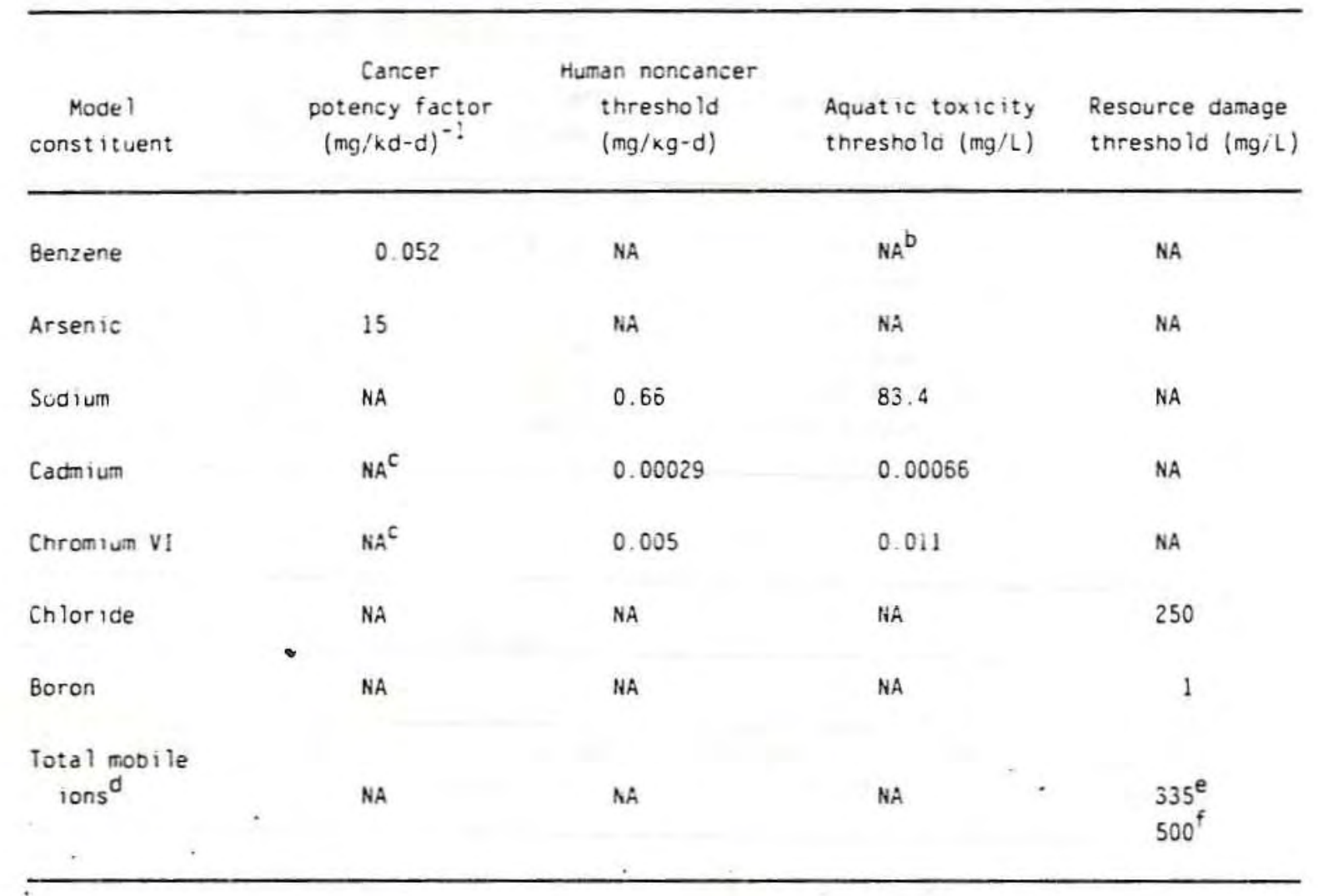

aSee USEPA 198\%a for detailed description and documentation.

${ }^{b}$ NA $=$ not applicable; indicates that an effect type was not modeled for a specific chemical.

CNot considered carcinogenic by the oral exposure route.

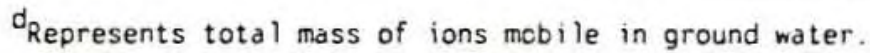

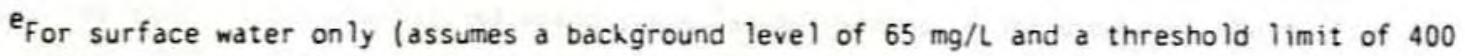
$\mathrm{mg} / \mathrm{L}$ ).

${ }^{f}$ For ground water only. 
The chemicals selected for risk modeling differ from the constituents of potential concern identified in Chapter II for at least three important reasons. First, the analys is in Chapter II considers the hazards of the waste stream itself but, unlike the selection process used for this risk analysis, does not consider the potential for waste constituents to migrate through ground water and result in exposures at distant locations. Second, certain constituents were selected based on their potential to cause adverse environmental (as opposed to human health) effects, while the analysis in Chapter II considers only human health effects. Third, frequency of detection was considered in selecting constituents for the risk modeling but was not considered in the Chapter II analysis.

\section{Waste Management Practices}

Three gerieral waste management practices were considered in this study: onsite reserve pits for drilling waste; underground injection wells for produced water; and direct discharge of produced water to rivers and streams (for stripper wells only). ${ }^{5}$ EPA considered the underground injection of produced water in disposal wells and waterflooding wells. ${ }^{6}$ The design characteristics and parameter values modeled for the different waste management practices are presented in Tables V-3 and V-4. These values were developed from an evaluation of EPA's and API's waste volume data (see Chapter II) and waste management practice survey results (see Chapter III) for the nation as a whole.

\footnotetext{
5 At present, there are no Federal effluent guideiines for stripper wells (1.e., oil wells producing less than ten barrels of crude oil per day), and, under Federal law, these wells are allowed to discharge directly to surface waters subject to certain restrictions. Most other onshore oil and gas facilities are subject to the Federal zero-discharge requirement.

6 Waterflooding is a secondary recovery method in which treated fresh water, seawater, or prodused water is injested into a petroleum-hearing formation to help maintain pressure and to displace a portion of the remaining crude oil toward produc:ion wells. Injection wells used for waterflooding may have different designs, operatir.g practices, and economic considerations than those of disposal wells, which are usted simply to dispose of unwanted fluid underground.
} 
Table V-3 Drilling Pit Waste (Water-Based) Management Practices

\begin{tabular}{|c|c|c|c|c|c|}
\hline \multirow{2}{*}{$\begin{array}{l}\text { Onsite } \\
\text { pit size }\end{array}$} & \multirow{2}{*}{$\begin{array}{l}\text { Waste } \\
\text { amount }^{\text {a }} \\
\text { (barrels) }\end{array}$} & \multirow[b]{2}{*}{ Disposal practice } & \multicolumn{3}{|c|}{$\begin{array}{c}\text { Pit } \\
\text { dimensions }(m)\end{array}$} \\
\hline & & & L & W & D \\
\hline \multirow[t]{2}{*}{ Large } & 26.000 & Reserve pit-unlined & 59 & 47 & $2.3^{b}$ \\
\hline & & $\begin{array}{l}\text { Reserve pit-lined. } \\
\text { capped }\end{array}$ & & & \\
\hline \multirow[t]{2}{*}{ Medium } & 5.900 & Reserve pit-unlined & 32 & 25 & $2.0^{\mathrm{b}}$ \\
\hline & & $\begin{array}{l}\text { Reserve pit-lined. } \\
\text { capped }\end{array}$ & & & \\
\hline \multirow[t]{2}{*}{ Small } & 1.650 & Reserve pit-unlined & 17 & 14 & $1.9^{b}$ \\
\hline & & $\begin{array}{l}\text { Reserve pit-lined. } \\
\text { capped }\end{array}$ & & & \\
\hline
\end{tabular}

aper well drilled (includes solids and liquids).

Waste depths for large, medium, and small pits were 1.5, 1.2, and 1.1 meters, respectively. 
Table V-6 Cefinition of Best-Est imate and Conservative Release Assumptions

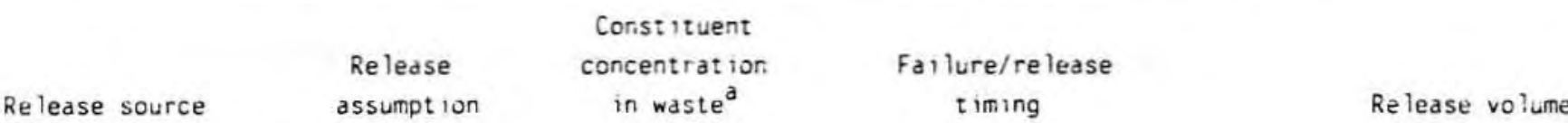

\begin{tabular}{|c|c|c|c|c|}
\hline \multirow[t]{2}{*}{ Unlined Pits } & Best-est imate & 50 th $\%$ (median) & Release begins in year 1 & Calculated by release equations \\
\hline & Conservat ive & $90 \operatorname{th} \%$ & Release begins in year 1 & $\begin{array}{l}\text { Calculated by release equations } \\
\text { (same as best-est irate) }\end{array}$ \\
\hline & & & . & \\
\hline \multirow[t]{2}{*}{ Lined Pits } & Best-est imate & 50 th $\%$ & $\begin{array}{l}\text { Liner failure begins in } \\
\text { year } 25\end{array}$ & Calculated by release equations \\
\hline & Conservative & $90 \operatorname{th} \%$ & $\begin{array}{l}\text { Liner fallure begins in } \\
\text { year } 5\end{array}$ & $\begin{array}{l}\text { Calculated by release equations } \\
\text { (same as best-est imate) }\end{array}$ \\
\hline \multirow[t]{2}{*}{$\begin{array}{l}\text { Injection Wells/ } \\
\text { Casing Failure }\end{array}$} & Best-est imate & $50 \operatorname{th} \%$ & $\begin{array}{l}\text { One year release in year } \\
1 \text { for waterflood wells: } \\
\text { constant annual releases } \\
\text { during years } 11-13 \text {. for } \\
\text { disposal wells }\end{array}$ & $\begin{array}{l}0.2-96 \mathrm{bbl} / \mathrm{d} \text { for waterf lood } \\
\text { wells: } 0.05-38 \text { bbl/d for } \\
\text { disposal wells }\end{array}$ \\
\hline & Conservat ive & 90 th $\%$ & $\begin{array}{l}\text { Constant annual releases } \\
\text { during years } 11-15 \text { for } \\
\text { waterf lood and disposal } \\
\text { wells }\end{array}$ & Same as best-est imate \\
\hline \multirow[t]{2}{*}{$\begin{array}{l}\text { Injection Wells/ } \\
\text { Grout Seal Failure }\end{array}$} & Best-est imate & $50 \operatorname{th} \%$ & $\begin{array}{l}\text { Constant annual releases } \\
\text { during years } 11-15 \text { for } \\
\text { waterf lood and disposal } \\
\text { wells }\end{array}$ & $\begin{array}{l}0.00025-0.0025 \text { bb } 1 / d \text { for } \\
\text { waterflood wells; } 0.00025 \text { - } \\
0.0075 \mathrm{bb} 1 / \mathrm{d} \text { for disposal we } 11 \mathrm{~s}\end{array}$ \\
\hline & Conservat ive & 90 th $\%$ & $\begin{array}{l}\text { Constant annual releases } \\
\text { during years } 1-20 \text { for } \\
\text { waterf lood and disposal } \\
\text { wells (imediate failure. } \\
\text { no detection) }\end{array}$ & $\begin{array}{l}0.05-0.5 \mathrm{bbl} / \mathrm{d} \text { for waterflood } \\
\text { wells: } 0.05-1.5 \mathrm{bb} 1 / \mathrm{d} \text { for } \\
\text { disposal wells }\end{array}$ \\
\hline
\end{tabular}

\footnotetext{
${ }^{\mathrm{a}}$ See Table $v-1$.
} 
the same layers considered during the active period. For unlined pits, release was assumed to begin immediately at the start of the modeling period. For lined pits, failure (i.e., increase in hydraulic conductivity of the liner) was assumed to occur either 5 or 25 years after the start of the modeling period. It was assumed that any liquids remaining in unlined reserve pits at the time of closure would be land applied adjacent to the pit. Liquids remaining in lined pits were assumed to be disposed offsite.

For modeling releases to surface aquifers from Class II injection wells, a 20-year injection well operating period was assumed, and two failure mechanisms were studied: (1) failure of the well casing (e.g., a corrosion hole) and (2) failure of the grout seal separating the injection zone from the surface aquifer. At this time, the Agency lacks the data necessary to estimate the probability of casing or grout seal failures occurring. A well casing failure assumes that injected fluids are exiting the well through a hole in the casing protecting the surface aquifer. In most cases, at least two strings of casing protect the surface aquifer and, in those cases, a release to this aquifer would be highly unlikely. The Agency has made exhaustive investigations of Class $I$ well (i.e., hazardous waste disposal well) failures and has found no evidence of release of injected fluids through two strings of casing. However, the Agency is aware that some Class II wells were constructed with only one string of casing; therefore, the scenarios modeled fall within the realm of possible failures. Since integrity of the casing must be tested every 5 years under current EPA guidelines (more frequently by some States), EPA assumed for the conservative scenarios that a release would begin on the first day after the test and would last until the next test (i.e., 5 years). For the best-estimate scenarios, EPA assumed that the release lasted 1 year (the minimum feasible modeling period) in the case of waterflood wells and 3 years in the case of disposal wells, on the supposition that shorter release durations would be more likely for 
waterflooding where injection flow rates and volumes are important economic considerations for the operation. EPA also assumed here that. the release flow from a failed well would remain constant over the duration of the failure. This simplifying assumption is more likely to. hold in low-pressure wells than in the high-pressure wells more typical of waterflooding operations. In high-pressure wells the high flow rate would likely enlarge the casing holes more rapidly, resulting in more injection fluid escaping into the wrong horizon and a noticeable drop of pressure in the reservoir.

For the grout seal type of failure, EPA estimated for conservative modeling purposes that the failure could last for 20 years (i.e., as long as the well operates). This is not an unreasonable worst-case assumption tecause the current regulations allow the use of cementing records to determine adequacy of the cement job, rather than actual testing through the use of logs. If the cementing records were flawed at the outset, a cementing failure might remain undetected. As part of its review of the Underground Injection Control (UIC) regulations, the A.gency is considering requiring more reliable testing of the cementing of wells, which would considerably lessen the likelihood of such scenarios. For an alternative best-estimate scenario, the Agency assumed a 5-year duration of failure as a more typical possibility.

Because of a lack of both data, and adequate modeling methods, other potentially important migration pathways by which underground injection of waste could contaminate surface aquifers (e.g., upward contaminant migration from the injection zone through fractures/faults in confining layers or abandoned boreholes) were not modeled.

Chemical transport was modeled for ground water and surface water (rivers). Ground-water flow and mass transport were modeled using EPA's Liner Location Risk and Cost Analysis Model (LLM) (USEPA 1986). The LLM 
uses a series of predetermined flow field types to define ground-water conditions (see Table V-7); a transient-source, one-dimensional, wetting-front model to assess unsaturated zone transport; and a modified version of the Random Walk Solute Transport Model (Prickett et al. 1981) to predict ground-water flow and chemical transport in the saturated zone. All ground water exposure and risk estimates presented in this report are for the downgradient center line plume concentration. Chemical transport in rivers was modeled using equations adapted from EPA (USEPA 1984a); these equations can account for dilution, dispersion, particulate adsorption, sedimentation, degradation (photolysis, hydrolysis, and biodegradation), and volatilization.

EPA used the LLM risk submodel to estimate cancer and chronic noncancer risks from the ingestion of contaminated ground and surface water. The measure used for cancer risk was the maximum (over the 200-year modeling period) lifetime excess ${ }^{7}$ individual risk, assuming an individual ingested contaminated ground or surface water over an entire lifetime (assumed to be 70 years). These risk numbers represent the estimated probability of occurrence of cancer in an exposed individual. For example, a cancer risk estimate of $1 \times 10^{-6}$ indicates that the chance of an individual getting cancer is approximate?y one in a million over a 70-year lifetime. The measure used for noncancer risk was the maximum (over the 200-year modeling period) ratio of the estimated chemical dose to the dose of the chemical at which health effects begin to occur (i.e., the threshold dose). Ratios exceeding 1.0 indicate the potential for adverse effects in some exposed individuals; ratios less than 1.0 indicate a very low likelihood of effect (assuming that background exposure is zero, as is done in this study). Although these ratios are not probabilities, higher ratios in general are cause for greater concern.

\footnotetext{
7 Excess refers to the risk increment attributable only to exposure resulting from the releases considered in this analysis. Background exposures were assumed to be zero.
} 
Table V-7 Definition of Fiow Fields Used in Ground-Water Transport Modeling

\begin{tabular}{|c|c|c|}
\hline \multirow[b]{2}{*}{ Flow field } & \multicolumn{2}{|c|}{ Key variab?es defining flom field } \\
\hline & Aquifer conf iguration ${ }^{b}$ & $\begin{array}{l}\text { Horizontal ground-water } \\
\text { velocity }\end{array}$ \\
\hline A & Unconf ined aquifer & $1 \mathrm{~m} / \mathrm{yr}$ \\
\hline B & Unconf ined aquifer & $10 \mathrm{~m} / \mathrm{yr}$ \\
\hline c & Unconf ined aquifer & $100 \mathrm{~m} / \mathrm{yr}$ \\
\hline D & Unconf ined aquifer & $1.000 \mathrm{~m} / \mathrm{yr}$ \\
\hline E & Uncenf ined aquifer & $10,000 \mathrm{~m} / \mathrm{yr}$ \\
\hline$F$ & Conf ined aquifer & $\begin{array}{l}0.05 \mathrm{~m} / \mathrm{yr} \text { in the conf ining layer and } \\
100 \mathrm{~m} / \mathrm{yr} \text { within the dquifer }\end{array}$ \\
\hline$k$ & Confined aquifer & $\begin{array}{l}0.05 \mathrm{~m} / \mathrm{yr} \text { in the confining layer and } \\
10 \mathrm{~m} / \mathrm{yr} \text { within the aquiter }\end{array}$ \\
\hline
\end{tabular}

\footnotetext{
'Several other variables, such as porosity, distinguish the flow fields, but the variables listed here are the most important for the purpose of this presentation.

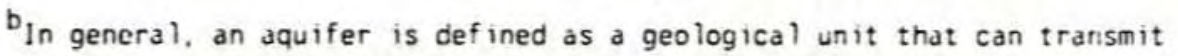
significant quantities of water. An unconfiried aquifer is one that is only partly filled with water, such that the upper surface of the saturated zone is free to rise and decline. A confined aquifer is one that is completely filled with water and that is overlain by a conf ining layer (a rock unit that restricts the movenent of ground water).
} 
As a means of assessing potential effects on aquatic organisms, EPA estimated, for each model scenario involving surface water, the volume contaminated above an aquatic effects threshold. EPA also estimated the volumes of ground and surface water contaminated above various resource damage thresholds (e.g., the secondary drinking water standard for chloride).

\section{QUANTITATIVE RISK MODELING RESULTS: HUMAN HEALTH}

This section summarizes the health risk modeling results for onsite reserve pits (drilling wastes), underground injection wells (produced water), and direct discharges to surface water (produced water, stripper well scenarios only). Cancer risk estimates are presented separately from noncancer risk estimates throughout. This section also sumiarizes EPA's preliminary estimates of the size of populations that could possibly be exposed through drinking water.

Onsite Reserve Pits--Drilling Wastes

Cancer and noncancer health risks were analyzed under both best-estimate and conservative modeling assumptions for 1,134 model scenarios ${ }^{8}$ of onsite reserve pits. Arsenic was the only potential carcinogen among the constituents modeled for onsite reserve pits. Of the noncarcinogens, only sodium exceeded its effect threshold; neither cadmiun nor chromilum VI exceeded their thresholds in any model scenarios (in its highest risk scenario, cadmium was at 15 percent of threshold; chromium VI, less than 1 percent).

$8 \quad 1,134=9$ infiltration/unsaturated zone types $\times 7$ ground. water flow field types $\times 3$ exposure distances $\times 3$ size categories $\times 2$ liner types. 
Nationally Weighted Risk Distributions

Figure $V-3$ presents the nationally weighted frequency distributions of human health risk estimates associated with unlined onsite reserve pits. The figure includes best-estimate and conservative modeling results for both cancer (top) and noncancer (bottom) risks. Only the results for unlined reserve pits are given because the presence or absence of a liner had little influence on risk levels (see section on major factors affecting health risk). Many of the scenarios in the figure show zero risk because the nearest potential exposure well was estimated to be more than 2 kilometers away (roughly 61 percent of all scenarios).

Under best-estimate assumptions, there were no cancer risks from arsenic because arsenic was not included as a constituent of the modeled waste (i.e., the median arsenic concentration in the field sampling data was below detaction limits; see Table V-1). Under conservative assumptions, nonzero cancer risks resulting. from arsenic were estimated for 18 percent of the nationally weighted reserve pit scenarios, with roughly 2 percent of the scenarios having cancer risks greater than $1 \times 10^{-7}$. Even under conservative modeling assumptions, drilling waste pit scenarios produced maximum lifetime cancer risks of less than 1 in 100,000 for individuals drinking affected water.

A few threshold exceedances for sodium were estimated under both best-estimate and conservative assumptions. Under best-estimate assumptions, more than 99 percent of nationally weighted reserve pit scenarios posed no noncancer risk (i.e., they were below threshold). A few model scenarios had norcancer risks, but none exceeded 10 times the sodium threshold. Under conservative assumptions, 98 percent of nationally weighted reserve pit scenarios did not pose a noncancer risk. The remaining 2 percent of reserve pit scenarios had estimated exposure point sodium concentrations between up to 32 times the threshold. 

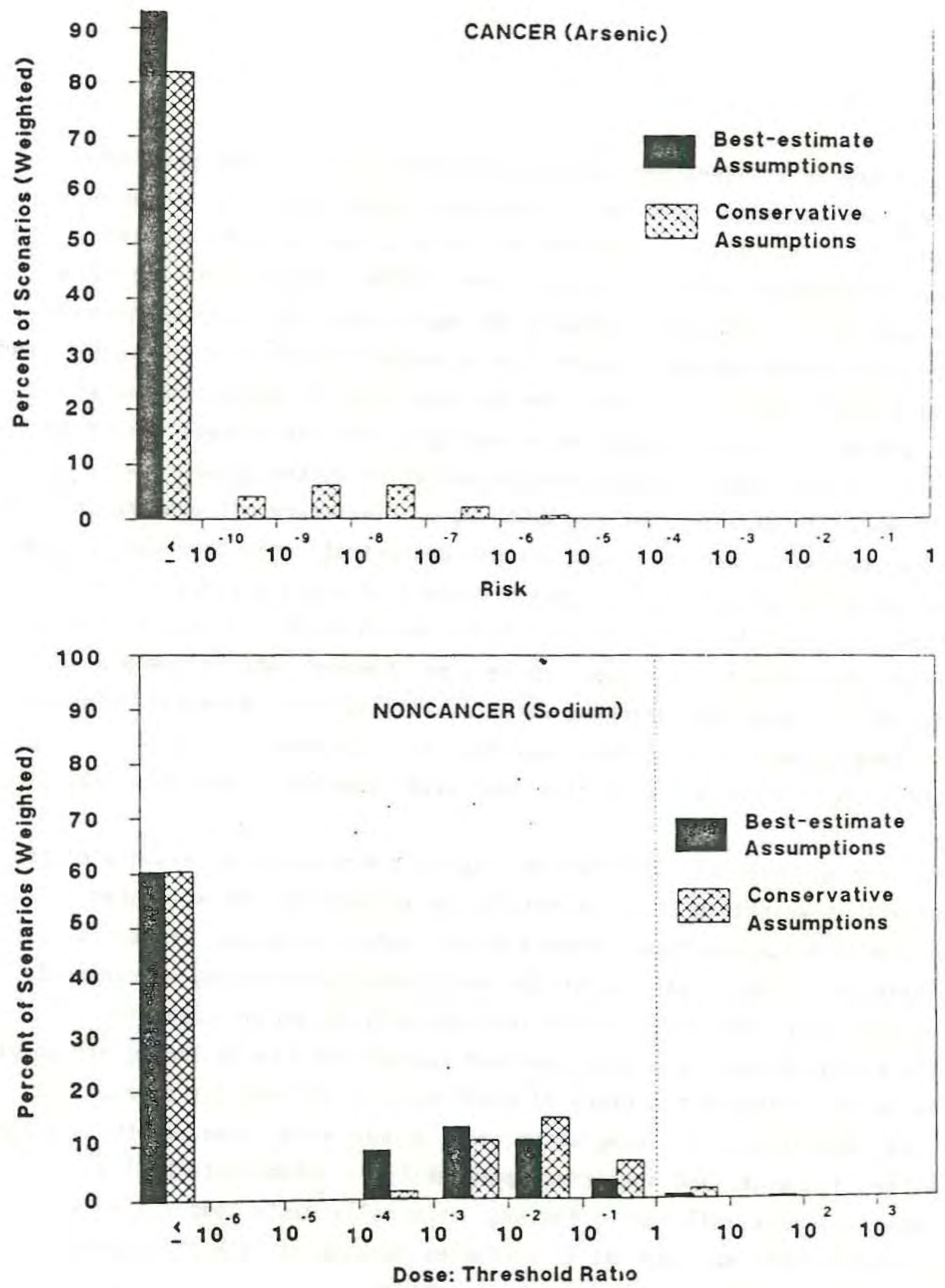

Figure V-3 Nationally Weighted Distribution of Health Risk Estimates. Unlined Reserve Pits 
Based on a literature review conducted as part of the development of the Liner Location Model data base (USEPA 1986), chloride is the only model drilling waste constituent for which either a taste or odor threshold concentration is known. EPA (1984b) reports that the taste threshold for chloride is roughly $250 \mathrm{mg} / \mathrm{L}$ (i.e., this is the minimum chloride concentration in water that a person may be atle to taste). For the highest cancer risk case, the maximum chloride concentration at the exposure well was estimated to be $400 \mathrm{mg} / \mathrm{L}$; for the highest noncancer risk case, the maximum chloride concentration at the exposure well was estimated to be approximately $5,000 \mathrm{mg} / \mathrm{L}$. Therefore, it appears that, if water contained a high enough arsenic concentration to pose cancer risks on the order of $1 \times 10^{-5}$ or sodium concentrations 100 times the effect threshold, people may be able to taste the chloride that would also likely be present. The question remains, however, whether people would actually discontinue drinking water containing these elevated chloride concentrations. EPA (1984b) cautions that consumers may become accustomed to the taste of chloride levels somewhat higher than $250 \mathrm{mg} / \mathrm{L}$.

For purposes of illustration, Figure V-4 provides an example of the effect of weighting the risk results to account for the estimated national frequency of occurrence of the model scenarios. Essentially, weighting allows risk results for more commonly occurring scenarios to "count" more than results from less commonly occurring scenarios. Weighting factors were developed and applied for the following variables, based on estimated frequency of occurrence at oil and gas sites: pit size, distance to drinking water well, ground-water type, depth to ground water, recharge, and subsurface permeability. Other potentially important risk-influencing factors, especially waste composition and strength, were not modeled as variables because of lack of information and thus are not accounted for by weighting.

In the example shown in Figure $\mathrm{V}-4$ (conservative-estimate cancer risks for unlined onsite pits), weighting the risk results decreases the 


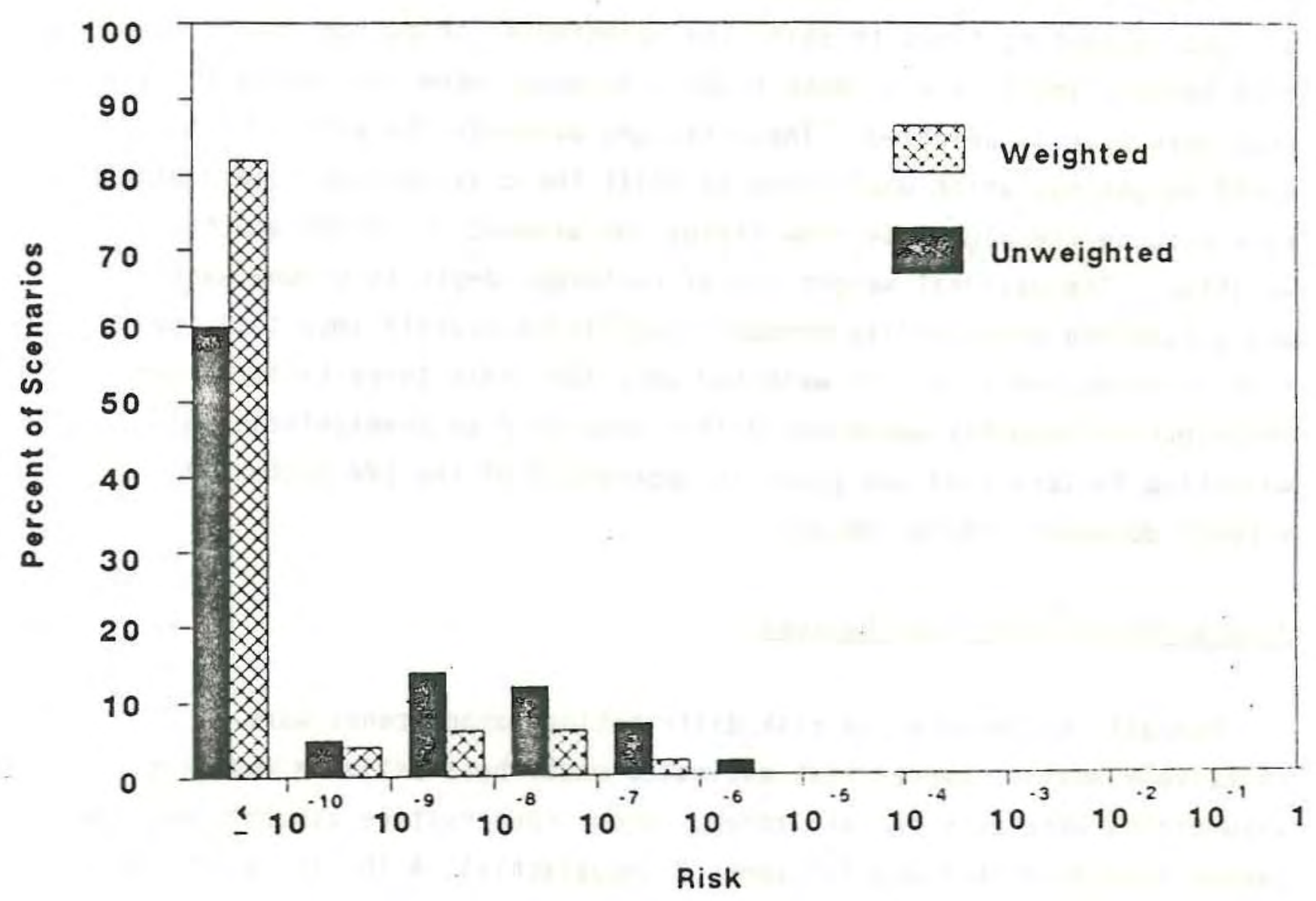

Figure V-4 Weighted vs. Unweighted Distribution of Cancer Risk Estimates. Unlined Reserve Pits. Conservative Modeling Assumptions 
risk (i.e., shifts the distribution toward lower risk). This happens primarily because close exposure distances (60 and 200 meters), which correspond to relatively high risks, occur less frequently and thus are less heavily weighted than greater distances. In addition, the effect of pit size weighting tends to shift the weighted distribution toward lower risk because small (i.e., lower risk) pits occur more frequently and are thus more heavily weighted. These factors override the effect of flow field weighting, which would tend to shift the distribution toward higher risk because the high-risk flow fields for arsenic ( $C$ and $D$ ) are heavily weighted. The national weightings of recharge, depth to ground water, and subsurface perneability probably had little overall impact on the risk distribution (i.e., if weighted only for these three factors, the distribution probably would not differ greatly from unweighted). All weighting factors used are given in Appendix $B$ of the EPA technical support document (USEPA 1987a).

\section{Zone-Weighted Risk Distributions}

Overall, differences in risk distributions among zones were relatively small. Cancer risk estimates under best-estimate modeling assumptions were zero for all zones. Under conservative assumptions, the cancer risk distributions for zones 2 (Appalachia), 4 (Gulf), 6 (Plains), and 7 (Texas/Oklahoma) were slightly higher than the distribution for the nation as a whole. The cancer risk distributions for zones 5 (Midwest), 8 (Northern Mountain), 9 (Southern Mountain), 10 (West Coast), and 11B (Alaska, non-North Slope) were lower than the nationally weighted distribution; zones 10 and $11 B$ were much lower. The risk distributions for individual zones generally varied from the national distribution by less than one order of magnitude.

Noncancer risk estimates under best-estimate modeling assumptions were extremely low for all zones. Under conservative assumptions, zones $2,4,5,7$, and 8 had a small percentage (1 to 10 percent) of weighted 
scenarios with threshold exceedances for sodium; other zones had less than 1 percent. There was little variability in the noncancer risk. distributions across zones.

The reasons behind the differences in risks across zones are related to the zone-specific relative weightings of reserve pit size, distance to receptor populations, and/or environmental variables. For example, the main reason zone 10 has low risks relative to other zones is that 92 percent of drilling sites were estimated to be in an arid setting above a relatively low-risk ground-water flow field having an aquitard (flow field $F$ ). Zone $11 \mathrm{~B}$ has zero risks because all potential exposure wells were estimated to be more than 2 kilometers away.

In summary, differences in cancer risks among the geographic zones were not great. Cancer risks were only prevalent in the faster aquifers (i.e., flow fields $C, D$, and $E$, with $C$ having the highest cancer risks). Zone 4, with the highest cancer risks overall, also was assigned the highest weighting among the zones for flow field $C$. Noncancer risks caused by sodium were highest in zone 5 . Noncancer risks occurred only in the more slow-moving flow fields (i.e., flow fields $A, B$, and $K$, with A having the highest noncancer risks); among the zones, zone 5 was assigned the highest weighting for flow field $A$. EPA considered the possible role of distributions of size and distance to exposure points, but determined that aquifer configuration and velocity probably contributed most strongly to observed zone differences in estimates of human health risks. The consistent lack of risk for zone 11B, however, is entirely because of the large distance to an exposure point. (See the section that follows on estimated population distributions.)

\section{Evaluation of Major Factors Affecting Health Risk}

EPA examined the effect of several parameters related to pit design ard environmental setting that were expected to influence the release and 
transport of contaminants leaking from onsite reserve pits. To assess the effect of each of these parameters in isolation, all other parameters were held constant for the comparisons. The results presented in this section are not weighted according to either national or zone-specific frequencies of occurrence. Instead, each model scenario is given equal weight. Thus, the following comparisons are not appropriate for drawing conclusions concerning leve?s of risk for the national population of onsite reserve pits. They are appropriate for examining the effect of selected parameters on estimates of human health risk.

The presence or absence of a conventional, single synthetic liner underneath an onsite reserve pit had virtually no effect on the 200-year maximum health risk estimates. A liner does affect timing of exposures and risks, however, by reducing the amounts of leachate (and chemicals) released early in the modeling period. EPA's modeling assumed a single synthetic liner with no leak detection or leachate collection. (Note that this is significantly different from the required Subtitle C liner system design for hazardous waste land disposal units.) Furthermore, EPA assumed that such a liner would eventually degrade and fail, resulting in release of the contaminants that had been contained. Thus, over a long modeling period, mobile contaminants that do not degrade or degrade very slowly (such as the ones modeled here) will produce similar maximum risks whether they are disposed of in single-synthetic-lined or unlined pits (unless a significant amount of the contained chemical is removed, such as by dredging). This finding should not be interpreted to discount the benefit of liners in general. Measures of risk over time periods shorter than 200 years would 1 ikely be lower for lined pits than for unlined ones. Moreover, by delaying any release of contaminants, liners provide the opportunity for management actions (e.g., removal) to help prevent contaminant seepage and to mitigate seepage should it occur. 
Figure V-5 represents unweighted risks associated with unlined reserve pits under the conservative modeling assumptions for three reserve pit sizes and three distances to the exposure point. Each combination of distance and reserve pit size includes the risk results from all environmental settings modeled (total of 63), equally weighted. Figure V-5 shows that the unweighted risk levels decline with increasing distance to the downgradient drinking water well. The decline is generally less than an order of magnitude from 60 to 200 meters, and greater than an order of magnitude from 200 to 1,500 meters. Median cancer risk values exceed $10^{-10}$ only at the 60 -meter distance, and median dose-to-threshold ratios for noncancer effects exceed 1.0 only for large pits at the 60-meter distance. Risks also decrease as reserve pit size decreases at all three distances, although risks for small and large pits are usually within the same order of magnitude.

Figure V- 6 compares risks across the seven ground-water flow field types modeled in this analysis. Both cancer and noncancer, risks vary substantially across flow fields. The noncancer risks (fron sodium) are greatest in the slower moving flow fields that provide less dilution (i.e., flow fields $A, B$, and $K$ ), while the cancer risks (from arsenic) are greatest in the higher velocity/higher flow settings (i.e., flow fields $C, D$, and E). Sodium is highly mobile in ground water, and it is diluted to below threshold levels more readily in the high-velocity/ high-flow aquifers. Arsenic is only moderately mobile in ground water and tends not to reach downgradient exposure points within the 200-year modeling period in the slower flow fields. If the modeling period were extended, cancer risks resulting from arsenic would appear in the more slowly moving flow field scenarios.

As would be expected, both cancer and noncancer risks increased with increasing recharge rate and with increasing subsurface permeability. Risk differences were generally less than an order of magnitude. Depth to ground water had very little effect on the 200-year maximum risk, 

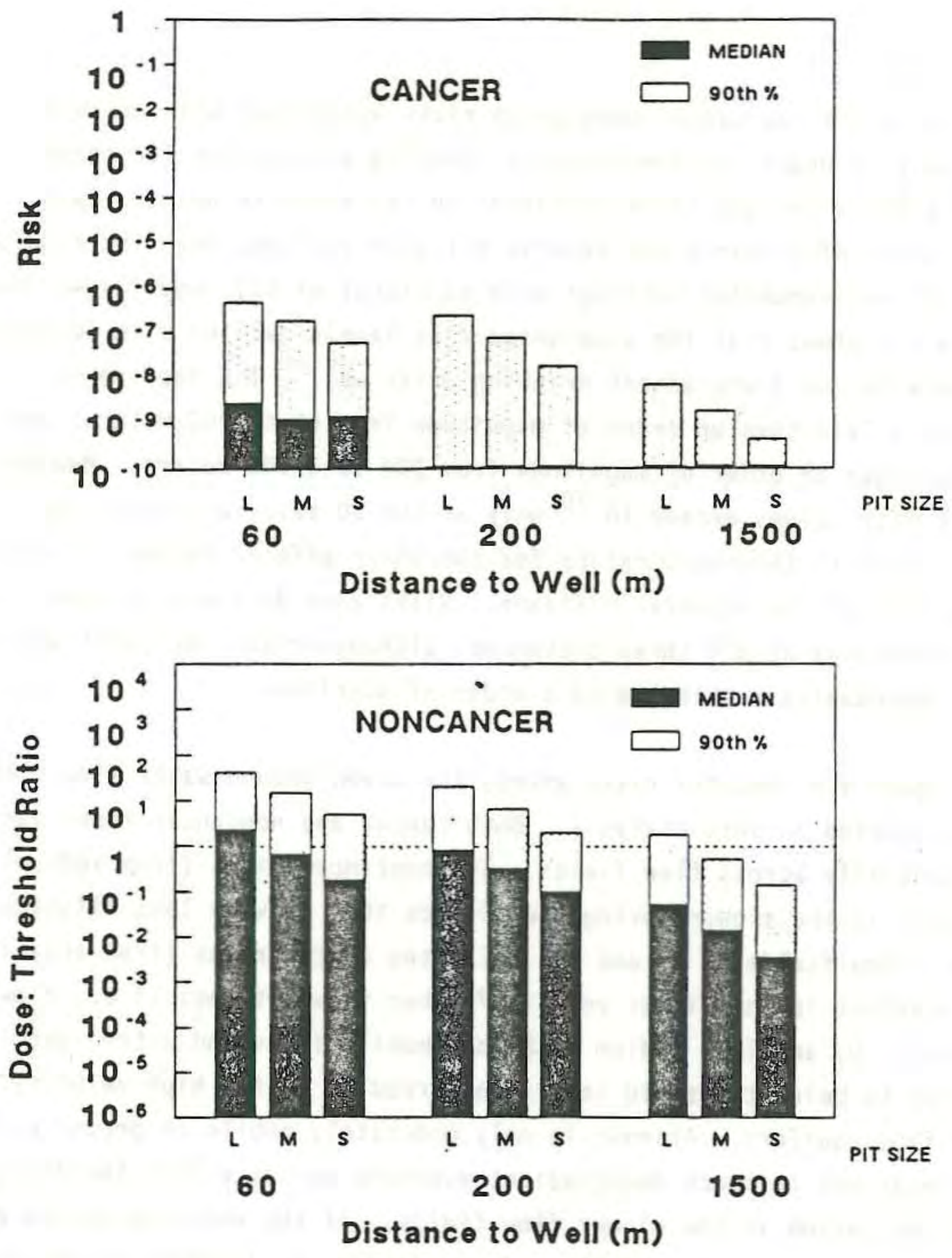

$L=L$ arge, $M=$ Medium, $S=$ Small Reserve PIts

Figure V-5 Health Risk Estimates (Unweighted) as a Function of Size and Distance. Unlined Reserve Pits. Conservative Modeling Assumptions 

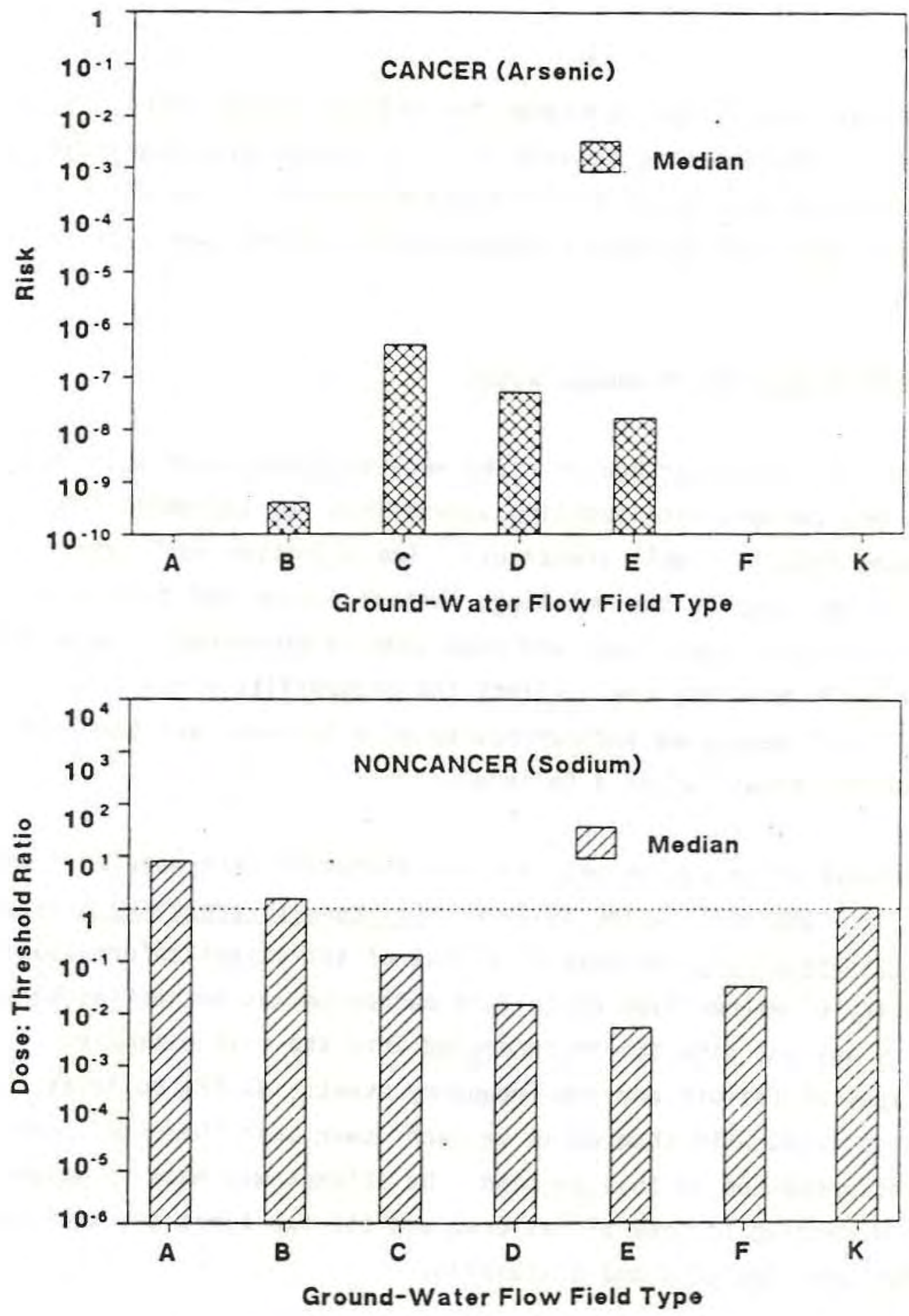

Figure V-6 Health Risk Estimates (Unweighted) as a Function of Ground-Water Type. Unlined Reserve Pits (Large). 60-Meter Exposure Distance. Conservative Modeling Assumptions 
a) though risks were slightly higher for shallow ground-water settings. This lack of effect occurs because the risk-producing contaminants are at least moderately mobile and do not degrade rapidly, if at all; thus, the main effect observed for deeper ground-water settings was a delay in exposures.

\section{Underground Injection--Produced Hater}

Cancer and noncancer health risks were analyzed under both bestestimate and conservative modeling assumptions for 168 model Class II underground injection well scenarios. ${ }^{9}$ Two injection well types were differentiated in the modeling: waterflooding and dedicated disposal. Design, operating, and regulatory differences between the two types of wells possibly could affect the probability of ofailure, the probability of detection and correction of a failure, and the likely magnitude of release given a failure.

Two types of injection well failure mechanism were modeled: grout seal failure and well casing failure. All results presented here assume that a failure occurs; because of a lack of sufficient information, the probability of either type of failure mechanism was not estimated and therefore was not directly incorporated into the risk estimates. If these types of failure are low-frequency events, as EPA believes, actual risks associated with them would be much lower than the conditional risk estimates preserited in this section. No attempt was made to weight risk results according to type of failure, and the two types are kept separate throughout the analysis and discussion.

\section{Nationally Weighted Risk Distributions}

The risk estimates associated with injection well failures were weighted based on the estimated frequency of occurrence of the following

\footnotetext{
$168=7$ ground-water flon field types $\times 3$ exposure distances $\times 2$ size categories $\times 2$ we 11 types $\times 2$ fallure mechanisms.
} 
variables: injection well type, distance to nearest drinking water well, and ground-water flow field type. In addition, all risk results for grout seal failure were weighted based on injection rate. As for reserve pits, insufficient information was available to account for waste characteristics and other possibly important variables by weighting.

Grout seal failure: Best-estimate cancer risks, given a grout seal failure, were estimated to be zero for more than 85 percent of the model scenarios. The remaining scenarios had slightly higher risks but never did the best-estimate cancer risk exceed $1 \times 10^{-7}$. Under conservative assumptions, roughly 65 percent of the scenarios were estimated to have zero cancer risk, while the remaining 35 percent were estimated to have cancer risks ranging up to $4 \times 10^{-4}$ (less than 1 percent of the scenarios had greater than $1 \times 10^{4}$ risk). These modeled cancer risks were attributable to exposure to two produced water constituents, benzene and arsenic. Figure V-7 (top portion) provides a nationally weighted frequency distribution of the best-estimate and conservative-estimate cancer risks, given a grout seal failure. Figure V-7 shows the combined distribution for the two well types and two injection rates considered in the analysis, the three exposure distances, and the seven ground-water settings. As with drilling pits, many of the zero risk cases were because the nearest potential exposure well was estimated to be more than 2 kiloneters away (roughly 64 percent of all scenarios).

Modeled noncancer risks, given a grout seal failure, are entirely attributable to exposures to sodium. There were no sodium threshold exceedances associated with grout seal failures under best-estimate conditions. Under conservative conditions, roughly 95 percent of the nationally weighted model scenarios also had no noncancer risk. The remaining 5 percent had estimated sodium concentrations at the exposure point that exceeded the effect threshold, with the maximum concentration exceeding the effect threshold by a factor of 70 . The nationally 

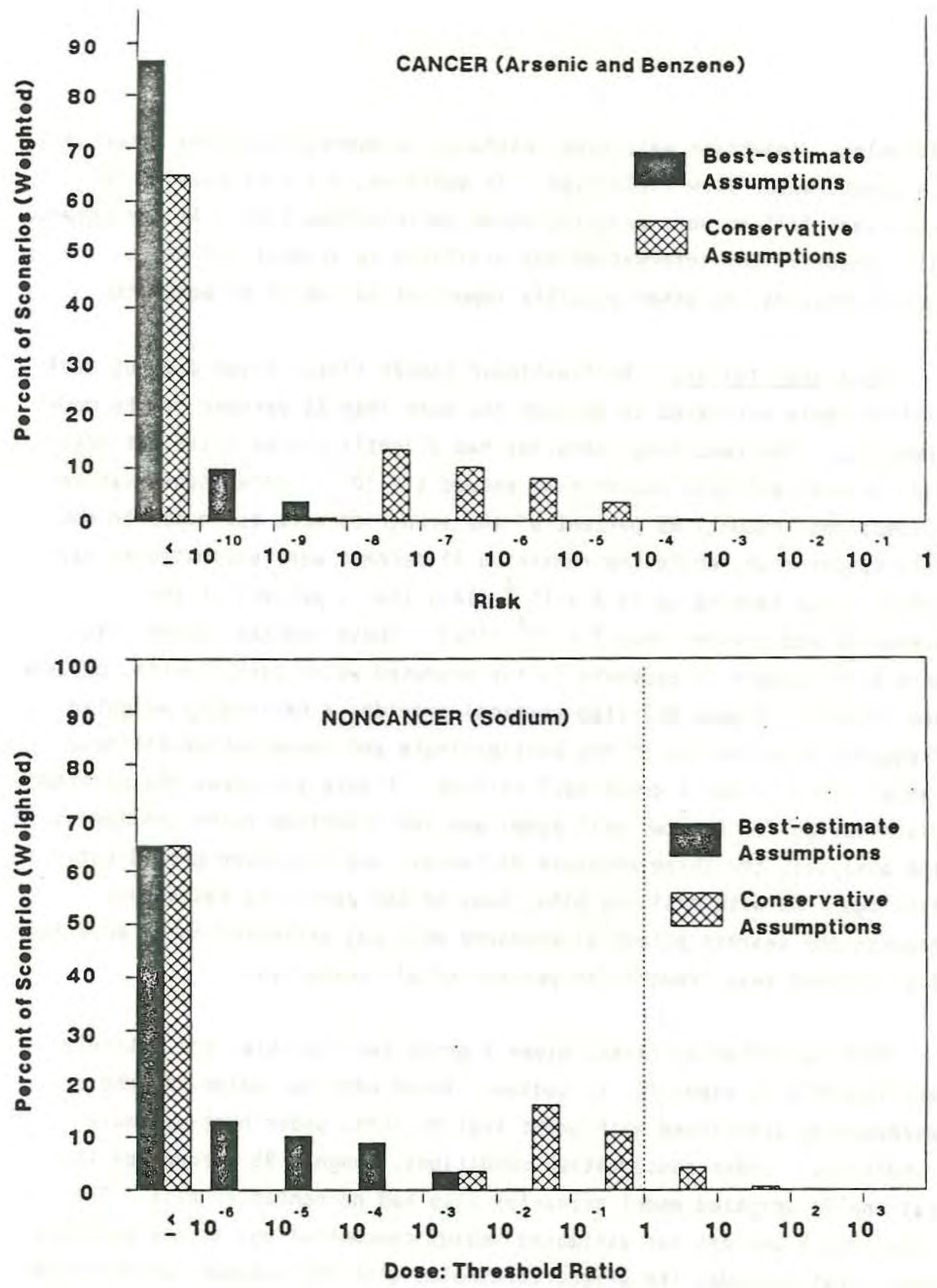

Figure V-7 Nationally Weighted Distribution of Health Risk Estimates. Underground Injection Wells: Grout Seal Failure Assumed 
weighted frequency distribution of the estimated dose/threshold ratios for sodium is shown in the bottom portion of Figure V-7.

Data are available on the taste and odor thresholds of two produced water model constituents: benzene ard chloride. For the maximum cancer risk scenario assuming a grout seal failure, the estimated concentrations of benzene and chloride at the exposure well were below their respective taste and odor thresholds. However, for the maximum noncancer risk scenario assuming a grout seal failure, the estimated chloride concentration did exceed the taste threshold by roughly a factor of three. Therefore, people might be able to taste chloride in the highest noncancer risk scenarios, but it is questionable whether anybody would discontinue drinking water containing such a chloride concentration.

Well casing failure: The nationally weighted distributions of estimated cancer and noncancer risks, given an injection well casing failure, are presented in Figures $V-8$ and $V-9$. Figure V-8 gives the risk distributions for scenarios with high injection pressure, and Figure V-9 gives the risk distributions for scenarios with low injection pressure. (Because of a lack of adequate data to estimate the distribution of injection pressures, results for the high and low pressure categories were not weighted and therefore had to be kept separate.)

Best-estimate cancer risks, given a casing failure, were zero for approximately 65 percent of both the high and low pressure scenarios; the remaining scenarios had cancer risk estimates ranging up to $5 \times 10^{-6}$ for high pressure and $1 \times 10^{-6}$ for low pressure. The majority (65 percent) of both high and low pressure scenarios also had no cancer risks under the conservative assumptions, although approximately 5 percent of the high pressure scenarios and 1 percent of the low pressure scenarios had conservative-estimate cancer risks greater than $1 \times 10^{-4}$ (maximum of $9 \times 10^{4}$ ). The rest of the scenarios had conservative-estimate cancer risks greater than zero and less than $1 \times 10^{-4}$. 

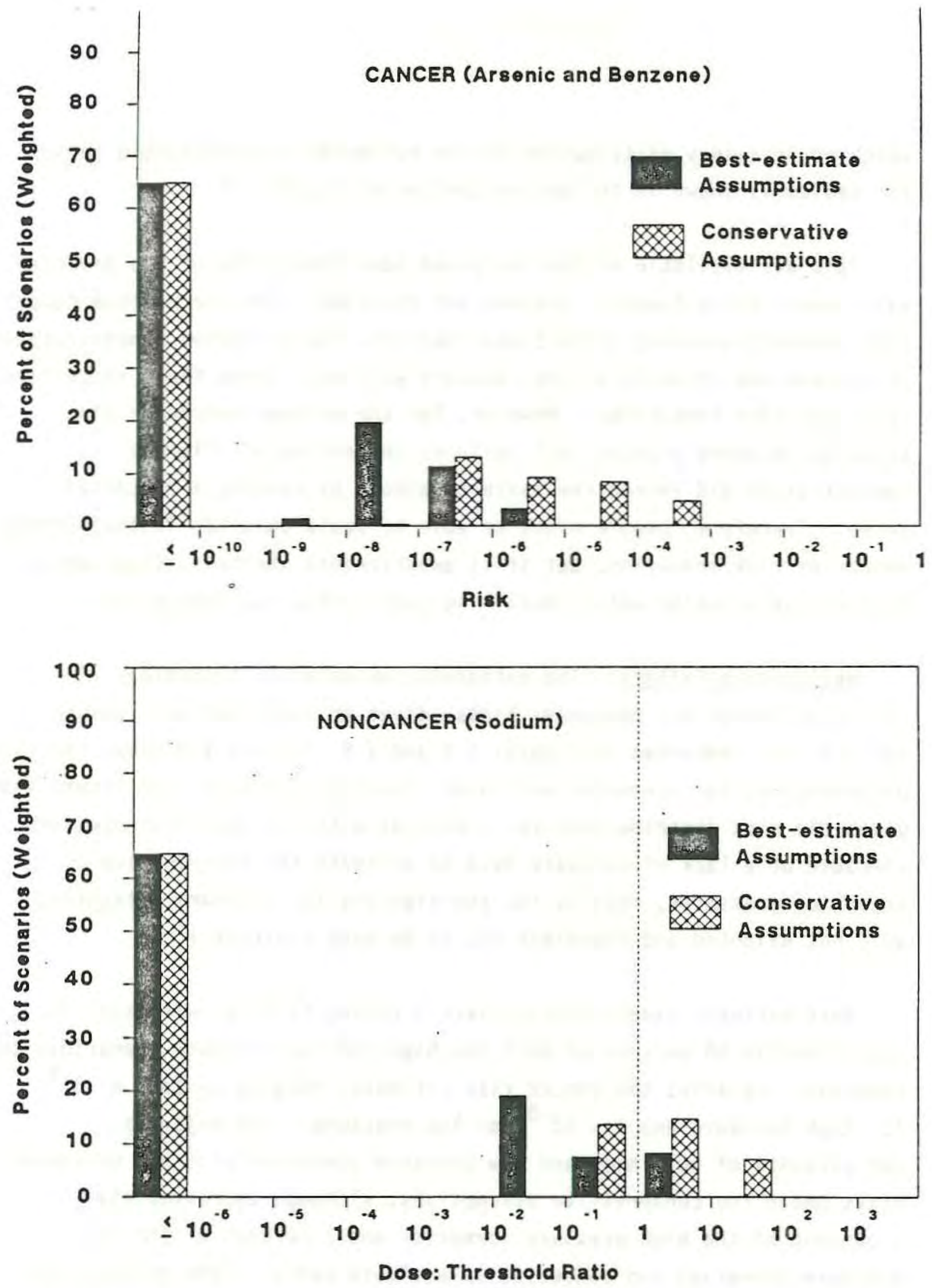

Figure V-8 Nationally Weighted Distribution of Health Risk Estimates. High Pressure Underground Injection Wells: Casing Failure Assumed 

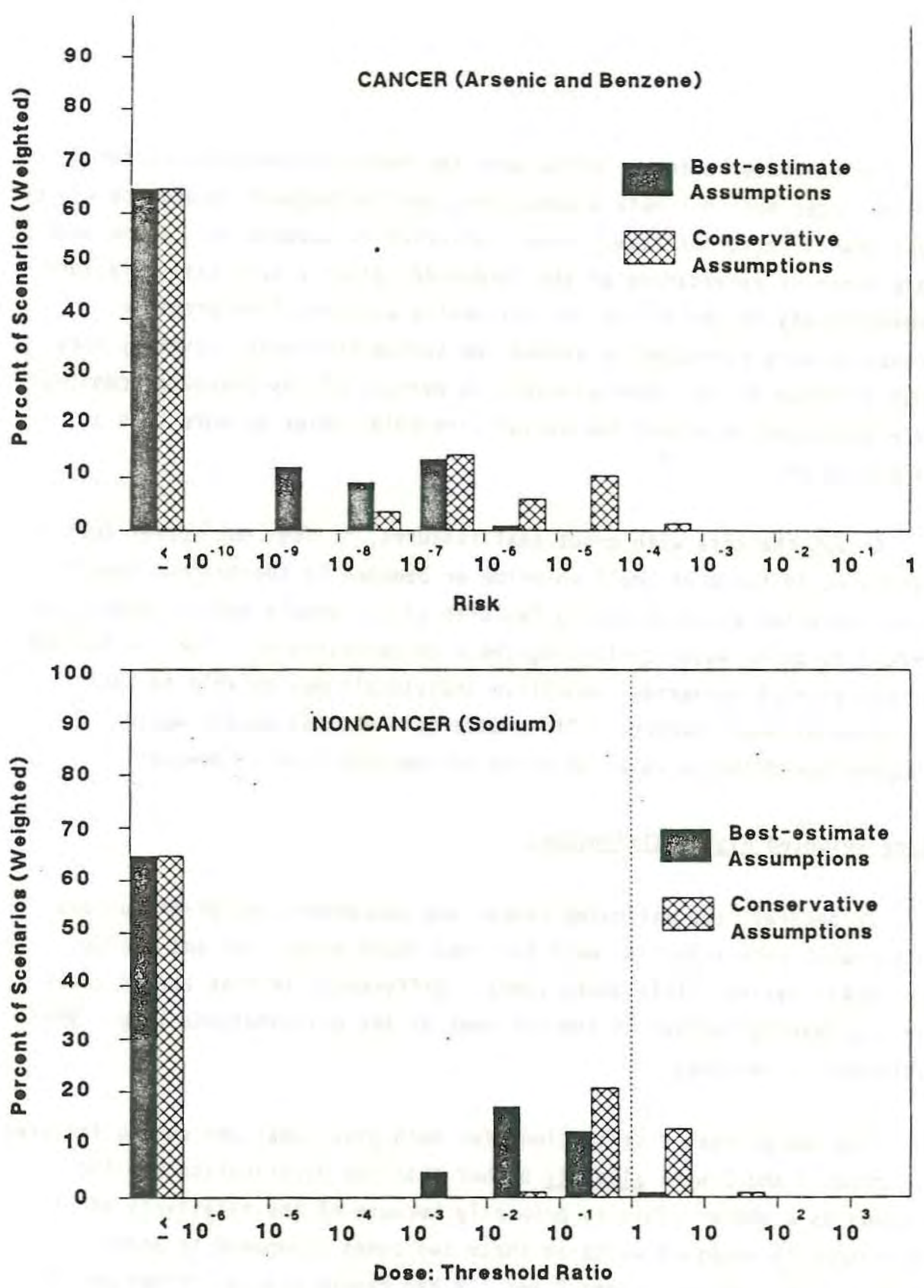

Figure V-9 Nationally Weighted Distribution of Health Risk Estimates. Low Pressure Underground Injection Wells: Casing Failure Assumed 
For noncancer effects, there were few threshold exceedances for sodium under best-estimate assumptions, and the highest exceedance was by less than a factor of five. Under conservative assumptions, there were more numerous exceedances of the threshold, given a well casing failure. Approximately 22 percent of the nationally weighted high pressure scenarios were estimated to exceed the sodium threshold, never by more than a factor of 70 . Approximately 14 percent of low pressure scenarios were estimated to exceed the sodium threshold, never by more than a factor of 35 .

As was the case with grout seal failures, it does not appear that people would taste or smell chloride or benzene in the maximum cancer risk scenarios assuming casing failures (i.e., people would probably not refuse to drink water containing these concentrations). For the maximum noncancer risk scenarios, sensitive individuals may be able to taste chloride or smell benzene. It is uncertain whether people would discontinue drinking water at these contaminant levels, however.

\section{Zone-Weighted Risk Distributions}

In general, the estimated cancer and noncancer risk distributions associated with injection well failures (both grout seal and casing failures) varied little among zones. Differences in risk across zones were primarily limited to the extremes of the distributions (e.g., 90th percentile, maximum).

The cancer risk distributions for both grout seal and casing failures in zones 2 and 5 were slightly higher than the distribution for the nation as a whole. This is primarily because of the relatively short distances to exposure wells in these two zones (compared to other zones). In contrast, zones 8 and $11 \mathrm{~B}$ had cancer risk distributions for injection well failures that were slightly lower than the national 
distribution. This difference is primarily because of the relatively long distance to exposure wells in these zones. (For almost 80 percent of production sites in both zones, it was estimated that the closest exposure well was more than 2 kilometers away.) A similar pattern of zone differences was observed for the noncancer risk results.

\section{Evaluation of Major Factors Affecting Health Risk}

In general, estimated risks associated with well casing failure are from one to two orders of magnitude higher than risks associated with grout seal failure. This is because under most conditions modeled, well casing failures are estimated to release a greater waste volume, and thus a larger mass of contaminants, than grout seal failures.

The risks estimated for disposal and waterflood wells are generally similar in magnitude. For assumed casing failures, waterflood wells are estimated to cause slightly (no more than a factor of 2.5 times) higher risks than disposal wells. This pattern is the net result of two differences in the way waterflood and disposal wells were modeled. The release durations modeled for disposal wells are longer than those for waterflood wells, but the injection pressures modeled for waterflood wells are greater than those modeled for disposal wells. For assumed grout seal failures, disposal wells are estimated to cause slightly (no more than a factor of 3 tines) higher risks than waterflood wells. This pattern results because the injection rates modeled for disposal wells are up to 3 times greater than those modeled for waterflood wells.

The distance to a potentially affected exposure well at an injection site is one of the most important indicators of risk potential. If all other parameters remain constant, carcinogenic risks decline slightly less than one order of magnitude between the 60-meter and 200-meter well distances; carcinogenic risks decline between one and two orders of 
magnitude from the 200-meter to the 1,500-meter well distances. The effect of well distance is a little less pronounced for noncarcinogenic risks. Sodium threshold exceedances drop by less than an order of magnitude between the 60-meter and 200-meter well distances and by approximately one order of magnitude between the 200-meter and 1,500-meter well distances. The reduction in exposure with increased distance from the well is attributable to three-dimensional dispersion of contaminants within the saturated zone. In addition, the 200-year modeling period limits risks resulting from less mobile constituents at greater distances (especially 1,500 meters). Degradation is not a factor because the constituents producing risk degrade very slowly (if at all) in the saturated zone.

Cancer and noncancer risk estimates decrease with decreasing injection rate/pressure. This relationship reflects the dependence of risk upon the total chemical mass released into the aquifer each year, which is proportional to either the assumed injection flow rate (grout seal failure) or pressure (casing failure).

Figure $V-10$ shows how the unweighted health risk estimates associated with injection well casing failures varied for the different ground-water flow fields. The figure includes only results for the conservative modeling assumptions, the high injection pressure, and the 60-meter modeling distance, because risk estimates under best-estimate assumptions and for other modeling conditions were substantially reduced and less varied. As shown, conservative-estimate carcinogenic risks ranged from roughly $2 \times 10^{-6}$ (for flow field $F$ ) to approximately $6 \times 10^{-4}$ (for flow field $D)$. The difference in the risk estimates for these two flow fields is due primarily to their different aquifer configurations. Flow field $D$ represents an unconfined aquifer, which is more susceptible to contamination than a confined aquifer setting represented by flow field $F$. 

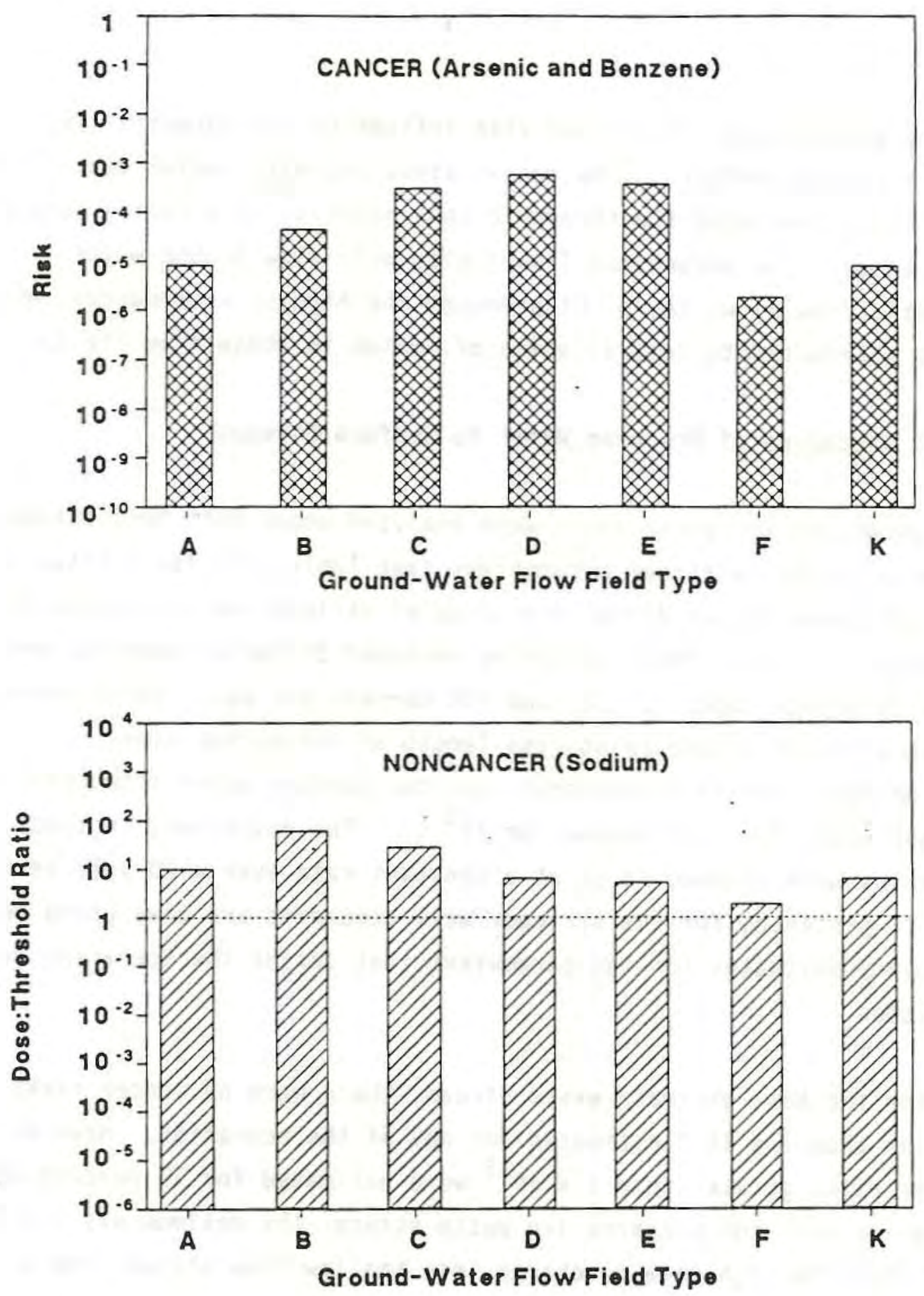

Figure V-10 Health Risk Estimates (Unweighted) as a Function of Ground-Water Type. High Pressure Underground Injection Wells: Casing Failure Assumed. 60-Meter Exposure Distance. Conservative Modeling Assumptions 
The ground-water flow field also influenced the potential for noncarcinogenic effects. The conservative-estimate sodium concentrations at 60 meters exceeded the threshold concentration by a factor ranging up to 70 times. The unconfined flow fields with slow ground-water velocities/low flows ( $A, B, C)$ produced the highest exceedances, which can be attributed to less dilution of sodium in these flow fields.

Direct Discharge of Produced Water to Surface Streams

Cancer and noncancer risks were analyzed under both best-estimate and conservative waste stream assumptions (see Table V-1) for a total of 18 model scenarios of direct discharge of stripper well-produced fluids to surface waters. These scenarios included different combinations of three discharge rates ( 1,10 , and 100 barrels per day), three downstream distances to an intake point (the length of the mixing zone, 5 kilometers, and 50 kilometers), and two surface water flow rates ( 40 and 850 cubic feet per second, or $\mathrm{ft}^{3} / \mathrm{s}$ ). The discharges in these scenarios were assumed to be at a constant rate over a 20 -yeár period. Results presented for the stripper well scenarios are unweighted because frequency estimates for the parameters that define the scenarios were not developed.

For the best-estimate waste stream, there were no cancer risks greater than $1 \times 10^{-5}$ estimated for any of the scenarios. However, cancer risks greater than $1 \times 10^{-5}$ were estimated for 17 percent of the scenarios with the conservative waste stream--the maximum was $3.5 \mathrm{x}$ $10^{-5}$ (for the high-rate discharge into the low-flow stream, and a drinking water intake immediately downstream of the discharge point). These cancer risks were due primarily to exposure to arsenic, although benzene also contributed slightly. For noncancer risks, none of the scenarios had a threshold exceedance for sodium, regardless of whether the best-estimate or conservative waste stream was assumed. 
EPA recognizes that the model surface water flow rates ( 40 and $850 \mathrm{ft}^{3} / \mathrm{s}$ ) are relatively high and that discharges into streams or rivers with flow rates less than $40 \mathrm{ft}^{3} / \mathrm{s}$ could result in greater risks than are presented here. Therefore, to supplement the risk results for the model scenarios, EPA analyzed what a river or stream flow rate would have to be (given the model waste stream concentrations and discharges rates) in order for the contaminant concentration in the mixing zone (assuming instantaneous and complete mixing but no other removal processes) to be at certain levels.

The results of this analysis, presented in Table V-8, demonstrate that reference concentrations of benzene would be exceeded only in very low-flow streams (i.e., less than $5 \mathrm{ft}^{3} / \mathrm{s}$ ) under all of the model conditions analyzed. It is unlikely that streams of this size would be used as drinking water sources for long periods of time. However, concentrations of arsenic and sodium under conservative modeling conditions could exceed reference levels in the mixing zone in relatively large streams, which might be used as drinking water sources. The concentrations would be reduced at downstream distances, although estimates of the surface water flow rates corresponding to reference concentrations at different distances have not been made.

\section{Potentially Exposed Population}

Preliminary estimates of the potentially exposed popu?ation were developed by estimating the number of individuals using private drinking water wells and public water supplies located downgradient from a sample of $0 i l$ and gas wells. These estimates were based on data obtained from local water suppliers and 300 USGS topographic maps. One hundred of the maps were selected from areas containing high levels of drilling activity, and 200 were selected from areas containing high levels of production. 
Table V-8 Surface Water Flow Rates At Which Concentrations of Waste Stream Constituents in the Mixing Zone Will Exceed Reference Levels ${ }^{a}$

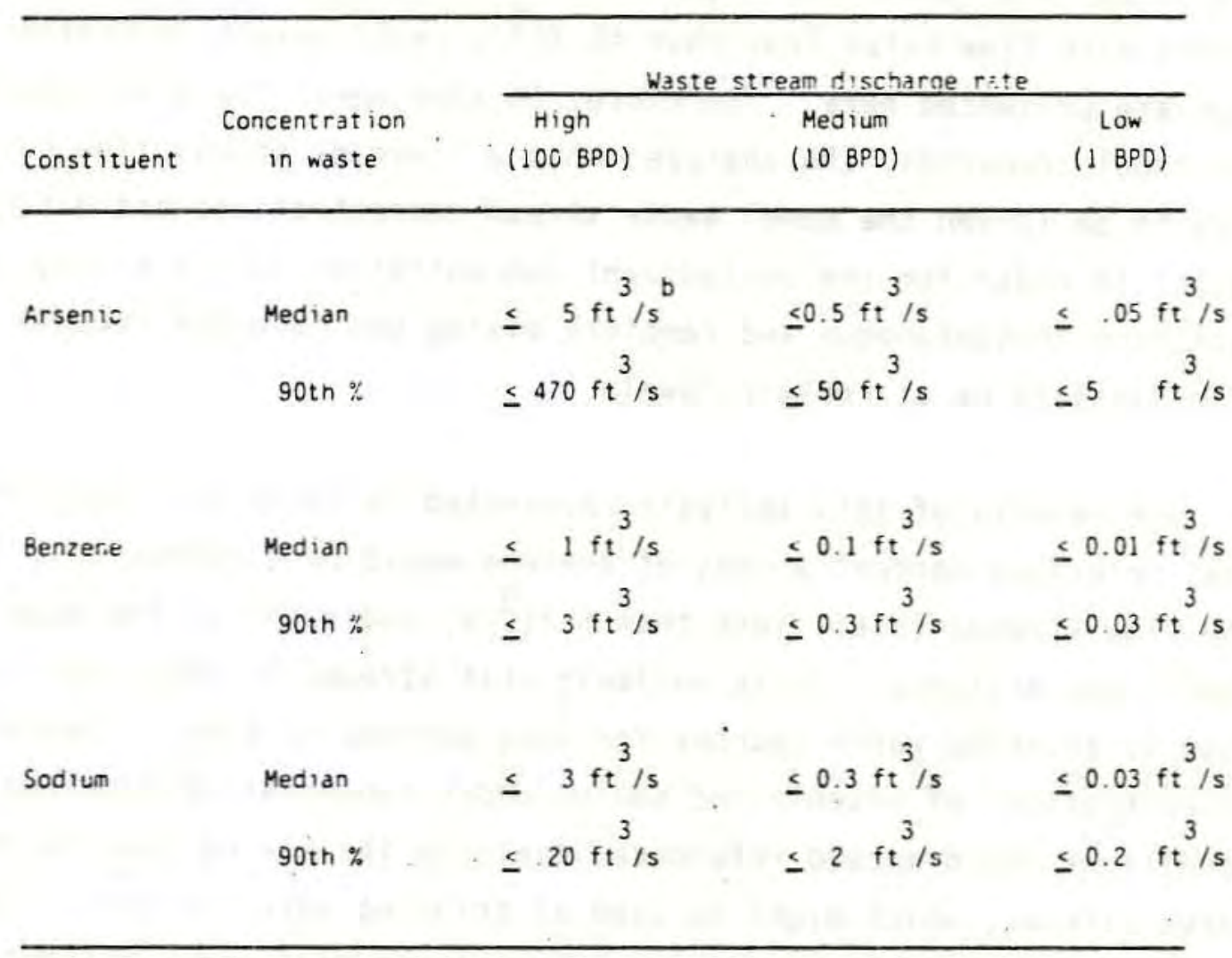

a The reference levels referred to are the arsenic and benzene concentrations that correspond to a $1 \times 10^{-5}$ lifet ime cancer risk level (assuming a $70-\mathrm{kg}$ individual ingests $2 \mathrm{~L} / \mathrm{d}$ ) and EPA's suggested guidance level for sodium for the prevention of hypertension in hign-risk individuals.

b Should be interpreted to mean that the concentration of arsenic in the mixing zone would exceed the $1 \times 10^{-5}$ lifet ime cancer rish level if the receiving stream or river was flowing at a rate of $5 \mathrm{ft}^{3} / \mathrm{s}$ or lower. If the stream or river was flowing at a higher rate, then the maximum concentration of arsenic would not exceed the $1 \times 10^{-5}$ lifet ime cancer risk level. 
Table V-9 summarizes the sample results for the population potentially exposed through private drinking water wells. As shown in this table, over 60 percent of the $0 i 1$ and gas wells in both the drilling and production sample did not have private drinking water wells within 2,000 meters downgradient and only 2 percent of the 0 il and gas wells were estimated to have private drinking water wells within the 60 -meter (i.e., higher-risk) distance category. Moreover, the numbers of potentially affected people per 011 and gas well in the 60-meter distance category were relatively small. One other interesting finding demonstrated in Table $V-9$ is that fewer potentially affected individuals were estimated to be in the 1,500-meter distance category than in the 200-meter category. This situation is believed to occur because some residences located farther from oil and gas wells were on the other side of surface waters that appeared to be a point of ground-water discharge.

The sample results for the population potentially exposed through public water supplies are summarized in Table $V-10$. These results show a pattern similar to those for private drinking water wells; this is, most 0 il and gas wells do not have public water supply intakes within 2,000 meters and of those that do only a small fraction have public water supply intakes within the 60-meter distance category.

The results in Tables $V-9$ and $V-10$ are for the nation as a whole. Recognizing the limitations of the sample and of the analysis methods, EPA's data suggest that zone 2 (Appalachia) and zone 7 (Texas/Oklahoma) have the greatest relative number of potentially affected individuals per oil and gas well (i.e., potentially affected individuals are, on the average, closer to oil and gas wells in these zones relative to other zones). In addition, zone 4 (Gulf) has a relatively large number of individuals potentially affected through public water supplies. Zone 11 (Alaska) and zone 8 (Northern Mountain) appear to have relatively fewer potentially affected individuals per oil and gas well. Further 
Table V-g Population Potentially Exposed Through Private Drinking Water Wells at Sample Drilling and Production Areas

\begin{tabular}{|c|c|c|c|c|}
\hline \multirow[b]{2}{*}{$\begin{array}{l}\text { Distance } \\
\text { category }\end{array}$} & \multicolumn{2}{|c|}{ Drilling samole results } & \multicolumn{2}{|c|}{ Production sample results } \\
\hline & $\begin{array}{l}\left.\text { No. ( } \begin{array}{l}\mu \\
w\end{array}\right) \text { of } 011 / \text { gas } \\
\text { wells with private } \\
\text { drinking water } \\
\text { wells within } \\
\text { distance category }\end{array}$ & $\begin{array}{l}\text { Maximum no. of } \\
\text { potentially affected } \\
\text { individuals per oil } \\
\text { and gas we } 1 l^{b}\end{array}$ & $\begin{array}{l}\text { No. }(\%) \text { of oil/gas } \\
\text { wells with private } \\
\text { drinking water } \\
\text { wells within } \\
\text { distance category }\end{array}$ & $\begin{array}{l}\text { Maximum no. of } \\
\text { potent ially affected } \\
\text { individuals per oil } \\
\text { and gas we } 11^{b}\end{array}$ \\
\hline 60 meters & $561(2)$ & 0.11 & $6+2(2)$ & 0.17 \\
\hline 200 meters & $4.765(17)$ & 0.44 & $5.139(16)$ & 0.58 \\
\hline 1.500 meters & $5.606(20)$ & 0.32 & $5,460(17)$ & 0.36 \\
\hline$>2,000$ meters & $17.096(61)$ & $\mathrm{NA}^{\mathrm{C}}$ & $20,879(65)$ & NA \\
\hline
\end{tabular}

aDrinhing water wells were counted as 80 meters downgradient if they were within 0 and 130 meters, were . counted as 200 meters downgradient if they were within 130 and 800 meters, and were counted as 1.500 meters duwngradient if they were within 800 and 2,000 meters.

bThese ratios largely overest imate the number of people actually affected per oil and gas well (see text) and should be used to est imate the tutal number of people affected only with caltion. The figures are intended simply to give a preliminary indication of the potentially exposed population and the distribution of that population in different distance categories.

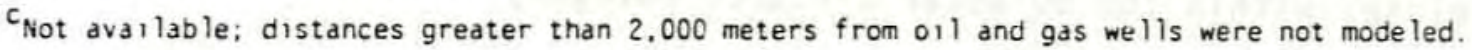


Table V-10 Population Potentially Exposed Through Public Water

Supplies at Sample Drilling and Production Areas

\begin{tabular}{|c|c|c|c|c|c|c|}
\hline \multirow{3}{*}{$\begin{array}{l}\text { Distance } \\
\text { Category }\end{array}$} & \multicolumn{3}{|c|}{ Drillina sample results } & \multicolumn{3}{|c|}{ Production sample results } \\
\hline & \multicolumn{2}{|c|}{$\begin{array}{l}\text { No. (洋) of } 011 / \text { gas } \\
\text { wells with private } \\
\text { drinking water } \\
\text { wells within } \\
\text { distance categury }\end{array}$} & \multirow{2}{*}{$\begin{array}{l}\text { Maximum no. of } \\
\text { potentially affected } \\
\text { individuals per o11 } \\
\text { and gas we } 11^{b} \\
3.6\end{array}$} & \multicolumn{2}{|c|}{$\begin{array}{l}\text { No. }(\%) \text { of } 0 i 1 / g a s \\
\text { wells with private } \\
\text { drinking water } \\
\text { wel's within } \\
\text { distance category }\end{array}$} & \multirow{2}{*}{$\begin{array}{l}\text { Maximum no. of } \\
\text { potentially affected } \\
\text { individuals per oil } \\
\text { and gas well } \\
96\end{array}$} \\
\hline & 87 & $(0.3)$ & & 54 & $(0.2)$ & \\
\hline 200 meters & 217 & $(0.8)$ & 0.76 & 210 & $(0.7)$ & 8.1 \\
\hline 1,500 meters & 232 & $(0.8)$ & 0.55 & 617 & (2) & 3.9 \\
\hline$>2.000$ meters & 27.492 & $(98)$ & $N A^{C}$ & 31,239 & (97) & $N A^{C}$ \\
\hline
\end{tabular}

${ }^{a}$ Public water supply intakes were counted as 60 meters downgradient if they were within 0 and 130 meters, were counted as 200 meters downgradient if they were within 130 and 800 meters, and were counted ds 1,500 meters downgradient if they were within 800 and 2,000 meters.

DThese ratios largely overestimate the number of people actually affected per oil and gas well (see text) and should be used to est unate the total number of people affected only with caution. The figures are intended simply to give a preliminary indication of the potentially exposed population and the distribution of that population in different distance categories.

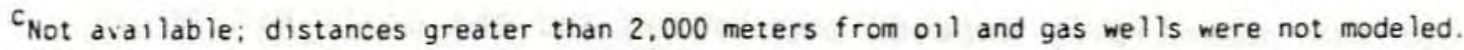


discussion of the differences in population estimates across zones is provided in the supporting technical report (USEPA 1987a).

The number of potentially affected people per oil and gas well in Tables $V-9$ and $V-10$ represents the maximum number of people in the sample that could be affected if all the oil and gas wells in the sample resulted in ground-water contamination out to 2,000 meters. The number of persons actually affected is probably much smaller because ground water may not be contaminated at all (if any) of the sites, some of the individuals may rely on surface water or rainwater rather than on ground water, and some of the individuals and public water supplies may not have drinking water wells that are hydraulically connected to possible release sources. Also, the sample population potentially exposed through public water supplies is probably far less than estimated, because public water is frequently treated prior to consumption (possibly resulting in the removal of oil and gas waste contaminants) and because many supply systems utilize multiple sources of water, with water only at times being drawn from possibly contaminated sources. Therefore, these ratios largely overestimate the number of people actually exposed per oil and gas well and should be used to estimate the total number of people affected only with caution. The figures are intended simply to give a preliminary indication of the potentially exposed population and the distribution of that population in different distance categories.

\section{QUANTITATIVE RISK MCDELING RESULTS: RESOURCE DAMAGE}

For the purposes of this study, resource damage is defined as the exceedance of pre-set threshold (i.e., "acceptable") concentrations for individual contaminants, based on levels associated with aquatic toxicity, taste and odor, or other adverse impacts. Potential ground-water and surface water damage was measured as the maximum (over the 200-year modeling time period) annual volume of contaminated water 
flowing past various points downgradient or downstream of the source. Only the volume of water that exceeded a damage threshold concentration was considered to be contaminated. This measure of potential ground-water and surface water damage was computed for each of three distances downgradient or downstream from a source: 60, 200, and 1,500 meters.

These estimates of resource damage supplement, but should be considered separate from, the damage cases described in Chapter IV. The resource damage results summarized here are strictly for the model scenarios considered in this analysis, which represent: (1) seepage of reserve pit wastes; (2) releases of produced water from injection well failures; and (3) direct discharge of produced water from stripper wells to streams and rivers. While these releases may be similar to some of the damage cases described in Chapter IV, no attempt was made to correlate the scenarios to any given damage case(s). In addition, Chapter IV describes damage cases from several types of releases (e.g., land application) that were not modeled as part of this quantitative risk analysis.

\section{Potential Ground-Water Damage--Drilling Wastes}

Two contaminants were modeled for ground-water resource damage associated with onsite reserve pits. These contaminants were chloride ions in concentrations above EPA's secondary maximum contaminant level and total mobile ions (TMI) in concentrations exceeding the level of total dissolved salts predicted to be injurious to sensitive and moderately sensitive crops. Chloride is highly mobile in ground water and the other ions were assumed to be equally mobile.

On a national basis, the risks of significant ground-water damage were very low for the model scenarios included in the analysis. Under 
the best-estimate modeling assumptions, only 2 percent of nationally weighted reserve pit scenarios were estimated to cause measurable ground-water damage at 60 meters resulting from TMI. Under the conservative modeling assumptions, less than 10 percent of reserve pits were associated with ground-water plumes contaminated by chloride and TMI at 60 meters and fewer than 2 percent at 200 meters. On a regional basis, the upper 90th percentile of the distributions for resource damage, under conservative modeling assumptions, were above zero for zones 2, 5, and 8 . This zone pattern is similar to the zone pattern of noncancer human health risks from sodium. Flow field A was more heavily weighted for these three zones than for the remaining zones, and this flow field also was responsible for the highest downgradient concentrations of sodium of all the flow fields modeled.

The mobilities of chloride and total mobile salts in ground water were the sane as the mobility of sodium, which was responsible for the noncancer human health risks. Thus, the effects of several pit design and environmental parameters on the volume of ground water contaminated above criteria concentrations followed trends very similar to those followed by the noncancer human health risks. These parameters included reserve pit size, net recharge, subsurface permeability, and depth to ground water. In contrast to the trend in noncancer human health risks, however, the magnitude of resource damage sometimes increased with increasing distance from the reserve pit. This is because contaminant concentrations (and thus health risks) decrease with distance traveled; however, the width of a contaminant plume (and thus the volume of contaminated water) increases up to a point with distance traveled. Eventually, however, the center line concentration of the plume falls below threshold, and the estimated volume of contaminated water at that distance falls to zero. Finally, as was the case with noncancer human health risks, only the slower aquifers were associated with significant estimates of resource damage. 
Potential Ground-Hater Damage--Produced Water

As they were for drilling wastes, chloride and total mobile ions were modeled to estimate ground-water resource damage associated with underground injection of produced water. Under best-estimate conditions, the risk of ground water becoming contaminated above the thresholds if injection well casing failures were to occur was negligible. Furthermore, in all but a few scenarios (approximately 1 percent of the nationally weighted scenarios), the resource damage estimates did not exceed zero under conservative assumptions. Estimated resource damage was almost entirely confined to the 60 -meter modeling distance.

Grout seal failures were estimated to pose a slightly snialler risk of contaminating ground water above the chloride or TMI thresholds than injection well casing failures. In roughly 99 percent of the nationally weighted scenarios, grout seal failures never resulted in threshold exceedances, regardless of the set of conditions assumed (best-estimate vs. conservative) or the downgradient distance analyzed. Again, estimated resource damage was almost entire?y confined to the 60 -meter modeling distance.

In general, injection well failures were estimated to contamiriate larger volumies of ground water above the damage criteria under conditions involving higher injection rates/pressures and lower ground-water velocities/flows (i.e., flow fields $A, B, C$, and $K$ ). The estimated TMI concentration exceeded its threshold for the low injection rate very rarely, and only out to a distance of 60 meters. Chloride and TMI threshold exceedances were limited almost exclusively to conditions involving the high injection rate or pressure. The slower velocity/lower flow ground-water settings permit less dilution (i.e., a higher probability of threshold exceedance) of constituents modeled for resource damage effects. In a trend similar to that observed for health risks, 
waterflood wells were estinated to contaminate larger volumes of ground water than disposal wells under conditions involving casing failures, but disposal wells were estimated to contaminate larger volumes under conditions involving grout seal failures. Finally, the resource damage estimates for injection well failures (and also for reserve pit leachate) indicate that TMI is a greater contributor to ground-water coritamination than chloride. The reason for this difference is that the mobile salts concentration in the model produced water waste stream is more than three times the chloride concentration (see Table $V-1$ ), while the resource damage thresholds differ by a factor of two (see Table V-2).

\section{Potential Surface Water Damage}

EPA examined the potential for surface water damage resulting from the influx of ground water contaminated by reserve pit seepage and injection well failures, as well as surface water damage resulting from direct discharge of stripper well produced water. For all model scenarios, EPA estinated the average annual surface water concentrations of waste constituents to be below their respective thresholds at the point where they enter the surface water; that is, the threshold concentrations for various waste constituents were not exceeded even at the point of maximum concentration in surface waters. This is because the input chemical mass is diluted substantially upon entering the surface water. Surface water usually flows at a much higher rate than ground water and also allows for more complete mixing than ground water. Both of these factor suggest that there will be greater dilution in surface water than in ground water. One would expect, therefore, that the low concentrations in ground water estimated for reserve pit seepage and injection well failures would be diluted even further upon seeping into surface water. 
These limited modeling results do not imply that resource damage could not occur from larger releases, either through these or other migration pathways or from releases to lower flow surface waters (i.e., streams. with flows below $\left.40 \mathrm{ft}^{3} / \mathrm{s}\right)$. In addition, surface water damages could occur during short periods (less than a year) of low stream flow or peak waste discharge, which were not modeled in this study.

EPA analyzed what a river or stream flow rate would have to be (given the model produced water concentrations and discharge rates from stripper wells) in order for contaminant concentrations in the mixing zone (assuming instantaneous and complete mixing but not other removal processes) to exceed resource damage criteria. The results of this analysis are summarized in Table V-11. As shown, the maximum concentrations of chloride, boron, sodium, and TMI in streams or rivers caused by the discharge of produced water from stripper wells would (under nost modeling conditions) not exceed resource damage criteria unless the receiving stream or river was flowing at a rate below $1 \mathrm{ft}^{3} / \mathrm{s}$. The exceptions are scenarios with a conservative waste stream concentration and high discharge rate. If produced water was discharged to streams or rivers under these conditions, the maximum concentrations of sodium and TMI could exceed resource damage criteria in surface waters flowing up to $5 \mathrm{ft}^{3} / \mathrm{s}$. (The maximum concentrations in any surface water flowing at a greater rate would not exceed the criteria.)

The results suggest that, if produced waters from stripper wells are discharged to streams and rivers under conditions that are similar to those modeled, resource damage criteria would be exceeded only in very small streams.

\section{ASSESSMENT OF WASTE DISPOSAL ON ALASKA'S NORTH SLOPE}

In accordance with the scope of the study required by RCRA Section $8002(\mathrm{~m})$, this assessment addresses only the potential impacts associated 
Table V-11 Surface Water flow Rates At Which Concentrations of Waste Stream

Constituents in the Mixing Zone Will Exceed

Aquatic Efiects and Resource Damage Threshoids ${ }^{a}$

\begin{tabular}{|c|c|c|c|c|c|}
\hline \multirow[b]{2}{*}{ Constituent } & \multirow{2}{*}{\multicolumn{2}{|c|}{$\begin{array}{c}\text { Concentration } \\
\text { in waste }\end{array}$}} & \multicolumn{3}{|c|}{ Waste stream discharce rate } \\
\hline & & & High (100 BPO) & Medium (10 BPD) & Lon (1 BPD) \\
\hline \multirow[t]{2}{*}{ Sodium } & & Median & $\leq 0.7 \mathrm{ft}^{3} / \mathrm{s}^{\mathrm{b}}$ & $\leq 0.07 \mathrm{ft}^{3} / \mathrm{s}$ & $\leq 0.007 \mathrm{ft}^{3} / \mathrm{s}$ \\
\hline & & $90 \operatorname{th} \approx$ & $\leq 5 \quad \mathrm{ft}^{3} / \mathrm{s}$ & $\leq 0.5 \mathrm{ft}^{3} / \mathrm{s}$ & $\leq 0.05 \mathrm{ft}^{3} / \mathrm{s}$ \\
\hline \multirow[t]{2}{*}{ Chloride } & & Median & $\leq 0.2 \mathrm{ft}^{3} / \mathrm{s}$ & $\leq 0.02 \mathrm{ft}^{3} / \mathrm{s}$ & $\leq 0.002 \mathrm{ft}^{3} / \mathrm{s}$ \\
\hline & & $90 t h \%$ & $\leq 0.9 \mathrm{ft}^{3} / \mathrm{s}$ & $\leq 0.09 \mathrm{ft}^{3} / \mathrm{s}$ & $\leq 0.009 \mathrm{ft}^{3} / \mathrm{s}$ \\
\hline \multirow[t]{2}{*}{ Boron. } & & Median & $\leq 0.00 \mathrm{ft}^{3} / \mathrm{s}$ & $\leq 0.006 \mathrm{ft}^{3} / \mathrm{s}$ & $\leq 0.0006 \mathrm{ft}^{3} / \mathrm{s}$ \\
\hline & - & $90 \operatorname{th} \%$ & $\leq 0.8 \mathrm{ft}^{3} / \mathrm{s}$ & $\leq 0.08 \mathrm{ft}^{3} / \mathrm{s}$ & $\leq 0.008 \mathrm{ft}^{3} / \mathrm{s}$ \\
\hline \multirow[t]{2}{*}{ Total Mobile Ions } & ${ }^{\circ}$ & Median & $\leq 0.4 \mathrm{ft}^{3} / \mathrm{s}$ & $\leq 0.04 \mathrm{ft}^{3} / \mathrm{s}$ & $\leq 0.004 \mathrm{ft}^{3} / \mathrm{s}$ \\
\hline & & $90 \operatorname{th} \%$ & $\leq 2 \quad \mathrm{ft}^{3} / \mathrm{s}$ & $\leq 0.2 \mathrm{ft}^{3} / \mathrm{s}$ & $\leq 0.02 \mathrm{ft}^{3} / \mathrm{s}$ \\
\hline
\end{tabular}

${ }^{a}$ The effect thresholds and effects considered in this analysis were as follows: Sodium- 83 $\mathrm{mg} / \mathrm{L}$. which might result in toxic effects or osmoregulatory problems for freshwater dquat ic organisms (note: while this threshold is based on toxicity data reported in the literature. it is dependent on several assumptions and is speculative); chloride-- $250 \mathrm{mg} / \mathrm{L}$, which is EPA's secondary drinking water standard designed to prevent excess corrosion of pipes in hot water systems and to prevent objectionable tastes; boron--1 $\mathrm{mg} / \mathrm{L}$, which is a concentration in irrigdtion water that could damage sensitive crops (e.g., citrus trees; plum, pear, and apple trees: grapes: and avocados): and total mobile lons--335 mg/L. which may be a tolerable level for freshwater species but would probably put them at a disadvantage in compet ing with brackish or marine organisms.

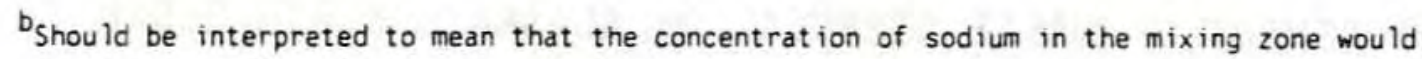
exceed the modeled effect threshold (described in footnote a) if the receiving stream or river was flowing at a rate of $0.7 \mathrm{ft}^{3} / \mathrm{s}$ or lower. If the stream or river was flowing at a higher rate, then the maximum concentration of sodium would not exceed the effect level. 
with the management of exempt oil and gas wastes on Alaska's North Slope. It does not analyze risks or impacts from other activities, such as site development or road construction. The North Slope is addressed in a separate, qualitative assessment because readily available release and transport models for possible use in a quantitative assessment are not appropriate for many of the characteristics of the North Slope, such as the freeze-thaw cycle, the presence of permafrost, and the typical reserve pit designs.

Of the various wastes and waste management practices on the North Slope, it appears that the management of drilling waste in above-ground reserve pits has the greatest potential for adverse environmental effects. The potential for drilling wastes to cause adverse human health effects is small because the potential for human exposure is small. Virtually all produced water on the North Slope is reinjected approximately 6,000 to 9,000 feet below the land surface in accordance with discharge permits issued by the State of Alaska. The receiving formation is not an underground source of drinking water and is effectively sealed from the surface by permafrost. Consequently, the potential for environmental or human health impacts associated with produced fluids is very small under routine operating conditions.

During the sunmer thaw, reserve pit fluids are disposed of in underground injection wells, released directly onto the tundra or applied to roads if they meet quality restrictions specified in Alaska discharge permits, or stored in reserve pits. Underground injection of reserve pit fluids should have minor adverse effects for the same reasons as were noted above for produced waters. If reserve pit fluids are nanaged through the other approaches, however, there is much greater potential for adverse environmental effects. 
Discharges of reserve pit fluids onto the tundra and roads are regulated by permits issued by the Alaska Department of Environmental Conservation (ADEC). In the past, reserve pit discharges have occasionally exceeded permit limitations for certain constituents. New permits, therefore, specify several pre-discharge requirements that must be met to help ensure that the discharce is carried out in an acceptable manner.

Only one U.S. Government study of the potential effects of reserve pit discharges on the North Slope is known to be complete. West and Snyder-Conn (1987), with the U.S. Fish and Wildlife Service, examined how reserve pit discharges in 1983 affected water quality and invertebrate communities in receiving tundra ponds and in hydrologically connected distant ponds. Although the nature of the data and the statistical analysis precluded a definitive determination of cause and effect, several constituents and characteristics (chromium, barium, arsenic, nickel, hardness, alkalinity, and turbidity) were found in elevated concentrations in receiving ponds when compared to control ponds. Also, alkalinity, chromiun, and aliphatic hydrocarbons were elevated in hydrologically connected distant ponds when compared to controls. Accompanying these water quality variations was a decrease in invertebrate taxonomic richness, diversity, and abundance from control ponds to receiving ponds.

West and Snyder-Conn, however, cautioned that these results cannot be wholly extrapolated to present-day oil field practices on the North Slope because some industry practices have changed since 1983. For example, they state that "chrome lignosulfonate drill muds have been partly replaced by non-chrome lignosulfonates, and diesel oil has been largely replaced with less toxic mineral oil in drilling operations." Also, State regulations concerning reserve pit discharges have become increasingly stringent since the time the study was conducted. West and 
Snyder-Conn additionally concluded that reserve pit discharges should be subject to standards for turbidity, alkalinity, chromium, arsenic, and barium to reduce the likelihood of biological impacts. ADEC's 1987 tundra discharge permit specifies effluent limitations for chromium, arsenic, barium, and several other inorganics, as well as an effluent limitation for settleable solids (which is related to turbidity). The 1987 permit requires monitoring for alkal inity, but does not specify an effluent limit for this parameter.

Reserve pits on the North Slope are frequently constructed above grade out of native soils and gravel. Below-grade structures are also built, generally at exploratory sites, and occasionally at newer production sites. Although the mud solids that settle at the bottom of the pits act as a barrier to fluid flow, fluids from above-ground reserve pits (when thawed) can seep through the pit walls and onto the tundra. No information was obtained on what percentage of the approximately 300 reserve pits on the North Slope are actually leaking; however, it has been documented that "some" pits do in fact seep (ARCO 1985, Standard 0i1 1987). While such seepage is expected to be sufficiently concentrated to adversely affect soil, water, vegetation, and dependent fauna in areas surrounding the reserve pits, it is not known how large an area around the pits may be affected. Preliminary studies provided by industry sources indicate that seepage from North Slope reserve pits, designed and managed in accordance with existing State regulations, should not cause damage to vegetation more than 50 feet away from the pit walls (ARCO 1986, Standard 0il 1987). It is important to note that ADEC adopted regulations that should help to reduce the occurrence of reserve pit seepage and any impacts of drilling waste disposal. These regulations became effective in September 1987.

While some of the potentially toxic constituents in reserve pit liquids are known to bioaccumulate (i.e., be taken up by organisms low in 
the food chain with subsequent accumulation in organisms higher in the food chain), there is no evidence to conclude that bioaccumulation from reserve pit discharge or seepage is occurring. In general, bioaccumulation is expected to be small because each spring thaw brings a large onrush of water that may help flush residual contamination, and higher level consumers are generally migratory and should not be exposed for extended periods. It is recognized, however, that tundra invertebrates constitute the major food source for many bird species on the Arctic coastal plain, particularly during the breeding and rearing seasons, which coincide with the period that tundra and road discharges occur. The Fish and Wildlife Service is in the process of investigating the effects of reserve pit fluids on invertebrates and birds, and these and other studies need to be completed before conclusions can be reached with respect to the occurrence of bioaccumulation on the North Slope.

With regard to the pit solids, the walls of operating pits have slumped on rare occasions, allowing mud and cuttings to spill onto the surrounding tundra. As long as these releases are promptly cleaned up, the adverse effects to vegetation, soil, and wildlife should be temporary (Pollen 1986, McKendrick 1986).

ADEC's new reserve pit closure regulations for the North Slope contain strengthened requirements for reserve pit solids to be dewatered, covered with earth materials, graded, and vegetated. The new regulations also require owners of reserve pits to continue monitoring and to maintain the cover for a minimum of 5 years after closure. If the reserve pit is constructed below grade such that the solids at closure are at least 2 feet below the bottom of the soil layer that thaws each spring, the solids will be kept permanently frozen (a phenomenon referred to as freezeback). The solids in closed above-grade pits will also undergo freezeback if they are covered with a sufficient layer of earth material to provide insulation. In cases where the solids are kept 
permanently frozen, no leaching or erosicn of the solid waste constituents should occur: However, $A D E C$ 's regulations do not require reserve pits to be closed in a manner that ensures freezeback.

Therefore, some operators may choose to close their pits in a way that permits the solids to thaw during the spring. Even when the, solids are not frozen, migration of the waste constituents will be inhibited by the reserve pit cover and the low rate of water infiltration through the solids. Nevertheless, in the long term, the cover could slump and allow increased snow accumulation in depressed areas. Melting of this snow could result in infiltration into the pit and subsequent leaching of the thawed solid waste contaminants. Also, for closed above-grade pits, long-term erosion of the cover could conceivably allow waste solids, if thawed, to migrate to surrounding areas. Periodic monitoring would forestall such possibilities.

\section{LOCATIONS OF OIL AND GAS ACTIVITIES IN RELATION TO ENVIRONMENTS OF SPECIAL IN'TEREST}

EPA analyzed the proximity of oil and gas activities to three categories of environments of special interest to the public: endangered and threatened species habitats, wetlands, and public lands. The results of this analysis are intended only to provide a rough approximation of the degree of and potential for overlap between oil and gas activities and these areas. The results should not be interpreted to mean that areas where oil and gas activities are located are necessarily adversely affected.

All of the 26 States having the highest levels of oil and gas activity are within the historical ranges of numerous endangered and threatened species habitats. However, of 190 counties across the U.S. identified as having high levels of exploration and production, only 13 
(or 7 percent) have Federally designated critical habitats ${ }^{10}$ within their boundaries. These 13 counties encompass the critical habitats for a total of 10 different species, or about 10 percent of the species for which critical habitats have been designated on the Federal level.

Wetlands create habitats for many forms of wildlife, purify natural waters by removing sediments and other contaminants, frovide flood and storm daniage protection, and afford a number of other benefits. In general, Alaska and Louisiana are the States with the most wetlands and $0 i 1$ and gas activity. Approximately 50 to 75 percent of the North Slope area consists of wetlands (Bergman et a1. 1977). Wetlands are also abundant throughout Florida, but oil and gas activity is considerably less in that State and is concentrated primarily in the panhandle area. In addition, oil and gas activities in 111 inois appear to be concentrated in areas with abundant wetlands. Other States with abundant wetlands (North Carolina, South Carolina, Georgia, New Jersey, Maine, and Minnesota) have very little onshore oil and gas activity.

For the purpose of this analysis, public lands are defined as the wide variety of land areas owned by the Federal Government and administered by the Bureau of Land Management (BLM), National Forest Service, or National Park Service. Any development on these lands must first pass through a formal environmental planning and review process. In many cases, these lands are not environmentally sensitive. National Forests, for example, are established for multiple uses, including timber development, mineral extraction, and the protection of environmental values. Public lands are included in this analysis, however, because they are considered "publicly sensitive," in the sense that they are commonly valued more highly by society than comparable areas outside

\footnotetext{
10 Critical habitats, which are much sinaller and more rigorously defined than historical ranges, are areas contairing physical or biological factors essential to the conservation of the species.
} 
their boundaries. The study focuses only on lands within the National Forest and National Park Systems because of recent public interest in oil and gas development in these areas (e.g., see Sierra Club 1986; Wilderness Society 1987).

The National Forest System comprises 282 National Forests, National Grasslands, and other areas and includes a total area of approximately 191 million acres. Federal oil and gas leases, for either exploration or production, have been granted for about $25 \mathrm{million}$ acres (roughly 27 percent) of the system. Actual oil and gas activity is occurring on a much smaller acreage distributed across 11 units in eight States. More than 90 percent of current production on all National Forest System lands takes place in two units: the Little Missouri National Grassland in North Dakota and the Thunder Basin National Grassland in Wyoming.

The National Park System contains almost 80 million acres made up by 337 units and 30 affiliated areas. These units include national parks, preserves, monuments, recreation areas, seashores, and other areas. All units have been closed to future leasing of Federal minerals except for four national recreation areas where mineral leasing has been authorized by congress and permitted under regulation. If deemed acceptable from an environmental standpoint, however, nonfederally owned minerals within a unit's boundaries can be leased. ${ }^{11}$ Ten units (approximately 3 percent of the total) currently have active oil and gas operations within their boundaries. Approximately 23 percent of the land area made up by these ten units is currently under lease (approximately 256,000 acres); however, 83 percent of the area within the ten units (almost one million acres) is leasable. The National Park Service also has identified 32 additional units that do not have active oil and gas operations at present, but do have the potential for such activities in the future.

\footnotetext{
11 Nonfederally owned minerals within National Park Systen units exist where the Federal Government does not own all the land within a unit's boundaries or does not possess the subsurface mineral rights. 
Several of these units also have acres that are under lease for 0 il and gas exploration, development, and production. In total, approximately 334,700 acres within the National Park System (or roughly 4 percent of the total) are currently under lease for $0 i 1$ and gas.

\section{CONCLUSIONS}

EPA's major conclusions, along with a summary of the main findings on which they are based, are listed below. EPA recognizes that the conclusions are limited by the lack of complete data and the necessary risk modeling assumptions. In particular, the limited amount of waste sampling data and the lack of empirical evidence on the probability of injection well failures have made it impossible to estimate precisely the absolute nationwide or regional risks from current waste management practices for $0 i 1$ and gas wastes. Nevertheless, EPA believes that the risk analysis presented here has yielded many useful conclusions relating to the nature of potential risks and the circumstances under which they are likely to occur.

\section{General Conclusions}

- For the vast majority of model scenarios evaluated in this study, only very small to negligible risks would be expected to occur even if the toxic chemical(s) of concern were of relatively high concentration in the wastes and there was a release into ground water as was assumed in this analysis. Nonetheless, the model results also show that there are realistic combinations of measured chemical concentrations (at the 90th percentile level). and release scenarios that could be of substantial concern. EPA cautions that there are other release modes not considered in this analysis that could also contribute to risks. In addition, there are almost certainly toxic contaminants in the large unsampled population of reserve pits and produced fluids that could exceed concentration levels measured in the relatively small number of waste samples analyzed by EPA. 
- EPA's modeling of resource damages to surface water--both in terms of ecological impact and of resource degradation--generally did not show significant risk. This was true both for groundwater seepage and direct surfagce water discharge (from stripper wells) pathways for drilling pit and produced water waste streams. This conclusion holds for the range of receiving water flow rates modeled, which included only moderate $\left(40 \mathrm{ft}^{3} / \mathrm{s}\right)$ to large $\left(850 \mathrm{ft}^{3} / \mathrm{s}\right)$ streams. It is clear that potential damages to smaller streams would be quite sensitive to relative discharge or ground-water seepage ratẹs.

- Of the hundreds of chemical constituents detected in both reserve pits and produced water, only a few from either scurce appear to be of primary concern relative to health or environmental damages. Based on an analysis of toxicological data, the frequency and measured concentrations of waste constituents in the relatively small number of sampled waste streams, and the mobility of these constituents in ground water, EPA found a limited number of constituents to be of primary relevance in the assessment of risks via ground water. Based on current data and arialysis, these constituents include arsenic, benzene, sodium, chloride, cadmium, chromium, boron, and mobile salts. All of these constituents were included in the quantitative risk modeling in this study. Cadmium, chromium, and boron did not produce risks or resource damages under the corditions modeled. Note: This coriclusion is qua? ified by the small number of sampled sites for which waste composition could be evaluated.

- Both for reserve pit waste and produced water, there is a very wide (six or more orders of magnitude) variation in estimated health risks across scenarios, depending on the different combinations of key variables influencing the individual scenarios. These variables include concentrations of toxic chemicals in the waste, hydrogeologic parameters, waste amounts and management practices, and distance to exposure points.

\section{Drilling Wastes Disposed of in Onsite Reserve Pits.}

- Most of the 1,134 onsite reserve pit scenarios had very small or no risks to human health via ground-water contamination of drinking water for the conditions modeled. Under the best-estimate assumptions, there were no carcinogenic waste constituents mode?ed (median concentrations for carcinogens in the EPA samples were zero or below detection), and more than 99 percent of the nationally weighted reserve pit scenarios resulted in exposure to noncarcinogens (sodium, cadmium, chromium) 
at concentration levels below health effect thresholds. Under more conservative assumptions, including toxic constituents at 90th percentile sam.ple concentrations, no scenarios evaluated yielded lifetime cancer risks as high as 1 in $100,000\left(1 \times 10^{-5}\right), 12$ and only 2 percent of the nationally weighted conservative scenarios showed cancer risks greater than $1 \times 10^{-7}$. Noncancer risks were estimated by threshold exceedances for only 2 percent of nationally weighted scenarios, even when the 90 th percentile concentration of sodium in the waste stream was assumed. The maximum sodium concentration at drinking water wells was estimated to be roughly 32 times the threshold for hypertension. In general, these modeling results suggest that most onsite reserve pits will present very low risks to human health through ground-water exposure pathways.

- It appears that people may be able to taste chloride in the drinking water in those scenarios with the highest cancer and noncancer risks. It is questionable, however, whether people would actually discontinue drinking water containing these elevated chloride concentrations.

- Weighting the risk results to account for different distributions of hydrogeologic variables, pit size, and exposure distance across geographic zones resulted in limited variability in risks across zones. Risk distributions for individual zones generally did not differ from the national distribution by more than one order of magnitude, except for zones 10. (West Coast) and 11B (Alaska, non-North Slope), which usually were extremely low. Note: EPA was unable to develop geographical comparisons of toxic constituent concentrations in drilling pit wastes.

- Several factors were evaluated for their individual effects on risk. Of these factors, ground-water flow field type and exposure distance had the greatest influence (several orders of magnitude); recharge rate, subsurface permeability, and pit size had less, but measurable, influence (approximately one order of magnitude). Typically, the higher risk cases occur in the context of the largest unljned pits, the short (60-meter) exposure distance, and high subsurface permeability and infiltration. Depth to ground water and presence/absence of a single synthetic liner had virtually no measurable influence over the 200-year modeling period; however, risk estimated over shorter time periods, such as 50 years, would likely be lower for lined pits compared to unlined pits, and lower for deep ground water compared to shallow ground water.

12 A cancer risk est imate of $1 \times 10^{-5}$ indicates that the chance of an individual contract ing cancer over a 70-year average lifet ine is approxitiately 1 in 100,000. The Agency establishes the cutoff between acceptable and unacceptabie levels of cancer risk between $1 \times 10^{-7}$ and $1 \times 10^{-4}$. 
- Estimated ground-water resource damage (caused by exceedance of water quality thresholds for chloride and total mobile ions) was very limited and essentially confined to the closest modeling distance (60 meters). These rescurce damage estimates apply only to the pathway modeled (leaching through the bottom of onsite pits) and not to other mechanisms of potential ground-water contamination at drilling sites, such as spills or intentional surface releases.

- No surface water resource damage (caused by exceedance of thresholds for chloride, sodium, cadmium, chromium VI, or total mobile ions) was predicted for the seepage of leachatecontaminated ground water into flowing surface water. This finding, based on limited modeling, does not imply that resource damage could not occur from larger releases, either through this or other pathways of migration, or from releases to lower flow surface waters (below $40 \mathrm{ft}^{3} / \mathrm{s}$ ).

\section{Produced Hater Disposal in Injection Hells}

- All risk results for underground injection presented in this chapter assume that either a grout seal or well casing failure occurs. However, as anticipated under EPA's Underground Injection Control (UIC) regulatory program, these failures are probably low-frequency events, and the actual risks resulting from grout seal and casing failures are expected to be much lower than the conditional risks presented here. The results do not, however, reflect other possible release pathways such as migration through unplugged boreholes or fractures in confining layers, which also could be of concern.

- Only a very small minority of injection well scenarios resulted in meaningful risks to human health, due to either grout seal or casing failure modes of release of produced water to drinking water sources. In terms of carcinogenic risks, none of the best-estimate scenarios (median arsenic and benzene sample concentrations) yielded lifetime risks greater than 5 per $1,000,000\left(5 \times 10^{-6}\right)$ to the maximally exposed individual. When the 90th percentile benzene and arsenic concentrations were examined, a maximum of 35 percent of EPA's nationally weighted scenarios had risks greater than $1 \times 10^{-7}$, with up to 5 percent having cancer risks greater than $1 \times 10^{-4}$ ' (the highest risk was $\left.9 \times 10^{-4}\right)$. The high cancer risk scenarios corresponded to a very short (60-meter) exposure distance combined with relatively high injection pressure/rates and a few specific ground-water flow fields (fields $C$ and $D$ in Table $V-7$ ). 
- Noncancer health effects modeled were limited to hypertension in sensitive individuals caused by ingestion of sodium in drinking water. In the best-estimate scenarios, up to 8 percent of EPA's nationally weighted scenarios had threshold exceedances for sodium in ground-water supplies. In the conservative scenarios, where goth percentile sodium concentrations were assumed in the injection waters, threshold exceedances in drinking water were predicted for a maximum of 22 percent of the nationally weighted scenarios. The highest sodiuin concentration predicted at exposure wells under conservative assumptions exceeded the threshold for hypertension by a factor of 70 . The high noncancer risk scenarios corresponded to a very short (60-meter) exposure distance, high injection pressures/rates, and relatively slow ground-water velocities/low flows.

- It appears that people would not taste or smell chloride or benzene at the concentration levels estimated for the highest cancer risk scenarios, but sensitive individuals would be more likely to detect chloride or benzene tastes or odors in those scenarios with the, highest noncancer risks. It is questionable, however, whether the detectable tastes or smells at these levels would generally be sufficient to discourage use of the water supply.

- As with the reserve pit risk modeling results, adjusting (weighting) the injection well results to account for differences among various geographic zones resulted in relatively small differences in risk distributions. Again, this lack of substantial variability in risk across zones may be the result of limitations of the study approach and the fact that geographic comparisons of toxic constituents in produced water was not possible.

- Of several factors evaluated for their effect on risk, exposure distance and ground-water flow field type had the greatest influence (two to three orders of magnitude). Flow rate/pressure had less, but measurable, influence (approximately one order of magnitude). Injection well type (i.e., waterflood vs. disposal) had moderate but contradictory effects on the risk results. For casing failures, high-pressure waterflood wells were estimated to cause health risks that were about 2 times higher than the risks from lower pressure disposal wells under otherwise similar conditions. However, for grout seal failures, the risks associated with disposal wells were estimated to be up to 3 times higher than the risks in similar circumstances associated with waterflood wells, caused by the higher injection rates for disposal. 
- Estimated ground-water resource damage (resulting from exceedance of thresholds for chloride, boron, and total mobile ions) was extremely limited and was essentially confined to the 60 -meter modeling distance. This conclusion applies only to releases from Class $I 1$ injection wells, and not to other mechanisms of potential ground-water contamination at oil and gas production sites (e.g., seepage through abandoned boreholes or fractures in confining layers, leaching from brine pits, spills).

- No surface water resource damage (resulting from exceedance of thresholds for chloride, sodium, boron, and total mobile ions) was predicted for seepage into flowing surface water of ground water contaminated by direct releases from injection wells. This finding does not imply that resource damage could not occur via mechanisms and pathways not covered by this limited surface water modeling, or in extremely low flow streams.

\section{Stripper Well Produced Water Discharged Directly into Surface Water}

- Under conservative modeling assumptions, 17 percent of scenarios (unweighted) had cancer risks greater than $1 \times 10^{-5}$ (the maximum cancer risk estimate was roughiy $\left.4 \times 10^{-5}\right) .{ }^{13}$ The maximum

cancer risk under best-est imate waste stream assumptions was $4 \times 10^{-7}$. No exceedances of noncancer effect thresholds or surface water resource damage thresholds were preaicted under any of the conditions modeled. The limited surface water modeling performed applies oply to scenarios with moderate- to high-flow streams ( 40 to $\left.850 \mathrm{ft}^{3} / \mathrm{s}\right)$ : Preliminary analyses indicate, however, that resource damage criteria would generally be exceeded in only very small streams (i.e., those flowing at less than $5 \mathrm{ft}^{3} / \mathrm{s}$ ), given the sampled waste stream chemical concentrations and discharge rates for stripper wells of up to 100 barrels per day.

\section{Drilling and Production Wastes Managed on Alaska's North Slope}

- Adverse effects to human health are expected to be negligible or nonexistent because the potential for human exposure to drilling waste and produced fluid contaminants on the North Slope is very small. The greatest potential for adverse environmental impacts is caused by discharge and seepage of reserve pit fluids containing toxic substances onto the tundra. A field study conducted in 1983 by the U.S. Fish and k'ildlife Service indicates that tundra discharges of reserve pit fluids may adversely affect water quality and invertebrates in surrounding areas; however, the

\footnotetext{
13 These rusults are unweighted because the frequency of occurrence of the parameters that define the stripper well scenarios was not estimated
} 
results of this study cannot be wholly extrapolated to present-day practices on the North Slope because some industry practices have changed and State regulations concerning reserve pit discharges have become increasingly more stringent since 1983. Preliminary studies from industry sources indicate that seepage from operating above-ground reserve pits on the North Slope may damage vegetation within a radius of 50 feet. The Fish and Wild? ife Service is in the process of studying the effects of reserve pit fluids on tundra organisms, and these studies need to be completed before more definitive conclusions can be made with respect to environnental impacts on the North Slope.

Locations of $0 i 1$ and Gas Activities in Relation to Environments of Special Interest

- All of the top 26 States that have the highest levels of onshore $0 i 1$ and gas activity are within the historical ranges of numerous endangered and threatened species habitats; however, of 190 counties identified as having high levels of exploration and production, only 13 (or 7 percent) have federally designated critical habitats for endangered species within their boundaries. The greatest potential for overlap between onshore oil and gas activities and wetlands appears to be in Alaska (particularly the North Slope), Louisiana, and 111 inois. Other States with abundant wetlands have very little onshore-oil and gas activity. Any development on public lands must first pass through a forma? environmental review process anú some public lands, such as National Forests, are managed for multiple uses including oil and gas development. Federal oil and gas leases have been granted for approximately 25 million acres (roughly 27 percent) of the National Forest System. All units of the National Park System have been closed to future leasing of federally owned minerals except for 4 National Recreation Areas where mineral leasing has been alithorized by Congress. If deemed acceptable from an environmental standpoint, however, nonfederally owned minerals within the park boundaries can be leased. In total, approximately 4 percent of the land area in the National Park System is currently under lease for oil and gas activity. 


\section{REFERENCES}

ARCO. 1986. ARCO Alaska, Inc. Preliminary outline: Environmental risk evaluation for drilling muds and cuttings on Alaska's North Slope. Comments on ADEC Solid Waste Regulations, Attachment B.

ARCO. 1985. Report on releases of hazardous waste or constituents from solid waste management units at the facility--Prudhoe Bay Unit Eastern Operating Area. Submitted to EPA Region $X$ in support of an Underground Injection Control permit application.

Bergman, R.D., Howard, R.L., Abraham, K.F., and Weller, M.W. 1977. Water birds and their wetland resources in relation to $0 i 1$ development at Storkersen Point Alaska. Fish and Wildlife Service Resource Publication 129. Washington, D.C.: U.S. Department of the Interior.

Mckendrick, J.D. 1986. Final wellsite cleanup on National Petroleum Reserve - Alaska. Volume 3 , Recording of tundra plant responses. U.S. Geological Survey.

NWWA. 1985. National Water Well Association. DRASTIC: A standardized system for evaluating ground-water pollution potential using hydrogeologic settings. NTIS PB-228145. Worthington, Ohio.

Pollen, M.R. 1986. Final wellsite cleanup on National Petroleum Reserve Alaska. Volume 2, Sampling and testing of waters and bottom muds in the reserve pits. U.S. Geological Survey.

Prickett, T.A., Naymik, T.C., and Lonnquist, C.G. 1981. A random walk solute transport model for selected ground-water quality evaluations. Bulletin $\$ 65$. Illinois State Water Survey. Champaign, Illinois.

Sierra Club. 1986. Yellowstone under siege: $0 i 1$ and qas leasing in the Greater Yellowstone Region. Washington, D.C.

Standard 0il. 1987. The Standard 0il Company. Additional information on Arctic exploration and production waste impact modeling.

USEPA. 1984a. U.S. Environmental Protection Agency. Technical quidance manual for performing waste load allocations: Book 2. Streams and rivers. 
USEPA. 1984b. U.S. Environmental Protection Agency. National secondary drinking water requlations. EPA 570,9-76-000. Washington, D.C.: U.S. Environmental Protection Agency.

USEPA. 1986. U.S. Environmental Protection Agency, Office of Solid Waste. Liner location risk and cost analysis model. Draft Phase II Report. Washington, D.C.: U.S. Environmental Protection Agency.

USEPA. 1987a. U.S. Envircnmental Protection Agency, Office of Solid Waste. Onshore oil arid cas and geothermal energy exploration, development, and production: human health and environmental risk assessment. Washington, D.C.: U.S. Environmental Protection Agency.

USEPA. 1987b. U.S. Environmental Protection Agency, Office of Solid Waste. Technical report: exploration, development, and production of crude oil and natural qas, field sampling and analysis report, and accompanying data tape. Washington, D.C.: U.S. Environmental Protection Agency.

West, R.L., and Snyder-Conn, E. 1987. Effects of Prudhoe Bay reserve pit fluids on water quality and macroinvertebrates of Arctic tundra ponds in Alaska. Biological Report 87(7). U.S. Department of the Interior. Fish and Wildlife Service, Washington, D.C.

Wilderness Society. 1987. Management directions for the national forests of the Greater Yellowstone ecosystem. Washington, D.C. 


\section{CHAPTER VI}

\section{COSTS AND ECONOMIC IMPACTS OF ALTERNATIVE WASTE MANAGEMENT PRACTICES}

\section{OVERVIEW OF THE COST AND ECONOMIC IMPACT ANALYSIS}

This chapter provides estimates of the cost and selected economic impacts of implementing alternative waste management practices by the oil and gas industry. The industry's current or "baseline" practices are described in Chapter III. In addition to current practices, a number of alternatives are available. Some of these offer the potential for higher levels of environinental control. Section $8002(m)$ of RCRA requires an assessment of the cost and impact of these alterriatives on oil and gas exploration, development, and production.

This chapter begins by providing cost estimates for baseline and alternative waste management practices. The most prevalent current practices are reserve pit storage and disposal for drilling wastes and Class II deep well injection for produced water. In addition, several other waste management practices are included in the cost evaluation. The cost estimates for the baseline and alternative waste management practices are presented as the cost per unit of waste disposal (e.g., cost per barrel of drilling waste, cost per barrel of produced water). These unit cost estimates allow for a comparison among disposal methods and are used as input information for the economic impact analysis.

After establishing the cost of baseline and alternative practices on a unit-of-waste basis, the chapter expands its focus to assess the impact of higher waste management costs both on individual oil and gas projects and on the industry as a whole. For the purpose of this assessment, three hypothetical regulatory scenarios for waste management are defined. Each scenario specifies a distinct set of alternative environmentally protective waste management practices for 
$0 i l$ and gas projects that generate potentially hazardous waste. Projects that do not generate hazardous waste may continue to use baseline practices under this approach.

After the three waste management scenarios have been defined, the remainder of the chapter provides estimates of their cost and economic impact. First, the impact of each scenario on the capital and operating cost and on the rate of return for representative new $0 i 1$ and gas projects is estimated. Using these cost estimates for individual projects as a basis, the chapter then presents regional-and nationallevel cost estimates for the waste management scenarios.

The chapter then describes the impact of the waste management scenarios on existing projects (i.e., projects that are already in production). It provides estimates of the number of wells and the amount of current production that would be shut down as a result of imposing alternative waste management practices under each scenario. Finally, the chapter provides estimates of the long-term decline in domestic production brought about by the costs of the waste managenent scenarios and estimates of the impact of that decline on the U.S. balance of payments, State and Federal revenues, and other selected economic aggregates.

The analysis presented in this chapter is based on the information available to EPA in November 1987. Although much new waste generation and waste management data was made available to this study, both by EPA and the American Petroleum Institute, certain data limitations did restrict the level of analysis and results. In particular, data on waste generation, management practices, and other important economic parameters were generally available only in terms of statewide or nationwide 
averages. Largely because of this, the cost study was conducted using "average regional projects" as the basic production unit of analysis. This lack of desired detail could obscure special attributes of both marginal and above average projects, thus biasing certain impact effects, such as the number of well closures.

The scope of the study was also somewhat 1 imited in other respects. For example, not all potential costs of alternative waste management under the RCRA amendments could be evaluated, most notably the land ban and corrective action regulations currently under development. The Agency recognizes that this could substantially understate potential costs of some of the regulatory scenarios studied. The analys is was able to distinguish separately between underground injection of produced water for disposal purposes and injection for waterflooding as a secondary or enhanced energy recovery method. However, it was not possible during the course of preparing this report to evaluate the costs or impacts of a)ternative waste management regulations on tertiary (chemical, thermal, and other advanced EOR) recovery, which is becoining an increasingly important feature of future U.S. 0il and gas production.

\section{COST OF BASELINE AND ALTERNATIVE WASTE MANAGEMENT PRACTICES}

\section{Identification of Waste Management Practices}

The predominant waste management practices currently employed by the oil and gas industry are described in Chapter III of this report. For drilling operations, wastes are typically stored in an unlined surface impoundment during drilling. After drilling, the wastes are dewatered, either by evaporation or vacuum truck, and buried onsite. Where vacuum trucks are used for dewatering, the fluids are removed for offsite 
disposal, typically in a Class II injection well. For production operations, the predominant disposal options are injection into a $\mathrm{Class}$ II onsite well or transportation to an offsite Class II disposal facility. Where onsite injection is used, the Class II well may be used for disposal only or it may be used to maintain pressure in the reservoir for enhanced oil recovery.

In addition to the above disposal options, a number of additional practices are considered here. Some of these options are fairly common (Table VI-1). For example, 37 percent of current drill sites use a lined disposal pit; 12 percent of production sites in the lower 48 States (Lower 48 ) discharge their produced water to the surface. Other disposal options considered here (e.g., incineration) are not employed to any significant extent at present.

For drilling waste disposal, nine alternative practices were reviewed for the purpose of estimating comparative unit costs and evaluating subsequent cost-effectiveness in complying with alternative regulatory options:

1. Onsite unlined surface impoundment;

2. Onsite single-synthetic-liner surface impoundment;

3. Offsite single-synthetic-liner surface impoundment;

4. Offsite synthetic composite liner with leachate collection (SCLC), Subtitle $C$ design;

5. Landfarming consistent with current State oil and gas field regulations;

6. Landfarming consistent with RCRA Subtitle $C$ requirements;

7. Waste solidification;

8. Incineration; and

9. Volume reduction. 
Table V1-1 Surmary of Baseline Disposal Practices, by Zone, 1985

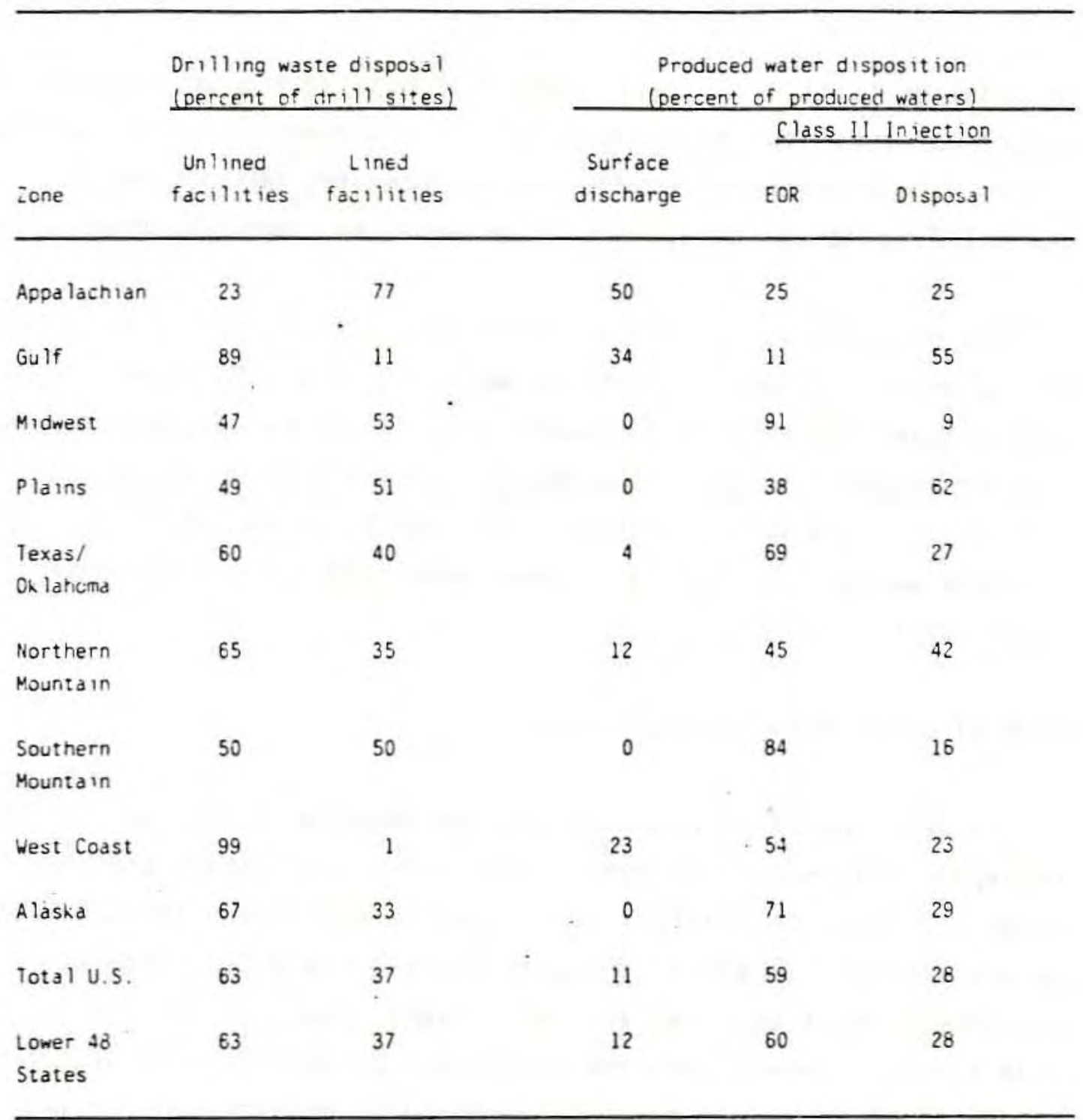

Sources: Drilling waste and produced water disposal information from AP1, 1987a except for produced water disposal percents for the Appalachian zone, which are based on personal cormunications with regional industry sources.

NOTE: Produced water disposition percents for total U.S. and Lower 48 are based on survey sample weights. Weighting by $0 i 1$ production results in a figure of 9 percent discharge in the Lower 48 (API 1987b). 
In addition to these disposal options, costs were also estimated for ground-water monitoring and general site management for waste disposal sites. These latter practices can be necessary adjunct requirements for various final disposal options to enhance environmental protection.

For produced water, two alternative practices were considered in the cost analysis: Class I injection wells and Class II injection wells. Both classes may be used for water disposal or for enhanced energy recovery waterflooding. They may be located either onsite or, in the case of disposal wells, offsite. To depict the variation in use patterns of these wells, cost estimates were developed for a wide range of injection capacities.

\section{Cost of Waste Management Practices}

For each waste disposal option, engineering design parameters of representative waste management facilities were established for the purpose of costing (Table VI-2). For the baseline disposal methods, parameters were selected to typify current practices. For waste management practices that achieve a higher level of environmental control than the most common baseline practices, parameters were selected to typify the best (i.e., most environmentally protective) current design practices. For waste management practices that would be acceptable for hazardous waste under Subtitle C of RCRA, parameters were selected to represent compliance with these regulations as they existed in early 1987.

Capital and operating and maintenance (OSM) costs were estimated for each waste managenent practice based on previous EPA engineering cost documents and tailored computer model runs, original contractor engineering cost estimates, vendor quotations, and other sources. ${ }^{1}$ Capital costs were annualized using an 8 percent discount rate, the

\footnotetext{
1 See footriotes to Tables VI-3 and VI-4 and Eastern Research Group 1987 for a detailed source list.
} 
Table VI-2 Summary of Engineering Design Elements for Baseline and Alternative Waste Management Practices

\begin{tabular}{|c|c|c|c|c|}
\hline Alternative & Capital costs & $0 \& M$ costs & Closure costs & Post-c losure costs \\
\hline Unlined pit & $\begin{array}{l}\text { - Pit excavation }(0.25 \text { acre }) \\
\text { - Clearing and grubbing } \\
\text { - Cont ingency } \\
\text { - Contractor fee }\end{array}$ & - Negligible & $\begin{array}{l}\text { - Pit burial (earth fill only) } \\
\text { - Cont ingency } \\
\text { - Contractor fee }\end{array}$ & \\
\hline $\begin{array}{l}\text { One-liner pit (waste buried } \\
\text { on site) }\end{array}$ & $\begin{array}{l}\text { - Clearing and grubbing } \\
\text { - Pit excavation ( } 0.25 \text { acre) } \\
\text { - Berm construct ion (grave) } \\
\text { and vegetation) } \\
\text { - } 30 \text {-mil synthet ic liner } \\
\text { - Liner protect ion } \\
\text { (geotext ile subliner) } \\
\text { - Engineering, contractor. } \\
\text { and inspection fee } \\
\text { - Cont ingency }\end{array}$ & - Negligible & $\begin{array}{l}\text { - Pit burial (earth fill) } \\
\text { - Capping } \\
\text { - } 30 \text {-mil PVC synthetic membrane } \\
\text { - topsoil } \\
\text { - Revegetation } \\
\text { - Engintering. contractor, and } \\
\text { inspection fee } \\
\text { - Cont ingency }\end{array}$ & \\
\hline offsite one-liner facility & $\begin{array}{l}\text { - Pit excavation ( } 15 \text { acres) } \\
\text { - Same costs as onsite one- } \\
\text { liner pit with addition of: } \\
\text { - land cost } \\
\text { - utility site work } \\
\text { - pumps } \\
\text { - spare parts } \\
\text { - dredging equipment } \\
\text { - inlet/out let structures } \\
\text { - construct ion and field } \\
\text { expense }\end{array}$ & $\begin{array}{l}\text { - Operating labor } \\
\text { - clerical staff } \\
\text { - forenen } \\
\text { - Maintenance, labor and } \\
\text { supplies } \\
\text { - Ut ilities } \\
\text { - Plant overhead } \\
\text { - Dredging }\end{array}$ & $\begin{array}{l}\text { - Same costs as onsite one- } \\
\text { liner pit } \\
\text { - Solidification } \\
\text { - Free liquid removal and } \\
\text { treatment }\end{array}$ & \\
\hline
\end{tabular}




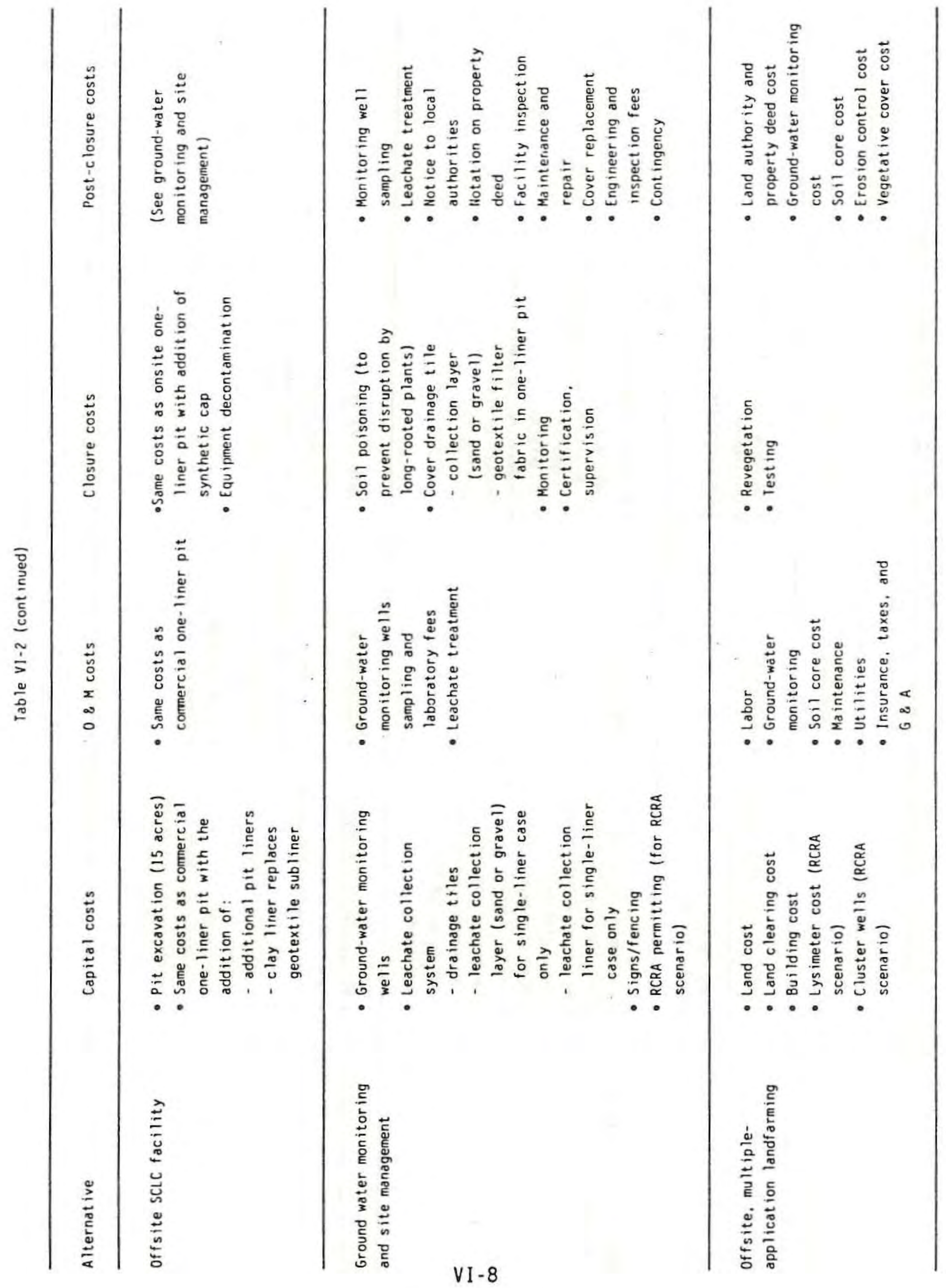




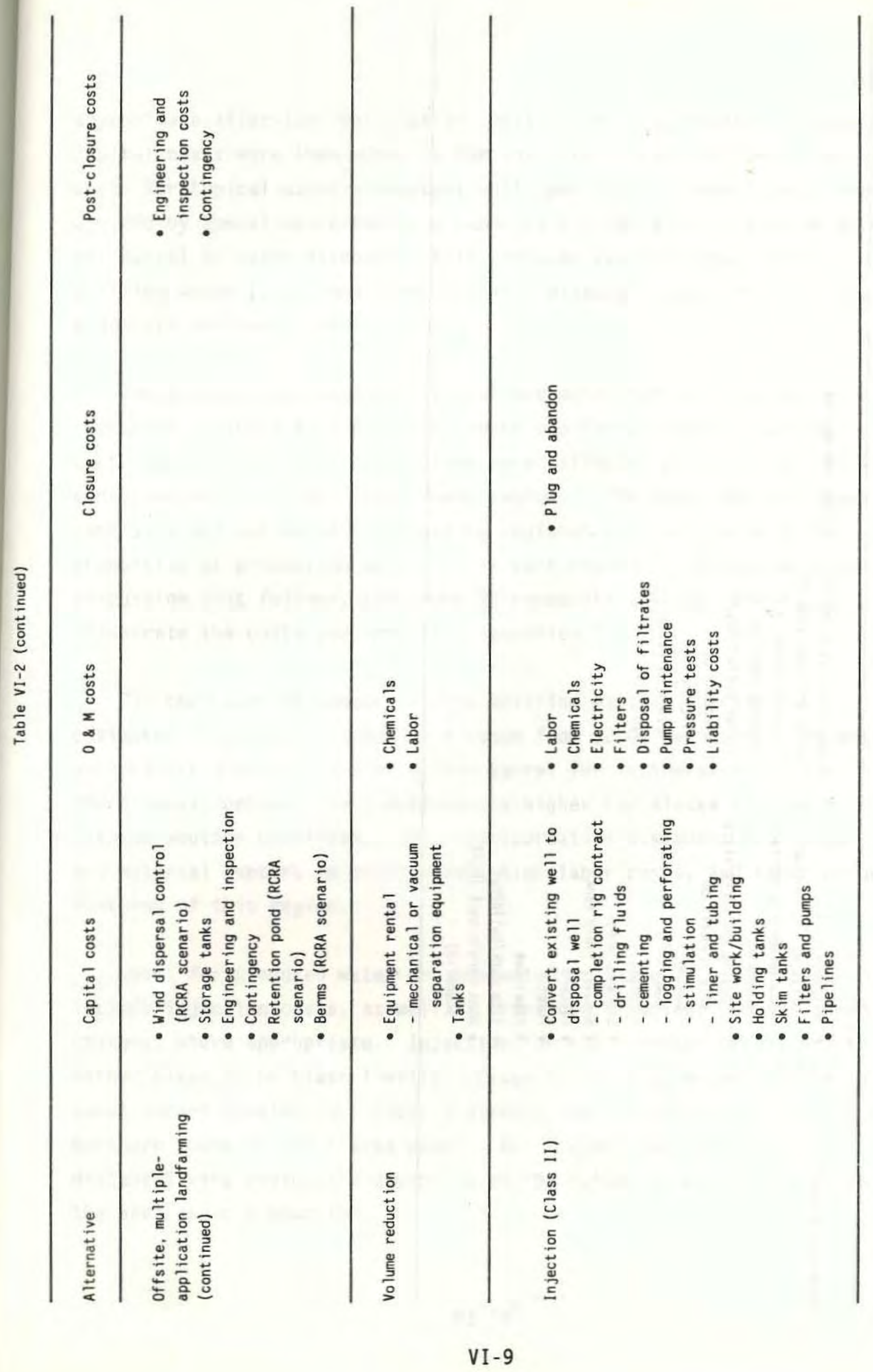




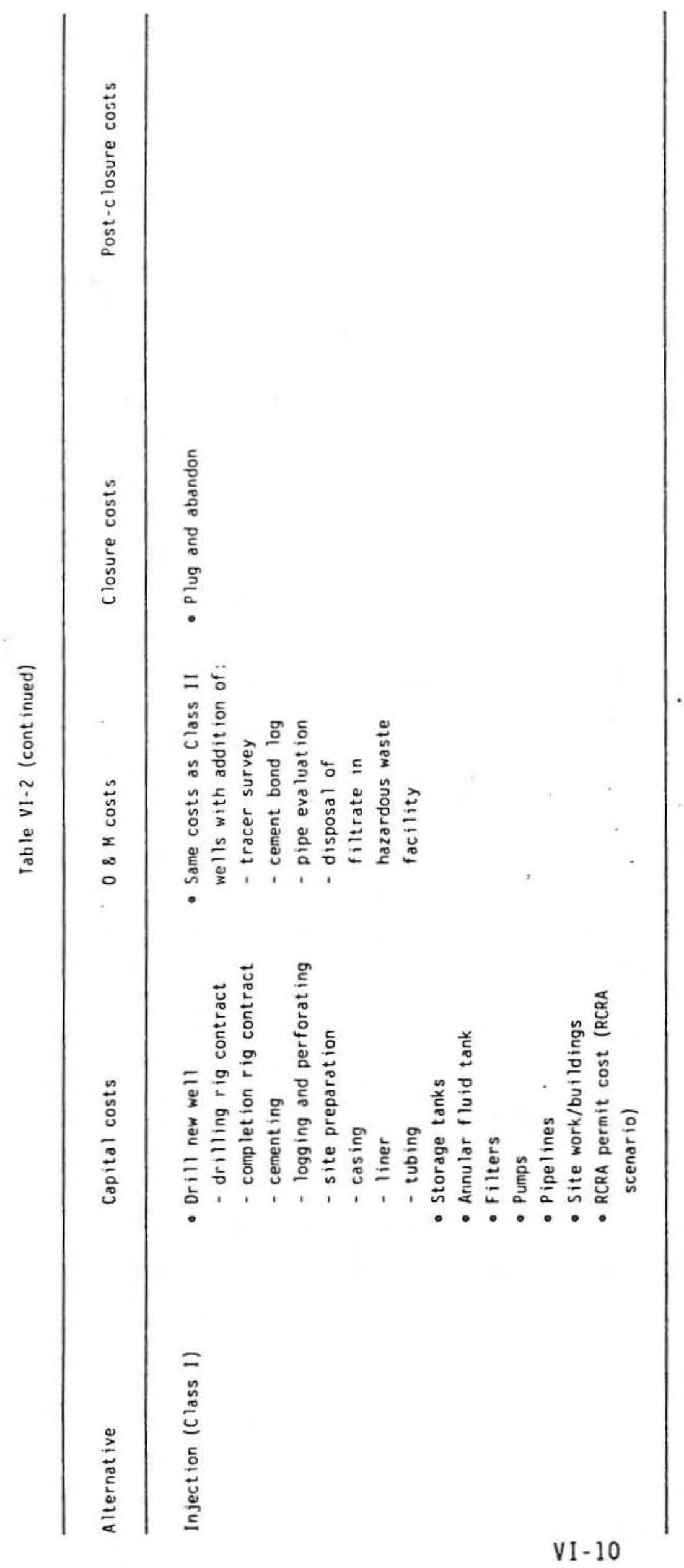


approximate after-tax real cost of capital for this industry. Annualized capital costs were then added to 0\&M costs to compute the total annual costs for typical waste management unit operations. Annual costs were divided by annual waste-handling capacity (in barrels) to provide a cost per barrel of waste disposal. Both produced water disposal costs and drilling waste (i.e., muds and cuttings) disposal costs are expressed on a dollars-per-barrel basis.

The average engineering unit cost estimates for drilling wastes are presented in Table VI-3 for each region and for a composite of the Lower 48. Regional cost variations were estimated based on varying land, construction, and labor costs among regions. The costs for the Lower 48 composite are estimated by weighting regional cost estimates by the proportion of production occurring in each region. (Throughout the discussion that follows, the Lower 48 composite will be referenced to illustrate the costs and impacts in question.)

For the Lower 48 composite, the drilling waste disposal cost estimates presented in Table VI-3 range from \$2.04 per barrel for onsite, unlined pit disposal to $\$ 157.50$ per barrel for incineration. Costs for the disposal options are significantly higher for Alaska because of the extreme weather conditions, long transportation distances from population and material centers to drill sites, high labor costs, and other unique features of this region.

Costs for produced water are presented in Table VI-4. Disposal costs include injection costs, as well as transport, loading, and unloading charges, where appropriate. Injection for EOR purposes occurs onsite in either Class II or Class I wells. Class. II disposal occurs onsite in all zones except Appalachia. Class I disposal occurs offsite except for the Northern Mountain and Alaska zones. Well capacities and transport distances vary regionally depending on the volume of water production and the area under production. 


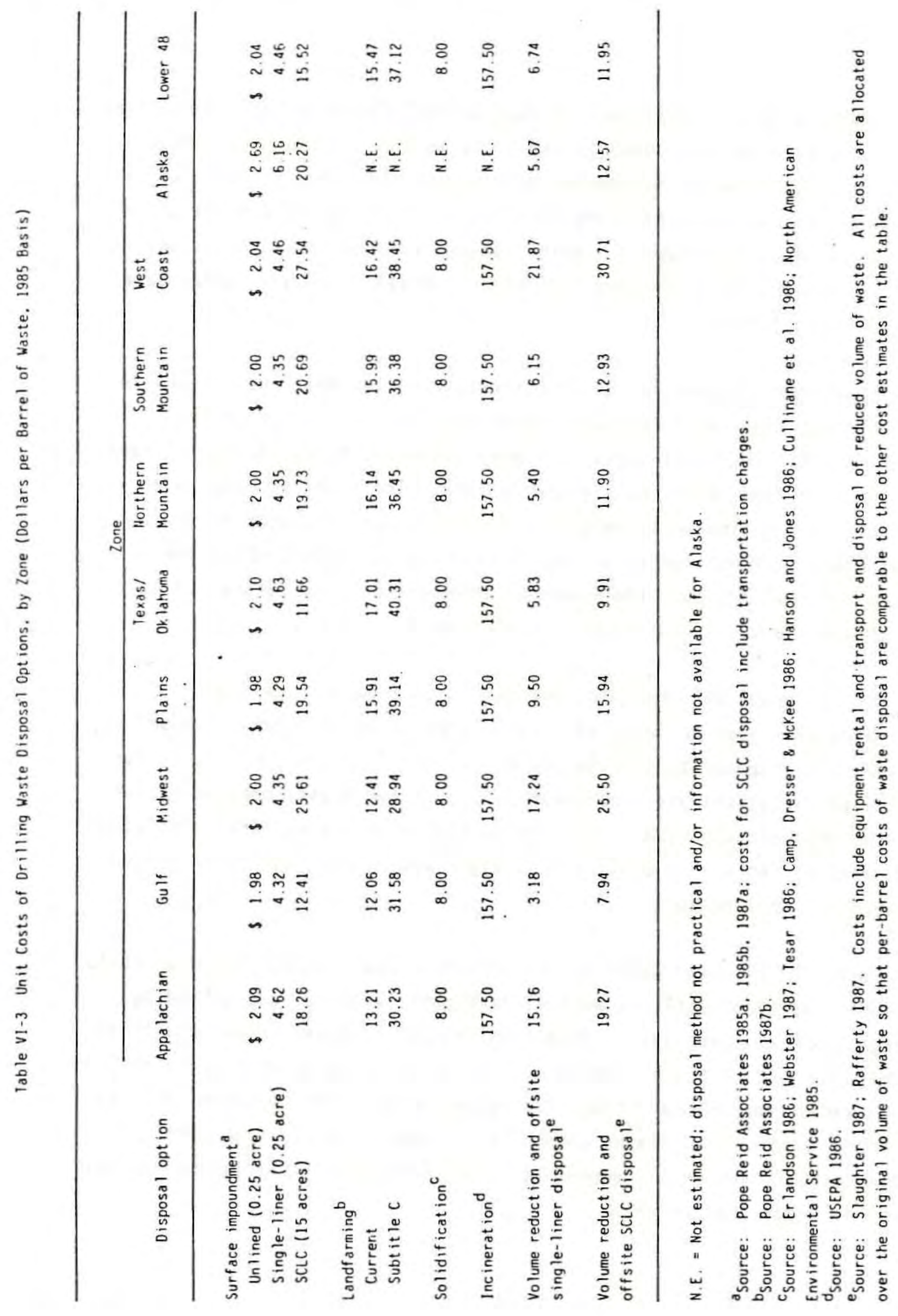


Table V1-4 Unit Costs of Underground Injection

of Produced Water, by Zone

(Dollars per Barrel of Water)

\begin{tabular}{|c|c|c|c|c|c|}
\hline \multirow[b]{2}{*}{ Zone } & \multicolumn{2}{|c|}{ Class 11 in lection } & \multirow{2}{*}{ - } & \multicolumn{2}{|c|}{ Class I in lection ${ }^{a}$} \\
\hline & Disposal & EOR & & Disposal & EOR \\
\hline Appalachian ${ }^{b}$ & $\$ 1.26-1.33$ & 30.75 & & $\$ 2,45$ & $\$ 6.12$ \\
\hline Gulf & 0.10 & 0.23 & & 0.84 & 1.35 \\
\hline Midwest & 0.29 & 0.13 & & 1.14 & 0.84 \\
\hline Pla ins & 0.14 & 0.19 & & 0.86 & 1.21 \\
\hline Texas/Ok lahoma & 0.11 & 0.14 & & 0.96 & 0.76 \\
\hline Northern Mount a in & 0.01 & 0.14 & & 0.40 & 0.58 \\
\hline Southern Mounta in & 0.07 & 0.14 & & 1.05 & 0.67 \\
\hline West Coast & 0.04 & 0.05 & & 0.72 & 0.25 \\
\hline & 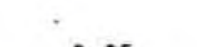 & & & & \\
\hline Alaska & 0.05 & 0.41 & & 1.28 & 2.15 \\
\hline & - & & & & \\
\hline Lower 48 States & 0.10 & 0.14 & & 0.92 & 0.78 \\
\hline
\end{tabular}

aisposal costs for Class I injection include transportation and loading/unloading charges except for the Northern Mountain zone and Alaska, where onsite disposal is expected to occur.

b Class 11 disposal costs for Appalachian zone includes transport and loading/unloading cnarges. Lower estimate is for intermediate scenarios: higher est imate is for baseline-practice due to change in transport distances. For all other zones, Class 11 disposal is assumed to occur onsite.

Sources: Tilden 1987a, 1987b.

NOTE: Base year for costs is 1985 . 
Produced water disposal costs range from $\$ 0.01$ to $\$ 1.33$ per barrel for Class II disposal and EOR injection and from $\$ 0.40$ to $\$ 6.12$ per barrel for Class I disposal and EOR injection. Costs for Class I facilities are substantially higher because of the increased drilling completion, monitoring, and surface equipment costs associated with waste management facilities that accept hazardous waste.

The transportation of waste represents an additional waste management cost for some facilities. Transportation of drilling or production waste for offsite centralized or commercial disposal is practiced now by some companies and has been included as a potential disposal option in the waste management scenarios. Drilling waste transport costs range from \$0.02 per barrel/mile for nonhazardous waste to $\$ 0.06 \mathrm{per}$ barrel/mile for hazardous waste. Produced water transport costs range from $\$ 0.01$ per barrel/mile (nonhazardous) to 50.04 per barrel/mile (hazardous). Distances to disposal facilities were estimated based on the volume of wastes produced, facility capacities, and the area served by each facility. Waste transportation also involves costs for loading and unloading.

\section{WASTE MANAGEMENT SCENARIOS AND APPLICABLE WASTE MANAGEMENT PRACTICES}

In order to determine the potential costs and impacts of changes in oil and gas waste disposal requirements, three waste management scenarios have been defined. The scenarios have been designed to illustrate the cost and impact of two hypothetical additional levels of environmental control in relation to current baseline practices. EPA has not yet identified, defined, or evaluated its regulatory options for the $0 i 1$ and gas industry; therefore, it should be noted that these scenarios do not represent regulatory determinations by EPA. A regulatory determination will be made by EPA following the Report to Congress. 


\section{Baseline Scenario}

The Baseline Scenario represents the current situation. It encompasses the principal waste management practices now permitted under State and Federal regulations. Several key features of current practice for both drilling waste and produced water were summarized in Table VI-1, and the distribution of disposal practices shown in Table VI-l is the baseline assumption for this analysis.

\section{Intermediate Scenario}

The Intermediate Scenario depicts a higher level of control. Operators generating wastes designated as hazardous are subject to requirements more stringent than those in the Baseline Scenario. An exact definition of "hazardous" has not been formulated for this scenario. Further, even if a definition were posited (e.g., failure of the E.P. toxicity test), available data are insufficient to determine the proportion of the industry's wastes that would fait any given test. Pending an exact regulatory definition of "hazardous" and the development of better analytical data, a range of alternative assumptions has been employed in the analysis. In the Intermediate 10\% Scenario, the Agency assumed, for the purpose of costing, that 10 percent of $0 i l$ and gas projects generate hazardous waste and in the Intermediate $70 \%$ Scenario that 70 percent of oil and gas projects generate hazardous waste.

For drilling wastes designated hazardous, operators would be required to use a single-synthetic-liner facility, landfarming with site management (as defined in Table VI-2), solidification, or incineration. Operators would select from these available compliance measures on the basis of lowest cost. Since a substantial number of operators now employ a single synthetic liner in drilling pits, only those sites not using a liner would be potentially affected by the drilling waste requirements of the Intermediate Scenario. 
For produced waters, the Intermediate Scenario assumes injection into Class II facilities for any produced water that is designated hazardous. Operators now discharging waste directly to water or land (approximately 9 to 12 percent of all water) would be required to use a Class II facility if their wastes were determined to be hazardous.

"Affected operations" under a given scenario are those oil and gas projects that would have to alter their waste management practices and incur costs to comply with the requirements of the scenario. For example, in the Intermediate $10 \%$ Scenario, it is assumed that only 10 percent of oil and gas projects generate hazardous waste. For drilling, an estimated 63 percent of oil and gas projects now use unlined facilities and are therefore potentially affected by the requirements of the scenario. Since 10 percent of these projects are assumed to generate hazardous waste, an estimated 6.3 percent of the projects are affected operations, which are subject to higher disposal costs.

\section{The Subtitle C Scenario}

In the Subtitle $C$ Scenario, wastes designated as hazardous are subject to pollution control requirements consistent with Subtitle $C$ of RCRA. For drilling wastes, those wastes that are defined as hazardous must be disposed of in a synthetic composite liner with leachate collection (SCLC) facility employing site management and ground-water monitoring practices consistent with RCRA Subtitle C, a landfarming facility employing Subtitle $C$ site management practices, or a hazardous waste incinerator. In estimating compliance costs EPA estimated that a combination of volume reduction and offsite dedicated SCLC disposal would be the least-cost method for disposal of drilling waste. For production wastes, those defined as hazardous must be injected into Class I disposal or EOR injection wells. 
Since virtually no drilling or production operations currently use Subtitle C facilities or Class $I$ injection wells in the baseline, all projects that generate produced water are potentially affected. In the Subtitle C $10 \%$ Scenario, 10 percent of these projects are assumed to be affected; in the Subtitle C $70 \%$ Scenario, 70 percent of these projects are affected. The Subtitle C Scenario, like the Intermediate Scenario, does not establish a formal definition of "hazardous"; nor does it attempt to estimate the proportion of wastes that would be hazardous under the scenario. As with the Intermediate Scenario, two assumptions (10 percent hazardous, 70 percent hazardous) are employed, and a range of costs and impacts is presented.

This Subtitle C Scenario does not, however, impose all possible technological requirements of the Solid Waste Act Amendments, such as the land ban and corrective action requirements of the Hazardous Solid Waste Amendments (HSWA), for which regulatory proposals are currently under development in the Office of Solid Waste. Although the specific regulatory requirements and their possible applications to oil and gas field practices, especially deep well injection practices, were not sufficiently developed to provide sufficient guidelines for cost evaluation in this report, the Agency recognizes that the full application of these future regulations could substantially increase the costs and impacts estimated for the Subtitle C Scenario.

\section{The Subtitle C-1 Scenario}

The Subtitle C-1 Scenario is exactly the same as the Subtitle C Scenario, except that produced water used in waterfloods is considered part of a production process and is therefore exempt from more stringent (i.e., Class I) control requirements, even if the water is hazardous. As shown in Table VI-1, approximately 60 percent of all produced water is used in waterfloods. Thus, only about 40 percent of produced water is potentially affected under the Subtitle C-1 Scenario. The requirements 
of the Subtitle C-1 Scenario for drilling wastes are exactly the same as those of the Subtitle C Scenario. As with the other scenarios, alternative assumptions of 10 and 70 percent hazardous are employed in the Subtitle C-1 Scenario.

\section{Summary of Waste Management Scenarios}

Table VI-5 summarizes the major features of all the waste management scenarios. It identifies acceptable disposal practices under each scenario and the percent of wastes affected under each scenario. The Subtitle C $70 \%$ Scenario enforces the highest level of environmental control in waste management practices, and it affects the largest percent of facilities.

\section{COST AND IMPACT OF THE WASTE MANAGEMENT SCENARIOS FOR TYPICAL NEW OIL AND GAS PROJECTS}

\section{Economic Models}

An economic simulation model, developed by Eastern Research Group (ERG) and detailed in the Technical Background Document (ERG 1987), was employed to analyze the impact of waste management costs on new oil and gas projects. The economic model simulates the performance and measures the profitability of oil and gas exploration and development projects both before and after the implementation of the waste management scenarios. For the purposes of this report, a "project" is defined as a single successful development well and the leasing and exploration activities associated with that well. The costs for the model project include the costs of both the unsuccessful and the successful leasing and exploratory and development drilling required, on average, to achieve one successful producing well. 
Tabie V1-5 Assumed haste Management Practices for Alternative Waste Managenent Scenarios

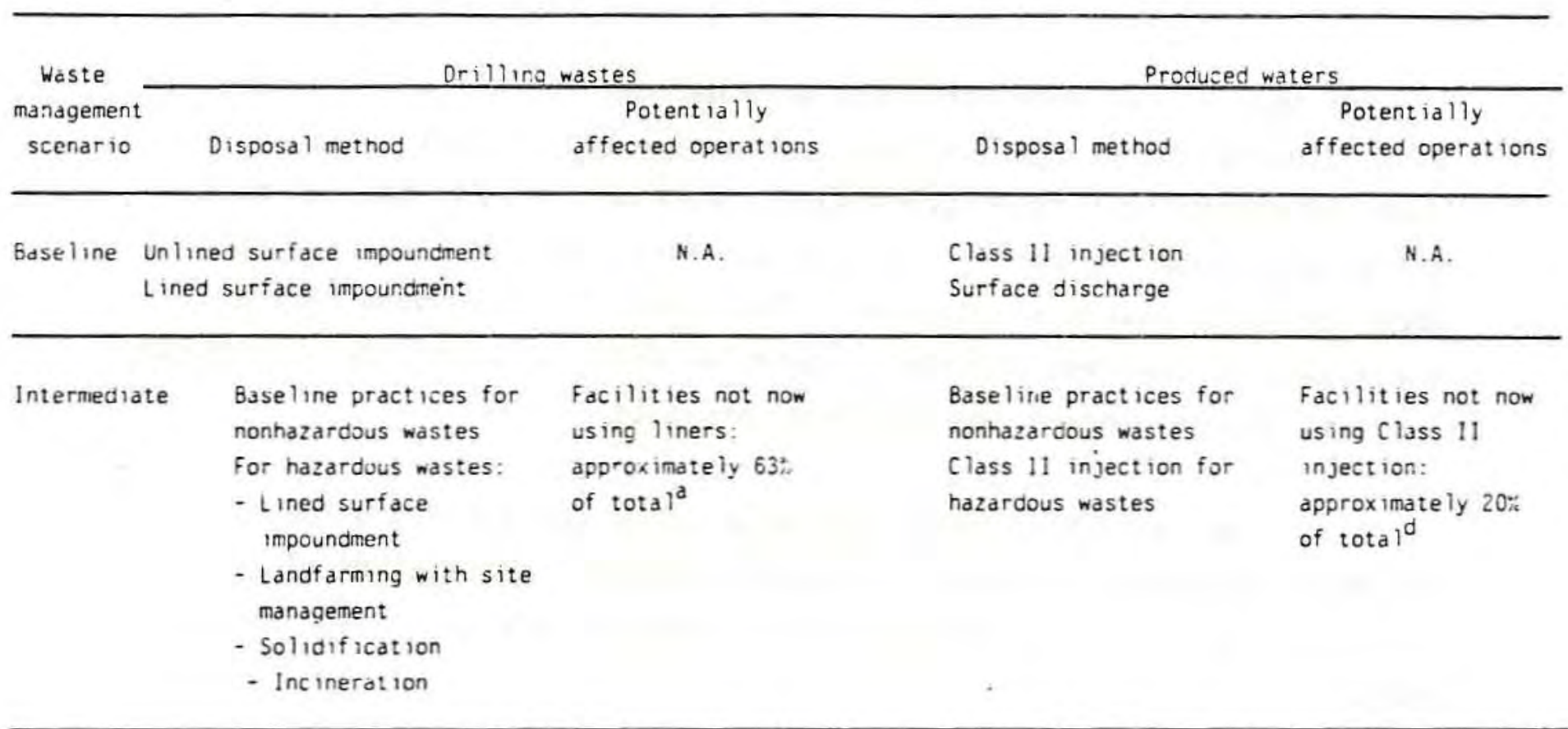

$\begin{array}{ll}\text { Subtitle C } & \text { Baseline practices for } \\ & \text { nonhazardous wastes } \\ & \text { For hazardous wastes: } \\ & - \text { SCLC impoundment } \\ & \text { with Subtitle C } \\ & \text { site management } \\ & - \text { Landfarming with } \\ & \text { Subtitle C site } \\ & \text { management } \\ & - \text { Hazardous waste } \\ & \text { incineration }\end{array}$

All facilities ${ }^{b}$

.

$\begin{array}{lll}\text { Subtitle } C-1 & \text { Same as Subtit le C } & \begin{array}{l}\text { Same as Subtit le } C \\ \text { scenario }\end{array} \\ & \text { scenario } c\end{array}$

Baseline practices for All facilities
nonhazardous wastes
Class 1 injection for
hazardous wastes

Facilities not now

injection:

approximately 20 : of $\operatorname{tota} l^{d}$ 
For this study, model projects were defined for oil wells (with associated casinghead gas) in the nine active oil and gas zones and for a Lower 48 composite. Model gas projects were defined for the two most active gas-producing zones (the Gulf and Texas/Oklahoma zones). Thus, 12 model projects have been analyzed. The Technical Background Document for the Report to Congress provides a detailed description of the assumptions and data sources underlying the model projects.

A distinct set of economic parameter values is estimated for each of the model projects, providing a complete economic description of each project. The following categories of parameters are specified for each project:

1. Lease Cost: initial payments to Federal or State governments or to private individuals for the rights to explore for and to produce oil and gas.

2. Geological and Geophyșical Cost: cost of analytic work prior to drilling.

3. Drilling Cost per Well.

4. Cost of Production Equipment.

5. Discovery Efficiency: the number of wells drilled for one successful well.

6. Production Rates: initial production rates of $0 i 1$ and gas and production decline rates.

7. Operation and Maintenance Costs.

8. Tax Rates: Rates for Federal and State income taxes, severance taxes, royalty payments, depreciation, and depletion.

9. Price: wellhead selling price of oil and gas (also called the "first purchase price" of the product).

10. Cost of Capital: real after-tax rate of return on equity and borrowed investment capital for the industry.

11. Timing: length of time required for each project phase (i.e., leasing, exploration, development, and production). 
The actual parameter values for the 12 model projects are summarized in Table VI-6.

For each of the 12 model projects, the economic performance is estimated before (i.e., baseline) and after each waste management scenario has been implemented. Two measures of economic performance are employed in the impact assessment presented here. One is the after-tax rate of return. The other is the cost of production per barrel of oil (here defined as the cost of the resources used in production, including profit to the owners of capital, excluding transfer payments such as royalties and taxes). A number of other economic output parameters are described in the Technical Background Document.

\section{Quantities of Wastes Generated by the Model Projects}

To calculate the waste management costs for each representative project, it was necessary to develop estimates of the quantities of drilling and production wastes generated by these facilities. These estimates, based on a recent API survey, are provided in Table VI-7. Drilling wastes are shown on the basis of barrels of waste per well. Production wastes are provided on the basis of barrels of waste per barrel of oil.

For the Lower 48 composite, an estimated 5,170 barrels of waste are generated for each well drilled. For producing wells, approximately 10 barrels of water are generated for every barrel of oil. This latter statistic includes waterflood projects, some of which operate at very high water-to-oil ratios.

\section{Model Project Waste Management Costs}

Model project waste management costs are estimated for the baseline and for each waste management scenario using the cost data presented in 


\begin{tabular}{|c|c|c|c|c|c|c|c|c|c|c|c|c|}
\hline Parameter & Appa lachian & Gulf & Gulf & Midwest & Plains & $\begin{array}{c}\text { Texas/ } \\
\text { Ok lahoma }\end{array}$ & $\begin{array}{c}\text { Texas/ } \\
\text { Ok lahoma }\end{array}$ & $\begin{array}{l}\text { Northern } \\
\text { Mounta in }\end{array}$ & $\begin{array}{l}\text { Southern } \\
\text { Mounta in }\end{array}$ & $\begin{array}{l}\text { West } \\
\text { Coast }\end{array}$ & Alaska & $\begin{array}{c}\text { Lower } 48 \\
\text { States }\end{array}$ \\
\hline Product ion & $0 i 1 /$ Gas & $0 i 1 /$ Gas & Gas & $0 \mathrm{il} / \mathrm{Gas}$ & $0 i 1 /$ Gas & $0 i 1 /$ Gas & Gas & $0: 1 /$ Gas & $0 i 1 /$ Gas & $0 \mathrm{il} / \mathrm{Gas}$ & $011 / \mathrm{Gas}$ & 0 il/Gas \\
\hline Yr of first prod. & 1 & 1 & 1 & 1 & 1 & 1 & 1 & 2 & 1 & 1 & 10 & 1 \\
\hline Lease cost & 1.146 & 19.296 & 154.368 & 2.509 & 2.080 & 11200 & 22.400 & 4,992 & 2.251 & 33.178 & 161.056 & 14.877 \\
\hline$G \& G$ expense & $58.3 \%$ & $58.3 x$ & $58.3 \%$ & $58.3 \%$ & $58.3 \%$ & $58.3 \%$ & $58.3 \%$ & $58.3 \%$ & $58.3 \%$ & $58.3 \%$ & $58.3 \%$ & $58.3 \%$ \\
\hline Well cost & 63.911 & 244.276 & 640.146 & 122.138 & 186.347 & 246.324 & 727.636 & 421.142 & 492.053 & 160.995 & $3,207,388$ & 248.607 \\
\hline Disc efficiency & $85 \%$ & $59 \%$ & $59 \%$ & $51 x$ & $52 \%$ & $71 \%$ & $71 \%$ & $55 \% \mathrm{q}$ & $72 \%$ & $90 \%$ & $88 \%$ & $69 \%$ \\
\hline Infrastructure cost & 45.000 & 73.183 & 35.297 & 60.788 & 81.855 & 86.820 & 39.824 & 102.662 & 109.357 & 82.560 & $45,938,400$ & 83.952 \\
\hline $0 \& M$ costs (per yr) & 4.500 & 13.349 & 18.486 & 11.807 & 14.529 & 15.114 & 21.048 & 17.015 & 17.781 & 13.370 & 690.900 & 14.463 \\
\hline \multicolumn{13}{|l|}{ Initial prod. rates } \\
\hline $0 i 1$ (bbl/day) & 4 & 60 & 0 & 16 & 26 & 37 & 0 & 53 & 32 & 35 & 3700 & 41 \\
\hline Gas (Mcf/day) & 16 & 82 & 1295 & 15 & 34 & 63 & 1038 & 72 & 69 & 0 & 686 & 57 \\
\hline Prod. decline rates & $9 \%$ & $19 \%$ & $19 \%$ & $17 x$ & $19 \%$ & $12 x$ & $12 \%$ & $13 \%$ & $13 x$ & $7 \%$ & $9 \%$ & $12 \%$ \\
\hline Federal corp. tax & $34 \%$ & $34 \%$ & $34 \%$ & $34 \%$ & $34 \%$ & $34 x$ & $34 \%$ & $34 \%$ & $34 \%$ & $34 \%$ & $34 \%$ & $34 \%$ \\
\hline State corp. tax & $0 \%$ & $8 \%$ & $8 \%$ & $4 \%$ & $6.75 \%$ & $5 \%$ & $5 \%$ & $0 \%$ & $6 \%$ & $9.35 \%$ & $9.40 \%$ & $6.14 \%$ \\
\hline Royalty rate & $18.75 \%$ & $18.75 \%$ & $18.75 \%$ & $12.50 \%$ & $12.50 \%$ & $20.00 \%$ & $20.00 \%$ & $12.50 \%$ & $16.00 \%$ & $18.75 \%$ & $14.30 \%$ & $18.24 \%$ \\
\hline \multicolumn{13}{|l|}{ Severance tax } \\
\hline 011 & $0.5 \%$ & $12.5 \%$ & $12.5 \%$ & $0 \%$ & $8 \%$ & $7 \%$ & $7 \%$ & $6 \%$ & $4 \%$ & $0.14 \%$ & a & $6.67 \%$ \\
\hline Gas & $1.5 \%$ & $4.25 \%$ & $4.25 \%$ & $4.84 \%$ & $0 \%$ & $8 \%$ & $7 \%$ & $7 \%$ & EY & $4 \%$ & $0.14 \%$ & a \\
\hline \multicolumn{13}{|l|}{ Wellhead price } \\
\hline $0 i 1(\$ / b b 1)$ & $\$ 20.90$ & $\$ 21.65$ & $\$ 21.65$ & $\$ 22.11$ & $\$ 21.14$ & $\$ 22.03$ & $\$ 22.03$ & $\$ 20.74$ & $\$ 21.16$ & $\$ 18.38$ & $\$ 16.37$ & $\$ 20.00$ \\
\hline Gas ( $\$ / M c f)$ & $\$ 2.00$ & $\$ 1.99$ & $\$ 1.99$ & $\$ 2.03$ & S 1.43 & $\$ 1.58$ & $\$ 1.58$ & $\$ 1.77$ & $\$ 1,98$ & $\$ 2.21$ & $\$ 0.49$ & $\$ 1.65$ \\
\hline
\end{tabular}

\footnotetext{
Tax based on formula in tax code, not a flat percentage.
}

Source: ERG 1987. 
Table VI-7 Average Quantities of Waste Generated, by Zone

\begin{tabular}{|c|c|c|}
\hline $\begin{array}{l}\text { Mode } 1 \text { project/ } \\
\text { zone }\end{array}$ & $\begin{array}{c}\text { Drilling waste } \\
\text { barrels/well }\end{array}$ & $\begin{array}{l}\text { Produced water } \\
\text { (barrels/barrel } \\
\text { of oil) }\end{array}$ \\
\hline Appa lachian & 2.344 & 2.41 \\
\hline Gulf & 10.987 & 8.42 \\
\hline Midwest & 1.853 & 23.61 \\
\hline Plains & 3.623 & 9.11 \\
\hline Texas/Ok lahoma & 5.555 & 10.62 \\
\hline Northern Mounta in & 8.569 & 12.30 \\
\hline Southern Mounta in & 7.153 & 7.31 \\
\hline West Coast & 1.414 & 8.05 \\
\hline Alaska & 7.504 & 0.15 \\
\hline$x^{2}+x^{2}$ & & \\
\hline Lower 48 States & 5.170 & 9.98 \\
\hline Gulf (gas only) & 10.987 & $17.17^{\mathrm{a}}$ \\
\hline Texas/Ok lahoma (gas on ly) & 5,555 & $17.17^{\mathrm{a}}$ \\
\hline
\end{tabular}

a Barrels of water per million cubic feet of natural gas.

Sources: API 1987a; Flannery and Lannan 1987. 
Tables VI-3 and VI-4 and the waste quantity data shown in Table VI-7. For each model project, waste management costs are calculated for each waste management scenario.

For each model project and scenario, the available compliance methods were identified (Table VI-5). Cost estimates for all available compliance methods, including transportation costs for offsite methods, were developed based on the unit cost factors (Tables VI-2 and VI-3) and the waste quantity estimates (Table VI-7). Each model facility was assumed to have selected the lowest cost compliance method. Based on compliance cost comparisons, presented in more detail in the Technical Background Document, the following compliance methods are employed by affected facilities under the waste management scenarios:

\section{Intermediate Scenario}

1. Drilling wastes - single-liner onsite facility; volume reduction and transport to offsite single-liner facility if cost-effective.

2. Production wastes - Class II onsite facility.

\section{Subtitle C Scenario}

1. Drilling wastes - transport to offsite SCLC facility with site management and with volume reduction if cost-effective.

2. Production wastes - for waterfloods, onsite injection in Class I facility; for nonwaterfloods, transport and disposal in offsite Class I facility.

\section{Subtitle C-1 Scenario}

1. Drilling wastes - transport to offsite SCLS facility with site management and with volume reduction if cost-effective.

2. Production wastes - waterfloods exempt; for nonwaterfloods, transport and injection in offsite Class I facility.

For each model facility under each scenario, the least-cost compliance method was assumed to represent the cost of affected projects. Costs for unaffected projects were estimated based on the cost 
of baseline practices. Weighted average costs for each model under each scenario (shown in Tables VI-8 and VI-9) incorporate both affected and unaffected projects. For example, in the Subtitle C 70\% Scenario, while 70 percent of projects must dispose of drilling wastes in Subtitle $C$ facilities, the other 30 percent can continue to use baseline practices. The weighted average cost is calculated as follows:

\begin{tabular}{|c|c|c|c|}
\hline Project category & $\begin{array}{l}\text { Percentage } \\
\text { of projects }\end{array}$ & $\begin{array}{l}\text { Drilling waste } \\
\text { disposal cost }\end{array}$ & $\begin{array}{c}\text { Weighted } \\
\text { cost } \\
\end{array}$ \\
\hline Affected operations & $70 \%$ & $\$ 61,782$ & $\$ 43,248$ \\
\hline Unaffected operations & $30 \%$ & $\$ 15,176$ & $\$ 4,552$ \\
\hline Weighted average & & & $\$ 47,800$ \\
\hline
\end{tabular}

For drilling wastes, the weighted average costs range from $\$ 15,176$ per well in the Baseline to $\$ 47,800$ per well in the RCRA Subtitle C $70 \%$ case. Thus, the economic analysis assumes that each well incurs an additional $\$ 32,624$ under the RCRA Subtitle C $70 \%$ Scenario. For produced water, costs per barrel of water disposed of range from $\$ 0.11$ in the Baseline to 50.62 in the RCRA Subtitle C $70 \%$ Scenario. Thus, there is an additional cost of $\$ 0.51$ per barrel of water under this scenario.

\section{Impact of Haste Management Costs on Representative Projects}

The new oil and gas projects incur additional costs under the alternative waste management scenarios for both drilling and production waste management. By incorporating these costs into the economic model simulations, the impact of these costs on financial performance of typical new oil and gas projects is assessed. These impacts are presented in Tables VI-10 and VI-11.

As shown in Table VI-10, the internal rate of return can be substantially affected by waste management costs, particularly in the Subtitle C $70 \%$ Scenario. From a base case level of 28.9 percent, model 
Tabie VI-8 Weighted Average Regional Costs of Drilling Waste Management

for Model Projects Under Alternative Waste Management Scenarios

(Dollars per well)

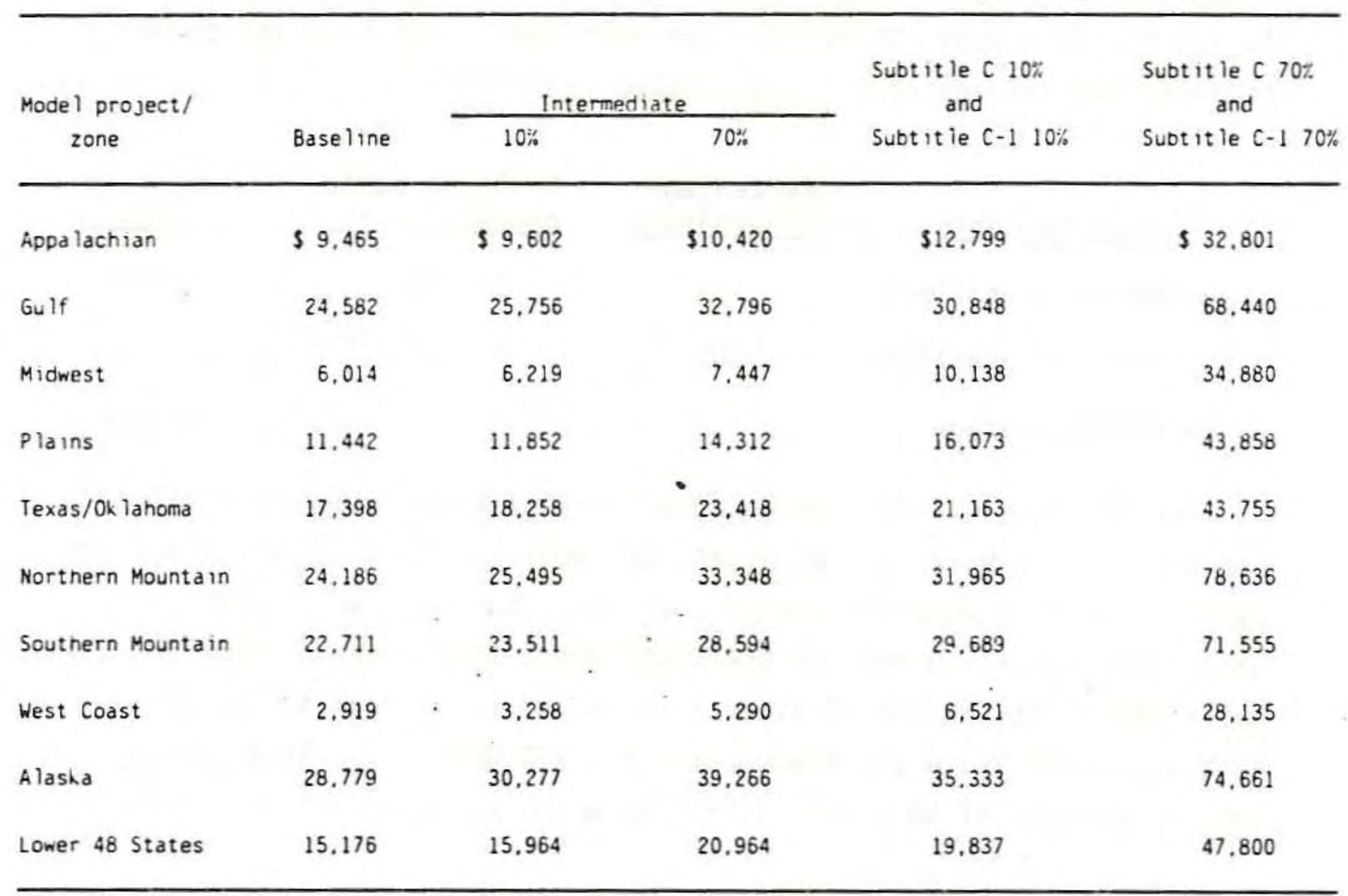

NOTE: Costs in 1985 dollars, based on 1985 cost factors.

Source: ERG est imates. 
Table VI-9 Weignted Average Unit Costs of Produced Water Management for Model Projects under Alternative Waste Management Scenarios

(Dollars per Earrel of Water)

\begin{tabular}{|c|c|c|c|c|c|c|c|}
\hline \multirow{2}{*}{$\begin{array}{l}\text { Model project } / \\
\text { zone }\end{array}$} & \multirow[t]{2}{*}{ Easeline } & \multicolumn{2}{|c|}{ Intermediate } & \multicolumn{2}{|c|}{ Subtit le C } & \multicolumn{2}{|c|}{ Sub: it le C-1 } \\
\hline & & $10 \%$ & $70 \%$ & $10 \%$ & $70 \%$ & $10 \%$ & $70 \%$ \\
\hline Appalachian & $\$ 0.52$ & \$o 57 & $\$ 0.94$ & $\$ 0.80$ & $\$ 2.51$ & $\$ 0.67$ & $\$ 1.57$ \\
\hline Gulf & 0.08 & 0.08 & 0.10 & 0.16 & 0.65 & 0.15 & 0.57 \\
\hline Midwest & 0.14 & 0.14 & 0.14 & 0.22 & 0.65 & 0.15 & 0.20 \\
\hline Plains & 0.16 & 0.16 & 0.16 & 0.24 & 0.74 & 0.20 & 0.47 \\
\hline Texas/Ok lanoma & 0.13 & 0.13 & 0.13 & 0.20 & 0.61 & 0.15 & C. 31 \\
\hline Northern Mounta in & 0.07 & 0.07 & .0 .07 & 0.11 & 0.36 & 0.09 & 0.22 \\
\hline Soutnern Mount a in & 0.13 & 0.13 & 0.13 & 0.19 & 0.55 & 0.14 & 0.24 \\
\hline West Coast & 0.04 & 0.04 & 0.04 & 0.08 & 0.34 & 0.07 & 0.26 \\
\hline Alaska & 0.31 & 0.31 & 0.31 & 0.46 & 1.42 & 0.34 & 0.56 \\
\hline Lower 48 States & 0.11 & 0.11 & 0.12 & 0.18 & 0.62 & 0.15 & 0.35 \\
\hline
\end{tabular}

NOTE: Waste management costs applied to both oil and gas production wastes.

Costs in 1985 dollars.

Source: ERG est Imates. 


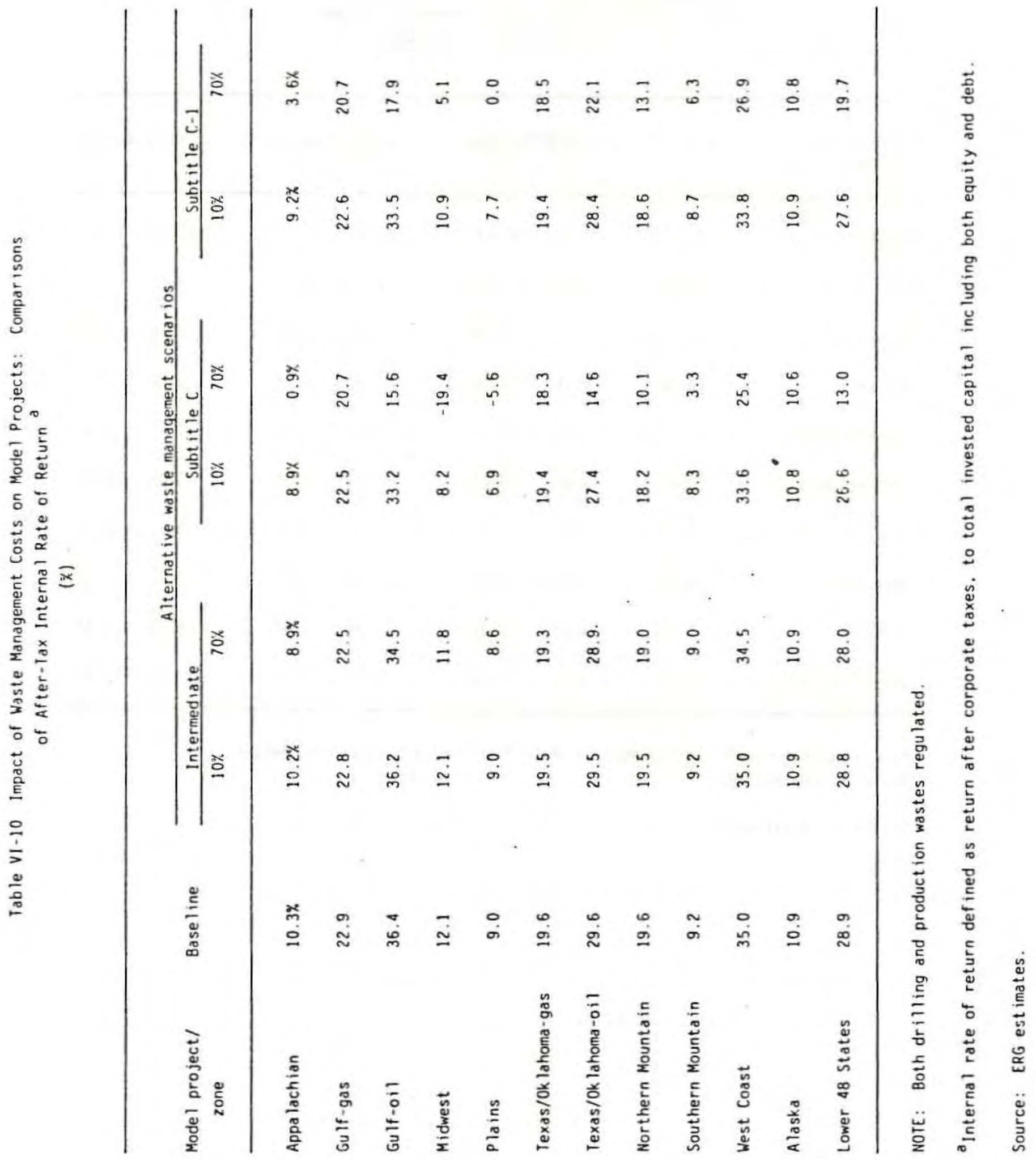




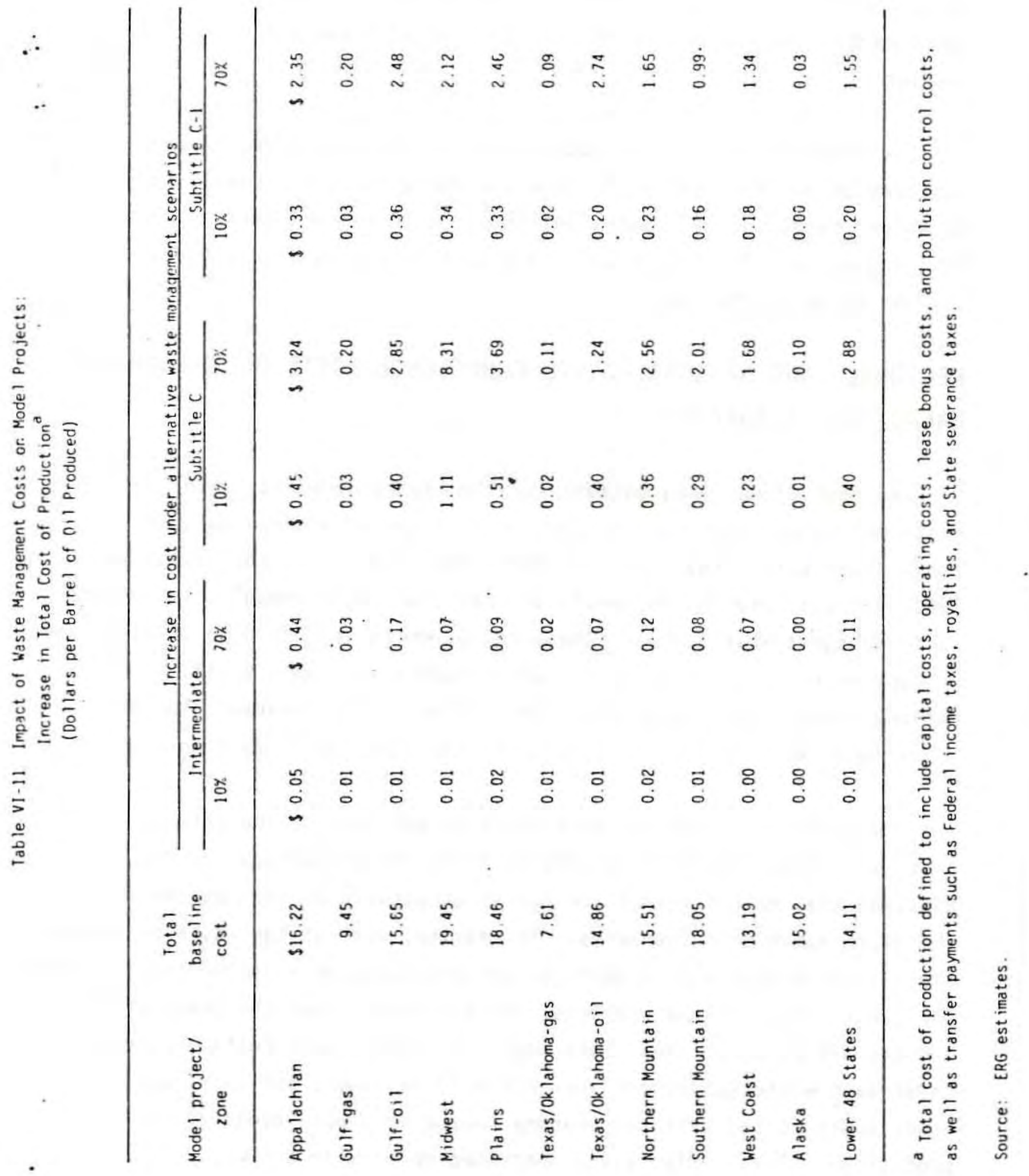


project after-tax internal rates of return decline under the waste management scenarios to the 13.0 to 28.8 percent range for the Lower 48 average.

The after-tax cost of producing hydrocarbons can also increase substantially. As Table VI-11 shows, these costs can increase by up to $\$ 2.98$ per barrel of oil equivalent (BOE), a 20 percent increase over basel ine costs. The impacts of these cost increases on a national level are described further below.

\section{REGIONAL - RND NATIONAL-LEVEL COMPLIANCE COSTS OF THE WASTE MANAGEMENT SCENARIOS}

The cost of waste management for the typical projects under each waste management scenario (see Tables VI-8 and VI-9) were used in conjunction with annual drilling (API 1986) and production levels (API 1987c) to estimate the regional- and national-level annual costs of the waste managenerit scenarios. These costs, which include both drilling and production waste disposal costs, are presented in Table VI-12. National-level costs range from $\$ 49$ million in the Intermediate $10 \%$ Scenario to more than $\$ 12.1$ billion in the Subtitle C $70 \%$ Scenario.

The costs presented in Table VI-12 do not include the effects of closures. They are based on 1985 drilling and production levels, assuming that no activities are curtailed because of the requirements of the waste management scenarios. In reality, each of the waste management scenarios would result in both the early closure of existing projects and the cancellation of new projects. To the extent that the level of oil and gas activity declines, total aggregate compliance costs incurred under each waste naanagement scenario will be lower, but there will be other costs to the national economy caused by lower levels of oil production. These effects are described more fully below. 
Table VI-12 Annual Regional and National RCRA Compliance Cost of Alternative Waste Menagement Scenarios (Millions of Dollars)

\begin{tabular}{|c|c|c|c|c|c|c|c|}
\hline \multirow{3}{*}{$\begin{array}{l}\text { Mode l project/ } \\
\text { zone }\end{array}$} & \multicolumn{7}{|c|}{ Waste management scenarios } \\
\hline & \multicolumn{3}{|c|}{ Intermediate } & \multicolumn{2}{|c|}{ Subtitile C } & \multicolumn{2}{|c|}{ Subtit le $C-1$} \\
\hline & $10 x$ & $70 x$ & & $10 \%$ & $70 \%$ & $10 \%$ & $70 x$ \\
\hline Appalachian & $\$ 5$ & $\$ 43$ & & $\$ 57$ & $\$ 403$ & $\$ 47$ & $\$ 328$ \\
\hline Gulf & 8 & 94 & & 200 & 1.417 & 180 & 1.239 \\
\hline Midnest & 1 & 6 & & 120 & 870 & 31 & 185 \\
\hline Plains & 2 & 17 & & 126 & 907 & 77 & 576 \\
\hline Texas/0k lahoma & 26 & 181 & & 879 & 6.156 & 442 & 2.873 \\
\hline Northern Mountains & 3 & 19 & & 94 & 677 & 55 & 404 \\
\hline Southern Mounta ins & 3 & 21 & & 92 & 643 & 47 & 297 \\
\hline West Coast & 1 & $3 \varepsilon$ & & 126 & 936 & 97 & 736 \\
\hline Alaska & 0 & 2 & . & 17 & 118 & 5 & 34 \\
\hline Lower 48 States & 49 & 418 & . & 1.693 & 12.007 & 975 & 6.637 \\
\hline Nat ional Total & 49 & 420 & & 1.710 & 12.125 & 980 & 6.671 \\
\hline
\end{tabular}

NOIE: Figures represent before-tax total annual increașe in waste management cost over baseline costs at 1985 levels of drilling and production. withcut adjusting for decreases in industry activity caused by higher production costs at affected sites. Column totals may differ because of independent rounding. Base year for all costs is 1385 . 


\section{CLOSURE ANALYSIS FOR EXISTING WELLS}

The potential of the waste management scenarios to shut down existing producing wells was estimated using the model facility approach. The model facility simulations for existing projects, however, do not include the initial capital cost of leasing and drilling the production well. For the analysis of existing projects, it is assumed that these costs have already been incurred. The projects are simulated for their operating years. If operatirg revenues exceed operating costs, the projects remain in production.

Closures of existing wells are estimated by using a variable called the economic limit (i.e., a level of production below which the project cannot continue to operate profitably). Under the waste management scenarios, produced water disposal costs are higher and, therefore, the economic limit is higher. Some projects that have production levels that exceed the baseline economic linit would fall below the economic limit under the alternative waste management scenarios. Those projects not meeting this higher level of production can be predicted to close. This analysis was conducted only with respect to stripper wells. To the extent that certain high-volume, low-margin wells may also be affected, the analysis may understate short-term project closures.

The economic limit analysis requires information on the distribution of current production levels across wells. Because of the lack of data for most States, the economic limit analysis is presented here only for Texas and on a national level. The 1985 distribution of production by volume size class for Texas and for the Nation as a whole is shown in Table VI-13.

Table VI-14 displays the results of the economic limit analysis. Under baseline assumptions, the representative Lower 48 project requires 2.40 barrels per day to remain in operation. The economic limit for 
Table VI-13 Distribution of 011 Production Across Existing Projects, 1985

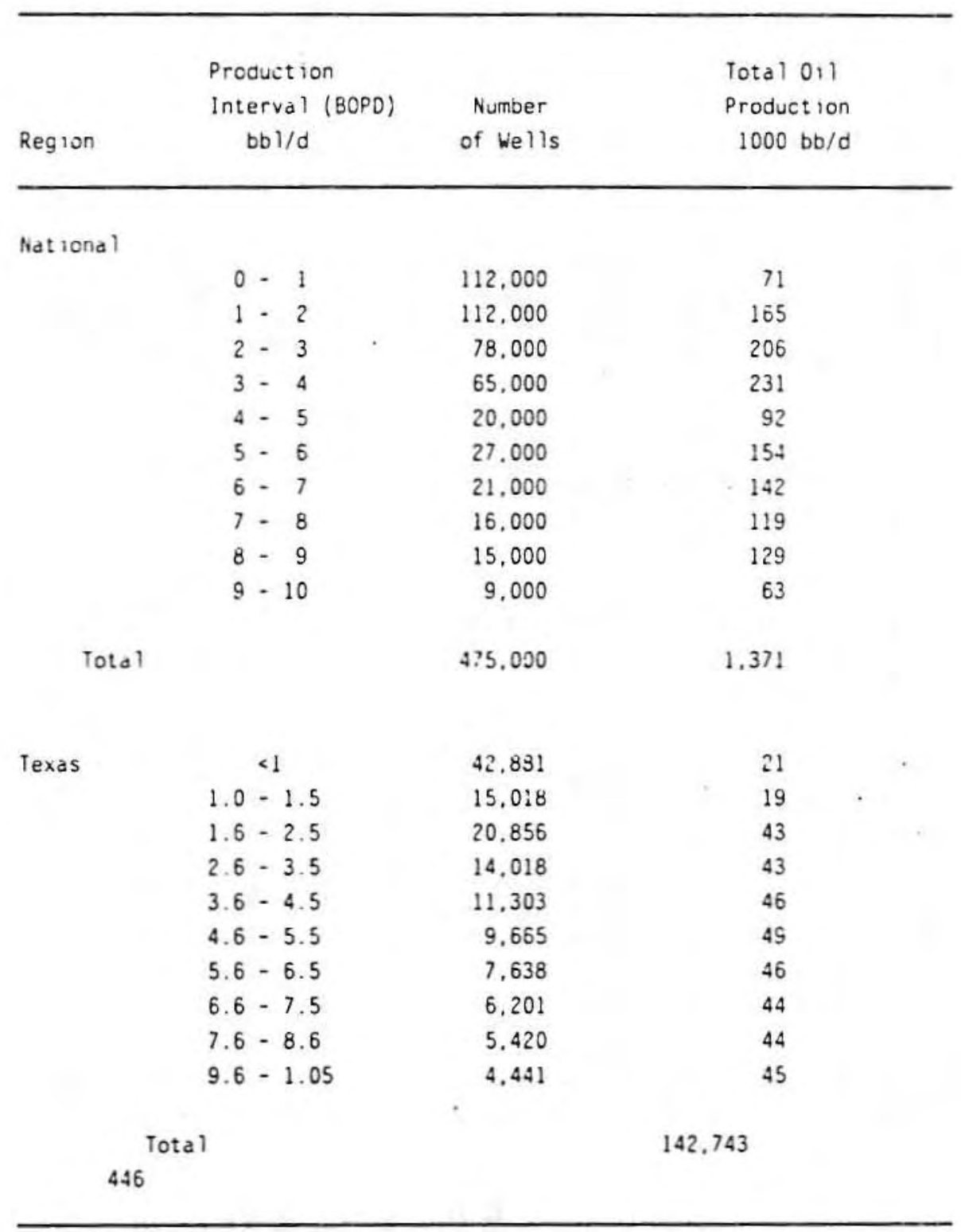

Sources: :The Effect of Lower Oil Prices on Production From Proved U.S. 011 Reserves," Energy and Environmental Analysis. Inc.. February 1987, taken from Figure 2-2. Indicators: A Monthly Data Review-April 1986, Railroad Commission of Teas, April 1986. 


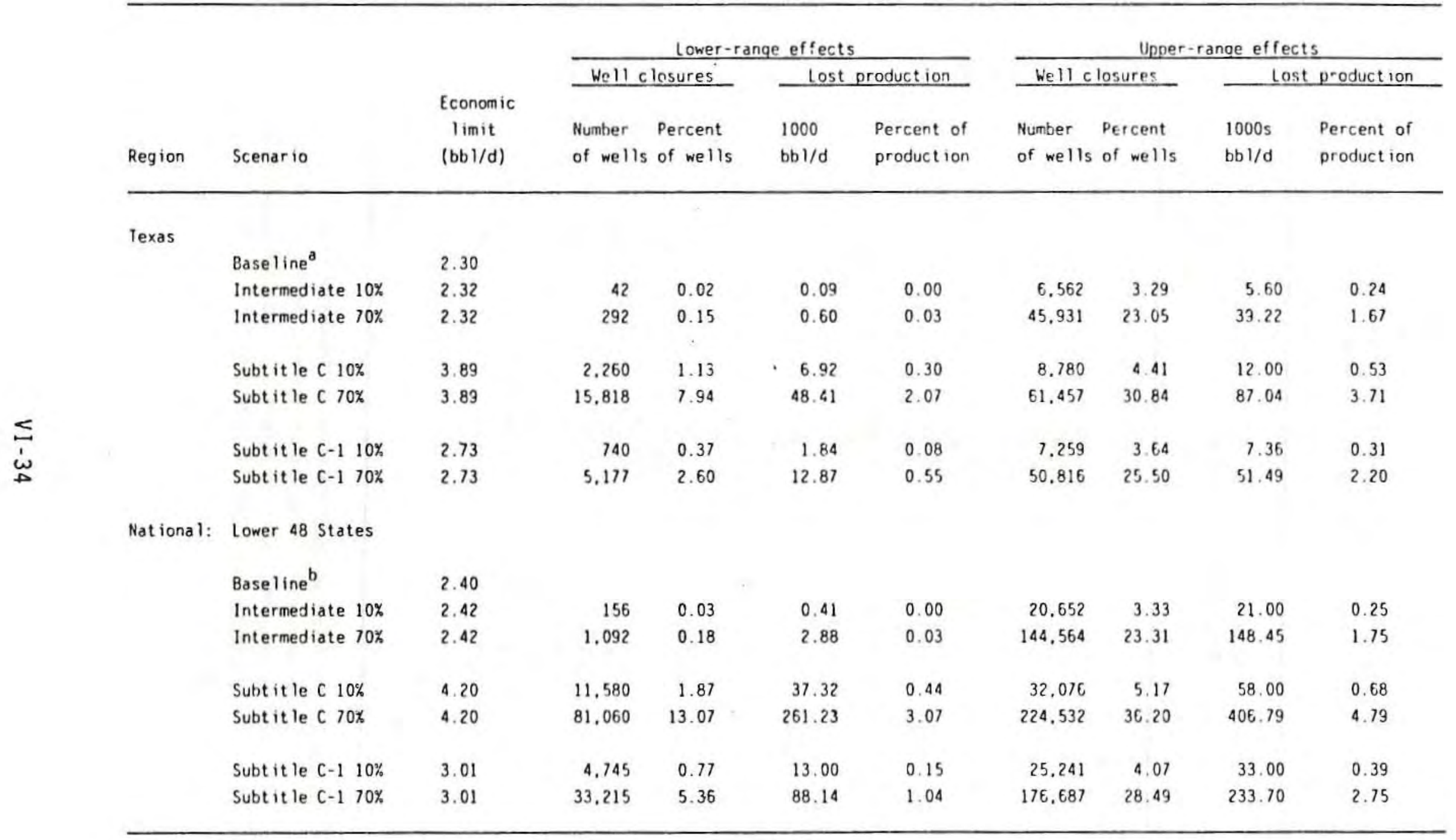

a Baseline production level is $2.3 \mathrm{million}$ bb $1 / \mathrm{d}$; baseline well total is 199,000 .

b Baseline production level is $8.6 \mathrm{million}$ bbl/d; baseline well total is 620,000 .

Source: ERG est imates. 
affected operations rises to 3.01 to 4.20 barrels per day under the waste management scenarios. The increase in the economic limit results in closures of from 0.03 percent to 36.20 percent of all producing wells.

The "lower-range effects" in Table VI-14 assume that only affected wells (i.e., wells generating hazardous produced waters) producing at levels between the baseline economic limit and the economic limit under the waste management scenarios will be closed. The "upper-range effects" assume that all affected wells producing at levels below the economic 1 imit under the waste management scenarios will be closed, and are adjusted to account for the change in oil prices from 1985 to 1986.

Under the lower-range effects case, production losses are estimated at between 0.00 and 3.07 percent of total production. Under the upper-range effects assumptions, production closures range from 0.25 to 4.79 percent of the total. These results are indicative of the imnediate, short-term impact of the waste management scenarios caused by well closures.

The results of the Texas simulation mirror those of the national-level analysis. This would be expected, since nearly 30 percent of all stripper wells are in Texas, and the State is, therefore, reflected disproportionately in the national-level analysis. Under the lower-range effects assumptions, Texas production declines between 0.00 and 2.07 percent. Under the upper-range effects assumptions, Texas production declines between 0.24 and 3.71 percent.

\section{THE INTERMEDIATE AND LONG-TERM EFFECTS OF THE WASTE MANAGEMENT SCENARIOS}

Production Effects of Compliance Costs

The intermediate and long-term effects of the waste management scenarios will exceed the short-term effects for two principal reasons. 
First, the increases in drilling waste management cost, which do not affect existing producers, can influence new project decisions. Second, the higher operating costs due to produced water disposal requirements may result in some project cancellations because of the expectation of reduced profitability during operating years. Although such projects might be expected to generate profits in their operating years (and therefore might be expected to operate if drilled), the reduced operating profits would not justify the initial investment.

The intermediate and long-term production effects were estimated using Department of Energy (DOE) production forecasting models. As described above, an economic simulation model was used to calculate the increase in the cost of resource extraction under each waste management scenario. These costs were used in conjunction with the DOE FOSSIL2 model (DOE 1985) and the DOE PROLOG model (DOE 1982) to generate estimates of intermediate and long-term production effects of the waste management scenarios.

For the FOSSIL2 model, an estimate of the increase in resource extraction costs for each waste management scenario, based on model project analysis, was provided as an input. Simulations were performed to measure the impact of this cost increase on the baseline level of production.

For the PROLOG model, no new simulations were performed. Instead, results of previous PROLOG modeling were used to calculate the elasticity of supply with respect to price in the PROLOG model. The model project simulation results were used to calculate an oil price decline that would have the same impact as the cost increase occurring under each alternative waste management scenario. These price increases were used in conjunction with an estimate of the price elasticity of supply from the PROLOG model to estimate an expected decline in production for each waste management scenario. 
Table VI-15 shows the results of this analysis. The long-term impacts of the waste management scenarios range from levels that are below the detection limits of the modeling system to declines in production ranging up to 32 percent in the year 2000, based on the PROLOG analysis. For the FOSSIL2 simulations, production declines were estimated to range from "not detectable" to 18 percent in the year 2000 and from "not detectabie" to 29 percent in the year 2010.

\section{Additional Impacts of Compliance Costs}

The decline in U.S. oil production brought about by the cost of the waste management scenarios would have wide-ranging effects on the U.S. economy. Domestic production declines would lead to increased oil imports, a deterioration in the U.S. balance of trade, a strengthening of OPEC'S position in world markets, and an increase in world oil prices. Federal and State revenues from leasing and from production and income taxes would decline. Jobs would be lost in the oil and gas drilling, servicing, and other supporting industries; jobs would be created in the waste management iridustries (e.g., contractors who drill and complete Class I injection wells).

It is beyond the scope of this report to fully analyze all of these and other macroeconomic effects. To illustrate the magnitude of some of these effects, however, five categories of impacts were defined and quantified (oil imports, balance of trade, oil price, Federal leasing revenues, and State production taxes). These are presented in Table VI-16. Measurable effects are evident for all but the lowest cost (Intermediate 10\% Scenario).

The impacts of the waste management scenarios on the U.S. economy were analyzed utilizing the DOE FOSSIL2/WOIL modeling system. Cost increases for U.S. oil producers create a slight decrease in the world oil supply curve (i.e., the amount of oil that would be brought to market at any oil price declines). The model simulates the impact of this shift on the world petroleum supply, demand, and price. 
Tatle V1-15 Long-Term Impacts on Production of Cost Increases under Waste Management Scenarios

\begin{tabular}{|c|c|c|c|c|c|c|}
\hline \multirow[b]{2}{*}{$(x)$} & \multirow{4}{*}{$\begin{array}{l}\text { Est imated resource } \\
\text { extraction cost } \\
\text { increase }(x)\end{array}$} & \multicolumn{5}{|c|}{ Decline of domest ic oll production in lower 49 States } \\
\hline & & \multirow{2}{*}{\multicolumn{2}{|c|}{ Year 1990}} & \multirow{2}{*}{\multicolumn{2}{|c|}{ Year 2000}} & \multirow{3}{*}{$\frac{\text { Year } 2010}{\text { rossilz }}$} \\
\hline & & & & & & \\
\hline Scenario & & FossIL2 & PROLOS & FOSSIL2 & PROLOG & \\
\hline Intermediate $10 \%$ & 0.16 & $\begin{array}{l}\text { No detectable } \\
\text { change }\end{array}$ & $\begin{array}{c}\text { Ho detectable } \\
\text { change }\end{array}$ & $\begin{array}{l}\text { No detectable } \\
\text { change }\end{array}$ & $\begin{array}{l}\text { No detectable } \\
\text { change }\end{array}$ & $\begin{array}{l}\text { No detectable } \\
\text { change }\end{array}$ \\
\hline Intermediate $70 \%$ & 2.49 & $\begin{array}{l}\text { No detectable } \\
\text { change }\end{array}$ & $\begin{array}{l}\text { No detectable } \\
\text { change }\end{array}$ & $1.4 x$ & $\begin{array}{l}\text { No detectable } \\
\text { change to } 0.4 \%\end{array}$ & $1.6 \%$ \\
\hline Subt it le C $10 \%$ & 9.51 & $\begin{array}{l}\text { No detectable } \\
\text { change }\end{array}$ & $0.3 \%$ to $0.4 \%$ & $4.2 \%$ & $1.6 \%$ to $3.5 \%$ & $6.3 \%$ \\
\hline Subtit le C $70 \%$ & 68.84 & $3.2 \%$ & $6.9 \%$ to $7.8 \%$ & $18.1 \%$ & $13.1 \%$ to $32.4 \%$ & $28.6 \%$ \\
\hline Subt it le C-1 10x & 4.73 & $\begin{array}{l}\text { No detectable } \\
\text { change }\end{array}$ & $\begin{array}{l}\text { No detectable } \\
\text { change }\end{array}$ & $1.4 x$ & $0.3 \%$ to $1.4 \%$ & $3.2 \%$ \\
\hline Subt it le C-1 $70 \%$ & 36.51 & $2.1 \%$ & $3.7 \%$ to $4.3 \%$ & $12.5 \%$ & $10.7 \%$ to $18.5 \%$ & $19.0 \%$ \\
\hline
\end{tabular}

Source: ERG est imates for extraction cost increase and for PROLOG impacts. Applied Energy Services of Arlington, Virginia. (Wood 1987) for FOSSIL2 results, based on specific runs of U.S. Department of Energy FosSIL2 Model for alternative scenario cost increases. Department of Energy baseline crude oil price per barrel assumptions in FoSS1L2 were $\$ 20.24$ in $1990, \$ 33.44$ in 2000 . and $\$ 52.85$ in 2010 . 
Table V1-16 Effect of Domestic Production Decline on

Selected Economic Parameters in the Year 2000

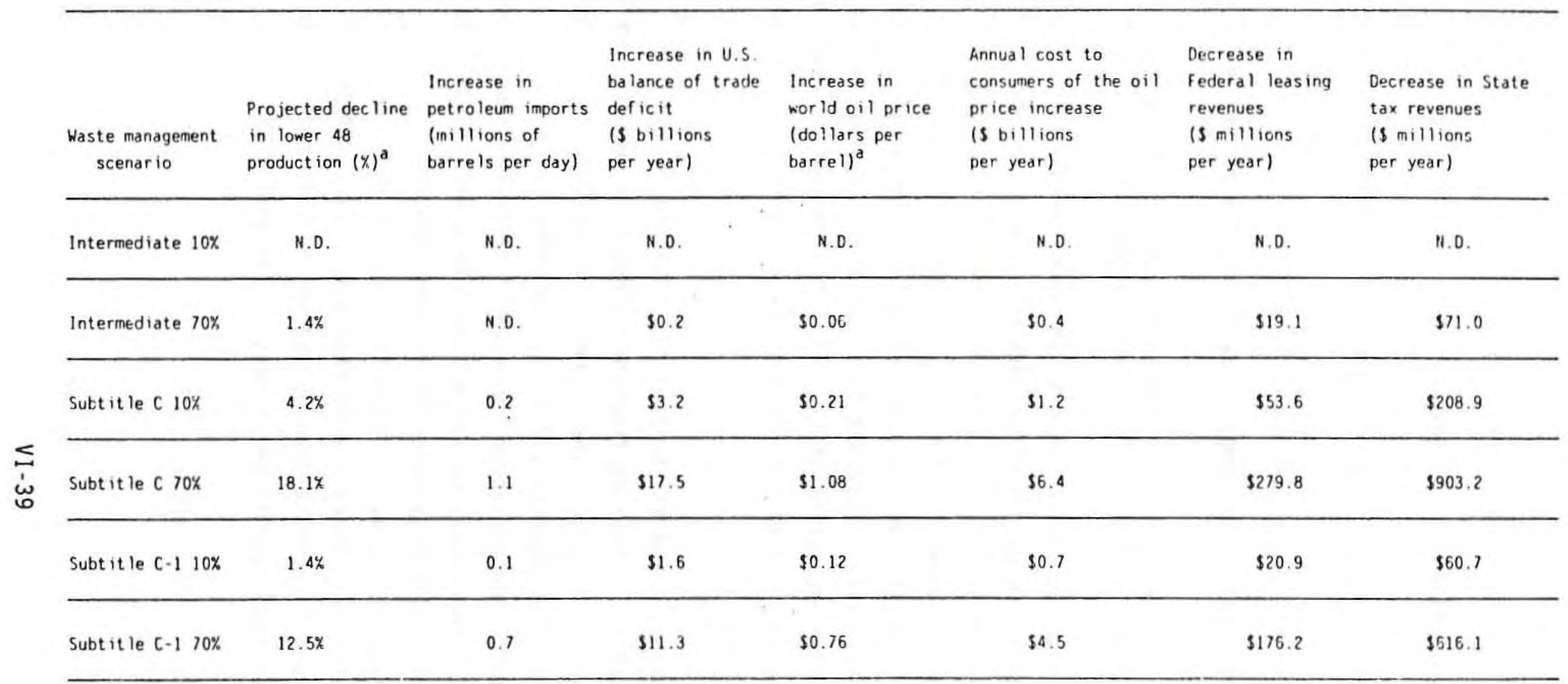

N.D. - Not detectable using the FOSSIL2/WOIL modeling system.

a Revised baseline values for year 2000 in the Foss 1 L2 modeling system include (1) lower 48 States crude oil production of 7.2 million barrels per day;

(2) U.S. imports of 9.2 million barrels per day: and (3) world crude oil price of $\$ 33.44$ per barre 1 .

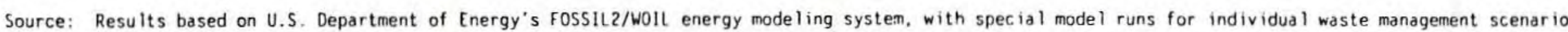
production costs effects conducted by Applied Energy Services of Arlington. Virginia (Wood 1987). ERG est imates based on FOSSIL2 results. 
A new equilibrium shows the following effects:

- A lower level of domestic supply (previously depicted in Table VI-15);

- A higher world oil price (see Table VI-16);

- A decrease in U.S. Oil consumption caused by the higher world oil price; and

- An increase in U.S. imports to partially substitute for the decline in domestic supply (also shown in Table VI-16).

The first numerical column in Table VI-16 shows the decline in U.S. production associated with each waste management scenario. These projections, derived from simulations of the FOSSIL2/WOIL modeling system, were previously shown in Table VI:15. The second column in Table VI-16 provides FOSSIL2/WOIL projections of the increase in petroleum imports necessary to replace the lost domestic supplies. The projections range from "not detectable" to 1.1 million barrels per day, equal to 1.4 to 18.1 percent of current imports of approximately 6.1 million barrels per day.

The third column in Table VI-16 shows the increase in the U.S. balance of trade deficit resulting from the increase in imports and the increase in the world oil price. The increase in the U.S. balance of trade deficit ranges from $\$ 0.2$ to $\$ 17.5$ billion under the waste management scenarios. The projected increase in petroleum imports under the most restrictive regulatory scenarios could be a matter for some concern in terms of U.S. energy security perspectives, making the country somewhat more vulnerable to import disruptions and/or world oil price fluctuations. In the maximum case estimated (Subtitle C $70 \%$ Scenario), import dependence would increase from 56 percent of U.S. crude oil requirements in the base case to 64 percent in the year 2000 . 
The fourth column shows the crude petroleum price increase projected under each of the waste management scenarios by the FOSSIL2/WOIL modeling system. This increase ranges from 50.06 to $\$ 1.08$ per barrel of oil (a 0.2 to 3 percent increase). This increase in oil price trarislates into an increase in costs to the consumer of $\$ 0.4$ to $\$ 6.4$ billion in the year 2000 (column five). These estimates are derived by multiplying FOSSIL2-projected U.S. crude oil consumption in the year 2000 by the projected price increase. The estimates assume that the price increase is fully passed through to the consumer with no additional downstream markups.

Federal leasing revenues will also decline under the waste management scenarios. These revenues consist of lease bonus payments (i.e., initial payments for the right to explore Federal lands) and royalties (i.e., payments to the Federal government based on the value of production on Federal lands). Both of these revenue sources will decline because of the production declines associated with the waste management scenarios. If the revenue sources are combined, there will be a reduction of $\$ 19$ to $\$ 280$ million in Federal revenues in the year 2000 .

State governments generally charge a tax on crude oil production in the form of severance taxes, set as a percentage of the selling price. On a national basis, the tax rate currently averages approximately 6.7 percent. Applying this tax rate, the seventh column in Table VI-16 shows the projected decline in State tax revenues resulting from the waste management scenarios. These estimates range from about $\$ 60$ million to $\$ 900$ million per year. 


\section{REFERENCES}

API. 1986. American Petroleum Institute. Joint association survey on drilling costs.

. 1987a. American Petroleum Institute. API 1985 production waste survey. June draft.

. 1987b. American Petroleum Institute. API 1985 production waste survey supplement. Unpublished.

. 1987c. American Petroleum Institute. Basic petroleum data

book. Volume VII, No. 3. September 1987.

Camp, Dresser \& McKee, Inc. 1986. Superfund treatment technologies: a vendor inventory. EPA 540/2-8/004.

Cull inane, M. John, Jones, Larry W., and Malone, Phillip G. 1986. Handbook for stabilization/solidification of hazardous waste. $E P A / 540 / 2-86 / 001$. June.

Eastern Research Group (ERG), Inc. 1987. Economic impacts of alternative waste management scenarios for the onshore. 0il and gas industry. Report 1: baseline cases. Report prepared for the U.S. Environmental Protection Agency, Office of Sol id Waste. Revised December 1987.

Erlandson, Steven. 1986. Personal communication between Anne Jones, ERG, and Steven Erlandson, Enreco, Inc., December 22, 1986.

Flannery, David. 1987. Personal comnunication between Maureen Kaplan, ERG, and David Flannery, Robinson and McElwee, Charleston, West Virginia, October 13, 1987.

Flannery, David, and Lannan, Robert E. 1987. An analysis of the economic impact of new hazardous waste requlations on the Appalachian Basin oil and gas industry. Charleston, West Virginia: Robinson \& McElwee.

Freeman, B.D., and Deuel, L.E. 1986. Closure of freshwater base drilling mud pits in wetland and upland areas in Proceedings of a National Conference on Drilling Muds: May 1986. Oklahoma: Environmental and Ground Water Institute.

Hanson, Paul M., and Jones, Frederick V. 1986. Mud disposal, an industry perspective. Drilling, May 1986.

North America Environmental Service. 1985. Closure Dlan for the Big Diamond Trucking Service, Inc., drilling mud disposal pit near sweet Lake. LA. 
Pope Reid Associates. 1985a. Appendix F - cost model in Liner location risk and cost analysis model. Prepared for U.S. Environmental

Protection Agency, Office of Solid Waste.

- 1985b. Engineering costs supplement to Appendix $F$ of the liner location report. Prepared for U.S. Environmental Protection Agency, office of Solid Waste.

- 1987a. Facilities design tool cost model. Available on the U.S. Environmental Protection Agency computer in Research Triangle Park, North Carolina.

1987b. Land treatment computer cost model. Available on the U.S. Environmental Protection Agency computer in Research Triangle Park, North Carolina.

Rafferty, Joe. 1987. Personal communication between Scott Carlin, ERG, and Joe Rafferty, Ramteck Systems, Inc., February 4, 1987.

- 1985. Recommended practices for the reduction of drill site wastes in Proceedings of a National Conference on Drilling Mud Wastes: May 1985. Oklahoma: Environmental and Ground Water Institute.

Slaughter, Ken, 1987. Personal communication between Scott Carlin, ERG, and Ken Slaughter, New Park Waste Treatment Systems, February 5, 1987.

Tesar, Laura, 1986. Personal communication between Anrie Jones, ERG, and Laura Tesar, VenVirotek, December 31, 1986.

Texas Railroad Commission. 1986. Indicators: a monthly data review, April 1986.

Tilden, Greg. 1987a. Class I and class II disposal well cost estimates. Prepared by Epps \& Associates Consulting Engineers, Inc., for Eastern Research Group, Inc., February 1987.

- 1987b. Revised class I and class II disposal well cost estimates. Prepared for Eastern Research Group, Inc., November 1987.

U.S. Departmient of Energy. 1982. Production of onshore Lower 48 il and gas - model methodology and data description. DOE/EIA -0345; DE83006461.

1985. National energy policy plan projections to 2010. DOE/PE - 0029/3.

USEPA. 1986. U.S. Environmental Protection Agency, Office of Policy Analysis. 1985 survey of selected firms in the commercial hazardous waste management industry. 
Vidas, E. Harry, 1987. The effect of lower $0 i 1$ prices on production from proved U.S. oil reserves. Energy and Environmental Analysis, Inc.

Webster, William. 1987. Personal communication between Anne Jones, ERG, and William Webster, Envirite, January 7, 1987.

Wood, Francis. 1987. Personal communication between David Meyers, ERG, and Francis Wood, Applied Energy Services of Arlington, Virginia, regarding FOSSIL2 results, December 1987. 


\section{CHAPTER VII}

\section{CURRENT REGULATORY PROGRAMS}

\section{INTRODUCTION}

A variety of programs exist at the State and Federal levels to control the environmental impacts of waste management related to the $0 i 1$ and gas industry. This chapter provides a brief overview of the requirements of these programs. It also presents summary statistics on the implementation of these programs, contrasting the numbers of wells and other operations regulated by these programs with resources available to implement regulatory requirements.

State programs have been in effect for many years, and many have evolved significantly over the last decade. The material presented here provides only a general introduction to these complex programs and does not attempt to cover the details of State statutes and current State implementation policy. Additional material on State regulatory programs can be found in Appendix A. Federal programs are administered both by the Environmental Protection Agency and by the Bureau of Land Management within the U.S. Department of the Interior.

\section{STATE PROGRAMS}

The tables on the following pages compare the principal functional requirements of the regulatory control programs in the principal 0il-and gas-producing States that have been the focus of most of the analysis of this study. These States are Alaska, Arkansas, California, Colorado, Kansas, Louisiana, Michigan, New Mexico, Ohio, Oklahoma, Texas, West Virginia, and Wyoming. 
Table VII-1 covers requirements for reserve pit design, construction, and operation; Table VII-2 covers reserve pit closure and waste removal. Table VII-3 presents requirements for produced water pit design and construction, while Table VII-4 compares requirements for the produced water surface discharge limits. Table VII-5 deals with produced water injection well construction; these requirements fall under the general Federal Underground Injection Control program, which is discussed separately below under Federal programs. Finally, Table VII-6 discusses requirements for well abandonment and plugging.

\section{FEDERAL PROGRAMS--EPA}

Federal programs discussed in this section include the Underground Injection Control (UIC) program and the Effluent Limitations Guidelines program administered by the EPA.

\section{Underground Injection Control}

The Underground Injection Control (UIC) program was established under Part $C$ of the Safe Drinking Water Act (SDWA) to protect underground sources of drinking water (USDWs) from endangerment by subsurface emplacement of fluids through wells. Part $C$ of the SDWA requires EPA to:

1. Identify the States for which UIC programs may be necessary--EPA listed all States and jurisdictions;

2. Promulgate regulations establishing minimum requirements for State programs which:

- prohibit underground injection that has not been authorized by permit or by rule;

- require applicants for permits to demonstrate that underground injection will not endanger USDWs;

- include inspection, monitoring, record-keeping, and reporting requirements. 
These minimum requirements are contained in 40 CFR Parts 144 and 146, and were promulgated in June 1980.

3. Prescribe by regulation a program applicable to the States, in cases where States cannot or will not assume primary enforcement responsibility. These direct implementation (DI) programs were codified in 40 CFR Part 147.

The regulations promulgated in 1980 set minimum requirements for 5 classes of wells including Class II wells--wells associated with oil and gas production and hydrocarbon storage. In December 1980, Congress amended the SDWA to allow States to demonstrate the effectiveness of their in-place regulatory programs for Class II wells, in lieu of demonstrating that they met the minimum requirements specified in the UIC regulations. In order to be deemed effective, State Class II programs had to meet the same statutory requirements as the other classes of wells, including prohibition of unauthorized injection and protection of underground sources of drinking water. (\$1425 SDWA). Because of the large number of $\mathrm{Class}$ II wells, the regulations allow for authorization by rule for existing enhanced recovery wells (i.e., wells that were injecting at the time a State program was approved or prescribed by EPA). In DI States, these wells are subject to requirements specified in Part 147 for authorization by rule, which are very similar to requirements applicable to permitted wells, with some relief available from casing and cementing requirements as long as the wells do not endanger USDWs. In reviewing State programs where the intent was to "grandfather" existing wells as long as they met existing requirements, EPA satisfied itself that these requirements were sufficient to protect USDWs. In addition, all States adopted the minimum requirements of $\$ 146.08$ for demonstrating mechanical integrity of the wells (ensuring that the well was not leaking or allowing fluid movement in the borehole), at least every 5 years. This requirement was deemed by EPA 
to be absolutely necessary in order to prevent endangerment of USDWs. In addition, EPA and the States have been conducting file reviews of all wells whether grandfathered or subject to new authorization-by-rule requirements. File reviews are assessments of the technical issues that would normally be part of a permit decision, including mechanical integrity testing, construction, casing and cementing, operational history, and monitoring records. The intent of the file review is to ensure that injection wells not subject to permitting are technically adequate and will not endanger underground sources of drinking water.

Because of $\$ 1425$ and the mandate applicable to Federal programs not to interfere with or impede underground injection related to $0 i 1$ and gas production, to avoid unnecessary disruption of State programs and to consider varying geologic, hydrologic, and historical conditions in different States, EPA has accepted more variability in this program than in many of its other regulatory programs. Now that the program has been in place for several years, the Agency is starting to look at the adequacy of the current requirements and may eventually require more specificity and less variation among States.

\section{Effluent Limitations Guidelines}

On October 30, 1976, the Interim Final BPT Effluent Limitations Guidelines for the Onshore Segment of the 0 il and Gas Extraction Point Source Category were promulgated as $41 \mathrm{FR}$ (44942). The rulemaking also proposed Best Available Technology Economically Achievable (BAT) and New Source Performance Standards. 
On April 13, 1979, BPT Effluent Limitations Guidelines were promulgated for the Onshore Subcategory, Coastal Subcategory, and Agricultural and Wildlife Water Use Subcategory of the $0 i l$ and Gas Extraction Industry (44 FR 22069). Effluent limitations were reserved for the Stripper Subcategory because of insufficient technical data.

The 1979 BPT regulation established a zero discharge limitation for all wastes under the Onshore Subcategory. Zero discharge Agricultural and Wildlife Subcategory limitations were established, except for produced water, which has a $35 \mathrm{mg} / \mathrm{L}$ oil and grease limitation.

The American Petroleum Institute (API) challenged the 1979 regulation (including the BPT regulations for the Offshore Subcategory) (661 F.2D.340(1981)). The court remanded EPA's decision transferring 1,700 wells from the Coastal to the Onshore Subcategory (47 FR 31554). The court also directed EPA to consider special discharge limits for gas wells.

Summary of Major Regulatory Activity Related to Onshore $0 i 1$ and Gas

October 13, 1976 - Interim Final BPT Effluent Limitations Guidelines and Proposed (and Reserved) BAT Effluent Limitations Guidelines and New Source Performance Standards for the Onshore Segment of the $0 i 1$ and Gas Extraction Point Source Category

April 13, 1979 - Final Rules

- BPT Final Rules for the Onshore, Coastal, and Wildlife and Agricultural Water Use Subcategories

- Stripper 0il Subcategory reserved

- BAT and NSPS never promulgated 
July 21, 1982 - Response to American Petroleum Institute vs. EPA Court Decision

- Recategorization of 1,700 "onshore" wells to Coastal Subcategory

- Suspension of regulations for Santa Maria Basin, California

- Planned reexamination of marginal gas wells for separate regulations

Onshore Segment Subcategories

Onshore

- BPT Limitation

-- Zero discharge

- Defined: NO discharge of wastewater pollutants into navigable waters from ANY source associated with production, field exploration, drilling, well completion, or well treatment (i.e., produced water, drilling muds, drill cuttings, and produced sand).

Stripper $(0 \mathrm{il} \text { Wells })^{1}$

- Category reserved

- Defined: IEN barrels per well per calendar day or less of crude oil.

1 This subcategory does not include marginal gas wells. 


\section{Coastal}

- BPT Limitations

-- No discharge of free oil (no sheen)

-. $0 \mathrm{il}$ and grease: $72 \mathrm{mg} / \mathrm{L}$ (daily)

$48 \mathrm{mg} / \mathrm{L}$ (average monthly)

(produced waters)

- Defined: Any body of water landward of the territorial seas or any wetlands adjacent to such waters.

Wildlife and Aariculture Use

- BPT Limitations

-- $0 \mathrm{il}$ and Grease: $35 \mathrm{mg} / \mathrm{L}$ (produced waters)

-. Zero Discharge: ANY waste pollutants

- Defined: That produced water is of good enough quality to be used for wildlife or livestock watering or other agricultural uses west of the 98 th meridian. 


\section{FEDERAL PROGRAMS--BUREAU OF LAND MANAGEMENT}

Federal programs under the Bureau of Land Management (BLM) within the U.S. Department of the Interior are discussed in this section.

\section{Introduction}

Exploration, development, drilling, and production of onshore oil and gas on Federal and Indian lands are regulated separately from non-Federal lands. This separation of authority is significant for western States where oil and gas activity on Federal and Indian lands is a large proportion of statewide activity.

\section{Regulatory Agencies}

The U.S. Department of the Interior exercises authority under 43 CFR 3160 for regulation of onshore $0 i 1$ and gas practices on Federal and Indian lands. The Department of the Interior administers its regulatory program through BLM offices in the producing States. These offices generally have procedures in place for coordination with State agencies on regulatory requirements. Where written agreements are not in place, BLM usually works cooperatively with the respective State agencies. Generally, where State requirements are more stringent than those of BLM, operators must comply with the State requirements. Where State requirements are less stringent, operators must meet the BLM requirements.

The Bureau works closely with the U.S. Forest Service for surface stipulations in Federal forests or Federal grasslands. This cooperative arrangement is specifically provided for in the Federal regulations. 


\section{Rules and Regulations}

BLM has authority over $0 i 1$ and gas activities on Federal lands. The authority includes leasing, bonding, royalty arrangements, construction and well spacing regulations, waste handling, most waste disposal, site reclamation, and site maintenance.

Historically, BLM has controlled oil and gas activities through Notices to Lessees (NTLs) and through the issuance of permits. The Bureau is working to revise all notices into 0 il and Gas Orders, which will be Federally promulgated. To date, 0 il and Gas Order No. 1 has been issued.

While the regulations, NTLs, and orders provide the general basis for regulation of $0 i l$ and gas activities on Federal and Indian lands, there are variations in actual application of some of the requirements among BLM districts. In many cases, the variations are in response to specific geographical or geological characteristics of particular areas:

For example, in middle and southern Florida, the water table is near the surface. As a result, BLM requires the use of tanks instead of mud pits for oil and gas drilling activities on Federal lands in this area. In southeast New Mexico, there is simultaneous development of potash resources and oil and gas resources, and drilling and development requirements are imposed to accommodate the joint development activities. In general, more stringent controls of wastes and of disposal activities are required for oil and gas activities that could affect ground-water aquifers used for drinking water. 
Drilling

Before beginning to drill on Federal land, operators must receive a permit to drill from BLM. The permit application must include a narrative description of waste handling and waste disposal methods planned for the we11. Any plans to line the reserve pit must be detailed.

The lease is required to be covered by a bond prior to beginning drilling of the well. But the bonds may be for multiple wells, on a lease basis, statewide basis, or nationwide basis. The current bond requirement for wells on a single lease is $\$ 10,000$. Statewide bonds are $\$ 25,000$, but bonds must be provided separately for wells on public land and wells on Federally acquired land. The requirement for a nationwide bond is $\$ 150,000$.

BLM considers reserve pits, and some other types of pits, as temporary. Except in special circumstances, reserve pits do not have to be lined. NTL-2B contains the following provisions for "Temporary Use of Surface Pits":

Unlined surface pits may be used for handling or storage of fluids used in drilling, redrilling, reworking, deepening, or plugging of a well provided that such facilities are promptly and properly emptied and restored upon completion of the operations. Mud or other fluids contained in such pits shall not be disposed of by cutting the pit walls without the prior authorization of the authorized officer.

Unlined pits may be retained as emergency pits, if approved by the authorized officer, when a well goes into production.

Landspreading of drilling and reworking wastes by breaching pit walls is allowed when approved by the authorized officer. 


\section{Production}

Produced waters may be disposed of by underground injection, by disposal into lined pits, or "by other acceptable methods." An application to dispose of produced water must specify the proposed method and provide information that will justify the method selected. One application may be submitted for the use of one disposal method for produced water from wells and leases located in a single field, where the water is produced from the same formation or is of similar quality.

Disposal in Pits: A number of general requirements apply to disposal into permanent surface disposal pits, whether fined or unlined. The pits must:

1. Have adequate storage capacity to safely contain all produced water even in those months when evaporation rates are at a minimum;

2. Be constructed, maintained, and operated to prevent unauthorized surface discharges of water; unless surface discharge is authorized, no siphon, except between pits, will be permitted;

3. Be fenced to prevent livestock or wildlife entry to the pit, when required by an authorized officer;

4. Be kept reasonably free from surface accumulations of liquid hydrocarbons by use of approved skimmer pits, settling tanks, or other suitable equipment; and

5. Be located away from the established drainage patterns in the area and be constructed so as to prevent the entrance of surface water.

Approval of disposal of produced water into unlined pits will be considered only if one or more of the following applies:

- The water is of equal or better quality than potentially affected ground water or surface waters, or contains less than 5,000 ppm total dissolved solids (annual average) and no objectionable levels of other toxic constituents; 
- A substantial proportion of the produced water is being used for beneficial purposes, such as irrigation or livestock or wildlife watering;

- The volume of water disposed of does not exceed a monthly average of 5 barrels/day/facility; and

- A National Pollutant Discharge Elimination System (NPDES) permit has been granted for the specific disposal method.

Operators using unlined pits are required to provide information regarding the sources and quantities of produced water, topographic map, evaporation rates, estimated soil percolation rates, and "depth and extent of all usable water aquifers in the area."

Unlined pits may be used for temporary containment of fluids in emergency circumstances as well as for disposal of produced water. The pit must be emptied and the fluids appropriately disposed of within 48 hours after the emergency.

Where disposal in lined pits is allowed, the linings of the pits must be impervious and must not deteriorate in the presence of hydrocarbons, acids, or alkalis. Leak detection is required for all lined produced water disposal pits. The recommended detection system is an "underlying gravel-filled sump and lateral system." Other systems and methods may be considered acceptable upon application and evaluation. The authorized officer must be given the opportunity to examine the leak detection system before installation of the pit liner.

When applying for approval of surface disposal into a lined pit, the operator must provide information including the lining material and leak detection method for the pit, the pit's size and location, its net evaporation rate, the method for disposal of precipitated solids, and an analysis of the produced water. The water analysis must include concentrations of chlorides, sulfates, and other (unspecified) constituents that could be toxic to animal, plant, or aquatic life. 
Injection: Produced waters may be disposed of into the subsurface, either for enhanced recovery of hydrocarbon resources or for disposal. Since the establishment of EPA's underground injection control program for Class II injection wells, BLM no longer directly regulates the use of injection wells on Federal or Indian lands. Instead, it defers to either EPA or the State, where the State has received primacy for its program, for all issues related to ground-water or drinking water protection. Operators must obtain their underground injection permits from either EPA or the State.

BLM still retains responsibility for making determinations on injection wells with respect to lease status, protection of potential oil and gas production zones, and the adequacy of pressure-control and other safety systems. It also requires monthly reports on volumes of water injected.

\section{Plugging/Abandonment}

When a well is a dry hole, plugging must take place before removal of the drilling equipment. The mud pits may be allowed to dry before abandonment of the site. No abandonment procedures may be started without the approval of an authorized BLM representative. Final approval of abandonment requires the satisfactory completion of all surface reclamation work called for in the approved drilling permit.

Within 90 days after a producing well ceases production, the operator may request approval to temporarily abandon the well. Thereafter, reapproval for continuing status as temporarily abandoned may be required every 1 or 2 years. Exact requirements depend on the District Office and on such factors as whether there are other producing wells on the lease. The well may simply be defined as shut-in if equipment is left in place. 
Plugging requirements for wells are determined by the BLM District Office. Typically, these will include such requirements as a 100 -foot cement plug over the shoe of the surface casing (half above, half below), a 20- to 50-foot plug at the top of the hole, and plugs (usually 100 feet across) above and below all hydrocarbon or freshwater zones.

\section{IMPLEMENTATION OF STATE AND FEDERAL PROGRAMS}

Table VII-7 presents preliminary summary statistics on the resources of State 0 il and gas regulatory programs for the 13 States for which State regulatory programs have been summarized in Tables VII-1 through VII-6. Topics covered include rates of gas and 011 production, the number of gas and oil wells, the number of injection wells, the number of new wells, the responsible State agency involved, and the number of total field staff in enforcemert positions.

Table VII-8 presents similar statistics covering activities of the Bureau of Land Management. Since offices in one State often have. responsibilities for other States, each office is listed separately along with the related States with which it is involved. Statistics presented include the number of oil and gas producing leases, the number of nonproducing oil and gas leases, and the number of enforcement personnel available to oversee producing leases. 


\begin{tabular}{|c|c|c|c|c|c|}
\hline State & $\begin{array}{l}\text { General statement of } \\
\text { object ive/purpose }\end{array}$ & Liners & Overtopping & $\begin{array}{l}\text { Comingling } \\
\text { provision }\end{array}$ & $\begin{array}{l}\text { Permitting/ } \\
\text { oversight }\end{array}$ \\
\hline
\end{tabular}

A laska

The pits must be rendered impervious.
Arkansas

(revisions due in ' 88

011 \& Gas Commission $(O G C)$ : no specif ic regulations governing construction or management of reserve pits. Dept. of Pollution Control \& Ecology (DPCE) incorporates specif ic requirements in letters of authorizataion serving as informal permits, but regulatory basis and legal enforceability not supported by OGC.

California

No degradation of ground-water quality: if waste is hazardous, detailed standards apply to the pits as "surface
Whether reserve pit requires lining (and what $k$ ind of lining) depends on proximity to surface water and populations. whether the pit is above permafrost, and what $k$ ind of pit management strategy is used: visual monitoring required, and ground water monitoring usually required.

OGC: No regulatory re quirement.

DPCE: 20-mil synthet ic or 18-24 inch thick liner (per authorization

letter).

Liners may or may not be required, depending on location and local regu. lations: in limited cases where fluids
Fluid mgmt provision entails use of dewatering practices to keep to a minimum the hydrostat ic head in a containnent structure to reduce the potential for seepage and to prevent overflow during spring thaw.

1-ft freeboard (DPCE: 2-ft per authorization letter).

DCE only: no high TDS completion fluids (per authorization letter). wastes" defined as including "drilling muds. cuttings, hydrocarbons brine, acid, sand, and enulsions or mixtures of fluids produced from and unique to the operation or maintenance of a well,"

Use of nonapproved additives and fluids renders the waste subject to regulation as a hazardous waste.
Individual permit for act ive and new pits.

OGC: No separate permit for reserve pit.

DPCE : Terms of permit$t$ ing for reserve pits incorporated in letter of authorization.

Regional Water Quality Control Boards (RWOCBs) have authority to permit, oversee management 


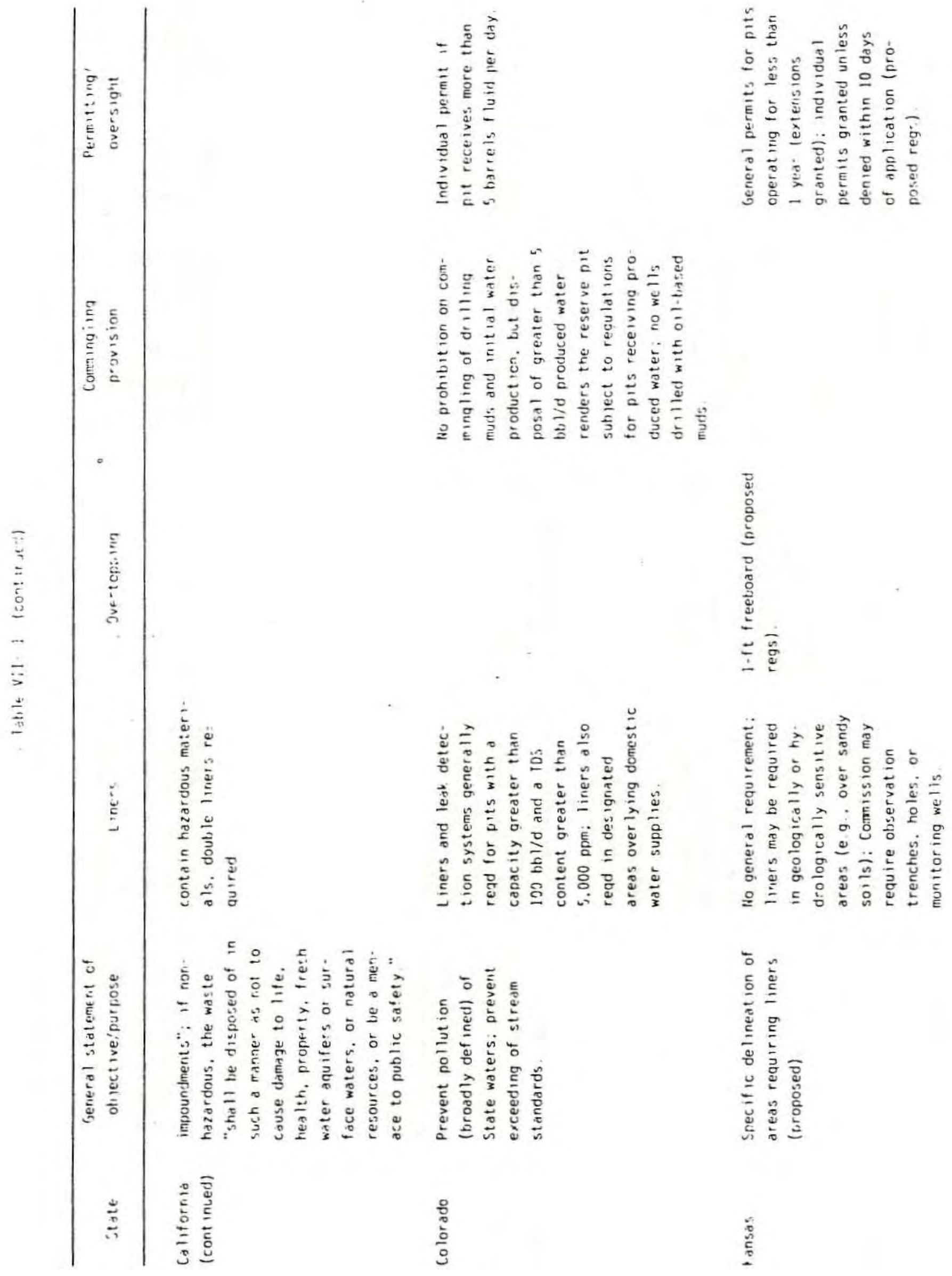




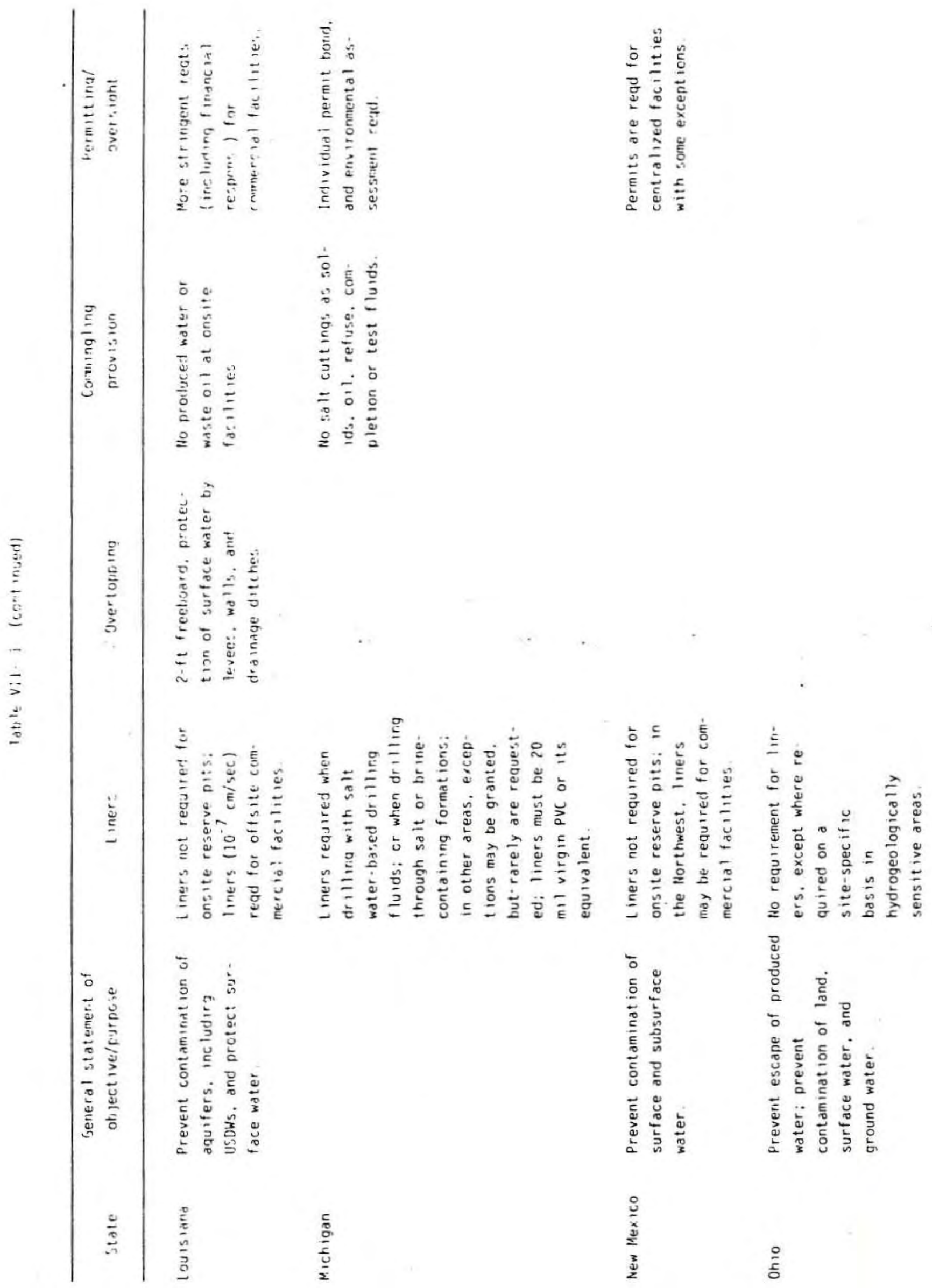




\begin{tabular}{|c|c|c|c|c|c|}
\hline Stater & $\begin{array}{l}\text { General statement of } \\
\text { oblect ive/purpose }\end{array}$ & I iners & Guertopping & $\begin{array}{l}\text { Comingling } \\
\text { provisien }\end{array}$ & $\begin{array}{l}\text { Permitting: } \\
\text { overeght }\end{array}$ \\
\hline Ok lahomi & $\begin{array}{l}\text { Prevent pollution of } \\
\text { surface and sutsurface } \\
\text { water, comercial p:ts } \\
\text { must be sealed w: an } \\
\text { impervious mater'al. }\end{array}$ & 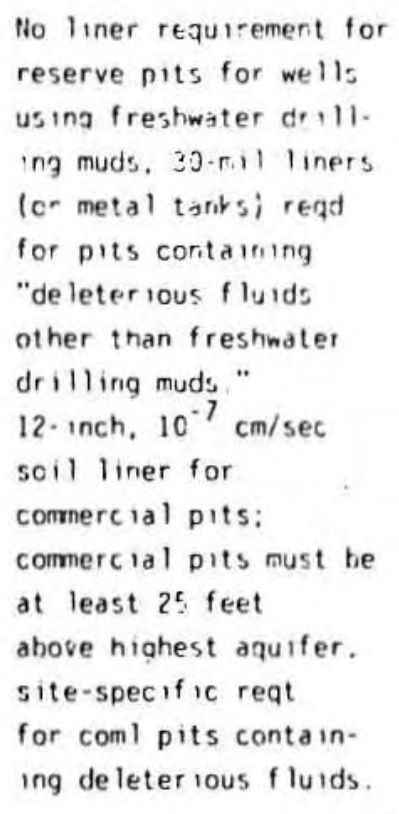 & $\begin{array}{l}\text { 18. nch freetioard and } \\
\text { run-on controls: } 36 \\
\text { inches for comercial } \\
\text { bits }\end{array}$ & $\begin{array}{l}\text { More strinaent req:s } \\
\text { (1.e. liners) for } \\
\text { fluids other than } \\
\text { water-based nuts. } \\
\text { provide an incen- } \\
\text { live to manage these } \\
\text { wastes separately. }\end{array}$ & $\begin{array}{l}\text { Permit rat requt for on- } \\
\text { site pits: notificat ion } \\
\text { rend for cmergency and } \\
\text { furn pits }\end{array}$ \\
\hline iexas & $\begin{array}{l}\text { May not cause or allow } \\
\text { pollut ion of surface or } \\
\text { subsurface water. }\end{array}$ & Liners not required. & · & $\begin{array}{l}\text { Use of reserve pits and } \\
\text { mud circulation pits is } \\
\text { restricted to drilling } \\
\text { fluids. drill cuttings. } \\
\text { sards. sits, wash } \\
\text { water, drill stem test } \\
\text { fluids, and blowsu: pre- } \\
\text { venter test fluids }\end{array}$ & $\begin{array}{l}\text { Reserve pits arid mud } \\
\text { circulation pits are } \\
\text { authorized by rule with- } \\
\text { out permits, individual } \\
\text { permit req' for coml } \\
\text { facilities, drilling } \\
\text { fluid storage pits } \\
\text { (other than mud circula- } \\
\text { tion pits). and } \\
\text { drilling fluid disposal } \\
\text { pits (other than } \\
\text { reserve pits). }\end{array}$ \\
\hline
\end{tabular}




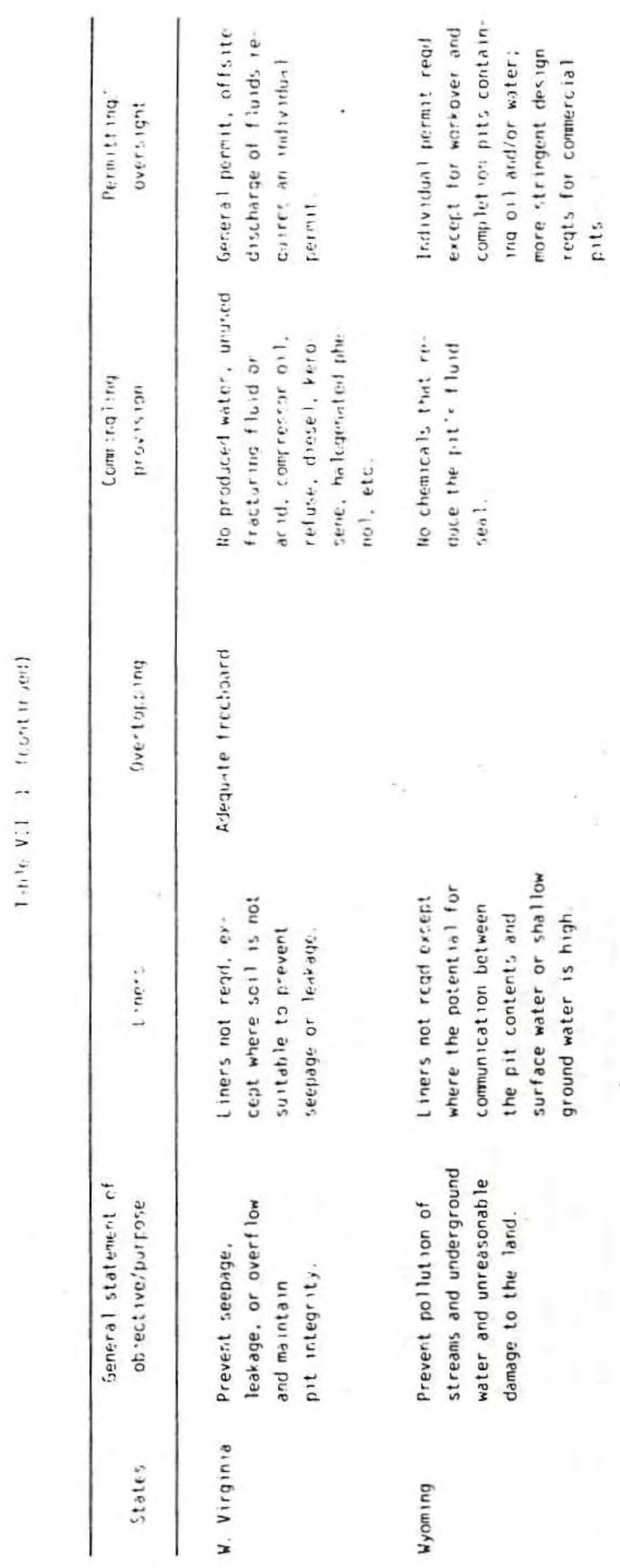


Table VII-2 Reserve Pit Closure/Waste Removal

\begin{tabular}{|c|c|c|c|c|c|}
\hline State & $\begin{array}{c}\text { Deadl inel } \\
\text { general standard }\end{array}$ & $\begin{array}{c}\text { Land disposal/ } \\
\text { application }\end{array}$ & $\begin{array}{c}\text { Road } \\
\text { application }\end{array}$ & $\begin{array}{c}\text { Surface water } \\
\text { discharge }\end{array}$ & $\begin{array}{l}\text { Annular } \\
\text { in ject ion }\end{array}$ \\
\hline
\end{tabular}

Alaska Must be operated with a fluid management plan and must be closed within 1 year after final disposal of drilling wastes in pit: or must be designed for 2 years' disposal and $c$ losed in that time period: numerous performance reats added.

Arkansas (revisions due in ${ }^{-88}$ )

OGC: No spec if ic regulatory requirements.

DPCE: within 60 days of rig's removal, reclaim to grade and reseed; fluids must be consigned to state-permitted disposal service (per authorization letter).

California When drilling operations cease, remove either (1) all wastes or (2) all free liquids and hazardous residuals.

For dry and abandoned wells, within 6 months of a well's closure, decant the fluids, back-

fill and reclaim.
General permit for discharge of fluids to tundra; prior written approval read: specs and effluent monitoring for metals and convent ional pollutants: only pits eligible are those that have received no drilling wastes since previous summer (last freeze-thaw cycle), to allow precipitation of contaminants.

DPCE only: waste analy$s$ is and landowner's consent reqd for land application (per authorization letter).

of fsite disposal reqts depend on whether waste is "hazardous" (double liners). "designated" (single liner) or nonhazardous.

Dewatered sediment may be tilled into the ground.
Individual permit; compliance point is edge of the road for same specs as for land application (except pH): no requirement for freeze-thaw cycle.
See land application: specs same as AK WQS (except TOS) pending study to determine effect on wildlife.

- Prohibited. .

Permit reqd from RWQCB: disposal may not cause damage to surface water.

Permits for discharge may be issued if eff luent meets stream's classification standard.
General perinit for $\mathrm{N}$. Slope; prior written approval reqd; discharge must occur below the permafrost into a zone containing greater than 3,000 ppm TDS.

DPCE: prior approval read (per authorization letter). 


\begin{tabular}{|c|c|c|c|c|c|}
\hline State & $\begin{array}{c}\text { Deadline/ } \\
\text { general standard }\end{array}$ & $\begin{array}{l}\text { Land disposal/ } \\
\text { application }\end{array}$ & $\begin{array}{c}\text { Road } \\
\text { application }\end{array}$ & $\begin{array}{l}\text { Surface water } \\
\text { discharge }\end{array}$ & $\begin{array}{l}\text { Annular } \\
\text { in jection }\end{array}$ \\
\hline
\end{tabular}

Kansas

As soon as practical. evaporate or dewater and backfi11; 365 days, or sooner if specifically required by Commission (proposed)

Louisiana

Within 6 months of completion of drilling or workover act ivities.

fluids must be analyzed for $\mathrm{pH}$, O\&G, metals and salinity, and then removed: exemption for wells less than $5,000 \mathrm{ft}$ deep if native mud used.
At closure, all free liquids must be removed and the residue encapsulated onsite or disposed of of fsite.
Landfarming is prohibited: in-situ disposal may be prohibited in sensitive areas.

Onsite land treatment or trenching of fluids and land treatment, burial or solidification of nonfluids allowed pro-

vided specs are met (including $\mathrm{pH}$, electrical conduct ivity, and certa in metals).

In-situ encapsulation. requires a 10-mil PVC cap $4 \mathrm{ft}$ be low grade: of $f$ site disposal must be in a lined landfill with leachate collection and ground-water monitoring

Pits are evaporated and residue generally buried onsite.
If approved by Kansas

Department of Health and Environment.

Permits issued for discharge of wastewater from treated drilling site reserve pits, so long as limitations

for oil and grease. TSS. metals, chlorides, $\mathrm{pH}$

are met. Dilut ion allowed to meet chloride limits.

Prohibited.

Prohibited.

Well must have produc$t$ ion casing and injected fluid must be isolated below freshwater horizons: except ion granted if, among other things, pressure gradient is less than 0.7 psi.
Surface casing must be at least $200 \mathrm{ft}$ below the lowest USOW.

Prohibited. 


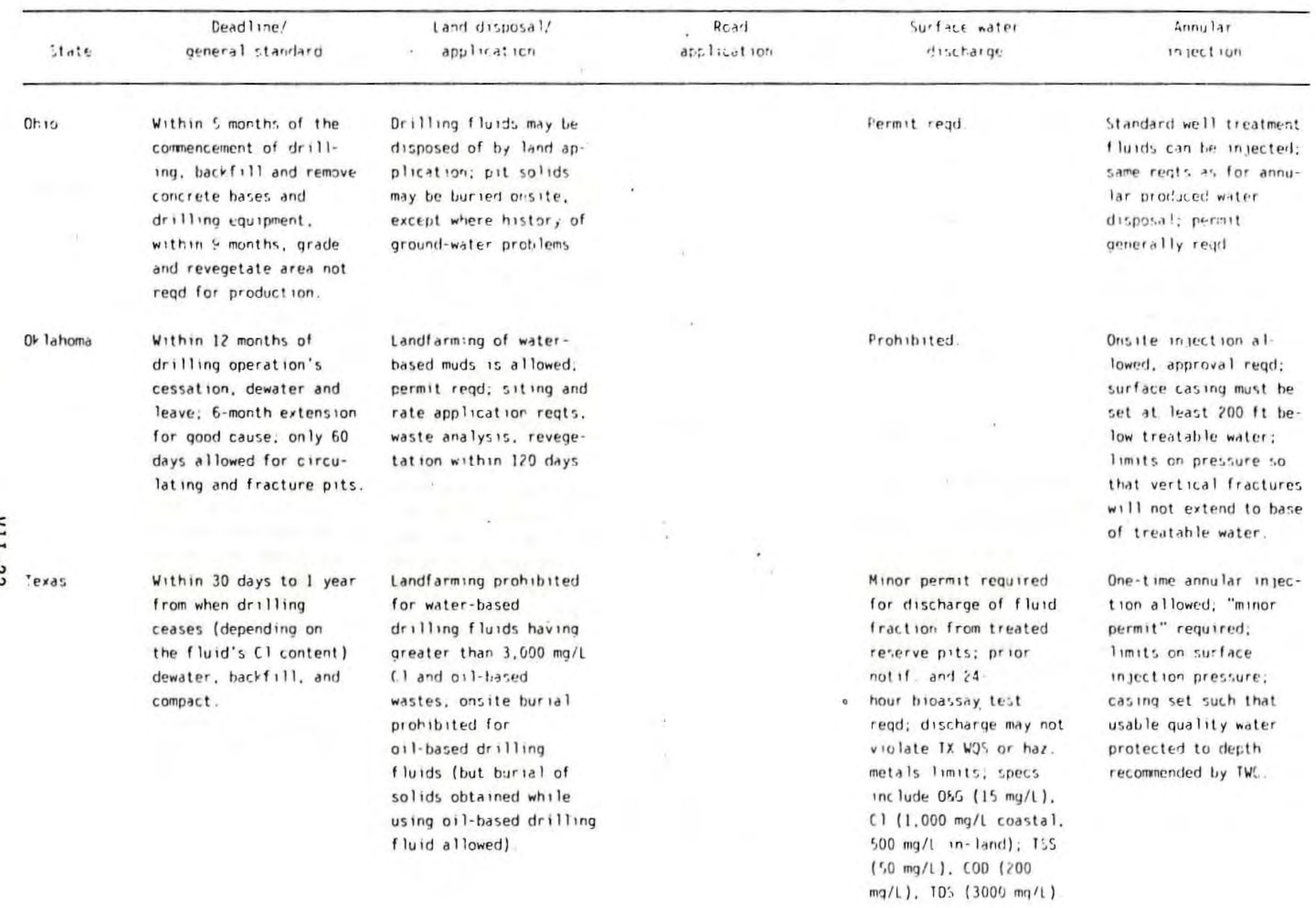




\begin{tabular}{|c|c|c|c|c|c|}
\hline State & $\begin{array}{l}\text { Deadlinel } \\
\text { general standard }\end{array}$ & $\begin{array}{l}\text { Land diofesali } \\
\text { apnleat } 10 \%\end{array}$ & 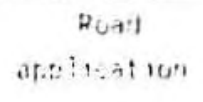 & $\begin{array}{l}\text { wefate nuter } \\
\text { Avirharad }\end{array}$ & 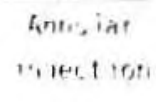 \\
\hline
\end{tabular}

W. Virqinis Within $E$ months from when drilling ceases.

wfoming
Cuttings may be bur ied onsite: after physical treatment. fluids meet.

ing specs can be apulied

to the land: specs $1 \mathrm{t}^{-}$

clude 01: (no vis ibie

sheen on land) and (.1

$(2 \%, 000 \mathrm{mg} / \mathrm{L})$, monitor-

ing read for other $p a$.

rameters.

Permit read for land application; discharge must meet water quality

1 imits. including 0\%s (2.000 or $20.000 \mathrm{lb} /$ acre, depending on

whether soil incorporat.

ed). Cl $(1.500 \mathrm{mg} / \mathrm{L})$
Prohibited. excent where DE $Q$ determires discharge w1ll not cause 519 envir damige or contaminate puthlic water sum. plies: application must inc lude complete arialy515. volute. location. and nam of receiving streas
One-t ime in iection a 1 lowed under sone tond. tions as in UIC permit. closure inspected and approved. and aplicat ron regts

mposed througt DEO memorandum 


\begin{tabular}{|c|c|c|c|c|}
\hline State & $\begin{array}{l}\text { General statement of } \\
\text { object ive/purpose }\end{array}$ & Liners & Exemptions & Permitt ing/oversight \\
\hline Alaska & $\begin{array}{l}\text { Produced water is a "drilling } \\
\text { waste" and is subject to the } \\
\text { same reats as in Table VII-1. }\end{array}$ & . & & \\
\hline $\begin{array}{l}\text { Arkansas } \\
\text { (revisions } \\
\text { due in '88) }\end{array}$ & $\begin{array}{l}\text { No discharge into any water of } \\
\text { the State (including ground } \\
\text { water). }\end{array}$ & $\begin{array}{l}\text { Pits must be lined or underlaid } \\
\text { by tight sol1; pits prohibited } \\
\text { over porous soil: (DPCE author- } \\
\text { izat ion letter requires tanks). }\end{array}$ & & $\begin{array}{l}\text { Individual perinit: application } \\
\text { reqd within } 30 \text { days of produc- } \\
\text { ing waste. }\end{array}$ \\
\hline California & $\begin{array}{l}\text { Nondegradation of State } \\
\text { waters: pits not permitted in } \\
\text { natural drainage channels or } \\
\text { where they may be in communica- } \\
\text { tion with freshwater-bearing } \\
\text { aquifers. }\end{array}$ & $\begin{array}{l}\text { Liners reqd where necessary to } \\
\text { comply with the State's nondeg- } \\
\text { radation policy: specific stan- } \\
\text { dards for construct ion/opera- } \\
\text { tion may be established by } \\
\text { RWQCBs. }\end{array}$ & & $\begin{array}{l}\text { Subject to permitting authority } \\
\text { of Regional WOCB. }\end{array}$ \\
\hline Colorado & $\begin{array}{l}\text { Prevent pollution (broadly de- } \\
\text { fined) of State waters: } \\
\text { prevent exceeding of stream } \\
\text { standards. }\end{array}$ & $\begin{array}{l}\text { Same as for reserve pits (for } \\
\text { pits receiving more than } 5 \text { bbl/d } \\
90 \% \text { of the pits are } \\
\text { lined; } 2 / 3 \text { clay, } 1 / 3 \text { synthet ic) }\end{array}$ & $\begin{array}{l}\text { Exemptions from liner } \\
\text { requirement for pits overlying } \\
\text { impermeable materials or } \\
\text { receiving water with less than } \\
5.000 \text { ppm TDS. }\end{array}$ & Individual permit. \\
\hline Kansas & $\begin{array}{l}\text { Consideration of protection of } \\
\text { soil and water resources from } \\
\text { pollution. }\end{array}$ & $\begin{array}{l}\text { Strict liner and seal } \\
\text { requirements in conjunct ion } \\
\text { with hydrogeologic } \\
\text { invest igation. }\end{array}$ & & $\begin{array}{l}\text { No permits issued for unlined } \\
\text { pits. }\end{array}$ \\
\hline Lou is iana & & $\begin{array}{l}\text { All pits must be lined such } \\
\text { that the hydraulic conduct ivity } \\
\text { is less than } 10^{-7} \mathrm{~cm} / \mathrm{sec} \text {. }\end{array}$ & $\begin{array}{l}\text { Pits in certain coastal areas. } \\
\text { provided they are part of a } \\
\text { treatment train for oil and } \\
\text { grease removal. }\end{array}$ & \\
\hline
\end{tabular}




\begin{tabular}{|c|c|c|c|c|}
\hline & General statement of & & & \\
\hline stater & object ive'vurpose & tinet: & txromst: $10 \%$ s & Fermitt inglovers saht \\
\hline
\end{tabular}

M:chigan trine cannot be run to earthen reservoirs or ponds.

Nen Mexics

Thio

Pits must be liquid tight: waste cannot be stored for more than 180 days: pits may not be used for ult inate disposal.

(1) lahonia Pits must be sealed with an impervious material; in add:tion. offsite pits must contain flu.
In the southeast. $30-m+1$ liners with leak. detesticn are rrat. in the northwest. iners are read cver specified vilnerahle aquifers liner for conl pits: sitespecif ic liner reqt if coml pit contains deleterious fluids

Generally, all pits other than emergency pits require. liners unless (1) there is no surface or subsurface water in the area, or (2) the pit is under. laid ty a naturally occurring impervious barrier: liners required for emergency pits in sensitive areas.

Same as for reserve pits

Liners not read excent where the potential for cormunication between the pit contents and surface water or shallow ground water is high.
Smin 11-volume pits and fits in snec it ie: arear that तोe al redily salue and ite areac with out fre:h water
If line requiref, midividual ferimit after heat inm

Ploduced water disposal plar. mus! be submitted.

Individual permits required.

Individual permit 


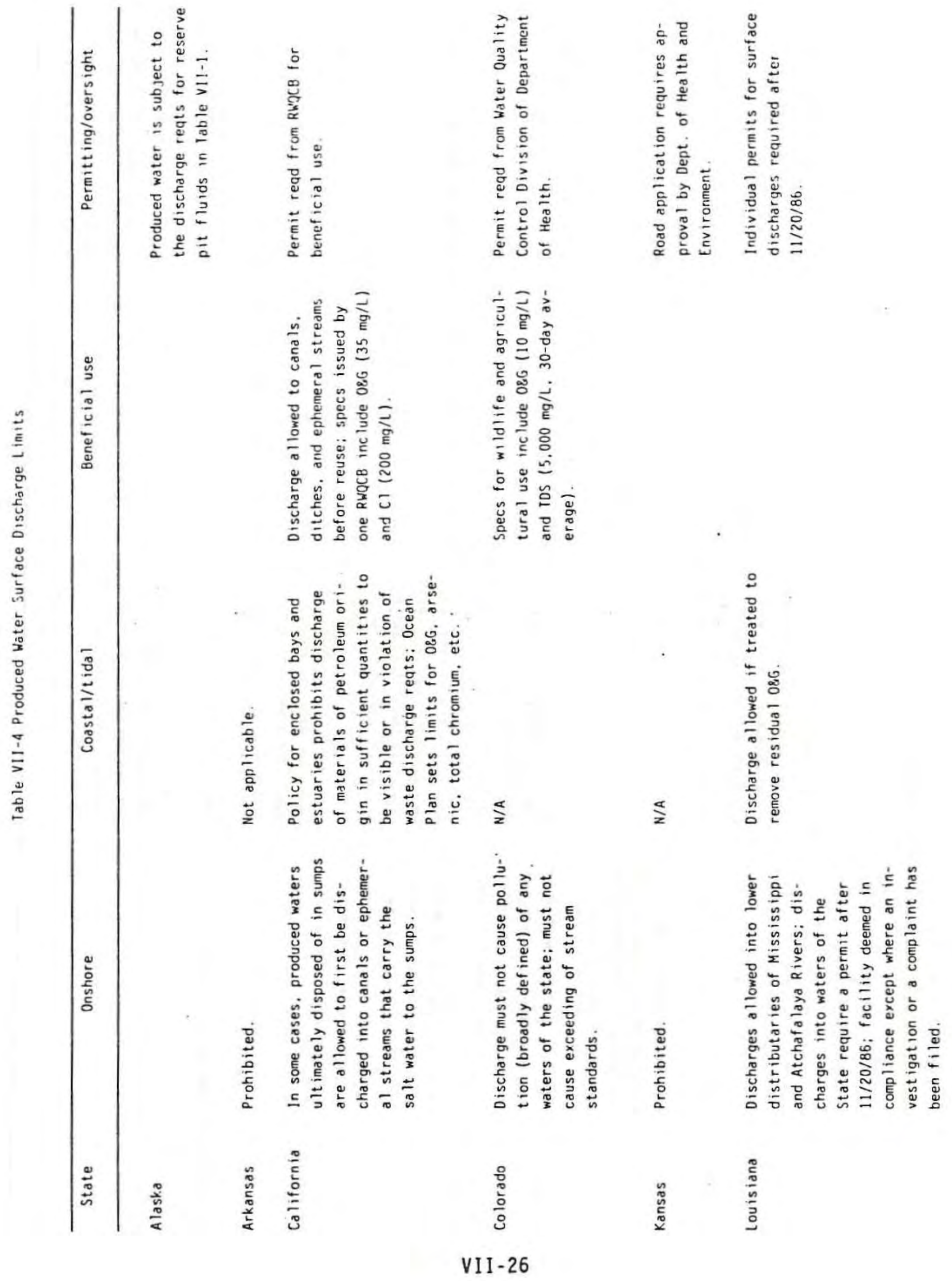




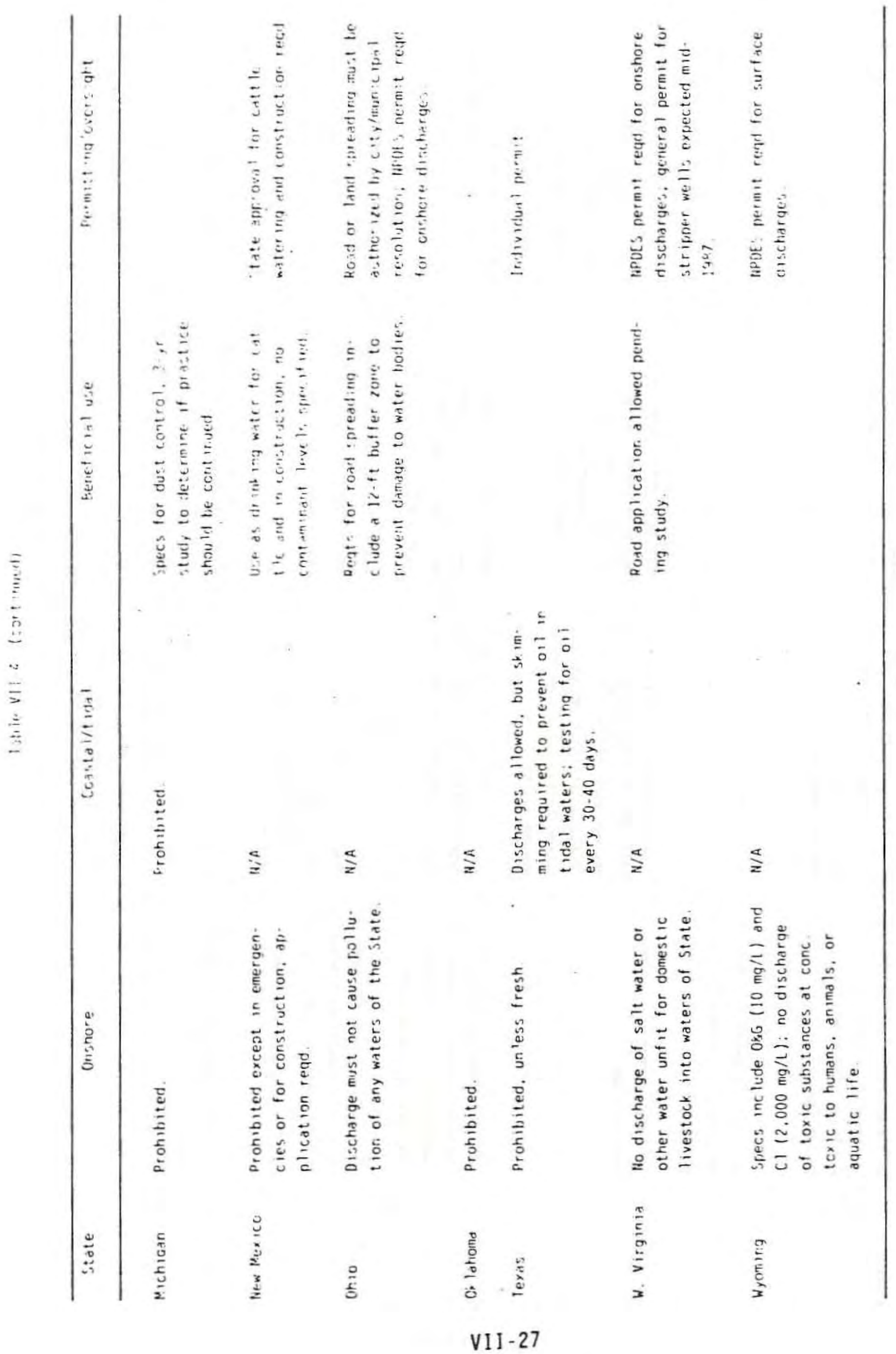




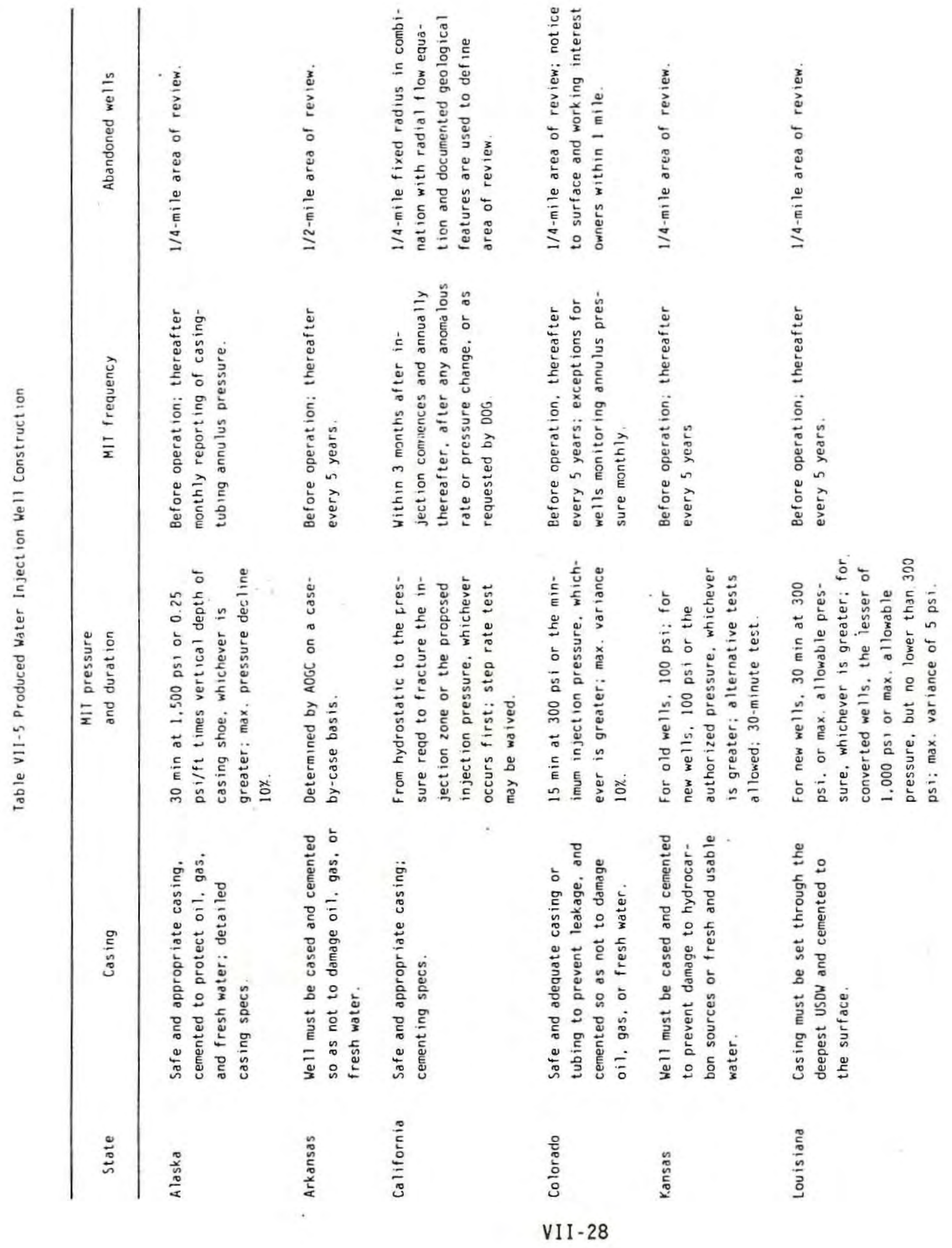




\begin{tabular}{|c|c|c|c|c|}
\hline State & Car, ing & $\begin{array}{l}\text { M!l pressure } \\
\text { arif durstion }\end{array}$ & M:T fregionic, & Al, otitined we. I). \\
\hline
\end{tabular}

Nichiga: Casing and seal to orevent the loss of producert water into an unapproved fornition

New Mexico Casing or tubirg to prevent leatage and fluid mevement from the inject ion zorie.

In addition to use of injection wells. annular disposal of produced water is allowed: max annular disposal 5-10 bbl/d: use only force of gravity. systems must be airtight.

Casing must be set at least 50 $f_{t}$ be low the deepest USOW and must be cemented to the surface.

$\mathrm{ft}$ he low the surface or $50 \mathrm{ft}$ be low treatable water. whichever is lower, and must be ce mented to the surtace

\section{Surface casing cemented to}

$30 \mathrm{~min}$ at $300 \mathrm{ps} 1.31$ allow athle bleedoff

15-30 $=$ in at $25 \mathrm{C}-300$ n:1: max variance $10 \%$

15 min at 300 psi. or may allowable pressure. whichever is greater: max. decline 5\%: alternative tests allowed

Same as Loursiana. except mari. mum blecdoff of $10 \%$ surface: tubing and cemented casing string to isolate injection zone.
As scheduled tiy Ri lfeiter di, admiristered

tefore operdilon. thereater every s, cars, special te:t can Le read more often; arnulus mowitorirg required monthly

Before operation: thereatter every 5 years.

Before ormation. thereat:er every s years: exception for wells moritoring pressure morithly and reporting annually

Before injection. after workover, and thereafter every 5 years lexception for wells monitoring annulus pressure inonthly and rpt'g annual. $1 y$, or for other viable alternetive test)
Stale prour alt to filug abanidoner we $11 \mathrm{~s}$

Siate prourati to plug abamianes welis: $21 / 2$-mile area of te view. variance allowing no less than 1/4 mile, corrective action regd to prevent miqration through condurts

1/4- to 1/2-mile area of review. depending on volume in jected, well plugging fund

[/\%-mile area of review; we 11 pluqqing fund.

1/4-mile area of review; not ice to surface owners and of fset operators: well pluqging fund Ime in source: $\$ 100 \mathrm{dr}$ illing permit fee) pressure stabilizes, 30

minutes with no variation. 


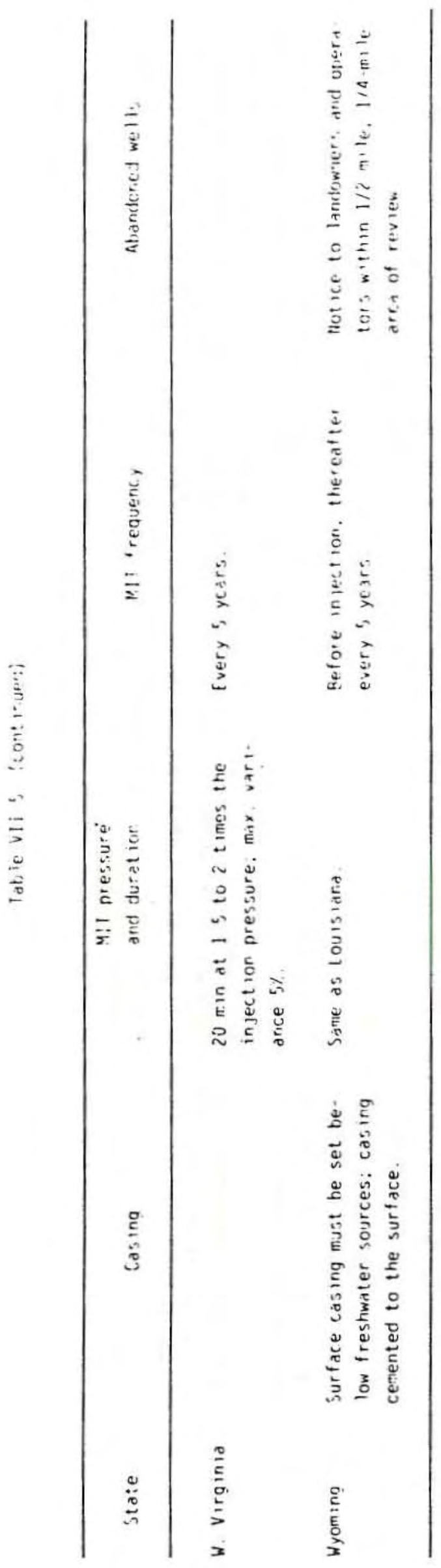




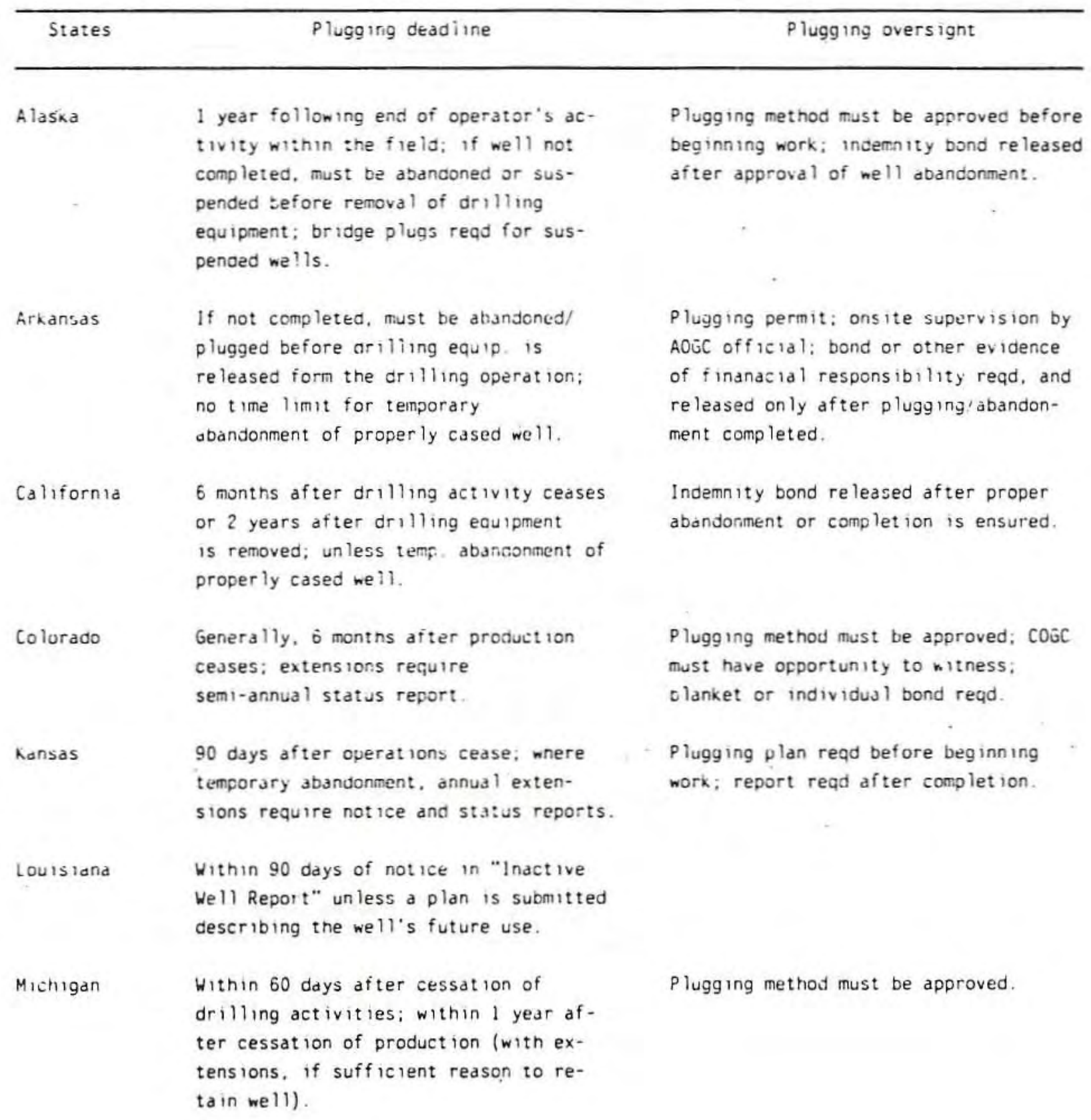




\begin{tabular}{|c|c|c|}
\hline state & Fluca'ng descitine & Plugging oversignt \\
\hline New Mex:co & 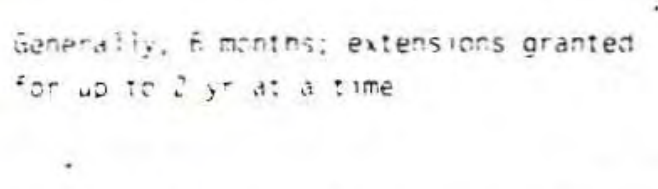 & $\begin{array}{l}\text { Well plugging oiar must be approved: } \\
\text { plugg:ng oona released after inspection } \\
\text { and Direc: or approval. }\end{array}$ \\
\hline$c=\cdots$ & 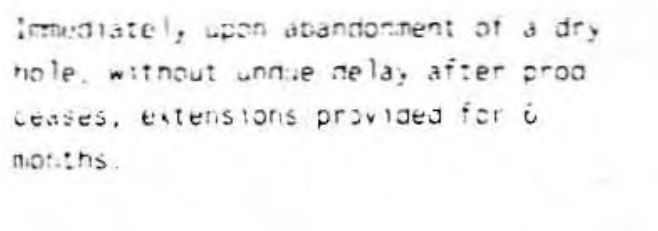 & 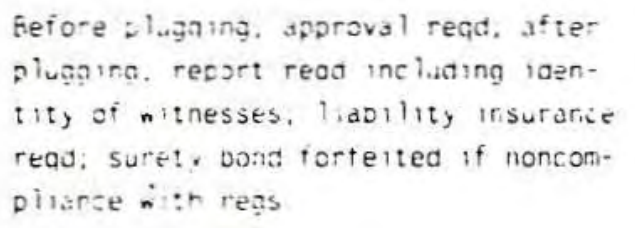 \\
\hline Un isnoma & 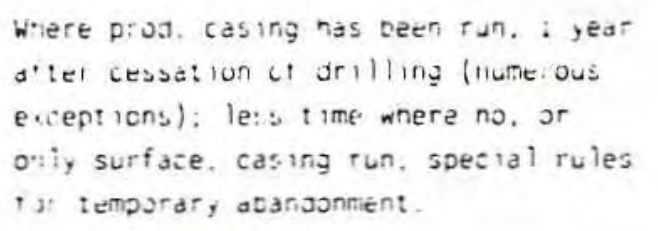 & 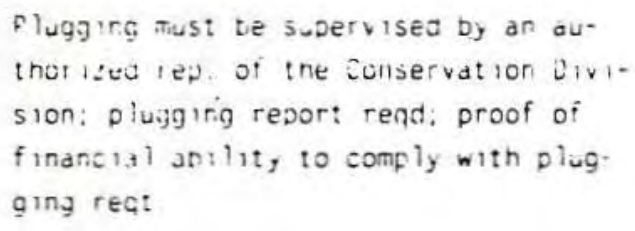 \\
\hline Tous & $\begin{array}{l}\text { Within is diys dfier drilling or osera- } \\
\text { tions cease. excep: where cessation oc } \\
\text { curred in oc or of (1 year). ex:en- } \\
\text { slons at Director's discretion (1f no } \\
\text { pollution nazard) with plugging bond } \\
\text { or letter of credit or plan to use for } \\
\text { ennanced recovery. }\end{array}$ & $\begin{array}{l}\text { Fefore fi..gging. not if ication and } \\
\text { approval reac, after plugging. report } \\
\text { reqd, operator must be present during } \\
\text { plugging. }\end{array}$ \\
\hline W Virginia & $\begin{array}{l}\text { Prompt olugging reat if } \mathrm{dr} \text { y holes and } \\
\text { wells not in use for } 12 \text { mo, exten- } \\
\text { sions for good cause. }\end{array}$ & $\begin{array}{l}\text { Plugging borid and not if to the Direc- } \\
\text { tor and nearby coal operators reqd. }\end{array}$ \\
\hline Wyoming & $\begin{array}{l}\text { Approval frum the state read if well } \\
\text { is "temporarily abandoned" for more } \\
\text { than } 1 \text { year. }\end{array}$ & $\begin{array}{l}\text { Before plugging, approval read; after } \\
\text { plugging. report read: well plugging } \\
\text { bond released after the State inspec- } \\
\text { tion. }\end{array}$ \\
\hline
\end{tabular}

\section{VII -32}


Table VII-7 State Enforcement Matrix

State Gas Production Oll Production Gas wells Oll wells Injection wolls New walls Agency

\begin{tabular}{|c|c|c|c|c|c|c|c|c|}
\hline Alaska & $316,000 \mathrm{Mmcl} 1986$ & $681,309,821$ bol 1986 & 104 & 1,191 & $\begin{array}{r}472 \text { Class II } \\
425 \text { EOR } \\
47 \text { Disposal } \\
\end{array}$ & $\begin{array}{r}100 \text { new onshore wells } \\
\text { completed in } 1985\end{array}$ & $\begin{array}{l}\text { Oil and Gas Conservation Commission } \\
\text { Department of Environmental Conservation }\end{array}$ & $\begin{array}{l}8 \text { enlorcement positions } \\
8 \text { enforcement positions } \\
\end{array}$ \\
\hline Arkansas & $194,483 \mathrm{Mmd} 1985$ & $19,715,691$ bbl 1985 & 2,492 & 9,490 & $\begin{array}{r}1,211 \text { Class II } \\
239 \text { EOR } \\
972 \text { Disposal } \\
\end{array}$ & $\begin{array}{r}1,055 \text { new wells } \\
\text { completed in } 1985\end{array}$ & $\begin{array}{l}\text { Arkansas Oil and Gas Commission } \\
\text { Department of Pollution Control and Ecology }\end{array}$ & $\begin{array}{l}\text { entorcement positions } \\
2 \text { enforcement positions } \\
\end{array}$ \\
\hline California & $493,000 \mathrm{Mmd} 1985$ & $423,900,000$ bbl 1985 & 1,566 & 55,079 & $\begin{array}{r}11,066 \text { Class in } \\
10,047 \text { EOR } \\
1,019 \text { Disposal }\end{array}$ & $\begin{array}{r}3,413 \text { new wells } \\
\text { completed in } 1985\end{array}$ & $\begin{array}{l}\text { Conservation Depl.. Division o Oil and Gas } \\
\text { Department of Fish and Game }\end{array}$ & 31 entorcement positions \\
\hline Kansas & $466,600 \mathrm{Mmcl} 1984$ & $75,723,000$ bbl 1984 & 12,680 & 57,633 & $\begin{array}{r}14,902 \text { Class II } \\
9,366 \text { EOR } \\
+5,536 \text { Disposal } \\
\end{array}$ & $\begin{array}{r}6.025 \text { new wells } \\
\text { completed in } 1985\end{array}$ & Kansas Corporalion Commission & 30 entorcement positions \\
\hline Lovisiana & $5,867,000$ Mmd 1984 & $449,545,000 \mathrm{bbl} 1984$ & 14.436 & 25,823 & $\begin{array}{r}4,436 \text { Class II } \\
1,283 \text { EOR } \\
3,153 \text { Disposal }\end{array}$ & $\begin{array}{r}5,447 \text { new onshore } \\
\text { wells completed } 1985\end{array}$ & $\begin{array}{l}\text { Department of Environmental Quality } \\
\text { Ollice of Conservation - Injection and Mining }\end{array}$ & $\begin{array}{l}32 \text { entorcement positions } \\
36 \text { entorcement positions }\end{array}$ \\
\hline New Mexico & 893,300 Mmc 1985 & $78,500,000$ bbl 1985 & 18,308 & 21,986 & $\begin{array}{r}3,871 \text { Class II } \\
3,508 \text { EOR } \\
363 \text { Disposal }\end{array}$ & $\begin{array}{r}1,747 \text { new wolls } \\
\text { completed in } 1985\end{array}$ & $\begin{array}{l}\text { Energy and Minerals Department, } \\
\text { Oil Conservation Division }\end{array}$ & 10 enlorcement positions \\
\hline Ohio & 182,200 Mmc 1985 & $14,987,592$ bol 1985 & 31,343 & 29,210 & $\begin{array}{r}3,956 \text { Class II } \\
127 \text { EOA } \\
3,829 \text { Disposal }\end{array}$ & $\begin{array}{r}6.297 \text { new wells } \\
\text { completed in } 1985\end{array}$ & $\begin{array}{l}\text { Ohio Department of Natural Resources, } \\
\text { Division of Oil and Gas }\end{array}$ & 66 enlorcement positions \\
\hline Oklahoma & $1,996,000 \mathrm{Mmd} 1984$ & $153,250,000 \mathrm{bb} 1984$ & 23,647 & 99,030 & $\begin{array}{r}22,803 \text { Class II } \\
14,901 \text { EOR } \\
7,902 \text { Disposal }\end{array}$ & $\begin{array}{r}9,176 \text { new wells } \\
\text { completed in } 1985\end{array}$ & Oklahorna Corporation Commission & 52 entorcement positions \\
\hline Pennsylvania & 166,000 Mmd 1984 & $4,825,000$ bbl 1984 & 24,050 & 20,739 & $\begin{array}{r}6,183 \text { Class II } \\
4,315 \text { EOR } \\
1,868 \text { Disposal }\end{array}$ & $\begin{array}{r}4,627 \text { new wells } \\
\text { completed in } 1985\end{array}$ & $\begin{array}{l}\text { Department of Environmental Resources, } \\
\text { Bureau of Oil and Gas Management }\end{array}$ & 34 enforcement positions \\
\hline Texas & $5,805,000$ Mmd 1985 & $830,000,000$ bbl 1985 & 68,811 & 210,000 & $\begin{array}{r}53,141 \text { Class II } \\
45,223 \text { EOR } \\
7,918 \text { Disposal }\end{array}$ & $\begin{array}{r}25,721 \text { new wells } \\
\text { completed in } 1985\end{array}$ & Texas Pailroad Commission & 120 enlorcement positions \\
\hline West Virginia & $142,500 \mathrm{Mmd} 1986$ & $3,600,000$ bbl 1986 & 32,500 & 15,895 & $\begin{array}{r}761 \text { Class II } \\
687 \text { EOR } \\
74 \text { Disposal }\end{array}$ & $\begin{array}{r}1,839 \text { new wells } \\
\text { completed in } 1985\end{array}$ & West Virginia Department of Energy & 15 entorcement positions \\
\hline Wyoming & $597,896 \mathrm{Mmd} 1985$ & $130,984,917$ bbl 1985 & 2,220 & 12,218 & $\begin{array}{r}5,880 \text { Class II } \\
5,257 \text { EOR } \\
623 \text { Disposal }\end{array}$ & $\begin{array}{r}1,735 \text { new wells } \\
\text { compleled in } 1985\end{array}$ & $\begin{array}{l}\text { Oil and Gas Conservation Commission } \\
\text { Department of Environmental Quality }\end{array}$ & $\begin{array}{l}7 \text { entorcement positions } \\
4.5 \text { entorcement positions }\end{array}$ \\
\hline
\end{tabular}

- Only fleld staft are included in tolal entorcement positions. 
Table VII-8 BLM Enforcement Matrix*

\begin{tabular}{|c|c|c|c|c|}
\hline $\begin{array}{l}\text { Office } \\
\text { location }\end{array}$ & $\begin{array}{l}\text { Other States } \\
\text { for which offlce } \\
\text { Is responsible }\end{array}$ & $\begin{array}{c}\text { Producing oll and gas } \\
\text { leases }\end{array}$ & $\begin{array}{l}\text { Nonproducing oil and gas } \\
\text { leases*. }\end{array}$ & $\begin{array}{l}\text { Personnel } \\
\text { (for producing leases only) }\end{array}$ \\
\hline Alaska & & 43 & 8,443 & 1 enforcement position \\
\hline \multicolumn{2}{|l|}{ Callfornla } & 305 & 1,383 & 7 enforcement positions \\
\hline \multicolumn{2}{|l|}{ Colorado } & 3,973 & 4,463 & 10 enforcement positions \\
\hline \multicolumn{2}{|l|}{ Idaho } & 0 & 471 & 0 enforcement positions \\
\hline \multicolumn{2}{|c|}{\begin{tabular}{l|} 
Mississippi \\
Alabama \\
Arkansas \\
Florida \\
Kentucky \\
Louisiana \\
Virginia
\end{tabular}} & $\begin{array}{r}116 \\
12 \\
161 \\
1 \\
13 \\
121 \\
1 \\
425 \\
\end{array}$ & $\begin{array}{r}1,519 \\
567 \\
1,099 \\
0 \\
65 \\
487 \\
523 \\
4,260 \\
\end{array}$ & 3 enforcement positions \\
\hline Montana & $\begin{array}{l}\text { North Dakota } \\
\text { South Dakota }\end{array}$ & $\begin{array}{r}958 \\
456 \\
98 \\
1512\end{array}$ & $\begin{array}{r}4,721 \\
1,991 \\
572 \\
7284 \\
\end{array}$ & 12 enforcement positions \\
\hline \multicolumn{2}{|l|}{ Nevada } & 43 & 3,045 & 1 enforcement position \\
\hline \multicolumn{2}{|c|}{$\begin{array}{c}\text { New Mexico } \\
\text { Arizona } \\
\text { Kansas } \\
\text { Oklahoma } \\
\text { Texas }\end{array}$} & $\begin{array}{r}5,725 \\
10 \\
150 \\
2,767 \\
61 \\
8,713 \\
\end{array}$ & $\begin{array}{r}9,306 \\
386 \\
227 \\
2,754 \\
279 \\
12,952 \\
\end{array}$ & 43 enforcement positions \\
\hline \multicolumn{2}{|l|}{ Oregon } & 0 & 1,513 & 0 \\
\hline Utah & & 1,654 & 7,202 & 10 enforcement positions \\
\hline Wisconsin & $\begin{array}{l}\text { Maryland } \\
\text { Michigan } \\
\text { Missouri } \\
\text { Ohio } \\
\text { Pennsylania } \\
\text { West Virginia }\end{array}$ & $\begin{array}{r}0 \\
2 \\
28 \\
1 \\
33 \\
6 \\
46 \\
116 \\
\end{array}$ & $\begin{array}{r}0 \\
11 \\
603 \\
6 \\
69 \\
1 \\
54 \\
844 \\
\end{array}$ & \\
\hline \multirow[t]{2}{*}{ Wyoming } & Nebraska & $\begin{array}{r}5,037 \\
42 \\
5,079 \\
\end{array}$ & $\begin{array}{r}28,044 \\
582 \\
28,626\end{array}$ & $\begin{array}{l}1 \text { enforcement position } \\
27 \text { enforcement positions }\end{array}$ \\
\hline & Total & 22,037 & & 115 enforcement positions \\
\hline
\end{tabular}

- Oil and gas inspectors working in the field as of March 30, 1987. At that time there were eight vacancies nationwide.

** Includes leases that have never been drilled, have been drilled and abandoned, or are producing wells that have been temporarily shut down. 


\section{REFERENCES}

43 CFR 3100 (entire group).

U.S. Bureau of Land Management. (Not dated.) Federal Onshore $0 i 1$ and Gas Leasing and Operating Regulations.

U.S. Bureau of Land Management. NTL-2B.

U.S. Department of the Interior - Geological Survey Division. (Not dated.) Notice to Lessees and Operators of Federal and Indian 0il and Gas Leases (NTL-2B).

Personal communication with Mr. Steve Spector, September 23, 1986. 


\section{CHAPTER VIII}

\section{CONCLUSIONS}

From the analysis conducted for this report, it is possible to draw a number of general conclusions concerning the management of $0 i 1$ and gas wastes. These conclusions are presented below.

Available waste management practices vary in their environmental performance.

Based on its review of current and alternative waste management practices, EPA concludes that the environmental performance of existing waste management practices and technologies varies significantly. The reliability of waste management practices will depend largely on the environmental setting. However, some methods will generally be less reliable than others because of more direct routes of potential exposure to contaminants, lower maintenance and operational requirements, inferiority of design, or other factors. Dependence on less reliable methods can in certain vulnerable locations increase the potential for environmental damage related to malfunctions and improper maintenance. Examples of technologies or practices that are less reliable in locations vulnerable to environmental damage include:

- Annular disposal of produced water (see damage case $\mathrm{OH} 38$, page IV-16);

- Landspreading or roadspreading of reserve pit contents (see damage case WV 13, page IV-24);

- Use of produced water storage pits (see damage case AR 10, page IV-36); and 
- Surface discharges of drilling waste and produced water to sensitive systems such as estuaries or ephemeral streams (see damage cases TX 55, page IV-49; TX 31, page IV-50; TX 29, page IV-51; WY 07, page IV-60; and CA 21, page IV-68).

Any program to improve management of oil and gas wastes in the near term will be based largely on technologies and practices in current use.

Current technologies and practices for the management of wastes from oil and gas operations are well established, and their environmental performance is generally understood. Improvements in State regulatory requirements over the past several years are tending to increase use of more desirable technologies and practices and reduce reliance on others. Examples include increased use of closed systems and underground injection and reduced reliance on produced water storage and disposal pits.

Long-term improvements in waste management need not rely, however, purely on increasing the use of better existing technology. The Agency does foresee the possibility of significant technical improvements in future technologies and practices. Examples include incineration and other thermal treatment processes for drilling fluids; conservation, recycling, reuse, and other waste minimization techniques; and wet air oxidation and other proven technologies that have not yet been applied to oil and gas operations.

Because of Alaska's unique and sensitive tundra environment, there has been special concern about the environmental performance of waste management practices on the North Slope. Although there are limited and preliminary data that indicate some environmental impacts may occur, these data and EPA's initial analysis do not indicate the need to curtail current or future oil exploration, development, and production operations on the North Slope. However, there is a need for more environmental data 
on the performance of existing technology to provide assurance that future operations can proceed with minimal possible adverse impacts on this sensitive and unique environment. The State of Alaska has recently enacted new regulations which will provide additional data on these practices.

EPA is concerned in particular about the environmental desirability of two waste management practices used in Alaska: discharge of reserve pit supernatant onto tundra and road application of reserve pit contents as a dust suppressant. Available data suggest that applicable discharge limits have sometimes been exceeded. This, coupled with preliminary biological data on wildlife impacts and tundra and surface water impairment, suggests the need for further examination of these two practices with respect to current and future operations. The new regulations recently enacted by the State of Alaska should significantly reduce the potential for tundra and wildlife impacts.

Increased segregation of waste may help improve management of oil and gas wastes.

The scope of the exemption, as interpreted by EPA in Chapter II of this report, excludes certain relatively low-volume but possibly high-toxicity wastes, such as unused pipe dope, motor oil, and similar materials. Because some such wastẹs could be hazardous and could be segregated from the large-volume wastes, it may be appropriate to require that they be segregated and that some of these low-volume wastes be managed in accordance with hazardous waste regulations. While the Agency recognizes that small amounts of these materials may necessarily become mixed with exempt wastes through normal operations, it seeks to avoid any deliberate and unnecessary use of reserve pits as a disposal mechanism. Segregation of these wastes from high-volume exempt wastes appears to be desirable and should be encouraged where practical. 
Although this issue is not explicitly covered in Chapter VII, EPA is aware that some States do require segregation of certain of these low-Volume wastes. EPA does not have adequate data on which to judge whether these State requirements are adequate in coverage, are enforceable, are environmentally effective, or could be extended to general operations across the country. The Agency concludes that further study of this issue is desirable.

Stripper operations constitute a special subcategory of the oil and gas industry.

Strippers cumulatively contribute approximately 14 percent of total domestic oil production. As such, they represent an economically important component of the U.S. petroleum industry. Two aspects of the stripper industry raise issues of consequence to this study.

First, generation of production wastes by strippers is more significant than their total petroleum production would indicate. Some stripper wells yield more than 100 barrels of produced water for each barrel of oil, far higher on a percentage production basis than a typical new well, which may produce little or no water for each barrel of oil.

Second, stripper operations as a rule are highly sensitive to small fluctuations in market prices and cannot easily absorb additional costs for waste management.

Because of these two factors--inherently high waste-production rates coupled with economic vulnerability--EPA concludes that stripper operations constitute a special subcategory of the oil and gas industry that should be considered independently when developing recommendations for possible improvements in the management of oil and gas wastes. In 
the event that additional Federal regulatory action is contemplated, such special consideration could indicate the need for separate regulatory actions specifically tailored to stripper operations.

Documented damage cases and quantitative modeling results indicate that, when managed in accordance with State and Federal requirements, exempted oil and gas wastes rarely pose significant threats to human health and the environment.

Generalized modeling of human health risks from current waste management practices suggests that risks from properly managed operations are low. The damage cases researched in the course of this project, however, indicate that exempt wastes from $0 i 1$ and gas exploration, development, and production can endanger human health and cause environmental damage when managed in violation of existing State requirements.

\section{Damage Cases}

In a large portion of the cases developed for this study, the types of mismanagement that lead to such damages are illegal under current State regulations although a few were legal under State programs at the time when the damage originally occurred. Evidence suggests that violations of regulations do lead to damages. It is not possible to determine from available data how frequently violations occur or whether violations would be less frequent if new Federal regulations were imposed.

Documented damages suggest that all major types of wastes and waste management practices have been associated to some degree with endangerment of human health and damage to the environment. The principal types of wastes responsible for the damage cases include general reserve pit wastes (primarily drilling fluids and drill cuttings, 
but also miscellaneous wastes such as pipe dope, rigwash, diesel fuel, and crude 0il); fracturing fluids; production chemicals; waste crude oil; produced water; and a variety of miscellaneous wastes associated with exploration, development, or production. The principal types of damage sometimes caused by these wastes include contamination of drinking-water aquifers and foods above levels considered safe for consumption, chemical contamination of livestock, reduction of property values, damage to native vegetation, destruction of wetlands, and endangerment of wildlife and impairment of wildlife habitat.

\section{Risk Modeling}

The results of the risk modeling suggest that of the hundreds of chemical constituents detected in both reserve pits and produced fluids, only a few from either source appear to be of concern to human health and the environment via ground-water and surface water pathways. The principal constituents of potential concern, based on an analysis of their toxicological data, their frequency of occurrence, and their mobility in ground water, include arsenic, benzene, sodium, chloride, boron, cadmium, chromium, and mobile salts. All of these constituents were included in the quantitative risk modeling; however, boron, cadmium, and chromium did not produce risks or resource damages under the conditions modeled.

For these constituents of potential concern, the quantitative risk modeling indicates that risks to human health and the environment are very small to negligible when wastes are properly managed. However, although the risk modeling employed several conservative assumptions, it was based on a relatively small sample of sites and was limited in scope to the management of drilling waste in reserve pits, the underground injection of produced water, and the surface water discharge of produced water from stripper wells. Also, the risk analysis did not consider 
migration of produced water contaminants through fractures or unplugged or improperly plugged and abandoned wells. Nevertheless, the relatively low risks calculated by the risk modeling effort suggest that complete adherence to existing State requirements would preclude most types of damages.

Damages may occur in some instances even where wastes are managed in accordance with currently applicable State and Federal requirements.

There appear to be some instances in which endangerment of human health and damage to the environment may occur even where operations are in compliance with currently applicable State and Federal requirements.

\section{Damage Cases}

Some documented damage cases illustrate the potential for human health endangerment or environmental damage from such legal practices as discharge to ephemeral streams, surface water discharges in estuaries in the Gulf Coast region, road application of reserve pit contents and discharge to tundra in the Arctic, annular disposal of produced waters, and landspreading of reserve pit contents.

\section{Risk Modeling}

For the constituents of potential concern, the quantitative evaluation did indicate some situations (less than 5 percent of those studied) with carcinogenic risks to maximally exposed individuals higher then 1 in $10,000\left(1 \times 10^{-4}\right)$ and sodium levels in excess of interim limits for public drinking water supplies. Although these higher risks resulted only under conservative modeling assumptions, including high (90th percentile) concentration levels for the toxic constituents, they do indicate potential for health or environmental impairment even under the 
general assumption of compliance with standard waste management procedures and applicable State and Federal requirements. Quantitative risk modeling indicates that there is an extremely wide variation (six or more orders of magnitude) in health and environmental damage potential among different sites and locations, depending on waste volumes, wide differences in measured toxic constituent concentrations, management practices, local hydrogeological conditions, and distances to exposure points.

Unplugged and improperly plugged abandoned wells can pose significant environmental problems.

Documentation assembled for the damage cases and contacts with State officials indicate that ground-water damages associated with unplugged and improperly plugged abandoned wells are a significant concern. Abandoned disposal wells may leak disposed wastes back to the surface or to usable ground water. Abandoned production wells may leak native brine, potentially leading to contamination of usable subsurface strata or surface waters.

Many older wells, drilled and abandoned prior to current improved requirements on well closure, have never been properly plugged. Many States have adequate regulations currently in place; however, even under some States' current regulations, wells are abandoned every year without being properly plugged.

Occasionally companies may file for bankruptcy prior to implementing correct plugging procedures and neglect to plug wells. Even when wells are correctly plugged, they may eventually leak in some circumstances in the presence of corrosive produced waters. The potential for environmental damage occurs wherever a well can act as a conduit between usable ground-water supplies and strata containing water with high 
chloride levels. This may occur when the high-chloride strata are pressurized naturally or are pressurized artificially by disposal or enhanced recovery operations, thereby allowing the chloride-rich waters to migrate easily into usable ground water.

Discharges of drilling muds and produced waters to surface waters have caused locally significant environmental damage where discharges are not in compliance with State and Federal statutes and regulations or where NPDES permits have not been issued.

Damage cases indicate that surface water discharges of wastes from exploration, development, and production operations have caused damage or danger to lakes, ephemeral streams, estuaries, and sensitive environments when such discharges are not carried out properly under applicable Federal and State programs and regulations. This is particularly an issue in areas where operations have not yet received permits under the Federal NPDES program, particularly along the Gulf Coast, where permit applications have been received but permits have not yet been issued, and on the Alaskan North Slope, where no NPDES permits have been issued.

For the Nation as a whole, Rrgulation of all oil and gas field wastes under unnodified Subtitle $C$ of RCRA would have a substantial impact on the U.S. economy.

The most costly hypothetical hazardous waste management program evaluated by EPA could reduce total domestic oil production by as much as 18 percent by the year 2000. Because of attendant world price increases, this would result in an annual direct cost passed on to consumers of over $\$ 6$ billion per year. This scenario assumes that 70 percent of all drilling and production wastes would be subject to the current requirements of Subtitle $C$ of RCRA. If only 10 percent of drilling wastes and produced waters were found to be hazardous, Subtitle $C$ regulation would result in a decline of 4 percent in U.S. production and 
a $\$ 1.2$ billion cost increase to consumers, compared with baseline costs, in the year 2000 .

EPA also examined the cost of a Subtitle $C$ scenario in which produced waters injected for the purpose of enhanced oil recovery would be exempt from Subtitle $C$ requirements. This scenario yielded production declines ranging from about 1.4 to 12 percent and costs passed on to consumers ranging from $\$ 0.7$ to $\$ 4.5$ billion per year, depending on whether 10 percent or 70 percent of the wastes (excluding produced waters injected for enhanced oil recovery) were regulated as hazardous wastes.

These Subtitle $C$ estimates do not, however, factor in all of the Hazardous and Solid Waste Act Amendments relating to Subtitle C land disposal restrictions and corrective action requirements currently under regulatory development. If these two requirements were to apply to oil and gas field wastes, the impacts of Subtitle $C$ regulation would be substantially increased.

The Agency also evaluated compliance costs and economic impacts for an intermediate regulatory scenario in which moderately toxic drilling wastes and produced waters would be subject to special RCRA requirements less stringent than those of Subtitle $C$. Under this scenario, affected drilling wastes would be managed in pits with synthetic liners, caps, and ground-water monitoring programs and regulated produced waters would continue to be injected into Class II wells (with no surface discharges allowed for produced waters exceeding prescribed constituent concentration limits). This scenario would result in a domestic production decline, and a cost passed on to consumers in the year 2000, of 1.4 percent and $\$ 400$ million per year, respectively, if 70 percent of 
the wastes were regulated. If only 10 percent of the wastes were subject to regulation, this intermediate scenario would result in a production decline of less than 1 percent and an increased cost to consumers of under $\$ 100$ million per year.

The economic impact analysis also estimates affects on U.S. foreign trade and State tax revenues. Ey the year 2000, based on U.S. Department of Energy models, the EPA cost results projected an increase in national petroleum imports ranging from less than 100 thousand to 1.1 million barrels per day and a corresponding increase in the U.S. balance of payments deficit ranging from less than $\$ 100$ thousand to $\$ 18$ billion annually, depending on differences in regulatory scenarios evaluated. Because of the decline in domestic production, aggregated State tax revenues would be depressed by an annual amount ranging from a few million to almost a billion dollars, depending on regulatory assumptions.

Regulation of all exempt wastes under full, unmodified RCRA Subtitle C appears unnecessary and impractical at this time.

There appears to be no need for the inposition of full, unmodified RCRA Subtitle $C$ regulation of hazardous waste for all high-volume exempt 0 il and gas wastes. Based on knowledge of the size and diversity of the industry, such regulations could be logistically difficult to enforce and could pose a substantial financial burden on the oil and gas industry, particularly on small producers and stripper operations. Nevertheless, elements of the Subtitle $C$ regulatory program may be appropriate in select circumstances. Reasons for the above tentative conclusion are described below.

The Agency considers imposition of full, unmodified Subtitle C regulations for all oil and gas exploration, development, and production wastes to be unnecessary because of factors such as the following. 
- Damages and risks posed by oil and gas operations appear to be linked, in the majority of cases, to violations of existing State and Federal regulations. This suggests that implementation and enforcement of existing authorities are critical to proper management of these wastes. Significant additional environmental protection could be achieved through a program to enhance compliance with existing requirements.

- State programs exist to regulate the management of oil and gas wastes. Although improvements may be needed in some areas of design, implementation, or enforcement of these programs, EPA believes that these deficiencies are correctable.

- Existing Federal programs to control underground injection and surface water discharges provide sufficient legal authority to handle most problems posed by oil and gas wastes within their purview.

The Agency considers the imposition of full Subtitle $C$ regulations for all oil and gas exploration, development, and production wastes to be impractical because of factors such as the following:

- EPA estimates that the Economic impacts of imposition of full Subtitle $C$ regulations (excluding the corrective action and land disposal restriction requirements), as they would apply without modification, would significantly reduce U.S. oil and gas production, possibly by as much as 22 percent.

- If reserve pits were considered to be hazardous waste management facilities, requiring permitting as Subtitle $C$ land disposal facilities, the administrative procedures and lengthy application processes necessary to issue these permits would have a drastic impact on development and production.

- Adding oil and gas operations to the universe of hazardous waste generators would potentially add hundreds of thousands of sites to the universe of hazardous waste generators, with many thousands of units being added and subtracted annually.

- Manifesting of all drilling fluids and produced waters offsite to RCRA Subtitle C disposal facilities would pose difficult logistical and administrative problems, especially for stripper operations, because of the large number of wells now in operation. 
States have adopted variable approaches to waste management.

State regulations governing proper management of Federally exempt oil and gas wastes vary to some extent to accommodate important regional differences in geological and climatic conditions, but these regional environmental variations do not fully explain significant variations in the content, specificity, and coverage of State regulations. For example, State well-plugging requirements for abandoned production wells range from a requirement to plug within 6 months of shutdown of operations to no time limit on plugging prior to abandonment.

Implementation of existing State and Federal requirements is a central issue in formulating recommendations in response to Section $8002(\mathrm{~m})$.

A preliminary review of State and Federal programs indicates that most States have adequate regulations to control the management of oil and gas wastes. Generally, these State programs are improving. Alaska, for example, has just promulgated new regulations. It would be desirable, however, to enhance the implementation of, and compliance with, certain waste management requirements.

Regulations exist in most States to prohibit the use of improper waste management practices that have been shown by the damage cases to lead to environmental damages and endangerment of human health. Nevertheless, the extent to which these regulations are implemented and enforced must be one of the key factors in forming recommendations to Congress on appropriate Federal and non-Federal actions. 


\section{CHAPTER IX}

\section{RECOMMENDATIONS}

Following public hearings on this report, EPA will draw more specific conclusions and make final recommendations to Congress regarding whether there is a need for new Federal regulations or other actions. These recommendations will be made to Congress and the public within 6 months of the publication of this report.

Use of Subtitle $D$ and other Federal and State authorities should be explored as a means for implementing any necessary additional controls on oil and gas wastes.

EPA has concluded that imposition of full, unmodified RCRA Subtitle C regulation of hazardous waste for all exempt oil and gas wastes nay be neither desirable nor feasible. The Agency believes, however, that further review of the current and potential additional future use of other Federal and State authorities (such as Subtitle D authority under RCRA and authorities under the Clean Water Act and the Safe Drinking Water Act) is desirable. These authorities could be appropriate for improved management of both exempt and nonexempt, high-volume or low-volume oil and gas wastes.

EPA may consider undertaking cooperative efforts with States to review and improve the design, implementation, and enforcement of existing State and Federal programs to manage oil and gas wastes.

EPA has concluded that most States have adequate regulations to control most impacts associated with the management of oil and gas wastes, but it would be desirable to enhance the implementation of, and compliance with, existing waste management requirements. EPA has also 
concluded that variations among States in the design and implementation of regulatory programs warrant review to identify successful measures in some States that might be attractive to other States. For example, EPA may want to explore, whether changes in State regulatory reporting requirements would make enforcement easier or more effective. EPA therefore recommends additional work, in cooperation with the States, to explore these issues and to develop improvements in the design, implementation, and enforcement of State programs.

During this review, EPA and the States should also explore nonregulatory approaches to support current programs. These might include development of training standards, inspector training and certification programs, or technical assistance efforts. They might also involve development of interstate commissions or other organizational approaches to address waste management issues common to operations in major geological regions (such as the Gulf Coast, Appalachia, or the Southwest). Such commissions might serve as a forum for discussion of regional waste management efforts and provide a focus for development and delivery of nonregulatory programs.

The industry should explore the potential use of waste minimization, recycling, waste treatment, innovative technologies, and materials substitution as long-term improvements in the management of oil and gas wastes.

Although in the near term it appears that no new technologies are available for making significant technical improvements in the management of exempt wastes from oil and gas operations, over the long term various innovative technologies and practices may emerge. The industry should explore the use of innovative approaches, which might include conservation and waste minimization techniques for reducing generation of drilling fluid wastes, use of incineration or other treatment technologies, and substitution of less toxic compounds wherever possible in oil and gas operations generally. 
Environmantal Protaction

Ageney

\section{DRAFT}

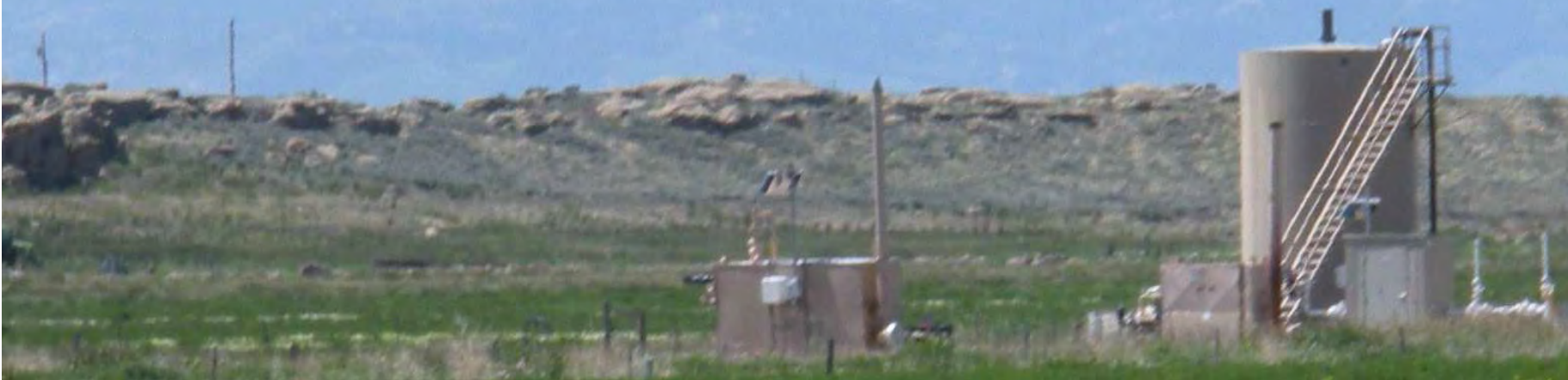

\section{Investigation of Ground Water Contamination near} Pavillion, Wyoming

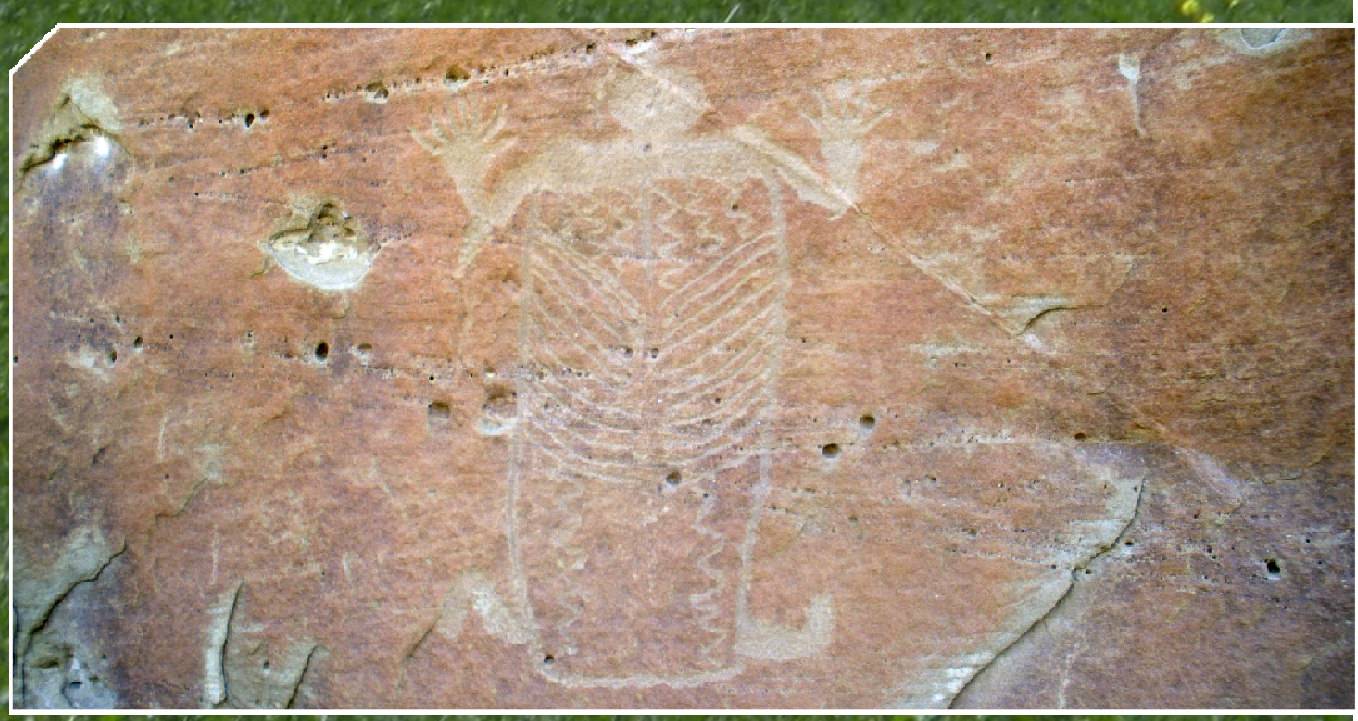




\section{DRAFT}




\title{
Investigation of Ground Water Contamination near Pavillion, Wyoming
}

\author{
Dominic C. DiGiulio \\ Richard T. Wilkin \\ Carlyle Miller \\ U.S. Environmental Protection Agency \\ Office of Research and Development \\ National Risk Management Research Laboratory \\ 919 Kerr Research Drive \\ Ada, OK 74820 \\ Gregory Oberley \\ U.S. Environmental Protection Agency \\ Region 8 \\ 1595 Wynkoop Street \\ Denver, CO 80202
}




\section{DRAFT}

\section{Notice}

This report has been reviewed and approved by the U.S. Environmental Protection Agency's Office of Research and Development. Approval does not signify that the contents necessarily reflect the views and policies of the Agency, nor does mention of trade names or commercial products constitute endorsement or recommendation for use. 


\section{DRAFT}

\section{Foreword}

The U.S. Environmental Protection Agency (EPA) is charged by Congress with protecting the Nation's land, air, and water resources. Under a mandate of national environmental laws, the Agency strives to formulate and implement actions leading to a compatible balance between human activities and the ability of natural systems to support and nurture life. The scientific arm of EPA, the Office of Research and Development (ORD), conducts leading-edge research that helps provide the solid underpinning of science and technology for the Agency. The work at ORD laboratories, research centers, and offices across the country helps improve the quality of air, water, soil, and the way we use resources. The research described in this report was designed and conducted by ORD's National Risk Management Research Laboratory in Ada, Oklahoma, working in close collaboration with scientists from EPA Region 8 in Denver, Colorado. 


\section{DRAFT}

\section{Acknowledgements}

The authors would to like to acknowledge valuable comments from 1 internal and 3 external reviewers used to improve this manuscript. We would also like to acknowledge Dr. Randall Ross, Dr. Junqi Huang, Dr. Doug Beak, Mr. Steve Acree, Mr. Tony Lee, Mr. Ken Jewell, Mr. Tim Lankford, Mr. Russell Neil, and Ms. Kristie Hargrove from ORD/NRMRL/Ada and Mr. Christopher Ruybal and Ms. Alexandra Kirkpatrick (student contractors) for their assistance in collecting ground water and gas samples. We would like to acknowledge Dr. Jennifer Gundersen of EPA's Region 3 Laboratory for conducting analysis water samples for glycols and 2-butoxyethanol and Dr. William Batschelet of EPA's Region 8 Laboratory for conducting and arranging the analysis of water samples for a number of classes of compounds. We also thank Mr. John Cox, Mr. Steve Markham, Ms. Tracy Pardue, Dr. Feng Lu, Mr. Joseph Karikari, Ms. Lisa Hudson, Dr. Sujith Kumar, Mr. Joe Tyburski, Mr. David Kessler, Mr. Jim Wilson (Shaw Environmental and Infrastructure), Mr. Mark White, Ms. Lynda Callaway, and Mr. Dennis Miller (ORD/NRMRL/Ada) for analytical support. We would like to thank Mr. Nathan Wiser, Mr. Robert Parker, and Ms. Johanna Miller of EPA Region 8 and Mr. Ron Mellor (SEE employee) for assistance in interpreting data and numerous helpful comments. We would like to acknowledge Mr. Steve Vandegrift of ORD/NRMRL/Ada for providing helpful comments in improving QA/QC aspects of this investigation and overseeing development of the QAPP and ADQs. We would like to acknowledge Dr. John Wilson for assistance in interpretation of data. We are grateful to Ms. Ayn Schmit of EPA Region 8 and Dr. David Jewett of ORD/NRMRL/Ada for ongoing support in their respective management roles and ability to effectively communicate technical details in this manuscript to others. We would like to express our appreciation to Mr. Jeff Locker and Ms. ZoeAnn Randall for access to their property for monitoring well installation and to Mr. Louis Meeks for access to his property for domestic well sampling. We are grateful to Mr. John Fenton for access to his property for domestic well sampling and facilitating contact with domestic well owners in the area. We are grateful to Ms. Kathy Tynsky of SRA for assistance in developing graphics in this document. 


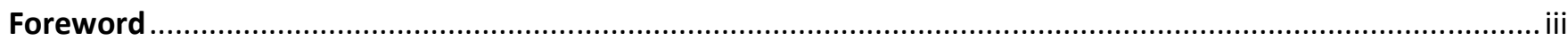

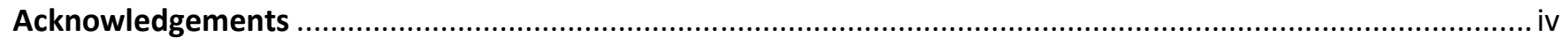

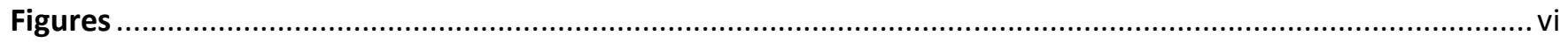

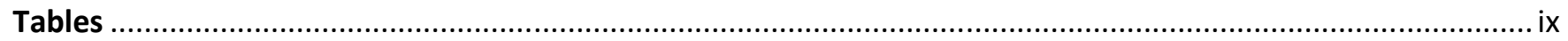

Extended Abstract.

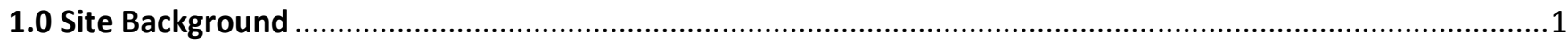

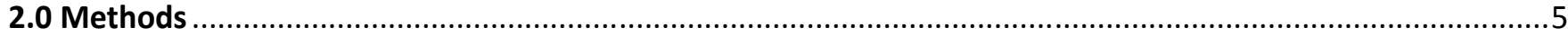

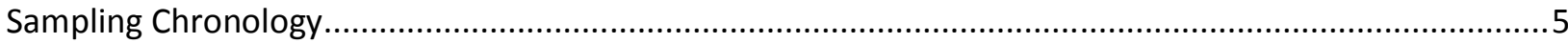

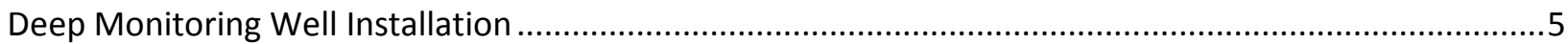

Ground Water Sampling of Deep Monitoring Wells in Phase III and IV ...............................................11

Gas Sampling from Casing of Deep Monitoring Wells in Phase III and IV .............................................15

Domestic Well Sampling for Methane Using a Closed System in Phase IV ..............................................15

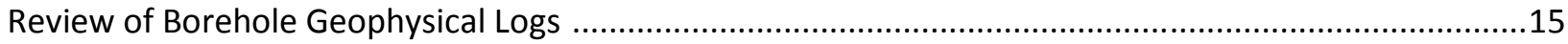

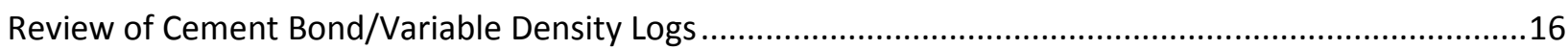

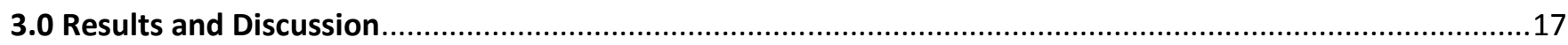

Ground Water and Soil Sample Results near Three Pits .....................................................................17

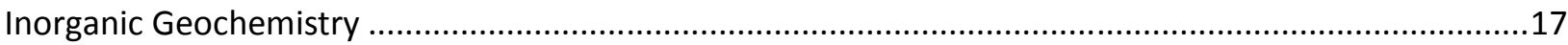

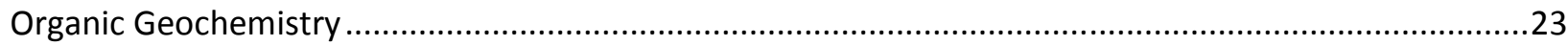

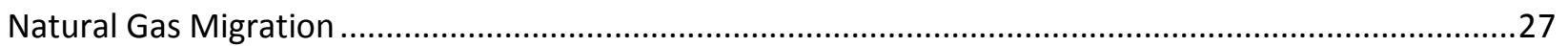

Evaluation of Cement Bond/Variable Density Logs Along Transect....................................................29

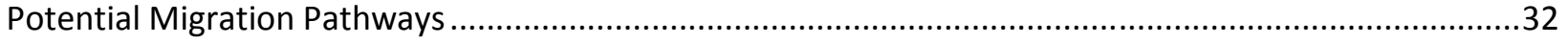

4.0 Conclusions

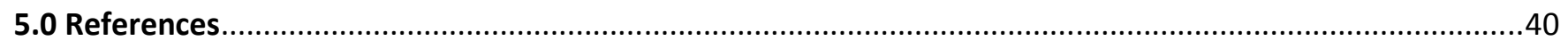

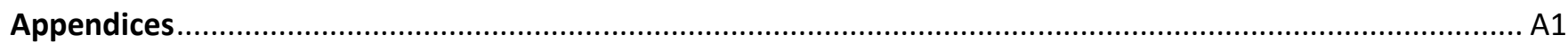

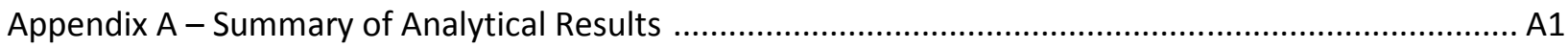

Appendix B - Quality Assurance and Quality Control (QA/QC) for Analysis .............................................

Appendix C - Photographic Log of Deep Monitoring Well Construction ...................................................

Appendix D - Photographic Log of Ground Water Sampling ................................................................ D1

Appendix E - Examples of Cement Bond/Variable Density Log Interpretation .......................................E1 


\section{DRAFT}

\section{Figures}

Figure 1. (a) Location of Wind River Basin in Wyoming. (b) Location of Pavillion Gas Field in the Wind River Basin. Figure from Johnson et al. 2007

\section{1}

Figure 2. Chronology of production well completion at the Pavillion Gas Field ..................................................2

Figure 3. Histograms summarizing depths of top of perforation interval of production wells, base of surface casing of production wells, and base of screened interval of domestic wells

Figure 4. Generalized stratigraphic columns and correlations of Mississippian through Eocene strata in the Wind River Basin, Wyoming. The Pavillion Gas Field is located in the Western Wind River Basin. Figure from Johnson et al. 2007

Figure 5. Map illustrating location of oil and gas production wells, sampled PGDWxx series domestic wells (only numbers shown to conserve space), two deep monitoring wells, and three shallow monitoring wells near pits. PGDW07 and PGDW08 are municipal wells in the town of Pavillion.

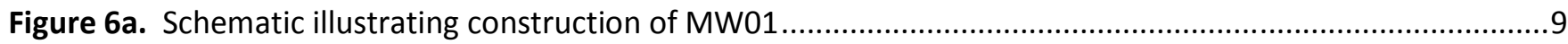

Figure 6b. Schematic illustrating construction of MW02

Figure 7. Resistivity as a function of depth in MW01 and MW02. MW01 and MW02 were screened at $233-239$ $\mathrm{m}$ and 293 - $299 \mathrm{~m}$ bgs respectively corresponding to elevated resistivity and presence of coarse-grained sandstone. FID readings in MW01 denote detections of methane during open air logging of mud. FID monitoring at MW02 was sporadic and is not illustrated here.

Figure 8. Variation of water level as a function of time in MW01 during Phase 4 well purging. The initial pumping rate was $24.2 \mathrm{~L} / \mathrm{min}$. After approximately 30 minutes of purging, the flow rate was decreased to 7.6 $\mathrm{L} / \mathrm{min}$. This reduced flow rate caused partial recovery of the water level and confirmation that formation water was being accessed

Figure 9. Flow-cell readings as a function of time for specific conductance, dissolved oxygen, $\mathrm{pH}$, and oxidationreduction potential (well MW02, Phase IV sampling)

Figure 10. Schematic of closed (no contact to atmosphere) sampling train for domestic wells. Water flow from domestic well and into sparge cell was approximately 5 and $1 \mathrm{~L} / \mathrm{min}$ respectively. Excess water bled through valve used for sampling prior to sample collection. Gas flow into sparge cell and portable FID/PID sparge cell was approximately 20 and $1 \mathrm{~L} / \mathrm{min}$. Excess air was bled through splitter above sparge cell

Figure 11. Durov diagram showing ground water chemistry trends obtained in Phase I - IV sampling events and the composition of irrigation water

Figure 12. Depth trends of chloride, $\mathrm{pH}$, sulfate, and potassium (filled black squares = domestic wells, filled red circles $=$ monitoring wells) 


\section{DRAFT}

Figure 13. Saturation indices for (a) gypsum versus sulfate concentration and (b) calcite versus calcium concentration. Saturation Index is equal to the logarithm of the ratio of the ion activity product to the mineral solubility product. A Saturation Index of 0 corresponds to chemical equilibrium; values less than 0 and greater than 0 correspond to undersaturated and oversaturated conditions, respectively.......

Figure 14. Concentration trends versus specific conductivity. Note the monitoring wells show high $\mathrm{pH}$ and low sulfate, calcium, and sodium relative to the general trend observed in the domestic wells (filled black squares = domestic wells, filled red circles $=$ monitoring wells)

Figure 15. (a) Results of $\mathrm{KOH}$ titration models plotted as $\mathrm{pH}$ versus grams of $\mathrm{KOH}$ added per kilogram of solution. Initial water compositions are from PGDW49, PGDW20, and PGDW32. Model accounts for reactions taking place in solution as $\mathrm{KOH}$ is added and equilibrated. $\mathrm{pH}$ range in deep monitoring wells shown for reference; (b) Buffer Intensity plot or first derivative of titration plot, $\mathrm{pH}$ versus change in concentration of base $\left(\mathrm{C}_{\mathrm{B}}\right)$ per change in $\mathrm{pH}$.....

Figure 16. Hydrogen and oxygen isotope values (permil, Vienna Standard Mean Ocean Water, VSMOW) for ground water samples (black squares=domestic wells; red circles=deep monitoring wells) relative to the Global Meteoric Water Line from Craig (1961)

Figure 17. Organic compounds detected in deep monitoring wells MW01 and MW02 during Phase III and IV sampling events.

Figure 18. (a) Stable isotope ratios of carbon of methane versus ratio of methane $\left(C_{1}\right)$ to ethane $\left(C_{2}\right)$ and propane $\left(C_{3}\right)$ in gas from production wells, monitoring wells, and domestic wells. Values of 100,000 are used to denote non detection of ethane and propane in samples. (b) Stable isotope ratios of carbon versus hydrogen of methane in gas from production wells (both literature and measured values), monitoring wells, and domestic wells. $\delta D$ was not determined for PGDW32. Oxidation pathway (enrichment of ${ }^{13} \mathrm{C}$ of remaining $\mathrm{CH}_{4}$ with biodegradation) is illustrated. (c) Methane concentration in domestic and monitoring wells as a function of proximity to production wells and depth. Values of 1.0 were used for non-detection (detection limit $5 \mu \mathrm{g} / \mathrm{L}$ ) ....28

Figure 19. Map illustrating transect used to develop lithologic cross section and evaluation of CBL/VDLs .30

Figure 20. Lithologic cross-section along transect illustrating production wells (with evaluation of CBL/VDLs), domestic wells, and blowout location. Red arrows denote depths of hydraulic fracturing of unknown areal extent

Figure C1. Photograph of drilling rig on platform with shakers for mud recirculation at MW02. .C2

Figure C2. Photograph of blowout prevention (BOP) for annular space at base of drilling rig platform at MW02

Figure C3. Photograph of blowout preventer for drillstem

Figure C4. Photograph of bit and drillstem with bit for mud rotary drilling at MW02 .C3

Figure C5. Photograph of water truck used to transport water to mix mud .C4

Figure C6. Photograph of Quik-Gel bentonite (Halliburton) used to create mud for drilling ..... .C4

Figure C7. Photograph of mud additives EZ Mud Gold (Halliburton) and Dense Soda Ash. .C4 


\section{DRAFT}

Figure C8. Photograph of mud additive Penetrol (Halliburton)

Figure C9. Photograph of flow of mud and cuttings from borehole at MW02.....

Figure C10. Photograph of monitoring of mud and cuttings using a Thermo Scientific TVA-1000B FID/PID at MW02

Figure C11. Photograph of pump used to transport mud and cuttings to shakers at MW02 ...........................C6

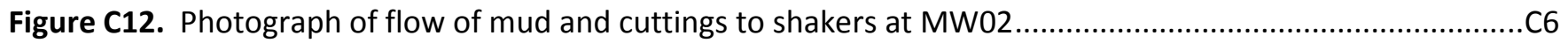

Figure C13. Photograph of shakers separating mud from cuttings at MW02 …............................................C7

Figure C14. Photograph of cuttings transported to disposal bins at MW02 ..................................................... 8

Figure C15. Photograph of pumping of mud back to borehole at MW02 …..................................................

Figure C16. Photograph of injection of mud to borehole at MW02 ….........................................................

Figure C17. Photograph of collection of cuttings for lithologic characterization at MW02 ….........................C11

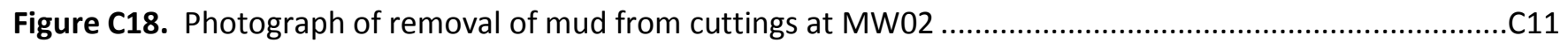

Figure C19. Photograph of white coarse-grained sand targeted by local well drillers and media in which screens are set in for both deep monitoring wells.

Figure C20. Photograph of setting of stainless-steel pre-packed screen and sand basket into borehole at MW02

Figure C21. Photograph of securing sand basket and casing above screen.

Figure C22. Photograph of placement of sand in sandbasket

Figure C23. Photograph of well development at MW02

Figure D1. Photograph of flow from submersible pump through flowmeter at MW02 .................................. D2

Figure D2. Photograph of flow of water to purge water disposal tank at MW02 …..................................... D2

Figure D3. Photograph (close-up) of flow of water into purge water disposal tank at MW02 .......................... D3

Figure D4. Photograph of water (foaming) flowing into YSI flow cell at MW02 …....................................... D3

Figure D5. Photograph of sampling at MW02. The sample train was split prior to entry into purge water disposal container

Figure D6. Photograph of field filtering samples for metals analysis at MW02 …......................................... D4

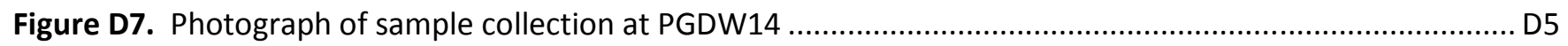

Figure D8. Photograph of cooler packed with samples for shipment........................................................... D5 


\section{DRAFT}

Figure E1. Example of CBL/VDL indicating "no cement" at Pavillion Fee 34-03B. The CBL/VDL indicates no cement 2750 feet below ground surface at the time of logging.

Figure E2. Example of "sporadic bonding" at Pavillion Fee 41-10 from 1000 to $1640 \mathrm{ft}$ bgs. Hydraulic fracturing occurred at 1618 feet below ground surface. Arrow denotes interval of hydraulic fracturing

Figure E3a. Example of "sporadic bonding" at Pavillion Fee 11-11B. Hydraulic fracturing occurred at 1516 feet below ground surface. Arrow denotes interval of hydraulic fracturing. Depths on CBL/VDL difficult to read and inserted on left margin

Figure E3b. Example of "sporadic bonding" Pavillion Fee 11-11B between 2350-3200 feet below ground suface. Hydraulic fracturing occurred at 3165 feet below ground surface. Arrow denotes interval of hydraulic fracturing. Depths on CBL/VDL difficult to read and inserted on left margin

Figure E4. Example of "Sporadic Bonding" at Tribal Pavillion 24-02. Hydraulic fracturing occurred at 1538 feet bgs. Arrow denotes interval of hydraulic fracturing

Figure E5. Example of "Good Bonding" (from surface casing at $645 \mathrm{ft}$ bgs to $820 \mathrm{ft} \mathrm{bgs}$ ) followed by "Sporadic Bonding" (from $820 \mathrm{ft}$ bgs $1310 \mathrm{ft}$ bgs) to "Good Bonding" at 1310 to target depth at Pavillion Fee 41-10B.

\section{Tables}

Table 1. Drilling additives, properties and product use recommendations.......................................................

Table 2. Analytical results of additives (compounds listed are those detected in ground water) .........................8

Table 3. Geochemical impacts in deep ground water monitoring wells..........................................................24

Table 4. Association of inorganic and organic anomalies with compounds used for hydraulic fracturing ............26

Table A1. Summary of subsurface sample locations, depth of sample collection, times (phases) of sampling, target analytes, laboratories utilized, and analytical methods .................................................................... A2

Table A2a. Geochemical results for Pavillion ground water ................................................................. A

Table A2b. Charge balance calculations for deep monitoring wells ............................................................... A9

Table A3a. Summary of aqueous analysis of light hydrocarbons …............................................................ A10

Table A3b. Summary of gas and headspace analysis of light hydrocarbons ............................................. A12

Table A3c. Summary of isotopic data for dissolved, gas phase, and headspace analysis.............................. A14

Table B1. Sample collection containers, preservation, and holding times for ground water samples ..................B2

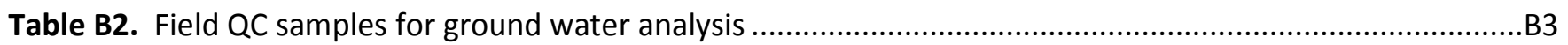




\section{DRAFT}

Table B3. QA/QC requirements for analysis of metals and major ions

Table B4. QA/QC requirements for analysis of dissolved gases, DIC/DOC, VOCs, low molecular weight acids and stable isotopes of water

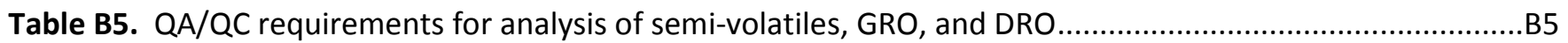

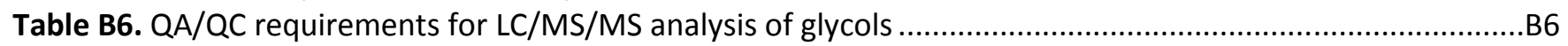

TableB7a. ICP-OES blank results for Phase III and Phase IV sampling ...........................................................

Table B7b. ICP-OES blank results for Phase III and Phase IV sampling ........................................................

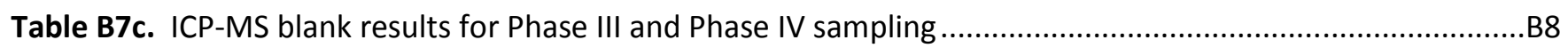

Table B8. Blank results for Capillary Electrophoresis, Lachat Flow Injection Analysis, Dissolved Inorganic Carbon (DIC) and Dissolved Organic Carbon analyses for Phase III and Phase IV sampling.....

Table B9. Blank results for Volatile Organic Compounds ( $\mu \mathrm{g} / \mathrm{L}$ ) in Phase III and Phase IV sampling (Region 8 laboratory, Golden, $\mathrm{CO})$

Table B10. Blank results for Volatile Organic Compounds $(\mu \mathrm{g} / \mathrm{L})$ in Phase IV sampling (ORD laboratory, Ada, OK)

Table B11. Blank results for Semi-Volatile Organic Compounds $(\mu \mathrm{g} / \mathrm{L})$ in Phase III and Phase IV sampling (Region 8 laboratory, Golden, $\mathrm{CO}$ )

Table B12. Blank results for GRO and DRO analyses for Phase III and Phase IV sampling (Region 8 laboratory, Golden, $\mathrm{CO}$ ) and blank results for glycol ethers in Phase IV sampling (Region 3 laboratory, Fort Meade, MD) . B13

Table B13. Duplicate data for selected major ions, DOC, and DIC in ground water samples collected during Phase III and Phase IV sampling activities.....

Table B14. Duplicate data for methane and selected dissolved organic compounds in ground water samples collected during Phase III and Phase IV sampling activities

Table B15. QA/QC requirements for analysis of $\delta^{13} \mathrm{C}$ of DIC. B16

Table B16. QA/QC requirements for analysis for $\delta^{13} \mathrm{C}$ and $\delta \mathrm{D}$ of light hydrocarbons for aqueous and gas samples

Table B17. QA/QC requirements for analysis of fixed gases and light hydrocarbons for aqueous and gas samples

Table B18. Summary of quality control samples, purpose, method, and frequency to support gas analysis.

Table B19. Summary of analytes, instruments, calibration, and check standards for portable gas analyzers....

Table B20. QA/QC Requirements for portable gas analyzers 


\section{DRAFT}

\section{Extended Abstract}

In response to complaints by domestic well owners regarding objectionable taste and odor problems in well water, the U.S. Environmental Protection Agency initiated a ground water investigation near the town of Pavillion, Wyoming under authority of the Comprehensive Environmental Response, Compensation, and Liability Act. The Wind River Formation is the principal source of domestic, municipal, and stock (ranch, agricultural) water in the area of Pavillion and meets the Agency's definition of an Underground Source of Drinking Water. Domestic wells in the area of investigation overlie the Pavillion gas field which consists of 169 production wells which extract gas from the lower Wind River Formation and underlying Fort Union Formation. Hydraulic fracturing in gas production wells occurred as shallow as 372 meters below ground surface with associated surface casing as shallow as 110 meters below ground surface. Domestic and stock wells in the area are screened as deep as 244 meters below ground surface. With the exception of two production wells, surface casing of gas production wells do not extend below the maximum depth of domestic wells in the area of investigation. At least 33 surface pits previously used for the storage/disposal of drilling wastes and produced and flowback waters are present in the area. The objective of the Agency's investigation was to determine the presence, not extent, of ground water contamination in the formation and if possible to differentiate shallow source terms (pits, septic systems, agricultural and domestic practices) from deeper source terms (gas production wells).

The Agency conducted four sampling events (Phase I - IV) beginning in March 2009 and ending in April, 2011. Ground water samples were collected from domestic wells and two municipal wells in the town of Pavillion in Phase I. Detection of methane and dissolved hydrocarbons in several domestic wells prompted collection of a second round of samples in January, 2010 (Phase II). During this phase, EPA collected additional ground water samples from domestic and stock wells and ground water samples from 3 shallow monitoring wells and soil samples near the perimeter of three known pit locations. Detection of elevated levels of methane and diesel range organics (DRO) in deep domestic wells prompted the Agency to install 2 deep monitoring wells screened at 233 - 239 meters (MW01) and 293 - 299 meters (MW02) below ground surface, respectively, in June 2010 to better evaluate to deeper sources of contamination. The expense of drilling deep wells while utilizing blowout prevention was the primary limiting factor in the number of monitoring wells installed. In September 2010 (Phase III), EPA collected gas samples from well casing from MW01 and MW02. In October 2010, EPA collected ground water samples from MW01 and MW02 in addition to a number of domestic wells. In April 2011 (Phase IV), EPA resampled the 2 deep monitoring wells to compare previous findings and to expand the analyte list to include glycols, alcohols, and low molecular weight acids.

Detection of high concentrations of benzene, xylenes, gasoline range organics, diesel range organics, and total purgeable hydrocarbons in ground water samples from shallow monitoring wells near pits indicates that pits are a source of shallow ground water contamination in the area of investigation. When considered separately, pits represent potential source terms for localized ground water plumes of unknown extent. When considered as whole they represent potential broader contamination of shallow ground water. A number of stock and domestic wells in the area of investigation are fairly shallow (e.g., $<30$ meters below ground surface) representing potential receptor pathways.

Determination of the sources of inorganic and organic geochemical anomalies in deeper ground water was considerably more complex than determination of sources in shallow media necessitating the use of mulitiple 


\section{DRAFT}

lines of reasoning approach common to complex scientific investigations. pH values in MW01 and MW01 are highly alkaline (11.2-12.0) with up to $94 \%$ of the total alkalinity contributed by hydroxide suggesting addition of a strong base as the causative factor. Reaction path modeling indicates that sodium-sulfate composition of ground water typical of deeper portions of the Wind River Formation provides little resistance to elevation of $\mathrm{pH}$ with small addition of potassium hydroxide. Potassium hydroxide was used in a crosslinker and in a solvent at this site.

The inorganic geochemistry of ground water from the deep monitoring wells is distinctive from that in the domestic wells and expected composition in the Wind River formation. Potassium concentration in MW02 (43.6 milligrams per liter) and MW01 (54.9 milligrams per liter) is between 14.5 and 18.3 times values in domestic wells and expected values in the formation. Chloride concentration in monitoring well MW02 (466 milligrams per liter) is 18 times the mean chloride concentration (25.6 milligrams per liter) observed in ground water from domestic wells and expected in the formation. Chloride enrichment in this well is significant because regional anion trends show decreasing chloride concentration with depth. In addition, the monitoring wells show low calcium, sodium, and sulfate concentrations compared to the general trend observed in domestic well waters. The formulation of fracture fluid provided for carbon dioxide foam hydraulic fracturing jobs typically consisted of $6 \%$ potassium chloride. Potassium metaborate was used in crosslinkers. Potassium hydroxide was used in a crosslinker and in a solvent. Ammonium chloride was used in crosslinker.

A number of synthetic organic compounds were detected in MW01 and MW02. Isopropanol was detected in MW01 and MW02 at 212 and 581 micrograms per liter, respectively. Diethylene glycol was detected in MW01 and MW02 at 226 and 1570 micrograms per liter, respectively. Triethylene glycol was detected in MW01 and MW02 at 46 and 310 micrograms per liter, respectively. Another synthetic compound, tert-butyl alcohol, was detected in MW02 at a concentration of 4470 micrograms per liter. Isopropanol was used in a biocide, in a surfactant, in breakers, and in foaming agents. Diethylene glycol was used in a foaming agent and in a solvent. Triethylene glycol was used in a solvent. Tert-butyl alcohol is a known breakdown product of methyl tert-butyl ether (a fuel additive) and tert-butyl hydroperoxide (a gel breaker used in hydraulic fracturing). Material Safety Data Sheets do not indicate that fuel or tert-butyl hydroperoxide were used in the Pavillion gas field. However, Material Safety Data Sheets do not contain proprietary information and the chemical ingredients of many additives. The source of tert-butyl alcohol remains unresolved. However, tert-butyl alcohol is not expected to occur naturally in ground water.

Benzene, toluene, ethylbenzene, and xylenes (BTEX) were detected in MW02 at concentrations of 246, 617, 67, and 750 micrograms per liter, respectively. Trimethylbenzenes were detected in MW02 at 105 micrograms per liter. Gasoline range organics were detected in MW01 and MW02 at 592 and 3710 micrograms per liter. Diesel range organics were detected in MW01 and MW02 at 924 and 4050 micrograms per liter, respectively. Aromatic solvent (typically BTEX mixture) was used in a breaker. Diesel oil (mixture of saturated and aromatic hydrocarbons including naphthalenes and alkylbenzenes) was used in a guar polymer slurry/liquid gel concentrate and in a solvent. Petroleum raffinates (mixture of paraffinic, cycloparaffinic, olefinic, and aromatic hydrocarbons) were used in a breaker. Heavy aromatic petroleum naphtha (mixture of paraffinic, cycloparaffinic and aromatic hydrocarbons) was used in surfactants and in a solvent. Toluene and xylene were used in flow enhancers and a breaker.

Detections of organic chemicals were more numerous and exhibited higher concentrations in the deeper of the two monitoring wells. Natural breakdown products of organic contaminants like BTEX and glycols include 


\section{DRAFT}

acetate and benzoic acid. These breakdown products are more enriched in the shallower of the two monitoring wells, suggesting upward/lateral migration with natural degradation and accumulation of daughter products. Hydraulic gradients are currently undefined in the area of investigation. However, there are flowing conditions in a number of deep stock wells suggesting that upward gradients exist in the area of investigation.

Alternative explanations were carefully considered to explain individual sets of data. However, when considered together with other lines of evidence, the data indicates likely impact to ground water that can be explained by hydraulic fracturing. A review of well completion reports and cement bond/variable density logs in the area around MW01 and MW02 indicates instances of sporadic bonding outside production casing directly above intervals of hydraulic fracturing. Also, there is little lateral and vertical continuity of hydraulically fractured tight sandstones and no lithologic barrier (laterally continuous shale units) to stop upward vertical migration of aqueous constituents of hydraulic fracturing in the event of excursion from fractures. In the event of excursion from sandstone units, vertical migration of fluids could also occur via nearby wellbores. For instance, at one production well, the cement bond/variable density log indicates no cement until $671 \mathrm{~m}$ below ground surface. Hydraulic fracturing occurred above this depth at nearby production wells.

A similar lines of reasoning approach was utilized to evaluate the presence of gas in monitoring and domestic wells. A comparison of gas composition and stable carbon isotope values indicate that gas in production and monitoring wells is of similar thermogenic origin and has undergone little or no degradation. A similar evaluation in domestic wells suggests the presence of gas of thermogenic origin undergoing biodegradation. This observation is consistent with a pattern of dispersion and degradation with upward migration observed for organic compounds.

Elevated levels of dissolved methane in domestic wells generally increase in those wells in proximity to gas production wells. Near surface concentrations of methane appear highest in the area encompassing MW01. Ground water is saturated with methane at MW01 which is screened at a depth (239 meters below ground surface) typical of deeper domestic wells in the area. A blowout occurred during drilling of a domestic well at a depth of only 159 meters below ground surface close to MW01. A mud-gas log conducted in 1980 (prior to intensive gas production well installation) located only $300 \mathrm{~m}$ from the location of the blowout does not indicate a gas show (distinctive peaks on a gas chromatograph) within 300 meters of the surface. Again, with the exception of two production wells, surface casing of gas production wells do not extend below the maximum depth of domestic wells in the area of investigation. A number of production wells in the vicinity of MW01 have sporadic bonding or no cement over large vertical instances. Again, alternate explanations of data have been considered. Although some natural migration of gas would be expected above a gas field such as Pavillion, data suggest that enhanced migration of gas has occurred within ground water at depths used for domestic water supply and to domestic wells. Further investigation would be needed to determine the extent of gas migration and the fate and transport processes influencing migration to domestic wells. 


\section{DRAFT}

1.0

Site Background

In early 2008, the U.S. Environmental Protection Agency (EPA) received complaints from several domestic well owners near the town of Pavillion, Wyoming regarding sustained objectionable taste and odor problems in well water following hydraulic fracturing at nearby gas production wells. In response to these complaints, EPA initiated a comprehensive ground water investigation in September 2008 under authority of the Comprehensive Environmental Response, Compensation, and Liability Act. The area of investigation is a sparsely populated rural area in west-central Wyoming directly east of the town of Pavillion. Land use by residents consists primarily of ranching (horse and cattle) and alfalfa hay production for use by ranchers and commercial sale. Fields are periodically flooded using water obtained from canals and laterals.
Domestic wells in the area of investigation overlie the Pavillion gas field which is one of several gas fields within the Wind River Basin - a large, complex, structural, asymmetric, deep sedimentary basin covering much of central Wyoming (Figure 1). Oil and gas exploration wells were drilled in the 1950s. Commercial natural gas extraction in the field commenced in 1960 (Single 1969) with gas production well installation activity intensifying in the late 1990s through 2006 (Figure 2). The field currently consists of approximately 169 vertical production wells. Ninety-seven production wells are designated as "Tribal Pavillion" and are regulated by the U.S. Bureau of Land Management (BLM). The remaining wells are designated as "Pavillion Fee" and are regulated by Wyoming Oil and Gas Conservation Commission (WOGCC).

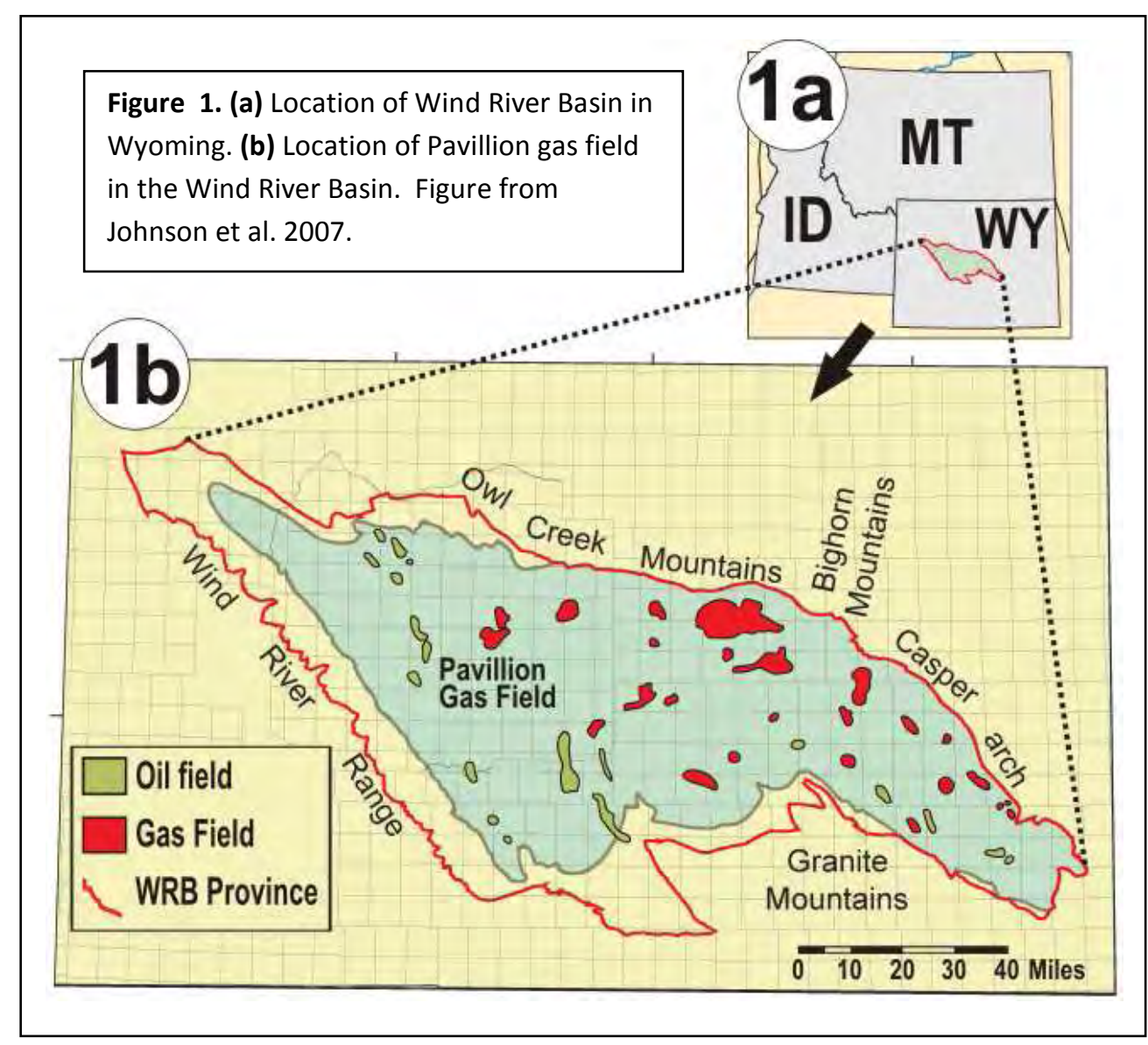




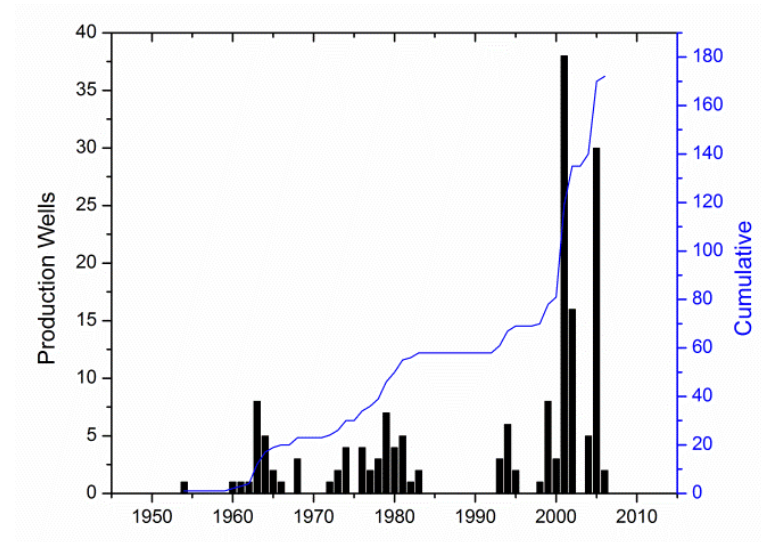

Figure 2. Chronology of production well completion at the Pavillion gas field.

A review of production well records obtained on line from WOGCC indicates that hydraulic fracturing in gas production wells occurred as shallow as $372 \mathrm{~m}$ (1220 $\mathrm{ft}$ ) below ground surface (bgs) with associated surface

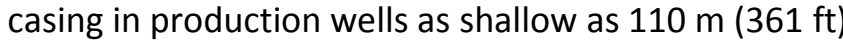
bgs. Information obtained from the Wyoming State Engineer's Office and homeowners indicates that domestic wells (including stock wells) in the area of investigation are screened as deep as $244 \mathrm{~m}(800 \mathrm{ft})$ bgs. With the exception of two production wells, surface casings of gas production wells do not extend below the maximum depth of domestic wells in the area of investigation (Figure $\mathbf{3}$ ).

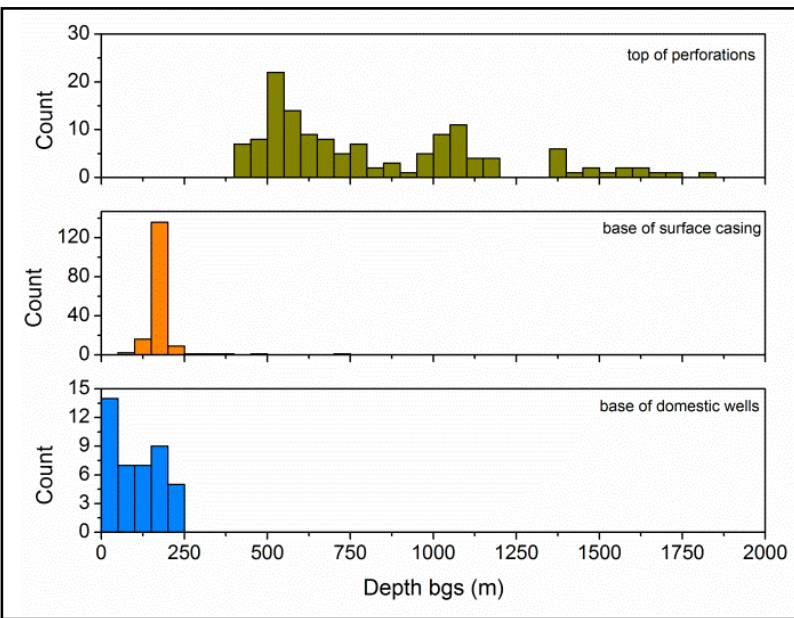

Figure 3. Histograms summarizing depths of top of perforation interval of production wells, base of surface casing of production wells, and base of screened interval of domestic wells.
Gas extraction occurs from both the lower Eocene Wind River Formation and underlying Paleocene Fort Union Formation (Figure 4). The Wind River Formation consists of interbedded layers of sandstones and shale with coarse-grained meandering stream channel deposits (Osiensky et al. 1984) and extends from the surface to approximately $1036 \mathrm{~m}$ (3400 ft) bgs. The Fort Union Formation ranges in thickness from 762 to $914 \mathrm{~m}$ ( 2500 to $3000 \mathrm{ft}$ ) in the area (Flores and Keighin 1993). The Waltman Shale Member in the Fort Union Formation is absent below the Pavillion Gas Field. The most productive zone of gas extraction in the Wind River Formation occurs at its base and is often targeted for gas extraction (Single 1969). Gas trapping in the lower Wind River and Fort Union Formations occurs in localized stratigraphic sandstone pinchouts on the crest and along flanks of a broad dome (Mueller 1989, Keefer and Johnson 1993).

There is substantial vertical and lateral stratigraphic variation over short distances in both formations (Single 1969, Flores and Keighin 1993). Individual productive sandstones in the two formations generally vary in thickness from 1 to $21 \mathrm{~m}$ with permeability varying from 0.1 to 300 millidarcies and porosity ranging from 4 to 28 percent (Single 1969). Gas from the Fort Union and lower Wind River Formations varies little in $\delta^{13} \mathrm{C}$ for methane, ethane, and propane with depth from the lower Eocene Wind River Formation to deeper mature and post-mature Upper Cretaceous source rocks (Figure 4) suggesting upward gas migration (Johnson and Rice 1993, Johnson and Keighin 1998) from deep source rocks. $\delta^{13} \mathrm{C}$ is defined as

$$
\delta^{13} \mathrm{C}(\% 0)=\left[\frac{\left({ }^{13} \mathrm{C} /{ }^{12} \mathrm{C}\right) \text { sample }}{\left({ }^{13} \mathrm{C} /{ }^{12} \mathrm{C}\right) \text { standard }}-1\right] \times 1000
$$

where the standard is the Pee Dee Belemnite (PDB) reference standard. Stable isotope ratios are reported as the relative difference in the ratio of the less abundant heavier isotope to the more abundant lighter isotope of the sample with respect to a 
DRAFT
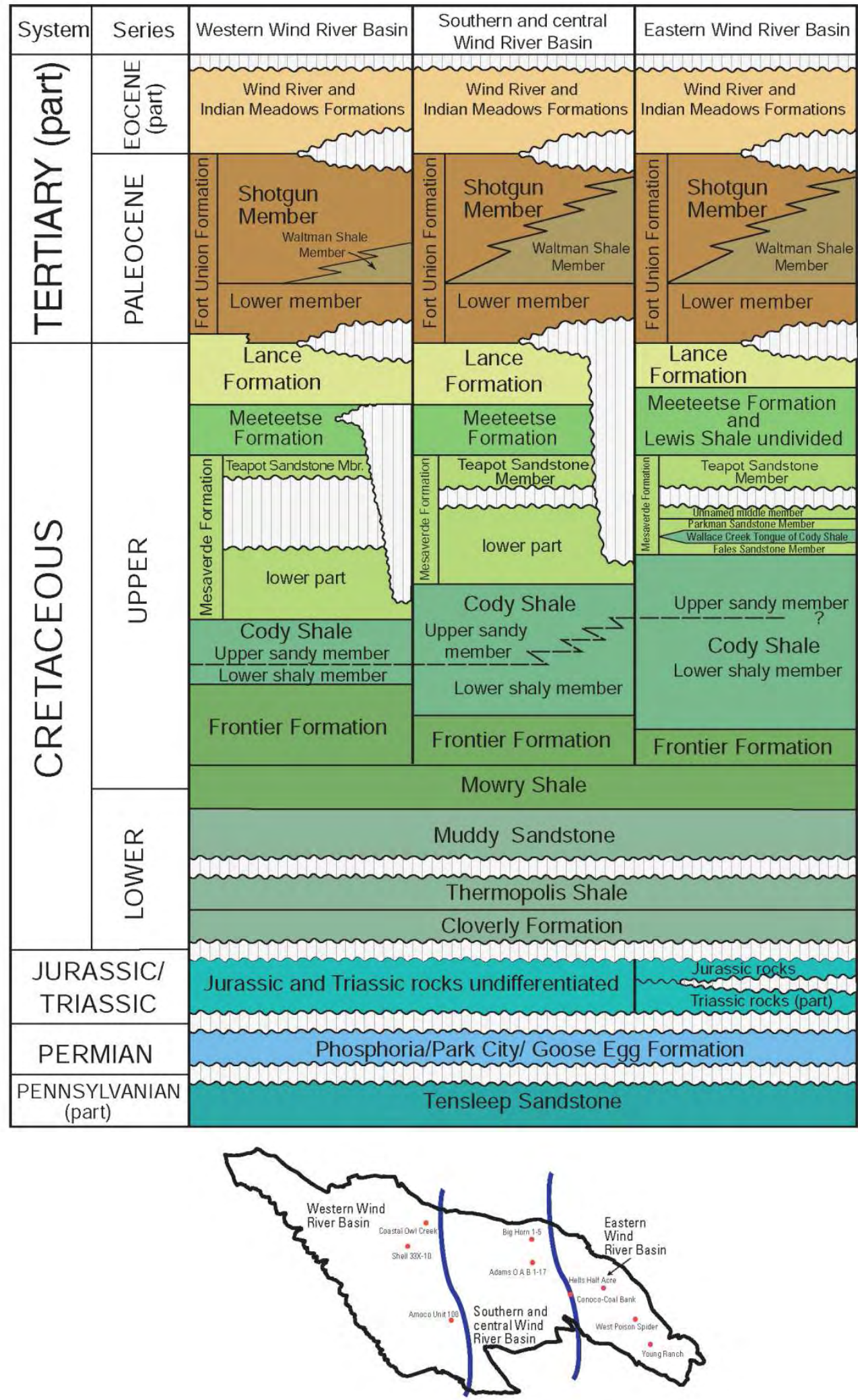

Figure 4. Generalized stratigraphic columns and correlations of Mississippian through Eocene strata in the Wind River Basin, Wyoming. The Pavillion Gas Field is located in the Western Wind River Basin. Figure from Johnson et al. 2007. 
reference standard. Ratios are expressed in parts per thousand or permil (\%). A substantial amount of additional compositional and isotopic data is available on the Wind River and Fort Union Formations but is classified as Confidential Business Information by the gas field operator.

Ground water from the upper Wind River Formation is the principal source of domestic, municipal, and stock (ranching, agriculture) water in the Pavillion area (WY State Water Plan 2003). The Wind River Formation meets the definition of an Underground Source of Drinking Water (USDW) under the United States Code of Federal Regulations, Title 40, Section 144.3. Water yields from wells in the upper Wind River Formation range up to $11,300 \mathrm{~L} / \mathrm{min}$ with total dissolved-solids (TDS) concentrations ranging from 100 to $5,110 \mathrm{mg} / \mathrm{L}$ (WY State Water Plan 2003, Daddow 1996). The town of Pavillion has five municipal wells screened at depths ranging from 122 to $158 \mathrm{~m}$ bgs with average daily use estimated at 60,000 L/day (WY State Water Plan 2003). Fluids used for hydraulic fracturing were injected directly into the Wind River Formation. 


\section{DRAFT}

2.0

Methods

\section{Sampling Chronology}

Four sampling events (Phase I - IV) were conducted commencing in March 2009 and ending in April 2011. In March 2009 (Phase I), EPA collected aqueous samples from 35 domestic wells (including two samples from post reverse osmosis systems) in the area of investigation and 2 municipal wells in the town of Pavillion. Detection of methane and dissolved hydrocarbons in several domestic wells prompted collection of a second round of samples in January 2010 (Phase II). During this phase, EPA collected: (1) ground water samples from 17 domestic wells (10 previously sampled), 4 stock wells, and 2 municipal wells; (2) a filter sample from a reverse osmosis system; (3) surface-water and sediment samples from 5 locations along Five-Mile Creek (a creek traversing the area of investigation); (4) gas and produced water/condensate samples (organic compounds only) from 5 production wells; and (5) ground water samples from 3 shallow monitoring wells and soil samples near the perimeter of three known pit locations.

Detection of elevated levels of methane and diesel range organics (DRO) in deep domestic wells prompted EPA to install 2 deep monitoring wells in June 2010 to differentiate potential deep (e.g., gas production related) versus shallow (e.g., pits) sources of ground water contamination. Monitoring wells MW01 and MW02 were screened at $233-239$ m (765 $-785 \mathrm{ft})$ and $293-299 \mathrm{~m}(960-980 \mathrm{ft}) \mathrm{bgs}$, respectively. The expense of drilling deep wells while utilizing blowout prevention was the primary limiting factor in the number of monitoring wells installed. In September 2010 (Phase III), EPA collected gas samples from well casing from MW01 and MW02. In October 2010, EPA collected ground water samples from MW01 and MW02 in addition to a previously unsampled domestic well and two previously sampled domestic wells. In April 2011 (Phase IV), EPA resampled the 2 deep monitoring wells to compare previous findings and expand the analyte list to include glycols, alcohols, and low molecular weight acids. Eight previously sampled domestic wells and three previously sampled stock/irrigation wells were also sampled at this time. Sampling chronology and analytical methods for all sampling events are summarized in Table A1. The location of production wells, monitoring wells, and sampled domestic wells is illustrated in Figure 5.

\section{Deep Monitoring Well Installation}

EPA installed two deep monitoring wells (designated as MW01 and MW02) using air (0 - $6 \mathrm{~m}$ bgs) and mud rotary ( $6 \mathrm{~m}$ bgs to target depth). Mud rotary was selected for installation of deep monitoring wells because it allowed the use of blowout prevention (BOP). Use of mud rotary with BOP was necessary given that a blowout occurred during installation of a domestic well at only $159 \mathrm{~m}$ (522 ft) bgs in December 2005 in the vicinity of MW01. Both deep monitoring wells were located away from gas production wells, known locations of pits, and areas of domestic waste disposal (abandoned machinery). There were no incidents of fuel spillage used to power pumps and generators.

Mud rotary required the use of drilling mud to remove cuttings and additives to avoid heaving of shale during drilling and well placement. Jet Lube Well Guard hydrocarbon free lubricant was used for outside threads for drillstem and submersible pipe connections. Mud composition consisted of formation water, municipal drinking water from Riverton, WY (transported on site by water truck), Quik-Gel high yield bentonite and additives listed on Table 1. Municipal water was mixed with bentonite to create drilling mud. The $\mathrm{pH}$ of mud during drilling varied between $\mathrm{pH} 8$ - 9. Aqua-Clear (Halliburton) was used during well development to facilitate removal of mud. Drilling additives were extracted in water (1:20 to 1:100 dilution) and analyzed for $\mathrm{pH}$, inorganics, organics, glycols, and alcohols. Despite the highly concentrated nature of these solutions (not 


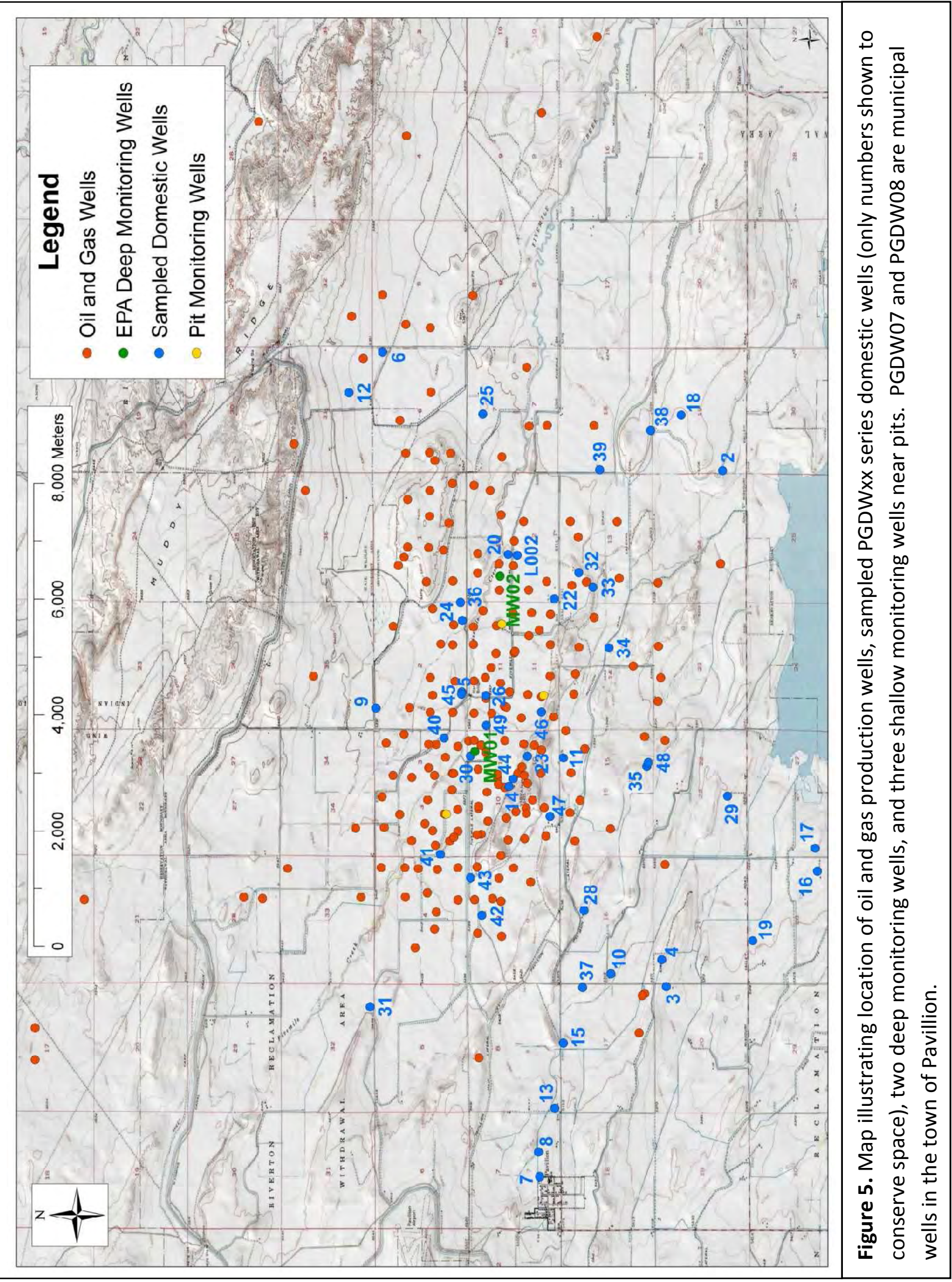


DRAFT

Table 1. Drilling additives, properties and product use recommendations

\begin{tabular}{|c|c|c|c|c|c|c|c|}
\hline Ingredient & Manufacturer & Purpose & $\begin{array}{l}\text { Composition from } \\
\text { MSDS }\end{array}$ & Specific gravity & $\begin{array}{l}\text { Recommended } \\
\text { mixture with } \\
\text { water (wt/wt) }\end{array}$ & pH & Properties \\
\hline $\begin{array}{l}\text { Aqua-Clear } \\
\text { PFD }\end{array}$ & Halliburton & $\begin{array}{l}\text { Dispersant/ } \\
\text { mud } \\
\text { removal }\end{array}$ & $\begin{array}{l}\text { anionic } \\
\text { polyacrylamide } \\
(30-60 \%)\end{array}$ & $1.2-1.4$ & $1: 2500$ & $\begin{array}{l}\text { neat } \\
6.5 \text { to } 7.5\end{array}$ & liquid \\
\hline Penetrol & Halliburton & $\begin{array}{l}\text { Non-ionic } \\
\text { wetting } \\
\text { agent }\end{array}$ & $\begin{array}{l}\text { diethanolamine } \\
(1-5 \%) \text { and coco } \\
\text { diethanolamide } \\
(10-30 \%)\end{array}$ & 0.98 & $1: 400$ to $1: 100$ & $\begin{array}{l}1 \% \\
\text { solution } \\
9.5\end{array}$ & liquid \\
\hline EZ-Mud Gold & Halliburton & $\begin{array}{l}\text { Clay/shale } \\
\text { stabilizer }\end{array}$ & $\begin{array}{l}\text { "no hazardous } \\
\text { substances" }\end{array}$ & $0.8-1$ & $1: 1400$ to $1: 350$ & $\begin{array}{l}1 \% \\
\text { solution } \\
7.75\end{array}$ & solid \\
\hline $\begin{array}{l}\text { Dense Soda } \\
\text { Ash }\end{array}$ & $\begin{array}{l}\text { OCl Chemical } \\
\text { Corp }\end{array}$ & $\begin{array}{l}\text { Improve } \\
\text { bentonite }\end{array}$ & $\begin{array}{l}\text { Sodium carbonate } \\
(100 \%)\end{array}$ & 2.5 & $1: 100$ to $1: 50$ & $\begin{array}{l}5 \% \\
\text { solution } \\
11.5\end{array}$ & solid \\
\hline Quik-Gel & Halliburton & $\begin{array}{l}\text { Viscosifier/ } \\
\text { bentonite }\end{array}$ & $\begin{array}{l}\text { bentonite }(60 \%), \\
\text { crystalline silica } \\
\text { quartz }(1-5 \%) \text {, } \\
\text { crystalline silica } \\
\text { cristobalite }(0-1 \%) \text {, } \\
\text { crystalline silica } \\
\text { tridymite }(0-1 \%) \text {. }\end{array}$ & 2.6 & $1: 60$ to $1: 30$ & $\begin{array}{l}3 \% \\
\text { solution } \\
8.9\end{array}$ & solid \\
\hline $\begin{array}{l}\text { Quik-Trol } \\
\text { Gold }\end{array}$ & Halliburton & $\begin{array}{l}\text { Ease of } \\
\text { mixing and } \\
\text { improved } \\
\text { filtration }\end{array}$ & $\begin{array}{l}\text { cellulose derivative } \\
\text { (polysaccharide) } \\
(60-100 \%)\end{array}$ & $0.6-0.9$ & $1: 3500$ to $1: 200$ & $\begin{array}{l}1 \% \\
\text { solution } \\
6-8 \\
\text { (listed) }\end{array}$ & solid \\
\hline
\end{tabular}

representative of significantly lower levels in drilling mud, see recommended product use mixture listed in Table 1), the $\mathrm{pH}$ of samples varied between 6.6 to 11.2 , potassium varied between 0.1 to $1.2 \mathrm{mg} / \mathrm{L}$, chloride varied between not detected to $214 \mathrm{mg} / \mathrm{L}$, ethanol and isopropanol detections were less than 90 $\mu \mathrm{g} / \mathrm{L}$, and acetone, tert-butyl alcohol (TBA), benzene, toluene, ethylbenzene, xylenes (BTEX), trimethylbenzenes, and glycols were not detected (Table 2). Organics were not analyzed in the dense soda ash and Quik-Gel because dissolved organic carbon concentrations were low and because of difficulties in analyzing the viscous gel (Quik-Gel). Since inorganic and organic concentration patterns measured in the drilling additives do not match patterns observed in the deep monitoring wells and because large volumes of ground water were extracted from the wells during development and prior to sampling, it is unlikely that ground water chemistry was impacted by drilling additives.
Composite samples of cuttings were collected and sent to TestAmerica Laboratories in Denver, Colorado for Toxic Characteristic Leaching Procedure (TCLP). Samples were analyzed for TCLP volatile organic compounds using gas chromatography-mass spectrometry (GC-MS) in accordance with EPA SW-846 Methods 1311/8260B, and for TCLP semivolatile organic compounds (GC-MS) in accordance with EPA SW-846 Methods $1311 / 8270$ C, for TCLP metals in accordance with EPA SW-846 Methods 1311/ 6010B, for TCLP mercury in accordance with EPA SW-846 Methods 1311/7470A. Acetone, toluene, and $m$ \& pxylene were detected in one sample at $6.9,0.63$, and $1.0 \mu \mathrm{g} / \mathrm{L}$, respectively. Cuttings were disposed offsite in a landfill.

A photographic log of drilling, mud circulation, examination of cuttings, screen placement, and well development is provided in Appendix C. Well construction schematics are provided for MW01 and 
DRAFT

Table 2. Analytical results of additives (compounds listed are those detected in ground water)

\begin{tabular}{|c|c|c|c|c|c|c|}
\hline & $\begin{array}{l}\text { Aqua-Clear } \\
\text { PFD }\end{array}$ & Penetrol & $\begin{array}{l}\text { EZ-Mud } \\
\text { Gold }\end{array}$ & $\begin{array}{c}\text { Dense } \\
\text { Soda Ash }\end{array}$ & Quik-Gel & Blank \\
\hline $\begin{array}{l}\text { Extraction ratio } \\
\text { (wt/wt) }\end{array}$ & $1: 20$ & $1: 20$ & $1: 100$ & $1: 100$ & $1: 100$ & ---- \\
\hline pH measured & 7.96 & 8.51 & 6.64 & 11.2 & 8.35 & $-\cdots$ \\
\hline $\begin{array}{l}\text { Specific } \\
\text { Conductance } \\
\text { (mS/cm) }\end{array}$ & 13.3 & 0.47 & 0.24 & 15.5 & 0.20 & ---- \\
\hline $\begin{array}{l}\text { Dissolved Organic } \\
\text { Carbon (ppm) }\end{array}$ & $1640(1650)+$ & 1500 & 388 & 0.58 & 2.11 & 0.28 \\
\hline $\mathrm{Cl}$ (ppm) & $214(230)+$ & 85 & 2.22 & 7.03 & nd & nd \\
\hline SO4 (ppm) & $121(117)+$ & 597 & nd & nd & 3.53 & nd \\
\hline $\mathrm{K}(\mathrm{ppm})$ & $0.40(0.40)+$ & 0.63 & 1.16 & 0.12 & 0.09 & $0.07 *$ \\
\hline Acetone $(\mu \mathrm{g} / \mathrm{L})$ & nd & nd & nd & $-\cdots$ & $-\cdots$ & nd \\
\hline $\begin{array}{l}\text { Tert-butyl alcohol } \\
(\mu \mathrm{g} / \mathrm{L})\end{array}$ & nd & nd & nd & $-\cdots$ & $-\cdots$ & nd \\
\hline Isopropanol ( $\mu \mathrm{g} / \mathrm{L})$ & $85(87)^{\dagger *}$ & $43^{*}$ & $27 *$ & $\ldots$ & $\cdots$ & nd \\
\hline Ethanol $(\mu \mathrm{g} / \mathrm{L})$ & $59(62)+*$ & $58 *$ & nd & $\ldots$ & $\ldots$ & nd \\
\hline Benzene $(\mu \mathrm{g} / \mathrm{L})$ & nd & nd & nd & $\cdots$ & 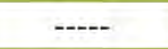 & nd \\
\hline Toluene $(\mu \mathrm{g} / \mathrm{L})$ & nd & nd & nd & 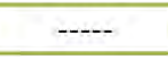 & $-\cdots$ & nd \\
\hline $\begin{array}{l}\text { Ethylbenzene } \\
(\mu \mathrm{g} / \mathrm{L})\end{array}$ & nd & nd & nd & 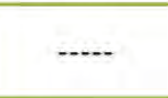 & ---- & nd \\
\hline $\begin{array}{l}\text { Xylene } \\
(\mu \mathrm{g} / \mathrm{L})\end{array}$ & nd & nd & nd & $-\cdots$ & ---- & nd \\
\hline $\begin{array}{l}\text { Trimethylbenzenes } \\
(\mu \mathrm{g} / \mathrm{L})\end{array}$ & nd & nd & nd & ---- & ---- & nd \\
\hline Naphthalene & nd & 2.00 & nd & $-\cdots$ & $-\cdots$ & nd \\
\hline $\begin{array}{l}\text { Ethylene glycol } \\
(\mu \mathrm{g} / \mathrm{L})\end{array}$ & nd & nd & nd & $\ldots$ & ---- & nd \\
\hline $\begin{array}{l}\text { Diethylene glycol } \\
(\mu \mathrm{g} / \mathrm{L})\end{array}$ & nd & nd & nd & $\ldots$ & ---- & nd \\
\hline
\end{tabular}

nd - not detected. ---- not measured. Drilling additives were extracted at the specified weight ratio into deionized water. $\dagger$ - Duplicate analysis. Blank sample is analysis of water used for the extraction of drilling additives. * Concentration above minimum detection limit, but below the level of quantification.

MW02 in Figures 6a and 6b, respectively. During installation of MW02, cuttings were allowed to settle at the cessation of drilling and form a $5 \mathrm{~m}(17 \mathrm{ft})$ base for placement of the screen. Cuttings were never added to the borehole. Since a significant vertical distance existed between the depth of drilling and screen placement at MW01, cement grout was utilized to form the base for screen placement. No lubricants were used to attach sections of casing or casing to screens. Well screens, sections of casing and tremie pipe were mounted above ground (never touched soil) and power washed (no detergents used) prior to (deployment. Locations of both MW01 and MW02 were in fields used for alfalfa hay production away from production wells, pads, and pits.

Cuttings were continuously examined during drilling by manually washing drilling mud from rock fragments with observations recorded as a function of depth in borehole logs. At the cessation of drilling, open-hole geophysical logging (caliper, density, resistivity, spontaneous potential, natural gamma) was conducted by Colog Inc., prior to placement of well 
DRAFT

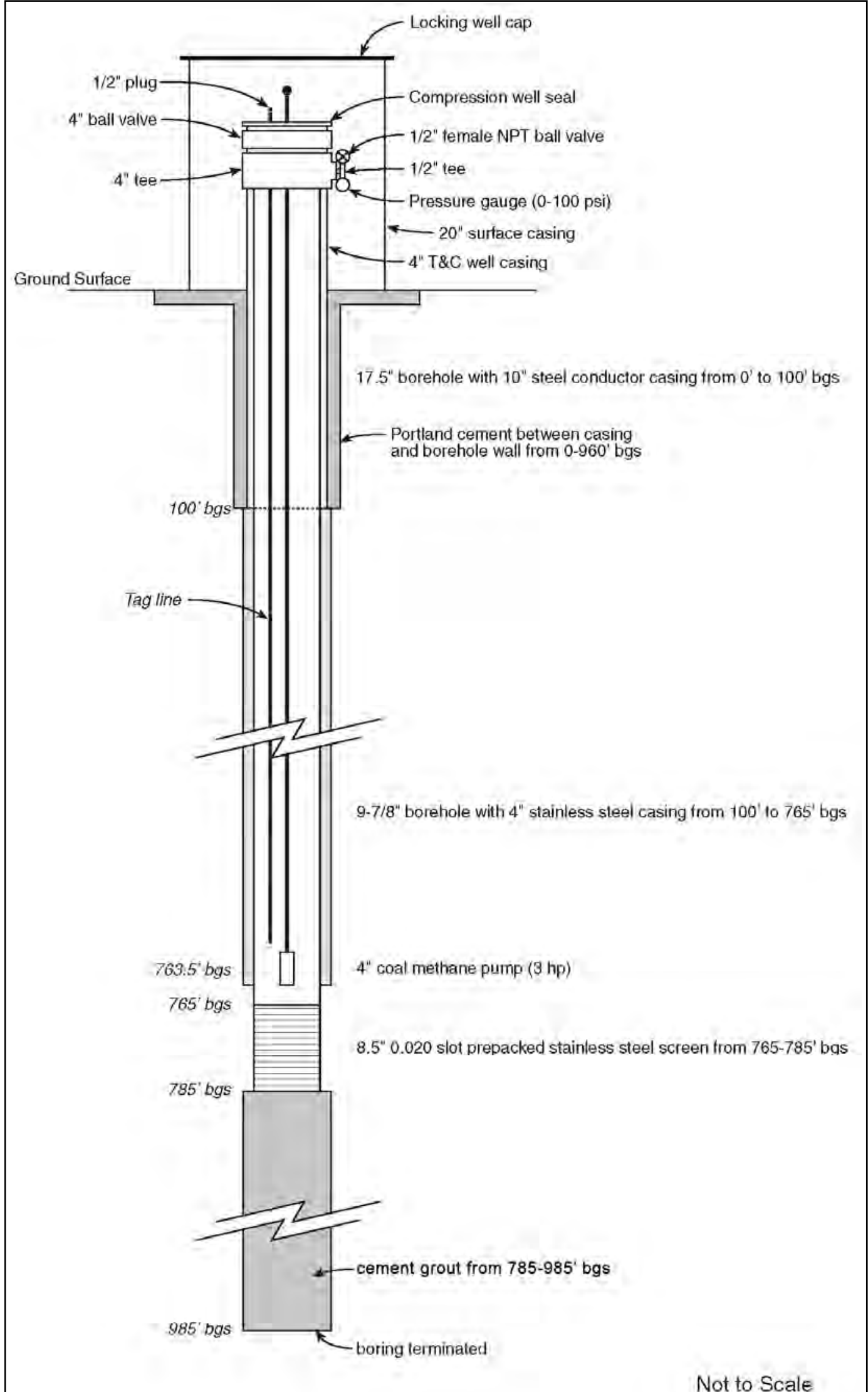

Figure 6a. Schematic illustrating construction of MW01. 
DRAFT

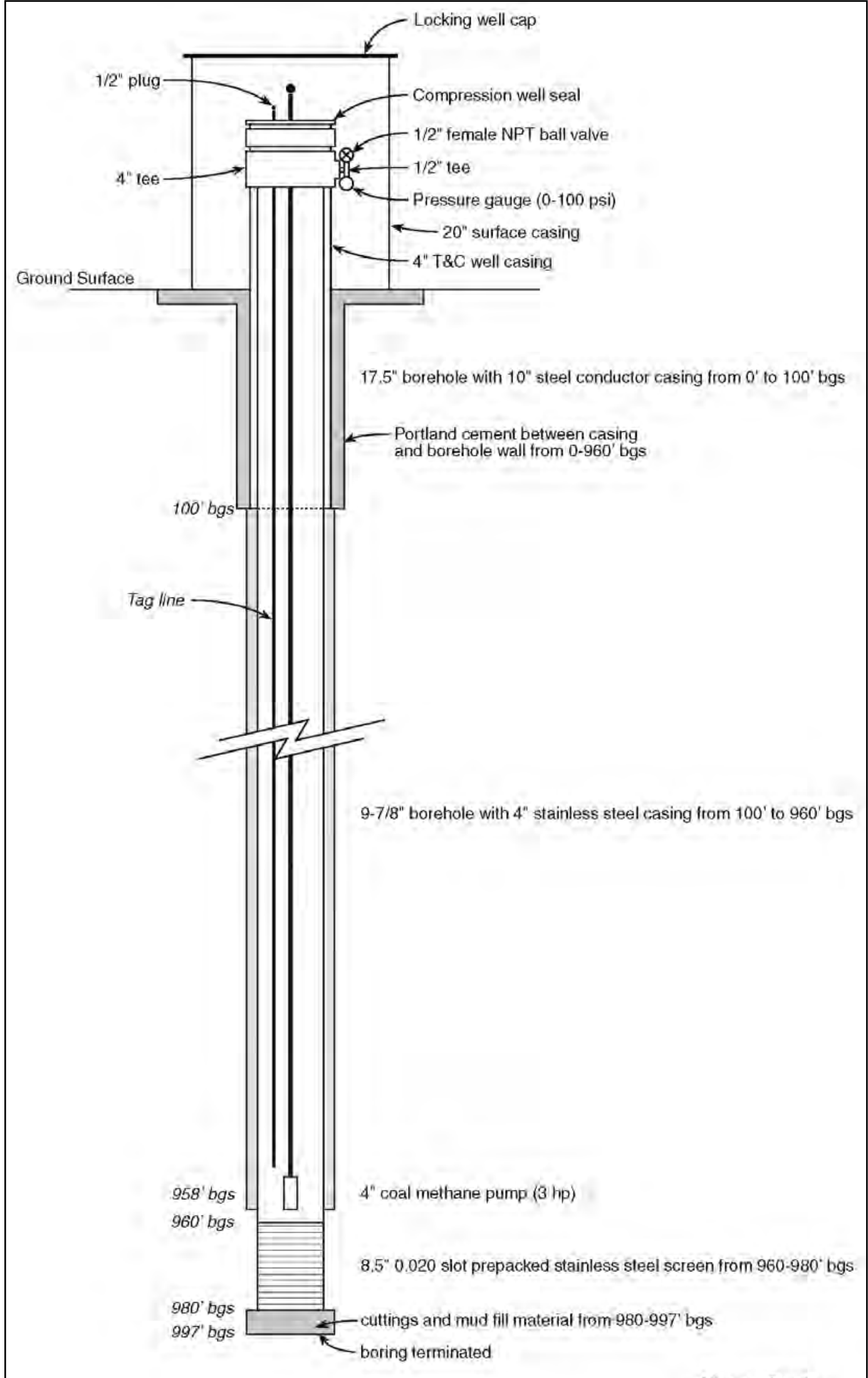

Not to Scale

Figure 6b. Schematic illustrating construction of MW02. 


\section{DRAFT}

construction materials. Examination of resistivity and cuttings indicated elevated resistivity at depths where white coarse-grained sandstone was observed. This relationship was utilized to place screens at both deep monitoring wells at the deepest observed interval of white coarse-grained sand (Figure 7). White coarsegrained sandstones in the area of investigation contain little or no shale and are targeted by local well drillers for domestic well installation. During drilling, mud and cuttings were monitored in an open atmosphere with a TVA-1000B Thermo-Scientific portable flame- and photo-ionization detector (FID/PID) for health and safety monitoring. Comparison of FID and PID readings (PID readings remained at background and are not sensitive to methane) indicates the presence of methane at various intervals from ground surface in MW01 (Figure 7).

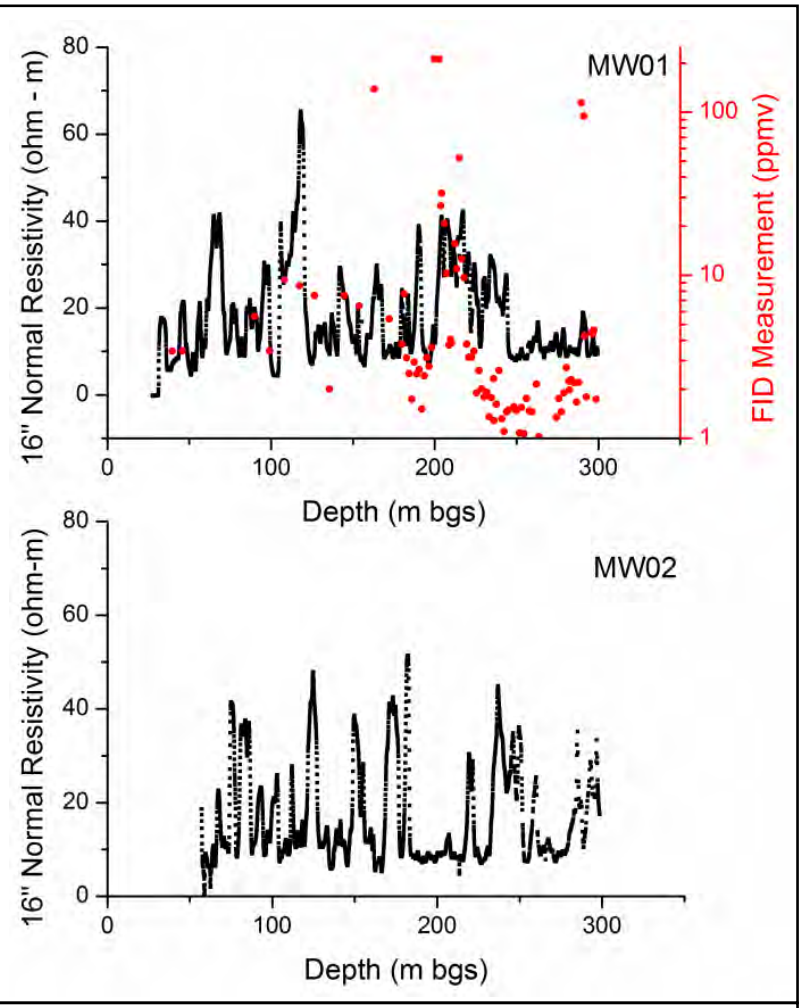

Figure 7. Resistivity as a function of depth in MW01 and MW02. MW01 and MW02 were screened at $233-239 \mathrm{~m}$ and $293-299 \mathrm{~m}$ bgs, respectively, corresponding to elevated resistivity and presence of coarse-grained sandstone. FID readings in MW01 denote detections of methane during open air logging of mud. FID monitoring at MW02 was sporadic and is not illustrated here.

\section{Ground Water Sampling of Deep Monitoring Wells in Phase III and IV}

Ground water in deep monitoring wells was sampled using dedicated explosion proof submersible pumps (10-cm Franklin Electric 3HP). Wells were purged at a flow rate of approximately 5 to $30 \mathrm{~L} / \mathrm{min}$. The rate of pumping was measured using a Model TM0050 in-line turbine flow meter with associated Model FM0208 flow monitor manufactured by Turbines, Inc. Drawdown during pumping was measured with a sonic water level sensor obtained from Eno Scientific, Inc. (Model WS2010 PRO). The flow was split, with one portion going to waste and the other portion going to a flow-cell equipped with a YSI 5600 multiparameter probe to track stabilization of $\mathrm{pH}$ ( $<0.02$ standard units per minute), oxidation-reduction potential ( $<2 \mathrm{mV}$ per minute), specific conductance ( $<1 \%$ per minute), dissolved oxygen (DO), and temperature. Purge volumes prior to sampling ranged from about 200 to $450 \mathrm{~L}$ (Phase III) and 1100 to $1250 \mathrm{~L}$ (Phase IV). Lower purge volumes in Phase III sampling were due to initial gas invasion into the screened intervals that caused cavitation and concern about prolonged pump operation. By the time of Phase IV sampling, disruptive gas invasion was no longer observed and extended purging was possible. Turbidity ranged from 1.7 to 29.7 Nephelometric Turbidity Units (NTUs) in domestic wells (Phase III and IV). Turbidity in MW01 was 7.5 NTUs in Phase III and 7.9 NTUs in Phase IV. Turbidity in MW02 was 28.8 NTUs in Phase III and 24.0 NTUs in Phase IV. Turbidity measurements in MWO1 and MW02 could be impacted by gas exsolution. A photographic log of deep monitoring and domestic well sampling is provided in Appendix D.

In April 2011, the static water level in MW01 prior to

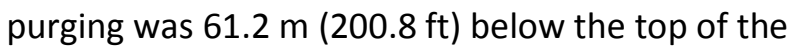
casing (BTOC) measured using the Well Sounder 2010. The initial pumping rate was approximately 27.6 $\mathrm{L} / \mathrm{min}$. The pumping rate declined during purging to approximately $24.2 \mathrm{~L} / \mathrm{min}$ as a result of the increasing depth to water. At approximately $30 \mathrm{~min}$ after the 


\section{DRAFT}

start of purging, the pumping rate was reduced using an in-line valve to $7.6 \mathrm{~L} / \mathrm{min}$. This resulted in

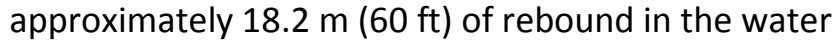
level within the well at the start of sampling (Figure 8). Given that the screen length is only $6.1 \mathrm{~m}(20 \mathrm{ft})$ and that the pump was set approximately $0.6 \mathrm{~m}(2 \mathrm{ft})$ above the screen, this indicates that ground water obtained during sampling was derived from the formation with no component of casing storage. The total volume of water purged at the start of sampling was approximately $1117 \mathrm{~L}$. The static water level in MW02 prior to purging was $80.5 \mathrm{~m}(264.2 \mathrm{ft})$ BTOC measured using the Well Sounder 2010 (April 2011). The initial pumping rate was approximately 18.9 $\mathrm{L} / \mathrm{min}$. The Eno Scientific well sounder was unable to measure the depth to water during most of the purging cycle perhaps due to a more rapid rate of decline in the water level in the casing. Sampling was initiated after approximately $1249 \mathrm{~L}$ of water were removed. The pump cavitated after approximately $1287 \mathrm{~L}$ were purged. The pump was subsequently stopped, allowed to cool, and restarted approximately $10 \mathrm{~min}$ later to complete the sampling.

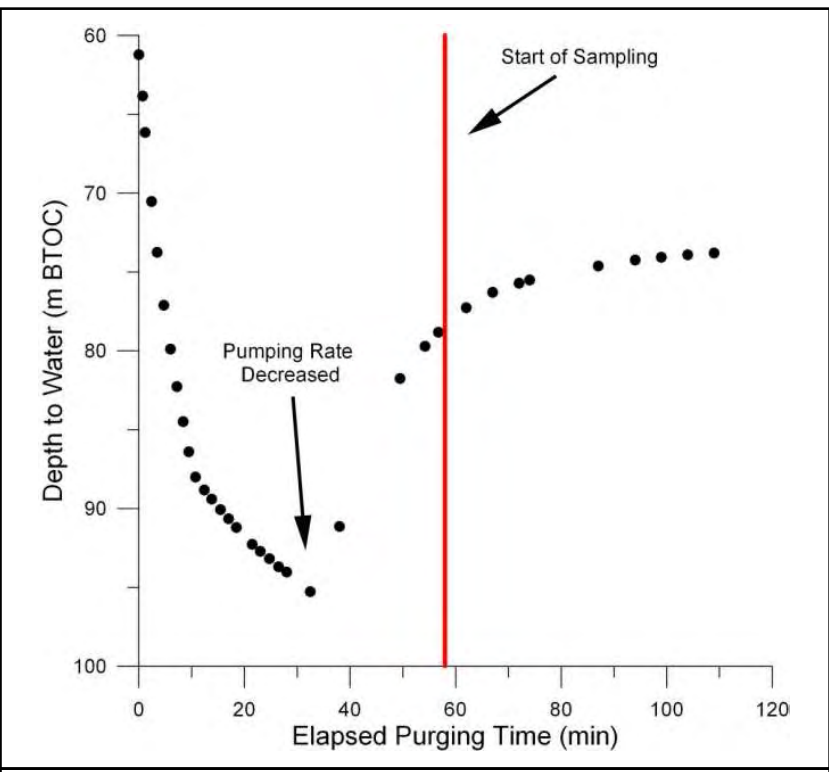

Figure 8. Variation of water level as a function of time in MW01 during Phase IV well purging. The initial pumping rate was $24.2 \mathrm{~L} / \mathrm{min}$. After approximately 30 minutes of purging, the flow rate was decreased to 7.6 $\mathrm{L} / \mathrm{min}$. This reduced flow rate caused partial recovery of the water level and confirmation that formation water was being accessed.
An example of flow-cell readings through the purging of well MW02 is shown in Figure 9. The electrode readings show fairly rapid equilibration of $\mathrm{pH}$ and dissolved oxygen. Oxidation-reduction potential steadily decreased with the rate of change falling into the desired range ( $<2 \mathrm{mV}$ per minute) by the end of purging. Specific conductance readings were typically variable, likely due to continuous off-gassing and bubble formation within the conductivity sensor. After field measurements stabilized, ground water was collected into sample bottles as summarized in Table B1. Samples were collected for a wide range of inorganic, organic, and stable isotope analyses. A 500 $\mathrm{mL}$ sample was collected for field determinations of alkalinity, turbidity, ferrous iron, and dissolved sulfide. Alkalinity was determined onsite by incremental titration of ground water with sulfuric acid. Turbidity measurements were made with a portable meter (Hach 2100Q). Measurements were made for dissolved sulfide and ferrous iron using the methylene blue and 1,10-phenanthroline colorimetric methods, respectively (APHA 1998a,b). Samples collected for dissolved gases, volatile organic compounds, semivolatile organic compounds, diesel-range organics, gasoline-range organics, glycols, low molecular weight acids, and $\delta^{13} \mathrm{C} / \delta \mathrm{D}$ of methane were not filtered. $\delta \mathrm{D}$ is defined as

$$
\delta \mathrm{D}(\% \mathrm{\%})=\left[\frac{\left({ }^{2} \mathrm{H} /{ }^{1} \mathrm{H}\right) \text { sample }}{\left({ }^{2} \mathrm{H} /{ }^{1} \mathrm{H}\right) \text { standard }}-1\right] \times 1000
$$

where the standard is the Vienna Standard Mean Ocean Water Standard (VSMOW). Samples collected for metals, anions, nutrients, dissolved organic carbon, dissolved inorganic carbon (DIC), $\delta^{13} \mathrm{C}$ of dissolved inorganic carbon, and $\delta^{18} \mathrm{O} / \delta \mathrm{D}$ of water were filtered onsite using 0.45 -micron pore-size, disposable-capsule filters. $\delta^{18} \mathrm{O}$ is defined as

$$
\delta^{18} \mathrm{O}(\% 0)=\left[\frac{\left({ }^{18} \mathrm{O} /{ }^{16} \mathrm{O}\right) \text { sample }}{\left({ }^{18} \mathrm{O} /{ }^{16} \mathrm{O}\right) \text { standard }}-1\right] \times 1000
$$

where the standard is the VSMOW. 


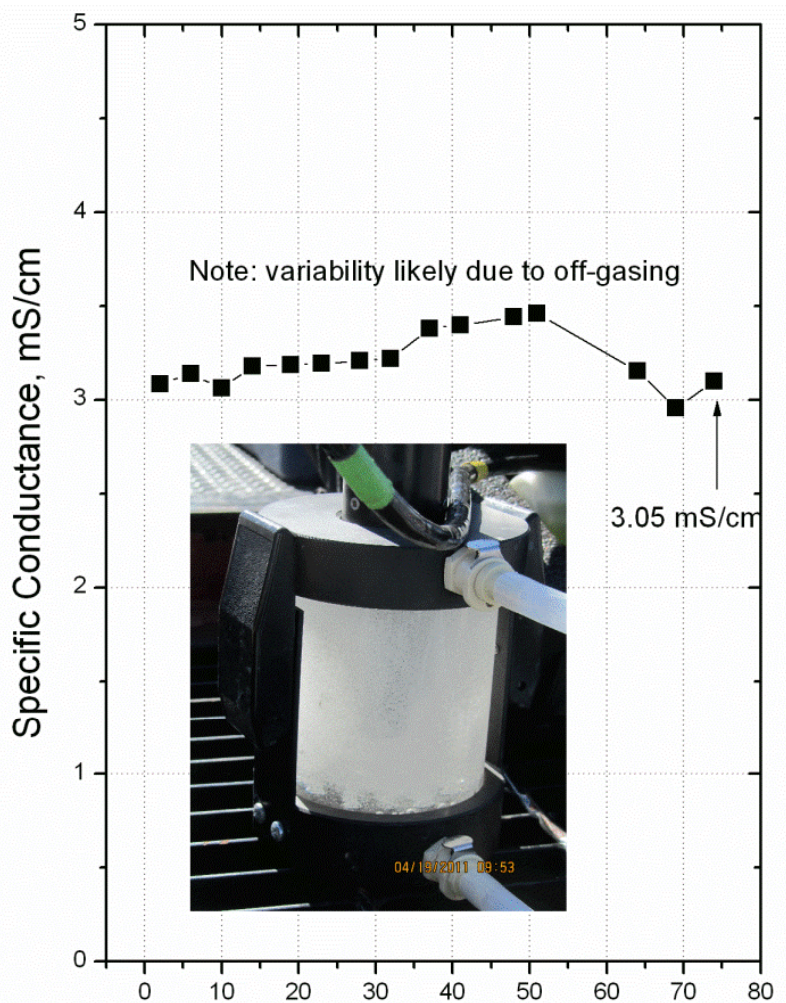

Time, $\min$

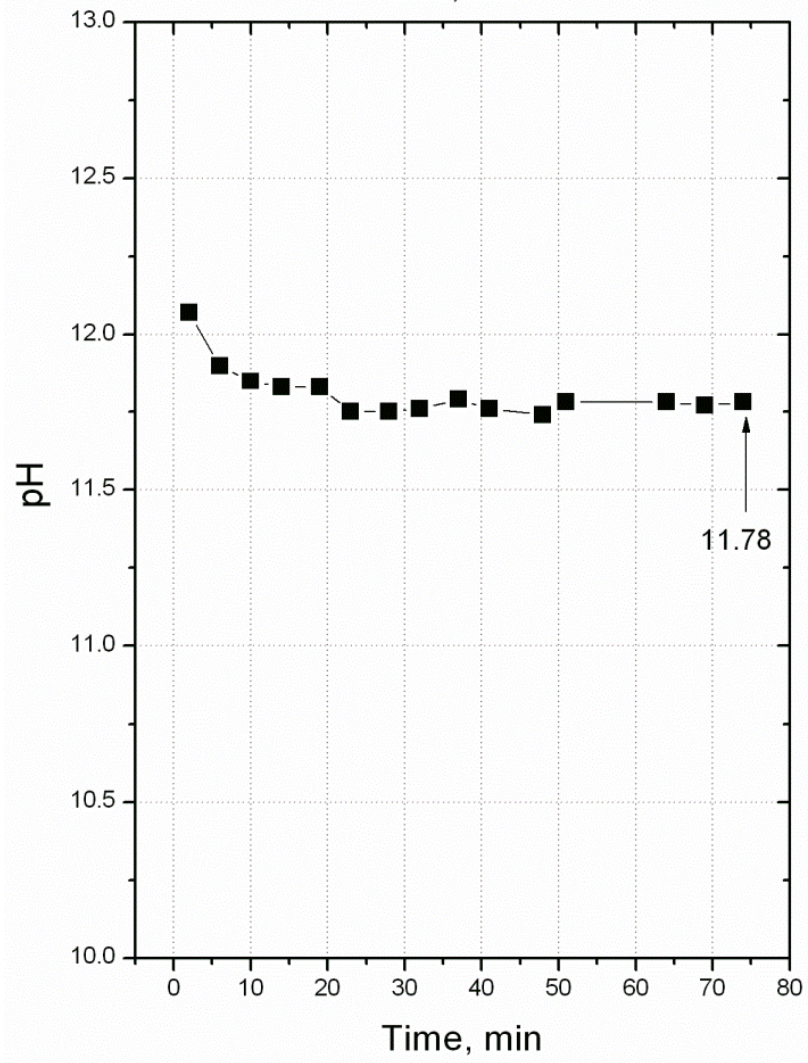

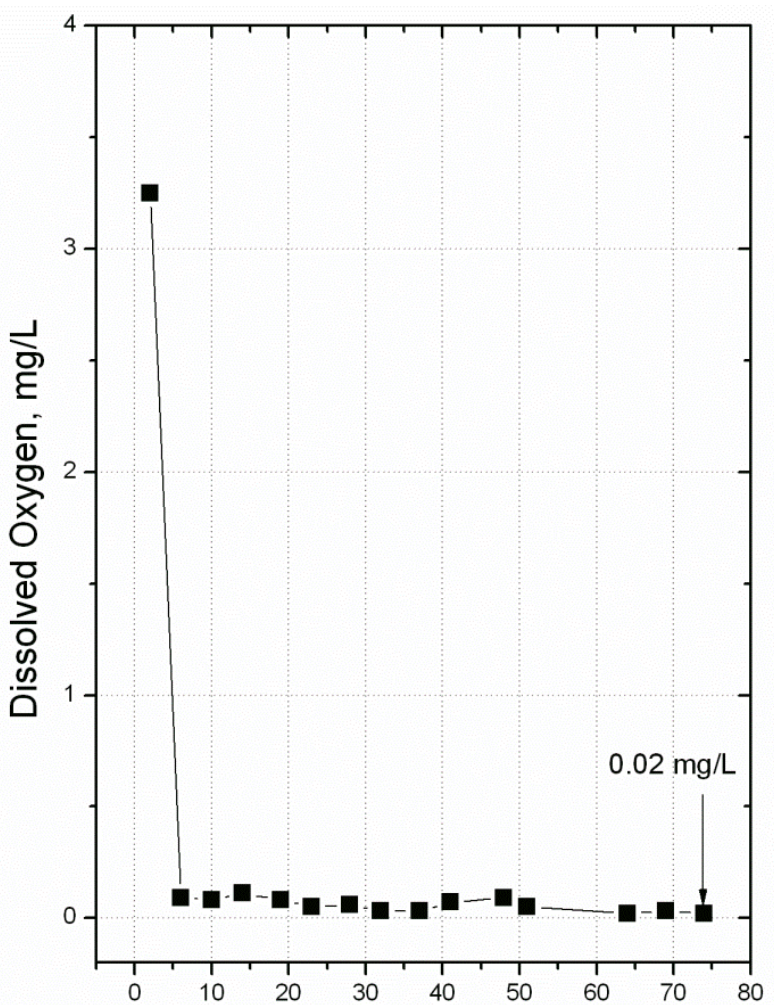

Time, $\min$

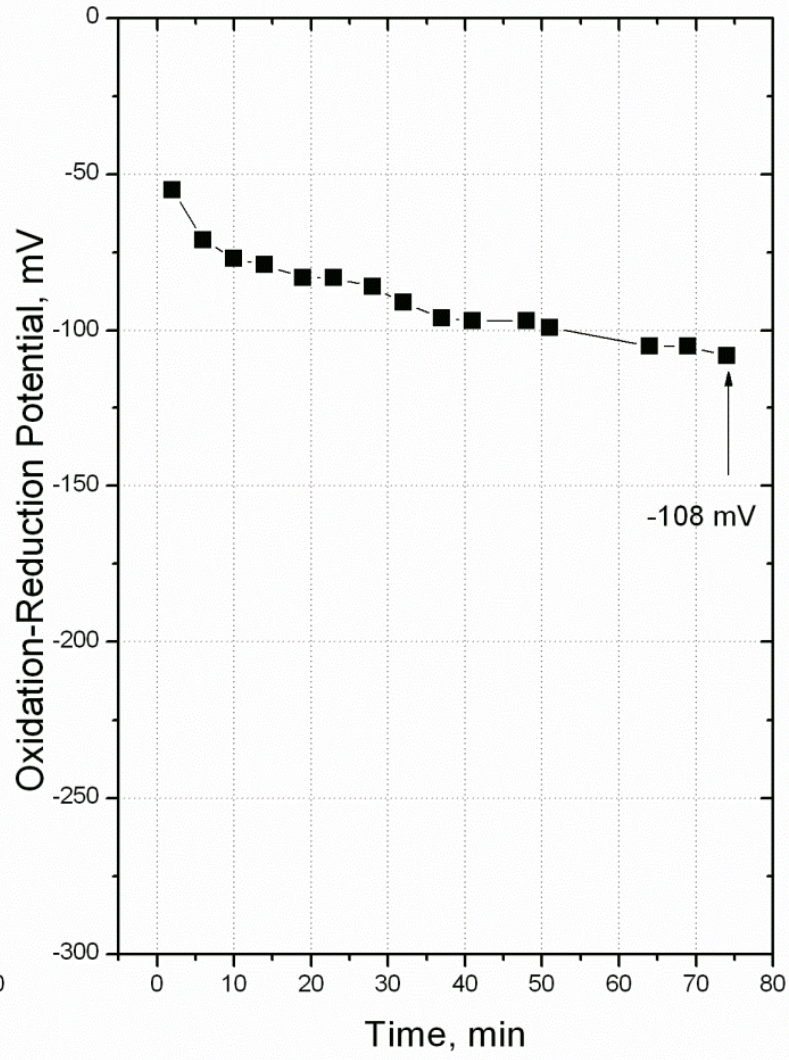

Figure 9. Flow-cell readings as a function of time for specific conductance, dissolved oxygen, $\mathrm{pH}$, and oxidation-reduction potential (well MW02, Phase IV sampling). 


\section{DRAFT}

Sample preservation and holding time criteria are listed in Table B1. Field quality control (QC) samples are summarized in Table B2. These included several types of blanks, duplicate samples, and field matrixspike samples. All of these QC sample types were collected, preserved, and analyzed using identical methodologies as used for the water samples collected in the field (Table B1). Quality assurance/quality control ( $Q A / Q C$ ) requirements for analysis of metals and major ions are summarized in Table B3. QA/QC requirements for analysis of dissolved gases, DIC/DOC, VOCs, low molecular weight acids and stable isotopes of water are summarized in Table B4. QA/QC requirements for analysis of semivolatile organic compounds (SVOCs), GRO, and DRO are summarized in Table B5. QA/QC requirements for analysis of glycols are summarized in Table B6. Results of Phase III and Phase IV blank samples are provided in Tables B7 to B12. Detections observed in the blank samples were generally very low-level and generally much lower than concentrations measured in the deep monitoring wells. Some blank samples showed detections of acetone $(1 \mu \mathrm{g} / \mathrm{L}$ ), m,p-xylene (up to $0.7 \mu \mathrm{g} / \mathrm{L}$ ), toluene (up to $0.5 \mu \mathrm{g} / \mathrm{L}$ ), benzoic acid ( $3 \mu \mathrm{g} / \mathrm{L}$ ), and tetraethylene glycol $(3 \mu \mathrm{g} / \mathrm{L})$. Concentrations of these analytes in MWO1 and MWO2 in Phase III and Phase IV sampling ranged from: 80 to $641 \mu \mathrm{g} / \mathrm{L}$ (acetone), nondetect to $750 \mu \mathrm{g} / \mathrm{L}$ (total xylenes), 0.6 to $617 \mu \mathrm{g} / \mathrm{L}$ (toluene), 209 to $457 \mu \mathrm{g} / \mathrm{L}$ (benzoic acid), and 7 to 27 $\mu \mathrm{g} / \mathrm{L}$ (tetraethylene glycol). Detected concentrations of toluene (Phase III), xylene (Phase IV), and tetraethylene glycol (Phase IV) in MW01 are within about 2 times the detected levels of these chemicals in some of the applicable blank samples.

Consequently, reported detections and concentrations of these chemicals in MW01 were used cautiously in this study. In one of the six blank samples collected for DRO, an elevated concentration of $135 \mu \mathrm{g} / \mathrm{L}$ or 6 times the reporting limit was observed (Table B12); all other DRO blank samples were non-detects ( $<20$ $\mu \mathrm{g} / \mathrm{L})$. Concentrations of DRO in the deep monitoring wells ranged from 634 to $4050 \mu \mathrm{g} / \mathrm{L}$.
Duplicate samples were collected in three locations during Phase III and Phase IV sampling activities. Results for the duplicate analyses are presented Tables B13 and B14. Relative percent differences (RPDs) were generally less than $10 \%$ for most inorganic constituents indicating very good precision. RPD is defined as

$$
\mathrm{RPD}=\left[\frac{\mathrm{x} 1-\mathrm{x} 2}{(\mathrm{x} 1+\mathrm{x} 2) / 2}\right] \times 1000
$$

where $x 1=$ sample and $x 2=$ sample duplicate. RPDs for methane, volatile organic compounds, and semivolatile organic compounds were generally less than 25\% (Table B14). The lower reproducibility for these compounds detetected in MW02 is likely due to difficulties in sampling and preserving water that is oversaturated in gas.

Major ions were quality checked by calculating ion balances. The AqQA (v.1.1.1) software package was used to evaluate cation/anion balance, which ranged from $<0.1$ to $17.2 \%$ with $90 \%$ of the calculated balances better than $5 \%$.

Geochemical equilibria in ground water were evaluated with the Geochemist's Workbench package (version 8; Bethke 1996). Speciation and mineral equilibria calculations were made by entering the concentrations of major cations $\left(\mathrm{Na}^{+}, \mathrm{K}^{+}, \mathrm{Ca}^{2+}, \mathrm{Mg}^{2+}\right)$, anions $\left(\mathrm{Cl}^{-}, \mathrm{SO}_{4}{ }^{2-}, \mathrm{HCO}_{3}{ }^{-}\right), \mathrm{pH}$, and temperature. For domestic well samples, bicarbonate concentrations were determined from alkalinity measurements. For the deep monitoring wells, because alkalinity included a significant contribution from hydroxide, concentrations of dissolved inorganic carbon were used for bicarbonate/carbonate input. Activity corrections were made using the Debye-Hückel equation. The LLNL (EQ3/6) thermodynamic database was selected for use in the calculations (Delany and Lundeen 1990). Model simulations were also conducted by tracing alkaline-addition titration paths. In order to do this, an additional entry was made to 


\section{DRAFT}

the thermodynamic database describing the solubility of $\mathrm{KOH}\left(\log \mathrm{K}=24.9 ; \mathrm{KOH}_{(\mathrm{s})}+\mathrm{H}^{+}=\mathrm{K}_{(\mathrm{aq})}^{+}+\mathrm{H}_{2} \mathrm{O}_{(\mathrm{I})}\right)$.

Audits of Data Quality (ADQs) were conducted by a contractor (independent of this investigation) or an EPA QA Manager for all analyses conducted outside EPA's Contract Laboratory Program (CLP) with the exception of data collected during Phase I, which is till in progress. This included data from EPA's Region VIII laboratory in Golden, Colorado, EPA's Region III laboratory in Fort Mead, MD, EPA's Office of Research and Development Laboratory in Ada, Oklahoma, and Isotech Laboratories in Champaign, Illinois. A technical systems audit of Isotech Laboratories included an on-site visit by the independent contractor and EPA QA Manager. Two on-site field technical system audits were also conducted by the independent contractor and the EPA QA Manager to ensure compliance with the Category I (highest of four levels in EPA) Quality Assurance Project Plan established for this site for ground water and gas sample collection.

\section{Gas Sampling from Casing of Deep Monitoring Wells in Phase III and IV}

Gas samples were collected from casing of deep monitoring wells by connecting a $12.7 \mathrm{~mm}$ NPT stainless-steel Swagelok quick-connect body and a Swagelok single-end shutoff stem to a $12.7 \mathrm{~mm}$ brass ball valve. The stem was connected to $6.35 \mathrm{~mm}$ internal diameter Tygon Masterflex tubing and a 0.5 liter Cali-5 Bond gas sampling bag equipped with a Leur-Fit Valve $^{\mathrm{TM}}$ and a Leur-taper Quick-Mate ${ }^{\mathrm{TM}}$ connector. A Masterflex $\mathrm{E} / \mathrm{S}$ portable peristaltic pump was used to extract gas at $1 \mathrm{~L} / \mathrm{min}$. Samples were collected after stabilization ( $\pm 1 \%$ ) of $\mathrm{O}_{2}, \mathrm{CO}_{2}$, and $\mathrm{CH}_{4}$ readings on a GEM-2000 Plus CES-LANDTEC portable gas analyzer.

\section{Domestic Well Sampling for Methane Using a Closed System in Phase IV}

During the Phase IV sample event, water from domestic wells was screened using a Thermo-Scientific
TVA-1000B portable FID/PID and a 10 L Plexiglas sparge cell (Figure 10). Samples from domestic wells were routed through a closed (no contact with the atmosphere to avoid offgassing) sample train and collected in 0.5 L Cali-5 Bond gas sample bags. Ultrapure $\mathrm{N}_{2}$ gas was introduced into the bags and placed on a rotary shaker for one hour prior to headspace analysis on site using a portable GC equipped with a thermal conductivity detector. Portable FID readings provided an immediate indication of methane in well water prior to GC analysis. Samples were also submitted to EPA's Office of Research and Development (ORD) laboratory in Ada, Oklahoma for analysis of dissolved gases.

\section{Review of Borehole Geophysical Logs}

Borehole geophysical logs available on line from WOGCC were utilized to map lithology in the area of investigation. Depending upon the specific well, various combinations of natural gamma, resistivity, self-potential, density, and neutron porosity logs were utilized. Log resolution was sufficient to discern distinct layers of shale $1 \mathrm{~m}$ or greater in thickness but not sufficient to differentiate coarse-, medium-, and fine-grained sandstones nor sandstones containing various proportions of shale. Descriptions of cuttings logged during installation of deep monitoring wells and domestic wells obtained from a local driller were used for near surface description. Neither grain size nor proportions of shale in sandstone were differentiated in near surface sandstones to maintain consistency with descriptions from geophysical logs. Lithology in the area of investigation is highly variable and difficult to correlate from borehole to borehole, even for boreholes in close proximity to one another consistent with other observations in the Wind River Formation (Osiensky 1984). Sandstone and shale layers appeared thin and of limited lateral extent, again consistent with previous observations of lithology in the Wind River Formation (Single 1969, Flores and Keighin 1993). 


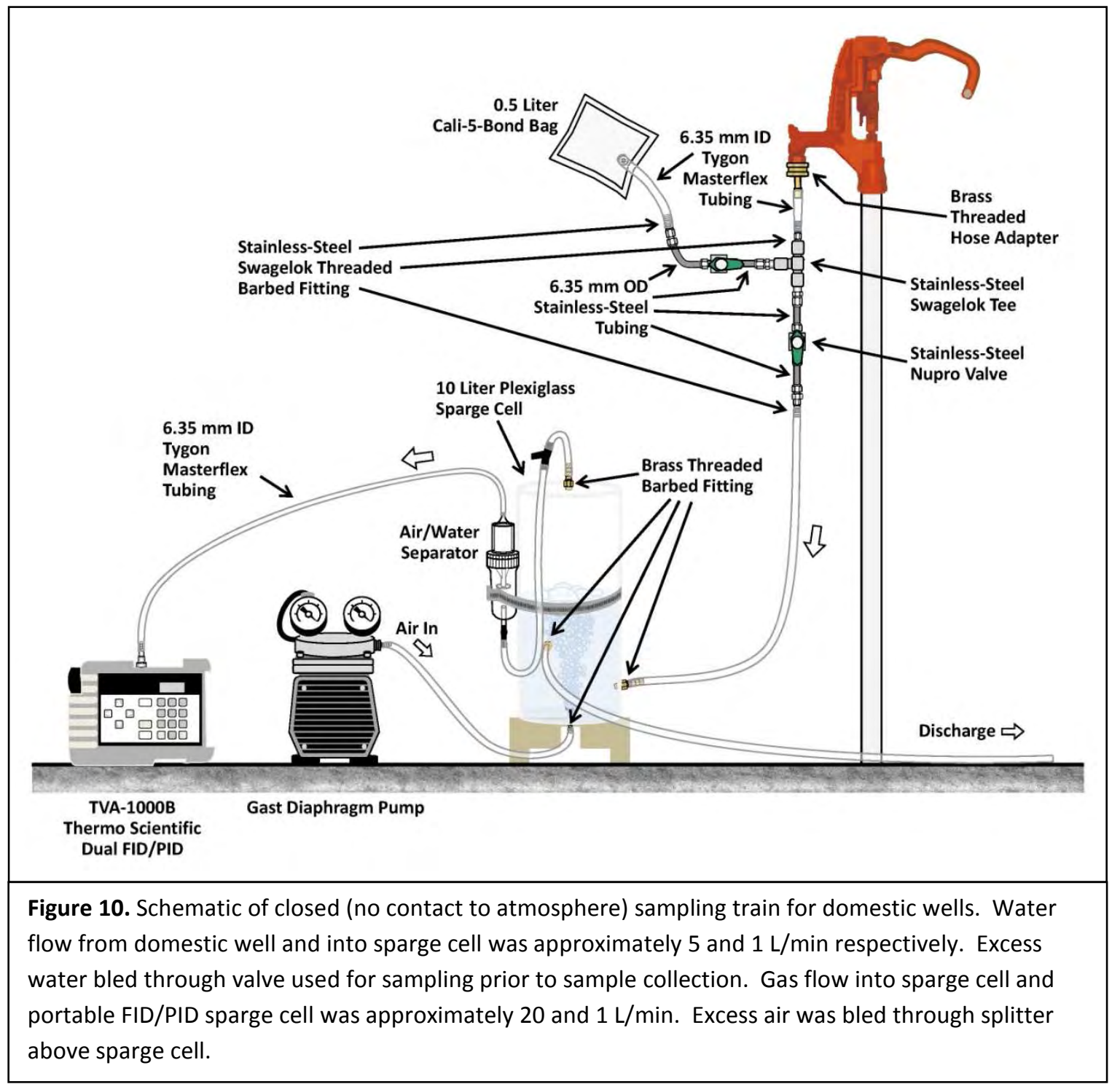

\section{Review of Cement Bond/Variable Density Logs}

Cement bond/variable density (CBL/VDL) logs, available for less than half of production wells, were obtained online from WOGCC to evaluate well integrity. Sporadic bonding is defined as an interval having an amplitude $(\mathrm{mV})$ greater than $\mathrm{A}_{80}$ (EPA 1994) where

$$
A_{80}=10^{0.2 \log A_{0}+0.8 \log A_{100}}
$$

and $A_{80}, A_{0}$, and $A_{100}=$ amplitude at $80 \%, 0 \%$, and $100 \%$ bond respectively. $A_{0}$ typically corresponds to amplitude in free pipe whereas $A_{100}$ corresponds to the best-bonded interval on the CBL. Examples of "no cement", "sporadic bonding", and "good bonding" are provided in Appendix E.
CBL/VDLs provide an average volumetric assessment of the cement in the casing-to-formation annular space and are considered low resolution tools compared to ultrasonic imaging tool logs which provide a high-resolution $360^{\circ}$ scan of the condition of the casing-to-cement bond (Bybee 2007). Acoustic imaging tools do not directly measure cement seal. Communication of fluids between intervals has been observed to occur despite indication of "good to excellent" cement bond on acoustic logs (Boyd et al. 2006). All CBL/VDLs available from WOGCC reflect pre-hydraulic fracturing conditions. 


\section{DRAFT}

3.0

\section{Results and Discussion}

\section{Ground Water and Soil Sample Results Near Three Pits}

There are at least 33 pits previously used for storage/disposal of drilling wastes, produced water, and flowback fluids in the area of investigation.

Discussions are ongoing with stakeholders to determine the location, delineate the boundaries, and extent (areal and vertical) of contamination associated with these pits. The operator has initiated remediation of selected pit areas. Concentrations of $\mathrm{DRO}$, gasoline range organics (GRO), and total purgeable hydrocarbons (TPH) detected in soil samples adjacent to three pits investigated in Phase II were as high as 5010,1760, and $6600 \mathrm{mg} / \mathrm{kg}$, respectively (EPA 2010). Concentrations of GRO, DRO, and TPH in ground water samples from shallow $(4.6 \mathrm{~m}$ bgs) monitoring wells were as high as $2.4,39$, and 3.8 $\mathrm{mg} / \mathrm{L}$, respectively (EPA 2010). A wide variety of organic compounds including benzene and $\mathrm{m}, \mathrm{p}$ xylene were detected at concentrations up to 390 and $150 \mu \mathrm{g} / \mathrm{L}$, respectively (EPA 2010), indicating pits as a source of shallow ground water contamination in the area of investigation. EPA's maximum concentration level (MCL) for benzene is $5 \mu \mathrm{g} / \mathrm{L}$.

\section{Inorganic Geochemistry}

Inorganic geochemical results for ground water (all phases) are summarized in Table A2a and Figure 11. Major ion chemistry of ground water in the Pavillion area varies as a function of aquifer depth. Shallow ground waters (< $31 \mathrm{~m}$ bgs) collected from drinking water wells and stock wells are near-neutral $(\mathrm{pH} 7.7 \pm$ $0.4, n=19$ ) (Figure 12) and display calciumbicarbonate composition. With increasing depth, ground water becomes moderately alkaline $(\mathrm{pH} 9.0 \pm$ 1.0, $n=55$ ) (Figure 12), and with only one exception (MW02), is dominated by sodium and sulfate as the major cation/anion pair (Figures 11 and 12, Table A2a). This gradient in $\mathrm{pH}$ and water chemistry likely arises from the wide-scale surface application of irrigation water from the Wind River to support

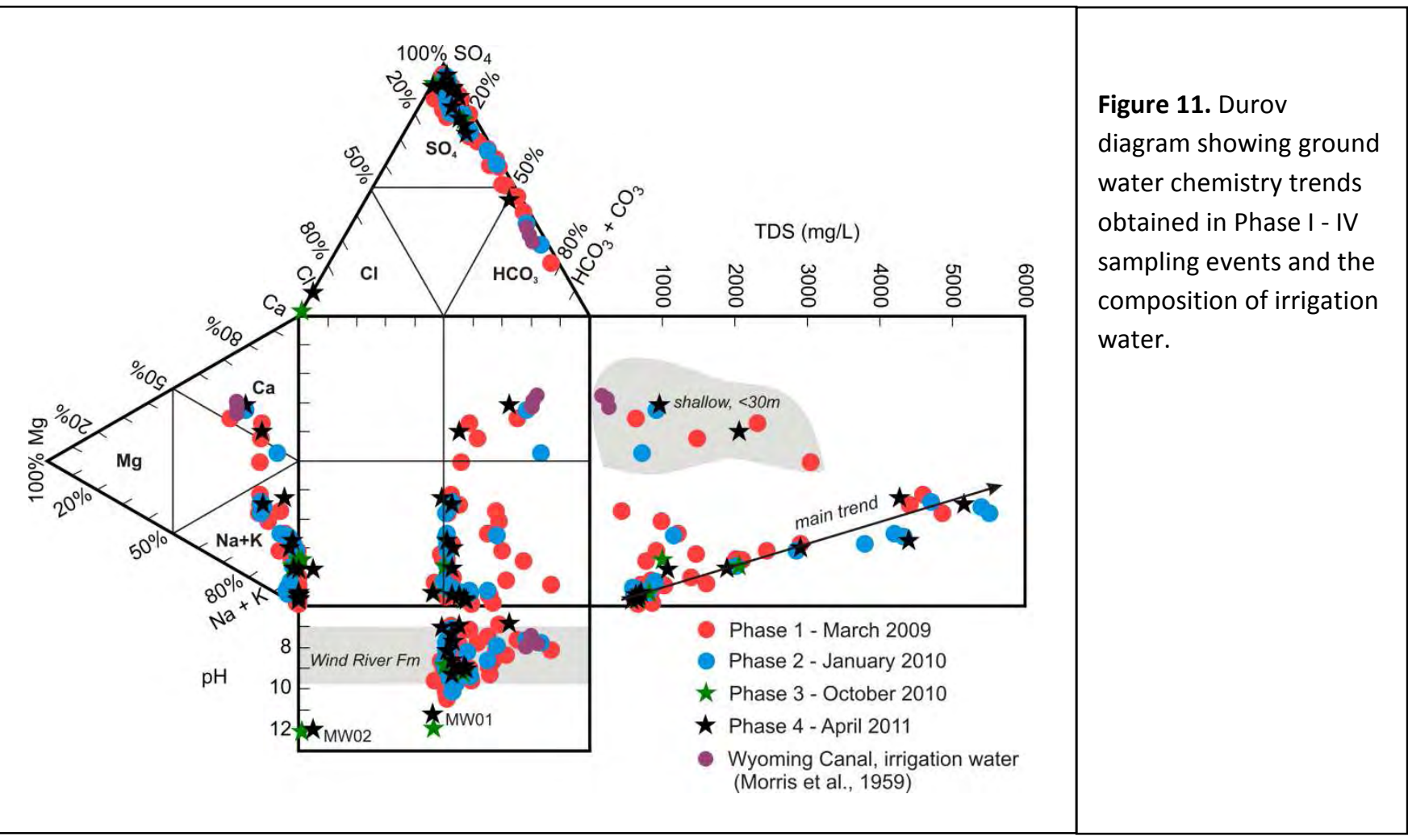


DRAFT
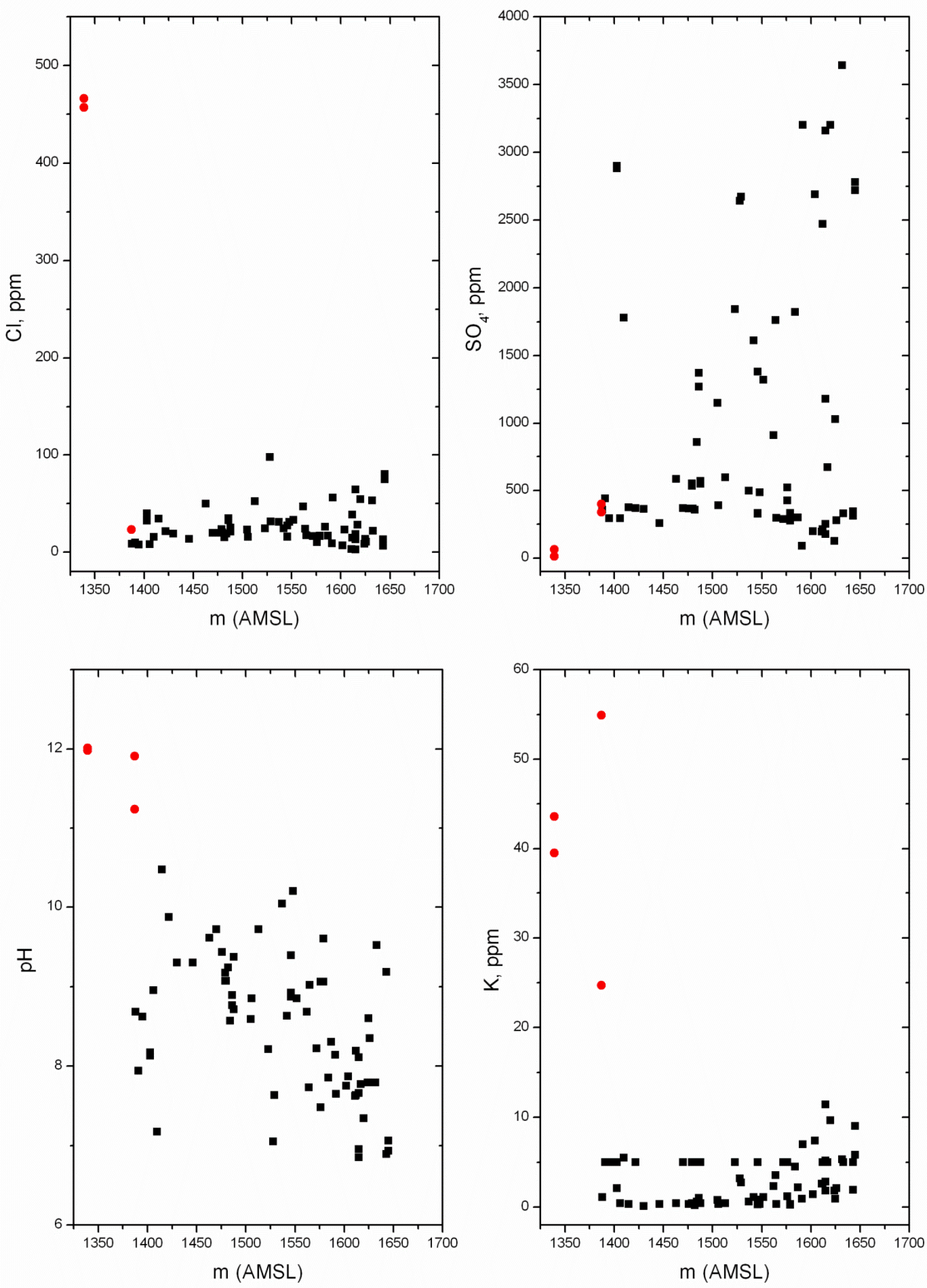

Figure 12. Depth trends of chloride, $\mathrm{pH}$, sulfate, and potassium (filled black squares $=$ domestic wells, filled red circles = monitoring wells). 


\section{DRAFT}

crop growth since irrigation water appears to represent an endmember composition (Figure 11).

The chemical alteration from bicarbonate-type recharge water to sulfate-type ground water involves multiple water-rock interactions, including salt dissolution, carbonate mineralization, and exchange of divalent cations for sodium (Morris et al. 1959). Total dissolved solids concentrations are $<6000 \mathrm{mg} / \mathrm{L}$ in all ground water samples collected to depths up to $296 \mathrm{~m}$ (Figure 11).

Saturation indices of gypsum $\left(\mathrm{CaSO}_{4} \cdot 2 \mathrm{H}_{2} \mathrm{O}\right)$ and calcite $\left(\mathrm{CaCO}_{3}\right)$, plotted against sulfate and calcium concentrations, are shown in Figure 13. The trend for gypsum saturation suggests that sulfate concentrations in the aquifer are limited by the solubility of gypsum. Ground water is also close to equilibrium with calcite which likely is an important control on $\mathrm{pH}$ and concentrations of calcium and bicarbonate. Some residents have described the development of particulates in ground water samples collected and stored in glass jars. Precipitates that formed from PGDW05 ground water were analyzed by powder X-ray diffraction and found to be dominantly calcite. Because calcite has retrograde solubility, precipitation of calcite is possibly triggered by warming calcite-saturated ground water to ambient conditions.

The geochemistry of ground water from the deep monitoring wells is distinctive from that in the domestic wells. Chloride enrichment in monitoring well MW02 is 18 times the mean chloride concentration $(25.6 \mathrm{mg} / \mathrm{L})$ observed in ground water from domestic wells. Chloride enrichment in this well is significant because regional anion trends tend to show decreasing $\mathrm{Cl}$ concentrations with depth. The mean potassium concentration in domestic wells
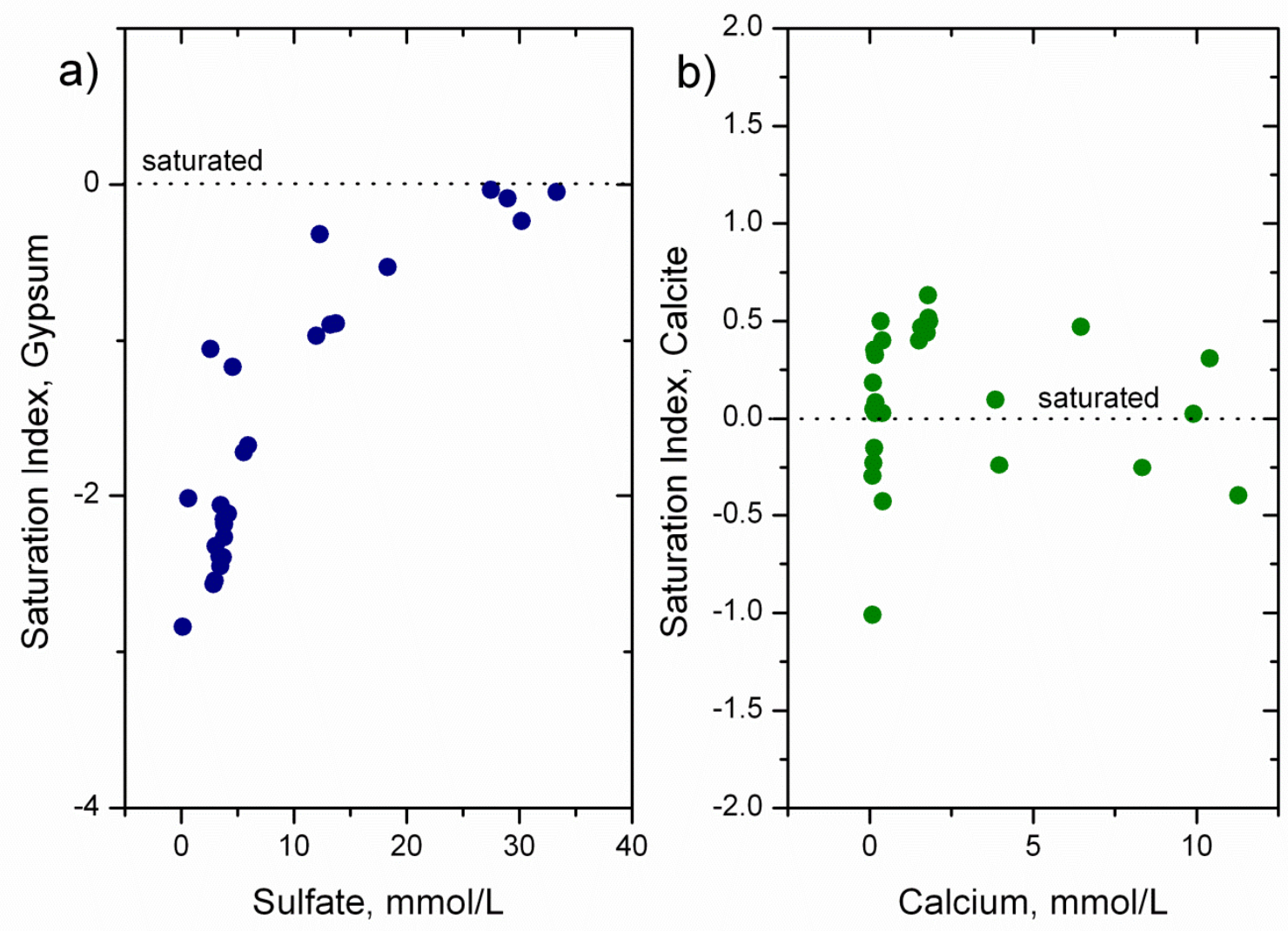

Figure 13. Saturation indices for (a) gypsum versus sulfate concentration and (b) calcite versus calcium concentration. Saturation Index is equal to the logarithm of the ratio of the ion activity product to the mineral solubility product. A Saturation Index of 0 corresponds to chemical equilibrium; values less than 0 and greater than 0 correspond to undersaturated and oversaturated conditions, respectively. 


\section{DRAFT}

screened to $244 \mathrm{~m}$ bgs is $3 \mathrm{mg} / \mathrm{L}$, with $99 \%$ of values $<10 \mathrm{mg} / \mathrm{L}$. Potassium enrichment in MW01 and MW02 is between 8.2 and 18.3 times the mean value of domestic wells (Table A2a). pH values in MW01 and MW02 are highly alkaline (11.2-12.0), above the $\mathrm{pH}$ range observed in domestic wells (6.9-10), and above the $\mathrm{pH}$ range previously reported for the Wind River Formation (Plafcan et al. 1995, Daddow 1996). In the deep monitoring wells, up to $94 \%$ of the total alkalinity is contributed by hydroxide. In addition, the monitoring wells show low calcium, sodium, and sulfate concentrations compared to the general trend observed in domestic well waters (Figure 14).

The high $\mathrm{pH}$ measured in the deep monitoring wells was unusual and unexpected. Although ground water $\mathrm{pH}$ in these wells was $>11$, total alkalinity was not particularly high ( $<500 \mathrm{mg} / \mathrm{kg}$ ), and as already noted up to $94 \%$ of the total alkalinity was present as hydroxide (see charge balance calculations, Table A2b). Alkalinity contributed by carbonate/bicarbonate was less than the hydroxide component. In fact, inorganic carbon concentrations were so low in $\mathrm{MWO2}$ as to prevent the measurement of $\delta^{13} \mathrm{C}$ of dissolved inorganic carbon. Presence of hydroxide alkalinity suggests strong base addition as the causative factor for elevated $\mathrm{pH}$ in the deep monitoring wells. The possibility of cement/grout intrusion into the screened intervals was considered as a possibility for both monitoring wells, although precautions were taken to prevent downward migration of cement during well construction. Cement intrusion typically leads to $\mathrm{pH}$ values between 10 and 11 , lower than the $\mathrm{pH}$ values measured in the deep monitoring wells (Gibb et al. 1987). Prolonged purging did not show decreasing $\mathrm{pH}$ trends (e.g., Figure 9) and water chemistry results indicate that ground water from the wells was highly undersaturated with respect to cement phases (e.g., portlandite), suggesting that cement was not the cause of elevated $\mathrm{pH}$.

In order to gain additional insight, reaction path modeling was conducted to evaluate $\mathrm{pH}$ response to addition of strong base (potassium hydroxide, $\mathrm{KOH}$ ).
Geochemical modeling was carried out by using ground water compositions for PGDW49, PGDW20, and PGDW32 (initial pH 7.3, 8.9, and 9.9, respectively). Modeled titration results are shown in Figure 15a; $\mathrm{pH}$ is plotted versus the mass of $\mathrm{KOH}$ added per $\mathrm{kg}$ of solution. Model titration results vary as a function of ground water composition. Samples PGDW20 and PGDW32 have Na-SO ${ }_{4}$-type compositions typical of deeper portions of the aquifer. In both of these cases, attainment of $\mathrm{pH}$ values between 11.2 and 12.0 requires small quantities of $\mathrm{KOH}$ addition $(<250 \mathrm{mg}$ $\mathrm{KOH}$ per kg of solution). Sample PGDW49 is elevated in $\mathrm{Ca}^{2+}$ and $\mathrm{Mg}^{2+}$, lower in $\mathrm{pH}$, and typical of shallower ground water compositions. In this case, significantly more $\mathrm{KOH}$ addition is required to attain $\mathrm{pH}$ values observed in the monitoring wells. The first derivative of the titration curve, or buffer intensity, is shown in Figure 15b. The buffer intensity indicates that ground water compositions like PGDW20 and PGDW32 inherently have little resistance to $\mathrm{pH}$ change up to about $\mathrm{pH} 12$, at which point increased $\mathrm{KOH}$ additions are necessary to further increase $\mathrm{pH}$. PGDW49 shows a broad peak on the buffer intensity diagram $(\mathrm{pH} 10$ to 11) which reflects precipitation reactions to form calcium carbonate and magnesium hydroxide, reactions that consume hydroxide and therefore limit $\mathrm{pH}$ increases, until divalent cations are completely consumed. The model results clearly show that ground water typical of the Pavillion aquifer below $100 \mathrm{~m}$ depth (Na-SO $\mathrm{S}_{4}$-type composition) is especially vulnerable to the addition of strong base, with small $\mathrm{KOH}$ additions driving significant upward $\mathrm{pH}$ changes.

Paired values of $\delta^{18} \mathrm{O}$ and $\delta^{2} \mathrm{H}$ in ground water samples plot below the Global Meteoric Water Line (Figure 16; -16.6 to $-12.4 \%$ o $\delta^{18} \mathrm{O}$ and -129.2 to $-97.4 \%$ o $\delta^{2} \mathrm{H}$ ). Shallow ground water samples generally tend to be depleted in ${ }^{18} \mathrm{O}$ and ${ }^{2} \mathrm{H}$ compared to deeper ground water samples and may be more reflective of local recharge. Ground water isotope data from the deep monitoring wells (red circles, Figure 16) follow along the same $\delta^{18} \mathrm{O}$ versus $\delta^{2} \mathrm{H}$ trajectory established by the domestic well data, suggesting similar recharge and evolutional paths (e.g., Bartos et al. 2008). 

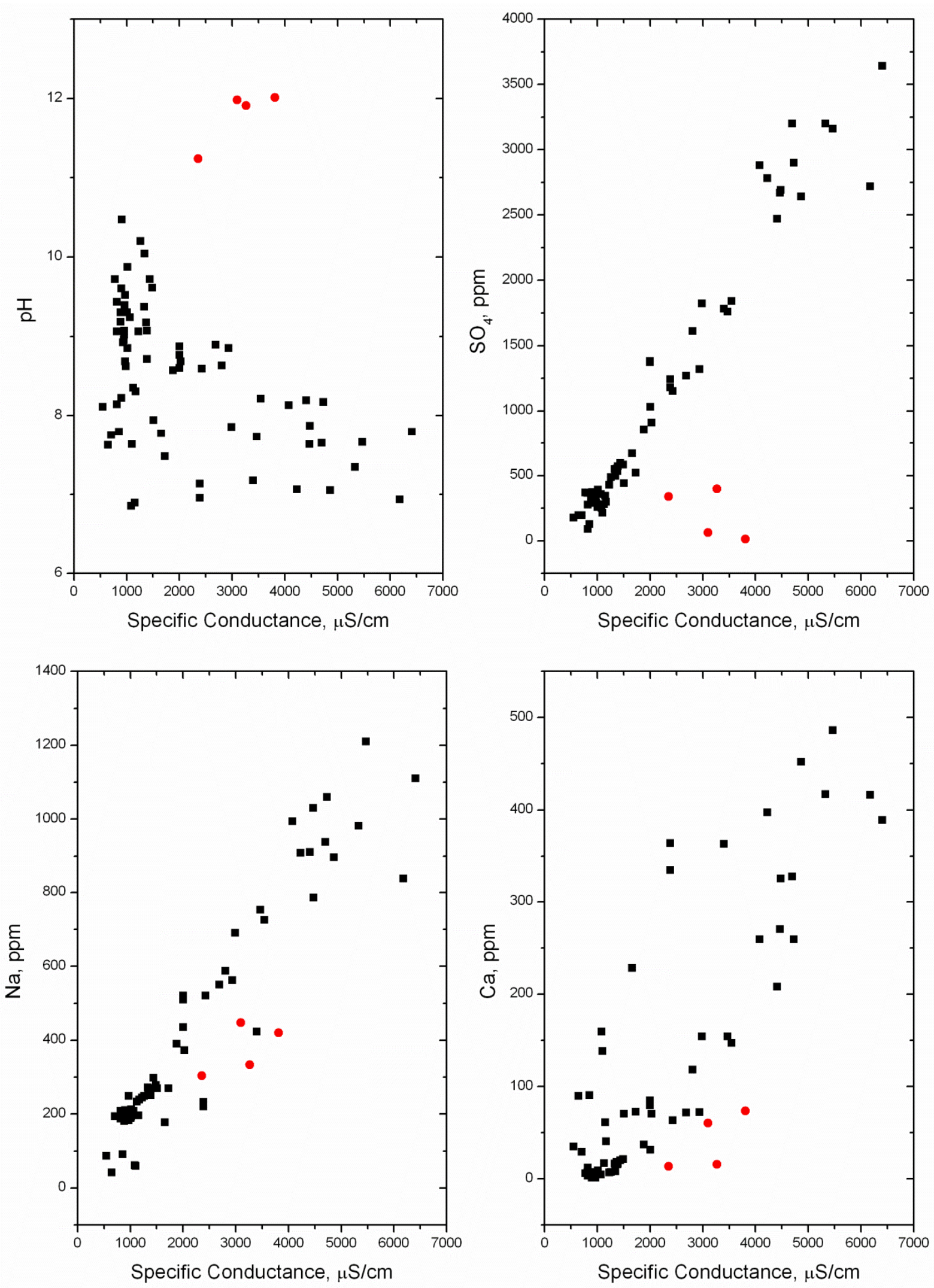

Figure 14. Concentration trends versus specific conductivity. Note the monitoring wells show high $\mathrm{pH}$ and low sulfate, calcium, and sodium relative to the general trend observed in the domestic wells (filled black squares = domestic wells, filled red circles $=$ monitoring wells). 

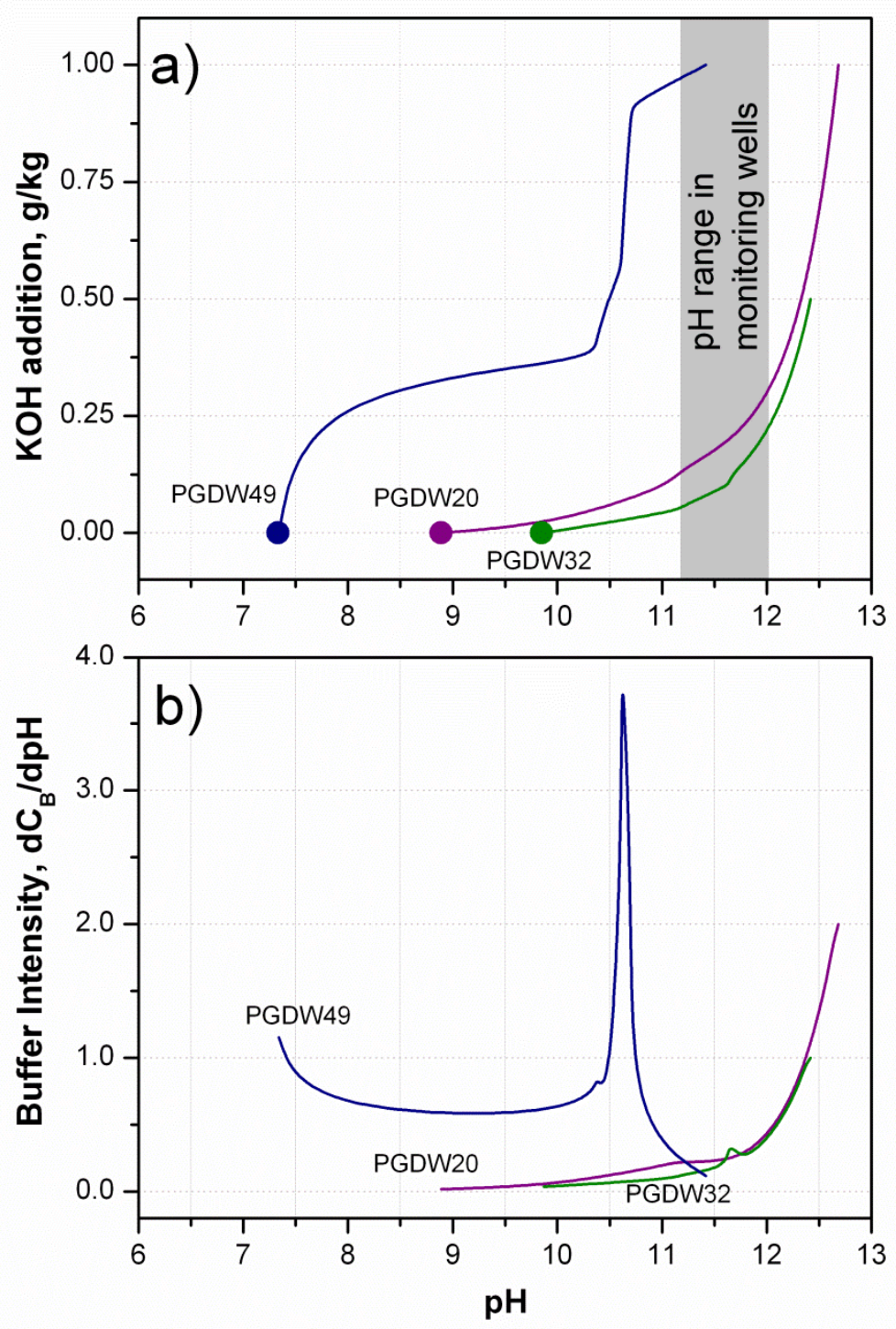

Figure 15. (a) Results of $\mathrm{KOH}$ titration models plotted as $\mathrm{pH}$ versus grams of $\mathrm{KOH}$ added per kilogram of solution. Initial water compositions are from PGDW49, PGDW20, and PGDW32. Model accounts for reactions taking place in solution as $\mathrm{KOH}$ is added and equilibrated. $\mathrm{pH}$ range in deep monitoring wells shown for reference; (b) Buffer Intensity plot or first derivative of titration plot, $\mathrm{pH}$ versus change in concentration of base $\left(C_{B}\right)$ per change in $\mathrm{pH}$.

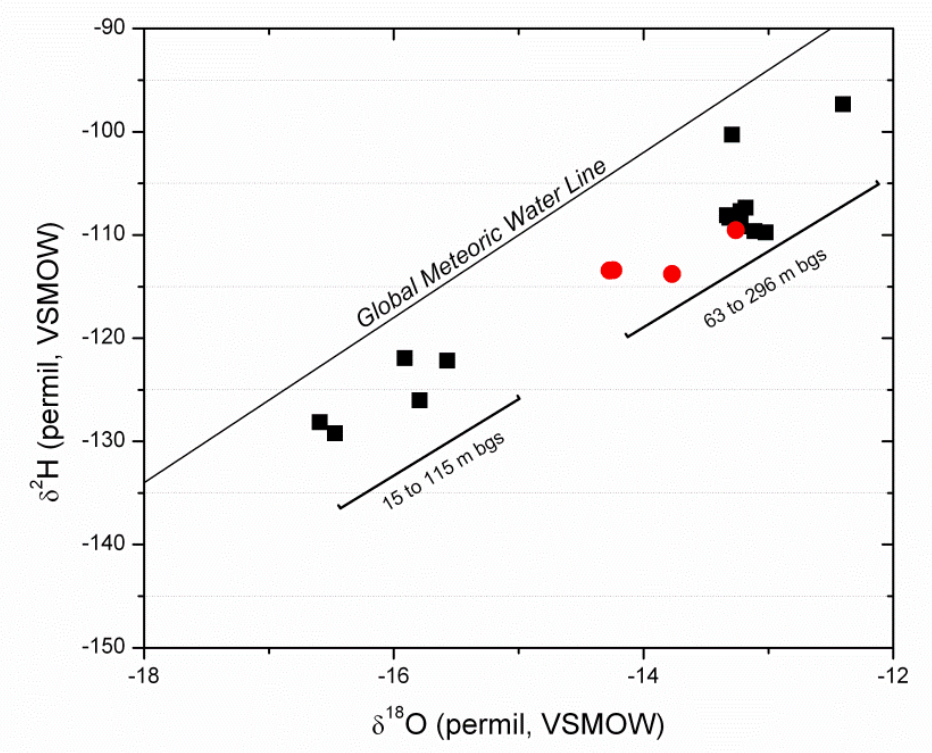

Figure 16. Hydrogen and oxygen isotope values (permil, Vienna Standard Mean Ocean Water, VSMOW) for ground water samples (black squares=domestic wells; red circles=deep monitoring wells) relative to the Global Meteoric Water Line from Craig (1961). 


\section{DRAFT}

\section{Organic Geochemistry}

Organic and inorganic geochemical impacts in deep ground water monitoring wells (Phase III and IV) are summarized in Table 3. The monitoring wells produce ground water near-saturated in methane at ambient pressure, with concentrations up to $19.0 \mathrm{mg} / \mathrm{L}$. Gas exsolution was observed while sampling at both MW01 and MW02. A wide variety of organic chemicals was detected in the monitoring wells including: GRO, DRO, BTEX, trimethylbenzenes, phenols, naphthalenes, acetone, isopropanol, TBA, 2butoxyethanol, 2-butanone, diethylene glycol, triethylene glycol, and tetraethylene glycol (Figure 17; Table 3). Concentrations of these chemicals range from $\mu \mathrm{g} / \mathrm{L}$ to $\mathrm{mg} / \mathrm{L}$ levels. Concentrations of benzene in MW02 exceed EPA's MCL in drinking by a factor of 49 times. Detections of organic chemicals are more numerous and exhibit higher concentrations in the deeper of the two monitoring wells (Figure 17, Table 3). This observation, along with trends in methane, potassium, chloride, and $\mathrm{pH}$, suggest a deep source (>299 m bgs) of contamination. Natural breakdown products of organic contaminants like BTEX and glycols include acetate and benzoic acid; these breakdown products are more enriched in the shallower of the two monitoring wells, suggesting upward/lateral migration with natural degradation and accumulation of daughter products (Corseuil et al. 2011, Caldwell and Suflita 2000, Dwyer and Tiedje 1983). Other trace-level detections of semi-volatile organic compounds included: bis(2-ethylhexyl) phthalate (MW01 and MW02, Phase III and IV), bis(2chloroethyl) ether, bis(2-ethylhexyl) adipate (MW01, Phase IV), butyl benzyl phthalate, and 4-methyl-2pentanone (MW02, Phase IV).

Well completion reports obtained online from WOGCC and Material Safety and Data Sheets (MSDSs) obtained from the operator were reviewed to examine inorganic and organic compounds in additives used for hydraulic fracturing and similarity with detected elements and compounds in ground water. Well completion reports were limited to a subset of production wells and included dates of injection, injection depths, pressure, flow, and volume for slickwater and carbon dioxide foam fracture jobs. Some MSDSs list chemical formulation as proprietary (e.g., proprietary alcohols) or list a chemical family (e.g., blend of organic surfactants) rendering identification of constituents impossible. This review is summarized in Table 4. Inorganic additives are potential sources of elevated $\mathrm{K}, \mathrm{Cl}$, and $\mathrm{OH}$ in deep monitoring wells.

Detection of compounds associated with petroleumbased additives in ground water samples using analytical methods employed in this investigation would be manifested as GRO, DRO, BTEX, naphthalenes, and trimethylbenzenes observed in deep monitoring wells.

TBA was detected in MW02 during Phase 4 sampling at a concentration of $4470 \mu \mathrm{g} / \mathrm{L}$. Two possible formation pathways for TBA are: 1 ) biodegradation of methyl tert-butyl ether (MTBE, synthetic chemical used as a fuel additive) under methanogenic conditions (e.g., Mormile et al. 1994, Bradley et al. 2001); and 2) breakdown of tert-butyl hydroperoxide (a gel breaker used in hydraulic fracturing; e.g., Hiatt et al. 1964). TBA biodegradation is generally slow compared to the degradation of MTBE; this suggests that TBA could be present and persist even after complete MTBE removal from ground water impacted by fuel releases (Wilson et al. 2005). MTBE was not detected in either of the deep monitoring wells. A second pathway of TBA production is from the decomposition of the gel breaker tert-butyl hydroperoxide. Hiatt et al. (1964) found that decomposition of tert-butyl hydroperoxide yielded a 10-fold molar quantity of TBA, oxygen, di-tert-butyl peroxide, and acetone. Acetone was detected in MW02 during Phase 4 sampling at a concentration of $641 \mu \mathrm{g} / \mathrm{L}$. This breaker is used in hydraulic fracturing formulations; however, the MSDSs made available to EPA do not indicate whether tert-butyl hydroperoxide was used in the Pavillion gas field for well stimulation. Elevated concentrations of TBA are not expected in unimpacted aquifers and its presence in MW02 remains unresolved. Additional insight about the occurrence of TBA (and other organic compounds) might be obtained by conducting compound-specific isotope analyses. 
DRAFT

Table 3. Geochemical impacts in deep ground-water monitoring wells

\begin{tabular}{|c|c|c|c|c|}
\hline Compound & $\begin{array}{l}\text { MW01 } \\
\text { Phase } 3 \\
10 / 6 / 2010 \\
\end{array}$ & $\begin{array}{l}\text { MW02 } \\
\text { Phase } 3 \\
10 / 6 / 2010 \\
\end{array}$ & $\begin{array}{l}\text { MW01 } \\
\text { Phase } 4 \\
4 / 20 / 2011 \\
\end{array}$ & $\begin{array}{l}\text { MW02 } \\
\text { Phase } 4 \\
4 / 19 / 2011 \\
\end{array}$ \\
\hline $\mathrm{pH}$ & 11.9 & 12.0 & 11.2 & 11.8 \\
\hline $\mathrm{K}, \mathrm{mg} / \mathrm{L}$ & 54.9 & 39.5 & 24.7 & 43.6 \\
\hline $\mathrm{Cl}, \mathrm{mg} / \mathrm{L}$ & 23.3 & 466 & 23.1 & 457 \\
\hline $\mathrm{CH}_{4}, \mathrm{mg} / \mathrm{L}$ & 16.0 & 19.0 & 17.9 & 18.8 \\
\hline Benzene $t$ & nd & 246 & nd & 139 \\
\hline Toluene & $0.75^{d}$ & 617 & 0.56 & 336 \\
\hline Ethylbenzene & nd & 67 & nd & 21.5 \\
\hline Xylenes (total) & nd & 750 & $0.89^{d}$ & 362 \\
\hline 1,2,4 Trimethylbenzene & nd & 69.2 & nd & 18.5 \\
\hline 1,3,5 Trimethylbenzene & nd & 35.5 & nd & nd \\
\hline Diesel Range Organics & 634 & 1440 & 924 & 4050 \\
\hline Gasoline Range Organics & 389 & 3710 & 592 & 2800 \\
\hline Phenol $^{a}$ & 11.1 & 56.1 & 20.9 & 64.9 \\
\hline Naphthalene ${ }^{b}$ & nd & 6.06 & nd & 6.10 \\
\hline Isopropanol & $-\cdots$ & $-\cdots--$ & 212 & 581 \\
\hline Tert-Butyl Alcohol & ---- & ---- & nd & 4470 \\
\hline 2-Butanone & ----- & $\begin{array}{l}---- \\
---\end{array}$ & nd & 120 \\
\hline Diethylene Glycol & ---- & ----- & 226 & 1570 \\
\hline Triethylene Glycol & ----- & ----- & 46 & 310 \\
\hline Tetraethylene Glycol & $-\mathrm{c}^{----}$ & ----- & $7.3^{c, d}$ & 27.2 \\
\hline 2-Butoxyethanol * & ---- & ----- & nd & nd \\
\hline 2-Butoxyethanol ** & nd & nd & 12.7 & nd \\
\hline Acetone & ----- & ----- & 79.5 & 641 \\
\hline Benzoic Acid & 212 & 244 & 457 & 209 \\
\hline Acetate & $-\cdots$ & ---- & 8050 & 4310 \\
\hline Formate & ---- & ---- & 112 & 558 \\
\hline Lactate & ---- & ----- & 69 & 213 \\
\hline Propionate & $-\overline{----}$ & $-\overline{----}$ & 309 & 803 \\
\hline
\end{tabular}

† All values in $\mu \mathrm{g} / \mathrm{L}$ unless otherwise noted.

---- not analyzed.

nd - not detected.

a Includes phenol, 2,4-dimethylphenol, 2-methylphenol, 3\&4 methylphenol.

${ }^{\mathrm{b}}$ Includes naphthalene, 1-methylnaphthalene, and 2-methylnaphthalene.

${ }^{c}$ Value below quantitation limit of $10 \mu \mathrm{g} / \mathrm{L}$.

${ }^{d}$ Chemical detected in a blank sample at a similar level

* 2-Butoxyethanol determined by HPLC-MS-MS.

** 2-Butoxyethanol determined by GC-MS 


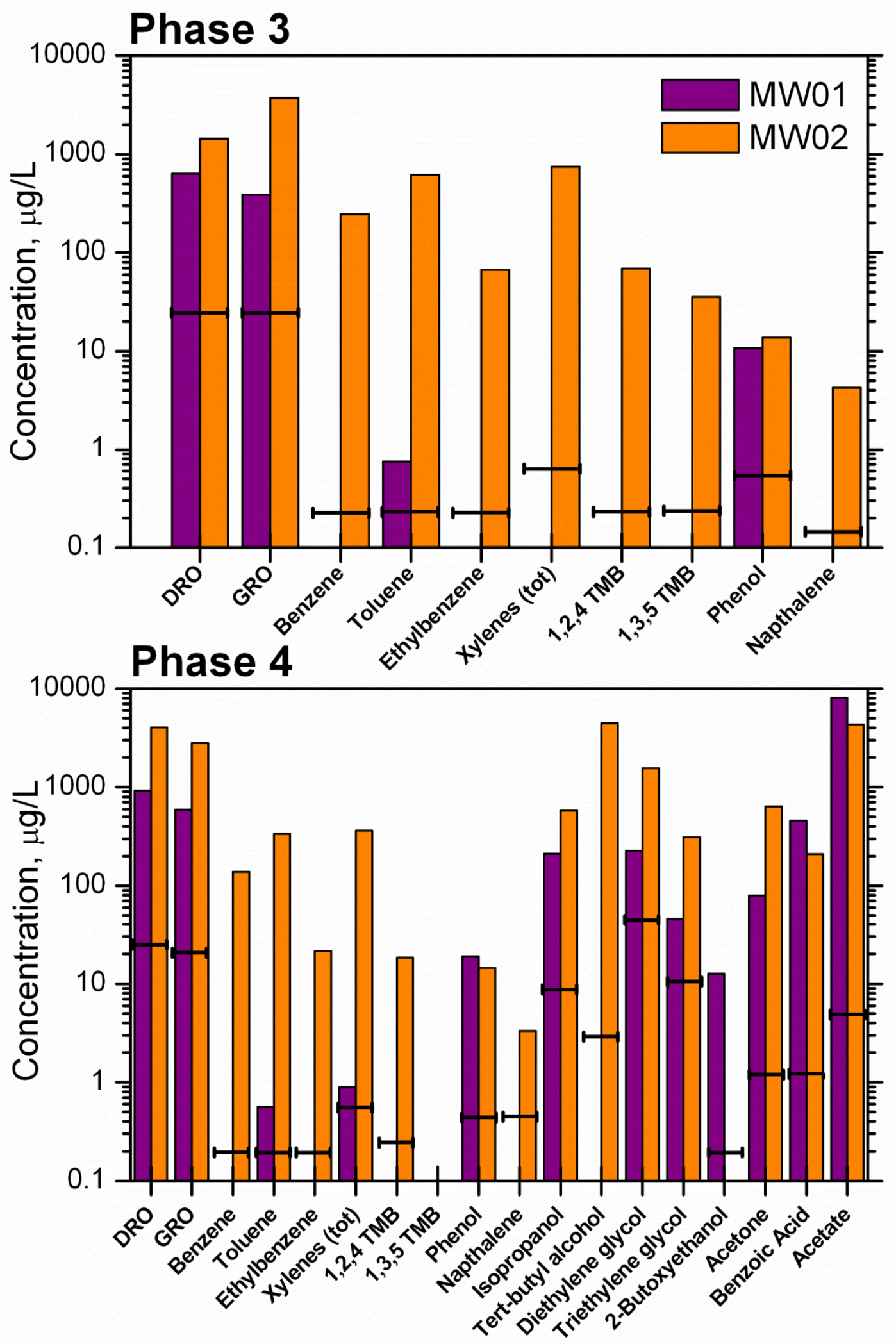

Figure 17. Organic compounds detected in deep monitoring wells MW01 and MW02 during Phase III and IV sampling events. Horizontal bars show method reporting limits for the individual analytes. 
Table 4. Association of inorganic and organic anomalies with compounds used for hydraulic fracturing

\begin{tabular}{|c|c|}
\hline $\begin{array}{l}\text { Compound/ } \\
\text { Compound Class }\end{array}$ & Information from MSDSs and Well Completion Reports \\
\hline pH & $\mathrm{KOH}$ was used in a crosslinker $(<5 \%)$ and in a solvent $(85-100 \%)$. \\
\hline $\mathrm{K}, \mathrm{Cl}$ & $\begin{array}{l}\text { The formulation of fracture fluid provided for foam jobs typically consisted of } \mathrm{CO}_{2}, 6 \% \\
\mathrm{KCl}, 10 \% \text { methanol, and "clean" fluid and "additives." Potassium metaborate was used } \\
\text { in crosslinkers }(5-10 \%, 30-60 \%) . \mathrm{KOH} \text { was used in a crosslinker (<5\%) and in a solvent } \\
(85-100 \%) \text {. }\end{array}$ \\
\hline $\mathrm{Cl}$ & Ammonium chloride was used in crosslinker (1-27\%). \\
\hline BTEX & $\begin{array}{l}\text { Aromatic solvent (typically BTEX mixture) was used in a breaker }(<75 \%) \text {. Diesel oil } \\
\text { (mixture of saturated and aromatic hydrocarbons including naphthalenes and } \\
\text { alkylbenzenes) was used in a guar polymer slurry/liquid gel concentrate }(30-60 \%) \text { and in } \\
\text { a solvent }(60-100 \%) \text {. Petroleum raffinates (mixture of paraffinic, cycloparaffinic, } \\
\text { olefinic, and aromatic hydrocarbons) was used in a breaker }(<30-60 \%) \text {. Heavy aromatic } \\
\text { petroleum naptha (mixture of paraffinic, cycloparaffinic and aromatic hydrocarbons) } \\
\text { was used in surfactants }(5-10 \%, 10-30 \%, 30-60 \%) \text { and in a solvent }(10-50 \%) \text {. Toluene } \\
\text { was used in a flow enhancer }(3-7 \%) \text {. Xylenes were used in a flow enhancer }(40-70 \%) \text { and } \\
\text { a breaker (confidential percentage). }\end{array}$ \\
\hline Trimethylbenzenes & $\begin{array}{l}\text { 1,2,4-trimethylbenzene was used in surfactants (0-1\%). Diesel oil (mixture of saturated } \\
\text { and aromatic hydrocarbons including naphthalenes and alkylbenzenes) was used in a } \\
\text { guar polymer slurry/liquid gel concentrate }(30-60 \%) \text { and in a solvent ( } 60-100 \%) . \\
\text { Petroleum raffinates (mixture of paraffinic, cycloparaffinic, olefinic, and aromatic } \\
\text { hydrocarbons) was used in a breaker }(<30-60 \%) \text {. Heavy aromatic petroleum naptha } \\
\text { (mixture of paraffinic, cycloparaffinic and aromatic hydrocarbons) was used in } \\
\text { surfactants (5-10\%, } 10-30 \%, 30-60 \%) \text { and in a solvent (10-50\%). }\end{array}$ \\
\hline DRO and GRO & $\begin{array}{l}\text { Diesel oil (mixture of saturated and aromatic hydrocarbons including naphthalenes and } \\
\text { alkylbenzenes) was used in a guar polymer slurry/liquid gel concentrate }(30-60 \%) \text { and in } \\
\text { a solvent (60-100\%). Petroleum raffinates (mixture of paraffinic, cycloparaffinic, } \\
\text { olefinic, and aromatic hydrocarbons) was used in a breaker (<30-60\%). Heavy aromatic } \\
\text { petroleum naptha (mixture of paraffinic, cycloparaffinic and aromatic hydrocarbons) } \\
\text { was used in surfactants }(5-10 \%, 10-30 \%, 30-60 \%) \text { and in a solvent }(10-50 \%) \text {. }\end{array}$ \\
\hline Naphthalene & $\begin{array}{l}\text { Naphthalene was used in surfactants }(0-1,5-10 \%) \text { and a breaker (confidential } \\
\text { percentage). Hydrotreated light petroleum distillates (mixture of C10-C14 naphthenes, } \\
\text { iso- and n-paraffins) were used in a guar polymer slurry/liquid gel concentrate }(40-60 \%) \text {. } \\
\text { Diesel oil (mixture of saturated and aromatic hydrocarbons including naphthalenes and } \\
\text { alkylbenzenes) was used in a guar polymer slurry/liquid gel concentrate }(30-60 \%) \text { and in } \\
\text { a solvent (60-100\%). }\end{array}$ \\
\hline Isopropanol & $\begin{array}{l}\text { Isopropanol was used in a biocide }(20-40 \%) \text {, in a surfactant }(30-60 \%) \text {, in breakers }(<1 \% \text {, } \\
10-30 \%) \text {, and in foaming agents }(<3 \%, 1-5 \%, 10-30 \%) \text {. }\end{array}$ \\
\hline Tert-Butyl Alcohol & $\begin{array}{l}\text { No MSDS listing. Breakdown product of methyl tert-butyl ether and tert-butyl } \\
\text { hydroperoxide - found in gel breakers. See discussion. }\end{array}$ \\
\hline Glycols & $\begin{array}{l}\text { Diethylene glycol was used in a foaming agent }(5-10 \%) \text { and in a solvent }(0.1-5 \%) \text {. } \\
\text { Triethylene glycol was used in a solvent }(95-100 \%) \text {. }\end{array}$ \\
\hline 2-Butoxyethanol & $\begin{array}{l}\text { 2-butoxyethanol was used in a surfactant }(10-30 \%) \text {, in foaming agents }(<10 \%,<11 \% \text {, } \\
<12 \%, 1-10 \%, 10-30 \%) \text { and in solvents }(15-40 \%, 60-100 \%) \text {. }\end{array}$ \\
\hline Acetone & Breakdown product of tert-butyl hydroperoxide - found in gel breakers. See discussion. \\
\hline $\begin{array}{l}\text { Benzoic Acid, } \\
\text { Acetate, Formate, } \\
\text { Lactate, Propionate, } \\
\text { 2-Butanone, Phenols }\end{array}$ & Natural breakdown products of organic contaminants (e.g., BTEX, glycols, etc.). \\
\hline
\end{tabular}




\section{DRAFT}

Natural gas condensates are composed primarily of aliphatic hydrocarbons; however, condensates may contain low quantities of aromatic compounds, such as BTEX. Gas from the Fort Union and lower Wind River Formations is generally dry $\left(C_{1} / C_{1}-C_{5}=0.95\right.$ 0.96 where methane $=C_{1}$, ethane $=C_{2}$, propane $=C_{3}$, butane $=C_{4}$, pentane $=C_{5}$ ) (Johnson and Rice 1993) and unlikely to yield liquid condensates at ground water pressure and temperature conditions. In addition, a condensate origin for BTEX compounds in ground water is doubtful because dissolved gas compositions and concentrations are similar between the two deep monitoring wells and therefore would yield similar liquid condensates, yet the compositions and concentrations of organic compounds detected in these wells are quite different (Figure 17) further suggesting a deep source of BTEX in MW02. The presence of synthetic compounds such as glycol ethers, along with enrichments in $\mathrm{K}, \mathrm{Cl}, \mathrm{pH}$, and the assortment of other organic components is explained as the result of direct mixing of hydraulic fracturing fluids with ground water in the Pavillion gas field.

As noted previously, this investigation was prompted by homeowner complaints over perceived changes in water quality. Domestic well results showed: the presence of DRO and GRO (in 23 of 28 samples), and trace levels of exotic organic compounds in some domestic wells including adamantanes, 2butoxyethanol phosphate, phenols, naphthalene, and toluene (EPA 2009, EPA 2010). Methane was detected in 10 of 28 samples at concentration levels below 0.8 $\mathrm{mg} / \mathrm{L}$. Foul odors associated with some domestic wells correlate with detections of GRO and DRO.

Anomalous trends in inorganic constituents observed in the deep monitoring wells (e.g., $\mathrm{K}, \mathrm{Cl}, \mathrm{pH}$ ) were not revealed in domestic well waters. In several instances, glycols were detected in domestic wells using gas chromatography with flame ionization detection (GCFID; EPA Standard Method 8015). However, glycol analysis using liquid chromatography with tandem mass spectroscopy (GC/MS/MS) failed to replicate these glycol detections, even though the method reporting limit was over an order of magnitude lower, suggesting that Method 8015 is prone to false positive results (possibly due to interactions between the chromatographic column and organic compounds in sample water). This result points to the need for continued and future improvements of analytical methods to detect and quantitate low levels of organic chemicals that may be associated with hydraulic fracturing fluids. Although contamination was detected in some domestic wells proximal to the deep monitoring wells, underscoring potential future risk, the existing data at this time do not establish a definitive link between deep and shallow contamination of the aquifer. An increased number of sampling points (monitoring wells) with vertical profiling in targeted locations are necessary to better define transport and fate characteristics of organic and inorganic contaminants in the ground water system and impact on domestic wells.

\section{Natural Gas Migration}

A review of open-hole geophysical logs obtained from the WOGCC internet site indicates the presence of gas-filled porosity at three locations at 198,208 , and $252 \mathrm{~m}$ bgs between the years 1965 - 1973 suggesting the presence of natural gas in ground water at depths used for domestic water supply prior to extensive commercial development. However, a review of 10 mud-gas logs recorded in the mid-1970s and early 1980s obtained on line from WOGCC, do not indicate gas shows within $300 \mathrm{~m}$ of the surface at any location.

Aqueous analysis of light hydrocarbons, gas and headspace analysis of light hydrocarbons, and isotopic data for dissolved, gas phase, and headspace analysis are summarized in Tables $\mathbf{A} \mathbf{3} \mathbf{a}, \mathbf{A} \mathbf{3} \mathbf{b}$, and $\mathbf{A} \mathbf{3} \mathbf{c}$ respectively (all investigative phases). Elevated levels of dissolved methane in domestic wells generally increase in those wells in proximity to gas production wells (Figure 18c). Methane was not detected in shallow domestic wells (e.g., $<50 \mathrm{~m}$ ) regardless of proximity to production wells (Figure 18c). With the exception of two domestic wells where methane was 

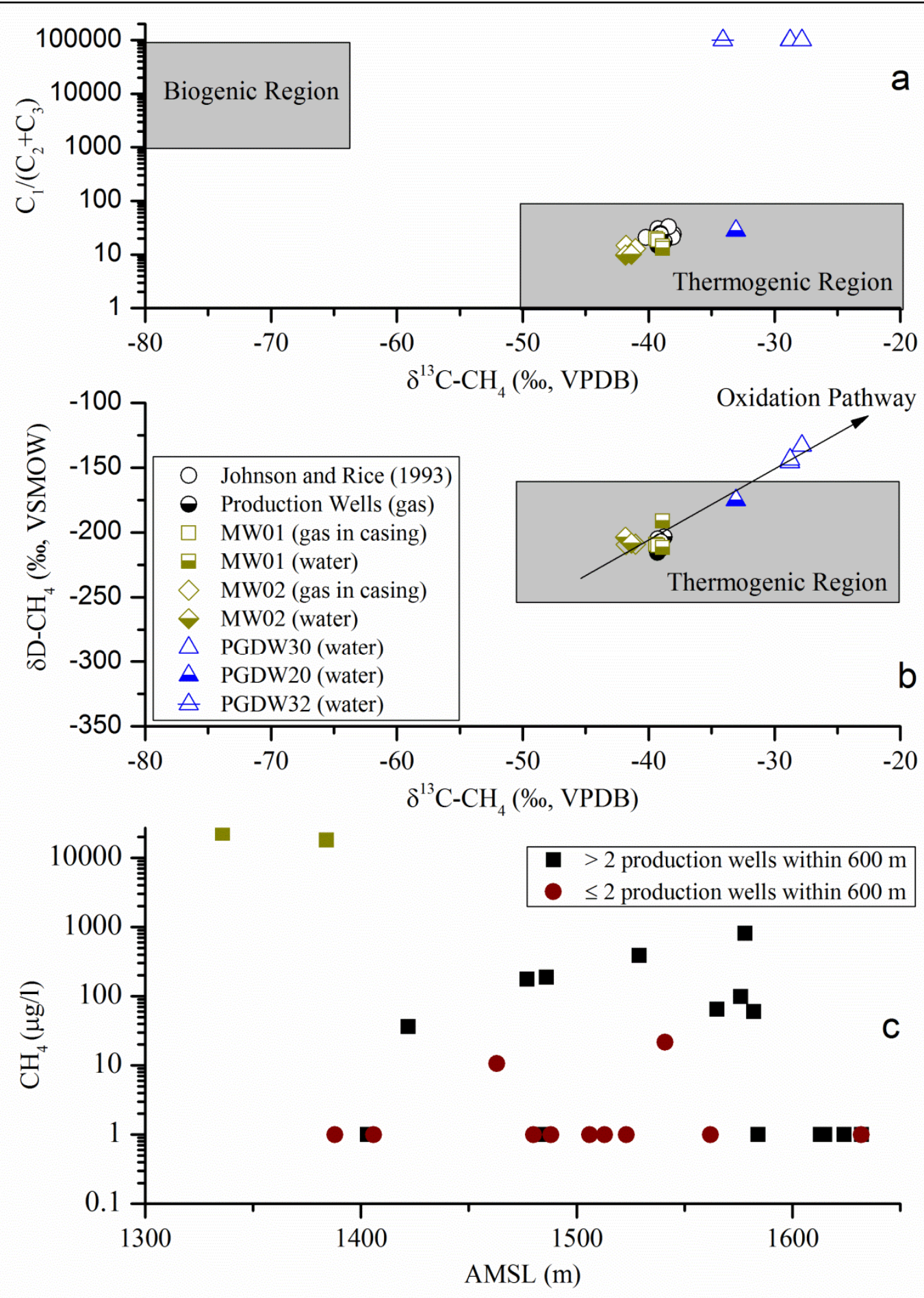

Figure 18. (a) Stable isotope ratios of carbon of methane versus ratio of methane $\left(C_{1}\right)$ to ethane $\left(C_{2}\right)$ and propane $\left(C_{3}\right)$ in gas from production wells, monitoring wells, and domestic wells. Values of 100,000 are used to denote non detection of ethane and propane in samples. (b) Stable isotope ratios of carbon versus hydrogen of methane in gas from production wells (both literature and measured values), monitoring wells, and domestic wells. $\delta$ D was not determined for PGDW32. Oxidation pathway (enrichment of ${ }^{13} \mathrm{C}$ of remaining $\mathrm{CH}_{4}$ with biodegradation) is illustrated. (c) Methane concentration in domestic (red circles and black squares) and monitoring wells (green squares) as a function of proximity to production wells and AMSL. Values of 1.0 were used for non-detection (detection limit $5 \mu \mathrm{g} / \mathrm{L}$ ). 


\section{DRAFT}

detected at less than $22 \mu \mathrm{g} / \mathrm{L}$, methane was not detected in domestic wells with 2 or less production wells within $600 \mathrm{~m}$ (Figure 18c). All domestic wells with the exception of PGDW25 with 2 or less production wells within $600 \mathrm{~m}$ are located on the periphery of the gas field (Figure 5). PGDW25 is located within $1600 \mathrm{~m}$ of 15 gas production wells.

Of particular interest is the area encompassing MW01, PGDW30, and PGDW05 (Figure 19). Ground water is saturated with methane at MW01 which is screened at a depth (239 m bgs) typical of deeper domestic wells in the area. Methane was detected in PGDW30 at $808 \mu \mathrm{g} / \mathrm{L}$ at a depth of only $80 \mathrm{~m}$, the highest level in any domestic well. A blowout occurred during drilling at a depth of only 159 m bgs in December 2005 adjacent to PGDW05. Natural gas exited the borehole for three days until the gas field operator was ordered to plug the borehole with a dense mud. The owner of PGDW05 was attempting at the time to replace this well due to taste, odor, and yield reduction he stated occurred after hydraulic fracturing at nearby production wells. A mud-gas log conducted on 11/16/1980 at Tribal Pavillion 14-2 (illustrated on Figure 19 as 14-2) located only $300 \mathrm{~m}$ from the location of the uncontrolled release does not indicate a gas show (distinctive peaks on a gas chromatograph) within $300 \mathrm{~m}$ of the surface. The owner of PGDW05 complained that well yield decreased after hydraulic fracturing at nearby production wells. Records obtained from the Wyoming State Engineer's office dated January 1973 indicate a yield of 30 to $38 \mathrm{~L} / \mathrm{min}$ with 1.2 meters of drawdown after 10 hours of pumping. During a sampling event in April 2005, PGDW05 became dry after pumping at a rate of 21.6 $\mathrm{L} / \mathrm{min}$ for 14 minutes. The cause of reduced well yield requires further investigation.

Similarity of $\delta^{13} \mathrm{C}$ values for methane, ethane, propane, isobutane, and butane between gas production and monitoring wells and plots of $\delta^{13} \mathrm{C}_{-}-\mathrm{CH}_{4}$ versus $\delta \mathrm{D}-\mathrm{CH}_{4}$ (Figure $1 \mathbf{8 b}$ ) and $\delta^{13} \mathrm{C}_{-}-\mathrm{CH}_{4}$ versus $\mathrm{C}_{1} /\left(\mathrm{C}_{2}\right.$ $+\mathrm{C}_{3}$ ) (Figure 18a) indicate that light hydrocarbons in casing and dissolved gas in deep monitoring wells are similar to produced gas and have undergone little oxidation or biodegradation. These observations combined with radiocarbon analysis of $\mathrm{CH}_{4}(<0.2 \%$ percent modern carbon) obtained from gas in casing of both MW01 and MW02 indicate that methane in deep monitoring wells is of thermogenic origin. Gas from the Fort Union and lower Wind River Formations is isotopically heavy $\left(\delta^{13} \mathrm{C}-\mathrm{CH}_{4}\right.$ from to -40.24 to $38.04 \%$ ) and as previously stated, dry (Johnson and Rice 1993, Johnson and Keighin 1998). Values of $\delta^{13} \mathrm{C}$ $\mathrm{CH}_{4}$ and $\delta \mathrm{D}-\mathrm{CH}_{4}$ more negative than $-64 \%$ ond $175 \%$, respectively, are indicative of microbial origin (Schoell 1980). The absence of ethane and propane in three of four domestic wells having sufficient methane to allow isotopic analysis and a shift of $\delta^{13} \mathrm{C}_{-}-\mathrm{CH}_{4}$ and $\delta \mathrm{D}-\mathrm{CH}_{4}$ values in a positive direction relative to produced gas suggests the presence of gas of thermogenic origin in domestic wells undergoing biodegradation and subsequent enrichment of $\delta^{13} \mathrm{C}$ and $\delta \mathrm{D}$. This observation is consistent with a pattern of dispersion and degradation with upward migration observed for organic compounds. Values of $\delta^{13} \mathrm{C}_{-} \mathrm{CH}_{4}$ more positive than $-64 \%$ and $C_{1} /\left(C_{2}+C_{3}\right)$ ratios above 1000 are often interpreted to indicate gas of mixed biogenic-thermogenic origin or gas of biogenic origin undergoing biodegradation (Whiticar 1999, Whiticar and Faber 1986) since neither ethane nor propane are biogenically generated in significant amounts. However, preferential loss of ethane and propane relative to methane in thermogenic gas produces a similar response (Valentine 2010, Kinnaman et al. 2007).

\section{Evaluation of Cement Bond/Variable Density Logs Along Transect}

CBL/VDLs and lithology were examined along a transect (Figure 19) which included the deep monitoring wells and three domestic wells where elevated levels of methane were detected. At Pavillion Fee 34-03B, a CBL/VDL conducted on $10 / 22 / 2004$ indicates no cement below surface casing until $802 \mathrm{~m} \mathrm{msl}$ (Figure 20) and sporadic bonding to $604 \mathrm{~m} \mathrm{msl}$ (not illustrated). The well completion 
DRAFT

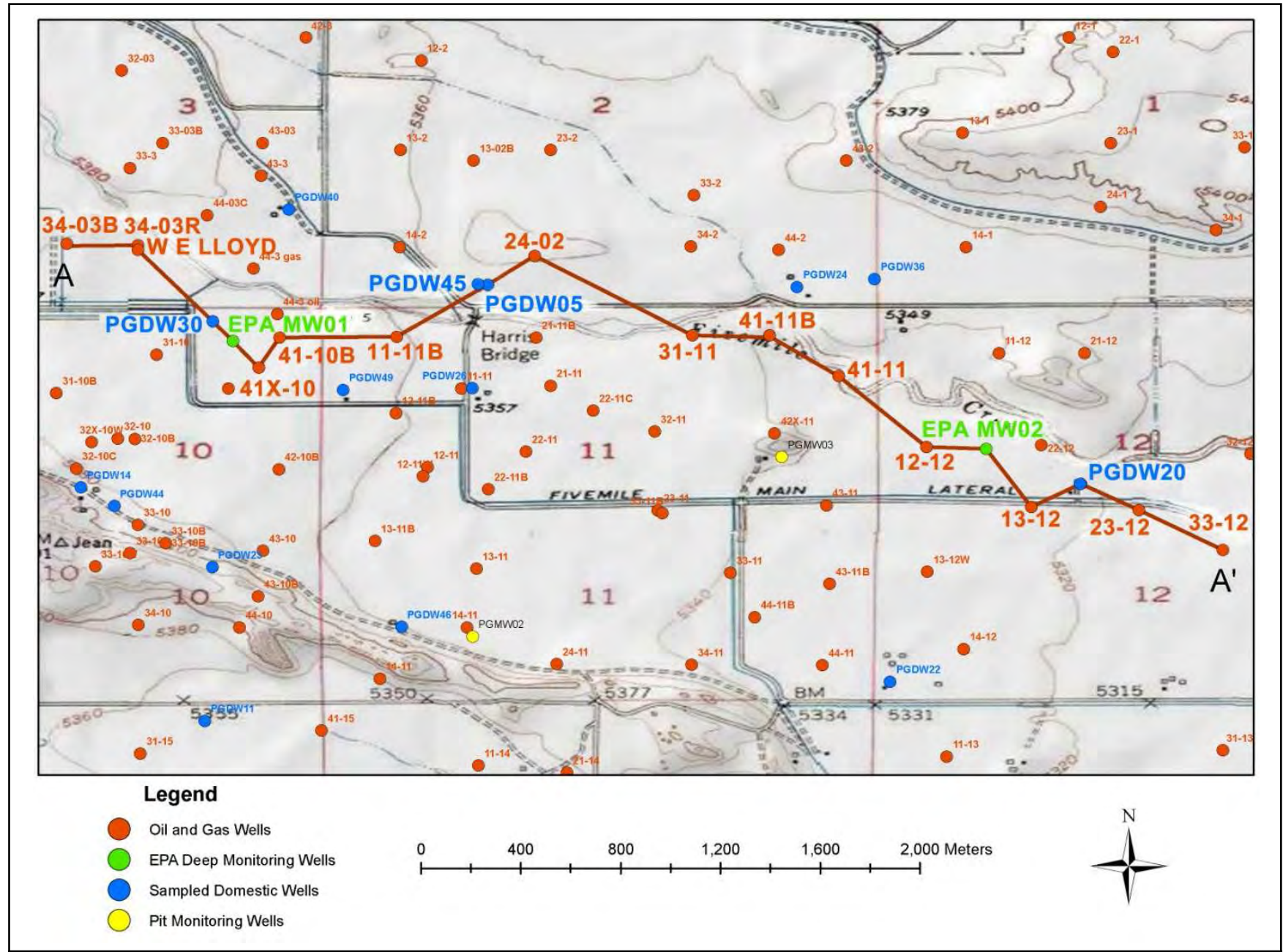

Figure 19. Map illustrating transect used to develop lithologic cross section and evaluation of CBL/VDLs.

report for this production well indicates that hydraulic fracturing was performed at $601 \mathrm{~m} \mathrm{msl}$ on 11/9/2004. A cement squeeze was subsequently performed at $802 \mathrm{~m} \mathrm{msl}$ on 4/1/2005 (no CBL/VDL after cement squeeze) with hydraulic fracturing at $689 \mathrm{~m} \mathrm{msl}$ on 4/19/2005. At Pavillion Fee 34-03R, the CBL/VDL indicates no cement below surface casing until $968 \mathrm{~m}$ msl (Figure 20). At Tribal Pavillion 41-10 and 41-10B, $\mathrm{CBL} / \mathrm{VDLs}$ indicate sporadic bonding over extensive intervals. A CBL/VDL conducted on 4/20/2005 at Tribal Pavillion 24-02 after a squeeze perforation at the base of the surface casing indicates poor bonding outside production casing below surface casing to the first perforation interval (Figure 20). At Tribal Pavillion 11-11B, a CBL/VDL indicates poor or sporadic bonding to $991 \mathrm{~m}$ bgs and no cement or cement bridging from 675 - 857 m msl. Thus, a review of well completion reports and CBL/VDLs indicates instances of sporadic bonding directly above intervals of hydraulic fracturing. This review also indicates instances where cement outside production casing is lacking over an extensive interval providing a potential conduit for fluid migration to within $300 \mathrm{~m}$ of the surface. As graphically illustrated in Figure 20, production wells having no or sporadic cement outside production casing are located in proximity to deep monitoring wells where aqueous constituents consistent with hydraulic fracturing were detected and methane exsolved from solution during sampling and locations of domestic wells where elevated levels of methane were detected and where an uncontrolled release of natural gas occurred. 


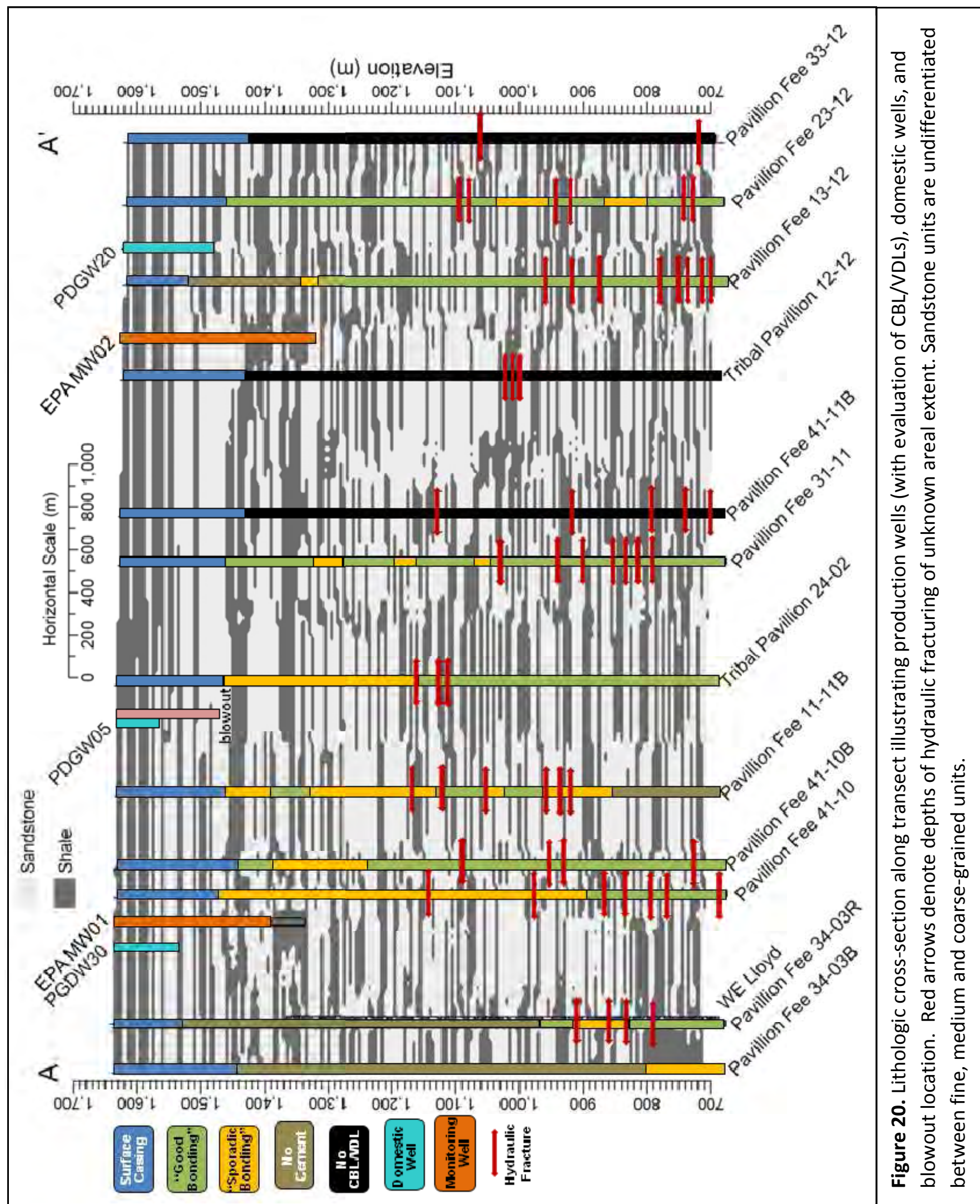




\section{DRAFT}

\section{Potential Migration Pathways}

Further investigation is necessary to determine mechanisms of aqueous and gas phase transport in the area of investigation. However, at least three mechanisms can be postulated at this time. The first mechanism is aqueous and/or gas transport via boreholes due to insufficient or inadequate cement outside production casing. Both aqueous (brine) and gas phase migration vertically up compromised wellbores have been simulated (Nordbotten et al. 2004, 2005a, 2005b) and indicate decreasing mass flux toward the surface with increasing number of permeable formations encountered along the way. Thus, the severity of ground water contamination increases with depth. Migration of gas via wellbores is well documented in the literature (e.g., Harrison 1983, Harrison 1985, Van Stempvoort et al. 2005, Taylor et al. 2000). In Bainbridge, Ohio, an operator initiated hydraulic fracturing despite knowing that only $24 \mathrm{~m}$ of cement was present above the perforation interval (Bair et al. 2010, ODNR 2008). Hydraulic fracturing fluid flowed to the surface via surface-production casing annulus which pressurized upon shut-in. Gas subsequently migrated through natural fractures to domestic wells eventually causing an explosion at one home. In northeastern Pennsylvania, two operators were fined for enhanced gas migration into domestic wells attributed to incomplete or inadequate cement outside production casing in wells used for hydraulic fracturing (PADEP 2009a, 2009b, 2010).

The second mechanism is fracture fluid excursion from thin discontinuous tight sandstone units into sandstone units of greater permeability. This would be accompanied by physical displacement of gas-rich solutions in both tight and more permeable sandstone formations. As illustrated in Figure 20, there is little lateral and vertical continuity to hydraulically fractured tight sandstones and no lithologic barrier (laterally continuous shale units) to upward vertical migration of aqueous constituents of hydraulic fracturing in the event of excursion from fractures. A third mechanism is that the process of hydraulic fracturing generates new fractures or enlarges existing ones above the target formation, increasing the connectivity of the fracture system.

In all three transport pathways, a general correlation (spatial relationships ultimately determined by fault and fracture systems in addition to lithology) would exist between proximity to gas production wells and concentration of aqueous and gas phase constituents in ground water. For instance, Osborn et al. (2011) observed a correlation between methane concentration and proximity to hydraulically fractured gas production wells at locations above the Marcellus and Utica formations in Pennsylvania and New York. Isotopic data and other measurements for methane in the drinking water were consistent with gas found in deep reservoirs such as the Marcellus and Utica shales at the active sites and matched gas geochemistry from shale-gas wells sampled nearby. Also, in all three transport pathways, advective/dispersive transport would be accompanied by degradation causing a vertical chemical gradient as observed during sampling of MWO1 and MW02. Reduced mass flux to the near surface environment and subsequent degradation along vertical and lateral transport pathways would explain lack of detection in domestic wells of compounds observed in MW02. 


\section{DRAFT}

\section{0 \\ Conclusions}

The objective of this investigation was to determine the presence of ground water contamination in the Wind River Formation above the Pavillion gas field and to the extent possible, identify the source of contamination. The combined use of shallow and deep monitoring wells allowed differentiation between shallow sources of contamination (pits) and deep sources of contamination (production wells). Additional investigation is necessary to determine the areal and vertical extent of shallow and deep ground water contamination.

Detection of high concentrations of benzene, xylenes, gasoline range organics, diesel range organics, and total purgeable hydrocarbons in ground water samples from shallow monitoring wells near pits indicates that pits are a source of shallow ground water contamination in the area of investigation. Pits were used for disposal of drilling cuttings, flowback, and produced water. There are at least 33 pits in the area of investigation. When considered separately, pits represent potential source terms for localized ground water plumes of unknown extent. When considered as whole they represent potential broader contamination of shallow ground water. A number of stock and domestic wells in the area of investigation are fairly shallow (e.g., $<30 \mathrm{~m}$ ) representing potential receptor pathways. EPA is a member of a stakeholder group working with the operator to determine the areal and vertical extent of shallow ground water contamination caused by these pits. The operator of the site is currently engaged in investigating and remediating several pit areas.

Detection of contaminants in ground water from deep sources of contamination (production wells, hydraulic fracturing) was considerably more complex than detection of contaminants from pits necessitating a multiple lines of reasoning approach common to complex scientific investigations. In this approach, individual data sets and observations are integrated to formulate an explanation consistent with each data set and observation. While each individual data set or observation represents an important line of reasoning, taken as a whole, consistent data sets and observations provide compelling evidence to support an explanation of data. Using this approach, the explanation best fitting the data for the deep monitoring wells is that constituents associated with hydraulic fracturing have been released into the Wind River drinking water aquifer at depths above the current production zone.

Lines of reasoning to support this explanation consist of the following.

1. High $\mathrm{pH}$ values

$\mathrm{pH}$ values in MWO1 and MW02 are highly alkaline (11.2-12.0), above the $\mathrm{pH}$ range observed in domestic wells (6.9-10), and above the $\mathrm{pH}$ range previously reported for the Wind River Formation with up to $94 \%$ of the total alkalinity contributed by hydroxide. The presence of hydroxide alkalinity suggests addition of base as the causative factor for elevated $\mathrm{pH}$ in the deep monitoring wells. Reaction path modeling indicates that sodiumsulfate composition ground water typical of deeper portions of the Wind River Formation provides little resistance to elevation of $\mathrm{pH}$ with small addition of potassium hydroxide.

With the exception of soda ash, the $\mathrm{pH}$ of drilling additives in concentrated aqueous solution was well below that observed in the deep monitoring wells. Dense soda ash was added to the drilling mud which varied between $\mathrm{pH} 8$ - 9.

The possibility of cement/grout intrusion into the screened intervals was considered as a possibility for elevated $\mathrm{pH}$ in both monitoring 


\section{DRAFT}

wells. However, cement intrusion typically leads to $\mathrm{pH}$ values between 10 and 11 - below that observed in deep monitoring wells. Prolonged purging did not show decreasing $\mathrm{pH}$ trends. Water chemistry results indicate that ground water from the wells was highly undersaturated with respect to cement phases (e.g., portlandite).

Material Safety Data Sheets indicate that potassium hydroxide was used in a crosslinker $(<5 \%)$ and in a solvent.

\section{Elevated potassium and chloride}

The inorganic geochemistry of ground water from the deep monitoring wells is distinctive from that in the domestic wells and expected composition in the Wind River formation. Potassium concentration in MW02 (43.6 $\mathrm{mg} / \mathrm{L})$ and MW01 $(54.9 \mathrm{mg} / \mathrm{L})$ is between 14.5 and 18.3 times the mean value of levels observed in domestic wells $(3 \mathrm{mg} / \mathrm{L}, 99 \%$ of values $<10 \mathrm{mg} / \mathrm{L}$ ). Chloride enrichment in monitoring well MW02 $(466 \mathrm{mg} / \mathrm{L})$ is 18 times the mean chloride concentration $(25.6 \mathrm{mg} / \mathrm{L})$ observed in ground water from domestic wells. Chloride concentration in this well is significant because regional anion trends show decreasing chloride concentrations with depth. In addition, the monitoring wells show low calcium, sodium, and sulfate concentrations compared to the general trend observed in domestic well waters.

Potassium levels in concentrated solutions of drilling additives were all less than $2 \mathrm{mg} / \mathrm{L}$. One additive (Aqua Clear used during well development) contained $230 \mathrm{mg} / \mathrm{L}$ chloride in a concentrated solution. Information from well completion reports and Material Safety Data Sheets indicate that the formulation of fracture fluid provided for foam jobs typically consisted of $6 \%$ potassium chloride.
Potassium metaborate was used in crosslinkers (5-10\%, 30-60\%). Potassium hydroxide was used in a crosslinker $(<5 \%)$ and in a solvent. Ammonium chloride was used in crosslinker (1-27\%).

Alternative explanations for inorganic geochemical anomalies observed in deep monitoring wells have been provided and considered. These alternate explanations include contamination from drilling fluids and additives, well completion materials, and surface soil, with contamination from all these sources exacerbated by poor well development. Contamination by drilling fluids and additives is inconsistent with analysis of concentrated solutions of bentonite and additives. Well construction materials (screen and sections of casing) consisted of stainless steel and were power-washed on site with detergent-free water prior to use. Sections of tremie pipe used to inject cement above screened intervals were also power washed with detergent-free water prior to use. Stainless-steel screens and sections of casing and tremie pipe remained above ground level (did not touch soil) prior to use. Both deep monitoring wells were purposefully located away from the immediate vicinity of gas production wells, known locations of pits, and areas of domestic waste disposal (abandoned machinery) to minimize the potential of surface soil contamination. Conductor pipe installed over the first $30.5 \mathrm{~m} \mathrm{(100} \mathrm{ft)} \mathrm{of}$ drilling at both deep monitoring wells eliminated the possibility of surface soil entry into the borehole. Turbidity measurements in MW01 during sampling ranged from 7.5 and 7.9 Nephelometric Turbidity Units (NTUs). Turbidity measurements in MW02 during sampling ranged from 24.0 to 28.0 NTUs, slightly above the stated goal of 10.0 NTUs but nevertheless was clear water typical of domestic wells during sampling. A low 


\section{DRAFT}

recharge rate in MW02 necessitated a

a surfactant $(30-60 \%)$, in breakers $(<1 \%, 10$ -

prolonged period of well development which

was likely due in part to gas flow (reduced

relative permeability to water) into the well

during development.

\section{Detection of synthetic organic compounds}

Isopropanol was detected in MW01 and MW02 at 212 and $581 \mu \mathrm{g} / \mathrm{L}$, respectively. Diethylene glycol was detected in MW01 and MW02 at 226 and $1570 \mu \mathrm{g} / \mathrm{L}$, respectively. Triethylene glycol was detected in MW01 and MW02 at 46 and $310 \mu \mathrm{g} / \mathrm{L}$, respectively. Another synthetic compound, tert-butyl alcohol, was detected in MW02 at a concentration of $4470 \mu \mathrm{g} / \mathrm{L}$. Tert-butyl alcohol is a known breakdown product of methyl tertbutyl ether (a fuel additive) and tert-butyl hydroperoxide (a gel breaker used in hydraulic fracturing). EPA methods were utilized for analysis when applicable for compounds or classes of compounds. Detection of synthetic organic compounds in MW01 and MW02 was made in part through the use of noncommercially available modified EPA analytical methods. For instance, high performance liquid chromatography/mass spectrometry/mass spectrometry was utilized for analysis of diethylene, triethylene and tetraethylene glycols. Ethylene glycol, which was widely used for well stimulation, required additional method modification and was not analyzed during this investigation.

Isopropanol was detected in concentrated solutions of drilling additives at a maximum concentration of $87 \mu \mathrm{g} / \mathrm{L}$, well below that detected in deep monitoring wells. Glycols were not detected in concentrated solutions of drilling additives.

Material Safety Data Sheets indicate that isopropanol was used in a biocide (20-40\%), in

$30 \%)$, and in foaming agents ( $<3 \%, 1-5 \%, 10-$ $30 \%)$. Diethylene glycol was used in a foaming agent (5-10\%) and in a solvent (0.1-5\%). Triethylene glycol was used in a solvent (95100\%). Material Safety Data Sheets do not indicate that tert-butyl hydroperoxide was used in the Pavillion gas field. The source of this compound remains unresolved. However, tert-butyl alcohol is not expected to occur naturally in ground water. Material Safety Data Sheets do not contain proprietary information and the chemical ingredients of many additives.

Alternative explanations provided to date and considered by EPA for detection of synthetic organic compounds in deep monitoring wells include arguments previously listed and addressed.

\section{Detection of petroleum hydrocarbons}

Benzene, toluene, ethylbenzene, and xylenes (BTEX) were detected in MW02 at concentrations of $246,617,67$, and $750 \mu \mathrm{g} / \mathrm{L}$ respectively. Trimethylbenzenes were detected in MW02 at $105 \mu \mathrm{g} / \mathrm{L}$. Gasoline range organics were detected in MWO1 and MW02 at 592 and $3710 \mu \mathrm{g} / \mathrm{L}$, respectively. Diesel range organics were detected in MW01 and MW02 at 924 and $4050 \mu \mathrm{g} / \mathrm{L}$ respectively. Naphthalene was detected in MWO2 at 6 $\mu \mathrm{g} / \mathrm{L}$. EPA methods were utilized for analysis.

BTEX and trimethylbenzenes were not detected in concentrated solutions of drilling additives.

Material Safety Data Sheets indicate that aromatic solvent (typically BTEX mixture) was used in a breaker ( $<75 \%)$. Diesel oil (mixture of saturated and aromatic hydrocarbons including naphthalenes and alkylbenzenes) was used in a guar polymer slurry/liquid gel 


\section{DRAFT}

concentrate (30-60\%) and in a solvent (60$100 \%$ ). Petroleum raffinates (a mixture of paraffinic, cycloparaffinic, olefinic, and aromatic hydrocarbons) were used in a breaker (<30-60\%). Heavy aromatic petroleum naphtha (mixture of paraffinic, cycloparaffinic and aromatic hydrocarbons) was used in surfactants $(5-10 \%, 10-30 \%, 30-$ $60 \%)$ and in a solvent (10-50\%). Toluene was used in a flow enhancer (3-7\%). Xylenes were used in a flow enhancer (40-70\%) and a breaker (confidential percentage). Gasoline range organics correspond to a hydrocarbon range of $\mathrm{C} 6-\mathrm{C} 10$. It includes a variety of organic compounds ketones, ethers, mineral spirits, stoddard solvents, and naphthas. Detection of gasoline range organics does not infer the use of gasoline for hydraulic fracturing.

Alternative explanations provided to date and considered by EPA for detection of petroleum compounds in deep monitoring wells include arguments previously listed and addressed. An additional alternate explanation for detection of petroleum compounds includes use of lubricants on the drillstem and well casing, use of electrical tape on submersible pumps, and components of submersible pumps. Jet Lube Well Guard hydrocarbon free lubricant specifically designed for monitoring well installation was used for drillstem connections. No lubricants were used to attach sections of casing or sections of tremie pipe during cementation. Clamps, not electrical tape, were used to bind electrical wires for submersible pumps. Water collected for samples during recharge at MW01 and MW02 would have a short contact time with components of submersible pumps. For components of submersible pumps to be a causative factor of high concentrations of petroleum hydrocarbons observed in MW01 and MW02, components of submersible pumps would have to contain high levels of water extractable petroleum compounds and consist of a matrix allowing rapid mass transfer, neither of which is plausible.

Another alternate explanation is that detection of petroleum hydrocarbons in ground water is expected above a natural gas field. Gas from Fort Union and Wind River Formations is dry and unlikely to yield liquid condensates at ground water pressure and temperature conditions. In addition, a condensate origin for petroleum hydrocarbons in ground water is doubtful because dissolved hydrocarbon gas compositions and concentrations are similar between the two deep monitoring wells and therefore would yield similar liquid condensates, yet the compositions and concentrations of organic compounds detected in these wells are quite different.

\section{Breakdown products of organic compounds}

Detections of organic chemicals were more numerous and exhibited higher concentrations in the deeper of the two monitoring wells. Natural breakdown products of organic contaminants like BTEX and glycols include acetate and benzoic acid. These breakdown products are more enriched in the shallower of the two monitoring wells, suggesting upward/lateral migration with natural degradation and accumulation of daughter products.

Hydraulic gradients are currently undefined in the area of investigation. However, there are flowing stock wells (e.g., PGDW44 - one of the deepest domestic wells in the area of investigation at $229 \mathrm{~m}$ below ground surface) suggesting that upward gradients exist in the area of investigation. In the Agency's report on evaluation of impacts to USDWs by hydraulic fracturing of coalbed methane 


\section{DRAFT}

reservoirs (EPA, 2004), hypothetical

conceptual models were presented on contaminant migration in a USDW during injection of fracturing fluids into a USDW. In these conceptual models, highly concentrated contaminant plumes exist within the zone of injection with dispersed lower concentration areas vertically and laterally distant from injection points. Data from deep monitoring wells suggests that this conceptual model may be appropriate at this site.

6. Sporadic bonding outside production casing directly above intervals of hydraulic fracturing

It is possible that wellbore design and integrity issues were one causative factor in deep ground water contamination at this site (surface casing of production wells not extending below deepest domestic wells, little vertical separation between fractured zones and domestic wells, no cement or sporadic bonding outside production casing).

A review of well completion reports and cement bond/variable density logs in the area around MW01 and MW02 indicates instances of sporadic bonding outside production casing directly above intervals of hydraulic fracturing. For instance, at Pavillion Fee 34-03B, a cement bond/variable density log conducted on 10/22/2004 indicated no cement until $838 \mathrm{~m}$ $(2750 \mathrm{ft}$ ) and sporadic bonding to $1036 \mathrm{~m}$ $(3400 \mathrm{ft}$ ) below ground surface. The well completion report for this production well indicates that hydraulic fracturing was performed at $1039 \mathrm{~m}$ (3409 ft) below ground surface on 11/9/2004 prior to cement squeeze jobs at $823 \mathrm{~m}(2700 \mathrm{ft})$ and $256 \mathrm{~m}(840 \mathrm{ft})$ below ground surface in April 2005. At Tribal Pavillion 41-10 a cement bond/variable density log indicates sporadic bonding directly above the interval of hydraulic fracturing at $493 \mathrm{~m}$ (1618 ft) below ground surface. A cement bond/variable density log conducted on Tribal Pavillion 24-02 after a squeeze job at the base of the surface casing indicates sporadic bonding outside production casing below surface casing to the interval of hydraulic fracturing at $469 \mathrm{~m}$ (1538 ft) below ground surface. At Tribal Pavillion 11-11B, a cement bond/variable density log indicates sporadic bonding between 305 to $503 \mathrm{~m}$ (1000 to $1650 \mathrm{ft}$ ) below ground surface with hydraulic fracturing occurring at $463 \mathrm{~m} \mathrm{(1516}$ $\mathrm{ft}$ ) below ground surface.

7. Hydraulic fracturing into thin discontinuous sandstone units

There is little lateral and vertical continuity to hydraulically fractured tight sandstones and no lithologic barrier (laterally continuous shale units) to stop upward vertical migration of aqueous constituents of hydraulic fracturing in the event of excursion from fractures.

Sandstone units are of variable grain size and permeability indicating a potentially tortuous path for upward migration.

In the event of excursion from sandstone units, vertical migration of fluids could also occur via nearby wellbores. For instance, at Pavillion Fee 34-03R, the cement bond/variable density log indicates no cement until $671 \mathrm{~m}(2200 \mathrm{ft})$ below ground surface. Hydraulic fracturing occurred above this depth at nearby production wells.

Although some natural migration of gas would be expected above a gas field such as Pavillion, data suggest that enhanced migration of gas has occurred to ground water at depths used for domestic water supply and to domestic wells. Lines of reasoning to support this explanation consist of following.

1. Hydrocarbon and isotopic composition of gas

The similarity of $\delta^{13} \mathrm{C}$ values for methane, ethane, propane, isobutane, and butane 


\section{DRAFT}

between gas production and monitoring wells and plots of $\delta^{13} \mathrm{C}-\mathrm{CH}_{4}$ versus $\delta \mathrm{D}-\mathrm{CH}_{4}$ and $\delta^{13} \mathrm{C}$ $\mathrm{CH}_{4}$ versus methane/(ethane + propane) indicate that light hydrocarbons in casing and dissolved gas in deep monitoring wells are similar to produced gas and have undergone little oxidation or biodegradation indicative of advective transport. The absence of ethane and propane in three of four domestic wells having sufficient methane to allow isotopic analysis and a shift of $\delta^{13} \mathrm{C}-\mathrm{CH}_{4}$ and $\delta \mathrm{D}-\mathrm{CH}_{4}$ values in a positive direction relative to produced gas suggests the presence of gas of thermogenic origin in domestic wells undergoing biodegradation. This observation is consistent with a pattern of dispersion and degradation with upward migration observed for organic compounds.

2. Elevation of dissolved methane concentrations in proximity to production wells

Levels of dissolved methane in domestic wells generally increase in those wells in proximity to gas production wells. With the exception of 2 domestic wells where methane was detected at less than $22 \mu \mathrm{g} / \mathrm{L}$, methane was not detected in domestic wells with 2 or less production wells within $600 \mathrm{~m}$.

\section{Spatial anomaly near PGDW05}

Methane concentrations in ground water appear highest in the area encompassing MW01, PGDW30, and PGDW05. Ground water is saturated with methane at MW01 which is screened at a depth (239 m bgs) typical of deeper domestic wells in the area. Methane was detected in PGDW30 at 808 $\mu \mathrm{g} / \mathrm{L}$ at a depth of only $80 \mathrm{~m}$, the highest level in any domestic well. A blowout occurred during drilling at a depth of only $159 \mathrm{~m}$ bgs in December 2005 adjacent to PGDW05.

An alternative explanation of high methane concentrations in this area is that it is close to the top of the dome comprising the Pavillion gas field which may facilitate natural gas migration toward the surface. However, this geologic feature would also facilitate enhanced gas migration. Also, a mud-gas log conducted on 11/16/1980 (prior to intensive gas production well installation) at Tribal Pavillion 14-2 located only $300 \mathrm{~m}$ from the location of the uncontrolled release does not indicate a gas show (distinctive peaks on a gas chromatograph) within $300 \mathrm{~m}$ of the surface.

4. Shallow surface casing and lack of cement or sporadic bonding outside production casing

With the exception of two production wells, surface casing of gas production wells do not extend below the maximum depth of domestic wells in the area of investigation. Shallow surface casing combined with lack of cement or sporadic bonding of cement outside production casing would facilitate migration of gas toward domestic wells.

The discussion on migration of fluids associated with hydraulic fracturing is relevant for gas migration and is not repeated here for brevity. Of particular concern are wellbores having no or little cement over large vertical instances. For instance, at Pavillion Fee 3403R, the cement bond/variable density log indicates no cement until $671 \mathrm{~m}(2200 \mathrm{ft})$ below ground surface. At Pavillion Fee 34-03B, a cement bond/variable density log conducted on 10/22/2004 indicated no cement until 838 $\mathrm{m}(2750 \mathrm{ft}$ ) below ground surface. Migration of gas via wellbores having no cement or poor cement bonding outside production casing is well documented in the literature.

An alternative explanation of wellbore gas migration provided to EPA and considered is that domestic wells are poorly sealed and thus 


\section{DRAFT}

constitute a potential gas migration pathway. However, lack of cement and sporadic bonding outside casing in production constitutes a major potential gas migration pathway to the depth of deep monitoring and domestic wells. It is possible that domestic wells could subsequently facilitate gas migration toward the surface.

\section{Citizens' complaints}

Finally, citizens' complaints of taste and odor problems concurrent or after hydraulic fracturing are internally consistent. Citizens' complaints often serve as the first indication of subsurface contamination and cannot be dismissed without further detailed evaluation, particularly in the absence of routine ground water monitoring prior to and during gas production.

An alternate explanation provided and considered by EPA is that other residents in the Pavillion area have always had gas in their wells. Unfortunately, no baseline data exists to verify past levels of gas flux to the surface or domestic wells.

A lines of reasoning approach utilized at this site best supports an explanation that inorganic and organic constituents associated with hydraulic fracturing have contaminated ground water at and below the depth used for domestic water supply. However, further investigation would be needed to determine if organic compounds associated with hydraulic fracturing have migrated to domestic wells in the area of investigation. A lines of evidence approach also indicates that gas production activities have likely enhanced gas migration at and below depths used for domestic water supply and to domestic wells in the area of investigation.

Hydraulic fracturing in the Pavillion gas field occurred into zones of producible gas located within an Underground Source of Drinking Water (USDW).
Hydraulic fracturing for coal-bed methane recovery is often shallow and occurs directly into USDWs (EPA 2004). TDS less than $10,000 \mathrm{mg} / \mathrm{L}$ in produced water is common throughout the Rocky Mountain portion of the United States (USGS 2011; Dahm et al. 2011). Ground water contamination with constituents such as those found at Pavillion is typically infeasible or too expensive to remediate or restore (GAO 1989). Collection of baseline data prior to hydraulic fracturing is necessary to reduce investigative costs and to verify or refute impacts to ground water.

Finally, this investigation supports recommendations made by the U.S. Department of Energy Panel (DOE 2011a, b) on the need for collection of baseline data, greater transparency on chemical composition of hydraulic fracturing fluids, and greater emphasis on well construction and integrity requirements and testing. As stated by the panel, implementation of these recommendations would decrease the likelihood of impact to ground water and increase public confidence in the technology. 


\section{DRAFT}

5.0

\section{References}

American Public Health Association; American Water Works Association; Water Environment Federation (1998a). Method 3500-Fe B. Phenanthroline Method. In: Standard Methods for the Examination of Water and Waste Water, 20th Edition. Editors Clesceri, L.S., Greenberg, A.E., and Eaton, A.D. Washington D.C.

American Public Health Association; American Water Works Association; Water Environment Federation (1998b). Method 4500-S2- D. Methylene Blue Method. In: Standard Methods for the Examination of Water and Waste Water, 20th Edition. Editors Clesceri, L.S., Greenberg, A.E., and Eaton, A.D. Washington D.C.

Bair, S.E., Freeman, D.C., and Senko, J.M. (2010). Expert Panel Technical Report Subsurface Gas Invasion Bainbridge Township, Geauga County, Ohio, submitted to Ohio Department of Natural Resources Division of Mineral Resources Management, June 2010.

Bartos, T.T., Quinn, T.L., Hallberg, L.L., and EddyMiller, C.A. (2008). Quality of shallow ground water in three areas of unsewered low-density development in Wyoming and Montana, 2001. U. S. Geological Survey Scientific Investigations Report 2008-5012, 118 p.

Bethke, C. M. (1996). Geochemical Reaction Modeling. Oxford University Press, New York.

Boyd, D., Al-Kubti, S., Khedr, O., N. Khan, and K. AlNayadi, prepared for the 2006 SPE Abu Dhabi International Petroleum Exhibition and Conference, Abu Dhabi, UAE, 5-8 November.

Bradley, P.M., Chapelle, F.H., and Landmeyer, J.E. (2001). Effect of redox conditions on MTBE biodegradation in surface water sediments. Environmental Science and Technology, v. 35, p. 46434647.
Bybee, K. (2007). Cement-bond-log interpretation reliability. Journal of Petroleum Technology, Feb. 2007, p. 64-66.

Caldwell, M.E. and Suflita, J.M. (2000). Detection of phenol and benzoate as intermediates of anaerobic benzene biodegradation under different terminal electron-accepting conditions. Environmental Science and Technology, v. 34, p. 1216-1220.

Corseuil, H.X., Monier, A.L., Fernandes, M., Schneider, M.R., Nunes, C.C. Rosario, M., and Alvarez, P.J.J. (2011). BTEX plume dynamics following an ethanol blend release: Geochemical footprint and thermodynamic constraints on natural attenuation. Environmental Science and Technology, v. 45, p. 34223429.

Craig, H. (1961). Isotopic variations in meteoric waters. Science, v. 133, p. 1702-1703.

Daddow, R.L. (1996). Water resources of the Wind River Indian Reservation, Wyoming. U.S. Geological Survey Water-Resources Investigation Report 954223, $121 \mathrm{p}$.

Dahm, K.G., Guerra, K.L., Xu, P., and Drewes, J.E. (2011). Composite geochemical database for coalbed methane produces water quality in the Rocky Mountain Region. Environmental Science and Technology, v. 45, p. 7655-7663.

Delany J.M. and Lundeen S.R. (1990). The LLNL thermochemical database. Lawrence Livermore National Laboratory Report, UCRL-21658. Lawrence Livermore National Laboratory.

Dwyer, D.F. and Tiedje, J.M. (1983). Degradation of ethylene glycol and polyethylene glycols by methanogenic consortia. Applied and Environmental Microbiology, v. 46, p. 185-190.

Flores, R.M. and Keighin, C.W. (1993). Reservoir anisotropy and facies stratigraphic framework in the Paleocene Front Union Formation, western Wind River Basin, Wyoming, in W.R. Keefer, W.J. Metzger and L.H. Godwin, eds., Oil and Gas and Other Resources of the Wind River Basin, Wyoming: Wyoming Geological Association Special Symposium, 1993, p. 121-141. 


\section{DRAFT}

Gibb, J.P. and Jennings, K.V.B. (1987). Forum: How drilling fluids and grouting materials affect the integrity of ground water samples from monitoring wells. Ground Water Monitoring and Remediation, v. 7, p. 33-42.

Harrison, S.S. (1983). Evaluating system for ground water contamination hazards due to gas-well drilling on the glaciated Appalachian Plateau. Ground Water, v. $21,689-700$.

Harrison, S.S. (1985). Contamination of aquifers by overpressuring the annulus of oil and gas wells. Ground Water, v. 23, 317-324.

Hiatt, R., Clipsham, J., and Visser, T. (1964). The induced decomposition of tert-butyl hydroperoxide. Canadian Journal of Chemistry, v. 42, p. 2754-2757.

Johnson, R.C. and Rice, D.D. (1993). Variations in composition and origins of gases from coal bed and conventional reservoirs, Wind River Basin, Wyoming, in W.R. Keefer, W.J. Metzger and L.H. Godwin, eds., Oil and Gas and Other Resources of the Wind River Basin, Wyoming: Wyoming Geological Association Special Symposium, 1993, p. 319-335.

Johnson, R.C. and Keighin, W.C. (1998). Origins of natural gases from upper Cretaceous reservoirs, Bighorn Basin, Wyoming and Montana, and comparison with gases from the Wind River Basin, Wyoming, In Forty-Ninth Guidebook, Wyoming Geological Association, p. 223- 249.

Keefer, W.R. and Johnson R.C. (1993). Stratigraphy and oil and gas resources in uppermost Cretaceous and Paleocene rocks, Wind River Reservation, Wyoming, in W.R. Keefer, W.J. Metzger and L.H. Godwin, eds., Oil and Gas and Other Resources of the Wind River Basin, Wyoming: Wyoming Geological Association Special Symposium, 1993, p. 71-86.

Johnson, R.C., Finn, T.M., Kirschbaum, M.A., Roberts, S.B., Roberts, L.N.R., Cook, T., and Taylor, D.J. (2007). The Cretaceous-Lower Tertiary Composite Total Petroleum System, Wind River Basin, Wyoming, Chapter 4 of Petroleum Systems and Geologic Assessment of Oil and Gas in the Wind River Basin Province, Wyoming. U.S. Geological Survey Digital Data Series DDS-69-J.
Kinnaman, F.S., Valentine, D.L., and Tyler, S.C. (2007). Carbon and hydrogen isotope fractionation associated with the aerobic microbial oxidation of methane, ethane, propane and butane. Geochimica et Cosmochimica Acta, v. 71, p. 271-283.

Mormille, M.R., Liu, S., and Suflita, J.M. (1994). Anaerobic biodegradation of gasoline oxygenates: Extrapolation of information to multiple sites and redox conditions. Environmental Science and Technology, v. 28, p. 1727-1732.

Morris, D.A., Hackett, O.M., Vanlier, K.E., Moulder, E.A., and Durum, W.H. (1959). Ground water resources of Riverton irrigation project area, Wyoming, Geological Survey Water-Supply Paper 1375, $205 \mathrm{p}$.

Mueller, C. (1989). Pavillion; Wyoming Geological Association, Wyoming Oil and Gas Fields Symposium, Bighorn and Wind River Basins, p. 356-358.

Nordbotten, J.M., Celia, M.A., and Bachu, S. (2004). Analytical solutions for leakage rates through abandoned wells. Water Resources Research, v. 40, W04204.

Nordbotten, J.M., Celia, M.A. and Bachu, S. (2005a). Injection and storage of $\mathrm{CO}_{2}$ in deep saline aquifers: Analytical solution for $\mathrm{CO}_{2}$ plume evolution during injection. Transport Porous Media, v. 58, p. 339-360.

Nordbotten, J.M., Celia, M.A., Bachu, S., and Dahle, H.K. (2005b). Semianalytical solution for $\mathrm{CO}_{2}$ leakage through an abandoned well. Environmental Science and Technology, v. 39, p. 602-611.

Ohio Department of Natural Resources, Division of Mineral Resources Management, Report on the Investigation of the Natural Gas Invasion of Aquifers in Bainbridge Township of Geauga County, Ohio September 1, (2008).

Osborn S.G., Vengosh, A., Warner, N.R., and Jackson, R.B. (2011). Methane contamination of drinking water accompanying gas-well drilling and hydraulic fracturing. Proceedings of the National Academy of Sciences, v. 108, p. 8172-8176. 


\section{DRAFT}

Osiensky, J.L., Winter, G.V., and Williams, R.E. (1984).

Monitoring and mathematical modeling of

contaminated ground water plumes in fluvial

environments. Ground Water, v. 22, p. 298-306.

Pennsylvania Department of Environmental Protection (PADEP) Consent Order and Agreement Cabot Oil and Gas Corporation Dimock and Springville Townships Susquehanna County (2009).

Pennsylvania Department of Environmental Protection (PADEP) Modification to Consent Order and Agreement dated November 4, 2009 - April 15, 2010.

Pennsylvania Department of Environmental Protection (PADEP) Modification to Consent Order and Agreement dated November 4, 2009 - April 15, 2010.

Plafcan, M., Eddy-Miller, C.A., Ritz, G.F., and Holland, J.P.R. (1995). Water resources of Fremont County, Wyoming. U.S. Geological Survey, Water-Resources Investigations Report 95-4095, 133 p.

Schoell, M. (1980). The hydrogen and carbon isotopic composition of methane from natural gases of various origins. Geochimica et Cosmochimica Acta, v. 44, p. 649-661.

U.S. Department of Energy. Secretary of Energy Advisory Board. Shale Gas Production Subcommittee. Ninety-Day Report - August 11, 2011.

\section{U.S. Department of Energy. Secretary of Energy}

Advisory Board. Shale Gas Production Subcommittee. Second Ninety-Day Report - November 18, 2011.

Single, E.L. (1969). in Wyoming Geological Association 21st Field Conference Guidebook, p. 101-103.

Taylor, S.W., Sherwood Lollar, B., and Wassenaar, L.I. (2000). Bacteriogenic ethane in near-surface aquifers: Implications for leaking hydrocarbon well bores.

Environmental Science and Technology, v. 34, p. 47274732.

U.S. Environmental Protection Agency (1987). Management of Wastes from Exploration, Development, and Production of Crude Oil, Natural Gas, and Geothermal energy, EPA/530-SW-88-003, December, 1987. Available at http://www.epa.gov/osw/nonhaz/industrial/special/oi l/rtc1987.pdf

U.S. Environmental Protection Agency - Region VIII, Ground Water Section Guidance No. 34 - March 31, 1994.

U.S. Environmental Protection Agency (2004).

Evaluation of Impacts to Underground Sources of Drinking Water by Hydraulic Fracturing of Coalbed Methane Reservoirs, Office of Water Office of Ground Water and Drinking Water (4606M), EPA 816-R-04003, June 2004.

U.S. Environmental Protection Agency (2009). Site Inspection - Analytical Results Report, Pavillion Area Ground Water Investigation Site, August 8, 2009. available at http://www.epa.gov/region8/superfund/wy/pavillion/

U.S. Environmental Protection Agency (2010). Expanded Site Inspection - Analytical Results Report, Pavillion Area Ground Water Investigation Site, August 30, 2010. available at

http://www.epa.gov/region8/superfund/wy/pavillion/

U.S. General Accounting Office (1989). Safeguards are not Preventing Contamination from Injected Oil and Gas Wastes, GAO/RCED-89-97, July 1989.

U.S. Geological Survey Produced Waters Database, Chemistry of Produced Water in the United States, http://energy.cr.usgs.gov/prov/prodwat/tds.htm. Site accessed November, 2011.

Valentine, D.L. et al. (2010). Propane respiration jumpstarts microbial response to a deep oil spill. Science, $\mathrm{v}$. 330, p. 208-211.

Van Stempvoort, D., Maathuis, H., Jaworski, E., Mayer, B., and Rich, K. (2005). Oxidation of fugitive methane in ground water linked to bacterial sulfate reduction, Ground Water, v. 43, p. 187-199.

Whiticar, M.J. (1999). Carbon and hydrogen isotope systematic of bacterial formation and oxidation of methane. Chemical Geology, v. 161, p. 291-314. 


\section{DRAFT}

Whiticar, M.J. and Faber, E. (1986). Methane oxidation in sediment and water column environments-isotopic evidence. Organic Geochemistry, v. 10, p. 759-768.

Wilson, J.T., Kaiser, P.M., and Adair, C. (2005).

Monitored natural attenuation of MTBE as a risk management option at leaking underground storage tank sites. EPA/600/R-04/1790.

Wyoming State Water Plan, Wyoming Water Development Office, Wind/Bighorn River Basin Plan, Jan. 14, 2003.

http://waterplan.state.wy.us/plan/bighorn/techmemo s/grnddet.html 


\section{DRAFT}

\section{Appendix A Summary of Analytical Results}


DRAFT

\begin{tabular}{|c|c|c|c|c|c|c|c|c|c|c|c|c|c|c|c|c|c|c|}
\hline है & 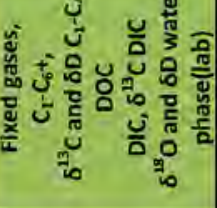 & $\bar{\equiv}$ & $\tilde{\Xi}$ & $\underline{\underline{\Xi}}$ & $\bar{\equiv}$ & $\bar{\equiv}$ & 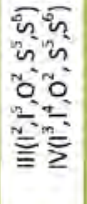 & 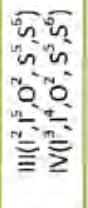 & 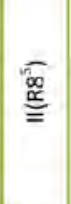 & 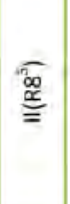 & 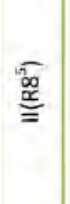 & 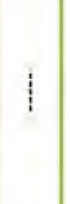 & 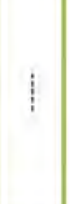 & 1 & 1 & : & 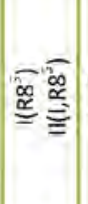 & 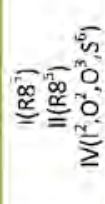 \\
\hline 范 & 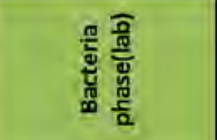 & 1 & 1 & 1 & 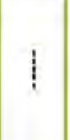 & 1 & 1 & 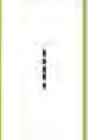 & 惡 & Ð & $\stackrel{\bar{ٍ}}{ٍ}$ & 1 & 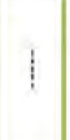 & 1 & 11 & ङ & 氞 & 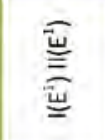 \\
\hline 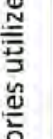 & 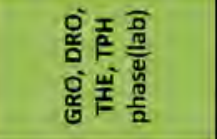 & 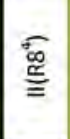 & 1 & 馬 & 总 & 尊 & 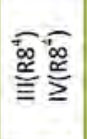 & 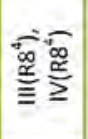 & 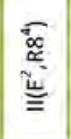 & 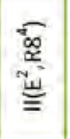 & 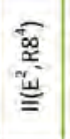 & 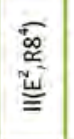 & 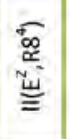 & 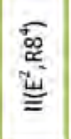 & 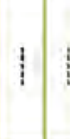 & 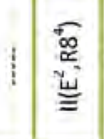 & 兽离 & 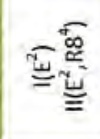 \\
\hline 党 & 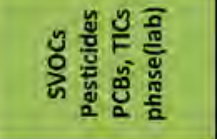 & 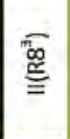 & 1 & 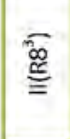 & 焉 & 可 & 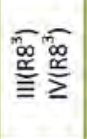 & 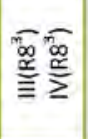 & 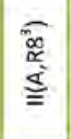 & 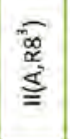 & 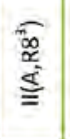 & $\begin{array}{l}\stackrel{\bar{\infty}}{\underline{\underline{c}}} \\
=\end{array}$ & 离 & 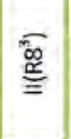 & $=$ & $=$ & 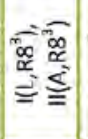 & 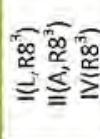 \\
\hline 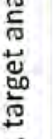 & 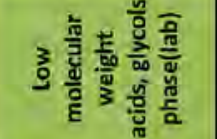 & 1 & 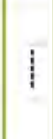 & 1 & 1 & 1 & 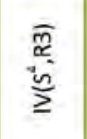 & 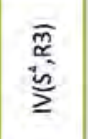 & 1 & 1 & 1 & 1 & 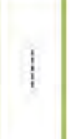 & 1 & 11 & 11 & 1 & $\begin{array}{l}\widehat{\widehat{\alpha}} \\
\stackrel{y}{\underline{n}}\end{array}$ \\
\hline 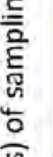 & 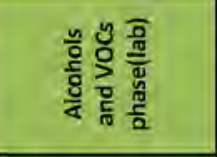 & 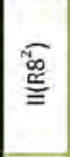 & 1 & 恿 & 营 & $\widetilde{\widetilde{\Phi}}$ & 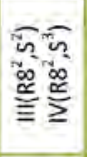 & 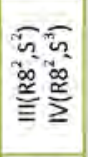 & 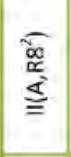 & 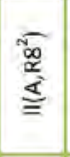 & 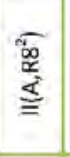 & 1 & 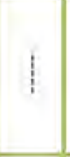 & 1 & $\equiv$ & 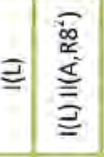 & 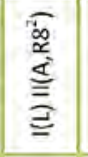 & 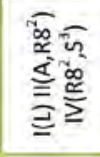 \\
\hline$\frac{g}{\frac{g}{2}}$ & 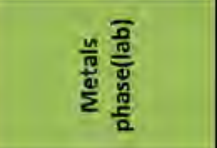 & 1 & 1 & 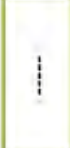 & 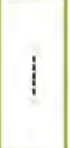 & 1 & 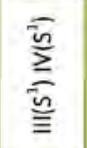 & $\frac{\bar{n}}{\sum_{\bar{n}}^{\bar{n}}}$ & 垔 & 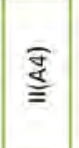 & $\stackrel{\bar{g}}{\leftrightarrows}$ & 1 & 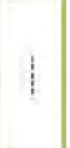 & 1 & $\underline{\underline{z}}$ & 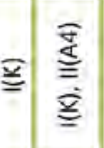 & $\begin{array}{l}\text { 过 } \\
\stackrel{=}{\underline{\underline{s}}}\end{array}$ & 要商 \\
\hline 产 & 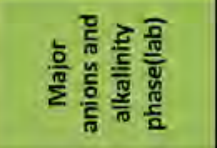 & 1 & 1 & 1 & 1 & 1 & $\widehat{\bar{o}} \stackrel{0}{\underline{o}}$ & $\widehat{\bar{o} \overline{0}}$ & 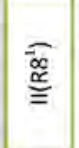 & 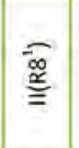 & 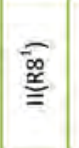 & 1 & 1 & 1 & 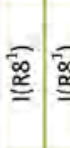 & 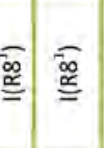 & 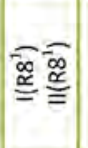 & 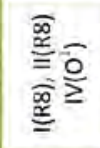 \\
\hline है & $\begin{array}{l}\frac{\pi}{\mathrm{g}} \\
\text { है }\end{array}$ & 畆竞 & 总 & 离䌟 & 営高 & 高哭 & 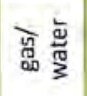 & 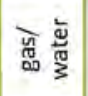 & $\frac{\frac{5}{v}}{\frac{5}{3}}$ & 产 & $\frac{\bar{g}}{\frac{\mathrm{g}}{3}}$ & $\overline{\bar{i}}$ & $\overline{\bar{\sigma}}$ & 言 & $\frac{2}{\frac{2}{3}}$ & 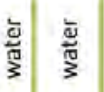 & $\frac{\grave{g}}{3}$ & 惢 \\
\hline 言 & בัँ & $\because$ & $\because$ & 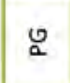 & $\therefore$ & 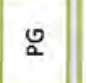 & $\frac{3}{2}$ & $\frac{3}{2}$ & $\sum_{\mathrm{g}}^{5}$ & $\sum_{0}^{\Sigma}$ & క్ర & : & $\ddot{z}$ & 气ू & 引े & 方 3 & בे & בे \\
\hline 한 & 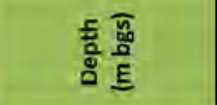 & & & & & & 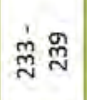 & ติ่ & $\stackrel{c}{+}$ & $\stackrel{\varphi}{\dot{*}}$ & $\stackrel{\leftrightarrow}{\dot{q}}$ & in & in & in & & 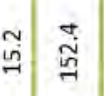 & 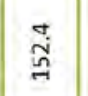 & : \\
\hline 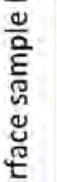 & 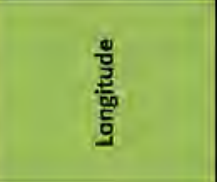 & 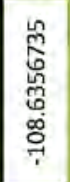 & 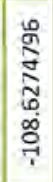 & 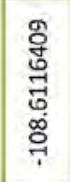 & 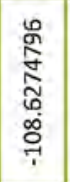 & $\begin{array}{l}8 \\
8 \\
0 \\
60 \\
60 \\
00 \\
7\end{array}$ & 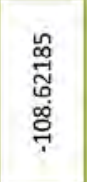 & 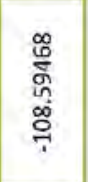 & 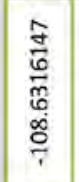 & 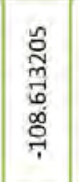 & 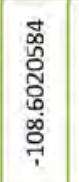 & 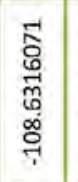 & 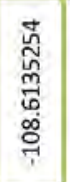 & 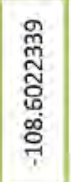 & 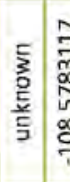 & 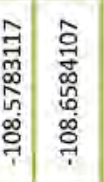 & 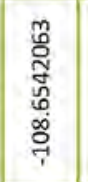 & 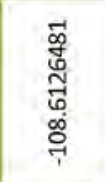 \\
\hline 范 & 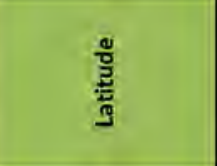 & 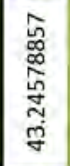 & 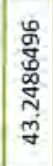 & 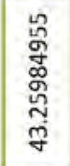 & 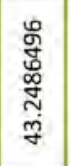 & 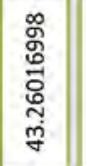 & 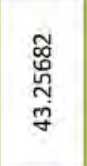 & 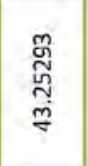 & 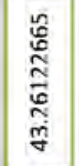 & 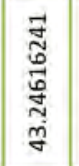 & 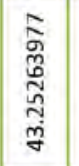 & 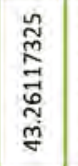 & 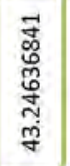 & 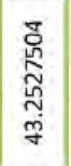 & 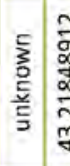 & 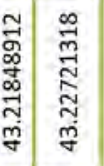 & 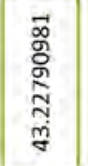 & 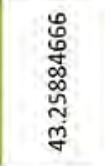 \\
\hline 这 & 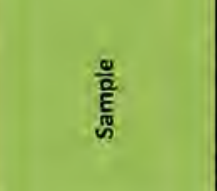 & 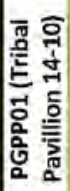 & & 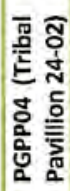 & & 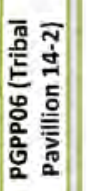 & है & 气ू & $\sum_{n=1}^{3}$ & & & & & & & 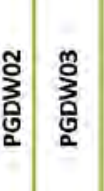 & 总 & 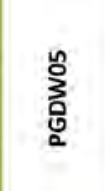 \\
\hline
\end{tabular}


DRAFT

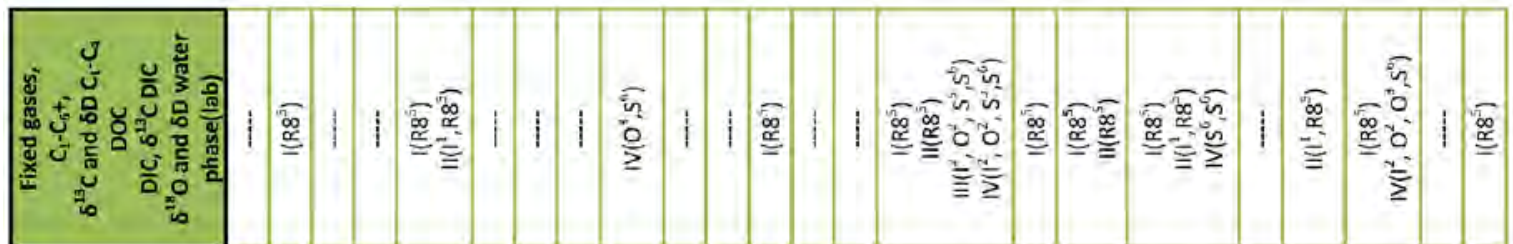

量㩊

$\underline{\underline{\underline{m}}}$

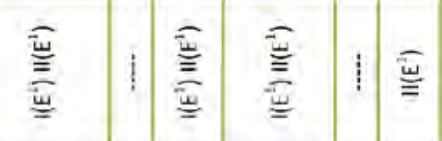

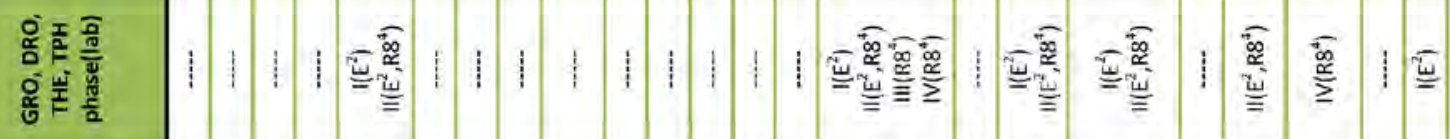

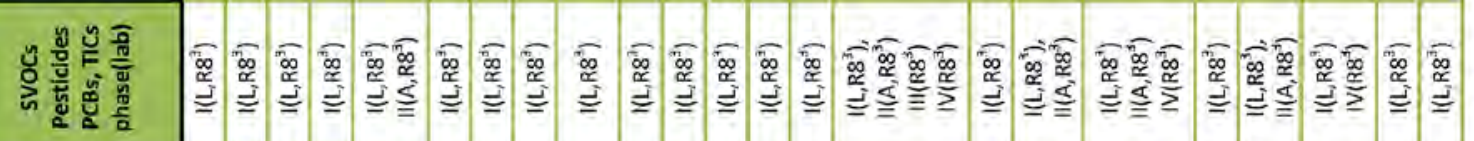

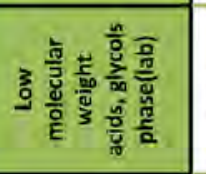

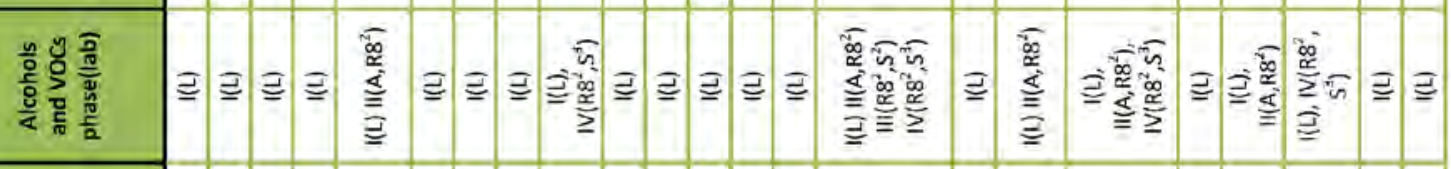

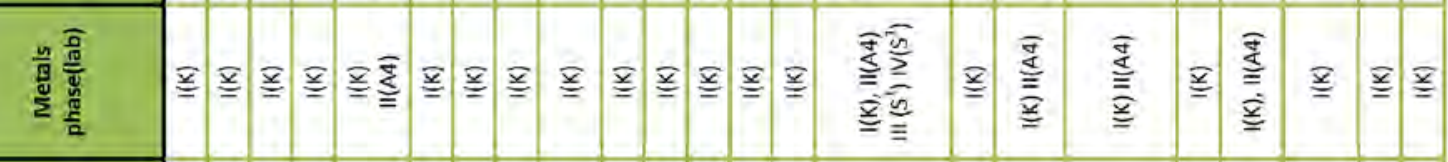

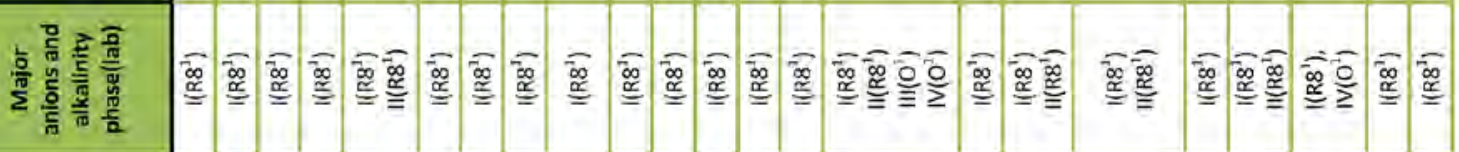

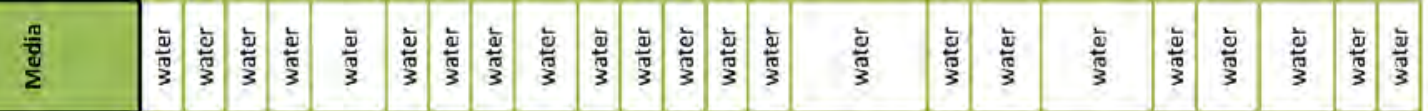

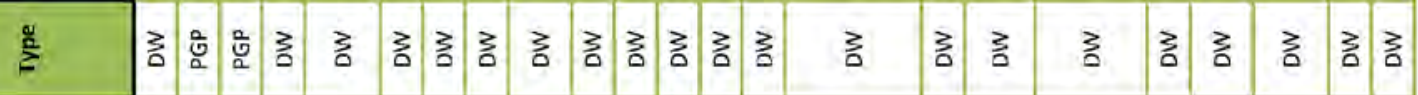

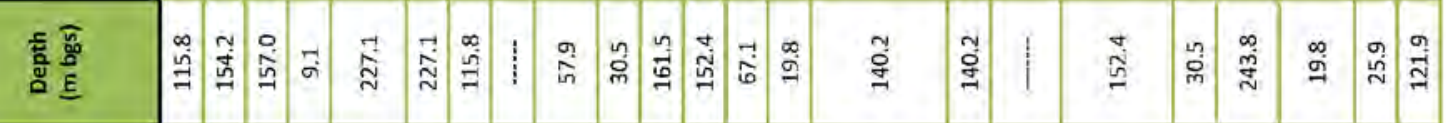

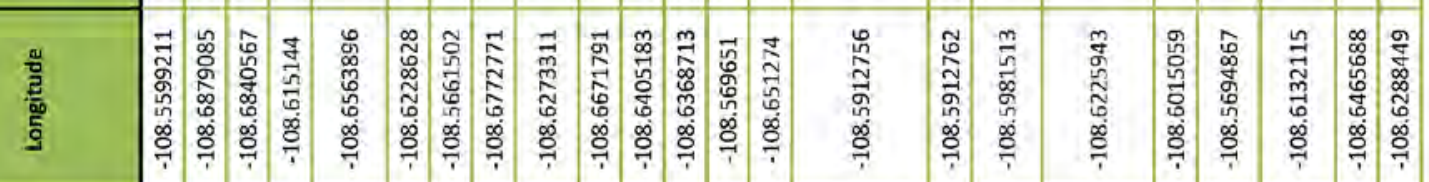

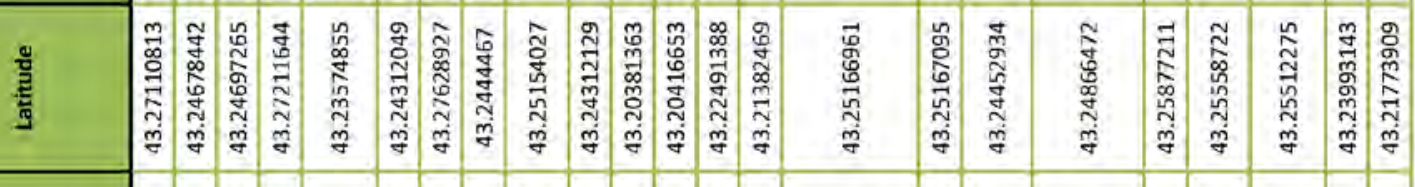

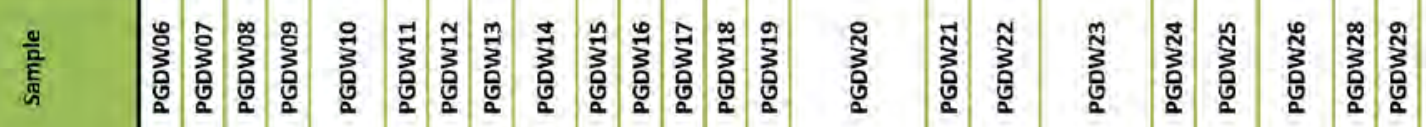


DRAFT

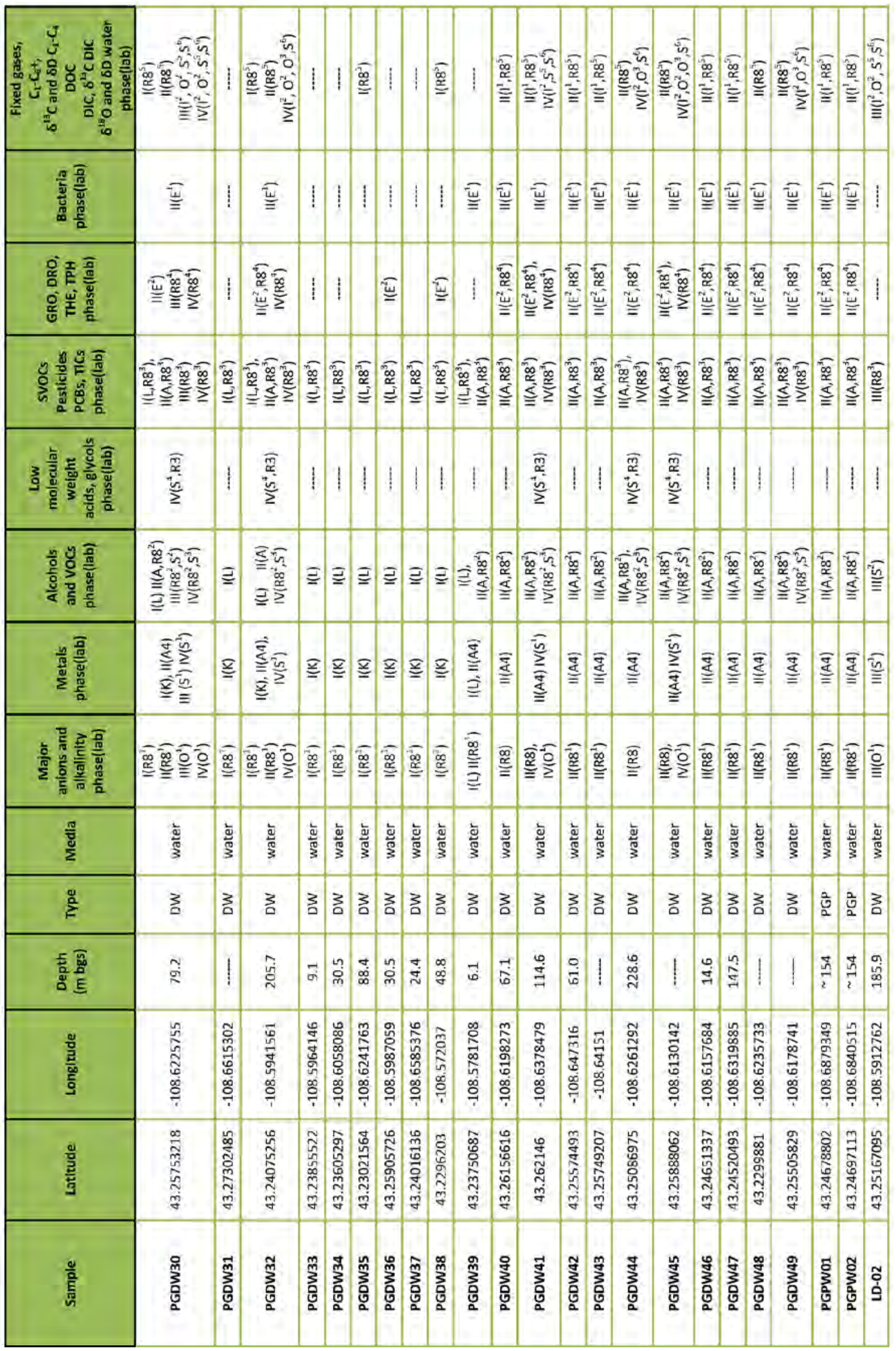




\section{DRAFT}

\section{Laboratories, Analytes, and Methods}

A - ALS Laboratory Group, Salt Lake City, UT. VOCs, SVOCs, pesticides, TCBs, TICs determined using methods specified under the CLP.

A4 - A4 Scientific, The Woodlands, TX. TAL metals determined using methods specified under the CLP.

$E^{1}$ - Energy Laboratories Inc., Billings, MT. Heterotrophic plate counts, iron reducing bacteria, sulfur reducing bacteria.

$E^{2}$ - Energy Laboratories Inc., Billings, MT. GRO, DRO, THE, and TPH.

$\mathrm{I}^{1}$ - Isotech Laboratories, Champaign, IL under contract by EnCana. Fixed gases and light hydrocarbons determined using ASTM D1945-03 in gas samples and headspace of aqueous samples. $\delta^{13} \mathrm{C}$ and $\delta \mathrm{D}$ for $\mathrm{C}_{1}$ determined using gas stripping and IRMS in aqueous samples. $\delta^{13} \mathrm{C}$ and $\delta \mathrm{D}$ for $\mathrm{C}_{1}-\mathrm{C}_{4}$ determined using IRMS for gas samples.

$I^{2}$ - Isotech Laboratories, Champaign, IL. Fixed gases and light hydrocarbons determined using ASTM D1945-03 in headspace of aqueous samples. $\delta^{13} \mathrm{C}$ and $\delta D$ for $C_{1}$ and $\delta^{13} C$ for $C_{2}$ and $C_{3}$ determined using gas stripping and IRMS in aqueous samples. $\delta^{13} C D I C$ using gas stripping and IRMS.

$I^{3}$ - Isotech Laboratories, Champaign, IL. Fixed gases and light hydrocarbons determined using ASTM D1945-03 in headspace of aqueous samples. $\delta^{13} \mathrm{C}$ and $\delta D$ for $C_{1}, \delta^{13} C$ for $C_{2}-C_{5}$, and $\delta^{13} C$ for DIC gas stripping and IRMS in aqueous samples.

$I^{4}$ - Isotech Laboratories, Champaign, IL. Fixed gases and light hydrocarbons determined using ASTM D1945-03 in gas samples. $\delta^{13} C$ and $\delta D$ for $C_{1}-C_{3}$ using IRMS in gas samples.

$I^{5}$ - Isotech Laboratories, Champaign, IL. Fixed gases and light hydrocarbons determined using ASTM D1945-03 in gas samples. $\delta^{13} C$ and $\delta D$ for $C_{1}-C_{3}$ using IRMS in gas samples. ${ }^{14} \mathrm{C}$ using AMS in gas samples.

K - KAP Laboratories, Vancouver, WA. TAL metals determined under the CLP.

L - Liberty Analytical, Salt Lake City, UT. VOCs, SVOCs, PCBs, and TICs determined under the CLP.

$\mathrm{O}^{1}$ - EPA, ORD, Ada, OK. $\mathrm{SO}_{4}, \mathrm{Cl}, \mathrm{F}$, and $\mathrm{Br}$ determined using RSKSOP $276 \mathrm{v} 3$ and EPA Method $6500 . \mathrm{NO}_{3}+\mathrm{NO}_{2}$ and $\mathrm{NH}_{4}$ determined using RSKSOP $214 \mathrm{v} 5$ and EPA Method 350.1 and 353.2

$\mathrm{O}^{2}$ - EPA, ORD, Ada, OK. DIC and DOC determined using RSKSOP-330v0 and EPA Method 9060A.

$\mathrm{O}^{3}$ - EPA, ORD, Ada, OK. $C_{1}$ determined using RSKSOP $175 \mathrm{v} 5$ and Cali-5 gas sampling bags.

R3 - U.S. EPA Region 3 Laboratory, Fort Mead, MD. Diethylene glycol, triethylene glycol, tetraethylene glycol, and 2-butoxyethanol analysis by LC/MS/MS. This method is under development with no finalized SOP. EPA Methods $8000 \mathrm{C}$ and 8321 were followed for method development and QA/QC limits where applicable.

R8 ${ }^{1}$ - U.S. EPA Region 8 Laboratory, Golden, CO (fluoride, chloride, nitrite-N, nitrate-N, orthophosphate-P, and sulfate determined using EPA Method 300.0 and EPA Region SOP 310. Alkalinity determined using EPA Method 310.0).

R8 ${ }^{2}$ - U.S. EPA Region 8 Laboratory, Golden, CO. VOCs determined using EPA Method 8260B.

R8 $8^{3}$ - U.S. EPA Region 8 Laboratory, Golden, CO. SVOCs determined using ORGM-515 r1.1 and EPA Method 8270D.

R8 ${ }^{4}$ - U.S. EPA Region 8 Laboratory, Golden, CO. GRO determined using ORGM-506 r1.0 and EPA Method 8015D. DRO determined using ORGM-508 r1.0 and EPA Method 8015D.

R8 ${ }^{5}$ - U.S. EPA Region 8 Laboratory, Golden, CO. Dissolved $C_{1}$ in Phase I and dissolved $C_{1}-C_{3}$ in Phase II using EPA Method 524.2.

$\mathrm{S}^{1}$ - Shaw Inc, Ada, OK in Phases III and IV. Metals and metals speciation determined using RSKSOP 213v4 and 257v2, or 332V0 and EPA Methods 200.7 and 6020 .

$\mathrm{S}^{2}$ - Shaw Inc, Ada, OK in Phases III and IV. Aromatics and chlorinated hydrocarbons determined using method RSKSOP-259v1 and EPA Method 5021A plus $8260 \mathrm{C}$.

$S^{3}$ - Shaw Inc, Ada, OK . Alcohols, aromatics, and chlorinated hydrocarbons determined using method RSKSOP-259v1.

$S^{4}$ - Shaw Inc, Ada, OK. Low molecular weight acids determined using RSKSOP-112v6.

$S^{5}$ - Shaw Inc, Ada, OK. Dissolved gases $C_{1}-C_{4}$ determined using RSKSOP $194 v 4$ and 175v5.

$S^{6}$ - Shaw Inc, Ada, OK. Hydrogen and oxygen isotope ratios of water determined using RSKSOP-296v0. 


\section{DRAFT}

\section{Abbreviations}

I () - Phase I(laboratory/method). Samples collected March, 2009

II() - Phase II(laboratory/method). Samples collected January, 2010

III() - Phase III(laboratory/method). Samples collected September and October 2010

IV() - Phase IV(laboratory/method). Samples collected April 2011.

PG - gas production well

MW - deep monitoring wells

PGM - shallow monitoring wells near pits

PGS - soil samples near pits

DW - domestic wells

PGP - municipal wells in the Town of Pavillion

IRMS - isotope-ratio mass spectrometry

AMS - accelerated mass spectrometry

$\mathrm{C}_{1}$ (methane), $\mathrm{C}_{2}$ (ethane), $\mathrm{C}_{3}$ (propane), $\mathrm{iC}_{4}$ (isobutane), $\mathrm{nC}_{4}$ (normal butane), $\mathrm{iC}_{5}$ (isopentane), $\mathrm{nC}_{5}$ (normal pentane), $\mathrm{C}_{6}{ }^{+}$(hexanes + other light hydrocarbons)

\section{Analytical Methods}

ORGM-506 r1.0 - Region 8 Standard Operating Procedure.

ORGM-508 r1.0 - Region 8 Standard Operating Procedure.

ORGM-515 r1.1 - Region 8 Standard Operating Procedure.

RSKSOP-112v6 - Standard Operating Procedure for Quantitative Analysis of Low Molecular Weight Acids in Aqueous Samples by HPLC, 22 p.

RSKSOP-175v5 - Sample Preparation and Calculations for Dissolved Gas Analysis in Water Samples Using a GC Headspace Equilibration Technique, 16 p.

RSKSOP-194v4 - Gas Analysis by Micro Gas Chromatographs (Agilent Mlcro 3000), 13 p.

RSKSOP-213v4 - Standard operating procedure for operation of Perkin Elmer Optima 3300 DV ICP-OES, 21 p.

RSKSOP-214v5 - Quality control procedures for general parameters analysis using Lachat Flow Injection analysis (FIA), 10 p.

RSKSOP-259v1 - Determination of volatile organic compounds (fuel oxygenates, aromatic and chlorinated hydrocarbons) in water using automated headspace gas chromatography/mass spectrometry TEKMAR 7000 HS-Varian 2100T GC/MS system-ION trap detector, 28 p.

RSKSOP-257v2 - Standard operating procedure for elemental analysis by ICP-MS, 16 p.

RSKSOP-299v1 - Determination of Volatile Organic Compounds (Fuel Oxygenates, Aromatic and Chlorinated Hydrocarbons) in Water Using Automated Headspace Gas Chromatography/Mass Spectrometry (Agilent 6890/5973 Quadruple GC/MS System), 25 p.

RSKSOP-276v3 - Determination of major anions in aqueous samples using capillary ion electrophoresis with indirect UV detection and Empower 2 software, $11 \mathrm{p}$.

RSKSOP-296v0 - Determination of hydrogen and oxygen isotope ratios in water samples using high temperature conversion elemental analyzer (TC/EA), a continuous flow unit, and an isotope ratio mass spectrometer (IRMS), $8 \mathrm{p}$.

RSKSOP-297v1 - Metals Speciation Determination by LC/ICP-MS, 21 p.

RSKSOP-298v1 - Arsenic Speciation Determination by LC/ICP-MS with Anion Suppression and NaOH Mobile Phase, 21 p.

RSKSOP-313v1 - Determination of R-123 using the H25-IR Infrared Refrigerant Gas Leak Detector, 12 p.

RSKSOP-314v1 - Determination of Fixed Gases using the GEM2000 and GEM2000 Plus Gas Analyzers \& Extraction Monitors, 13 p.

RSKSOP-320v1 - Determination of Organic and Inorganic Vapors Using the TVA-1000B Toxic Vapor Analyzer, 18 p.

RSKSOP-330v0 - Determination of Various Fractions of Carbon in Aqueous Samples Using the Shimadzu TOC-VCPH Analyzer, 16 p.

U.S. EPA Method 200.7 - Determination of Metals and Trace Elements in Water and Wastes by Inductively Coupled Plasma-Atomic Spectrometry, Rev. 5, Jan 2001.

U.S. EPA Method 300.0 - Determination of Inorganic Anions by lon Chromatography, Rev. 2.1, Aug. 1993.

U.S. EPA method 310.1 - Alkalinity (Titrimetric, pH 4.5), Rev. 1978.

U.S. EPA Method 350.1 - Determination of Ammonia Nitrogen by Semi-Automated Colorimetry, Rev. 2, Aug. 1993. 


\section{DRAFT}

U.S. EPA Method 5021A - Volatile Organic Compounds in Various Sample Matrices Using Equilibrium Headspace Analysis, Rev. 1, June 2003.

U.S. EPA Method 6020 - Inductively Coupled Plasma-Mass Spectrometry, Rev. 1, Feb. 2007.

U.S. EPA Method 6500 - Dissolved Inorganic Anions in Aqueous Matrices by Capillary Electrophoresis, Rev. 0, Feb. 2007.

U.S. EPA Method 8260C - Volatile Organic Compounds by Gas Chromatography/Mass Spectrometry (GC/MS), Rev. 3, Aug. 2006.

U.S. EPA Method 8015B - Determination of Nonhalogenated Organics Using GC/FID, Rev. 2, Dec. 1996.

U.S. EPA Method 8015D - Nonhalogenated Organics Using GC/FID, Rev. 4, May 2003.

U.S. EPA Method 8270D - Determination of Semivolatile Organic Compounds by Gas Chromatography/Mass Spectrometry (GC/MS), Rev. 4, Feb. 2007.

U.S. EPA Method 8000C - Determinative Chromatographic Separations, Rev. 3, Mar. 2003.

U.S. EPA Method 8260C - Volatile Organic Compounds by Gas Chromatography/Mass Spectrometry (GC/MS), Rev. 3, Aug. 2006.

U.S. EPA Method 8270D - Semivolatile Organic Compounds by Gas Chromatography/Mass Spectrometry (GC/MS), Rev. 4, Feb. 2007.

U.S. EPA Method 9060A - Total Organic Carbon, Rev. 1, Nov. 2004. 
DRAFT

Table A2a. Geochemical results for Pavillion ground water

\begin{tabular}{|c|c|c|c|c|c|c|c|c|c|c|c|c|}
\hline $\begin{array}{l}\text { Sample } \\
\text { ID }\end{array}$ & $\begin{array}{l}\mathrm{T} \\
\left({ }^{\circ} \mathrm{C}\right)\end{array}$ & pH & $\begin{array}{l}\mathrm{SC} \\
(\mu \mathrm{S} / \mathrm{cm})\end{array}$ & $\begin{array}{l}\text { Alkalinity } \\
\text { (mg/kg) }\end{array}$ & $\begin{array}{l}\mathrm{Na} \\
\text { (ppm) }\end{array}$ & $\begin{array}{l}\text { K } \\
\text { (ppm) }\end{array}$ & $\begin{array}{l}\mathrm{Ca} \\
\text { (ppm) }\end{array}$ & $\begin{array}{l}\mathrm{Mg} \\
\text { (ppm) }\end{array}$ & $\begin{array}{l}\mathrm{Cl} \\
\text { (ppm) }\end{array}$ & $\begin{array}{l}\mathrm{SO}_{4} \\
(\mathrm{ppm})\end{array}$ & $\begin{array}{l}\text { F } \\
\text { (ppm) }\end{array}$ & $\begin{array}{l}\mathrm{NO}_{3} \\
(\mathrm{~N}) \\
(\mathrm{ppm})\end{array}$ \\
\hline PGDW01 & ----- & ------ & ----- & 234 & 808 & 6.2 & 398 & 93.6 & 34.3 & 1860 & 0.4 & 6.2 \\
\hline PGDW02 & 13.4 & 8.11 & 551 & 108 & 86 & 1.8 & 34.8 & 5.3 & 2.6 & 175 & 0.7 & $<0.5$ \\
\hline PGDW03 & 11.1 & 9.37 & 1333 & 40 & 272 & 0.4 & 16.3 & 0.3 & 25.1 & 549 & 0.9 & $<0.5$ \\
\hline PGDW04 & 11.8 & 9.17 & 1370 & 29 & 270 & 0.4 & 18.0 & 0.1 & 21.6 & 551 & 0.9 & $<0.5$ \\
\hline PGDW05 & 12.0 & 9.02 & 956 & 93 & 192 & 0.3 & 3.6 & 0.1 & 17 & 295 & 0.9 & $<0.5$ \\
\hline PGDW06 & 13.8 & 10.20 & 1262 & 35 & 249 & 0.3 & 7.1 & $<0.1$ & 31 & 485 & 1.3 & $<0.5$ \\
\hline PGDW07 & 12.4 & 8.85 & 1016 & 61 & 213 & 0.3 & 8.9 & 0.1 & 15.7 & 390 & 1.2 & $<0.5$ \\
\hline PGDW08 & 12.4 & 8.57 & 1883 & 83 & 390 & 0.6 & 36.7 & 0.2 & 18.9 & 857 & 0.5 & $<0.5$ \\
\hline PGDW09 & 12.4 & 8.35 & 1128 & 254 & 233 & 2.1 & 16.6 & 4.1 & 10.5 & 279 & 2.4 & 3.2 \\
\hline PGDW10 & 12.2 & 8.95 & 948 & 147 & 204 & 0.4 & 6.1 & 0.1 & 8.0 & 293 & 0.9 & $<0.5$ \\
\hline PGDW11 & 13.1 & 7.17 & 3400 & 312 & 423 & 5.5 & 363 & 80.9 & 15.3 & 1780 & 0.2 & 1.3 \\
\hline PGDW12 & 12.4 & 10.04 & 1344 & 37 & 256 & 0.6 & 7.8 & 0.4 & 30.8 & 497 & 1.5 & $<0.5$ \\
\hline PGDW13 & 10.9 & 6.89 & 1155 & 303 & 196 & 1.9 & 61.0 & 19.9 & 6.2 & 343 & 0.7 & 1.0 \\
\hline PGDW14 & 10.8 & 7.85 & 2990 & 159 & 690 & 4.5 & 154 & 18.1 & 26.1 & 1820 & 0.4 & 0.7 \\
\hline PGDW15 & 11.4 & 7.48 & 1728 & 277 & 269 & 1.2 & 72.2 & 10.2 & 9.9 & 520 & 0.6 & 1.8 \\
\hline PGDW16 & 13.2 & 9.30 & 1011 & 145 & 188 & 0.3 & 6.4 & 0.1 & 13.4 & 258 & 0.8 & $<0.5$ \\
\hline PGDW17 & 12.7 & 9.61 & 1490 & 21 & 278 & 0.4 & 21.2 & 0.5 & 49.5 & 583 & 2.0 & $<0.5$ \\
\hline PGDW18 & 10.3 & 8.87 & 2002 & 21 & 509 & 0.8 & 84.5 & 0.3 & 27 & 1380 & 1.8 & 0.5 \\
\hline PGDW19 & 11.8 & 7.75 & 707 & 291 & 194 & 1.4 & 29.0 & 3.2 & 6.9 & 196 & 0.9 & 2.6 \\
\hline PGDW20 & 9.3 & 8.76 & 2005 & 70 & 520 & 1.0 & 79.3 & 9.3 & 34.5 & 1370 & 0.8 & $<0.5$ \\
\hline PGDW22 & 8.3 & 6.93 & 6180 & 332 & 837 & 9.0 & 416 & 126 & 79.9 & 2720 & $<0.2$ & 43.6 \\
\hline PGDW23 & 11.5 & 9.43 & 816 & 61 & 208 & 0.3 & 6.5 & 0.1 & 19.8 & 365 & 1.2 & $<0.5$ \\
\hline PGDW24 & 9.7 & 7.65 & 4700 & 165 & 938 & 7.0 & 327 & 131 & 55.7 & 3200 & 0.6 & $<0.5$ \\
\hline PGDW25 & 13.3 & 8.68 & 972 & 205 & 249 & 1.1 & 1.1 & 1.1 & 8.4 & 355 & 4.1 & $<0.5$ \\
\hline PGDW26 & 9.2 & 7.13 & 2390 & 337 & 220 & 6.8 & 364 & 57.7 & 14.6 & 1240 & 0.7 & 1.5 \\
\hline PGDW28 & 10.7 & 8.30 & 1170 & 258 & 239 & 2.2 & 40.6 & 12.9 & 16.7 & 298 & 0.5 & 3.7 \\
\hline PGDW/29 & 11.5 & 9.72 & 1442 & 52 & 298 & 0.4 & 19.7 & 0.5 & 52.3 & 596 & 0.9 & $<0.5$ \\
\hline PGDW30 & 10.4 & 9.60 & 902 & 96 & 210 & 0.3 & 0.9 & 0.1 & 16.3 & 331 & 0.9 & $<0.5$ \\
\hline PGDW31 & 9.0 & 8.60 & 2006 & 83 & 435 & 0.9 & 31.2 & 0.8 & 13.3 & 1030 & 0.4 & 0.5 \\
\hline PGDW32 & 9.5 & 10.47 & 908 & 34 & 199 & 0.3 & 7.2 & $<0.1$ & 34.1 & 373 & 2.3 & $<0.5$ \\
\hline PGDW33 & 3.7 & 7.77 & 1662 & 276 & 178 & 5.0 & 228 & 40.9 & 28 & 670 & 0.2 & 2.1 \\
\hline PGDW34 & 8.3 & 7.87 & 4480 & 373 & 786 & 7.4 & 325 & 113 & 23 & 2690 & 0.5 & 3.5 \\
\hline PGDW35 & 10.6 & 8.63 & 2810 & 84 & 587 & 1.1 & 118 & 1.1 & 24.1 & 1610 & 0.3 & 0.5 \\
\hline PGDW36 & 9.8 & 7.62 & 649 & 232 & 42 & 2.6 & 89.5 & 28.9 & 3.2 & 195 & 1.0 & 1.2 \\
\hline PGDW37 & 10.5 & 8.14 & 819 & 342 & 187 & 0.9 & 12.1 & 1.3 & 8.7 & 89.9 & 0.9 & 1.2 \\
\hline PGDW38 & 9.5 & 8.68 & 2030 & 47 & 373 & 2.3 & 70.0 & 2.3 & 46.9 & 908 & 1.3 & 5.9 \\
\hline PGDW39 & 6.1 & 1.19 & 6410 & 121 & 1110 & $b .3$ & 389 & $14 /$ & $\mathrm{b} 2.9$ & 3640 & 0.4 & 0.6 \\
\hline PGDW40 & 11.5 & 9.06 & 1229 & 86 & 244 & 5.0 & 6.6 & 5.0 & 13.1 & 426 & -...-. & $<0.3$ \\
\hline PGDW41 & 7.2 & 7.63 & 4470 & 108 & 1030 & 2.7 & 270 & 57.5 & 31.4 & 2670 & 0.5 & $<0.3$ \\
\hline PGDW42 & 12.1 & 9.18 & 888 & 89 & 181 & 5.0 & 5.1 & 5.0 & 13.2 & 311 & 1.0 & $<0.3$ \\
\hline PGDW43 & 0.2 & 8.19 & 4410 & 113 & 911 & 5.0 & 208 & 13.7 & 38.4 & 2470 & 0.4 & $<0.3$ \\
\hline PGDW44 & 9.4 & 8.13 & 4080 & 100 & 994 & 5.0 & 259 & 28.3 & 39.5 & 2880 & 0.3 & $<0.3$ \\
\hline PGDW45 & 9.3 & 7.63 & 1103 & 379 & 59 & 2.6 & 138 & 31.2 & 14.5 & 213 & 1.9 & 0.3 \\
\hline PGDW46 & 7.9 & 7.79 & 855 & 329 & 91 & 1.8 & 90.3 & 9.9 & 8.4 & 126 & 0.5 & 2.3 \\
\hline PGDW47 & 8.2 & 9.52 & 970 & 44 & 183 & 5.0 & 6.9 & 5.0 & 21.6 & 330 & 1.5 & $<0.3$ \\
\hline PGDW48 & 8.7 & 8.21 & 3550 & 90 & 725 & 5.0 & 147 & 4.4 & 24.1 & 1840 & 0.3 & $<0.3$ \\
\hline PGDW49 & 7.8 & 7.66 & 5470 & 243 & 1210 & 11.4 & 486 & 153 & 64.3 & 3160 & 0.4 & 7.7 \\
\hline PGDW03-0110 & 8.3 & 8.71 & 1390 & 28 & 251 & 5.0 & 16.3 & 5.0 & 20.7 & 570 & 0.8 & $<0.3$ \\
\hline PGDW04-0110 & 8.3 & 9.07 & 1388 & 38 & 265 & 5.0 & 15.5 & 5.0 & 23.3 & 532 & 0.9 & ----- \\
\hline PGDW05-0110 & 9.4 & 8.22 & 900 & 88 & 188 & 5.0 & 3.3 & 5.0 & 16.5 & 287 & 0.9 & $<0.3$ \\
\hline PGDW10-0110 & 10.4 & 8.62 & 985 & 147 & 195 & 5.0 & 5.8 & 5.0 & 7.5 & 293 & 0.9 & $<0.3$ \\
\hline PGDW20-0110 & 9.3 & 8.89 & 2690 & 68 & 550 & 5.0 & 71.7 & 8.1 & 32.6 & 1270 & 0.8 & $<0.3$ \\
\hline PGDW22-0110 & 8.2 & 7.06 & 4230 & 337 & 908 & 5.8 & 397 & 130 & 74.6 & 2780 & ----- & 40.7 \\
\hline PGDW23-0110 & 8.2 & 9.72 & 780 & 54 & 194 & 5.0 & 5.8 & 5.0 & 19.7 & 368 & 1.5 & $<0.3$ \\
\hline PGDW25-0110 & 7.2 & 7.94 & 1511 & 295 & 269 & 5.0 & 70.1 & 9.6 & 9.5 & 441 & $\cdots$ & 1.7 \\
\hline PGDW30-0110 & 9.2 & 9.39 & 967 & 94 & 195 & 5.0 & 4.1 & 5.0 & 15.5 & 333 & 0.9 & $<0.3$ \\
\hline PGDW32-0110 & 8.3 & 9.87 & 1018 & 32 & 193 & 5.0 & 6.9 & 5.0 & 21.4 & 368 & 2.4 & $<0.3$ \\
\hline
\end{tabular}


DRAFT

\begin{tabular}{|c|c|c|c|c|c|c|c|c|c|c|c|c|}
\hline $\begin{array}{l}\text { Sample } \\
\text { ID }\end{array}$ & $\begin{array}{l}\mathrm{T} \\
\left({ }^{\circ} \mathrm{C}\right)\end{array}$ & pH & $\begin{array}{l}\mathrm{SC} \\
(\mu \mathrm{S} / \mathrm{cm})\end{array}$ & $\begin{array}{l}\text { Alkalinity } \\
\mathrm{mg} / \mathrm{kg}\end{array}$ & $\begin{array}{l}\mathrm{Na} \\
\text { (ppm) }\end{array}$ & $\begin{array}{l}\text { K } \\
\text { (ppm) }\end{array}$ & $\begin{array}{l}\mathrm{Ca} \\
\text { (ppm) }\end{array}$ & $\begin{array}{l}\mathrm{Mg} \\
(\mathrm{ppm})\end{array}$ & $\begin{array}{l}\mathrm{Cl} \\
(\mathrm{ppm})\end{array}$ & $\begin{array}{l}\mathrm{SO}_{4} \\
(\mathrm{ppm})\end{array}$ & $\begin{array}{l}\text { F } \\
(\mathrm{ppm})\end{array}$ & $\begin{array}{l}\mathrm{NO}_{3} \\
\text { (N) } \\
\text { (ppm) }\end{array}$ \\
\hline MW01 & 11.8 & 11.91 & 3265 & 430 & 334 & 54.9 & 15.6 & 0.05 & 23.3 & 398 & 1.6 & 0.15 \\
\hline MW02 & 12.3 & 12.01 & 3812 & 456 & 420 & 39.5 & 73.3 & 0.03 & 466 & 12.1 & 1.0 & 0.38 \\
\hline RD01 & 11.5 & 9.24 & 1068 & 78 & 208 & 0.2 & 4.3 & 0.10 & 15.2 & 357 & 1.0 & 0.23 \\
\hline LD01 & 10.9 & 8.85 & 2940 & 54 & 562 & 1.1 & 71.9 & 8.1 & 33.0 & 1320 & 0.9 & 0.35 \\
\hline PGDW05-0411 & 10.5 & 9.06 & 820 & 80 & 190 & 0.24 & 3.35 & 0.08 & 16.8 & 276 & 1.2 & ND \\
\hline PGDW14-0411 & 8.5 & 7.73 & 3473 & 156 & 753 & 3.52 & 154 & 18.6 & 23.7 & 1760 & $<0.05$ & 0.36 \\
\hline PGDW20-0411 & 8.3 & 8.59 & 2430 & 102 & 520 & 0.78 & 63 & 6.86 & 22.9 & 1150 & 1.3 & $<0.03$ \\
\hline PGDW23-0411 & 11.0 & 9.07 & 959 & 72 & 208 & 0.31 & 6.7 & 0.17 & 19.9 & 365 & 1.6 & $<0.03$ \\
\hline PGDW26-0411 & 8.3 & 6.95 & 2390 & 196 & 232 & 5.15 & 334 & 56 & 13.2 & 1180 & 1.0 & 1.37 \\
\hline PGDW30-0411 & 10.4 & 8.92 & 938 & 82 & 210 & 0.29 & 4.5 & 0.09 & 16.1 & 327 & 1.1 & $<0.03$ \\
\hline PGDW32-0411 & 11.1 & 9.30 & 885 & 46 & 198 & 0.09 & 7.2 & 0.03 & 18.8 & 361 & 2.0 & $<0.03$ \\
\hline PGDW41-0411 & 8.2 & 7.05 & 4866 & 112 & 896 & 3.18 & 452 & 46.9 & 97.6 & 2640 & $<0.05$ & 17.5 \\
\hline PGDW44-0411 & 10.0 & 8.17 & 4730 & 94 & 1060 & 2.09 & 259 & 19.2 & 32.1 & 2900 & $<0.05$ & $<0.03$ \\
\hline PGDW45-0411 & 9.1 & 6.85 & 1085 & 364 & 61.6 & 2.81 & 159 & 34.5 & 18.4 & 251 & 1.7 & 0.64 \\
\hline PGDW49-0411 & 10.4 & 7.34 & 5333 & 296 & 982 & 9.66 & 417 & 127 & 54.3 & 3200 & $<0.05$ & 8.75 \\
\hline MW01-0411 & 11.2 & 11.24 & 2352 & 388 & 304 & 24.7 & 13.6 & 0.12 & 23.1 & 339 & 1.9 & $<0.03$ \\
\hline MW02-0411 & 12.0 & 11.78 & 3099 & 482 & 448 & 43.6 & 60.5 & 0.03 & 457 & 63 & 1.5 & $<0.03$ \\
\hline
\end{tabular}

----- not measured. SC - specific conductance. Alkalinity $-\mathrm{mg} / \mathrm{kg} \mathrm{CaCO}$. Other cations detected include $\mathrm{Al}$ ( 0.05 to $0.74 \mathrm{ppm}$ ), Ba (0.01 to 0.21 ppm), Fe (<0.02 to $2.4 \mathrm{ppm}), \mathrm{Mn}(<0.01$ to $0.23 \mathrm{ppm}), \mathrm{NH}_{4}{ }^{+}(0.4$ to $4.6 \mathrm{ppm})$, and $\mathrm{Sr}$ (0.06 to 8.4 ppm). Sulfide was detected in LD01 (0.16 ppm, Phase III, same location as PGDW20), PGDW20 (0.12 ppm, Phase IV), and MW01 (1.1 ppm Phase III, 1.8 ppm Phase IV). Turbidity ranged from 1.7 to 29.7 in domestic wells (Phase III and IV). Turbidity in MW01 was 7.5 (Phase III) and 7.9 (Phase IV). Turbidity in MW02 was 28.8 (Phase III) and 24.0 (Phase IV). All turbidity values are in Nephelometric Turbidity Units (NTUs). Turbidity measurements in MW01 and MW02 could be impacted by gas exsolution.

Table A2b. Charge balance calculations for deep monitoring wells

\begin{tabular}{|c|c|c|c|c|c|c|c|c|c|c|c|c|c|}
\hline Well & Phase & $\begin{array}{l}\text { Ca, } \\
\text { meq }\end{array}$ & $\begin{array}{l}\text { Mg, } \\
\text { meq }\end{array}$ & $\begin{array}{l}\mathrm{Na}, \\
\mathrm{meq}\end{array}$ & $\begin{array}{l}\mathrm{K} \text {, } \\
\text { meq }\end{array}$ & $\begin{array}{l}\mathrm{SO}_{4} \\
\text { meq }\end{array}$ & $\begin{array}{l}\mathrm{CO}_{3} \\
\text { meq }\end{array}$ & $\begin{array}{l}\mathrm{Cl}, \\
\text { meq }\end{array}$ & $\begin{array}{l}\mathrm{F}, \\
\text { meq }\end{array}$ & $\begin{array}{l}\text { OH, } \\
\text { meq }\end{array}$ & $\begin{array}{l}\text { ¿cat, } \\
\text { meq }\end{array}$ & $\begin{array}{l}\text { इan, } \\
\text { meq }\end{array}$ & $\begin{array}{c}\text { Balance, } \\
\%\end{array}$ \\
\hline & & \multicolumn{4}{|c|}{ cations } & \multicolumn{5}{|c|}{ anions } & & & \\
\hline MW01 & III & 0.78 & 0.00 & 14.53 & 1.40 & 8.29 & 4.48 & 0.66 & 0.08 & 9.56 & 16.71 & 23.08 & 16.0 \\
\hline MW02 & III & 3.66 & 0.00 & 18.27 & 1.01 & 0.25 & 3.40 & 13.14 & 0.05 & 12.04 & 22.94 & 28.89 & 11.5 \\
\hline MW01 & IV & 0.68 & 0.01 & 13.22 & 0.63 & 7.06 & 2.12 & 0.65 & 0.10 & 1.97 & 14.54 & 11.90 & 10.0 \\
\hline MW02 & IV & 3.02 & 0.00 & 19.49 & 1.12 & 1.30 & 0.23 & 12.89 & 0.08 & 7.01 & 23.62 & 21.52 & 4.7 \\
\hline
\end{tabular}

Balance $(\%)=\mid\left(\sum\right.$ cat $-\sum$ an $) /\left(\sum \text { cat }+\sum \text { an }\right)^{*} 100 \mid$. meq OH is calculated as $1000^{*}\left[a_{\mathrm{OH}^{-}} / \mathrm{YOH}_{\mathrm{OH}}\right]$, where $a_{\mathrm{OH}^{-}}=10^{-(14-\mathrm{pH})}$ and $\gamma_{\mathrm{OH}^{-}}=0.85$ to 0.88 . meq $\mathrm{CO}_{3}$ is estimated from measurements of Dissolved Inorganic Carbon (DIC) as $2^{*}[\mathrm{DIC} / 12]$, where $\mathrm{DIC}$ is in $\mathrm{mg} / \mathrm{L}$. 
DRAFT

\begin{tabular}{|c|c|c|c|c|c|c|}
\hline Sample (matrix) & Phase & Date & $\begin{array}{c}C_{1} \\
\text { (ug/l) }\end{array}$ & $\begin{array}{c}C_{2} \\
\text { (ug/I) }\end{array}$ & $\begin{array}{c}C_{3} \\
\text { (ug/I) }\end{array}$ & $\begin{array}{c}\mathrm{C}_{4} \\
\text { (ug/I) }\end{array}$ \\
\hline MW01(w) & III & $10 / 6 / 2010$ & 15950 & 2230 & 790 & 158 \\
\hline MW01(w) & IV & $4 / 20 / 2011$ & 17930 & 2950 & 1250 & 172 \\
\hline MW02(w) & III & $10 / 6 / 2010$ & 18990 & 3290 & 1820 & 355 \\
\hline MW02(w) & IV & $4 / 19 / 2011$ & 18820 & 2550 & 2260 & 276 \\
\hline MW02(w)-dup & IV & $4 / 19 / 2011$ & 22620 & 3120 & 2770 & 356 \\
\hline PGMW01(w) & $\|$ & $01 / 21 / 10$ & 474 & $\mathrm{nd}(10)$ & $\mathrm{nd}(15)$ & $\cdots$ \\
\hline PGMW02(w) & ॥ & $01 / 21 / 10$ & 361 & 299 & 43.8 & -...-. \\
\hline PGMW03(w) & II & $01 / 21 / 10$ & 528 & $\mathrm{nd}(10)$ & $n d(15)$ & -..-- \\
\hline PGDW03(w) & ॥ & $01 / 20 / 10$ & $\mathrm{nd}(5.0)$ & $\mathrm{nd}(10)$ & $n d(15)$ & --.-- \\
\hline PGDW04(w) & 1 & 03/03/09 & $n d(5.0)$ & $\ldots$ & -.-- & $\ldots$ \\
\hline PGDW04(w) & ॥ & $01 / 21 / 10$ & $\operatorname{nd}(5.0)$ & $\mathrm{nd}(10)$ & $n d(15)$ & $\ldots$ \\
\hline PGDW05(w) & 1 & 03/03/09 & 16.6 & (-.... & -..-- & $\ldots$ \\
\hline PGDW05(w) & ॥ & $01 / 18 / 10$ & 5.44 & $\mathrm{nd}(10)$ & $\mathrm{nd}(15)$ & -..-- \\
\hline PGDW05(w) & IV & $04 / 19 / 11$ & $65^{*}$ & discarded & $\mathrm{nd}(1.3)$ & $\mathrm{nd}(1.6)$ \\
\hline PGDW07(w) & 1 & $03 / 03 / 09$ & $\operatorname{nd}(5.0)$ & $\ldots$ & $\ldots$ & 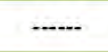 \\
\hline PGDW10(w) & 1 & 03/03/09 & $\mathrm{nd}(5.0)$ & -...- & $-\cdots$ & -..-- \\
\hline PGDW10(w) & ॥ & $01 / 18 / 10$ & $\mathrm{nd}(5.0)$ & $\mathrm{nd}(10)$ & nd(15) & $\cdots$ \\
\hline PGDW14(w) & IV & $04 / 20 / 11$ & discarded & $\mathrm{nd}(1.3)$ & $\mathrm{nd}(1.4)$ & $\mathrm{nd}(1.7)$ \\
\hline PGDW17(w) & 1 & $03 / 04 / 09$ & 10.6 & $\ldots$ & -..- & $\ldots$ \\
\hline PGDW20(w) & 1 & $03 / 04 / 09$ & 137 & $\cdots$ & $\cdots$ & $\cdots$ \\
\hline PGDW20 (w) & III & $10 / 06 / 10$ & 189 & 24.3 & $\mathrm{nd}(0.22)$ & $\mathrm{nd}(0.21)$ \\
\hline PGDW20(w)-dup & III & $10 / 06 / 10$ & 168 & 17.4 & $\mathrm{nd}(0.22)$ & $\mathrm{nd}(0.21)$ \\
\hline PGDW2O(w) & IV & $04 / 18 / 11$ & 137 & discarded & $n d(1,43)$ & 2.93 \\
\hline PGDW21(w) & 1 & $03 / 04 / 09$ & 54.3 & -..- & $\cdots$ & --- \\
\hline PGDW22(w) & 1 & $03 / 04 / 09$ & $\mathrm{nd}(5.0)$ & …-. & $\cdots$ & -.... \\
\hline PGDW22(w) & II & $01 / 18 / 10$ & $n d(5.0)$ & $\mathrm{nd}(10)$ & $n d(15)$ & -.-- \\
\hline PGDW23(w) & 1 & 03/04/09 & 146 & -...- & $-\cdots$ & $\ldots$ \\
\hline PGDW23(w) & $\|$ & $01 / 18 / 10$ & 149 & $\mathrm{nd}(10)$ & nd(15) & ..... \\
\hline PGDW23(w) & IV & $04 / 21 / 11$ & 176 & $\mathrm{nd}(5.7)$ & $\mathrm{nd}(6.6)$ & $\mathrm{nd}(6.9)$ \\
\hline PGDW25(w) & ॥ & $01 / 19 / 10$ & $\mathrm{nd}(5.0)$ & $\mathrm{nd}(10)$ & $\mathrm{nd}(15)$ & (....... \\
\hline PGDW26(w) & 1 & $03 / 05 / 09$ & $\mathrm{nd}(5.0)$ & -.--- & -.-.- & …-. \\
\hline PGDW26(w) & IV & $04 / 18 / 11$ & $\mathrm{nd}(2.2)^{*}$ & $\mathrm{nd}(1.4)$ & $\mathrm{nd}(1.5)$ & $\mathrm{nd}(1.8)$ \\
\hline PGDW29(w) & 1 & $03 / 05 / 09$ & $\mathrm{nd}(5.0)$ & $\ldots$ & $\ldots$ & w... \\
\hline PGDW30(w) & 1 & 03/05/09 & 558 & $\ldots$ & $\ldots$ & -.... \\
\hline PGDW30(w) & $\|$ & $01 / 19 / 10$ & 808 & $\mathrm{nd}(10)$ & nd(15) & $\ldots$ \\
\hline PGDW30(w) & III & $10 / 05 / 10$ & 762 & $n d(0.19)$ & $\mathrm{nd}(0.23)$ & $\mathrm{nd}(0.21)$ \\
\hline PGDW30(w) & IV & $04 / 18 / 11$ & 644 & discarded & $\mathrm{nd}(1.5)$ & 4.6 \\
\hline PGDW32(w) & 1 & $03 / 05 / 09$ & 21.4 & -..- & $\cdots$ & -.- \\
\hline
\end{tabular}


DRAFT

\begin{tabular}{|c|c|c|c|c|c|c|}
\hline Sample (matrix) & Phase & Date & $\underset{\text { (ug/l) }}{C_{1}}$ & $\begin{array}{c}\mathrm{C}_{2} \\
\text { (ug/l) }\end{array}$ & $\begin{array}{c}C_{3} \\
(\mathrm{ug} / \mathrm{l})\end{array}$ & $\underset{\text { (ug/l) }}{\mathrm{C}_{4}}$ \\
\hline PGDW32(w) & ॥ & $01 / 20 / 10$ & 36.3 & $\mathrm{nd}(10.0)$ & $\mathrm{nd}(15.0)$ & $\ldots$ \\
\hline PGDW32(w) & IV & $04 / 18 / 11$ & $\mathrm{nd}(2.2)^{*}$ & $\mathrm{nd}(1.2)$ & $\mathrm{nd}(1.3)$ & $\mathrm{nd}(1.5)$ \\
\hline PGDW32(w)-dup & IV & $04 / 18 / 11$ & discarded & discarded & $\mathrm{nd}(1.4)$ & discarded \\
\hline PGDW35(w) & 1 & 03/05/09 & 21.6 & -.... & $-\cdots$ & -...- \\
\hline PGDW38(w) & I & 03/05/09 & $\mathrm{nd}(5.0)$ & $\cdots$ & $-\cdots$ & $\ldots$ \\
\hline PGDW39(w) & II & $01 / 19 / 10$ & $\mathrm{nd}(5.0)$ & $n d(10.0)$ & $\mathrm{nd}(15.0)$ & -..- \\
\hline PGDW40(w) & ॥ & $01 / 22 / 10$ & 98.9 & $\mathrm{nd}(10.0)$ & $\mathrm{nd}(15.0)$ & ...... \\
\hline PGDW41(w) & ॥ & $01 / 21 / 10$ & $n d(5.0)$ & $n d(10.0)$ & $\mathrm{nd}(15.0)$ & $\cdots$ \\
\hline PGDW41(w) & IV & $04 / 20 / 11$ & 385 & 142 & $\mathrm{nd}(1.35)$ & discarded \\
\hline PGDW42(w) & ॥ & $01 / 19 / 10$ & 60 & $n d(10.0)$ & $\mathrm{nd}(15.0)$ & -.--- \\
\hline PGDW43(w) & ॥ & $01 / 21 / 10$ & $n d(5.0)$ & $\mathrm{nd}(10.0)$ & $\mathrm{nd}(15.0)$ & -..-- \\
\hline PGDW44(w) & ॥ & $01 / 18 / 10$ & $\mathrm{nd}(5.0)$ & $\mathrm{nd}(10.0)$ & $\mathrm{nd}(15.0)$ & $\ldots$ \\
\hline PGDW44(w) & IV & $4 / 21 / 2011$ & $\mathrm{nd}(2.2)^{*}$ & $\mathrm{nd}(1.3)$ & $n d(1.4)$ & $\mathrm{nd}(1.7)$ \\
\hline PGDW45(w) & $\|$ & $01 / 18 / 10$ & $n d(5.0)$ & $n d(10.0)$ & $\mathrm{nd}(15.0)$ & --.- \\
\hline PGDW45(w) & IV & $04 / 19 / 11$ & $\mathrm{nd}(2.2)^{*}$ & discarded & $\mathrm{nd}(1.3)$ & $\mathrm{nd}(1.6)$ \\
\hline PGDW46(w) & $\|$ & $01 / 20 / 10$ & $n d(5.0)$ & $n d(10.0)$ & $\mathrm{nd}(15.0)$ & -.-. \\
\hline PGDW47(w) & ॥ & $01 / 19 / 10$ & $\mathrm{nd}(5,0)$ & $\mathrm{nd}(10.0)$ & $\mathrm{nd}(15.0)$ & $\cdots$ \\
\hline PGDW48(w) & ॥ & $01 / 20 / 10$ & $n d(5.0)$ & $\mathrm{nd}(10.0)$ & $\mathrm{nd}(15.0)$ & - \\
\hline PGDW49(w) & ॥ & $01 / 20 / 10$ & $\mathrm{nd}(5.0)$ & $n d(10.0)$ & $\mathrm{nd}(15.0)$ & $\cdots$ \\
\hline PGDW49(w) & IV & $4 / 20 / 2011$ & $\mathrm{nd}(2.2)^{*}$ & discarded & $\mathrm{nd}(1.3)$ & $\mathrm{nd}(1.6)$ \\
\hline $\operatorname{LD02}(w)$ & III & $10 / 20 / 2010$ & 229 & 21 & $\mathrm{nd}(0.24)$ & $\mathrm{nd}(0.23)$ \\
\hline PGPW01(w) & ॥ & $01 / 20 / 10$ & $n d(5.0)$ & $n d(10.0)$ & $\mathrm{nd}(15.0)$ & $-\cdots$ \\
\hline PGPW02(w) & ॥ & $01 / 20 / 10$ & $n d(5.0)$ & $n d(10.0)$ & $\mathrm{nd}(15.0)$ & $\ldots$ \\
\hline Travel Blank(w) & III & $10 / 6 / 2010$ & 23.3 & $\mathrm{nd}(2.0)$ & $\mathrm{nd}(0.24)$ & $\mathrm{nd}(0.23)$ \\
\hline $\begin{array}{c}\text { Equipment } \\
\text { Blank(w) }\end{array}$ & III & $10 / 6 / 2010$ & 23.0 & $\mathrm{nd}(2.0)$ & $\mathrm{nd}(0.29)$ & $\mathrm{nd}(0.27)$ \\
\hline Field Blank(w) & III & $10 / 6 / 2010$ & 76.4 & $\mathrm{nd}(2.0)$ & $\mathrm{nd}(0.28)$ & $\mathrm{nd}(0.26)$ \\
\hline Travel Blank(w) & IV & $4 / 14 / 2011$ & 18.5 & 56.4 & $n d(1.63)$ & $\mathrm{nd}(1.6)$ \\
\hline Field Blank(w) & IV & $4 / 18 / 2011$ & 45.0 & 67.9 & $\mathrm{nd}(1.36)$ & $\mathrm{nd}(1.66)$ \\
\hline $\begin{array}{c}\text { equipment } \\
\text { blank(w) (on-site } \\
\text { GC analysis) }\end{array}$ & IV & $4 / 18 / 2011$ & $\mathrm{nd}(2.2)$ & $-\cdots$ & -..- & $-\cdots$ \\
\hline $\begin{array}{c}\text { equipment } \\
\text { blank(w) (on-site } \\
\text { GC analysis) }\end{array}$ & IV & $4 / 19 / 2011$ & $\mathrm{nd}(2.2)$ & -..- & $\ldots$ & $\cdots$ \\
\hline $\begin{array}{c}\text { equipment } \\
\text { blank(w) (on-site } \\
\text { GC analysis) }\end{array}$ & IV & $4 / 20 / 2011$ & $\mathrm{nd}(2.2)$ & $-\cdots$ & $\cdots$ & -... \\
\hline $\begin{array}{c}\text { equipment } \\
\text { blank(w) (on-site } \\
\text { GC analysis) }\end{array}$ & IV & $4 / 20 / 2011$ & $\mathrm{nd}(2.2)$ & --.- & --.-. & -.--.- \\
\hline field blank(w) & IV & $4 / 21 / 2011$ & $\mathrm{nd}(0.32)$ & $\mathrm{nd}(1.18)$ & $\mathrm{nd}(1.27)$ & $\mathrm{nd}(1.54)$ \\
\hline
\end{tabular}

* Determined by on-site GC analysis in Phase IV. Fixed laboratory analysis rejected in Phase IV if detection of methane and ethane less than $100 \mu \mathrm{g} / \mathrm{L}$.

All values of methane in Phase III greater than $100 \mu \mathrm{g} / \mathrm{L}$ accepted.

Ultrapure nitrogen was used for equipment and travel blanks for on-site GC analysis.

nd() - not detected(detection limit) _..-- not analyzed 


\section{DRAFT}

\begin{tabular}{|c|c|c|c|c|c|c|c|c|c|c|c|}
\hline $\begin{array}{l}\text { Sample } \\
\text { (matrix) }\end{array}$ & Phase & Date & $\begin{array}{c}C_{1} \\
(\%)\end{array}$ & $\begin{array}{c}\mathrm{C}_{2} \\
(\%)\end{array}$ & $\begin{array}{l}\mathrm{C}_{2} \mathrm{H}_{4} \\
(\%)\end{array}$ & $\begin{array}{c}C_{3} \\
(\%)\end{array}$ & $\begin{array}{l}\mathrm{iC}_{4} \\
(\%)\end{array}$ & $\begin{array}{l}\mathrm{nC}_{4} \\
(\%)\end{array}$ & $\begin{array}{l}\mathrm{iC}_{5} \\
(\%)\end{array}$ & $\begin{array}{l}\mathrm{nC}_{5} \\
(\%)\end{array}$ & $\begin{array}{l}\mathrm{C}_{6}+ \\
(\%)\end{array}$ \\
\hline $\begin{array}{l}\text { Tribal Pavillion } \\
\text { 14-6(g) (WR) }\end{array}$ & -..- & $\begin{array}{l}\text { Johnson } \\
\text { and Rice } \\
(1993)\end{array}$ & 95.28 & 2.83 & ---- & 0.3 & 0.11 & 0.18 & 0.05 & 0.02 & ---- \\
\hline $\begin{array}{l}\text { Govt 21-5(g) } \\
\text { (WR) }\end{array}$ & ---- & $\begin{array}{l}\text { Johnson } \\
\text { and Rice } \\
\text { (1993) }\end{array}$ & 93.24 & 3.75 & ----- & 0.73 & 0.33 & 0.22 & 0.16 & 0.09 & ----- \\
\hline $\begin{array}{l}\text { Tribal Pavillion } \\
41-09(\mathrm{~g})(\mathrm{FU})\end{array}$ & ---- & $\begin{array}{l}\text { Johnson } \\
\text { and Rice } \\
\text { (1993) }\end{array}$ & 88.17 & 3.35 & ----- & 0.36 & 0.14 & 0.09 & nd & nd & ----- \\
\hline $\begin{array}{l}\text { Tribal Pavillion } \\
\text { 14-11(g) (FU) }\end{array}$ & --- & $\begin{array}{l}\text { Johnson } \\
\text { and Rice } \\
\text { (1993) }\end{array}$ & 66.00 & 1.96 & ----- & 0.06 & 0.054 & 0.006 & 0.006 & 0.002 & ----- \\
\hline $\begin{array}{l}\text { Blankenship } \\
\text { 4-8(g) (FU) }\end{array}$ & $\cdots$ & $\begin{array}{l}\text { Johnson } \\
\text { and Rice } \\
\text { (1993) }\end{array}$ & 93.38 & 4.00 & ----- & 0.41 & 0.05 & 0.06 & 0.07 & 0.01 & ---- \\
\hline $\begin{array}{c}\text { Tribal Pavillion } \\
\text { 14-10(g) } \\
\text { (WR)(PGPP01) }\end{array}$ & II & $01 / 21 / 10$ & 92.47 & 4.04 & 0.001 & 1.21 & 0.415 & 0.372 & 0.183 & 0.114 & 0.486 \\
\hline $\begin{array}{c}\text { Tribal Pavillion } \\
43-10(\mathrm{~g}) \\
\text { (FU)(PGPP02) }\end{array}$ & II & $01 / 21 / 10$ & 94.86 & 3.48 & 0.0001 & 0.356 & 0.143 & 0.0618 & 0.0501 & 0.0194 & 0.18 \\
\hline $\begin{array}{c}\text { Tribal Pavillion } \\
\text { 24-2(g) } \\
\text { (WR)(PGPP04) }\end{array}$ & II & $01 / 21 / 10$ & 90.16 & 4.64 & 0.0017 & 1.46 & 0.581 & 0.512 & 0.335 & 0.211 & 1.39 \\
\hline $\begin{array}{l}\text { Tribal Pavillion } \\
\text { 33-10(g) } \\
\text { (FU)(PGPP05) }\end{array}$ & $\|$ & $01 / 21 / 10$ & 94.68 & 3.64 & nd & 0.373 & 0.131 & 0.055 & 0.0427 & 0.014 & 0.107 \\
\hline $\begin{array}{c}\text { Tribal Pavillion } \\
\text { 14-2(g) } \\
\text { (FU)(PGPP06) }\end{array}$ & II & $01 / 21 / 10$ & 93.23 & 3.93 & 0.0012 & 0.903 & 0.321 & 0.25 & 0.151 & 0.0905 & 0.506 \\
\hline MW01(g) & III & $9 / 23 / 2010$ & 84.22 & 3.43 & 0.0007 & 0.791 & 0.327 & 0.191 & 0.143 & 0.0632 & 0.111 \\
\hline $\operatorname{MW01}(w)$ & III & $10 / 6 / 2010$ & 35.11 & 2.02 & 0.0008 & 0.414 & 0.114 & 0.0871 & 0.0499 & 0.0241 & 0.0539 \\
\hline MW01(g) & IV & $4 / 18 / 2011$ & 89.43 & 3.92 & 0.0013 & 0.907 & 0.298 & 0.211 & 0.109 & 0.0574 & 0.0972 \\
\hline MW01(g)-dup & IV & $4 / 18 / 2011$ & 89.49 & 3.91 & 0.0013 & 0.902 & 0.295 & 0.206 & 0.103 & 0.0533 & 0.0804 \\
\hline MW01(w) & IV & $4 / 20 / 2011$ & 38.33 & 2.46 & 0.0016 & 0.504 & 0.113 & 0.101 & 0.0422 & 0.0229 & 0.0566 \\
\hline MW02(g) & III & $9 / 24 / 2010$ & 1.05 & 0.048 & nd & 0.022 & 0.0089 & 0.0053 & 0.0020 & 0.0008 & 0.0012 \\
\hline MW02(g)-dup & III & $9 / 24 / 2010$ & 1.04 & 0.048 & nd & 0.022 & 0.0089 & 0.0053 & 0.0020 & 0.0008 & 0.0009 \\
\hline$M W 02(w)$ & III & $10 / 6 / 2010$ & 28.03 & 2.16 & nd & 0.693 & 0.128 & 0.101 & 0.0185 & 0.0067 & 0.0174 \\
\hline MW02(g) & IV & $4 / 18 / 2011$ & 6.74 & 0.383 & nd & 0.142 & 0.0401 & 0.026 & 0.0070 & 0.0025 & 0.0034 \\
\hline MW02(g)-dup & IV & $4 / 18 / 2011$ & 7.41 & 0.422 & nd & 0.156 & 0.0439 & 0.0284 & 0.0077 & 0.0027 & 0.0035 \\
\hline MW02(w) & IV & $4 / 19 / 2011$ & 26.17 & 1.80 & nd & 0.765 & 0.259 & 0.147 & 0.0416 & 0.0141 & 0.0237 \\
\hline MW02(w)-dup & IV & $4 / 19 / 2011$ & 21.32 & 1.49 & nd & 0.623 & 0.204 & 0.118 & 0.0324 & 0.011 & 0.018 \\
\hline PGMW01(w) & II & $01 / 21 / 10$ & 2.47 & nd & nd & nd & 0.0054 & 0.005 & 0.0287 & 0.0092 & 0.537 \\
\hline PGMW02(w) & II & $01 / 21 / 10$ & 3.57 & 1.13 & nd & 0.103 & 0.402 & 0.0134 & 0.13 & 0.0003 & 0.398 \\
\hline PGDW03(w) & II & $01 / 20 / 10$ & 0.0122 & nd & nd & nd & nd & nd & nd & nd & nd \\
\hline PGDW04(w) & II & $01 / 21 / 10$ & 0.0036 & nd & nd & nd & nd & nd & nd & nd & nd \\
\hline PGDW05(w) & IV & 04/19/11 & 0.0966 & nd & nd & nd & nd & nd & nd & nd & nd \\
\hline PGDW10(w) & II & $01 / 18 / 10$ & 0.0266 & nd & nd & nd & nd & nd & nd & nd & nd \\
\hline PGDW14(w) & IV & $04 / 20 / 11$ & 0.0005 & nd & nd & nd & nd & nd & nd & nd & nd \\
\hline
\end{tabular}


DRAFT

\begin{tabular}{|c|c|c|c|c|c|c|c|c|c|c|c|}
\hline $\begin{array}{l}\text { Sample } \\
\text { (matrix) }\end{array}$ & Phase & Date & $\begin{array}{l}C_{1} \\
(\%)\end{array}$ & $\begin{array}{c}\mathrm{C}_{2} \\
(\%)\end{array}$ & $\begin{array}{l}\mathrm{C}_{2} \mathrm{H}_{4} \\
(\%)\end{array}$ & $\begin{array}{l}C_{3} \\
(\%)\end{array}$ & $\begin{array}{l}\mathrm{iC}_{4} \\
(\%)\end{array}$ & $\begin{array}{l}\mathrm{nC}_{4} \\
(\%)\end{array}$ & $\begin{array}{l}\mathrm{iC}_{5} \\
(\%)\end{array}$ & $\begin{array}{l}\mathrm{nC}_{5} \\
(\%)\end{array}$ & $\begin{array}{l}C_{6}+ \\
(\%)\end{array}$ \\
\hline PGDW20 (w) & III & $10 / 06 / 10$ & 0.191 & 0.007 & nd & 0.0006 & nd & nd & nd & nd & nd \\
\hline $\begin{array}{c}\text { PGDW2O(w)- } \\
\text { dup }\end{array}$ & III & $10 / 06 / 10$ & 0.134 & 0.005 & nd & nd & nd & nd & nd & nd & nd \\
\hline PGDW20(w) & IV & $04 / 18 / 11$ & 0.221 & 0.007 & nd & 0.0007 & nd & nd & nd & nd & nd \\
\hline PGDW22(w) & ॥ & $01 / 18 / 10$ & nd & nd & nd & nd & nd & nd & nd & nd & nd \\
\hline PGDW23(w) & IV & $04 / 21 / 11$ & 0.248 & nd & nd & nd & nd & 0.0015 & nd & nd & 0.0008 \\
\hline PGDW25(w) & ॥ & $01 / 19 / 10$ & nd & nd & nd & nd & nd & nd & nd & nd & nd \\
\hline PGDW26(w) & IV & $04 / 18 / 11$ & nd & nd & nd & nd & nd & nd & nd & nd & nd \\
\hline PGDW30(w) & ॥ & $01 / 19 / 10$ & 5.99 & nd & nd & nd & nd & nd & nd & nd & nd \\
\hline PGDW30(g) & III & $09 / 23 / 10$ & 0.0123 & nd & nd & nd & nd & nd & nd & nd & nd \\
\hline PGDW30(w) & III & $10 / 05 / 10$ & 1.19 & nd & nd & nd & nd & nd & nd & nd & nd \\
\hline PGDW30(w) & IV & $04 / 18 / 11$ & 1.46 & nd & nd & nd & nd & nd & nd & nd & nd \\
\hline PGDW32(w) & $\|$ & $01 / 20 / 10$ & 0.197 & nd & nd & nd & nd & nd & nd & nd & 0.0085 \\
\hline PGDW32(w) & IV & $04 / 18 / 11$ & 0.0752 & nd & nd & nd & nd & nd & nd & nd & 0.0019 \\
\hline $\begin{array}{c}\text { PGDW32(w)- } \\
\text { dup }\end{array}$ & IV & $04 / 18 / 11$ & 0.0522 & nd & nd & nd & nd & nd & nd & nd & 0.0013 \\
\hline PGDW39(w) & ॥ & $01 / 19 / 10$ & nd & nd & nd & nd & nd & nd & nd & nd & nd \\
\hline PGDW40(w) & ॥ & $01 / 22 / 10$ & 0.418 & nd & nd & nd & nd & nd & nd & nd & nd \\
\hline PGDW41(w) & II & $01 / 21 / 10$ & 0.0091 & nd & nd & nd & nd & nd & nd & nd & nd \\
\hline PGDW41(w) & IV & $04 / 20 / 11$ & 0.0005 & nd & nd & nd & nd & nd & nd & nd & nd \\
\hline PGDW42(w) & ॥ & $01 / 19 / 10$ & 0.291 & nd & nd & nd & nd & nd & nd & nd & nd \\
\hline PGDW43(w) & ॥ & $01 / 21 / 10$ & 0.0016 & nd & nd & nd & nd & nd & nd & nd & nd \\
\hline PGDW44(w) & IV & $4 / 21 / 11$ & 0.0022 & nd & nd & nd & nd & nd & nd & nd & nd \\
\hline PGDW45(w) & ॥ & $01 / 18 / 10$ & nd & nd & nd & nd & nd & nd & nd & nd & nd \\
\hline PGDW45(w) & IV & $04 / 19 / 11$ & nd & nd & nd & nd & nd & nd & nd & nd & nd \\
\hline PGDW46(w) & II & $01 / 20 / 10$ & 0.0016 & nd & nd & nd & nd & nd & nd & nd & nd \\
\hline PGDW47(w) & ॥ & $01 / 19 / 10$ & 0.0428 & nd & nd & nd & nd & nd & nd & nd & nd \\
\hline $\begin{array}{c}\text { PGDW47(w)- } \\
\text { dup }\end{array}$ & ॥ & $01 / 19 / 10$ & 0.0365 & nd & nd & nd & nd & nd & nd & nd & nd \\
\hline PGDW49(w) & IV & $4 / 20 / 11$ & nid & nid & nid & nid & nid & nid & nid & nid & nid \\
\hline LD02(w) & III & $10 / 20 / 10$ & 0.12 & 0.007 & nd & 0.001 & 0.0008 & 0.0007 & nd & 0.0005 & nd \\
\hline PGPW01(w) & ॥ & $01 / 20 / 10$ & 0.0253 & nd & nd & nd & nd & nd & nd & nd & nd \\
\hline PGPW02(w) & ॥ & $01 / 20 / 10$ & 0.0389 & nd & nd & nd & nd & nd & nd & nd & nd \\
\hline field blank(w) & ॥ & $01 / 21 / 10$ & 0.0068 & nd & nd & nd & nd & nd & nd & nd & 0.0021 \\
\hline field blank(w) & ॥ & $01 / 22 / 10$ & nd & nd & nd & nd & nd & nd & nd & nd & nd \\
\hline travel blank(g) & III & $9 / 23 / 10$ & nd & nd & nd & nd & nd & nd & nd & nd & nd \\
\hline $\begin{array}{l}\text { equipment } \\
\text { blank(g) }\end{array}$ & III & $9 / 23 / 10$ & 0.0029 & nd & nd & nd & nd & nd & nd & nd & nd \\
\hline travel blank(g) & III & $9 / 24 / 10$ & nd & nd & nd & nd & nd & nd & nd & nd & nd \\
\hline $\begin{array}{l}\text { equipment } \\
\text { blank(g) }\end{array}$ & III & $9 / 24 / 10$ & nd & nd & nd & nd & nd & nd & nd & nd & nd \\
\hline travel blank(g) & IV & $4 / 18 / 11$ & nd & nd & nd & nd & nd & nd & nd & nd & nd \\
\hline $\begin{array}{l}\text { equipment } \\
\text { blank(g) }\end{array}$ & IV & $4 / 18 / 11$ & nd & nd & nd & nd & nd & nd & nd & nd & nd \\
\hline $\begin{array}{l}\text { equipment } \\
\text { blank(g) }\end{array}$ & IV & $4 / 18 / 11$ & nd & nd & nd & nd & nd & nd & nd & nd & nd \\
\hline
\end{tabular}

WR - Wind River Formation 
DRAFT

\begin{tabular}{|c|c|c|c|c|c|c|c|c|c|c|c|c|c|c|c|c|c|c|c|}
\hline & $\begin{array}{l}0 \\
0 \\
0 \\
0 \\
0\end{array}$ & 1 & 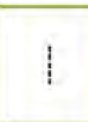 & 1 & 1 & 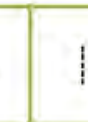 & 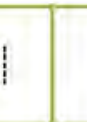 & 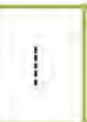 & 1 & 1 & 1 & 1 & 1 & 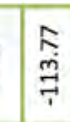 & 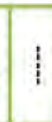 & 1 & $\begin{array}{l}0 \\
0 \\
0 \\
\vdots \\
?\end{array}$ & 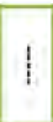 & 1 \\
\hline & 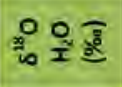 & 1 & 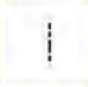 & 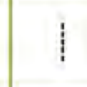 & 1 & 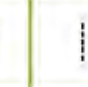 & : & 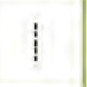 & 1 & 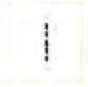 & 1 & 1 & 1 & 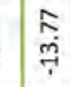 & 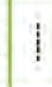 & 1 & $\begin{array}{l}\stackrel{\mathscr{0}}{1} \\
\stackrel{7}{7}\end{array}$ & 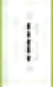 & 1 \\
\hline & ॠ高 & 1 & 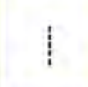 & 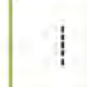 & 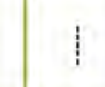 & 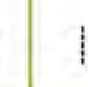 & : & 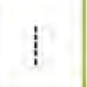 & 1 & 1 & 1 & 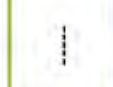 & & $\stackrel{\infty}{\underset{7}{7}}$ & : & 1 & 뭄 & 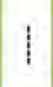 & 1 \\
\hline & ज产 & 1 & 1 & 1 & 1 & 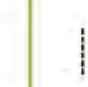 & & 1 & 1 & 1 & 1 & 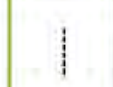 & ণ̃. & 1 & ; & 1 & 1 & $\underset{\substack{\text { Oj } \\
\text { v }}}{ }$ & đo \\
\hline & 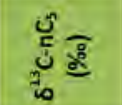 & 1 & 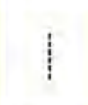 & 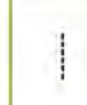 & 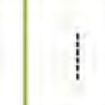 & 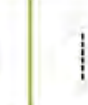 & & 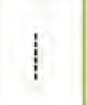 & 1 & 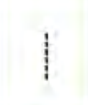 & 1 & 1 & 1 & 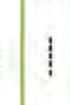 & 1 & 1 & خे & 1 & 1 \\
\hline & 施 & 1 & 1 & 1 & 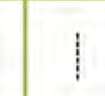 & 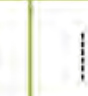 & & 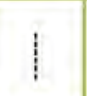 & 1 & 1 & 1 & 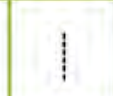 & 1 & 1 & 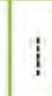 & 1 & : & 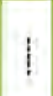 & 1 \\
\hline & t్ & 1 & 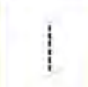 & 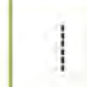 & 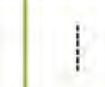 & 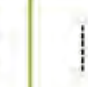 & 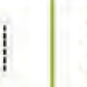 & $\stackrel{m}{\vec{n}}$ & 1 & 苛 & 1 & $\stackrel{\sim}{7}$ & 1 & 1 & 1 & 1 & 1 & 1 & 1 \\
\hline & 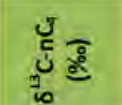 & 1 & 1 & 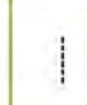 & 1 & 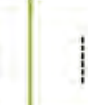 & 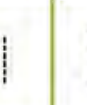 & 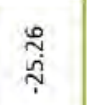 & 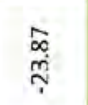 & & ț. & 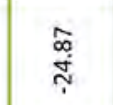 & 1 & 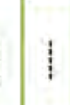 & 1 & 1 & $\bar{\nabla}$ & 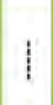 & 1 \\
\hline & 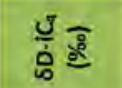 & 1 & 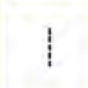 & 1 & 1 & 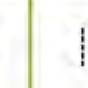 & 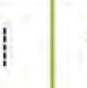 & đ્ّ & 1 & 凋 & 1 & 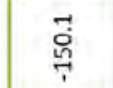 & 1 & 1 & 1 & 1 & 1 & 1 & 1 \\
\hline$\frac{n}{n}$ & 通 & 1 & 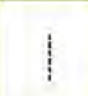 & 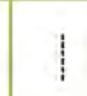 & 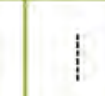 & 1 & 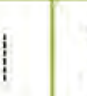 & 芯 & 1 & 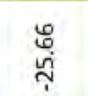 & ্ֻল & 愛 & & 1 & 1 & 1 & : & 1 & 1 \\
\hline 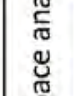 & 通 & 1 & 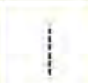 & 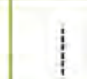 & 1 & 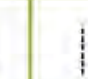 & & $\approx$ & 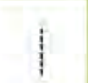 & 另 & $\hat{\overrightarrow{0}}$ & $\tilde{y}$ & g్g & 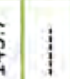 & $\vec{~}$ & 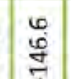 & 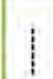 & 1 & 1 \\
\hline 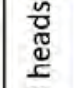 & 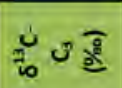 & 1 & 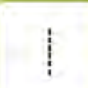 & 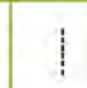 & : & 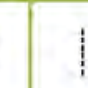 & 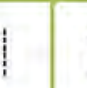 & ֶָ & ఫ़ & 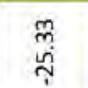 & 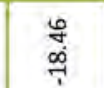 & : & 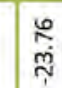 & 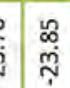 & 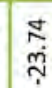 & $\begin{array}{l}\bar{m} \\
\tilde{\sim}\end{array}$ & 竞 & 1 & 1 \\
\hline 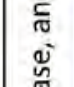 & $\frac{\pi}{8}$ & 1 & 1 & 1 & ! & ; & ; & 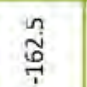 & $\stackrel{n}{n}$ & శึّ & 离 & مَّ & 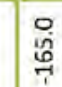 & 1 & 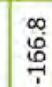 & 离 & 1 & 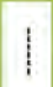 & 1 \\
\hline \begin{tabular}{|l} 
\\
0 \\
0 \\
0 \\
$a$ \\
$a$
\end{tabular} & $\approx 00$ & 1 & 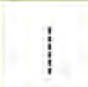 & 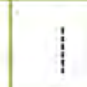 & 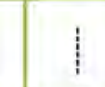 & 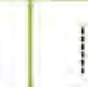 & 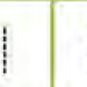 & 艿 & $\begin{array}{l}\text { g } \\
\text { wุ }\end{array}$ & 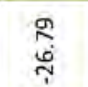 & तु & 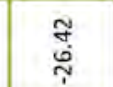 & 苗 & : & 它 & 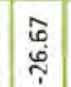 & 尽 & 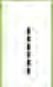 & 1 \\
\hline 竞 & 递 & 1 & 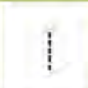 & 1 & 1 & 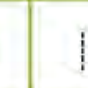 & : & 范 & $\begin{array}{l}\text { ने } \\
\text { ते }\end{array}$ & ఫั่ & 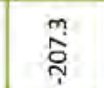 & : & 궁 & $\frac{9}{9}$ & สี & ㄱ. & تُ & पั. & ఫัฐ \\
\hline$\stackrel{\circ}{\circ}$ & 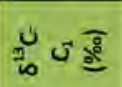 & 志 & đ̊ & 曽 & 晜 & 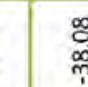 & : & $\underset{\substack{n \\
\infty}}{\infty}$ & ô & 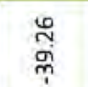 & 足 & 趈 & 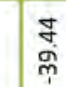 & 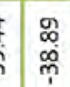 & $\begin{array}{l}\stackrel{\sim}{2} \\
\text { } \\
\end{array}$ & 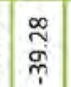 & 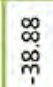 & $\begin{array}{l}\text { 品 } \\
\text { Fे }\end{array}$ & 疍 \\
\hline $\begin{array}{l}0.0 \\
\frac{0}{2} \\
\frac{0}{0}\end{array}$ & 亏ัँ & 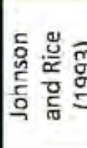 & 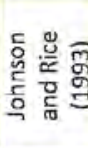 & 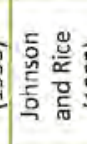 & إِ & 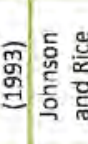 & 害兽 & 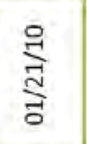 & $\underset{\stackrel{\Xi}{I}}{\stackrel{\Xi}{\Xi}}$ & $\begin{array}{l}\stackrel{\Xi}{\vec{N}} \\
\stackrel{\Xi}{0}\end{array}$ & 옹 & 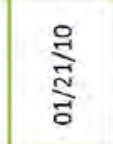 & $\begin{array}{l}\text { 워 } \\
\frac{d}{\tilde{N}} \\
\frac{\pi}{\sigma}\end{array}$ & $\begin{array}{l}0 \\
\frac{a}{0} \\
\frac{0}{0}\end{array}$ & 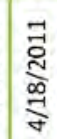 & $\begin{array}{l}\bar{\Xi} \\
\stackrel{\Xi}{\infty} \\
\frac{\pi}{y}\end{array}$ & 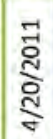 & $\begin{array}{l}\text { 莒 } \\
\text { 竎 }\end{array}$ & 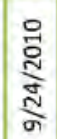 \\
\hline 离 & $\begin{array}{l}\frac{y}{0} \\
\frac{\tilde{m}}{\alpha}\end{array}$ & 1 & 1 & 1 & i & ; & ! & $=$ & $=$ & $=$ & $=$ & $=$ & $\equiv$ & $\equiv$ & $\geq$ & $\geq$ & $\geq$ & $\equiv$ & $\equiv$ \\
\hline 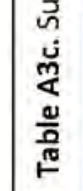 & 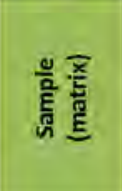 & 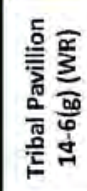 & 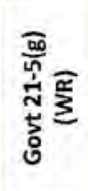 & 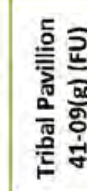 & 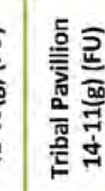 & 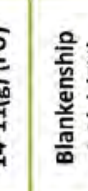 & 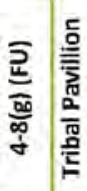 & 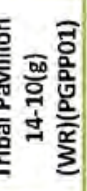 & 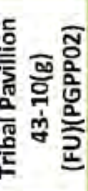 & 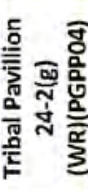 & 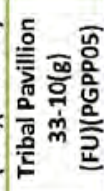 & 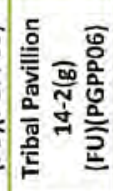 & 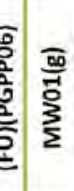 & $\begin{array}{l}\frac{5}{3} \\
\frac{3}{5} \\
\Sigma\end{array}$ & 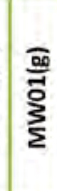 & 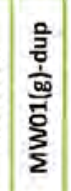 & 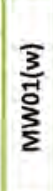 & 离 & 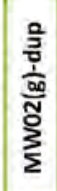 \\
\hline
\end{tabular}




\section{DRAFT}

\begin{tabular}{|c|c|c|c|c|c|c|c|c|c|c|c|c|c|c|c|c|c|c|c|c|c|}
\hline 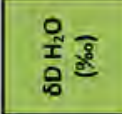 & $\stackrel{\nexists}{\leftrightarrows}$ & & & 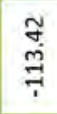 & $\begin{array}{l}\stackrel{f}{*} \\
\stackrel{m}{7}\end{array}$ & 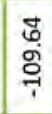 & 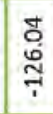 & $\begin{array}{l}\stackrel{R}{0} \\
\stackrel{0}{1}\end{array}$ & 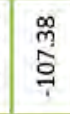 & \begin{tabular}{l} 
足 \\
0 \\
0 \\
\hdashline
\end{tabular} & $\frac{5}{9}$ & & $\begin{array}{l}\infty \\
0 \\
0 \\
7\end{array}$ & $\begin{array}{l}7 \\
\stackrel{7}{0} \\
\stackrel{0}{1}\end{array}$ & 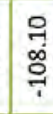 & 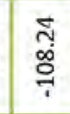 & 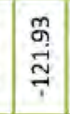 & 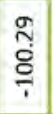 & 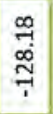 & 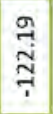 & 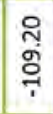 \\
\hline$\therefore 00$ & 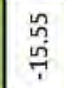 & 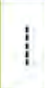 & & 范 & 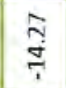 & $\underset{7}{\stackrel{7}{7}}$ & 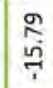 & $\begin{array}{l}\underset{\pi}{\pi} \\
\stackrel{?}{?}\end{array}$ & $\stackrel{\infty}{\stackrel{\infty}{m}}$ & $\begin{array}{l}\vec{m} \\
\stackrel{m}{m}\end{array}$ & 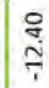 & 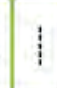 & 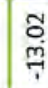 & 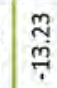 & 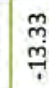 & 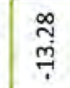 & $\begin{array}{l}\overrightarrow{5} \\
\vec{v} \\
\overrightarrow{7}\end{array}$ & $\begin{array}{l}\stackrel{?}{2} \\
\stackrel{m}{\longrightarrow}\end{array}$ & 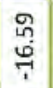 & $\begin{array}{l}\hat{n} \\
\text { ñ. }\end{array}$ & $\begin{array}{l}\tilde{\pi} \\
\stackrel{\sim}{\sim}\end{array}$ \\
\hline$\because 00 \bar{g}$ & 30 & ! & $!$ & $\frac{3}{9} \frac{0}{1}$ & 3 & 章 & $\begin{array}{l}\text { के } \\
\text { ने }\end{array}$ & ఫ్ & $\begin{array}{l}\overrightarrow{7} \\
\text { ज़ } \\
\text { ?. }\end{array}$ & 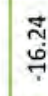 & $\begin{array}{l}\stackrel{9}{2} \\
\stackrel{2}{?}\end{array}$ & & $\begin{array}{l}\infty \\
\stackrel{\infty}{7}\end{array}$ & $\begin{array}{l}\circ \\
7 \\
7\end{array}$ & $\stackrel{\widetilde{m}}{7}$ & 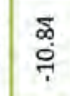 & $\begin{array}{l}\vec{m} \\
\underset{\tilde{J}}{\mathrm{~T}}\end{array}$ & $\begin{array}{l}\stackrel{\mathscr{m}}{0} \\
\stackrel{0}{T}\end{array}$ & 常 & $\begin{array}{l}\stackrel{0}{0} \\
\overrightarrow{7}\end{array}$ & 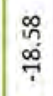 \\
\hline$=\sum_{g}^{\bar{J}}$ & 1 & 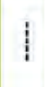 & 1 & 1 & 1 & 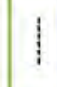 & 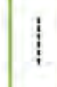 & 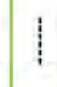 & 1 & I & 1 & 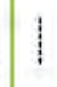 & 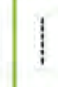 & 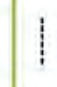 & 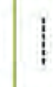 & 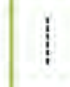 & 1 & 1 & 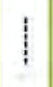 & 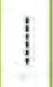 & 1 \\
\hline 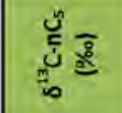 & 1 & 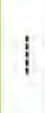 & 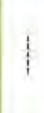 & 1 & 1 & 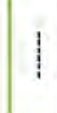 & 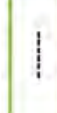 & 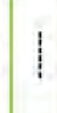 & 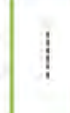 & 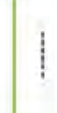 & 1 & 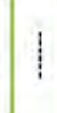 & 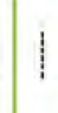 & 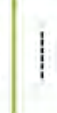 & 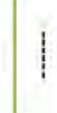 & 1 & 1 & 1 & 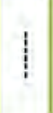 & 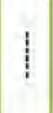 & 1 \\
\hline 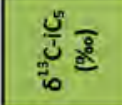 & 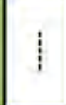 & 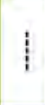 & 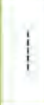 & 1 & 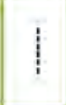 & 1 & 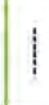 & 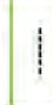 & 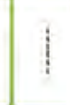 & 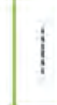 & 1 & 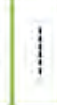 & 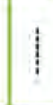 & I & I & 1 & 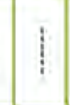 & $!$ & 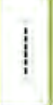 & 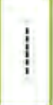 & 1 \\
\hline 乩高 & 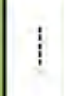 & 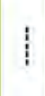 & 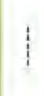 & 1 & 1 & 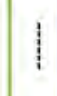 & 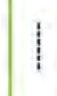 & 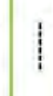 & 1 & 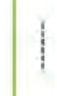 & 1 & 1 & 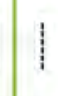 & 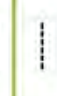 & 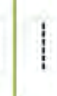 & 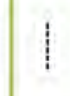 & 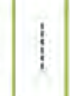 & 1 & 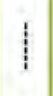 & 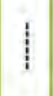 & 1 \\
\hline${ }_{a_{0}^{5}}^{5}$ & 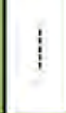 & 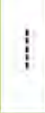 & 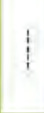 & $\stackrel{m}{\stackrel{*}{*}}$ & $\stackrel{\text { ñ }}{7}$ & 1 & 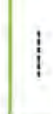 & 1 & 1 & 1 & 1 & 1 & 1 & 1 & 1 & 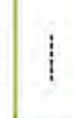 & 1 & 1 & 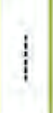 & 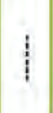 & 1 \\
\hline 눔용 & 1 & 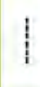 & 1 & 1 & 1 & 1 & 1 & 1 & 1 & 1 & 1 & 1 & 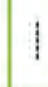 & 1 & 1 & 1 & 1 & 1 & 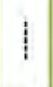 & 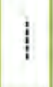 & 1 \\
\hline 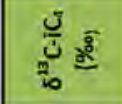 & 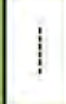 & 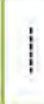 & 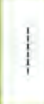 & 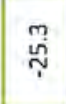 & $\stackrel{m}{\mathfrak{n}}$ & 1 & 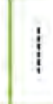 & 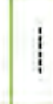 & 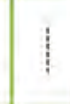 & 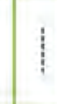 & 1 & 1 & 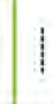 & 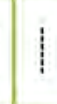 & I & 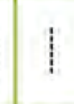 & 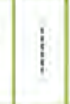 & 1 & 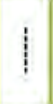 & 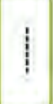 & 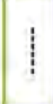 \\
\hline 行 & 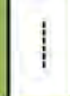 & 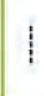 & 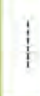 & 1 & 1 & 1 & 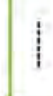 & 1 & 1 & 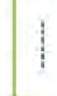 & 1 & I & 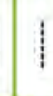 & 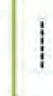 & 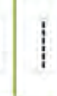 & 1 & 1 & 1 & 1 & 1 & 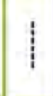 \\
\hline$\frac{4}{10} \mathrm{~g}$ & ্ָ & $\dot{f}$ & ب. & స్తి & 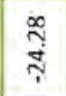 & 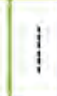 & I & 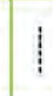 & 1 & 1 & 1 & 1 & 1 & 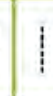 & 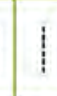 & 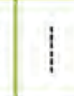 & 1 & 1 & 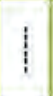 & 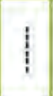 & 1 \\
\hline 要 & 1 & 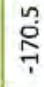 & $\stackrel{3}{7}$ & 1 & 1 & 1 & 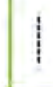 & 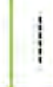 & 1 & 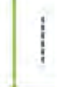 & 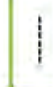 & 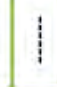 & 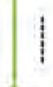 & 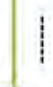 & 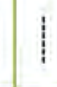 & 1 & 1 & 1 & 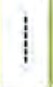 & 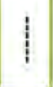 & 1 \\
\hline$\frac{5}{10} \mathrm{~g}$ & 芦 & के & ণ্ّ & 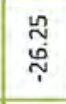 & \begin{tabular}{l}
$\infty$ \\
\hdashline \\
\hdashline
\end{tabular} & 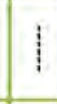 & 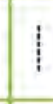 & 1 & 1 & 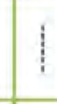 & 1 & 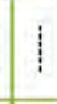 & 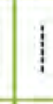 & 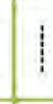 & 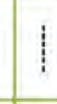 & 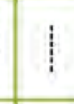 & 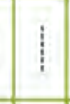 & 1 & 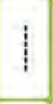 & 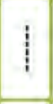 & 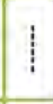 \\
\hline प. & . & : & $\stackrel{\infty}{\stackrel{\infty}{\sim}}$ & )ิ & 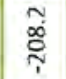 & 1 & 1 & 1 & 1 & $\stackrel{n}{7}$ & & 尊 & 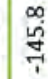 & $\stackrel{m}{?}$ & 1 & 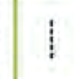 & 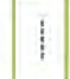 & 1 & 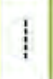 & 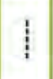 & 1 \\
\hline$\ddot{0} 0 \mathrm{~g}$ & $\begin{array}{l}\mathscr{B} \\
+ \\
\end{array}$ & 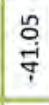 & वं & $\begin{array}{l}0 \\
7 \\
7\end{array}$ & $\frac{\bar{m}}{7}$ & 1 & 1 & 1 & 1 & ल. & & ๙ָ. & 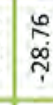 & $\stackrel{\infty}{\sim}$ & 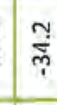 & 号 & 1 & 1 & 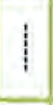 & 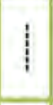 & 1 \\
\hline ปัँ & 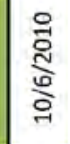 & -1 & $\stackrel{\tilde{N}}{\infty}$ & $\frac{\overrightarrow{\tilde{N}}}{\frac{\pi}{\sigma}}$ & $\frac{\bar{J}}{\frac{\tilde{J}}{g}}$ & $\begin{array}{l}\frac{7}{0} \\
\frac{7}{8}\end{array}$ & $\begin{array}{l}\frac{7}{2} \\
\frac{\tilde{d}}{0}\end{array}$ & $\begin{array}{l}\stackrel{9}{0} \\
\stackrel{0}{0} \\
\end{array}$ & $\begin{array}{l}\frac{9}{1} \\
0 \\
0 \\
\end{array}$ & $\frac{\text { F }}{\stackrel{3}{0}}$ & $\frac{\bar{d}}{\frac{d}{d}}$ & $\frac{9}{9}$ & 옹 & $\sum_{\delta}^{\frac{F}{\delta}}$ & $\frac{\underset{7}{0}}{\overline{0}}$ & $\overbrace{\bar{\delta}}^{\bar{\sigma}}$ & $\frac{\vec{z}}{\tilde{d}}$ & 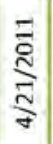 & $\frac{\frac{j}{3}}{\frac{7}{8}}$ & $\begin{array}{l}\text { 范 } \\
\stackrel{a}{\frac{d}{8}}\end{array}$ & 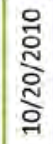 \\
\hline $\begin{array}{l}\frac{5}{\tilde{m}} \\
\frac{\tilde{T}}{2}\end{array}$ & $\equiv$ & $\geq$ & $\geq$ & $\geq$ & $\geq$ & $\geq$ & $\geq$ & $\equiv$ & $\equiv$ & $\geq$ & $\geq$ & $=$ & $\equiv$ & $\geq$ & $\geq$ & $\geq$ & $\geq$ & $\geq$ & $\geq$ & $\geq$ & $\equiv$ \\
\hline 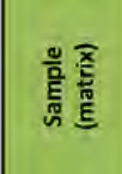 & 旁 & & & 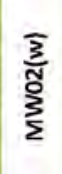 & & 旁 & $\begin{array}{l}\frac{3}{3} \\
\frac{3}{3} \\
0 \\
0\end{array}$ & 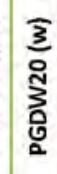 & 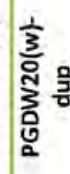 & 竞 & $\begin{array}{l}\frac{3}{3} \\
\text { ज्ञ } \\
\text { : }\end{array}$ & 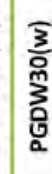 & 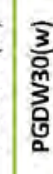 & $\begin{array}{l}3 \\
0 \\
0 \\
0 \\
0 \\
0\end{array}$ & & 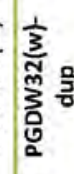 & $\frac{3}{\frac{3}{7}}$ & $\begin{array}{l}\frac{3}{3} \\
\frac{3}{3} \\
\frac{0}{0} \\
\frac{0}{2}\end{array}$ & $\begin{array}{l}\frac{3}{3} \\
\frac{3}{y} \\
\frac{0}{0} \\
\vdots\end{array}$ & $\begin{array}{l}\frac{3}{9} \\
\frac{3}{3} \\
\frac{6}{2} \\
\frac{0}{2}\end{array}$ & 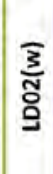 \\
\hline
\end{tabular}




\section{DRAFT}




\section{DRAFT}

Appendix B

\section{Quality Assurance and Quality Control (QA/QC) for Analysis}


DRAFT

Table B1. Sample collection containers, preservation, and holding times for ground-water samples for Phase III and IV

\begin{tabular}{|c|c|c|c|c|}
\hline Sample Type & $\begin{array}{l}\text { Analysis Method } \\
\text { (EPA Method) }\end{array}$ & Sample Bottles/\# of bottles* & $\begin{array}{l}\text { Preservation/ } \\
\text { Storage }\end{array}$ & Holding Time(s) \\
\hline Dissolved gases & $\begin{array}{l}\text { RSKSOP-194v4 \&-175v5 } \\
\text { (No EPA Method) }\end{array}$ & $60 \mathrm{~mL}$ serum bottles $/ 2$ & $\begin{array}{l}\text { No Headspace } \\
\mathrm{TSP}^{+}, \mathrm{pH}>10 \text {; refrigerate } \\
4^{\circ} \mathrm{C}^{++}\end{array}$ & 14 days \\
\hline Metals (filtered) & $\begin{array}{l}\text { RSKSOP-213v4 \&-257v3 } \\
\text { (EPA Methods } 200.7 \text { and } \\
6020 \text { ) }\end{array}$ & $125 \mathrm{~mL}$ plastic bottle $/ 1$ & $\begin{array}{l}\mathrm{HNO}_{3}, \mathrm{pH}<2 ; \text { room } \\
\text { temperature }\end{array}$ & $\begin{array}{l}6 \text { months } \\
\text { (Hg } 28 \text { days })\end{array}$ \\
\hline $\mathrm{SO}_{4}, \mathrm{Cl}, \mathrm{F}, \mathrm{Br}$ & $\begin{array}{l}\text { RSKSOP-276v3 (EPA } \\
\text { Method 6500) }\end{array}$ & $30 \mathrm{~mL}$ plastic/1 & Refrigerate $\leq 4^{\circ} \mathrm{C}$ & 28 days \\
\hline $\mathrm{NO}_{3}+\mathrm{NO}_{2}, \mathrm{NH}_{4}$ & $\begin{array}{l}\text { RSKSOP-214v5 } \\
\text { (EPA Method } 350.1 \text { and } \\
353.2 \text { ) }\end{array}$ & $30 \mathrm{~mL}$ plastic/1 & $\begin{array}{l}\mathrm{H}_{2} \mathrm{SO}_{4}, \mathrm{pH}<2 ; \text { refrigerate } \\
\leq 4^{\circ} \mathrm{C}\end{array}$ & 28 days \\
\hline DIC & $\begin{array}{l}\text { RSKSOP-102v5 or 330v0 } \\
\text { (EPA Method 9060A) }\end{array}$ & $40 \mathrm{~mL}$ clear glass VOA vial $/ 2$ & refrigerate $\leq 4^{\circ} \mathrm{C}$ & 14 days \\
\hline DOC & $\begin{array}{l}\text { RSKSOP-102v5 or } 330 v 0 \\
\text { (EPA Method } 9060 \mathrm{~A})\end{array}$ & $40 \mathrm{~mL}$ clear glass VOA vial $/ 2$ & $\begin{array}{l}\mathrm{H}_{3} \mathrm{PO}_{4}, \mathrm{pH}<2 \text {; refrigerate } \\
\leq 44^{\circ} \mathrm{C}\end{array}$ & 28 days \\
\hline VOCs & $\begin{array}{l}\text { RSKSOP-299v1 or 259v1 } \\
\text { (EPA Method 5021A plus } \\
8260 \text { C) }\end{array}$ & $40 \mathrm{~mL}$ amber glass VOA vial $/ 2$ & $\begin{array}{l}\text { No Headspace } \\
\mathrm{TSP}^{+}, \mathrm{pH}>10 \text {; refrigerate } \\
\leq 4^{\circ} \mathrm{C}\end{array}$ & 14 days \\
\hline $\begin{array}{l}\text { Low Molecular } \\
\text { Weight Acids }\end{array}$ & $\begin{array}{l}\text { RSKSOP-112V6 } \\
\text { (No EPA Method) }\end{array}$ & $40 \mathrm{~mL}$ glass $\mathrm{VOA}$ vial $/ 2$ & $\begin{array}{l}\mathrm{TSP}^{\dagger}, \mathrm{pH}>10 \text {; refrigerate } \leq \\
4^{\circ} \mathrm{C}\end{array}$ & 30 days \\
\hline $\begin{array}{l}\mathrm{O}, \mathrm{H} \text { stable } \\
\text { isotopes of } \\
\text { water }\end{array}$ & $\begin{array}{l}\text { RSKSOP-296v0 } \\
\text { (No EPA Method) }\end{array}$ & $20 \mathrm{~mL}$ glass VOA vial/1 & Refrigerate at $\leq 4^{\circ} \mathrm{C}$ & Stable \\
\hline$\delta^{13} \mathrm{CDIC}$ & $\begin{array}{l}\text { Isotech: gas stripping and } \\
\text { IRMS } \\
\text { (No EPA Method) }\end{array}$ & $60 \mathrm{~mL}$ plastic bottle $/ 1$ & Refrigerate $\leq 4^{\circ} \mathrm{C}$ & No information \\
\hline $\begin{array}{l}\delta^{13} \mathrm{C} \text { and } \delta \mathrm{D} \text { of } \\
\text { methane }\end{array}$ & $\begin{array}{l}\text { Isotech: gas stripping and } \\
\text { IRMS } \\
\text { (No EPA Method) }\end{array}$ & $1 \mathrm{~L}$ plastic bottle/ 1 & $\begin{array}{l}\text { Caplet of benzalkonium } \\
\text { chloride; refrigerate } \leq 4^{\circ} \mathrm{C}\end{array}$ & No information \\
\hline SVOCS & $\begin{array}{l}\text { ORGM-515 r1.1, EPA } \\
\text { Method } 8270 \mathrm{D}\end{array}$ & $\begin{array}{l}1 \mathrm{~L} \text { amber glass bottle/ } 2 \text { and for } \\
\text { every } 10 \text { samples of ground } \\
\text { water need } 2 \text { more bottles for } \\
\text { one selected sample, or if }<10 \\
\text { samples collected, collect } 2 \\
\text { more bottles for one select } \\
\text { sample }\end{array}$ & Refrigerate $\leq 4^{\circ} \mathrm{C}$ & $\begin{array}{l}7 \text { days until extraction, } \\
30 \text { days after extraction }\end{array}$ \\
\hline DRO & $\begin{array}{l}\text { ORGM-508 r1.0, EPA } \\
\text { Method 8015D }\end{array}$ & $\begin{array}{l}1 \mathrm{~L} \text { amber glass bottle/ } 2 \text { and for } \\
\text { every } 10 \text { samples of ground } \\
\text { water need } 2 \text { more bottles for } \\
\text { one selected sample, or if }<10 \\
\text { samples collected, collect } 2 \\
\text { more bottles for one select } \\
\text { sample }\end{array}$ & $\begin{array}{l}\mathrm{HCl}, \mathrm{pH}<2 ; \\
\text { refrigerate } \leq 4^{\circ} \mathrm{C}\end{array}$ & $\begin{array}{l}7 \text { days until extraction, } \\
40 \text { days after extraction }\end{array}$ \\
\hline GRO & $\begin{array}{l}\text { ORGM-506 r1.0, EPA } \\
\text { Method 8015D }\end{array}$ & $\begin{array}{l}40 \mathrm{~mL} \text { amber glass VOA vial } / 2 \\
\text { and for every } 10 \text { samples of } \\
\text { ground water need } 2 \text { more } \\
\text { bottles for one selected sample, } \\
\text { or if }<10 \text { samples collected, } \\
\text { collect } 2 \text { more bottles for one } \\
\text { select sample }\end{array}$ & $\begin{array}{l}\text { No headspace; } \mathrm{HCl}, \mathrm{pH}<2 ; \\
\text { refrigerate } \leq 4^{\circ} \mathrm{C}\end{array}$ & 14 days \\
\hline Glycols & $\begin{array}{l}\text { Region III method** } \\
\text { (No EPA Method) }\end{array}$ & $40 \mathrm{~mL}$ amber glass VOA vial/ 2 & Refrigerate $\leq 4^{\circ} \mathrm{C}$ & 14 days \\
\hline
\end{tabular}

${ }^{\dagger}$ Trisodium phosphate

"Above freezing point of water

*Spare bottles made available for laboratory QC samples and for replacement of compromised samples (broken bottle, QC failures, etc.).

**EPA Methods $8000 \mathrm{C}$ and 8321 were followed for method development and QA/AC limits were applicable. 
DRAFT

Table B2. Field QC samples for ground-water analysis

\begin{tabular}{|c|c|c|c|}
\hline QC Sample & Purpose & Method & Frequency \\
\hline $\begin{array}{l}\text { Trip Blanks (VOCs and } \\
\text { Dissolved Gases only) }\end{array}$ & $\begin{array}{l}\text { Assess contamination } \\
\text { during transportation. }\end{array}$ & $\begin{array}{l}\text { Fill bottles with reagent } \\
\text { water and preserve, take } \\
\text { to field and returned } \\
\text { without opening. }\end{array}$ & $\begin{array}{l}\text { One in an ice chest with } \\
\text { VOA and dissolved gas } \\
\text { samples. }\end{array}$ \\
\hline Equipment Blanks & $\begin{array}{l}\text { Assess contamination } \\
\text { from field equipment, } \\
\text { sampling procedures, } \\
\text { decontamination } \\
\text { procedures, sample } \\
\text { container, preservative, } \\
\text { and shipping. }\end{array}$ & $\begin{array}{l}\text { Apply only to samples } \\
\text { collected via equipment, } \\
\text { such as filtered samples: } \\
\text { Reagent water is filtered } \\
\text { and collected into bottles } \\
\text { and preserved same as } \\
\text { filtered samples. }\end{array}$ & $\begin{array}{l}\text { One per day of sampling } \\
\text { with submersible pumps }\end{array}$ \\
\hline Field Duplicates & $\begin{array}{l}\text { Represent precision of } \\
\text { field sampling, analysis, } \\
\text { and site heterogeneity. }\end{array}$ & $\begin{array}{l}\text { One or more samples } \\
\text { collected immediately } \\
\text { after original sample. }\end{array}$ & $\begin{array}{l}\text { One in every } 10 \text { samples, } \\
\text { or if }<10 \text { samples } \\
\text { collected for a water type } \\
\text { (ground or surface), } \\
\text { collect a duplicate for one } \\
\text { sample. }\end{array}$ \\
\hline Temperature Blanks & $\begin{array}{l}\text { Measure temperature of } \\
\text { samples in the cooler. }\end{array}$ & $\begin{array}{l}\text { Water sample that is } \\
\text { transported in cooler to } \\
\text { lab. }\end{array}$ & One per cooler. \\
\hline Field Blanks** & $\begin{array}{l}\text { Assess contamination } \\
\text { introduced from sample } \\
\text { container with applicable } \\
\text { preservative. }\end{array}$ & $\begin{array}{l}\text { In the field, reagent water } \\
\text { is collected into sample } \\
\text { containers with } \\
\text { preservatives. }\end{array}$ & One per day of sampling. \\
\hline
\end{tabular}

* Reporting limit or Quantitation Limit

** Blank samples were not collected for isotope measurements, including $\mathrm{O}, \mathrm{H}, \mathrm{C}$.

Table B3. $Q A / Q C$ requirements for analysis of metals and major ions

\begin{tabular}{|c|c|c|c|c|c|c|}
\hline Measurement & $\begin{array}{l}\text { Analysis } \\
\text { Method }\end{array}$ & $\begin{array}{l}\text { Blanks } \\
\text { (Frequency) }\end{array}$ & $\begin{array}{l}\text { Calibration Checks } \\
\text { (Frequency) }\end{array}$ & $\begin{array}{l}\text { Second } \\
\text { Source } \\
\text { (Frequency) }\end{array}$ & $\begin{array}{l}\text { Duplicates } \\
\text { (Frequency) }\end{array}$ & $\begin{array}{l}\text { Matrix Spikes } \\
\text { (Frequency) }\end{array}$ \\
\hline Metals & $\begin{array}{l}\text { RSKSOP-213v4 } \\
\text { (EPA Methods } \\
200.7 \text { and } \\
6020 \text { ) }\end{array}$ & $\begin{array}{l}<Q L \text { for } 80 \% \text { of } \\
\text { metals; } \\
\text { (Beginning and } \\
\text { end of each } \\
\text { sample queue, } 10- \\
15 \text { samples) }\end{array}$ & $\begin{array}{l}90-110 \% \text { of known } \\
\text { value } \\
\text { ( Beginning and end } \\
\text { of each sample } \\
\text { queue, } 10-15 \\
\text { samples) }\end{array}$ & $\begin{array}{l}\text { PE sample } \\
\text { acceptance } \\
\text { limits or } 90 \text { - } \\
110 \% \text { of } \\
\text { known value } \\
\text { (Immediately } \\
\text { after first } \\
\text { calibration } \\
\text { check) }\end{array}$ & $\begin{array}{l}\text { RPD }<10 \text { for } 80 \% \\
\text { of metals; } \\
\text { for results }<5 x \\
Q L \text {, difference of } \\
\leq Q L \text { (Every } 15 \\
\text { samples) }\end{array}$ & $\begin{array}{l}90-110 \% \text { Rec. for } 80 \% \\
\text { of metals w/ no } \\
\text { individual exceeding } \\
50-150 \% \text { Rec, (one per } \\
\text { sample set, } 10-15 \\
\text { samples) }\end{array}$ \\
\hline Metals & $\begin{array}{l}\text { RSKSOP-257v3 } \\
\text { (EPA Methods } \\
200.7 \text { and } \\
6020 \text { ) }\end{array}$ & $\begin{array}{c}<Q L \text { for } 80 \% \text { of } \\
\text { metals; } \\
\text { none }>10 \times \mathrm{MDL} \\
\text { (Beginning and } \\
\text { end of each } \\
\text { sample queue, 10- } \\
15 \text { samples) }\end{array}$ & $\begin{array}{c}90-110 \% \text { of known } \\
\text { value } \\
\text { (Beginning and end } \\
\text { of each sample } \\
\text { queue, } 10-15 \\
\text { samples) }\end{array}$ & $\begin{array}{c}\text { PE sample } \\
\text { acceptance } \\
\text { Jimits or } 90- \\
110 \% \text { of } \\
\text { known value } \\
\text { (Immediately } \\
\text { after first } \\
\text { calibration } \\
\text { check) }\end{array}$ & $\begin{array}{l}\text { RPD }<10 \text { for } 80 \% \\
\text { of metals; for } \\
\text { results }<5 \times \mathrm{xL} \text {, } \\
\text { difference of }<\mathrm{QL} \\
\text { (Every } 15 \\
\text { samples) }\end{array}$ & $\begin{array}{c}90-110 \% \text { Rec. for } 80 \% \\
\text { of metals w/ no } \\
\text { individual exceeding } \\
70-130 \% \text { (one per } \\
\text { sample set, } 10-15 \\
\text { samples) }\end{array}$ \\
\hline $\mathrm{SO}_{4}, \mathrm{Cl}, \mathrm{F}, \mathrm{Br}$ & $\begin{array}{l}\text { RSKSOP-2 } \\
\text { (EPA Method } \\
6500) 76 v 3\end{array}$ & $\begin{array}{l}\quad<\mathrm{MDL} \\
\text { (Beginning and } \\
\text { end of each } \\
\text { sample queue) }\end{array}$ & $\begin{array}{l}90-110 \% \text { Rec. } \\
\text { (Beginning, end, } \\
\text { and every } 10 \\
\text { samples) }\end{array}$ & $\begin{array}{l}\text { PE sample } \\
\text { acceptance } \\
\text { limits } \\
\text { (One per } \\
\text { sample set) }\end{array}$ & $\begin{array}{l}\text { RPD }<10 \\
\text { (every } 15 \\
\text { samples) }\end{array}$ & $\begin{array}{c}80-120 \% \text { Rec. } \\
\text { (one per every } 20 \\
\text { samples) }\end{array}$ \\
\hline $\begin{array}{c}\mathrm{NO}_{3}+\mathrm{NO}_{2}, \\
\mathrm{NH}_{4}\end{array}$ & $\begin{array}{l}\text { RSKSOP-214v5 } \\
\text { (EPA Method } \\
350.1 \text { and } \\
353.2 \text { ) }\end{array}$ & $\begin{array}{l}<1 / 2 \text { lowest calib. } \\
\text { std. } \\
\text { (Beginning and } \\
\text { end of each } \\
\text { sample queue) }\end{array}$ & $\begin{array}{l}90-110 \% \text { Rec. } \\
\text { (Beginning, end, } \\
\text { and every } 10 \\
\text { samples) }\end{array}$ & $\begin{array}{l}\text { PE sample } \\
\text { acceptance } \\
\text { limits } \\
\text { (One per } \\
\text { sample set) }\end{array}$ & $\begin{array}{l}\text { RPD }<10 \\
\text { (every } 10 \\
\text { samples) }\end{array}$ & $\begin{array}{c}80-120 \% \text { Rec } \\
\text { (one per every } 20 \\
\text { samples) }\end{array}$ \\
\hline
\end{tabular}


DRAFT

Table B4. QA/QC requirements for analysis of dissolved gases, DIC/DOC, VOCs, low molecular weight acids and stable isotopes of water

\begin{tabular}{|c|c|c|c|c|c|c|}
\hline Measurement & $\begin{array}{l}\text { Analysis } \\
\text { Method }\end{array}$ & $\begin{array}{l}\text { Blanks } \\
\text { (Frequency) }\end{array}$ & $\begin{array}{l}\text { Calibration } \\
\text { Checks } \\
\text { (Frequency) }\end{array}$ & $\begin{array}{l}\text { Second Source } \\
\text { (Frequency) }\end{array}$ & $\begin{array}{l}\text { Duplicates } \\
\text { (Frequency) }\end{array}$ & $\begin{array}{l}\text { Matrix Spikes } \\
\text { (Frequency) }\end{array}$ \\
\hline Dissolved gases & $\begin{array}{l}\text { RSKSOP-194v4 } \\
\&-175 v 5^{*} \text { (No } \\
\text { EPA Method) }\end{array}$ & $\begin{array}{l}\mathrm{MDL} \\
\text { (He/Ar blank, } \\
\text { first and last in } \\
\text { sample queue; } \\
\text { water blank } \\
\text { before samples) }\end{array}$ & $\begin{array}{l}85-115 \% \text { of } \\
\text { known value } \\
\text { (After helium/Ar } \\
\text { blank at first of } \\
\text { analysis queue, } \\
\text { before } \\
\text { helium/Ar blank } \\
\text { at end of sample } \\
\text { set, and every } \\
15 \text { samples) }\end{array}$ & $\begin{array}{l}85-115 \% \text { of } \\
\text { known value } \\
\text { (After first } \\
\text { calibration } \\
\text { check) }\end{array}$ & $\begin{array}{l}\text { RPD } \leq 20 \\
\text { (Every } 15 \\
\text { samples) }\end{array}$ & $\mathrm{NA}$ \\
\hline DIC/DOC & $\begin{array}{l}\text { RSKSOP-102v5 } \\
\text { (Phase III) or } \\
\text { 330v0 (Phase IV) } \\
\text { (EPA Method } \\
\text { 9060A) }\end{array}$ & $\begin{array}{l}-102 v 5:<1 / 2 \mathrm{QL} \\
\text { (after initial } \\
\text { calib., every } 10- \\
15 \text { samples, and } \\
\text { at end) } \\
\text {-330v0: < MDL } \\
\text { (Bcginning and } \\
\text { end of sample } \\
\text { set) }\end{array}$ & $\begin{array}{l}-102 v 5: 80-120 \% \\
\text { of known value } \\
\text { (after initial } \\
\text { calib., every 10- } \\
15 \text { samples, and } \\
\text { at end-330v0: } \\
90100 \% \text { of } \\
\text { known value } \\
\text { (Beginning and } \\
\text { end of sample } \\
\text { set and every } 10 \\
\text { samples) }\end{array}$ & $\begin{array}{l}\text {-102v5: } 80-120 \% \\
\text { of known value } \\
\text { (Immediately } \\
\text { after calibration) } \\
\text {-330v0: PE } \\
\text { sample reported } \\
\text { acceptance } \\
\text { limits. Others: } \\
90-100 \% \\
\text { recovery (one } \\
\text { per sample set) }\end{array}$ & $\begin{array}{l}\text {-102v5: RPD<10 } \\
\text { (every } 15 \\
\text { samples) } \\
\text {-330v0: RPD<10 } \\
\text { (every 10 } \\
\text { samples) }\end{array}$ & $\begin{array}{l}-102 v 5: 80-120 \% \\
\text { Rec. } \\
\text { (one per } 20 \text { or } \\
\text { every set) } \\
-330 v 0: 80-120 \% \\
\text { Rec. }\end{array}$ \\
\hline $\begin{array}{l}\text { Volatile organic } \\
\text { compounds } \\
\text { (VOC) }^{* *}\end{array}$ & $\begin{array}{l}\text { RSKSOP-299v1 } \\
\text { and -259v1 } \\
\text { (EPA Method } \\
\text { 5021A plus } \\
8260 \text { C) }\end{array}$ & $\begin{array}{l}<\mathrm{MDL} \\
\text { (Beginning and } \\
\text { end of each } \\
\text { sample set) }\end{array}$ & $\begin{array}{l}80-120 \% \text { Rec. } \\
\text { (Beginning, end, } \\
\text { and every } 20 \\
\text { samples) }\end{array}$ & $\begin{array}{l}80-120 \% \text { of } \\
\text { known value } \\
\text { Once at } \\
\text { beginning } \\
\text { (and at end for - } \\
259 \mathrm{v} 1 \text { ) }\end{array}$ & $\begin{array}{l}-299 v 1 \\
\text { RPD }<20 \\
-259 v 1 \\
\text { RPD }<25 \\
\text { (every 20 } \\
\text { samples) }\end{array}$ & $\begin{array}{l}70-130 \% \text { Rec. } \\
\text { (every } 20 \\
\text { samples) }\end{array}$ \\
\hline $\begin{array}{l}\text { Low Molecular } \\
\text { Weight Acids }\end{array}$ & $\begin{array}{l}\text { RSKSOP-112v6 } \\
\text { (No EPA } \\
\text { Method) }\end{array}$ & $\begin{array}{l}<\mathrm{MDL} \\
\text { (Beginning of a } \\
\text { sample queue; } \\
\text { every } 10 \\
\text { samples; and } \\
\text { end of sample } \\
\text { queue) }\end{array}$ & $\begin{array}{l}85-115 \% \text { of the } \\
\text { recovery } \\
\text { (Prior to sample } \\
\text { analysis; every } \\
10 \text { samples; end } \\
\text { of sample } \\
\text { queue) }\end{array}$ & $\begin{array}{l}85-115 \% \text { of } \\
\text { recovery } \\
\text { (Prior to sample } \\
\text { analysis) }\end{array}$ & $\begin{array}{l}<15 \text { RPD } \\
\text { (Every } 20 \\
\text { samples through } \\
\text { a sample queue) }\end{array}$ & $\begin{array}{l}80-120 \% \\
\text { recovery } \\
\text { (Every } 20 \\
\text { samples through } \\
\text { a sample queue) }\end{array}$ \\
\hline $\begin{array}{l}\text { O, H stable } \\
\text { isotopes of } \\
\text { water*** }^{* *}\end{array}$ & $\begin{array}{l}\text { RSKSOP-296v1 } \\
\text { (No EPA } \\
\text { Method) }\end{array}$ & NA & $\begin{array}{l}\text { Difference of } \\
\text { calibrated/true< } \\
1 \% \text { for } \delta^{2} \mathrm{H} \& \\
<0.2 \% \text { of } \delta^{18} \mathrm{O} \\
\text { (Beginning, end } \\
\text { and every tenth } \\
\text { sample) }\end{array}$ & $\begin{array}{l}\text { Working stds } \\
\text { calibrated } \\
\text { against } \\
\text { lAEAstds. } t \\
\text { (Beginning, end, } \\
\text { and every tenth } \\
\text { sample) }\end{array}$ & $\begin{array}{l}\text { Standard } \\
\text { deviation } \leq 1 \% \\
\text { for } \delta^{2} \mathrm{H} \text { and }< \\
0.2 \% \circ \text { for } \delta^{18} \mathrm{O} \\
\text { (every sample) }\end{array}$ & NA \\
\hline
\end{tabular}

"This table only provides a summary; SOPs should be consulted for greater detail.

**Surrogate compounds spiked at $100 \mathrm{ug} / \mathrm{L}$ : p-bromofluorobenzene and 1,2-dichlorobenzene-d4,

$85-115 \%$ recovery.

***Additional checks: internal reproducibility prior to each sample set, std dev $\leq 1 \%$ for $\delta^{2} \mathrm{H}$ and $\leq 1 \%$ ofor $\delta^{18} \mathrm{O}$

tInternational Atomic Energy Agency (VSMOW, GISP, and SLAP)

Corrective actions are outlined in the SOPs.

$\mathrm{MDL}=$ Method Detection Limit

$\mathrm{QL}=$ Quantitation Limit

$\mathrm{PE}=$ Performance Evaluation 
DRAFT

Table B5. QA/QC requirements for analysis of semi-volatiles, GRO, and DRO

\begin{tabular}{|c|c|c|c|c|}
\hline QC Type & Semivolatiles & DRO & GRO & Frequency \\
\hline Method Blanks & $\begin{array}{l}<\mathrm{RL} \\
\text { Preparation or Method Blank, } \\
\text { one with each set of extraction } \\
\text { groups. Calibration Blanks are } \\
\text { also analyzed }\end{array}$ & $\begin{array}{l}<\mathrm{RL} \\
\text { Preparation or } \\
\text { Method Blank }\end{array}$ & $\begin{array}{l}<\mathrm{RL} \\
\text { Preparation or Method } \\
\text { Blank and IBL }\end{array}$ & $\begin{array}{l}\text { At least one per } \\
\text { sample set }\end{array}$ \\
\hline Surrogate Spikes & $\begin{array}{l}\text { l imits based upon DoD } \\
\text { statistical study (rounded to } 0 \\
\text { or 5) for the target compound } \\
\text { analyses. }\end{array}$ & $\begin{array}{l}60-140 \% \text { of } \\
\text { expected value }\end{array}$ & $\begin{array}{l}70-130 \% \text { of experted } \\
\text { value }\end{array}$ & $\begin{array}{l}\text { Fvery field and } \mathrm{OC} \text {. } \\
\text { sample }\end{array}$ \\
\hline Internal Standards Verification & $\begin{array}{l}\text { Every sample, } \\
\text { EICP area within }-50 \% \text { to } \\
+100 \% \text { of last ICV or first CCV. }\end{array}$ & NA & NA & $\begin{array}{l}\text { Every field and QC } \\
\text { sample }\end{array}$ \\
\hline Initial multilevel calibration & $\begin{array}{l}\text { ICAL: minimum of } 6 \text { levels } \\
(0.25-12.5 \mathrm{ug} / \mathrm{L}), \text { one is at the } \\
\text { MRL }(0.50 \mathrm{ug} / \mathrm{L}) \text {, prior to } \\
\text { sample analysis (not daily) } \\
\text { RSD } \leq 20 \%, r^{2} \geq 0.990\end{array}$ & $\begin{array}{l}\text { ICAL: } 10-500 \mathrm{ug} / \mathrm{L} \\
\mathrm{RSD}<=20 \% \text { or } \\
\mathrm{r}^{2}>=0.990\end{array}$ & $\begin{array}{l}\text { ICAL: . } 25-12.5 \mathrm{ug} / \mathrm{L} \text { for } \\
\text { gasoline } \\
\text { (different range for other } \\
\text { compounds) } \\
\text { RSD }<=20 \% \text { or } \mathrm{r} 2>=0.990\end{array}$ & $\begin{array}{l}\text { As required (not daily } \\
\text { if pass } I C V \text { ) }\end{array}$ \\
\hline $\begin{array}{l}\text { Initial and Continuing } \\
\text { Calibration Checks }\end{array}$ & $80-120 \%$ of expected value & $\begin{array}{l}80-120 \% \text { of } \\
\text { expected value }\end{array}$ & $\begin{array}{l}80-120 \% \text { of expected } \\
\text { value }\end{array}$ & $\begin{array}{l}\text { At beginning of } \\
\text { sample set, every } \\
\text { tenth sample, and } \\
\text { end of sample set }\end{array}$ \\
\hline Second Source Standards & $\begin{array}{l}\text { ICV1 } \\
70-130 \% \text { of expected value }\end{array}$ & $\begin{array}{l}\text { ICV1 } \\
80-120 \% \text { of } \\
\text { expected value }\end{array}$ & $\begin{array}{l}\text { ICVs } \\
80-120 \% \text { of expected } \\
\text { value }\end{array}$ & $\begin{array}{l}\text { Each time calibration } \\
\text { performed }\end{array}$ \\
\hline $\begin{array}{l}\text { Laboratory Control Samples } \\
\text { (LCS) }\end{array}$ & $\begin{array}{l}\text { Statistical Limits from DoD LCS } \\
\text { Study (rounded to } 0 \text { or } 5 \text { ) or if } \\
\text { SRM is used based on those } \\
\text { certified limits }\end{array}$ & $\begin{array}{l}\text { Use an SRM: } \\
\text { Values of all } \\
\text { analytes in the } \\
\text { LCS should be } \\
\text { within the limits } \\
\text { determined by } \\
\text { the supplier. } \\
\text { Otherwise } 70 \text { - } \\
130 \% \text { of expected } \\
\text { value }\end{array}$ & $\begin{array}{l}\text { Use and SRM: Values of } \\
\text { all analytes in the LCS } \\
\text { should be within the } \\
\text { limits determined by the } \\
\text { supplier. } \\
\text { Otherwise } 70-130 \% \text { of } \\
\text { expected value }\end{array}$ & $\begin{array}{l}\text { One per analytical } \\
\text { batch or every } 20 \\
\text { samples, whichever is } \\
\text { greater }\end{array}$ \\
\hline $\begin{array}{l}\text { Laboratory Control Samples } \\
\text { (LCS) }\end{array}$ & $\begin{array}{l}\text { Statistical Limits from DoD LCS } \\
\text { Study (rounded to } 0 \text { or } 5 \text { ) or if } \\
\text { SRM is used based on those } \\
\text { certified limits }\end{array}$ & $\begin{array}{l}\text { Use an SRM: } \\
\text { Values of all } \\
\text { analytes in the } \\
\text { LCS should be } \\
\text { within the limits } \\
\text { determined by } \\
\text { the supplier. } \\
\text { Otherwise } 70- \\
\text { 130\% of expected } \\
\text { value }\end{array}$ & $\begin{array}{l}\text { Use and SRM: Values of } \\
\text { all analytes in the LCS } \\
\text { should be within the } \\
\text { limits determined by the } \\
\text { supplier. } \\
\text { Otherwise } 70-130 \% \text { of } \\
\text { expected value }\end{array}$ & $\begin{array}{l}\text { One per analytical } \\
\text { batch or every } 20 \\
\text { samples, whichever is } \\
\text { greater }\end{array}$ \\
\hline Matrix Spikes (MS) & Same as LCS & Same as LCS & $\begin{array}{l}70-130 \% \text { of expected } \\
\text { value }\end{array}$ & $\begin{array}{l}\text { One per sample set or } \\
\text { every } 20 \text { samples, } \\
\text { whichever is more } \\
\text { frequent }\end{array}$ \\
\hline MS/MSD & $\begin{array}{l}\% \text { Recovery same as MS } \\
\mathrm{RPD} \leq 30\end{array}$ & $\begin{array}{l}\% \text { Recovery same } \\
\text { as MS } \\
\text { RPD } \leq 25\end{array}$ & $\begin{array}{l}\% \text { Recovery same as MS } \\
\mathrm{RPD} \leq 25\end{array}$ & $\begin{array}{l}\text { One per sample set or } \\
\text { every } 20 \text { samples, } \\
\text { whichever is more } \\
\text { frequent }\end{array}$ \\
\hline Reporting Limits* & $\begin{array}{l}0.1 \mathrm{\mu g} / \mathrm{L} \text { (generally) }{ }^{1} \text { for target } \\
\text { compounds HF special } \\
\text { compounds are higher }\end{array}$ & $20 \mu \mathrm{g} / \mathrm{L}^{1}$ & $20 \mu g / L^{2}$ & NA \\
\hline
\end{tabular}

${ }^{1}$ Based on $1000 \mathrm{~mL}$ sample to $1 \mathrm{~mL}$ extract

${ }^{2}$ Based on a $5 \mathrm{~mL}$ purge 
DRAFT

Table B6. QA/QC requirements for LC/MS/MS analysis of glycols

\begin{tabular}{|l|l|l|}
\hline QC Type & Performance Criteria & Frequency \\
\hline Method Blanks & $<R L$ & One per every 20 samples \\
\hline Solvent Blanks & $<R L$ & One per every 10 samples \\
\hline $\begin{array}{l}\text { Initial and Continuing Calibration } \\
\text { Checks }\end{array}$ & $80-120 \%$ of expected value & $\begin{array}{l}\text { At beginning of sample set, after every tenth sample, } \\
\text { and end of sample set }\end{array}$ \\
\hline Second Source Standards & $80-120 \%$ of expected value & Each time calibration performed \\
\hline Laboratory Control Samples (LCS) & $80-120 \%$ of expected value & $\begin{array}{l}\text { One per analytical batch or every } 20 \text { samples, } \\
\text { whichever is greater }\end{array}$ \\
\hline Matrix Spikes (MS) & $70-130 \%$ of expected value & $\begin{array}{l}\text { One per sample set or every } 20 \text { samples, whichever is } \\
\text { more frequent }\end{array}$ \\
\hline MS/MSD & RPD $\leq 25$ & $\begin{array}{l}\text { One per sample set or every } 20 \text { samples, whichever is } \\
\text { more frequent }\end{array}$ \\
\hline
\end{tabular}

$\mathrm{RL}=$ Reporting Limit

Corrective Actions: If re-analysis was not possible (such as lack of sample volume), the data was qualified with a determination about the impact on the sample data. 


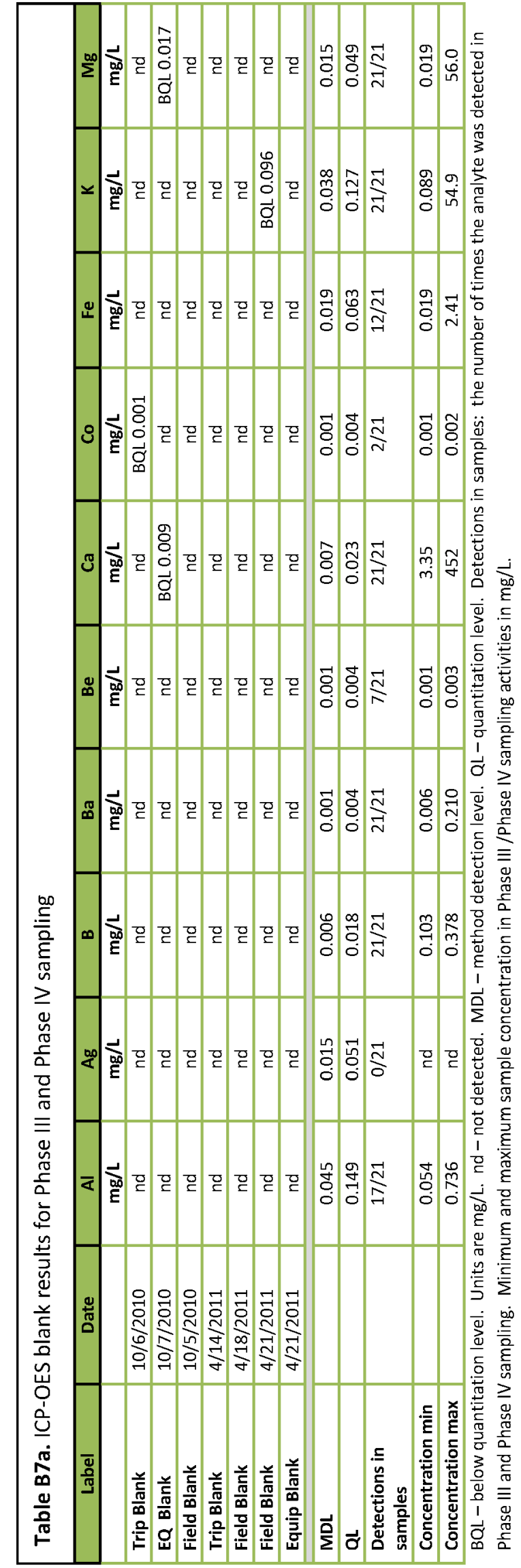

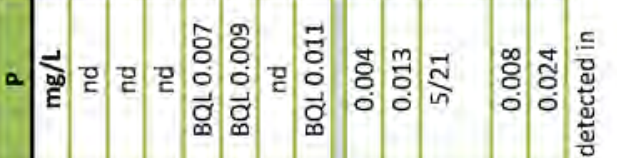

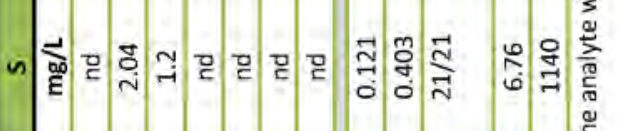

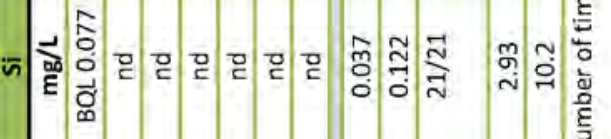

S

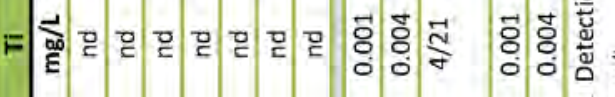

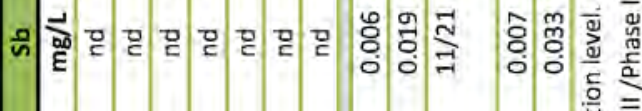

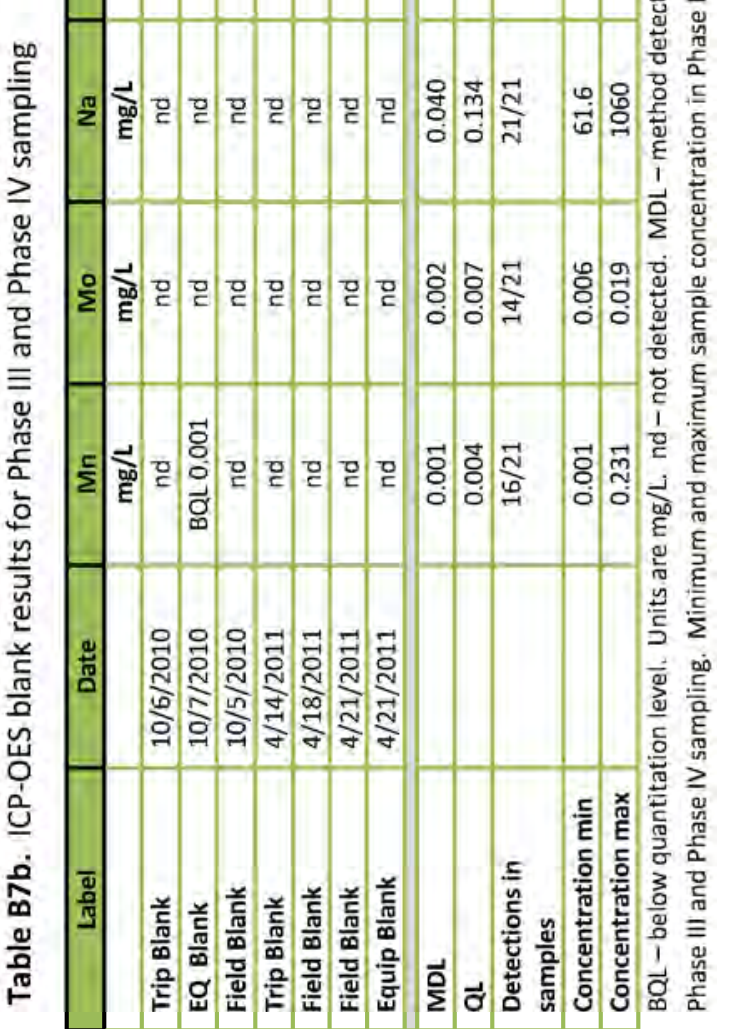




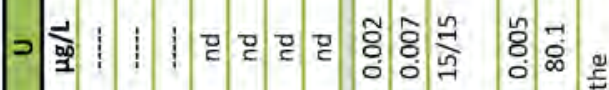

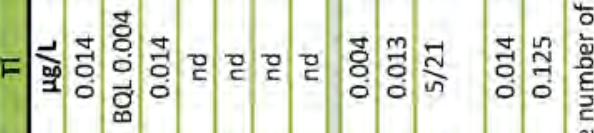
๓

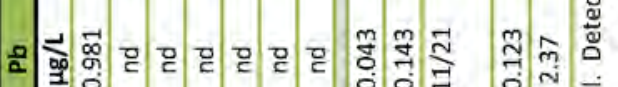

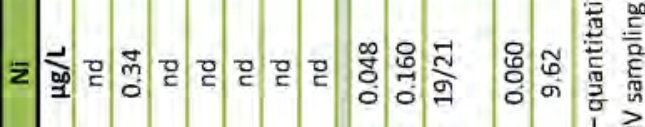

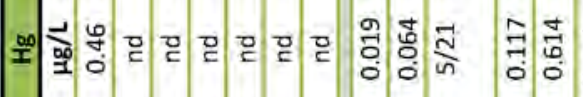
ठำ

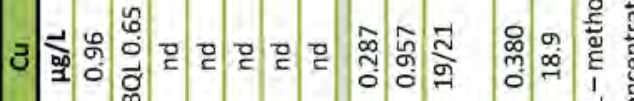
定

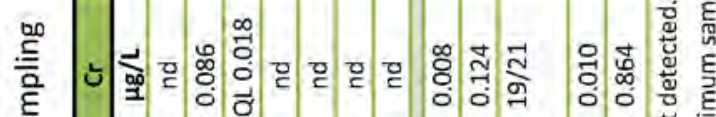
胥

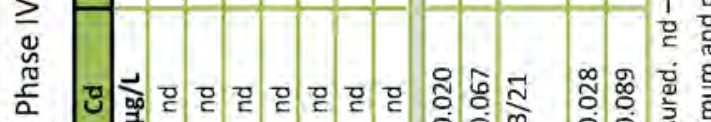

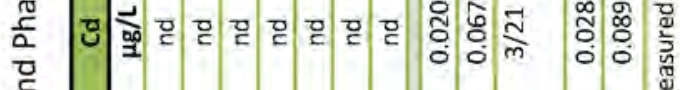$$
\equiv
$$$$
\text { 西 }
$$$$
4
$$

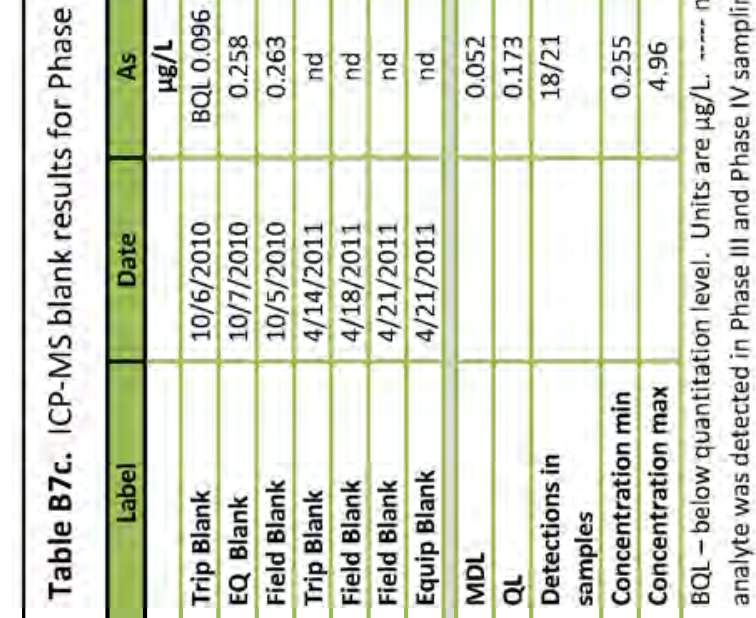

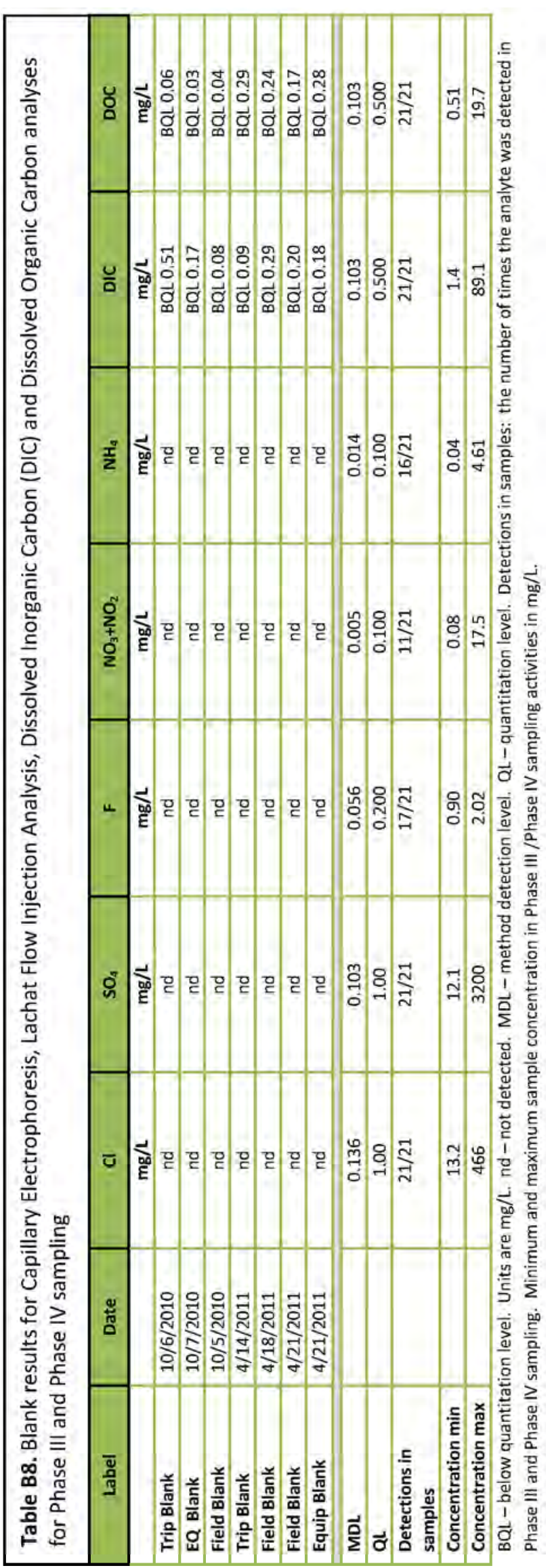


DRAFT

Table B9. Blank results for Volatile Organic Compounds $(\mu \mathrm{g} / \mathrm{L}$ ) in Phase III and Phase IV sampling (Region 8 laboratory, Golden, $\mathrm{CO}$ )

\begin{tabular}{|c|c|c|c|c|c|c|c|}
\hline & Trip Blank & EQ Blank & Field Blank & Trip Blank & Field Blank & Field Blank & $\mathbf{R L}$ \\
\hline & $10 / 6 / 2010$ & $10 / 7 / 2010$ & $10 / 5 / 2010$ & $4 / 14 / 2011$ & $4 / 18 / 2011$ & $4 / 21 / 2011$ & \\
\hline 1,1,1,2-Tetrachloroethane & nd & nd & nd & nd & nd & nd & 0.25 \\
\hline 1,1,1-Trichloroethane & nd & nd & nd & nd & nd & nd & 0.25 \\
\hline 1,1,2,2-Tetrachloroethane & nd & nd & nd & nd & nd & nd & 0.25 \\
\hline 1,1,2-Trichloroethane & nd & nd & nd & nd & nd & nd & 0.25 \\
\hline 1,1-Dichloroethane & Ind & rid & Ind & rid & rid & rid & 0.25 \\
\hline 1,1-Dichloroethene & nd & nd & nd & nd & nd & nd & 0.25 \\
\hline 1,1-Dichloropropene & nd & nd & nd & nd & nd & nd & 0.25 \\
\hline 1,2,3-Trichlorobenzene & nd & nd & nd & nd & nd & nd & 0.25 \\
\hline 1,2,3-Trichloropropane & nd & nd & nd & nd & nd & nd & 0.25 \\
\hline 1,2,4-Trichlorobenzene & nd & nd & nd & nd & nd & nd & 0.25 \\
\hline 1,2,4-Trimethylbenzene & nd & nd & nd & nd & nd & nd & 0.25 \\
\hline 1,2-Dibromo-3-chloropropane & nd & nd & nd & nd & nd & nd & 0.25 \\
\hline 1,2-Dibromoethane (EDB) & nd & nd & nd & nd & nd & nd & 0.25 \\
\hline 1,2-Dichlorobenzene & nd & nd & nd & nd & nd & nd & 0.25 \\
\hline 1,2-Dichloroethane & nd & nd & nd & nd & nd & nd & 0.25 \\
\hline 1,2-Dichloropropane & nd & nd & nd & nd & nd & nd & 0.25 \\
\hline 1,3,5-Trimethylbenzene & nd & nd & nd & nd & nd & nd & 0.25 \\
\hline 1,3-Dichlorobenzene & nd & nd & nd & nd & nd & nd & 0.25 \\
\hline 1,3-Dichloropropane & nd & nd & nd & nd & nd & nd & 0.25 \\
\hline 1,3-Dimethyl adamantane & nd & nd & nd & nd & nd & nd & 0.25 \\
\hline 1,4-Dichlorobenzene & nd & nd & nd & nd & nd & nd & 0.25 \\
\hline 2,2-Dichloropropane & nd & nd & nd & nd & nd & nd & 0.25 \\
\hline 2-Butanone & ---- & ----. & ---- & nd & 0.64 & 0.82 & 0.50 \\
\hline 2-Chlorotoluene & nd & nd & nd & nd & nd & nd & 0.25 \\
\hline 4-Chlorotoluene & nd & nd & nd & nd & nd & nd & 0.25 \\
\hline 4-IMethyl-2-pentanone & ----- & ----- & ----- & nd & nd & nd & 0.25 \\
\hline 2-Hexanone & ---- & ----- & ---- & nd & 0.29 & 0.41 & 0.25 \\
\hline Acetone & ----- & ----- & ---- & nd & 1.03 & 1.38 & 1.00 \\
\hline Acrylonitrile & nd & nd & nd & nd & nd & nd & 0.25 \\
\hline Adamantane & nd & nd & nd & nd & nd & nd & 0.25 \\
\hline Allyl chloride & nd & nd & nd & nd & nd & nd & 0.25 \\
\hline Benzene & nd & nd & nd & nd & nd & nd & 0.03 \\
\hline Bromobenzene & nd & nd & nd & nd & nd & nd & 0.25 \\
\hline Bromochloromethane & nd & nd & nd & nd & nd & nd & 0.25 \\
\hline Bromodichloromethane & nd & nd & nd & nd & nd & nd & 0.25 \\
\hline Bromoform & nd & nd & nd & nd & nd & nd & 0.25 \\
\hline Bromomethane & nd & nd & nd & nd & nd & nd & 0.25 \\
\hline Carbon disulfide & nd & nd & nd & nd & nd & nd & 0.25 \\
\hline Carbon tetrachloride & nd & nd & nd & nd & nd & nd & 0.25 \\
\hline Chlorobenzene & nd & nd & nd & nd & nd & nd & 0.25 \\
\hline Chlorodibromomethane & nd & nd & nd & nd & nd & nd & 0.25 \\
\hline Chloroethane & nd & 0.25 & nd & nd & nd & nd & 0.25 \\
\hline Chloroform & nd & nd & nd & nd & nd & nd & 0.25 \\
\hline Chloromethane & nd & nd & nd & 1.04 & nd & nd & 0.25 \\
\hline cis-1,2-Dichloroethene & nd & nd & nd & nd & nd & nd & 0.25 \\
\hline cis-1,3-Dichloropropene & nd & nd & nd & nd & nd & nd & 0.25 \\
\hline Dibromomethane & nd & nd & nd & nd & nd & nd & 0.25 \\
\hline Dichlorodifluoromethane & nd & nd & nd & nd & nd & nd & 0.25 \\
\hline Ethyl Ether & nd & nd & nd & nd & nd & nd & 0.25 \\
\hline Ethylbenzene & nd & nd & nd & nd & nd & nd & 0.25 \\
\hline Hexachlorobutadiene & nd & nd & nd & nd & nd & nd & 0.25 \\
\hline Hexachloroethane & nd & nd & nd & nd & nd & nd & 0.25 \\
\hline lodomethane & nd & nd & nd & nd & nd & nd & 0.25 \\
\hline Isopropylbenzene & nd & nd & nd & nd & nd & nd & 0.25 \\
\hline m,p-Xylene & nd & nd & nd & nd & 0.69 & 0.70 & 0.50 \\
\hline Methacrylonitrile & nd & nd & nd & nd & 0.27 & nd & 0.25 \\
\hline
\end{tabular}


DRAFT

\begin{tabular}{|c|c|c|c|c|c|c|c|}
\hline & Trip Blank & EQ Blank & Field Blank & Trip Blank & Field Blank & Field Blank & $\mathbf{R L}$ \\
\hline & $10 / 6 / 2010$ & $10 / 7 / 2010$ & $10 / 5 / 2010$ & $4 / 14 / 2011$ & $4 / 18 / 2011$ & $4 / 21 / 2011$ & \\
\hline Methyl Acrylate & nd & nd & nd & nd & nd & nd & 0.25 \\
\hline Methyl tert-Butyl Ether & nd & nd & nd & nd & nd & nd & 0.25 \\
\hline Methylene chloride & nd & nd & nd & nd & nd & nd & 0.25 \\
\hline Naphthalene & nd & nd & nd & nd & nd & nd & 0.25 \\
\hline n-Butyl Benzene & nd & nd & nd & nd & nd & nd & 0.25 \\
\hline n-Propyl Benzene & nd & nd & nd & nd & nd & nd & 0.25 \\
\hline o-Xylene & nd & nd & nd & nd & nd & nd & 0.25 \\
\hline p-Isopropyltoluene & nd & nd & nd & nd & nd & nd & 0.25 \\
\hline sec-Butylbenzene & nd & nd & nd & nd & nd & nd & 0.25 \\
\hline Styrene & nd & nd & nd & nd & nd & nd & 0.25 \\
\hline tert-Butylbenzene & nd & nd & nd & nd & nd & nd & 0.25 \\
\hline Tetrachloroethene & nd & nd & nd & nd & nd & nd & 0.25 \\
\hline Toluene & 0.54 & 0.16 & 0.16 & nd & nd & nd & 0.25 \\
\hline trans-1,2-Dichloroethene & nd & nd & nd & nd & nd & nd & 0.25 \\
\hline trans-1,3-Dichloropropene & nd & nd & nd & nd & nd & nd & 0.25 \\
\hline Trichloroethene & nd & nd & nd & nd & nd & nd & 0.25 \\
\hline Trichlorofluoromethane & nd & nd & nd & nd & nd & nd & 0.25 \\
\hline Vinyl chloride & nd & nd & nd & nd & nd & $\mathrm{nd}$ & 0.25 \\
\hline Xylenes (total) & nd & nd & nd & nd & nd & nd & 0.75 \\
\hline
\end{tabular}

$\mathrm{RL}$ - Reporting Limit ( $\mathrm{g} / \mathrm{L})$. nd - not detected. ----- not measured. 
DRAFT

Table B10. Blank results for Volatile Organic Compounds ( $\mu \mathrm{g} / \mathrm{L}$ ) in Phase IV sampling (ORD laboratory, Ada, OK)

\begin{tabular}{|c|c|c|c|c|c|}
\hline & Trip Blank & Field Blank & Field Blank & MDL & $\mathbf{Q L}$ \\
\hline & $4 / 14 / 2011$ & $4 / 18 / 2011$ & $4 / 21 / 2011$ & & \\
\hline Vinyl chloride & nd & nd & nd & 0.14 & 1.0 \\
\hline 1,1-Dichloroethene & nd & nd & nd & 0.07 & 0.5 \\
\hline Methylene Chloride & nd & nd & nd & 0.19 & 0.5 \\
\hline trans-1,2-Dichloroethene & nd & nd & nd & 0.05 & 0.5 \\
\hline cis-1,2-Dichloroethene & nd & nd & nd & 0.15 & 0.5 \\
\hline Chloroform & nd & nd & nd & 0.07 & 0.5 \\
\hline 1,1,1-Trichloroethane & nd & nd & nd & 0.03 & 0.5 \\
\hline Carbon Tetrachloride & nd & nd & nd & 0.04 & 0.5 \\
\hline 1,2-Dichloroethane & nd & nd & nd & 0.03 & 0.5 \\
\hline Trichloroethene & nd & nd & nd & 0.07 & 0.5 \\
\hline 1,1,2-Trichloroethane & nd & nd & nd & 0.03 & 0.5 \\
\hline Tetrachloroethene & nd & nd & nd & 0.09 & 0.5 \\
\hline Chlorobenzene & nd & nd & nd & 0.04 & 0.5 \\
\hline 1,3-Dichlorobenzene & nd & nd & nd & 0.06 & 0.5 \\
\hline 1,4-Dichlorobenzene & nd & nd & nd & 0.04 & 0.5 \\
\hline 1,2-Dichlorobenzene & nd & nd & nd & 0.03 & 0.5 \\
\hline Ethanol & nd & nd & nd & 0.11 & 1.0 \\
\hline Isopropanol & nd & nd & nd & 24.7 & 100 \\
\hline n-Propanol & nd & nd & nd & 11.4 & 100 \\
\hline Isobutanol & nd & nd & nd & 13.5 & 100 \\
\hline n-Butanol & nd & nd & nd & 15.6 & 100 \\
\hline tert-Butyl Alcohol & nd & nd & nd & 15.5 & 100 \\
\hline Methyl tert-Butyl Ether & nd & nd & nd & 1.72 & 5.0 \\
\hline di-Isopropyl Ether & nd & nd & nd & 0.11 & 0.5 \\
\hline Ethyl tert-Butyl Ether & nd & nd & nd & 0.11 & 0.5 \\
\hline Benzene & nd & nd & nd & 0.03 & 0.5 \\
\hline tert-Amyl Methyl Ether & nd & nd & nd & 0.06 & 0.5 \\
\hline 2,5-Dimethylfuran & nd & nd & nd & 0.06 & 0.5 \\
\hline Toluene & BQL 0.228 & nd & BQL 0.227 & 0.03 & 0.5 \\
\hline 1,2-Dibromoethane & nd & nd & nd & 0.03 & 0.5 \\
\hline Ethyl Benzene & nd & nd & nd & 0.09 & 1.0 \\
\hline m+p Xylene & BQL 0.229 & nd & BQL 0.133 & 0.03 & 0.5 \\
\hline o-Xylene & nd & nd & nd & 0.08 & 0.5 \\
\hline 1,3,5-Trimethylbenzene & nd & nd & nd & 0.03 & 0.5 \\
\hline 1,2,4-Trimethylbenzene & nd & nd & nd & 0.04 & 1.0 \\
\hline 1,2,3-Trimethylbenzene & nd & nd & nd & 0.02 & 1.0 \\
\hline Naphthalene & nd & nd & nd & 0.04 & 1.0 \\
\hline
\end{tabular}

All results in $\mu \mathrm{g} / \mathrm{L}$. MDL - method detection level. QL - quantitation level. nd - not detected. 
DRAFT

Table B11. Blank results for Semi-Volatile Organic Compounds $(\mu \mathrm{g} / \mathrm{L})$ in Phase III and Phase IV sampling (Region 8 laboratory, Golden, $\mathrm{CO}$ )

\begin{tabular}{|c|c|c|c|c|c|c|c|}
\hline & Trip Blank & EQ Blank & Field Blank & Trip Blank & Field Blank & Field Blank & $\mathbf{R L}$ \\
\hline & $10 / 6 / 2010$ & $10 / 7 / 2010$ & $10 / 5 / 2010$ & $4 / 14 / 2011$ & $4 / 18 / 2011$ & $4 / 21 / 2011$ & \\
\hline 1,2,4-Trichlorobenzene & nd & nd & nd & nd & nd & nd & 0.100 \\
\hline 1,2-Dichlorobenzene & nd & nd & nd & nd & nd & nd & 0.100 \\
\hline 1,2-Dinitrobenzene & nd & nd & nd & nd & nd & nd & 0.100 \\
\hline 1,3-Dichlorobenzene & nd & nd & nd & nd & nd & nd & 0.100 \\
\hline 1,3-Dinitrobenzene & nd & nd & nd & nd & nd & nd & 0.100 \\
\hline 1,4-Dichlorobenzene & nd & nd & nd & nd & nd & nd & 0.100 \\
\hline 1,4-Dinitrobenzene & nd & nd & nd & nd & nd & nd & 0.100 \\
\hline 1-Methylnaphthalene & nd & nd & nd & nd & nd & nd & 0.100 \\
\hline 2,3,4,6-Tetrachlorophenol & nd & nd & nd & nd & nd & nd & 0.250 \\
\hline 2,3,5,6-Tetrachlorophenol & nd & nd & nd & nd & nd & nd & 0.250 \\
\hline 2,4,5-Trichlorophenol & nd & nd & nd & nd & nd & nd & 0.100 \\
\hline 2,4,6-Trichlorophenol & nd & nd & nd & nd & nd & nd & 0.100 \\
\hline 2,4-Dichlorophenol & nd & nd & nd & nd & nd & nd & 0.100 \\
\hline 2,4-Dimethylphenol & nd & nd & nd & nd & nd & nd & 0.100 \\
\hline 2,4-Dichlorophenol & nd & nd & nd & nd & nd & nd & 0.100 \\
\hline 2,4-Dimethylphenol & nd & nd & nd & nd & nd & nd & 0.100 \\
\hline 2,4-Dinitrophenol & nd & nd & nd & nd & nd & nd & 1.00 \\
\hline 2,4-Dinitrotoluene & nd & nd & nd & nd & nd & nd & 1.00 \\
\hline 2,6-Dinitrotoluene & nd & nd & nd & nd & nd & nd & 0.100 \\
\hline 2-Chloronaphthalene & nd & nd & nd & nd & nd & nd & 0.100 \\
\hline 2-Chlorophenol & nd & nd & nd & nd & nd & nd & 0.100 \\
\hline 2-Methylnaphthalene & nd & nd & nd & nd & nd & nd & 0.100 \\
\hline 2-Methylphenol & nd & nd & nd & nd & nd & nd & 0.100 \\
\hline 2-Nitroaniline & nd & nd & nd & nd & nd & nd & 0.100 \\
\hline 2-Nitrophenol & nd & nd & nd & nd & nd & nd & 0.100 \\
\hline 3 \& 4-IMethylphenol & nd & nd & nd & nd & nd & nd & 0.200 \\
\hline 3,3'-Dichlorobenzidine & nd & nd & nd & nd & nd & nd & 0.500 \\
\hline 3-Nitroaniline & nd & nd & nd & nd & nd & nd & 0.100 \\
\hline 4,6-Dinitro-2-methylphenol & nd & nd & nd & nd & nd & nd & 0.500 \\
\hline 4-Bromophenyl phenyl ether & nd & nd & nd & nd & nd & nd & 0.100 \\
\hline 4-Chloro-3-methylphenol & nd & nd & nd & nd & nd & nd & 0.100 \\
\hline 4-Chloroaniline & nd & nd & nd & nd & nd & nd & 0.100 \\
\hline 4-Chlorophenyl phenyl ether & nd & nd & nd & nd & nd & nd & 0.100 \\
\hline 4-Nitroaniline & nd & nd & nd & nd & nd & nd & 0.500 \\
\hline 4-Nitrophenol & nd & nd & nd & nd & nd & nd & 1.00 \\
\hline Acenaphthene & nd & nd & nd & nd & nd & nd & 0.100 \\
\hline Acenaphthylene & nd & nd & nd & nd & nd & nd & 0.100 \\
\hline Aniline & nd & nd & nd & nd & nd & nd & 0.100 \\
\hline Anthracene & nd & nd & nd & nd & nd & nd & 0.100 \\
\hline Azobenzene & nd & nd & nd & nd & nd & nd & 0.100 \\
\hline Benzo (a) anthracene & nd & nd & nd & nd & nd & nd & 0.100 \\
\hline Benzo (a) pyrene & nd & nd & nd & nd & nd & nd & 0.100 \\
\hline Benzo $(\mathrm{g}, \mathrm{h}, \mathrm{i})$ perylene & nd & nd & nd & nd & nd & nd & 0.100 \\
\hline Benzo (k) fluoranthene & nd & nd & nd & nd & nd & nd & 0.100 \\
\hline Benzo(b)fluoranthene & nd & nd & nd & nd & nd & nd & 0.100 \\
\hline Benzoic acid & 0.83 & 0.78 & nd & 3.00 & nd & nd & 0.500 \\
\hline Benzyl alcohol & nd & 0.40 & 0.63 & nd & nd & nd & 0.500 \\
\hline Bis(2-chloroethoxy)methane & nd & nd & nd & nd & nd & nd & 0.100 \\
\hline Bis(2-chloroethyl)ether & nd & nd & nd & nd & nd & nd & 0.100 \\
\hline Bis(2-chloroisopropyl)ether & nd & nd & nd & nd & nd & nd & 0.100 \\
\hline Bis-(2-Ethylhexyl) Adipate & nd & nd & nd & nd & nd & nd & 0.100 \\
\hline Bis(2-ethylhexyl)phthalate & nd & nd & nd & 5.44 & nd & nd & 0.500 \\
\hline Butyl benzyl phthalate & nd & nd & nd & nd & nd & nd & 0.100 \\
\hline Carbazole & nd & nd & nd & nd & nd & nd & 0.100 \\
\hline Chrysene & nd & nd & nd & nd & nd & nd & 0.100 \\
\hline Dibenz $(a, h)$ anthracene & nd & nd & nd & nd & nd & nd & 0.100 \\
\hline
\end{tabular}


DRAFT

\begin{tabular}{|c|c|c|c|c|c|c|c|}
\hline & Trip Blank & EQ Blank & Field Blank & Trip Blank & Field Blank & Field Blank & $\mathbf{R L}$ \\
\hline & $10 / 6 / 2010$ & $10 / 7 / 2010$ & $10 / 5 / 2010$ & $4 / 14 / 2011$ & $4 / 18 / 2011$ & $4 / 21 / 2011$ & \\
\hline Dibenzofuran & nd & nd & nd & nd & nd & nd & 0.100 \\
\hline Diethyl phthalate & nd & nd & nd & nd & nd & nd & 0.100 \\
\hline Dimethyl phthalate & nd & nd & nd & nd & nd & nd & 0.100 \\
\hline Di-n-butyl phthalate & nd & nd & nd & nd & nd & nd & 0.100 \\
\hline Di-n-octyl phthalate & nd & nd & nd & nd & nd & nd & 0.100 \\
\hline Diphenylamine & nd & nd & nd & nd & nd & nd & 0.100 \\
\hline Fluoranthene & nd & nd & nd & nd & nd & nd & 0.100 \\
\hline Fluorene & nd & nd & nd & nd & nd & nd & 0.100 \\
\hline Hexachlorobenzene & nd & nd & nd & nd & nd & nd & 0.100 \\
\hline Hexachlorobutadiene & nd & nd & nd & nd & nd & nd & 0.100 \\
\hline Hexachlorocyclopentadiene & nd & nd & nd & nd & nd & nd & 0.100 \\
\hline Hexachloroethane & nd & nd & nd & nd & nd & nd & 0.100 \\
\hline Indeno $(1,2,3-c d)$ pyrene & nd & nd & nd & nd & nd & nd & 0.100 \\
\hline Isophorone & nd & nd & nd & nd & nd & nd & 0.100 \\
\hline Naphthalene & nd & nd & nd & nd & nd & nd & 0.100 \\
\hline Nitrobenzene & nd & nd & nd & nd & nd & nd & 0.100 \\
\hline N-Nitrosodi-n-propylamine & nd & nd & nd & nd & nd & nd & 0.100 \\
\hline Pentachlorophenol & nd & nd & nd & nd & nd & nd & 0.500 \\
\hline Phenanthrene & nd & nd & nd & nd & nd & nd & 0.100 \\
\hline Phenol & nd & nd & nd & nd & nd & nd & 0.100 \\
\hline Pyrene & nd & nd & nd & nd & nd & nd & 0.100 \\
\hline Limonene & nd & nd & nd & nd & nd & nd & 0.100 \\
\hline 1,3-Dimethyl adamantane & nd & nd & nd & nd & nd & nd & 0.100 \\
\hline 2-Butoxyethanol & nd & nd & nd & nd & nd & nd & 0.100 \\
\hline Adamantane & nd & 0.32 & nd & nd & nd & nd & 0.100 \\
\hline Squalene & 0.36 & 0.49 & 0.23 & nd & nd & nd & 1.00 \\
\hline Terpiniol & nd & nd & nd & nd & nd & nd & 0.100 \\
\hline Tri(2-butoxyethyl) Phosphate & nd & 2.53 & nd & nd & nd & nd & 0.500 \\
\hline
\end{tabular}

$\mathrm{RL}-$ Reporting Limit $(\mu \mathrm{g} / \mathrm{L})$. nd - not detected. ----- not measured.

Table B12. Blank results for GRO and DRO analyses for Phase III and Phase IV sampling (Region 8 laboratory, Golden, $\mathrm{CO}$ ) and blank results for glycol ethers in Phase IV sampling (Region 3 laboratory, Fort Meade, MD)

\begin{tabular}{|l|c|c|c|c|c|c|c|}
\hline & Trip Blank & EQ Blank & Field Blank & Trip Blank & Field Blank & Field Blank & RL \\
\hline & $\mathbf{1 0 / 6 / 2 0 1 0}$ & $\mathbf{1 0 / 7 / 2 0 1 0}$ & $\mathbf{1 0 / 5 / 2 0 1 0}$ & $\mathbf{4 / 1 4 / 2 0 1 1}$ & $\mathbf{4 / 1 8 / 2 0 1 1}$ & $\mathbf{4 / 2 1 / 2 0 1 1}$ & \\
\hline Gasoline Range Organics & nd & nd & nd & nd & 21.3 & nd & 20 \\
\hline Diesel Range Organics & nd & nd & nd & nd & nd & 135 & 22 \\
\hline 2-Butoxyethanol & ---- & ---- & ----- & nd & nd & nd & 10 \\
\hline Diethylene Glycol & ---- & ---- & ---- & nd & nd & nd & 50 \\
\hline Triethylene Glycol & ----- & ---- & ---- & nd & nd & nd & 10 \\
\hline Tetraethylene Glycol & ---- & ---- & ---- & 3.6 & 3.1 & 3.4 & 10 \\
\hline
\end{tabular}

RL - Reporting Limit ( $\mu \mathrm{g} / \mathrm{L})$. nd - not detected. ----- not measured. 


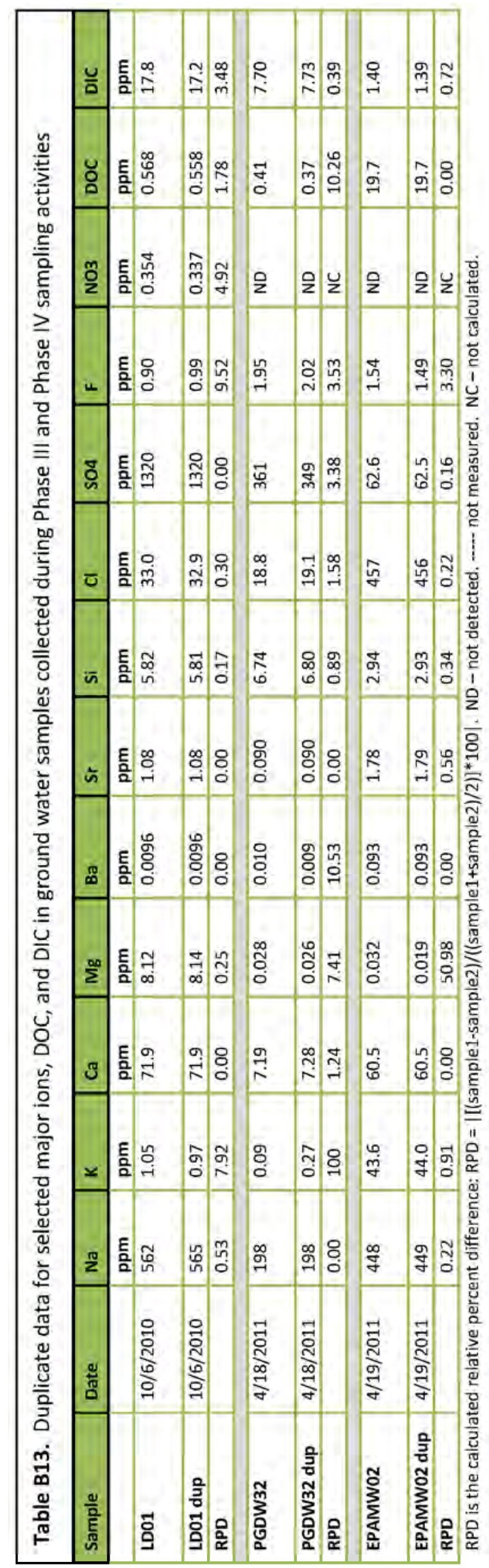




\section{DRAFT}

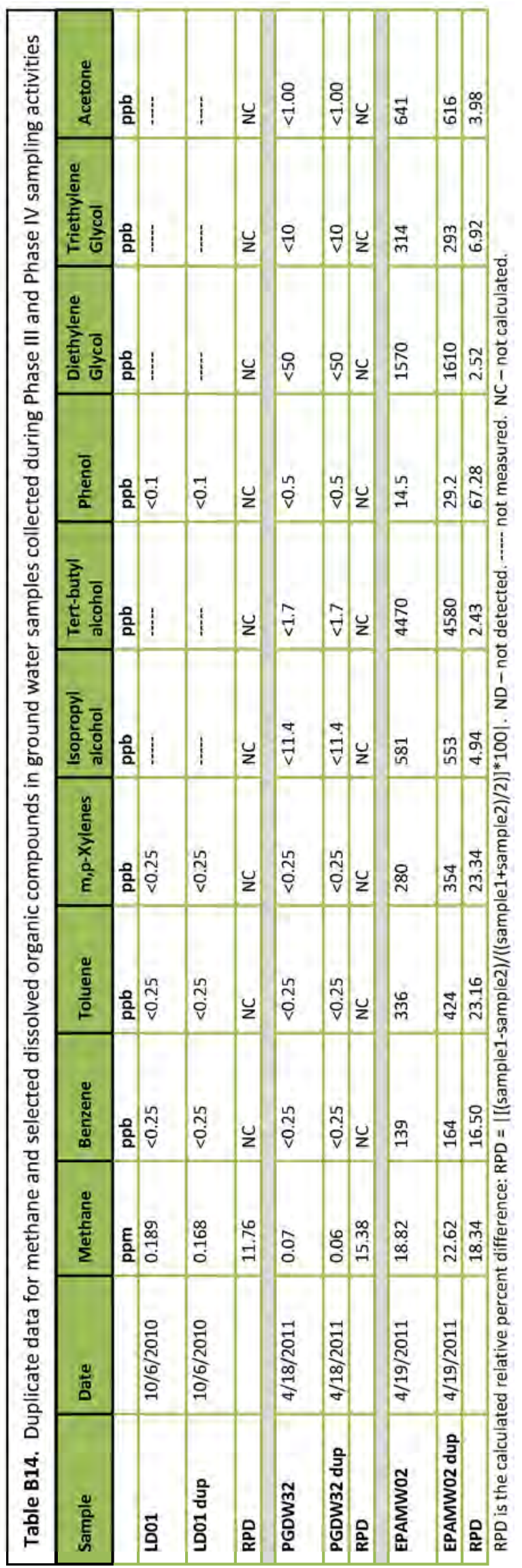


DRAFT

\begin{tabular}{|l|l|l|}
\hline \multicolumn{2}{|l|}{ Table B15. QA/QC requirements for analysis of $\delta^{13} \mathrm{C}$ of DIC } & Frequency \\
\hline QC Type & Performance Criteria & One at beginning of day, and one after sample is analyzed. \\
\hline Mass Spec Calibration Check & Difference of calibrated/true $\leq 0.5 \% \circ$ & Once a day \\
\hline Mass Spec Zero Enrichment Check & $0+1-0.1 \% 0$ & 1 per every 5 samples* \\
\hline Lab Duplicates & $\leq 1 \% \circ$ & .
\end{tabular}

Working standards were calibrated against IAEA (International Atomic Energy Agency) standard LSVEC and NBS-19; referenced to $\delta^{13} \mathrm{C}$ of the PeeDee belemnite (NIST material). *If $<5$ samples were submitted, a duplicate was run regardless of total number.

Corrective Actions: If re-analysis was not possible (such as lack of sample volume), the data was qualified with a determination about the impact on the sample data.

Table B16. QA/QC requirements for analysis for $\delta^{13} \mathrm{C}$ and $\delta \mathrm{D}$ of light hydrocarbons for aqueous and gas samples

\begin{tabular}{|c|c|c|}
\hline Mass Spec Calibration Check & $\begin{array}{l}\text { Difference of calibrated/true } \\
\leq 0.5 \% \text { for } \delta^{13} \mathrm{C} \text { and } \\
\leq 3 \% \text { for } \delta \mathrm{D} \\
+/-1 \text { pMC for }{ }^{14} \mathrm{C}\end{array}$ & $\begin{array}{l}\text { One at beginning of day and after samples are } \\
\text { analyzed for } \delta^{13} \mathrm{C}^{*} \text {; one at beginning of day and every } \\
\text { tenth sample for } \delta \mathrm{D}^{* *}\end{array}$ \\
\hline Mass Spec Zero Enrichment Check & $0+/-0.1 \%$ for $\delta^{13} C$ and $0+/-1 \%$ for $\delta D$ & Once a day for $\delta^{13} \mathrm{C}$ and every tenth sample for $\delta \mathrm{D}$ \\
\hline Lab Duplicates & $\begin{array}{l}\leq 1 \% \text { for } \delta^{13} \mathrm{C} \text { and } \\
\leq 3 \% \text { for } \delta \mathrm{D} \\
+/-1 \mathrm{pMC} \text { for }{ }^{14} \mathrm{C}\end{array}$ & 1 per every 10 samples for $\delta^{13} \mathrm{C}$ and $\delta \mathrm{D} * * *$ \\
\hline $\begin{array}{l}\text { Preparation System } \\
\text { Check/Reference Standards }\end{array}$ & $\begin{array}{l}\leq 1 \% \text { for } \delta^{13} C \text { and } \\
\leq 3 \% \text { for } \delta \mathrm{D} \\
+/-1 \mathrm{pMC}\end{array}$ & One per every 10 samples for $\delta^{13} \mathrm{C}$ and $\delta D$ \\
\hline
\end{tabular}

*Working standards calibrated against IAEA (International Atomic Energy Agency) standard LSVEC and NBS-19; referenced to $\delta^{13} \mathrm{C}$ of the PeeDee belemnite (NIST material) **Working standards calibrated against VSMOW, SLAP, and GISP; referenced to VSMOW.

***If < 10 samples were submitted, duplicate run regardless of total number.

Corrective Actions: If re-analysis is not possible (such as lack of sample volume), the data will be qualified with a determination about the impact on the sample data.

Table B17. QA/QC requirements for analysis of fixed gases and light hydrocarbons for aqueous and gas samples

\begin{tabular}{|c|c|c|c|c|c|c|}
\hline Measurement & $\begin{array}{l}\text { Analysis } \\
\text { Method }\end{array}$ & $\begin{array}{c}\text { Blanks } \\
\text { (Frequency) }\end{array}$ & $\begin{array}{l}\text { Calibration Checks } \\
\text { (Frequency) }\end{array}$ & $\begin{array}{l}\text { Second Source } \\
\text { (Frequency) }\end{array}$ & $\begin{array}{l}\text { Duplicates } \\
\text { (Frequency) }\end{array}$ & $\begin{array}{l}\text { Matrix Spikes } \\
\text { (Frequency) }\end{array}$ \\
\hline $\begin{array}{c}\mathrm{Ar}, \mathrm{He}, \mathrm{H}_{2}, \mathrm{O}_{2}, \mathrm{~N}_{2}, \\
\mathrm{CO}_{2}, \mathrm{CH}_{4}, \mathrm{C}_{2} \mathrm{H}_{6}, \\
\mathrm{C}_{2} \mathrm{H}_{4}, \mathrm{C}_{3} \mathrm{H}_{5}, \mathrm{C}_{3} \mathrm{H}_{8} \\
\mathrm{iC}_{4} \mathrm{H}_{10}, \mathrm{nC}_{4} \mathrm{H}_{10} \\
\mathrm{C}_{5} \mathrm{H}_{12}, \mathrm{nC}_{5} \mathrm{H}_{12}, \mathrm{C}_{6}+\end{array}$ & $\begin{array}{c}\text { Modification } \\
\text { of ASTM } \\
\text { D1945-03 }\end{array}$ & $\begin{array}{l}\text { None Detected } \\
\text { (beginning every } \\
10 \text { samples, end } \\
\text { of run) }\end{array}$ & $\begin{array}{l}85-115 \% \\
\text { (beginning every } 10 \\
\text { samples, end of run) }\end{array}$ & $\begin{array}{l}85-115 \% \\
\text { (after each } \\
\text { calibration) }\end{array}$ & $\begin{array}{l}\text { RPD }<15 \% \\
\text { (every } 10 \\
\text { samples) }\end{array}$ & NA \\
\hline
\end{tabular}




\section{DRAFT}

Table B18. Summary of quality control samples, purpose, method, and frequency to support gas analysis

\begin{tabular}{|l|l|l|l|l|}
\hline QC Sample & Purpose & Method & Frequency & Acceptance Criteria \\
\hline Equipment Blanks & $\begin{array}{l}\text { Ensure that construction } \\
\text { materials in gas sample bags and } \\
\text { the sample train are not a } \\
\text { source of vapors or gases of } \\
\text { concern }\end{array}$ & $\begin{array}{l}\text { Fill sample bags with } \\
\text { ultrapure } N_{2} \text { gas via the } \\
\text { sample train. }\end{array}$ & One sample per day & $<$ Detection limit \\
\hline Travel Blanks & $\begin{array}{l}\text { Ensure that cross-contamination } \\
\text { does not occur during sampling } \\
\text { or transport to the laboratory }\end{array}$ & $\begin{array}{l}\text { Fill sample bags with } \\
\text { ultrapure } \mathrm{N}_{2} \text { gas and place } \\
\text { in shipping container with } \\
\text { other samples. }\end{array}$ & One sample per shipment & $<$ Detection limit \\
\hline Duplicates & $\begin{array}{l}\text { Check precision of sampling } \\
\text { method and analysis }\end{array}$ & $\begin{array}{l}\text { Use a tee to collect two } \\
\text { samples simultaneously. }\end{array}$ & $\begin{array}{l}\text { One sample every } 10 \\
\text { samples }\end{array}$ & RPD <20\% \\
\hline
\end{tabular}

Table B19. Summary of analytes, instruments, calibration, and check standards for portable gas analyzers

\begin{tabular}{|c|c|c|c|c|c|c|}
\hline Analyte & $\begin{array}{l}\text { Instrument } \\
\text { (Detector) }\end{array}$ & Method & Range & Calibration & Check Standard & Accuracy \\
\hline$\overline{\mathrm{O}_{2}}$ & $\begin{array}{l}\text { GEM-2000 Plus } \\
\text { CES-LANDTEC } \\
\text { (EC Cell) }\end{array}$ & $\begin{array}{l}\text { RSKSOP- } \\
314 v 1\end{array}$ & $0-21 \%$ & $\begin{array}{l}4 \%, 10 \% \text {, or } \\
20.9 \%\end{array}$ & $4 \% 10 \%, 20.9 \%$ & $\begin{array}{l} \pm 1.0 \%(0-5 \%) \\
\pm 1.0 \%(5-21 \%)\end{array}$ \\
\hline $\mathrm{CH}_{4}$ & $\begin{array}{l}\text { GEM-2000 Plus } \\
\text { CES-LANDTEC } \\
\text { (IRGA) }\end{array}$ & $\begin{array}{l}\text { RSKSOP- } \\
314 \mathrm{v} 1\end{array}$ & $0-100 \%$ & $2.5 \%$ or $50 \%$ & $2.5 \%, 50 \%$ & $\begin{array}{l} \pm 0.3 \%(0-5 \%) \\
\pm 1 \%(5-15 \%) \\
\pm 3 \%(15-100 \%)\end{array}$ \\
\hline $\mathrm{CO}_{2}$ & $\begin{array}{l}\text { GEM-2000 Plus } \\
\text { CES-LANDTEC } \\
\text { (IRGA) }\end{array}$ & $\begin{array}{l}\text { RSKSOP- } \\
314 v 1\end{array}$ & $0-100 \%$ & $\begin{array}{l}5 \%, 20 \% \text {, or } \\
35 \%\end{array}$ & $5 \%, 20 \%, 35 \%$ & $\begin{array}{l} \pm 0.3 \%(0-5 \%) \\
\pm 1.0 \%(5-15 \%) \\
\pm 3.0 \%(15-50 \%)\end{array}$ \\
\hline VOCs & $\begin{array}{l}\text { Thermo Scientific } \\
\text { TVA-1000B (FID) }\end{array}$ & $\begin{array}{l}\text { RSKSOP- } \\
320 v 1\end{array}$ & $\begin{array}{l}1.0- \\
10,000 \\
\text { ppmv }\end{array}$ & $\begin{array}{l}0.0,10,100 \\
1000,9000 \\
\text { ppmv CH }\end{array}$ & $\begin{array}{l}\text { 10, 100, } 1000 \\
9000 \mathrm{ppmv} \mathrm{CH}_{4}\end{array}$ & $\begin{array}{l} \pm 25 \% \text { or } \pm 2.5 \text { ppmv, } \\
\text { whichever is greater, from } \\
1.0 \text { to } 10,000 \text { ppmv. }\end{array}$ \\
\hline VOCs & $\begin{array}{l}\text { Thermo Scientific } \\
\text { TVA-1000B (PID) }\end{array}$ & $\begin{array}{l}\text { RSKSOP- } \\
320 v 1\end{array}$ & $\begin{array}{l}0.5-500 \\
\text { ppmv }\end{array}$ & $\begin{array}{l}0.0,250,475 \\
\text { ppmv }\end{array}$ & $\begin{array}{l}250 \\
475 \text { ppmv } \\
\text { Isobutylene }\end{array}$ & $\begin{array}{l} \pm 25 \% \text { or } \pm 2.5 \text { ppmv, } \\
\text { whichever is greater, from } \\
0.5 \text { to } 500 \text { ppmv. }\end{array}$ \\
\hline
\end{tabular}

Table B20. QA/QC Requirements for portable gas analyzers

\begin{tabular}{|l|l|l|l|l|}
\hline Measurement & Analysis Method & $\begin{array}{l}\text { Blanks* } \\
\text { (Frequency) }\end{array}$ & $\begin{array}{l}\text { Calibration Check Standards } \\
\text { (Frequency) }\end{array}$ & $\begin{array}{l}\text { Second Source Standards } \\
\text { (Frequency) }\end{array}$ \\
\hline $\mathrm{O}_{2}, \mathrm{CO}_{2}, \mathrm{CH}_{4}$, & RSKSOP-314v1 & $\begin{array}{l}\text { beginning \& end of each } \\
\text { sample event) }\end{array}$ & $\begin{array}{l}+/-1 \% \text { of reading } \\
\text { (beginning \& end of each sample event) }\end{array}$ & $\begin{array}{l}\text { (after each calibration, } \\
\text { optional for this project) }\end{array}$ \\
\hline Hydrocarbons & RSKSOP-320v1 & $\begin{array}{l}\text { beginning \& end of each } \\
\text { sample event) }\end{array}$ & $\begin{array}{l}90-110 \% \text { of known value for FID and 80- } \\
120 \% \text { for PID } \\
\text { (after calibration, beginning \& end of each } \\
\text { sample event) }\end{array}$ & NA \\
\hline
\end{tabular}

Corrective actions are detailed in the SOPs.

*Duplicate sample not appropriate for measurements from a sample train.

*** Meter reading 


\section{DRAFT}


Appendix C

\section{Photographic Log of Deep Monitoring Well Construction}




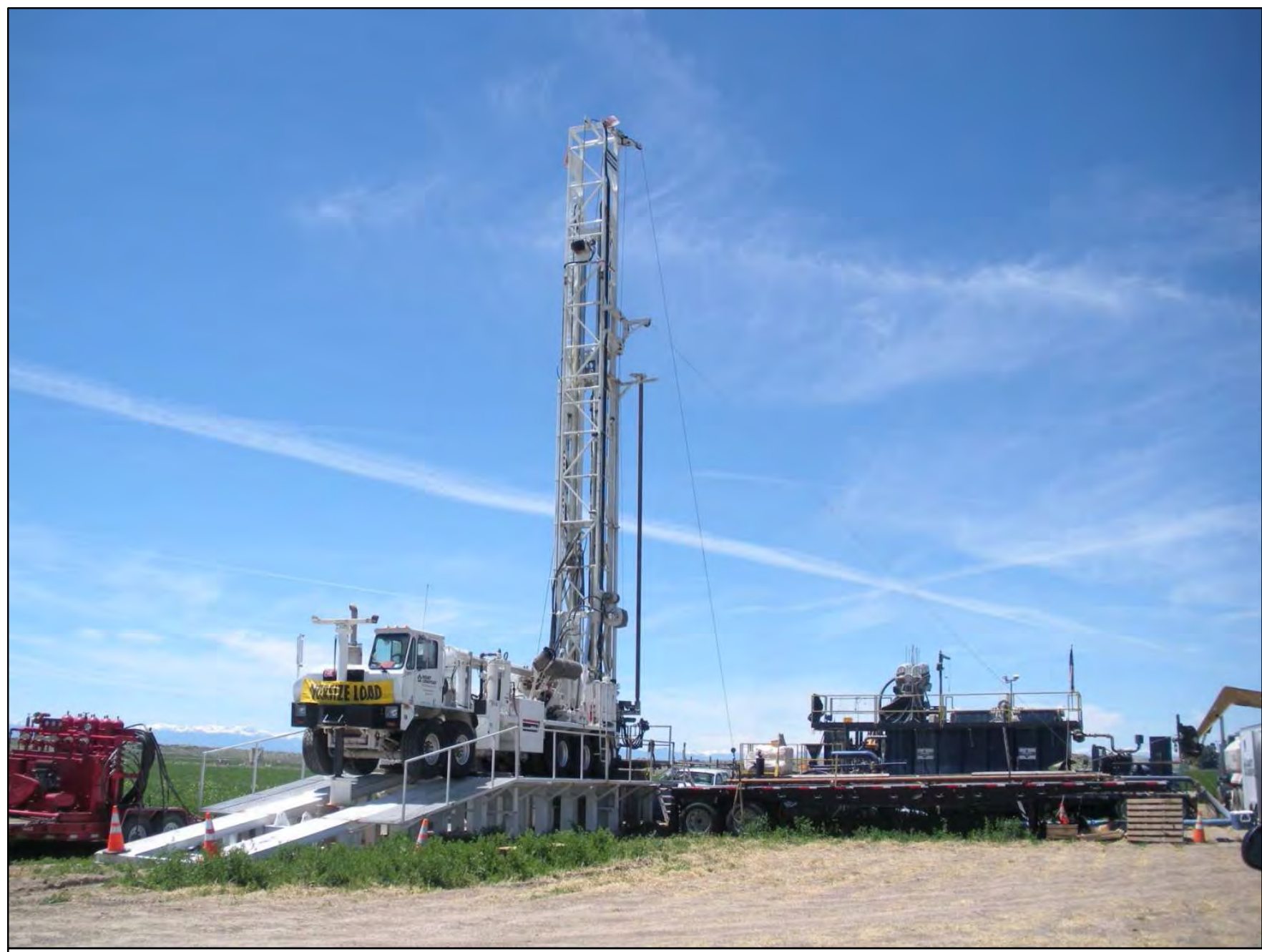

Figure C1. Photograph of drilling rig on platform with shakers for mud recirculation at MW02.

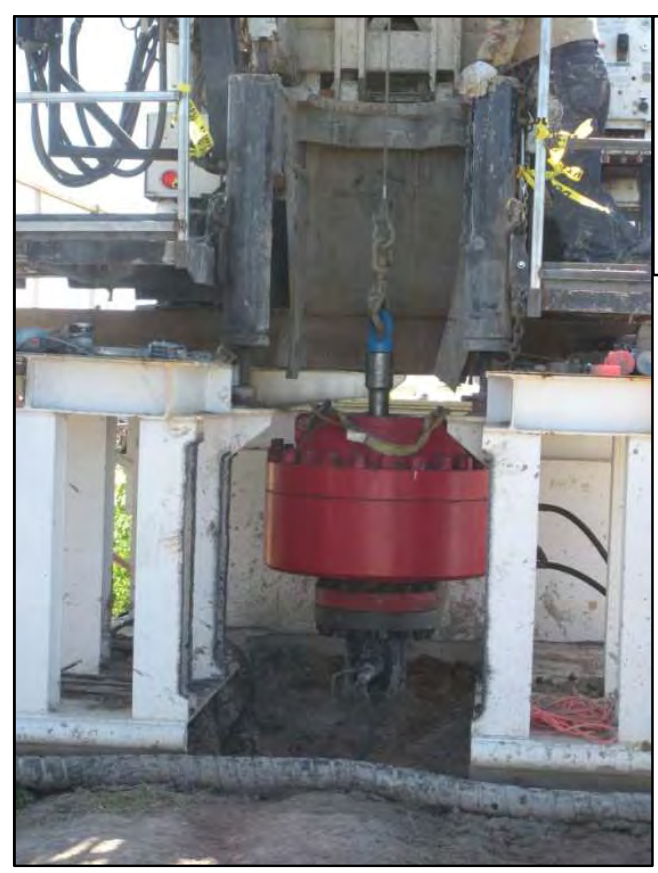

Figure C2. Photograph of blowout prevention (BOP) for annular space at base of drilling rig platform at MW02.

Figure C3. Photograph of blowout preventer for drillstem.

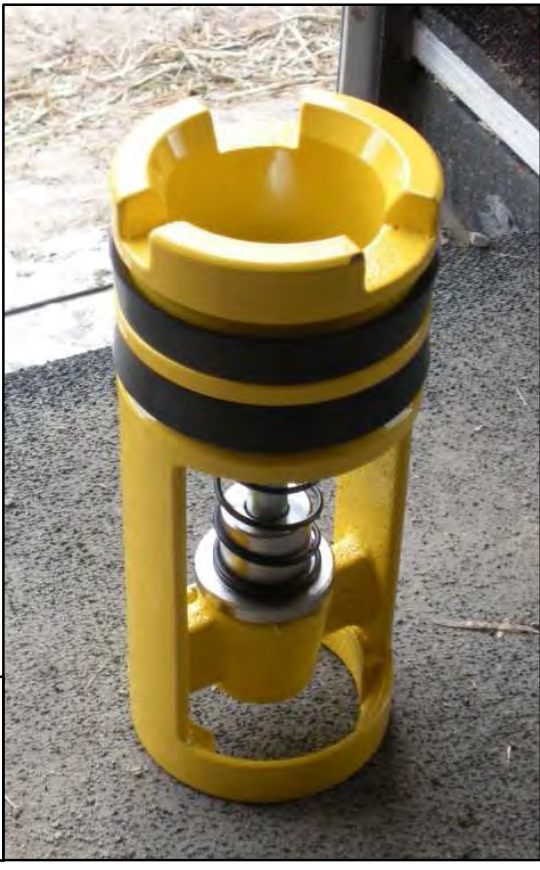




\section{DRAFT}

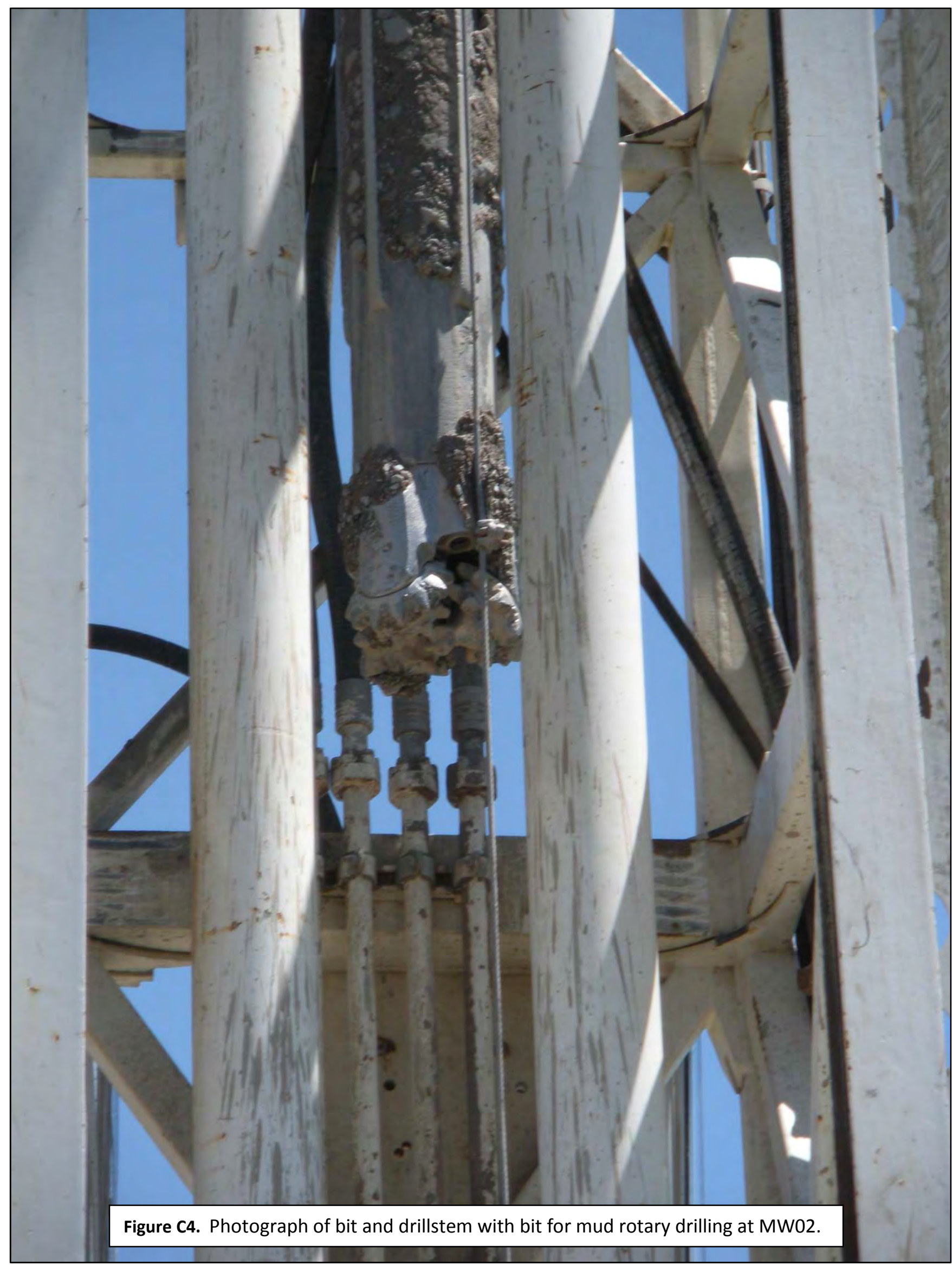




\section{DRAFT}

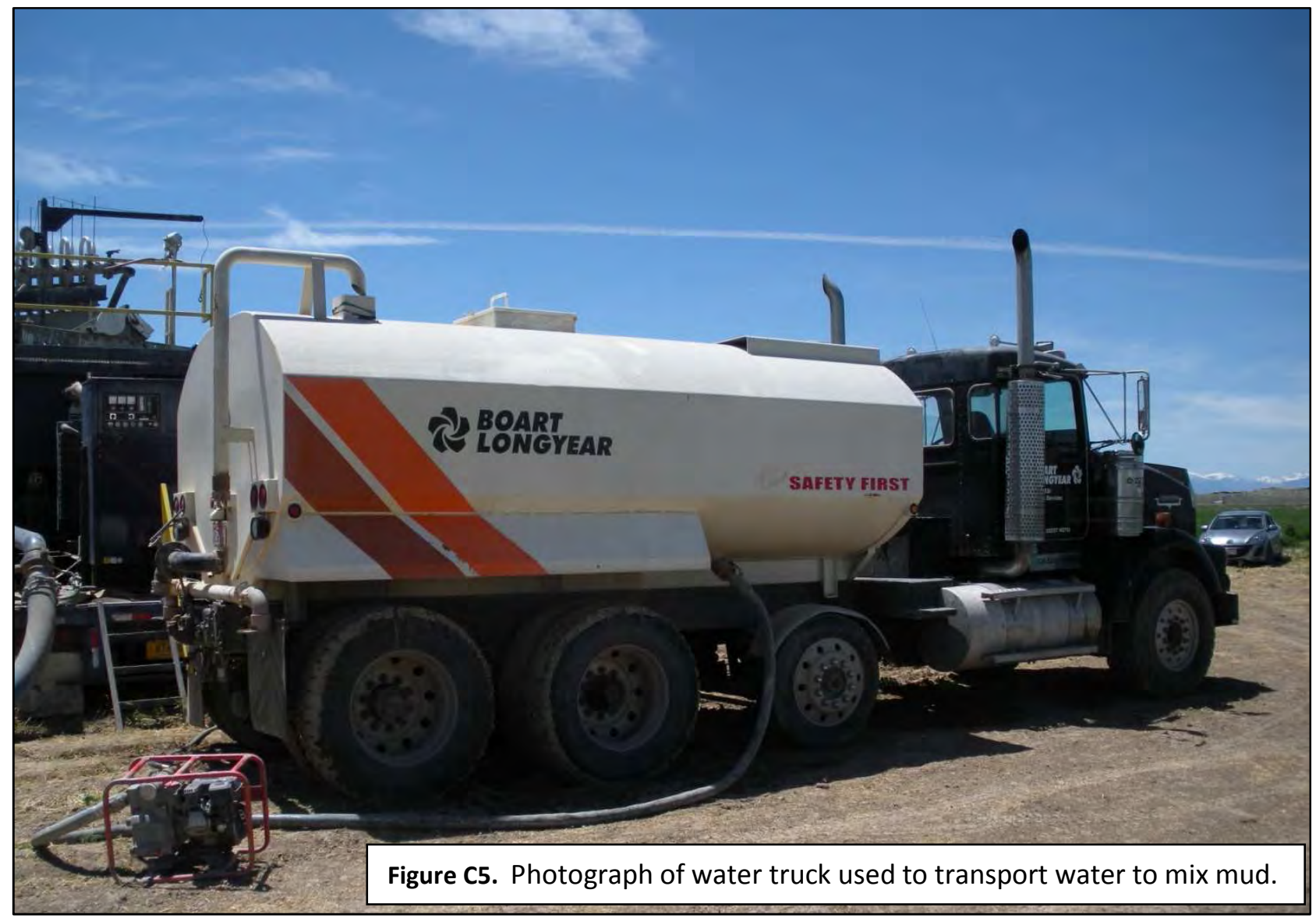

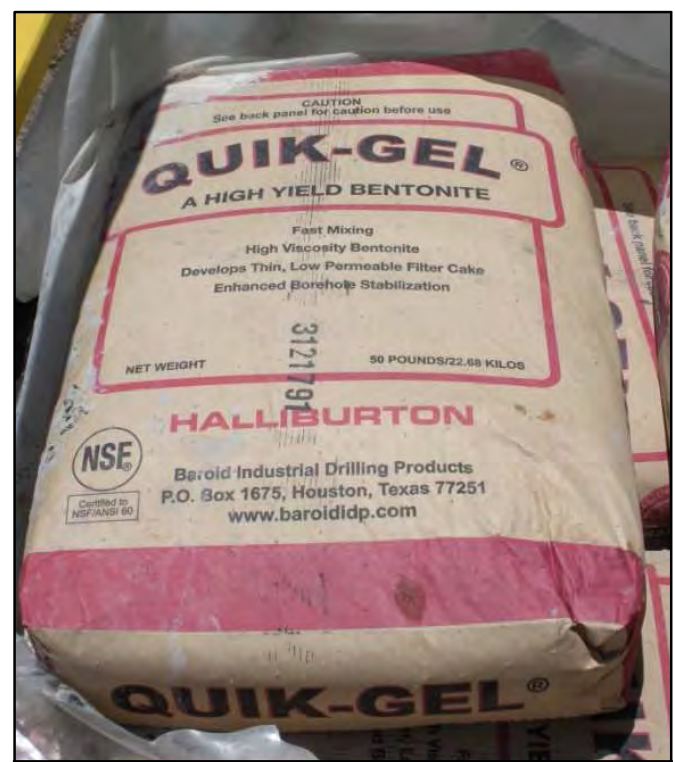

Figure C6. Photograph of Quik-Gel bentonite (Halliburton) used to create mud for drilling.
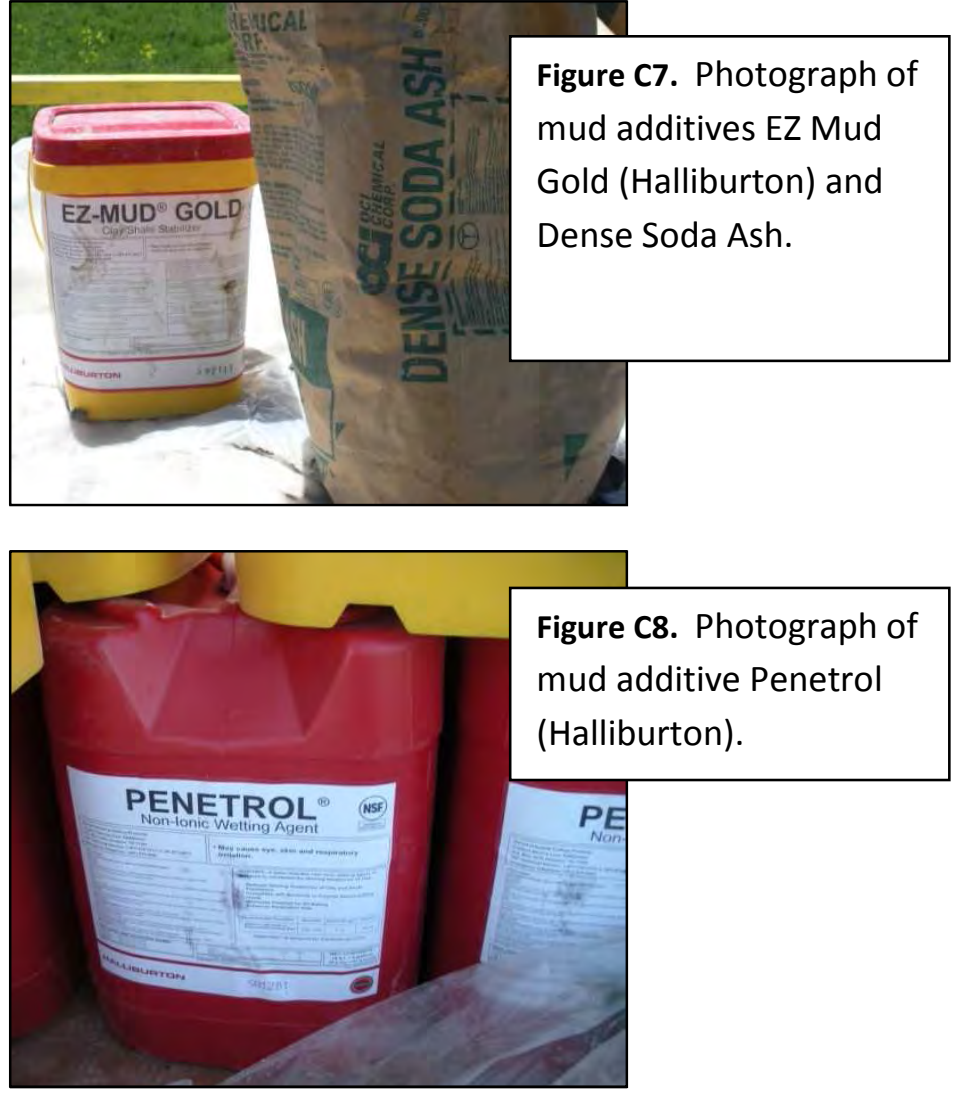


\section{DRAFT}
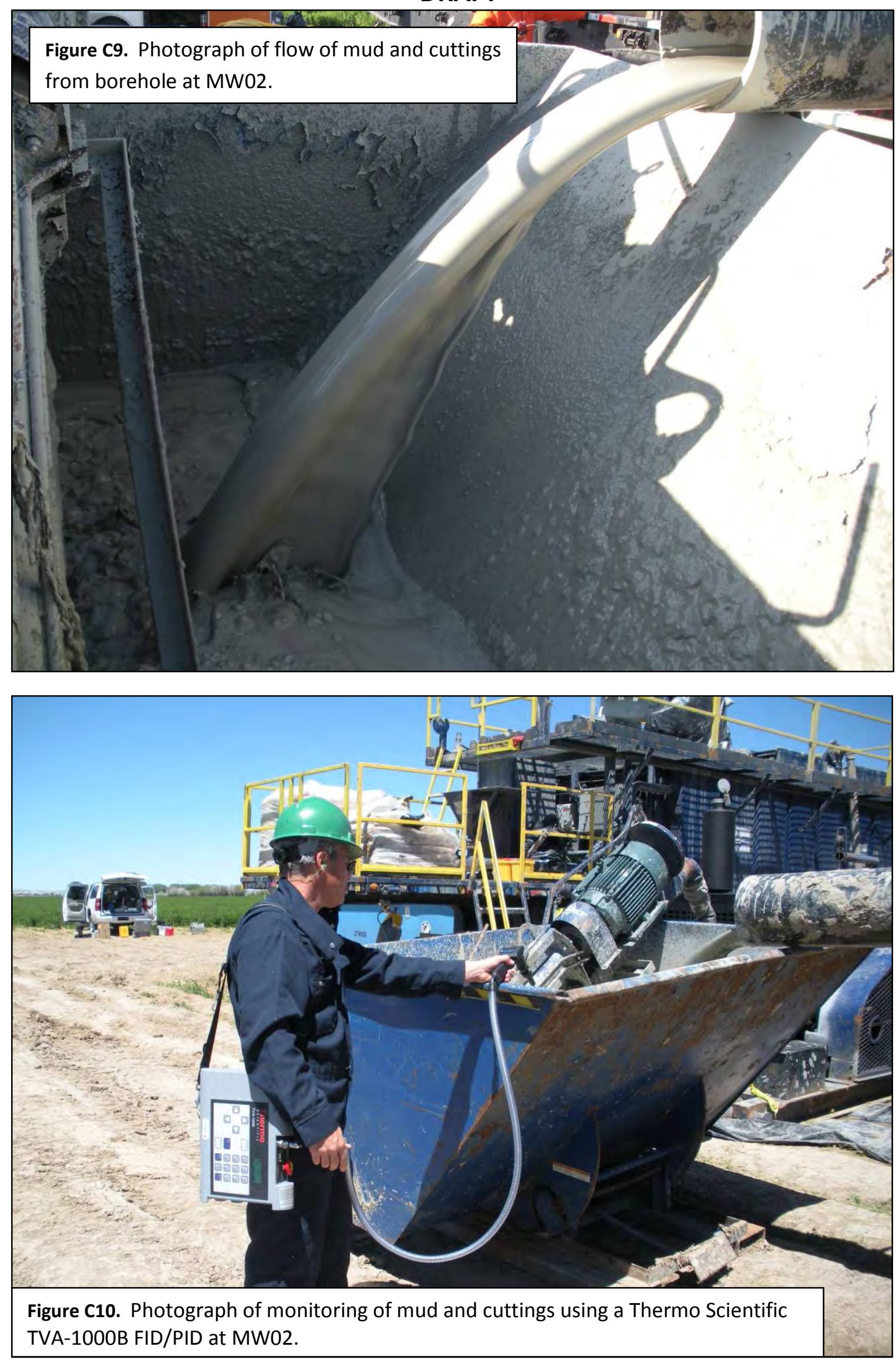

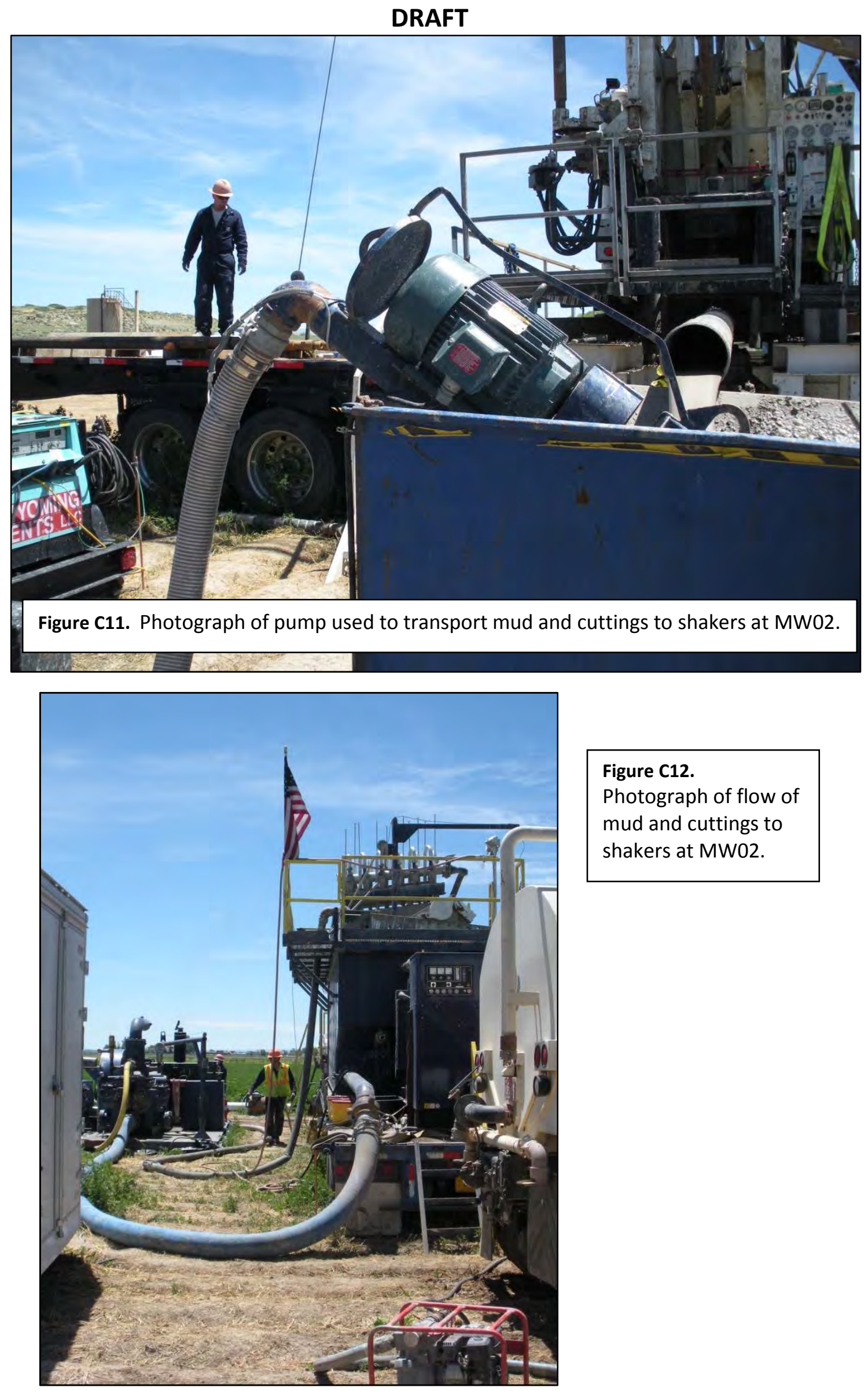

Figure C12.

Photograph of flow of mud and cuttings to shakers at MW02. 


\section{DRAFT}

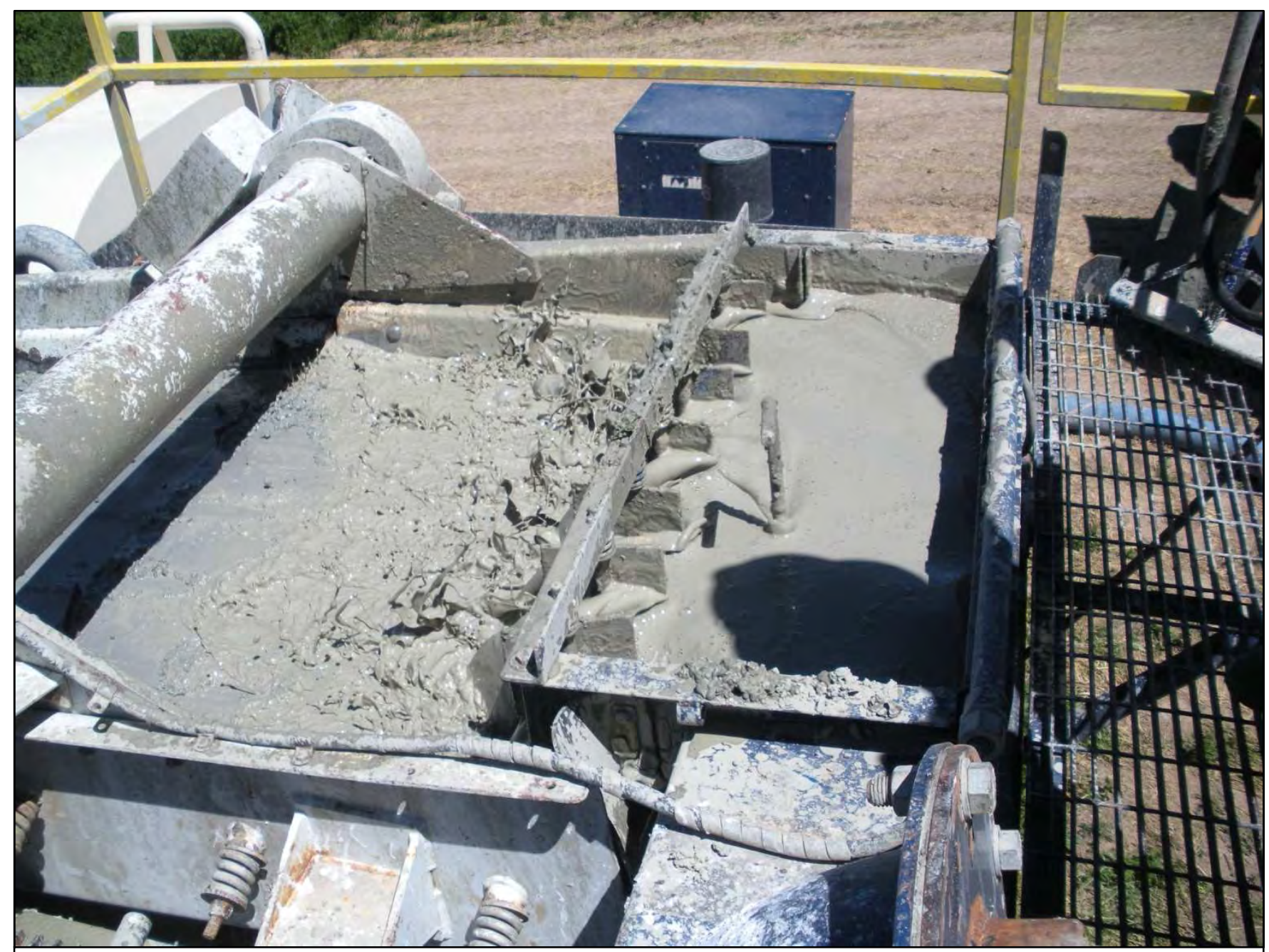

Figure C13. Photograph of shakers separating mud from cuttings at MW02. 


\section{DRAFT}

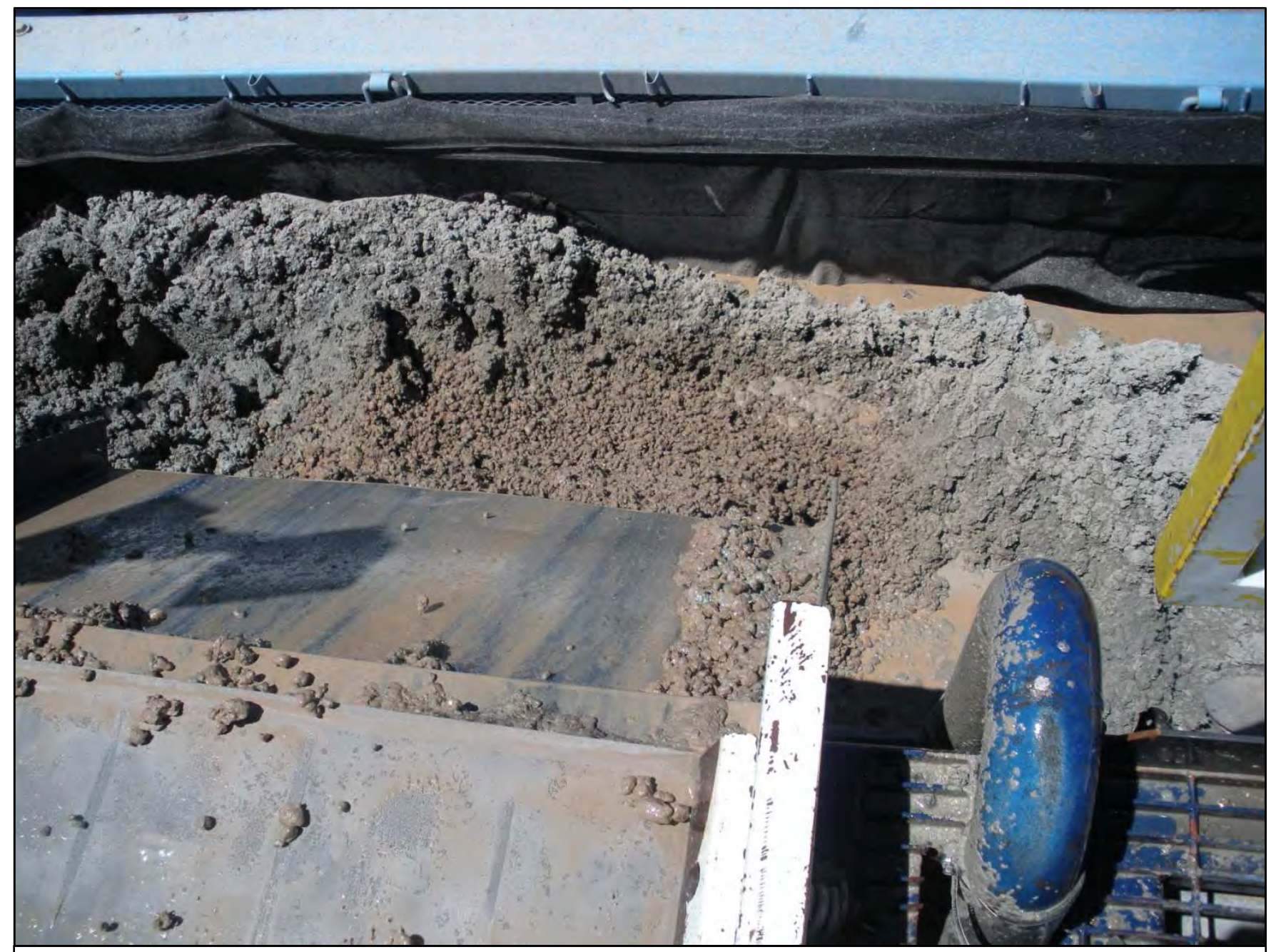

Figure C14. Photograph of cuttings transported to disposal bins at MW02. 


\section{DRAFT}

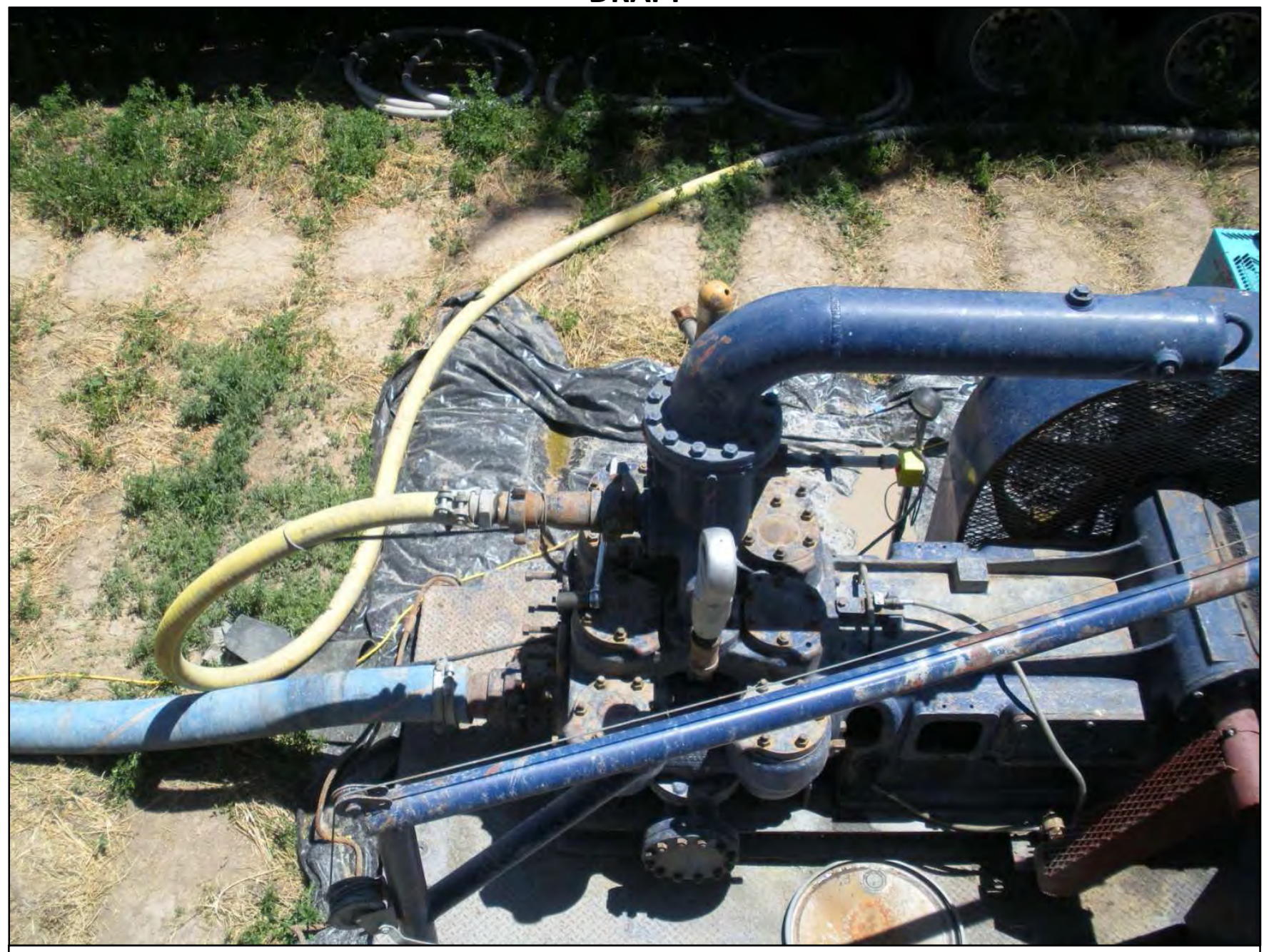

Figure C15. Photograph of pumping of mud back to borehole at MW02. 


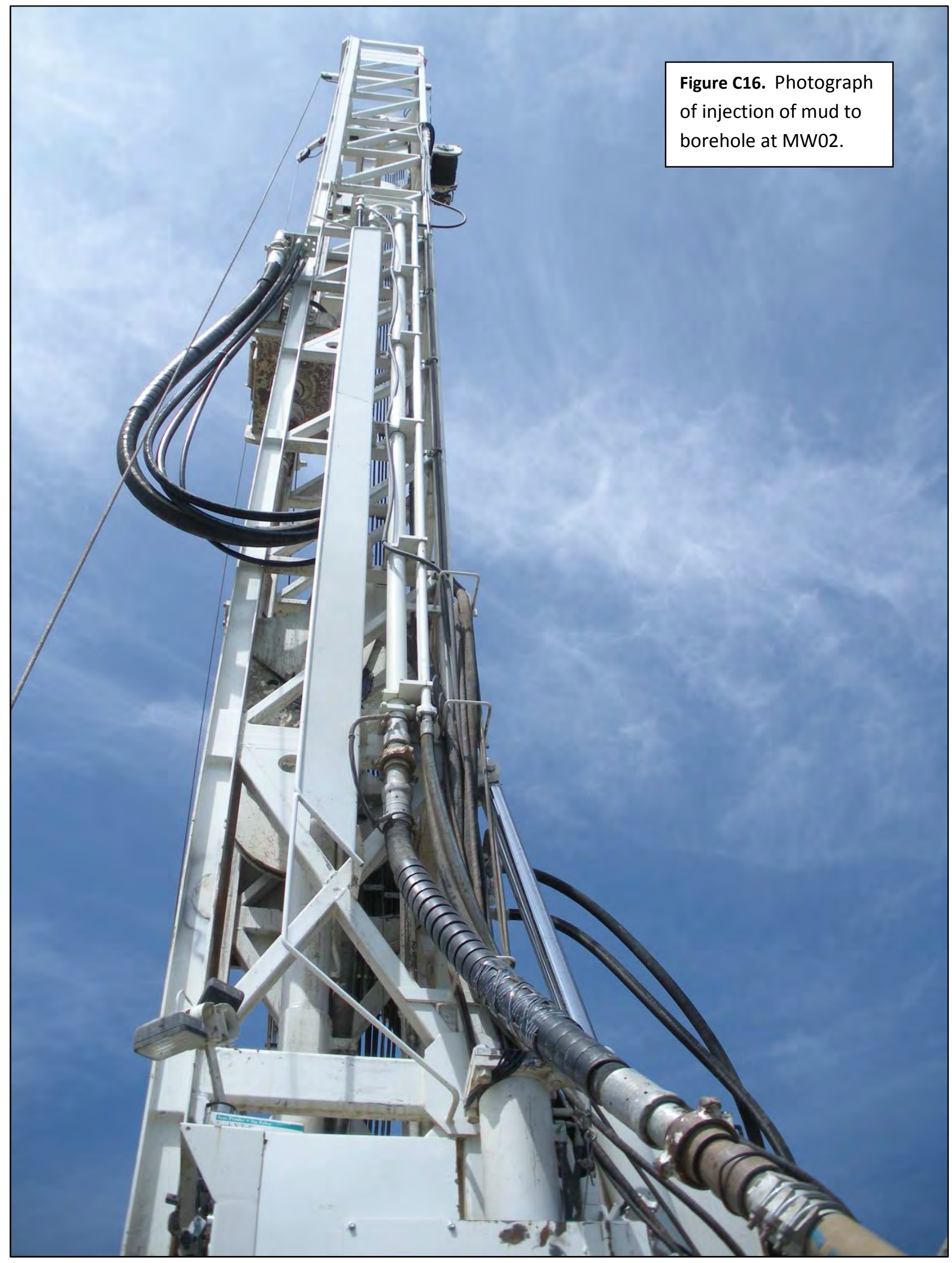




\section{DRAFT}

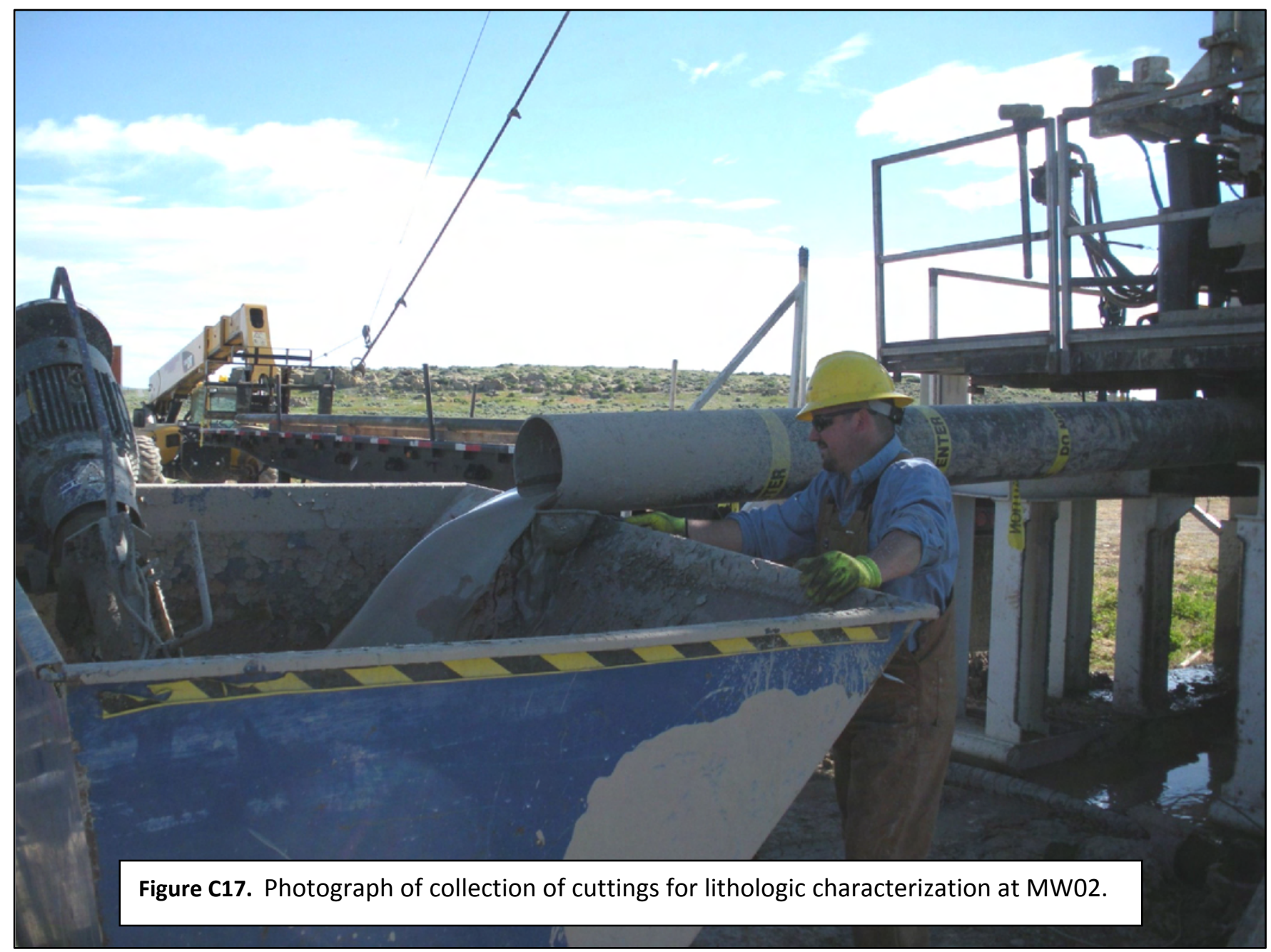

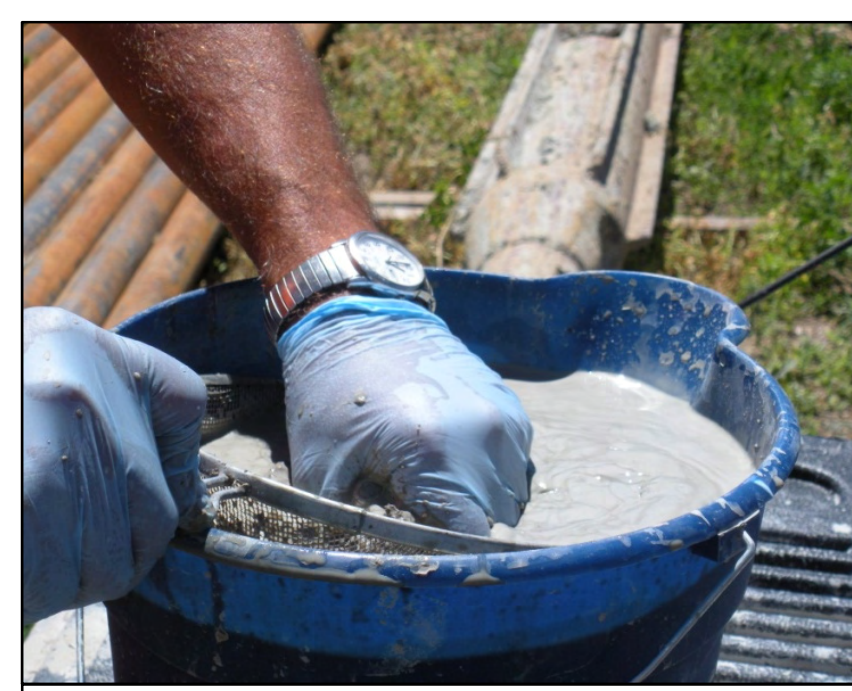

Figure C18. Photograph of removal of mud from cuttings at MW02.

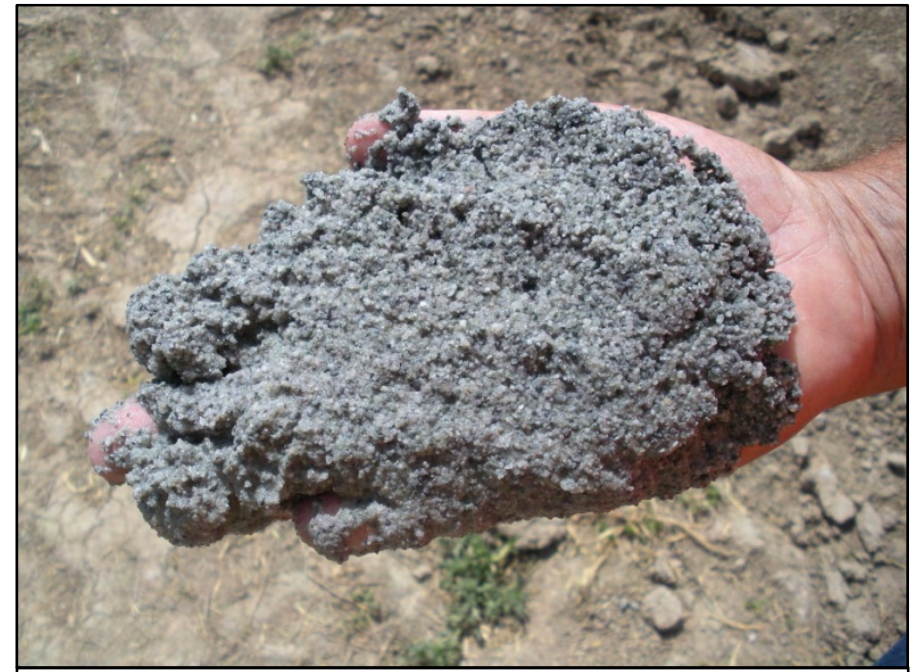

Figure C19. Photograph of white coarse-grained sand targeted by local well drillers and media in which screens are set in for both deep monitoring wells. 


\section{DRAFT}

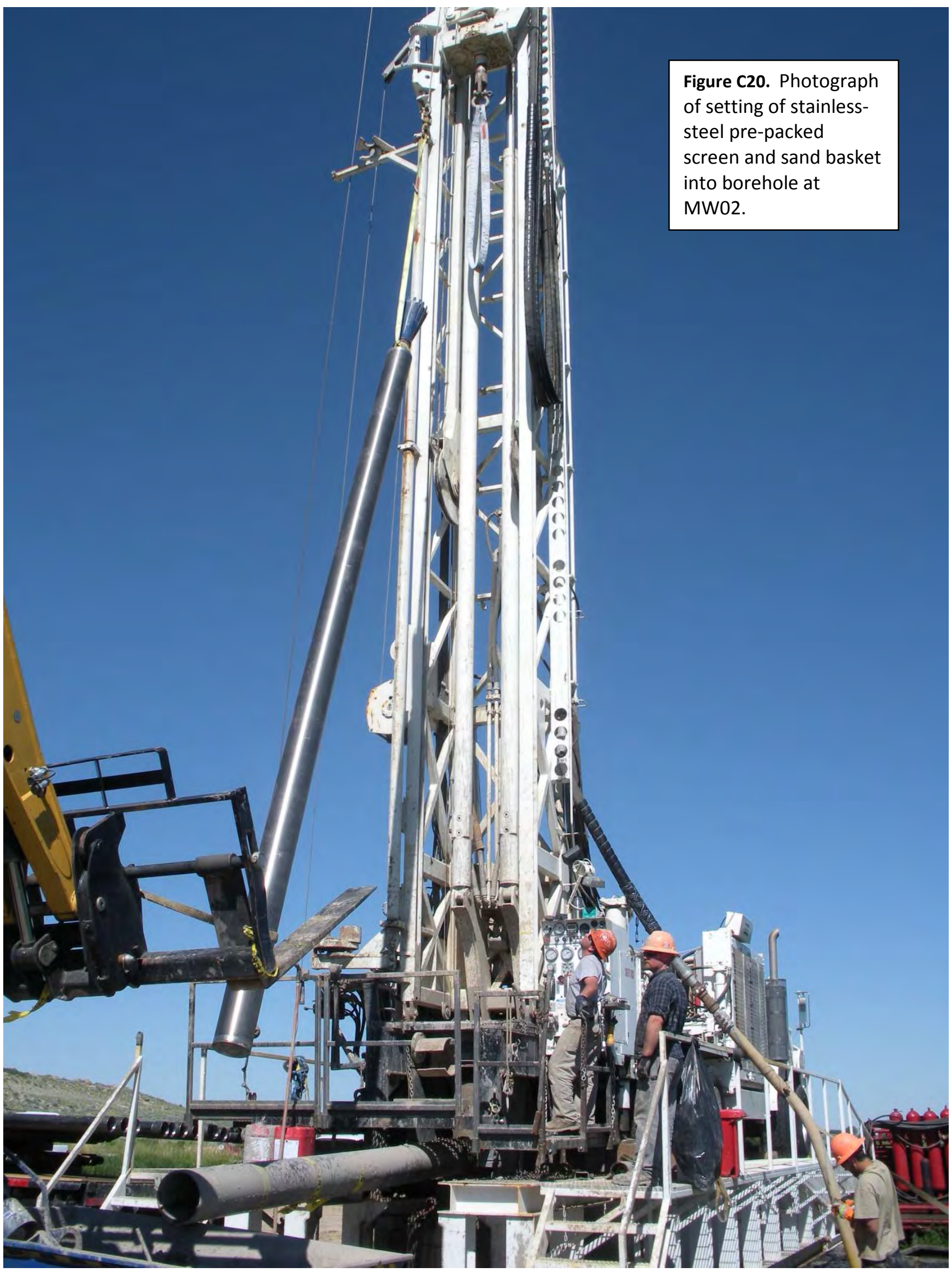



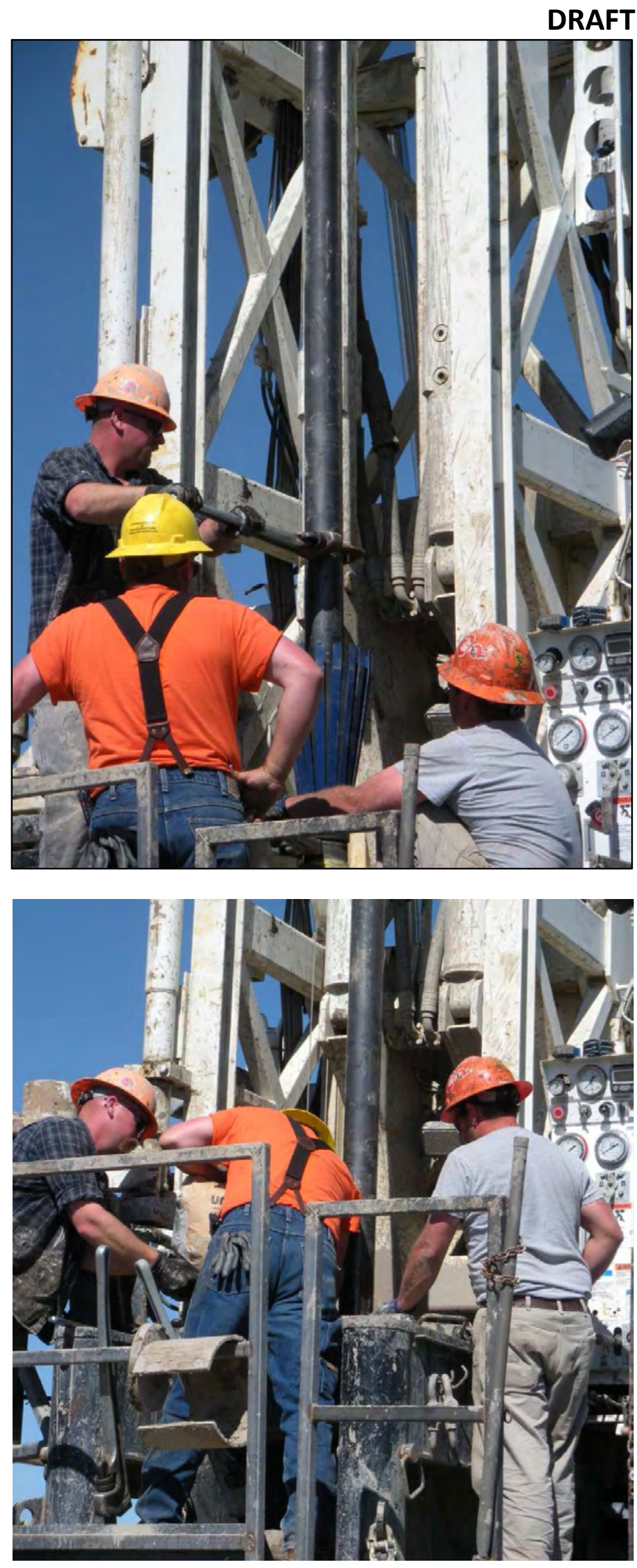

Figure C22. Photograph of placement of sand in sandbasket. 


\section{DRAFT}

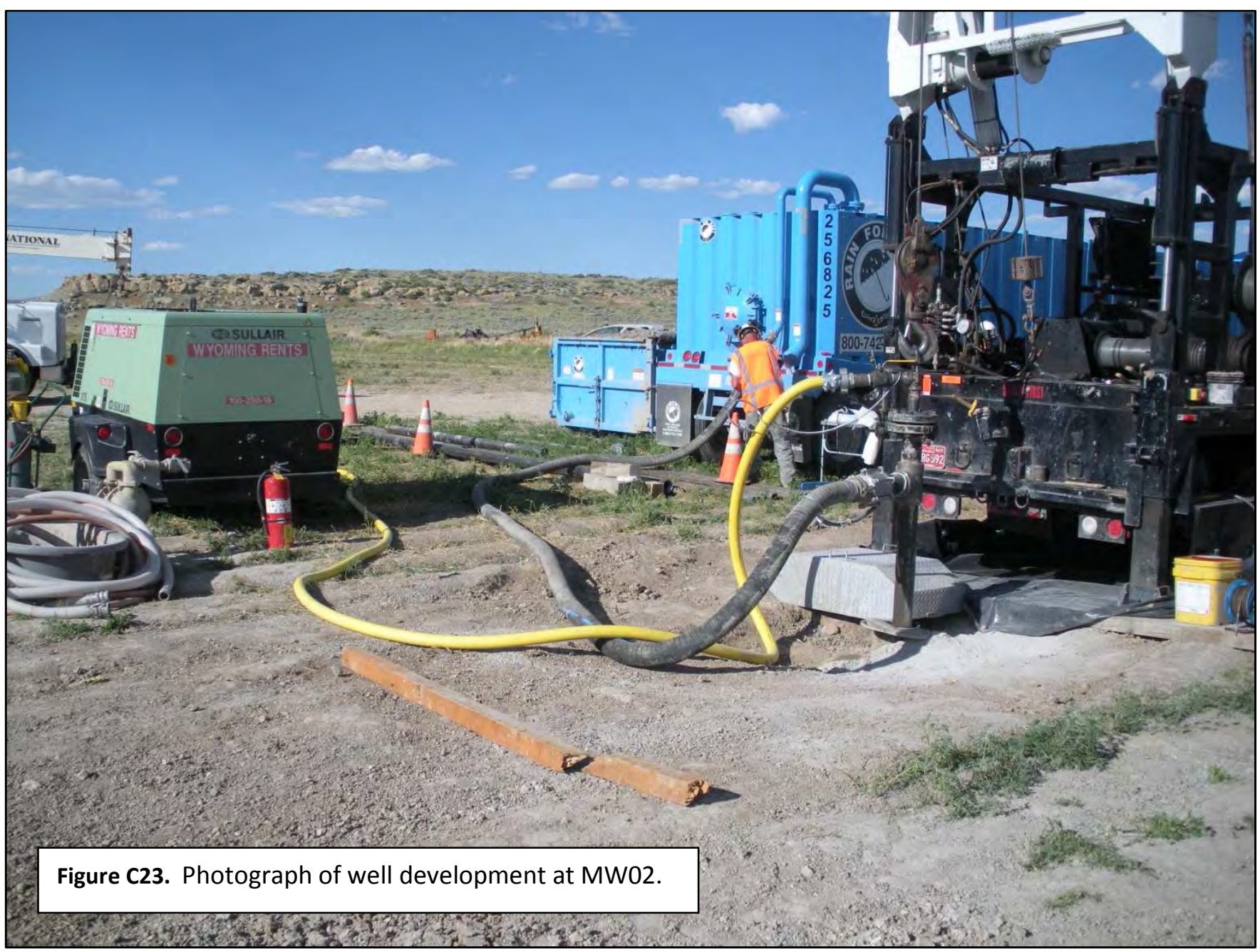




\section{DRAFT}

\section{Appendix D}

Photographic Log of Ground Water Sampling 
Figure D1. Photograph of flow from submersible pump through flowmeter at MW02.
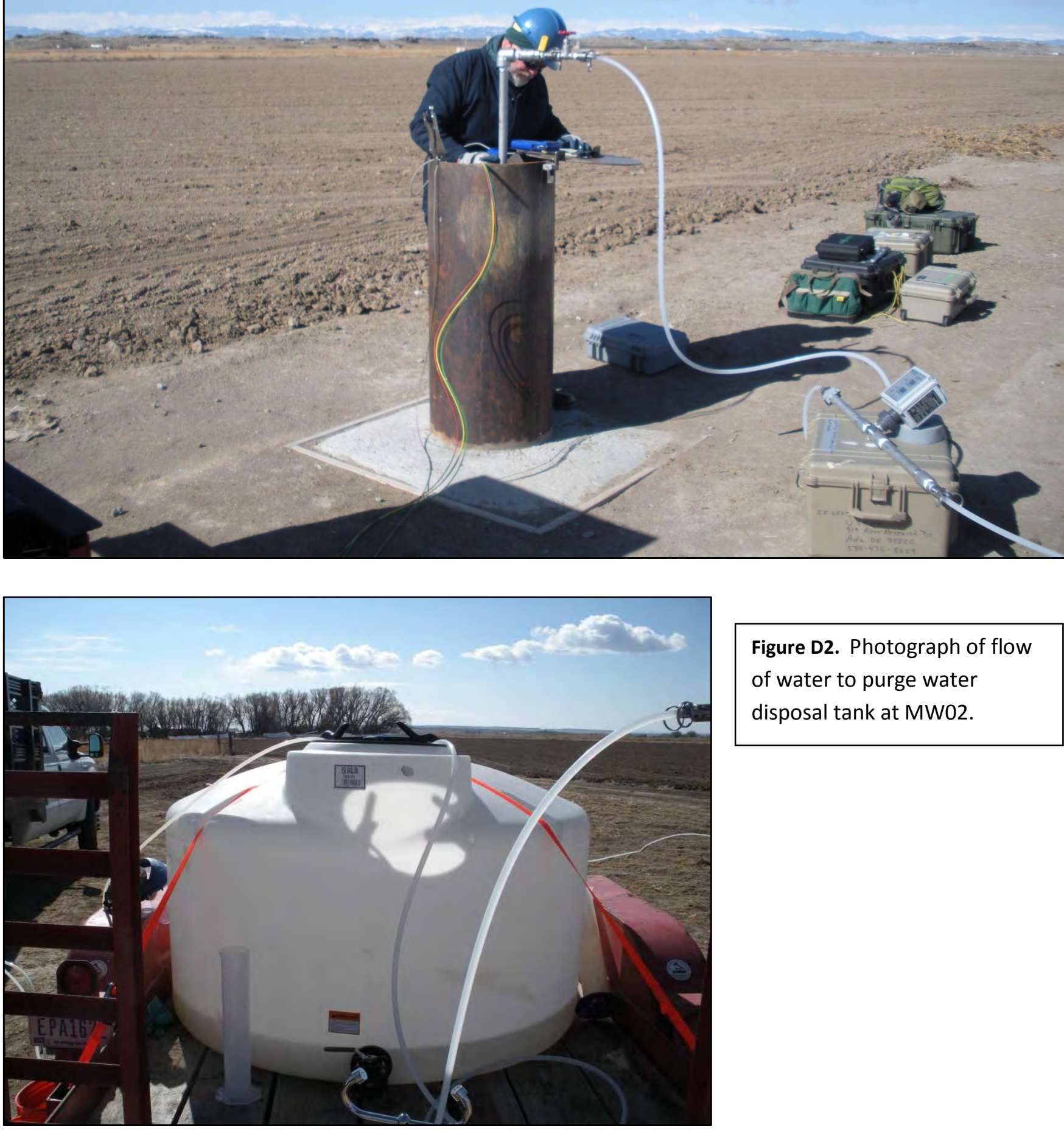

Figure D2. Photograph of flow of water to purge water disposal tank at MW02. 


\section{DRAFT}
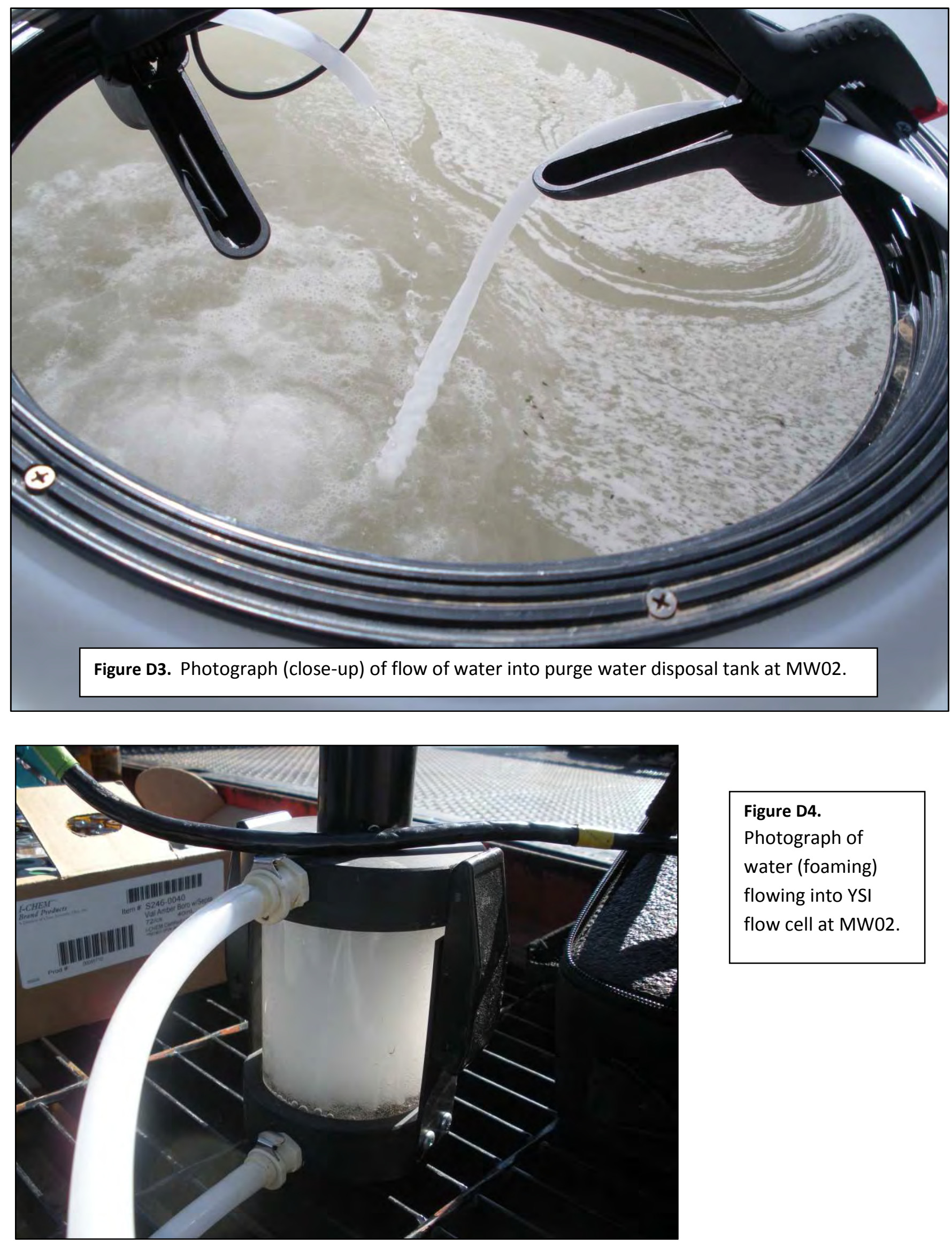

Figure D4.

Photograph of

water (foaming)

flowing into YSI

flow cell at MW02. 

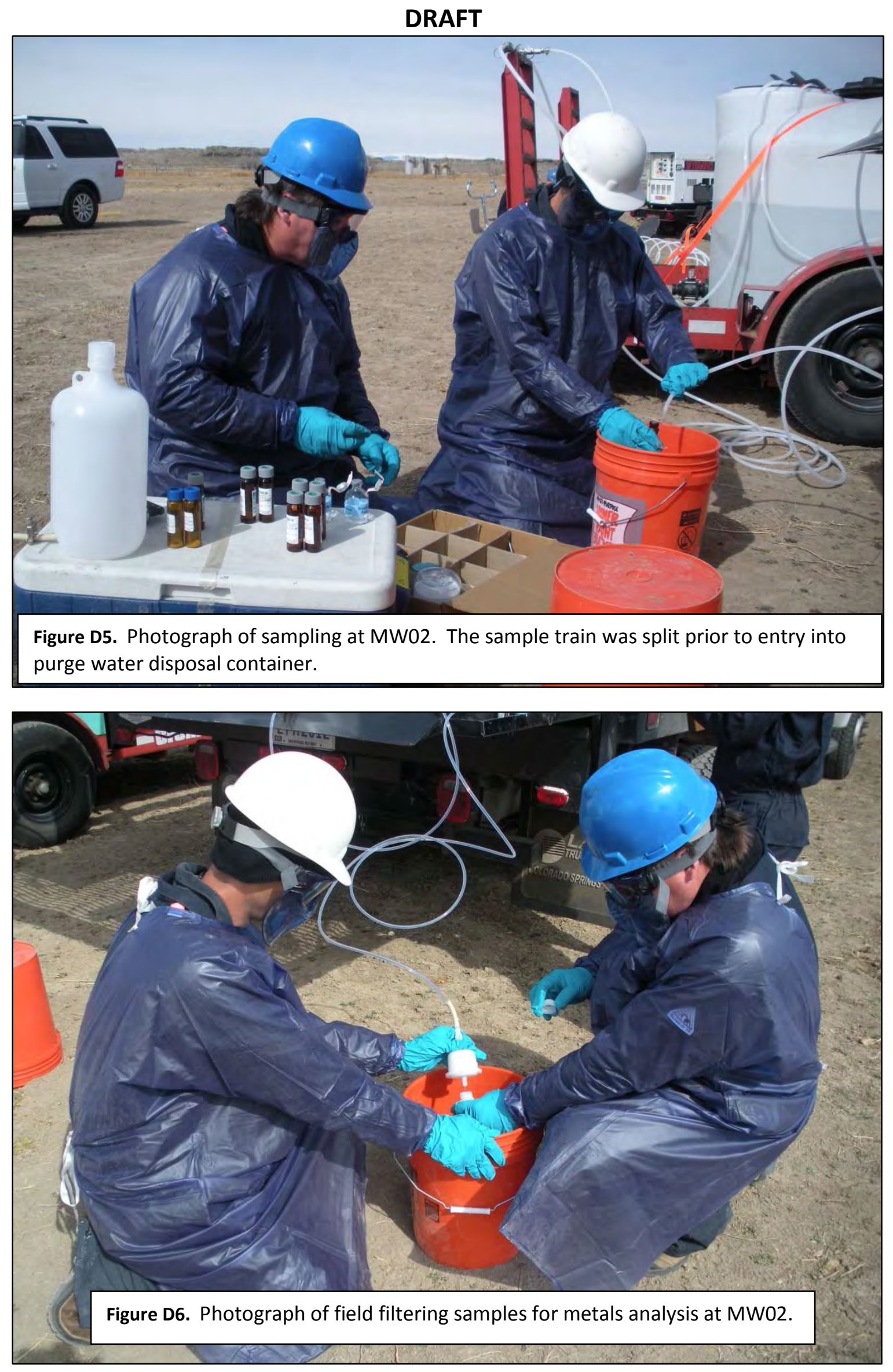


\section{DRAFT}

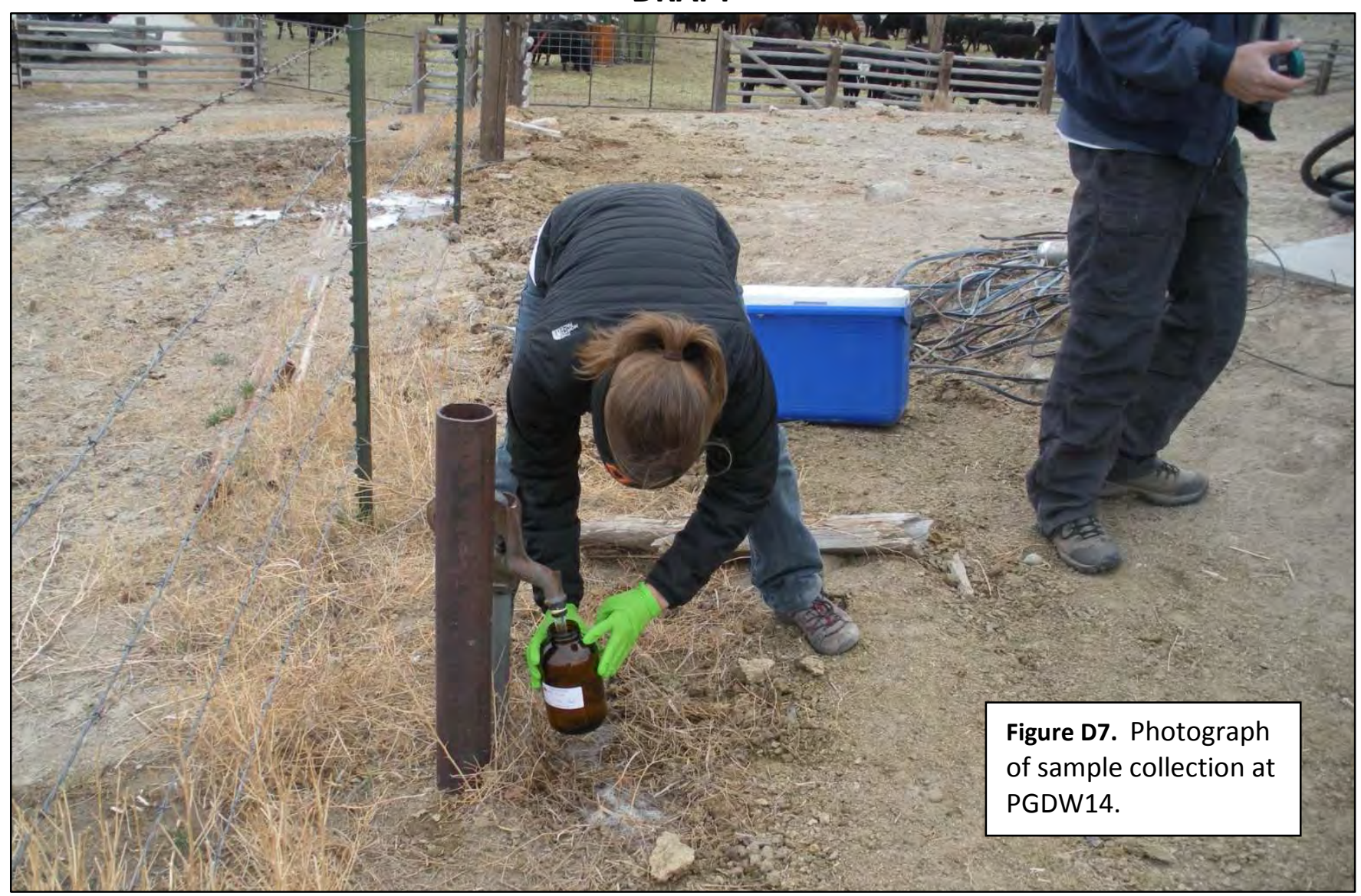

Figure D8. Photograph of cooler packed with samples for shipment.

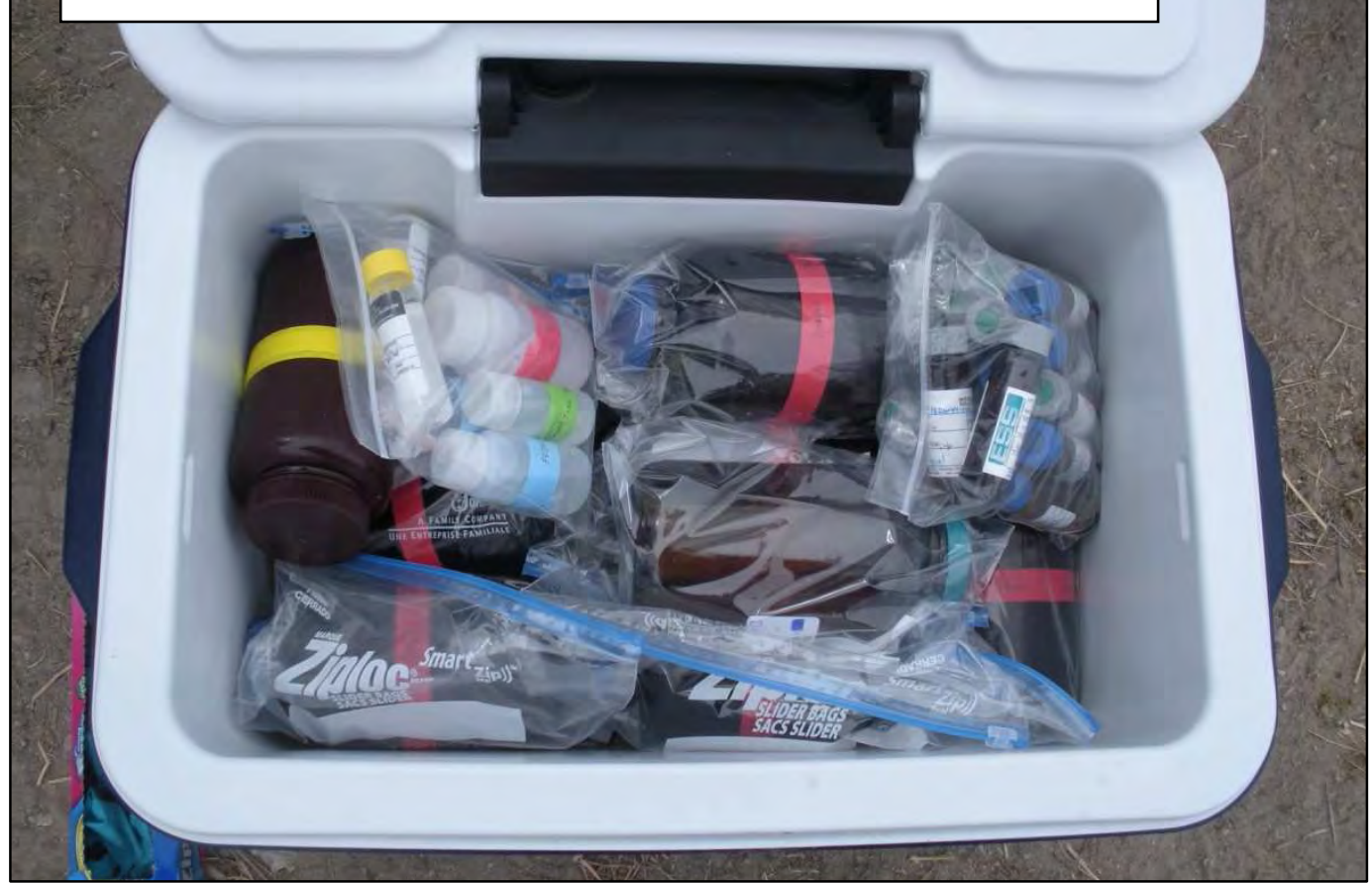




\section{DRAFT}




\section{Appendix E}

\section{Examples of Cement Bond/Variable Density Log Interpretation}


DRAFT

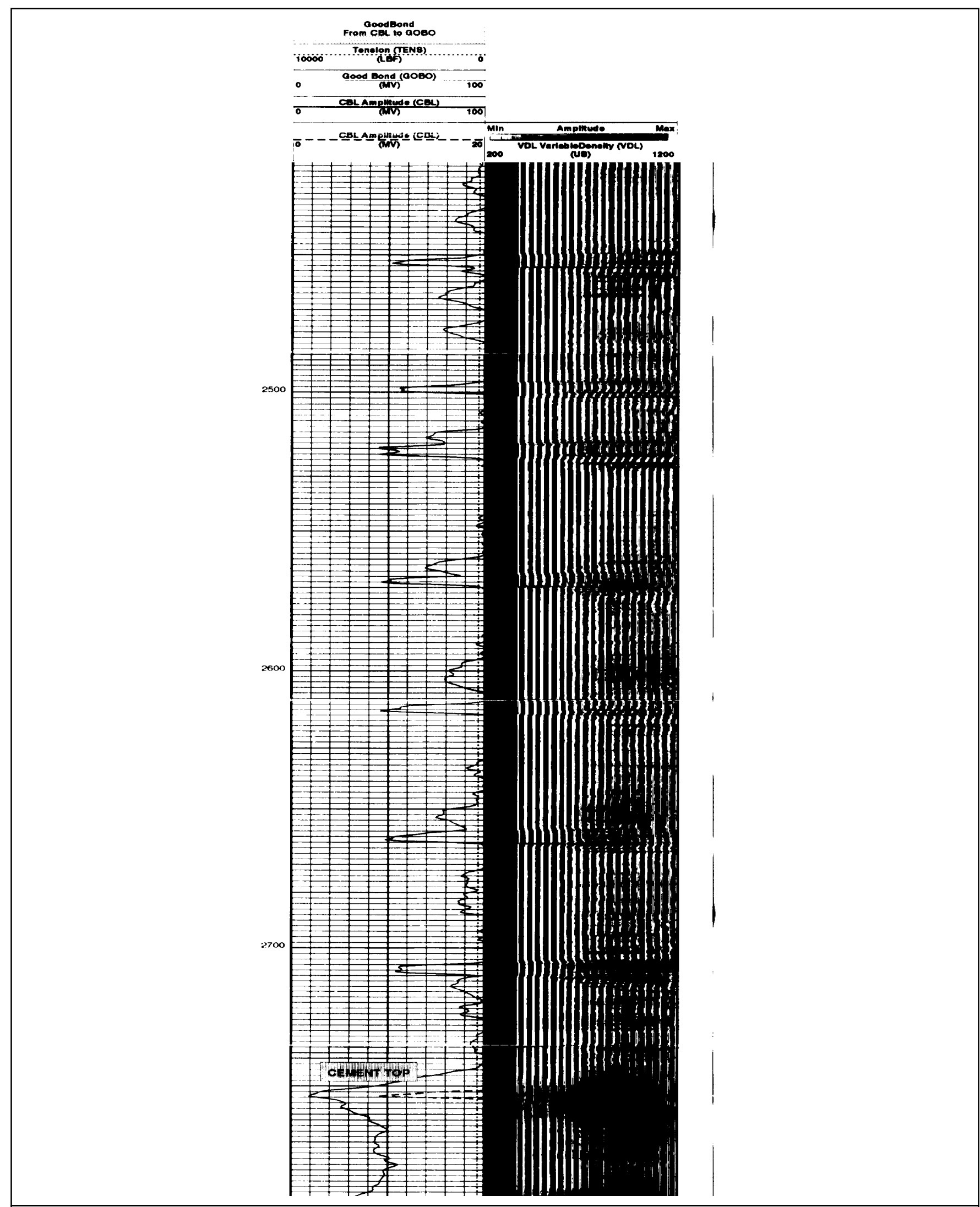

Figure E1. Example of CBL/VDL indicating "no cement" at Pavillion Fee 34-03B. The CBL/VDL indicates no cement 2750 feet below ground surface at the time of logging. 
DRAFT

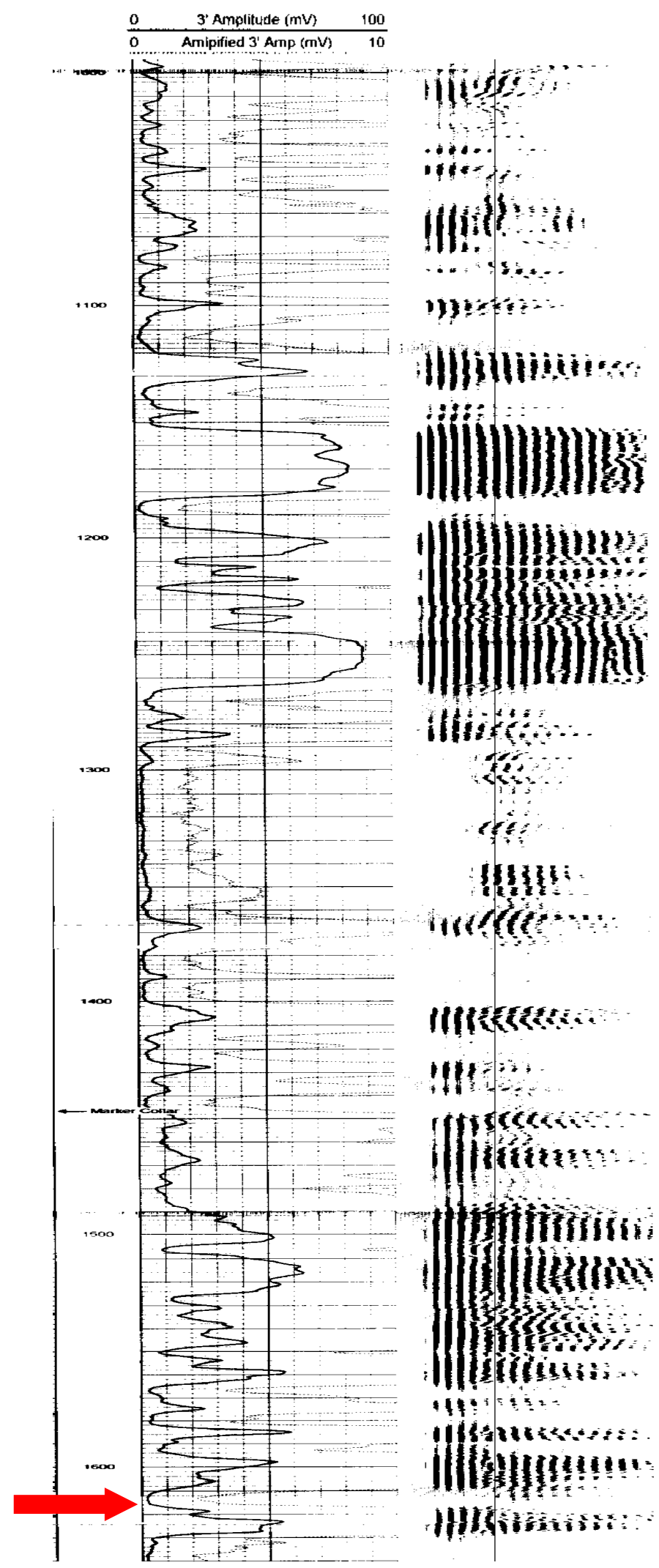

Figure E2. Example of "sporadic bonding" at Pavillion Fee 41-10 from 1000 to $1640 \mathrm{ft}$ bgs. Hydraulic fracturing occurred at 1618 feet below ground surface. Arrow denotes interval of hydraulic fracturing. 
DRAFT

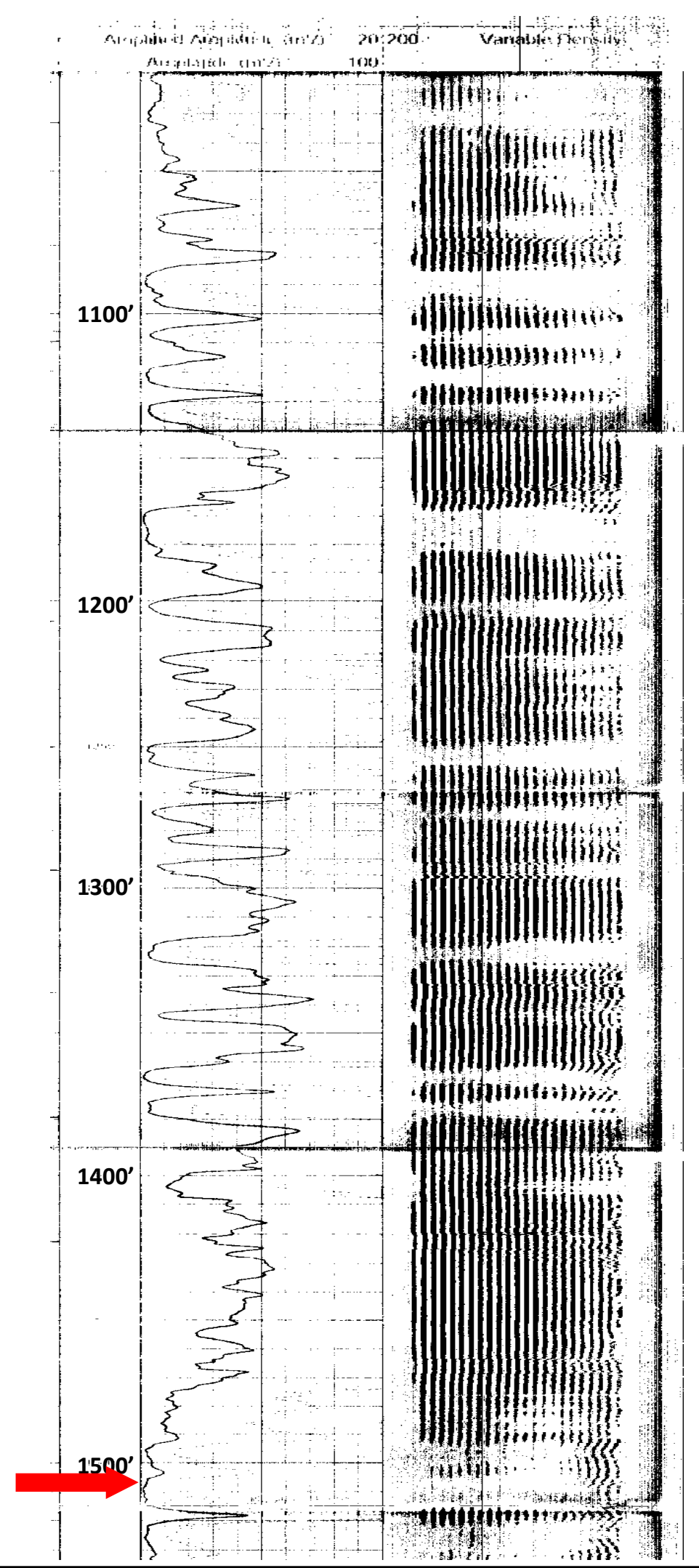

Figure E3a. Example of "sporadic bonding" at Pavillion Fee 11-11B. Hydraulic fracturing occurred at 1516 feet below ground surface. Arrow denotes interval of hydraulic fracturing. Depths on CBL/VDL difficult to read and inserted on left margin. 
DRAFT

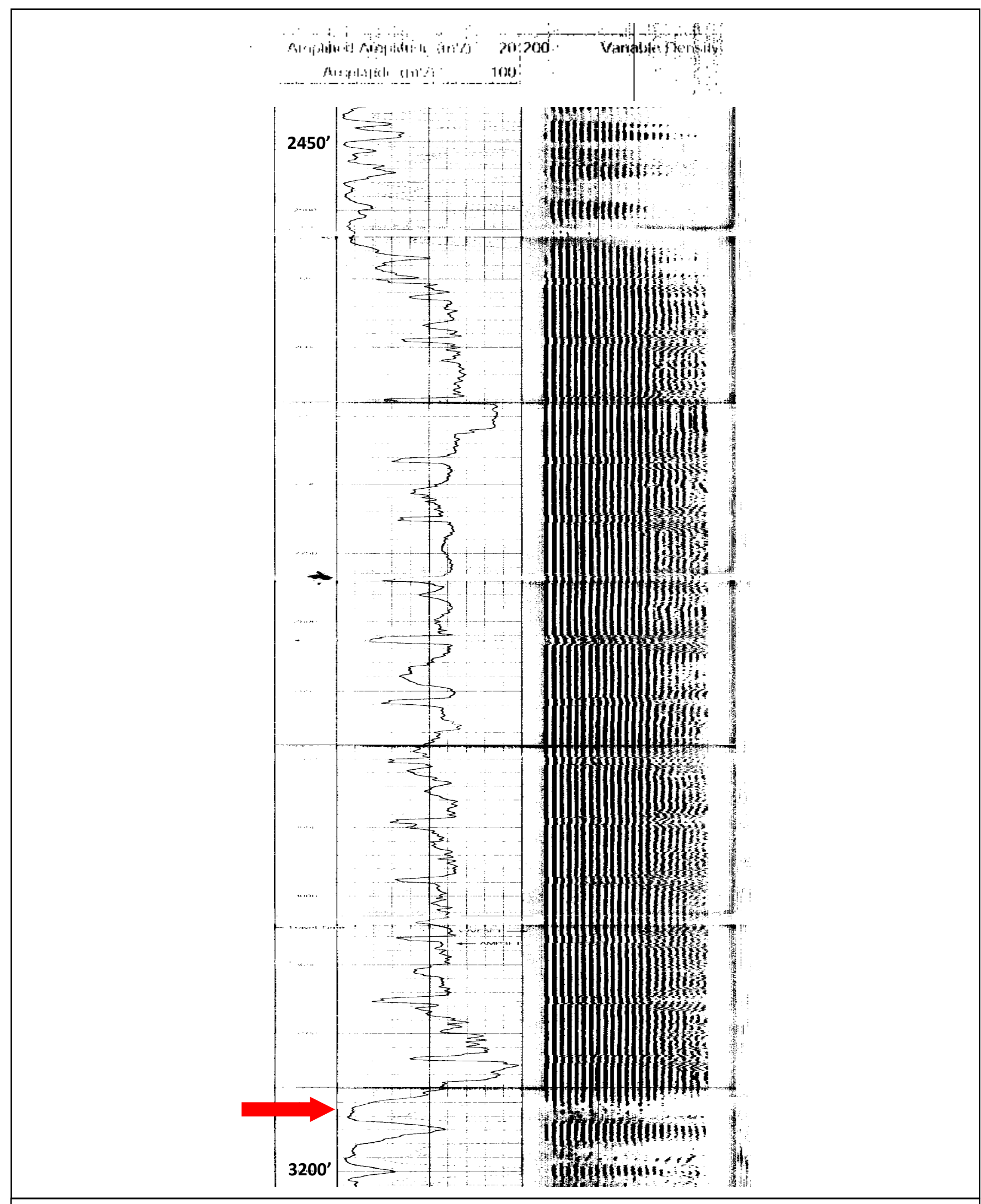

Figure E3b. Example of "sporadic bonding" Pavillion Fee 11-11B between 2350-3200 feet below ground suface. Hydraulic fracturing occurred at 3165 feet below ground surface. Arrow denotes interval of hydraulic fracturing. Depths on CBL/VDL difficult to read and inserted on left margin. 


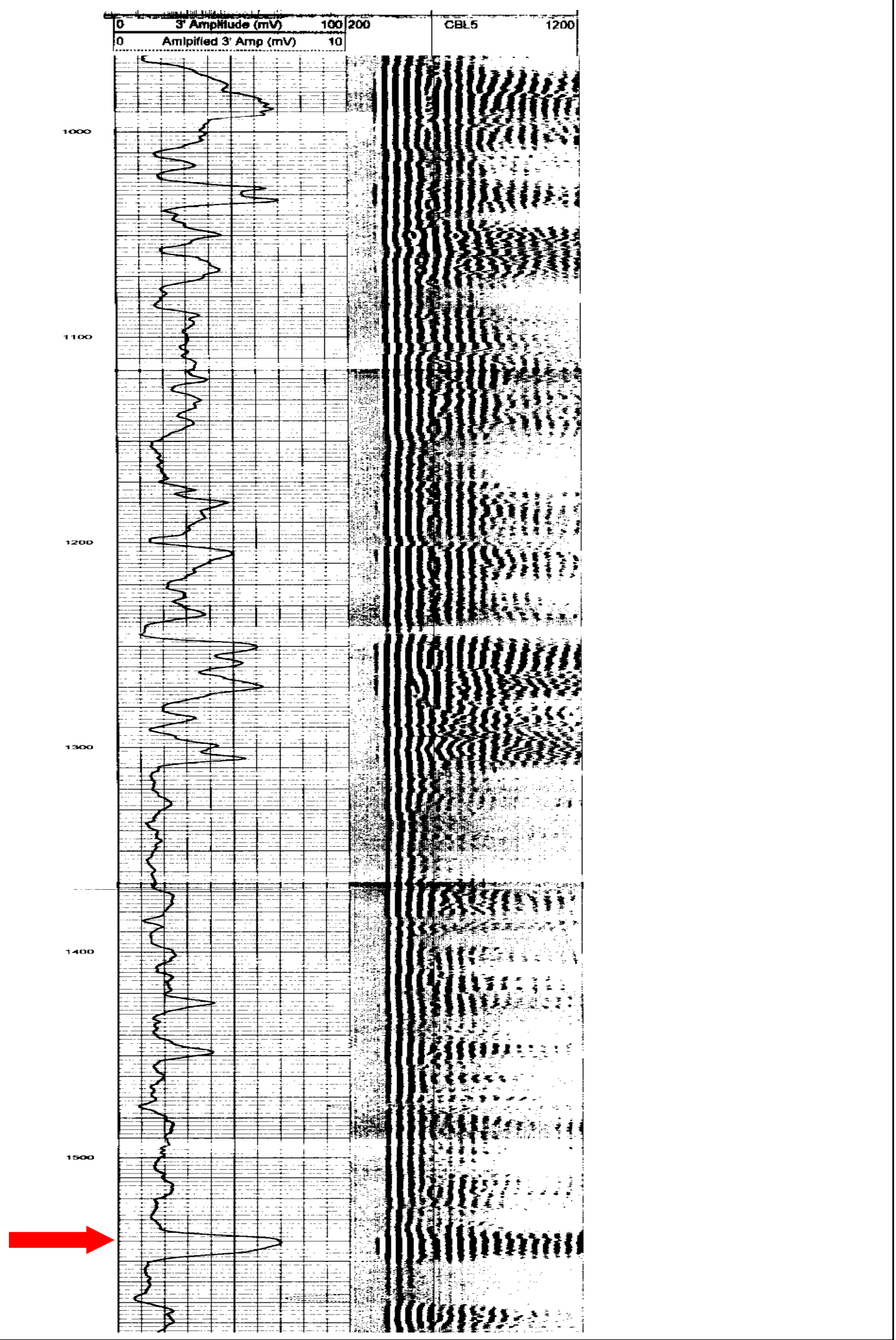

Figure E4. Example of "Sporadic Bonding" at Tribal Pavillion 24-02. Hydraulic fracturing occurred at 1538 feet bgs. Arrow denotes interval of hydraulic fracturing. 


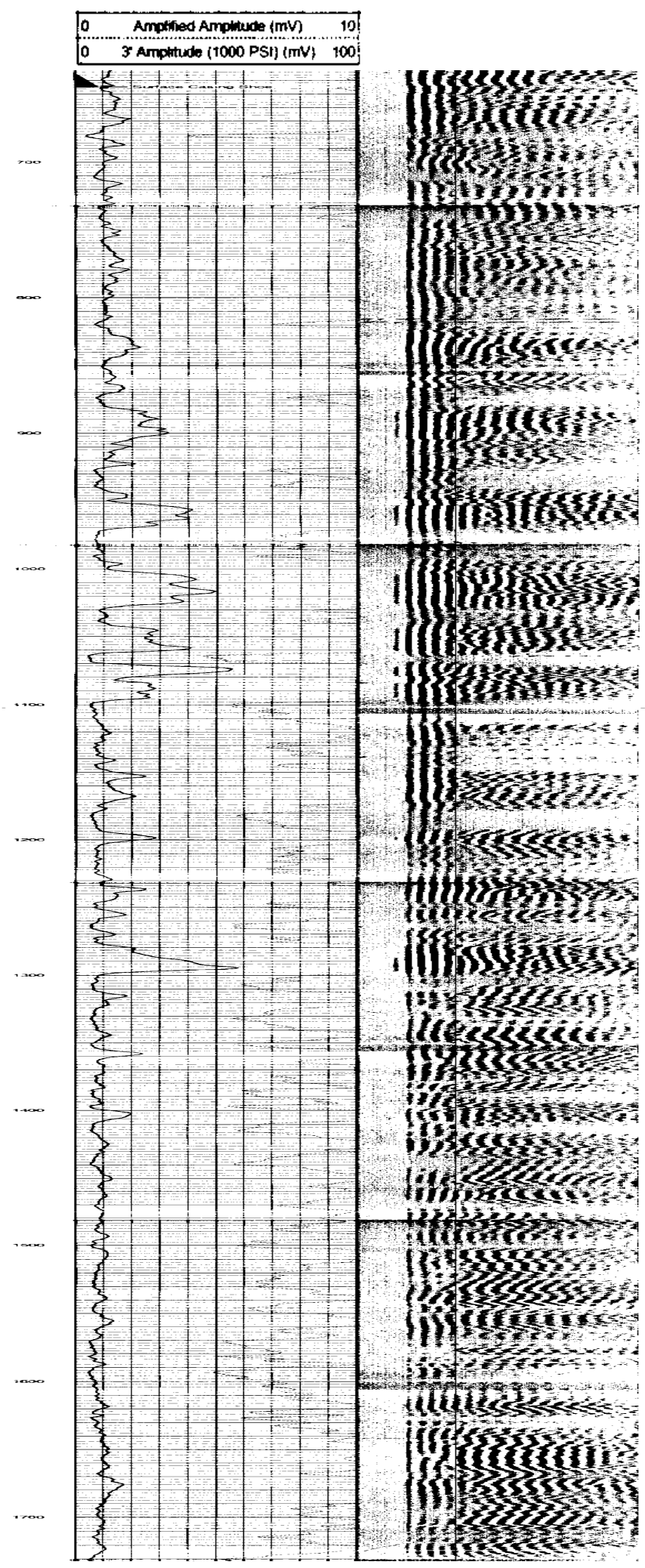

Figure E5. Example of "Good Bonding" (from surface casing at $645 \mathrm{ft}$ bgs to $820 \mathrm{ft}$ bgs) followed by "Sporadic Bonding" (from $820 \mathrm{ft}$ bgs $1310 \mathrm{ft}$ bgs) to "Good Bonding" at 1310 to target depth at Pavillion Fee 41-10B. 


\section{DRAFT}




\section{DRAFT}
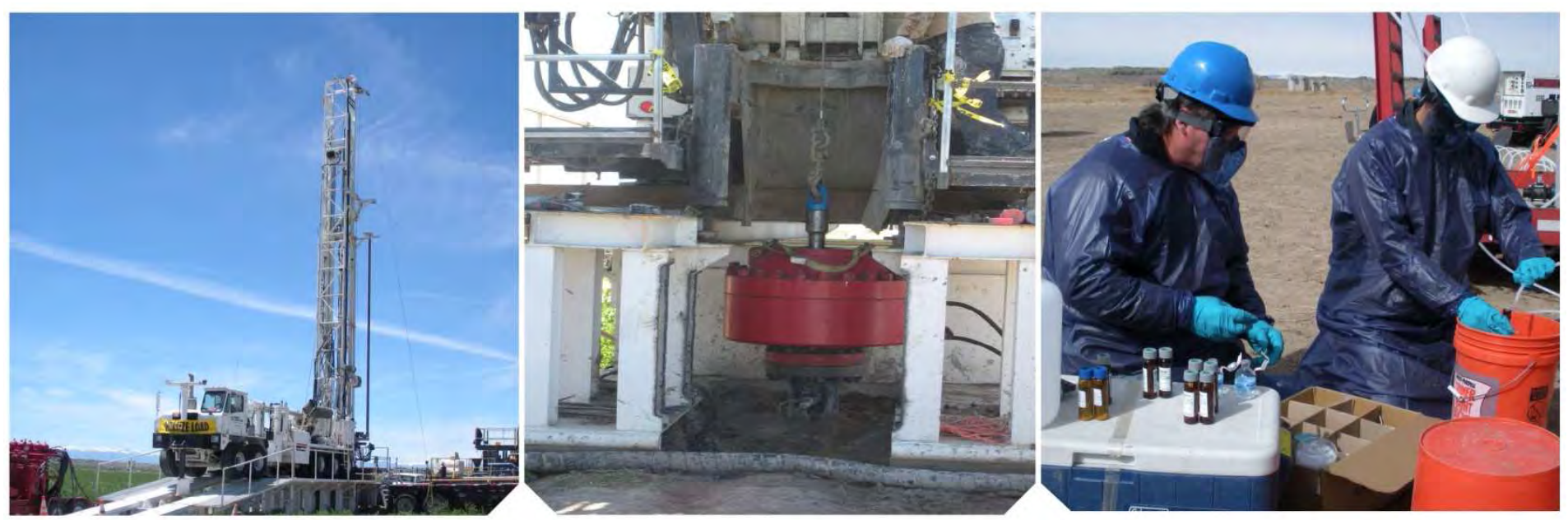

Office of Research and Development (8101R)

Washington, DC 20460

Official Business

Penalty for Private Use $\$ 300$ 
In cooperation with the Wyoming Department of Environmental Quality

Groundwater-Quality and Quality-Control Data for Two Monitoring Wells near Pavillion, Wyoming, April and May 2012

Data Series 718 



\section{Groundwater-Quality and Quality-Control Data for Two Monitoring Wells near Pavillion, Wyoming, April and May 2012}

By Peter R. Wright, Peter B. McMahon, David K. Mueller, and Melanie L. Clark

In cooperation with the Wyoming Department of Environmental Quality

Data Series 718 


\title{
U.S. Department of the Interior \\ KEN SALAZAR, Secretary \\ U.S. Geological Survey \\ Marcia K. McNutt, Director
}

\author{
U.S. Geological Survey, Reston, Virginia: 2012
}

For more information on the USGS - the Federal source for science about the Earth, its natural and living resources, natural hazards, and the environment, visit http://www.usgs.gov or call 1-888-ASK-USGS.

For an overview of USGS information products, including maps, imagery, and publications, visit http://www.usgs.gov/pubprod

To order this and other USGS information products, visit http://store.usgs.gov

Any use of trade, firm, or product names is for descriptive purposes only and does not imply endorsement by the U.S. Government.

Although this information product, for the most part, is in the public domain, it also may contain copyrighted materials as noted in the text. Permission to reproduce copyrighted items must be secured from the copyright owner.

Suggested citation:

Wright, P.R., McMahon, P.B., Mueller, D.K., Clark, M.L., 2012, Groundwater-quality and quality-control data for two monitoring wells near Pavillion, Wyoming, April and May 2012: U.S. Geological Survey Data Series 718, 26 p. 


\section{Contents}

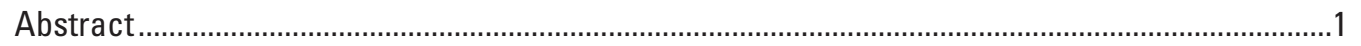

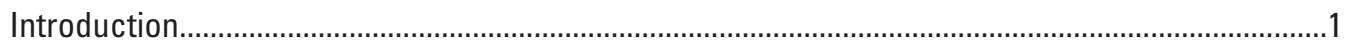

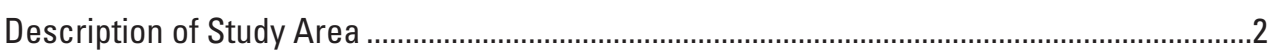

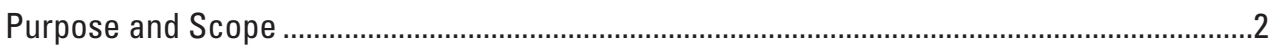

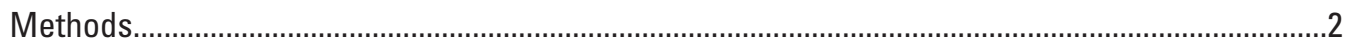

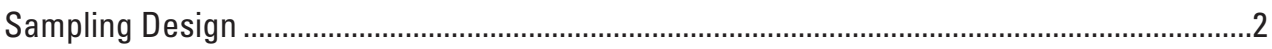

Sample Collection at Monitoring Well MW01 ........................................................................4

Redevelopment of Monitoring Well MW02 and Collection of Associated Quality-Control

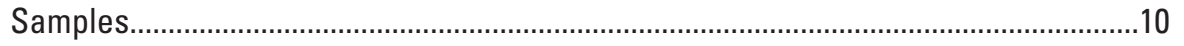

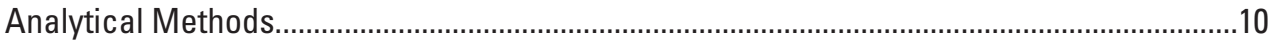

Quality-Control Sample Collection and Data Analysis .......................................................10

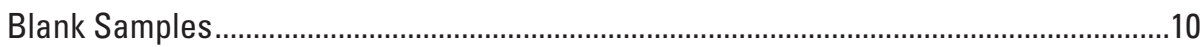

Laboratory Spike Samples ................................................................................. 10

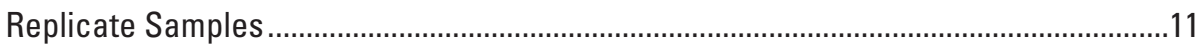

Major-Ion Balances....................................................................................................

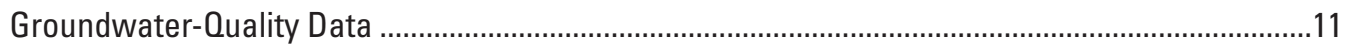

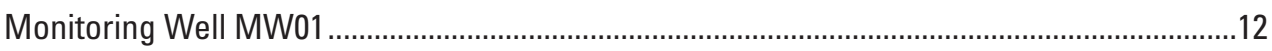

Field Water-Quality Properties and Hydrologic Data Measured During the Well Purge ..............................................................................................................12

Field Water-Quality Properties and Inorganic and Radioactive Constituents.................12

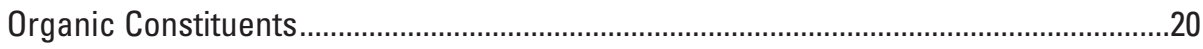

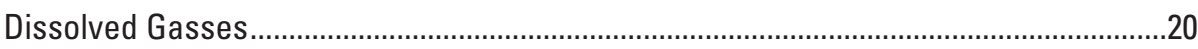

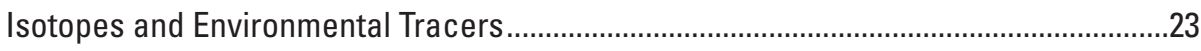

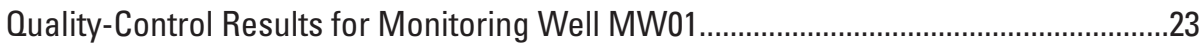

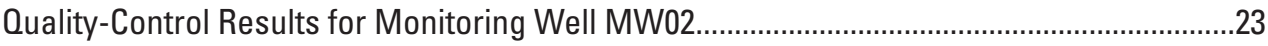

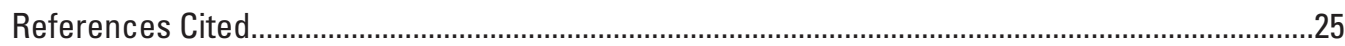

Appendix 1. Monitoring Well MW01 field notes-Field instrument calibration notes, general project notes, groundwater-quality notes for samples 1 and 2, alkalinity/acid neutralizing capacity titration field notes and results (figures 1.1.1-1.3.2) ..................... link

Appendix 2. Monitoring Well MW01 laboratory-related documents-Analytical Services Request forms, Chain of Custody records (figures 2.1.1-2.9.7) ..................................... link

Appendix 3. Monitoring Well MW01 photographs (figures 3.1-3.1.6)....................................... link

Appendix 4. Monitoring Well MW02 field notes-Groundwater-quality and field notes for collection of samples related to work at this well (figures 4.1-4.2)............................... link

Appendix 5. Monitoring Well MW02 laboratory-related documents-Analytical Services Request forms, Chain of Custody records (figures 5.1.1-5.2.4) ..................................... link

Appendix 6. Monitoring Well MW02 photographs (figures 6.1-6.6).......................................... link

Appendix 7. Tentatively identified compounds quantified in environmental and quality-control samples collected for monitoring well MW01 near Pavillion, Wyoming .......................... link 


\section{Figures}

1. Location of monitoring wells MW01 and MW02 near the town of Pavillion, Wyoming....3

2. Graphs showing water level, specific conductance, and $\mathrm{pH}$ measured during purge of monitoring well MW01 and beginning of collection of environmental samples 1 and 2 .

\section{Tables}

1 Stabilization criteria and calibration guidelines for field water-quality properties...........4

2 Environmental and quality-control samples collected for monitoring wells MW01 and MW02 near Pavillion, Wyoming, April and May 2012 …..........................................5

3 Analyses conducted on environmental and quality-control samples collected for monitoring wells MW01 and MW02 near Pavillion, Wyoming, April and May 2012..........6

4. Field water-quality properties measured during purge of monitoring well MW01 near Pavillion, Wyoming, April 2012

5. Field water-quality properties and inorganic constituents in environmental samples collected from monitoring well MW01 near Pavillion, Wyoming, April 2012.

6. Inorganic constituents in quality-control samples collected for monitoring well MW01 near Pavillion, Wyoming, April 2012. link

7. Organic constituents in environmental samples collected from monitoring well MW01 near Pavillion, Wyoming, April 2012. link

8. Organic constituents in quality-control samples collected for monitoring well MW01 near Pavillion, Wyoming, April 2012. link

9. Dissolved gasses in environmental samples collected from monitoring well MW01 near Pavillion, Wyoming, April 2012.

10. Dissolved gasses in quality-control samples collected for monitoring well MW01 near Pavillion, Wyoming, April 2012. link

11. Isotopes and environmental tracers in environmental samples collected from monitoring well MW01 near Pavillion, Wyoming, April 2012.

12. Inorganic constituents in quality-control samples collected for monitoring well MW02 near Pavillion, Wyoming, May 2012 link

13. Organic constituents in quality-control samples collected for monitoring well MW02 near Pavillion, Wyoming, May 2012

14. Dissolved gasses in quality-control samples collected for monitoring well MW02 near Pavillion, Wyoming, May 2012 


\section{Conversion Factors}

Inch/Pound to SI

\begin{tabular}{lcl}
\hline \multicolumn{1}{c}{ Multiply } & By & To obtain \\
\hline foot $(\mathrm{ft})$ & Length & meter $(\mathrm{m})$ \\
\hline & 0.3048 & \\
\hline gallon (gal) & Volume & liter $(\mathrm{L})$ \\
\hline & 3.785 & \\
\hline gallon per minute $(\mathrm{gal} / \mathrm{min})$ & Flow rate & liter per second $(\mathrm{L} / \mathrm{s})$ \\
gallon per hour $(\mathrm{gal} / \mathrm{h})$ & 0.06309 & liter per hour $(\mathrm{L} / \mathrm{h})$ \\
\hline & 3.785 & \\
\hline part per million $(\mathrm{ppm})$ & Concentration & milligram per liter $(\mathrm{mg} / \mathrm{L})$ \\
part per billion & 1.0 & microgram per liter $(\mu \mathrm{g} / \mathrm{L})$ \\
\hline
\end{tabular}

Temperature can be converted to degrees Fahrenheit $\left({ }^{\circ} \mathrm{F}\right)$ or degrees Celsius $\left({ }^{\circ} \mathrm{C}\right)$ as follows:

${ }^{\circ} \mathrm{F}=\left(1.8 x^{\circ} \mathrm{C}\right)+32$

${ }^{\circ} \mathrm{C}=\left({ }^{\circ} \mathrm{F}-32\right) / 1.8$

Horizontal coordinate information is referenced to the North American Datum of 1983 (NAD 83).

Specific conductance is given in microsiemens per centimeter at 25 degrees Celsius $(\mu \mathrm{S} / \mathrm{cm}$ at $\left.25^{\circ} \mathrm{C}\right)$.

Concentrations of most chemical constituents in water are given either in milligrams per liter (mg/L) or micrograms per liter ( $\mu \mathrm{g} / \mathrm{L})$. 


\section{Abbreviations}

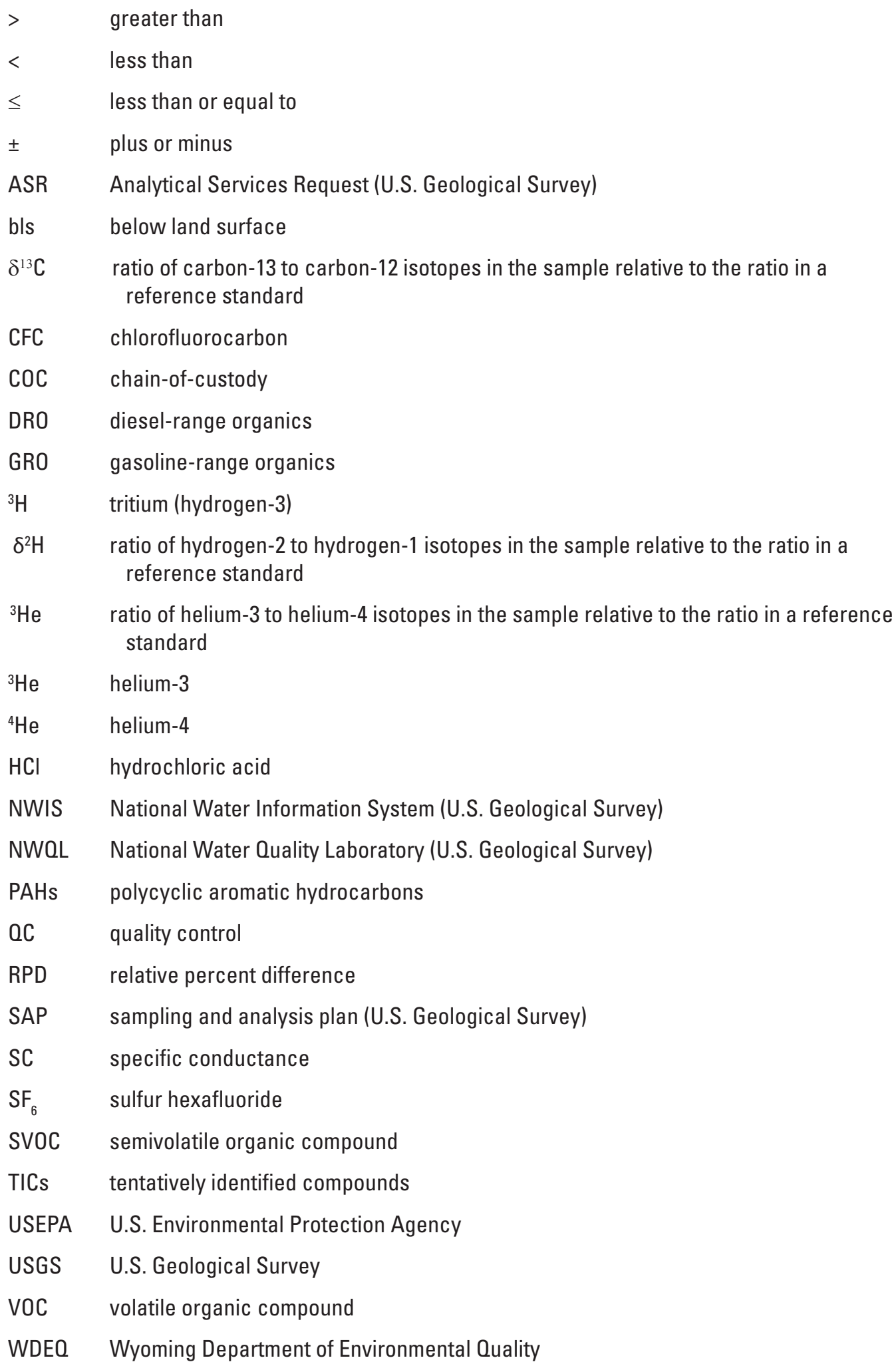




\title{
Groundwater-Quality and Quality-Control Data for Two Monitoring Wells near Pavillion, Wyoming, April and May 2012
}

\author{
By Peter R. Wright, Peter B. McMahon, David K. Mueller, and Melanie L. Clark
}

\begin{abstract}
In June 2010, the U.S. Environmental Protection Agency installed two deep monitoring wells (MW01 and MW02) near Pavillion, Wyoming, to study groundwater quality. During April and May 2012, the U.S Geological Survey, in cooperation with the Wyoming Department of Environmental Quality, collected groundwater-quality data and quality-control data from monitoring well MW01 and, following well redevelopment, quality-control data for monitoring well MW02. Two groundwater-quality samples were collected from well MW01 - one sample was collected after purging about 1.5 borehole volumes, and a second sample was collected after purging 3 borehole volumes. Both samples were collected and processed using methods designed to minimize atmospheric contamination or changes to water chemistry. Groundwaterquality samples were analyzed for field water-quality properties (water temperature, $\mathrm{pH}$, specific conductance, dissolved oxygen, oxidation potential); inorganic constituents including naturally occurring radioactive compounds (radon, radium-226 and radium-228); organic constituents; dissolved gasses; stable isotopes of methane, water, and dissolved inorganic carbon; and environmental tracers (carbon-14, chlorofluorocarbons, sulfur hexafluoride, tritium, helium, neon, argon, krypton, xenon, and the ratio of helium-3 to helium-4). Quality-control sample results associated with well MW01 were evaluated to determine the extent to which environmental sample analytical results were affected by bias and to evaluate the variability inherent to sample collection and laboratory analyses. Field documentation, environmental data, and quality-control data for activities that occurred at the two monitoring wells during April and May 2012 are presented.
\end{abstract}

\section{Introduction}

Groundwater is the primary source of domestic water supply for the town of Pavillion, Wyoming, and its rural residential neighbors. On December 8, 2011, the U.S. Environmental Protection Agency (USEPA) released the draft report Investigation of Ground Water Contamination near Pavillion, Wyoming (U.S. Environmental Protection Agency, 2011) for public review. The report described and interpreted data collected for two USEPA monitoring wells from 2010 to 2011, and indicated that groundwater may contain chemicals associated with gas production practices. The Wyoming Department of Environmental Quality (WDEQ) wanted additional groundwater-quality samples collected from these USEPA monitoring wells and discussed this need with the U.S. Geological Survey (USGS) Wyoming Water Science Center. The monitoring wells are identified as wells MW01 and MW02. During April and May 2012, the USGS, in cooperation with the WDEQ, collected groundwater-quality and associated quality-control (QC) data from monitoring well MW01, and redeveloped and collected QC data from monitoring well MW02.

Both USEPA monitoring wells were installed during the summer of 2010 as part of a multi-phase investigation of groundwater quality in the Pavillion area (U.S. Environmental Protection Agency, 2011). Well MW01 was completed to a depth of 785 feet (ft) below land surface (bls) and well MW02 was completed to a depth of $980 \mathrm{ft}$ bls. Both wells have a 20 -ft screened interval. A dedicated submersible 3-horsepower pump was installed in each well. Detailed construction information for both wells is presented in the USEPA report (U.S. Environmental Protection Agency, 2011).

Well MW01 was purged and sampled by the USGS and USEPA on April 24, 2012. Only data collected by the USGS are presented in this report. The USGS collected two groundwater-quality (environmental) samples from well MW01 —one sample was collected after purging about 1.5 borehole volumes of water from the well, and a second sample was collected after purging 3 borehole volumes. QC samples were collected in conjunction with both environmental samples from well MW01.

Using well hydraulic data collected in 2011, the USEPA estimated a yield of about 1 gallon per hour, or about 0.017 gallon per minute from well MW02 (U.S. Environmental Protection Agency, oral commun., 2012). Because of low yield, resulting in long recovery or purge times relative to the standard procedures and recommendations given in the 
USGS National Field Manual (U.S. Geological Survey, variously dated), well MW02 was redeveloped by the USGS in an attempt to increase well yield. A description of the USGS efforts to redevelop well MW02 during the week of April 30, 2012, is provided in the Sampling and Analysis Plan for the Characterization of Groundwater Quality in Two Monitoring Wells near Pavillion, Wyoming (SAP) (Wright and McMahon, 2012). After well MW02 was redeveloped, well yield data were collected by the USEPA with assistance from the USGS. These data are described in the USGS SAP (Wright and McMahon, 2012). Well yield was not increased as a result of the redevelopment effort; consequently, well MW02 was not sampled for this study. Nevertheless, QC samples were collected to characterize water added to well MW02 during redevelopment, and to ensure that a downhole camera used to examine the well screen was clean. Analytical results for the QC samples associated with redevelopment of well MW02 are presented in this report.

\section{Description of Study Area}

The study area is in Fremont County near the town of Pavillion, Wyoming (fig. 1). This small, sparsely populated agricultural community of 231 people (U.S. Census Bureau, 2010) is composed primarily of large-acreage irrigated farms. Natural-gas development began in the area northeast of Pavillion in the early 1960s, increased in the 1980s, and in recent years has increased again, under a succession of different owner-operators (James Gores and Associates, 2011). The town of Pavillion and rural households in the area obtain their water supply from wells installed in the areally extensive, Tertiaryage (Eocene) Wind River Formation (James Gores and Associates, 2011) that underlies the town and adjacent areas.

\section{Purpose and Scope}

The purposes of this report are to present (1) the analytical results for groundwater-quality samples collected from USEPA well MW01 during April 2012; (2) analytical results for QC samples collected in association with sampling of well MW01 during April 2012; and (3) analytical results for QC samples collected in association with USGS redevelopment of USEPA well MW02 during May 2012. Methods used to collect and analyze the groundwater-quality and QC samples are described in the Methods section. Groundwaterquality samples were analyzed for field water-quality properties (water temperature, $\mathrm{pH}$, specific conductance, dissolved oxygen, oxidation potential); inorganic constituents including naturally occurring radioactive compounds (radon, radium-226 and radium-228); organic constituents; dissolved gasses; stable isotopes of methane, water, and dissolved inorganic carbon; and environmental tracers [carbon-14, chlorofluorocarbons (CFCs), sulfur hexafluoride $\left(\mathrm{SF}_{6}\right)$, tritium $\left({ }^{3} \mathrm{H}\right)$, helium, neon, argon, krypton, and xenon, and the ratio of helium-3 to helium- 4 isotopes in the sample relative to the ratio in a reference standard $\left.\left(\delta^{3} \mathrm{He}\right)\right]$.

\section{Methods}

Samples collected during this study included two groundwater-quality samples from well MW01, several QC samples associated with well MW01, and two QC samples related to the redevelopment of well MW02. A brief description of the sampling design and sample collection at well MW01, the collection of QC samples related to well MW02 redevelopment, and methods used for laboratory and quality-control analyses are presented in this section.

\section{Sampling Design}

Groundwater-quality and QC samples were collected and processed using procedures described in the Sampling and Analysis Plan for the Characterization of Groundwater Quality in Two Monitoring Wells near Pavillion, Wyoming (SAP) (Wright and McMahon, 2012). A brief summary of the field sampling design described in the SAP is provided in this section.

Collection of two sets of groundwater-quality samples was planned for well MW01. The first sample set (environmental sample 1) was to be collected after one borehole volume of water was purged from the well. For this study, a borehole volume is defined as the wetted volume of unscreened casing plus the borehole volume throughout the screened interval, but excluding the volume of prepacked sand adjacent to the screened interval. An example of how the borehole volume was calculated is included in Wright and McMahon (2012). Sample collection also was contingent on stabilization of water temperature, specific conductance (SC), and $\mathrm{pH}$ of the water in successive field measurements. Stabilization of these properties was evaluated on the basis of the variability of five consecutive measurements made during a period of about 20 minutes at regularly timed intervals (Wilde, variously dated) (table 1). Water-quality properties are listed in table 1 (water temperature, $\mathrm{SC}, \mathrm{pH}$, dissolved oxygen, turbidity, and oxidation-reduction potential) that regularly are collected during groundwater sampling. Based on data USEPA had collected from well MW01, including low dissolved oxygen concentrations and excessive degassing in the sampling line, measurements of three of the properties (dissolved oxygen, turbidity, and oxidation-reduction potential) were thought to be less reliable than measurements of temperature, $\mathrm{SC}$, and $\mathrm{pH}$; therefore, the properties of dissolved oxygen, turbidity, and oxidation-reduction potential were not used as stabilization criteria. The second sample set (environmental sample 2) was to be collected after removal of three borehole volumes of water; sample collection was contingent on meeting the stabilization criteria for the same three field water-quality properties. In addition to the environmental samples, many different types of QC samples were proposed for the study. Three blank samples were scheduled to be collected before the well purge began (a source-solution blank, ambient blank, and a field blank), three replicate QC 


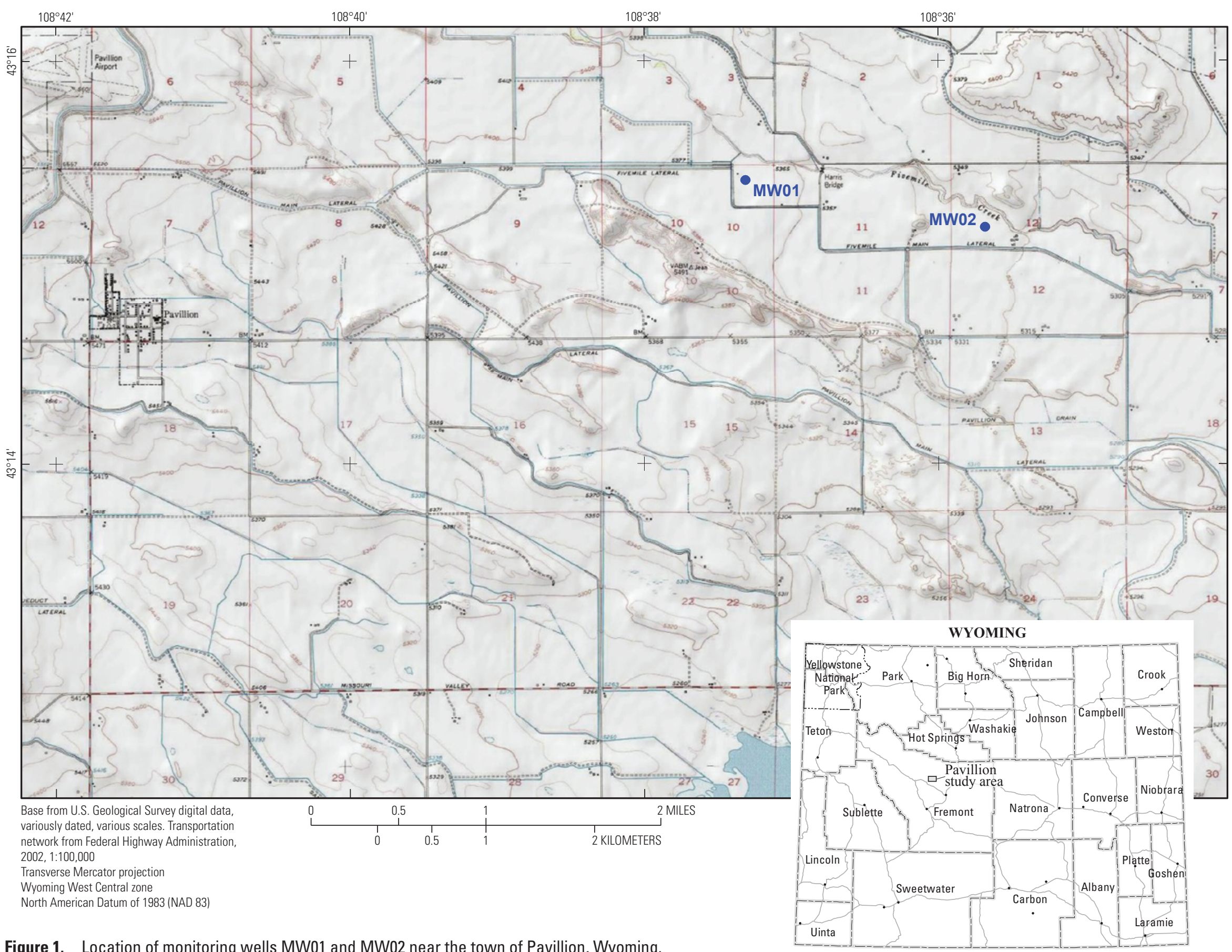


samples were scheduled to be collected with each environmental sample (a replicate, matrix spike, and matrix-spike duplicate), and a trip blank traveled with sample bottles at all times. These QC sample types are defined in the SAP (Wright and McMahon, 2012).

\section{Sample Collection at Monitoring Well MW01}

On April 23 and 24, 2012, the USGS collected several blank samples, two groundwater-quality (environmental) samples, and several QC samples from monitoring well MW01 (table 2.) The USGS 15-digit site number and the date and time each sample was collected are shown in table 2. Sample collection generally followed the sampling design described in the SAP (Wright and McMahon, 2012), with a few modifications as described in this section. Documentation of field activities at monitoring well MW01 including field instrument calibration notes, general project notes, groundwater-quality notes for samples 1 and 2, purge logs, and alkalinity/acid-neutralizing capacity titration field notes are included in appendix 1 (figs. 1.1-1.4). As planned, three QC samples (source-solution blank, ambient blank, and field blank) were collected before beginning the well purge.

USEPA personnel measured the water level in well MW01 before and during the well purge using a sonic water-level meter. USEPA personnel also measured the pumping rate during the well purge. The pumping rate was measured using a flow meter and was verified using a bucket and a stopwatch.

Collection of environmental sample 1 and the associated QC samples was intended to begin after one borehole volume of water was purged from the well. Once a sufficient volume had been purged, sample collection started as soon as values for both $\mathrm{SC}$ and $\mathrm{pH}$ met stabilization criteria (table 1). The stabilization criterion for temperature was not used because the water line was exposed to solar heating and air temperature, so by the time water temperature was measured it was not a good indication of conditions in the well. Turbidity was not a stabilization criterion, and a turbidity sensor was not included on the multiparameter water-quality instrument. Only two turbidity measurements were made (sample aliquots collected from the sample discharge line and turbidity measured with a HACH 2100P meter; Hach Chemical Company, 2008) and noted on the purge log; both were very low, and were similar to each other. Values of SC met the criterion only briefly, but by then sampling had begun. Because it took longer for field water-quality properties of $\mathrm{SC}$ and $\mathrm{pH}$ to reach stability (based on criteria in table 1), collection of environmental sample 1 and associated QC samples actually began after about 1.5 borehole volumes had been purged from well MW01.

Table 1. Stabilization criteria and calibration guidelines for water-quality properties (modified from Wilde, variously dated).

$\left[ \pm\right.$, plus or minus value shown; ${ }^{\circ} \mathrm{C}$, degrees Celsius; $\leq$, less than or equal to value shown; $\mu \mathrm{S} / \mathrm{cm}$, microsiemens per centimeter at $25^{\circ} \mathrm{C} ;>$, greater than value shown; NA, not applicable; NTRU, nephelometric turbidity ratio units; $<$, less than value shown; $\mathrm{mg} / \mathrm{L}$, milligrams per liter]

\begin{tabular}{|c|c|c|}
\hline Water-quality property & $\begin{array}{l}\text { Stabilization } \\
\text { criteria } \\
\text { (variability should be } \\
\text { within value shown) }\end{array}$ & Calibration guidelines \\
\hline $\begin{array}{l}\text { Specific conductance (SC): } \\
\text { for } \leq 100 \mu \mathrm{S} / \mathrm{cm} \text { at } 25^{\circ} \mathrm{C} \\
\text { for }>100 \mu \mathrm{S} / \mathrm{cm} \text { at } 25^{\circ} \mathrm{C}\end{array}$ & $\begin{array}{l} \pm 5 \text { percent } \\
\pm 3 \text { percent }\end{array}$ & $\begin{array}{l}\text { Calibrate each morning and at end of each day. Check calibration at each } \\
\text { additional site; recalibrate if not within } 3 \text { to } 5 \text { percent of standard value. }\end{array}$ \\
\hline $\begin{array}{l}\text { pH: } \\
\quad \text { (displays to } 0.01 \text { standard units) }\end{array}$ & $\begin{array}{l} \pm 0.1 \text { standard } \mathrm{pH} \text { units. } \\
\text { Allow } \pm 0.3 \mathrm{pH} \text { units } \\
\text { if drifting persists. }\end{array}$ & $\begin{array}{l}\text { Calibrate each morning and at end of each day. Check calibration at each } \\
\text { additional site; recalibrate if not within } 0.05 \mathrm{pH} \text { units of standard . }\end{array}$ \\
\hline $\begin{array}{l}\text { Dissolved oxygen: } \\
\text { Amperometric or optical/ } \\
\text { luminescent-method sensors }\end{array}$ & $\mathrm{NA}^{2}$ & $\begin{array}{l}\text { Calibrate each morning and at end of each day. If electrode uses a Teflon }{ }^{\circledR} \\
\text { membrane, inspect electrode for bubbles under membrane at each sample site; } \\
\text { replace if necessary. }\end{array}$ \\
\hline Oxidation-reduction potential & $\mathrm{NA}^{2}$ & $\begin{array}{l}\text { Check against Zobell's solution each morning and at end of each day. } \\
\text { Recalibrate if not within } \pm 5 \text { millivolts. }\end{array}$ \\
\hline
\end{tabular}


Table 2. Environmental and quality-control samples collected for monitoring wells MW01 and MW02 near Pavillion, Wyoming, April and May 2012.

[USGS, U.S. Geological Survey; NWQL, National Water Quality Laboratory; IBW, inorganic free blank water; OWB, organic free blank water]

\begin{tabular}{|c|c|c|c|}
\hline Sample & $\begin{array}{c}\text { Sample } \\
\text { collection date }\end{array}$ & Type of water & $\begin{array}{c}\text { Assigned } \\
\text { sample time }\end{array}$ \\
\hline \multicolumn{4}{|c|}{ Well MW01 (431525108371901) } \\
\hline Ambient blank & $4 / 24 / 2012$ & USGS NWQL certified IBW and OBW & 0800 \\
\hline Field blank & $4 / 24 / 2012$ & USGS NWQL certified IBW and OBW & 0830 \\
\hline Primary environmental sample 1 & $4 / 24 / 2012$ & Environmental water & 1330 \\
\hline Matrix spike & $4 / 24 / 2012$ & Environmental water & 1332 \\
\hline Matrix-spike duplicate & $4 / 24 / 2012$ & Environmental water & 1333 \\
\hline Trip blank & $4 / 24 / 2012$ & Laboratory-prepared blank water & 1334 \\
\hline Primary environmental sample 2 & $4 / 24 / 2012$ & Environmental water & 1830 \\
\hline Sample 2 replicate & $4 / 24 / 2012$ & Environmental water & 1831 \\
\hline \multicolumn{4}{|c|}{ Well MW02 (431511108354101) } \\
\hline
\end{tabular}

In addition to collection of environmental sample 1, all the planned QC samples (replicate, matrix spike, and matrixspike duplicate samples) were collected. Laboratory analyses for each sample are listed in table 3. Sample collection was sequential; collecting a full set of containers for each analytical method - first, the environmental sample was collected; then, the replicate sample was collected; finally, the matrix spike and matrix-spike duplicate were collected. All water samples sent to the TestAmerica, Eberline, Woods Hole Oceanographic Institute, and USGS Tritium laboratories were collected inside a sampling chamber (a polyvinyl chloride frame with a clear plastic bag mounted inside, reducing sample exposure to airborne contamination sources) located within a mobile water-quality laboratory. The sample for analysis of the ratio of carbon- 13 to carbon- 12 isotopes $\left(\delta^{13} \mathrm{C}\right)$ of dissolved inorganic carbon, sent to the USGS Reston Stable Isotopes laboratory, also was collected inside the sampling chamber. After these samples were collected, dissolved gas, radon, remaining isotopes, and environmental tracer samples were collected outside of the mobile laboratory next to the well head. For each of these analyses, different sampling equipment was required such that the sampling chamber in the mobile laboratory could not be used; however, airborne contamination sources were not a concern. The SAP provides additional information on collection of these types of samples (Wright and McMahon, 2012).

All matrix spike and matrix-spike duplicate samples were spiked at the laboratory. Analytical Services Request (ASR) forms and chain-of-custody (COC) records are presented in appendix 2 (figs. 2.1-2.9). Photographs of groundwater-sampling activities are presented in appendix 3 (figs. 3.1-3.16).
Samples for analysis of some organic constituents were collected in duplicate with one set of bottles preserved with hydrochloric acid $(\mathrm{HCl})$ and a second bottle set unpreserved. Field data collected by the USEPA during previous investigations of well MW01 indicated the $\mathrm{pH}$ of the groundwater would be greater than 11. Samples for volatile organic compounds (VOCs), gasoline-range organics (GRO), and some of the hydrocarbon gasses [ethane, ethylene, methane, and propane analyzed by USEPA method RSKSOP-175 (U.S. Environmental Protection Agency, 1994)] commonly are preserved by adding $\mathrm{HCl}$ to each sample container at the time of sample collection to lower the $\mathrm{pH}$ to less than 2 , thus extending the sample holding time (time before a sample must be analyzed by a laboratory). Because $\mathrm{HCl}$ reactions within these samples potentially could cause gas loss resulting in a decrease in constituent recoveries, two bottle sets were sequentially collected for VOCs, GRO, and hydrocarbon gasses. One set of bottles was preserved with $\mathrm{HCl}$ at the time of collection and the second bottle set was left unpreserved.

Collection of environmental sample 2 began after three borehole volumes of water were purged from well MW01. Because collection of sample 2 began late in the day (time 1830) and it would not be safe to complete field activities after dark, the matrix spike and matrixspike duplicate samples were not collected. In the end, a full suite of samples was collected for the environmental sample and a partial suite of samples was collected in replicate (table 3 ).

Field water-quality properties measured during the purge of well MW01 are presented in table 4. 
[--, sample not collected; X, sample collected; USEPA, U.S. Environmental Protection Agency; mod, modified; SIM, selective ion monitoring; DAI, direct aqueous injection; BTEX, the compounds benzene, toluene, ethyl benzene, and xylene; MTBE, methyl tert-butyl ether; $\mathrm{N}_{2}$, nitrogen; $\mathrm{Ar}$, argon; $\mathrm{CH}_{4}$, methane; $\mathrm{CO}_{2}$, carbon dioxide; $\mathrm{O}_{2}$, oxygen; $\delta^{18} \mathrm{O}$, ratio of oxygen- 18 to oxygen- 16 isotopes in the sample relative to the ratio in a reference standard; $\delta^{2} \mathrm{H}$, ratio of hydrogen- 2 to hydrogen-1 isotopes in the sample relative to the ratio in a reference standard; $\delta^{13} \mathrm{C}$, ratio of carbon- 13 to carbon- 12 isotopes in the sample relative to the ratio in a reference standard; $\delta^{3} \mathrm{He}$, ratio of helium-3 to helium- 4 isotopes in the sample relative to the ratio in a reference standard]

\begin{tabular}{|c|c|c|c|c|c|c|c|c|c|c|c|c|c|c|c|}
\hline \multirow[b]{2}{*}{$\begin{array}{l}\text { Laboratory } \\
\text { analytical } \\
\text { method' }^{1}\end{array}$} & \multirow[b]{2}{*}{ Analysis } & \multirow[b]{2}{*}{$\begin{array}{l}\text { Analysis } \\
\text { group }\end{array}$} & \multicolumn{10}{|c|}{ MW01 } & \multicolumn{3}{|c|}{ MW02 } \\
\hline & & & $\begin{array}{l}\text { Source } \\
\text { solution } \\
\text { blank }\end{array}$ & $\begin{array}{l}\text { Ambient } \\
\text { blank }\end{array}$ & $\begin{array}{l}\text { Field } \\
\text { blank }\end{array}$ & $\begin{array}{l}\text { Environmental } \\
\text { sample } 1\end{array}$ & $\begin{array}{l}\text { Sample } 1 \\
\text { replicate }\end{array}$ & $\begin{array}{l}\text { Matrix } \\
\text { spike }\end{array}$ & $\begin{array}{l}\text { Matrix } \\
\text { spike } \\
\text { duplicate }\end{array}$ & $\begin{array}{c}\text { Trip } \\
\text { blank }\end{array}$ & $\begin{array}{l}\text { Environmental } \\
\text { sample } 2\end{array}$ & $\begin{array}{l}\text { Sample } 2 \\
\text { replicate }\end{array}$ & $\begin{array}{l}\text { Riverton } \\
\text { development } \\
\text { water }\end{array}$ & $\begin{array}{c}\text { Trip } \\
\text { blank }\end{array}$ & $\begin{array}{l}\text { Camera } \\
\text { blank }\end{array}$ \\
\hline \multicolumn{16}{|c|}{ U.S. Geological Survey field analyses } \\
\hline & Ferrous iron, field & Inorganic constituents & -- & -- & -- & $\mathrm{X}$ & -- & -- & -- & -- & $\mathrm{X}$ & -- & -- & -- & -- \\
\hline & $\begin{array}{l}\text { Dissolved oxygen, low } \\
\text { range, field }\end{array}$ & Inorganic constituents & -- & -- & -- & $\mathrm{X}$ & -- & -- & -- & -- & $\mathrm{X}$ & -- & -- & -- & -- \\
\hline & $\begin{array}{l}\text { Alkalinity and associated } \\
\text { constituents, field }\end{array}$ & Inorganic constituents & -- & -- & -- & $\mathrm{X}$ & -- & -- & -- & -- & $\mathrm{X}$ & -- & -- & -- & -- \\
\hline & $\begin{array}{l}\text { Acid neutralizing capac- } \\
\text { ity and associated } \\
\text { constituents, field }\end{array}$ & Inorganic constituents & -- & -- & -- & $\mathrm{X}$ & -- & -- & -- & -- & $\mathrm{X}$ & -- & -- & -- & -- \\
\hline \multicolumn{16}{|c|}{ TestAmerica Laboratories } \\
\hline $\begin{array}{l}\text { USEPA method } \\
\text { 6010B }\end{array}$ & Major cations and silica & Inorganic constituents & -- & $\mathrm{X}$ & $\mathrm{X}$ & $\mathrm{X}$ & $\mathrm{X}$ & $\mathrm{X}$ & $\mathrm{X}$ & -- & $\mathrm{X}$ & -- & $\mathrm{X}$ & $\mathrm{X}$ & $\mathrm{X}$ \\
\hline $\begin{array}{l}\text { USEPA method } \\
\quad 9056\end{array}$ & Major anions & Inorganic constituents & -- & $\mathrm{X}$ & $\mathrm{X}$ & $\mathrm{X}$ & $\mathrm{X}$ & $\mathrm{X}$ & $\mathrm{X}$ & -- & $\mathrm{X}$ & -- & $X$ & $X$ & $\mathrm{X}$ \\
\hline $\begin{array}{l}\text { USEPA method } \\
350.1\end{array}$ & Nitrogen, ammonia & Inorganic constituents & -- & $\mathrm{X}$ & $\mathrm{X}$ & $\mathrm{X}$ & $\mathrm{X}$ & $\mathrm{X}$ & $\mathrm{X}$ & -- & $\mathrm{X}$ & -- & $\mathrm{X}$ & $\mathrm{X}$ & $\mathrm{X}$ \\
\hline $\begin{array}{l}\text { USEPA method } \\
353.2\end{array}$ & Nitrate + nitrite & Inorganic constituents & -- & $\mathrm{X}$ & $\mathrm{X}$ & $\mathrm{X}$ & $\mathrm{X}$ & $\mathrm{X}$ & $\mathrm{X}$ & -- & $\mathrm{X}$ & -- & $\mathrm{X}$ & $\mathrm{X}$ & $\mathrm{X}$ \\
\hline $\begin{array}{l}\text { USEPA method } \\
\quad 365.1\end{array}$ & Phosphorus, dissolved & Inorganic constituents & -- & $X$ & $\mathrm{X}$ & $\mathrm{X}$ & $\mathrm{X}$ & $\mathrm{X}$ & $\mathrm{X}$ & -- & $X$ & -- & $X$ & $\mathrm{X}$ & $\mathrm{X}$ \\
\hline $\begin{array}{l}\text { USEPA method } \\
6010 \mathrm{~B} \text { and } \\
6020\end{array}$ & Trace elements & Inorganic constituents & -- & $\mathrm{X}$ & $\mathrm{X}$ & $\mathrm{X}$ & $\mathrm{X}$ & $\mathrm{X}$ & $\mathrm{X}$ & -- & $\mathrm{X}$ & -- & $\mathrm{X}$ & $\mathrm{X}$ & $\mathrm{X}$ \\
\hline $\begin{array}{l}\text { USEPA method } \\
7470\end{array}$ & Mercury & Inorganic constituents & -- & $\mathrm{X}$ & $\mathrm{X}$ & $\mathrm{X}$ & $\mathrm{X}$ & $\mathrm{X}$ & $\mathrm{X}$ & -- & $\mathrm{X}$ & -- & $\mathrm{X}$ & $\mathrm{X}$ & $\mathrm{X}$ \\
\hline $\begin{array}{l}\text { USEPA method } \\
\text { 8260B }\end{array}$ & $\begin{array}{l}\text { Volatile organic com- } \\
\text { pounds (VOCs) }\end{array}$ & Organic constituents & $X$ & $\mathrm{X}$ & $\mathrm{X}$ & $\mathrm{X}$ & $\mathrm{X}$ & $\mathrm{X}$ & $\mathrm{X}$ & $\mathrm{X}$ & $\mathrm{X}$ & $\mathrm{X}$ & $\mathrm{X}$ & $\mathrm{X}$ & $\mathrm{X}$ \\
\hline $\begin{array}{l}\text { USEPA method } \\
8260 \mathrm{~B}\end{array}$ & $\begin{array}{l}\text { Volatile organic com- } \\
\text { pounds (VOCs), } \\
\text { unpreserved }\end{array}$ & Organic constituents & $X$ & $\mathrm{X}$ & $X$ & $\mathrm{X}$ & $\mathrm{X}$ & $\mathrm{X}$ & $\mathrm{X}$ & $\mathrm{X}$ & $X$ & $X$ & -- & -- & -- \\
\hline $\begin{array}{l}\text { USEPA method } \\
8270 \mathrm{C} \text { and } \\
8270 / \mathrm{SIM}\end{array}$ & $\begin{array}{l}\text { Semivolatile organic } \\
\text { compounds (SVOCs) } \\
\text { and polycylic aro- } \\
\text { matic hydrocarbons } \\
\text { (PAHs) }\end{array}$ & Organic constituents & -- & $\mathrm{X}$ & $\mathrm{X}$ & $\mathrm{X}$ & $\mathrm{X}$ & $X$ & $\mathrm{X}$ & -- & $\mathrm{X}$ & $\mathrm{X}$ & $\mathrm{X}$ & $\mathrm{X}$ & $\mathrm{X}$ \\
\hline $\begin{array}{l}\text { EPA 8015B } \\
\text { DAI in } \\
\text { Water } \\
(8015 B)\end{array}$ & $\begin{array}{l}\text { Diesel range organics } \\
\text { (DRO) }\end{array}$ & Organic constituents & $\mathrm{X}$ & -- & $\mathrm{X}$ & $\mathrm{X}$ & $\mathrm{X}$ & $X$ & $\mathrm{X}$ & -- & $X$ & $\mathrm{X}$ & $X$ & $X$ & $X$ \\
\hline
\end{tabular}


Table 3. Analyses done for environmental and quality-control samples collected for monitoring wells MW01 and MW02 near Pavillion, Wyoming, April and May 2012.—Continued

[--, sample not collected; X, sample collected; USEPA, U.S. Environmental Protection Agency; mod, modified; SIM, selective ion monitoring; DAI, direct aqueous injection; BTEX, the compounds benzene, toluene, ethyl benzene, and xylene; MTBE, methyl tert-butyl ether; $\mathrm{N}_{2}$, nitrogen; $\mathrm{Ar}$, argon; $\mathrm{CH}_{4}$, methane; $\mathrm{CO}_{2}$, carbon dioxide; $\mathrm{O}_{2}$, oxygen; $\delta^{18} \mathrm{O}$, ratio of oxygen-18 to oxygen-16 isotopes in the sample relative to the ratio in a reference standard; $\delta^{2} \mathrm{H}$, ratio of hydrogen- 2 to hydrogen-1 isotopes in the sample relative to the ratio in a reference standard; $\delta^{13} \mathrm{C}$, ratio of carbon- 13 to carbon- 12 isotopes in the sample relative to the ratio in a reference standard; $\delta^{3} \mathrm{He}$, ratio of helium-3 to helium-4 isotopes in the sample relative to the ratio in a reference standard]

\begin{tabular}{|c|c|c|c|c|c|c|c|c|c|c|c|c|c|c|c|}
\hline \multirow[b]{2}{*}{$\begin{array}{l}\text { Laboratory } \\
\text { analytical } \\
\text { method }^{1}\end{array}$} & \multirow[b]{2}{*}{ Analysis } & \multirow[b]{2}{*}{$\begin{array}{l}\text { Analysis } \\
\text { group }\end{array}$} & \multicolumn{10}{|c|}{ MW01 } & \multicolumn{3}{|c|}{ MW02 } \\
\hline & & & $\begin{array}{l}\text { Source } \\
\text { solution } \\
\text { blank }\end{array}$ & $\begin{array}{l}\text { Ambient } \\
\text { blank }\end{array}$ & $\begin{array}{l}\text { Field } \\
\text { blank }\end{array}$ & $\begin{array}{l}\text { Environmental } \\
\text { sample } 1\end{array}$ & $\begin{array}{l}\text { Sample } 1 \\
\text { replicate }\end{array}$ & $\begin{array}{l}\text { Matrix } \\
\text { spike }\end{array}$ & $\begin{array}{l}\text { Matrix } \\
\text { spike } \\
\text { duplicate }\end{array}$ & $\begin{array}{c}\text { Trip } \\
\text { blank }\end{array}$ & $\begin{array}{l}\text { Environmental } \\
\text { sample } 2\end{array}$ & $\begin{array}{l}\text { Sample } 2 \\
\text { replicate }\end{array}$ & $\begin{array}{l}\text { Riverton } \\
\text { development } \\
\text { water }\end{array}$ & $\begin{array}{c}\text { Trip } \\
\text { blank }\end{array}$ & $\begin{array}{l}\text { Camera } \\
\text { blank }\end{array}$ \\
\hline $\begin{array}{l}\text { USEPA 8015B } \\
\text { DAI in } \\
\text { Water } \\
(8015 \mathrm{~B})\end{array}$ & $\begin{array}{l}\text { Glycols, ethanol, } \\
\text { isobutanol, isopropyl } \\
\text { alcohol, n-butanol }\end{array}$ & Organic constituents & $\mathrm{X}$ & -- & $\mathrm{X}$ & $\mathrm{X}$ & $\mathrm{X}$ & $\mathrm{X}$ & $\mathrm{X}$ & $\mathrm{X}$ & $\mathrm{X}$ & $\mathrm{X}$ & $\mathrm{X}$ & $\mathrm{X}$ & $\mathrm{X}$ \\
\hline $\begin{array}{l}\text { USEPA } \\
8015 \mathrm{~B} / 8021 \\
\bmod \end{array}$ & $\begin{array}{l}\text { Gasoline range organics } \\
\text { (GRO) + BTEX + } \\
\text { MTBE }\end{array}$ & Organic constituents & $\mathrm{X}$ & $\mathrm{X}$ & $\mathrm{X}$ & $\mathrm{X}$ & $\mathrm{X}$ & $\mathrm{X}$ & $\mathrm{X}$ & $\mathrm{X}$ & $\mathrm{X}$ & $\mathrm{X}$ & $\mathrm{X}$ & $\mathrm{X}$ & $\mathrm{X}$ \\
\hline $\begin{array}{l}\text { USEPA } \\
8015 \mathrm{~B} / 8021 \\
\bmod \end{array}$ & $\begin{array}{c}\text { Gasoline range organics } \\
\text { (GRO) + BTEX + } \\
\text { MTBE, unpreserved }\end{array}$ & Organic constituents & $\mathrm{X}$ & $\mathrm{X}$ & $\mathrm{X}$ & $\mathrm{X}$ & $\mathrm{X}$ & $\mathrm{X}$ & $\mathrm{X}$ & $\mathrm{X}$ & $\mathrm{X}$ & $\mathrm{X}$ & -- & -- & -- \\
\hline RSK-SOP 175 & $\begin{array}{l}\text { Methane, ethane, ethyl- } \\
\text { ene, and propane }\end{array}$ & Dissolved gases & $\mathrm{X}$ & $\mathrm{X}$ & $\mathrm{X}$ & $\mathrm{X}$ & $\mathrm{X}$ & $\mathrm{X}$ & $\mathrm{X}$ & $\mathrm{X}$ & $\mathrm{X}$ & $\mathrm{X}$ & $\mathrm{X}$ & $\mathrm{X}$ & $\mathrm{X}$ \\
\hline RSK-SOP 175 & $\begin{array}{l}\text { Methane, ethane, } \\
\text { ethylene, and propane } \\
\text { (unpreserved) }\end{array}$ & Dissolved gases & $\mathrm{X}$ & $X$ & $\mathrm{X}$ & $\mathrm{X}$ & $\mathrm{X}$ & $\mathrm{X}$ & $\mathrm{X}$ & $\mathrm{X}$ & $X$ & $X$ & -- & -- & -- \\
\hline $\begin{array}{l}\text { USEPA method } \\
\quad 425.1 \\
\end{array}$ & $\begin{array}{l}\text { Methylene blue active } \\
\text { substances }\end{array}$ & Organic constituents & -- & $\mathrm{X}$ & $\mathrm{X}$ & $\mathrm{X}$ & $\mathrm{X}$ & $\mathrm{X}$ & $\mathrm{X}$ & -- & $\mathrm{X}$ & -- & $\mathrm{X}$ & $\mathrm{X}$ & $\mathrm{X}$ \\
\hline \multicolumn{16}{|c|}{ Eberline Laboratory } \\
\hline & $\begin{array}{l}\text { Radium-226 and } \\
\text { radium-228 }\end{array}$ & Inorganic constituents & -- & -- & -- & $\mathrm{X}$ & -- & -- & -- & -- & $\mathrm{X}$ & -- & -- & -- & -- \\
\hline \multicolumn{16}{|c|}{ U.S. Geological Survey National Water Quality Laboratory } \\
\hline & Radon-222 & Inorganic constituents & -- & -- & -- & $\mathrm{X}$ & -- & -- & -- & -- & -- & -- & -- & -- & -- \\
\hline \multicolumn{16}{|c|}{ Isotech Laboratories, Inc. } \\
\hline & $\begin{array}{l}\text { Compositional analysis } \\
\text { of hydrocarbon gasses }\end{array}$ & Dissolved gases & -- & -- & -- & $\mathrm{X}^{2}$ & -- & -- & -- & -- & $\mathrm{X}$ & -- & -- & -- & -- \\
\hline & $\delta^{13} \mathrm{C}$ and $\delta^{2} \mathrm{H}$ of methane & Stable isotopes & -- & -- & -- & $\mathrm{X}^{2}$ & -- & & -- & -- & $\mathrm{X}$ & -- & -- & -- & -- \\
\hline \multicolumn{16}{|c|}{ Lamont-Doherty Laboratory } \\
\hline & $\begin{array}{l}\text { Helium, neon, argon, } \\
\text { krypton, xenon, and } \\
\delta^{3} \mathrm{He}\end{array}$ & Environmental tracers & -- & -- & -- & $\mathrm{X}^{3}$ & -- & -- & -- & -- & -- & -- & -- & -- & -- \\
\hline \multicolumn{16}{|c|}{ U.S. Geological Survey Reston Chlorofluorocarbon Laboratory } \\
\hline & $\begin{array}{l}\text { Dissolved gasses }\left(\mathrm{N}_{2}, \mathrm{Ar} \text {, }\right. \\
\left.\qquad \mathrm{CH}_{4}, \mathrm{CO}_{2}, \mathrm{O}_{2}\right)\end{array}$ & Dissolved gases & -- & -- & -- & $\mathrm{X}$ & $\mathrm{X}$ & -- & -- & -- & $\mathrm{X}$ & -- & -- & -- & -- \\
\hline & Helium & Environmental tracers & -- & -- & -- & $\mathrm{X}$ & -- & -- & -- & -- & $\mathrm{X}$ & -- & -- & -- & -- \\
\hline & $\begin{array}{l}\text { Chlorofluorocarbons } \\
\text { (CFCs) }\end{array}$ & Environmental tracers & -- & -- & -- & $\mathrm{X}$ & $\mathrm{X}$ & -- & -- & -- & -- & -- & -- & -- & -- \\
\hline & Sulfur hexafluoride $\left(\mathrm{SF}_{6}\right)$ & Environmental tracers & -- & -- & -- & $\mathrm{X}$ & $\mathrm{X}$ & -- & -- & -- & $\mathrm{X}$ & -- & -- & -- & -- \\
\hline \multicolumn{16}{|c|}{ U.S. Geological Survey Reston Stable Isotope Laboratory } \\
\hline LC 1142 & $\delta^{18} \mathrm{O}$ and $\delta^{2} \mathrm{H}$ of water & Stable isotopes & -- & -- & -- & $\mathrm{X}$ & -- & -- & -- & -- & -- & -- & -- & -- & -- \\
\hline
\end{tabular}


[--, sample not collected; X, sample collected; USEPA, U.S. Environmental Protection Agency; mod, modified; SIM, selective ion monitoring; DAI, direct aqueous injection; BTEX, the compounds benzene, toluene, ethyl benzene, and xylene; MTBE, methyl tert-butyl ether; $\mathrm{N}_{2}$, nitrogen; $\mathrm{Ar}$, argon; $\mathrm{CH}_{4}$, methane; $\mathrm{CO}_{2}$, carbon dioxide; $\mathrm{O}_{2}$, oxygen; $\delta^{18} \mathrm{O}$, ratio of oxygen- 18 to oxygen- 16 isotopes in the sample relative to the ratio in a reference standard; $\delta^{2} \mathrm{H}$, ratio of hydrogen- 2 to hydrogen-1 isotopes in the sample relative to the ratio in a reference standard; $\delta^{13} \mathrm{C}$, ratio of carbon- 13 to carbon- 12 isotopes in the sample relative to the ratio in a reference standard; $\delta^{3} \mathrm{He}$, ratio of helium-3 to helium- 4 isotopes in the sample relative to the ratio in a reference standard]

\begin{tabular}{|c|c|c|c|c|c|c|c|c|c|c|c|c|c|c|c|}
\hline \multirow[b]{2}{*}{$\begin{array}{l}\text { Laboratory } \\
\text { analytical } \\
\text { method }^{1}\end{array}$} & \multirow[b]{2}{*}{ Analysis } & \multirow[b]{2}{*}{$\begin{array}{l}\text { Analysis } \\
\text { group }\end{array}$} & \multicolumn{10}{|c|}{ MW01 } & \multicolumn{3}{|c|}{ MW02 } \\
\hline & & & $\begin{array}{c}\text { Source } \\
\text { solution } \\
\text { blank }\end{array}$ & $\begin{array}{c}\text { Ambient } \\
\text { blank }\end{array}$ & $\begin{array}{l}\text { Field } \\
\text { blank }\end{array}$ & $\begin{array}{l}\text { Environmental } \\
\text { sample } 1\end{array}$ & $\begin{array}{l}\text { Sample } 1 \\
\text { replicate }\end{array}$ & $\begin{array}{l}\text { Matrix } \\
\text { spike }\end{array}$ & $\begin{array}{l}\text { Matrix } \\
\text { spike } \\
\text { duplicate }\end{array}$ & $\begin{array}{c}\text { Trip } \\
\text { blank }\end{array}$ & $\begin{array}{l}\text { Environmental } \\
\text { sample } 2\end{array}$ & $\begin{array}{l}\text { Sample } 2 \\
\text { replicate }\end{array}$ & $\begin{array}{c}\text { Riverton } \\
\text { development } \\
\text { water }\end{array}$ & $\begin{array}{c}\text { Trip } \\
\text { blank }\end{array}$ & $\begin{array}{c}\text { Camera } \\
\text { blank }\end{array}$ \\
\hline \multicolumn{16}{|c|}{ U.S. Geological Survey Menlo Park Tritium Laboratory } \\
\hline LC 1565 & Tritium & Environmental tracers & -- & -- & -- & $\mathrm{X}^{3}$ & -- & -- & -- & -- & -- & -- & -- & -- & -- \\
\hline \multicolumn{16}{|c|}{ Woods Hole Oceanographic Institute } \\
\hline LC 3212 & $\begin{array}{l}\delta^{13} \mathrm{C} \text { and carbon-14 of } \\
\text { dissolved inorganic } \\
\text { carbon }\end{array}$ & $\begin{array}{l}\text { Stable isotopes and } \\
\text { environmental } \\
\text { tracers }\end{array}$ & -- & -- & -- & $\mathrm{X}$ & -- & -- & -- & -- & $\mathrm{X}$ & -- & -- & -- & -- \\
\hline
\end{tabular}

${ }^{1}$ Laboratory analytical methods, approaches and method references are provided in table 3 of Wright and McMahon (2012).

${ }^{2}$ Sample was collected but could not be analyzed because of broken bottle.

${ }^{3}$ Sample was collected but has not yet been analyzed as of August 20, 2012.

Table 4. Field water-quality properties measured during purge of monitoring well MW01 near Pavillion, Wyoming, April 2012.

[Highlighted value indicates property met purge criteria ${ }^{1}$ for last five measurements. $\mathrm{ft}$, feet; BMP, below measuring point; gal/min, gallons per minute; ${ }^{\circ} \mathrm{C}$, degrees Celsius; $\mathrm{SC}$, specific conductance at 25 degrees Celsius; $\mu \mathrm{S} / \mathrm{cm}$, microsiemens per centimeter; DO, dissolved oxygen; $\mathrm{mg} / \mathrm{L}$, milligrams per liter; ORP, oxidation reduction potential; mV, millivolts; NTRU, nephelometric turbidity ratio units; --, no data; $<$, less than]

\begin{tabular}{|c|c|c|c|c|c|c|c|c|c|c|c|c|c|c|c|}
\hline Time & $\begin{array}{c}\text { Water } \\
\text { level } \\
\text { (ft BMP) }\end{array}$ & $\begin{array}{c}\text { Draw } \\
\text { down } \\
\text { (ft) }\end{array}$ & $\begin{array}{l}\text { Pumping } \\
\text { rate } \\
\text { (gal } / \mathrm{min} \text { ) }\end{array}$ & $\begin{array}{l}\text { Volume } \\
\text { (gallons) }\end{array}$ & $\begin{array}{l}\text { Borehole } \\
\text { volumes }\end{array}$ & $\begin{array}{c}\text { Water } \\
\text { Temper- } \\
\text { ature } \\
\left({ }^{\circ} \mathrm{C}\right)\end{array}$ & $\begin{array}{c}\text { Variability }^{2} \\
\text { of last } 5 \\
\text { temperature } \\
\text { measure- } \\
\text { ments }\end{array}$ & $\begin{array}{l}\text { SC } \\
(\mu \mathrm{S} / \\
\mathrm{cm})\end{array}$ & $\begin{array}{c}\text { Variability }^{3} \\
\text { of last } 5 \text { SC } \\
\text { measure- } \\
\text { ments } \\
\text { (percent) }\end{array}$ & $\begin{array}{c}\mathrm{pH} \\
\text { (standard } \\
\text { units) }\end{array}$ & $\begin{array}{l}\text { Vari- } \\
\text { ability }\end{array}$ & $\begin{array}{c}\text { DO } \\
\text { (mg/L) }\end{array}$ & $\begin{array}{l}\text { ORP } \\
(\mathrm{mV})\end{array}$ & $\begin{array}{l}\text { Turbidity } \\
\text { (NTRU) }\end{array}$ & Comments \\
\hline $11: 10$ & 201.35 & 0.00 & -- & 0 & 0.00 & -- & -- & -- & -- & & -- & -- & -- & -- & Pump started. \\
\hline $11: 20$ & 287.94 & 86.59 & 6.05 & 61 & 0.14 & 19.02 & -- & -- & -- & 11.5 & -- & 0.5 & -170.50 & -- & \\
\hline $11: 30$ & 315.58 & 114.23 & 6.05 & 121 & 0.28 & 14.45 & -- & 3,396 & -- & 12.1 & -- & $<0.2$ & -236.30 & -- & \\
\hline $11: 40$ & 329.73 & 128.38 & 6.11 & 182 & 0.42 & 14.96 & -- & 3,101 & -- & 12.1 & -- & $<0.2$ & -248.20 & -- & \\
\hline $11: 50$ & 334.04 & 132.69 & 6.10 & 243 & 0.57 & 15.74 & -- & 2,839 & -- & 12.0 & -- & $<0.2$ & -262.80 & -- & \\
\hline $12: 00$ & 334.42 & 133.07 & 6.04 & 304 & 0.71 & 15.73 & 4.57 & 2,549 & -- & 11.9 & 0.64 & $<0.2$ & -272.80 & -- & \\
\hline 12:09 & 325.58 & 124.23 & 6.00 & 358 & 0.83 & 17.45 & 3.00 & 2,306 & 38.40 & 11.8 & 0.33 & $<0.2$ & -283.00 & -- & Pumping rate decreased to 2.61 . \\
\hline $12: 15$ & 301.47 & 100.12 & 2.63 & 373 & 0.87 & 12.83 & 4.62 & 2,087 & 39.36 & 11.8 & 0.30 & $<0.2$ & -288.60 & -- & \\
\hline $12: 20$ & 294.34 & 92.99 & 2.50 & 386 & 0.90 & 14.60 & 4.62 & 2,181 & 31.43 & 11.8 & 0.23 & $<0.2$ & -294.00 & -- & \\
\hline $12: 25$ & 287.15 & 85.80 & 2.58 & 399 & 0.93 & 14.52 & 4.62 & 1,930 & 28.00 & 11.7 & 0.21 & $<0.2$ & -296.10 & -- & \\
\hline $12: 30$ & 281.73 & 80.38 & 2.58 & 412 & 0.96 & 14.55 & 4.62 & 1,831 & 22.98 & 11.6 & 0.17 & $<0.2$ & -299.40 & 1.95 & \\
\hline $12: 35$ & 278.47 & 77.12 & 2.60 & 425 & 0.99 & 14.45 & 1.77 & 1,812 & 18.75 & 11.6 & 0.21 & $<0.2$ & -302.20 & -- & \\
\hline $12: 40$ & 278.48 & 77.13 & 2.68 & 438 & 1.02 & 14.31 & 0.29 & 1,735 & 23.50 & 11.6 & 0.21 & $<0.2$ & -303.90 & -- & \\
\hline $12: 45$ & 273.66 & 72.31 & 2.52 & 451 & 1.05 & 15.11 & 0.80 & 1,763 & 10.75 & 11.5 & 0.16 & $<0.2$ & -307.50 & -- & \\
\hline $12: 50$ & 271.89 & 70.54 & 2.56 & 463 & 1.08 & 14.54 & 0.80 & 1,751 & 5.40 & 11.5 & 0.10 & $<0.2$ & -310.30 & -- & \\
\hline
\end{tabular}


Table 4. Field water-quality properties measured during purge of monitoring well MW01 near Pavillion, Wyoming, April 2012.-Continued

[Highlighted value indicates property met purge criteria ${ }^{1}$ for last five measurements. $\mathrm{ft}$, feet; BMP, below measuring point; gal/min, gallons per minute; ${ }^{\circ} \mathrm{C}$, degrees Celsius; $\mathrm{SC}$, specific conductance at 25 degrees Celsius; $\mu \mathrm{S} / \mathrm{cm}$, microsiemens per centimeter; DO, dissolved oxygen; $\mathrm{mg} / \mathrm{L}$, milligrams per liter; ORP, oxidation reduction potential; mV, millivolts; NTRU, nephelometric turbidity ratio units; --, no data; $<$, less than]

\begin{tabular}{|c|c|c|c|c|c|c|c|c|c|c|c|c|c|c|c|}
\hline Time & $\begin{array}{c}\text { Water } \\
\text { level } \\
\text { (ft BMP) }\end{array}$ & $\begin{array}{l}\text { Draw } \\
\text { down } \\
\text { (ft) }\end{array}$ & $\begin{array}{l}\text { Pumping } \\
\text { rate } \\
\text { (gal } / \mathrm{min} \text { ) }\end{array}$ & $\begin{array}{l}\text { Volume } \\
\text { (gallons) }\end{array}$ & $\begin{array}{l}\text { Borehole } \\
\text { volumes }\end{array}$ & $\begin{array}{c}\text { Water } \\
\text { Temper- } \\
\text { ature } \\
\left({ }^{\circ} \mathrm{C}\right)\end{array}$ & $\begin{array}{c}\text { Variability }^{2} \\
\text { of last } 5 \\
\text { temperature } \\
\text { measure- } \\
\text { ments }\end{array}$ & $\begin{array}{l}\text { SC } \\
(\mu \mathrm{S} / \\
\mathrm{cm})\end{array}$ & $\begin{array}{c}\text { Variability }^{3} \\
\text { of last } 5 \text { SC } \\
\text { measure- } \\
\text { ments } \\
\text { (percent) }\end{array}$ & $\begin{array}{c}\mathrm{pH} \\
\text { (standard } \\
\text { units) }\end{array}$ & $\begin{array}{c}\text { Vari- } \\
\text { ability }\end{array}$ & $\begin{array}{c}\text { DO } \\
\text { (mg/L) }\end{array}$ & $\begin{array}{l}\text { ORP } \\
(\mathrm{mV})\end{array}$ & $\begin{array}{c}\text { Turbidity } \\
\text { (NTRU) }\end{array}$ & Comments \\
\hline $12: 55$ & 270.84 & 69.49 & 2.59 & 476 & 1.11 & 14.53 & 0.80 & 1,757 & 4.37 & 11.5 & 0.06 & $<0.2$ & -312.70 & -- & \\
\hline 13:00 & 269.96 & 68.61 & 2.65 & 490 & 1.14 & 15.09 & 0.80 & 1,701 & 3.56 & 11.5 & 0.05 & $<0.2$ & -316.30 & -- & \\
\hline 13:05 & 269.24 & 67.89 & 2.55 & 502 & 1.17 & 14.86 & 0.58 & 1,704 & 3.57 & 11.5 & 0.03 & $<0.2$ & -318.40 & -- & \\
\hline $13: 12$ & 268.41 & 67.06 & 2.57 & 520 & 1.21 & 14.18 & 0.91 & 1,700 & 3.31 & 11.5 & 0.04 & $<0.2$ & -319.90 & 1.22 & \\
\hline $13: 15$ & 268.24 & 66.89 & 2.59 & 528 & 1.23 & 14.19 & 0.91 & 1,737 & 3.31 & 11.5 & 0.03 & $<0.2$ & -320.70 & -- & \\
\hline $13: 31$ & 267.92 & 66.57 & 2.58 & 569 & 1.33 & 14.57 & 0.91 & 1,665 & 4.23 & 11.5 & 0.05 & $<0.2$ & -328.10 & -- & \\
\hline $13: 40$ & 266.64 & 65.29 & 2.62 & 593 & 1.38 & 15.04 & 0.86 & 1,657 & 4.73 & 11.5 & 0.06 & $<0.2$ & -335.50 & -- & \\
\hline $13: 48$ & 266.42 & 65.07 & 2.52 & 613 & 1.43 & 14.89 & 0.86 & 1,635 & 6.08 & 11.4 & 0.08 & $<0.2$ & -336.70 & -- & \\
\hline 13:56 & 265.21 & 63.86 & 2.63 & 634 & 1.48 & 15.54 & 1.35 & 1,642 & 6.12 & 11.4 & 0.10 & $<0.2$ & -340.20 & -- & \\
\hline 14:10 & 266.21 & 64.86 & 2.46 & 669 & 1.56 & 14.99 & 0.97 & 1,621 & 2.68 & 11.4 & 0.10 & $<0.2$ & -343.70 & -- & Collection of environmental sample 1 began. \\
\hline $14: 20$ & 266.37 & 65.02 & 2.32 & 692 & 1.61 & 15.77 & 0.88 & 1,602 & 3.37 & 11.3 & 0.12 & $<0.2$ & -347.60 & -- & \\
\hline $14: 30$ & 261.41 & 60.06 & 2.18 & 714 & 1.66 & 15.45 & 0.88 & 1,566 & 4.71 & 11.3 & 0.12 & $<0.2$ & -349.80 & -- & \\
\hline $14: 45$ & 268.03 & 66.68 & 2.63 & 753 & 1.76 & 15.47 & 0.78 & 1,519 & 7.74 & 11.3 & 0.16 & $<0.2$ & -355.50 & -- & \\
\hline $15: 15$ & 268.56 & 67.21 & 2.63 & 832 & 1.94 & 14.92 & 0.85 & 1,459 & 10.43 & 11.2 & 0.15 & $<0.2$ & -360.80 & -- & \\
\hline $15: 30$ & 268.50 & 67.15 & 2.67 & 872 & 2.03 & 14.81 & 0.96 & 1,442 & 10.54 & 11.2 & 0.15 & $<0.2$ & -364.40 & -- & \\
\hline $15: 45$ & 268.60 & 67.25 & 2.59 & 911 & 2.12 & 14.88 & 0.66 & 1,455 & 8.33 & 11.1 & 0.18 & $<0.2$ & -368.40 & -- & \\
\hline 16:00 & 269.94 & 68.59 & 2.70 & 951 & 2.22 & 15.10 & 0.66 & 1,458 & 5.25 & 11.1 & 0.18 & $<0.2$ & -371.40 & -- & \\
\hline $16: 15$ & 269.00 & 67.65 & 2.67 & 991 & 2.31 & 15.34 & 0.53 & 1,401 & 4.02 & 11.0 & 0.18 & $<0.2$ & -374.90 & -- & \\
\hline $16: 30$ & 269.22 & 67.87 & 2.30 & 1,026 & 2.39 & 15.39 & 0.58 & 1,426 & 3.97 & 11.0 & 0.20 & $<0.2$ & -377.80 & -- & \\
\hline $16: 45$ & 269.33 & 67.98 & 2.67 & 1,066 & 2.48 & 15.14 & 0.51 & 1,401 & 3.99 & 11.0 & 0.17 & $<0.2$ & -380.30 & -- & \\
\hline $17: 00$ & 269.55 & 68.20 & 2.59 & 1,105 & 2.58 & 15.05 & 0.34 & 1,403 & 4.02 & 10.9 & 0.16 & $<0.2$ & -382.20 & -- & \\
\hline $17: 15$ & 269.83 & 68.48 & 2.23 & 1,138 & 2.65 & 15.31 & 0.34 & 1,416 & 1.77 & 10.9 & 0.17 & $<0.2$ & -384.20 & -- & \\
\hline $17: 30$ & 269.93 & 68.58 & 2.58 & 1,177 & 2.74 & 15.10 & 0.34 & 1,396 & 2.13 & 10.8 & 0.15 & $<0.2$ & -385.80 & -- & \\
\hline $17: 35$ & 269.88 & 68.53 & 2.52 & 1,190 & 2.77 & 15.04 & 0.27 & 1,380 & 2.57 & 10.8 & 0.15 & $<0.2$ & -385.50 & -- & \\
\hline $17: 40$ & 269.82 & 68.47 & 2.61 & 1,203 & 2.80 & 15.08 & 0.27 & 1,392 & 2.58 & 10.8 & 0.11 & $<0.2$ & -386.20 & -- & \\
\hline $17: 45$ & 269.99 & 68.64 & 2.57 & 1,215 & 2.83 & 15.02 & 0.29 & 1,393 & 2.58 & 10.8 & 0.07 & $<0.2$ & -387.40 & -- & \\
\hline $17: 50$ & 269.98 & 68.63 & 2.57 & 1,228 & 2.86 & 14.96 & 0.14 & 1,398 & 1.29 & 10.8 & 0.03 & $<0.2$ & -389.10 & -- & \\
\hline $17: 55$ & 270.04 & 68.69 & 2.62 & 1,241 & 2.89 & 15.01 & 0.12 & 1,378 & 1.44 & 10.8 & 0.03 & $<0.2$ & -388.40 & -- & \\
\hline 18:00 & 270.04 & 68.69 & 2.44 & 1,254 & 2.92 & 15.09 & 0.13 & 1,373 & 1.80 & 10.7 & 0.06 & $<0.2$ & -388.60 & -- & \\
\hline 18:05 & 270.09 & 68.74 & 2.59 & 1,267 & 2.95 & 14.86 & 0.23 & 1,380 & 1.81 & 10.7 & 0.06 & $<0.2$ & -388.90 & -- & \\
\hline $18: 10$ & 270.15 & 68.80 & 2.47 & 1,279 & 2.98 & 14.93 & 0.23 & 1,379 & 1.81 & 10.7 & 0.06 & $<0.2$ & -390.00 & -- & \\
\hline $18: 15$ & 270.15 & 68.80 & 2.61 & 1,292 & 3.01 & 14.86 & 0.23 & 1,373 & 0.51 & 10.7 & 0.07 & $<0.2$ & -389.80 & -- & Collection of environmental sample 2 began. \\
\hline $18: 25$ & 270.31 & 68.96 & 2.42 & 1,316 & 3.07 & 14.58 & 0.51 & 1,379 & 0.51 & 10.7 & 0.05 & $<0.2$ & -389.90 & -- & \\
\hline $18: 35$ & 270.42 & 69.07 & 2.09 & 1,337 & 3.12 & 14.71 & 0.35 & 1,383 & 0.73 & 10.7 & 0.07 & $<0.2$ & -391.50 & -- & \\
\hline $18: 45$ & 270.31 & 68.96 & 2.49 & 1,362 & 3.17 & 14.71 & 0.35 & 1,382 & 0.73 & 10.7 & 0.08 & $<0.2$ & -393.00 & -- & \\
\hline 19:00 & 270.15 & 68.80 & 2.10 & 1,393 & 3.25 & 15.07 & 0.49 & 1,375 & 0.73 & 10.6 & 0.12 & $<0.2$ & -392.90 & -- & \\
\hline 19:15 & 270.09 & 68.74 & 2.39 & 1,429 & 3.33 & 14.74 & 0.49 & 1,385 & 0.72 & 10.6 & 0.11 & $<0.2$ & -394.20 & -- & \\
\hline $19: 27$ & 270.19 & 68.84 & 2.73 & 1,462 & 3.41 & 14.58 & 0.49 & 1,373 & 0.87 & 10.6 & 0.10 & $<0.2$ & -395.90 & -- & Pump shut off. \\
\hline
\end{tabular}

${ }^{1}$ Purge criteria for this sampling program are listed in table 1.

${ }^{2}$ Variability for this property was calculated by subtracting the minimum of the last five measurements from the maximum of the last five measurements.

${ }^{3}$ Variability for this property was calculated by subtracting the minimum of the last five measurements from the maximum of the last five measurements and dividing this result by the average of the last five measurements. The result is then multiplied by 100 . 


\section{Redevelopment of Monitoring Well MW02 and Collection of Associated Quality-Control Samples}

In an attempt to increase well yield, monitoring well MW02 was redeveloped by the USGS during the week of April 30, 2012. Redevelopment included surging the well and bailing from the top and the bottom of the water column. As part of the redevelopment effort, potable water obtained from the public water supply of the city of Riverton was added to well MW02 before pump removal in order to decrease methane concentrations in the well and reduce the explosion hazard. A sample of the Riverton water added to the well was collected to characterize its chemical quality. The sample was collected from a sampling port in the pumping line while water was recirculated through the pump, hose, and tank used by the driller to add water to well MW02. This water, identified as Riverton development water, was analyzed for the chemical constituents listed in table 3. Documentation of field activities, including instrumentation and sampling logs; ASR forms COC records; and photographs of field activities are in appendixes 4 (figs. 4.1-4.7), 5 (figs. 5.1-5.2), and 6 (figs. 6.1-6.6), respectively.

During redevelopment of well MW02, a downhole camera was used to view and evaluate the condition of the well casing and screen. Before deploying the downhole camera, an equipment blank was collected for the camera. This camera blank was collected by pouring blank water over the camera and collecting it in sample containers. The camera blank samples were analyzed for the chemical constituents listed in table 3.

\section{Analytical Methods}

Nine laboratories analyzed samples for this study: TestAmerica Laboratories in Arvada, Colorado, Woods Hole Oceanographic Institute-National Ocean Sciences Accelerator Mass Spectrometry Facility in Woods Hole, Massachusetts, and Eberline Laboratories in Richmond, Calif., under contract with the USGS National Water Quality Laboratory (NWQL) in Lakewood, Colorado; four USGS laboratories (NWQL, Reston Chlorofluorocarbon Laboratory, Reston Stable Isotope Laboratory, and Menlo Park Tritium Laboratory); Lamont-Doherty Earth Observatory Noble Gas Laboratory in Palisades, New York (contracted by the Reston Chlorofluorocarbon Laboratory); and Isotech Laboratories, Inc., in Champaign, Illinios. Analytical methods for each laboratory are listed in table 3. A list of analytical methods and method references are provided in table 3 of the SAP (Wright and McMahon, 2012).

\section{Quality-Control Sample Collection and Data Analysis}

Analytical results from QC samples collected in the field and prepared in the laboratories were used to assess the quality of data reported for environmental samples. Data from QC samples collected at well MW01 (table 2) were evaluated to determine whether qualification of environmental sample analytical data was warranted before use in interpretive reports. Specifically, QC sample results were used to evaluate the extent to which environmental data were affected by bias (for example, contamination of samples in the field or laboratory) and were used to evaluate the variability inherent to sample collection and laboratory analyses. The QC samples used to estimate bias included a variety of blanks, prepared with water that is certified free of analytes of interest (blank water), and samples that were spiked with known concentrations of target analytes. Variability was estimated by collecting replicate samples in the field and comparing the analytical results to results for the primary environmental samples.

\section{Blank Samples}

Procedures for the collection of field QC samples included in this report are described in the SAP (Wright and McMahon, 2012). Four types of blank samples were submitted to TestAmerica Laboratories for analysis: source-solution, ambient, field, and trip blanks. Each of these blank samples could have been subjected to contamination during various stages of sample collection, processing, shipping, and analysis. In addition, TestAmerica Laboratories provided results for a laboratory blank sample, prepared with reagent water. A quantified result in any blank sample was considered evidence that contamination could have affected environmental sample analytical results; consequently, analytical results for the two primary samples (environmental sample 1 and environmental sample 2) and associated replicates were compared to the maximum quantified concentration in the five blanks. In accordance with USEPA guidance (U.S. Environmental Protection Agency, 1989, p. 5-17), a reported concentration in an environmental sample that is less than five times the concentration in a related blank sample should be treated as a nondetection, and the reported concentration should be considered the quantitation limit for the analyte in that sample. These analytes are identified by a project data qualifier in the data tables (tables 5-14) presented in this report. Overall, results were qualified for 18 constituents detected in the 2 primary environmental samples. All these qualifications were based on quantified results in laboratory, ambient, or field blank samples; results for all analyses of source-solution and trip blank samples were less than method detection limits. For 13 of the constituents detected in blank samples, quantified concentrations were reported for more than 1 type of blank sample.

\section{Laboratory Spike Samples}

Laboratory reagent and matrix spike samples also contribute to evaluation of analytical bias that can affect results. This bias can be evaluated by determining the recovery of a known amount of an analyte that is spiked into reagent water or sample matrix (water collected at the field site). For this study, duplicate matrix spike samples were collected in addition to environmental sample 1. TestAmerica Laboratories spiked 
these matrix samples, as well as duplicate reagent samples, at the laboratory. Analyte recovery from matrix spike samples was calculated by adjusting for background concentration in the environmental sample using the following equation:

$$
R=\frac{C_{m s}-C_{e n v}}{C_{\text {spiked }}} \times 100
$$

where

$R=$ analyte recovery, in percent

$C_{m s}=$ concentration of the analyte in the matrix spike sample,

$C_{e n v}=$ background concentration of the analyte in the environmental sample,

and $C_{\text {spiked }}=$ concentration of the spiked analyte expected in the matrix sample.

All matrix spikes collected from well MW01 were associated with environmental sample 1, so analyte concentrations in that sample were used as background concentrations in recovery calculations. Analyte recovery in the laboratory reagent samples was calculated simply as the ratio of the analyte concentration in the matrix spike sample to the expected concentration of the spiked analyte, because no background concentrations were present.

Control limits on acceptable recovery are established by the analyzing laboratory for each analyte. Recoveries outside acceptable limits are identified in the laboratory data qualifiers column in the data tables presented in this report. In addition, the project data qualifiers identify analytes with recoveries less than 70 percent or greater than 130 percent. Although these recoveries do not necessarily correspond to control limits, they provide a consistent identification of analytes for which results might be low or high because of analytical bias. Another laboratory data qualifier identifies matrix samples for which the background concentration exceeds four times the spiked concentration, in which case recovery is uncertain and control limits are not applicable. In these cases, project data qualifiers for low and high bias also were considered inapplicable. Finally, project data qualifiers for high bias were not applied if the analyte concentration was censored (reported as less than the method detection limit), because, in this case, the potential bias did not have a measurable effect. Overall, the low-bias qualifier was applied to 10 constituents and the high-bias qualifier was applied to 4 constituents.

\section{Replicate Samples}

Potential variability in reported analyte concentrations is estimated by comparison of replicate samples. Replicates were collected for both environmental samples 1 and 2 from well MW01, although the replicate for environmental sample 2 was not analyzed for all analytes. Variability for each analyte is estimated as the relative percent difference (RPD) between the two replicates:

$$
R P D=\frac{\left|C_{e n v}-C_{r e p}\right|}{\left(C_{e n v}+C_{r e p}\right) / 2} \times 100
$$

where

$\left|C_{e n v}-C_{r e p}\right|=$ absolute value of the difference between concentrations of the analyte in the primary environmental sample and the replicate sample, and $\left(C_{e n v}+C_{r e p}\right) / 2=$ mean concentration of the analyte in the primary environmental sample and replicate sample.

The RPD cannot be calculated if the concentration is censored in either or both samples. For this study, RPD values greater than 20 percent were considered indicative that analytical results might be affected by high variability. Analytes with RPDs outside this criterion are identified with a project data qualifier on the primary environmental sample and replicate sample in the relevant data tables. Overall, eight constituents were qualified because of high variability in environmental sample 1, and three constituents were qualified in environmental sample 2 .

In summary, four criteria for inclusion of project data qualifiers were applied to analytes in environmental samples and replicates:

1. Contamination bias: quantified concentration was less than five times the maximum concentration in a blank sample,

2. Recovery bias: potential low bias - recovery was less than 70 percent in one or more spike samples,

3. Recovery bias: potential high bias - recovery was greater than 130 percent in one or more spike samples (applied only to constituents with quantified results), and

4. Variability: RPD between the environmental sample and replicate sample was greater than 20 percent.

\section{Major-Ion Balances}

Major-ion data were quality assured by calculating a cation-anion balance. The sum of concentrations of dissolved cations in milliequivalents per liter should equal the sum of concentrations of dissolved anions in milliequivalents per liter (Hem, 1985). The percent difference between the sum of concentrations of cations and anions in milliequivalents per liter was calculated using equation 3 .

$$
\text { Percent difference }=\left(\frac{\text { sum of dissolved cations-sum of dissolved anions }}{\text { sum of dissolved cations }+ \text { sum of dissolved anions }}\right) \times 100
$$

\section{Groundwater-Quality Data}

Results from analyses of groundwater and QC samples collected from monitoring well MW01 are presented in tables 5 through 11. Many organic constituents were collected in duplicate (one set of bottles preserved with $\mathrm{HCl}$ and a second 
bottle set unpreserved). To identify the preservation method used for each of the organic constituents, a column was added to tables 7 through 10 to indicate whether preservative was added to the sample bottle. Constituent concentrations for samples that were preserved using $\mathrm{HCl}$ are identified in the "preservative added to bottle" column with Yes, and constituent concentrations for samples that were unpreserved are identified with No. The QC samples collected for well MW02 are included in tables 12 through 14 . Analytical results for tritium, some noble gasses (neon, krypton, and xenon), and helium isotope ratios had not been received as of August 17, 2012, and are not presented in this report; when received from the laboratories, analytical results for these constituents will be available through the USGS National Water Information System (NWIS) Web Interface, accessible at $h t t p: / / w a t e r d a t a$. usgs.gov/wy/nwis/qw. Analytical results for tritium have been added to table 11 . The analysis for some noble gasses (neon, krypton, xenon) and helium isotope ratios were not completed due to a compromised sample container. Hence, analytical results for neon, krypton, xenon and helium isotope ratios are not available. The USGS 15-digit site number, sample collection dates, and times needed to access water-quality data using the NWIS Web Interface are listed in table 2.

\section{Monitoring Well MW01}

\section{Field Water-Quality Properties and Hydrologic Data Measured During the Well Purge}

Field water-quality properties and basic hydrologic data measured during the purge of monitoring well MW01 are listed in table 4 . Field water-quality properties and basic hydrologic data were measured at regular intervals and recorded on a purge log (see appendix 1, figs. 1.16-1.20). Water levels and pumping rates were measured to calculate water-level drawdown in response to pumping and the total volume of water purged from the well. The water level in well MW01 during the purge and sampling is shown in figure $2 A$. Variability of water temperature, $\mathrm{SC}$, and $\mathrm{pH}$ of the pumped water during purging also were evaluated (table 4). Values of specific conductance and $\mathrm{pH}$ are shown in relation to purge volume in figures $2 B$ and $2 C$, respectively. A graph of water temperature is not included in this report because these data were affected by heating in the sampling line between the well and the point of measurement; therefore, they do not represent conditions in the well.

The borehole volume of water purged from well MW01 was calculated using equation 2 in the SAP (Wright and McMahon, 2012); one borehole volume was about 429 gallons. Sample collection began after this amount of water had been pumped and as soon as both $\mathrm{SC}$ and $\mathrm{pH}$ met stabilization criteria. Stabilization criteria were met and collection of environmental sample began at time 14:10 on April 24, 2012 (table 4), and although SC only met the stabilization criteria briefly, sampling had already begun. The sample time associated with environmental sample 1 (time 13:30 on April 24, 2012; table 2) had been assigned to the sample in advance, in anticipation of sample collection starting after one borehole volume had been purged from the well. Collection of a water sample from MW01 after purging one borehole volume of water had been a stated objective in the SAP (Wright and McMahon, 2012). Collection of environmental sample 1 and associated QC samples included the filling of 214 sample containers, equaling collection of approximately 18 gallons of water, and took more than 2 hours to complete.

\section{Field Water-Quality Properties and Inorganic and Radioactive Constituents}

Concentrations of inorganic constituents, including naturally occurring radioactive constituents (radon, radium-226, and radium-228), in the environmental samples and replicates collected from well MW01 are listed in table 5. The data for blank and spike samples are listed in table 6 .

Samples were titrated in the field to determine alkalinity (filtered sample) and acid-neutralizing capacity (unfiltered sample). Based on these titration data, the USGS alkalinity calculator, which is described in Chapter A6, Section 6.6.5.C of the USGS National Field Manual (Wilde, variously dated), was used to calculate concentrations of bicarbonate, carbonate, and hydroxide.

Ionic charge balances calculated for environmental sample 1, sample 1 replicate, and environmental sample 2 were $-1.94,0.03$, and 0.23 percent, respectively. An ionic charge balance within plus or minus 5 percent is considered acceptable (Clesceri and others, 1998). An ionic charge balance was not calculated for the sample 2 replicate because major ions were not included in the analysis of that sample set.

Of the inorganic constituents detected in the environmental samples (table 5), sodium and sulfate were measured at the highest concentrations. Six detected inorganic constituents (filtered magnesium and unfiltered ammonia, phosphorus, cadmium, thallium, and uranium) were measured at concentrations less than five times the maximum concentration detected in the blank samples. Quantified concentrations for several constituents in tables 5 and 6 include an "E" remark because the concentrations are less than the reporting level, but equal to or greater than the method detection limit. Most of the nondetected inorganic constituents are trace elements (for example, beryllium, chromium, cobalt, copper, lead, mercury, selenium, silver, and zinc). 

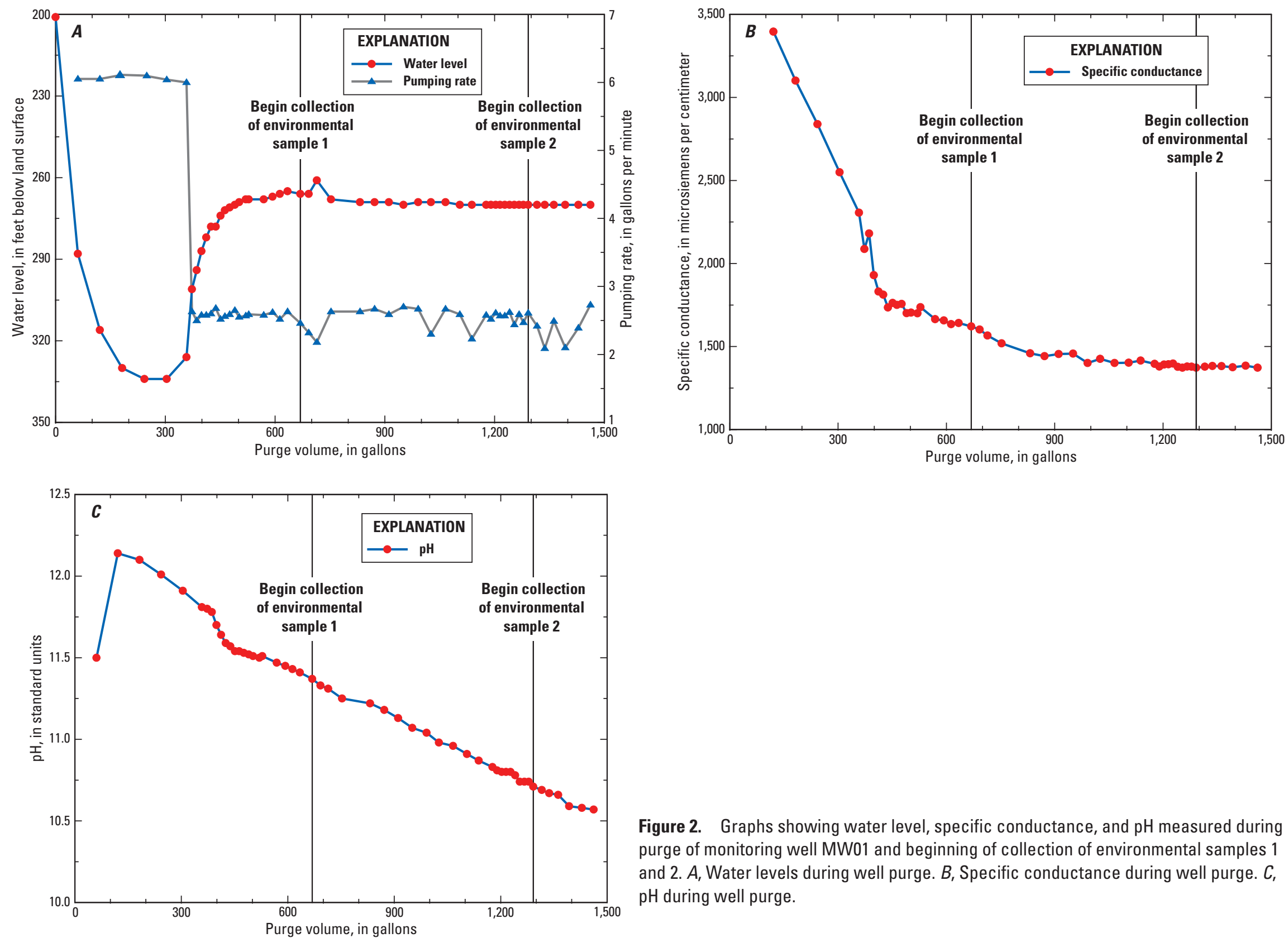

Figure 2. Graphs showing water level, specific conductance, and pH measured during purge of monitoring well MW01 and beginning of collection of environmental samples 1 and 2. $A$, Water levels during well purge. $B$, Specific conductance during well purge. $C$, $\mathrm{pH}$ during well purge. 
$\left[R P D\right.$, relative percent difference; $\mu \mathrm{s} / \mathrm{cm}$, microsiemens per centimeter; $\mathrm{mg} / \mathrm{L}$, milligrams per liter; $\mathrm{CaCO}_{3}$, calcium carbonate; $\mu \mathrm{g} / \mathrm{L}$, micrograms per liter; $\mathrm{pCi} / \mathrm{L}$, picocuries per liter; $\mathrm{N}$, value was not determined; --, not applicable]

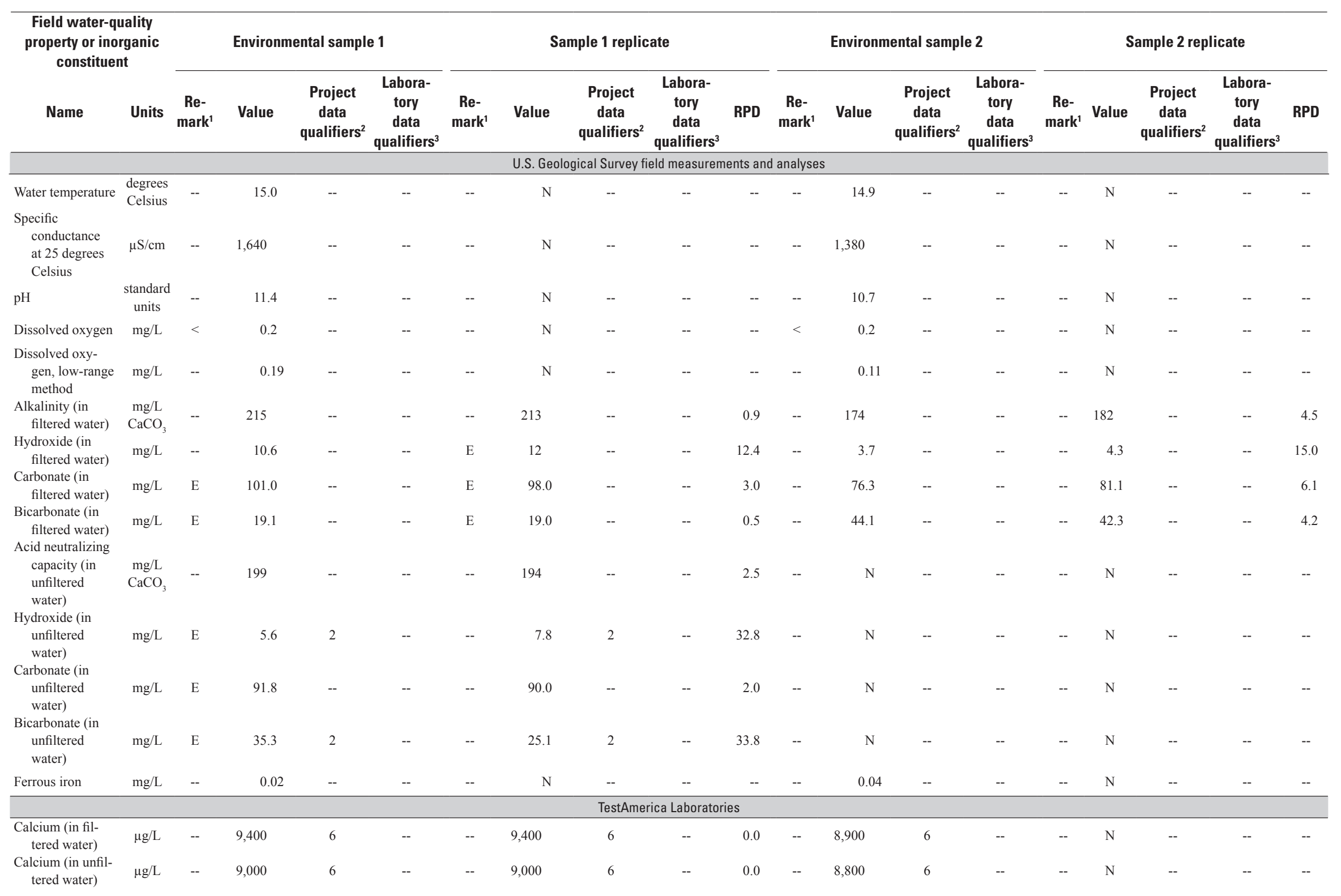


Table 5. Field water-quality properties and inorganic constituents in environmental samples collected from monitoring well MW01 near Pavillion, Wyoming, April 2012.-

\section{Continued}

$\left[R P D\right.$, relative percent difference; $\mu \mathrm{s} / \mathrm{cm}$, microsiemens per centimeter; $\mathrm{mg} / \mathrm{L}$, milligrams per liter; $\mathrm{CaCO}_{3}$, calcium carbonate; $\mu \mathrm{g} / \mathrm{L}$, micrograms per liter; $\mathrm{pCi} / \mathrm{L}$, picocuries per liter; $\mathrm{N}$, value was not determined; --, not applicable]

\begin{tabular}{|c|c|c|c|c|c|c|c|c|c|c|c|c|c|c|c|c|c|c|c|}
\hline \multicolumn{2}{|c|}{$\begin{array}{c}\text { Field water-quality } \\
\text { property or inorganic } \\
\text { constituent }\end{array}$} & \multicolumn{4}{|c|}{ Environmental sample 1} & \multicolumn{5}{|c|}{ Sample 1 replicate } & \multicolumn{4}{|c|}{ Environmental sample 2} & \multicolumn{5}{|c|}{ Sample 2 replicate } \\
\hline Name & Units & $\begin{array}{c}\text { Re- } \\
\text { mark' }^{1}\end{array}$ & Value & $\begin{array}{c}\text { Project } \\
\text { data } \\
\text { qualifiers }^{2}\end{array}$ & $\begin{array}{c}\text { Labora- } \\
\text { tory } \\
\text { data } \\
\text { qualifiers }^{3}\end{array}$ & $\begin{array}{c}\text { Re- } \\
\text { mark' }^{1}\end{array}$ & Value & $\begin{array}{c}\text { Project } \\
\text { data } \\
\text { qualifiers }^{2}\end{array}$ & $\begin{array}{l}\text { Labora- } \\
\text { tory } \\
\text { data } \\
\text { qualifiers }^{3}\end{array}$ & RPD & $\begin{array}{l}\text { Re- } \\
\text { mark }^{1}\end{array}$ & Value & $\begin{array}{c}\text { Project } \\
\text { data } \\
\text { qualifiers }^{2}\end{array}$ & $\begin{array}{c}\text { Labora- } \\
\text { tory } \\
\text { data } \\
\text { qualifiers }^{3}\end{array}$ & $\begin{array}{c}\text { Re- } \\
\text { mark' }^{1}\end{array}$ & Value & $\begin{array}{l}\text { Project } \\
\text { data } \\
\text { qualifiers }{ }^{2}\end{array}$ & $\begin{array}{l}\text { Labora- } \\
\text { tory } \\
\text { data } \\
\text { qualifiers }^{3}\end{array}$ & RPD \\
\hline $\begin{array}{l}\text { Magnesium (in } \\
\text { filtered water) }\end{array}$ & $\mu \mathrm{g} / \mathrm{L}$ & $\mathrm{E}$ & 140 & 1 & $\mathrm{~J}$ & $\mathrm{E}$ & 150 & 1,6 & $\mathrm{~J}$ & 6.9 & E & 170 & 1 & $\mathrm{~J}$ & -- & $\mathrm{N}$ & & -- & -- \\
\hline $\begin{array}{l}\text { Magnesium (in } \\
\text { unfiltered } \\
\text { water) }\end{array}$ & $\mu \mathrm{g} / \mathrm{L}$ & E & 140 & -- & $\mathrm{J}$ & E & 140 & 6 & $\mathrm{~J}$ & 0.0 & E & 180 & -- & $\mathrm{J}$ & -- & $\mathrm{N}$ & -- & -- & -- \\
\hline $\begin{array}{l}\text { Sodium (in fil- } \\
\text { tered water) }\end{array}$ & $\mu \mathrm{g} / \mathrm{L}$ & -- & 270,000 & -- & B & -- & 280,000 & 6 & B & 3.6 & -- & 280,000 & 6 & B & -- & $\mathrm{N}$ & -- & -- & -- \\
\hline $\begin{array}{l}\text { Sodium (in unfil- } \\
\text { tered water) }\end{array}$ & $\mu \mathrm{g} / \mathrm{L}$ & -- & 270,000 & -- & -- & -- & 270,000 & 6 & -- & 0.0 & -- & 270,000 & 6 & -- & -- & $\mathrm{N}$ & -- & -- & -- \\
\hline $\begin{array}{l}\text { Potassium (in } \\
\text { filtered water) }\end{array}$ & $\mu \mathrm{g} / \mathrm{L}$ & -- & 15,000 & -- & -- & -- & 16,000 & 6 & -- & 6.5 & -- & 13,000 & -- & -- & -- & $\mathrm{N}$ & -- & -- & -- \\
\hline $\begin{array}{l}\text { Potassium (in } \\
\text { unfiltered } \\
\text { water) }\end{array}$ & $\mu \mathrm{g} / \mathrm{L}$ & -- & 15,000 & -- & -- & -- & 15,000 & 6 & -- & 0.0 & -- & 13,000 & -- & -- & -- & $\mathrm{N}$ & -- & -- & -- \\
\hline $\begin{array}{l}\text { Chloride (in fil- } \\
\text { tered water) }\end{array}$ & $\mathrm{mg} / \mathrm{L}$ & -- & 26 & -- & -- & -- & 26 & -- & -- & 0.0 & -- & 27 & -- & -- & -- & $\mathrm{N}$ & -- & -- & -- \\
\hline $\begin{array}{l}\text { Sulfate (in filtered } \\
\text { water) }\end{array}$ & $\mathrm{mg} / \mathrm{L}$ & -- & 380 & -- & -- & -- & 380 & -- & -- & 0.0 & -- & 410 & -- & -- & -- & $\mathrm{N}$ & -- & -- & -- \\
\hline $\begin{array}{l}\text { Bromide (in fil- } \\
\text { tered water) }\end{array}$ & $\mathrm{mg} / \mathrm{L}$ & E & 0.2 & -- & $\mathrm{J}$ & E & 0.2 & -- & $\mathrm{J}$ & 0.0 & E & 0.2 & -- & $\mathrm{J}$ & -- & $\mathrm{N}$ & -- & -- & -- \\
\hline $\begin{array}{l}\text { Fluoride (in fil- } \\
\text { tered water) }\end{array}$ & $\mathrm{mg} / \mathrm{L}$ & -- & 3 & -- & -- & -- & 3 & -- & -- & 3.3 & -- & 3 & -- & -- & -- & $\mathrm{N}$ & -- & -- & -- \\
\hline $\begin{array}{l}\text { Silicon (in filtered } \\
\text { water) }\end{array}$ & $\mu \mathrm{g} / \mathrm{L}$ & -- & 9,000 & -- & -- & -- & 8,700 & -- & -- & 3.4 & -- & 6,400 & -- & -- & -- & $\mathrm{N}$ & -- & -- & -- \\
\hline $\begin{array}{l}\text { Silica (in unfil- } \\
\text { tered water) }\end{array}$ & $\mu \mathrm{g} / \mathrm{L}$ & -- & 18,000 & -- & B & -- & 18,000 & -- & B & 0.0 & -- & 13,000 & -- & B & -- & $\mathrm{N}$ & -- & -- & -- \\
\hline $\begin{array}{l}\text { Dissolved solids } \\
\quad \text { (in filtered } \\
\text { water) }\end{array}$ & $\mathrm{mg} / \mathrm{L}$ & -- & 800 & -- & -- & -- & 800 & -- & -- & 0.0 & -- & 800 & -- & -- & -- & $\mathrm{N}$ & -- & -- & -- \\
\hline $\begin{array}{l}\text { Ammonia as } \\
\text { nitrogen (in } \\
\text { unfiltered } \\
\text { water) }\end{array}$ & $\mathrm{mg} / \mathrm{L}$ & -- & 0.79 & 1,3 & B & E & 0.71 & 1,3 & B & 10.7 & E & 0.34 & 1,3 & B & -- & $\mathrm{N}$ & -- & -- & -- \\
\hline $\begin{array}{l}\text { Nitrate-plus- } \\
\text { nitrite as } \\
\text { nitrogen (in } \\
\text { unfiltered } \\
\text { water) }\end{array}$ & $\mathrm{mg} / \mathrm{L}$ & $<$ & 0.019 & -- & -- & $<$ & 0.019 & -- & -- & -- & $<$ & 0.02 & -- & -- & -- & $\mathrm{N}$ & -- & -- & -- \\
\hline $\begin{array}{l}\text { Phosphorus (in } \\
\text { filtered water) }\end{array}$ & $\mu \mathrm{g} / \mathrm{L}$ & -- & 57 & 2,3 & -- & -- & 89 & 2,3 & -- & 43.8 & -- & 61 & 3 & -- & -- & $\mathrm{N}$ & -- & -- & -- \\
\hline $\begin{array}{l}\text { Phosphorus (in } \\
\text { unfiltered } \\
\text { water) }\end{array}$ & $\mu \mathrm{g} / \mathrm{L}$ & -- & 100 & 1 & B & -- & 98 & 1 & B & 2.0 & -- & 84 & 1 & B & -- & $\mathrm{N}$ & -- & -- & -- \\
\hline
\end{tabular}


Table 5. Field water-quality properties and inorganic constituents in environmental samples collected from monitoring well MW01 near Pavillion, Wyoming, April 2012.-

Continued

$\left[R P D\right.$, relative percent difference; $\mu \mathrm{s} / \mathrm{cm}$, microsiemens per centimeter; $\mathrm{mg} / \mathrm{L}$, milligrams per liter; $\mathrm{CaCO}_{3}$, calcium carbonate; $\mu \mathrm{g} / \mathrm{L}$, micrograms per liter; $\mathrm{pCi} / \mathrm{L}$, picocuries per liter; $\mathrm{N}$, value was not determined; --, not applicable]

\begin{tabular}{|c|c|c|c|c|c|c|c|c|c|c|c|c|c|c|c|c|c|c|c|}
\hline \multicolumn{2}{|c|}{$\begin{array}{l}\text { Field water-quality } \\
\text { property or inorganic } \\
\text { constituent }\end{array}$} & \multicolumn{4}{|c|}{ Environmental sample 1} & \multicolumn{5}{|c|}{ Sample 1 replicate } & \multicolumn{4}{|c|}{ Environmental sample 2} & \multicolumn{5}{|c|}{ Sample 2 replicate } \\
\hline Name & Units & $\begin{array}{c}\text { Re- } \\
\text { mark'1 }^{1}\end{array}$ & Value & $\begin{array}{c}\text { Project } \\
\text { data } \\
\text { qualifiers }^{2}\end{array}$ & $\begin{array}{c}\text { Labora- } \\
\text { tory } \\
\text { data } \\
\text { qualifiers }^{3} \\
\end{array}$ & $\begin{array}{c}\text { Re- } \\
\text { mark'1 }\end{array}$ & Value & $\begin{array}{l}\text { Project } \\
\text { data } \\
\text { qualifiers }^{2}\end{array}$ & $\begin{array}{l}\text { Labora- } \\
\text { tory } \\
\text { data } \\
\text { qualifiers } \\
\end{array}$ & RPD & $\begin{array}{l}\text { Re- } \\
\text { mark' }^{1}\end{array}$ & Value & $\begin{array}{c}\text { Project } \\
\text { data } \\
\text { qualifiers }^{2}\end{array}$ & $\begin{array}{c}\text { Labora- } \\
\text { tory } \\
\text { data } \\
\text { qualifiers }^{3} \\
\end{array}$ & $\begin{array}{c}\text { Re- } \\
\text { mark' }^{1}\end{array}$ & Value & $\begin{array}{c}\text { Project } \\
\text { data } \\
\text { qualifiers }{ }^{2}\end{array}$ & $\begin{array}{l}\text { Labora- } \\
\text { tory } \\
\text { data } \\
\text { qualifiers }^{3} \\
\end{array}$ & RPD \\
\hline $\begin{array}{l}\text { Dissolved organic } \\
\text { carbon (in } \\
\text { filtered water) }\end{array}$ & $\mathrm{mg} / \mathrm{L}$ & -- & 4.3 & 6 & -- & -- & 4.4 & 6 & -- & 2.3 & -- & 3 & 6 & -- & -- & $\mathrm{N}$ & -- & -- & -- \\
\hline $\begin{array}{l}\text { Total organic } \\
\text { carbon (in } \\
\text { unfiltered } \\
\text { water) }\end{array}$ & $\mathrm{mg} / \mathrm{L}$ & -- & 4.0 & 6 & -- & -- & 4.1 & 6 & -- & 2.5 & -- & 2.9 & 6 & -- & -- & $\mathrm{N}$ & -- & -- & -- \\
\hline $\begin{array}{l}\text { Dissolved inor- } \\
\text { ganic carbon } \\
\text { (in filtered } \\
\text { water) }\end{array}$ & $\mathrm{mg} / \mathrm{L}$ & -- & 20 & -- & -- & -- & 19 & -- & -- & 5.1 & -- & 21 & -- & -- & -- & $\mathrm{N}$ & -- & -- & -- \\
\hline $\begin{array}{l}\text { Total inorganic } \\
\quad \text { carbon (in } \\
\text { unfiltered } \\
\text { water) }\end{array}$ & $\mathrm{mg} / \mathrm{L}$ & -- & 22 & -- & -- & -- & 21 & -- & -- & 4.7 & -- & 22 & -- & -- & -- & $\mathrm{N}$ & -- & -- & -- \\
\hline $\begin{array}{l}\text { Aluminum (in } \\
\text { filtered water) }\end{array}$ & $\mu \mathrm{g} / \mathrm{L}$ & -- & 170 & -- & -- & -- & 170 & -- & -- & 0.0 & -- & 100 & -- & -- & -- & $\mathrm{N}$ & -- & -- & -- \\
\hline $\begin{array}{l}\text { Aluminum (in } \\
\text { unfiltered } \\
\text { water) }\end{array}$ & $\mu \mathrm{g} / \mathrm{L}$ & -- & 170 & -- & -- & -- & 170 & -- & -- & 0.0 & -- & 110 & -- & -- & -- & $\mathrm{N}$ & -- & -- & -- \\
\hline $\begin{array}{l}\text { Antimony (in } \\
\text { filtered water) }\end{array}$ & $\mu \mathrm{g} / \mathrm{L}$ & $<$ & 0.4 & -- & -- & E & 0.54 & 1,6 & $\mathrm{~J}, \wedge, \mathrm{B}$ & -- & $<$ & 0.4 & -- & -- & -- & $\mathrm{N}$ & -- & -- & -- \\
\hline $\begin{array}{l}\text { Antimony (in } \\
\text { unfiltered } \\
\text { water) }\end{array}$ & $\mu \mathrm{g} / \mathrm{L}$ & $<$ & 0.4 & -- & -- & $<$ & 0.4 & 6 & -- & -- & $<$ & 0.4 & -- & -- & -- & $\mathrm{N}$ & -- & -- & -- \\
\hline $\begin{array}{l}\text { Arsenic (in fil- } \\
\text { tered water) }\end{array}$ & $\mu \mathrm{g} / \mathrm{L}$ & E & 0.62 & 6 & $\mathrm{~J}$ & $<$ & 0.33 & -- & -- & -- & $<$ & 0.33 & -- & -- & -- & $\mathrm{N}$ & -- & -- & -- \\
\hline $\begin{array}{l}\text { Arsenic (in unfil- } \\
\text { tered water) }\end{array}$ & $\mu \mathrm{g} / \mathrm{L}$ & E & 0.38 & 2,6 & $\mathrm{~J}$ & E & 0.51 & 2 & $\mathrm{~J}$ & 29.2 & E & 0.48 & -- & $\mathrm{J}$ & -- & $\mathrm{N}$ & -- & -- & -- \\
\hline $\begin{array}{l}\text { Barium (in filtered } \\
\text { water) }\end{array}$ & $\mu \mathrm{g} / \mathrm{L}$ & -- & 23 & 6 & -- & -- & 20 & -- & -- & 14.0 & -- & 21 & -- & -- & -- & $\mathrm{N}$ & - & -- & - \\
\hline $\begin{array}{l}\text { Barium (in unfil- } \\
\text { tered water) }\end{array}$ & $\mu \mathrm{g} / \mathrm{L}$ & -- & 19 & 6 & -- & -- & 20 & -- & -- & 5.1 & -- & 21 & -- & -- & -- & $\mathrm{N}$ & -- & -- & -- \\
\hline $\begin{array}{l}\text { Beryllium (in } \\
\text { filtered water) }\end{array}$ & $\mu \mathrm{g} / \mathrm{L}$ & $<$ & 0.08 & -- & -- & $<$ & 0.08 & -- & -- & -- & $<$ & 0.08 & -- & -- & -- & $\mathrm{N}$ & -- & -- & -- \\
\hline $\begin{array}{l}\text { Beryllium (in } \\
\text { unfiltered } \\
\text { water) }\end{array}$ & $\mu \mathrm{g} / \mathrm{L}$ & $<$ & 0.08 & -- & -- & $<$ & 0.08 & -- & -- & -- & $<$ & 0.08 & -- & -- & -- & $\mathrm{N}$ & -- & -- & -- \\
\hline $\begin{array}{l}\text { Boron (in filtered } \\
\text { water) }\end{array}$ & $\mu \mathrm{g} / \mathrm{L}$ & -- & 130 & -- & -- & -- & 130 & 6 & -- & 0.0 & -- & 120 & 6 & -- & -- & $\mathrm{N}$ & -- & -- & -- \\
\hline $\begin{array}{l}\text { Boron (in unfil- } \\
\text { tered water) }\end{array}$ & $\mu \mathrm{g} / \mathrm{L}$ & -- & 130 & -- & -- & -- & 120 & 6 & -- & 8.0 & -- & 110 & 6 & -- & -- & $\mathrm{N}$ & -- & -- & -- \\
\hline
\end{tabular}


Table 5. Field water-quality properties and inorganic constituents in environmental samples collected from monitoring well MW01 near Pavillion, Wyoming, April 2012.-

\section{Continued}

$\left[R P D\right.$, relative percent difference; $\mu \mathrm{s} / \mathrm{cm}$, microsiemens per centimeter; $\mathrm{mg} / \mathrm{L}$, milligrams per liter; $\mathrm{CaCO}_{3}$, calcium carbonate; $\mu \mathrm{g} / \mathrm{L}$, micrograms per liter; $\mathrm{pCi} / \mathrm{L}$, picocuries per liter; $\mathrm{N}$, value was not determined; --, not applicable]

\begin{tabular}{|c|c|c|c|c|c|c|c|c|c|c|c|c|c|c|c|c|c|c|c|}
\hline \multicolumn{2}{|c|}{$\begin{array}{c}\text { Field water-quality } \\
\text { property or inorganic } \\
\text { constituent }\end{array}$} & \multicolumn{4}{|c|}{ Environmental sample 1} & \multicolumn{5}{|c|}{ Sample 1 replicate } & \multicolumn{4}{|c|}{ Environmental sample 2} & \multicolumn{5}{|c|}{ Sample 2 replicate } \\
\hline Name & Units & $\begin{array}{c}\text { Re- } \\
\text { mark' }^{1}\end{array}$ & Value & $\begin{array}{l}\text { Project } \\
\text { data } \\
\text { qualifiers }\end{array}$ & $\begin{array}{c}\text { Labora- } \\
\text { tory } \\
\text { data } \\
\text { qualifiers }\end{array}$ & $\begin{array}{c}\text { Re- } \\
\text { mark' }^{1}\end{array}$ & Value & $\begin{array}{l}\text { Project } \\
\text { data } \\
\text { qualifiers }\end{array}$ & $\begin{array}{l}\text { Labora- } \\
\text { tory } \\
\text { data } \\
\text { qualifiers }\end{array}$ & RPD & $\begin{array}{l}\text { Re- } \\
\text { mark' }^{1}\end{array}$ & Value & $\begin{array}{c}\text { Project } \\
\text { data } \\
\text { qualifiers }^{2}\end{array}$ & $\begin{array}{c}\text { Labora- } \\
\text { tory } \\
\text { data } \\
\text { qualifiers }^{3}\end{array}$ & $\begin{array}{l}\text { Re- } \\
\text { mark'1 }\end{array}$ & Value & $\begin{array}{c}\text { Project } \\
\text { data } \\
\text { qualifiers }^{2}\end{array}$ & $\begin{array}{l}\text { Labora- } \\
\text { tory } \\
\text { data } \\
\text { qualifiers } \\
\end{array}$ & RPD \\
\hline $\begin{array}{l}\text { Cadmium (in } \\
\text { filtered water) }\end{array}$ & $\mu \mathrm{g} / \mathrm{L}$ & $<$ & 0.1 & -- & -- & $<$ & 0.1 & -- & -- & -- & $<$ & 0.1 & -- & -- & -- & $\mathrm{N}$ & -- & -- & -- \\
\hline $\begin{array}{l}\text { Cadmium (in } \\
\text { unfiltered } \\
\text { water) }\end{array}$ & $\mu \mathrm{g} / \mathrm{L}$ & E & 0.11 & 1 & $\mathrm{~J}$ & $<$ & 0.1 & -- & -- & -- & $<$ & 0.1 & -- & -- & -- & $\mathrm{N}$ & -- & -- & -- \\
\hline $\begin{array}{l}\text { Chromium (in } \\
\text { filtered water) }\end{array}$ & $\mu \mathrm{g} / \mathrm{L}$ & $<$ & 0.5 & -- & -- & $<$ & 0.5 & -- & -- & -- & $<$ & 0.5 & -- & -- & -- & $\mathrm{N}$ & -- & -- & -- \\
\hline $\begin{array}{l}\text { Chromium (in } \\
\text { unfiltered } \\
\text { water) }\end{array}$ & $\mu \mathrm{g} / \mathrm{L}$ & $<$ & 0.5 & -- & -- & $<$ & 0.5 & -- & -- & -- & $<$ & 0.5 & -- & -- & -- & $\mathrm{N}$ & -- & -- & -- \\
\hline $\begin{array}{l}\text { Cobalt (in filtered } \\
\text { water) }\end{array}$ & $\mu \mathrm{g} / \mathrm{L}$ & $<$ & 0.054 & -- & -- & $<$ & 0.054 & -- & -- & -- & $<$ & 0.054 & -- & -- & -- & $\mathrm{N}$ & -- & -- & -- \\
\hline $\begin{array}{c}\text { Cobalt (in unfil- } \\
\text { tered water) }\end{array}$ & $\mu \mathrm{g} / \mathrm{L}$ & $<$ & 0.054 & -- & -- & $<$ & 0.054 & -- & -- & -- & $<$ & 0.054 & -- & -- & -- & $\mathrm{N}$ & -- & -- & -- \\
\hline $\begin{array}{l}\text { Copper (in filtered } \\
\text { water) }\end{array}$ & $\mu \mathrm{g} / \mathrm{L}$ & $<$ & 0.56 & -- & -- & $<$ & 0.56 & -- & -- & -- & $<$ & 0.56 & -- & -- & -- & $\mathrm{N}$ & -- & -- & -- \\
\hline $\begin{array}{l}\text { Copper (in unfil- } \\
\text { tered water) }\end{array}$ & $\mu \mathrm{g} / \mathrm{L}$ & $<$ & 0.56 & -- & -- & $<$ & 0.56 & -- & -- & -- & $<$ & 0.56 & -- & -- & -- & $\mathrm{N}$ & -- & -- & -- \\
\hline $\begin{array}{l}\text { Iron (in filtered } \\
\text { water) }\end{array}$ & $\mu \mathrm{g} / \mathrm{L}$ & $<$ & 22 & -- & -- & $<$ & 22 & -- & -- & -- & $<$ & 22 & -- & -- & -- & $\mathrm{N}$ & -- & -- & -- \\
\hline $\begin{array}{l}\text { Iron (in unfiltered } \\
\quad \text { water) }\end{array}$ & $\mu \mathrm{g} / \mathrm{L}$ & $<$ & 22 & -- & -- & $<$ & 22 & -- & -- & -- & E & 55 & -- & $\mathrm{J}^{\wedge}$ & -- & $\mathrm{N}$ & -- & -- & -- \\
\hline $\begin{array}{l}\text { Lead (in filtered } \\
\quad \text { water) }\end{array}$ & $\mu \mathrm{g} / \mathrm{L}$ & $<$ & 0.18 & -- & -- & $<$ & 0.18 & -- & -- & -- & $<$ & 0.18 & -- & -- & -- & $\mathrm{N}$ & -- & -- & -- \\
\hline $\begin{array}{l}\text { Lead (in unfiltered } \\
\quad \text { water) }\end{array}$ & $\mu \mathrm{g} / \mathrm{L}$ & $<$ & 0.18 & -- & -- & $<$ & 0.18 & -- & -- & -- & $<$ & 0.18 & -- & -- & -- & $\mathrm{N}$ & -- & -- & -- \\
\hline $\begin{array}{l}\text { Lithium (in fil- } \\
\text { tered water) }\end{array}$ & $\mu \mathrm{g} / \mathrm{L}$ & -- & 44 & -- & -- & -- & 45 & 6 & -- & 2.2 & -- & 33 & -- & -- & -- & $\mathrm{N}$ & -- & -- & -- \\
\hline $\begin{array}{l}\text { Lithium (in unfil- } \\
\quad \text { tered water) }\end{array}$ & $\mu \mathrm{g} / \mathrm{L}$ & -- & 44 & -- & -- & -- & 43 & 6 & -- & 2.3 & -- & 36 & -- & -- & -- & $\mathrm{N}$ & -- & -- & -- \\
\hline $\begin{array}{l}\text { Manganese (in } \\
\text { filtered water) }\end{array}$ & $\mu \mathrm{g} / \mathrm{L}$ & $<$ & 0.31 & -- & -- & -- & 1 & 6 & -- & -- & E & 0.42 & -- & $\mathrm{J}$ & -- & $\mathrm{N}$ & -- & -- & -- \\
\hline $\begin{array}{l}\text { Manganese (in } \\
\text { unfiltered } \\
\text { water) }\end{array}$ & $\mu \mathrm{g} / \mathrm{L}$ & E & 0.57 & 2 & $\mathrm{~J}$ & E & 0.46 & 2,6 & $\mathrm{~J}$ & 21.4 & E & 0.80 & -- & $\mathrm{J}$ & -- & $\mathrm{N}$ & -- & -- & -- \\
\hline $\begin{array}{l}\text { Mercury (in fil- } \\
\text { tered water) }\end{array}$ & $\mu \mathrm{g} / \mathrm{L}$ & $<$ & 0.027 & -- & -- & $<$ & 0.027 & -- & -- & -- & $<$ & 0.027 & -- & -- & -- & $\mathrm{N}$ & -- & -- & -- \\
\hline $\begin{array}{l}\text { Mercury (in unfil- } \\
\text { tered water) }\end{array}$ & $\mu \mathrm{g} / \mathrm{L}$ & $<$ & 0.027 & -- & -- & $<$ & 0.027 & -- & -- & -- & $<$ & 0.027 & -- & -- & -- & $\mathrm{N}$ & -- & -- & -- \\
\hline $\begin{array}{l}\text { Molybdenum (in } \\
\text { filtered water) }\end{array}$ & $\mu \mathrm{g} / \mathrm{L}$ & -- & 10 & 6 & -- & -- & 9.7 & -- & -- & 3.0 & -- & 7.6 & -- & -- & -- & $\mathrm{N}$ & -- & -- & -- \\
\hline
\end{tabular}


Table 5. Field water-quality properties and inorganic constituents in environmental samples collected from monitoring well MW01 near Pavillion, Wyoming, April 2012.Continued

$\left[R P D\right.$, relative percent difference; $\mu \mathrm{s} / \mathrm{cm}$, microsiemens per centimeter; $\mathrm{mg} / \mathrm{L}$, milligrams per liter; $\mathrm{CaCO}_{3}$, calcium carbonate; $\mu \mathrm{g} / \mathrm{L}$, micrograms per liter; $\mathrm{pCi} / \mathrm{L}$, picocuries per liter; $\mathrm{N}$, value was not determined; --, not applicable]

\begin{tabular}{|c|c|c|c|c|c|c|c|c|c|c|c|c|c|c|c|c|c|c|c|}
\hline \multicolumn{2}{|c|}{$\begin{array}{l}\text { Field water-quality } \\
\text { property or inorganic } \\
\text { constituent }\end{array}$} & \multicolumn{4}{|c|}{ Environmental sample 1} & \multicolumn{5}{|c|}{ Sample 1 replicate } & \multicolumn{4}{|c|}{ Environmental sample 2} & \multicolumn{5}{|c|}{ Sample 2 replicate } \\
\hline Name & Units & $\begin{array}{c}\text { Re- } \\
\text { mark'1 }\end{array}$ & Value & $\begin{array}{c}\text { Project } \\
\text { data } \\
\text { qualifiers }^{2}\end{array}$ & $\begin{array}{c}\text { Labora- } \\
\text { tory } \\
\text { data } \\
\text { qualifiers }^{3}\end{array}$ & $\begin{array}{l}\text { Re- } \\
\text { mark' }\end{array}$ & Value & $\begin{array}{c}\text { Project } \\
\text { data } \\
\text { qualifiers }^{2}\end{array}$ & $\begin{array}{l}\text { Labora- } \\
\text { tory } \\
\text { data } \\
\text { qualifiers } \\
\end{array}$ & RPD & $\begin{array}{c}\text { Re- } \\
\text { mark' }\end{array}$ & Value & $\begin{array}{c}\text { Project } \\
\text { data } \\
\text { qualifiers }\end{array}$ & $\begin{array}{c}\text { Labora- } \\
\text { tory } \\
\text { data } \\
\text { qualifiers }^{3}\end{array}$ & $\begin{array}{l}\text { Re- } \\
\text { mark' }\end{array}$ & Value & $\begin{array}{c}\text { Project } \\
\text { data } \\
\text { qualifiers }^{2}\end{array}$ & $\begin{array}{l}\text { Labora- } \\
\text { tory } \\
\text { data } \\
\text { qualifiers }^{3}\end{array}$ & RPD \\
\hline $\begin{array}{l}\text { Molybdenum } \\
\quad \text { (in unfiltered } \\
\text { water) }\end{array}$ & $\mu \mathrm{g} / \mathrm{L}$ & -- & 9.8 & 6 & -- & -- & 10 & -- & -- & 2.0 & -- & 7.8 & -- & -- & -- & $\mathrm{N}$ & -- & -- & -- \\
\hline $\begin{array}{l}\text { Nickel (in filtered } \\
\text { water) }\end{array}$ & $\mu \mathrm{g} / \mathrm{L}$ & $<$ & 0.3 & -- & -- & $<$ & 0.3 & -- & - & -- & $<$ & 0.3 & -- & -- & -- & $\mathrm{N}$ & -- & -- & -- \\
\hline $\begin{array}{l}\text { Nickel (in unfil- } \\
\text { tered water) }\end{array}$ & $\mu \mathrm{g} / \mathrm{L}$ & E & 0.3 & 2 & $\mathrm{~J}$ & E & 0.44 & 2 & $\mathrm{~J}$ & 37.8 & $<$ & 0.3 & -- & -- & -- & $\mathrm{N}$ & -- & -- & -- \\
\hline $\begin{array}{l}\text { Selenium (in } \\
\quad \text { filtered water) }\end{array}$ & $\mu \mathrm{g} / \mathrm{L}$ & $<$ & 0.7 & -- & -- & $<$ & 0.7 & -- & -- & -- & $<$ & 0.7 & -- & -- & -- & $\mathrm{N}$ & -- & -- & -- \\
\hline $\begin{array}{l}\text { Selenium (in } \\
\text { unfiltered } \\
\text { water) }\end{array}$ & $\mu \mathrm{g} / \mathrm{L}$ & $<$ & 0.7 & -- & -- & $<$ & 0.7 & -- & -- & -- & $<$ & 0.7 & -- & -- & -- & $\mathrm{N}$ & -- & -- & -- \\
\hline $\begin{array}{l}\text { Silver (in filtered } \\
\text { water) }\end{array}$ & $\mu \mathrm{g} / \mathrm{L}$ & $<$ & 0.033 & -- & -- & $<$ & 0.033 & -- & -- & -- & $<$ & 0.033 & -- & -- & -- & $\mathrm{N}$ & -- & -- & -- \\
\hline $\begin{array}{l}\text { Silver (in unfil- } \\
\text { tered water) }\end{array}$ & $\mu \mathrm{g} / \mathrm{L}$ & $<$ & 0.033 & -- & -- & $<$ & 0.033 & -- & -- & -- & $<$ & 0.033 & -- & -- & -- & $\mathrm{N}$ & -- & -- & -- \\
\hline $\begin{array}{l}\text { Strontium (in } \\
\quad \text { filtered water) }\end{array}$ & $\mu \mathrm{g} / \mathrm{L}$ & -- & 300 & -- & -- & -- & 310 & 6 & -- & 3.3 & -- & 280 & -- & -- & -- & $\mathrm{N}$ & -- & -- & -- \\
\hline $\begin{array}{l}\text { Strontium (in } \\
\quad \text { unfiltered } \\
\text { water) }\end{array}$ & $\mu \mathrm{g} / \mathrm{L}$ & -- & 300 & -- & -- & -- & 300 & 6 & -- & 0.0 & -- & 280 & -- & -- & -- & $\mathrm{N}$ & -- & -- & -- \\
\hline $\begin{array}{l}\text { Thallium (in } \\
\text { filtered water) }\end{array}$ & $\mu \mathrm{g} / \mathrm{L}$ & $<$ & 0.05 & -- & -- & $<$ & 0.05 & -- & -- & -- & $<$ & 0.05 & -- & -- & -- & $\mathrm{N}$ & -- & -- & -- \\
\hline $\begin{array}{l}\text { Thallium (in } \\
\text { unfiltered } \\
\text { water) }\end{array}$ & $\mu \mathrm{g} / \mathrm{L}$ & E & 0.068 & 1 & $\mathrm{~J}$ & $<$ & 0.05 & -- & -- & -- & E & 0.096 & 1 & $\mathrm{~J}$ & -- & $\mathrm{N}$ & -- & -- & -- \\
\hline $\begin{array}{l}\text { Titanium (in fil- } \\
\text { tered water) }\end{array}$ & $\mu \mathrm{g} / \mathrm{L}$ & $<$ & 0.6 & -- & -- & $<$ & 0.6 & -- & -- & -- & $<$ & 0.6 & -- & -- & -- & $\mathrm{N}$ & -- & -- & -- \\
\hline $\begin{array}{l}\text { Titanium (in unfil- } \\
\text { tered water) }\end{array}$ & $\mu \mathrm{g} / \mathrm{L}$ & $<$ & 0.6 & -- & -- & $<$ & 0.6 & -- & -- & -- & E & 0.69 & -- & $\mathrm{J}$ & -- & $\mathrm{N}$ & -- & -- & -- \\
\hline $\begin{array}{l}\text { Uranium (in fil- } \\
\text { tered water) }\end{array}$ & $\mu \mathrm{g} / \mathrm{L}$ & $<$ & 0.05 & -- & -- & $<$ & 0.05 & -- & -- & -- & $<$ & 0.05 & -- & -- & -- & $\mathrm{N}$ & -- & -- & -- \\
\hline $\begin{array}{l}\text { Uranium (in unfil- } \\
\text { tered water) }\end{array}$ & $\mu \mathrm{g} / \mathrm{L}$ & E & 0.14 & 1 & $\mathrm{~J}$ & $<$ & 0.05 & -- & -- & -- & E & 0.14 & 1 & $\mathrm{~J}$ & -- & $\mathrm{N}$ & -- & -- & -- \\
\hline $\begin{array}{l}\text { Vanadium (in } \\
\quad \text { filtered water) }\end{array}$ & $\mu \mathrm{g} / \mathrm{L}$ & E & 0.6 & 6 & $\mathrm{~J}$ & $<$ & 0.5 & -- & -- & -- & $<$ & 0.5 & -- & -- & -- & $\mathrm{N}$ & -- & -- & -- \\
\hline $\begin{array}{l}\text { Vanadium (in } \\
\text { unfiltered } \\
\text { water) }\end{array}$ & $\mu \mathrm{g} / \mathrm{L}$ & $<$ & 0.5 & 6 & -- & $<$ & 0.5 & -- & -- & -- & E & 0.53 & -- & $\mathrm{J}$ & -- & $\mathrm{N}$ & -- & -- & -- \\
\hline $\begin{array}{l}\text { Zinc (in filtered } \\
\text { water) }\end{array}$ & $\mu \mathrm{g} / \mathrm{L}$ & $<$ & 2 & -- & $\wedge$ & $<$ & 2 & - & $\wedge$ & - & $<$ & 2 & - & $\wedge$ & -- & $\mathrm{N}$ & - & -- & -- \\
\hline $\begin{array}{l}\text { Zinc (in unfiltered } \\
\text { water) }\end{array}$ & $\mu \mathrm{g} / \mathrm{L}$ & $<$ & 2 & -- & -- & $<$ & 2 & -- & -- & - & $<$ & 2 & -- & -- & -- & $\mathrm{N}$ & -- & -- & -- \\
\hline
\end{tabular}


Table 5. Field water-quality properties and inorganic constituents in environmental samples collected from monitoring well MW01 near Pavillion, Wyoming, April 2012.Continued

$\left[R P D\right.$, relative percent difference; $\mu \mathrm{s} / \mathrm{cm}$, microsiemens per centimeter; $\mathrm{mg} / \mathrm{L}$, milligrams per liter; $\mathrm{CaCO}_{3}$, calcium carbonate; $\mu \mathrm{g} / \mathrm{L}$, micrograms per liter; $\mathrm{pCi} / \mathrm{L}$, picocuries per liter; $\mathrm{N}$, value was not determined; --, not applicable]

\begin{tabular}{|c|c|c|c|c|c|c|c|c|c|c|c|c|c|c|c|c|c|c|c|}
\hline \multicolumn{2}{|c|}{$\begin{array}{c}\text { Field water-quality } \\
\text { property or inorganic } \\
\text { constituent }\end{array}$} & \multicolumn{4}{|c|}{ Environmental sample 1} & \multicolumn{5}{|c|}{ Sample 1 replicate } & \multicolumn{4}{|c|}{ Environmental sample 2} & \multicolumn{5}{|c|}{ Sample 2 replicate } \\
\hline Name & Units & $\begin{array}{c}\text { Re- } \\
\text { mark' }^{1}\end{array}$ & Value & $\begin{array}{c}\text { Project } \\
\text { data } \\
\text { qualifiers }{ }^{2}\end{array}$ & $\begin{array}{c}\text { Labora- } \\
\text { tory } \\
\text { data } \\
\text { qualifiers }^{3}\end{array}$ & $\begin{array}{c}\text { Re- } \\
\text { mark' }^{1}\end{array}$ & Value & $\begin{array}{c}\text { Project } \\
\text { data } \\
\text { qualifiers }{ }^{2}\end{array}$ & $\begin{array}{l}\text { Labora- } \\
\text { tory } \\
\text { data } \\
\text { qualifiers }^{3}\end{array}$ & RPD & $\begin{array}{c}\text { Re- } \\
\text { mark'1 }^{1}\end{array}$ & Value & $\begin{array}{c}\text { Project } \\
\text { data } \\
\text { qualifiers }^{2}\end{array}$ & $\begin{array}{l}\text { Labora- } \\
\text { tory } \\
\text { data } \\
\text { qualifiers }\end{array}$ & $\begin{array}{c}\text { Re- } \\
\text { mark }^{1}\end{array}$ & Value & $\begin{array}{l}\text { Project } \\
\text { data } \\
\text { qualifiers }^{2}\end{array}$ & $\begin{array}{l}\text { Labora- } \\
\text { tory } \\
\text { data } \\
\text { qualifiers }^{3}\end{array}$ & RPD \\
\hline \multicolumn{20}{|c|}{ Eberline Laboratory } \\
\hline $\begin{array}{l}\text { Radium-226 (in } \\
\text { filtered water) } \\
\text { with radon } \\
\text { method }\end{array}$ & $\mathrm{pCi} / \mathrm{L}$ & -- & 0.087 & -- & -- & -- & $\mathrm{N}$ & -- & -- & -- & -- & 0.100 & -- & -- & -- & $\mathrm{N}$ & -- & -- & -- \\
\hline $\begin{array}{l}\text { Radium-228 (in } \\
\text { filtered water) }\end{array}$ & $\mathrm{pCi} / \mathrm{L}$ & $\mathrm{R}$ & 0.16 & -- & -- & -- & $\mathrm{N}$ & -- & -- & -- & -- & 0.23 & -- & -- & -- & $\mathrm{N}$ & -- & -- & -- \\
\hline \multicolumn{20}{|c|}{ U.S. Geological Survey National Water Quality Laboratory } \\
\hline $\begin{array}{l}\text { Radon-222 (in } \\
\text { unfiltered } \\
\text { water) }\end{array}$ & $\mathrm{pCi} / \mathrm{L}$ & -- & 1,060 & -- & -- & -- & $\mathrm{N}$ & -- & -- & -- & -- & $\mathrm{N}$ & -- & -- & -- & $\mathrm{N}$ & -- & -- & -- \\
\hline
\end{tabular}

Remarks used in table:

$<$, less than.

$\mathrm{E}$, less than the reporting level, but equal to or greater than the method detection limit.

$\mathrm{R}$, value below sample-specific critical level.

${ }^{2}$ Project data qualifiers used in table:

1 - Quantified concentration in the environmental sample is less than five times the maximum concentration in a blank sample.

2 - Relative percent difference (RPD) between the environmental sample and replicate sample was greater than 20 percent.

3 - Potential low bias; recovery was less than 70 percent in one or more spike samples.

4 - Potential high bias; recovery was greater than 130 percent in one or more spike samples (only applied to constituents with quantified results).

5 - Value is mean of two results reported by the laboratory.

6 - Filtered value exceeds unfiltered value.

${ }^{3}$ Laboratory data qualifiers used in table:

$\wedge$ - Instrument related quality control exceeds the control limits.

4 - The analyte present in the environmental sample is four times greater than the matrix spike concentration; therefore, control limits are not applicable.

E - Result exceeded calibration range.

F - Recovery in the matrix spike or matrix-spike duplicate exceeds the control limits.

B - Detected compound was also found in the laboratory blank.

$\mathrm{J}$ - Result is less than the reporting limit but greater than or equal to the method detection limit, and the concentration is an approximate value. 
Table 6. Inorganic constituents in quality-control samples collected for monitoring well MW01 near Pavillion, Wyoming, April 2012. (Excel file)

\section{Organic Constituents}

Concentrations of organic constituents included in analysis of the environmental samples and sample replicates collected from well MW01 are listed in table 7. Blank and spike sample analytical results are listed in table 8 . Acrylonitrile was the only VOC detected, and that compound was detected only in the sample 1 replicate. Acrylonitrile is a component of nitrile gloves, which were worn during sample collection and processing. Nitrile gloves also were used by TestAmerica Laboratories (TestAmerica Laboratories, oral commun., 2012). VOCs could go undetected in an environmental sample if the analytical method used to measure them has poor recovery for those compounds. Of the 80 VOCs that were analyzed, only 1,1,2,2-tetrachloroethane, carbon disulfide, and isopropanol had spike recoveries less than 70 percent for any spiked sample.

Four semivolatile organic compounds (SVOCs) - 3- and 4-methylphenol, benzoic acid, benzyl alcohol, and phenolwere detected in environmental samples; however, the concentration for benzyl alcohol (table 7) was less than five times the maximum concentration detected in associated laboratory and field blank samples (table 8). Benzoic acid was detected in all the environmental samples; however, spike recoveries for this compound were greater than 130 percent (table 8), indicating these concentrations might be biased high. Reported concentrations for several SVOCs include an "E" remark (table 7) because they are less than the reporting level, but equal to or greater than the method detection limit. Five of the SVOCs (2,4-dimethylphenol, 3,3'-dichlorobenzidine, aniline, hexachlorocyclopentadiene, and hexachloroethane) that were not detected in environmental samples had spike recoveries less than 70 percent (table 8). For example, the recovery for hexachlorocyclopentadiene was as low as 12 percent.

Analytical results from methods used to analyze VOCs and SVOCs included tentatively identified compounds (TICs), which are not part of the standard suite of reported analytes. TIC analyses provide a qualitative measure of the presence of compounds, but require additional analytical testing to confirm. Concentrations of TICs included in analysis of the environmental samples and QC samples (replicates and blanks) collected from well MW01 are listed in appendix 7. Thirty VOC TICs and three SVOC TICs were quantified in various environmental samples and blanks. One of these compounds (cyclotetrasiloxane, octamethyl-) was identified only in a laboratory blank; one other compound (silanol, trimethyl-) was identified in a single environmental sample, but also in two blanks at similar concentrations, indicating potential contamination bias. Eight compounds were identified in all environmental samples, both preserved and unpreserved. Concentrations of these were similar within each sample set (environmental sample and replicate), but were different between the two samples (1 and 2). Concentrations of propane in the TIC analyses were less than one-half the concentrations reported by TestAmerica Laboratories for dissolved gas analysis (table 9). One compound of interest in the Pavillion area, 2-butoxyethanol, was not identified in the TIC analyses of any of the environmental samples.

Table 7. Organic constituents in environmental samples collected from monitoring well MW01 near Pavillion, Wyoming, April 2012. (Excel file)

Table 8. Organic constituents in quality-control samples collected for monitoring well MW01 near Pavillion, Wyoming, April 2012. (Excel file)

Concentrations for several other classes of organic compounds (tables 7 and 8) also included an "E" remark (less than the reporting level, but equal to or greater than the method detection limit). Diesel-range organics and gasolinerange organics were detected in all environmental samples and associated replicates, although all the concentrations for diesel-range organics (DRO) included an "E" remark. Twelve polycyclic aromatic hydrocarbons (PAHs) were detected in the environmental samples and associated replicates, but the maximum concentrations for 10 of these PAHs were less than five times the maximum concentration detected in associated laboratory and field blanks. All reported PAH concentrations included an "E" remark. No glycols were detected in any samples. Spike recoveries for glycols ranged from 93 to 106 percent, and method detection limits ranged from 7.73 to 18.70 milligrams per liter $(\mathrm{mg} / \mathrm{L})$. Methylene blue active substances were detected in the environmental samples, but all reported concentrations included an "E" remark and are less than five times the maximum concentration detected in the field blank.

\section{Dissolved Gasses}

Dissolved gasses measured in environmental samples and QC samples (replicates) collected from well MW01 are listed in table 9. Blank and spike sample analytical results are listed in table 10. Several different hydrocarbon gasses, including methane, ethane, propane, and several higher molecular weight compounds, were detected in the groundwater-quality samples. Many of the gasses (including argon, carbon dioxide, ethane, ethylene, methane, nitrogen, oxygen, and propane) were analyzed by more than one laboratory; using different analytical methods. For example, methane was analyzed by TestAmerica Laboratories, Isotech Laboratories, Inc., and the USGS Chlorofluorocarbon Laboratory. Because of the laboratory overlap of analyses of several dissolved gasses, a short description of the differences in gas concentrations between laboratories follows.

Methane concentrations reported by TestAmerica Laboratories and the USGS Reston Chlorofluorocarbon Laboratory are similar (table 9). For example, TestAmerica reported 
Table 9. Dissolved gasses in environmental samples collected from monitoring well MW01 near Pavillion, Wyoming, April 2012.

[All constituents analyzed in unfiltered water. RPD, relative percent difference; $\mu \mathrm{g} / \mathrm{L}$, micrograms per liter; mg/L, milligrams per liter; --, not applicable; N, value was not determined]

\begin{tabular}{|c|c|c|c|c|c|c|c|c|c|c|c|c|c|c|c|c|c|c|c|c|c|}
\hline \multicolumn{3}{|c|}{ Dissolved Gas } & \multirow{2}{*}{$\begin{array}{l}\text { Preser- } \\
\text { vative } \\
\text { added } \\
\text { to } \\
\text { bottle }\end{array}$} & \multicolumn{4}{|c|}{ Environmental sample 1} & \multicolumn{5}{|c|}{ Sample 1 replicate } & \multicolumn{4}{|c|}{ Environmental sample 2} & \multicolumn{5}{|c|}{ Sample 2 replicate } \\
\hline Name & $\begin{array}{l}\text { Alterna- } \\
\text { tive } \\
\text { name }\end{array}$ & Units & & Remark $^{1}$ & Value & $\begin{array}{c}\text { Project } \\
\text { data } \\
\text { qualifiers }\end{array}$ & $\begin{array}{c}\text { Laboratory } \\
\text { data } \\
{ }^{2} \text { qualifiers }\end{array}$ & Remark $^{1}$ & Value & $\begin{array}{c}\text { Project } \\
\text { data } \\
\text { qualifiers }\end{array}$ & $\begin{array}{c}\text { Laboratory } \\
\text { data } \\
\text { qualifiers }\end{array}$ & RPD & Remark' & Value & $\begin{array}{c}\text { Project } \\
\text { data } \\
\text { qualifiers }\end{array}$ & $\begin{array}{l}\text { Laboratory } \\
\text { data } \\
2 \text { qualifiers }\end{array}$ & Remark $^{1}$ & Value & $\begin{array}{c}\text { Project } \\
\text { data } \\
\text { qualifiers }\end{array}$ & $\begin{array}{l}\text { Laboratory } \\
\text { data } \\
\text { qualifiers }\end{array}$ & RPD \\
\hline \multicolumn{22}{|c|}{ TestAmerica Laboratories } \\
\hline Methane & -- & $\mu \mathrm{g} / \mathrm{L}$ & Yes & -- & 27,500 & 5 & -- & -- & 30,500 & 5 & -- & 10.3 & -- & 25,500 & 5 & -- & -- & 27,000 & 5 & -- & 5.7 \\
\hline Methane & -- & $\mu \mathrm{g} / \mathrm{L}$ & No & -- & 27,000 & 5 & -- & -- & 27,000 & 5 & -- & 0.0 & -- & 20,000 & 5 & -- & -- & 22,000 & 5 & -- & 9.5 \\
\hline Ethane & -- & $\mu \mathrm{g} / \mathrm{L}$ & Yes & -- & 3,600 & 4 & -- & -- & 4,000 & 4 & -- & 10.5 & -- & 3,200 & 4 & -- & -- & 3,300 & 4 & -- & 3.1 \\
\hline Ethane & -- & $\mu \mathrm{g} / \mathrm{L}$ & No & -- & 3,800 & 4 & -- & -- & 3,800 & 4 & -- & 0.0 & -- & 2,600 & 4 & -- & -- & 2,800 & 4 & -- & 7.4 \\
\hline Ethylene & -- & $\mu \mathrm{g} / \mathrm{L}$ & Yes & $<$ & 7.2 & 5 & -- & $<$ & 7.2 & 5 & -- & -- & $<$ & 7.2 & 5 & -- & $<$ & 7.2 & 5 & -- & -- \\
\hline Ethylene & -- & $\mu \mathrm{g} / \mathrm{L}$ & No & $<$ & 7.2 & 5 & -- & $<$ & 7.2 & 5 & -- & -- & $<$ & 7.2 & 5 & -- & $<$ & 7.2 & 5 & -- & -- \\
\hline Propane & -- & $\mu \mathrm{g} / \mathrm{L}$ & Yes & -- & 1,400 & -- & -- & -- & 1,300 & -- & -- & 7.4 & -- & 1,100 & -- & -- & -- & 1,000 & -- & -- & 9.5 \\
\hline Propane & -- & $\mu \mathrm{g} / \mathrm{L}$ & No & -- & 1,300 & -- & -- & -- & 1,100 & -- & -- & 16.7 & -- & 1,000 & -- & -- & -- & 970 & -- & -- & 3.0 \\
\hline \multicolumn{22}{|c|}{ Isotech Laboratories, Inc. } \\
\hline Argon & -- & $\begin{array}{l}\text { mole } \\
\text { percent }\end{array}$ & Yes & -- & $\mathrm{N}$ & -- & -- & -- & $\mathrm{N}$ & -- & -- & -- & -- & 0.446 & -- & -- & -- & $\mathrm{N}$ & -- & -- & -- \\
\hline $\begin{array}{l}\text { Carbon } \\
\text { monoxide }\end{array}$ & -- & $\begin{array}{c}\text { mole } \\
\text { percent }\end{array}$ & Yes & -- & $\mathrm{N}$ & -- & -- & -- & $\mathrm{N}$ & -- & -- & -- & $\mathrm{U}$ & -- & -- & -- & -- & $\mathrm{N}$ & -- & -- & -- \\
\hline $\begin{array}{l}\text { Carbon } \\
\text { dioxide }\end{array}$ & -- & $\begin{array}{l}\text { mole } \\
\text { percent }\end{array}$ & Yes & -- & $\mathrm{N}$ & -- & -- & -- & $\mathrm{N}$ & -- & -- & -- & $\mathrm{U}$ & -- & -- & -- & -- & $\mathrm{N}$ & -- & -- & -- \\
\hline Hydrogen & -- & $\begin{array}{c}\text { mole } \\
\text { percent }\end{array}$ & Yes & -- & $\mathrm{N}$ & -- & -- & -- & $\mathrm{N}$ & -- & -- & -- & $\mathrm{U}$ & -- & -- & -- & -- & $\mathrm{N}$ & -- & -- & -- \\
\hline Oxygen & -- & $\begin{array}{c}\text { mole } \\
\text { percent }\end{array}$ & Yes & -- & $\mathrm{N}$ & -- & -- & -- & $\mathrm{N}$ & -- & -- & -- & -- & 0.078 & -- & -- & -- & $\mathrm{N}$ & -- & -- & -- \\
\hline Nitrogen & -- & $\begin{array}{l}\text { mole } \\
\text { percent }\end{array}$ & Yes & -- & $\mathrm{N}$ & -- & -- & -- & $\mathrm{N}$ & -- & -- & -- & -- & 20.40 & -- & -- & -- & $\mathrm{N}$ & -- & -- & -- \\
\hline Methane & -- & $\begin{array}{l}\text { mole } \\
\text { percent }\end{array}$ & Yes & -- & $\mathrm{N}$ & -- & -- & -- & $\mathrm{N}$ & -- & -- & -- & -- & 73.44 & -- & -- & -- & $\mathrm{N}$ & -- & -- & -- \\
\hline Ethane & -- & $\begin{array}{l}\text { mole } \\
\text { percent }\end{array}$ & Yes & -- & $\mathrm{N}$ & -- & -- & -- & $\mathrm{N}$ & -- & -- & -- & -- & 4.18 & -- & -- & -- & $\mathrm{N}$ & -- & -- & -- \\
\hline Ethylene & -- & $\begin{array}{l}\text { mole } \\
\text { percent }\end{array}$ & Yes & -- & $\mathrm{N}$ & -- & -- & -- & $\mathrm{N}$ & -- & -- & -- & -- & 0.001 & -- & -- & -- & $\mathrm{N}$ & -- & -- & -- \\
\hline Propane & -- & $\begin{array}{l}\text { mole } \\
\text { percent }\end{array}$ & Yes & -- & $\mathrm{N}$ & -- & -- & -- & $\mathrm{N}$ & -- & -- & -- & -- & 0.913 & -- & -- & -- & $\mathrm{N}$ & -- & -- & -- \\
\hline Propylene & -- & $\begin{array}{l}\text { mole } \\
\text { percent }\end{array}$ & Yes & -- & $\mathrm{N}$ & -- & -- & -- & $\mathrm{N}$ & -- & -- & -- & -- & 0.001 & -- & -- & -- & $\mathrm{N}$ & -- & -- & -- \\
\hline n-Butane & -- & $\begin{array}{l}\text { mole } \\
\text { percent }\end{array}$ & Yes & -- & $\mathrm{N}$ & -- & -- & -- & $\mathrm{N}$ & -- & -- & -- & -- & 0.178 & -- & -- & -- & $\mathrm{N}$ & -- & -- & -- \\
\hline Iso-butane & $\begin{array}{l}\text { 2-Methyl- } \\
\text { propane }\end{array}$ & $\begin{array}{l}\text { mole } \\
\text { percent }\end{array}$ & Yes & -- & $\mathrm{N}$ & -- & -- & -- & $\mathrm{N}$ & -- & -- & -- & -- & 0.213 & -- & -- & -- & $\mathrm{N}$ & -- & -- & -- \\
\hline n-Pentane & -- & $\begin{array}{c}\text { mole } \\
\text { percent }\end{array}$ & Yes & -- & $\mathrm{N}$ & -- & -- & -- & $\mathrm{N}$ & -- & -- & -- & -- & 0.030 & -- & -- & -- & $\mathrm{N}$ & -- & -- & -- \\
\hline Iso-pentane ${ }^{2}$ & $\begin{array}{l}\text { 2-Methyl- } \\
\text { butane }\end{array}$ & $\begin{array}{l}\text { mole } \\
\text { percent }\end{array}$ & Yes & -- & $\mathrm{N}$ & -- & -- & -- & $\mathrm{N}$ & -- & -- & -- & -- & 0.066 & -- & -- & -- & $\mathrm{N}$ & -- & -- & -- \\
\hline
\end{tabular}


[All constituents analyzed in unfiltered water. RPD, relative percent difference; $\mu \mathrm{g} / \mathrm{L}$, micrograms per liter; $\mathrm{mg} / \mathrm{L}$, milligrams per liter; --, not applicable; N, value was not determined]

\begin{tabular}{|c|c|c|c|c|c|c|c|c|c|c|c|c|c|c|c|c|c|c|c|c|c|}
\hline \multicolumn{3}{|c|}{ Dissolved Gas } & \multirow{2}{*}{$\begin{array}{c}\text { Preser- } \\
\text { vative } \\
\text { added } \\
\text { to } \\
\text { bottle }\end{array}$} & \multicolumn{4}{|c|}{ Environmental sample 1} & \multicolumn{5}{|c|}{ Sample 1 replicate } & \multicolumn{4}{|c|}{ Environmental sample 2} & \multicolumn{5}{|c|}{ Sample 2 replicate } \\
\hline Name & $\begin{array}{l}\text { Alterna- } \\
\text { tive } \\
\text { name }\end{array}$ & Units & & Remark $^{1}$ & Value & $\begin{array}{c}\text { Project } \\
\text { data } \\
\text { qualifiers }^{2}\end{array}$ & $\begin{array}{c}\text { Laboratory } \\
\text { data } \\
\text { qualifiers }\end{array}$ & Remark $^{1}$ & Value & $\begin{array}{c}\text { Project } \\
\text { data } \\
\text { qualifiers }\end{array}$ & $\begin{array}{l}\text { Laboratory } \\
\text { data } \\
\text { qualifiers }\end{array}$ & RPD & Remark $^{1}$ & Value & $\begin{array}{c}\text { Project } \\
\text { data } \\
\text { qualifiers }\end{array}$ & $\begin{array}{l}\text { Laboratory } \\
\text { data } \\
2 \text { qualifiers }\end{array}$ & Remark $^{1}$ & Value & $\begin{array}{c}\text { Project } \\
\text { data } \\
\text { qualifiers }^{2}\end{array}$ & $\begin{array}{l}\text { Laboratory } \\
\text { data } \\
\text { qualifiers }\end{array}$ & RPD \\
\hline $\begin{array}{c}\text { Hexanes } \\
\text { plus }\end{array}$ & -- & $\begin{array}{c}\text { mole } \\
\text { percent }\end{array}$ & Yes & -- & $\mathrm{N}$ & -- & -- & -- & $\mathrm{N}$ & -- & -- & -- & -- & 0.053 & -- & -- & -- & $\mathrm{N}$ & -- & -- & -- \\
\hline \multicolumn{22}{|c|}{ U.S. Geological Survey Reston Chlorofluorocarbon Laboratory } \\
\hline Argon & -- & $\mathrm{mg} / \mathrm{L}$ & No & -- & 0.183 & 5 & -- & -- & 0.186 & 5 & -- & 1.3 & -- & 0.305 & 5 & -- & -- & $\mathrm{N}$ & -- & -- & -- \\
\hline $\begin{array}{l}\text { Carbon } \\
\text { dioxide }\end{array}$ & -- & $\mathrm{mg} / \mathrm{L}$ & No & -- & 129.1 & 5 & -- & -- & 125.0 & 5 & -- & 3.2 & -- & 121.1 & 5 & -- & -- & $\mathrm{N}$ & -- & -- & -- \\
\hline Oxygen & -- & $\mathrm{mg} / \mathrm{L}$ & No & -- & 0.1 & 5 & -- & -- & 0.1 & 5 & -- & 0.0 & -- & 0.1 & 5 & -- & -- & $\mathrm{N}$ & -- & -- & -- \\
\hline Methane & -- & $\mathrm{mg} / \mathrm{L}$ & No & -- & 26 & 5 & -- & -- & 26 & 5 & -- & 1.6 & -- & 28 & 5 & -- & -- & $\mathrm{N}$ & -- & -- & -- \\
\hline Nitrogen & -- & $\mathrm{mg} / \mathrm{L}$ & No & -- & 3.86 & 5 & -- & -- & 4.01 & 5 & -- & 3.8 & -- & 7.95 & 5 & -- & -- & $\mathrm{N}$ & -- & -- & -- \\
\hline
\end{tabular}

Remarks used in table:

$$
<\text {, less than. }
$$

$\mathrm{U}$, analyzed for but not detected.

${ }^{2}$ Project data qualifiers used in table:

1 - Quantified concentration in the environmental sample is less than five times the maximum concentration in a blank sample.

2 - Relative percent difference (RPD) between the environmental sample and replicate is greater than 20 percent.

3 - Potential low bias; recovery is less than 70 percent in one or more spike samples.

4 - Potential high bias; recovery is greater than 130 percent in one or more spike samples (only applied to constituents with quantified results).

5 - Value is mean of two results reported by the laboratory.

6 - Filtered value exceeds unfiltered value. 
methane concentrations ranging from 20 to $30.5 \mathrm{mg} / \mathrm{L}$ (or 20,000 to 30,500 micrograms per liter) for environmental sample 1 and the sample 1 replicate, and the USGS Reston Chlorofluorocarbon Laboratory reported methane concentrations ranging from 26 to $28 \mathrm{mg} / \mathrm{L}$.

Carbon dioxide concentrations reported by Isotech Laboratories, Inc., and the USGS Reston Chlorofluorocarbon Laboratory are not similar. Isotech Laboratories, Inc., did not detect carbon dioxide in environmental sample 2, whereas the USGS Reston Chlorofluorocarbon Laboratory reported carbon dioxide concentrations in environmental sample 2 greater than $100 \mathrm{mg} / \mathrm{L}$. This difference may be due to different methods for stripping gas from solution before the analysis. Isotech Laboratories, Inc., and the USGS Reston Chlorofluorocarbon Laboratory reported very small concentrations of dissolved oxygen in the samples, which is in agreement with the field measurements (table 5).

A full suite of QC samples (replicates; laboratory, source solution, trip, ambient and field blanks; and reagent and matrix spikes) were collected and analyzed for dissolved gas samples sent to TestAmerica Laboratories (table 10). Dissolved gasses were not detected in any of the blank samples. Recoveries of dissolved gasses in the reagent spikes ranged from 89 to 95 percent. Recoveries in the matrix spikes were much more variable ranging from -33 to 1,004 percent; this large variability likely is due to the dissolved gasses present at concentrations at least four times greater than the matrix spike concentration. In these cases, recovery-control limits likely are not applicable.

Two dissolved gas samples (environmental sample 1 and environmental sample 2) were sent to Isotech Laboratories, Inc., for analysis. The container for environmental sample 1 was cracked, and therefore, was not analyzed. Environmental sample 2 was analyzed for 16 dissolved gasses; 13 gasses were detected (table 9). These data have no qualifiers because no QC samples were sent to Isotech Laboratories, Inc., for analysis.

Table 10. Dissolved gasses in quality-control samples collected for monitoring well MW01 near Pavillion, Wyoming, April 2012. (Excel file)

\section{Isotopes and Environmental Tracers}

Isotopic values and concentrations of environmental tracers in environmental samples collected from well MW01 are listed in table 11. Stable isotopic data are provided for methane (hydrogen and carbon), water (hydrogen and oxygen), and dissolved inorganic carbon (carbon). Groundwater-quality samples also were analyzed for environmental tracers, including carbon-14 of dissolved inorganic carbon, the chlorofluorocarbons $\mathrm{CFC}-11, \mathrm{CFC}-12$, and $\mathrm{CFC}-113$; $\mathrm{SF}_{6}$; tritium; the noble gasses helium, neon, argon, krypton, and xenon; and $\delta^{3} \mathrm{He}$. Analytical results for tritium, neon, krypton, xenon, and $\delta^{3} \mathrm{He}$ had not been reported by the laboratories as of August 17, 2012, but analytical results will be entered in the USGS NWIS database when available and will be accessible through the USGS NWIS Web Interface at http:// waterdata.usgs.gov/wy/nwis/qw. Many of these environmental tracers can be used to determine the presence of young or modern water or the apparent age of groundwater (Dunkle and others, 1993; Ekwurzel and others, 1994; Busenberg and Plummer, 2000; Plummer and others, 2004; McMahon and others, 2011).

\section{Quality-Control Results for Monitoring Well MW01}

The implications of QC results for the environmental sample results from monitoring well MW01 can be summarized from project data qualifiers listed in tables 5, 7, 9, and 11. Laboratory analytical results were reported for 234 constituents in various samples. Results were less than method detection limits in all blank samples for 215 (92 percent) of those constituents. There were 1,194 total analytical results for those 234 constituents in the 2 environmental samples and 2 replicate samples. Forty-three results (3.6 percent) were qualified because they were less than 5 times the maximum concentration in associated blanks. Concentrations for replicate samples were reported for 244 constituents in 570 environmental-sample/replicate pairs. Variability was within 20 percent for 559 (98 percent) of those pairs. One result each for 11 constituents was qualified because replicate variability exceeded the 20-percent criterion. Recoveries for spike samples were available for 210 constituents. Recoveries were within 70-130 percent for 195 (93 percent) of those constituents. Of the 1,050 results for those 210 constituents in the 2 environmental samples and 2 replicates, 42 results (4 percent) were qualified because of low recovery and 16 results ( 1.5 percent) were qualified because of high recovery. Overall, 646 analytical results were available for constituents with some type of QC data for the 2 primary environmental samples. Sixty-one of these results (9.4 percent) were qualified because of potential blank contamination, high variability, high recovery, or low recovery.

\section{Quality-Control Results for Monitoring Well MW02}

Groundwater-quality samples were not collected from monitoring well MW02. The USGS redeveloped well MW02 during the week of April 30, 2012. Two QC samples were collected during redevelopment.

The QC samples were analyzed for several inorganic and organic constituents and dissolved gasses (table 3). Analytical results for both QC samples are listed in tables 12, 13, and 14. Analytical results from these two samples are not described further in this report because well MW02 was not sampled. 
Table 11. Isotopes and environmental tracers in environmental samples collected from monitoring well MW01 near Pavillion, Wyoming, April 2012.

[All constituents analyzed in unfiltered water except $813 \mathrm{C}$ of dissolved inorganic carbon and carbon-14 of dissolved inorganic carbon, which were filtered using a 0.45-micron capsule filter. RPD, relative percent difference; $813 \mathrm{C}$, ratio of carbon-13 to carbon-12 isotopes in the sample relative to the ratio in a reference standard; per mil, parts per thousand; VPDB, Vienna PeeDee Belemnite; $82 \mathrm{H}$, ratio of hydrogen-2 to hydrogen-1 isotopes in the sample relative to the ratio in a reference standard; VSMOW, Vienna Standard Mean Ocean Water; CFC, chlorofluorocarbon; --, not applicable; N, value was not determined]

\begin{tabular}{|c|c|c|c|c|c|c|c|c|c|c|c|c|c|c|}
\hline \multirow[b]{2}{*}{ Analyte } & \multirow[b]{2}{*}{ Units } & \multicolumn{4}{|c|}{ Environmental sample 1} & \multicolumn{5}{|c|}{ Sample 1 replicate } & \multicolumn{4}{|c|}{ Environmental sample 2} \\
\hline & & Remark $^{1}$ & Value & $\begin{array}{l}\text { Project } \\
\text { data } \\
\text { qualifiers }^{2}\end{array}$ & $\begin{array}{l}\text { Laboratory } \\
\text { data } \\
\text { qualifiers }\end{array}$ & Remark $^{1}$ & Value & $\begin{array}{l}\text { Project } \\
\text { data } \\
\text { qualifiers }{ }^{2}\end{array}$ & $\begin{array}{l}\text { Laboratory } \\
\quad \text { data } \\
\text { qualifiers }^{3}\end{array}$ & RPD & Remark $^{1}$ & Value & $\begin{array}{l}\text { Project } \\
\text { data } \\
\text { qualifiers }^{2}\end{array}$ & $\begin{array}{c}\text { Laboratory } \\
\text { data } \\
\text { qualifiers }\end{array}$ \\
\hline \multicolumn{15}{|c|}{ Isotech Laboratories, Inc. } \\
\hline$\delta 13 \mathrm{C}$ of methane & per mil, relative to VPDB & -- & $\mathrm{N}$ & -- & & -- & -- & -- & -- & -- & -- & -38.54 & -- & -- \\
\hline$\delta 2 \mathrm{H}$ of methane & per mil, relative to VSMOW & -- & $\mathrm{N}$ & -- & & -- & -- & -- & -- & -- & -- & -208.0 & -- & -- \\
\hline \multicolumn{15}{|c|}{ U.S. Geological Survey Reston Chlorofluorocarbon Laboratory } \\
\hline CFC-11 & picogram per kilogram & -- & 2 & -- & -- & -- & -- & -- & -- & -- & -- & $\mathrm{N}$ & -- & -- \\
\hline CFC-113 & picogram per kilogram & $\mathrm{U}$ & -- & -- & -- & -- & -- & -- & -- & -- & -- & $\mathrm{N}$ & -- & -- \\
\hline CFC-12 & picogram per kilogram & -- & 13 & -- & -- & -- & -- & -- & -- & -- & -- & $\mathrm{N}$ & -- & -- \\
\hline Helium & $\begin{array}{l}\text { 10-9 cubic centimeters of } \\
\text { helium per gram of water } \\
\text { at standard temperature } \\
\text { and pressure }\end{array}$ & -- & 1,170 & 5 & -- & -- & 1,190 & 5 & -- & 0.8 & -- & 2,940 & -- & -- \\
\hline Sulfur hexafluoride (SF6) & femtogram per kilogram & $<$ & 1.00 & -- & -- & -- & -- & -- & -- & -- & $<$ & 1.00 & -- & -- \\
\hline \multicolumn{15}{|c|}{ U.S. Geological Survey Reston Stable Isotope Laboratory } \\
\hline$\delta 180$ of water & per mil, relative to VSMOW & -- & -13.32 & -- & -- & -- & -13.38 & -- & -- & -0.4 & -- & -13.39 & -- & -- \\
\hline$\delta 2 \mathrm{H}$ of water & per mil, relative to VSMOW & -- & -113 & - & -- & -- & -113 & -- & -- & 0.0 & -- & -113 & -- & -- \\
\hline \multicolumn{15}{|c|}{ Woods Hole Oceanographic Institute } \\
\hline $\begin{array}{l}813 \mathrm{C} \text { of dissolved inorganic } \\
\text { carbon }\end{array}$ & per mil, relative to VPDB & -- & -14.39 & -- & -- & -- & -- & -- & -- & -- & -- & -14.11 & -- & -- \\
\hline $\begin{array}{l}\text { Carbon-14 of dissolved inorganic } \\
\text { carbon }\end{array}$ & percent carbon, normalized & -- & 2.22 & -- & -- & -- & -- & -- & -- & -- & -- & 1.53 & -- & -- \\
\hline \multicolumn{15}{|c|}{ U.S. Geological Survey Menlo Park Tritium Laboratory } \\
\hline Tritium in water & picocuries per liter & -- & 0.60 & -- & - & $<$ & 0.2 & -- & $\mathrm{R}$ & - & -- & 0.30 & -- & -- \\
\hline \multicolumn{15}{|c|}{$\begin{array}{l}{ }^{1} \text { Remarks used in table: } \\
<, \text { less than. } \\
\text { U, analyzed for but not detected. }\end{array}$} \\
\hline $\begin{array}{l}{ }^{2} \text { Project data qualifiers used in t } \\
1 \text { - Quantified concentration } \\
2 \text { - Relative percent differeno } \\
3 \text { - Potential low bias; recove } \\
4 \text { - Potential high bias; recov } \\
5 \text { - Value is mean of two resu } \\
6 \text { - Filtered value exceeds un }\end{array}$ & $\begin{array}{l}\text { table. } \\
\text { in the environmental sample is } \\
\text { ce (RPD) between the environ } \\
\text { ery is less than } 70 \text { percent in on } \\
\text { rery is greater than } 130 \text { percent } \\
\text { ults reported by the laboratory. } \\
\text { filtered value. }\end{array}$ & $\begin{array}{l}\text { less than five } \\
\text { hental sample } \\
\text { e or more spi } \\
\text { in one or mor }\end{array}$ & $\begin{array}{l}\text { imes the me } \\
\text { and replicate } \\
\text { e samples. } \\
\text { spike samp }\end{array}$ & $\begin{array}{l}\text { aximum conce } \\
\text { pe is greater tha } \\
\text { ples (only appl }\end{array}$ & $\begin{array}{l}\text { entration in a } \\
\text { an } 20 \text { percent. }\end{array}$ & $\begin{array}{l}\text { lank sample. } \\
\text { ents with qua }\end{array}$ & tified result & & & & & & & \\
\hline $\begin{array}{l}{ }^{3} \text { Laboratory data qualifiers used } \\
\mathrm{R} \text { - radchem non-detect, belo }\end{array}$ & $\begin{array}{l}\text { in table. } \\
\text { w sample specific critical level }\end{array}$ & & & & & & & & & & & & & \\
\hline
\end{tabular}


Table 12. Inorganic constituents in quality-control samples collected for monitoring well MW02 near Pavillion, Wyoming, May 2012. (Excel file)

Table 13. Organic constituents in quality-control samples collected for monitoring well MW02 near Pavillion, Wyoming, May 2012. (Excel file)

Table 14. Dissolved gasses in quality-control samples collected for monitoring well MW02 near Pavillion, Wyoming, May 2012. (Excel file)

\section{References Cited}

Busenberg, E., and Plummer, L.N., 2000, Dating young groundwater with sulfur hexafluoride-Natural and anthropogenic sources of sulfur hexafluoride: Water Resources Research, v. 36, p. 3,011-3,030.

Clesceri, L.S., Greenberg, A.E., and Franson, M. A. H., eds.., 1998, Standard methods for the examination of water and wastewater (20th ed.): Washington, D.C., American Public Health Association [variously paged].

Dunkle, S.A., Plummer, L.N., Busenberg, E., Phillips, P.J., Denver, J.M., Hamilton, P.A., Michel, R.L., and Coplen, T.B., 1993, Chlorofluorocarbons $\left(\mathrm{CCl}_{3} \mathrm{~F}\right.$ and $\left.\mathrm{CCl}_{2} \mathrm{~F}_{2}\right)$ as dating tools and hydrologic tracers in shallow groundwater of the Delmarva Peninsula, Atlantic Coastal Plain, United States: Water Resources Research, v. 29, p. 3,837-3,860.

Ekwurzel, B., Schlosser, P., Smethie, W.M., Plummer, L.N., Busenberg, E., Michel, R.L., Weppernig, R., and Stute, M., 1994, Dating shallow groundwater: comparison of the transient tracers ${ }^{3} \mathrm{H} /{ }^{3} \mathrm{He}$, chlorofluorocarbons, and ${ }^{85} \mathrm{Kr}$ : Water Resources Research, v. 30, p. 1,693-1,708.

Hach Chemical Company, 2008, Portable Turbidimeter, Model 2100P, Instrument and Procedure Manual: accessed September 9, 2012, at http://www.hach.com/2100p-portableturbidimeter/product-downloads?id=7640450099.

Hem, J.D., 1985, Study and interpretation of chemical characteristics of natural water (3d ed.): U.S. Geological Survey Water-Supply Paper 2220, 81 p.

James Gores and Associates, 2011, Pavillion area water supply, Level I study: Riverton, Wyo., James Gores and Associates, P.C. Report, 136 p.
McMahon, P.B., Plummer, L.N. , Böhlke, J.K. , Shapiro, S., and Hinkle, S.R., 2011, A comparison of recharge rates in aquifers of the United States based on groundwater-age data: Hydrogeology Journal, v. 19, p. 779-800.

Plummer, L.N., Bexfield, L.M., Anderholm, S.K., Sanford, W.E., and Busenberg, E., 2004, Geochemical characterization of groundwater flow in the Santa Fe Group aquifer system, Middle Rio Grande Basin, New Mexico: U.S. Geological Survey Water-Resources Investigations Report 03-4131, $395 \mathrm{p}$.

U.S. Census Bureau, 2010, 2010 Census interactive population search, accessed January 21, 2012, at http://2010.census. gov/2010census/popmap/ipmtext.php? $f=56$.

U.S. Environmental Protection Agency, 1989, Data evaluation, chap. 5 in Risk assessment guidance for Superfund-Volume I-Human health evaluation manual (Part A): Washington, D.C., Office of Emergency and Remedial Response, U.S. Environmental Protection Agency Report EPA/540/189/002, 30 p., accessed July 17, 2012, at http://www.epa. gov/oswer/riskassessment/ragsa/pdf/ch5.pdf.

U.S. Environmental Protection Agency, 1994, Sample preparation and calculations for dissolved gas analysis in water samples using a GC headspace equilibration technique, RSKSOP-175, rev. 0, August 1994: Ada, Oklahoma, U.S. Environmental Protection Agency, R.S. Kerr Environmental Research Laboratory, 14 p.

U.S. Environmental Protection Agency, 2011, Investigation of groundwater contamination near Pavillion, Wyoming: U.S. Environmental Protection Agency Report EPA600-R-00-000, 104 p., accessed July 25, 2012, at http:// www.epa.gov/region8/superfund/wy/pavillion/.

U.S. Geological Survey, variously dated, National field manual for the collection of water-quality data: U.S. Geological Survey Techniques of Water-Resources Investigations, book 9, chaps. A1-A9, accessed August 13, 2012, at http://water. usgs.gov/owq/FieldManual/.

Wilde, F.D., ed., variously dated, Field measurements: U.S. Geological Survey Techniques of Water-Resources Investigations, book 9, chap. A6, with sec. 6.0-6.8, accessed August 13, 2012, at http://pubs.water.usgs.gov/twri9A6/.

Wright, P.R., and McMahon, P.B., 2012, Sampling and analysis plan for the Characterization of groundwater quality in two monitoring wells near Pavillion, Wyoming: U.S. Geological Survey Open-File Report 2012-1197, 91 p. 
Appendix 1. Monitoring Well MW01 field notes-Field instrument calibration notes, general project notes, groundwater-quality notes for samples 1 and 2, alkalinity/acid-neutralizing capacity titration field notes and results (figures 1.1.1-1.3.2)

This appendix contains copies of field related project notes collected for activities related to monitoring well MW01. Specifically this appendix contains field instrument calibration notes (figures 1.1.1 and 1.1.2), general project notes (figures 1.2.1 through 1.2.12), groundwater-quality notes for Monitoring Well MW01 environmental sample 1 (figures 1.2 .13 through $1.2 .15,1.2 .21$ ), the purge log for Monitoring Well MW01 samples 1 and 2 (figures 1.2.16 through 1.2.20), a list of analytes collected from Monitoring Well MW01 during sample 1 (figures 1.2.22 through 1.2.24), groundwater-quality notes for Monitoring Well MW01 environmental sample 2 (figures 1.2.25 through 1.2.27), field analysis notes for alkalinity, acid-neutralization capacity and miscellaneous measurements for Monitoring Well MW01 samples 1 and 2 (figures 1.3.1 through 1.3.9), and alkalinity and acid-neutralization capacity results for Monitoring Well MW01 samples 1 and 2 (figures 1.4.1 through 1.4.6).

\section{Appendix 2. Monitoring Well MW01 laboratory-related documents- Analytical Services Request forms, Chain of Custody records (figures 2.1.1-2.9.7)}

This appendix contains copies of laboratory analytical request forms (ASRs) and chain-of-custody forms (CoC), which accompanied environmental and quality-control samples during shipment to respective laboratories. This appendix includes ASR/CoC forms for the source solution (figures 2.1.1 through 2.1.3); ambient (figures 2.2.1 through 2.2.4) and field blanks (figures 2.3.1 through 2.3.5); ASR and COC forms for environmental sample 1 (figures 2.4.1 through $2.4 .8,2.4 .10$, and 2.4.17); the sample 1 replicate (2.5.1 through 2.5.5); environmental sample 2 (figures 2.6.1 through 2.6.7); the sample 2 replicate (2.7.1 through 2.7.4); the matrix spike sample (figures 2.8.1 through 2.8.5); the matrix-spike duplicate sample (figures 2.9.1 through 2.9.5); and the trip blank (2.9.6 and 2.9.7). Chain-of-custody records that relate to both samples 1 and 2 are included as figures 2.4.9 and 2.4.11 through 2.4.16.

\section{Appendix 3. Monitoring Well MW01 photographs (figures 3.1-3.1.6)}

This appendix contains a selection of photographs taken April 24, 2012, to document sampling activities at Monitoring Well MW01.

\section{Appendix 4. Monitoring Well MW02 field notes-Groundwater-quality and field notes for collection of samples related to work at this well (figures 4.1-4.7)}

This appendix contains copies of field related project notes collected for activities related to monitoring well MW02. Specifically, this appendix includes project notes (figure 4.1), groundwater- quality notes for the collection of a sample of public water supply of the city of Riverton, Wyoming (figures 4.2 through 4.6), and field notes for the collection of a downhole camera equipment blank (figure 4.7).

\section{Appendix 5. Monitoring Well MW02 laboratory-related documents- Analytical Services Request forms, Chain of Custody records (figures 5.1.1-5.2.4)}

This appendix contains copies of laboratory analytical request forms (ASRs) and chain-of-custody forms $(\mathrm{CoC})$ that accompanied the sample of public water supply of the city of Riverton, Wyoming (figures 5.1.1 through 5.1.5) and the downhole camera blank (figures 5.2.1 through 5.2.4) to TestAmerica Laboratories.

\section{Appendix 6. Monitoring Well MW02 photographs (figures 6.1-6.6)}

This appendix contains a selection of photographs taken May 1st and 2nd, 2012 to document redevelopment related activities at Monitoring Well MW02.

\section{Appendix 7. Tentatively identified compounds identified in environmental and quality-control samples collected for monitoring well MW01 near Pavillion, Wyoming}




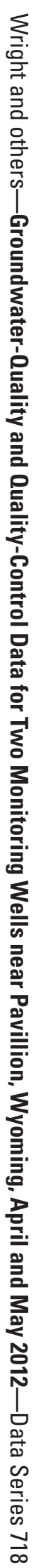




\section{TECHNICAL MEMORANDUM}

September 30, 2012

Prepared by:

Tom Myers, Ph.D.,

Hydrogeologic Consultant

Reno NV

Re: Assessment of Groundwater Sampling Results Completed by the U.S. Geological Survey

\section{Summary}

The organic chemistry at MW01 has not changed substantially since the EPA sampled the well; some constituents have increased and some have decreased, as would be expected with organic contaminants discharging from a series of event, the hydraulic fracturing of natural gas wells. Because the water chemistry data at MW01 has essentially been replicated, the evidence supporting the hypothesis that natural gas drilling activities, including fracking, have contaminated the Wind River aquifer near Pavillion WY has been strengthened. The conclusions based on that analysis should be more widely accepted now that the water quality has been replicated.

The concentrations of gas, including methane and ethane, have increased and that of propane has remained relatively constant. The ratio of ethane and propane to methane and the isotopic signature of methane all indicate that the gas source is thermogenic, meaning a deep formation. An increasing concentration indicates the formation is likely the source because the concentration will increase as more of the formation contributes to gas at the monitoring well.

EPA monitoring well 2 was not sampled because it did not yield sufficient water. The EPA had been able to purge over a borehole's volume of water, therefore they were clearly sampling formation water. There is no reason to consider that the current condition of MW02 negates the results of the EPA in 2011.

The problems with MW02 however indicate other problems with the sampling of these wells. The USGS used standard purge techniques, not techniques designed to minimize losses of volatile organics to the atmosphere. Purging too fast or drawing the water level too low could cause the measurement to be biased too low.

\section{Introduction}

The U.S. Environmental Protection Agency (EPA) published in late 2011 a study assessing the association of various organic compounds, which could be associated with the presence of 
natural gas development, or hydraulic fracturing (fracking), in water wells and monitoring wells near Pavillion WY. This study was one of the first to document fracking fluid chemicals in water wells and monitor wells away from the actual natural gas wells. The U.S. Geological Survey (USGS) recently published a data-series report (Wright et al 2012) that reports groundwater quality sampling completed in one of EPA's monitoring wells that had been constructed and sampled for the EPA study.

Wright et al (2012) do not make any conclusions regarding the data presented nor do they compare it to the original EPA report (EPA 2011). They present sampling and quality control data in detail. This memorandum takes the USGS study an additional step by comparing the results released in the new study with the original EPA report (EPA 2011). It considers whether the new data refutes the original EPA study, either with the actual chemistry data collected or by showing problems with EPA monitoring well 2.

\section{Sampling and Chemistry of EPA Monitoring Well 1}

USGS sampled EPA monitoring well \# 1 (MW01) in late April 2012. The USGS collected four types of blank samples and two replicates from the well after purging more than a borehole's volume of water. Spike samples were also created to assess the accuracy of the testing equipment at the labs. EPA monitoring well \# 2 (MW02) was not similarly sampled for reasons discussed in a following section.

Sampling commenced by purging groundwater from the well to remove the static water from the borehole. Their goal had been to remove at least one borehole volume, or 429 gallons, or to the point where several parameters including $\mathrm{pH}$ and EC stabilized. The USGS began pumping about 6 gpm which lowered the water level about 135 feet within the time that 300 gallons were removed from the well bore. At that point, the pumping rate dropped to about $2.5 \mathrm{gpm}$ and the water level quickly recovered about 60 feet. Sampling commenced at about 670 cumulative gallons. Purging continued, and the second environmental sample commenced after about 1300 cumulative gallons. Thus the samples were taken after about one and half and three bore holes volume, respectively. The purge rate was commensurate with that used by the EPA for MW01 in that they started at $7.3 \mathrm{gpm}$ and reduced it to about $6 \mathrm{gpm}$ as the water level quickly dropped (EPA 2011).

The USGS did not sample exactly the same constituents as did the EPA. The USGS sampled many constituents and their Table 7 lists many that had below detect (ND) levels, as did the EPA. Table 1 compares constituents found by either the EPA (2011) or the USGS (Wright et al 2012), or by both. 
Table 1: Comparison of water chemistry for EPA Monitoring Well \# 1 for EPA phase 3 and 4 sampling (EPA 2011) with environmental samples 1 and 2 as reported by Wright et al (2012). The table includes only constituents for which there were detectable values at least once. $\mathrm{Nd}$ means no detect. Blank table cells under Phase 3 or 4 mean no sample. P means preservative added.

\begin{tabular}{|c|c|c|c|c|c|}
\hline Name & Units & Phase 3 & Phase 4 & $\begin{array}{c}\text { Env } \\
\text { Sample } \\
1\end{array}$ & $\begin{array}{c}\text { Env } \\
\text { Sample } \\
2\end{array}$ \\
\hline $\mathrm{pH}$ & & 11.9 & 11.2 & 11.4 & 10.7 \\
\hline K & $\mathrm{mg} / \mathrm{l}$ & 54.9 & 24.7 & 15 & 13 \\
\hline $\mathrm{Cl}$ & $\mathrm{mg} / \mathrm{l}$ & 23.3 & 23.1 & 26 & 27 \\
\hline $\begin{array}{l}\text { Diesel-range organics [C10- } \\
\text { C28] }\end{array}$ & $\mu \mathrm{g} / \mathrm{L}$ & 634 & 924 & 180 & 85 \\
\hline $\begin{array}{l}\text { Gasoline-range organics [C6- } \\
\text { C10] }\end{array}$ & $\mu \mathrm{g} / \mathrm{L}$ & 389 & 592 & 700 & 730 \\
\hline $\begin{array}{l}\text { Gasoline-range organics [C6- } \\
\text { C10] }\end{array}$ & $\mu g / L$ & & & $1100 p$ & $700 p$ \\
\hline 3 \& 4 Methylphenol & $\mu \mathrm{g} / \mathrm{L}$ & $\begin{array}{c}\text { included in } \\
\text { phenol }\end{array}$ & & 0.95 & 0.47 \\
\hline Benzoic acid & $\mu \mathrm{g} / \mathrm{L}$ & 212 & 457 & 340 & 190 \\
\hline Benzyl alcohol & $\mu \mathrm{g} / \mathrm{L}$ & & & 0.59 & nd \\
\hline Phenol & $\mu \mathrm{g} / \mathrm{L}$ & 11.1 & 20.9 & 10 & 6.1 \\
\hline 1-Methylnaphthalene & $\mu \mathrm{g} / \mathrm{L}$ & & & 0.0096 & nd \\
\hline 2-Methylnaphthalene & $\mu \mathrm{g} / \mathrm{L}$ & & & 0.0110 & 0.0072 \\
\hline Benzo[a]anthracene & $\mu g / L$ & & & nd & 0.0042 \\
\hline Benzo[a]pyrene & $\mu \mathrm{g} / \mathrm{L}$ & & & nd & 0.0410 \\
\hline Benzo[b]fluoranthene & $\mu g / L$ & & & nd & 0.0310 \\
\hline Benzo[g,h,i]perylene & $\mu \mathrm{g} / \mathrm{L}$ & & & 0.0410 & 0.0740 \\
\hline Benzo[k]fluoranthene & $\mu \mathrm{g} / \mathrm{L}$ & & & nd & 0.0290 \\
\hline Chrysene & $\mu \mathrm{g} / \mathrm{L}$ & & & nd & 0.0037 \\
\hline Dibenz $(a, h)$ anthracene & $\mu g / L$ & & & nd & 0.0510 \\
\hline Fluoranthene & $\mu \mathrm{g} / \mathrm{L}$ & & & nd & 0.0063 \\
\hline Indeno[1,2,3-cd]pyrene & $\mu g / L$ & & & 0.0160 & 0.0570 \\
\hline Pyrene & $\mu \mathrm{g} / \mathrm{L}$ & & & 0.0089 & 0.0130 \\
\hline $\begin{array}{l}\text { Methylene blue active } \\
\text { substances }\end{array}$ & $\mathrm{mg} / \mathrm{L}$ & & & 0.14 & 0.15 \\
\hline Methane & $\mu \mathrm{g} / \mathrm{L}$ & 15950 & 17930 & 27,500 & 25,500 \\
\hline Methane & $\mu \mathrm{g} / \mathrm{L}$ & & & $27,000 p$ & $20,000 p$ \\
\hline Ethane & $\mu g / L$ & 2230 & 2950 & 3,600 & 3,200 \\
\hline Ethane & $\mu \mathrm{g} / \mathrm{L}$ & & & $3,800 p$ & $2,600 p$ \\
\hline Ethylene & $\mu g / L$ & & & 7.2 & 7.2 \\
\hline Ethylene & $\mu \mathrm{g} / \mathrm{L}$ & & & $7.2 p$ & $7.2 p$ \\
\hline
\end{tabular}




\begin{tabular}{|l|l|r|r|r|r|}
\hline Propane & $\mu \mathrm{g} / \mathrm{L}$ & 790 & 1250 & 1,400 & 1,100 \\
\hline Propane & $\mu \mathrm{g} / \mathrm{L}$ & & & $1,300 \mathrm{p}$ & $1,000 \mathrm{p}$ \\
\hline Toluene & $\mu \mathrm{g} / \mathrm{L}$ & 0.75 & 0.56 & nd & nd \\
\hline xylenes (total) & $\mu \mathrm{g} / \mathrm{L}$ & & 0.89 & nd & nd \\
\hline isopropanol & $\mu \mathrm{g} / \mathrm{L}$ & & 212 & nd & nd \\
\hline diethylene glycol & $\mu \mathrm{g} / \mathrm{L}$ & & 226 & nd & nd \\
\hline triethylene glycol & $\mu \mathrm{g} / \mathrm{L}$ & & 46 & nd & nd \\
\hline tetraethylene glycol & $\mu \mathrm{g} / \mathrm{L}$ & & 7.3 & nd & nd \\
\hline 2-butoxyethanol & $\mu \mathrm{g} / \mathrm{L}$ & & 12.7 & not tested \\
\hline acetate & $\mu \mathrm{g} / \mathrm{L}$ & & 8050 & not tested \\
\hline formate & $\mu \mathrm{g} / \mathrm{L}$ & & 112 & not tested \\
\hline lactate & $\mu \mathrm{g} / \mathrm{L}$ & & 69 & not tested \\
\hline propionate & $\mu \mathrm{g} / \mathrm{L}$ & & 309 & \multicolumn{2}{|c|}{ not tested } \\
\hline
\end{tabular}

The concentrations of potassium $(\mathrm{K})$ and the $\mathrm{pH}$ level are still much higher than the background levels in the formation, although $\mathrm{K}$ has decreased since the EPA sampling. EPA linked the presence of potassium to its use as a crosslinker and solvent during fracking, according to the Material Data Safety Sheets provided by the industry. Most of the fracking occurred several years ago, therefore the source is not a continuous release. A relatively conservative element such as potassium could move through the aquifer much more quickly than some of the organics.

Gasoline range organics and the various carbon-chain gases were found at concentrations that have increased significantly since the EPA study. Benzoic acid was found at concentrations similar to the EPA (2011). Diesel range organics and phenol remained present but at lower concentrations. The USGS found at least nine organic constituents that the EPA had either not found or not tested for. USGS found acrylonitrile at $21 \mathrm{ug} / \mathrm{l}$ in one of the replicate samples, not presented in Table $1^{1}$. At least six constituents that had been detected by the EPA (2011) were not detected by the USGS. At least six constituents that EPA has found at various concentrations were not tested for by the USGS.

The concentration of organics at Pavillion should vary for several reasons. Changes from one sampling event to the next do not represent a trend. A non-detect does not prove the constituent does not exist.

Organics are measured at very low concentrations, parts per billion, so a relatively small change proportionally seems much larger. An acceptable spike sample is one for which the measured

\footnotetext{
${ }^{1}$ According to Dr. Glenn Miller, acrylonitrile is "perhaps the single best indicator of fracing, and should be considered presumptive evidence that fracing fluids have contaminated the groundwater", although he also acknowledged that one observation, in a replicated sample, is not proof. Email communication, 9/27/2012.
} 
concentration varies from 70 t $130 \%$ of the known concentration which indicates just how variable the test methods are. Even $70 \%$ recovery could cause a sample which otherwise should have had a detectable concentration to be missed; a 130\% recovery means however that a concentration can be overestimated, although it will not find a constituent in a sample in which it does not exist.

Organics attenuate by interactions with clay and silt sized particles so seasonal changes could be expected. This sampling occurred during late April, a time period during which recharge should be highest, since there is a mound in the shallow groundwater suggesting downward movement of water. Such vertical flow could dilute the formation water and cause seasonal changes not accounted for in spot samples as collected by the USGS.

The concentration of methane and ethane increased substantially and that of propane remained relatively constant. The stable isotope ratios of carbon vs. hydrogen in methane are also almost exactly as found by the EPA. The gas in MW01 is thermogenic, and its concentration is increasing. An increasing concentration of thermogenic gas suggests its source is the formation rather than a leaky gas well. The continued increase in concentration reflects that gas flow from more of the formation has reached the monitoring well, a process which will continue until it reaches equilibrium; in other words, the flow of gas through the formations, released by fracking, could reach equilibrium at the current or a higher concentration. If the formation is the source, the gas contamination will continue as long as the source releases gas.

In summary, the organic chemistry at MW01 has not changed substantially since the EPA sampled the well. The chemistry of MW01 found by the USGS is similar to that found by the EPA (2011). The new data does not disprove the hypothesis made by the EPA that natural gas drilling activities, including fracking, have contaminated the Wind River aquifer near Pavillion WY. The conclusions based on that analysis should be more widely accepted because the water quality has been replicated.

\section{Monitoring Well 2}

The USGS did not sample MW02 because the well reportedly yielded only about 1 gallon per hour (Wright et al 2012). This differs from the EPA's purging which for Phase IV reportedly removed 1249 liters (330 gallons) of water prior to sampling; EPA did find that the water level lowered more quickly than they could measure it. The USGS redeveloped the well but this did not improve the yield sufficiently for sampling, therefore they did not obtain a sample.

MW02 had been completed in a layer of sandstone approximately 20 feet thick with a shale confining layer both above and below. The resistivity logs also suggest this should be a productive zone. There is no good explanation for the well's failure to produce sufficient water for sampling, but its failure does not obviate the results found by the EPA for that well. The fact 
that the well produced substantial water from the sandstone twice indicates that the formation contained the constituents.

\section{Bias Due to Volatilization}

Most of the organic chemicals sampled for at the EPA monitoring wells will volatilize, meaning be lost to the air from the sample, under the correct conditions. In general those conditions are due to exposure to air which can be enhanced due to turbulence (Nielsen and Nielsen 2006). Sampling a well just after purging without allowing the well to recover without pumping can cause more volatilization and decrease the amount of constituent recovered in the sample (Herzog et al 1988). Too much purging or purging that causes too much drawdown can also increase volatilization because of the speed with which groundwater flows back into the well (McAlary and Barker 1987). Purging too rapidly or not sampling at the correct time after recovery can cause a bias in the resulting sample concentration. This could have occurred at both the USGS sampling of MW01 and in the EPA's sampling of MW01 and MW02. Concentrations of organics, particularly VOCs, should be considered as potentially low compared to the background groundwater.

\section{References}

Herzog BL, SFJ Chou, JR Valkenburg, RA Griffin (1988) Changes in volative organic chemical concentrations after purging slowly recovering wells. Ground Water Monitoring and Remediation 8(4):93-99.

McAlary TA, JF Barker (1987) Volatilization losses of organics during ground water sampling from low permeability materials. Ground Water Monitoring and Remediation 7(4): 63-68.

Nielsen, DM, GL Nielsen (2006) Chapter 15, Ground-Water Sampling. In Nielsen DM (ed) Environmental Site Characterization and Ground-Water Monitoring. CRC Press. 1318 p.

U.S. Environmental Protection Agency (EPA) (2011) Investigation of groundwater contamination near Pavillion, Wyoming: U.S. Environmental Protection Agency Report EPA-600-R-00-000, 104 p., accessed July 25, 2012, at http://www.epa.gov/region8/superfund/wy/pavillion/.

Wright PR, PB McMahon, DK Mueller, ML Clark, (2012) Groundwater-quality and quality-control data for two monitoring wells near Pavillion, Wyoming, April and May 2012: U.S. Geological Survey Data Series 718, 23 p. 


\section{Is fracking behind contamination in Wyoming groundwater?}

Questions about whether hydraulic 'fracking' is to blame remain as the US EPA prepares for peer review.

\section{Jeff Tollefson}

\section{October 2012 Clarified: 10 October 2012}

The US Environmental Protection Agency (EPA) sparked a firestorm in December last year when it released a draft report ${ }^{1}$ suggesting that the use of hydraulic fracturing or 'fracking' — to extract natural gas had contaminated groundwater near Pavillion, Wyoming. Industry officials have long denied that fracking affects groundwater, and Pavillion has become the first high-profile test of this claim. On 26 September, the US Geological Survey (USGS) released data showing the presence of groundwater contamination in the region ${ }^{2}$. Although the data would seem to support the EPA's assessment - as does an independent analysis released by environmental groups

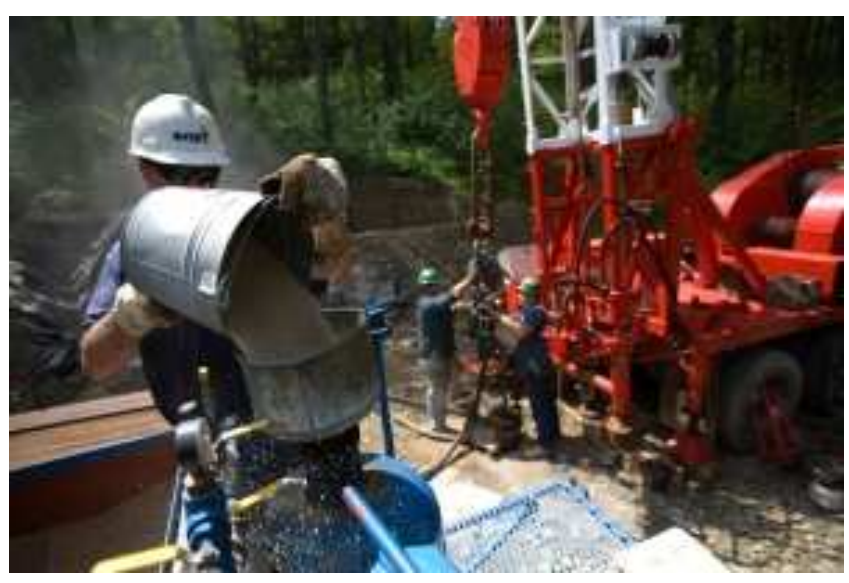

Natural gas extraction via hydraulic fracturing has been linked to contamination in groundwater. GETTY IMAGES this week ${ }^{3}$ - the survey did not seek to determine the source of the contamination. Nature examines the on-going debate and how it relates to broader questions about groundwater contamination from fracking across the United States.

\section{How did this investigation begin?}

After local landowners complained about the smell and taste of their water, the EPA began in 2009 to analyse the groundwater outside Pavillion. The agency tested the water in the shallow wells that tap the groundwater above the 169 gas-producing wells in the field; in two municipal wells in the town; and in several surface and deep wells that it drilled for monitoring purposes. It found evidence of contamination in both the shallow and deep wells, and attributed the shallow contamination to the 33 or so nearby surface pits used to store drilling wastes ${ }^{1}$. The pits could not, however, explain the contamination in the deeper groundwater.

\section{What is the evidence that fracking contaminated the deep groundwater?}

A range of hydrocarbons showed up in the deep wells, as did some synthetic organic chemicals associated with fracking fluids and drilling activities. The EPA also found high $\mathrm{pH}$ levels that could be explained by 
potassium hydroxide, which was used in a solvent at the site. The agency also analyzed the evolution of the pollution plume to determine that groundwater seems to be migrating upward, suggesting that the source of contamination came from the gas production zone rather than the surface pits.

Officials with both industry and the state of Wyoming questioned the EPA's data as well as its interpretation, arguing that some hydrocarbons are to be expected through natural migration from the gas field. The state then asked the USGS to conduct a new analysis and provide the data to the state. The USGS provided those data last week ${ }^{2}$; it also sent samples to the EPA, which is conducting its own analysis.

\section{Related stories}

- Fracking boom spurs environmental audit

- Air sampling reveals high emissions from gas field

\section{What do the latest results suggest?}

The USGS provided only the raw data and no interpretation. An analysis released this week by two environmental groups found that the data support the EPA's original conclusion. A scientist who has investigated possible contamination at other sites, Rob Jackson of Duke University in Durham, North Carolina, says that multiple lines of evidence are certainly "suggestive" of fracking as a source of contamination.

\section{Does this settle the debate?}

No. Encana Corporation, an energy producer based in Calgary, Canada, that has wells in the field near Pavillion, maintains that neither the EPA draft report nor the USGS results provide any proof that drilling operations are to blame.

\section{Is this case unique?}

There have been allegations of groundwater contamination at other locations where fracking has taken place, but it is not yet clear how common the problem might be. It is less likely, for instance, in regions where the gas is very deep in the ground, such as in Pennsylvania, where production takes place at depths of 1,500 meters or more. In Pavillion, the gas wells are as shallow as 372 metres, while wells tapping groundwater are up to 244 metres deep; this makes communication between the two zones much easier.

A report in February by the University of Texas at Austin's Energy Institute found no evidence of contamination from fracking near wells in Texas, Pennsylvania or New York, but the university is currently reviewing that report after the lead scientist, Charles Groat, was accused of having a conflict of interest (see 'Unfortunate oversight').

A 2011 study in the Proceedings of the National Academy of Sciences by Jackson and his colleagues ${ }^{4}$ documented high concentrations of methane and other hydrocarbons in groundwater close to fracking operations in Pennsylvania and New York. But Jackson says that the contamination may have come not from the fracking but from the wells themselves, which can serve as a conduit between geological formations if 
not properly sealed.

\section{What comes next?}

The EPA plans to complete its analysis of the water samples and then turn over all of the data for an independent peer review later this year. In a press conference on Tuesday, Wyoming Governor Matt Mead said that the state would analyse the USGS data and then determine whether it needs to change its rules on fracking operations.

In parallel, the EPA is conducting a national assessment of environmental and public-health issues associated with fracking and expects to produce an initial report later this year.

Nature doi:10.1038/nature.2012.11543

\section{Clarifications}

Clarified: An earlier version of this story did not make clear that an analysis of USGS data by environmental groups found that the data are consistent with but do not confirm - with EPA conclusions about water contamination due to fracking. This has been clarified.

\section{References}

1. US Environmental Protection Agency. Investigation of Ground Water Contamination near Pavillion, Wyoming (EPA, 2011). available at http://www.epa.gov/region8/superfund/wy/pavillion/EPA_ReportOnPavillion_Dec-8-2011.pdf

Show context

2. US Geological Survey Groundwater-Quality and Quality-Control Data for Two Monitoring Wells near Pavillion, Wyoming, April and May 2012 (USGS, 2012). available at http://pubs.usgs.gov/ds/718/DS718_508.pdf

Show context

3. Myers, T. Technical Memorandum: Assessment of Groundwater Sampling Results Completed by the U.S. Geological Survey (2012). available at http://www.sierraclub.org/pressroom/downloads/myers-techmemo-093012.pdf

Show context

4. Osborne, S. G., Vengosh, A., Warner, N. R. \& Jackson, R. B. Proc. Natl Acad. Sci. USA advance online publication http://dx.doi.org/10.1073/pnas.1100682108 (2011).

Show context

\section{Related stories and links}




\title{
From nature.com
}

- Fracking boom spurs environmental audit

29 May 2012

- Air sampling reveals high emissions from gas field

07 February 2012

\section{Comments}

2012-10-04 06:49 AM

Sherif Hindi said: Induced hydraulic fracturing is a technique used to increase the released petroleum and/or natural gas. This type of fracturing creates fractures from a wellbore drilled into reservoir rock formations. Potential environmental impacts, including contamination of ground water, risks to air quality, the migration of gases and hydraulic fracturing chemicals to the surface, surface contamination from spills and flowback and the health effects of these factors. For these reasons, hydraulic fracturing has come under scrutiny internationally, with some countries suspending or even banning it. Hydraulic fracturing has raised environmental concerns and is challenging the adequacy of existing regulatory regimes. These concerns have included ground water contamination, risks to air quality, migration of gases and hydraulic fracturing chemicals to the surface, mishandling of waste, and the health effects of all these. Accordingly, a fair decision must be regarded for selecting either profit or human health, especially when the petroleum projects approaches to residential communities. However, accurate fracturing monitoring must be regarded by measuring of the pressure and rate during the growth of a hydraulic fracture, the fluid properties along with geology information that provide the simplest monitoring method. In addition, injection of radioactive tracers is sometimes used for this monitoring task. Furthermore, microseismic monitoring is sometimes used to estimate the size and orientation of hydraulically induced fractures by placing an array of geophones in a nearby wellbore. Tiltmeter arrays, deployed on the surface or down a well, provide another technology for monitoring the strains produced by hydraulic fracturing. Dr. Sherif Shawki Zaki Hindi King Abdull-Aziz Univ. Saudi Arabia

You need to be registered with Nature and agree to our Community Guidelines to leave a comment. Please log in or register as a new user. You will be re-directed back to this page.

\section{See other News \& Comment articles from Nature}

\author{
Nature ISSN 0028-0836 EISSN 1476-4687
}





\section{TECHNICAL MEMORANDUM}

April 30, 2012

Review of DRAFT: Investigation of Ground Water Contamination near Pavillion Wyoming Prepared by the Environmental Protection Agency, Ada OK

Prepared by: Tom Myers, Ph.D.

Hydrologic Consultant

Reno NV

\section{SUMMARY AND RECOMMENDATIONS}

After consideration of the evidence presented in the EPA report and in URS (2009 and 2010), it is clear that hydraulic fracturing (fracking (Kramer 2011)) has caused pollution of the Wind River formation and aquifer. The EPA documents that pollution with up to four sample events in the domestic water wells and two sample events in two monitoring well constructed by the EPA between the level of the domestic water wells and the gas production zone. The EPA's conclusion is sound.

Three factors combine to make Pavillion-area aquifers especially vulnerable to vertical contaminant transport from the gas production zone or the gas wells - the geology, the well design, and the well construction. Natural flow barriers are not prevalent in this area, so there are likely many pathways for gas and contaminants to move to the surface, regardless of the source. There is also a vertical gradient, evidenced by flowing water wells, although its magnitude and extend are undefined, to drive advective vertical transport. The entire formation is considered an underground source of drinking water, but 169 gas wells have been constructed into it; this is fracking fluid injection directly into an underground source of drinking water.

The well design is poor because the surface casing does not extend below the level of the water wells, as is required in many other states, and because the wells contain substantial borehole lengths without surface casing or cement between the production casing and the edge of the borehole. This allows vertical transport of gas and fluids and decreases the protection against leakage during fracking or gas production. Third, the EPA documented many instances of sporadic bonding, which simply means the cement does not completely seal the annulus between the production casing and the edge of the borehole. This provides pathways which could allow gas and contaminant transport along the well bore.

The EPA also appropriately accounted for the potential that their monitoring well construction could have explained the contamination. "Since inorganic and organic concentration patterns measured in the drilling additives do not match patterns observed in the deep monitoring wells and because large volumes of ground water were extracted from the wells during development and prior to sampling, it is unlikely that ground-water chemistry was at all impacted by drilling additives."(EPA, 2011, p 7). 
The EPA also demonstrated that the inorganic geochemistry in the monitoring wells is substantially different than that which would occur naturally in the area, and that the enrichment of numerous constituents is most likely due to the interaction of fracking fluid with the groundwater near the sampled well. This is particularly true for the elevated levels of potassium, chloride, and $\mathrm{pH}$.

Any of the three contaminant transport pathways suggested by the EPA could be responsible for the contamination moving from the fracking zone to the drinking water wells. The EPA has also presented evidence that contamination in surface ponds has not caused the contamination in the water wells or their monitoring wells.

The situation at Pavillion is not an analogue for other gas plays because the geology and regulatory framework may be different. The vertical distance between water wells and fracking wells is much less at Pavillion than in other areas, so the transport time through the pathways may also be low compared to other gas plays. It is important, however, to consider that the pathways identified at Pavillion could be applicable elsewhere (Myers, 2012; Osborn et al, 2011). In addition to improving and enforcing the relevant regulations, monitoring the pathways between the target formation and aquifers should be standard at all gas plays with fracking.

The following recommendations would improve the analysis and continue the study into the future made throughout this review.

1. The EPA should continue data collection to better verify the sources and map the potential contaminant plumes.

2. EPA should map the gas production wells according to their construction date. The EPA should also compare the locations of observed contamination with the nearby well construction dates to estimate the travel times from the sources to the well receptors.

3. The EPA should map the depth to water prior to sampling in the water wells. Using this, they should map vertical gradients and correlate these gradients to areas with contaminants most likely sourced to deep aquifers.

4. The EPA should install deeper monitoring wells near the shallow pits to better map the depth of the plume emanating from those pits.

5. Data collection should continue so the results can be replicated. An additional, deeper monitoring well should be constructed in the gas production zone between the existing monitoring wells to determine the vertical gradient and estimate the rate of vertical flow.

6. The EPA presents no evidence regarding the extent that fracturing extends above targeted formations. It may not be possible to prove whether this occurred at this site, but the EPA should at least discuss the possibility. It would be useful to perform some simple testing to map the extent of fractures, as described by Fisher and Warpinski (2010). 


\section{INTRODUCTION}

The Environmental Protection Agency (EPA) has released a study of groundwater contamination in the Pavillion gas play in west-central Wyoming. Their preliminary conclusion is that gas well development and hydraulic fracturing (fracking (Kramer, 2011)) has caused the contamination. The EPA report is in draft form and is open for comment until March 12, 2012. This technical memorandum reviews the EPA report. This review was prepared with support from the Natural Resources Defense Council, Wyoming Outdoor Council, Earthworks, Oil and Gas Accountability Project and Sierra Club.

This review discusses in detail the appropriateness of the study design, methodology, execution, results, and interpretation and the reasonableness of the conclusions. It specifically follows and considers the EPA's "lines of reasoning" approach used to reach its conclusion.

\section{STUDY AREA}

The study area is in the Pavillion gas field in west-central Wyoming. It lies northeast of the Wind River Range. The general geology for uppermost 1000 meters $(\mathrm{m})$ is the Eocene-aged ( $(56$ to 34 million years before present) Wind River Formation, which is interbedded sandstone and shale with coarse-grained meandering stream channel deposits. The presence of stream channel deposits indicates that the formation has been carved by river beds which left fluvial deposits interspersed among formation layers These fluvial deposits often provide connectivity among formation layers and can fragment otherwise continuous sedimentary layers.

The area has experienced gas development since the 1960s, with 169 gas wells constructed in the study area. EPA Figure 2 shows the gas well construction chronology. There were three main periods of construction - 1963-65, 1975-83, and 1998 - 2006, with each subsequent period having more new wells constructed than the previous period. EPA does not specify when fracking first occurred, however.

Recommendation: Add a map of gas production wells coded for the year or time period during which the well was completed (or fracking occurred if substantially different). This would allow an assessment of travel time for contaminants to flow from production zones to the monitoring wells and domestic wells.

The US Geological Survey studied the water resources on the Wind River Reservation (Daddow 1996), which surround this study area (but does not include it). The Wind River Formation is the primary source of drinking water on the reservation. Daddow's (1996) description of the formation indicates that the formation consists of interbedded shale and sandstone with extremely variable permeability that could lead to highly variable contaminant loads throughout the formation (Osiensky et al 1984).

Recommendation: A more detailed description of the geology and hydrogeology of the area, perhaps based on the relevant Geological Survey reports would provide more insight regarding geochemical trends as found by the USGS. 


\section{STUDY LAYOUT AND DESIGN}

EPA started this study in response to citizen complaints regarding contamination in their water wells. EPA established dedicated monitoring wells after two rounds of sampling various water wells rather than prior to construction of the gas wells. For much of their study data, the EPA had to use sample data collected from existing water wells. Water wells are not the best tool for monitoring groundwater quality because, even if the well construction is of similar quality to a dedicated monitoring well, water wells have much longer screens, or open intervals, than do monitoring wells. They screen the most productive formation layers, usually based on observations made during drilling, to maximize the pumping rate while minimizing the drawdown. Wells drilled specifically for monitoring wells also screen productive zones, but target the screen to a specific zone, usually 20 feet or less thick, so that the sample represents a given aquifer level.

Samples from water wells are therefore a mixture of water from all productive zones of the entire open interval, weighted according to the transmissivity of each zone. A domestic water well sample is useful for determining whether a contaminant exists at some point in the aquifer, but a dedicated monitoring well is necessary to determine which layer is contaminated.

EPA established two dedicated monitoring wells to supplement the data obtained from the water wells. The new monitoring wells were primarily screened below the level of the water wells (Figure 1) and above the gas production wells to "differentiate potential deep (e.g., gas production related) versus shallow (e.g., pits) sources of groundwater contamination" (EPA p 5). The EPA established just two monitoring wells due to a limited budget (Id.). EPA placed the monitoring wells' screened interval along the conceptualized vertical pathway between the potential contaminant source (i.e. the production wells and/or zone) and the water wells. The monitoring wells were designed appropriately to detect and monitor contaminant movement upward from the production zone to the water wells; if the monitoring wells had been constructed at the same depth as the water wells, they would not have added substantial useful information.

Figure 1 (EPA Figure 3) shows that domestic water wells in the regions are screened at all levels down to about $250 \mathrm{~m}$, or more than 800 feet, with half of the wells being deeper than 300 feet, similar to the depths found by Daddow (1996) in other areas of the aquifer. However, the EPA states the information source was from the State Engineer and homeowner interviews (EPA p 2). It is unclear whether both were used for each well. It is my experience that homeowners have a poor concept of the depth of their well unless they have paperwork that documents it.

Recommendation: The EPA should provide more information about the source of its water well construction data, showing it in EPA Table A1.

The following table summarizes in general terms the wells that were sampled during each sampling phase (other media were also sampled but not included in this table). It is apparent that the wells sampled in phases subsequent to the first phase depended in part on the results of the prior phases. 


\begin{tabular}{|l|l|l|l|l|l|l|}
\hline Phase & Date & $\begin{array}{l}\text { Domestic } \\
\text { and Stock } \\
\text { Wells }\end{array}$ & $\begin{array}{l}\text { Municipal } \\
\text { Wells }\end{array}$ & Stock Wells & $\begin{array}{l}\text { Monitoring } \\
\text { Wells }\end{array}$ & Comments \\
\hline I & $3 / 09$ & 35 & 2 & 0 & 0 & \\
\hline II & $1 / 10$ & $\begin{array}{l}17(10 \\
\text { previously } \\
\text { sampled) }\end{array}$ & 2 & 4 & 0 & $\begin{array}{l}\text { This phase came about } \\
\text { because EPA had detected } \\
\text { methane and dissolved } \\
\text { hydrocarbons during Phase I. }\end{array}$ \\
\hline III & $10 / 10$ & $\begin{array}{l}3(2 \\
\text { previously } \\
\text { sampled) }\end{array}$ & 0 & 0 & 2 & $\begin{array}{l}\text { Gas samples also collected } \\
\text { from the well casing of EPA's } \\
\text { two deep monitoring wells. }\end{array}$ \\
\hline IV & $4 / 11$ & $\begin{array}{l}8 \text { previously } \\
\text { sampled }\end{array}$ & 0 & $\begin{array}{l}3 \text { previously } \\
\text { sampled }\end{array}$ & 2 & $\begin{array}{l}\text { Added glycols, alcohols, low } \\
\text { molecular weight acids }\end{array}$ \\
\hline
\end{tabular}
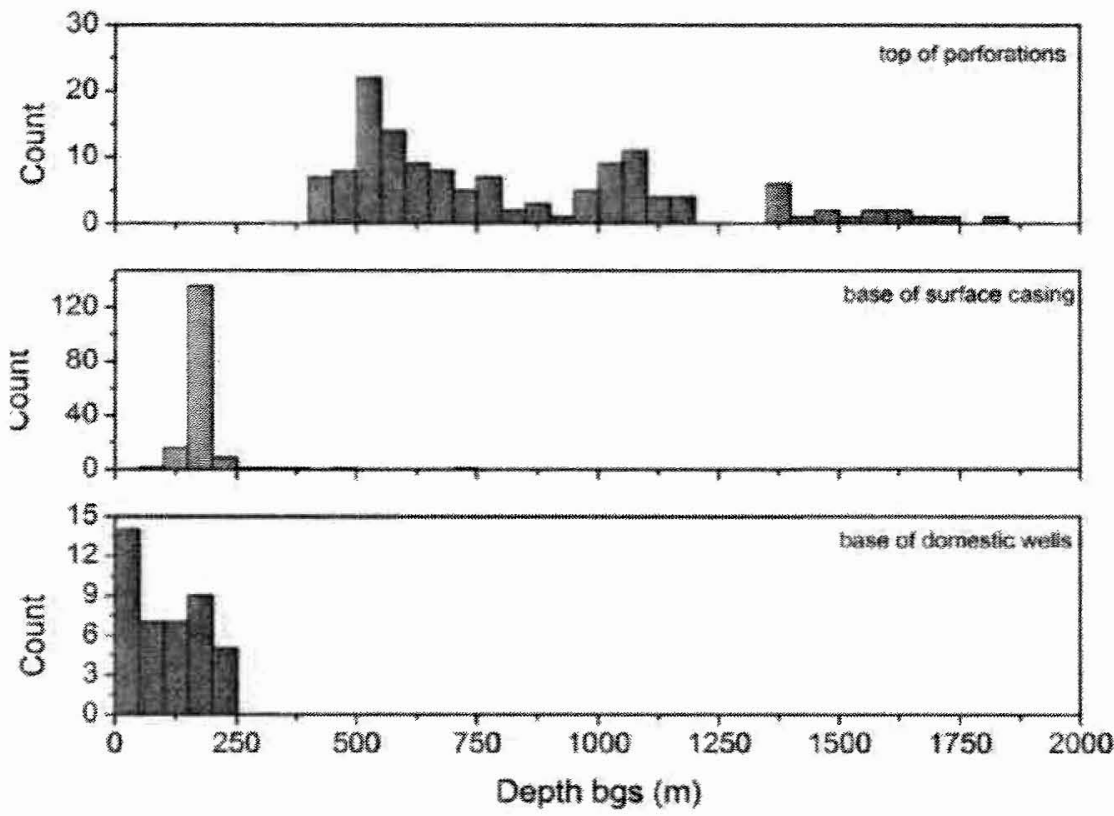

Figure 1: Snapshot from EPA (2011) Figure 3 showing frequency of depth for gas wells (top), surface casing for gas wells, and base of domestic wells.

EPA Table A1 lists the wells and the phase during which they were sampled, broken into eight data types.

1. anions and alkalinity

2. metals

3. alcohols and VOCs

4. low molecular weight acids and glycols

5. semi-volatile organic compounds (SVOCs), pesticides, PCBs, and tentatively identified compounds (TICS); 
6. gas/diesel related compounds, and hydrocarbons

7. bacteria

8. fixed gases, heavy hydrocarbons, dissolved carbon, and gas and water isotopic ratios

EPA Table A2a presents the geochemical results - anions, cations, and alkalinity. Unfortunately, this table does not consistently state in which phase the initial sample was taken. Additional samples are identified with a suffix on the sample number. The other data tables in Appendix A provide results by phase, but some results are found only in other reports, including URS (2009 and 2010).

URS (2009) reports the Phase 1 sampling (water wells only) in their Table 9, which shows concentration of SVOC contaminants, including caprolactam at $1.4 \mathrm{ug} / \mathrm{I}$ at PGDW20, dimethylphthalate detected at nine wells, and Bis (2-ethylhexyl)phthata at 9.8, 6.4 and $12 \mathrm{ug} / \mathrm{l}$ in PGDW25, -20 and $-14^{1}$, respectively, and detect levels at ten other wells. Total purgeable hydrocarbons were 26 and $25 \mathrm{ug} / \mathrm{l}$ in wells PGDW05 and PGDW30, respectively. Measurable methane concentrations were found in 8 wells. Total purgeable organics are generally gasoline and diesel range organics. PGDW25 is one of the deeper wells at $243.8 \mathrm{~m}$ below ground surface (bgs) and PGDW05 and -30 are at 64.0 and $79.2 \mathrm{~m}$ bgs, respectively. URS (2010) reports the Phase 2 sampling in more detail. It shows more than 20 wells with detectable levels of a variety of semi-volatile organics (URS 2010, Table 9). The report does not assess these detects with the depth of the well, but a quick glance suggests that most of them are on the deeper half of the domestic wells. An exception is PGDW39, reported to be just $6.1 \mathrm{~m}$ deep, although the EPA should consider whether " 6.1 " is correct because if so it would be tens of meters shallower than any other water well in the aquifer.

Recommendation: The EPA should present and discuss the correlation of contaminant detects in the domestic wells with depth.

EPA based this study on four sample events including various subsets of domestic, municipal, and stock wells and two sample events in the monitoring wells. A reasonable question is whether the number of samples is sufficient for developing an opinion? A time series would help to identify a trend, but is not necessary to establish presence/absence. Objections to this data on the basis of there being just two samples are without merit - simple presence of a substance that would not naturally occur in the aquifer, if other causes can be eliminated, is sufficient to reach a preliminary conclusion that fracking fluid has affected the aquifer. However, the EPA should continue the sampling to determine whether the concentrations are trending higher, or not, and determine how or whether the plume expands.

\section{TRANSPORT PATHWAYS}

The EPA identifies three potential pathways for contaminants to reach the water wells from the fracking (EPA, p 32).

- Fluid and gas movement up compromised gas wells.

\footnotetext{
'The table did not highlight the values at PGDW14 and -20 as being exceedences. 
- Fluid excursion from thin discontinuous tight sandstone units into sandstone units of greater permeability.

- Out-of-formation fracking, whereby new fractures are created or existing fractures are enlarged above the target formation, increasing the connectivity of the fracture system.

The EPA does not conclude which or whether any of these pathways actually facilitated the contamination at Pavillion, although arguments throughout the document (and reviewed in this report) support the potential for any of them. EPA correctly notes that for all three pathways there would be a correlation between the concentration of gas in the water wells and the proximity to gas well, as found by Osborn et al (2011) in the Marcellus shale in Pennsylvania. They also note that for all three pathways, "advective/dispersive transport would be accompanied by degradation causing a vertical chemical gradient" (EPA, p 32) as discussed in other portions of the report. In other words, with increasing distance from the source, both vertical and horizontal, the contaminant concentration would decrease. This would be due in part to chemical degradation, dispersion of a finite mass over a larger volume, attenuation due to chemicals adsorbing to soil particles, and dilution by mixing with groundwater..

The following sections consider evidence from various aspects of the EPA report in context of the pathways.

\section{Lithologic Barriers}

Very low permeability layers can prevent or impede the upward movement of fluid or gas from depth to the water well zone, which in the Wind River Formation is the upper 250 meters (based on the reported water well depth). Extensive layers of shale are often sources of gas and/or capstones, which prevent gas in underlying sandstone from escaping to the surface. However, the shale must be horizontally extensive and not fractured to be an effective seal, which is not the situation in the Pavillion field as quoted above. The formation is most productive (for gas) at its base with gas trapping occurring in "localized stratigraphic sandstone pinchouts on the crest and along flanks of a broad dome" (EPA p 2).

Hypothesis: The lithology in the Pavillion area does not prevent the vertical movement of gas or contaminants to the surface because it is either not sufficiently extensive or impervious. EPA claims there is no "lithologic barrier ... to stop upward vertical migration" (EPA p viii) and also that "there is little lateral and vertical continuity of hydraulically fractured tight sandstones" (Id.).

Evidence: EPA presented a lithologic cross-section (Figure 20) showing mapped shale layers, production, water, and monitoring wells and the points where the production wells had been fracked. EPA found that the lithology is "highly variable and difficult to correlate from borehole to borehole" (EPA p 15). "Sandstone and shale layers appeared thin and of limited lateral extent" (Id.). Pathways could go around the intermittent shale so that contaminants in a given monitoring well may not result from the nearest production well. Pathways for movement through sandstone could be tortuous (EPA p 37); vertical pathways through sandstone could be more tortuous than horizontal pathways because the particles in sandstone tend to be elongated with the longer side being horizontal. 
Fracking has occurred for up to 45 years, so there is potential for many pathways from various sources to a receptor well. The travel time to a given point could be any time period up to 45 years.

Additionally, out-of-formation fracking occurring at any time could have shortened the pathway.

Conclusion: The lithology in most areas would not prevent the vertical movement of contaminants to the water wells because of the lateral variation.

\section{Vertical flow and gradient}

In order for contaminants to move from the fracked zones or from deep well bores to surface aquifers, there should be a vertical hydraulic gradient. Lacking such a gradient, movement could still be possible due to lateral dispersion and upward concentration gradients, but it would be much slower.

Hypothesis: There is upward flow in the Pavillion gas field that would support advection of contaminants associated with fracking fluids to the monitoring and water wells.

Evidence: In the Pavillion area, there are flowing wells, which would indicate an upward gradient, at least at depth, which could drive vertical advection, or contaminant transport with the groundwater flow. Daddow (1996) also documented flowing wells in other areas of the Wind River Range, with the depth range from 225 to 450 feet bgs. EPA uses PGDW44 as an example ( $p$ 36). This water well lies near the middle of the field near MW01. MW01 showed a depth to water equal to $61.2 \mathrm{~m}$ at the beginning of a purge for sampling ( 11 and Figure 8). MW02 had depth to water of $80.5 \mathrm{~m}$ (p 12). The depth to water in the monitoring wells does not support the idea of an upward gradient, but being the only wells at that depth, the data is not conclusive. Table A1 reports the PGDW44 well depth is $228.6 \mathrm{~m}$; PGDW25 is deeper, at $243.8 \mathrm{~m}$ bgs. MW01 is just $10 \mathrm{~m}$ deeper. There is apparently an upward gradient at that point because the well is flowing, but the analysis could be improved, as follows.

EPA documents that the shallower monitoring well has more natural breakdown products of the organic contaminant like BTEX or glycol that are found in the deeper monitoring well and in fracking fluids ( $p$ 36). It suggests that the contaminants in the shallow well are derived from the natural breakdown of the contaminants found in the deeper well. This could only occur if the wells represent a vertical flow path, which they do and therefore these findings support the hypothesis of upward movement.

The gas found in the deep Wind River Formation is chemically similar to gas in the underlying Fort Union Formation suggesting that gas in the Wind River Formation has naturally moved upward until captured in localized capstones, or "localized stratigraphic sandstone pinchouts" (EPA, p 2). EPA concludes that differences in gas composition and isotopes support the hypothesis of upward migration through the various layers in the Wind River formation ( $p 29$ ). The fraction of ethane and propane in the gas from domestic wells is mostly less than in the produced gas, but the isotopic composition is clearly thermogenic, which suggest there is an ongoing "preferential loss of ethane and propane relative to methane" ( $p 29,38)$. This evidence supports the hypothesis of upward fluid and gas movement.

Vertical movement could occur in the absence of a vertical gradient, if the pressurization caused by the fracking is sufficient and there is a poorly developed well bore nearby. Contaminants can migrate 
quickly upward through a leaky borehole due to the transient pressure gradient across an aquitard created by the fracking pressure (Lacombe et al, 1995).

Conclusion: There is evidence to support the concept of upward movement in the area, but it is not conclusive. The EPA should complete more studies documenting the vertical hydraulic gradient throughout the area.

Recommendation: The EPA report should document the depth to water in the domestic wells prior to sampling so that they could map water levels for different well depths and determine the zones of upward gradient.

\section{Contamination from shallow pits}

The presence of shallow disposal pits is an alternative source of contamination. EPA notes that there are 33 shallow pits that had been used for the "storage/disposal of drilling wastes, produced water, and flowback fluids in the area of investigation" (EPA p 17). As part of this study, the EPA communicated with stakeholders to further determine the location of pits. Shallow monitoring wells have found very high concentrations of several contaminants that were also found in deeper water wells and the EPA monitoring wells. These pits could have received the detritus of fracking operations in the past.

Hypothesis: Contaminated water seeping from these pits could be responsible for the observed contamination.

Evidence: Shallow monitoring wells that had been installed previously for reasons not associated with this project (EPA, p 11) are reported to have very high contaminant concentrations, although this data is not well summarized in the report. The shallow monitoring wells are only $4.6 \mathrm{~m}$ bgs (EPA p 17), so there is little information about how deep the contamination extends beneath the pits. Assuming the pits are some distance away from homes and people avoided them when constructing their water wells, it is possible the shallow disposal pits are sources of contamination beyond the level the EPA considers shallow, or $31 \mathrm{~m}$ bgs (Id.).

Irrigation could help to contain the contamination near the shallow pits because they would be located in low recharge areas, either by design or in comparison with irrigated fields. It would be unlikely that the pits would have been constructed within irrigated fields, so the seepage from the pits may be much less than the seepage beneath irrigated fields because of the continuous application of water to the field, and for a much shorter time period. Irrigation water would have seeped deeper and faster due to the likely higher rate of application and effectively diluted or prevented the deeper circulation of seepage from the pit.

Conclusion: The EPA concludes that these shallow pits are not the source of contaminants found in deeper water wells. Because there is little contamination in intermediate-depth wells, their conclusion is sound, but the document would benefit from more analysis and discussion.

Recommendation: The EPA should document more fully the contaminant plumes near the pits. Specifically, deeper monitoring wells near the pits should be constructed to construct a contamination 
profile beneath the pits. Better investigation of the pits as a source would also facilitate the remediation of the groundwater near those pits.

\section{LINES OF REASONING}

The EPA used a line of reasoning analysis regarding the presence of fracking fluid constituents and gas in monitoring wells in support of their preliminary conclusion that fracking has contaminated aquifers in Pavillion Wyoming. This is critical because the conclusion is not just that leakage from the wells or spills caused contamination, but that the fracking process itself caused the contamination. EPA deemed the multiple lines of reasoning approach necessary due to the complexity in detecting contaminants in groundwater from deep sources. This section critically reviews each of the EPA's lines of reasoning.

\section{High pH Values}

The EPA monitoring wells both have very high $\mathrm{pH}$, ranging from 11.2 to 12.0 , which is much higher than the level seen in the domestic water wells in the Wind River formation. EPA concluded the high pH was due to hydroxide $(\mathrm{OH})$ which indicated the addition of a strong base to the background water (EPA $p$ xii). $E P A$ 's reaction path modeling suggested that the addition of just a small amount of potassium hydroxide to the sodium-sulfate waters typical of deep portions of the Wind River formation would cause such a $\mathrm{pH}$ change; EPA concludes from the modeling that the typical groundwater in the Pavillion aquifer "is especially vulnerable to the addition of a strong base" (EPA p 20).

Potassium hydroxide was used as a crosslinker and solvent for fracking the production wells in the area (EPA p 33), which could be a source of the $\mathrm{OH}$ to increase the $\mathrm{pH}$ of the water in the area of the production wells.

The use of soda ash as a drilling additive when drilling the monitoring wells, often to control the $\mathrm{pH}$, is a possible alternate explanation for the elevated $\mathrm{pH}^{2}$. Soda ash is $100 \% \mathrm{Na}_{2} \mathrm{CO}_{3}$. At a 1:100 mixing ratio with water, the $\mathrm{pH}$ of dense soda ash was 11.2 (EPA Table 2). The recommended ratio for use in fracking fluid is 1:100 to 1:50 (EPA Table 1). The $\mathrm{pH}$ of drilling mud varied between 8 and 9 . The concentrations of neither sodium nor carbonate are abnormal in the monitoring wells. If the soda ash did separate from the drilling mud, mixing with background groundwater would further dilute it so that the $\mathrm{pH}$ would be less than observed at the 1:100 mixing ratio.

EPA Figure 12 verifies these $\mathrm{pH}$ values are higher than in the domestic wells, but also shows they fall on the general trend of $\mathrm{pH}$ with elevation of the well open interval. Based on this information, it is not possible to conclude that the high $\mathrm{pH}$ is not natural, but the EPA's conclusion appears to be justified based cumulatively on all of the facts concerning $\mathrm{pH}$. EPA should consider geophysical logging completed by the industry if it includes $\mathrm{pH}$ logs to improve their analysis; such logs could provide $\mathrm{pH}$ values for deeper areas that could be compared with the $\mathrm{pH}$ values for their monitoring wells.

\footnotetext{
${ }^{2} \mathrm{http}: / /$ www.halliburton.com/ps/default.aspx?navid=125\&pageid=60\&prodgrpid= MSE\%3a\%3a1053024648177449, visited 1/13/12
} 
Chemistry in the shallow wells has been affected by irrigation with Wind River water. This irrigation water has very low total dissolved solids (TDS) and neutral $\mathrm{pH}(<8)$ (EPA Figure 11) but the other shallow groundwater wells show that the irrigation water picks up contaminants as it seeps.

The methods used to collect samples probably minimized contamination causing high $\mathrm{pH}$ in the monitoring wells. EPA purged the monitor wells until pH stabilized, a process which would minimize the potential that any residual contamination from well development would have been sampled.

EPA's analysis associated with Figures 11 and 12, explaining the shallow water geochemistry, is accurate and useful. It utilizes data from all of the wells in the area and surface waters to show water chemistry trends through the study area. It also shows how EPA's monitoring wells differ substantially from the general trends, supporting the conclusion that elevated $\mathrm{pH}$ in water samples from EPA's deep monitoring wells was likely caused by contamination with hydraulic fracturing chemicals.

\section{Elevated potassium and chloride}

The monitoring wells both have concentrations of $\mathrm{K}$ and $\mathrm{Cl}$ much higher, 14 to 18 times, than the domestic water wells (EPA p 34). Potassium concentration ranged from 43.6 to $53.9 \mathrm{mg} / \mathrm{l}$ and $\mathrm{Cl}$ concentration averaged $466 \mathrm{mg} / \mathrm{l}$ (Id.). The drilling additives reported by EPA to have been used at Pavillion had a much lower concentration for both anions. The fracking fluid contained several compounds with high concentrations of both ions (Id.). Therefore, the high concentrations of $\mathrm{K}$ and $\mathrm{Cl}$ suggest contamination with fracking fluid.

The chloride concentration data plotted in EPA Figure 12 shows clearly that $\mathrm{Cl}$ concentration in two of the three samples from EPA's deep monitoring wells are much higher than those in domestic wells, and EPA correctly assesses there must be a cause other than natural variation for the high concentrations. However, in this case I disagree with EPA's assessment that "regional anion trends tend to show decreasing $\mathrm{Cl}$ concentrations with depth" (EPA p 19) because EPA Figure 12 shows little variation with depth although there are a couple of high concentration outliers near the surface. Regardless of the interpretation of trend, concentrations from the EPA monitoring wells plot far higher than the $\mathrm{Cl}$ data from domestic wells.

The chloride concentrations reported from the EPA monitoring wells are also much higher than reported by the USGS in their Wind River study (Daddow 1996). He describes the formation water as having TDS concentration as high as $5000 \mathrm{mg} / \mathrm{l}$, but $\mathrm{Cl}$ is a small proportion of that. He also reported that the highest $\mathrm{Cl}$ concentration on surface water sites was less than about $30 \mathrm{mg} / \mathrm{l}$, so assuming the river recharges the alluvial aquifer, the source of the groundwater is relatively clean with respect to chloride. $\mathrm{Cl}$ concentrations at EPA's monitoring wells are much higher than the regional values reported by USGS in either ground or surface water on the Wind River Reservation, and are unlikely to be properly considered "naturally occurring".

For potassium, it is much clearer that the monitoring well concentrations exceed the domestic water well concentrations by many times (EPA Figure 12, p 20). 
There is too little of either $\mathrm{K}$ or $\mathrm{Cl}$ in drilling mud or additives for it to have been the source or cause of the enrichment in the monitoring wells. Also, purging prior to sampling occurred until the specific conductivity $(\mathrm{SC})$ of the purged water reached a relative steady state (EPA Figure 9 ). $\mathrm{K}$ and $\mathrm{Cl}$ both contribute to the $\mathrm{SC}$ of the water being sampled. Any potential contamination due to well construction or development has most likely been purged from the system.

The high $\mathrm{K}$ and $\mathrm{Cl}$ concentrations are clearly present in the formation water near the monitoring wells. Without a natural source as explanation, the mostly likely source is the fracking fluid which used compounds that have high concentrations of both anions. EPA has reasonably concluded the most likely source of elevated $\mathrm{K}$ and $\mathrm{Cl}$ is fracking fluid.

\section{Detection of synthetic organic compounds}

The EPA found in the monitoring wells significant concentrations of isopropanol, diethylene glycol, triethylene glycol, and tert-butyl alcohol (TBA) (in MW02). TBA was not directly used as a fracking fluid, but "is a known breakdown product of methyl tert-butyl ether and tert-butyl hydroperoxide". The first three products are found in fracking fluid based on the material safety data sheets (MSDSs) analyzed by EPA, but the parent compounds of TBA have not been reported as such; importantly, MSDSs, which are the source of the fracking fluid additives lists in the report, do not list all chemicals because the formulas are proprietary. That a chemical is missing from the list of additives is not evidence they were never in fracking fluid.

Isopropanol was found in "concentrated solutions of drilling additives" at concentrations much lower than detected in the monitoring wells (EPA p 35) and the others, glycols and alcohols, were not used for drilling.

None of these compounds naturally occur in groundwater. The EPA is correct in its conclusion that there is no acceptable alternative explanation and the most likely source of these contaminants is fracking fluid.

\section{Detection of petroleum hydrocarbons}

EPA detected benzene, toluene, ethylbenzene, and xylenes (BTEX), trimethylbenzenes, and naphthalene at MWO2 (EPA, p 35). They detected gasoline and diesel range organics at both monitoring wells (Id.). These are not found in drilling additives, but the MSDSs showed a long list of additives in the fracking fluid that could be the source of the contamination just cited (EPA p 35, 36). For example, a BTEX mixture had been used in the fracking fluid as a breaker and a diesel oil mixture was used in guar polymer slurry (Id.).

EPA rejects alternative explanations that claim that substances, used on the well or pump, caused these contaminant detections. Specifically, the agency points out that the contact time for water with the well or pump during purging and sampling would be so low that contamination would be unlikely, especially after purging. This would be especially true for the Phase 4 sampling which would have occurred after 
the well had been purged for sampling twice and had several months of natural groundwater flow through it.

An alternate explanation considered by EPA is that the constituents are due to the groundwater being above a natural gas field. In fact, the EPA has noted that historically some wells encountered gas at levels shallower than the monitoring wells. EPA encountered methane while logging MW01 (EPA p 11). EPA notes that the gas from the Wind River formation is "dry and unlikely to yield liquid condensates" (EPA $p$ 36). They also argue that the monitoring wells have substantially different compositions of liquid condensates, which would not result if they came from a common source of gas. The explanation is reasonable, unless there is a variation with depth. Because these contaminants occur only at low concentrations in the deepest domestic wells, the data does not rule out a natural gradient from the gas sources at depth to the shallower zones of the formation. However, the EPA explanation is supported by the fact that the monitoring wells are far enough apart, more than a mile, that they must have different gas well sources and represent different pathways..

Recommendation: To further decrease the uncertainty, the EPA should complete an additional sampling event with more domestic wells sampled. It would also be desirable to have another monitor well screened at the level of the gas wells. The EPA could then develop a concentration profile as a function of depth and formation layer.

\section{Breakdown products of organic compounds}

EPA verified a vertical pathway by showing that organic compounds in the shallower monitoring wells are daughter products of the organic compounds found in the deeper monitoring wells. This supports the concept of upward migration with ongoing biologic transformation or natural degradation. It supports the concept of an upward flow gradient. It cannot be asserted that the EPA monitoring wells are on the same flow pathway, as they are more than a mile apart, therefore, the presence of contaminants in the monitoring wells is evidence that there are multiple sources of contaminants at the level of the gas production wells.

As part of this line of reasoning, the EPA presents the "hypothetical conceptual model" that "highly concentrated contaminant plumes exist within the zone of injection with dispersed lower concentration areas vertically and laterally distant from the injection points". This refers to how the fracking fluids, once injected, simply disperse in all directions because there are no confinements, similar to how they disperse from coal seam fracking. It is consistent with the lower concentrations found further from the source.

EPA's hypothesis is reasonable and explains the vertical movement of contaminants from a broad zone of production wells. Its simplicity indicates that fracking in such a formation will eventually lead to contamination moving vertically from the gas wells - it is only a matter of time (Myers, 2012).

\section{Sporadic bonding outside of production casing and hydraulic fracturing in thin discontinuous sandstone}


The last two lines of reasoning are considered together because they describe two pathways for fracking fluid to get into the aquifer. The fracking that occurs in the Pavillion gas field directly injects fracking fluid into an underground source of drinking water. Fracking occurs as little as $150 \mathrm{~m}$ below the bottom of the deeper water wells. The sandstone and intervening shale zones are discontinuous, which suggests there are no significant continuous barriers to a vertical component of flow and contaminant movement. Fracking has also occurred for up to 40 years, so the pathways could have required up to 40 years for transport. Sporadic bonding above the zone being fracked basically means the annulus between the production zone and surface casing may not be fully sealed with cement which may allow gas or fluids to move vertically among formation layers. During fracking, the high pressure could force some of the fracking fluid through improperly sealed well bores to contaminate formations nearer the water wells.

Both of these lines of reasoning correctly describe potential pathways and sources of fluids in the aquifer. The EPA's conclusions in this regard are reasonable and appropriate and conform to the available facts and data.

\section{Gas in Monitoring and Shallow Wells}

Many shallow water wells have gas concentrations that exceed expected background levels. EPA also uses several lines of reasoning to conclude that gas has migrated to domestic wells from the fracked zones, in addition to or instead of it occurring naturally in those wells.

Isotopic composition of gas samples from shallow wells, deeper monitoring wells and produced gas are all similar in that all have a thermogenic origin. However, the shallower domestic water wells have very little higher chain carbon-based gas, which suggests some dispersion and decomposition with vertical movement (ethane and propane degrade faster). The isotopic composition of most wells is thermogenic and indicative of a deep source; URS (2010) noted that methane in one domestic well of eight sampled with measurable methane had biogenic origins.

EPA also found that the concentration of methane in domestic water wells was generally higher in areas of higher gas production, as counted by the number of gas wells. Although it could be coincidental because more gas wells are constructed where more gas naturally occurs, this seems unlikely because the presence of gas in domestic water wells shows that gas is occurring outside of the production zones deep in the Wind River Formation or high in the underlying Fort Union Formation. Gas would only move naturally from depth to areas near the surface if there is a lack of containment which would have depleted the gas source at some point in the last $40,000,000$ years. Thus, the gas wells have apparently provided a migration pathway for gas released by fracking into overlying formations; this migration occurred at a rate sufficient to allow gas to accumulate to a concentration capable of causing a blowout at $159 \mathrm{~m}$ bgs near well PDGW05.

The area also generally has gas well designs that are below current industry standards in some states, with surface casing not extending below the maximum depth of water wells and with a "lack of cement or sporadic bonding of cement outside of production casing" (EPA p 38). This would provide a pathway from depth to at least the bottom of the surface casing, and allow gas leakage to higher levels in the 
aquifer. Many states and areas require surface casing to extend below the maximum depth of USDWs (a USDW must generally have TDS less than $10,000 \mathrm{mg} / \mathrm{l}$ ). The gas well design in Pavillion appears to be below industry standards because the surface casing does not extend even below the bottom of the zone of domestic wells. The pathways discussed above for fluid movement would also facilitate gas movement (Id.).

The EPA acknowledges that poorly sealed domestic wells could also be a pathway (EPA p 38-39). This is true but not a relevant argument because the gas wells are much deeper and actually tap formation layers with gas. Once gas reaches a domestic well, it is possible that the well provides an additional pathway, but it is not the source of the contamination or the primary pathway from the gas source zone to the aquifers.

The EPA also references the fact of citizen's complaints (EPA p 39) as an indicator that gas contamination started after fracking. Citizens do not complain until a problem occurs. Assuming their water well was initially acceptable, they would complain when they noticed a change.

\section{DISCUSSION OF CONTAMINANT TRANSPORT PATHWAYS}

The general dispersion of contaminants upward from the fracking zone would result from either well bore transport or transport through overlying higher permeability sandstone. Transport through wellbores that cross multiple aquifer layers, as the gas wells do near Pavillion, would allow contaminants to reach the different levels. However, the concentration reaching shallower formations would be much less because the contaminants bleed off to the deeper aquifer zones (Nordbotten et al 2004). Fracking could also create the vertical gradient to temporarily cause contaminants to move vertically upward through wellbores to contaminate shallower aquifer layers (Lacombe et al 1995).

Because there are not any significant horizontal confining units within the Pavillion Field, the upward vertical contaminant transport is partially due to dispersion through relatively porous media. In areas with extensive horizontal confining layers, such as the Marcellus shale areas, transport through vertical fractures, similar to that through wellbores, could transport substantial contaminant mass through the impervious zones (Myers, 2012). If the bulk media bounding the fractures have conductivity less than one hundredth that in the fracture, the contaminants will transport with little dispersion, or loss, into the bulk media (Zheng and Gorelick, 2003).

This appears to be the case in the Pavillion Field, given the existing geology. Thus, unless fracking is very carefully done, and well bores are solidly (not intermittently) bonded, this result is to be expected. In the case of the Pavillion Field, sporadic bonding is revealed and reported for 9 of the wells that EPA examined well bore data made available to them. To the extent that this is indicative of the entire field, it would greatly increase the likelihood that transport of contaminants from the gas wells to the water wells of the rural Pavillion residents would occur. 


\section{REFERENCES}

Daddow, R.L. 1996. Water Resources of the Wind River Indian Reservation, Wyoming. U.S. Geological Survey Water-Resources Investigations Report 95-4223.

Fisher, K, and N. Warpinski. 2010. Hydraulic fracture-height growth: real data. Paper SPE 145949 presented at the Annual Technical Conference and Exhibition held in Denver, CO, October 30 November 2, 2011. Doi: 10.2118/145949-MS

Kramer, D. 2011. Shale-gas extraction faces growing public and regulatory challenges. Physics Today 64, no. 7: 23-25.

Lacombe, S., E.A. Sudicky, S.K. Frape, and A.J.A. Unger. 1995. Influence of leaky boreholes on crossformational groundwater flow and contaminant transport. Water Resources Research 31(8):1871-1882.

Myers, T. 2012. Potential contaminant pathways from hydraulically fractured shale to aquifers. Ground Water, doi: 10.1111/j.1745-6584.2012.00933.x.

Nordbotten, J.M., M.A. Celia, and S. Bachu. 2004. Analytical solutions for leakage rates through abandoned wells. Water Resources Research v 40, W04204.

Osborn S.G., Vengosh, A., Warner, N.R., and Jackson, R.B. (2011). Methane contamination of drinking water accompanying gas-well drilling and hydraulic fracturing. Proceedings of the National Academy of Sciences, v. 108, p. 8172-8176.

Osiensky, J.L., G.V. Winter, R.E. Williams. 1984. Monitoring and mathematical modeling of contaminated ground-water plumes in fluvial environments. Ground Water 22, no. 3: 298-307.

U.S. Environmental Protection Agency (EPA). 2011. Draft, Investigation of Ground Water Contamination near Pavillion, Wyoming. Office of Research and Development, Ada, OK.

URS Operating Services, Inc. (URS) 2010. Expanded Site Investigation - Analytical Results Report, Pavillion Area Groundwater Investigation, Pavillion, Fremont County, Wyoming, CERCLIS ID \# WYN000802835. Denver, CO.

URS Operating Services, Inc. (URS) 2009. Site Inspection - Analytical Results Report, Pavillion Area Groundwater Investigation Site, CERCLIS ID\# WYN000802735. File Pavillion_GWInvestigationARRTestAndMaps.pdf. Denver, CO

Zheng, C., and S. M. Gorelick 2003. Analysis of solute transport in flow fields influenced by preferential flowpaths at the decimeter scale. Ground Water 41, no. 2: 142-155. 


\section{UNITED STATES ENVIRONMENTAL PROTECTION AGENCY REGION III 1650 Arch Street \\ Philadelphia, Pennsylvania 19103-2029}

Subject: $\quad$ Action Memorandum - Request for Funding for a Removal Action at the Dimock Residential Groundwater Site, Intersection of PA Routes 29 \& 2024

Dimock Township, Susquehanna County, Pennsylvania

From: $f \begin{aligned} & \text { GeQ } \\ & \text { Richard M. Fetzer, On-Scene Coordinator } \\ & \text { Eastern Response Branch (3HS31) }\end{aligned}$

To: $\quad$ Dennis P. Carney, Associate Division Director Hazardous Site Cleanup Division (3HS30)
JAN 192012

\section{PURPOSE}

The purpose of this Action Memorandum is to request and document approval of an emergency removal action to prevent, limit, or mitigate the threats posed by the presence of hazardous substances at the Dimock Residential Groundwater Site (the "Site"), pursuant to Section 104(a) of the Comprehensive Environmental Response, Compensation and Liability Act, 42 U.S.C. $\S$ 9604(a) (CERCLA). The Site is located in Dimock Township, Susquehanna County, Pennsylvania. The OSC has initiated a removal site evaluation in accordance with the National Oil and Hazardous Substances Pollution Contingency Plan (NCP), 40 C.F.R. Part 300. The OSC has determined, based on Pennsylvania Department of Environmental Protection (PADEP) and Cabot Oil and Gas Corporation (Cabot) sampling information, consultation with an EPA toxicologist, the Agency for Toxic Substances and Disease Registry (ATSDR) Record Of Activity (AROA), issued 12/28/11, and the recent EPA well survey effort, that a number of home wells in the Dimock area contain hazardous substances, some of which are not naturally found in the environment. Inorganic hazardous substances are present in four home wells at levels that present a public health concern. These four specific homes have been dependent upon donated water for drinking and/or household use and the reliability of the sources for donated water is at this point uncertain.

Historic drilling activities in the Dimock area may have used materials containing hazardous substances. Spills and other releases have been documented by PADEP from these drilling activities. There is reason to believe that a release of hazardous substances has occurred. The presence of hazardous substances in the four home wells constitutes a release or substantial threat of a release and the situation meets the criteria for conducting a removal action under Section 300.415 of the NCP. The OSC has determined that funds in the amount of $\$ 100,000$ are needed to mitigate the human health concern initially at four homes and therefore proposes the actions included in this Action Memorandum. This action includes provision of alternate water to four homes and home well sampling at approximately 61 homes within the Site area. 


\section{SITE CONDITIONS AND BACKGROUND}

A. Background

1. Site Description - The Site area is located in Dimock, a rural area of northeastern Pennsylvania in Susquehanna County. A map of the area is included below.

2. History - Cabot began drilling for natural gas in the Dimock area in 2008. Methane contamination was detected in private wells thereafter in concentrations exceeding those previously found. PADEP had the lead in investigating the environmental complaints in Dimock. PADEP entered into a Consent Order and Agreement (CO\&A) with Cabot which required permanent restoration or replacement of the

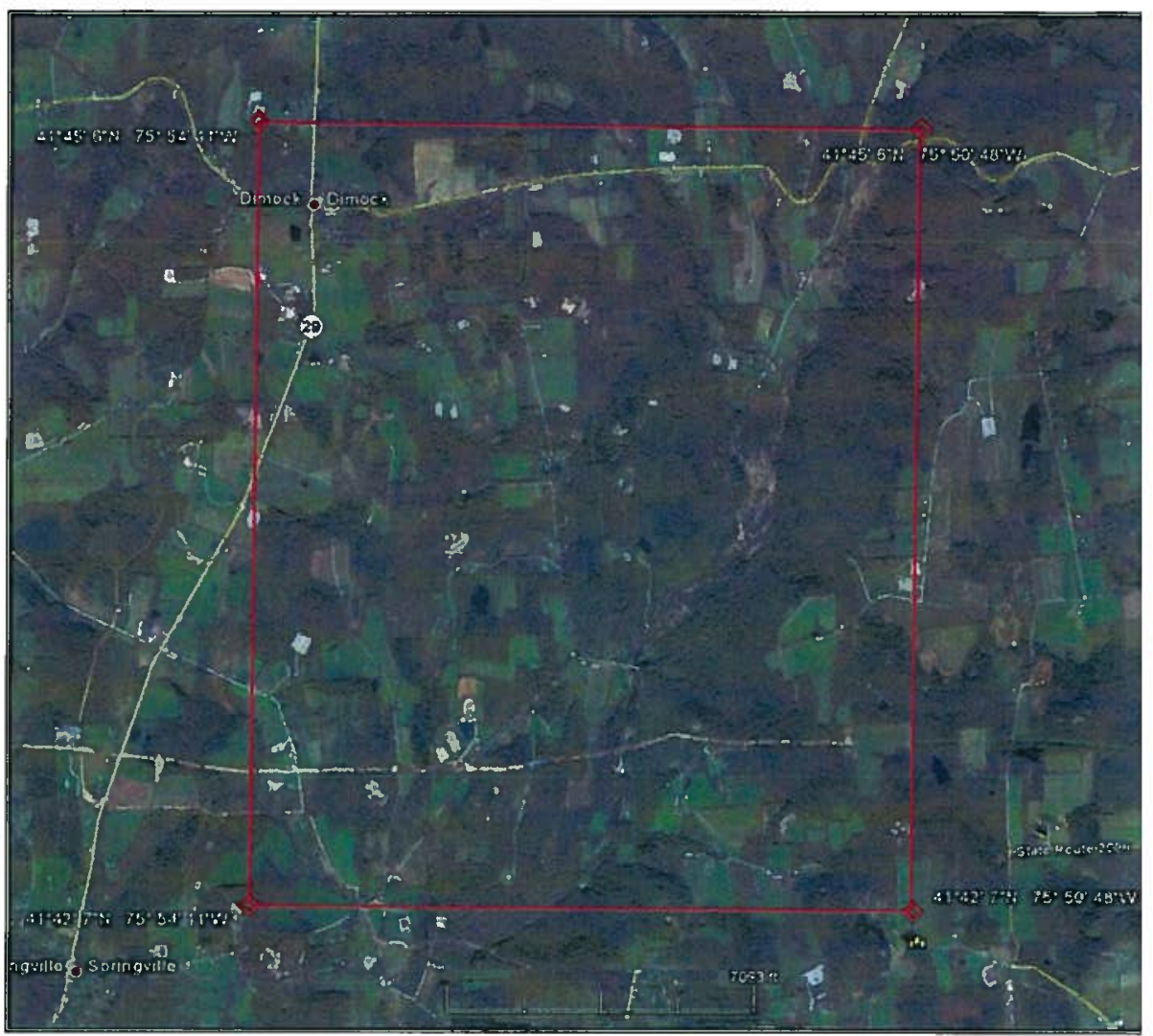
affected water supply. A public water line was initially considered. PADEP later modified the CO\&A to require installation of "gas mitigation" systems for 19 homes served by 18 private wells in the Site area. ${ }^{1}$ Until the gas mitigation systems were installed, Cabot was to provide a temporary water source. Some well owners, within the scope of the PADEP CO\&A, have gas mitigation systems installed, but others do not. While the gas mitigation systems were designed to remove methane, a potential exists that they may remove some hazardous substances as a by-product of their operation. Regardless, EPA does not know what, if any, hazardous substances these "gas mitigation" systems, originally designed to address methane, are removing. Therefore, EPA is including both preand post-treatment sampling in the scope of this action. Furthermore, there are

${ }^{1}$ It had originally been reported that 19 homes were served by the 18 wells included within the scope of the CO\&A but the door-to-door home well survey conducted to date by EPA has identified that there are currently 21 homes served by 20 wells on those same properties. 
other homes served by private wells that were not covered by the scope of the PADEP CO\&A, but are within this Site area.

III. Quantities/Types of Substances Present

1. Arsenic* - Arsenic is a naturally occurring element widely distributed in the earth's crust. Arsenic may also be present at elevated concentrations in the groundwater due to the use and effects of drilling fluids. Arsenic is classified as a known human carcinogen. This classification is based on animal and human studies, which indicate an increased risk for developing cancers of the skin, lung, bladder, kidney, liver, and prostate from consuming arsenic containing water. Non-cancer health effects associated with ingestion of arsenic include circulatory problems and skin damage.

2. Barium - Barium is a silvery-white metal that exists in nature only in ores containing mixtures of elements. It combines with other chemicals such as sulfur or carbon and oxygen to form barium compounds. Barium sulfate is sometimes used by doctors to perform medical tests and to take x-rays of the gastrointestinal tract. Ingesting drinking water containing levels of barium above the EPA drinking water guidelines for relatively short periods of time can cause gastrointestinal disturbances and muscle weakness. Ingesting high levels for a long time can damage the kidneys. Barium is known to be a common constituent of drilling fluids.

3. Bis(2-ethylhexyl)phthalate (DEHP)* - DEHP is a manufactured chemical that is commonly added to plastics to make them flexible. The phthalates are generally considered to be of slight to moderate toxicity. DEHP may be irritating to the eyes, skin, and mucous membranes. Mild gastric disturbances and diarrhea may occur following ingestion of larger doses. Central nervous system (CNS) depression may occur if large amounts of phthalate acid esters are absorbed. EPA has determined that DEHP is a probable human carcinogen. These determinations were based entirely on liver cancer in rats and mice. DEHP is known to be associated with drilling activities.

4. Glycol Compounds (including Ethylene Glycol* and 2-Methoxyethanol) Glycol compounds are a class of organic compounds belonging to the alcohol family. Exposure to large amounts of ethylene glycol can damage the kidneys, nervous system, lungs, and heart. Exposure to high concentrations of 2-methoxyethanol is associated with testicular damage, impaired nervous system, and anemia. Glycols are known to be common in drilling fluids.

5. Manganese* - Manganese is a naturally occurring substance found in many types of rock and soil. Manganese is also known to be a constituent of some specialized drilling fluids. Eating a small amount of manganese from food or water is needed to stay healthy. At high levels, it can cause damage to the nervous system. 
6. Phenol* - Phenol is both a manufactured chemical and a natural substance. Phenol is used as a disinfectant and is found in a number of consumer products. Skin exposure to high amounts can produce skin burns, liver damage, dark urine, and irregular heart beat. Various phenols are commonly associated with drilling fluids.

7. Sodium* - Sodium is an essential nutrient and occurs naturally in most foods. Excessive sodium intake is associated with high blood pressure. Various sodium containing compounds are associated with drilling fluids.

*A hazardous substance, as defined under CERCLA Section 101(14) and designated in Section 302.4 of the National Contingency Plan (NCP), 40 C.F.R. Section 302.4.

B. National Priorities List

The Dimock Residential Groundwater Site is not on the CERCLA National Priorities List (NPL).

C. State and Local Authorities' Roles

Cabot had been sampling the home wells and providing bottled drinking water and alternate water for non-potable use, through a Consent Order and Agreement (CO\&A) with PADEP. The CO\&A applies only to a specific list of homes, and does not include other homes, also located within the same geographic area. Some of these additional homes have had limited sampling conducted by Cabot and/or PADEP. PADEP determined that Cabot has complied with the terms of the CO\&A, as it applies to the provision of temporary water, and subsequently approved Cabot's request to stop the delivery of alternate water.

\section{THREATS TO PUBLIC HEALTH OR WELFARE OR THE ENVIRONMENT}

Section 300.415 of the NCP lists the factors to be considered in determining the appropriateness of a Removal Action. Paragraphs (b)(2)(i), (ii), and (vii) of Section 300.415 directly apply to the conditions found at the Dimock Residential Groundwater Site.

In evaluating the situation, the OSC first considered whether hazardous substances were present in a home well. The levels of those hazardous substances were then considered against primary Maximum Contaminant Levels (MCLs). They were also considered for non-cancer risk to determine if the levels generate a hazard quotient greater than 2 . The presence of inorganic and organic chemicals in a number of wells supports the need for this action. 


\subsection{5 (b)(2)(i) "Actual or potential exposure to nearby human populations, animals or the food chain from hazardous substances or pollutants or contaminants"}

The hazardous substances listed above, present in water from home wells at this Site based on sampling data described below, could cause adverse health impacts when chronic exposure through drinking water or other uses of water in the home occurs. There are other contaminants discussed in the Agency for Toxic Substances and Disease Registry's (ATSDR) Record of Activity (AROA) issued on December 28, 2011, which could also cause adverse health impacts. ATSDR has concluded for the area originally included with the PADEP/Cabot CO\&A, which includes the four homes being considered here for alternate water, that a chronic health risk exists for most wells and that the situation supports a "Do Not Use the Water" action including the consideration of alternative home water supplies until further characterization is completed. An EPA Region III toxicologist's opinion is that, of the homes evaluated to date in an on-going effort, that four home wells contain contaminants at levels that present a public health concern. In one home, manganese was detected at $628 \mathrm{ug} / \mathrm{L}$. Exposure to this concentration would yield a Hazard Quotient of approximately 2. In another home, manganese $(1360 \mathrm{ug} / \mathrm{L})$ was detected at a level that generates a Hazard Quotient of approximately 4 . Note that children reside at this location. In the third home, arsenic was observed at a concentration $(37 \mathrm{ug} / \mathrm{L})$ that exceeds its MCL of $(10 \mathrm{ug} / \mathrm{L})$ and would pose a long-term cancer risk of $8 \mathrm{E}-04$. Note that children reside at this location. In the fourth home, manganese was detected at 669 $\mathrm{ug} / \mathrm{L}$. Exposure to this concentration would yield a Hazard Quotient of approximately 2.3. Available data also indicate that hazardous substances may be present in a number of other homes. Because the available data is not complete and is of uncertain quality, additional sampling is needed to facilitate a further evaluation of any potential health concerns from the drinking water at home wells in the Site area.

EPA is providing water based upon a risk of exposure to hazardous substances above health-based levels. Furthermore, the OSC notes that for those homes where the EPA toxicologist has not identified contaminants that present a public health concern, that the limited data available does identify the existence of hazardous substances. In addition, PADEP's CO\&A determined that 18 home wells were impacted by drilling activities; such impact may be evidence of the migration of hazardous substances.

Again, it is noted that this determination is based upon data which was collected by parties other than EPA (Cabot and PADEP). The quality assurance/quality control (QA/QC) information has not been verified. However, what is clear is that this data strongly suggests that hazardous substances have been released and are present in some home wells at levels that may present a public health concern. Current data does show arsenic and manganese at higher levels than may be typically found, in post drilling samples. Since arsenic and manganese are naturally occurring substances, EPA's assessment will include comparisons of background concentrations and post drilling concentrations present. EPA routinely acts under CERCLA to protect public health first while it acts to further define contamination. Thus, within this action, EPA will complete an assessment of the water quality of the home wells in the Site area to close information gaps as soon as possible. This sampling will be focused initially on evaluating those homes in the Site area that have been sampled in the past. Beyond that, sampling at homes will be based upon a sampling rationale using information regarding alleged health impacts and 
data gaps. In addition, EPA will continue to evaluate the updated data, and may revise its actions to provide water to any of the additional homes, or to cease provision of water, as warranted by the data.

300.415 (b)(2)(ii) “Actual or potential contamination of drinking water supplies or sensitive ecosystems"

The discussion of 300.415 (b) (2) (i) above applies to this factor. Both organic and inorganic contaminants have been detected in home wells. Although this action is predominantly based upon inorganic data at the four homes, it should be noted that organic compounds have been detected at other homes as detailed in the ATSDR AROA. Glycol detections included ethylene glycol, triethylene glycol, and 2,2'oxybisethanol (diethylene glycol). Some wells had all three reported glycols present in their wells but no exceedances of risk based screening criteria (note: the analytical detection level used appeared to be higher than screening levels). Bis(2-ethylhexyl) phthalate (DEHP) was detected in five samples and ranged from $0.14 \mu \mathrm{g} / \mathrm{L}$ to $22 \mathrm{ug} / \mathrm{L}$. 2-methoxyethanol concentrations (ranging from $880 \mathrm{ug} / \mathrm{L}$ to $1,300 \mathrm{ug} / \mathrm{L}$ ) were detected in each of six wells.

\subsection{5 (b) (2) (vii) "The availability of other appropriate federal or state response mechanisms to respond to the release"}

The four homes being considered for alternate water under this action were all dependent upon donated water, either bottled, water buffaloes (temporary storage tanks) or both. It is the OSC's understanding that the last delivery of bulk water from those organizations ceased on January 3,2012 . In any case the reliability of sources for donated water is at best uncertain.

\section{PROPOSED ACTIONS AND ESTIMATED COSTS}

\section{A. Proposed Action}

\section{Proposed Action Description}

Throughout the duration of Site activities, all personnel involved with execution of this proposed action will comply with the requirements of CERCLA and with all other applicable Federal and State regulations to the extent practicable considering the exigencies of the situation in accordance with 40 CFR $\S 300.415(j)$. Available data indicate that a number of homes in the area have hazardous substances present in the home wells, but only four indicate concentrations identified by the EPA toxicologist at a level of concern. Thus, those four homes will be immediately supplied with water. At the same time, approximately 61 home wells will be sampled by EPA to obtain data of known quality assurance to support future evaluations and response decisions. EPA will continue to evaluate the updated data, and may revise its actions to provide water to any of the additional homes, or to cease provision of water, as warranted by the data. The Removal activities at the Site will include the following: 
1. Mobilize and demobilize personnel and equipment to conduct the action;

2. Delivery of a temporary source of clean water for household use to the four (4) homes with wells that contain contaminants at levels of public health concern. This provision of temporary water will continue until potential exposures are further understood and mitigated as needed.

3. The sampling program will include analysis for a broad range of parameters with a special priority being placed on quick turnaround for those parameters which are most frequently observed in the data available to EPA at this time. The Agency will also do some limited sampling for methane and bacteriological constituents. Home well water sampling will be performed by EPA in the Site area using the following assigned priority:

i. The four (4) homes considered for provision of alternate water, to assess the potential exposure to hazardous substances and to determine whether continued temporary provision of clean water for household use is required.

ii. The seventeen (17) remaining homes located on properties included in the PADEP/Cabot CO\&A ${ }^{2}$, which were identified as being impacted by drilling activities.

iii. Approximately thirty (30) additional homes in the immediate area that have been sampled in the past.

iv. Additional homes in the Site area where one or more of the factors below supports sampling.

1. Direct observation or other evidence (home well surveys) of adverse health effects potentially attributable to contaminated groundwater use.

2. Where data gaps in groundwater measurement or sampling need to be filled to gain an adequate understanding of Site conditions.

Approximately ten (10) homes are currently identified from well surveys, but more could be added based upon data review.

4. Maintain necessary documentation of Site activities.

5. Develop and implement appropriate health and safety protocols for the removal activity.

${ }^{2}$ It had originally been reported that 19 homes were served by the 18 wells included within the scope of the CO\&A but the door-to-door home well survey conducted to date by EPA has identified that there are currently 21 homes served by 20 wells on those same properties. 


\section{Contribution to Remedial Performance}

A remedial action is not anticipated and therefore this removal action is not inconsistent with any proposed remedial action.

\section{Applicable or Relevant and Appropriate Requirements ("ARARs")}

Actions will be conducted in compliance with Applicable or Relevant and Appropriate Regulations (ARARs) to the extent practicable considering the exigencies of the situation, in accordance with 40 CFR $300.415(\mathrm{j})$.

\section{B. Estimated Costs}

Extramural Costs

Total

Regional Allowance Costs: (ERRs

$\$ 50,000$

Contractors and Subcontractors)

Other Extramural Costs Not Funded

$\$ 25,000$

From the Regional Allowance:

START Contractor

Subtotal, Extramural

$\$ 75,000$

Extramural Costs Contingency

$\$ 25,000$

Total Removal Action Project Ceiling

$\$ 100,000$

\section{EXPECTED CHANGE IN SITUATION SHOULD ACTION BE DELAYED OR NOT TAKEN}

If no action is taken, the residents may utilize well water which poses a potential public health concern.

\section{OUTSTANDING POLICY ISSUES}

Because this response action could be considered nationally significant or precedent setting, it requires the prior concurrence of the Assistant Administrator, Office of Solid Waste and Emergency Response (AA-OSWER). Furthermore, because the action appears to be nationally significant and/or precedent-setting, the Region will continue to coordinate closely with Headquarters. EPA also will maintain coordination and communications with PADEP. In taking this action, EPA is aware of and has considered the potential applicability of the natural gas exclusion under CERCLA, the Bentsen Amendment under the Resource Conservation and Recovery Act (RCRA), and the exclusions to the definition of 'underground injection' under the Safe Drinking Water Act (SDWA). EPA has concluded that this action is appropriate under CERCLA at this time. 


\section{ENFORCEMENT}

The total EPA costs for this removal action based upon full-cost accounting practices that will be eligible for cost recovery are estimated below as follows: ${ }^{3}$

$\begin{array}{ll}\text { Direct Extramural Costs } & \$ 100,000 \\ \text { Direct Intramural Costs } & \$ 25,000 \\ \text { Total Direct Costs } & \$ 125,000 \\ \text { Indirect Cost (67.13\% x Direct Costs) } & \$ 83,912 \\ \text { Total Costs (Direct and Indirect) } & \$ 208,912\end{array}$

\section{RECOMMENDATION}

This Action Memorandum represents the selected Removal Action for the Dimock Residential Groundwater Site in Dimock Township, Susquehanna County, Pennsylvania, developed in accordance with CERCLA, as amended, and is consistent with the NCP. This decision is based on the administrative record for the Site. The administrative record consists of the following documents

1. 1/13/12 "Dimock Home Well Data" memo from EPA Toxicologist Dawn Ioven.

2. ATSDR AROA Issued $12 / 28 / 11$.

3. Summary of Portions of data received by EPA and reviewed by the OSC.

4. PADEP Consent Order and Agreement, dated December 15, 2010.

5. EPA Data Review Memo, January 13, 2012.

6. EPA $104 \mathrm{e}$ request to Cabot, January 6, 2012

Conditions at the Site meet the Removal Action requirements of Section 300.415(b) of the NCP and I recommend your approval of the proposed removal action and exemption from the statutory limits. The total project ceiling, if approved, will be $\$ 100,000$. Of this, as much as, $\$ 50,000$ comes from the Regional removal allowance. Please indicate your approval or disapproval below.

${ }^{3}$ Direct Costs include direct extramural costs and direct intramural costs. Indirect costs are calculated based on an estimated indirect cost rate expressed as a percentage of site-specific direct costs, consistent with the full cost accounting methodology effective October 2, 2000. These estimates do not include pre-judgment interest, do not take into account other enforcement costs, including Department of Justice costs, and may be adjusted during the course of a removal action. The estimates are for illustrative purposes only and their use in not intended to create any rights for responsible parties. Neither the lack of a total cost estimate nor deviation of actual total costs from this estimate will affect the United States' right to cost recovery. 


\section{Action by the Approving Official:}

I have reviewed the above-stated facts and, based upon those facts and the information compiled in the documents described above, I hereby approve/disapprove the selected removal action.
APPROVED: Dennis P. Carney, Associate Division Director Hazardous Site Cleanup Division EPA Region 3

\section{DISAPPROVED:}

Dennis P. Carney, Associate Division Director Hazardous Site Cleanup Division EPA Region 3
DATE $1 / 19 / 2012$

DATE 


\section{Newsroom News Releases By Date}

\section{EPA Completes Drinking Water Sampling in Dimock, Pa.}

Release Date: 07/25/2012

Contact Information: Terri White white.terri-a@epa.gov (215) 814-5567

PHILADELPHIA (July 25, 2012) - The U.S. Environmental Protection Agency announced today that it has completed its sampling of private drinking water wells in Dimock, Pa. Data previously supplied to the agency by residents, the Pennsylvania Department of Environmental Protection and Cabot Oil and Gas Exploration had indicated the potential for elevated levels of water contaminants in wells, and following requests by residents EPA took steps to sample water in the area to ensure there were not elevated levels of contaminants. Based on the outcome of that sampling, EPA has determined that there are not levels of contaminants present that would require additional action by the Agency.

"Our goal was to provide the Dimock community with complete and reliable information about the presence of contaminants in their drinking water and to determine whether further action was warranted to protect public health," said EPA Regional Administrator Shawn M. Garvin. "The sampling and an evaluation of the particular circumstances at each home did not indicate levels of contaminants that would give EPA reason to take further action. Throughout EPA's work in Dimock, the Agency has used the best available scientific data to provide clarity to Dimock residents and address their concerns about the safety of their drinking water."

EPA visited Dimock, $\mathrm{Pa}$. in late 2011, surveyed residents regarding their private wells and reviewed hundreds of pages of drinking water data supplied to the agency by Dimock residents, the Pennsylvania Department of Environmental Protection and Cabot. Because data for some homes showed elevated contaminant levels and several residents expressed concern about their drinking water, EPA determined that well sampling was necessary to gather additional data and evaluate whether residents had access to safe drinking water

Between January and June 2012, EPA sampled private drinking water wells serving 64 homes, including two rounds of sampling at four wells where EPA was delivering temporary water supplies as a precautionary step in response to prior data indicating the well water contained levels of contaminants that pose a health concern. At one of those wells EPA did find an elevated level of manganese in untreated well water. The two residences serviced by the well each have water treatment systems that can reduce manganese to levels that do not present a health concern.

As a result of the two rounds of sampling at these four wells, EPA has determined that it is no longer necessary to provide residents with alternative water. EPA is working with residents on the schedule to disconnect the alternate water sources provided by EPA.

Overall during the sampling in Dimock, EPA found hazardous substances, specifically arsenic, barium or manganese, all of which are also naturally occurring substances, in well water at five homes at levels that could present a health concern. In all cases the residents have now or will have their own treatment systems that can reduce concentrations of those hazardous substances to acceptable levels at the tap. EPA has provided the residents with all of their sampling results and has no further plans to conduct additional drinking water sampling in Dimock.

For more information on the results of sampling, visit: http://www.epa.gov/aboutepa/states/pa.html .
Search this collection of releases | or search all news releases

Get news releases by email

View selected historical press releases from 1970 to 1998 in the EPA History w ebsite.

\section{Recent additions}

01/24/2013 EPA Details Results of $\$ 100 \mathrm{M}$ Federal Effort to Clean up Navajo Uranium Contamination

01/23/2013 EPA to Host Third Chemtronics Superfund Site CAG Formation Meeting

01/22/2013 EPA orders Lapwai School District maintenance shop to cleanup threat to nearby drinking water wells

01/22/2013 Phillips 66 Company Settles Hazardous Waste Violations at its Former Refinery in Irainer, $\mathrm{Pa}$.

01/18/2013 EPA Proposal for Navajo Generating Station Cuts Harmful Emissions $84 \%$. Improves Visibility at National Parks, Protects Public Health 
September 8, 2010

By FedEx and e-mail

The Honorable Lisa Jackson

Administrator

United States Environmental Protection Agency

Ariel Rios Building

1200 Pennsylvania Avenue, N.W.

Washington, D.C. 20460

\section{Re: Petition for Rulemaking Pursuant to Section 6974(a) of the Resource Conservation and Recovery Act Concerning the Regulation of Wastes Associated with the Exploration, Development, or Production of Crude Oil or Natural Gas or Geothermal Energy.}

Dear Administrator Jackson:

To best protect human health, food sources, and our environment from the toxicity of contaminants found in wastes associated with the exploration, development and production of oil, gas, and geothermal energy, we believe it is appropriate for the Environmental Protection Agency (EPA) to reconsider its 1988 Regulatory Determination and regulate these wastes under Subtitle $\mathrm{C}$ of the Resource Conservation and Recovery Act (RCRA). The Natural Resources Defense Council (Petitioner) is submitting the attached rulemaking petition pursuant to Section 6974(a) of RCRA, 42 U.S.C. $\S 6974(a)$. In support of this petition, we identify numerous reports and data produced since the EPA's Regulatory Determination for Oil, Gas, and Geothermal Exploration, Development, and Production Wastes (July 6, 1988) which quantify the waste's toxicity, threats to human health and the environment, inadequate state regulatory programs, and readily available solutions.

The Natural Resources Defense Council (NRDC) is a nonprofit environmental action group established in 1970 by a group of law students and attorneys at the forefront of the environmental movement. The Natural Resources Defense Council's purpose is to safeguard the Earth: its people, its plants and animals and the natural systems on which all life depends. NRDC uses law, science and the support of 1.2 million members and online activists to protect the planet's wildlife and wild places and 
to ensure a safe and healthy environment for all living things. NRDC has worked for many years to ensure the proper regulation of oil and gas exploration and production operations.

Section 6974(a) of RCRA allows any person to petition the Administrator of the EPA to promulgate an environmental regulation. Within a reasonable time following receipt of such petition, the Administrator shall take action with respect to such petition and shall publish notice of such action in the Federal Register, together with the reasons therefor. This petition asks the EPA to take specific actions and directs the EPA's attention to the ample documentation in the record, which provides full support for the designation of wastes associated with the exploration, development, or production of crude oil or natural gas or geothermal energy as hazardous waste under RCRA and provides a firm and compelling basis for the reconsideration of the EPA's July 1998 Regulatory Determination.

Thank you in advance for your consideration of this petition.

Respectfully submitted by:

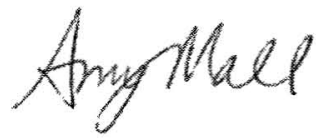

Amy Mall

Senior Policy Analyst

Diane Donnelly

Legal Intern

Natural Resources Defense Council

1918 Mariposa Avenue

Boulder, CO 80302

Phone: 720-565-0188

e-mail: amall@nrdc.org 


\section{TABLE OF CONTENTS}

\section{THE EPA SHOULD REGULATE WASTE FROM THE EXPLORATION, DEVELOPMENT} AND PRODUCTION OF CRUDE OIL AND NATURAL GAS UNDER SUBTITLE C OF RCRA. 4

A. The EPA Has Authority to Reconsider Its 1988 Regulatory Determination...................................... 4

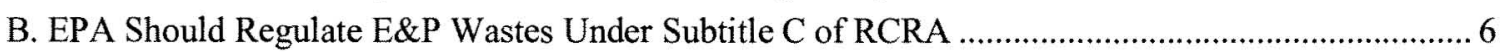

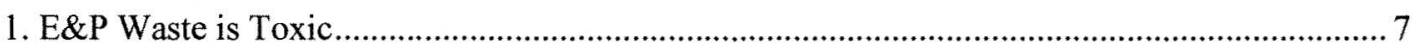

a. Contaminants Found in Different Types of E\&P Waste............................................. 7

i. Produced Water \& Hydraulic Fracturing Wastewater................................... 8

ii. Drilling Fluids and Drill Cuttings................................................................. 10

iii. Associated Wastes ........................................................................................ 11

b. Contaminants Found in Specific E\&P Waste Disposal Sites.................................... 12

c. The risks associated with these contaminants ........................................................... 13

i. Substances in E\&P Wastes Endanger Human Health................................... 13

ii. Substances in E\&P Wastes Endanger Wildlife and Livestock..................... 15

2. Current State Regulations and Enforcement Are Inadequate and Allow E\&P Waste to Be

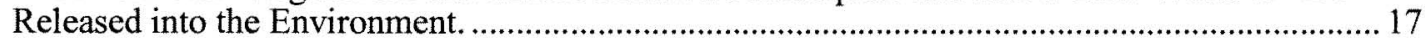
a. Pits

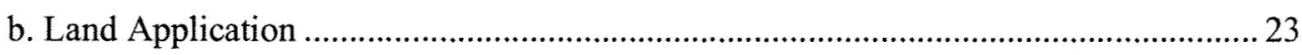

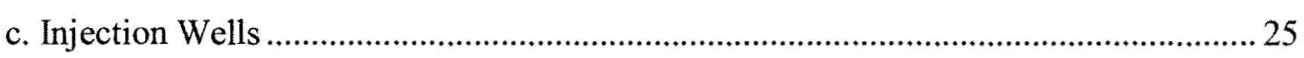
d. Wastewater Treatment Facilities.............................................................................. 27
e. Other spills, leaks, and intentional dumping ..................................................... 28

3. Oil \& Gas Production Has Increased Dramatically Since 1988 ..............................................30

4. Regulation Under Subtitle C of RCRA Would Not Harm the Oil \& Gas Industry .................. 31

a. New Waste Disposal Technologies............................................................. 32

b. Waste Minimization, Reuse, and Recycling Techniques.......................................... 35

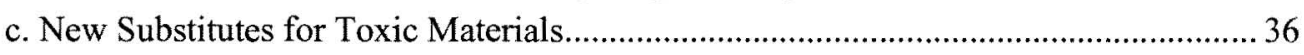

5. Oil and Gas Waste Meets the Statutory and Regulatory Criteria for Hazardous

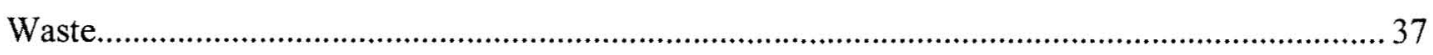

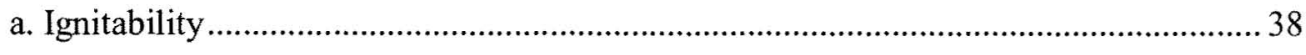

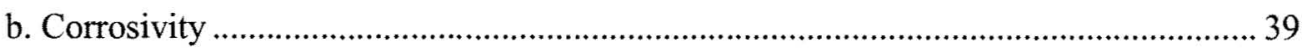

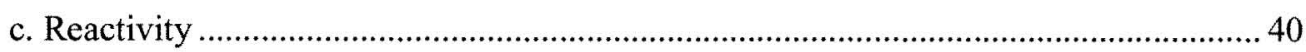

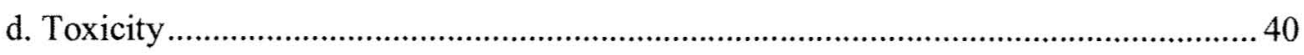

II. REQUEST FOR PROMULGATION OF REGULATIONS ...............................................41

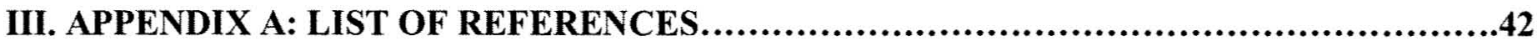

IV. APPENDIX B: CD WITH ALL REFERENCE DOCUMENTS 


\section{THE EPA SHOULD REGULATE WASTE FROM THE EXPLORATION, DEVELOPMENT AND PRODUCTION OF CRUDE OIL AND NATURAL GAS UNDER SUBTITLE C OF RCRA.}

We request that the U.S. Environmental Protection Agency (EPA) promulgate regulations that subject wastes associated with the exploration, development, or production of crude oil or natural gas or geothermal energy to the hazardous waste provisions of Subtitle $C$ of the Resource Conservation and Recovery Act (RCRA). We submit this petition pursuant to 42 U.S.C. $\S$ 6974(a), seeking that EPA ensure safe management of these wastes throughout their life cycle from cradle to grave, including generation, transportation, treatment, storage and disposal. Reports concerning the toxicity of exploration, development and production wastes, their release into the environment, threats to human health, the increasing amount of these types of wastes being generated, the inadequacy of existing state regulations, enforcement and oversight, and the feasibility and economic benefits of using disposal techniques that are less harmful to the environment all support regulation under Subtitle C, as described in detail below.

\section{A. The EPA Has Authority to Reconsider Its 1988 Regulatory Determination.}

Congress gave EPA the authority to prescribe necessary regulations to carry out its functions under RCRA. ${ }^{1}$ Congress charged EPA with the task of "assuring that hazardous waste management practices are conducted in a manner which protects human health and the environment." 2 Congress ensured that the public had a way to seek additional protections from hazardous wastes by allowing "[a]ny person ... [to] petition the Administrator for the promulgation, amendment, or repeal of any regulation under" RCRA, and by requiring that "[w]ithin a reasonable time following receipt of such petition, the Administrator shall take action with respect to such petition and shall publish notice of such action in the Federal Register, together with the reasons therefor." 3

With these provisions, Congress expressed its intent that RCRA would adapt to changing hazardous waste management needs. Foreseeing the need to update regulations promulgated under RCRA to account for changing circumstances, ${ }^{4}$ Congress provided the public a way to bring about EPA review of its regulations. ${ }^{5}$ These provisions authorize EPA to reconsider its current treatment of wastes associated with the exploration, development, or production of oil and gas (E\&P wastes).

\footnotetext{
${ }^{1} 42$ U.S.C. \$ 6912(a)(1).

242 U.S.C. $\$ 6902(a)(4)$.

${ }^{3} 42$ U.S.C. $\$ 6912$ (a)(1)

${ }^{4} 42$ U.S.C. $\$ 6912$ (b).

${ }^{5} 42$ U.S.C. $\$ 6912(\mathrm{a})(1)$.
} 
Congress passed RCRA in 1976 as an amendment to the Solid Waste Disposal Act of 1965 in an effort to enact more comprehensive waste disposal standards nationwide. ${ }^{6}$ Through RCRA, Congress declared that the "disposal of solid waste . . . without careful planning and management [was] a danger to human health and the environment." Congress later amended RCRA with the Solid Waste Disposal Act Amendments of $1980 .{ }^{8}$ One of the 1980 amendments, the so-called Bentsen Amendment, temporarily exempted "drilling fluids, produced waters, and other wastes associated with the exploration, development, or production of crude oil or natural gas" from regulation under RCRA. ${ }^{9}$

Under the Bentsen Amendment, Congress directed EPA to conduct a study to determine whether or not E\&P wastes should be regulated as hazardous wastes under RCRA. ${ }^{10}$ EPA completed the required study and submitted a Report to Congress on the Management of Waste from the Exploration, Development, and Production of Crude Oil, Natural Gas, and Geothermal Energy. ${ }^{11}$ Shortly after submitting its report to Congress, EPA issued its Regulatory Determination for Oil, Gas, and Geothermal Exploration, Development, and Production Wastes, in which it decided that regulation of E\&P wastes under Subtitle C of RCRA was unwarranted. ${ }^{12}$

In the more than twenty years that have passed since EPA issued its Regulatory Determination on E\&P wastes, both the oil and gas industry and the risks associated with E\&P wastes have expanded dramatically, making EPA's 1988 Regulatory Determination unjustified. While E\&P wastes have always been hazardous to human health and the environment, the recent expansion of drilling operations to more densely populated areas places even more people at risk. EPA's reconsideration of its 1988 Regulatory Determination is especially necessary now that the basis for its Regulatory Determination no longer reflects current conditions. In its 1988 Regulatory Determination, EPA identified three factors as the basis for its decision not to regulate E\&P wastes under Subtitle C. These factors included: (1) the infeasibility of implementing alternative regulations, (2) the adequacy of state regulations, and (3) the economic harm that would befall the oil and gas industry if additional regulatory controls were imposed. ${ }^{13}$

\footnotetext{
${ }^{6}$ Joseph F. Scavetta, RCRA 101: A Course in Compliance for Colleges and Universities, 72 NOTRE DAME L. REV. 1647 (1997).

${ }^{7}$ Natasha Ernst, Note, Flow Control Ordinances in a Post-Carbone World, 13 PENN ST. ENVTL. L. REV. 53 (2004) (citing 42 U.S.C $\$ \S 6901-6992 \mathrm{k}(2003)$ ).

${ }^{8}$ Pub. L. 96-482; see also James R. Cox, Revisiting RCRA'S Oilfield Waste Exemption as to Certain Hazardous Oilfield Exploration and Production Wastes, 14 VILL. ENVTL. L.J. 1, 3 (2003).

${ }^{9} 42$ U.S.C. $\$ 6921($ b) $(2)($ A).

${ }^{10} 42$ U.S.C. $\$ 6921$ (b)(2)(B).

"EPA, REPORT TO CONGRESS, MANAGEMENT OF W ASTES FROM THE EXPLORATION, DEVELOPMENT, AND Production of Crude OIL, NATURAL Gas, AND Geothermal ENERGY, Vols. 1-3 EPA530-SW-88-003 (1987) [hereinafter REPORT TO CONGRESS].

12 Regulatory Determination for Oil and Gas and Geothermal Exploration, Development and Production Wastes, 53 Fed. Reg. 25446, 25447 (July 6, 1988).

${ }^{13}$ Regulatory Determination for Oil and Gas and Geothermal Exploration, Development and Production Wastes, 53 Fed. Reg. at 25446.
} 
As will be discussed at greater length below, new evidence clearly demonstrates that alternative disposal practices are feasible, state regulations remain inadequate, and the oil and gas industry is unlikely to be severely harmed by the imposition of more stringent waste disposal requirements. Because this evidence shows that the assumptions on which EPA's 1988 Regulatory Determination was based are no longer correct, EPA must revisit its decision. ${ }^{14}$

Nothing in RCRA prevents the EPA from reconsidering its 1988 Regulatory Determination. In American Portland Cement Alliance,${ }^{15}$ the court upheld EPA's authority to reconsider regulatory determinations made pursuant to the 1980 amendments to RCRA. ${ }^{16}$ Moreover, statements made by EPA in its 1988 Regulatory Determination indicate that EPA never intended the Regulatory Determination to be its final word on E\&P waste. Instead, EPA established a three-pronged plan and intended to take further action to fill in existing gaps in the regulations governing the disposal of E\&P wastes. ${ }^{17}$ To date this three-pronged plan has not been fulfilled. Gaps in the regulatory system governing E\&P wastes have grown even wider and evidence of the substantial harm E\&P wastes can cause to human health and the environment has continued to accumulate. EPA must revisit its 1988 Regulatory Determination to fulfill its obligations under the 1988 Regulatory Determination and protect human health and the environment from the significant risks posed by E\&P wastes.

Unless EPA revisits its 1988 Regulatory Determination and recommends that E\&P wastes be regulated under Subtitle C of RCRA, E\&P wastes will continue to present substantial hazards to human health and the environment. ${ }^{18}$

\section{B. EPA Should Regulate E\&P Wastes Under Subtitle C of RCRA.}

In light of the documented toxicity of contaminants found in E\&P waste, the failure of states to adequately regulate the disposal of $\mathrm{E} \& \mathrm{P}$ wastes, the dramatic increase in oil and gas production that has occurred since 1988, and the availability of safer cost-effective disposal alternatives, EPA must take action in order to prevent further harm to human health and the

\footnotetext{
${ }^{14}$ EPA Region 8 itself stated that "EPA may need to revisit the continued validity of the exemption in light of the advancements in practices." EPA REGION 8, AN ASSESSMENT OF THE ENVIRONMENTAL IMPLICATIONS OF OIL AND Gas Production: A Regional CASE Study 3-14 (Working Draft 2008).

${ }^{15} 101$ F.3d 772 (D.C. Cir. 1996).

${ }^{16} \mathrm{Id}$.

${ }^{17}$ Regulatory Determination for Oil and Gas and Geothermal Exploration, Development and Production Wastes, 53 Fed. Reg. at 25,447 .

${ }^{18}$ [This footnote intentionally deleted in corrected copy.]
} 
environment. EPA should reconsider its 1988 Regulatory Determination and regulate E\&P wastes under Subtitle C of RCRA. Regulation under Subtitle C is not only appropriate, given that $\mathrm{E} \& \mathrm{P}$ wastes fall within the regulatory criteria for characteristic hazardous waste, ${ }^{19}$ but necessary because, without such action, the oil and gas industry will lack the incentives to implement safer techniques as quickly as is necessary. ${ }^{20}$

\section{E\&P Waste Is Toxic.}

E\&P waste that is exempt from regulation under Subtitle $\mathrm{C}$ includes: drilling fluids and cuttings, produced water, used hydraulic fracturing fluids, rigwash, workover wastes, tank bottom sludge, glycol-based dehydration wastes, amine-containing sweetening wastes, hydrocarbon-bearing soil, and many other individual waste products. ${ }^{21}$ In its 1988 Regulatory Determination, EPA admitted that E\&P wastes contain toxic substances that endanger both human health and the environment. ${ }^{22}$ Despite noting that benzene, phenanthrene, lead, arsenic, barium, antimony, fluoride, and uranium found in E\&P wastes were of major concern and present at "levels that exceed 100 times EPA's health based standards," 23 EPA declined to regulate these toxic substances under Subtitle C of RCRA. But EPA can no longer refuse to act: an ever-increasing amount of evidence demonstrates that E\&P wastes are toxic, have had substantial negative effects on human health and the environment, and should be a major concern for EPA. Since 1988, numerous reports, studies, and cases have demonstrated that E\&P wastes contain toxic substances that threaten both human health and the environment.

\section{a. Contaminants Found in Different Types of E\&P Wastes}

E\&P wastes are generally divided into three categories: produced water, drilling fluids and cuttings, and associated wastes. ${ }^{24}$ All of these wastes contain a variety of toxic substances that present substantial risks to human health and the environment. Despite these risks, these E\&P wastes are currently exempt from regulation under Subtitle C.

\footnotetext{
${ }^{19}$ See notes 282-313 infra and accompanying text.

${ }^{20}$ Closing Argument of the New Mexico Citizens for Clean Air and Water, Dec. 2007, OCD Document Image No. 14015_648_CF[1] at 9-10; see also AMY MALL, DrILLING DOWN: ProteCting WeSTERn COMMUNITIES FROM THE HEALTH AND ENVIRONMENTAL EFFECTS OF OIL AND GAS PRODUCTION vi (2007) [hereinafter "DrILLING DOWN"].

${ }^{21}$ See RaIlRoAd COMmission OF TEXAS, Hazardous and Nonhazardous Oil and Gas Waste 3-6, in WASTE MINIMIZATION IN THE OIL FIELD (2001).

${ }_{22}$ Regulatory Determination for Oil and Gas and Geothermal Exploration, Development and Production Wastes, 53 Fed. Reg. at 25448.

${ }^{23}$ Id.; see also Cox, supra note 8 , at 9.

${ }^{24}$ Claudia Zagrean Nagy, California Dep'T OF TOXiC Substances CONTROL, OIL Exploration AND PRODUCTION WASTES INITIATIVE 6 (2002).
} 


\section{i. Produced Water \& Hydraulic Fracturing Wastewater}

Produced water, also known as brine, is generally - but erroneously - considered to be "relatively clean" and contain less contaminants than other E\&P waste. ${ }^{25}$ Despite this common misconception, a study sponsored by the U.S. Department of Energy demonstrated that oil production yields "environmentally hazardous" produced water. ${ }^{26}$ The West Virginia Department of Environmental Protection (WVDEP) found many contaminants of concern present in oil and gas wastewaters, ${ }^{27}$ including arsenic, lead, and hexavalent chromium, while EPA Region 8 identified the presence of barium, chloride, sodium, sulfates, and other minerals, ${ }^{28}$ and the Oklahoma Corporation Commission Oil and Gas Conservation Division stated that produced water can contain high levels of boron. ${ }^{29}$ In 2009 , the Colorado Oil and Gas Conservation Commission (COCG) documented multiple spills of produced water containing benzene levels exceeding the state's water quality standards, at least one of which was confirmed to have impacted groundwater. ${ }^{30}$

Knowledge of the hazardous nature of produced water is not new. In 1972, Chevron Oil Field Research Company found that "oil field produced waters contain dissolved organic compounds that are toxic to marine life." ${ }^{31}$ More than a decade later, the U.S. General Accounting Office (GAO) acknowledged that " $[\mathrm{b}]$ rines associated with oil and gas production contain very high levels of chlorides .... Brines may also contain ... petroleum hydrocarbons and additives, such as corrosion inhibitors, ... and other radioactive materials." ${ }^{32}$ EPA was aware of these hazardous constituents when it issued its 1988 Regulatory Determination. In its 1987 Report to Congress, EPA knew that "PAHs [polycyclic aromatic hydrocarbons] are a typical component of some produced waters," that "very low concentrations . . . of PAH are lethal to some forms of aquatic wildlife," and that the practice of disposing of "produced water in

\footnotetext{
${ }^{25}$ Kelly Corcoran, Katherine Joseph, Elizabeth Laposata, \& Eric SCOt, UC Hastings College of the LaW's Public Law Research Institute, Selected Topics in STATE and LOCAL Regulation of OIL and GaS EXPLORATION AND PRODUCTION 31-32.

${ }_{26}^{26}$ C. TSOURis, OAK Ridge National Laboratory, EmERging Applications of Gas Hydrates 7.

${ }^{27}$ The contaminants of concern included: "sulfate, chloride, arsenic, titanium, cobalt, nickel, silver, zinc, vanadium, tin, cadmium, lead, chromium, hexavalent chromium, copper, fluoranthene, cyanide, mercury, selenium, antimony, beryllium, barium, ammonia nitrogen, fluoride, nitrite nitrogen, nitrate nitrogen, oil and grease, total suspended solids, iron, aluminum, chloroform, benzene, phthalate esters, strontium, strontium-90, boron, lithium, gross alpha radiation, gross beta radiation, radium $226+$ [and] radium 228." Letter from West Virginia Department of Environmental Protection to William Goodwin, Superintendent Clarksburg Sanitary Board, July 23, 2009.

${ }^{28}$ EPA REGION 8, AN ASSESSMENT OF THE ENVIRONMENTAL IMPLICATIONS OF OIL AND GAS PRODUCTION: A REGIONAL CASE STUdy, WORKING DRAFT 3-11 (2008).

${ }^{29}$ OKLAHOMA CORPORATION COMMISSION OIL AND GAS CONSERVATION DIVISION, GuIDELINES FOR RESPONDING TO AND REMEDIATING NEW OR HISTORIC BRINE SPILLS 2 (2009).

${ }^{30}$ Colorado OIL and Gas CONSERVATION COMmission, InSPECTION/INCIDENT INQUIRY, SPILl REPORTS, DOC. NOS. 1631502,1631508 (groundwater impact confirmed).

${ }^{31}$ A.H. Beyer, Chevron OIl Field Research Co., TeChnical Memorandum, Purification of Produced WATER, PART 1 - Removal OF Volatile DisSOlved OIL By STRIPPING 1 (1972).

32 U.S. GENERAL ACCOUNTING OFFICE, RCED-89-97, SAFEguARDS ARE NOT PREVENTING CONTAMINATION FROM INJECTED OIL AND GAS WELLS 11 (1989).
} 
unlined percolation pits [allows] PAHs and other constituents to migrate into and accumulate in soils." 33

In addition to containing dangerous contaminants, produced water can also be radioactive. This problem first attracted national attention 1988 in southern and Gulf Coast states. ${ }^{34}$ Shortly thereafter, GAO's 1989 report openly acknowledged the hazard. ${ }^{35}$ A more recent analysis of normally occurring radioactive materials (NORM) levels in produced waters from the Marcellus Shale indicates that the dangers may be greater than initially thought. ${ }^{36}$ Samples of produced water in the Marcellus Shale analyzed by the New York State Department of Environmental Conservation (NYSDEC) were reported to contain "levels of radium 226, a derivative of uranium, as high as 267 times the limit safe for people to drink." ${ }^{37}$

Despite knowledge of these risks, the data currently available may underestimate the actual radiation levels in produced water. A common method used by industry and EPA to measure radiation levels in produced water has been criticized because of its tendency to underestimate actual radiation levels. In the late 1980s, Exxon Mobil, along with Rogers and Associates Engineers (RAE) and the American Petroleum Institute (API), formulated correlations that could be used to estimate NORM in levels of equipment used to hold produced water. ${ }^{38}$ The external measurement process chosen by RAE to measure the NORM levels has since been challenged as "seriously flawed" and has resulted in the reporting of a "greatly reduced radioactivity concentration of $480 \mathrm{pCi} / \mathrm{gm} . " 39$ Accurate testing could reveal that the NORM levels in produced water are even higher than currently being reported.

Wastewaters from hydraulic fracturing, largely composed of used fracturing fluids, are also toxic. Common substances found in these wastewaters include: surfactants, friction reducing chemicals, biocides, scale inhibitors, polymers, cross linkers, $\mathrm{pH}$ control agents, gel breakers, clay control agents and propping agents. ${ }^{40}$ Many of these substances are possible and probable carcinogens. ${ }^{41}$ Analysis of fracturing fluid flowback waters from Pennsylvania and West Virginia found the known carcinogen benzene present in nearly half of all fracturing fluid flowback waters at average concentrations nearly one hundred times the maximum acceptable

${ }^{33}$ EPA, REPORT TO CONGRESS, supra note 11 , at II-44.

${ }^{34}$ Keith Schneider, Radiation Danger Found in Oilfields Across the Nation, N.Y. TIMES, Dec. 3, 1990, at A1.

${ }^{35}$ GAO, RCED-89-97, supra note 32.

${ }^{36}$ N.Y. DeP'T OF ENVTL. CONSERVATION, Draft SUPPlemental GENERIC ENVIRONMENTAL IMPACT STATEMENT ON THE OIL, GAS AND SOLUTION Mining REgulatory Program 6-130 (2009) [hereinafter Draft SGEIS].

${ }^{37}$ Abrahm Lustgarten, ProPublica, Natural Gas Drilling Produces Radioactive Wastewater, SCIENTIFIC AMERICAN, Nov. 9, 2009; see also DRAFT SGEIS, supra note 36, at app. 13.

${ }^{38}$ Motion in Limine to Exclude Rogers and Associates Engineering Reports, Lester v. Exxon Mobil Corp., No. 630402 (La. 24th Jud. Dist. Ct. 2009), at 6-7.

${ }^{39}$ Id. at $7-8$.

${ }^{40}$ Wilma Subra, Louisiana Environmental Action Network, Comments on Hydraulic Fracturing to the Louisiana Senate Environmental Quality Committee, Mar. 11, 2010.

${ }^{41} I d$. 
contaminant levels established by EPA. ${ }^{42}$ While this information demonstrates that these wastes contain toxic compounds, the true extent of the risks associated with hydraulic fracturing wastewaters is currently unknown as many of the compounds used in fracturing fluids and returned in the wastewaters are not publically disclosed. ${ }^{43}$

\section{ii. $\quad$ Drilling Fluids and Drill Cuttings}

Drilling fluids and cuttings make up two to four percent of oil and gas wastes. ${ }^{44}$ They include rock removed during drilling (drill cuttings) and drilling muds, also known as drilling fluids, which can be either water or oil-based and often contain various additives. ${ }^{45} \mathrm{~A}$ joint EPA/API survey found drilling fluids in reserve pits to contain "chromium, lead and pentachlorophenol at hazardous levels." ${ }^{46}$ The survey also found that "oil-based fluids may contain benzene" ${ }^{47}$ and that when oil-based fluids are used, "potentially toxic hydrocarbons" will be present in greater quantities. ${ }^{48}$ Drilling muds may also contain other "potentially hazardous substances including . . . cadmium, arsenic . . . mercury, copper . . . diesel oil; grease; and various other hydrocarbons and organic compounds (e.g., methanol, chlorinated phenols, formaldehyde, benzene, toluene, ethyl benzene, xylene, and acrylamide)," as well as additives including acids and caustics, corrosion inhibitors, bactericides and biocides, surfactants, defoamers, emulsifiers, filtrater

\footnotetext{
${ }^{42}$ Susan Riha et al, Comments on the Draft SGEIS on the Oil, Gas and Solution Mining Regulatory Program, Jan. 2010, at 5; see also N.Y. DEP'T OF ENVTL. CONSERVATION, DRAFT SGEIS 5-104 (2009).

${ }^{43}$ Wilma Subra, Comments on Hydraulic Fracturing, supra note 40. See also DRAFT SGEIS, supra note 36, at 5-51 (stating that the fracturing fluid additives list "[c]hemical constituents are not linked to product names in Table 5.6 because a significant number of product composition and formulas have been justified as trade secrets as defined [under New York law] ....”.).

${ }^{44}$ U.S. CONGRESS, OFFICE OF TECHNOLOGY ASSESSMENT, MANAGING INDUSTRIAL SOLID W ASTES FROM MANUfaCturing, Mining, Oll and Gas PRODUCTION, AND UTILITY COAL COMBUSTION-BaCKGROUND PAPER 67 (1992).

${ }^{45}$ Id; see also U.S. FISH \& WILDLIFE SERV., REgION 6, ENVTL. CONTAMINANTS PROGRAM, RESERVE PIT

MANAGEMENT: RISKS TO MIGRATORY BIRDS 4-5 (2009).

"Water-based drilling muds can contain glycols, chromium, zinc, polypropylene glycol, and acrylamide copolymers. Synthetic-based muds contain mineral oil and oil-based muds can contain diesel oil, although diesel oil is being replaced by a palm oil derivative or hydrated caster [sic] oil. Other additives typically used in drilling fluids include: polymers (partially hydrolyzed polyacrylamide (PHPA) and polyanionic cellulose (PAC)); drilling detergents; and sodium carbonate (soda ash). PHPA is used to increase viscosity of fluid and inhibit clay and shale from swelling and sticking. PAC is used to increase the stability of the borehole in unconsolidated formations. Drilling detergents or surfactants are used with bentonite drilling fluids to decrease the surface tension of the drill cuttings. Soda ash is used to raise the $\mathrm{pH}$ of the water and precipitate calcium out of the water." Id. (internal citations omitted).

${ }^{46}$ U.S. CONGRESS, OFFICE OF TECHNOLOGY ASSESSMENT, MANAGING INDUSTRIAL SOLID WASTES FROM Manufacturing, Mining, Oll and Gas Production, and UtIlity COAL COMBustion-BaCkgRound PAPER 5 (1992).

${ }^{47} \mathrm{Id}$.

${ }^{48}$ Oil \& Gas accountability Project, Pit Pollution-Backgrounder on the Issues, with a New MeXico CASE STUDY 6 (2004).
} 
reducers, shale control inhibitors, thinners and dispersants, weighing materials, bentonite clay, and acrylamide. $^{49}$

The use of these additives increases the risks associated with E\&P waste, as many are hazardous compounds themselves. ${ }^{50}$ EPA has already classified at least one additive, flocculant acrylamide, as a probable carcinogen. ${ }^{51}$ Another frequently used additive, barite weighting agent, can contain cadmium and mercury. ${ }^{52}$ When Greenpeace analyzed the heavy metal contents of one drilling fluid additive, SOLTEX ${ }^{\mathbb{1}}$ (a scale inhibitor used in both on- and off-shore drilling muds), it identified the presence of antimony, arsenic, barium, cadmium, chromium, cobalt, copper, fluoride, lead, mercury, nickel, vanadium, and zinc. ${ }^{53}$ These reports alone create cause for concern; yet, the full extent of the risk these chemicals present is unknown, as the additives' formulas, and thus the concentrations of the various chemicals, are proprietary information and undisclosed by oil and gas companies. ${ }^{54}$

\section{iii. $\quad$ Associated Wastes}

Associated wastes include oily sludges, workover wastes, well completion and abandonment wastes and other small volume wastes associated with oil or gas production. ${ }^{55}$ Oily sludges consist of "oily sands and untreatable emulsions segregated from the production stream, and sediment accumulated on the bottom of crude oil and water storage tanks. ${ }^{56}$ Workover wastes include foam treatment wastes and stimulation fluids. ${ }^{57}$ Of all the E\&P wastes, associated wastes are generated in the lowest volume ${ }^{58}$ however, this does not mean that they are safe or that current regulations ensure they are disposed of properly. Indeed, "[a]lthough associated wastes constitute a relatively small proportion of total wastes, they are most likely to contain a range of chemicals and naturally occurring materials that are of concern to health and safety." associated wastes identified in Colorado have the "potential to be ignitable" while others "can exhibit toxicity for heavy metals such as lead." 60

\footnotetext{
${ }^{49} I d$.

${ }^{50} \mathrm{Id}$.

${ }^{51}$ U.S. EPA, Technology Transfer Air Toxics: Acrylamide.

${ }^{52}$ T.A. Kassim, Waste Minimization and Molecular Nanotechnology: Toward Total Environmental Sustainability, in 3 ENVIRONMENTAL IMPACT ASSESSMENT OF RECYCLED WASTES ON SURFACE AND GROUND WATERS: ENGINEERING Modeling And Sustainability 191, 204 (Tarek A. Kassim ed., 2005); Texas Railroad Commission, Waste Minimization in Drilling Operations.

53 JONATHAN WILLS, MUDDIED WATERS, A SURVEY OF OFFSHORE OILFIELD DRILLING W ASTES AND DisPosal. TECHNiQues to REDUCE THE ECOLOGICAL IMPACT OF SEA DUMPING (2000).

${ }_{55}^{5}$ OIL \& GAS ACCOUNTABILITY PROJECT, supra note 48, at 6-7.

${ }^{55} \mathrm{NAGY}$, supra note 24 , at 6.

${ }_{56}^{56}$ Id. at 13 .

${ }^{57}$ Id. at 14 .

${ }^{58}$ Id. at 6; American Petroleum Institute, Waste Management.

${ }^{59}$ Dara O'Rourke \& Sarah Connolly, Just Oil? The Distribution of Environmental and Social Impacts of Oil Production and Consumption, 28 ANNUAL REV. ENVTL. RESOURCES 587, 595 (2003).

${ }^{60}$ Testimony of Margaret A. Ash, OGCC Envtl. Supervisor, In the Matter of Changes to the Rules and Regulations of the Oil and Gas Conservation Commission of the State of Colorado, at 15.
} 


\section{b. Contaminants Found in Specific E\&P Waste Disposal Sites}

The hazardous contaminants used in oil and gas exploration and production and whose presence has been identified in E\&P wastes end up being disposed of in a variety of methods. Pits, burial, land application, and injection wells are the methods most frequently used to dispose of E\&P wastes. Wastewater treatment facilities are also increasing in use. Studies of some of these different types of common E\&P waste disposal sites provide further evidence of the toxicity of E\&P wastes.

Pits are a common E\&P waste disposal method used both to store drilling muds and cuttings brought to the surface in drilling operations and to hold produced water, production fluids, used hydraulic fracturing fluid, and other wastes. ${ }^{61}$ Numerous studies have found pits to contain toxic levels of many hazardous compounds. In 2007, an industry committee of oil and gas companies in New Mexico sponsored a sampling and analysis program of waste pits in the San Juan Basin. ${ }^{62}$ Forty-two substances, including the "BTEX" chemicals ${ }^{63}$ (benzene, toluene, ethylbenzene, and xylene), acetone, arsenic, barium, mercury, and radium were found in the samples. ${ }^{64}$ Eleven of the chemicals were present at concentration levels above state limits. ${ }^{65} \mathrm{~A}$ more recent sampling of an oilfield pit in Texas identified the presence of high levels of mercury and chromium. ${ }^{66}$ Dirt removed from a pit in Oklahoma was contaminated with "high levels of arsenic, dioxins and total petroleum hydrocarbons." ${ }^{, 7}$

Analysis of land application sites, another method for disposing of E\&P wastes, provides further evidence illustrating the hazards of E\&P wastes. A study of landfarms conducted by the Arkansas Department of Environmental Quality (ADEQ) found that the substances in E\&P wastes that were being land applied exceeded Arkansas' acceptable limits for chloride concentrations in most of the facilities it tested. ${ }^{68}$ In addition, "[n]ine out of eleven facilities had

\footnotetext{
${ }^{61}$ CORCORAN ET AL., supra note 25, at 20-21.

${ }^{62}$ The Endocrine Disruption Exchange, Potential Health Effects of Residues in 6 New Mexico Oil and Gas Drilling Reserve Pits Based on Compounds Detected in at Least One Sample, Nov. 15, 2007.

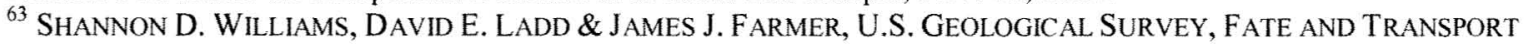
of Petroleum Hydrocarbons in SOIL AND Ground W ATER at Big SOUTH Fork National River AND ReCreAtion AREA, TENNESSEe AND KENTUCKy, 2002-2003 10 (2006) ("The BTEX compounds . . . appear on The Clean Water Act Priority Pollutant list of 126 chemical substances (Office of the Federal Register, 2002)."). Testing obtained by individuals residing near the pits has also confirmed the presence of dangerous contaminants. DRILLING Down, supra note 20, at 26 n.156.

${ }^{64}$ The Endocrine Disruption Exchange, supra note 62.

${ }^{65}$ The Endocrine Disruption Exchange, Number of Chemicals Detected in Reserve Pits for 6 Wells in New Mexico That Appear on National Toxic Chemicals Lists: Amended Document, Nov. 15, 2007.

${ }^{66}$ Letter from Roy Staiger, District Office Cleanup Coordinator, Texas Railroad Commission, to Exxon Mobil Corporation, Dec. 31, 2009.

${ }^{67}$ OIL \& GAS ACCOUNTABILITY ProjeCt, SPRING/SUMmer 2006 REPORT (2006).

${ }^{68}$ Arkansas Dep't of Envtl. Quality, Report on Landfarms ("Four facilities had pond chlorides greater than 3,000 $\mathrm{mg} / \mathrm{L}$ and the ponds were full .... Eight out of eleven facilities had soil concentrations greater than $1,000 \mathrm{mg} / \mathrm{Kg}$ on at least one application area. Most were several times higher than $1,000 \mathrm{mg} / \mathrm{Kg} \ldots .$.$) .$
} 
TPH concentrations that would indicate the application of [oil-based drilling fluids] had taken place." ${ }^{69}$ Analysis of soil samples taken from a residential property in Texas, where pit sludge had been land applied less than 300 feet from a residence, "confirmed the presence of numerous hydrocarbons identified as Recognized and Suspected human carcinogens and neurotoxins $(1,2$, 4 Trimethylbenzene, 1, 3, 5 Trimethylbenzene, 4-Isopropyltoluene, Acetone, Benzene, Carbon disulfide, Ethylbenzene, Isopropylbenzene, m\&m Xylene, n-Butylbenzene, n-Propylbenzene, oXylene, sec-Butylbenzene, tert-Butylbenzene, Toluene). ${ }^{70}$ The residents of this property all reported skin rashes after the waste was applied to their land. ${ }^{71}$

\section{c. The risks associated with these contaminants}

\section{i. $\quad$ Substances in E\&P Wastes Endanger Human Health.}

Many of these substances identified in E\&P wastes are known carcinogens. ${ }^{72}$ The most prevalent contaminants found in E\&P wastes are the "BTEX" chemicals: ${ }^{73}$ benzene, ${ }^{74}$ toluene, ${ }^{75}$ ethylbenzene, ${ }^{76}$ and xylene ${ }^{77}$ Exposure to benzene has been "associated with an increased risk of leukemia in industrial workers" 78 and other serious health conditions, exposure to toluene can cause nervous system damage, ${ }^{79}$ while xylenes can "cause dizziness, headaches and loss of balance among other problems." ${ }^{80}$ Many of the other chemicals found in E\&P waste, including

${ }^{69} \mathrm{Id}$.

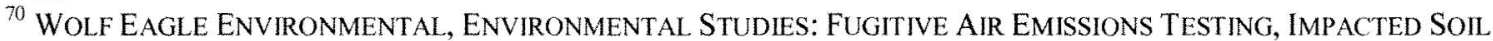
TESTING, Mr. AND MRS. Timothy RUGGIERO (2010).

${ }^{71}$ Eric Griffey, Toxic drilling waste is getting spread all over Texas farmland, FORT WORTH WEEKLY, May 12 , 2010.

72 See Cox, supra note 8 , at 4.

${ }^{73}$ CORCORAN ET AL., supra note 25, at 21.; see also WILLIAMS ET AL., supra note 63, at 10 ("The BTEX compounds ... appear on The Clean Water Act Priority Pollutant list of 126 chemical substances (Office of the Federal Register, 2002).’); U.S.G.S., TOXIC SubSTAnCE Hydrology Program: BTEX.

74 "Benzene is a known human carcinogen and causes leukemia." DRILLING DoWN, supra note 20, at vi; see also WILLIAMS ET AL., supra note 63, at 26. ("Because of the high degree of toxicity and mobility of benzene (compared to other petroleum hydrocarbons), it is commonly the main ground-water contaminant of concern at petroleum release sites.").

75 "Toluene can cause fatigue, confusion, weakness, memory loss, nausea, hearing loss, central nervous system damage, and may cause kidney damage. It is also known to cause birth defects and reproductive harm." DRILLING Down, supra note 20, at vi (footnotes omitted).

76 "Ethylbenzene can cause dizziness, throat and eye irritation, respiratory problems, fatigue, and headaches. It has been linked to tumors and birth defects in animals, as well as to damage in the nervous system, liver, and kidneys." Id. (footnote omitted).

77 "Xylene can cause headaches; dizziness; confusion; balance changes; irritation of the skin, eyes, nose and throat; breathing difficulty; memory difficulties; stomach discomfort; and possibly changes in the liver and kidneys." Id. (footnote omitted).

${ }^{78}$ N.Y. DEP'T OF ENVTL. CONSERVATION, supra note 36, at 5-62 (2009).

${ }^{79}$ CORCORAN ET AL., supra note 25 , at 21 .

${ }^{80} \mathrm{Id}$. 
acetone,${ }^{81}$ arsenic, ${ }^{82}$ barium, ${ }^{83}$ mercury, ${ }^{84}$ and radium, ${ }^{85}$ all found in E\&P waste samples, also raise serious concerns for human health.

The impacts of these contaminants have been documented. In a 1997 Louisiana case against U.S. Liquids \& Exxon, plaintiffs reported that shortly after the dumping of more than fifty million gallons of E\&P waste containing benzene, toluene, and lead occurred at a facility located less than 500 feet from the nearest resident's home, "[a] strange smell blew over the community and .... [m]any people in the area felt sick .... For nearly three weeks, most residents, including children, suffered from stomach pains, sinus problems and other ailments." ${ }^{86}$ Other evidence demonstrates that exposure to contaminants in E\&P wastes can result in delayed and long-term health effects. One study conducted in the Amazon Basin of Ecuador found that pregnant women who resided in areas where there was discharge of untreated oilfield wastes into the environment experienced higher levels of spontaneous abortion. ${ }^{87}$ Another epidemiological study in the same area showed "significantly higher incidence of cancer for all sites combined in both men and women living in proximity to oil fields .... [specifically,] [s]ignificantly higher incidences were observed for cancers of the stomach, rectum skin melanoma, soft tissue and

\footnotetext{
${ }^{81}$ Acetone can cause nose, throat, lung and eye irritation, respiratory problems, fatigue and headaches. See AGENCY FOR TOXIC Substances AND Disease REgISTRY, U.S. DEP'T OF HEALTH \& HuMAN SERVS., TOXFAQS FOR ACETONE (1995); Drilling Down, supra note 20, at vi (footnote omitted).

82 "Chronic arsenic exposure can cause damage to blood vessels, a sensation of 'pins and needles' in hands and feet, darkening and thickening of the skin, and skin redness. It is a known human carcinogen and can cause cancer of the skin, lung, bladder, liver, kidney, and prostate." DRILLING DOWN, supra note 20, at vi (footnote omitted); see also Agency for Toxic Substances and Disease Registry, U.S. DeP'T OF HEAlth \& Human SERVS., TOXFAQS FOR ARSENIC (2007) ("Exposure to lower levels can cause nausea and vomiting, decreased production of red and white blood cells, abnormal heart rhythm ....”); SCIENCELAB.COM, CHEMICALS \& LABORATORY EQUIPMENT, MATERIAL SAFETY DATA SHEET: ARSENIC MSDS 1 (2008), ("[Arsenic is] toxic to kidneys, lungs, the nervous system, mucous membranes.")

83 "Ingesting drinking water containing levels of barium above the EPA drinking water guidelines for relatively short periods of time can cause gastrointestinal disturbances and muscle weakness. Ingesting high levels for a long time can damage the kidneys .... Some people who eat or drink amounts of barium above background levels found in food and water for a short period may experience vomiting, abdominal cramps, diarrhea, difficulties in breathing, increased or decreased blood pressure, numbness around the face, and muscle weakness. Eating or drinking very large amounts of barium compounds that easily dissolve can cause changes in heart rhythm or paralysis and possibly death. Animals that drank barium over long periods had damage to the kidneys, decreases in body weight, and some died." Agency for Toxic Substances and Disease Registry, U.S. DeP'T OF Health \& Human SERVS.,

TOXFAQS FOR BARIUM (2007).

84 "Mercury can permanently damage the brain, kidneys, and developing fetus and may result in tremors, changes in vision or hearing, and memory problems. Even in low does, mercury may affect an infant's development, delaying walking and talking, shortening attention 'span,' and causing learning disabilities." DrILLING Down, supra note 20, at vi (footnote omitted).

85 "Radium is a known human carcinogen, causing bone, liver, and breast cancer." Id. (footnote omitted); see also

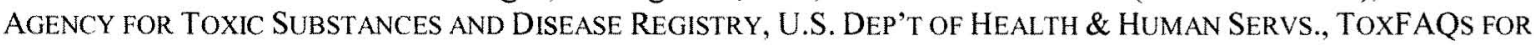
RADIUM (1999).

${ }^{86}$ Chris Gray, Pits Cause Stink in Lafourche, TIMES-PICAYUNE, July 14, 1997, at A1.

${ }^{87}$ Miguel San Sebastian, Ben Armstrong, \& Carolyn Stephens, Outcomes of Pregnancy among Women Living in the Proximity of Oil Fields in the Amazon Basin of Ecuador, 8 INTL. J. OF OCCUPATIONAL AND ECON. HEALTH 312 (2002).
} 
kidney in men and for cancers of the cervix and lymph nodes in women. ${ }^{88}$ As reports and firsthand accounts indicate, the risks posed by the contaminants found in E\&P waste are not merely speculative. And the risks will not decrease anytime soon. As many pits containing E\&P wastes are buried and forgotten, the buried E\&P wastes have the potential to threaten future generations who will be unaware of the hazards just below the surface.

Human health can also be harmed by exposure to radiation in NORM-contaminated E\&P wastes. Exposure can occur through inhalation of radium-bearing particles, through direct contact with NORM-contaminated soils and water, or through ingestion of radium-barium particles found in plants or animals exposed to NORM-contaminated soils or water. ${ }^{89}$ Exposure to radium can result "in an increased risk of bone, liver, and breast cancer . . . . [it] has been shown to cause effects on the blood (anemia) and eyes (cataracts). It also has been shown to affect the teeth, causing an increase in broken teeth and cavities." NORM-contaminated soils and waters can persist for decades. In particular, land contaminated by radium 226 , such as that found in produced water from the Marcellus Shale, ${ }^{91}$ can pose a threat to "many generations of individuals living or working on NORM-contaminated land for a period covering nearing 20,000 years." 92

\section{ii. $\quad$ Substances in E\&P Wastes Endanger Wildlife and Livestock.}

In addition to harming human health, exposure to contaminants in E\&P waste can sicken and kill wildlife. A recent report prepared by the U.S. Fish and Wildlife Service (USFWS) indicates that pits present significant risks to wildlife. Pits can "entrap and kill migratory birds and other wildlife ... . Birds are attracted to reserve pits by mistaking them for bodies of water. . . The sticky nature of oil entraps birds in the pits and they die from exposure and exhaustion." ${ }^{93}$ In 2009, ExxonMobil pled guilty to violating the Migratory Bird Treaty Act, ${ }^{94}$ after numerous birds (including mallard ducks, grebes, white-faced ibis, gadwell ducks, owls, Wilson pharalopes, Northern Shoveler ducks, avocets, curlew, a green-winged teal, a Cassin's sparrow, a purple

\footnotetext{
${ }^{88}$ Anna-Karin Hurtig \& Miguel San Sebastian, Geographical Differences in Cancer Incidence in the Amazon Basin of Ecuador in Relation to Residence near Oil Fields, 31 INT'L. J. OF EPIDEMIOLOGY 1021, 1025 (2002).

${ }^{89}$ Henry Spitz, Kennith Lovins \& Christopher Becker, Evaluation of Residual Soil Contamination From Commercial Oil Well Drilling Activities and Its Impact on the Naturally Occurring Background Radiation Environment, 6 SOIL \& SEDIMENT CONTAMINATION: AN INT'L J. 37, 43 (1997).

${ }^{90}$ AGENCY FOR TOXIC SUBSTANCES AND DISEASE REGISTRY, supra note 85.

${ }^{91}$ See supra note 37.

${ }^{92}$ Henry Spitz, Kennith Lovins \& Christopher Becker, Evaluation of Residual Soil Contamination From Commercial Oil Well Drilling Activities and Its Impact on the Naturally Occurring Background Radiation Environment, 6 SOIL \& SEDIMENT CONTAMINATION: AN INT'L J. 37, 41 (1997).

${ }^{93}$ U.S. Fish \& WildLifE SERV., REgion 6, ENVTl. CONTAMINANTS PROGRAM, RESERve Pit MANAGEMENT: Risks TO MIGRATORY BIRDS i (2009).

${ }^{94} 16$ U.S.C. $\$ \$ 703-708$.
} 
martin, and a hawk) were found sick and dead after being exposed to pit contents, including hydrocarbons, in multiple states. ${ }^{95}$

E\&P wastes have the potential to destroy lands upon which wildlife depend, disrupt food chains, and prevent wildlife from reproducing. ${ }^{96}$ The New Mexico Department of Game \& Fish has expressed concern about the hazards of hydrocarbon toxicity to wildlife including "acute and chronic ingestion or absorption toxicity, loss of thermal stability from oiling of fur or feathers, and reproductive failure due to absorption of chemicals from the maternal bird body through the shell of eggs. ${ }^{97}$ Other researchers are concerned about the bioaccumulation of E\&P wastes in wildlife, a process that would cause their harmful effects to magnify as they progress up the food chain. ${ }^{98}$ Wildlife habitat may also be harmed by E\&P waste. The New Mexico Department of Game and Fish has stated that it "is concerned that chloride contamination of the soil vadose zone may permanently impact the ability of a closed pit location to support vegetation necessary for productive wildlife habitat." 99 Just as E\&P wastes can harm humans in ways that are not immediately apparent but can cause harm to future generations, so too can they harm successive generations of wildlife.

Domesticated animals are also harmed by E\&P wastes. The Pennsylvania Department of Agriculture quarantined cattle after they came into contact with hydraulic fracturing wastewater being stored in a pit that leaked into an adjacent field. The owners of the property where the pit was located noticed seepage from the pit for as long as two months prior to the leak. The Department stated that wastewater "contains dangerous chemicals and metals." Tests of the wastewater found that it contained strontium as well as other substances. ${ }^{100}$ E\&P waste is sometimes disposed of on land used for cattle grazing. ${ }^{101}$ Residents of the Barnett Shale have reported seeing cattle drinking from sludge pits. ${ }^{102}$ Cattle have been lost due to exposure to E\&P waste in New Mexico ${ }^{103}$ and 54 out of 56 hair samples from sick cattle analyzed by the Texas Veterinary Medical Diagnostic Laboratory contained petroleum. ${ }^{104}$

\footnotetext{
95 Joint Factual Statement, U.S. v. Exxon Mobil Corp., 191 10-27 (D.Col. 2009).

${ }^{96}$ BRYAN M. Clark, DiRTy DRILling: The ThrEAT OF OIL AND GAS DRILLING IN LAKE ERIE 25 (2002).

${ }^{97}$ Letter from Lisa Kirkpatrick, Chief, New Mexico Dep't of Game \& Fish, Conservation Services Division, to Florene Davidson, Commission Secretary, EMNRD Oil Conservation Division (Jan. 20, 2006); see also Letter from Lisa Kirkpatrick, Chief, New Mexico Dep't of Game \& Fish, Conservation Services Division, to Florene Davidson, Commission Secretary, EMNRD Oil Conservation Division (Mar. 7, 2006).

${ }_{98}^{9}$ BRYAN M. CLARK, supra note 96, at 25.

${ }^{99}$ Letter from Lisa Kirkpatrick, Chief, New Mexico Dep't of Game \& Fish, Conservation Services Division, to EMNRD Oil Conservation Division (Feb. 2, 2007).

${ }^{100}$ Press Release, Pa. Dep't of Envtl. Prot., Cattle from Tioga County Farm Quarantined after Coming in Contact with Natural Gas Drilling Wastewater (July 1, 2010).

${ }^{101}$ See e.g., Amended Complaint, Sweet Lake Land and Oil Co. v. Exxon Mobil Corp., No. 209CV01100, at \ 32

(W.D. La. filed Sept. 14, 2009), 2009 WL 4701364.

${ }^{102}$ Bluedaze: Drilling Reform for Texas blog (July 25, 2008).

${ }^{103}$ DRILLING DOWN, supra note 20, at 26.

${ }^{104}$ Test results from Veterinary Medical Diagnostic Laboratory on July 26, 2005, August 18, 2005, and September 6, 2005; DrILLING Down, supra note 20, at 26.
} 
In response to occurrences like these, cattle ranchers and others whose animals are at risk have sought to prevent E\&P waste disposal facilities from opening near their properties. ${ }^{105}$ Protecting cattle and other domesticated animals from exposure to E\&P wastes is particularly important as the hazardous contaminants of E\&P wastes have the potential to bioaccumulate in these animals and potentially make their way into the human food chain. ${ }^{106}$

\section{Current State Regulations and Enforcement Are Inadequate and Allow E\&P Waste to Be Released into the Environment.}

Waste produced in E\&P operations is disposed of in a variety of ways, with underground injection and burial of waste historically being the most widely used methods. ${ }^{107}$ Wastewater treatment facilities are another growing disposal method. Even before EPA made its 1988 Regulatory Determination, data indicated that commonly used disposal practices failed to prevent E\&P wastes from contaminating soil and groundwater. ${ }^{108}$ A 1987 report documented "the migration of leachate 400 feet from reserve pits buried in . . North Dakota and reported groundwater contamination 50 feet below the buried reserve pits." ${ }^{109}$ Incidences of soil and groundwater contamination have continued to occur since then.

E\&P wastes may leak, spill, or evaporate into the air, allowing the chemicals used in oil and gas operations to be released into the environment. These releases occur in large part because many states' regulations do not adequately account for all of these potential modes of contamination, despite the fact that releases are occurring with alarming regularity, or are not vigorously enforced. The regulations of the Railroad Commission (RRC) of Texas have been described as providing only weak assurance that the "quality of waters (and land) will not be impacted by a gas operator's activity." ${ }^{110}$ Assurances are similarly minimal in other states where regulations provide virtually useless oversight of E\&P waste disposal because they fail to "clearly indicate acceptable disposal practices for all drilling wastes." 111

An Ohio resident with 23 years of experience in drilling oil and gas wells testified before the state legislature that existing regulations are inadequate and cannot be appropriately enforced: "... the [Ohio Department of Natural Resources] has a serious lack of ability to enforce their own regulations due to the way the current law and this bill are written." ${ }^{112}$ A review of Tennessee oil

\footnotetext{
${ }^{105}$ Susan Hylton, Drilling Waste Feud, Neighbors of Maverick Energy Services Think Water is Being Polluted, TULSA WORLD, Mar. 21, 2010, at A11

${ }^{106}$ DRILLING DOWN, supra note 20, at 26.

107 See E\&P FORUM, EXPLORATION AND Production (E\&P) WASTE MANAGEMENT Guidelines 5 (Report No. 2.58/196, 1993).

${ }_{108}$ U.S. FISH \& WILDLIFE SERV., supra note 93, at 4.

${ }^{109} \mathrm{Id}$.

${ }^{110}$ League of Women Voters of Tarrant County, Gas Drilling Waste-Water Disposal (2008).

111 BRYAN M. ClARK, supra note 96 , at 35.

112 Testimony of James E. McCartney to the $128^{\text {th }}$ General Assembly, Ohio Senate Environmental and Natural Resources Committee. Opponent Testimony on Senate Bill 165, Oct. 28, 2009.
} 
and gas regulations found that the state does not have technical criteria for E\&P waste management practices or any certification for E\&P haulers. ${ }^{113}$ Although all pits must be lined in Tennessee, pits are not considered or tracked through the permitting process and there are no security or wildlife protection measures. ${ }^{114}$

A 2009 letter from the EPA to the RRC of Texas states that the Commission should have "more rigorous evaluation" of conditions for waste disposal wells. ${ }^{115}$ Texas also "allows companies to hire their own environmental consultants to check for contamination." 116 These regulatory failures existed when EPA issued its 1988 Regulatory Determination, and have been exacerbated in the wake of EPA's decision not to regulate E\&P wastes under Subtitle C of RCRA.

a. Pits

Pit construction requirements vary greatly across the country. While a few states, such as New Mexico and Colorado, have recently adopted stricter rules governing the disposal of E\&P wastes in pits, other states have minimal regulations and often do not even require the use of pit liners. ${ }^{117}$

The open design of pits, combined with the often minimal regulatory requirements governing their construction and use, present greater opportunities for their dangerous contents to be released into the environment. Reports indicate that the release of E\&P wastes from pits is far too common.

In September 2008, New Mexico compiled its data on cases where pit substances contaminated New Mexico's groundwater. ${ }^{118}$ The numbers were staggering: More than 700 incidents of groundwater contamination by oilfield wastes or products were documented. ${ }^{119}$ Elsewhere, in 2001, E\&P wastes from the Black Mountain disposal facility in Colorado contaminated nearby soil and groundwater when its clay lined pits began to leak. ${ }^{120}$ Since then, many more releases of E\&P wastes have occurred in Colorado. The Colorado Oil and Gas Conservation Commission (COGCC) documented several pits at the same pad site in Garfield

\footnotetext{
113 TENNESSEE DEP'T OF ENV'T \& CONSERVATION, STATE REVIEW OF OIL AND NATURAL Gas ENVIRONMENTAL Regulations, InC., TENNESSEE STATE REVIEW 13, 19, 22, 24 (2007).

114 Id. at 30.

${ }^{115}$ FY2008 EPA Region 6 End-of-year Evaluation of the Railroad Commission of Texas Underground Injection Control Program, with transmittal letter from Bill Luthans, Acting Director, Water Quality Protection Division, Region 6 to Tommie Seitz, Director, Oil and Gas Division (June 19, 2009).

${ }^{116}$ Joe Carroll, Exxon's Oozing Texas Oil Pits Haunt Residents as XTO Deal Nears, Bloomberg Businessweek, April 16, 2010.

${ }^{117}$ See infra notes 146-160 and accompanying text; see also OKLA. ADMIN. CODE $\$ 165: 10-7-16$ (b)(1)(B)(iii), (2)(b).

118 New Mexico Energy, Minerals and Natural Res. DeP'T, OIl CONSERVATION Div., Cases Where PIT Substances CONTAMINATEd NEW MEXICO's GROUND WATER (2008).

${ }_{119}$ Oil \& Gas Accountability Project, Groundwater Contamination.

${ }^{120}$ Kim Weber, Regarding Support of HB 1414 -Evaporative Waste Facilities Regulations.
} 
County whose liners had torn and allowed wastes to be released on multiple occasions between April and August 2008. ${ }^{12 \mathrm{I}}$ The reports indicated that the pits were located on rocky terrain and that some of the liners had been torn by rocks on the site. ${ }^{122}$ In total, more than 6,000 barrels of pit contents escaped the pits because of the tears. ${ }^{123}$ In La Plata County, a landowner reported the possible contamination of his well by an unlined reserve pit located a mere 350 feet uphill from his well. ${ }^{124}$ The COGCC eventually concluded that "it appear[ed] that fluids from the unlined reserve pit infiltrated into the shallow groundwater, flowed downhill and impacted the Thomson water well." 125 The COGCC has documented numerous other incidents where pits have leaked, ${ }^{126}$ overflowed, ${ }^{127}$ or been unlined, ${ }^{128}$ thereby allowing their contents to be absorbed by unprotected ground.

In May, 2008, a Colorado citizen drank water from his spring and fell ill. The COGCC found benzene in the groundwater that exceeded standards by 32 times and benzene in faucet water that exceeded standards by 13 times, as well as elevated levels of toluene and xylenes. Although the COGCC began investigating this complaint in June, 2008, it wasn't until October, 2008, that the operator stated that it became aware that the production pit was never permitted. The state appears to have been unaware that the pit was never permitted even though it was investigating the pit as a possible source of groundwater contamination. In July, 2010, the COGCC found that the operator failed to properly permit, construct, maintain, and repair the pit, leading to a release or releases of E\&P waste that impacted groundwater. The agency found that the liner had been stretched over rocks and had improperly sealed seams. ${ }^{129}$

In addition to the reports from New Mexico and Colorado, there have been many complaints by citizens of contamination reportedly caused by E\&P wastes in other states. NYSDEC has received numerous reports of $E \& P$ waste releases, many of which have contaminated soil and

\footnotetext{
${ }^{121}$ COlorado OIL ANd Gas CONSERVATION COMMISSION, InSPECTION/INCIDENT INQUiRy, SPILl REPORTS, DOC. NOS. $1630424,1630426,1630427,1630428,1630429,1630430$.

122 COlorado OIL ANd Gas CONSERVATION COMMISSION, INSPECTION/INCIDENT INQUiRy, SPILl REPORTS, DOC. NO. 1630428 .

${ }^{123}$ COlorado OIl and Gas CONSERVATION COMMISSION, InSPECTION/INCIDENT INQUiRy, SPILl RePORTS, DOC. Nos. 1630424 (714 bbls), 1630426 (2000 bbls), 1630427 (500 bbls), 1630428 (1250 bbls), 1630429 (204 bbls), 1630430 ( 2017 bbls).

${ }^{124}$ Oil \& Gas Accountability Project, Contamination Incidents Related to Oil and Gas Development, Maralex Drilling Fluids in Drinking Water; COLORADO OIL AND GAS CONSERVATION COMMISSION, INSPECTION/INCIDENT INQUIRY, SPILL REPORT, DOC. NO. 1953000.

${ }_{125}$ COLORADO OIL AND GAS CONSERVATION COMMISSION, INSPECTION/INCIDENT INQUIRY, NOAV REPORT, DOC. No. 200085988; see also Oil \& Gas Accountability Project, Contamination Incidents Related to Oil and Gas Development, Maralex Drilling Fluids in Drinking Water.

${ }^{126}$ COLORADO OIL AND GAS CONSERVATION COMMISSION, INSPECTION/INCIDENT INQUiRY, SPILl REPORTS, DOC. Nos. $1631518,1631599,2605176,2605847$.

${ }^{127}$ COLORADO OIL AND GAS CONSERVATION COMMISSION, INSPECTION/INCIDENT INQUIRY, SPILL REPORTS, DOC. NOS. 200225543, $200225547,200225546$.

128 COLORADO OIL AND GAS CONSERVATION COMMISSION, INSPECTION/INCIDENT INQUIRY, SPILl REPORTS, DOC. No. 1632846 .

${ }^{129}$ Colorado Oil and Gas Conservation Commission, Cause No. 1V, Order No. 1V, Docket No. 1008-OV-06
} 
groundwater. ${ }^{130}$ In June 1987, in West Seneca, N.Y., product from an open pit containing oil and other solvents was found running from the pit towards a nearby creek. ${ }^{131}$ In November 1996, in Reading, N.Y., a produced water pit overflowed and spilled approximately two hundred gallons of produced water into a creek feeding into Seneca Lake. ${ }^{132}$ NYSDEC determined that no cleanup was possible. ${ }^{133}$ When a property owner in Bolivar, N.Y., called in June 2002 to report leaking oil wells, NYSDEC inspectors also found unlined leaking containment ponds. ${ }^{134}$

E\&P wastes in pits have been released into the environment in other states as well. Pennsylvania's Department of Environmental Protection (PADEP) has documented several incidents of dangerous E\&P waste releases into the environment. Notably, at two of Atlas Resources LLC's well sites in Pennsylvania, "compromised" pit liners allowed fracturing flowback fluids to escape. ${ }^{135}$ In Ohio, a fracturing flowback pit was cut with a track hoe in 2010 , causing more than 1.5 million gallons of fluid were spilled into the environment. ${ }^{136}$ In 2008 , the back wall of a pit in Ohio gave way, causing pit contents to spill and flow towards a creek. ${ }^{137}$

In addition to releases caused by torn liners and overflows, pits allow the hazardous contaminants in $\mathrm{E} \& \mathrm{P}$ wastes to be released into the environment through evaporation into the air. E\&P wastes such as produced water stored in open pits can "release methane, toxic volatile organic chemicals and sulfur based compounds into the air." 138 Rocky Mountain Clean Air Action collected data showing that wastewater evaporation pits in Garfield County, Colorado are "major sources of air pollution and pose greater threats to human health than previously reported." $" 139$ The data indicated that high levels of hydrocarbons and other hazardous air pollutants were being released into the air. ${ }^{140}$ Also in Garfield County, beginning in October 2005, a resident repeatedly notified the COGCC that severe odors were emanating from an E\&P waste pit located close to her home. ${ }^{141}$ In early December 2005 , the resident reported smelling "a different sort of stench ... the "Benzene smell"' to the COGCC and requested that the agency

\footnotetext{
${ }^{130}$ TOXICS TARGETING, INC., HAZARDOUS MATERIALS SPILlS INFORMATION REQUEST (2009).

131 TOXICS TARGETING, INC., HAZARDOUS MATERIALS SPILlS INFORMATION REQUEST 37 (2009) (Spill Number: 8702469).

132 TOXICS TARgeting, INC., HAZARdOUS MATER IALS SPIlls INFORMATION REQUEST 53 (2009) (Spill Number: 9610217).

${ }^{133} \mathrm{Id}$.

134 TOXics TARgETING, INC., HAZARDOUS MATERIALS SPIlls INFORMATION REQUEST 124-25 (2009) (Spill Number: 0275147).

${ }^{135}$ Consent Assessment of Civil Penalty, In re Atlas Resources LLC, Dancho-Brown 4, $1 \uparrow \mathrm{AV}-\mathrm{AZ}$, Groves 8 , ๆๆ BA-BE.

${ }^{136}$ Ohio Department of Natural Resources, Notice of Violation No. 1278508985, June 21, 2010.

${ }^{137}$ Ohio Department of Natural Resources, Notice of Violation No. 2016754140, May 16, 2008.

${ }^{138}$ Subra, supra note 43.

${ }^{139}$ Phillip Yates, Clean Air Group Contends Evaporation Ponds in Garfield County More Dangerous than Previously Believed, POST INDEPENDENT, Jan. 9, 2008.

${ }^{140} I d$.

${ }^{141}$ Oil \& Gas Accountability Project, Contamination Incidents Related to Oil and Gas Development.
} 
install full-time air monitoring equipment. ${ }^{142}$ At the end of the month, the resident learned that sampling of the air fairly close to the pit "showed that benzene and xylenes exceeded the [EPA's] 'non-cancer risk levels' for these compounds - at $67 \mu \mathrm{g} / \mathrm{m} 3$, benzene was present at more than double the risk level. Other detectable compounds included acetone, toluene and ethylbenzene." 143

While some incidents are effectively reported and prosecuted by state authorities, many more incidents occur that are not addressed adequately by state officials. In these cases, the citizens affected by such releases into the environment have instead turned to the judicial system in order to hold the oil and gas companies accountable. John Preston Stephenson, Jr. sued Chevron U.S.A alleging that waste from Chevron oil pits contaminated his property with "hazardous toxic and carcinogenic chemicals." ${ }^{144}$ Similarly, the Sweet Lake Land and Oil Company sued multiple defendants, including Exxon, Noble Energy, Inc., and Texas Eastern Skyline Oil Company, for contamination of "the soil and groundwater with produced water, oil, drilling muds, technologically enhanced naturally occurring radioactive materials (sometimes referred to as 'TENORM'), hydrocarbons, metals, and other toxic and/or hazardous substances, wastes and pollutants," claiming that the defendants knew the pits contents would contaminate the plaintiff's surface and subsurface soil and water. ${ }^{145}$ Sweet Lake Land and Oil Company further alleged that " $[t]$ he presence of the pits, substances and scrap on and under the Property constitutes a nuisance." 146 These claims are only a handful of many more by citizens who have been harmed by E\&P wastes released from pits. ${ }^{147}$

These reports of contamination are at least partially attributable to inadequate state efforts to regulate E\&P waste disposal in pits. Despite the fact that pit contents have been found to contain hazardous contaminants, ${ }^{148}$ many states fail to require operators to use the most basic of precautions. Tennessee, for example, does not even take pits into account in its permitting process, thereby "making their management and disposal difficult to track" and increasing the

\footnotetext{
${ }^{142}$ COLORADO OIL AND GAS CONSERVATION COMMISSION, InSPECTION/INCIDENT INQUIRY, COMPLAINT REPORT, DOC. No. 200081602.

${ }_{143}$ Oil \&Gas Accountability Project, supra note 141.

${ }^{144}$ Amended Complaint at 9 9, Stephenson v. Chevron U.S.A, Inc., No. 209CV01454, (W.D. La. filed Sept. 11, 2009), 2009 WL 4701406.

${ }^{145}$ Sweet Lake Land and Oil Co. v. Exxon Mobil Corp., supra note 101, at $\uparrow 10$.

${ }^{146} \mathrm{Id}$. at 927.

${ }^{147}$ See also Petition for Damages, Brownell Land Corp., LLC v. Honey Well Int'l., No. 08CV04988, 9 ศ 11-12 (E.D. La. filed Nov. 21, 2008), 2008 WL 5366168; Rice Agricult. Corp., Inc., v. HEC Petroleum Inc., 2006 WL 2032688

(E.D. La); Petition for Damages, Tensas Poppadoc, Inc. v. Chevron U.S.A., Inc., No. 040769, 8 (7th Judicial Court La. filed Sept. 21, 2005), 2005 WL 6289654; Petition for Damages to School Lands, Louisiana v. Shell Oil Co., No. CV04-2224 L-O, (W.D. La. filed Oct. 29, 2004), 2004 WL 2891505 (where the State of Louisiana and the Vermilion Parish School Board made similar allegations against Shell Oil, claiming they had contaminated school property. In July 2006 , the case was remanded to state court).

${ }^{148}$ See notes 62-67 supra.
} 
likelihood that the locations of the wastes will be forgotten in the future. ${ }^{149}$ In addition, Tennessee has no freeboard or liner integrity requirements, ${ }^{150}$ does not require testing or tracking of pit wastes, ${ }^{151}$ and fails to require oil to be removed from pits. ${ }^{152}$ Kentucky similarly turns a blind eye to the risks E\&P wastes present to the public through its failure to require testing of E\&P waste characteristics and its treatment of all E\&P wastes except production brines and drilling muds as solid wastes, subject to less stringent disposal requirements "irrespective of the risk posed to human health or the environment from the waste." 153

States also fail to take other simple steps that would dramatically decrease the likelihood of $E \& P$ wastes being released into the environment, for example, requiring pits to be lined with impermeable barriers. In Oklahoma, neither emergency pits nor pits holding water-based drilling fluids are required to have any lining. ${ }^{154}$ This failure to require the use of a liner in pits holding water-based drilling fluids increases the risk that the "barite, clays, lignosulfonate, lignite, caustic soda and other specialty additives" found in water-based muds will contaminate the environment. ${ }^{155}$ Kentucky's liner requirements are also inadequate. Kentucky does not require the use of liners in drilling pits that are used for less than thirty day storage and has "minimal liner requirements for holding pits" for storage over thirty days. ${ }^{156}$

Wildlife protection devices are another important and too often underused safety measure. Tennessee, ${ }^{157}$ Louisiana, ${ }^{158}$ and Kentucky all fail to require any "fencing, flagging or netting of pits," thereby increasing the risks the pits present to wildlife and domestic animals. ${ }^{159}$ And according to a recent report prepared by Region 6 of the U.S. Fish \& Wildlife Service, these three states are not alone. ${ }^{160}$ As reported by Region 6 , only thirteen states require pits or open tanks to be screened or netted to prevent wildlife from coming into contact with E\&P wastes. ${ }^{161}$ The failure to require pit operators to use even the most basic protection devices such as fencing or netting greatly increases the likelihood that wildlife will come into contact with E\&P waste and suffer significant harm.

149 TENNESSEE DEP'T OF ENV'T \& CONSERVATION, supra note 113 , at 30.

${ }^{150} \mathrm{Id}$.

${ }^{151} \mathrm{Id}$. at 32.

152 Id. at 31 .

${ }^{153}$ State ReView of Oil and Natural Gas Environmental Regulations, InC., Kentucky State Review 50 51 (2006).

${ }^{154}$ OKLA. Admin. CODE $\$ 165: 10-7-16(\mathrm{~b})(1)(\mathrm{B})(\mathrm{iii}),(2)(\mathrm{b})$.

${ }^{155}$ CORCORAN ET AL., supra note 25, at 20; see also U.S. FISH \& WILDLIFE SERV., supra note 93, at 4-5 ("Waterbased drilling muds can contain glycols, chromium, zinc, polypropylene glycol, and acrylamide copolymers.").

${ }^{156}$ KENTUCKY STATE REVIEW, supra note 153 , at 54.

157 TENNESSEE DEP'T OF ENV'T \& CONSERVATION, supra note 113 , at 30.

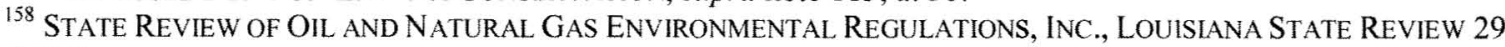
(2004).

${ }^{159} \mathrm{Id}$.

${ }^{160}$ U.S. FISH \& WILDLIFE SERVICE, supra note 93, at 13 fig. 15.

${ }^{161} \mathrm{Id}$. 
States also fail to regulate where pits may be located, allowing them to be placed near residences, schools, and other areas frequently used by the public. In some cases, homes are located so close to pits that residents have been forced indoors because of the foul odors and health symptoms emanating from the pits. One Pennsylvania family reported severe headaches caused by fumes from a pit less than 200 feet from their home. ${ }^{162}$ As of 2005 , when STRONGER, Inc. conducted a review of Indiana's E\&P waste disposal practices and regulations, Indiana regulations had no requirements regarding "specifications for the location, orientation and construction of drilling pits. There [were] no required setbacks of minimum distances from buildings, homes or other structures for drilling pits." Since then, although Indiana has adopted a new rule requiring pits to be located at least one hundred feet from streams, rivers, lakes and drainage ways, it still does not specifically require pits to be setback from other structures. ${ }^{163}$ By allowing pits to be sited close to where people live and children attend school, state regulators are bringing health risks literally closer to the citizens across the country.

\section{b. Land application}

EPA has stated that hazards also exist with land application of E\&P wastes, finding that hydrocarbons, salts, and metals can all cause contamination when E\&P wastes are land applied. ${ }^{164}$ The Oil Industry International Exploration and Production Forum (E\&P Forum), an international industry association, has also issued warnings, stating that land application may result in contaminants accumulating "in the soil [at] a level that renders the land unfit for further use." 165 New York State allows waste to be disposed of in municipal landfills. ${ }^{166}$ Land where only oil and gas waste is applied is often called a "landfarm." Studies of landfarm conditions confirm that these hazards are real. When the Arkansas Department of Environmental Quality conducted a study of landfarms in Arkansas, it found that "all 11 sites that land applied fluids at some point had improperly discharged the fluids so as to cause runoff into the waters of the state." 167

Land application sites outside of Arkansas are sources of similar concerns. Near Holdenville, Oklahoma, residents protested the opening of a landfarm because they were worried about

\footnotetext{
${ }^{162}$ Christie Campbell, Foul Odor from Impoundment Upsets Hopewell Woman, OBSERVER-REPORTER, Apr. 14, 2010. June Chappel, who lives near a pit, stated that the odor "reminded her of a hair perm. It smelled like ammonia ... [and] "took your breath away." Id. Other times the fumes have smelled like gasoline, diesel fuel, and sewage. Id.

163312 IND. ADMIN. CODE 16-5-13 (2010).

164 EPA OFFICE OF COMPLIANCE SECTOR Notebook Project, Profile of the OIL AND Gas EXtraction INDUSTRY, EPA/310-R-99-006, at 49 (2000).

${ }^{165}$ E\&P FORUM, supra note 107, at 17.

${ }^{166}$ Letter from Gary M. Maslanka, New York State Division of Solid \& Hazardous Materials, to Joseph Boyles, Casella (April 27, 2010).

${ }^{167}$ Press Release, Arkansas Dep't of Envtl. Quality, ADEQ Releases Landfarm Study Report (Apr. 20, 2009).
} 
potential "water contamination and land spoilage." ${ }^{168}$ After the residents lost two appeals in which they tried to prevent its opening, the landfarm finally began operations and made the residents' fears a reality. Claudia Olivo, who owns a cattle ranch adjacent to the landfarm, filed a complaint with EPA after she noticed "strange glistening spots in the water" on her property. ${ }^{169}$ In response, EPA issued a cease-and-desist order against the landfarm after finding that it had made unauthorized discharges of drilling mud into a creek that ran through Olivo's property, in violation of the Clean Water Act. ${ }^{170}$ The Crouch Mesa landfarm in Aztec, New Mexico, is located directly across the street from a residential area and is the source of considerable visible dust observed blowing toward homes. ${ }^{171}$

Despite these risks, many states inadequately regulate land application. In Oklahoma, onetime land applications may occur as close as one hundred feet from any perennial stream, freshwater pond, lake or wetland. ${ }^{172}$ Tennessee regulations fail to provide any explicit guidance regarding the use of land applications. ${ }^{173}$ Meanwhile, Kentucky has no siting criteria for land application specific to E\&P wastes. ${ }^{174}$

These lax regulations result in E\&P wastes being land applied near, and in some cases, on residential property, increasing the likelihood that humans will be exposed to E\&P waste's toxic compounds. ${ }^{175}$ In Martha, Kentucky, produced water and tank bottoms were land applied on farmland near where a family of two adults and two children lived. ${ }^{176}$ The family grew the majority of the vegetables and meat they consumed on the farm, ${ }^{177}$ and the portion of the family's land used for storing E\&P waste disposal was located a mere 100 feet from a small creek which "drains into a marsh, which then drains into a larger creek" from which the farm's cattle drank. ${ }^{178}$ The family no longer drinks from its well, which has been contaminated with benzene. ${ }^{179}$ Lead and arsenic were found in soil samples. ${ }^{180}$ In addition, areas of the farm where E\&P wastes had been disposed were found to be NORM-contaminated sites which "will remain radioactive for many thousands of years," "creating many opportunities for radium to enter the soil and be taken up by plants or cattle grazing on the land," and threatening "[f]uture inhabitants or workers on the NORM-contaminated land [who] may also be directly exposed to ionizing

\footnotetext{
${ }^{168}$ Susan Hylton, supra note 105 , at A11.

${ }^{169} \mathrm{Id}$.

${ }^{170} \mathrm{Id}$.

${ }^{171}$ DRILLING DOWN, supra note 20, at 22.

172 OKLA. ADMIN. CODE $\$ 165: 10-7-26$ (c)(6) (2009).

${ }^{173}$ TENNESSEE DEP'T OF ENV'T \& CONSERVATION, supra note 113 , at 32.

${ }^{174}$ KeNTUCKY STATE REVIEW, supra note 153 , at 50.

${ }^{175}$ See WOLF EAGLE ENVIRONMENTAL, supra note 70.

${ }^{176}$ Spitz et al., supra note 92, at, 45.

${ }^{177}$ Id. at 46.

${ }^{178} \mathrm{Id}$. at 45.

${ }^{179} \mathrm{Id}$.

${ }^{180} \mathrm{Id}$. at 55.
} 
radiation or inhale radium-bearing particles." ${ }^{181}$ As demonstrated by the contamination that occurred in Martha, Kentucky, inadequate state regulations too frequently fail to protect the public and the environment from the hazards associated with land application of E\&P wastes.

A Texas resident lives fifty feet away from a 100-acre land farm, where the Texas Railroad Commission issued 22 minor permits for 22 different operations that are all located on one property. A second land farm is located just down the road. ${ }^{182}$

\section{c. Injection Wells}

Underground injection, the most widely used disposal method, ${ }^{183}$ also poses concerns. If the formation into which $\mathrm{E} \& \mathrm{P}$ wastes are injected does not meet certain levels of permeability, porosity, and low reservoir pressure, the formations can form a poor seal around the E\&P wastes and threaten nearby aquifers. ${ }^{184}$ Under the Underground Injection Control (UIC) Program, E\&P wastes may be injected in Class II wells, while wastes designated as hazardous under RCRA can only be disposed of in the more strictly regulated Class I wells. ${ }^{185}$

The lower standards applicable to Class II wells have proven inadequate to prevent E\&P wastes from contaminating groundwater. In 1988, GAO released a report, Safeguards Are Not Preventing Contamination from Injected Oil and Gas Wells, which examined the effectiveness of EPA's UIC program. ${ }^{186}$ Although GAO speculated that it was likely that more incidents had occurred, it reported that the EPA was aware of at least 23 cases across the country where Class II injection wells had contaminated drinking water supplies. ${ }^{187}$ Since then more incidences of concern have occurred.

In September 2007, a state inspector in Texas inspected an underground injection disposal well site outside of Fort Worth and found no problems. Yet a resident complained of "spilled oil, overflowing dikes and green-colored fluid in standing puddles." Inspectors returned and found that "oil-stained soil" had seeped several inches into the ground, that the "containment dike will not hold estimated capacity," and that standing water had oil in it. State records showed that the well site was not being used, when in fact it was actively being injected with oil and gas waste. $^{188}$

${ }^{181}$ Id. at 57.

${ }^{182}$ See Griffey, supra note 71

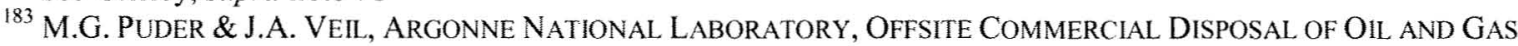
EXPLORATION AND PRODUCTION WASTE: AVAILABILITY, OPTIONS, AND COSTS, S-2 (2006) ("By far, the most common commercial disposal method for produced water is injection.").

${ }_{184}$ See E\&P FORUM, supra note 107, at 15.

${ }^{185}$ DRILLING Down, supra note 20, at 17; see also 42 U.S.C $\$ 300 \mathrm{~h}-4 ; 42$ U.S.C $\$ 300 \mathrm{~h}(\mathrm{~b}) ; 42$ U.S.C. $\$ 300$ (h)-1(c).

${ }^{186}$ U.S. GENERAL ACCOUNTING OFFICE, supra note 32, at 2.

${ }^{187} \mathrm{Id}$. at 3 .

${ }^{188}$ Abrahm Lustgarten, State Oil and Gas Regulators Are Spread Too Thin to Do Their Jobs, ProPublica, December $30,2009$. 
Residents in DeBerry, Panola County, Texas, first began complaining that their groundwater was contaminated in $1996 .{ }^{189}$ An underground injection disposal facility began operations oneeighth of a mile away from the community in 1987, injecting produced water into the ground at depths between 1,080 and 1,110 feet. ${ }^{190}$ In 1996, while the well was still in operation, DeBerry residents told an EPA Region 6 employee that their water was discolored, was staining their kitchen and bath fixtures, and that they were experiencing gastrointestinal problems. ${ }^{191}$ The residents of DeBerry ultimately stopped using their drinking water and instead began to obtain water from other sources. ${ }^{192}$ No government agency tested DeBerry's drinking water for several years after residents first complained. Not until 2002 did the site operator of the injection wells in DeBerry, Basic Energy, sample the drinking water. ${ }^{193}$ When it did, the residents' suspicions were confirmed. The results showed the presence of contaminants above the EPA's maximum contaminant levels. ${ }^{194}$ In 2003, the Texas RRC found benzene, barium, arsenic, cadmium, lead and mercury in wells at levels exceeding the state's drinking water standards. ${ }^{195}$ Because the Texas RRC never completed a full assessment of the contamination, the source of the contamination is not definitively known; however, residents strongly believe the injection wells were the cause of the contamination, and EPA has been unable to rule this possibility out conclusively. ${ }^{196}$

Also in Texas, an underground injection disposal facility in Daisetta is linked to contamination of a fresh water aquifer. The EPA found a lack of compliance reviews, inappropriate monitoring, and incomplete record-keeping, as well as a lack of evidence that all problems were ever remedied. This problematic facility led to a surface collapse and a large sinkhole. ${ }^{197}$

The likelihood that similar incidents will continue to occur exists as long as underground injection associated with oil and gas exploration, production, and development only has to meet the requirements for Class II wells and states fail to require better monitoring.

In addition, a vast amount of E\&P waste is being injected underground without any UIC regulation whatsoever. Used hydraulic fracturing fluid-perhaps millions of gallons per each

\footnotetext{
${ }^{189}$ EPA OFFICE OF THE INSPECTOR GENERAL, COMPLETE ASSESSMENT NEEDED TO ENSURE RURAL TEXAS COMMUNITY HAS SAFE DRINKING W ATER, No. 2007-P-00034 2 (2007).

${ }^{190} \mathrm{Id}$. at 3.

${ }^{191} I d$. at 2.

${ }^{192}$ Id.

${ }^{193}$ Id.

${ }^{194} \mathrm{Id}$.

${ }^{195}$ Hearing Before the Subcomm. on Superfund and Environmental Health of the S. Comm. on Environment and Public Works 12-13 ( 2007) (statement of Robert D. Bullard, Dir. Environmental Justice Resource Center).

${ }^{196}$ EPA, OFFICE OF THE INSPECTOR GENERAL, supra note 189 , at 3.

${ }^{197}$ EPA, supra note 115.
} 
well-remain underground permanently. It has been estimated that up to $90 \%$ of hydraulic fracturing fluids used in the Marcellus shale formation remain underground. ${ }^{198}$ Yet this waste disposal and storage activity is not subject to any federal underground injection regulations.

\section{d. Wastewater Treatment Facilities}

In regions where underground injection is not readily available, hydraulic fracturing wastewater and produced water may be sent to wastewater treatment plants prior to release to surface water. The plants may be publicly owned treatment works (POTWs) that typically process municipal sewage or centralized wastewater treatment (CWT) facilities that process industrial wastes. None of the POTWs and few of the CWT plants currently in operation have the capacity to reduce to safe levels all of the chemical contaminants commonly found in E\&P waste. As a result, toxins are released to surface water, with adverse impacts on drinking water quality. The very high concentrations of total dissolved solids (TDS) - principally salts - that are common in hydraulic fracturing wastewater and produced water present a particular problem for wastewater treatment facilities.

Without adequate pretreatment, pollutants in oil and gas waste will pass through a POTW into the receiving stream, and they may interfere with ordinary sewage treatment systems. ${ }^{199}$ Even with pretreatment, POTWs are not effective in removing salts from those wastes. ${ }^{200}$ The use of POTWs for treatment of E\&P waste in western Pennsylvania produced TDS levels in the Monongahela River in excess of drinking water standards, forcing the Commonwealth to limit the waste to one percent of influent at nine plants along the river. ${ }^{201}$ Unauthorized discharges of pollutants, including fecal matter, from a POTW into the Susquehanna River were attributed to the plant's acceptance of oil and gas wastes. ${ }^{202}$ Even CWT plants rarely have the evaporation and crystallization technologies needed to reduce extremely high levels of TDS in hydraulic fracturing wastewater and produced water (up to $300,000 \mathrm{mg} / \mathrm{l}$ ) to levels consistent with water quality standards $(500 \mathrm{mg} / \mathrm{l})$. There is not a single CWT facility with that capacity in all of New York or Pennsylvania. ${ }^{203}$

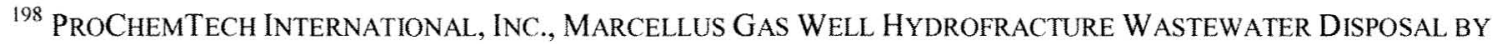
RECYClE TREATMENT PROCESS.

${ }^{199}$ N.Y. State Water Res. Inst., Waste Management of Cuttings, Drilling Fluids, Hydrofrack Water and Produced Water; Oh. Envtl. Prot. Agency, Marcellus Shale Gas Well Production Wastewater. ${ }^{200}$ Id.

201 Joaquin Sapien, With Natural Gas Drilling Boom, Pennsylvania Faces an Onslaught of Wastewater, ProPublica, Oct. 4, 2009; Municipal Authorities ' Perspective: Marcellus Shale Natural Gas Wastewater Treatment, Hearing Before the S. Comm. on Envtl. Res. \& Energy (Pa. 2010) (statement of Peter Slack, Pennsylvania Municipal Authorities Ass'n).

${ }^{202}$ Press Release, Pa. Dep't Envtl. Prot., DEP Says Jersey Shore Borough Exceeds Wastewater Permit Limits (June 23, 2009).

${ }^{203}$ N.Y. State Water Res. Inst., supra note 199; Joaquin Sapien, supra note 201.
} 


\section{e. Other spills, leaks, and intentional dumping}

In addition to those releases that commonly occur when these common E\&P waste disposal methods are being used properly, many other spills and releases occur before E\&P wastes reach these storage or disposal sites. These other releases can be the result of equipment failure, accidents, negligence, or intentional dumping. Consistent federal regulations for waste management, storage and disposal would help prevent them in the future.

For example, in Pennsylvania, Atlas Resources LLC "discharged residual and industrial waste, including diesel and production fluids, onto the ground at seven of the 13 well sites."204 At three of the wells Atlas allowed produced water to be released into the environment. ${ }^{205}$ Pennsylvania records also show that pipes used to transport waste, sometimes for miles, have leaked. In October, 2009, a pipe carrying diluted wastewater spilled about 10,500 gallons into a high-quality stream, killing about 170 small fish and salamanders. In December, 2009, a pipe failed in five places, spilling an estimated 67,000 total gallons of fluid, tests of which found elevated levels of salts, barium and strontium. ${ }^{206}$

NYSDEC has documented numerous other examples of releases. In October 1997, a produced water tank in Willing, New York, containing produced water from natural gas extraction overflowed and contaminated the surrounding soil and a nearby creek from which cows drank with fifteen thousand gallons of produced water. ${ }^{207}$ The produced water killed vegetation in its path. ${ }^{208}$ More recently, in September 2005, eight hundred gallons of production brine from another tank in Pine City, New York, overflowed when it was not emptied on schedule, causing an impact on nearby streams. ${ }^{209}$ In July 1996, crude oil tank bottoms were dumped into a pit and set on fire. ${ }^{210}$ In March 2003, a property owner in Ithaca, New York, called to report that a driller was dumping mud on his property. ${ }^{211}$ In May 2007, NYSDEC received an anonymous tip indicating that produced water from a natural gas well was being

\footnotetext{
${ }^{204}$ Press Release, Pa. Dep't Envtl. Prot., DEP Fines Atlas $\$ 85,000$ for Violations at 13 Well Sites, Jan. 7, 2010.

${ }^{205}$ Consent Assessment of Civil Penalty, In re Atlas Resources $L L C$, Pevarnik 8, $19 \mathrm{Z}-\mathrm{AD}$, Willis 18, $19 \mathrm{AE}-\mathrm{AI}$, Thompson 3391 AP-AU.

${ }^{206}$ Laura Legere, Massive Use of Water in Gas Drilling Presents Myriad Chances for Pollution, SCRANTON TIMESTRIBUNE, June 22, 2010.

${ }^{207}$ TOXICS TARGETING, INC., HAZARDOUS MATERIALS SPILlS INFORMATION REQUEST 3 (2009) (Spill Number: 9707892).

${ }^{208}$ TOXICS TARGETING, INC., HAZARDOUS MATERIALS SPILlS INFORMATION REQUEST 4 (2009) (Spill Number: 9707892).

209 TOXiCs TARgeting, INC., HAZARDOUS MATERIALS SPIlls InFORMATION REQueSt 8 (2009) (Spill Number: 0507041).

${ }^{210}$ TOXICS TARgETING, INC., HAZARDOUS MATERIALS SPILls INFORMATION REQUEST 23 (2009) (Spill Number: 9604701).

211 TOXICS TARGETING, INC., HAZARDOUS MATERIALS SPILlS INFORMATION REQUEST 68 (2009) (Spill Number: 0212276).
} 
dumped on the ground near Cayuga Creek in Sheldon, New York. ${ }^{212}$ In May 2009, eight hundred gallons of produced water contaminated soils in Westfield, New York, after equipment failed and allowed the fluids to be released into the environment a mere 1200 yards away from nearby homes. $^{213}$

The COGCC has also documented incidents where tanks have been improperly sealed ${ }^{214}$ or allowed to overflow, ${ }^{215}$ where corroded equipment allowed produced water to contaminate the ground, ${ }^{216}$ and where equipment failure has allowed produced water to escape from underground injection wells. ${ }^{217}$ Between June 2002 and June 2006, 555 produced water spills were reported to the COGCC. $^{218}$

In Texas, between 2001 and 2006, thirty percent of spill complaints were inspected "either late or not at all." ${ }^{219}$ Most recently in the Texas town of Flower Mound, the Texas RRC sent out a notification stating that approximately 3,000 gallons of "flowback water containing fracturing fluid and associated additives" spilled out of gas well pad site. ${ }^{220}$ To date, the RRC has not publically released either the cause of the spill or the exact contents of the flowback water. ${ }^{221}$

The mayor of West Union, West Virginia, wrote a letter to the WVDEP in October 2009 to express his concern over WVDEP's failure to notify the town until two months after a spill occurred. $^{222}$ The mayor was even more concerned about WVDEP's failure to have any emergency notification system in place, stating that the continued failure to establish such a system "will only result in less time for the water system to react [to future spills] and [result in] a greater chance of catastrophe." 223 Elsewhere in West Virginia, Luanne McConnell Fatora reported a release of between fifty and seventy barrels of some type of oil and gas waste in a

212 TOXiCS TARgETING, INC., HAZARdous MATERIALs SPILlLS INFormation REQUEST 159 (2009) (Spill Number: 0750225).

${ }^{213}$ TOXICS TARGETING, INC., HAZARDOUS MATERIALS SPILlS INFORMATION REQUEST 143 (2009) (Spill Number: 0902327).

${ }^{214}$ Colo. Oll \& Gas CONSERVATION COMm'N, InSPECTION/INCIDENT INQUiRy, SPILl REPORT, DOC. No. 1630697.

${ }^{215}$ Colo. Oll \& Gas CONSERVATION COMm'N, InSPECtion/INCIDENT InQuiry, SPILl Reports, DOC. NOS. $1631155,1631831,1631794,1632853$.

${ }^{216}$ COLO. OIL \& GAS CONSERVATION COMM'N, INSPECTION/INCIDENT INQUIRY, SPILl REPORTS, DOC. NOS. $1630885,1631496,1631519,1632057,2605191,1632995$.

${ }^{217}$ COLO. OIL \& GAS CONSERVATION COMM'N, INSPECTION/INCIDENT INQUIRY, SPILl REPORTS, DOC. NOS. $200226284,200225725,2605709$.

${ }^{218}$ OIL \& GAS ACCOUNTABILTTY PROJECT, COLORADO OIL AND GAS INDUSTRY SPILlS: A REVIEW OF COGCC DATA (JUNE 2002-JUNE 2006) 1-2 (2006).

${ }_{219}^{219}$ Lustgarten, supra note 188.

${ }^{220}$ Frac Fluid Spill Reported in Flower Mound, Cross Timbers GazeTte, Mar. 17, 2010.

${ }^{221} I d$.

${ }^{222}$ Letter from Robert F. Fetty, Mayor, Town of West Union, to Barbara Taylor, Director, WVBPH/Office of Environmental Health Services, Oct. 28, 2009. ${ }_{223}^{2} I d$. 
stream in Doddridge County. ${ }^{224}$ Fatora's son discovered the spill when he tried to go fishing in the stream in late August 2009 and found the water to be "acrid" and covered with a "red/orange gel" that had an oily smell which got on his hands and did not "go away for some time despite repeated washing." 225 Although the Chief of the West Virginia Oil and Gas Office stated that the fluids were consistent with oil and gas waste, more than a month after the spill the WVDEP remained uncertain about what caused the release. ${ }^{226}$

These releases, and the undoubtedly numerous other unreported incidents, demonstrate that current regulations and regulatory enforcement is inadequate to prevent $\mathrm{E} \& \mathrm{P}$ wastes from being released into the environment.

\section{Oil \& Gas Production Has Increased Dramatically Since 1988.}

When EPA released its 1988 Regulatory Determination, the domestic oil and natural gas industry was struggling. Since then, oil and natural gas production in the United States has increased dramatically. Tens of thousands of new oil wells have been drilled. According to the U.S. Energy Information Administration (US EIA), between 1989 and 2008 the number of producing gas wells nationwide almost doubled, increasing from roughly 262,000 to 479,000 wells. $^{227}$

Bureau of Land Management (BLM) statistics also demonstrate the growth in oil and gas operations under its jurisdiction. In most years during the $1990 \mathrm{~s}$, there were less than four thousand applications for permits to drill (APDs) filed with the BLM. ${ }^{228}$ BLM has stated that "[s]ince 1996, the number of new APDs has risen dramatically.,"229 BLM received more than ten thousand APDs in $2006 .{ }^{230}$ Although BLM projects that the number of APDs will decline by $2010,{ }^{231} \mathrm{BLM}$ still expects to receive a staggering number, approximately 7,000 , of APDs in 2010. Furthermore, BLM attributes this projected decrease to the fact that a larger percentage of proposed drilling is expected to occur on existing leases and not to a decrease in drilling. ${ }^{232}$

State agency statistics also demonstrate an increase in the amount of domestic drilling: one example is Texas, where the number of permits issued by the RRC for drilling in the Barnett

\footnotetext{
${ }^{224}$ Ken Ward Jr., What Caused Big Fracking Fluid Spill in Doddridge County?, SUSTAINED OUTRAGE: A GAZETTE WATCHDOG BLOG (Oct. 2, 2009); see also Letter from Louanne McConnell Fatora to Gov. Manchin, West Highlands Conservancy (Aug. 30, 2009).

${ }^{225}$ Letter from Louanne McConnell Fatora to Gov. Manchin, (Aug. 30, 2009).

${ }^{226}$ Ward Jr., supra note 224.

${ }^{227}$ U.S. ENERGY INFo. AdMIN., Number of Producing GAS Wells (2009).

${ }^{228}$ BUREAU OF LAND MGT., BLM FY 2010 BUDGET JUSTIFICATIONS III-120 (2010).

${ }^{229}$ Id. at III-119.

${ }^{230} \mathrm{Id}$. at III- 120 .

${ }^{231} I d$.

$232 \mathrm{Id}$. at III-122.
} 
Shale increased from 273 in 2000 to 3,653 in $2007,{ }^{233}$ and 4,145 in $2008 .{ }^{234}$ Industry-wide, API statistics confirm that these increases are not isolated incidents. The API reported that 2006 was a record year for gas drilling, in which more than 29,000 new wells were drilled. ${ }^{235}$ The API expected that this trend would continue and it did: a new 21-year record was reached when 11,771 wells were drilled in the first-quarter of $2007 .^{236}$

Along with this increase in drilling, there has been an associated increase in the amount of E\&P waste produced. In Utah's Uintah County the amount of produced water generated from oil and gas operations increased from approximately 800,000 barrels per month in January 1999 to over 1,600,000 barrels per month in January 2007. ${ }^{237}$ Even though some techniques have been implemented to reduce the amount of produced water generated from oil and gas extraction activities, EPA's Region 8 noted an overall two percent increase in the amount of produced water generated from 2002 to $2008 .{ }^{238}$ The increases in both drilling and E\&P waste that have occurred since 1988 indicate that the risks associated with E\&P wastes have become even more substantial and that EPA must revisit its Regulatory Determination in light of these developments.

\section{Regulation Under Subtitle C of RCRA Would Not Harm the Oil \& Gas Industry.}

In its 1988 Regulatory Determination, EPA placed significant weight on the potential harm that increased regulation of E\&P waste could cause the oil and natural gas industry in making its determination not to regulate E\&P wastes under Subtitle C of RCRA. EPA claimed that regulating E\&P wastes under Subtitle C would be "extremely costly" for industry. ${ }^{239}$ EPA also asserted that "[a]ny program to improve management of oil and gas wastes in the near term will be based largely on technologies and practices in current use." 240 While in 1988 EPA did not believe that the oil and gas industry would develop new waste management technologies, its belief has proved to be incorrect.

\footnotetext{
${ }^{233}$ Hannah Wiseman, Untested Waters: The Rise of Hydraulic Fracturing in Oil and Gas Production and the Need to Revisit Regulation, 20 FordHAM ENVTL. L. REV. 115, 124 (2009) (citing Texas Railroad Commission, Newark, East (Barnett Shale), Drilling Permits Issued (1993-2007)).

${ }^{234}$ Texas Railroad Commission, Newark, East (Barnett Shale) Field, Drilling Permits Issued (1993-2009).

${ }^{235}$ Daniel Cusick, Industry Sets Record for Drilling, Well Completions, LAND LETTER, Jan. 18, 2007.

${ }^{236}$ Am. Petroleum Inst., "U.S. Q1 drilling \& completion estimates at 21-year high-API," Apr. 26, 2007.

${ }^{237}$ Div. Of OIL, Gas and Mining, Utah DeP'T OF NATURAL ReS., Produced Water Disposal, graph slide 6 (2007).

${ }^{238}$ EPA REGION 8, supra note 28, at fig. 3-9.

23953 FED. REG. at 25446-01, 25456.

${ }^{240}$ Id. at 25,451. EPA's Report to Congress indicates that EPA did not truly believe this assertion that it made in the 1988 Regulatory Determination: "Long-term improvements in waste management need not rely, however, purely on increasing the use of better existing technology. The Agency does foresee the possibility of significant technical improvements in future technologies and practices." EPA, REPORT TO CONGRESS, MANAGEMENT OF WASTES FROM the EXPloration, DEVElopment, and Production of Crude OIL, NATURAL Gas, and GeOthermal ENERGY III-2 (1987)
} 
Evidence since 1988 demonstrates that new technologies and practices are available and that the use of these safer practices often results in significant cost savings. In 2008, EPA itself stated that "It has been 20 years since the RCRA exemption for oil and gas exploration and production was implemented, and many practices and chemicals used have changed during that time,",241 and has noted that many safer drilling fluids have been developed ${ }^{242}$ and the use of alternatives to pits has become increasingly practical. ${ }^{243}$ In addition to the savings that can result from the use of these new disposal methods, companies using safer disposal practices also obtain cost benefits by preventing pollution in the first place, as opposed to being allowed to use "cheaper" practices and later required to clean up the damage they create. ${ }^{244}$ The State of New Mexico found that drilling activity more than doubled in the year immediately following establishment of more protective rules for oil and gas waste pits. ${ }^{245}$

It is time for EPA to require oil and gas companies to use these new, safer technologies.

\section{a. New Waste Disposal Technologies}

Safer disposal methods for E\&P wastes have been developed since 1988. Although EPA acknowledged that such developments were likely in its 1987 Report to Congress, it chose not to require the use of then-emerging safer technologies because it believed that requiring their use would be prohibitively expensive for the oil and gas industry. Recent cost analyses indicate that those fears were unfounded; in many instances, the use of more environmentally sound disposal practices actually saves oil and gas companies money. For example, a study conducted in New Mexico found that eliminating pits, traditionally considered the cheapest disposal method, is actually more cost-effective than their continued use. ${ }^{246}$

${ }^{241}$ EPA REGION 8, supra note 28, at 3-13.

${ }^{242}$ EPA OfFice of Compliance Sector Notebook Project, Profile of THE OIL AND Gas EXtraction INDUSTRY, EPA/310-R-99-006, at 29 (2000).

${ }^{243}$ EPA, REGION 8, OIL AND GAS ENVIRONMENT AL ASSESSMENT REPORT 1996-2002 13 (2003).

[W] e've had testimony through here that the costs of remediation are, you know, in the hundreds of thousands to, typically millions of dollars. And there's a huge cost benefit to business to prevent pollution versus us allowing them to pollute water and then come back and require them to clean it up. I think that's really a disservice to industry, not to help them prevent that from occurring.

Statement of Commissioner William Olson before the New Mexico Oil Conservation Division, Apr. 16, 2008, OCD Document Image 14015_657_CF[1] at 30.

${ }_{245}$ Press Release, State of New Mexico, Governor Bill Richardson Announces Oil and Gas Drilling Activity in New Mexico Is Strong: Environmental regulations are not driving business away (May 19, 2010).

${ }^{246}$ DORSEy Rogers, Gary Fout \& William A. PiPER, NeW InNOVATIVE Process Allows Drilling Without PITS IN NEW MEXICO (2006). 
An Oil and Gas Accountability Project (OGAP) analysis demonstrates that closed-loop drilling systems, which use storage tanks and other equipment instead of pits, are cost-effective and can save money compared to conventional waste management with pits. ${ }^{247}$ Mary Ellen Denomy, an expert in petroleum accounting, testified before the New Mexico Oil Conservation Division and reported her findings that the costs associated with a typical closed loop drilling system, also known as a pitless drilling system, are only $3.58 \%$ of total drilling costs, a significant reduction from the costs associated with typical on-site pit burial $(6.58 \%$ of total drilling costs) and digging up and hauling wastes to a centralized facility $(9.38 \%$ of total drilling costs). ${ }^{248}$ While initial costs may be higher, closed-loop drilling systems create long-term savings because there is no need to construct pits, drilling waste can be dramatically reduced, water use can be reduced by as much as eighty percent, truck traffic is reduced by as much as seventy-five percent, and tanks can be reused. ${ }^{249}$ Comparisons have found closed-loop drilling can result in a cost savings of up to $\$ 180,000$ per pit, ${ }^{250}$ and a project in New Mexico found that:

[T] he average cost of using a pit and hauling the waste elsewhere for disposal is about $45 \%$ more compared to following the same process without a reserve pit. Moreover, the analysis showed that burying the waste on-site costs about $24 \%$ more when using a reserve pit as opposed to employing the closed-loop system. ${ }^{251}$

Individual case studies provide further support for these conclusions. A survey of Prima Energy Corporation's closed-loop system in Colorado indicated that closed-loop drilling could be more cost effective than conventional rotary drilling with reserve pits. ${ }^{252}$ Prima Energy Corporation drilled over 68 wells in Colorado using closed-loop systems and compared their costs to the costs of using conventional rotary drilling with reserve pits. ${ }^{253}$ The closed-loop drilling systems' average cost was $\$ 15,600$ compared to conventional rotary drilling's cost of $\$ 17,020 .^{254}$ The study further demonstrated that closed-loop drilling systems result in significant waste minimization. Conventional rotary drilling was found to generate 5,200 barrels more barrels of produced water than closed-loop drilling. ${ }^{255}$

\footnotetext{
${ }^{247}$ Oil \& Gas Accountability Project, Alternatives to Pits.

${ }^{248}$ Oil \& Gas Accountability Project, Closing Argument and Proposed Changes to Proposed Rule 50, Case 14015: Application of New Mexico Oil Conservation Division for Repeal of Existing Rule 50 Concerning Pits, etc., Dec. 10, 2007 , at 10 .

${ }^{249}$ Oil \& Gas Accountability Project, supra note 247.

${ }^{250}$ Id; see also ROGERS ET AL., supra note 246, at $4-5$.

${ }^{251}$ Dorsey Rogers, Dee Smith, Gary Fout \& Will Marchbanks, Closed-loop drilling system: A Viable Alternative to Reserve Waste Pits, WORLD OIL, Dec. 2008, at 46.

${ }^{252}$ See Oil \& Gas Accountability Project, supra note 247.

${ }^{253}$ Exhibit 8, Closed-Loop Drilling Case Studies, Re: Case 14015: Application of New Mexico Oil Conservation Division for Repeal of Existing Rule 50 Concerning Pits, etc., OCD Document Image No. 14015637 [CF]1.

${ }^{254}$ Id.

${ }^{255} \mathrm{Id}$.
} 
Similarly a study of two wells drilled two hundred feet apart in Matagorda County, Texas provides further support for assertions that closed-loop drilling systems can provide cost savings. ${ }^{256}$ In Matagorda County, two wells were drilled two hundred feet apart "through the same formations, using the same rig crew, mud company and bit program. ${ }^{, 257}$ One well used a closed-loop system while the other used traditional solids-control equipment. The closed-loop system "resulted in some significant savings" including: a forty-three percent savings in drilling fluid costs, twenty-three percent fewer rotating hours, fewer days to drill the wells to comparable depths, a thirty-seven percent reduction in bits used, and up to thirty-nine percent improvement in penetration rates. ${ }^{258}$

EPA's own studies confirm that closed-loop drilling systems are a safer and cost-saving waste disposal process. ${ }^{259}$ Because of these types of findings, EPA has promoted the use of closed-loop drilling systems in Region $8 .{ }^{260}$ The RRC of Texas has confirmed that closed-loop systems can result in significant cost savings; ${ }^{261}$ and many other government agencies also support the use of closed-loop drilling systems. ${ }^{262}$ In addition to the already demonstrated economic advantages of closed-loop systems, there is a great likelihood that the costs of constructing closed-loop systems will decrease even more in the future "as economies of scale and innovations in operations" continue to occur. ${ }^{263}$ If these systems are manufactured in the United States, they add the benefit of new job creation in addition to lower environmental risk.

Although safer and economical, even closed loop systems can leak or spill. Strong regulations are required to govern the storage and transport of toxic waste. In some cases, waste may be transported via pipeline to storage or disposal sites. Yet in Texas, State officials declared at a public meeting that the state has no "rule-making authority" over such pipelines. ${ }^{264}$

\footnotetext{
${ }^{256} \mathrm{Id}$.

${ }^{257} \mathrm{Id}$.

258 Id.

${ }^{259}$ EPA OfFice of COMPliance Sector Notebook Project, Profile of THE OIL AND Gas Extraction INDUSTRY, EPA/310-R-99-006, at 69 (2000).

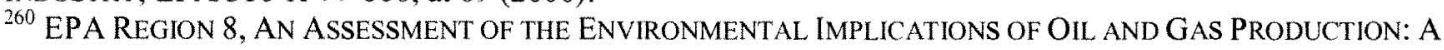
REGIONAL CASE STUDY 4-4 (Working Draft 2008).

${ }^{261}$ Abrahm Lustgarten, Underused Drilling Practices Could Avoid Pollution, ProPublicA, Dec. 14, 2009.

${ }^{262}$ U.S. Fish \& Wildlife Serv., Wildlife Mortality Risk in Oil Field Waste Pits, U.S. FWS CONTAMINANTS INFORMATION BULLETIN (2000) (recommending the use of closed loop containment systems and elimination of open pits and ponds); BUREAU OF LAND MGT, THE GOLD BOOK: SURFACE OPERATING STANDARDS AND GUIDELINES FOR OIL AND GAS EXPLORATION AND DEVELOPMENT (4th ed. 2007). "To prevent contamination of ground water and soils ... it is recommended that operators use a closed-loop drilling system or line reserve pits with an impermeable liner." Id. at 17.

${ }^{263}$ Controlled Recovery Inc.'s Written Closing Argument, Re: Case 14015: Application of New Mexico Oil Conservation Division for Repeal of Existing Rule 50 Concerning Pits, etc., Dec. 10, 2007, at 3.

${ }^{264}$ Lowell Brown, Officials Give Few Answers to Argyle, DENTON RECORD-CHRONiCLE, Jan. 30, 2010.
} 


\section{b. Waste Minimization, Reuse, and Recycling Techniques}

Waste minimization, reuse and recycling techniques also can be economical for companies. According to the RRC of Texas, "[w] aste minimization has been proven to be an effective and beneficial operating procedure," while recycling "is becoming a big business and more recycling options are available every day." ${ }^{265}$ Both serve to reduce the total amount of E\&P wastes that must be disposed and thereby decrease the risks associated with E\&P wastes. In its manual Waste Minimization in the Oilfield, the RRC of Texas offers oil and gas companies more than one hundred ways to minimize wastes. ${ }^{266}$ This manual, along with reports from individual companies implementing various waste minimization and recycling techniques, demonstrates that improved practices are possible.

Studies by the E\&P Forum attest to the benefits of waste recycling ${ }^{267}$ and identify several ways industry can reduce waste, "through process and procedure modifications ... [For example,] improved solids control equipment and new technology can reduce the volumes [of drilling fluids] discharged to the environment, ... more effective drillbits can reduce the need for chemical additions, [and] gravel packs and screens may reduce the volume of formation solids/sludge produced." 268 An analysis by OGAP found that the use of closed-loop drilling systems, in addition to providing cost benefits, maximizes the ability to reuse and recycle drilling fluids. ${ }^{269}$ And waste reduction is not just beneficial from an environmental perspective. It can provide further opportunities for the oil and gas industry to save money. A study on land owned by the U.S. Army Corps of Engineers in Oklahoma found that a reduction in "wastes by close to 1.5 million pounds" resulted in "[a] material and disposal cost savings of $\$ 12,700 ., 270$

Both the government and industry are aware of the cost saving opportunities associated with the use of waste minimizing technologies and recycling and reuse projects. For example, STW Resources has developed a technology for use in the Barnett Shale that can reclaim approximately seventy percent of the flowback water produced by hydraulic fracturing operations in the region and thereby reduce the total amount of waste associated with hydraulic fracturing while also enabling the wastes to be reused. ${ }^{271}$ And in July of 2008, the RRC of Texas approved Devon Energy's "third pilot program to treat and reuse frac fluid ... As a result of its water recycling efforts, Devon is the industry leader in water recycling and now used recycled

\footnotetext{
${ }^{265}$ Railroad Commission of Texas, supra note 52.

${ }^{266}$ DRILLING DOWN, supra note 20, at 29.

${ }^{267}$ E\&P FORUM, supra note 107, at 14 ("There are potential benefits in the sale of recovered hydrocarbons. All hydrocarbon wastes should be returned to the production stream where possible.").

${ }^{268}$ UNEP E\&P FORUM, ENVIRONMENTAL MANAGEMENT IN OIL AND GAS EXPLORATION AND PRODUCTION: AN OVERVIEW OF ISSUES AND MANAGEMENT APPROACHES 54 (1997).

${ }^{269}$ Oil \& Gas Accountability Project, supra note 247.

${ }^{270}$ Exhibit 8, Closed-Loop Drilling Case Studies, Re: Case 14015: Application of New Mexico Oil Conservation Division for Repeal of Existing Rule 50 Concerning Pits, etc., OCD Document Image No. 14015_637_[CF]1.

${ }^{271}$ STW RES., INC., CONTAMINATED WASTE WATER RECLAMATION OPPORTUNITIES 2-3.
} 
frac water at one out of every 10 frac jobs in its Barnett Shale operations." 272 Devon's wastewater recycling program "is projected to produce 75 percent reusable fracture fluid and 25 percent high concentrate and solids. The concentrate will be used as a drilling fluid or disposed of in an authorized facility." ${ }^{273}$ Devon Energy Production Central Division's vice president estimated that "[a]t full treatment capacity, up to 85 percent of [the] water [Devon] recover[s] from fracture completions in the Barnett Shale could be reused." 274 And Devon Energy is not alone: Fountain Quail Water Management, DTE Gas Resources Inc., Burlington Resources, and Stroud Energy have all engaged in reuse and recycling efforts. ${ }^{275}$

New projects are underway at the national level: the U.S. Department of Energy's National Energy Technology Laboratory launched nine new projects in October 2009 focused on developing new technologies "to improve management of water resources, water usage, and water disposal." 276 These projects add to the fifteen already underway that are focused on "assess[ing] options and technologies for handling, cleaning, and reuse of produced and flowback water" in the Barnett and Appalachian shale plays. ${ }^{277}$ When combined with pitless drilling through a closed-loop system, recycling of waste is clearly an effective, available, and economical way to manage E\&P waste more safely and allow for compliance with stronger regulations.

\section{c. New Substitutes for Toxic Materials}

Studies indicate that the use of less toxic drilling and hydraulic fracturing fluids can both reduce the risks associated with E\&P wastes and also reduce oil and gas companies' liability, thus potentially saving them money in the long run. ${ }^{278}$ Other agencies confirm EPA's findings on the benefits of using safer cost effective alternatives. Numerous agencies encourage operators "to substitute less toxic, yet equally effective products for conventional drilling products." most recently, ExxonMobil announced that it "supports the disclosure of the identity of the ingredients being used in fracturing fluids." ${ }^{280}$ OGAP sees ExxonMobil's statement as a "significant step" and believes that "[o]nce the chemicals are widely known . . . companies will

\footnotetext{
${ }^{272}$ News Release, Railroad Commission of Texas, Commissioners Approve of Devon Water Recycling Project for the Barnett Shale, July 29, 2008.

${ }^{273}$ Id.

${ }^{274}$ Energy Companies Strive to Reuse Water, WEATHERFORD TELEGRAM, July 25, 2007, at 3C.

${ }^{275} \mathrm{Id}$.

${ }^{276}$ U.S. Dep't of Energy, National Energy Technology Lab, Nine New Projects, OIL \& GAS ProGRAM NEWSLETTER (Dep't), Winter 2009, at 8 .

${ }_{277} \mathrm{Id}$. at 6.

${ }^{278}$ EPA Office of Compliance Sector Notebook Project, Profile of the Oll and Gas Extraction INDUSTRY, EPA/310-R-99-006 (2000).

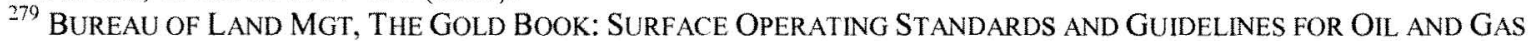
EXPLORATION AND DEVELOPMENT, at 39 (4th ed. 2007).

${ }^{280}$ Katie Burford, ExxonMobil Favors Fracing Disclosure, Environmental Group Welcomes Position from Oil Industry Giant, DuRANGO HERALD, Apr. 19, 2010.
} 
be more likely to use green alternatives" which will result in "a lessening of the toxicity of the fluids" over time. ${ }^{281}$

In addition, the search for chemicals with lower potential environmental impacts has "result[ed] in the generation of less toxic wastes ... . [For] example . . mud and additives that do not contain significant levels of biologically available heavy metals or toxic compounds."282 These types of new synthetic drilling fluids already have been developed and are less toxic, "free of polynuclear aromatic hydrocarbons and have . . f faster biodegradability and lower bioaccumulation potential." 283 Safer alternatives to current drilling fluids are available- all that remains is for the oil and gas industry to adopt widespread use of them.

Industry has already proven itself to be capable of switching to less hazardous compounds in the past. In the 1990s many drilling companies voluntarily phased out the use of benzene in their operations. ${ }^{284}$ EnCana stopped using a chemical, 2-Butoxyethanol, linked with reproductive problems in animals, while BJ Services, "one of the largest fracturing service providers in the world, has discontinued the use of fluorocarbons, a family of compounds that are persistent environmental pollutants." ${ }^{285}$ Schlumberger has developed "GreenSlurry," which the company claims is "earth-friendly." 286 Antero Resources Corporation pledged to use only "green frac" materials in the communities of Rifle, Silt and New Castle in western Colorado. ${ }^{287}$ Yet these reported less toxic fluids are not used everywhere. While the oil and gas industry clearly has the capability to adapt its operations to safer technologies, most companies have been reluctant to make such changes. EPA should thus act and require the oil and gas industry to expand the use of the safer, less toxic drilling fluids that are currently available.

\section{Oil and Gas Waste Meets the Statutory and Regulatory Criteria for Hazardous Waste.}

Absent their special exclusion from RCRA, E\&P wastes would properly be regulated under Subtitle C of RCRA. Congress defined hazardous wastes under RCRA as:

[A] solid waste, or combination of solid wastes, which because of its quantity, concentration, or physical, chemical or infectious characteristic may-

\footnotetext{
${ }^{281} I d$.

${ }^{282}$ E\&P FORUM, supra note 107, at12-23.

${ }^{283}$ Drilling Waste Management Information System, Drilling Waste Management Fact Sheet: Using Muds and Additives with Lower Environmental Impacts.

${ }^{284}$ Susan Riha et al., supra note 42 , at 6.

${ }^{285}$ Lustgarten, supra note 261.

${ }^{286}$ Schlumberger, "Earth-friendly GreenSlurry system for uniform marine performance," March, 2003.

287 The Rifle, Silt, New Castle Community Development Plan, Jan. 1, 2006.
} 
(A) cause, or significantly contribute to an increase in mortality or an increase in serious irreversible, or incapacitating reversible, illness; or

(B) pose a substantial present or potential hazard to human health or the environment when improperly treated, stored, transported, or disposed of, or otherwise managed. $^{288}$

Under RCRA, Congress instructed EPA to "define hazardous waste using two different mechanisms: by listing certain specific solid wastes as hazardous . . . and by identifying characteristics ... which, when exhibited by a solid waste, make it hazardous." 289 Under RCRA, "[c] ]haracteristic wastes are wastes that exhibit measurable properties which indicate that a waste poses enough of a threat to warrant regulation as a hazardous waste. ${ }^{, 290}$ The four technical criteria EPA uses to determine if a waste is a characteristic waste include: ${ }^{291}$ ignitability, corrosivity, reactivity, and toxicity. ${ }^{292}$ Waste will be considered hazardous if it exhibits any of the four characteristics. ${ }^{293}$ Because various types of E\&P wastes exhibit several of these characteristics, E\&P wastes should properly be regulated under Subtitle C of RCRA as characteristic hazardous wastes.

\section{a. Ignitability}

Ignitability is a criterion used to identify wastes that "can readily catch fire and sustain combustion." 294 A substance's flashpoint is indicative of its ignitability. ${ }^{295}$ A waste's flash point is "the lowest temperature at which the fumes above a waste will ignite when exposed to flame." ${ }^{296}$ Eleven percent of oily sludges sampled in California had a flash point exceeding the regulatory threshold. ${ }^{297}$

The risks associated with E\&P wastes having hazardous flashpoints under RCRA's criteria have been demonstrated in the past decade. In January 2003, a fire occurred when hydrocarbon vapor from basic sediment and water, a type of E\&P waste, ignited at a Texas open area collection pit. ${ }^{298}$ Three people were killed in the fire and four others were severely burned. ${ }^{299}$ In

${ }^{288} 42$ U.S.C. $\$ 6903(5)$.

${ }^{289}$ EPA, RCRA ORIENTATION MANUAL, CHAPTER III: RCRA SUBTITLE C-MANAGING HAZARdOUS W ASTE, at III17.

${ }^{290} \mathrm{Id}$. at III-22.

${ }^{291}$ Hazardous Waste Treatment Council v. U.S. EPA, 861 F.2d 277, 279 (D.C. Cir. 1988).

${ }^{292}$ See 40 CFR $\$ 261.20$ et seq.

${ }^{293}$ Id.

${ }^{294}$ EPA, supra note 2899, at III-22.

${ }^{295}$ NAGY, supra note 24 , at 36.

${ }^{296}$ EPA, supra note 2899, at III-23.

${ }^{297}$ NAGY, supra note 24, at 31.

${ }^{298}$ U.S. Dep't. of Labor, Occupational Safety \& Health Admin., Potential Flammability Hazard Associated with Bulk Transportation of Oilfield Exploration and Production (E\&P) Waste Liquids, SHIB-03-24-2008.

${ }^{299} \mathrm{Id}$. 
May 2006, a natural gas condensate tank and pit caught on fire in Colorado. ${ }^{300}$ Nearby residents were described as "“terrified' by the 200 -foot flames." ${ }^{301}$ Residents were also concerned because they were not able to learn what potential health impacts they were exposed to from the burning waste "since neither the company nor local or state authorities bothered taking air quality samples during the blaze." 302

More recently, a wastewater impoundment pond in Washington County, Pennsylvania caught fire ${ }^{303}$ George Zimmerman reported seeing "flames shooting 100 feet in the air" at the fire that occurred at the hydraulic fracturing site located on his property. ${ }^{304}$ A state police fire marshal determined that the fire was an accident caused by "a malfunction [that] ignited fumes [most likely in the frac tank] and caused $\$ 375,000$ in damages." 305 The fire also "badly damaged" the frac pit liner, causing a spokeswoman from the Pennsylvania DEP to be concerned that the pit's contents might escape. ${ }^{306}$ Instances such as these fires and the sampling data from California indicate that E\&P wastes are ignitable, and that this characteristic of E\&P wastes has resulted in serious harm. E\&P wastes with these flash points would appropriately be regulated as characteristic hazardous wastes under Subtitle C of RCRA. Such regulation is necessary to prevent future incidents similar to the January 2003 and March 2010 fires.

\section{b. Corrosivity}

Waste is corrosive if "it is acqueous and has a $\mathrm{pH}$ less than or equal to 2 or greater than or equal to 12.5 " or if "[i]t is a liquid and corrodes steel ... at a rate greater than $6.35 \mathrm{~mm}$ per year." ${ }^{307}$ Drilling wastes sampled in California had elevated $\mathrm{pH}$ levels approaching the 12.5 regulatory limit. ${ }^{308}$ In addition, corrosive chemicals are frequently found in E\&P wastes. For example, hydrogen sulfide is a corrosive and "toxic gas occurring naturally in some oil and gas reservoirs." ${ }^{309}$ The corrosive characteristics of E\&P wastes have already been responsible for many incidents where E\&P wastes have been improperly released. On numerous occasions, spills of E\&P wastes have been reported as originating from corroded equipment that had begun to leak because of corrosion attributed to the substances the equipment contained. ${ }^{310}$ Again, because a waste is properly regulated under Subtitle C of RCRA when it exhibits any of the four

\footnotetext{
${ }^{300}$ OIL \& GAS ACCOUNT ABILITY PrOJECT, SPRING/SUMMER 2006 REPORT (2006).

${ }^{301} I d$.

${ }^{302}$ Id.

${ }^{303}$ Janice Crompton, Residents Reported Gas Odors Before Explosion, PITTSBuRgh PoST-GAZETTE, Apr. 1, 2010, at B-1.

${ }^{304}$ Kathie O. Warco, Fumes Ignite at Gas Well, OBSERVER-REPORTER, Apr. 1, 2010.

${ }^{305} \mathrm{Id}$.

${ }^{306} \mathrm{Id}$.

30740 CFR $\$ 261.22$

${ }^{308} \mathrm{NAGY}$, supra note 24, at 37.

${ }^{309}$ E\&P FORUM, supra note 107 , at 28.

${ }^{310}$ See supra note 216 and accompanying text.
} 
criteria of characteristic hazardous wastes, corrosive E\&P wastes should be regulated under Subtitle C.

\section{c. $\quad \underline{\text { Reactivity }}$}

A waste is reactive if "(1) it is normally unstable and readily undergoes violent change without detonating, (2) [i]t reacts violently with water, (3) [i]t forms potentially explosive mixtures with water, (4) [w]hen mixed with water, it generates toxic gases, vapors or fumes in a quantity sufficient to present a danger to human health or the environment, (5) [i]t is a cyanide or sulfide bearing waste which, when exposed to $\mathrm{pH}$ conditions between 2 and 12.5 , can generate toxic gases, vapors or fumes in a quantity sufficient to present a danger to human health or the environment, (6) [i]t is capable of detonation or explosive reaction if it is subjected to a strong initiating source or if heated under confinement, (7) [i]t is readily capable of detonation or explosive decomposition or reaction at standard temperature and pressure, [or] (8) [i]t is a forbidden explosive ...."311

Out of the four criteria for determining characteristic hazardous wastes, reactivity is the most difficult to test: "In many cases, there is no reliable test method to evaluate a waste's potential to explode, react violently, or release toxic gas under common waste handling conditions." 312 In some cases, a waste's reactivity can be evaluated by a releasable sulfide test. ${ }^{313}$ Although no regulatory threshold valuable for releasable sulfides has been established, EPA established an interim guidance value. ${ }^{314}$ Testing of E\&P wastes in California found samples of sludge and tank bottoms exceeding EPA's interim guidance value. ${ }^{315}$

\section{d. Toxicity}

The Code of Federal Regulations describes the specific levels/concentrations at which various chemicals will be considered toxic for the purposes of RCRA. To determine whether a chemical meets the required level, EPA uses the Toxicity Characteristic Leaching Procedure (TCLP). Many E\&P wastes would be considered toxic under this test. The New Mexico Oil Conservation Division (OCD) found that several samples taken from E\&P waste disposal pits in the state contained levels of chemicals that failed the TCLP test. ${ }^{316}$ Specifically, the OCD found pits that contained levels of arsenic, lead, mercury, 2,4-Dinitrotoluene, and 2-Methylnaphthalene that exceeded TCLP levels. ${ }^{317}$ Its report indicated that the levels of lead they found alone would have allowed the wastes to be considered characteristically hazardous if not for the RCRA

31140 CFR $\$ 261.23$.

${ }^{312}$ EPA, supra note 2899 , at III-23.

313 NAGY, supra note 24 , at 38 .

${ }^{314} \mathrm{Id}$.

$315 \mathrm{Id}$. at $38-39$.

${ }^{316}$ See Earthworks, OCD's 2007 Pit Sampling Program: What Is in that Pit?, at 31.

${ }^{317}$ Id. at 34. 
exemption. ${ }^{318}$ Analysis of E\&P waste in California determined that both produced water and oily sludge met the federal toxicity characteristic and would be considered hazardous, again, if not for the RCRA exemption. ${ }^{319}$ Because of this evidence, and the multitude of evidence discussed above indicating that E\&P wastes have caused, and present substantial risk of continuing to cause, hazards to human health and the environment, EPA should reconsider its 1988 Regulatory Determination and regulate E\&P wastes under Subtitle C of RCRA, as would be proper given the fact that they frequently exhibit the same traits as characteristic hazardous wastes.

\section{REQUEST FOR PROMULGATION OF REGULATIONS}

The Petitioner, the Natural Resources Defense Council, respectfully requests that the EPA promulgate regulations classifying wastes from the exploration, development and production of oil and natural gas as hazardous waste subject to provisions of Subtitle $\mathrm{C}$ of RCRA. This request is based on overwhelming evidence that waste from the exploration, development and production of oil and natural gas is hazardous, taking into account its toxicity, corrosivity, and ignitability, that it is released into the environment where it can cause harm, that state regulations are inadequate, and that there are numerous methods available to manage it as hazardous waste. As set forth in this Petition, evidence exists for EPA to document that, because of its quantity, concentration, and chemical characteristics, E\&P waste may cause or significantly contribute to an increase in mortality and serious incapacitating illness and that it may pose a substantial present or potential hazard to wildlife and the environment when improperly treated, transported or disposed of, or otherwise managed, as is occurring throughout the U.S. in the absence of sufficient mandatory federal oversight. See 42 U.S.C. § 6902(4)-(5).

The Petitioner requests that the EPA consider the relevant statutory and regulatory factors, as well as the factors set forth in the July 1988 Regulatory Determination, and promulgate regulations applying to wastes from the exploration, development and production of oil and natural gas under Subtitle C of RCRA.

Respectfully submitted this 8th day of September, 2010.

\footnotetext{
${ }^{318} I d$. at 35 .

${ }^{319}$ NAGY, supra note 24 , at 40 .
} 


\section{List of References}

1. Joseph F. Scavetta, RCRA 101: A Course in Compliance for Colleges and Universities, 72 Notre Dame Law Review (1997)

2. Natasha Ernst, Note, Flow Control Ordinances in a Post-Carbone World, 13 Penn State Environmental Law Review (2004)

3. James R. Cox, Revisiting RCRA'S Oilfield Waste Exemption as to Certain Hazardous Oilfield Exploration and Production Wastes, 14 Villanova Environmental Law Journal (2003)

4. EPA, Report to Congress, Management of Wastes from the Exploration, Development, and Production of Crude Oil, Natural Gas, and Geothermal Energy, Volumes 1-3 EPA530-SW-88-003 (1987)

5. Regulatory Determination for Oil and Gas and Geothermal Exploration, Development and Production Wastes, 53 Fed. Reg. 25 (July 6, 1988)

6. EPA Region 8, An Assessment of the Environmental Implications of Oil and Gas Production: A Regional Case Study (Working Draft 2008)

7. $\quad 101$ F.3d 772 (D.C. Cir. 1996)

8. Closing Argument of the New Mexico Citizens for Clean Air and Water, Dec. 2007, OCD Document Image No. 14015_648_CF[1]

9. Drilling Down: Protecting Western Communities from the Health and Environmental Effects of Oil and Gas Production (2007)

10. Railroad Commission of Texas, Waste Minimization in the Oil Field

11. Claudia Zagrean Nagy, California Department of Toxic Substances Control, Oil Exploration and Production Wastes Initiative (2002)

12. Kelly Corcoran, Katherine Joseph, Elizabeth Laposata, \& Eric Scot, UC Hastings College of the Law' Public Law Research Institute, Selected Topics in State and Local Regulation of Oil and Gas Exploration and Production

13. C. Tsouris, Oak Ridge National Laboratory, Emerging Applications of Gas Hydrates

14. Letter from West Virginia Department of Environmental Protection to William Goodwin, Superintendent Clarksburg Sanitary Board, July 23, 2009

15. Oklahoma Corporation Commission Oil and Gas Conversation Division, Guidelines for Responding to and Remediating New or Historic Brine Spills (2009) 
16. Colorado Oil and Gas Conservation Commission, Inspection/Incident Inquiry, Spill Reports, Document Nos. 1631502, 1631508

17. A.H. Beyer, Chevron Oil Field Research Co., Technical Memorandum, Purification of Produced Water, Part 1-Removal of Volatile Dissolved Oil by Stripping (1972)

18. U.S. General Accounting Office, RCED-89-97, Safeguards Are Not Preventing Contamination from Injected Oil and Gas Wells (1989)

19. Keith Schneider, Radiation Danger Found in Oilfields Across the Nation, N.Y. Times, Dec. 3, 1990

20. N.Y. Department of Environmental Conservation, Draft Supplemental General Environmental Impact Statement (2009)

21. Abrahm Lustgarten \& ProPublica, Natural Gas Drilling Produces Radioactive Wastewater, Scientific American, Nov. 9, 2009

22. Motion in Limine to Exclude Rogers and Associates Engineering Reports, Lester v. Exxon Mobil Corp., No. 630-402 (La. 24th Jud. Dist. Ct. 2009)

23. Wilma Subra, Louisiana Environmental Action Network, Comments on Hydraulic Fracturing to the Louisiana Senate Environmental Quality Committee, Mar. 11, 2010

24. Susan Riha et al, Comments on the Draft SGEIS on the Oil, Gas and Solution Mining Regulatory Program, Jan. 2010

25. U.S. Congress, Office of Technology Assessment, Managing Industrial Solid Wastes from Manufacturing, Mining, Oil and Gas Production, and Utility Coal CombustionBackground Paper (1992)

26. U.S. Fish \& Wildlife Service, Region 6, Environmental Contaminants Program, Reserve Pit Management: Risks to Migratory Birds (2009)

27. Oil \& Gas Accountability Project, Pit Pollution - Backgrounder on the Issues, with a New Mexico Case Study (2004)

28. U.S. Environmental Protection Agency, Technology Transfer Air Toxics: Acrylamide

29. T.A. Kassim, Waste Minimization and Molecular Nanotechnology: Toward Total Environmental Sustainability, in 3 Environmental Impact Assessment of Recycled Wastes on Surface and Ground Waters: Engineering Modeling and Sustainability (Tarek A. Kassim ed., 2005)

30. Texas Railroad Commission, Waste Minimization in Drilling Operations 
31. Jonathan Wills, Muddied Waters, A Survey of Offshore Oilfield Drilling Wastes and Disposal Techniques to Reduce the Ecological Impact of Sea Dumping (2000)

32. American Petroleum Institute, Waste Management

33. Dara O'Rourke \& Sarah Connolly, Just Oil? The Distribution of Environmental and Social Impacts of Oil Production and Consumption, 28 Annual Review of Environment and Resources (2003)

34. Testimony of Margaret A. Ash, OGCC Environmental Supervisor, In the Matter of Changes to the Rules and Regulations of the Oil and Gas Conservation Commission of the State of Colorado

35. The Endocrine Disruption Exchange, Potential Health Effects of Residues in 6 New Mexico Oil and Gas Drilling Reserve Pits Based on Compounds Detected in at Least One Sample, Nov. 15, 2007

36. Shannon D. Williams, David E. Ladd \& James J. Farmer, U.S. Geological Survey, Fate and Transport of Petroleum Hydrocarbons in Soil and Ground Water at Big South Fork National River and Recreation Area, Tennessee and Kentucky, 2002-2003 (2006)

37. The Endocrine Disruption Exchange, Number of Chemicals Detected in Reserve Pits for 6 Wells in New Mexico That Appear on National Toxic Chemical Lists: Amended Document, Nov. 15, 2007

38. Letter from Roy Staiger, District Office Cleanup Coordinator, Texas Railroad Commission, to Exxon Mobil Corporation, Dec. 31, 2009

39. Oil \& Gas Accountability Project, Spring/Summer 2006 Report (2006)

40. Wolf Eagle Environmental, Environmental Studies: Fugitive Air Emissions Testing, Impacted Soil Testing, Mr. and Mrs. Timothy Ruggiero (2010)

41. U.S.G.S., Toxic Substance Hydrology Program: BTEX

42. Eric Griffey, "Toxic drilling waste is getting spread all over Texas farmland," Fort Worth Weekly (May 12, 2010)

43. U.S. Department of Health \& Human Services, Agency for Toxic Substances and Disease Registry, ToxFAQs for Acetone (1995)

44. U.S. Department of Health \& Human Services, Agency for Toxic Substances and Disease Registry, ToxFAQs for Arsenic (2007) 
45. ScienceLab.com, Chemicals \& Laboratory Equipment, Material Safety Data Sheet: Arsenic MSDS 1 (2008)

46. U.S. Department of Health \& Human Services, Agency for Toxic Substances and Disease Registry, ToxFAQs for Barium (2007)

47. U.S. Department of Health \& Human Services, Agency for Toxic Substances and Disease Registry, ToxFAQs for Radium (2007)

48. Chris Gray, Pits Cause Stink in Lafourche, Times-Picayune, July 14, 1997

49. Miguel San Sebastian, Ben Armstrong, \& Carolyn Stephens, Outcomes of Pregnancy among Women Living in the Proximity of Oil Fields in the Amazon Basin of Ecuador, 8 International Journal of Occupational and Environmental Health (2002)

50. Anna-Karin Hurtig \& Miguel San Sebastian, Geographical Differences in Cancer Incidence in the Amazon Basin of Ecuador in Relation to Residence near Oil Fields, 31 International Journal of Epidemiology (2002)

51. Henry Spitz, Kennith Lovins \& Christopher Becker, Evaluation of Residual Soil Contamination From Commercial Oil Well Drilling Activities and Its Impact on the Naturally Occurring Background Radiation Environment, 6 Soil \& Sediment Contamination: An International Journal (1997)

52. Joint Factual Statement, ๆๆ 10-27, U.S. v. Exxon Mobil Corp., (D.Col. 2009)

53. Bryan M. Clark, Dirty Drilling: The Threat of Oil and Gas Drilling in Lake Erie (2005)

54. Letter from Lisa Kirkpatrick, Chief, New Mexico Dept. of Game \& Fish, Conservation Services Division, to Florene Davidson, Commission Secretary, EMNRD Oil Conservation Division (Jan. 20, 2006)

55. Letter from Lisa Kirkpatrick, Chief, New Mexico Dept. of Game \& Fish, Conservation Services Division, to Florene Davidson, Commission Secretary, EMNRD Oil Conservation Division (Mar. 7, 2006)

56. Letter from Lisa Kirkpatrick, Chief, New Mexico Dept. of Game \& Fish, Conservation Services Division, to Florene Davidson, Commission Secretary, EMNRD Oil Conservation Division (Feb. 2, 2007) 
57. Press Release, Pennsylvania Department of Environmental Protection, Cattle from Tioga County Farm Quarantined after Coming in Contact with Natural Gas Drilling Wastewater (July 12010 )

58. Amended Complaint at 932 , Sweet Lake Land and Oil Co. v. Exxon Mobil Corp., No. 209CV01100, (W.D. La. filed Sept. 14, 2009), 2009 WL 4701364

59. Test results from Veterinary Medical Diagnostic Laboratory on 26 July 2005, 18 August 2005, and 6 September 2005

60. Bluedaze: Drilling Reform for Texas, http://txsharon.blogspot.com/2008/07/morebarnett-shale-sludge-pond.html. (July 25, 2008)

61. Susan Hylton, Drilling Waste Feud, Neighbors of Maverick Energy Services Think Water is Being Polluted, Tulsa World, March 21, 2010

62. E\&P Forum, Exploration and Production (E\&P) Waste Management Guidelines (1993)

63. League of Women Voters of Tarrant County, Gas Drilling Waste-Water Disposal (2008)

64. Testimony of James E. McCartney to the $128^{\text {th }}$ General Assembly, Ohio Senate Environmental and Natural Resources Committee. Opposition Testimony on Senate Bill 165, Oct. 28, 2009

65. State Review of Oil and Natural Gas Environmental Regulations, Inc., Tennessee State Review (2007)

66. FY2008 EPA Region 6 End-of-year Evaluation of the Railroad Commission of Texas Underground Injection Control Program, with transmittal letter from Bill Luthans, Acting Director, Water Quality Protection Division, Region 6 to Tommie Seitz, Director, Oil and Gas Division (June 19, 2009)

67. Joe Carroll, Exxon's Oozing Texas Oil Pits Haunt Residents as XTO Deal Nears. Bloomberg. April 16, 2010

68. New Mexico Energy, Minerals and Natural Resources Department, Oil Conservation Division, Cases Where Pit Substances Contaminated New Mexico's Ground Water (2008)

69. Oil \& Gas Accountability Project, Groundwater Contamination 
70. Kim Weber, Regarding Support of HB 1414 Evaporative Waste Facilities Regulations

71. Colorado Oil and Gas Conservation Commission, Inspection/Incident Inquiry, Spill Reports, Document Nos. 1630424, 1630426, 1630427, 1630428, 1630429, 1630430

72. Oil \& Gas Accountability Project, Contamination Incidents Related to Oil and Gas Development, Maralex Drilling Fluids in Drinking Water

73. Colorado Oil and Gas Conservation Commission, Inspection/Incident Inquiry, Spill Report, Document No. 1953000

74. Colorado Oil and Gas Conservation Commission, Inspection/Incident Inquiry, NOAV Report, Document No. 200085988

75. Colorado Oil and Gas Conservation Commission, Inspection/Incident Inquiry, Spill Reports, Document Nos. 1631518, 1631599, 2605176, 2605847

76. Colorado Oil and Gas Conservation Commission, Inspection/Incident Inquiry, Spill Reports, Document Nos. 200225543, 200225547, 200225546

77. Colorado Oil and Gas Conservation Commission, Inspection/Incident Inquiry, Spill Reports, Document No.1632846

78. COGCC Prather Springs Administrative Order by Consent

79. Toxics Targeting, Inc., Hazardous Materials Spills Information Request (2009)

80. Consent Assessment of Civil Penalty, In re Atlas Resources LLC, Dancho-Brown 4, ๆ1 AV-AZ, Groves 8, ๆ $\mathrm{BA}-\mathrm{BE}$

81. Ohio Department of Natural Resources, Notice of Violation No. 1278508985, June 21, 2010.

82. Ohio Department of Natural Resources, Notice of Violation No. 2016754140, May 16, 2008.

83. Phillip Yates, Clean Air Group Contends Evaporation Ponds in Garfield County More Dangerous than Previously Believed, Post Independent, Jan. 9, 2008

84. Colorado Oil and Gas Conservation Commission, Inspection/Incident Inquiry, Complaint Report, Document No. 200081602 
85. Amended Complaint, Stephenson v. Chevron U.S.A, Inc., No. 209CV01454, (W.D. La. filed Sept. 11, 2009), 2009 WL 4701406

86. Petition for Damages, Brownell Land Corp., LLC v. Honey Well Int'l., No. 08CV04988, (E.D. La. filed Nov. 21, 2008), 2008 WL 5366168

87. Rice Agricult. Corp., Inc., v. HEC Petroleum Inc., 2006 WL 2032688 (E.D. La)

88. Petition for Damages, Tensas Poppadoc, Inc. v. Chevron U.S.A., Inc., No. 040769, (7th Judicial Court La. filed Sept. 21, 2005), 2005 WL 6289654

89. Petition for Damages to School Lands, Louisiana v. Shell Oil Co., No. CV04-2224 LO, (W.D. La. filed Oct. 29, 2004), 2004 WL 2891505

90. State Review of Oil and Natural Gas Environmental Regulations, Inc., Kentucky State Review (2006)

91. State Review of Oil and Natural Gas Environmental Regulations, Inc., Louisiana State Review (2004)

92. Christie Campbell, Foul Odor from Impoundment Upsets Hopewell Woman, Observer-Reporter, Apr. 14, 2010

93. EPA Office of Compliance Sector Notebook Project, Profile of the Oil and Gas Extraction Industry, EPA/310-R-99-006 (2000)

94. Letter from Gary M. Maslanka, New York State Division of Solid \& Hazardous Materials, to Joseph Boyles, Casella (April 27, 2010)

95. Press Release, Arkansas Dept. of Envtl. Quality, ADEQ Releases Landfarm Study Report (Apr. 20, 2009)

96. M.G. Puder \& J.A. Veil, Argonne National Laboratory, Offsite Commercial Disposal of Oil and Gas Exploration and Production Waste: Availability, Options, and Costs (2006)

97. Abrahm Lustgarten, State Oil and Gas Regulators Are Spread Too Thin to Do Their Jobs, ProPublica, December 30, 2009

98. EPA, Office of the Inspector General, Complete Assessment Needed to Ensure Rural Texas Community Has Safe Drinking Water, No. 2007-P-00034 (2007) 
99. Robert D. Bullard, Testimony before the Subcommittee on Superfund and Environmental Health of the Senate Environment and Public Works Committee (July $25,2007)$

100. Marcellus Gas Well Hydrofracture Wastewater Disposal by Recycle Treatment Process, ProChemTech International, Inc.

101. New York State Water Resources Institute, Waste Management of Cuttings, Drilling Fluids, Hydrofrack Water and Produced Water

102. Ohio Environmental Protection Agency, Marcellus Shale Gas Well Production Wastewater

103. Joaquin Sapien, With Natural Gas Drilling Boom, Pennsylvania Faces an Onslaught of Wastewater, ProPublica, October 4, 2009

104. Marcellus Shale Natural Gas Wastewater Treatment, Hearing Before the S. Comm. on Environmental Resources and Energy (Pa. 2010) (statement of Peter Slack, Pennsylvania Municipal Authorities Association)

105. Press Release, Pennsylvania Department of Environmental Protection, DEP Says Jersey Shore Borough Exceeds Wastewater Permit Limits (June 23 2009)

106. Pennsylvania Department of Environmental Protection, Press Release, DEP Fines Atlas $\$ 85,000$ for Violations at 13 Well Sites, Jan. 7, 2010

107. Laura Legere, Massive use of water in gas drilling presents myriad chances for pollution, Scranton Times-Tribune, June 22, 2010

108. Colorado Oil and Gas Conservation Commission, Inspection/Incident Inquiry, Spill Report, Document No. 1630697

109. Colorado Oil and Gas Conservation Commission, Inspection/Incident Inquiry, Spill Reports, Document Nos. 1631155, 1631831, 1631794, 1632853

110. Colorado Oil and Gas Conservation Commission, Inspection/Incident Inquiry, Spill Reports, Document Nos. 1630885, 1631496, 1631519, 1632057, 2605191, 1632995

111. Colorado Oil and Gas Conservation Commission, Inspection/Incident Inquiry, Spill Reports, Document Nos. 200226284, 200225725, 2605709

112. Oil \& Gas Accountability Project, Colorado Oil and Gas Industry Spills: A review of COGCC data (June 2002-June 2006) (2006) 
113. Frac Fluid Spill Reported in Flower Mound, Cross Timbers Gazette, Mar. 17, 2010

114. Letter from Robert F. Fetty, Mayor, Town of West Union, to Barbara Taylor, Director, WVBPH/Office of Environmental Health Services, Oct. 28, 2009

115. Posting of Ken Ward Jr. to Sustained Outrage: A Gazette Watchdog Blog

116. Letter from Louanne McConnell Fatora to Governor Manchin, West Highlands Conservancy (Aug. 30, 2009)

117. U.S. Energy Information Administration, Number of Producing Gas Wells (2009)

118. Bureau of Land Management, BLM FY 2009 Budget Justifications III-1834 (2009)

119. Hannah Wiseman, Untested Waters: The Rise of Hydraulic Fracturing in Oil and Gas Production and the Need to Revisit Regulation, 20 Fordham Environmental. Law Review (2009)

120. Texas Railroad Commission, Newark, East (Barnett Shale) Field, Drilling Permits Issued

121. Newark, East (Barnett Shale) Drilling Permits Issued (1993-2009), Texas Railroad Commission

122. Industry Sets Record For Drilling, Well Completions, Land Letter, Jan. 18, 2007

123. API: US Drilling at 21-year High in 1Q, Oil \& Gas Journal, May 7, 2007

124. Utah Department of Natural Resources, Division of Oil, Gas and Mining, Produced Water Disposal(2007)

125. EPA, Region 8, Oil and Gas Environmental Assessment Report 1996-2002 (2003)

126. Statement of Commissioner William Olson before the New Mexico Oil Conservation Division, Apr. 16, 2008, OCD Document Image 14015_657_CF[1]

127. "Governor Bill Richardson Announces Oil and Gas Drilling Activity in New Mexico Is Strong: Environmental regulations are not driving business away," State of New Mexico, Press Release, May 19, 2010

128. Dorsey Rogers, Gary Fout \& William A. Piper, New Innovative Process Allows Drilling Without Pits in New Mexico (2006)

129. Oil \& Gas Accountability Project, Alternatives to Pits 
130. Oil \& Gas Accountability Project, Notice of Errata in the Oil \& Gas Accountability Project's Closing Argument and Proposed Changes, Re: Case 14015: Application of New Mexico Oil Conservation Division for Repeal of Existing Rule 50 Concerning Pits, etc., Dec. 11, 2007, OCD Document Image No.14015_654_CF[1]

131. Dorsey Rogers, Dee Smith, Gary Fout \& Will Marchbanks, Closed-loop drilling system: A Viable Alternative to Reserve Waste Pits, World Oil, Dec. 2008

132. Exhibit 8, Closed-Loop Drilling Case Studies, Re: Case 14015: Application of New Mexico Oil Conservation Division for Repeal of Existing Rule 50 Concerning Pits, etc., OCD Document Image No. 14015_637_[CF]1

133. Abrahm Lustgarten, Underused Drilling Practices Could Avoid Pollution, ProPublica, Dec. 14, 2009

134. U.S. Fish \& Wildlife Service, Wildlife Mortality Risk in Oil Field Waste Pits, U.S. FWS Contaminants Information Bulletin (2000)

135. Bureau of Land Management, The Gold Book: Surface Operating Standards and Guidelines for Oil and Gas Exploration and Development (4th ed. 2007)

136. Controlled Recovery Inc.'s Written Closing Argument, Re: Case 14015: Application of New Mexico Oil Conservation Division for Repeal of Existing Rule 50 Concerning Pits, etc., Dec. 10, 2007

137. Lowell Brown, Officials Give Few Answers to Argyle, Denton Record-Chronicle, Jan. 30,2010

138. E\&P Forum/UNEP Technical Publication, Environmental Management in Oil and Gas Exploration and Production: An Overview of Issues and Management Approaches (1997)

139. STW Resources, Inc., Contaminated Waste Water Reclamation Opportunities

140. Railroad Commission of Texas, News Release, Commissioners Approve of Devon Water Recycling Project for the Barnett Shale, July 29, 2008

141. Energy Companies Strive to Reuse Water, Weatherford Telegram, July 25, 2007

142. Nine New Projects, Oil \& Gas Program Newsletter (U.S. Dept. of Energy, National Energy Technology Lab), Winter 2009 
143. Katie Burford, ExxonMobil Favors Fracing Disclosure, Environmental Group Welcomes Position from Oil Industry Giant, Durango Herald, Apr. 19, 2010

144. Drilling Waste Management Information System, Drilling Waste Management Fact Sheet: Using Muds and Additives with Lower Environmental Impacts

145. Schlumberger, Earth-friendly Green Slurry system for uniform marine performance, March 2003

146. Rifle, Silt, New Castle Community Development Plan, January 1, 2006

147. EPA, RCRA Orientation Manual, Chapter III: RCRA Subtitle C-Managing Hazardous Waste, Hazardous Waste Identification.

148. Hazardous Waste Treatment Council v. U.S. EPA, 861 F.2d 277, 279 (D.C. Cir. 1988)

149. U.S. Dept. of Labor, Occupational Safety \& Health Administration, Potential Flammability Hazard Associated with Bulk Transportation of Oilfield Exploration and Production (E\&P) Waste Liquids, SHIB-03-24-2008

150. Janice Crompton, Residents Reported Gas Odors Before Explosion, Pittsburgh PostGazette, Apr. 1, 2010

151. Kathie O. Warco, Fumes Ignite at Gas Well, Observer-Reporter, Apr. 1, 2010

152. Earthworks, OCD's 2007 Pit Sampling Program: What is in That Pit? 


\section{ลิ}

\section{- News \& Events}

Research News

- News Archive

News Release Inquiries

LDEO in the Media

Publications Database

- eNewsletter Signup

eNewsletter Archive

- Events

\section{Calendar of Events}

- Colloquium

- Open House

- Public Lectures

Home » News \& Events

\section{Ohio Quakes Probably Triggered by Waste Disposal Well, Say Seismologists \\ January 6, 2012}

Earthquakes that have shaken an area just outside Youngstown, Ohio in the last nine months -including a substantial one on New Year's Eve-are likely linked to a disposal well for injecting wastewater used in the hydraulic fracturing process, say seis mologists at Columbia University's Lamont-Doherty Earth Observatory who were called in to study the quakes. Ohio Gov. John Kasich has shut down the injection well and put four other proposed wells on hold. In the meantime, steps have been taken to ease pressure in the well to avert further rumblings.

The concern comes as natural gas drilling in shale formations that underlie much of the Northeast grows. To extract the gas, a mix of water, sand and chemicals is pumped under high pressure into shale rocks, in a process called hydraulic fracturing, or fracking. Once the gas has been removed, wastewater is either recycled or trucked off-site and injected deep underground. As the pressurized water seeps through cracks deep below ground, it can sometimes cause earthquakes on ancient fault lines.

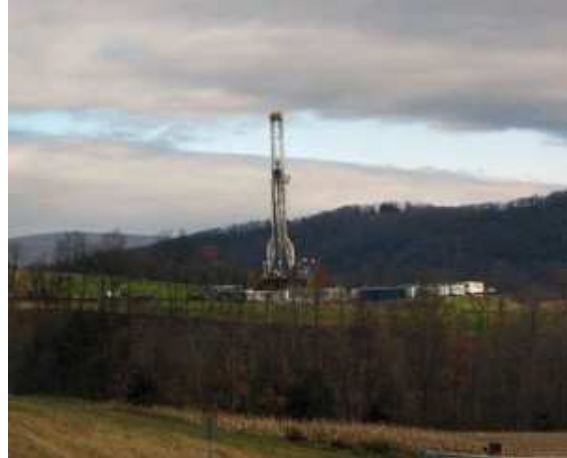

A tower for removing gas at the Marcellus Shale Formation in

Ohio is home to 177 such disposal wells, including the Youngstown well, which lies in a seismically dormant region bordering Pennsylvania. The first rumblings surfaced in March, several months after injection of fracking waste from Pennsylvania began. Nine small temblors followed. In late November, Ohio authorities asked Lamont scientists to monitor the area with mobile instruments that could provide a more accurate location of subsequent earthquakes. On Dec. 24 , the four instruments recorded a magnitude 2.7 quake 2.2 miles below the surface-a half-mile away and about 2,000 feet below the 1.7 mile deep well.

"The location of the earthquake was sufficient evidence that there could be a link," Lamont seismologist John Armbruster told NPR's All Things Considered. Later in the week, D\&L Energy, which owns the site, agreed to shut down the well. Then, on Dec. 31, a magnitude 4.0 quake struck. The Lamont instruments located it at about 300 feet east, and some 500 feet under the previous event. A 4.0 is about 40 times more powerful than a 2.7. At that point, the state put a moratorium on activity on four other wells within a five-mile radius, all of them already inactive.

Hydrofracking by its nature causes tiny earthquakes, because it involves fracturing of rock-but these are largely imperceptible, as the process takes place in relatively weak, shallow shales that crack before building up much strain. Quakes triggered by waste injection wells can be potentially more powerful because more fluid is usually being pumped underground at a site for longer periods, said Roger Anderson, an energy geophysicist at Lamont-Doherty who is not involved in the study. Once fluid enters a preexisting fault, it can pressurize the rocks enough to move; the more stress placed on the rock formation, the more powerful the earthquake. The Lamont data suggests that the Dec. 31 movement near the Ohio well was a strike-slip motion, in which one rock face slides across the other horizontally.

The chance of triggering an ancient fault by injecting fluid underground is relatively slim-maybe one in 200 , said Lamont seismologist Won-Young Kim, who heads the Lamont-Doherty Cooperative Seismic Network. But, he said, the potential damage and injuries from an earthquake could far outweigh the cost of closing the well. "Once you get one earthquake, it's better to stop then, because you may get another," he said. That point was echoed by Armbruster on NPR: "I would advocate monitoring of wells to know when triggering of earthquakes first begins," he said. "Then you can decide whether to continue using that well."

Seis mologists have known about the potential for injection wells to trigger earthquakes since the 1960s, when injected wastewater from weapons production at the Rocky Mountain Arsenal in Colorado was tied to a series of earthquakes including several of magnitude 5.0 or greater that caused minor damage in Denver and other cities. Earthquakes in Arkansas, Texas, Oklahoma and the United Kingdom have been linked in recent years to dis posal of fracking fluids. In 2001 scientists linked a magnitude 4.2 quake in Ashtabula, Ohio to a waste disposal well there, a "carbon copy" of the recent activity near Youngstown, said Kim.

After the New Year's quake, Kim said that the risk could continue for another year or two, as it could take that long for pressurized fluid to dissipate. To minimize that risk, Ohio officials announced Jan. 5 that they would start letting the injected fluids bubble back into storage tanks at the surface rather than capping the well under standard procedures.

The Lamont-Doherty scientists will continue to monitor the area with colleagues from Youngstown State University and Ohio Geological Survey. They are also talking with the university about upgrading its own seismic station.

More:

Watch how injected fluids trigger an earthquake in this video from Next media Animation.

For ongoing coverage of the scientific debate over hydrofracking see Scientific American's Storify blog. 
MEDIA INQUIRIES:

Kim Martineau

kmartine@Ideo.columbia.edu

Office:(845) 365-8708

Cell: (646)-717-0134

TAGS: EARTHQUAKES | HYDROFRACKING

(4) SHRRE

The Earth Institute | LDEO home | webmaster | sitemap | terms-of-use | support LDEO | Open Positions | Login Copyright $\odot 2013$ by The Trustees of Columbia University in the City of New York, Lamont -Doherty Earth Observatory. All rights reserved. 


\section{SSF 12012}

Session: The M5.8 Central Virginia and the M5.6 Oklahoma Earthquakes of 2011

\section{ARE SEISMICITY RATE CHANGES IN THE MIDCONTINENT NATURAL OR MANMADE?}

ELLSWORTH, W. L., US Geological Survey, Menlo Park, CA; HICKMAN, S. H., US Geological Survey, Menlo Park, CA; LLEONS, A. L., US Geological Survey, Menlo Park, CA; MCGARR, A., US Geological Survey, Menlo Park, CA; MICHAEL, A. J., US Geological Survey, Menlo Park, CA; RUBINSTEIN, J. L., US Geological Survey, Menlo Park, CA

A remarkable increase in the rate of $\mathrm{M} 3$ and greater earthquakes is currently in progress in the US midcontinent. The average number of $M>=3$ earthquakes/year increased starting in 2001 , culminating in a six-fold increase over 20th century levels in 2011. Is this increase natural or manmade? To address this question, we take a regional approach to explore changes in the rate of earthquake occurrence in the midcontinent (defined here as $85^{\circ}$ to $108^{\circ}$ West, $25^{\circ}$ to $50^{\circ}$ North) using the USGS Preliminary Determination of Epicenters and National Seismic Hazard Map catalogs. These catalogs appear to be complete for $M>=3$ since 1970 . From 1970 through 2000, the rate of $M>=3$ events averaged $21+-7.6 /$ year in the entire region. This rate increased to $29+-3.5$ from 2001 through 2008. In 2009, 2010 and 2011, 50, 87 and 134 events occurred, respectively. The modest increase that began in 2001 is due to increased seismicity in the coal bed methane field of the Raton Basin along the Colorado-New Mexico border west of Trinidad, CO. The acceleration in activity that began in 2009 appears to involve a combination of source regions of oil and gas production, including the Guy, Arkansas region, and in central and southern Oklahoma. Horton, et al. (2012) provided strong evidence linking the Guy, AR activity to deep waste water injection wells. In Oklahoma, the rate of $M>=$ 3 events abruptly increased in 2009 from 1.2/year in the previous half-century to over 25/year. This rate increase is exclusive of the November 2011 M 5.6 earthquake and its aftershocks. A naturally-occurring rate change of this magnitude is unprecedented outside of volcanic settings or in the absence of a main shock, of which there were neither in this region. While the seismicity rate changes described here are almost certainly manmade, it remains to be determined how they are related to either changes in extraction methodologies or the rate of oil and gas production.

Wednesday, April 18th / 3:45 PM Oral / Pacific Salon 4 \& 5 


\section{NRDC DOCUMENT}

MAY 2012 D:12-05-A

\section{In Fracking's Wake: New Rules are Needed to Protect Our Health and Environment from Contaminated Wastewater}

\author{
AUTHORS \\ Rebecca Hanmer \\ Natual Resources Defense Council \\ Jeanne VanBriesen, Ph.D., PE \\ Camegie Miellon University
}

\author{
PROJECT DESIGN \\ AND DEVELOPMENT \\ Láry Levine \\ Naturai Resources Defense Council
}

This report combines an evaluation of federal and state laws regulating fracking wastewater with a thorough review, compiled for NRDC by an independent scientist, of the health and environmental risks posed by this high-volume waste stream and the currently available treatment and disposal methods. It finds that the currently available options are inadequate to protect human health and the environment, but that stronger safeguards at the state and federal levels could better protect against the risks associated with this waste. The most significant of the policy changes needed now are (a) closing the loophole in federal law that exempts hazardous oil and gas waste from treatment, storage, and disposal requirements applicable to other hazardous waste, and (b) improving regulatory standards for wastewater treatment facilities and the level of treatment required before discharge to water bodies.

In examining a number of different fracking wastewater disposal methods that are being used in the Marcellus Shale region, the report finds that although all are problematic, with better regulation some could be preferable while others should not be allowed at all. NRDC opposes expanded fracking without effective safeguards. States such as New York that are considering fracking should not move forward until the available wastewater disposal options are fully evaluated and safeguards are in place to address the risks and impacts identified in this report. Where fracking is already taking place, the federal government and states must move forward swiftly to adopt the policy recommendations in this report to better protect people and the environment. 


\section{About NRDC}

NRDC (Natural Resources Defense Council) is a national nonprofit environmental organization with more than 1.3 million members and online activists. Since 1970, our lawyers, scientists, and other environmental specialists have worked to protect the world's natural resources, public health, and the environment. NRDC has offices in New York City, Washington, D.C., Los Angeles, San Francisco, Chicago. Montana, and Beijing. Visit us at www.nrdc.org.

\section{Acknowledgments}

NRDC would like to acknowledge the generous support of the William Penn Foundation. The authors would like to thank Amy Mall, Kate Sinding, Jon Devine, John Wood, Briana Mordick, and Matt McFeeley for their guidance and expertise in developing the report. The authors would also like to thank the following individuals for their review of this report: Emily Collins (University of Pittsburgh), Wilma Subra (Subra Company), and Danny Reible (University of Texas) (our external peer reviewers).

This report and its recommendations are solely attributable to NRDC and do not necessarily represent the views of these individuals.

\section{Author's Note}

The authors would like to acknowledge that Dr. VanBriesen, Ph.D., PE, is the author of sections on management options, treatment methods, and potential impacts, while Ms. Hammer is the author of sections on regulatory framework and policy recommendations.

NRDC Director of Communications: Phil Gutis NRDC Deputy Director of Communications: Lisa Goffredi NRDC Publications Director: Alex Kennaugh Design and Production: Sue Rossi

(9) Natural Resources Defense Council 2012 
7 his paper analyzes the problem of wastewater generated from the hydraulic fracturing process of producing natural gas, particularly with regard to production in the Marcellus Shale." It shows that, while hydraulic fracturing (often called "hydrofracking" or "fracking") generates massive amounts of polluted wastewater that threaten the health of our drinking water supplies, rivers, streams, and groundwater, federal and state regulations have not kept up with the dramatic growth in the practice and must be significantly strengthened to reduce the risks of fracking throughout the Marcellus region and elsewhere."

Hydrofracking and the production of natural gas from fracked wells yield byproducts that must be managed carefully to avoid significant harms to human health and the environment. These wastewater by-products are known as "flowback" (fracturing fluid injected into a gas well that returns to the surface when drilling pressure is released) and "produced water" (all wastewater emerging from the well after production begins, much of which is salty water contained within the shale formation).

Both types of wastewater contain potentially harmful pollutants, including salts, organic hydrocarbons (sometimes referred to simply as oil and grease), inorganic and organic additives, and naturally occurring radioactive material (NORM). These pollutants can be dangerous if they are released into the environment or if people are exposed to them. They can be toxic to humans and aquatic life, radioactive, or corrosive. They can damage ecosystem health by depleting oxygen or causing algal blooms, or they can interact with disinfectants at drinking water plants to form cancer-causing chemicals.

\footnotetext{
'This paper focuses primarily on hydraulic fracturing in the Marcellus Shale, athough the issues raised herein are relevant anywhere fracking occurs. Thanks to the knowledge gained from years of expertence with fracking in the Marcelius, highlighting that region can provide insight for other regions undergoing new or expanded iracking.

* Due to the breadth and depth of this topic, there are certain issues relating to the management of shale gas wastewater that we do not attempt to address in this paper although they can present important environmental concerns in their own right. These include stormwater issues, accidental spills, waste genefated belore fracking flurd is injected, and impacts of wastewater management that are not water-related. Also not addressed in this paper are the impacts of water withdrawals for use in the hydraulic fracluring process or impacts from well drilling and development (including contamination of groundwater during hydraulic fracturusg).
} 


\begin{tabular}{|c|c|c|c|}
\hline $\begin{array}{l}\text { Chemical constituent or surrogate } \\
\text { parameter }\end{array}$ & Unit of measure & $\begin{array}{l}\text { Range reported in produced } \\
\text { water from wells drilled in } \\
\text { Marcellus Shale at } 5 \text { days post } \\
\text { hydraulic fracturing }\end{array}$ & $\begin{array}{l}\text { Range reported in produced } \\
\text { water from wells drilled in } \\
\text { Marcellus Shale at } 14 \text { days } \\
\text { post hydraulic fracturing }\end{array}$ \\
\hline Total Suspended Solids (TSS) & $\mathrm{mg} / \mathrm{L}$ & $10.8-3,220$ & $17-1,150$ \\
\hline Turbidity & NTU & $2.3-1.540$ & $10.5-1,090$ \\
\hline Total Dissolved Solids (TDS) & $\mathrm{mg} / \mathrm{L}$ & $38,500-238,000$ & $3,010-261,000$ \\
\hline Specific Conductance & umhos/cm & $79,500-470,000$ & $6,800-710,000$ \\
\hline Total Organic Carbon (TOC) & $\mathrm{mg} / \mathrm{L}$ & $3.7-388$ & $1.2-509$ \\
\hline Dissolved Organic Carbon (DOC) & $\mathrm{mg} / \mathrm{L}$ & $30.7-501$ & $5-695$ \\
\hline Chemical Oxygen Demand (COD) & $\mathrm{mg} / \mathrm{L}$ & $195-17,700$ & $228-21,900$ \\
\hline Biochemical Oxygen Demand (BOD) & $\mathrm{mg} / \mathrm{L}$ & $37.1-1,950$ & $2.8-2,070$ \\
\hline BOD/COD Ratio ( $\%$ biodegradable) & & & $0.1(10 \%)$ \\
\hline Alkalinity & $\mathrm{mg} / \mathrm{L}$ & $48.8-327$ & $26.1-121$ \\
\hline Acidity & $\mathrm{mg} / \mathrm{L}$ & $<5-447$ & $<5-473$ \\
\hline Hardness (as $\mathrm{CaCO}_{3}$ ) & $\mathrm{mg} / \mathrm{L}$ & $5,100-55,000$ & $630-95,000$ \\
\hline Total KjeldahI Nitrogen (TKN) & $\mathrm{mg} / \mathrm{L}$ as $\mathrm{N}$ & $38-204$ & $5.6-261$ \\
\hline Ammonia Nitrogen & $\mathrm{mg} / \mathrm{L}$ as $\mathrm{N}$ & $29.4-199$ & $3.7-359$ \\
\hline Nitrate-N & $\mathrm{mg} / \mathrm{L}$ as $\mathrm{N}$ & $<0.1-1.2$ & $<0.1-0.92$ \\
\hline Chloride & $\mathrm{mg} / \mathrm{L}$ & $26,400-148,000$ & $1,670-181,000$ \\
\hline Bromide & $\mathrm{mg} / \mathrm{L}$ & $185-1,190$ & $15.8-1,600$ \\
\hline Sodium & $\mathrm{mg} / \mathrm{L}$ & $10,700-65,100$ & $26,900-95,500$ \\
\hline Sulfate & $\mathrm{mg} / \mathrm{L}$ & 2.4-106 & $<10-89.3$ \\
\hline Oil and Grease & $\mathrm{mg} / \mathrm{L}$ & $4.6-655$ & $<4.6-103$ \\
\hline $\begin{array}{l}\text { BTEX (benzene, toluene, } \\
\text { ethylbenzene, xylene) }\end{array}$ & $\mu \mathrm{g} / \mathrm{L}$ & & Non-detect $-5,460$ \\
\hline VOC (volatile organic compounds) & $\mu \mathrm{g} / \mathrm{L}$ & & Non-detect-7,260 \\
\hline $\begin{array}{l}\text { Naturally occurring radioactive } \\
\text { materials (NORM) }\end{array}$ & $\mathrm{pCi} / \mathrm{L}$ & \multicolumn{2}{|c|}{ Non-detect-18,000 pCi/L; median $2,460 \mathrm{pCi} / \mathrm{L}$} \\
\hline Barium & $\mathrm{mg} / \mathrm{L}$ & $21.4-13,900$ & $43.9-13,600$ \\
\hline Strontium & $\mathrm{mg} / \mathrm{L}$ & $345-4,830$ & $163-3,580 \mathrm{~J}$ \\
\hline Lead & $\mathrm{mg} / \mathrm{L}$ & Non-detect-0.606 & Non-detect-0.349 \\
\hline Iron & $\mathrm{mg} / \mathrm{L}$ & $21.4-180$ & $13.8-242$ \\
\hline Manganese & $\mathrm{mg} / \mathrm{L}$ & $0.881-7.04$ & $1.76-18.6$ \\
\hline
\end{tabular}

1 T. Hayes, Gas Technology Institute, Sampling and Analysis of Water Streams Associated with the Development of Marcellus Shaie Gas, report prepared for Marcellus Shaie Coalition, December 2009, http:/wwww.bucknell.edu/script/environmentaicenter/marcellus/default.aspx?articleid=14; E.L. Rowan et al., Radium Content of Oil- and Gas-Field Produced Waters in the Northern Appalachian Basin (USA): Summary and Discussion of Data, 2011, 31, http:/fpubs.usgs.gov/ sir/2011/5135/pdf/sir2011-5135.pdf.

" These data are from a single source (Hayes، "Sampling and Analysis of Water Streams"), with the exception of NORM (from Rowan et al., "Radium Content of Oil- and Gas-Field Produced Waters"). NORM data did not specify how long after well completion the samples were taken, and thus cannot be associated with either 5 or 14 days post hydraulic fracturing. BTEX and VOC data provided here have significant uncertainty. Data marked $\mathrm{J}$ are estimated due to analytical limitations associated with very high concentrations. Extensive data on produced water quality throughout the United States are available isee energy.cr.usgs. gov/prov/prodwat/intro.htm). Additional data specific to Narcellus are available from a variety of sources ( produced water treatment plants, PADEP, drilling companiesi. although they have not been collated into a single database, making summative analysis difficult. 
Because of these risks, shale gas wastewater must be carefully managed. The most common management options currently in use are recycling for additional hydraulic fracturing, treatment and discharge to surface waters, underground injection, storage in impoundments and tanks. and land application (road spreading). All of these options present some risk of harm to health or the environment. so they are regulated by the federal government and the states. But many of the current regulatory programs are not adequate to keep people and ecosystems safe. Consequently, this paper concludes with policy recommendations regarding how the regulation of shale gas wastewater management should be strengthened and improved.

\section{MANAGEMENT OPTIONS FOR SHALE GAS WASTEWATER}

There are five basic options to manage wastewater generated during the production of natural gas from shale formations: minimization of produced water generation, recycling and reuse within gas drilling operations, treatment, disposal, and beneficial reuse outside of operations. On-site options associated with minimization, recycling, and reuse are used mostly for water during the flowback period; off-site treatment and disposal methods dominate the management of produced water.
Minimization and Recycling/Reuse. Minimization of wastewater generation and recycling/reuse within operations take place at the well site during drilling. While these have not been popular management choices in oil and gas drilling previously, they are increasingly being used in the Marcellus Shale because traditional off-site disposal methods are not often available in close proximity to wells. On-site recycling can have significant cost and environmental benefits as operators reduce their freshwater consumption and decrease the amount of wastewater destined for disposal. However, it can generate concentrated residual by-products (which must be properly managed) and can be energy-intensive.

Disposal. Direct discharge of wastewater from shale gas wells to surface waters is prohibited by federal law. Consequently, when operators want to dispose of wastewater with little or no treatment, they do so predominantly through underground injection. Disposal through underground injection requires less treatment than other management methods, and when done with appropriate safeguards, it creates the least risk of wastewater contaminants' being released into the environment. However, it does create a risk of earthquakes and can require transportation of wastewater over long distances if disposal wells are not located near the production well. Almost all onshore produced water in the U.S. (a category that includes natural gas produced water) is injected, either for disposal or to maintain formation

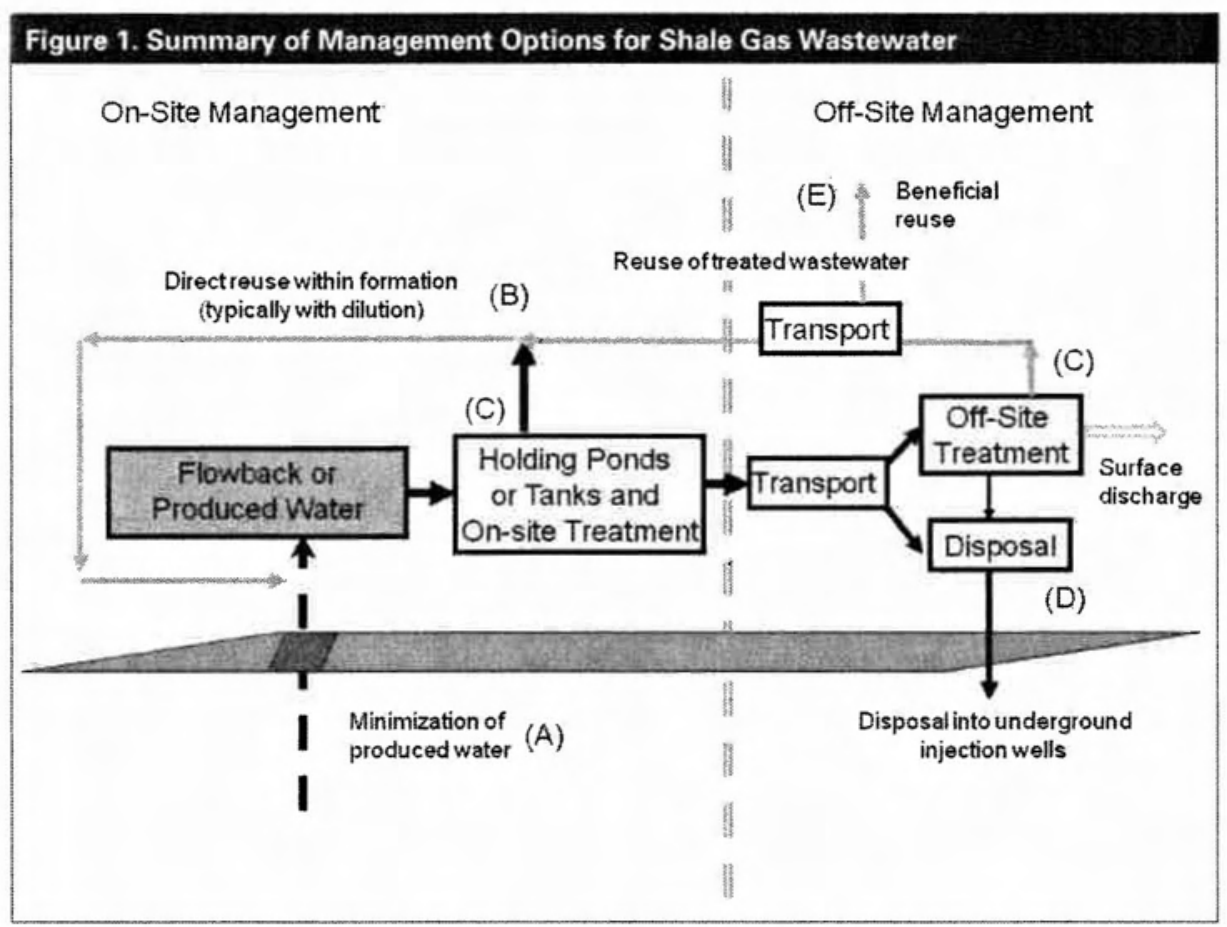

PAGE 3 | In Fracking's Wake: Wew Fules are Neoded to Protect Our thegth and Enwronment from Contaninated Wastewater 
pressure in oil fields. Marcellus wastewater is often transported to injection wells in Pennsylvania, Ohio, and West Virginia.

Treatment. Treatment is the most complex management option. It can occur on-site or off-site and in conjunction with recycling/reuse, discharge, and disposal. While treatment can be costly and energy-intensive, all methods of wastewater management generally involve some form of treatment - e.g., to prepare wastewater for subsequent reuse in gas development or for injection into disposal wells, or to generate clean water for discharge or partially treated water and/or residuals for beneficial reuse.

When wastewater is bound for subsequent reuse within hydraulic fracturing operations or for injection in disposal wells, treatment focuses on removing organic contaminants and inorganic constituents that can cause the fouling of wells. Treatment for other objectives-to produce a water clean enough for reuse or discharge, or to produce a brine or solid residual for subsequent reuse-may include additional, targeted removal of other constituents.

Shale gas operators in some regions, including the Marcellus, have sent wastewater to publicly owned treatment works (POTWs) for treatment, but this practice can have serious environmental consequences. With regard to salts, among the most prevalent contaminants in Marcellus wastewater, POTWs do not provide any meaningful treatment at all because they are not designed to remove dissolved solids; most salts that enter POTWs will be discharged directly to receiving water bodies. Additionally, high concentrations of salt, organics, and heavy metals in wastewater can disrupt the treatment process in POTWs. Consequently, sending wastewater to POTWs without pretreatment to remove salts is generally no longer permitted in Pennsylvania. (Some POTWs were exempted from state regulations requiring pretreatment, but they have been asked voluntarily to stop accepting shale gas wastewater.)

An alternative to POTW treatment for removal of suspended solids and organic constituents is treatment at dedicated brine or industrial wastewater facilities, also called centralized waste treatment (CWT) facilities. These plants use many of the same treatment processes that are found in POTWs but may also add coagulation and precipitation techniques to remove dissolved solids. However, while CWTs may be designed to remove more pollutants from wastewater than POTWs do, their discharges may still contain high levels of pollutants such as bromide. Brine treatment plants have been operating in the Marcellus production basin for many decades. After treatment at a CWT, water can be discharged to a surface water body or discharged to sewers for subsequent discharge from a POTW.
Beneficial Reuse. The beneficial reuse of oil and gas brines has a long history in many states. In many areas, produced water is used for dust control on unpaved roads and for deicing or ice control on roads in northern climates during the winter. Such application of Marcellus brines to roadways is permitted in Pennsylvania, provided the brines meet certain water quality requirements. Selling wastewater to local governments for this use allows gas operators to recover some of their treatment and management costs, but applying wastewater onto land surfaces increases the risk that pollutants will be washed into nearby water bodies or leach into groundwater.

Management Options for Residuals. In addition to the treated wastewater, all treatment methods produce residuals-waste materials, mostly in solid, sludge, or liquid form, that remain after treatment. In the Marcellus region and elsewhere, solids and sludges are managed through conventional processes: land application or landfill, depending on their characteristics. Highly concentrated liquid brine wastes (i.e., highly salty water) have the same disposal options as the original produced waters, at lower transportation costs. The most common disposal option for concentrated brines from desalination is deep well injection. If desalination brines are sent to treatment facilities that are not subject to discharge limits on dissolved solids (as is often the case with POTWs), the benefits of concentrating these wastewaters are completely lost.

Use of These Practices in Pennsylvania in 2011. Based on data from the Pennsylvania Department of Environmental Protection, in 2011, about half of all wastewater from shale gas production in Pennsylvania was treated at CWTs that are subject to the state's recently updated water pollution discharge limits, described below. (It is not possible to determine from the data what volumes of wastewater treated at CWTs were subsequently discharged to surface waters, reused, or disposed of in another way.) About onethird was recycled for use in additional hydraulic fracturing. Less than one-tenth was injected into disposal wells, and a similar amount was treated at CWTs not subject to updated treatment standards. Less than 1 percent was treated at POTWs. The remainder (less than 1 percent) was reported as in storage pending treatment or disposal.

From the first half to the second half of 2011, total reported wastewater volumes more than doubled. Treatment at CWTs increased nearly four-fold, even as wastewater volumes directed to "exempt" CWTs decreased by 98 percent. Deepwell injection more than tripled, and re-use in fracking operations increased by about 10 percent. Treatment at POTWs was virtually eliminated. 
Figure 2. Technologies for Removing Oil, Grease, and Organics from Produced Water.

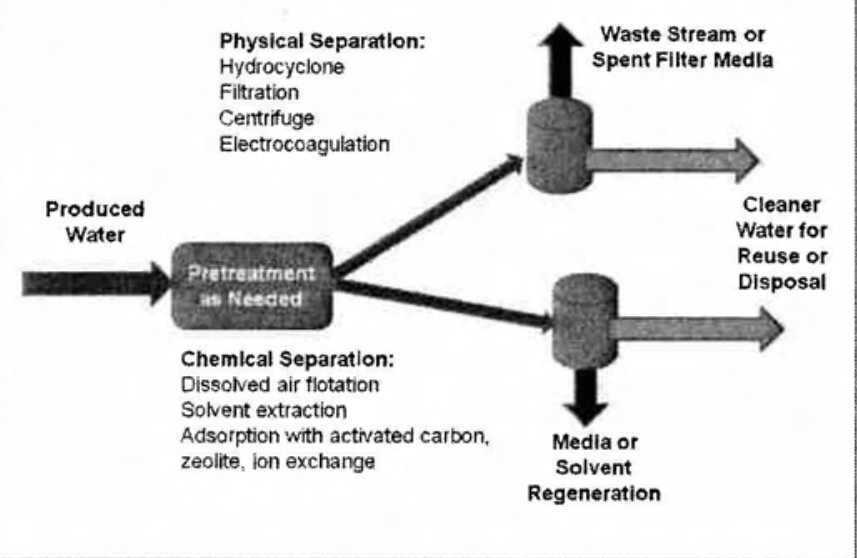

\section{TECHNICAL ANALYSIS OF TREATMENT METHODS}

Many technologies are available for treating shale gas wastewater. Regardless of the ultimate fate of the wastewater, some degree of treatment is typically necessary. The choice of a specific treatment method will depend on the nature and concentration of the contaminants in the wastewater as well as the intended disposition of the treated water, which determines the necessary levels of pollutant reduction.

Discharge to surface waters requires extensive treatment to protect drinking water supplies and aquatic ecosystems. Reuse may require partial treatment to avoid reintroducing into the next well contaminants that will affect production. Wastewater used in road spreading may also require treatment to reduce pollutant concentrations in runoff. Similarly, when wastewater is injected into disposal wells, partial treatment is often done to minimize the risk of clogging the well.

For any given drilling operation, once the wastewater is characterized and the necessary water quality is known, a treatment system made up of different components can be selected. Treatment begins with removal of suspended solids, inorganic or organic, and then removal of dissolved organics and potentially scale-forming constituents. When all that remains is simple dissolved salts, desalination can be done, as would often be necessary for discharge to surface waters. Additionally, high levels of NORM will require special handling.
Figure 3. Technologies for Removing Dissolved lonic Constituents from Produced Water

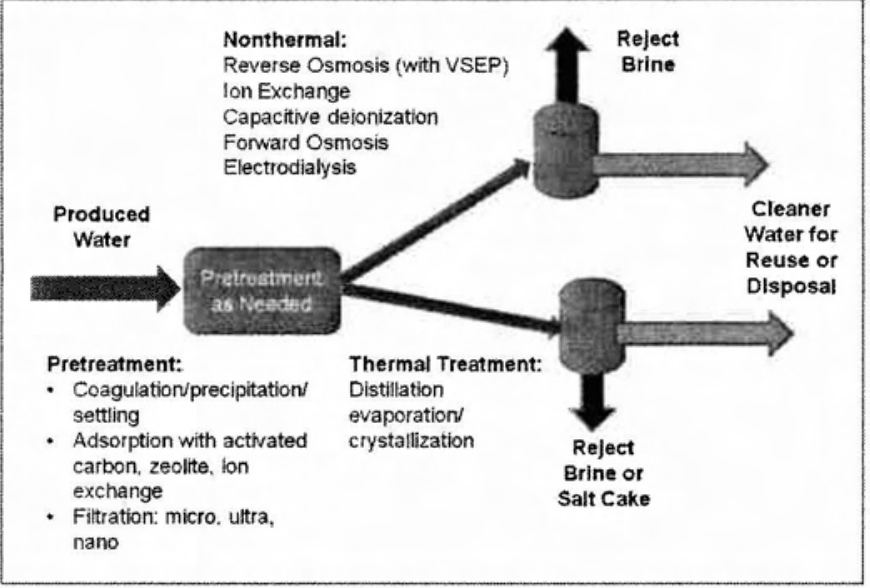

Other factors can also influence the selection of appropriate treatment methods, such as the energy intensity of a treatment method and the nature of the residuals generated by treatment. For all types of treatment, the separation of the contaminant from the water will generally require significant chemical and energy inputs, depending upon the process, the quality of the influent wastewater, and the desired quality of the effluent finished water. Likewise, all treatment methods generate a residual waste that contains the contaminants that have been removed or the by-products of their transformation. This residual can be a liquid stream, a solid or sludge product, or a gaseous stream, and it must be managed appropriately to avoid environmental harms. For example, brines and sludges created through treatment processes can be disposed of as solid waste or sent to disposal wells.

Applicable treatment technologies involve chemical, physical, and/or biological processes. These include settling, filtration, coagulation, centrifugation, sorption, precipitation, and desalination. Desalination can be achieved through thermal methods (like vapor compression, distillation, multistage flash, dew vaporization, freeze-thaw, evaporation, and crystallization) or non-thermal methods (like reverse osmosis, nanofiltration, electrodialysis, electrodeionization, capacitative deionization, membrane distillation, and forward osmosis). In Pennsylvania, treatment plants use a wide range of technologies like these; however, because desalination is the most energy intensive, many facilities treat only up to the point at which desalination would occur and then repurpose the water for additional activities in oil and gas development. 


\section{POTENTIAL WATER IMPACTS OF SHALE GAS WASTEWATER MANAGEMENT}

Wastewater associated with hydraulic fracturing itself and, later, with the production of gas from a fractured well must be managed to avoid environmental harms. However, many of the available management techniques may directly cause environmental harm due to the release of pollutants to surface waters, soil, and groundwater.

On-Site Impoundments and Tanks. As with any liquid material in storage, accidental spills and mismanagement can cause releases to the environment that could contaminate nearby waters and soils. Open impoundments, also called pits, are typically subject to requirements designed to minimize the risk of contamination, though the adequacy of those requirements varies from place to place. Closed tanks are also sometimes used for collection of produced water during the flowback period. sometimes with secondary containment, a best management practice where the tank sits within a traylike structure with raised sides, such that materials released during a tank rupture would be contained and not leach into soil or travel to nearby waterways.

Impacts Away from the Well Site. The most significant potential for water impacts from shale gas wastewater is associated with the long-term production of water from the well and occurs away from the well site. Produced water is generally shipped off-site for management and disposal, at which point pollutants in wastewater can be intentionally released directly to the environment, either with or without appropriate treatment and safeguards to limit pollution discharges. Additionally, at any of the locations where produced water is handled, accidental releases can occur, and best practices and good management are necessary to avoid accidents, as are contingency plans to reduce the impact of accidental releases.

Deep Well Injection. Underground injection of wastewater is designed to isolate materials that could cause harm if released to the biosphere. A U.S. Environmental Protection Agency (EPA) risk analysis determined that injection via strictly regulated Class I hazardous waste wells is a safe and effective technology that presents a low risk to human health and the environment. Additional studies have confirmed this assessment. However, oil and gas wastes are currently injected into Class II disposal wells, which are subject to fewer safety requirements and therefore pose a greater risk of contaminating groundwater and triggering earthquakes. Partial treatment of produced water, either prior to injection or at the injection well facility, is often used to reduce the likelihood of well clogging.
Surface Water Discharge. Inadequate treatment at a CWT or POTW followed by discharge of treated water can pollute surface waters-including drinking water sourcesdownstream of the discharge. If quantities or concentrations of contaminants in the discharge are too high, or if the receiving water lacks adequate assimilative capacity, the pollution can seriously harm ecosystems and human health. Some contaminants (e.g., benzene, toluene, ethylbenzene, and xylenes) are directly toxic to ecosystems or people; others interact in the environment to produce unwanted effects (e.g., nutrients like ammonia that can encourage harmful algal blooms). Some are a concern because they can affect the beneficial use of the water downstream (e.g., sulfate. which can make drinking water taste bad), and still others can disrupt ecosystems (e.g., chloride, which alters fish reproduction).

Land Application. Application of produced water to roads for dust control has several potential impacts. Rainfall and snowmelt wash salts and other chemicals off roadways, which can result in stream or groundwater contamination. The potential for such harm increases when application rates are high or take place in close proximity to rainfall events. Moreover, when produced waters are used for road spreading, they may replace equally effective dust suppressant and deicing agents while resulting in higher levels of chloride pollution to surface water and groundwater (due to higher concentrations or more frequent application).

Residuals Management. Regardless of the treatment option selected, residuals - the concentrated brines and solids containing the chemicals removed from the produced water-will be created as a by-product. Since chemicals in these residual wastes are present at higher concentrations than in the original produced waters, careful management is essential to avoid undermining the value of the treatment process through release of residuals to the environment. For example, in light of the high pollutant concentrations, surface water discharge of residual brines or land or road application of brines or solid salts produced through treatment can result in watershed impacts equal to, or greater than, the potential impact of the original produced water.

\section{REGULATORY FRAMEWORK FOR SHALE GAS WASTEWATER}

A number of federal and state statutes and regulations govern the treatment, disposal, and reuse of shale gas wastewater. These regulations are intended to minimize or eliminate the risk of harm from exposure to wastewater pollutants, but many regulatory programs are not adequately protective. 
and several even have complete exemptions for shale gas wastewater (or exemptions for oil and gas wastewater of all kinds, including Marcellus Shale wastewater).

Treatment and Discharge to Water Bodies. The Federal Water Pollution Control Act, more commonly called the Clean Water Act, regulates the treatment and discharge of shale gas wastewater into surface water bodies. Under the Act, facilities must obtain permits if they intend to discharge shale gas wastewater, or any by-product resulting from treatment of that wastewater, into a surface water body. These permits contain limitations on pollutants that may be discharged in the wastewater.

Federal regulations completely prohibit the direct discharge of wastewater pollutants from point sources associated with natural gas production. Instead of discharging wastewater directly to surface waters, then, many hydraulic fracturing operators send wastewater to treatment facilities that are authorized to discharge under Clean Water Act permits issued (typically) by the states under authority delegated by the EPA. These facilities include POTWs and CWTs. EPA regulations set pretreatment requirements for the introduction of industrial wastewater to POTWs (known in EPA regulations as "indirect discharge") and for the discharge of industrial wastewater from CWTs. However, the Clean Water Act regulatory program is not comprehensive; for example, there are no pretreatment requirements specifically for shale gas wastewater, and discharge standards for CWTs are out of date.

States may also establish requirements for these discharges that are stricter than the federal standards. For example, the Pennsylvania Department of Environmental Protection (PADEP) has issued regulations implementing the Clean Water Act and the state's Clean Streams Law with industrial waste discharge standards. In 2010 PADEP finalized revisions to state regulations addressing the discharge to surface waters of wastewater from natural gas operations. The regulations prohibit the discharge of "new and expanding" discharges of shale gas wastewater unless the discharge is authorized by a state-issued permit. Such discharges may be authorized only from CWTs; POTWs may be authorized to discharge new or increased amounts of shale gas wastewater only if the wastewater has been treated at a CWT first.

Underground Injection. The federal Safe Drinking Water Act (SDWA) regulates the underground injection of wastewater. SDWA establishes the Underground Injection Control (UIC) program. This program is designed to prevent the injection of liquid wastes into underground sources of drinking water by setting standards for safe wastewater injection practices and banning certain types of injection altogether. All underground injections are prohibited unless authorized under this program.
Under the UIC program, the EPA groups underground injection wells into five classes, with each class subject to distinct requirements and standards. Because of a regulatory determination by the EPA not to classify shale gas wastewater as "hazardous" (discussed below), it is not required to be injected into Class I wells for hazardous waste. Rather, shale gas wastewater may be injected into Class II wells for fluids associated with oil and gas production. Class II wells are subject to less stringent requirements than Class I hazardous waste wells.

In the Marcellus region, Maryland, Ohio, and West Virginia have assumed primacy and implement the UIC program. New York, Virginia, and Pennsylvania have not assumed primacy, so the EPA directly implements the UIC program in those states.

Reuse for Additional Hydraulic Fracturing. In contrast to the injection of shale gas wastewater as a disposal practice, the injection of fluids (which may include recycled wastewater) for the hydraulic fracturing process itself is exempted from regulation under the federal Safe Drinking Water Act. As a result, if shale gas wastewater is managed or treated for the sole purpose of reuse for further hydraulic fracturing, it is not subject to federal regulation.

However, states can have their own regulations that apply to the reuse of shale gas wastewater. In Pennsylvania, facilities that process wastewater for beneficial reuse may be authorized under PADEP-issued general permits, which establish generally applicable standards. Operations authorized under these general permits do not require individualized permits for wastewater processing.

Impoundments. Because of an exemption from federal law (discussed below), the storage and disposal of shale gas wastewater in impoundments is regulated solely by the states. In Pennsylvania, facilities that store and dispose of shale gas wastewater in impoundments must obtain permits under PADEP solid waste regulations, which contain construction and design specifications and operating requirements for those impoundments. Pennsylvania has also enacted a law that limits the ability of municipalities to regulate the siting of impoundments; several municipalities are challenging this law in court.

Land Application. Because of an exemption from federal law (discussed below), the land application of shale gas wastewater is regulated primarily at the state level. While Pennsylvania's oil and gas well regulations generally prohibit operators of oil and gas wells from discharging brine and other produced tluids onto the ground, the state's solid waste management regulations state that PADEP may issue permits authorizing land application of waste. Using this authority, PADEP has issued a general permit authorizing 
the application of natural gas well brines specifically for roadway prewetting, anti-icing, and deicing purposes as long as the brines meet certain pollutant concentration limits. In some other states, however, the road spreading of shale gas wastewater is prohibited.

Handling, Storage, and Transport Prior to Disposal. State regulations govern the handling, storage, and transport of shale gas wastewater prior to its ultimate disposal. Oil and gas wastes are currently exempt from the federal Resource Conservation and Recovery Act (RCRA), which generally regulates the handling and disposal of waste. A 1980 amendment to the statute exempted oil and gas wastes from coverage under RCRA for two years. In the meantime, it directed the EPA to determine whether regulation of those wastes under RCRA was warranted. In 1988, the EPA made a determination that such regulation was not warranted. Consequently, oil and gas wastes remain exempt from the hazardous waste provisions of RCRA. This means that natural gas operators transporting shale gas wastewater, along with the POTWs, CWTs, and any other facilities receiving it, are not transporting or receiving "hazardous" wastes and thus do not need to meet the cradle-to-grave safeguards established by RCRA regulations.

In the absence of federal regulations, states regulate the handling, storage, and transport of shale gas wastewater. In Pennsylvania, wastewater from industrial operations is classified as nonhazardous, and it must be managed and disposed of in accordance with the state's Solid Waste Management Act.

Residual Waste. Residual wastes are subject to various regulations depending on their composition (liquid or solid) and method of disposal (surface water discharge, injection, land application, etc.). Many of the regulatory issues described above arise with residuals as well.

\section{POLICY RECOMMENDATIONS}

The current regulation of shale gas wastewater management, treatment, and disposal is inadequate because it fails to safeguard against foreseeable risks of harm to human health and the environment. Government oversight of wastewater treatment and disposal must be improved at both the federal and the state level.

Treatment and Discharge to Water Bodies. Currently, discharge of pollutants in shale gas wastewater is allowed in amounts and concentrations inadequate to protect water quality. The EPA and the states must develop limits both on the discharge of shale gas wastewater from POTWs and CWTs and on the amount of pollution allowable in surface water bodies. a The EPA and the states should ban or more strictly regulate the discharge of shale gas wastewater to POTWs.

- The EPA and the states should update pollution control standards for CWTs that accept shale gas wastewater.

- The EPA and the states should develop water quality criteria for all chemicals in shale gas wastewater. Water quality criteria are numeric limitations on pollutants in a particular water body that are adequate to support the water body's designated uses.

a The EPA and the states should identify water bodies impaired by pollutants in shale gas wastewater, or with the reasonable potential to become impaired, and should require reductions in pollution loads to those waters.

* The EPA and the states should protect water bodies not yet impaired by shale gas wastewater.

Handling, Storage, and Transport Prior to Disposal. Improper handling, storage, or transport of shale gas wastewater can lead to spills and other releases of pollutants that contaminate land and water with toxic or radioactive material.

s Congress or the EPA should eliminate the RCRA hazardous waste exemption for shale gas wastewater and subject such wastewater to regulation as "hazardous waste" in cases where it does, in fact, display physical and chemical characteristics that qualify as hazardous.

s Regardless of whether the federal RCRA exemption is eliminated, states can and should classify shale gas wastewater as hazardous when it meets relevant technical criteria and should regulate it accordingly.

a States should require regular testing of shale gas wastewater to assess whether wastewater from any given source, at any given time, possesses hazardous characteristics.

Underground Injection. Injection into wells creates a risk that injection fluids will migrate into sources of drinking water, as well as a risk of triggering earthquakes. These unnecessary risks should be minimized.

Wastewater with hazardous characteristics should be injected into Class I hazardous waste wells, which are subject to regulations more stringent than those governing Class II wells. This can be achieved if Congress or the EPA eliminates the RCRA hazardous waste exemption for oil and gas wastes, or if the EPA amends UIC program regulations.

In the interim, states should use their authority to more strictly regulate Class II wells for oil and gas wastewater. 
Reuse for Additional Hydraulic Fracturing. The hydraulic fracturing process itself should be federally regulated. However, when fracking occurs, reuse of wastewater for additional hydraulic fracturing can offer many benefits (although these benefits can in some cases be offset by energy use and the generation of concentrated residuals). Where appropriate, states should encourage or even require the reuse and recycling of shale gas wastewater.

angress should eliminate the Safe Drinking Water Act exemption for hydraulic fracturing to ensure that injection of fracturing fluid will not endanger drinking water sources.

When the benefits of recycling outweigh disadvantages, states should encourage or require reuse of shale gas wastewater in the hydraulic fracturing process.

Impoundments and Tanks. States should prohibit or strictly regulate impoundments to minimize the risk of spills or leakage.

States should not allow the storage or disposal of shale gas wastewater in open impoundments. Flowback and produced water should be collected at the well and either recycled or directly routed to disposal. In the event that storage of wastewater is necessary, it should be done in closed tanks.

If states do not prohibit impoundments, they should regulate them more strictly with regard to location, construction, operation, and remediation.

States should also regulate closed storage tanks more strictly; this regulation should require, among other things, secondary containment.

Land Application. Because application of shale gas wastewater to land and roadways can lead to environmental contamination through runoff of toxic pollutants into surface waters, it should be prohibited, or at minimum strictly regulated.

in States should prohibit the land application or road spreading of shale gas wastewater. Other available substances are equally effective but have less environmental impact, and these should be used on roads for dust suppression and de-icing.

: If land application and road spreading are not prohibited, they should only be authorized subject to strict limits on pollutant concentrations and required preventive measures to limit runoff.
The EPA and states should enforce existing Clean Water Act requirements for controlling polluted runoff from municipal storm sewer systems to ensure that any road spreading does not violate those requirements. The EPA should also complete its ongoing development of new rules to strengthen the CWA stormwater regulatory program.

Residual Waste. Just as shale gas wastewater should not be categorically exempt from RCRA hazardous waste regulations, residual waste derived from the treatment of that wastewater should not be exempt from regulation if it displays the characteristics of a hazardous waste.

Shale gas wastewater treatment residuals should be subject to RCRA's hazardous waste regulations. Congress or the EPA should require that residual waste with hazardous characteristics be regulated as hazardous by eliminating the RCRA hazardous waste exemption for oil and gas wastes.

Public Disclosure. Regardless of which treatment or disposal method an operator uses to manage its shale gas wastewater, it should be required to publicly disclose the final destination of the waste.

Model Regulations. The federal Bureau of Land Management (BLM) regulations now under development for hydraulic fracturing activities on federal lands should be as protective of health and environment as possible and should include at minimum (to the extent BLM has regulatory jurisdiction) all recommendations set forth in this paper. Since BLM has expansive authority over development of federal oil and gas resources and other activities on federal lands, strong BLM rules could serve as model regulations on which states could base their own.

NRDC supports establishing a fully effective system of safeguards to ensure that natural gas is produced, processed, stored, and distributed in a way that helps protect our water, air, land, climate, human health, and sensitive ecosystems. NRDC opposes expanded fracking until effective safeguards are in place. For more information on NRDC's position on natural gas and fracking, go to http://www.nrdc.org/energy/ gasdrilling/. 


\section{Introduction}

Natural gas development has exploded at breakneck speed in recent years, fueled by advances in an extraction technique known as hydraulic fracturing (or "fracking"), which has allowed the oil and gas industry to access previously out-of-reach reserves. Unfortunately, federal and state safeguards to protect people and the environment from the hazards of fracking have not kept pace. As a result, this development has proved dangerous, destructive, and polluting.

This paper describes the health and environmental risks from one aspect of fracking: polluted wastewater generated by the fracturing process. It evaluates the available methods for management of those wastes, identifies the shortcomings of the existing regulatory regime, and offers recommendations for improving regulations to protect public health and the environment. Ultimately, the problem of managing this wastewater is one for which there are no easy answers, and one that many regulators are not adequately prepared to address.

\section{Overview of Hydraulic Fracturing and Wastewater Generation}

Natural gas is found in underground layers of rock referred to as formations. Shale gas formations are generally tighter and much less permeable than other formations, causing the gas to be much less free-flowing. ${ }^{1}$ The Marcellus Shale, of particular focus in this paper, is one such formation. The Marcellus is the largest shale gas play in the United States by geographic area-it spans six states: New York, Pennsylvania, Ohio, Maryland, Virginia, and West Virginia- - and contains the greatest total quantity of technically recoverable gas. ${ }^{2}$

Shale gas is often referred to as "unconventional" gas. Whereas "conventional" sources of oil and gas are generally produced using traditional methods of drilling and pumping, unconventional oil and gas sources generally require more complex and expensive technologies for production. ${ }^{3}$ Along with shale, other sources of unconventional gas include coal seams and impermeable sandstone formations. ${ }^{4}$ As of 2008 , unconventional production accounted for 46 percent of total U.S. natural gas production. ${ }^{5}$

In the case of shale gas, the technology used for production is known as hydraulic fracturing. Hydraulic fracturing involves the injection of liquid under pressure to fracture the rock formation and prop open the fractures, allowing natural gas to flow more freely from the formation into the well for collection. ${ }^{6}$ The development of hydraulic fracturing technology, along with advances that allow the horizontal drilling of wells, has facilitated the expansion of shale gas development over the past 20 years. Prior to these innovations, shale gas development was not viewed as economically feasible, but recently such development has exploded. ${ }^{7}$ The first economically producing wells in the Marcellus were drilled in 2003; in 2010, 1,386 Marcellus wells were drilled in Pennsylvania alone (up from 763 drilled in 2009). ${ }^{8}$

The liquids used in the hydraulic fracturing process consist primarily of water, either fresh or recycled, along with chemicals used to modify the water's characteristics (for example, to reduce friction or corrosion) and sand or other agents, referred to as "proppants," that hold open the fractures in the formation. ${ }^{9}$

The process of producing natural gas via this process yields by-products that must be managed as part of the operation's waste stream, and these by-products present significant risks to human 
health and the environment if not managed properly. This paper focuses on the wastewater that returns to the surface of the well after the fracturing process.

When the pressure used to inject the fracturing fluid into the well is released, some of the fluid returns to the surface during what is known as the "flowback" period. This period lasts approximately 10 to 14 days, or until the well begins natural gas production. Water that returns to the surface during the flowback period is usually called "flowback water" or just "flowback." Its characteristics are defined by the chemicals added to it and the chemicals present in the shale that are released into the water during contact. Flowback volumes in shale formations range from 10 to 25 percent of the fracturing fluid originally injected into the well, or approximately 10,000 to 60,000 barrels ( 420,000 to $2,520,000$ gallons) per well for each hydraulic fracture, depending on the characteristics of the formation. ${ }^{10, \mathrm{a}}$

Once gas production begins at the well, all wastewater emerging from the well is called "produced water" or "production phase water." The characteristics of produced water are generally less related to the chemicals used in the fracturing operation and more related to the geochemistry of the formation. Concentrations of formation-derived chemicals in produced water generally increase over the lifetime of the well, while the overall volume of produced water may remain stable or decline with time. Long-term produced water volumes range from 200 to 1,000 gallons per million cubic feet of gas produced, depending on the formation, typically at a rate of 2 to 10 barrels ( 84 to 420 gallons) per day. ${ }^{11}$ Because the lifetime of a shale gas well can extend to 40 years, the total amount of produced water generated can reach into the millions of gallons. ${ }^{12}$ However, each shale formation yields different volumes of produced water. The Marcellus Shale is a relatively dry formation, generating less produced water than other formations around the country (though the amount generated is still significant). ${ }^{13}$

Both types of wastewater - flowback and production phase water-contain potentially harmful constituents. These constituents can be broadly grouped into several principal categories: salts (often expressed as total dissolved solids, or TDS), organic hydrocarbons (sometimes referred to as "oil and grease"), metals, chemical additives (from the fracturing fluid), and naturally occurring radioactive material (NORM). Because of these constituents, shale gas wastewater must be carefully managed to prevent harm to human health and the environment. If wastewater is accidentally spilled onto nearby lands or into local waters, or if it is intentionally released into the environment without adequate treatment, exposure to the pollutants it contains can be dangerous to people and ecosystems.

The same types of management practices are generally used for the two types of wastewater, so this paper discusses the two separately only when differences in their chemical composition or spatiotemporal availability make their management options distinct. Throughout the paper (and particularly in its technical chapters), the inclusive term "produced water" is often used to refer to both flowback and production phase water without distinction, as flowback is technically considered a subset of produced water. The generic term "wastewater" is also intended to refer to both types without differentiating between them.

\footnotetext{
${ }^{a}$ An individual shale gas well is typically fractured 10 to 16 times. One barrel is equal to 42 gallons.
} 


\section{Topics Addressed in this Paper}

This paper consists of two main parts. Chapters 1 through 3 detail the technical considerations relating to management of shale gas wastewater. Chapters 4 and 5 describe the current regulatory regime and offer recommendations for improving those regulations to protect human health and the environment.

Specifically, Chapter 1 broadly describes the various management options available for wastewater produced during shale gas development. These management options include the recycling of wastewater for additional hydraulic fracturing, disposal in injection wells, discharge to surface waters, and land application. Chapter 2 presents a more detailed technical overview of specific wastewater treatment methods and how those methods are selected for specific wastewaters. As the chapter describes, the quality of the wastewater and the desired destination or use of the wastewater dictate the options for treatment. Chapter 3 presents a description of potential water-related environmental and health impacts that can result from the various management options. This overview considers both the effects of current management practices on water resources and the impacts that could be mitigated through changes in those practices.

Chapter 4 summarizes the current regulatory framework governing shale gas wastewater management options. This chapter describes relevant statutes and regulations at the federal level and the state level in Pennsylvania and identifies some of their key limitations. Finally, Chapter 5 presents policy recommendations regarding how the current regulatory approach - which is inadequate in many ways - should be improved to prevent harmful impacts to health and the environment.

\section{Topics Not Addressed in this Paper}

Due to the breadth and depth of this topic, there are certain issues relating to the management of shale gas wastewater that we do not attempt to address in this paper, although they can present important environmental concerns in their own right. These include:

- Non-water-related impacts of wastewater management (with limited exceptions). Such impacts include air emissions from open wastewater storage pits and trucks used to haul wastewater, noise and traffic impacts from those trucks, soil contamination, land disturbance impacts from the construction of wastewater management facilities, and energy demand associated with wastewater treatment processes.

- Impacts of spills during off-site transport of wastewater. Such spills may result from accidents, from inadequate management or training, or from illicit dumping. Major spills from trucks carrying shale gas wastewater have occurred in Pennsylvania; indeed, spills and leaks account for many of the environmental violations cited in connection with shale gas development by the Pennsylvania Department of Environmental Protection. ${ }^{14}$

- Waste generated while a well is being drilled (before fracturing fluid is injected). Waste generation during drilling consists of drilling muds and cuttings. This waste is stored onsite; drilling muds are often recycled, and cuttings are dewatered and disposed of as solid waste in landfills.

Additionally, there are many other major impacts of hydraulic fracturing on water resources, which are beyond the scope of this paper. These include: 
- Stormwater discharges from well sites. In order to create an area for drilling a new well, operators clear and grade an area that can accommodate the wellhead(s); pits for holding water, drill cuttings, and used drilling fluids; and space for trucks used to transport equipment and wastes. Typically, this space ranges from 3 to 5 acres. ${ }^{15}$ During rain events, stormwater runoff can carry sediment from this cleared area into nearby water bodies. Large volumes of runoff also erode stream banks and riverbanks. Oil and gas operations are exempt from stormwater permitting requirements under the Clean Water Act. $^{16}$

- Impacts of water withdrawals for use in the hydraulic fracturing process. Because hydraulic fracturing requires large amounts of water-around 3,800,000 gallons of fracturing fluid per well in the Marcellus Shale, on average - this is a concern in areas of the country with water scarcity. ${ }^{17}$ Even in areas with water abundance, withdrawals from smaller headwater streams can diminish streamflow enough to negatively affect aquatic life. $^{18}$

- Impacts from well drilling and development (including contamination of groundwater during hydraulic fracturing). The process of developing a shale gas well-drilling through an overlying aquifer, stimulating the well via fracturing, completing the well, and producing the gas - creates a risk of contaminating groundwater. ${ }^{19}$ For example, in December 2011 the U.S. Environmental Protection Agency released a draft report finding evidence that groundwater in Pavillion, Wyoming, was contaminated by chemicals consistent with constituents in hydraulic fracturing fluid. ${ }^{20, b}$

- Groundwater contamination may result from a failure of well integrity or the migration of hydraulic fracturing fluid chemicals from the target formation. Abandoned wells that are improperly sealed may also cause environmental contamination.

\footnotetext{
bIn March 2012, the EPA agreed to retest Pavillion's water supplies to "clarify questions" about the initial report's monitoring results. See Timothy Gardner, "EPA to Retest Wyoming Water Said Tainted by Fracking," Reuters, March 9, 2012, reuters.com/article/2012/03/09/usa-epa-fracking-idUSL2E8E9ASA20120309.
} 


\section{Chapter 1. Management Options for Water Produced During Shale Gas Development}

There are five basic options for managing water produced during the production of natural gas from unconventional formations: minimization of produced water generation; recycling and reuse within operations; treatment; disposal; and beneficial reuse outside of operations. Table 1 summarizes the options for on- and off-site management as well as the target type of water for different options; dot size indicates frequency of use. Figure 1 shows on-site options on the left and off-site options on the right. As Table 1 indicates, on-site options associated with minimization, recycling, and reuse are more frequently employed for water during the flowback period, while off-site treatment and disposal methods dominate the management of production phase water. As noted, "produced water" refers to all water that returns during the flowback and production periods. A distinction between early produced water ("flowback") and later produced water will be made only when chemical constituents or management are different.

Table 1. Management of Water During Flowback and Production

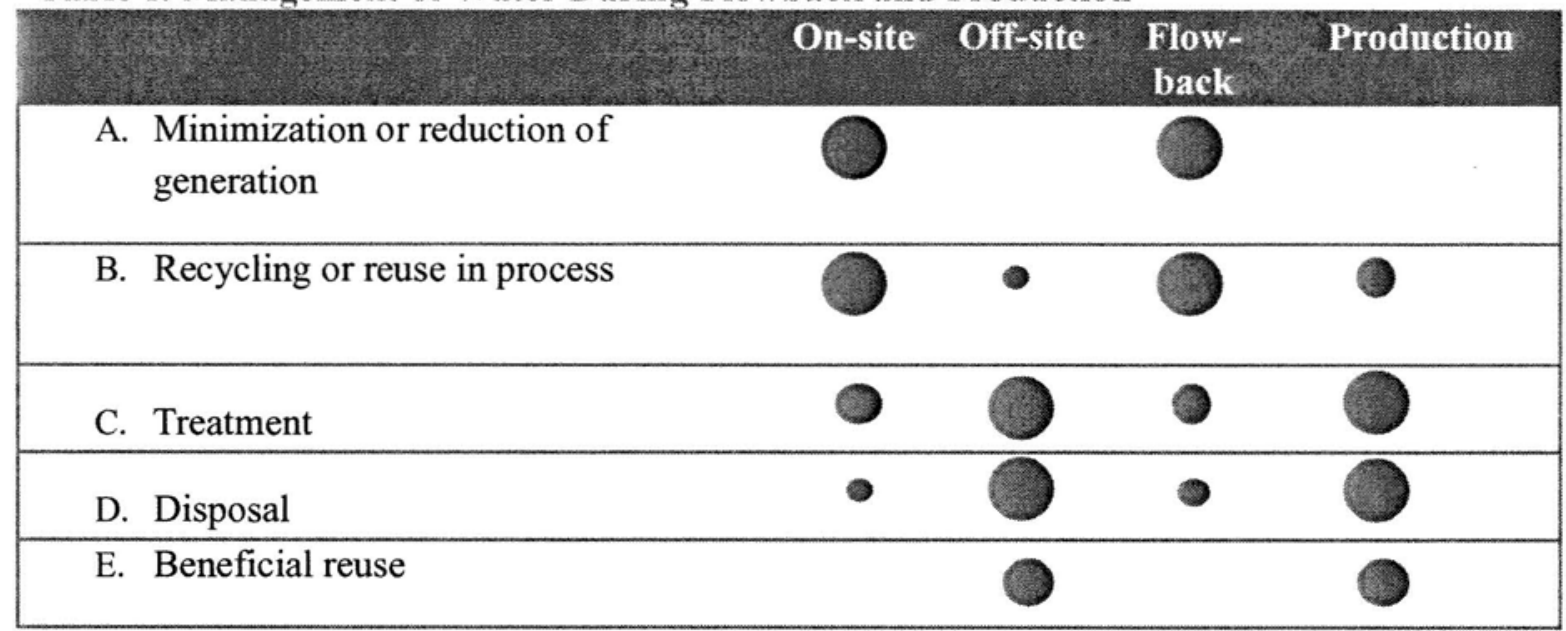


Figure 1. Summary of Management Options for Shale Gas Wastewater

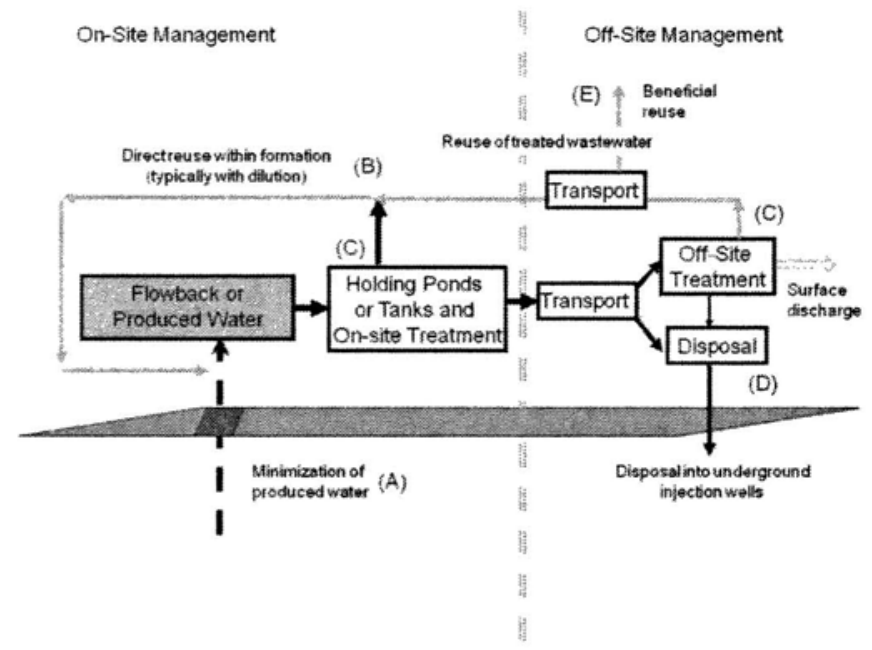

Table 2 provides a summary of the produced water management options being chosen in Pennsylvania for Marcellus Shale formation produced water in 2011. Data are from the Pennsylvania Department of Environmental Protection (PADEP).

Table 3. Wastewater Management from Marcellus Shale in Pennsylvania in 2011 (barrels)c

\begin{tabular}{|c|c|c|}
\hline 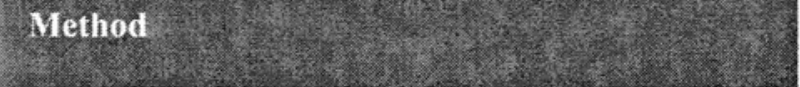 & Jan-June 2011 & July-Dec. 2011 \\
\hline Reuse within operations (not road spreading) & $5,028,566$ & $5,670,753$ \\
\hline Disposal at injection well & 521,983 & $1,718,410$ \\
\hline Industrial treatment plants (CWT), exempt ${ }^{d}$ & $1,971,019$ & 42,345 \\
\hline Industrial treatment plants (CWT), nonexempt ${ }^{d}$ & $1,691,171$ & $13,920,901$ \\
\hline Municipal sewage treatment plants (POTWs) & 101,897 & 408 \\
\hline Storage pending disposal or reuse & 228,618 & 6,884 \\
\hline Landfill (liquid waste only) & 26,735 & 6,005 \\
\hline Other (not specified) & & 6,640 \\
\hline TOTAL & $9,679,990$ & $21,372,346$ \\
\hline
\end{tabular}

"For purposes of these data, "wastewater" includes fracturing fluid, brine, and drilling wastewater. Spent lubricant, drill cuttings, and flowback fracturing sand are not included in wastewater.

d "The terms "exempt" and "nonexempt" refer to whether the waste treatment facility was exempt from, or subject to (i.e., nonexempt from), Pennsylvania's so-called "Chapter 95 " requirements for wastewater treatment, which established maximum concentrations of total dissolved solids and chlorides permissible in surface water discharges from treatment facilities. Those requirements are discussed later in this Chapter as well as in Chapter 4.

PAGE 15 | In Fracking's Wake: New Rules are Needed to Protect Our Health and Environment from Contaminated Wastewater 
The PADEP data used for Table 2 contain some misclassifications. For exempt CWTs and POTWs, specific analysis by permit number was used to ensure correct totals. For nonexempt CWTs and injection wells, DEP classifications were used, although some facilities listed as brine-treatment CWTs in January-June data are then listed as a disposal well in July-December data.

Despite these misclassifications, it is possible to draw some general conclusions about the approximate proportional breakdown of wastewater management methods. In 2011, approximately half of all Pennsylvania wastewater was treated at CWTs that are subject to the state's new water pollution discharge limitations (i.e., nonexempt). (It is not possible to determine from the data what volumes of wastewater treated at CWTs were subsequently discharged to surface waters, reused, or disposed of by another method.) About one-third of the wastewater was recycled for additional hydraulic fracturing. Less than one-tenth was injected into disposal wells. A similar amount was treated at CWTs that are exempt from the state's new discharge regulations, with most of that treatment occurring in the first half of the year, before the state asked operators to stop sending their wastewater to such facilities (as discussed below). Less than 1 percent was treated at POTWs. The remainder (less than 1 percent) was reported as in storage pending disposal or reuse.

From the first half to the second half of 2011, total reported wastewater volumes more than doubled. Treatment at CWTs increased nearly four-fold, even as wastewater volumes directed to exempt CWTs decreased by 98 percent. Deep-well injection more than tripled, and reuse in hydraulic fracturing operations increased by about 10 percent. Treatment at POTWs was virtually eliminated.

\section{Minimization of Wastewater Generation \& Reuse and Recycling Within Operations}

Minimization of wastewater generation and recycling/reuse within operations take place on-site at the well during development. While these have not been popular management choices in oil and gas drilling previously, extensive development of these options has been undertaken in the Marcellus gas field due to low availability of traditional off-site disposal methods in close proximity to well development. Reduced cost and significant environmental benefits accrue with reduction, reuse, and recycling, as reduced volumes of wastewater result in less trucking and less treatment and disposal.

Minimization of produced water generation, especially in the early flowback period, is generally achieved either through completion techniques that require less water or through technologies applied within the well bore ("downwell"). For oil-producing wells, mechanical blocking devices and downwell oil/water separators are used; however, oil wells typically produce many times more water than gas wells, despite these technologies. ${ }^{21}$ For hydraulically fractured natural gas wells, water use and wastewater minimization technologies are still being developed, and the effect they will have on long-term produced water quantities is uncertain.

Reuse of produced water for enhanced oil recovery has been practiced for decades, but reuse of produced water in gas development has only recently been explored. Challenges to reuse may include removing constituents that could affect well performance (salts, suspended solids

PAGE 16 | In Fracking's Wake: New Rules are Needed to Protect Our Heath and Enwronment from Contaminated Wastewater 
including microorganisms, and scale-forming chemicals) and adjusting the stimulation chemistry with chemical additives that work in saltier waters, ${ }^{22}$ although many producers in the Marcellus formation report use of produced water from the flowback period without treatment. ${ }^{23}$ Recently, Pennsylvania issued a general permit (WMGR121) that covers the treatment of produced water for subsequent reuse in hydraulic fracturing. ${ }^{\mathrm{f}}$ A 2010 report listed two facilities that operate under the general permit. ${ }^{24}$ This same report surveyed seven operators and reported that six were practicing recycling and reuse, with several attempting to reuse all produced water from their operations. $^{25, \mathrm{~g}}$

The rapidity with which the industry has adopted resource conservation suggests that these techniques have the potential to be transferred to many existing gas fields to reduce water usage and wastewater generation. The opportunity for reuse and recycling is greater during the flowback period than during the production phase. After the pad is fully developed, with all wells producing, options for minimization and recycling/reuse decline. Produced water generated during the lifetime of the well can be collected and repurposed for operations at other wells, but this requires transport to new well pads, and this may be more costly than transport to disposal or treatment locations, depending upon the distances involved and the quality of the produced water. Logistics and economics control reuse opportunity.

Off-site reuse of untreated produced water is rare. Generally only very clean water, typical of some coal bed methane sites, can be directly reused. Wastewaters low in pollutants such as organics and dissolved solids can be used for irrigation, livestock watering, base flow augmentation in streams, injection into aquifers for recharge, and road application for dust suppression or deicing. Off-site reuse for industrial operations, including in hydroelectric power plant cooling and as a working fluid in geothermal energy production, are emerging options. Limited trials for cooling operations indicate that high TDS precludes this use. ${ }^{26}$ Thus, reuse in the non-extractive energy sector is likely to be an option only for low-concentration wastewaters with little scaling potential. Due to the high concentration of salt in produced water from the Marcellus formation, none of these options are currently used. Reuse of partially treated wastewater, both on-site and off-site, will be discussed in the treatment section below.

\section{Disposal}

On-site management via disposal or discharge is permitted only under specific and limited conditions, and Marcellus gas operations do not qualify. Discharge of wastewater at the point of generation (direct discharge on-site) is not permitted at most onshore oil and gas wells. (Further discussion of the direct discharge prohibition can be found in Chapter 4.)

Direct disposal aboveground or to soils in the near-surface environment, on- or off-site, was routine in the early part of the 20th century, and on-site unlined ponds and nearby off-site land application were common disposal techniques. ${ }^{27}$ Today on-site unlined ponds are no longer used because such ponds - percolation ponds in particular - can cause salt contamination in soils and

\footnotetext{
${ }^{f}$ For more information on regulation of produced water recycling, see Chapter 4.

${ }^{g}$ The six operators reporting recycle and reuse were Chesapeake Energy, Range Resources, EQT, East Resources, BLX, and Norse Energy.
}

PAGE 17 | In Fracking's Wake: New Rules are Needed to Protect Our Health and Environment from Contaninated Wastewater 
aquifers. ${ }^{28}$ Land application of untreated water by spraying is generally not permitted or is allowable only for wastewater with a low salt content.

Off-site disposal is done predominantly via underground injection into a disposal well, and almost all onshore produced water in the United States is managed in this fashion. ${ }^{29}$ Typically, oil and suspended solids are removed from the produced water at the disposal well prior to injection to reduce well plugging and formation clogging from scale-forming chemicals or microbial growth. Alternatively, if no treatment is undertaken, periodic downhole workovers may be performed to remove formation clogs. ${ }^{\mathrm{h}}$

Injection wells are suitable in areas with porous sedimentary rock. Good potential for injection exists in the mid-continent and Great Plains; conditions are less favorable along the Atlantic Coast, in New England, and in the Appalachian Mountain area. In many regions, the permitting of a new injection well requires the plugging of old and orphan wells, due to extensive prior development of other gas formations.

Injection of wastewaters for disposal is regulated as part of the Underground Injection Control (UIC) section of the Safe Drinking Water Act of 1974; UIC Class II wells are specific to injection of brines and other fluids associated with oil and gas production. (Further discussion of the Underground Injection Control program can be found in Chapter 4.)

There are 1,855 Class II wells in Pennsylvania; however, only eight were licensed for disposal in 2010 (see Table 3). Two were subsequently closed, and two additional wells were approved in 2011. ${ }^{i}$ The State Review of Oil and Natural Gas Environmental Regulations (STRONGER), an independent regulatory review for Pennsylvania, indicates that there are at least 20 well injectivity reviews (the first stage of application) pending for UIC wells in Pennsylvania. ${ }^{30}$ In addition to current or future Pennsylvania disposal wells, oil and gas wastewater is transported to injection wells in Ohio and West Virginia. Prior to Marcellus development, West Virginia had only two Class II disposal wells operating. By January 2010, nine such wells had been approved in West Virginia, and seven were operating. In addition to these commercial wells, West Virginia has 62 private brine disposal injection wells. Ohio has 2,801 Class II wells; 177 are permitted for disposal. In 2011 Ohio reviewed its brine disposal regulations and increased the fees for out-of-state users. In early 2012, the Ohio Department of Natural Resources halted wastewater injection at a disposal well near the site of a series of earthquakes in northeastern Ohio. On March 9, 2012, Ohio DNR released a report linking the earthquakes to the injection well and a previously unknown fault in the area. ${ }^{31}$ Seismic concerns related to underground injection have been raised in other parts of the country as well. ${ }^{32, \mathrm{j}}$

Numerous surveys over the past few decades have documented the extensive use of disposal wells for oil and gas produced water disposal. Argonne National Laboratory reports that 98

\footnotetext{
h A "workover" is the term for any repair or modification after a well is in operation. "Downhole" refers to repairs that take place within the well itself rather than at the surface.

${ }^{i}$ A brine disposal well in Greene County owned by CNX Gas was closed in August 2010. An XTO Energy well in Indiana County was closed in 2011. Two new wells were approved in Columbus Township (Warren County) in 2011 but as of early 2012 had not yet begun accepting wastewater.

${ }^{\mathrm{j}}$ The Arkansas Oil and Gas Commission banned disposal wells in the state after they were linked to increased seismic activity.
}

PAGE 18 | In Fracking's Wake: New Rules are Needed to Protect Our Health and Environment from Contaninated Wastewater 
percent of onshore produced water (a category that includes natural gas produced water) is injected, either to maintain formation pressure in oil fields or for disposal.33 In 2010 four of seven surveyed gas companies indicated using disposal wells for produced water, with three identifying Ohio wells and one not disclosing the disposal well location.34

Table 3. Permitted Oil and Gas Brine Disposal Wells in Pennsylyania

\begin{tabular}{|l|l|l|l|l|}
\hline Facility & County & Formation & $\begin{array}{l}\text { Pressure } \\
\text { (psi) }\end{array}$ & $\begin{array}{l}\text { Injection } \\
\text { Volume } \\
\text { (Barrels/Month) }\end{array}$ \\
\hline Columbia Gas & Beaver & $\begin{array}{l}\text { Huntersville/ } \\
\text { Oriskany }\end{array}$ & 1,300 & 21,000 \\
\hline EXCO-North Coast & Clearfield & Oriskany & 3,240 & 4,260 \\
\hline CNX Gas & Greene & Mine Void & 0 & 150,000 \\
\hline $\begin{array}{l}\text { Great Lakes Energy (now } \\
\text { Range Resources) }\end{array}$ & Erie & Gatesburg & 1,570 & 20,000 \\
\hline XTO Energy & Indiana & Balltown & 1,930 & 3,600 \\
\hline Cottonwood & Somerset & Oriskany & 3,250 & 27,000 \\
\hline EXCO-North Coast & Clearfield & Oriskany & 1,450 & 4,200 \\
\hline Dominion & Somerset & $\begin{array}{l}\text { Huntersville / } \\
\text { Oriskany }\end{array}$ & 3,218 & 30,000 \\
\hline
\end{tabular}

${ }^{a}$ Facility closed by EPA order, August 2010 .

${ }^{\mathrm{b}}$ Commercial facility

${ }^{\mathrm{c}}$ Facility closed, well plugged.

Two injection wells in Pennsylvania were the subject of concern during the expansion of produced water generation and disposal concomitant with the rapid development of the Marcellus Shale in 2008 through 2010. The CNX Gas well (permit PAS2D210BGRE) involved disposal of coal bed methane produced water into the Morris Run Borehole, which was drilled into an inactive coal mine. Mine void disposal is not unusual for some kinds of wastewaters, especially those that are alkaline, which may reduce the acidity of the mine discharge. ${ }^{k}$ Disposal of oil and gas produced water into this type of formation is not typical; however, coal bed methane water is relatively low in dissolved solids, and the permit specifically allowed only this type of wastewater. This facility was the site of violations from September 2007 to March $2009 .{ }^{35}$ Violations related to poor security (unlocked gates), poor management (no flow meters operational), and poor recordkeeping (disposal records incomplete). PADEP requested that EPA revoke the permit. CNX stated its intention to close the well in early 2010 (by letter to EPA on March 12, 2010). EPA issued a fine and a final order to close the facility in August 2010.

Hydraulic connectivity between the $\mathrm{CNX}$ disposal well and a nearby mine discharging to surface waters had also been suspected, but not demonstrated. ${ }^{36}$ Still, this concern highlights the fundamental issue associated with disposal into mine voids. Mine voids may be at or above the

\footnotetext{
${ }^{k}$ Such discharge to mine voids as a beneficial practice is legal when authorized by EPA in advance. See 40 CFR 144.24 and 144.84 .
} 
level of underground drinking-water reservoirs, and if hydraulically connected to active mine locations may be subject to pumping activities that cause fluids to flow back to the surface. For this reason, disposal into mine voids is typically limited to wastewaters that will have a beneficial effect on mine pool water quality.

Tunnelton Liquids Company ("TLC"; permit PA0091472) was in operation for many years, treating predominantly acid mine discharge. The operations included the receipt of produced water from oil and gas operations, which was mixed with the acid mine discharge and partially treated. Treated water was discharged to the Conemaugh River, and the residual sludge was disposed of into a mine void in the Marion mine. This operation was approved in a Consent Order and Agreement with PADEP in 1997, and a permit was issued for discharge in 1997 and renewed in 2002. Treatment was permitted for 100,000 gallons per day of oil- and gas-related wastes, as well as 900,000 gallons per day of acid mine drainage wastewater. In May 2011, the

EPA issued a notice of violation, stating that TLC was operating an unlicensed UIC well. ${ }^{37} \mathrm{EPA}$ informed PADEP of this action and requested confirmation that no other mine void injection plans had been approved by PADEP. ${ }^{38}$

To the authors' knowledge, with the closure of the CNX well and the Tunnelton Liquids facility, produced water from oil and gas operations is no longer being disposed of in mine voids in southwestern Pennsylvania. Thus, the potential for these fluids to enter adjacent mines and find paths to groundwater or surface water is reduced.

\section{Treatment}

Treatment is the most complex management option. It can occur on-site or off-site and in conjunction with recycling, reuse, discharge, and disposal. It can be utilized to prepare wastewater for subsequent reuse in gas development or for disposal, or it can be used to generate clean water for discharge or distinct qualities of finished water or residuals for beneficial reuse. The many potential outcomes of different treatment options will be discussed in Chapter 2.

Figure 2 shows additional detail of the steps involved in treatment. On the left, on-site treatment is associated only with treatment for reuse at the well pad. Since no discharges are permitted from the well location, only an evaporative treatment with water discharged to the air would reduce the volume of produced water requiring off-site transport (though this could have other adverse impacts, including emissions of air pollutants and increased risk of spills or accidental overflows). Reuse (with or without dilution or treatment) is the dominant on-site management option (as discussed above). Most treatment associated with produced water takes place off-site and thus requires transport of the wastewater. Shown in the middle of Figure 2, transport is either to disposal wells, discussed above, or to treatment facilities. Treatment generates treated water, which may be discharged, shipped back to the well site for reuse, or diverted for beneficial reuse or resource extraction (top right). Finally, residuals generated during treatment, either concentrated liquid wastes (brines) or solid waste, can be sent to disposal (deep well or landfill) sites or diverted for beneficial reuse (bottom right). 
Figure 2. Treated Water and Residual Product Flows

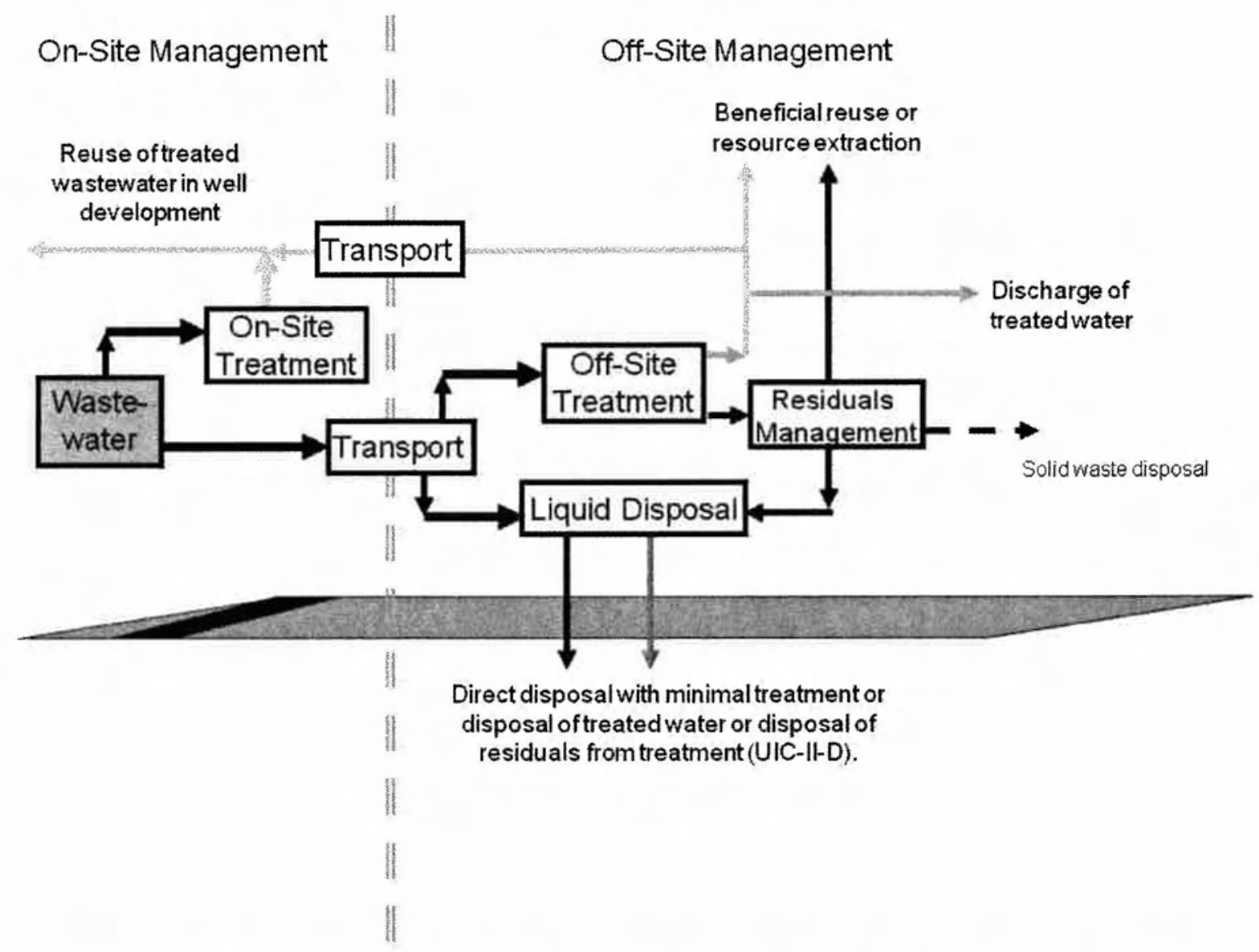

On-site and off-site treatment methods utilize very similar techniques. The choice of methods generally depends on the desired water products rather than the location of treatment. Treating wastewater for subsequent reuse within hydraulic fracturing, either on- or off-site, focuses on removal of organic contaminants and inorganic species known to induce fouling when reused. Treatment for other objectives - to produce a water clean enough for reuse or discharge, or to produce a brine or solid residual for subsequent reuse - may require more selective targeted removal technologies.

\section{Contaminants to remove in treatment}

For all kinds of wastewaters, treatment design begins with evaluation of the constituents to remove and assessment of methods to remove those targets. The major constituents of concern in produced water from natural gas development are (1) salt content, including metals, (2) organic hydrocarbons (sometimes referred to as "oil and grease"), (3) inorganic and organic additives, and (4) naturally occurring radioactive material (NORM).

Salts. Inorganic dissolved ionic components are usually measured by electrical conductivity or by gravimetric methods after water evaporation. They are expressed as salinity, conductivity, or total dissolved solids or reported as specific concentrations of soluble ions. Ionic constituents 
found in produced water include calcium, magnesium, sodium, potassium, carbonate, bicarbonate, sulfate, nitrate, chloride, and bromide. While the generic chemical term "salts" or "ions" is used for all dissolved inorganics, and the measurement techniques will provide a surrogate summary term, in practice some sources consider only monovalent ions in salts and create a separate category for other inorganic constituents (e.g., calcium, magnesium, sulfate), often called "scale-formers." Heavy metals (e.g., zinc, lead, manganese, iron, barium) are predominantly ionic salts and thus are part of this category as well, although they are often discussed separately. These distinctions are sometimes relevant for treatment technologies, but such differences can be evaluated only through complete chemical analysis of the water.

Organic compounds. These carbon-based compounds include oil and grease, which are sparingly soluble in water, as well as organics commonly found with petroleum and natural gas, including benzene, toluene, xylene, phenols, organic acids, and high-molecular-weight organics (e.g., polycyclic aromatic hydrocarbons, or PAHs). Again, this represents a large class of chemicals, which may be assessed broadly (e.g., as "petroleum hydrocarbons"). However, solubility is a critical characteristic affecting treatability, and therefore important differences in chemicals in this broad group must be considered.

Chemical additives. These compounds, while not a distinct chemical class, are often considered separately in produced water treatment. The exact chemical makeup of a hydraulic fracturing mixture varies, but the following classes of chemicals may be present:

- Proppants (sand)

- Clay stabilizers, which prevent the formation clay from swelling

- Acids to dissolve minerals and initiate cracks

- Gelling agents, which thicken the water to suspend the proppant

- Breakers, which allow a delayed breakdown of the gel

- Bactericides/antimicrobial agents to eliminate corrosion-enhancing bacteria

- Corrosion inhibitors, scale inhibitors, and iron controls to prevent corrosion and scaling

- Cross-linking agents, which maintain fluid viscosity as temperature increases

- Friction reducers

- Surfactants to increase viscosity

The makeup of hydraulic fracturing fluid is based on an evaluation of well conditions, the experience of the contractor handling the well completion, and evolving industry practices.

Significant concern has been raised regarding the nature of these additives, with 29 identified as of particular concern for human health and 13 identified as probable or known human carcinogens. ${ }^{39}$ Among the most notable are 2-butoxyethanol (2BE), naphthalene, benzene, and polyacrylamide. At least one study notes that $2 \mathrm{BE}$ is being replaced in hydraulic fracturing with a less toxic product. ${ }^{40}$ Table 4 summarizes the chemicals identified by a congressional study and their detection in produced water from the Marcellus formation. ${ }^{41}$ 
Table 4. Chemical Components of Particular Concern That May Be Present in Hydraulic Fluids Fracturing, as Identified in a Congressional Study ${ }^{42}$

\begin{tabular}{|c|c|c|}
\hline $\begin{array}{l}\text { Chemical conponent } \\
\text { used } 2005-2009\end{array}$ & Chemical category & $\begin{array}{l}\text { Detected in at least one } \\
\text { produced water sample } \\
\text { (MSC report) }\end{array}$ \\
\hline Merthanol & HAP & Not tested \\
\hline Ethylene glvent (1,2-ethanediol) & HAP & Yes \\
\hline Diesel & $\begin{array}{l}\text { Carcinogen, SDWA, } \\
\text { HAP }\end{array}$ & Not tested \\
\hline Naphibalene & Carcinogen, HAP, PC & Yes \\
\hline Xvlone & SDWA, HAP & Yes (total xylenes) \\
\hline Hedruchloric acid & HAP & Not tested \\
\hline Tolucne: & SDWA, HAP & Yes \\
\hline Ethylbenzene as: & SDWA, HAP & Yes \\
\hline Diethrunolamine & HAP & Not tested \\
\hline Fornaldebide & Carcinogen, HAP & Not tested \\
\hline Sulfuric Acid & Carcinogen & Not tested \\
\hline Thiourea & Carcinogen & Not tested \\
\hline Benzul chloride & Carcinogen, HAP & Not fested \\
\hline Cumene: & HAP & Not tested \\
\hline Nitrilotriacetic acid (NI) & Carcinogen & Not tested \\
\hline Dimethyl farmanide & HAP & Not tested \\
\hline Phenol & HAP & Yes \\
\hline Benzene: & $\begin{array}{l}\text { Carcinogen, SDWA, } \\
\text { HAP }\end{array}$ & Yes \\
\hline Di (2-ethylhexyl) plithalate. & $\begin{array}{l}\text { Carcinogen, SDWA, } \\
\text { HAP }\end{array}$ & Not tested \\
\hline Aerylamilite & $\begin{array}{l}\text { Careinogen, SDWA, } \\
\text { HAP }\end{array}$ & Not tested \\
\hline Hotnolluoric acid & HAP & Not tested \\
\hline Phthalic sunbodride: & HAP & Not tested \\
\hline Acetaldehyde & Carcinogen, HAP & Not tested \\
\hline Acetoplusnone & HAP & Yes \\
\hline Copper & SDWA & Yes. \\
\hline Erhvlene oxide & Carcinogen, HAP & Not tested \\
\hline Gead & $\begin{array}{l}\text { Carcinogen, SDWA, } \\
\text { HAP, PC }\end{array}$ & Yes \\
\hline Propslene oxide & Carcinogen, HAP & Not tested \\
\hline pexulene: & HAP & Yes (total xylenes) \\
\hline
\end{tabular}

Naturally occurring radioactive material (NORM). Shale gas produced water in the United States typically contains NORM at levels elevated from background, ${ }^{43}$ and oil and gas development in other states has produced elevated NORM at levels of concern on production equipment and in wastewaters. This has generally not been the case in Pennsylvania, where

\footnotetext{
' HAP= Hazardous Air Pollutant. SDWA=Safe Drinking Water Act Regulated Chemical. PC=Priority Chemical.
} 
routine surveys at oil and gas facilities producing hydrocarbons from conventional formations have rarely found levels above background. ${ }^{44}$ Unlike more typical Pennsylvania sources, the Marcellus Shale is considered radioactive, as is common for organic rich shales. ${ }^{45}$ The most abundant types of NORM in produced water from the Marcellus formation are radium-226 and radium-228, produced from radioactive decay of uranium and thorium present in the shale formation. Evaluation of drill cuttings and produced waters from Marcellus wells confirms that elevated levels of radioactivity are not uncommon for wastewaters associated with Marcellus Shale development. ${ }^{46}$

\section{Treatment technologies}

Produced water, including flowback, that is not reused generally requires treatment prior to disposal. As noted above, once contaminants of concern are evaluated, treatment options that target those constituents are considered. ${ }^{\mathrm{m}}$ For produced water, treatment options typically focus on removal of suspended solids, organics like oil and grease, and minerals (dissolved solids or salts). NORM is most often removed through treatments that target the three major constituents. Suspended solids are typically removed through settling (often in holding ponds or tanks) or filtration. Oil and grease treatment methods include physical separation processes, such as hydrocyclones, filtration, and centrifuge, and chemical separation processes, such as dissolved air flotation, solvent extraction, and adsorption (see Figure 3). When organics must be removed to very low levels (below the levels at which they become soluble in water), multistage treatment operations may be needed. For example, many soluble organics can be sorbed onto surfactantmodified zeolite (SMZ) and stripped to the air, and the off-gas subsequently mineralized in vapor phase bioreactors. ${ }^{47}$

Figure 3. Technologies for Removing Oil, Grease, and Organics from Produced Water

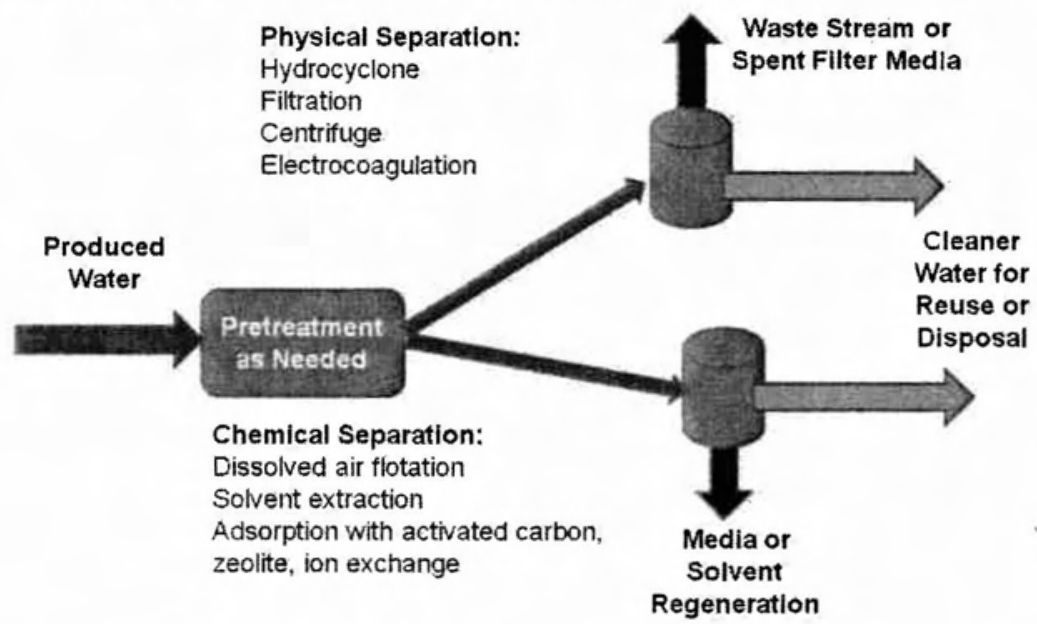

\footnotetext{
${ }^{\mathrm{m}}$ Treatment technologies are briefly introduced here but are covered in more detail in Chapter 2.
} 
Treatment methods for removal of suspended solids and organics will rarely affect dissolved solids. When targeted salt removal is an objective, precipitation methods are generally effective only for multivalent ions (e.g., calcium, magnesium, iron, sulfate) and do not remove monovalent ions (e.g., sodium, chloride, bromide). ${ }^{\mathrm{n}}$ The removal of monovalent ions is commonly referred to as desalination or demineralization. Desalination treatment options include thermal methods, such as distillation, evaporation, and crystallization, and non-thermal methods, such as reverse osmosis (RO) with or without vibratory shear-enhanced processing (VSEP), ion exchange, capacitive deionization, forward osmosis, and electrodialysis (see Figure 4).

Figure 4. Technologies for Removing Dissolved Ionic Constituents from Produced Water

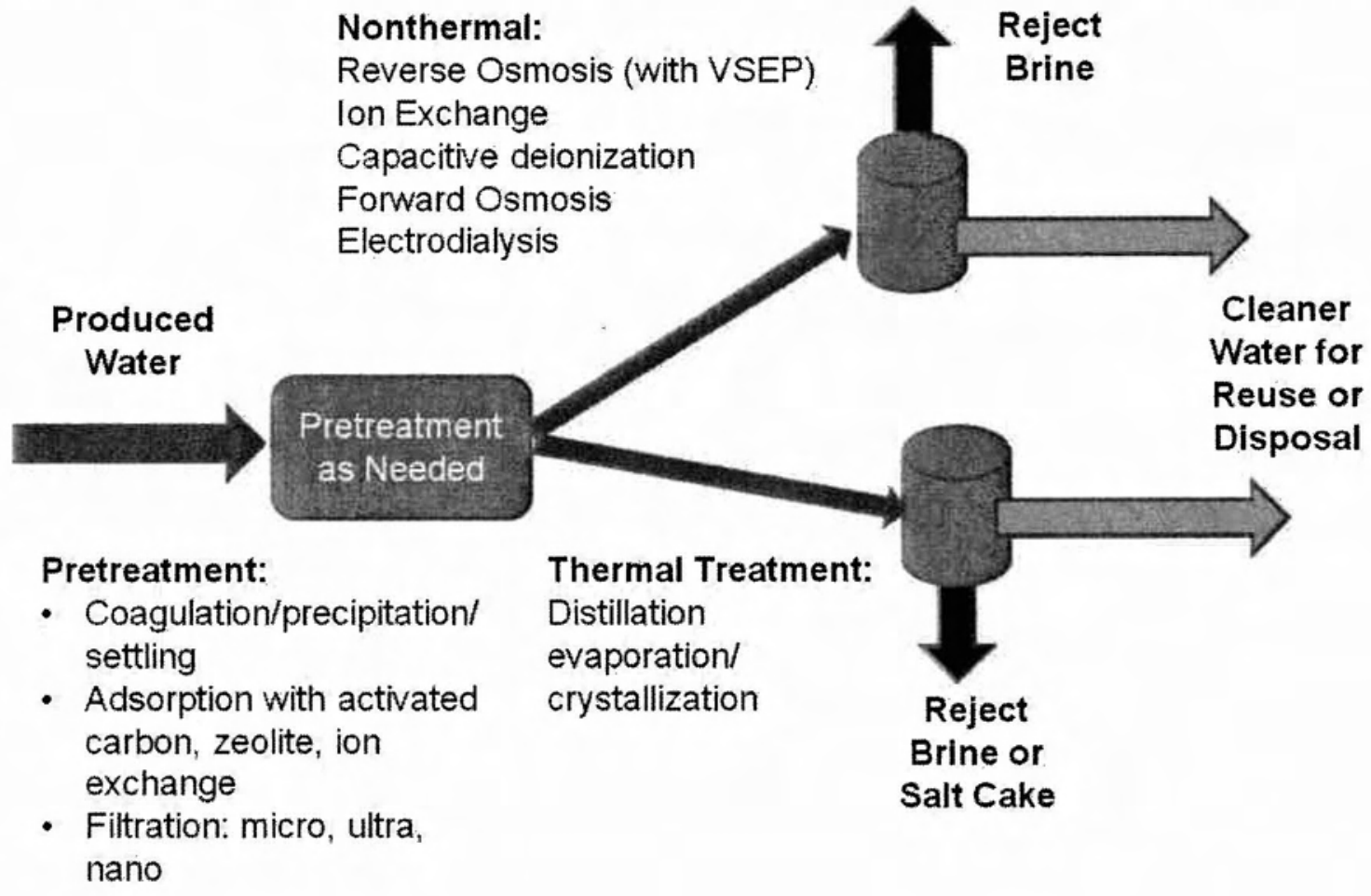

The simplest thermal desalination technique is evaporation from on-site holding ponds. Using energy from sunlight, evaporation reduces the volume of wastewater for disposal. It is widely practiced in arid areas, where evaporation exceeds precipitation. This method is unsuitable in the humid eastern part of the United States, particularly in areas of the Ohio River Basin where significant precipitation is evenly spaced throughout the year. On-site evaporation ponds are not utilized in the Marcellus production range. On-site holding ponds in precipitation-dominated regions collect water from rainfall, which dilutes the wastewater. Dilution can potentially increase the suitability of produced water for reuse (because it is less salty), but it clearly

\footnotetext{
${ }^{n}$ Valency refers to the charge on the ion, with monovalent being +1 or -1 as ions and multivalent being other values.
}

PAGE 25 | In Fracking's Wake: New Rules are Needed to Protect Our Health and Environment from Conlaminated Wastewater 
eliminates the evaporative potential to reduce volume for disposal. Open-pond evaporation may also contribute to air releases if volatile chemicals are present in the wastewater.

More complex desalination techniques use either thermal methods or membrane methods. Thermal methods involve heating the water to boiling and recapturing the steam as clean water. The salts that were in the produced water will be in the residual brine or salt cake left behind after the water has been boiled off. Other contaminants in the water will partition into the solid residual or the air, depending on their chemical characteristics, with metals and NORM in the residual. Membrane methods use small pores that allow only water to pass through while rejecting dissolved ions. Clean water comes out, and a more concentrated, lower-volume brine is left behind. Again, this brine will contain the contaminants that were removed from the water. Additional details of the methods for desalination and their challenges are provided in Chapter 2 .

\section{Treatment Facility Options for Produced Water}

As noted, treatment processes are selected to remove specific constituents. Wastewaters that contain multiple contaminants of concern are generally treated in specially designed plants that have multiple unit operations to remove the targets. An example is a conventional wastewater treatment plant designed to treat municipal sewage. Wastewater generated by homes and businesses contains a wide variety of constituents (e.g., organic matter, nutrients, suspended solids). Consequently, a municipal wastewater plant, often called a publicly owned treatment works (POTW), has multiple steps designed to remove suspended solids, dissolved organic compounds that cause oxygen demand in receiving waters, and sometimes nutrients, like ammonia or nitrate. POTWs are not designed to remove salts, as the typical wastewater they receive does not contain high loads of dissolved inorganic chemicals like salt. POTWs have permits that allow discharge of treated water to surface waters. Treated wastewater is not pure water; it contains small amounts of the contaminants that were targeted for removal. Since salts are not targeted for removal, most salts that enter a POTW will be in the treated water and will be discharged to the receiving water.

\section{Produced Water Disposal at Publicly Owned Treatment Works}

Publicly owned treatment works (POTWs) can receive industrial wastewater in addition to municipal wastewater. Because POTWs are designed primarily to treat municipal sewage, industrial wastes are generally subject to pretreatment requirements to ensure that constituents in the industrial waste do not interfere with the conventional treatment processes in the POTW. High concentrations of salt in produced water can disrupt biological treatment in POTWs, although this is rarely observed, as permits often restrict POTWs to receiving oil and gas wastewater at less than 1 percent or 5 percent of total flow. ${ }^{48}$ Heavy metals can disrupt nitrification in POTWs that include this nutrient removal process; however, this disruption is typically seen at higher concentrations of metals than are in produced waters. ${ }^{49}$ Some organics that can be present in produced water (e.g., formaldehyde) have specific inhibitory effects on nitrification; again, this is seen at high concentrations. ${ }^{50}$

Treatment of produced waters at POTWs in systems that face capacity limitations is also a concern. POTWs are typically designed to treat a specific average flow rate of sewage. They have some additional capacity to manage short-term higher flows during storm events, but many systems do not have significant excess capacity under all conditions (e.g., during a period 
marked by multiple storm events). Systems with capacity limitations - due to inflow and infiltration associated with aging pipe systems or wet-weather flows that exceed pipe or plant capacity - could exacerbate uncontrolled overflow conditions if the volume or timing of produced water treatment is not adequately managed.

When needed to prevent disruption of the POTW or because they will not be removed in conventional processes, organics can be removed from produced water through several pretreatment methods. For example, Kwon et al. reported on the use of a surfactant-modified zeolite absorption followed by a membrane bioreactor for removal of BTEX (benzene, toluene, ethylbenzene, xylene). ${ }^{51} \mathrm{Yi}$ et al. reported on the pretreatment of coke-plant wastewater to improve biodegradability in POTW processes. ${ }^{52}$

Treatment of oil and gas produced waters through POTWs, with or without pretreatment, is likely to remove suspended solids, some metals, and biodegradable organics. Suspended solids and some metals present in the produced water are likely to be removed through physical processes that will retain these contaminants in the sludge produced in conventional POTWs. The solids settle with other solids produced through treatment, and metals sorb onto these solids, ending up in the sludge. ${ }^{53}$ Many organics, even those that are toxic, can be removed by the microbial species present in the treatment plant (e.g., phenol and NTA are biodegradable in POTWs). ${ }^{54}$ Biodegradable organics are transformed by the bacteria into carbon dioxide and cell materials. Organic compounds that are resistant to microbial degradation will not be removed in POTWs, and dissolved ions (salts) will not be affected by treatment.

Nationally, POTW treatment followed by dilution in surface receiving waters is not frequently used as a produced water treatment/disposal option. However, it was a common practice in southwestern Pennsylvania during the long development of conventional fossil fuels and was initially practiced for disposal of produced waters from Marcellus development. In the Argonne National Laboratory survey, three of seven producers indicated sending produced water to POTWs at some time. ${ }^{55}$

As described in Chapter 4, in 2011 Pennsylvania updated Chapter 95 regulations setting maximum concentrations of total dissolved solids and chlorides permissible in discharges from POTWs (and other facilities, as discussed below). However, as of July 2011, 15 facilities in Pennsylvania were exempt from compliance with the regulations, meaning that they were allowed to continue discharging treated wastewater with concentrations exceeding the TDS and chlorides limits. Nine of these facilities are POTWs (listed in Table 5). Several of these, including Allegheny Valley Joint Sewage Authority and Altoona City Authority, stopped accepting oil and gas wastewaters in early 2011, and three listed in Table 5 declared their intention to stop receiving this wastewater in September $2011 .^{56}$ The remaining facilities may continue to receive produced water from oil and gas operations; however, PADEP requested in May 2011 that Marcellus drillers stop taking produced water to these facilities. ${ }^{57}$ Data from PADEP indicate a 99.5 percent reduction in produced water from Marcellus operations going to exempt POTWs between the first half of 2011 and the second half (see Table 5). ${ }^{58,0}$

\footnotetext{
${ }^{\circ}$ Note that the classifications of some facilities in the PADEP data exports are incorrect. Where this is the case, totals presented here will not match a cursory examination of PADEP data. However, the totals presented here are based on facility-level evaluation of the DEP database.
}

PAGE 27 | in Fracking's Wake: New Rues are Needed to Proted Our Health and Enwronment from Contaminated Wastewater 
Table 5. POTW Facilities Permitted to Accept Produced Water from Oil and Gas Under Chapter 95 Exemption

\begin{tabular}{|c|c|c|c|c|c|c|c|}
\hline Name & $\begin{array}{l}\text { Permit } \\
\text { Number }\end{array}$ & $\begin{array}{l}\text { Receiving } \\
\text { Stream }\end{array}$ & $\begin{array}{l}\text { Total } \\
\text { Flow } \\
\text { (MGD) }\end{array}$ & $\begin{array}{l}\text { Oil and } \\
\text { Gas Flow } \\
\text { (MGD) }\end{array}$ & $\begin{array}{l}\text { Marcellus } \\
\text { Produced Water? }\end{array}$ & $\begin{array}{r}\text { Marcellus } \\
\text { Produced Water } \\
\text { Received } \\
\text { Jan.-J une } 2011 \\
\text { (bbl) }\end{array}$ & $\begin{array}{r}\text { Marcellus Produced } \\
\text { Water Received } \\
\text { July-Dec. 2011 } \\
\text { (bbl) }\end{array}$ \\
\hline $\begin{array}{l}\text { Altoona City } \\
\text { Authority, Water and } \\
\text { Sewer Division }\end{array}$ & $\begin{array}{l}\text { Not provided } \\
\text { in PADEP } \\
\text { database }\end{array}$ & & & & & 21,822 & \\
\hline $\begin{array}{l}\text { Williamsport Sanitary } \\
\text { Authority }\end{array}$ & PA0027057 & $\begin{array}{l}\text { West Branch } \\
\text { Susquehanna } \\
\text { River }\end{array}$ & 8.4 & 0.12 & $\begin{array}{l}\text { Indirect wastewater } \\
\text { from CWT }\end{array}$ & 3,030 & \\
\hline $\begin{array}{l}\text { Punxsutawney } \\
\text { Borough Municipal } \\
\text { Authority }\end{array}$ & PA0020346 & $\begin{array}{l}\text { Mahoning } \\
\text { Creek }\end{array}$ & 2.2 & 0.02 & Not in 2011 & 0 & 0 \\
\hline $\begin{array}{l}\text { Municipal Authority } \\
\text { City of McKeesport }\end{array}$ & PA0026913 & $\begin{array}{l}\text { Monongahela } \\
\text { River }\end{array}$ & $11.5^{\mathrm{a}}$ & 0.102 & $\begin{array}{l}\text { None since May 19, } \\
2011\end{array}$ & 22,525 & 0 \\
\hline $\begin{array}{l}\text { Clariton Municipal } \\
\text { Authority }^{\mathrm{b}}\end{array}$ & PA0026824 & Peters Creek & $6^{\mathrm{a}}$ & 0.035 & $\begin{array}{l}\text { None since } \\
\text { September } 2011\end{array}$ & 309 & 0 \\
\hline $\begin{array}{l}\text { Ridgway Borough } \\
\text { Sewage Treatment } \\
\text { Plant }\end{array}$ & PA0023213 & Clarion River & 2.2 & 0.02 & $\begin{array}{l}\text { None since May 19, } \\
2011\end{array}$ & 30,702 & 0 \\
\hline $\begin{array}{l}\text { Bockway Area Sewage } \\
\text { Authority }\end{array}$ & PA0028428 & Toby Creek & 1.5 & 0.014 & $\begin{array}{l}\text { No (per letter to } \\
\text { EPA March 31, } \\
\text { 2011) }\end{array}$ & 0 & 0 \\
\hline
\end{tabular}

PAGE 28 | in Fracking's Wake: New Rules are Needed to Protect Our Health and Environment from Contaminated Wastewater 


\begin{tabular}{|c|c|c|c|c|c|c|c|}
\hline $\begin{array}{l}\text { Reynoldsville Borough } \\
\text { Authority }\end{array}$ & PA0028207 & $\begin{array}{l}\text { Sandy Lick } \\
\text { Creek }\end{array}$ & 0.8 & 0.011 & Yes & 6,928 & 80 \\
\hline $\begin{array}{l}\text { New Castle City } \\
\text { Sanitary Authority }\end{array}$ & PA0027511 & $\begin{array}{l}\text { Mahoning } \\
\text { River }\end{array}$ & 17 & $\begin{array}{l}0.55 \\
\text { (indirect) }\end{array}$ & $\begin{array}{l}\text { Indirect wastewater } \\
\text { from Advanced } \\
\text { Waste Services }\end{array}$ & $0^{c}$ & $0^{c}$ \\
\hline $\begin{array}{l}\text { Johnstown } \\
\text { Redevelopment } \\
\text { Authority, Domick } \\
\text { Point STP }\end{array}$ & PA0026034 & $\begin{array}{l}\text { Conemaugh } \\
\text { River }\end{array}$ & $12^{\mathrm{a}}$ & 0.076 & $\begin{array}{l}\text { None since } \\
\text { September } 2011\end{array}$ & $16,581.34$ & 328 \\
\hline Kiski Valley $^{b}$ & PA0027626 & $\begin{array}{l}\text { Kiskiminetas } \\
\text { River }\end{array}$ & 7 & $\begin{array}{l}0.09 \\
\text { (indirect) }\end{array}$ & $\begin{array}{l}\text { Indirect wastewater } \\
\text { from McCutcheon } \\
\text { Enterprises }\end{array}$ & $0^{c}$ & $0^{c}$ \\
\hline
\end{tabular}

${ }^{a}$ These POTWs may receive no more than 1 percent of their daily flow in oil and gas produced water

${ }^{\mathrm{b}}$ These POTWs stopped receiving oil and gas produced water as of September 30, 2011. Kiski Valley ordered McCutcheon to cease discharges to the plant May 19, 2011.

${ }^{\mathrm{c}}$ See amounts in Table 6 from pretreatment facilities.

${ }^{d}$ ln docket CWA-03-2011-0272DN, EPA ordered New Castle Sanitation Authority to discontinue its acceptance of oil and gas exploration and/or production wastewater as of September 28,2011. Additional sampling was required.

${ }^{\mathrm{p}}$ DEP spreadsheet with these data incorrectly lists Clariton Municipal Authority, Ridgway Borough Sewage Treatment Plant, Williamsport Sanitary Authority, and Altoona City Authority as CWTs and Castle Environmental as a POTW. Totals in these tables will not match a cursory analysis of the DEP spreadsheet data.

PAGE 29 | In Fracking's Wake: New Rules are Needed to Protect Our Health and Environment from Contaminated Wastewater 
Produced Water Disposal at Centralized Waste Treatment Facilities

An alternative to POTW treatment for removal of suspended solids and organic constituents is treatment at dedicated brine or industrial wastewater facilities, also called centralized waste treatment (CWT) facilities. These treatment plants utilize many of the same unit operations that are found in POTWs but may also add coagulation and precipitation techniques to remove a select set of dissolved solids. For example, removal of iron or barium or radium salts can be achieved through $\mathrm{pH}$ control and addition of chemicals that facilitate precipitation. Brine treatment plants using conventional techniques have been operating in the Marcellus production basin for many decades. After treatment, water can be discharged to surface water under a discharge permit, discharged to sewers for subsequent treatment in a POTW with a pretreatment permit, or subjected to additional treatment for removal of salts.

There were 17 dedicated brine treatment plants in Pennsylvania operating prior to August 21, 2010, when new Chapter 95 discharge regulations took effect. As of July 2011, 6 of the 15 facilities in Pennsylvania that were exempt from the new regulations were dedicated brine treatment facilities (see Table 6). ${ }^{9}$ Assessment of wastewater management from Marcellus drilling companies (provided to PADEP) indicates a 95 percent reduction in wastewater volumes going to Chapter 95-exempt CWT facilities between the first half of 2011 and the second half. ${ }^{59}$

There are also nonexempt brine treatment facilities that operate under the updated Chapter 95 regulations. These plants can process and return produced water for reuse or can discharge to surface water through permits, provided their treated water meets the new discharge limits (e.g., TDS must be less than $500 \mathrm{mg} / \mathrm{L}$ ). Due to a significant increase in volumes of produced waters associated with gas development, additional treatment facilities have been proposed and sited in Pennsylvania in the past two years. In Pennsylvania, as of April 2011, 25 new dedicated brine treatment facilities had applied for DEP permits. As of October 2010, three permits had been issued, two in Lycoming County and one in Somerset County. ${ }^{60}$ These plants are currently operating to provide partial treatment with return of water to the industry for reuse. Desalination stages are planned for many of the proposed plants; however, most plants recognize the significant cost differential to produce desalinated waters. Thus, treatment that includes full desalination is unlikely until reuse opportunities decline for their current product.

Five of seven drillers surveyed by Argonne National Laboratory reported sending some produced water to disposal companies in Pennsylvania or West Virginia. ${ }^{61}$ CWTs received significant volumes of wastewater in 2011 (see Table 2, above). The exact nature of treatment at CWTs, as well as the ultimate disposition of wastewaters sent to these plants and treated waters generated at these plants, are beyond the scope of the present analysis. Chapter 2 provides general information on removal techniques and summarizes available data on effluent characteristics at a few brine treatment plants.

\footnotetext{
${ }^{q}$ Note that there are 7 CWTs listed in Table 6. However, Advanced Waste Services discharges only to the New Castle City Sanitary Authority (a POTW listed in Table 5). This combination is considered a single facility since Advanced Waste Services does not have a permit for discharge.
} 
Table 6. CWT Facilities Permitted to Receive Produced Water Under Chapter 95 Exemption

\begin{tabular}{|c|c|c|c|c|c|c|}
\hline Name & Permit Number & $\begin{array}{l}\text { Receiving } \\
\text { Stream }\end{array}$ & $\begin{array}{l}\text { Total Permitted } \\
\text { Flow of Oil and } \\
\text { Gas Wastewater } \\
\text { (MGD) }\end{array}$ & Effluent Water Quality Data & $\begin{array}{r}\text { Marcellus } \\
\text { Produced } \\
\text { Water } \\
\text { Received } \\
\text { Jan.- June } \\
2011 \text { (bbl) }\end{array}$ & $\begin{array}{r}\text { Marcellus } \\
\text { Produced } \\
\text { Water } \\
\text { Received } \\
\text { July-Dec. } \\
2011 \text { (bbl) }\end{array}$ \\
\hline & & & & & $161,718.5$ & $7,908.73$ \\
\hline PA Brine Josephine & PA0095273 & $\begin{array}{l}\text { Blacklick } \\
\text { Creek }\end{array}$ & 0.144 & $\begin{array}{l}\text { Quarterly data provided to EPA. }{ }^{a} \text { DMR } \\
\text { data for November and December } 2011 \\
\text { available. }\end{array}$ & & \\
\hline PA Brine Franklin & PA0101508 & $\begin{array}{l}\text { Allegheny } \\
\text { River }\end{array}$ & & $\begin{array}{l}\text { Quarterly data provided to EPA. } \\
\text { DMR data for December } 2011 \text { available. }^{\text {b }}\end{array}$ & $584,524.86$ & $8,410.79$ \\
\hline $\begin{array}{l}\text { Hart Resource } \\
\text { Technologies }\end{array}$ & PA0095443 & McKee Run & $\begin{array}{l}0.045 \text { flowback; } \\
0.018 \text { gal } / \text { day } \\
\text { produced water }\end{array}$ & $\begin{array}{l}\text { Quarterly data provided to EPA. }{ }^{\mathrm{a}} \\
\text { Monthly DMR data available since } \\
\text { March 2011. }\end{array}$ & 106,769 & 86 \\
\hline Tunnelton Liquids & PA0091472 & $\begin{array}{l}\text { Conemaugh } \\
\text { River }\end{array}$ & $\begin{array}{l}0.1 \text { oil and gas and } \\
0.9 \text { acid mine } \\
\text { drainage }\end{array}$ & $\begin{array}{l}\text { No DMR Data } 2007-20100^{b} \\
\text { Limited data supplied to EPA. } \\
\text { Action by EPA pursuant to operation of } \\
\text { an unlicensed UIC well for disposal of } \\
\text { sludge from operations. }{ }^{62}\end{array}$ & $275,845.78$ & 0 \\
\hline $\begin{array}{l}\text { Advanced Waste } \\
\text { Services of PA } \\
\text { (formerly Castle } \\
\text { Environmental Inc.) }\end{array}$ & $\begin{array}{l}\text { PAR00051 } \\
\text { AWS and } \\
\text { PAR00002 as } \\
\text { CE }\end{array}$ & $\begin{array}{l}\text { N/A. } \\
\text { Discharges to } \\
\text { New Castle } \\
\text { City POTW }\end{array}$ & 0.2 & No DMR data. & $\begin{array}{r}544,006.6 \text { as } \\
\mathrm{AWS} \\
\text { and } 1,187 \text { as } \\
\mathrm{CE}\end{array}$ & 8,050 \\
\hline $\begin{array}{l}\text { McCutcheon } \\
\text { Enterprises }\end{array}$ & PAD013826847 & $\begin{array}{l}\text { N/A. } \\
\text { Discharges to } \\
\text { Kiski Valley }\end{array}$ & & $\begin{array}{l}\text { No DMR data. }{ }^{b} \text { Kiski Valley ordered } \\
\text { McCutcheon to cease discharges to the } \\
\text { plant May } 19,2011 \text {. }\end{array}$ & 83.559 & $16,867.61$ \\
\hline $\begin{array}{l}\text { Waste Treatment } \\
\text { Corporation }\end{array}$ & PA0102784 & $\begin{array}{l}\text { Allegheny } \\
\text { River }\end{array}$ & 0.21 & $\begin{array}{l}\text { DMR data monthly since } 2008 \text {, but no } \\
\text { TDS data. }\end{array}$ & $91,540.16$ & $1,014.28$ \\
\hline $\begin{array}{l}\text { Sunbury Generation } \\
\text { Wastewater } \\
\text { Treatment System }\end{array}$ & PA0008451 & $\begin{array}{l}\text { Susquehanna } \\
\text { River }\end{array}$ & 0.08 & $\begin{array}{l}\text { This is a power generating facility. DMR } \\
\text { data available but not specific to brine. } \\
\text { Suspended intake of Marcellus produced } \\
\text { water in April } 2011 \text {. }\end{array}$ & $121,868.4$ & 0 \\
\hline & & & & & $1,971,019.2$ & $41,331.13$ \\
\hline
\end{tabular}

${ }^{a}$ See requested analyses at epa.gov/region $3 /$ marcellus shale/\#npdeslets.

${ }^{\mathrm{b}}$ Some Discharge Monitoring Report (DMR) data are available at cfpub.epa.gov/dmr/index.cfm. Some additional data are also available at ahs.dep.state.pa.us/NRS/.

PAGE 31 | in Fracking's Wake: New Rules are Needed to Protect Our Health and Environment from Contaminated Wastewater 


\section{Beneficial Reuse}

The beneficial reuse of oil and gas brines has a long history in many states. For low-TDS produced water, a number of beneficial reuses have been investigated, including livestock watering, wildlife watering and habitat, aquaculture and hydroponic vegetable culture, irrigation of crops, washing of equipment, and fire control. ${ }^{63}$ None of these reuses are applicable to produced water from highly saline formations like the Marcellus Shale. They are not discussed further here.

In many areas, produced water can be used for dust control on unpaved roads (including lease roads in the oil or gas field and rural roads in the region) and for deicing or ice control on roads in northern climates during the winter. In 1983 Michigan published an evaluation of produced water that began with review of management in 1937. In the 1930s and 1940s, brine was either returned to the subsurface, used by the chemical industry for extraction of sodium or calcium chloride, or left in pits to evaporate or seep away. Application to roadways was first reported in 1952 (although it has occurred since the advent of the industry) and increased with the reduction in the use of earthen pit disposal in the early 1960s. ${ }^{64}$

The use of oil field brines for roadway dust suppression was previously studied by a number of states as management of production brines became more common. In general, produced waters are not as effective as commercial products and require more frequent reapplication; however, they are generally cost-effective. ${ }^{65}$ Produced waters can also be used for dust suppression in coal mining; it is not clear how widespread this use might be in coal regions as commercial products provide superior control. $^{66}$

Brine spreading management plans are usually prescriptive in the application rate and frequency; they also contain restrictions on proximity to water bodies and application during rain or when rain is imminent. ${ }^{67}$ The application of Marcellus brines for this beneficial reuse is permitted in Pennsylvania, provided they meet specified parameters for total salts, chloride, barium, and other constituents. According to press reports, in 200510 million gallons of brine were sprayed on roads in Pennsylvania. ${ }^{68}$

\section{Residuals Disposal}

In addition to the treated wastewater, all treatment methods produce residuals. These are solids removed in settling, coagulation, and precipitation processes; concentrated brines created through membrane desalination; and solid salts created through thermal desalination processes. These residuals must be managed. Wastewater sludges that are not dominated by salts can be managed through conventional processes, such as land application or landfill, depending on their characteristics. POTW sludge management is regulated on the basis of pathogen removal and metals content. ${ }^{69}$ Potential management options include land application, stabilization, and composting. Completely dewatered salt solids can go to solid waste disposal in a landfill. In Pennsylvania, landfills are required to monitor for radioactivity in waste. ${ }^{r}$

\footnotetext{
${ }^{\mathrm{r}}$ The solid waste facility operator must investigate any truck containing greater than $10 \mu \mathrm{R} /$ hour. Vehicles exceeding $2 \mathrm{mR} /$ hour in the cab or $50 \mathrm{mR} /$ hour on any other surface require notification of PADEP and isolation of
} 
Highly concentrated brine wastes have the same disposal options as the original produced waters, at lower transportation costs. The predominant disposal option for concentrated brines from inland desalination is deep well injection. If desalination brines are sent to conventional brine treatment facilities without TDS discharge limits, benefits of the concentration of these wastewaters are completely lost. For example, during a recent demonstration process, after treatment the residual brine that had been concentrated was then trucked to an approved commercial produced water disposal facility that operates under exemption to the Chapter 95 TDS standards. ${ }^{70}$ The concentrated brine was effectively re-diluted in the surface water discharge of the facility, negating all environmental benefit of the treatment process. ${ }^{\mathrm{s}}$ While the PADEP requests that drillers not take Marcellus produced waters to Chapter 95-exempt facilities, it does not specifically mention treatment residuals. It is not reasonable to concentrate produced water through an energy-intensive process and then dispose of the concentrate through dilution in surface waters. Concentrated brine should be disposed of through deep well injection (at UIC Class II wells).

\section{Resource Extraction}

A potential technology applied to other oil and gas brines, but not yet to shale gas produced water, is resource extraction. ${ }^{71}$ Methods for recovery of iodine and bromine from oil field brines were pioneered by Dow Chemical Company in the 1920s; this represented the only domestic production of iodine for many decades. Today iodine is produced in the United States from oil field brines in Oklahoma and Montana. ${ }^{72}$ Similarly, bromine recovery from oil field brines also has a long history. Current commercial production comes from non-oil-associated brines in Arkansas and Michigan. ${ }^{73}$ Lithium has also been extracted from brines in Nevada. ${ }^{74}$

waste and/or the vehicle for further investigation. See details in PADEP guidance: elibrary.dep.state.pa.us/dsweb/Get/Document-48337/250-3100-001.pdf.

${ }^{s}$ The system manufacturer notes that the brine disposal method selected for the demonstration will not reduce salt load to surface water, and that highly concentrated waste brines should be disposed of through deep well injection. 


\section{Chapter 2. Technology Analysis for Produced Water Treatment}

This chapter builds on the content of Chapter 1, which presented an overview of produced water management that included wastewater treatment options. This chapter summarizes technical details of treatment options and discusses how options are selected for specific produced waters.

Wastewater treatment can involve a number of different techniques, almost all of which have been tried for produced water from oil and natural gas development. There have been numerous reviews of produced water technologies for oil and coal bed methane produced water; Appendix A provides a list of these resources. Many of the same technologies are applicable to produced water from hydraulically fracturing shale formations for gas extraction. A critical difference for produced water from shale formations, and especially from the Marcellus formation, is the high concentration of salts. ${ }^{75}$

The quality of the produced water, regardless of its source, dictates the options for management. As described in the previous chapter, options include reuse and recycling, disposal, and treatment. This chapter deals exclusively with treatment. Treatment choices are determined by the nature and concentration of the contaminants in the wastewater, but other factors are also important. Treatment is designed to remove contaminants to specific target concentrations, so initial analysis of the wastewater and the objective in terms of the final water quality together influence treatment choices.

\section{Contaminants of Concern}

As discussed in Chapter 1, the major constituents of concern in produced water from natural gas development are (1) salts (measured as salinity, conductivity, or total dissolved solids), including metal ions, some of which are toxic, (2) organic hydrocarbons (sometimes referred to as oil and grease), (3) inorganic and organic additives, and (4) naturally occurring radioactive material (NORM). Many of these are present in produced waters from any oil and gas activity, although produced water from hydraulic fracturing may also include diluted quantities of the chemicals used for fracturing.

There are many ways to categorize the contaminants present in produced water from shale gas development. Contaminants can be organic or inorganic; soluble, insoluble, or suspended; scaleforming; oxygen-demanding; toxic; and naturally occurring or anthropogenic. Because the present analysis focuses on treatment options, contaminants will be categorized as they would be divided in specific routine analyses. It is always possible to produce a complete chemical analysis of any wastewater, but it is often prohibitively expensive to do so. Treatment decisions are often made on the basis of surrogate or lumped terms, or according to representative analyses rather than full chemical speciation of the wastewater.

Figure 1 shows the typical division of wastewater components in standard analysis. Filtration separates a wastewater into components that are suspended particles (like sand) and those that are dissolved chemicals (like salt or sugar). Suspended contaminants can be measured as total 
suspended solids (TSS, in mg/L) or as turbidity (in nephelometric turbidity units, or NTU). ${ }^{t}$ Suspended inorganic components are typically sand, grit, and scale. Suspended organic components include bacteria, oil and grease, and high-molecular-weight organic compounds such as natural and anthropogenic colloids and polymers. Inorganic and organic components of suspended solids can be determined separately by additional analysis. In analysis, organics are removed by heating the sample to volatilization temperature. The residual inorganics are called nonvolatile suspended solids, and the organics are classified as volatile suspended solids (VSS). When measured, VSS may also include smaller compounds that are sorbed to particulates; these chemicals might normally be soluble, but in the presence of suspended solids they may be removed as if they were solids themselves. This characteristic can be used to increase removal of dissolved organic compounds by addition of suspended solids with high sorptive capacity, such as powdered activated carbon.

Dissolved contaminants can be measured as total dissolved solids (TDS, in $\mathrm{mg} / \mathrm{L}$ ) or indirectly assessed by evaluating the electrical conductance of the water $(\mathrm{EC}$, in $\mathrm{mS} / \mathrm{cm})$. Dissolved inorganics can be individually quantified (as in measures of chloride concentration) or can be assessed through lumped terms (e.g., hardness, alkalinity). Dissolved organics include ionizable organic acids (e.g., acetic acid) and uncharged low-molecular-weight organics with moderate or high solubility (e.g., alcohols, BTEX). A lumped term, dissolved organic carbon (DOC), can be measured and represents the soluble organics in the system. Total organic carbon (TOC) can also be measured before filtration and will represent the dissolved and suspended carbon in the system.

Organic compounds can also be measured in units of oxygen demand. Oxygen demand units are routinely used in wastewater treatment to represent the amount of oxygen that would be used up if the contaminant were released into a water body. When oxygen-demanding waste enters the environment, microbial systems biodegrade it, using up oxygen; this leads to poor water quality and impairment of aquatic life. Chemical oxygen demand (COD) includes all oxygen demand, whether available to microbial systems or not, while biochemical oxygen demand (BOD) is generally measured using bacterial systems and represents compounds that are biodegradable. The $\mathrm{BOD} / \mathrm{COD}$ ratio is widely used to characterize the biodegradability of a wastewater. A high $\mathrm{BOD} / \mathrm{COD}$ ratio indicates that most of the compounds in the water that use up oxygen are biodegradable, while a low ratio indicates that the waste contains more materials that are not biodegradable. Biodegradable compounds are likely to be removed in conventional wastewater treatment in POTWs. Non-biodegradable compounds have less direct effect on oxygen consumption in the environment, but they may have other deleterious effects. And, by their nature, they are less likely to break down, possibly leading to accumulation in natural systems.

\footnotetext{
'Turbidity is a measure of the cloudiness of the water and is determined by measuring light attenuation through the sample.
} 
Figure 5. Wastewater Component Characterization

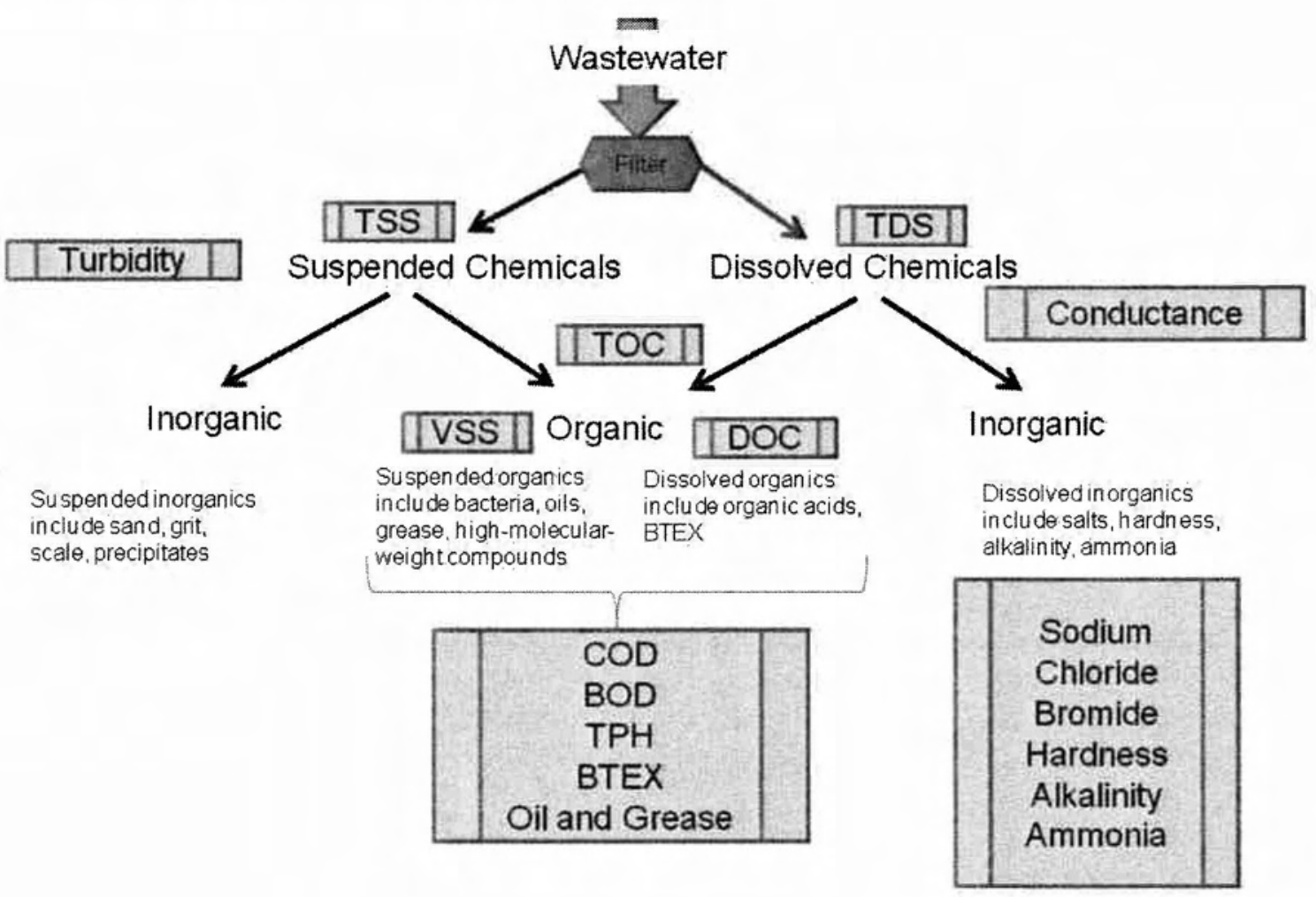


Table 1 provides summary data for the analysis of produced water from Marcellus Shale development. Most notable is the wide range of values for most constituents, suggesting high variability in the wastewater that will require treatment.

Table 1. Chemical Constituents in Produced Water from Marcellus Shate Development ${ }^{76, u}$

\begin{tabular}{|c|c|c|c|}
\hline $\begin{array}{l}\text { Ghemical constituent or surrogate } \\
\text { parameter }\end{array}$ & $\begin{array}{l}\text { Unit of } \\
\text { measure }\end{array}$ & $\begin{array}{l}\text { Range reported in } \\
\text { produced water from } \\
\text { wells drilled in } \\
\text { Marcellus Shiale at } 5 \\
\text { days post hydraulic } \\
\text { fracturing }\end{array}$ & $\begin{array}{l}\text { Range reported in } \\
\text { produced water from } \\
\text { wells drilled in } \\
\text { Marcellus Shale at } 14 \\
\text { days post hydraulic } \\
\text { fracturing }\end{array}$ \\
\hline Total Suspended Solids (TSS) & $\mathrm{mg} / \mathrm{L}$ & $10.8-3,220$ & $17-1,150$ \\
\hline Turbidity & NTU & $2.3-1,540$ & $10.5-1,090$ \\
\hline Total Dissolved Solids (TDS) & $\mathrm{mg} / \mathrm{L}$ & $38,500-238,000$ & $3,010-261,000$ \\
\hline Specific Conductance & umhos/cm & $79,500-470,000$ & $6,800-710,000$ \\
\hline Total Organic Carbon (TOC) & $\mathrm{mg} / \mathrm{L}$ & $3.7-388$ & $1.2-509$ \\
\hline Dissolved Organic Carbon (DOC) & $\mathrm{mg} / \mathrm{L}$ & $30.7-501$ & $5-695$ \\
\hline Chemical Oxygen Demand (COD) & $\mathrm{mg} / \mathrm{L}$ & $195-17,700$ & $228-21,900$ \\
\hline Biochemical Oxygen Demand (BOD) & $\mathrm{mg} / \mathrm{L}$ & $37.1-1,950$ & $2.8-2,070$ \\
\hline BOD/COD Ratio (\% biodegradable) & & & $0.1(10 \%)$ \\
\hline Alkalinity & $\mathrm{mg} / \mathrm{L}$ & $48.8-327$ & $26.1-121$ \\
\hline Acidity & $\mathrm{mg} / \mathrm{L}$ & $<5-447$ & $<5-473$ \\
\hline Hardness (as $\left.\mathrm{CaCO}_{3}\right)$ & $\mathrm{mg} / \mathrm{L}$ & $5,100-55,000$ & $630-95,000$ \\
\hline Total Kjeldahl Nitrogen (TKN) & $\mathrm{mg} / \mathrm{L}$ as $\mathrm{N}$ & $38-204$ & $5.6-261$ \\
\hline Ammonia Nitrogen & $\mathrm{mg} / \mathrm{L}$ as $\mathrm{N}$ & $29.4-199$ & $3.7-359$ \\
\hline Nitrate-N & $\mathrm{mg} / \mathrm{L}$ as $\mathrm{N}$ & $<0.1-1.2$ & $<0.1-0.92$ \\
\hline
\end{tabular}

\footnotetext{
"These data are from a single source (Hayes, "Sampling and Analysis of Water Streams"), with the exception of NORM (from Rowan et al., "Radium Content of Oil- and Gas-Field Produced Waters"). NORM data did not specify how long after well completion the samples were taken, and thus cannot be associated with either 5 or 14 days post hydraulic fracturing. BTEX and VOC data provided here have significant uncertainty. Data marked J are estimated due to analytical limitations associated with very high concentrations. Extensive data on produced water quality throughout the United States are available (see energy.cr.usgs.gov/prov/prodwat/intro.htm). Additional data specific to Marcellus are available from a variety of sources ( produced water treatment plants, PADEP, drilling companies), although they have not been collated into a single database, making summative analysis difficult.
} 


\begin{tabular}{|c|c|c|c|}
\hline $\begin{array}{l}\text { Chemieal constituent or surrogate } \\
\text { parameter }\end{array}$ & $\begin{array}{l}\text { Unit of } \\
\text { measure }\end{array}$ & $\begin{array}{l}\text { Range reported in } \\
\text { produced water from } \\
\text { wells drilled in } \\
\text { Marcellus Shale at } 5 \\
\text { days post hydraulic } \\
\text { fracturing }\end{array}$ & $\begin{array}{l}\text { Range reported in } \\
\text { produced water from } \\
\text { wells drilled in } \\
\text { Marcellus Shale at } 14 \\
\text { days post hydraulic } \\
\text { fracturing }\end{array}$ \\
\hline Chloride & $\mathrm{mg} / \mathrm{L}$ & $26,400-148,000$ & $1,670-181,000$ \\
\hline Bromide & $\mathrm{mg} / \mathrm{L}$ & $185-1,190$ & $15.8-1,600$ \\
\hline Sodium & $\mathrm{mg} / \mathrm{L}$ & $10,700-65,100$ & $26,900-95,500$ \\
\hline Sulfate & $\mathrm{mg} / \mathrm{L}$ & $2.4-106$ & $<10-89.3$ \\
\hline Oil and Grease & $\mathrm{mg} / \mathrm{L}$ & $4.6-655$ & $<4.6-103$ \\
\hline $\begin{array}{l}\text { BTEX (benzene, toluene, ethylbenzene, } \\
\text { xylene) }\end{array}$ & $\mu \mathrm{g} / \mathrm{L}$ & & Non-detect to 5,460 \\
\hline VOC (volatile organic compounds) & $\mu \mathrm{g} / \mathrm{L}$ & & Non-detect to 7,260 \\
\hline $\begin{array}{l}\text { Naturally occurring radioactive materials } \\
\text { (NORM) }\end{array}$ & $\mathrm{pCi} / \mathrm{L}$ & \multicolumn{2}{|c|}{$\begin{array}{l}\text { Non-detect- } 18,000 \mathrm{pCi} / \mathrm{L} ; \text { median } \\
2,460 \mathrm{pCi} / \mathrm{L}\end{array}$} \\
\hline Barium & $\mathrm{mg} / \mathrm{L}$ & $21.4-13,900$ & $43.9-13,600$ \\
\hline Strontium & $\mathrm{mg} / \mathrm{L}$ & $345-4,830$ & $163-3,580 \mathrm{~J}$ \\
\hline Lead & $\mathrm{mg} / \mathrm{L}$ & Non-detect- 0.606 & Non-detect-0.349 \\
\hline Iron & $\mathrm{mg} / \mathrm{L}$ & $21.4-180$ & $13.8-242$ \\
\hline Manganese & $\mathrm{mg} / \mathrm{L}$ & $0.881-7.04$ & $1.76-18.6$ \\
\hline
\end{tabular}

\section{Finished Water Quality Targets}

As described in Chapter 1, produced water management can include recycling/reuse, disposal, and treatment. Partial treatment is required for some reuse and disposal options, and water treatment criteria depend on the ultimate disposition of the water. Reuse may require partial treatment to avoid the reintroduction of scale-forming or biofouling contaminants into the next well. Similarly, disposal wells can become clogged if untreated produced water is disposed, and partial treatment is often undertaken to minimize this potential. Preventing well fouling generally requires removing suspended solids, organics that might encourage bacterial growth, and inorganics that precipitate (calcium carbonate and barium sulfate) with constituents expected in the formation. ${ }^{77}$ Reuse may also require reducing dissolved solids that alter water characteristics (e.g., increasing friction) or inactivate key additives. Table 2 provides general characteristics required for specific end uses of treated water. Most reuse water quality criteria would not permit the direct use of produced water from a high-salinity shale gas formation like the Marcellus, 
although water that returns during the early flowback period is often suitable for reuse. Partial treatment of produced waters from high-salinity formations might enable their use in applications requiring lower salt contents.

Table 2. Finished Water Quality Criteria for Specific Treatment Goals ${ }^{78}$

\begin{tabular}{|c|c|c|}
\hline Treatment Goal & Water Quality Needed & Potential for Use \\
\hline $\begin{array}{l}\text { Discharge to surface water } \\
\text { in Pennsylvania }\end{array}$ & $\begin{array}{l}<500 \mathrm{mg} / \mathrm{L} \text { TDS } \\
<250 \mathrm{mg} / \mathrm{L} \text { chloride } \\
<250 \mathrm{mg} / \mathrm{L} \text { sulfates } \\
<10 \mathrm{mg} / \mathrm{L} \text { total barium } \\
<10 \mathrm{mg} / \mathrm{L} \text { total strontium }\end{array}$ & Only with extensive treatment. \\
\hline $\begin{array}{l}\text { Reuse for hydraulic } \\
\text { fracturing }\end{array}$ & $\begin{array}{l}\text { Moderate TDS } \\
\text { Low SS } \\
\text { Low } \mathrm{Ca}, \mathrm{Mg}, \mathrm{Fe} \text {, sulfate (scale formers) }\end{array}$ & $\begin{array}{l}\text { Very likely and routinely } \\
\text { practiced, often with partial } \\
\text { treatment or dilution. }\end{array}$ \\
\hline Deep well disposal & $\begin{array}{l}\text { Low } \mathrm{Ca}, \mathrm{Mg}, \mathrm{Fe} \text {, sulfate (scale formers) } \\
\text { Low SS }\end{array}$ & $\begin{array}{l}\text { Very likely and routinely } \\
\text { practiced, sometimes with partial } \\
\text { treatment to reduce scale-forming } \\
\text { potential. }\end{array}$ \\
\hline Crop irrigation & $\begin{array}{l}\text { Low salinity (TDS) } \\
\text { Low sodium adsorption ratio ( } \mathrm{SAR}<6 \text { ) } \\
\text { Low toxicity }\end{array}$ & Only with extensive treatment. \\
\hline $\begin{array}{l}\text { Wildlife and livestock } \\
\text { consumption }\end{array}$ & $\begin{array}{l}\text { Moderate TDS }(<5,000 \mathrm{mg} / \mathrm{L}) \\
\text { pH } 6.5-8 \\
\text { SAR 5-8 }\end{array}$ & Only with extensive treatment. \\
\hline $\begin{array}{l}\text { Aquaculture and } \\
\text { hydroponic vegetable } \\
\text { culture }\end{array}$ & $\begin{array}{l}\text { Moderate TDS } \\
\text { Low metals }\end{array}$ & Only with extensive treatment. \\
\hline $\begin{array}{l}\text { Dust control on roads and } \\
\text { in mining }\end{array}$ & $\begin{array}{l}\text { Low SS } \\
\text { Low in specific constituents like metals }\end{array}$ & $\begin{array}{l}\text { Possible for some produced water } \\
\text { and for treated brines. }\end{array}$ \\
\hline $\begin{array}{l}\text { Vehicle and equipment } \\
\text { washing }\end{array}$ & $\begin{array}{l}\text { Low SS } \\
\text { Moderate TDS }\end{array}$ & Possible with dilution. \\
\hline Power-generation cooling & $\begin{array}{l}\text { Low SS } \\
\text { Moderate TDS } \\
\text { Low } \mathrm{Ca}, \mathrm{Mg}, \mathrm{Fe} \text {, sulfate (scale formers) }\end{array}$ & $\begin{array}{l}\text { Possible but unlikely due to } \\
\text { fouling problems. }\end{array}$ \\
\hline Fire control & $\begin{array}{l}\text { Low SS } \\
\text { Low organics }\end{array}$ & Possible but unlikely. \\
\hline Potable reuse & $\begin{array}{l}\text { SDWA }^{v} \text { criteria } \\
\text { Low DBP formation potential } \\
\text { Adequate mineral content }\end{array}$ & $\begin{array}{l}\text { Very unlikely. Indirect potable } \\
\text { reuse through aquifer recharge } \\
\text { possible with extensive treatment. }\end{array}$ \\
\hline
\end{tabular}

\section{Generic Treatment Technology Analysis}

${ }^{\vee}$ SDWA: Safe Drinking Water Act. Potable reuse requires meeting all primary drinking-water standards. Drinkingwater users may also desire water that meets secondary standards for aesthetics like color, taste, and odor. 
All treatment methods have the same general characteristics (see Figure 2). Wastewater containing a mixture of contaminants $\left(\mathrm{C}_{1}, \mathrm{C}_{2} \ldots \mathrm{C}_{\mathrm{i}}\right)$ enters the treatment process at a specific flow rate $(\mathrm{Q})$. A chemical, physical, or biological process takes place in the treatment system to produce a finished water that is lower in the target contaminants. The process creates a residual containing the contaminants that have been removed or the by-products of their transformation. This residual can be a liquid stream, a solid or sludge product, or a gaseous stream. The separation of the contaminant from the water generally requires significant chemical and energy inputs. The nature of the inputs depends dvon the process, the quality of the influent wastewater, and the desired quality of the effluent finished water.

Figure 6. Generic Wastewater Treatment

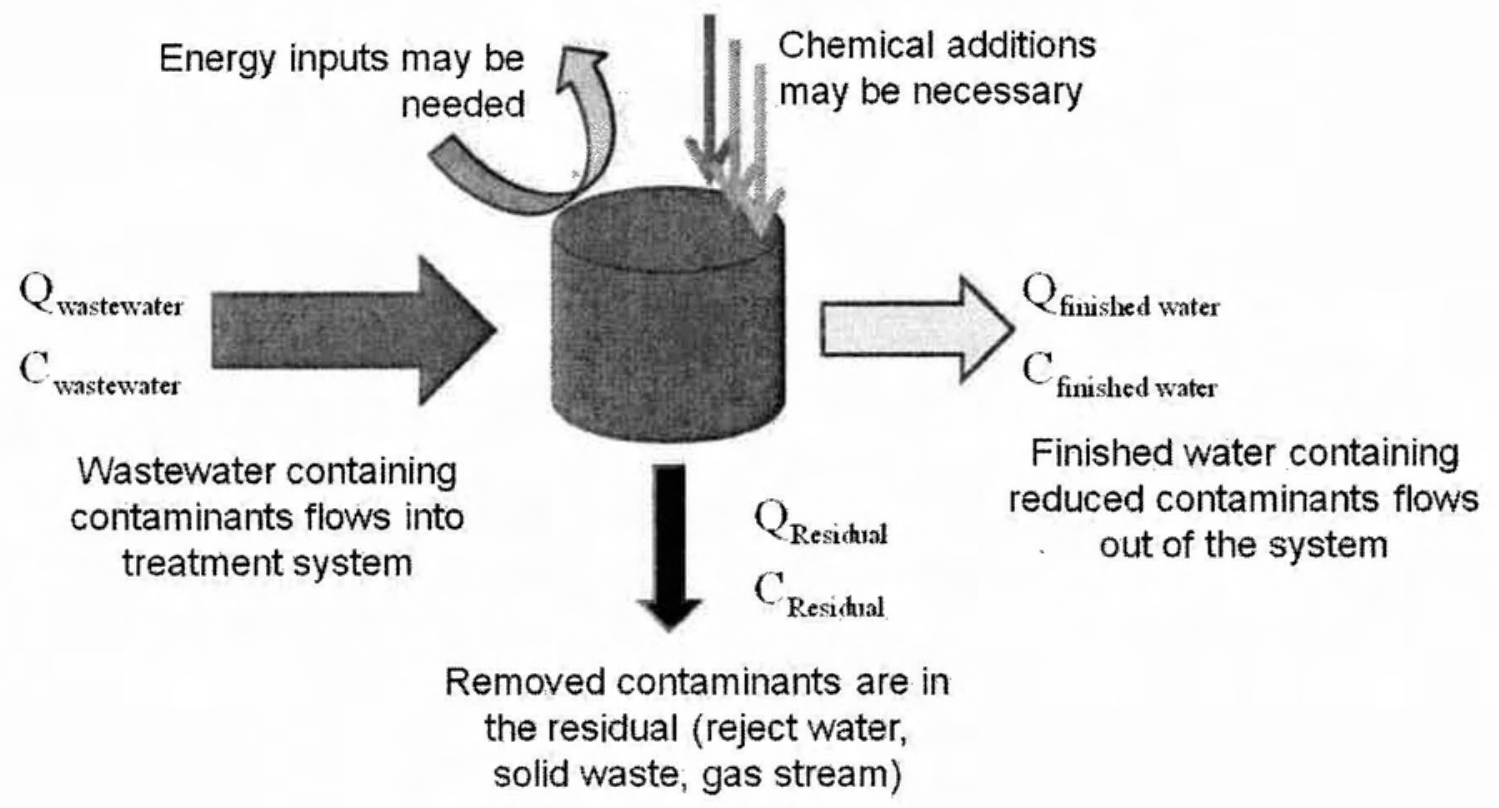

\section{Selecting Treatment Processes}

Once the influent wastewater is characterized (see Figure 1), and the final water quality desired is known (see Table 2), a treatment system made up of different components can be selected (see Table 3). Figure 3 details the decision framework for a generic wastewater that might contain all the constituents of concern described above. A treatment system must begin with removal of suspended solids, inorganic or organic, and then remove dissolved organics and potentially scaleforming constituents. Finally, when all that remains is simple dissolved salts, desalination can be 
accomplished. While it is possible to combine treatment steps, desalination is typically very sensitive to contaminants that foul membranes or reduce efficiency. Thus, if the target is water quality suitable for discharge to surface water, all of the shown treatment steps will be necessary, with water moving through each stage. Reuse or disposal targets that do not require desalinated water will need fewer stages. Shown on the left of Figure 3, partially treated water can be sent to reuse or disposal after any unit operation. Shown on the right, residuals are formed from each treatment step. At the bottom, fully desalinated water can be used for any application; however, distilled water is corrosive and requires re-mineralization for most uses. Within each treatment step, there are various technologies that can be employed. For example, soluble organics can be removed through biodegradation, sorption, or chemical oxidation. Table 3 shows the treatment options for each type of removal. Treatment methods are summarized in this section.

\section{Table 3. Treatment Methods for Classes of Contaminants in Produced Water}

\begin{tabular}{|c|c|c|c|}
\hline Class & Examples. & Surrogate Parameter & Treatment Wethods \\
\hline $\begin{array}{l}\text { Suspended } \\
\text { solids }\end{array}$ & $\begin{array}{l}\text { Sand, grit, scale } \\
\text { Bacteria }\end{array}$ & $\begin{array}{l}\text { Total suspended solids } \\
\text { Turbidity }\end{array}$ & $\begin{array}{l}\text { - Coagulation/flocculation with } \\
\text { sedimentation and filtration } \\
\text { - } \quad \text { Microfiltration or ultrafiltration }\end{array}$ \\
\hline $\begin{array}{l}\text { Suspended } \\
\text { organics }\end{array}$ & $\begin{array}{l}\text { Oil, grease, } \\
\text { colloids, bacteria }\end{array}$ & $\begin{array}{l}\text { Oil and Grease } \\
\text { Total organic carbon } \\
\text { Chemical or biological } \\
\text { oxygen demand }\end{array}$ & $\begin{array}{l}\text { - Dissolved air flotation } \\
\text { - } \quad \text { Biodegradation } \\
\text { - } \text { Adsorption (activated carbon, } \\
\text { - } \quad \text { Microfites) } \\
\end{array}$ \\
\hline $\begin{array}{l}\text { Dissolved } \\
\text { organics }\end{array}$ & $\begin{array}{l}\text { BTEX: benzene, } \\
\text { toluene, } \\
\text { ethylbenzene, } \\
\text { xylene } \\
\text { Phenols, organic } \\
\text { acids }\end{array}$ & $\begin{array}{l}\text { Dissolved organic carbon } \\
\text { BTEX } \\
\text { VOC } \\
\text { Specific chemical additives } \\
\text { (see Table } 4 \text { in Chapter } 1 \text { ) }\end{array}$ & $\begin{array}{l}\text { - Adsorption (activated carbon, } \\
\text { organoclays, zeolite, resins) } \\
\text { - } \quad \text { Chemical (ozonation, fenton) } \\
\text { - } \\
\text { oxidactrochemical or photocatalytic } \\
\text { - } \quad \text { Biodegradation } \\
\text { - }\end{array}$ \\
\hline $\begin{array}{l}\text { Dissolved } \\
\text { multivalent } \\
\text { ionic species }\end{array}$ & $\begin{array}{l}\text { Scale-formers: } \\
\mathrm{Ca}, \mathrm{Mg}, \mathrm{Fe} \text {, } \\
\mathrm{Sr}, \mathrm{Ba} \text {, sulfate } \\
\text { NORM }\end{array}$ & $\begin{array}{l}\text { Hardness } \\
\text { Specific metals (Iron, } \\
\text { Strontium, Barium) } \\
\text { Specific anions (sulfate, } \\
\text { nitrate-nitrogen) }\end{array}$ & $\begin{array}{l}\text { - Metals: aeration, settling, } \\
\text { filtration; ion exchange, reverse } \\
\text { osmosis } \\
\text { - Hardness: ion exchange } \\
\text { - } \quad \text { NORM: ion exchange, lime } \\
\text { softening, reverse osmosis }\end{array}$ \\
\hline $\begin{array}{l}\text { Dissolved } \\
\text { monovalent } \\
\text { ionic species }\end{array}$ & $\begin{array}{l}\mathrm{Na}, \mathrm{K}, \mathrm{Cl}, \\
\mathrm{Br}, \mathrm{I} \\
\mathrm{NH}_{4}^{+}\end{array}$ & $\begin{array}{l}\text { Specific ions: } \mathrm{Na}, \mathrm{Cl}, \mathrm{Br} \\
\text { Ammonia-nitrogen }\end{array}$ & $\begin{array}{l}\text { - Thermal desalination } \\
\text { - } \text { Membranes } \\
\text { - Electrochemical }\end{array}$ \\
\hline
\end{tabular}


Figure 7. Decision Flow chart for Produced Water Treatment

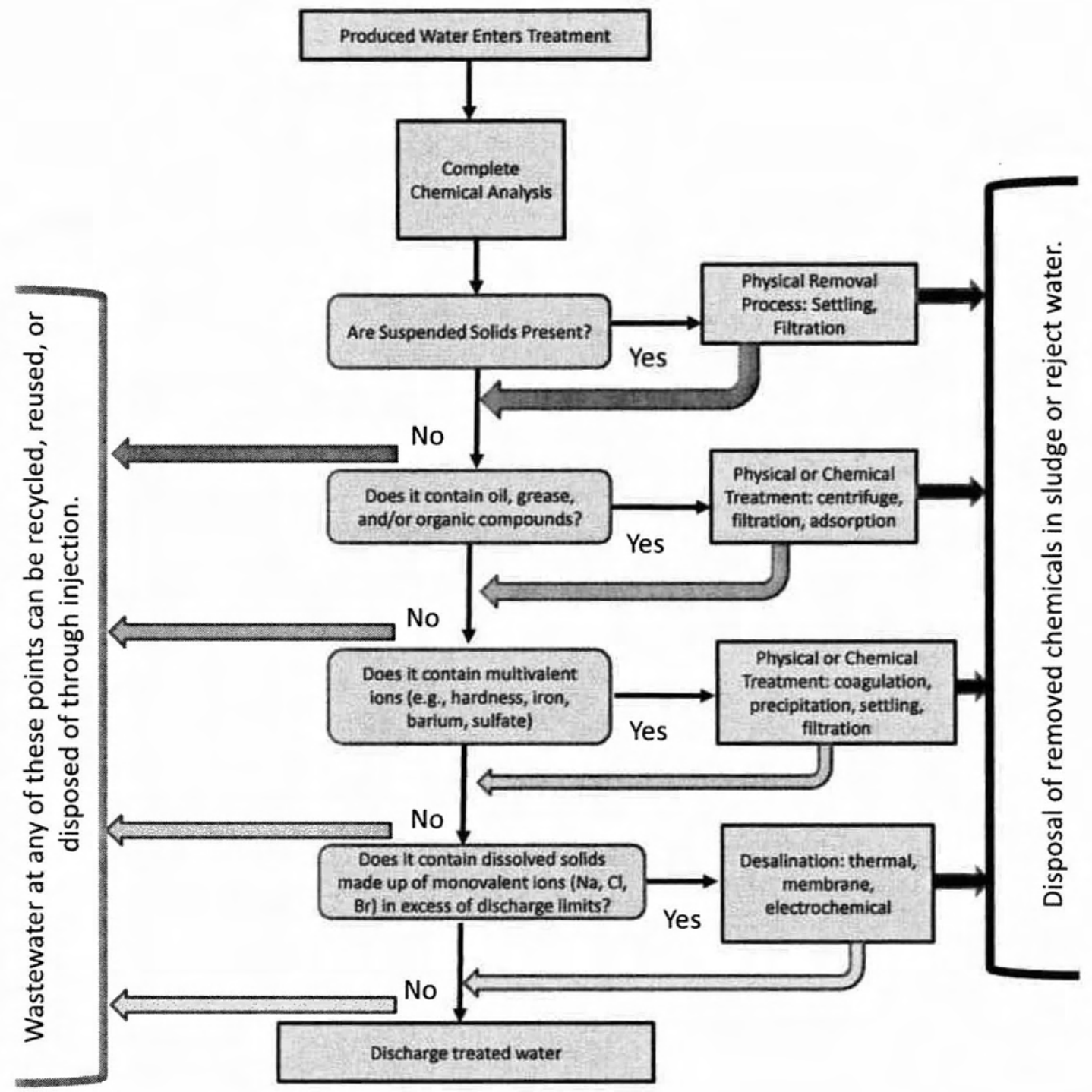

\section{Treatment Processes}

As the right side of Figure 3 shows, numerous treatment methods might be employed for produced water, depending largely on the target contaminants for removal. There are some overlaps, with certain physical, chemical, and biological processes suitable for multiple targets. For detailed technical analysis, refer to the Produced Water Management Information System (PWMIS) developed by Argonne National Laboratory and accessible on the U.S. Department of Energy website, managed by the National Energy Technology Laboratory (NETL). ${ }^{79}$ The PWMIS includes a decision support tool that incorporates technological as well as policy and 
regulatory aspects into selection of an appropriate produced water management decision. Similar decision support tools have been suggested to include an evaluation of trade-offs including environmental effects, costs, and health and safety issues. ${ }^{80}$

\section{Physical Processes for Removal of Suspended Solids}

Particles settle out of the water when they are of sufficient size and density. For example, sand particles will settle out of water that is not moving. Simple gravity settling tanks are sufficient for large particles. If particles are smaller or less dense, filtration can be used. Simple filtration removes suspended solids from produced water by passing the water through a medium (e.g., sand and gravel) where particles are captured by physical sieving or by electrostatic interaction with the media. Membrane filtration systems (e.g., ceramic or cellulosic) can also be used for suspended solids removal, but energy needed for these systems increases as pore size decreases. When smaller particles or higher amounts of suspended solids are present, coagulation can be used. Chemical addition encourages the formation of larger particles that can be removed through gravity settling tanks or filtration.

Marcellus Shale produced water has moderate suspended solids, and simple gravity-driven settling or media filtration at the well is routinely practiced to allow reuse of water produced during the flowback period. Similar separation is often included in pretreatment of water that will be disposed of through deep well injection, as solids can damage equipment and cause premature clogging of the formation receiving the produced water.

Physical or Chemical Treatment for Removal of Organic Compounds

Removal of organics in produced water is typically via physical or chemical methods. Physical means are well suited to organics that exist in a separate phase from water, such as oil and grease, which are often removed in the same settling tanks used to remove particles. Oil and organics that are dissolved in the oil are less dense than water, forming a separate phase that rises to the top of settling tanks, also called "knockout tanks" in the oil production industry. Selective withdrawal of materials from the tank allows removal of the oil layer at the top and the sediment layer at the bottom. Cleaner water is withdrawn from the mid-level. Additional physical processes including centrifugation and cyclones can also be used to separate materials by density, with lighter oils and organics separated from heavier water and suspended solids. Membrane-based physical methods for oil and organics removal have also been used for produced water. ${ }^{81}$ Multistage filtration is often required to reduce fouling on small-pore filters. Ultra- and nanofiltration are based on metal oxides and carbides that are stable under harsh chemical and thermal conditions; however, they have high initial costs and large footprints. Physical treatment based on sorption (onto activated carbon or zeolite) can also be used.

Chemical treatment methods can involve addition of chemicals that oxidize the organic matter to $\mathrm{CO}_{2}$ and water. Such additives can also oxidize inorganics (e.g., metals) to forms that are less soluble and can be removed after precipitation. Biological processes can also be used for oxidation of organics; however, halophilic (salt-tolerant) organisms must be used due to the high salinity of the produced water. ${ }^{82}$

\section{Physical or Chemical Treatment for Removal of Dissolved Multivalent Ions}

Many dissolved metals can be removed from water through chemical processes that enhance formation of insoluble precipitates. For example, raising the $\mathrm{pH}$ will increase precipitation of 
hydroxides of many different metals, and chemical oxidants will oxidize metals to less soluble forms (e.g., $\mathrm{Fe}^{2+}$ to $\mathrm{Fe}^{3+}$ ). Addition of sulfate will precipitate barium salts. Such processes have been used in industrial and potable water treatment systems for many decades and are well understood and relatively simple to operate. Once dissolved solids are converted to insoluble form, they can be removed as other suspended solids through coagulation, settling, and filtration systems. For example, lime softening involves addition of chemicals that precipitate $\mathrm{Mg}$ and $\mathrm{Ca}$ ions (removing hardness). Lime softening is also effective at removal of radium- 226 and radium-228 (constituents of NORM). Polyvalent anions can also often be removed through precipitation. For example, sulfate and phosphate can be removed through addition of aluminum or iron salts that form insoluble precipitates that are then settled or filtered.

Ion exchange is a physical process that can be used to remove specific ions by replacing them with ions of less concern (e.g., barium can be exchanged for calcium). Ion exchange is effective for a wide range of metals including NORM ( $\mathrm{Ra} 226 / 228$, uranium, and beta particle emitters).

Chemical additives are not inexpensive; however, such processes are much less costly than desalination. Produced water treatment systems based on this type of chemical processing are widespread. An example process, the Advanced Oxidation and Precipitation Process (AOPP), involves oxidation of metals with ozone to induce precipitation and is designed to facilitate reuse of produced water by reducing scale and microbial growth. ${ }^{83}$

\section{Existing Physical-Chemical Treatment Plants in the Marcellus Region}

Many of the brine treatment plants currently operating in Pennsylvania (as described in Chapter 1) use the technologies for removal of suspended solids, soluble organics, and multivalent ions reviewed above. The final step shown in Figure 3, desalination, is the most energy intensive, and consequently many facilities treat to this point and then repurpose the water for activities in oil and gas development. Specifically, reuse of produced water that contains only simple salts (e.g., $\mathrm{NaCl}, \mathrm{KBr}$ ) is widespread and generally economical if disposal wells are distant or freshwater sources are limited.

For example, Reserved Environmental Services, located in Hempfield Township in Pennsylvania's Westmoreland County, operates a treatment facility designed to handle 1 million gallons per day of produced water from gas development in the Marcellus Shale. Currently it removes multivalent ions (metals like iron and anions like sulfate) and organics through coagulation, settling, and filtration. It produces a finished water that is still quite high in TDS, but predominantly sodium and chloride. Similarly, Hydro Recovery LP is using a Siemens Water system composed of staged precipitation and dewatering to treat produced water in Tioga County, Pennsylvania. Suspended solids, metals, and hardness are removed, and the resulting brine is reused after dilution in subsequent hydraulic fracturing.

Brine treatment facilities that process produced water with subsequent discharge under exemption to the Chapter 95 TDS standards also usually follow a conventional treatment process that removes suspended solids and uses physical and chemical reactions to remove sulfate and multivalent cations (e.g., iron, calcium, barium). Effluent monitoring from these facilities indicates high TDS and detectable concentrations of other contaminants. Table 4 summarizes 
data for three facilities in southwestern Pennsylvania. ${ }^{\text {w }}$ Because no specific data are available regarding influent concentrations of the brine entering these plants, which is likely a mixture of coal bed methane produced water and oil and gas produced water from many different formations, treatment efficiencies cannot be assessed. However, it is clear that multistep conventional treatment does not remove all contaminants, either organic (measured here as oil and grease) or inorganic (measured as TDS and specific ions). The wide variability in finished water quality is likely related to the wide variability in water quality sent to these plants rather than any operational variability; however, this cannot be confirmed. Treatment plants using traditional physical-chemical methods will usually remove significant amounts of suspended solids, some organic constituents, and some dissolved multivalent ions. Some organic and inorganic dissolved constituents and almost all monovalent salts will pass through treatment, as indicated by high levels of TDS, chloride, and bromide in the discharged water reported in Table 5 .

\footnotetext{
${ }^{w}$ See Chapter 1, Table 6, for facility details and volumes of Marcellus wastewater delivered to these facilities in 2011.
} 
Table 4. Water Quality Analysis of Brine Treatment Plant Effluent ${ }^{2}$

\begin{tabular}{|c|c|c|c|c|c|}
\hline 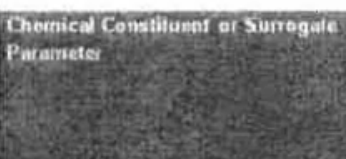 & $\begin{array}{l}\text { Thir of } \\
\text { Mesure: }\end{array}$ & 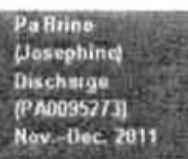 & 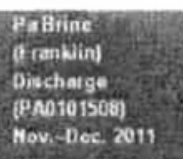 & 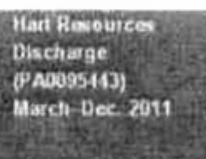 & 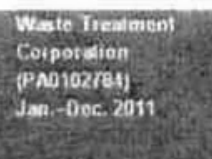 \\
\hline Flow & MGD & 0.155 & 0.18 & 0.018 .0 .045 & $0.164 \cdot 0.214$ \\
\hline Total Suspended Solids (TSS) & $\mathrm{mg} / \mathrm{L}$ & 20.5-32 & $<10$ to 33 & $6-19.5$ & $2.5 \cdot 17$ \\
\hline Oil and Grease & $\mathrm{mgh}$ & $5.25 \cdot 10.6$ & 2.25 .9 .49 & $3.8-22$ & $<56.8$ \\
\hline Total Dissolved Solids (TDS) & $\mathrm{mg} / \mathrm{L}$ & $133,050-198,400$ & $91,600-108,000$ & $7,200-179,900$ & Not reported \\
\hline Alkalinity $\left(2 \mathrm{CaCO}_{3}\right)$ & $\mathrm{mg} / \mathrm{L}$ & 185.236 & 57.95 & $45-258$ & 45.56 \\
\hline Acidity $\left(\mathrm{as} \mathrm{CaCO}_{3}\right)$ & $\mathrm{mg} / \mathrm{L}$ & 0 & 0 & 1 to $<2$ & 1.31 \\
\hline Chlotide & $\mathrm{mgh}$ & $64,404.96,909$ & $48,500-54,300$ & $3300-91,728$ & $69,800-131,725$ \\
\hline Bromide & $\mathrm{mg} / \mathrm{h}$ & $1100-8290$ & $603-727$ & $76.20-6630$ & Not reported \\
\hline Sulfate & $\mathrm{mgh}$ & $975-1000$ & 534.841 & $104-1500$ & Not reported \\
\hline Iron & $\mathrm{mg} \Omega$ & 0 & $0.31-0.519$ & $0.14-1.37$ & $0.13 \cdot 1.84$ \\
\hline Strontium & $\mathrm{mg} / \mathrm{L}$ & Not reparted & 299.303 & Not reported & Not reported \\
\hline Barium & $\mathrm{mg} / \mathrm{h}$ & $12.3-18.5$ & $6.78-8.99$ & $2.775-13.78$ & Not reported \\
\hline NORM: & & NO & ND & NO & Nat Renerted \\
\hline $\begin{array}{l}\text { U1 anium } \\
\text { Radium_228 }\end{array}$ & $\begin{array}{l}\mu g / 2 \\
\mathrm{pcin}\end{array}$ & $8.39-15.6$ & $3.6-15.6$ & $2.63-8.31$ & \\
\hline Gross Alpha & pCir. & 0.132 & $0.132-156$ & $6.39-117$ & \\
\hline Radium-226 & $\mathrm{pCuL}$ & $1.75 \cdot 2.23$ & $1.75-1.77$ & $0.815-7.94$ & \\
\hline
\end{tabular}

These data from the DMR website at http //umw . ahs.dep. state.pa. uSNRS/ and from data submissions to EPA posted at

itto: / Mnmwepa goviregion03imarcellius shalef Note that DMR data and EPA web ste disclosure data to not agree on a number of

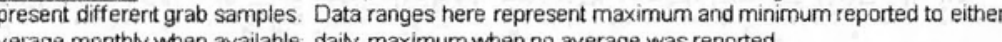

agency, Values are based on average monthly when available; daily maximum when no average was reported

\footnotetext{
${ }^{\mathrm{x}}$ These data are from the DMR website at ahs.dep.state.pa.us/NRS/and from voluntary data submissions to EPA posted at epa.gov/region03/marcellus_shale/. Note that DMR data and EPA website disclosure data do not agree on a number of constituents, suggesting they represent different grab samples. Data ranges here represent maximums and minimums reported to either agency. Values are based on monthly average when available and daily maximum when no average was reported. All available data are provided; no data are reported for items not specified in the permit, for example, hydraulic fracturing chemical additives. NORM and bromide were reported separately in response to a special request from EPA and are not routinely monitored for permit compliance.
} 
Treatment for Removal of Monovalent Ions: Desalination

While treatment to remove suspended solids, dissolved organics, and multivalent ions is widespread and relatively cost-effective, treatment to remove monovalent ions (e.g., $\mathrm{Na}, \mathrm{K}, \mathrm{Cl}$, $\mathrm{Br}$ ) is much more challenging. The removal of monovalent ions is commonly referred to as desalination or demineralization. Desalination has been used to produce potable water from seawater for thousands of years, and simple methods based on boiling water and collecting the condensate remain relatively easy to execute. However, they are prodigious consumers of energy. Extensive research on lower-cost desalination methods has yielded a number of viable thermal-based methods such as vapor compression, distillation, multistage flash, dew vaporization, freeze-thaw, evaporation, and crystallization. New non-thermal-based methods are also being developed, including reverse osmosis (RO) with or without vibratory shear-enhanced processing (VSEP), nanofiltration, electrodialysis, electrodeionization, capacitive deionization, membrane distillation, and forward osmosis. Each method has its challenges, and no method works across all produced water characteristics. Table 5 summarizes the treatability range (in TDS) and energy required for the major desalination methods. Details are briefly provided in this section. Again, please refer to the PWMIS for detailed technical specifications relevant to produced water treatment.

\section{Thermal Methods}

Thermal desalination methods are all based on the fundamental process of changing the phase of the water. Evaporation of water from brine results in water vapor and a more concentrated brine or solid salt residual. Significant energy is required to evaporate water, which must be supplied by sunlight in the case of evaporation ponds ${ }^{84}$ or solar-driven desalination plants, ${ }^{85}$ or by the freeze-thaw cycle ${ }^{86}$ or externally supplied heat in the case of industrial desalination plants. ${ }^{87}$ Conventional desalination techniques can be more energy efficient when water is being produced under pressure or returns at an elevated temperature, and therefore on-site treatment may be preferable to centralized facilities that would not have access to the warm produced water. ${ }^{88}$

A wide variety of methods have been developed based on thermal processes, and traditional distillation/evaporation methods have been applied to shale gas produced water. ${ }^{89}$ For example, in Fort Worth in the Barnett Shale, Devon Energy has a thermal desalination system that treats 2,500 barrels/day of produced water and yields 2,000 barrels/day of freshwater. It requires 100 $\mathrm{MCF} /$ day of natural gas as the energy source. ${ }^{90}$ Also in Fort Worth, Chesapeake employs an evaporative method using waste heat from a compressor. ${ }^{y}$

The potential to use waste heat is an important consideration in energy-intensive operations, and co-location of the desalination system with the gas compression equipment provides this opportunity. ${ }^{91}$ Altela, Inc. has a patented process based on evaporation/condensation that uses waste heat or natural gas (AltelaRain ${ }^{\circledR}$ ). Finished water from the process has been permitted for reuse and discharge in New Mexico and Colorado and meets discharge criteria for Pennsylvania. ${ }^{92}$ This is an evaporation-based humidification-dehumidification process, which is typically quite energy intensive ${ }^{93}$ However, several reports indicate costs are 30 percent of comparable distillation/evaporation processes. ${ }^{94}$ Finished water is 80 percent of source water by volume and contains significantly reduced dissolved solids $(9-400 \mathrm{mg} / \mathrm{L}) .{ }^{95}$

\footnotetext{
${ }^{y}$ Waste heat is heat that is generated from electrical units unintentionally. This heat is typically dissipated in the environment, but it can be captured and used for evaporative processes.
} 
AquaPure Ventures has teamed with Eureka Resources to provide treatment of produced water with the Fountain Quail Water Management System. Portable pretreatment and mechanical vapor recompression evaporation provides treatment to $500 \mathrm{mg} / \mathrm{L}$ TDS. ${ }^{96}$ Purestream Technology markets several thermal desalination methods for produced water, including AARA, a vapor compression method, and Trilogy, a flash evaporation method. General Electric (GE) markets a truck-mounted mobile evaporator with crystallization. ${ }^{97}$

Non-Thermal Membrane Methods

Membrane-based methods include desalting membranes (reverse osmosis, nanofiltration, forward osmosis, direct-contact membrane distillation) and electrically driven processes (electrodialysis, electrodialysis reversal, electrodeionization). Membrane methods are designed to remove small monovalent ions; reverse osmosis is also known to be effective for removal of constituents of NORM, including alpha and beta particle emitters, radium-226, radium-228, and uranium. Methods and their applications in produced water are summarized here, but most of these methods are not viable for Marcellus-associated produced water, which usually have TDS greater than $60,000 \mathrm{mg} / \mathrm{L}$.

Reverse osmosis (RO) membranes are well suited to desalination of moderate brines (up to $35,000 \mathrm{mg} / \mathrm{L}$ ) in the absence of oil and other organics. ${ }^{98}$ Organics cause membrane fouling and reduce the efficiency of salt removal; consequently, extensive pretreatment is often necessary to control water chemistry and reduce fouling. Reverse osmosis has been used on lower-TDS produced waters from natural gas extraction. EnCana is operating an RO membrane with a $10,000 \mathrm{barrel} /$ day throughput. It can handle chloride content of up to $20,000 \mathrm{ppm}$, and it requires $100 \mathrm{MCF} /$ day of natural gas as the energy source. ${ }^{99} \mathrm{GE}$ developed a mobile unit based on RO to process low-TDS flowback water $(<35,000-45,000 \mathrm{mg} / \mathrm{L}$ TDS $) .{ }^{100}$ Advances in membrane technology may improve RO performance, but at present most Marcellus-derived produced waters cannot be treated through RO as TDS exceeds $40,000 \mathrm{mg} / \mathrm{L} .^{101}$

Forward osmosis (FO) is an osmotically driven membrane process that uses high-salinity water to draw water across a membrane. ${ }^{102}$ It can be used to desalinate with input energy or to generate energy with input freshwater. In 2010, NETL reported funding a project at West Virginia University to evaluate the use of FO for Marcellus produced water. Separately, the U.S. Department of Energy's National Energy Technology Laboratory funded the New Mexico Institute of Mining and Technology to test a produced water treatment system based on FO. ${ }^{103}$ Results are not available for these studies yet; however, FO has well-known challenges having to do with fouling.

Direct-contact membrane distillation (DCMD) induces a partial vapor pressure gradient and direct condensation of extracted vapor in a cold freshwater stream. ${ }^{104}$ DCMD can desalinate high-concentration brines, and it can take advantage of the heat associated with the brine as it returns to the surface. ${ }^{105}$ In 2010, NETL reported on research ongoing at Sandia National Laboratory in membrane distillation for treatment of Marcellus produced water.

Electrodialysis (ED) is an electrically driven membrane process using stacks of alternating anion and cation selective membranes that separate dissolved ions from water as it passes through. ED reversal (EDR) involves reversing the polarity of the electrodes frequently to reduce the 
formation of scales, which reduce efficiency. ED and EDR achieve low final TDS ( $\sim 200 \mathrm{mg} / \mathrm{L})$ and can be used to remove multivalent as well as monovalent ions, eliminating the need for some pretreatment steps. Lower pressures are needed than for RO, reducing energy costs, and the product stream is 90 percent of the influent stream. Sirivedhin et al. report on treatment of produced water from multiple locations using ED, which worked well for low-salt waters $(\sim 5,000 \mathrm{mg} / \mathrm{L})$ but was prohibitively expensive for high-salt waters $(>60,000 \mathrm{mg} / \mathrm{L}){ }^{106}$ Electrodeionization (EDI) is a modification of ED whereby ion-exchange media are placed between the membranes. This enables removal of salt to very low concentrations $(<10 \mathrm{mg} / \mathrm{L}$ TDS) with reduced energy input. ${ }^{107}$ EDI is often used where very low-salt process water is needed, but it is rarely applied to produced waters due to the high cost associated with high TDS.

Capacitive deionization (CDI) is a "new" technology based on an old process, the removal of ions dissolved in water with electric current. ${ }^{108}$ Capital costs are higher than for membrane systems, but operation and maintenance costs are lower. CDI can also regenerate electricity during a capacitive discharge step. Organics can foul the electrodes and reduce performance, so pretreatment is necessary in this application as in most membrane-based processes. CDI is suited to low-TDS wastewaters $(1,500-5,000 \mathrm{mg} / \mathrm{L})$ and is not likely to be applied to shale gas produced water. ${ }^{109}$ A modified CDI-ED method has been applied to coal bed methane produced water; however, the range of TDS treated remains low $(2,000-10,000 \mathrm{mg} / \mathrm{L}) .{ }^{110}$ A modification called membrane capacitive deionization (MCDI) has been applied to higher-TDS waters. ${ }^{111}$ Advances in CDI/MCDI are expected as improved membranes are developed, particularly those based on carbon nanotubes. ${ }^{112}$ In 2010, NETL reported funding a project at West Virginia University on capacitive deionization for coal bed methane produced water; results are not yet available.

Table 5 summarizes desalination treatment technologies. Most methods are suitable for low- and moderate-TDS wastewaters (up to $40,000 \mathrm{mg} / \mathrm{L}$ ). Thermal methods must generally be used above that level. All methods are energy intensive and produce concentrated brine or solid salt residuals. Finished water from desalination can be of very high quality, with the TDS in the product water controlled by the energy inputs. Very low-TDS water can be produced; however, caution should be used when designing a system to achieve distilled water quality. Soft water (low in calcium and magnesium) can be corrosive; pipe transport of desalinated water will leach metals and pipe wall precipitates. Fully desalinated water is not considered potable, and remineralization is necessary, ${ }^{113}$ so full desalination is not typically the target unless a constituent (e.g., bromide) must be reduced to very low levels (below tens of mgs/L). 
Table 5. Desalination Technologies and Their Characteristics ${ }^{114}$

\begin{tabular}{|c|c|c|c|c|}
\hline Desalination Technology & $\begin{array}{l}\text { Maximum } \\
\text { TDS } \\
\text { Treatable } \\
\text { (mg/L) }\end{array}$ & $\begin{array}{l}\text { Finished } \\
\text { Water } \\
\text { TDS } \\
\text { (img/L) }\end{array}$ & Energy Requirement & Residual Produced \\
\hline $\begin{array}{l}\text { Humidification- } \\
\text { dehumidification }\end{array}$ & & $<10$ & $\begin{array}{l}\text { Using waste heat: } \\
485 \mathrm{MCF} / 100 \text { bbl or } \\
5-7 \mathrm{kWh} / \mathrm{m}^{3} \text { water }\end{array}$ & Concentrated brine \\
\hline Capacitive deionization & 5,000 & Variable & $20 \mathrm{kWh} / 100 \mathrm{bbl}$ & Concentrated brine \\
\hline Reverse osmosis (RO) & 45,000 & $200-500^{\mathrm{a}}$ & $\begin{array}{r}15-30 \mathrm{kWh} / 100 \mathrm{bbl} \\
\text { or } 2.5-7 \mathrm{kWh} / \mathrm{m}^{3} \\
\text { water }\end{array}$ & Concentrated brine \\
\hline $\begin{array}{l}\text { Electrodialysis, } \\
\text { electrodialysis reversal } \\
\text { (EDR), and } \\
\text { eletrodeionization (EDI) }\end{array}$ & 40,000 & $\begin{array}{r}200(\mathrm{ED} \\
\text { and } \mathrm{EDR}), \\
<10(\mathrm{EDI})\end{array}$ & $\begin{array}{r}\text { Less than RO. } \\
0.5 \mathrm{kWh} / \mathrm{m}^{3} \text { water per } \\
1,000 \mathrm{mg} / \mathrm{L} \text { of ionic } \\
\text { species removed }\end{array}$ & Concentrated brine \\
\hline Evaporation & 100,000 & $<10$ & $400 \mathrm{kWh} / 100 \mathrm{bbl}$ & Solid salts or concentrated brine \\
\hline Membrane distillation & 250,000 & Variable & $600-700 \mathrm{kWh} / 100 \mathrm{bbl}$ & Concentrated brine \\
\hline Crystallization & 300,000 & $<10$ & $\begin{array}{r}1,000-1,300 \mathrm{kWh} / 100 \\
\text { bbl }\end{array}$ & Solid salts \\
\hline
\end{tabular}

${ }^{a}$ Finished water quality is under operational control in RO. Single-pass RO of seawater typically achieves drinking water standard of $500 \mathrm{mg} / \mathrm{L}$ TDS. Additional passes are needed for lower TDS, or to treat influent water that is higher in TDS than seawater.

\section{Evaluating Treatment Options}

Selecting a treatment process for produced water is made on the basis of influent wastewater characteristics and desired effluent water quality, as described above. Also relevant are system criteria such as the cost of construction, operation, and maintenance (including expenditures on energy and chemical additives) and the reliability and robustness of the system. Table 6 provides a list of typical criteria for selection of a technological solution for produced water treatment. 
Table 6. Criteria for Evaluation of Treatment Technologies

\begin{tabular}{|l|}
\hline Criteria for Evaluation of Treatment Technology \\
\hline Product water recovery \\
\hline Product water quality $\quad \%$ Recovery $=\frac{Q_{\text {finishedwater }}}{Q_{\text {wastewater }}}$ \\
\hline $\begin{array}{l}\text { Quantity and quality of residual wastes (see product recovery } \\
\text { and product water quality) }\end{array}$ \\
\hline Energy requirements \\
\hline Treatment chemicals needed \\
\hline Reliability and robustness of treatment \\
\hline Treatment cost (see energy and chemicals) \\
\hline Residual waste management options \\
\hline Known challenges: biological fouling, system failure points \\
\hline Ability to operate at field conditions \\
\hline
\end{tabular}

\section{Selecting a Management Option}

This chapter has dealt exclusively with treatment options for produced water. The reader will recall that Chapter 1 discussed all management options very generally. It is now possible to integrate treatment into that broader perspective of off-site management options. Chapter 1 summarized options for management and focused on treatment options with disposal and residuals management. With the details of treatment steps and processes now described in this chapter, we return to overall management options with a deeper understanding of decision points.

On-site treatment is designed for reuse only and will incorporate the minimum treatment technology necessary for reuse without compromising the chemistry of the hydraulic fracturing makeup water. Desalination is possible for on-site operations but is rarely necessary to produce water suitable for re-fracturing operations.

Off-site options and decisions are more complex. Once produced water leaves the drilling site, it can be sent to a POTW or a CWT for treatment or to a UIC well for disposal. At all these sites, initial analyses of the water will determine its fate. High levels of NORM will require special handling, as will high levels of scale-forming chemicals and suspended solids if deep well 
injection is planned. Regardless of its ultimate fate, preliminary treatment of some kind is likely. Figure 4 shows this schematically. After some preliminary treatment, the partially treated produced water can be returned to the well site for use in hydraulic fracturing, undergo additional treatment for demineralization with subsequent surface discharge or reuse, be disposed of via deep well injection, or, in Pennsylvania, be discharged to surface water for dilution. Brines and sludges created through treatment processes can be disposed of as solid waste or sent to UIC wells for disposal.

Figure 8. Comprehensive Produced Water Treatment Options

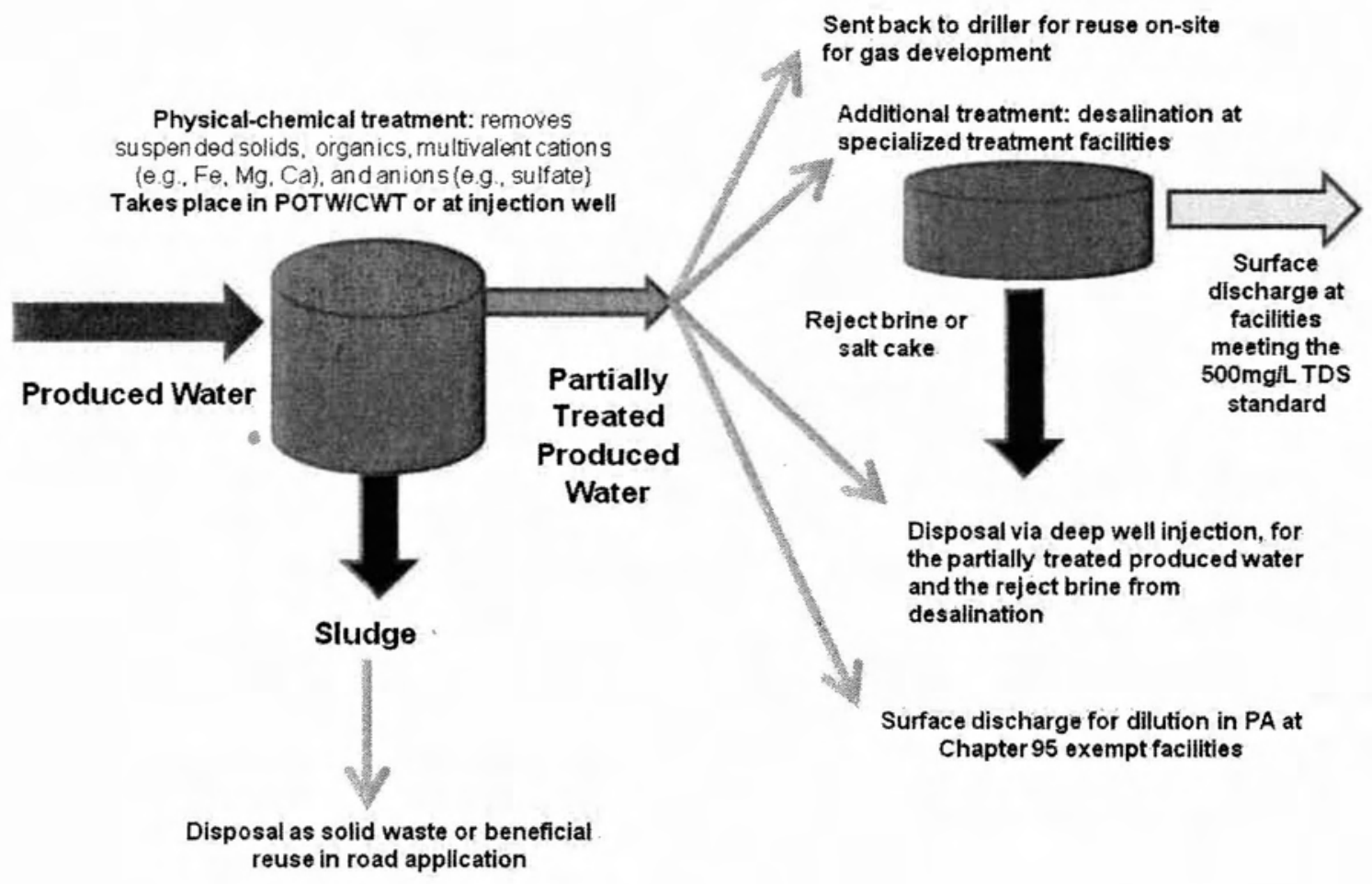


Appendix A. Studies and Surveys of Produced Water Management in the Oil and Gas Industry

Year

Published

Geochemistry of Oilfield Waters, Chapter 14, "Subsurface Disposal," and 1975

Chapter 16, "Environmental Impacts." 115

EPA Report to Congress: "Management of Wastes from the Exploration,

Development, and Production of Crude Oil, Natural Gas, and Geothermal Energy," EPA/530-SW-88-003. ${ }^{116}$

Produced Water, J. P. Ray and F. R. Engelhart, eds., Plenum Press. ${ }^{117}$

Produced Water 2, M. Reed and S. Johnsen, Plenum Press. ${ }^{118}$

"Overview of Emerging Produced Water Treatment Technologies," T.

Hayes and D. Arthur, 11th Annual International Petroleum Environmental Conference. $^{119}$

"Guide to Practical Management of Produced Water from Onshore Oil and

Gas Operations in the United States," Interstate Oil and Gas Compact

Commission. ${ }^{120}$

"An Integrated Framework for Treatment and Management of Produced

Water," RPSEA Project at Colorado School of Mines. ${ }^{121}$ Also see related management tool: aqwatec.mines.edu/produced_water/index.htm

"Water Management Technologies Used by Marcellus Shale Gas

Producers," DOE Project, Argonne National Laboratory for NETL. ${ }^{122}$

Working Paper from the NPC North American Resource Development

Study 2-17, "Management of Produced Water from Oil and Gas Wells."123

Produced Water: Environmental Risks and Advances in Mitigation

Technologies, Kenneth Lee and Jerry Neff, eds., Springer. ${ }^{124}$ 


\section{Chapter 3. Potential Water Impacts of Shale Gas Produced Water Management}

Chapter 1 provided an overview of management options, and Chapter 2 presented a detailed analysis of treatment choices. We now return to the larger perspective of all management options and evaluate potential water impacts related to wastewater management choices. This evaluation will describe the potential impacts that can result from current wastewater management practices, along with the health and environmental effects of particular wastewater constituents. We will also assess impacts that could be mitigated through changes in those practices. Nonwater impacts (e.g., effects on air quality or soil productivity) and indirect impacts on water from the full life cycle of natural gas development (e.g., water used in the creation of drilling equipment and chemicals, or water used in the consumption of the natural gas as a fuel) will not be considered.

\section{Introduction}

Shale gas development occurs in multiple stages, including site preparation, drilling, hydraulic fracturing (also called well completion), and operation. Wastewaters can be generated during all of these phases, and water can be affected by operations as well as by the generation of wastewater. Figure 1 shows several ways water (in blue) can be stored (centralized impoundments, impoundments at the well pad, tanks at the well pad) as well as ways wastewater (gray/black) can be stored (impoundments at the well pad, tanks at the well pad). Trucks transport water from sources to the well and from the well to wastewater management options. Pipelines are also an option for water transit, as shown.

Figure 9. Water and Wastewater During Well Development

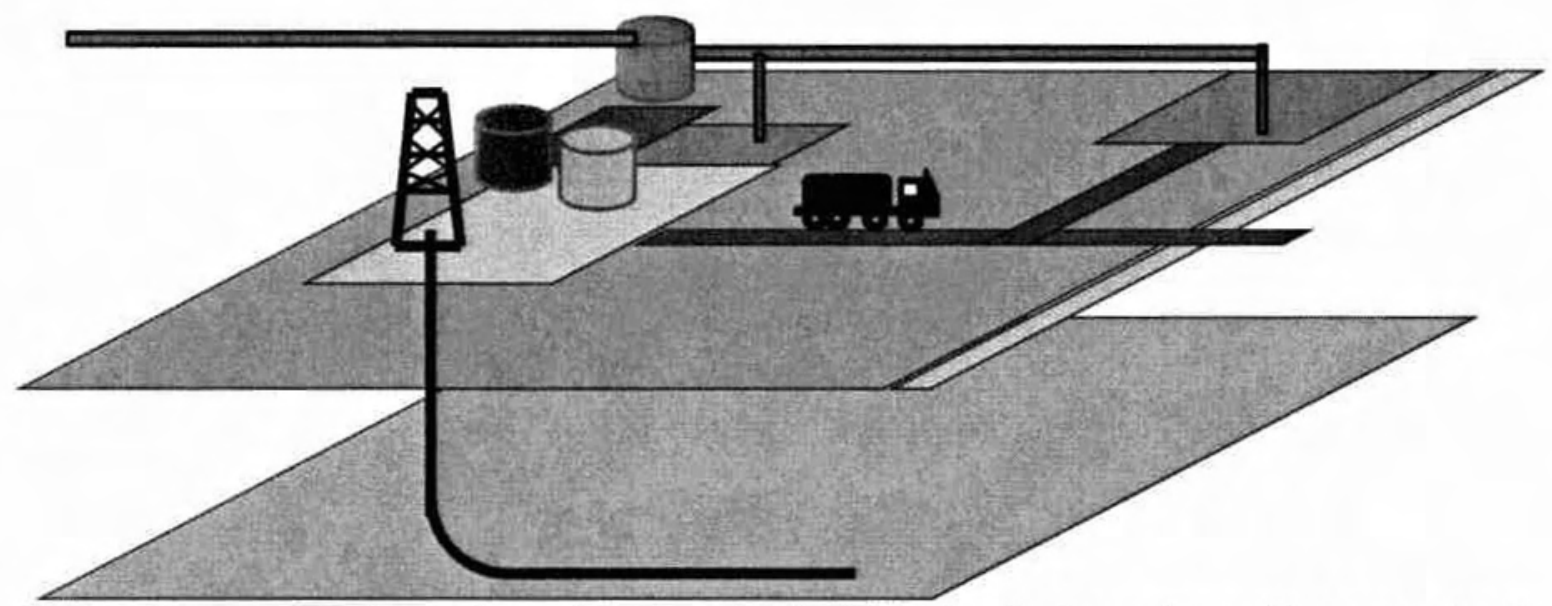

Produced water returning to the surface associated with hydraulic fracturing and later associated with the production of gas must be managed to ensure low risk of environmental harm. 


\section{Pathways to Environmental Effects}

Environmental effects begin with the interaction between an activity and an environment in which it could cause harm. Many management techniques discussed in Chapters 1 and 2 are designed to prevent or reduce environmental effects. This section provides a review of the management options described in Chapter 1 and their potential environmental effects due to release of chemical constituents in produced waters to environmental systems.

\section{Potential Impacts During Well Development: On-Site Impoundments and Tanks}

As with any liquid material in storage, accidental spills and mismanagement can cause releases to the environment that could contaminate nearby waters and soils. Open impoundments, also called pits, should be designed and constructed to minimize the risk of contamination. Liners prevent leaching of water and contaminants into the soil under the impoundment. The maintenance of a target freeboard reduces the risk of water rising to the top of the impoundment and spilling over the edges. ${ }^{\mathrm{z}}$ In Pennsylvania, liners are recommended (although not required) around impoundments to provide additional protection should a large storm increase the volume in the pit high enough to overtop the berms. Closed tanks are also sometimes used for collection of produced water during the flowback period; secondary containment is recommended but not required for these tanks. Secondary containment is a best management practice where the tank sits within a traylike structure with raised sides or berms such that materials released during a tank rupture would be contained and not leach into soil or travel to nearby waterways. Secondary containment is required for many types of wastewaters; all hazardous waste materials must be stored within secondary containment. ${ }^{\text {aa }}$ (This requirement does not apply to shale gas wastewater due to a statutory exemption discussed in Chapter 4.)

The recent State Review of Oil and Natural Gas Environmental Regulations (STRONGER) regulatory review included a recommendation that Pennsylvania require secondary containment for tanks used in hydraulic fracturing operations. It further recommended that inspection or certification of pit construction be required, in order to assess pit preparation and liner placement. ${ }^{125}$ These recommendations to strengthen preventive measures related to leaks and spills are consistent with reviews of environmental violations at drilling sites in Pennsylvania, which indicate that 25 percent of violations in 2010 were associated with pit and storage problems, including leaks and improper construction. ${ }^{126}$ Industry best management practices do not universally include a secondary containment recommendation for tanks or a liner recommendation for impoundments. ${ }^{127, \mathrm{bb}}$ Neither the STRONGER recommendation nor American Petroleum Institute best management practices specifically deal with produced water storage tanks.

\footnotetext{
${ }^{\mathrm{z}}$ Freeboard is the depth between the water level and the top edge of the impoundment. In Pennsylvania, the freeboard requirement for water and wastewater impoundments is 2 feet, as codified in $25 \mathrm{~Pa}$ Code 78.56 and 57 . ${ }^{\text {aa }}$ RCRA requires secondary containment for all hazardous waste tanks in Section 265.193.

bb API E5 (API 1997) indicates liners should be used for "any area subject to spillage or contact," while API HF2 (API 2010) is silent on the use of liners outside of the impoundment itself. Neither document discusses secondary containment for tanks. API HF3 (API 2011) briefly mentions that operators should evaluate the potential for spills and use this information to determine the type and size of primary and secondary containment.
} 


\section{Potential Impacts Away From the Well Site}

Despite the significant utilization and management of water and production of wastewater during the short process of drilling and completing a well, the most significant potential for water impacts from generated wastewaters occurs away from the well site and is associated with the long-term production of water from the well. Figure 2 presents wastewater management options during production schematically. To the left, on-site tank storage of produced water occurs at the well site while gas is produced from the formation. Wastewater is trucked from the storage tank to one of three types of facilities: (1) a disposal well for injection, with or without pretreatment, (2) a centralized wastewater treatment (CWT) facility that returns partially treated water to the drilling company for reuse, or (3) a CWT or municipal facility (sometimes called a publicly owned treatment works, or POTW) that provides partial treatment with discharge of treated water to a surface water like a stream or river. Residuals generated at any of these locations might be sent to a disposal injection well (1) if they are liquid brines or to a landfill (4) if they are solids. There is also another option for the original produced waters or the treated brines in some states: beneficial reuse, such as spreading on roads for dust suppression or ice control (5).

\section{Figure 10. Produced Water Generation and Transport to Waste Management Facilities}

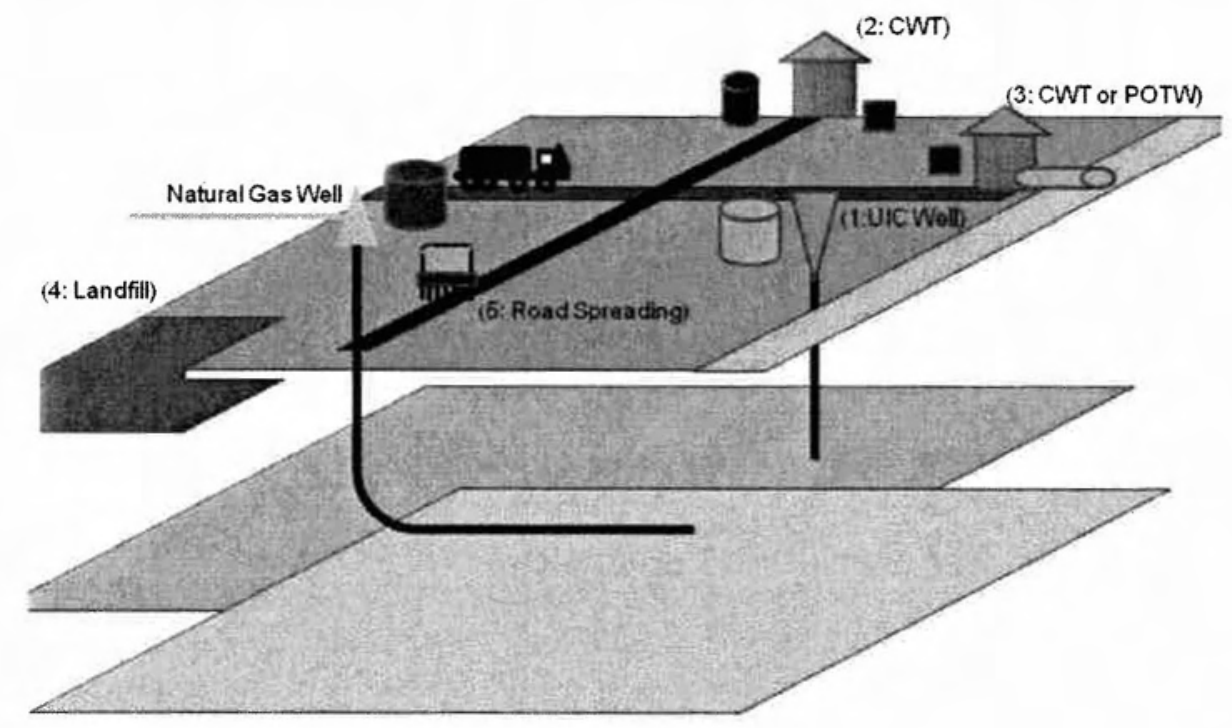

At any of the locations where produced water is handled, the potential exists for releases due to accidents, inadequate facilities management or staff training, or illicit dumping. ${ }^{128}$ There is a need for best practices and good management to minimize this potential and for contingency plans to reduce the impact of accidental or illicit releases.

This chapter will not focus on the risk of such events, as significant uncertainty surrounds accident rates, current practices and their relationship to best practices, and operator variability in 
management and training. Recent legal action in Pennsylvania alleging long-term illegal dumping raises questions about the difficulty of detecting this behavior and quantifying it on a regional basis. ${ }^{129}$ Increased oversight of operators who accept, transport, or manage produced water should be undertaken to ensure that best practices are being used and legal disposal is being provided.

The focus of this chapter is on the impacts of current wastewater management techniques that fall within current regulatory requirements.

\section{Deep Well Injection Potential Effects}

Underground injection of wastewaters was designed to isolate materials that could cause harm if released to the surface water environment. Partial treatment of produced waters either prior to injection or at the injection well facility is often used to reduce the likelihood of well clogging due to suspended solids, precipitation of constituents in the wastewater, or growth of bacteria. This treatment generally involves settling and filtration, producing a residual solid waste or spent filter media. These residuals are disposed of with other solids waste. Residuals management is discussed below.

Many kinds of wastes have been disposed of via underground injection, including hazardous and nonhazardous wastes, brines associated with oil and gas production, fluids associated with solution mining, and $\mathrm{CO}_{2}$ for sequestration. Different types of wastes are disposed of in different classes of injection well; the classes of wells subject to federal regulation are described in Chapter 4. An EPA risk analysis determined that injection via strictly regulated Class I hazardous waste wells is a safe and effective technology that presents a low risk to human health and the environment. ${ }^{130}$ Additional studies have confirmed this assessment. ${ }^{131}$ Such comprehensive studies of other classes of injection well, like the Class II wells into which oil and gas wastes are injected, have not been completed. Prior to the establishment of the current federal regulatory program, four significant cases of injectate migration occurred at hazardous waste wells due to practices that are not permitted under current regulations. ${ }^{132}$

\section{Surface Water Discharge Potential Effects}

Treatment at a CWT or POTW followed by discharge of treated water has the potential to affect surface water downstream of the discharge, depending upon the discharge limits for specific chemicals and the assimilative capacity of the receiving water. In many cases, the impact of a treated wastewater discharge cannot be determined a priori, without consideration of the receiving water and the other activities taking place in the basin. Chemical hazards, both to ecosystems and to human health, are generally concentration-dependent. Only when waste discharges in combination with contaminants from other sources exceed the assimilative capacity of natural systems do impacts emerge. Discharges that have little or no impact are rarely restricted. For example, while calcium and magnesium ions contribute to water hardness, which can affect water aesthetics, in general the presence of these ions is not a problem and may even be beneficial. ${ }^{133}$

The Clean Water Act limits pollutant discharges. Pollutants may present a concern because of their direct toxicity to ecosystems or human health (e.g., BTEX) or because of their interaction in 
the environment to produce unwanted effects (e.g., nutrients like ammonia, which can encourage harmful algal blooms). Other pollutants are a concern because of their potential to affect the beneficial use of the water downstream (e.g., sulfate, which can make drinking water taste bad) or to disrupt ecosystems (e.g., chloride, which alters fish reproduction).

Water quality standards for many pollutants are set by the EPA or state regulatory agencies, and discharges are not permitted that would cause the receiving water to exceed these standards. For example, consider the schematic of a watershed shown in Figure 3. If a new wastewater treatment plant is to be sited in this basin, the multiple point and non-point discharges and their volumes and concentrations of wastes must be considered along with the total flow in the river at all the different points, as freshwater entering the system through runoff or tributary streamflows dilutes existing contaminants. This type of full-watershed analysis is complex and requires significant data on the natural and engineered systems operating in an area.

There are many constituents in produced water that might be of concern if directly discharged to surface water. These have been described in Chapters 1 and 2 and include naturally occurring radioactive materials (NORM), chemicals associated with hydraulic fracturing fluids, ammonia, and salts and organics from the formation. As discussed in Chapter 2, CWTs and POTWs may remove some constituents. Residuals that are likely to be released to surface water even after conventional POTW or CWT treatment include total dissolved solids and the monovalent ions sodium, chloride, and bromide. Other constituents may be partially removed, including metals, sulfate, organic carbon, oxygen demand, and forms of nitrogen (TKN, ammonia, and nitrate). POTWs that have nutrient limits in their permits may find the increased nitrogen loading from produced water to be a problem.

CWT treatment that includes desalination is expected to remove constituents to very low levels. When CWTs target a TDS concentration of $500 \mathrm{mg} / \mathrm{L}$, pretreatment for membrane systems or thermal methods usually removes most organics, metals, and multivalent anions, which can interfere with desalination techniques. Thus, CWTs that meet the revised Pennsylvania discharge limits for TDS are expected to have significantly less impact in the environment. Discharges meeting low TDS levels are not without impact, however, as they may still contain concentrations of bromide that can affect downstream drinking water plants.

Specific effects associated with each class of contaminant are discussed later in this chapter. 
Figure 11. Schematic of Watershed with Multiple Wastewater Inputs

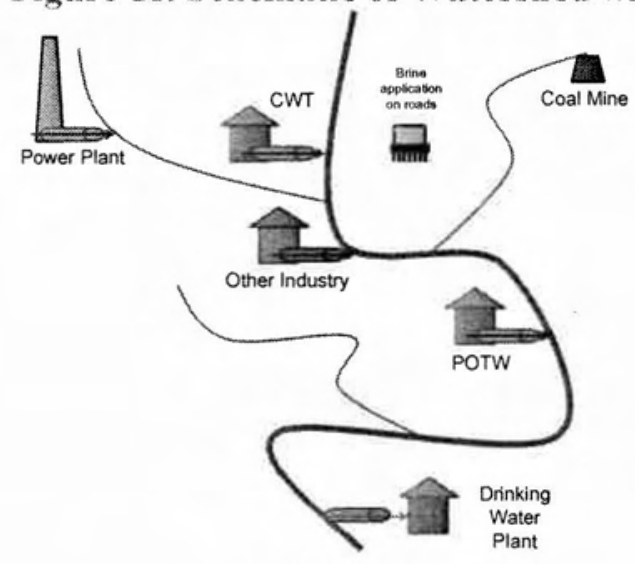

Land Application Potential Effects

Management choices that result in land or road application of produced waters or treatment residuals from produced waters can result in environmental effects. This is due to the potential for runoff from rainfall to introduce the materials in the produced water to surface waters and groundwaters that support ecosystems and may be sources of drinking water.

While the specific impact of applying produced water to land surfaces has been studied only somewhat, several closely related practices have yielded extensive information that is relevant to the potential impacts of this practice. This section will provide background on the application, known environmental effects, and specifics for produced water application when available. ${ }^{134}$

Road application of produced waters is either for dust suppression or for deicing. Produced water brines from oil and gas development are not identical to traditional dust suppression or deicing chemicals, but to the extent they are useful in these applications, they share certain characteristics. They contain salts, and they are prewetted (being brines, not solids).

The environmental impact of dust suppression chemical applications has been studied. ${ }^{135}$ A wellknown case in Times Beach, Missouri, illustrates the potential negative effects of using waste products for dust suppression. This practice led to evacuation and subsequent abandonment of the town in 1983 . $^{\mathrm{cc}}$ An expert panel, convened in 2002 by the EPA, identified the need for increased information about the potential environmental and health impact of dust suppressants, citing the following potential environmental impacts: surface and groundwater deterioration; soil contamination; toxicity to soil and water biota; toxicity to humans during and after application; air pollution from volatile dust suppressant components; accumulation in soils; changes in hydrologic characteristics of soils; and impacts on native flora and fauna populations.

Most dust suppression chemicals contain salts, such as calcium and magnesium chlorides, which are easily dissolved in water and can migrate from the road surface during rainfall events. ${ }^{136}$ Calcium and magnesium, which are ubiquitous, naturally occurring metal cations, are unlikely to

${ }^{c c}$ A documentary of the events at Times Beach was produced by the History Channel as part of its Modern Marvels series Engineering Disasters. 
migrate far from the application site. Chloride ions are likely to move easily from the application site and are of greater concern, with chloride toxicity to aquatic and terrestrial organisms well documented. ${ }^{137}$ Produced waters also contain significant chloride (see Table 4, Chapter 2) and significantly more sodium than calcium or magnesium.

Some other dust abatement chemicals contain organics that have the potential to raise the biological oxygen demand (BOD) in nearby receiving waters, although quantities are low and effects are thought to be negligible. ${ }^{138}$ Produced waters contain highly variable concentrations of organics that might demand oxygen in receiving waters; however, reported BOD to COD ratios for Marcellus Shale produced water suggest the constituents are not readily biodegradable. Consequently, they are unlikely to cause oxygen depletion, although their persistence is a concern if they are toxic or bioaccumulative.

While the use of produced waters for anti-icing and deicing in northern climates is permitted in some states, the environmental impacts of this practice have not been widely studied. ${ }^{\text {dd }}$ However, the effect of the application of road salt in the United States has been extensively reviewed. ${ }^{139}$ The effects of road salt application and produced water road spreading may be similar due to the presence of chlorides in both substances. Road salt application is known to increase chloride concentrations in downstream locations near roads ${ }^{140}$ and to create a long-term source of chloride to groundwater. ${ }^{141}$ Chlorides from road salt are transported in surface runoff and infiltrated through soils into groundwater. ${ }^{142}$ Road salt storage in recharge areas contaminates water supplies, and addition of brine to antiskid material piles (i.e., sand and cinder) is prohibited for this reason. ${ }^{143}$ Road salt movement through the environment has been linked to a variety of negative ecological effects. ${ }^{144, \mathrm{ee}}$ As previously noted, effects of elevated chloride concentrations on aquatic life have been extensively studied. ${ }^{145}$ Deicing chemicals are also known to accelerate the deterioration of concrete and steel structures and to cause vehicle corrosion.

The use of oil field brines as roadway dust suppressants was previously studied by a number of states as management of production brines became more common. In general, produced waters are not as effective as commercial products and require more frequent reapplication; however, they are generally cost-effective. ${ }^{146}$ Produced waters can also be used for dust suppression in coal mining, It is not clear how widespread this use might be in coal regions because commercial products provide superior control. ${ }^{147}$

Several potential impacts on water may be associated with application of produced water to roads during summer for dust control. First, transport of materials away from the application site through rainfall and runoff may result in stream or groundwater contamination. This potential is increased when application rates are high or take place in close proximity to rainfall events. When brines contain volatilizable organic matter, their distribution via spraying on roads is likely to result in transfer of the volatile compounds to the air. Brine spreading management plans are usually prescriptive in the application rate and frequency of application, and they usually contain restrictions on proximity to water and on application during rain or when rain is imminent. ${ }^{148}$ In the past, significant violations of these plans have been commonly observed in some locations. ${ }^{149}$

${ }^{\mathrm{dd}}$ Deicing is the application after snow has fallen, while anti-icing applications are completed in advance of a storm.

ee The literature in this area is beyond the scope of this report. See D'Itri (1992) for an introduction to this extensive research topic. 
When produced waters are used for road spreading, they may replace equally effective dust suppressant and deicing agents yet result in higher chloride loads (due to higher concentrations or more frequent applications). Many years ago, Michigan reported on seven cases of well water contamination that were linked to road brining activities and summarized previous reports of runoff from brine-treated roads affecting nearby trees. ${ }^{150}$ In Ohio, a study was conducted to identify and quantify changes in the quality of groundwater in aquifers underlying roads where brine spreading is practiced. Chloride concentrations that exceed EPA public drinking water standards were observed in down-gradient wells from an oil field brine application on a gravel roadbed despite 99 percent dilution of the solutes in the brine. ${ }^{151}$ Attenuation of strontium by adsorption and benzene by volatilization and adsorption were also reported, suggesting benzene release to the air and strontium held in the soil, where subsequent release to groundwater is possible. ${ }^{152}$ Eckstein reports on a much more recent case of aquifer contamination near Wooster, Ohio. $^{153}$

\section{Residuals Management Potential Effects}

Regardless of the treatment option selected, there will be residuals: concentrated brines and solids containing the chemicals removed from the produced water. Management of these residuals is just as critical as management of the original produced water.

Residuals from oil and gas brine treatment are typically disposed of at injection wells or landfills, or they can be put to beneficial reuse. ${ }^{154}$ Concerns related to brines are similar to those detailed for the original produced waters. Solid wastes from POTWs will contain mixtures of contaminants from domestic wastewater as well as from produced water. Solid wastes from CWTs contain the original contaminants from the wastewater as well as treatment chemical residuals.

Since chemicals present in these residual wastes are present at higher levels than in the original produced waters, careful management is essential to avoid negating the value of the treatment process through release of residuals to the environment. Surface discharge of concentrated brines or land or road application of solid salts produced through treatment will result in watershed effects of greater concern than those associated with the original produced water as even more dilution will be required.

Concentrated brines should be disposed of in injection wells to avoid introducing contaminants removed from produced water back to the environment, where human health and ecological impacts might occur. Similarly, solids and sludges generated in treatment plants for produced water should be disposed of in landfills with adequate protection against the formation of subsequent brines in the leachate. Environmental releases of by-products of produced water management should be avoided.

\section{Specific Contaminants and Their Environmental Effects}

The management options described above have the potential to release constituents in produced water to surface waters and near-surface groundwaters in ways that can affect ecosystems and human health. This section summarizes known effects of specific constituents in produced water that are likely to be released to the environment under the management options described above. 
By statutory exemption, wastes produced in oil and gas development are not classified as hazardous wastes under the Resource Conservation and Recovery Act (RCRA). ${ }^{\mathrm{ff}}$ Despite the exemption, the contaminants in produced water fall into several groups, all of which can contain hazardous and nonhazardous components. When not exempt by statute, wastes are defined by RCRA as solid hazardous waste ${ }^{g g}$ if the "quantity, concentration or physical, chemical or infectious characteristics may (a) cause, or significantly contribute to, an increase in mortality or an increase in serious irreversible, or incapacitating reversible, illness; or (b) pose a substantial present or potential hazard to human health or the environment when improperly treated, stored, transported, or disposed of, or otherwise managed." Determining if a waste is hazardous involves ascertaining if it is a "listed" hazardous waste or if it meets the narrative criteria defined in (a) and (b) above.

Certain types of wastes are categorically "listed" as hazardous under the statute and are grouped into categories (F, K, P, and U). Non-listed hazardous wastes are categorized by the characteristics that define their hazard: ignitability (I), corrosivity $(\mathrm{C})$, reactivity $(\mathrm{R})$, toxicity $(\mathrm{E})$, acutely hazardous $(\mathrm{H})$, and toxic $(\mathrm{T}){ }^{\text {hh }}$

Testing is required to evaluate a hazardous waste for toxicity. A toxicity characteristic leaching procedure (TCLP) is completed, and the concentration of chemicals in the leachate is compared with TCLP limits set for arsenic, barium, cadmium, chromium, lead, mercury, selenium, and silver and for a longer list of organics. A few states further require testing for zinc, copper, and nickel. Produced water from the Marcellus formation has reported concentrations from nondetect to above the TCLP limit for barium (which is $100 \mathrm{mg} / \mathrm{L}$ ). ${ }^{155}$ (Other metals sometimes detected at lower concentrations are arsenic, chromium, lead, mercury, and selenium.) Some produced waters would therefore be classified as hazardous wastes due to toxicity associated with barium. Treated waters from some CWT plants (see Table 4, Chapter 2) show much lower levels of measured barium (below $20 \mathrm{mg} / \mathrm{L}$ in all samples reported). Treated waters from CWT plants meeting new discharge limits for TDS would be expected to be even lower in dissolved metals and thus unlikely to be categorized as hazardous due to toxic metal concentrations; however, chemical analyses of treated waters from CWTs meeting the Chapter 95 discharge limits for TDS were not available for review in the preparation of this report.

In addition to listed wastes and characteristic wastes, EPA has published a Priority Chemicals (PC) list. ${ }^{156}$ The National Waste Minimization Program focuses on reducing these 31 chemicals. PCs present in additives used in hydraulic fracturing include naphthalene and lead (see Table 4, Chapter 1). Lead was detected in produced water from Marcellus Shale gas wells at levels reported from non-detect to $606 \mu \mathrm{g} / \mathrm{L} .^{157}$

\footnotetext{
${ }^{\text {ff }}$ The details of the RCRA exemption are discussed in Chapter 4.

${ }^{\mathrm{gg}}$ Note "solid" here does not refer to a state of matter. Solid, liquid, and gaseous wastes can be classified as hazardous solid wastes under RCRA.

hh "Toxicity" and "toxic" are defined differently. Toxic wastes contain a toxic constituent and pose a risk due to the presence of that toxic constituent. Toxicity characteristic wastes are based on the toxicity characteristic leaching procedure (TCLP), which assesses the release of constituents that demonstrate toxicity to test organisms.
} 
The identification of hazardous characteristics is complicated by the fact that materials in waste streams are often evaluated on the basis of composite measurements. For example, total dissolved solids or salts can include hazardous elements such as lead and barium as well as nonhazardous elements such as sodium and chloride. Lead and barium are classified as hazardous due to their characteristics (and evaluation of the waste via TCLP). If a wastewater process removes barium, for example, but leaves other salts, the TDS may not be much different from that of a wastewater that contains low-hazard salts as well as heavy metals.

The determination of hazard for oil and gas produced waters does not follow the procedures described above because they are exempt from RCRA classification. This is discussed further in Chapter 4.

\section{Total Dissolved Solids}

By far the largest constituent of concern that is not removed through current treatment in CWTs or POTWs is salt, predominantly sodium and chloride ions, but also calcium and bromide ions and other dissolved cations and anions. ${ }^{\text {ii }}$ As shown in Table 1, Chapter 2, produced waters from the Marcellus formation have sodium concentrations from 26,900 to $95,500 \mathrm{mg} / \mathrm{L}$ and chloride concentrations from 1,670 to $181,000 \mathrm{mg} / \mathrm{L}$ (measured 14 days after well completion). These levels of salt alone make the water 3 to 10 times saltier than ocean water. Effluent concentrations from CWTs (Table 4, Chapter 2) show chloride concentrations from 3,300 to $131,725 \mathrm{mg} / \mathrm{L}$ in waters with TDS from 7,200 to $198,400 \mathrm{mg} / \mathrm{L}$.

Discharge of waters at the salinity of produced waters from the Marcellus formation would require either treatment to reduce salinity or dilution with pure water to 100 to 500 times their volume to reach drinking water levels. While large rivers in the United States have significant flow rates, many others, like those in southwestern Pennsylvania, already receive significant TDS loads from current industrial activities, other resource extraction activities (including coal mining, coal bed methane extraction, and conventional oil and natural gas production), and legacy wastes like acid drainage from abandoned coal mines. There is little additional assimilative capacity for salts in these systems, especially during low-flow conditions. This is a well-documented problem throughout the Appalachian region. ${ }^{158}$

Water is considered fresh when TDS is less than $1,500 \mathrm{mg} / \mathrm{L}$, and the secondary drinking water standard in the United States is $500 \mathrm{mg} / \mathrm{L} .{ }^{\mathrm{jj}}$ Secondary standards are non-mandatory and not enforced. The secondary standard for TDS is set due to the objectionable taste, odor, or color associated with high-TDS waters. High-TDS water is also associated with increased corrosivity and scaling and sedimentation, which can have significant economic impacts. Corrosive water can stain household fixtures, can have an unacceptable metallic taste, and can reduce the usable life of water pipes in the distribution system and in households. Highly scaling water causes mineral deposits to build up in pipes and in water fixtures (especially those associated with heating, including hot water pipes, boilers, heat exchanges, hot water heaters, and dishwashers).

\footnotetext{
${ }^{\text {ii }}$ CWTs that meet Pennsylvania's revised effluent requirements for discharge remove salt to $500 \mathrm{mg} / \mathrm{L}$. Those facilities will not have the effects discussed in this section.

ij Primary drinking water standards address human health effects, while secondary standards are associated with taste, odor, corrosivity, and scale-forming potential. Some pollutants, like TDS, do not have primary standards, either because they do not cause health impacts or because they have never been observed at drinking water plants at concentrations that could cause health impacts.
} 
Drinking water treatment plants do not include methods to remove TDS, but their use of treatment chemicals to remove other contaminants may actually increase TDS in finished water. Therefore, it is critical that source waters remain below $500 \mathrm{mg} / \mathrm{L}$ TDS to ensure finished drinking water meets customer requirements for usability.

Produced waters containing high TDS should be disposed of in ways that do not raise surface water concentrations of TDS above the secondary drinking water standard of $500 \mathrm{mg} / \mathrm{L}$ for potable water. Seasonal variation in flow conditions may require different management options during different flow conditions to avoid exceeding this level in source waters.

\section{Chloride}

As noted above, produced waters from the Marcellus formation have chloride concentrations from 1,670 to $181,000 \mathrm{mg} / \mathrm{L}$ (14 days post completion), and effluent concentrations from CWTs (Table 4, Chapter 2) show chloride concentrations from 3,300 to $131,725 \mathrm{mg} / \mathrm{L}$. Chloride has a high solubility and moves easily in the environment. Produced waters applied on land or roads will lead to chloride runoff into surface waters and groundwaters.

The effect of high-salt loads on watersheds has been extensively documented through the study of road salt effects, ${ }^{159}$ and aquatic ecosystem impacts can be significant and far-reaching. ${ }^{160}$ Toxicity studies have focused on fish and macroinvertebrates, and toxicity is species-dependent. Fathead minnow embryos show toxicity below $1,000 \mathrm{mg} / \mathrm{L},{ }^{161}$ while some aquatic invertebrates can tolerate values in the 5,000 to $10,000 \mathrm{mg} / \mathrm{L}$ range ${ }^{162}$ Beyond direct toxicity to aquatic life, salinity affects the structure and function of aquatic ecosystems. For example, salinity affects microbes, macrophytes, riparian vegetation, invertebrates, fish, amphibians, reptiles, mammals, and birds that make up the complex food web in aquatic systems. ${ }^{163}$

Further, disposal of waters that contain dissolved solids (salts) in rivers can have effects beyond an increase in salinity of the receiving water. Kefford found saltwater disposal was associated with increased total phosphorus (TP), soluble phosphorus $\left(\mathrm{PO}_{4}{ }^{3-}\right)$, total Kjeldahl nitrogen (TKN), and suspended solids and with changes in macroinvertebrate community structure independent of direct salinity effects. ${ }^{164}$ High chloride levels are also known to be associated with the invasive and devastating golden algae (Prymnesium parvum), although high salinity alone cannot trigger a toxic bloom. ${ }^{165}$ A Prymnesium bloom was responsible for the loss of all gill-breathing organisms in 26 miles of Dunkard Creek in southwestern Pennsylvania in the fall of $2009 .^{166}$

For chloride, the EPA in-stream recommended standard to protect aquatic life is $250 \mathrm{mg} / \mathrm{L}$, set in 1988 and based on limited toxicity studies with sodium chloride. ${ }^{167}$ Potassium, magnesium, and calcium chlorides are generally more toxic than sodium chloride. ${ }^{168}$ The Iowa Department of Natural Resources, in setting its chloride standard in 2009, reviewed more extensively available data and took into account the synergistic effects of sulfate and hardness (calcium and magnesium) on chloride toxicity. ${ }^{169}$ British Columbia set standards for freshwater aquatic life at a maximum of $600 \mathrm{mg} / \mathrm{L}$ and a 30 -day average of $150 \mathrm{mg} / \mathrm{L} .{ }^{170}$ Discharge standards for chloride can be much higher as they take into account dilution in the receiving water.

\section{Bromide}

A recently identified concern in produced waters is the concentration of bromide. Bromide is a trace element in the earth's crust, with typical concentrations below $6 \mathrm{mg} / \mathrm{kg}$, except in shales, 
which can have bromide concentrations in the $4-24 \mathrm{mg} / \mathrm{kg}$ range. ${ }^{171}$ Bromide is also a trace element in seawater, with a concentration of $65-80 \mathrm{mg} / \mathrm{L}$, about one three-hundredth the chloride concentration. Bromide is rarely observed at significant concentrations in fresh surface water systems (e.g., inland rivers and lakes in the United States). For example, Bowen reports $0.014-0.2 \mathrm{mg} / \mathrm{L}(14-200 \mu \mathrm{g} / \mathrm{L})$ in surface water systems. ${ }^{172}$

Bromide is present in produced waters from Marcellus Shale in the range of $15.8-1,600 \mathrm{mg} / \mathrm{L}$ and is reported in treated brine from CWTs at approximately five times those concentrations, in the range of $76-8,290 \mathrm{mg} / \mathrm{L}$ (see Tables 1 and 4, Chapter 2). ${ }^{\mathrm{kk}}$ The source of produced water at the CWTs when these effluent values were measured is not known; however, these concentrations, if not diluted, are of concern for direct bromide effects on ecology as well as indirect effects on downstream drinking water plants.

Bromide itself is not a significant human health or environmental concern except at very high levels. Bromide has been used medicinally for more than 100 years, and its human toxicity is well established. ${ }^{173}$ Acute toxicity is very rare in humans. Chronic toxicity effects on the endocrine and reproductive systems in animals have been observed at high doses. The World Health Organization recommends an acceptable daily intake of up to $1 \mathrm{mg} / \mathrm{kg}$ body weight; Flury and Papritz recommend no more than $0.1 \mathrm{mg}$ bromide per $\mathrm{kg}$ body weight. ${ }^{174}$ An intake of 0.4 $\mathrm{mg} / \mathrm{kg}$ body weight yields an acceptable total daily intake of $24 \mathrm{mg} /$ person. Assuming 50 percent from food and 50 percent from water, an adult consuming 2 liters/day could consume water containing up to $6 \mathrm{mg} / \mathrm{L}$; for a $10-\mathrm{kg}$ child consuming $1 \mathrm{~L} / \mathrm{day}$, the value would be up to 2 $\mathrm{mg} / \mathrm{L} .{ }^{175}$

Ecotoxicity of bromide is also generally low, with impaired growth of evaluated organisms only at high bromide concentrations ( $>2 \mathrm{~g} / \mathrm{L}$ for microorganisms and $>2.5-7.8 \mathrm{~g} / \mathrm{L}$ for fish). ${ }^{176}$ Canton et al. propose a critical acceptable maximum concentration for water based on the ecotoxicology effects of $1.0 \mathrm{~g} / \mathrm{L} .{ }^{177}$

The main concern regarding bromide in the environment is its role in drinking water systems. The presence of bromide in water that is subject to disinfection for pathogen control in drinking water increases the formation of disinfection by-products (DBPs) that are regulated due to their carcinogenic and possibly teratogenic characteristics. "When source waters are higher in bromide, DBPs contain more bromide, ${ }^{178}$ and those with bromide are suspected to be more of a concern for human health. ${ }^{179}$

For drinking water treatment plants in the U.S. that employ chlorine as a disinfectant, the average observed concentration of bromide in source water is $0.043 \mathrm{mg} / \mathrm{L}$ and the maximum concentration is $0.6 \mathrm{mg} / \mathrm{L}$. ${ }^{180} \mathrm{EPA}$ conducted a nationwide survey of drinking water utilities. The resultant report describes moderate bromide as $0.15 \mathrm{mg} / \mathrm{L}$ and high bromide to be $0.4 \mathrm{mg} / \mathrm{L} .{ }^{181}$ High bromide levels in source waters were associated with increased levels of DBPs in finished waters.

\footnotetext{
${ }^{\mathrm{kk}}$ Bromide concentrations in treated brine that are higher than concentrations in Marcellus wastewater can result from other types of wastewater also being treated at the CWT, or from treatment methods that result in a concentrated finished water.

${ }^{11}$ Carcinogens cause cancer. Teratogens cause birth defects.
} 
In the fall of 2008, when total dissolved solids increased in the Monongahela River in southwestern Pennsylvania, drinking water utilities using this source water reported increases in a type of DBP called trihalomethane (THM). Plants in the river basin reported that 85 percent to 94 percent of the formed DBPs were brominated. ${ }^{182}$ Since that time several researchers have reported increasing source water bromide concentrations in the Monongahela River and the Allegheny River. ${ }^{183}$ In the spring of 2011, in response to reports of increasing bromide concentrations and the associated increases in brominated THM at drinking water plants on both rivers, the PADEP issued a request to companies drilling in the Marcellus Shale formation to stop delivering produced water from the Marcellus formation to POTWs and CWTs that were not designed to remove bromide. As described in Chapter 2, there was a 99 percent reduction in produced water from Marcellus Shale development going to these surface discharge facilities. Bromide levels in the Monongahela River in mid- and late 2011 were lower; however, a very wet season made detection more challenging, and conclusions regarding the effect of restricting this wastewater cannot yet be drawn. ${ }^{184}$ Many water utilities in the region continue to monitor source water bromide. ${ }^{185}$

Produced waters containing bromide above levels that will adequately dilute in surface waters should not be discharged to the environment without treatment specifically to remove bromide. Since bromide removal is generally not economical, produced water enriched in bromide should be disposed of through underground injection to avoid contamination of surface waters used as drinking water sources.

\section{Naturally Occurring Radioactive Material (NORM)}

As discussed in Chapter 1, NORM is typically present in shale gas produced water at levels slightly above background. ${ }^{186}$ Oil and gas development in some states has produced elevated NORM at levels of concern, and some states have adopted regulations with action levels. ${ }^{\mathrm{mm}}$ Elevated NORM has not typically been observed and conventional oil and gas facilities in Pennsylvania; ${ }^{187}$ however, produced water from Marcellus wells does show elevated radioactivity. ${ }^{188}$ The most abundant types of NORM in produced water are radium-226 and radium-228, produced from radioactive decay of uranium and thorium present in the shale formation.

Data on produced water from the Marcellus Shale indicate NORM is sometimes detected at levels above background and above drinking water standards (see Table 4, Chapter 2). Drinking water standards require uranium below $30 \mu \mathrm{g} / \mathrm{L}$; radium- 226 and radium- 228 combined below 5 $\mathrm{pCi} / \mathrm{L}$, alpha emitters below $15 \mathrm{pCi} / \mathrm{L}$, and beta particle radioactivity below $4 \mathrm{mRem} /$ year. CWTtreated wastewaters summarized in Table 4, Chapter 2, report non-detect for uranium, and radium-226 and radium-228 levels between $0.8-15.6 \mathrm{pCi} / \mathrm{L}$, with gross alpha reported between $0.132-156 \mathrm{pCi} / \mathrm{L}$.

In 2011 in southwestern Pennsylvania, concerns were raised regarding the potential for surface water discharges of treated produced water to raise levels of radioactivity above acceptable source water levels for drinking water. PADEP requested testing at all public drinking water

${ }^{\mathrm{mm}}$ Louisiana, Texas, Arkansas, and Michigan set action levels at $50 \mathrm{microR} / \mathrm{hr}$. Mississippi set a level of 25 $\mathrm{microR} / \mathrm{hr}$. 
supplies in the region, and no levels of concern were reported. ${ }^{189}$ The effect of NORM on other water uses and on ecosystem health was not evaluated in the present work.

Produced water intended for treatment followed by discharge to waterways or for surface application should be tested for NORM, and restrictions on levels of NORM in waters that will be managed in these ways should be set to avoid environmental releases that could compromise drinking water resources downstream of discharges.

\section{Conventional Pollutants}

Produced water contains conventional pollutants that have well-studied effects on ecosystems. Conventional pollutants are those amenable to removal in POTWs using conventional treatment; they do not include toxic substances. Conventional pollutants include bacteria, BOD, COD, TSS, oil and grease, and nutrients. Wastewater treatment plants are designed to remove organic carbon-containing compounds that would cause oxygen depletion if released to the environment. Some wastewater treatment plants are also designed to remove nutrients (nitrogen and phosphorus) to prevent eutrophication in receiving waters. The BOD in produced waters is not very degradable (see Table 1, Chapter 2 for the BOD/COD ratio) and so is not expected to be removed in conventional POTW treatment or to have significant oxygen-depleting effects in the receiving stream. The recalcitrant organic materials might slowly degrade in the environment or might be persistent.

Organic and inorganic nitrogen levels in produced water are a concern for surface discharge because they can contribute to oxygen depletion in receiving streams and nutrient loading leading to eutrophication. Nitrogen is unlikely to be completely removed in conventional POTWs or CWTs; however, ammonia can be removed in POTWs designed for nitrification, which will control the oxygen-depleting effects of the nitrogen. Produced water that contains high levels of ammonia could increase concentrations such that treatment plants that previously did not need to include nitrification might have to begin doing so to meet their discharge permit limits. Plants that do include nitrification might have to adjust their processes (e.g., increase aeration) to achieve treatment with higher influent loads. ${ }^{\text {nn }}$ Of course, plants without discharge standards for nitrogen do not include treatment technologies for this contaminant, and any addition to their influent will lead to an increase in their effluent discharge of this chemical. Nitrogen in wastewaters released to surface waters should be considered in context with other nutrient loads in receiving waters to ensure that the cumulative effects are sufficiently controlled by dilution.

Similarly, produced waters may contain chemical constituents such as sulfate, hardness, and chloride that are regulated in drinking water due to taste, odor, and scaling considerations, rather than human health effects. Produced waters may contain constituents at concentrations much higher than secondary standards designed to reduce unpleasant characteristics. Surface discharge without adequate dilution could cause source waters to exceed secondary standards, leading to taste, odor, or color development in finished drinking water at plants downstream from discharge

nn POTWs with discharge limits on "total nitrogen," as opposed to discharge limits on ammonia-nitrogen only, may see their treatment processes (and their ability to meet permit limits) affected in more complex ways because of the more complex treatment processes that are required to meet total nitrogen limits. 
points. This may lead to customer complaints and additional cost to the drinking water provider to remove these contaminants. Secondary standards relevant to produced water constituents are summarized in Table 1, below. Based on the analysis of produced water from Marcellus Shale development summarized in Table 1, Chapter 2, and analysis of CWT effluent from plants without desalination summarized in Table 4, Chapter 2, effluent from CWTs treating Marcellus produced water is likely to contain high levels of chloride and TDS and may contain high levels of iron and manganese. While produced water is generally low in sulfate, treatment methods to remove barium often involve addition of sulfate, and CWT effluent (Table 4, Chapter 2) can be higher in sulfate than produced water.

Table 7. Secondary Drinking Water Standards for Constituents That May Be Present in Produced Water

\begin{tabular}{|c|c|c|}
\hline Contaminant & Secondary MCL & Effect \\
\hline Aluminum & $0.05-0.2 \mathrm{mg} / \mathrm{L}$ & Color \\
\hline Chloride & $250 \mathrm{mg} / \mathrm{L}$ & Salty taste \\
\hline Copper & $1.0 \mathrm{mg} / \mathrm{L}$ & Metallic taste, staining \\
\hline Iron & $0.3 \mathrm{mg} / \mathrm{L}$ & Color, metallic taste, staining \\
\hline Manganese & $0.05 \mathrm{mg} / \mathrm{L}$ & Color, metallic taste, staining \\
\hline Sulfate & $250 \mathrm{mg} / \mathrm{L}$ & Salty taste, laxative \\
\hline Total Dissolved Solids & $500 \mathrm{mg} / \mathrm{L}$ & $\begin{array}{r}\text { Hardness, color, staining, salty taste (depends } \\
\text { upon constituents in TDS) }\end{array}$ \\
\hline Zine & $5 \mathrm{mg} / \mathrm{L}$ & Metallic taste \\
\hline
\end{tabular}

\section{Hydraulic Fracturing Fluid and Formation-Associated Organic Compounds}

Some chemicals present in hydraulic fracturing fluids are toxic at very low levels (ppb), as would be expected of biocides. Most hydraulic fracturing fluid will remain in the subsurface; however, water that does return to the surface will not have the same characteristics during early production (flowback period) as it will have later. Chemicals associated with the hydraulic fracturing fluid are more likely to return in the early phase, while those associated with the formation are more likely to return in the later phase. ${ }^{190}$ Early-phase water is more likely to be recycled, as discussed in Chapter 1.

However, there is the potential for some added chemicals to remain at very low levels in later produced water, and some organic compounds are present in fracturing additives as well as naturally occurring in the formation (e.g., benzene). Of particular concern are contaminants that are intended to be biologically active (e.g., antimicrobial agents like glutaraldehyde) and those that are known to present human health effects (e.g., benzene, 2-butoxyethanol). Alternatives to chemical antimicrobial agents include surface UV systems, although these inactivate only 
microbes in the water and do not prevent growth of organisms in the well itself, where bacterial activity may cause corrosion or formation of hydrogen sulfide $\left(\mathrm{H}_{2} \mathrm{~S}\right)$. Organic chemicals that are naturally occurring in the formation (e.g., BTEX) will be in the produced water and cannot be avoided through new technology or the development of new chemical additives.

Some produced water additives and organics present in the rock formation will be removed in conventional POTW or CWT treatment, predominantly through biodegradation or sorption to solids that are removed by precipitation or settling. Little data are available to assess levels of chemicals used in hydraulic fracturing or those from the formation in treated POTW or CWT effluent. Hydraulic fracturing chemical additives are not specifically regulated in discharge permits and thus are not measured for compliance. Salts and some specific components (e.g., TDS, chloride, sulfate) have been measured for compliance with discharge permits (see data presented in Chapter 1). Analysis of the organic compounds would be necessary to determine if the concentrations of specific chemicals such as those in hydraulic fracturing fluids and produced water would be of concern in produced water after treatment. ${ }^{191}$ Methods for pretreatment targeting these specific chemicals exist and could be deployed to ensure removal prior to POTW treatment or discharge.

Since some produced waters contain contaminants of concern at concentrations of concern (e.g., BTEX), discharge without treatment or land application of untreated produced waters would release these chemicals to the environment and should be avoided. Full chemical characterization may be prohibitively expensive, so targeted analysis focused on chemicals of concern expected to be present could be used.

\section{Cumulative and Long-Term Impacts}

One of the most difficult aspects of evaluating the potential effects of any environmental management decision is considering the cumulative and long-term impacts. Soeder suggests that understanding the longer-term and cumulative effects of shale gas extraction on ecosystems (landscape, terrestrial, and aquatic), water resources, and air quality is an area requiring more attention. $^{192}$

Chemical constituents used in hydraulic fracturing have been the focus of intense public discussion in the past several years, but analysis of produced water suggests that these represent a small part of the overall wastewater management challenge. Most additives will return to the surface in the initial flowback period and will be recycled into subsequent hydraulic fracturing activities, allowing for reduced chemical additions for the next cycle. Formation chemicals, including toxic organics commonly found in hydrocarbon formations (e.g., BTEX) and naturally occurring radioactive materials (NORM), will require careful monitoring within the produced water sent to management options that result in direct or indirect release to the environment.

In regard to total dissolved solids (especially those containing chloride), we are just beginning to focus on the long-term effects of increased use of deicing/anti-icing and dust control chemicals in general. If current trends in use continue, chloride concentrations in streams in some parts of the country are projected to exceed drinking water standards and will become toxic to freshwater life within the next century. ${ }^{193}$ This projection suggests a need for renewed focus on alternative 
approaches to deicing/anti-icing and dust control. Produced water, with its high concentration of chlorides and increased application frequency, is not an alternative that is likely to reduce this problem.

Similarly, for bromide discharges, recent work has focused on significant negative impacts on drinking water at very low levels. Regulatory action to set standards for in-stream concentrations in drinking water sources and discharge limits for Clean Water Act permits is likely to evolve over the next few years in several places in the country. While this will doubtless be a contentious process, the management of produced waters as well as other bromide sources (e.g., mining, coal-based power plants) will have to be considered in the cumulative loading of bromide to drinking water sources.

Residuals associated with the treatment of produced waters (concentrated brines and solids) contain the chemicals removed from the water and therefore continue to present challenges in management. Improper handling of residuals will negate the value of the treatment and must be avoided.

Where produced waters contain toxic organics, NORM, very high chloride, and high bromide, management methods that result in releases of these chemicals to the environment should be avoided. This type of management is widely utilized for produced water from coal bed methane and shallow oil and gas wells, and depending upon the constituents of those produced waters, these management choices may be appropriate. However, partial CWT treatment followed by surface water discharge and beneficial reuse as a deicing or dust control agent is inappropriate for produced waters from the Marcellus Shale formation. These activities have the potential for cumulative and long-term impacts that are difficult to predict. These management options should be avoided until the potential impacts are better understood. 


\section{Chapter 4. Current Regulatory Framework}

Federal regulations prohibit the discharge of shale gas wastewater directly from a production site into surface waters. This prohibition is a primary reason that natural gas operators must use the various treatment and disposal methods described in the preceding chapters. It has also triggered the application of a number of statutes and regulations governing those methods. At the federal level, the Clean Water Act regulates the treatment and discharge of wastewater into the surface waters of the United States, while the Safe Drinking Water Act regulates the underground injection of wastewater. Both of these regulatory programs may be administered at the state level, in states that have been given the authority to do so. The Resource Conservation and Recovery Act, a federal statute that governs the handling of most solid and hazardous wastes, does not apply to oil and gas wastewater due to a statutory exemption. Most other aspects of wastewater handling, treatment, reuse, and disposal are regulated solely by the states.

\section{Treatment and Discharge to Water Bodies}

The federal statute regulating the treatment and discharge of shale gas wastewater into surface water bodies is the Federal Water Pollution Control Act, more commonly called the Clean Water Act. Under the Act, "point sources" - often facilities like factories and wastewater treatment plants - may not discharge pollutants into waters of the United States unless the discharge is authorized. ${ }^{194}$ Point source discharges may be authorized under Section 402, which establishes the National Pollutant Discharge Elimination System (NPDES) program. Under that program, the U.S. Environmental Protection Agency (EPA), or a state that has been given the authority, issues permits authorizing discharges into surface waters. ${ }^{195}$ Consequently, facilities must obtain NPDES permits if they intend to discharge shale gas wastewater-or any by-product resulting from treatment of the wastewater - into a surface water body. ${ }^{196}$

The conditions of NPDES permits are a function of both federal and state law, as the Clean Water Act sets a national baseline that states may exceed through stricter local rules. These permits contain two general types of conditions. The first are technology-based, requiring a minimum level of treatment of pollutants based on available treatment technologies. The second are water quality-based, limiting the discharge of pollutants according to the desired quality of the receiving water. ${ }^{197}$ Water quality-based limitations are unique to each discharger and are tailored to local conditions; NPDES permits must contain limits for all pollutants in a facility's discharge that may cause a violation of state water quality standards. ${ }^{198}$ Technology-based limitations, on the other hand, are typically set at the national level for major polluting industries. The EPA establishes effluent limitations guidelines (ELGs) for entire categories of industrial dischargers based on the degree of pollutant reduction they can attain by using available technology. ${ }^{199}$

The technology-based requirements for direct discharges from oil and gas facilities into water bodies are contained in 40 C.F.R. Part 435 . Those regulations completely prohibit the discharge of wastewater pollutants from point sources associated with natural gas production. ${ }^{200}$

Exceptions exist for produced water clean enough for use in agriculture or wildlife propagation west of the 98th meridian (which runs through North Dakota, South Dakota, Nebraska, Kansas, Oklahoma, and Texas), and for oil wells producing less than 10 barrels per day. ${ }^{201}$ Neither of these exemptions apply to gas wells east of the 98th meridian. Consequently, hydraulic fracturing operators in the Marcellus formation may not discharge their wastewater directly into 
waters of the United States, even with treatment that reduces (but does not eliminate) pollutant levels.

Instead of discharging wastewater directly to surface waters, then, many hydraulic fracturing operators send wastewater to treatment facilities that are authorized to discharge. These facilities include publicly owned treatment works (POTWs) and centralized waste treatment facilities (CWTs). POTWs are plants designed to treat municipal sewage and are typically owned and operated by state or local governments. CWTs are privately owned plants designed to treat industrial wastewater. CWTs may discharge either directly to surface waters or to POTWs (or may completely recycle wastewater for reuse without discharging). The regulations in 40 C.F.R. Part 435 that deal with discharges by natural gas facilities directly to surface waters do not cover discharges into or out of POTWs or CWTs. Rather, separate EPA regulations set requirements for the introduction of industrial wastewater to POTWs (known in EPA regulations as "indirect discharge" ${ }^{202}$ ) and for the discharge of industrial wastewater from CWTs. States may also establish requirements for these discharges that are stricter than the federal requirements. ${ }^{203}$

\section{Discharges Into and From Publicly Owned Treatment Works}

EPA regulations establish three kinds of limits on wastewater introduced to a POTW. First, they forbid industrial facilities from introducing any pollutant to a POTW that will disrupt the functions or processes of the POTW (referred to as "interference"), or that exit the POTW into surface waters in quantities or concentrations that will cause the POTW to violate the pollutant limits contained within its discharge permit (called "pass through"). ${ }^{204}$ For example, some POTWs' permits contain limits on total dissolved solids (TDS). Shale gas wastewater contains high quantities of TDS, which POTWs are not designed to remove, so introduction of sufficient quantities of that wastewater to a POTW might create the potential for a permit violation. Additionally, some of the individual constituents of TDS may disrupt POTW function in facilities that use activated sludge, nitrification, and anaerobic digestion processes. ${ }^{205}$ Second, the regulations contain categorical pretreatment standards, which set limits on pollutant discharges to POTWs from particular types of industrial wastewater. The EPA develops these technology-based standards under Section 307 of the Clean Water Act. ${ }^{206}$ While no categorical pretreatment standards currently exist for shale gas wastewater introduced to POTWs, in October 2011 the EPA announced its plans to develop such standards. ${ }^{207}$

Third, the regulations require POTWs receiving industrial wastewater that causes pass through or interference to develop their own pretreatment programs that contain "local limits" reflecting their specific needs and capabilities. ${ }^{208}$ Essentially, local limits translate the general prohibition on pollutants causing pass through and interference into site-specific limitations. EPA provides municipalities with guidance on developing local limits, assisting them with their calculations of maximum allowable pollutant loadings to their POTWs. ${ }^{209}$ Many states also provide guidance on establishing local limits, though Pennsylvania has not written its own guidance because the EPA administers the pretreatment program there. ${ }^{210}$ All facilities indirectly discharging shale gas wastewater through POTWs must comply with each POTW's local pollutant limits. In practice, however, POTWs have rarely established local limits on pollutants contained in shale gas wastewater, according to the EPA. ${ }^{211}$

In addition to these pretreatment regulations, POTWs must comply with their own NPDES discharge permits. Many POTWs have conditions in their permits limiting the volume of 
wastewater they accept from oil and gas operations to no more than 1 percent of their average daily flow. ${ }^{212}$ (In Pennsylvania, PADEP has sometimes imposed these limits on POTWs through administrative orders rather than through formal permit conditions. ${ }^{213}$ ) Additionally, under NPDES regulations, permits must include conditions requiring POTWs to provide "adequate notice" to the EPA (and the state permitting authority, if applicable) when the POTW intends to accept new or additional pollutants or waste streams. ${ }^{214}$ In practice, this requirement means that the POTW must provide notification before it begins to accept the new wastewater. This is to ensure that the permitting authority has enough time to determine if the POTW's permit needs to be modified in order to address the possible effects of the new indirect discharger. ${ }^{215}$ As a result, POTWs that intend to accept shale gas wastewater when they have not previously done so must collect information from the natural gas operator on the quality and quantity of wastewater that the operator plans to introduce to the POTW, assess the potential impact of that wastewater on the POTW's discharges, and report this information to the EPA and/or the state. ${ }^{216}$

\section{Discharges From Centralized Waste Treatment Facilities}

While some shale gas wastewater is discharged through POTWs, many operators send wastewater to CWTs for treatment and discharge directly to water bodies. (Some wastewater treated at CWTs is reused instead of discharged; regulation of those uses is discussed later in this section.) The technology-based standards for CWT discharges are codified at 40 C.F.R. Part 437. These standards set numerical limits on the discharge of individual pollutants from CWTs based on what can be achieved using available technologies. The standards were developed in 2000 and amended in 2003, before large-scale development of shale gas became widespread. ${ }^{217}$ Consequently, the regulations do not include standards for all of the pollutants commonly found in shale gas wastewater. Shale gas wastewater pollutants covered by the standards include oil and grease, total suspended solids, and biochemical oxygen demand. Pollutants not covered by the standards include total dissolved solids, bromide, and radioactive materials.

For pollutants not included in the national standards, limitations must nevertheless be developed for individual CWTs' discharge permits. These are based on state limitations if such standards exist; for example, Pennsylvania regulations set numeric limits for CWT discharges of total dissolved solids and chlorides, as discussed below. In addition to the application of any relevant state standards, additional permit limits are developed on a case-by-case "best professional judgment" basis. ${ }^{218}$ When the permit writer (at the EPA or a delegated state's permitting authority) develops limits on this basis, the writer must consider the same factors that the EPA considers when it establishes technology-based nationwide standards. ${ }^{219}$ These factors include the age of the facility and its equipment, the treatment processes the facility uses, and the cost of achieving pollutant reductions. Regulations governing discharges from CWTs impose no responsibilities on the generators of shale gas wastewater; the CWTs themselves are responsible for ensuring that their treatment of that wastewater is adequate.

\section{Water Quality Standards}

In addition to technology-based requirements, NPDES permits for POTWs and CWTs discharging treated wastewater must also include any more stringent requirements necessary to meet water quality standards. ${ }^{220}$ The EPA and delegated states develop standards for each water body by identifying the uses to be made of the water (for example, fishing, swimming, or drinking water supply) and then setting water quality criteria necessary to protect these uses. ${ }^{221}$ 
The criteria are generally numeric limitations on pollutants in a particular water body that are adequate to support the water body's designated uses. ${ }^{222}$

The EPA has published recommended national water quality criteria as guidance for delegated states. These recommendations include criteria for some pollutants of concern in shale gas wastewater, such as chloride, oil and grease, suspended solids, turbidity, and nitrates. ${ }^{223}$

Permitting authorities use the criteria to determine whether a facility's discharge might lead to an exceedance of water quality standards. If so, that facility's permit must contain water quality- based limitations. ${ }^{224}$ Thus, where a POTW's or CWT's discharge of shale gas wastewater has the potential to cause or contribute to exceedances of water quality standards, the permit for that facility must contain water quality-based limits adequate to protect water quality. This requirement may arise for shale gas wastewater pollutants like total dissolved solids and sulfates, which have been known to cause violations of water quality standards in water bodies such as the Monongahela River. ${ }^{225}$

\section{Pennsylvania's Discharge Requirements and Water Quality Standards}

Pennsylvania has been delegated authority to administer the Clean Water Act NPDES permitting program. The Pennsylvania Department of Environmental Protection (PADEP) has issued regulations implementing the Act and the state's Clean Streams Law. ${ }^{226}$ These regulations require NPDES permits for facilities discharging industrial waste to comply with both EPApromulgated effluent limitation guidelines and the state's own industrial waste discharge standards. ${ }^{227}$ The state wastewater quality standards are set out in Chapter 95 of the Pennsylvania State Code, which contains all requirements for wastewater treatment within the state. ${ }^{228}$

In 2010, PADEP finalized revisions to Chapter 95 addressing the discharge to surface waters of wastewater from natural gas operations. ${ }^{229}$ The regulations now require each natural gas operator to implement a wastewater source reduction strategy, identifying the methods and procedures the operator will use to maximize recycling and reuse of wastewater. ${ }^{230}$ The regulations prohibit "new and expanding" discharges of shale gas wastewater unless the discharge is authorized by a state-issued permit. ${ }^{231}$ Such discharges may be authorized only from CWTs; POTWs may be authorized to discharge shale gas wastewater only if the wastewater has been treated at a CWT first. ${ }^{232}$ The regulations provide limits on certain pollutants contained in the wastewater discharged from CWTs, including limits on monthly averages of total dissolved solids $(500 \mathrm{mg} / \mathrm{l})$ and chlorides $(250 \mathrm{mg} / \mathrm{l}){ }^{233}$

These limits and restrictions apply only to "new and expanding" wastewater discharges. The regulations define these as discharges causing a net increase in total dissolved solids of more than 5,000 pounds per day above a facility's previously authorized loading. ${ }^{234}$ Discharges not falling under this definition (i.e., all previously authorized discharges that have not increased beyond the threshold) were "grandfathered" under the Chapter 95 revisions and thus not required to meet these new limits. The grandfathered facilities include both POTWs and CWTs.

In April 2011, after surface water sampling found elevated levels of bromide in western Pennsylvania rivers, the PADEP called on all Marcellus Shale natural gas drilling operators to voluntarily stop delivering their wastewater to grandfathered facilities. ${ }^{235}$ At the time, 15 facilities had been accepting wastewater; within two months, PADEP announced that Marcellus operators were largely complying with the voluntary ban and that drilling wastewater was no 
longer being discharged to rivers or streams in Pennsylvania without treatment sufficient to meet the updated Chapter 95 standards. ${ }^{236}$ An independent evaluation of wastewater reports from Marcellus drilling companies to PADEP largely confirms the state's announcement; the reports indicate a 99.5 percent reduction in wastewater volumes being sent to exempt POTWs in the second half of 2011, and a 95 percent reduction in volumes being sent to exempt CWTs in the same period. ${ }^{237}$ Pennsylvania's voluntary approach differs from the more mandatory approach taken by states like Ohio, which does not allow any disposal of oil and gas wastewater at POTWs. Ohio regulations list the options for disposing of oil and gas wastewater; disposal to a surface water body, either directly or via a POTW, is not one of them. ${ }^{238}$

In addition to Pennsylvania's Chapter 95 standards for permits, Chapter 93 of the state's regulations designates water quality standards for Pennsylvania water bodies. ${ }^{239}$ These standards affect the permitting of facilities discharging to Pennsylvania waters. When a particular facility's discharges may cause water quality violations in a receiving water body, the Clean Water Act requires the state to develop more stringent permit limits.

PADEP has established water quality standards for several pollutants contained in shale gas wastewater: alkalinity, ammonia nitrogen, chloride, nitrate, sulfate, and total dissolved solids. ${ }^{240}$ In May 2010 the agency proposed new standards for chloride, one of whose major anthropogenic sources is wastewater from oil and gas wells. ${ }^{241}$ Freshwater fish and other aquatic species cannot survive high concentrations of chlorides, so PADEP proposed stricter standards to protect aquatic life from the impacts of increased Marcellus activity. ${ }^{242}$ The proposed standard was based on 1988 EPA guidance. In July 2010 an independent regulatory commission reviewed the standard, expressing concerns that the 1988 EPA guidance was out of date. ${ }^{243}$ PADEP is now considering a new proposed standard based on Iowa's chloride criteria. ${ }^{244}$ In the meantime, EPA has indicated that it may develop new guidance on chlorides. ${ }^{245}$

\section{Underground Injection}

While the Clean Water Act regulates the surface discharge of shale gas wastewater, the Safe Drinking Water Act (SDWA) regulates the underground injection of that wastewater. ${ }^{\circ 0}$ The SDWA established the Underground Injection Control (UIC) program, which prevents the injection of liquid wastes into underground sources of drinking water by setting standards for safe wastewater injection practices and banning certain types of injection altogether. ${ }^{246}$ All underground injections are prohibited unless authorized under this program (except for the hydraulic fracturing process itself, which, as discussed below, is exempt from regulation under the SDWA) ${ }^{247}$ As with the Clean Water Act, EPA implements the UIC program unless a state has been given authority, or primacy, to take over control of the program. ${ }^{248}$ Even where the EPA implements the UIC program, it must consider local geological, hydrological, and historical conditions. $^{249}$

Under the UIC program, EPA groups underground injection wells into five classes, with each class subject to distinct requirements and standards. ${ }^{250}$ Because of a regulatory determination by EPA not to classify shale gas wastewater as "hazardous" (discussed below), it is not required to be injected into Class I wells for hazardous waste. Rather, shale gas wastewater may be injected

\footnotetext{
${ }^{\circ 0}$ The Clean Water Act's definition of "pollutant" specifically excludes oil and gas wastewater that is pumped into a well, either to facilitate oil and gas production or for disposal. Consequently, shale gas wastewater injection is exempted from regulation under the Clean Water Act, 33 U.S.C. $\$ 502(6)$.
} 
into Class II wells for fluids associated with oil and gas production. Class I hazardous waste wells are subject to more stringent requirements than are Class II wells, such as consideration of earthquake risk in well siting, analysis of a larger geographic area surrounding the well, and more stringent procedures for reporting and correcting problems. Class I hazardous waste wells must also be drilled deeper, below the lowest underground source of drinking water, to prevent contamination. ${ }^{251}$ Class II wells, while not subject to all of these conditions, are also subject to a number of regulatory requirements under the UIC program.

Before the EPA (or a delegated state) may authorize a Class II well, it must consider the location of existing wells and other geographical features in the area; the well operator's proposed operating data, including daily rate, volume, and pressure of injection; the injection fluid's characteristics; the geological characteristics of the injection zone; the construction details of the proposed well; and the operator's demonstration of mechanical integrity. ${ }^{252}$

When Class II wells are constructed, they must be sited so that they inject into an underground formation which is separated by a fault- and fracture-free zone from any underground source of drinking water (USDW). ${ }^{253}$ Moreover, all wells must be cased and cemented to prevent the movement of fluids into or between USDWs. ${ }^{254}$ During operation of the well, at no point must the injection pressure exceed a precalculated maximum, to assure that the pressure does not initiate new fractures or enlarge existing fractures in the zone adjacent to USDWs. Well operators must not inject at a pressure that will cause the movement of injection or formation fluids into a USDW. ${ }^{255}$ Generally, operators must maintain the mechanical integrity of the well, and if they cannot, they must cease injection. ${ }^{256}$

In the Marcellus region, Maryland, Ohio, and West Virginia have assumed primacy and implement the UIC program. New York, Virginia, and Pennsylvania have not assumed primacy, so EPA directly implements the UIC program in those states. While Pennsylvania does not regulate the injection of wastewater into disposal wells, the state does require a permit for the initial drilling of a wastewater disposal well. ${ }^{257}$ To obtain a permit, the driller must show that the well has been approved under the federal UIC program, and also must have a pollution prevention plan (called a "control and disposal plan") and an erosion and sedimentation plan. ${ }^{258}$ Unlike states like New York, which requires a site-specific environmental impact review for each disposal well that is drilled, Pennsylvania does not require a general review of all environmental impacts that could result from each well. ${ }^{259}$

\section{Reuse for Additional Hydraulic Fracturing}

In contrast to the injection of shale gas wastewater as a disposal practice, the injection of fluids (which may include recycled wastewater) for the hydraulic fracturing process itself is exempted from regulation under the federal Safe Drinking Water Act. The statute's definition of "underground injection" specifically excludes "the underground injection of fluids or propping agents (other than diesel fuels) pursuant to hydraulic fracturing operations related to oil, gas, or geothermal production activities." ${ }^{260}$ A bill introduced in Congress in 2011 would remove this exemption and explicitly authorize regulation of hydraulic fracturing under the SDWA. ${ }^{261}$ Under current law, however, if shale gas wastewater is managed or treated for the sole purpose of reuse for further hydraulic fracturing, it is not subject to federal regulation.

However, state regulations do apply to the reuse of shale gas wastewater. In Pennsylvania, facilities that process wastewater for beneficial reuse may be authorized under PADEP-issued 
"general permits," which establish generally applicable standards. Operations authorized under these general permits are not required to obtain individualized permits for wastewater processing. ${ }^{262}$ In Pennsylvania, general permit WMGR123 authorizes the processing of Marcellus wastewater for use in further hydraulic fracturing and other extraction of natural gas, provided that the resulting fluid conforms to industry quality standards for gas well fracturing fluid. ${ }^{263}$ This permit, a consolidation of three prior general permits for beneficial reuse, contains new operating conditions developed to allow storage of processed water in tanks and impoundments prior to use for fracturing a well. In effect, the permit relieves operators of the obligation to handle wastewater destined for reuse as a "waste" if it has been treated to meet specified concentration limits, which are based on drinking water standards and water quality standards. Operators must demonstrate that the wastewater meets the constituent limits by submitting analytical data to PADEP. However, any wastewater that is not ultimately reused for further fracturing must be handled as a waste. The permit also contains new recordkeeping and reporting requirements.

\section{Impoundments}

Because of an exemption from federal law (discussed below), the storage and disposal of shale gas wastewater in impoundments is regulated solely by the states. In Pennsylvania, facilities that store and dispose of shale gas wastewater in impoundments must obtain permits under Chapter 289 of the PADEP solid waste regulations. Chapter 289 contains construction and design specifications and operating requirements for those impoundments. ${ }^{264}$ Under these regulations, operators of impoundments must have water quality monitoring plans to prevent the contamination of groundwater. They are also forbidden from causing any "water pollution" within or outside the impoundment site. ${ }^{265}$ This prohibition is a freestanding regulatory requirement unconnected to the impoundment permitting process. According to PADEP regulations defining "pollution," this means that impoundments must be designed and operated to ensure they do not cause water contamination that could lead to a public nuisance; a threat to public health, safety, or welfare; a detriment to beneficial uses; or harm to livestock or wildlife. $^{266}$

In February 2012, Pennsylvania enacted a law that limited the ability of municipalities to regulate the siting of impoundments. Under this new law, the maximum setback that a local government may require for an impoundment is 300 feet from a residential structure. (The law also establishes maximum setbacks for wells and well pads.) The law also bars local governments from using zoning laws to regulate the siting of impoundments. ${ }^{267}$ In March 2012, seven Pennsylvania municipalities filed a lawsuit challenging the statute for infringing on local governments' control over land use; this lawsuit is still pending. ${ }^{268}$

\section{Land Application}

Because of an exemption from federal law (discussed below), the land application of shale gas wastewater is regulated primarily at the state level. This practice is regulated at the federal level only to the extent that stormwater runoff associated with road spreading of wastewater could lead to violations of the Clean Water Act, such as the Act's prohibition against direct discharges of oil and gas waste ${ }^{269}$ or regulations applicable stormwater discharges from roadways. ${ }^{270}$ While Pennsylvania's oil and gas well regulations generally prohibit operators of such wells from discharging brine and other produced fluids onto the ground, ${ }^{271}$ the state's solid waste 
management regulations state that PADEP may issue permits authorizing land application of waste. $^{272}$

Using this authority, PADEP has issued a general permit authorizing the application of natural gas well brines specifically for roadway pre-wetting, anti-icing, and deicing purposes, ${ }^{273}$ as long as the brine meets certain pollutant concentration limits. If shale gas wastewater contains pollutants exceeding these limits-and Marcellus wastewater is likely to exceed them for some pollutants, like oil and grease - then it may not be applied to roads without first being treated to meet the limits. The general permit also limits the quantity of brine that may be applied. The permit states that it does not authorize the runoff of wastewater to surrounding lands and waters. Runoff from road spreading may be minimized through the use of certain management practices, ${ }^{274}$ but in reality a certain amount of runoff may be expected to occur. ${ }^{275}$ PADEP is currently proposing to amend the permit to also authorize the beneficial use of brines as a dust suppressant and a stabilizer for unpaved roads. ${ }^{276}$ These uses were previously allowed, but PADEP was required to approve each operator's use for these purposes on a case-by-case basis. ${ }^{277}$ Amending the general permit to include dust suppression and stabilization as authorized beneficial uses will mean that operators will no longer need to seek individual approval.

By contrast, some states prohibit the road spreading of shale gas wastewater. For example, New York prohibits the road spreading of flowback under any circumstances. ${ }^{278}$ Additionally, while the state accepts permit applications for road spreading of production-phase water, the New York State Department of Environmental Conservation has stated that it does not anticipate granting any such applications at present because the available data on NORM are insufficient to show that the land application of that water is safe. ${ }^{279}$

\section{Handling, Storage, and Transport Prior to Disposal}

State regulations govern the handling, storage, and transport of shale gas wastewater prior to its ultimate disposal. Oil and gas wastes are currently exempt from the hazardous waste provisions of the federal Resource Conservation and Recovery Act (RCRA), which generally regulates the handling and disposal of waste. RCRA Subtitle C creates a federal program that manages hazardous waste from cradle to grave, including regulations for the generation, transportation, treatment, storage, and disposal of hazardous wastes. However, an amendment to the statute passed in 1980 exempted "drilling fluids, produced waters, and other wastes associated with the exploration, development, or production of crude oil or natural gas or geothermal energy" from coverage under RCRA for two years. ${ }^{280}$ In the meantime, the amendment directed the EPA to determine whether regulation of those wastes under RCRA was warranted. ${ }^{281}$

In 1988, long before the large-scale development of shale gas became widespread, the EPA made a determination that such regulation was not warranted because existing state and federal regulations were generally adequate to control the management of oil and gas wastes. ${ }^{282}$ The agency also found that applying RCRA Subtitle $C$ regulation to these wastes would impose excessive costs on the industry. The EPA concluded that it would be more efficient and appropriate to fill any existing regulatory gaps by strengthening the Clean Water Act and UIC programs. ${ }^{283}$ The agency also discussed the possibility of developing tailored management criteria for oil and gas wastes under Subtitle D of RCRA, which provides general environmental performance standards for disposal of solid wastes, but it has never done so. ${ }^{284}$ 
Consequently, oil and gas wastes remain exempt from the hazardous waste provisions of RCRA. This means that natural gas operators transporting shale gas wastewater, along with the POTWs, CWTs, and any other facilities receiving it, are not transporting or receiving legally "hazardous" wastes and thus do not need to meet the "cradle to grave" safeguards established by RCRA regulations.

In the absence of federal regulations, states control the handling, storage, and transport of shale gas wastewater. ${ }^{285}$ In Pennsylvania, wastewater from industrial operations is classified as nonhazardous, and it must be managed and disposed of in accordance with the state's Solid Waste Management Act. ${ }^{286, \mathrm{pp}, \mathrm{qq}}$ As a general matter, the statute requires anyone who stores, processes, transports, or disposes of nonhazardous waste to comply with all PADEP waste management regulations. It also prohibits them from endangering public health or the environment and from causing a public nuisance. ${ }^{287}$

PADEP's waste management regulations impose certain duties on the generators of nonhazardous waste if they generate more than 2,200 pounds of waste per month. ${ }^{288}$ Those exceeding this threshold must prepare a strategy aimed at reducing the quantity of waste. ${ }^{289}$ They must also submit to PADEP an annual report (Form 26R) containing a chemical analysis of their waste, and a biennial report detailing the types of waste generated and the location or method of the waste's ultimate disposal. ${ }^{290}$ Other types of records concerning the ultimate fate of the generators' waste must be kept on site and made available for inspection. ${ }^{291}$

All waste must be transported to processing and disposal facilities that hold appropriate PADEP waste management permits. ${ }^{292}$ State regulations provide detailed standards for the storage and transportation of waste. ${ }^{293}$ If a spill or accidental discharge occurs during transport, the transporter must notify PADEP and take immediate steps to contain and clean up the spill. ${ }^{294}$

\section{Residual Waste}

One additional regulatory issue that arises with regard to shale gas wastewater concerns the handling of residual waste, the material that remains after treatment. This material can be subject to various regulations depending on its composition and the method of disposal. ${ }^{295}$

Liquid residuals from treatment plants, such as concentrated brines, may be discharged to surface waters in compliance with a NPDES permit, or indirectly discharged via a POTW in compliance with applicable pretreatment standards. Nonhazardous liquid residuals may also be disposed of through land application in compliance with state solid waste rules, or injected underground in compliance with UIC regulations.

Residuals in solid form, like sludge or residual "cakes," are typically subject to RCRA regulations and are classified as hazardous or nonhazardous. As discussed, shale gas wastewater is exempt from RCRA, and the EPA has interpreted this exemption as applying to residual wastes in most circumstances. Solid residual waste falling under the RCRA exemption, even if it displays hazardous or radioactive characteristics, may legally be sent to local municipal landfills.

\footnotetext{
pp The Pennsylvania regulations refer to industrial wastewater as "residual waste." Because of the potential confusion with the use of the term "residual waste" to refer to the material that remains after the process of waste treatment has taken place, we use the term "nonhazardous waste" here.

${ }^{\mathrm{qq}}$ Similarly, in New York, regulations exempt industrial wastewater, including oil and gas produced water, from the definition of "hazardous waste." 6 N.Y.C.R.R. $\$ 371.1(\mathrm{e})(2)(\mathrm{v})$.
} 
However, under certain circumstances, residual waste streams generated by treatment and disposal methods may be subject to regulation as hazardous waste under RCRA Subtitle C. ${ }^{296}$ To the extent RCRA applies, solid residuals' classification as hazardous or nonhazardous affects the type of landfill in which they may be placed. Nonhazardous waste may be sent to municipal solid waste landfills; hazardous waste landfills are subject to stricter standards. In addition to (or in lieu of) RCRA requirements, state solid waste regulations may also apply. If solid residuals are disposed of through land application practices like road spreading, compliance with the state's land application rules is required.

Finally (again, to the extent RCRA applies), residuals containing concentrated radioactive material greater than a certain threshold must be disposed of in a radioactive waste landfill licensed by the Nuclear Regulatory Commission. 


\section{Chapter 5: Policy Recommendations}

The current regulation of shale gas wastewater is inadequate to prevent harm to human health and the environment. As described in the preceding chapters of this paper, the improper handling, treatment, and disposal of shale gas wastewater can expose people, fish, and wildlife to toxic, radioactive, or carcinogenic chemicals, and to chemicals that deplete oxygen levels in receiving waters, in the following ways: ${ }^{\text {rt }}$

- Wastewater that receives inadequate processing at public sewage treatment plants, or at private industrial wastewater treatment facilities, can be discharged directly to rivers, lakes, and streams.

- Spills from impoundments and holding tanks can contaminate nearby waters and soils.

- Improper injection of wastewater can pollute drinking water supplies or cause earthquakes.

- Partially treated wastewater applied to roads for dust suppression, deicing, and anti-icing can run off into adjacent waterways and seep into groundwater.

- Residual solid wastes left over from treatment processes can be sent to landfills that provide insufficient containment of hazardous pollutants.

To prevent these harms, government oversight of wastewater treatment and disposal must be improved at both the federal and the state levels. This chapter presents a number of policy recommendations for improving the regulation of the primary methods used to manage wastewater from hydraulic fracturing operations. While not an exhaustive list, these recommendations, if adopted, would significantly strengthen regulatory safeguards.

\section{Treatment and Discharge to Water Bodies}

Improved regulations are needed to protect surface waters from the impacts of pollutants contained in shale gas wastewater. Currently, discharge of such pollutants, including total dissolved solids, bromide, and radioactive materials, can occur in amounts and concentrations detrimental to water quality. EPA and the states must develop limits on both the discharge of shale gas wastewater from POTWs and CWTs and on the amount of pollution allowable in surface water bodies.

\section{EPA and states should ban or more strictly regulate the discharge of shale gas} wastewater to POTWS.

At present, a regulatory gap exists with regard to shale gas wastewater that is sent to POTWs. The discharge of shale gas wastewater to POTWs is allowed in most jurisdictions. (As discussed, Pennsylvania regulations require shale gas wastewater sent to certain POTWs to be treated at CWT facilities first; the state has asked operators not to send untreated wastewater to POTWs exempted from the regulations, but compliance with this request is voluntary. ${ }^{297}$ ) However,

\footnotetext{
$"$ As noted in the Introduction, polluted wastewater may also be released into the environment through accidental spills associated with the transport of wastewater, but that topic is beyond the scope of this paper. Accordingly, spill prevention and cleanup is not addressed in the recommendations in this chapter. Similarly, pollution from wastewater generated while wells are being drilled (i.e., before fracturing fluid is injected) is also beyond the scope of this paper.
} 
POTW discharge of shale gas wastewater can have serious environmental consequences, since it includes pollutants, such as dissolved solids (i.e., salts), that pass through POTWs untreated or interfere with POTW functions by disrupting biological treatment units. The Clean Water Act's general prohibition against pass-through and interference at POTWs is difficult to implement and enforce for shale gas wastewater because many POTWs are not required to test their discharges for the pollutants that such wastewater contains. ${ }^{298}$ In addition, POTWs have rarely established local limits on those pollutants. ${ }^{299}$ Many states have not developed their own pretreatment standards for shale gas wastewater. Consequently, national pretreatment standards are needed to fill this regulatory gap and create a uniform baseline that will provide consistent protection for water quality in areas undergoing shale gas development.

EPA recently announced plans to develop categorical pretreatment standards for shale gas wastewater. ${ }^{300}$ In doing so, the agency should set a no-discharge standard for POTWs (i.e., ban the discharge of shale gas wastewater to POTWs altogether), as NRDC and other groups recommended in comments on EPA's proposed plan. ${ }^{301}$ Even if standards could be set that limit the pollutants in pretreated shale gas wastewater adequately to protect POTWs and the environment, POTWs have limited capacity, and that capacity is already needed to treat municipal wastewater. Regulators must be careful to avoid situations in which a growing volume of shale gas wastewater displaces other types of wastewater that need POTW treatment. This is a dynamic that could occur if shale gas operators were to offer higher prices to POTWs in return for the ability to discharge. While all forms of shale gas wastewater management present certain risks and potential impacts to health and the environment, other disposal options are likely less harmful and more appropriate than discharge through POTWs.

EPA has the legal authority to set a "no discharge" standard. The Clean Water Act directs the agency to set pretreatment standards that are adequate to "prevent the discharge of any pollutant through [POTWs], which pollutant interferes with, passes through, or otherwise is incompatible with such works. ${ }^{302}$ The most reliably effective way to prevent these impacts is to forbid the introduction of shale gas wastewater to POTWs altogether. Consistent with this understanding of the Act, the agency's guidance document for the national pretreatment program states that one of the possible types of categorical pretreatment standards for industrial wastewater is "[s]tandards that prohibit discharges of any kind." 303 Indeed, the agency has set such a "no discharge" standard for several other types of industrial wastewater, including coastal oil and gas wastewater. ${ }^{304}$ EPA should do the same with its shale gas wastewater categorical pretreatment standards and set a "no discharge to POTWs" standard for shale gas wastewater.

If EPA does continue to allow discharge to POTWs, pretreatment standards should be set as stringently as possible. Under the Clean Water Act, pretreatment standards for existing sources are to be based on the "best available technology economically achievable." 305 This standard means that EPA must take into account not only the best available technology currently used in the treatment of shale gas wastewater, but also the best available technology currently used in other subcategories, even when it is not common practice in the shale gas industry. ${ }^{306} \mathrm{In}$ addition, pretreatment standards for new sources are to be based on the best available demonstrated control technology. ${ }^{307}$ The agency should exercise the maximum authority allowed under the law to establish pretreatment standards that will prevent pass-through and interference.

These pretreatment standards should be comprehensive (applying to all constituents found in shale gas wastewater) and protective (imposing an appropriately low maximum concentration for 
each constituent). They should also specify the total maximum volume of shale gas wastewater that POTWs may accept. At minimum, EPA's pretreatment standards should be as stringent as the standards that have been set by the states, like Pennsylvania's pretreatment standard of 500 $\mathrm{mg} / \mathrm{L}$ total dissolved solids and $250 \mathrm{mg} / \mathrm{L}$ chlorides. ${ }^{308}$ Creating a consistent pretreatment baseline will ensure that all surface waters are protected and that industry does not cluster in locations that are subject to a lesser pretreatment standard, a situation that could create pollution "hot spots."

If EPA does not ban shale gas wastewater discharges to POTWs or develop sufficiently stringent pretreatment standards, states should take these actions on their own. Regardless of whether a state is authorized to implement either the NPDES or the pretreatment program, if it develops its own pretreatment program, it may enforce requirements that are more stringent than federal standards. ${ }^{309}$

2. EPA or the states should update pollution control standards for CWTs that accept shale gas wastewater.

CWTs are subject to federally established effluent limitation guidelines (ELGs) limiting the pollutants that they may discharge ${ }^{310}$ However, these ELGs are out of date; they were developed prior to the emergence of hydraulic fracturing methods of shale gas extraction and do not address all pollutants of concern in the wastewater generated by such operations. The ELGs were adopted in 2000 and revised in $2003,{ }^{311}$ yet large-scale shale gas extraction was not practiced at all until 1997 and did not become common until the mid-2000s. ${ }^{312}$ For example, in Pennsylvania, no Marcellus Shale produced water was reported in natural gas operators' wastewater reports until $2004 .{ }^{313}$ In fact, although shale gas represents about 30 percent of total U.S. natural gas production today (as of August 2011), in 2001, when the CWT ELGs were first developed, shale gas provided less than 2 percent of the total. ${ }^{314}$

EPA should update the CWT ELGs to adequately address all of the constituents present in shale gas wastewater, as NRDC and other groups recommended in comments on EPA's plan to develop pretreatment standards for such wastewater. ${ }^{315}$ In particular, the ELGs should be revised to include limitations on discharges of NORM, total dissolved solids, and bromides, which were not considered in developing the original guidelines. The state of Pennsylvania has recommended that EPA update the CWT ELGs to include limits on these pollutants. ${ }^{316}$ The ELGs' limits on toxic organics, NORM, chlorides, and bromides should not allow any releases of these chemicals to the environment. These pollutants have the potential for cumulative and long-term impacts, such as chronic toxicity to aquatic life and violations of drinking water standards, that are difficult to predict and not yet well understood.

If EPA does not update these standards, states should develop and implement more protective standards on their own. Under the Clean Water Act, states have the authority to develop their own limitation guidelines or to impose limitations in individual permits that are more stringent than those contained in federal ELGs.

3. EPA and the states should develop water quality criteria for all chemicals in shale gas wastewater. 
Water quality criteria are numeric limitations on pollutants in a particular water body that are adequate to support the water body's designated uses. EPA develops recommended water quality criteria, which states uses as guidance in setting and updating their own local criteria.

Additionally, EPA must approve state water quality standards and can promulgate standards for a state if the state fails to adopt adequate ones on its own. ${ }^{317}$ When a facility's discharge has the potential to cause criteria for a receiving water body to be violated, that facility's permit must contain water quality- based limitations to ensure that water quality is protected.

EPA has developed criteria for some pollutants of concern in shale gas wastewater, such as chloride, oil and grease, suspended solids, turbidity, and nitrates. ${ }^{318}$ However, many other pollutants of concern - like total dissolved solids, bromide, and NORM-lack EPArecommended criteria. EPA is currently updating its recommended water quality criteria for chlorides, which were developed in $1988 .{ }^{319}$ The agency has also expressed interest in developing criteria for bromides but has not taken any formal steps to do so. ${ }^{320}$

EPA should proceed with both actions. More generally, it should update all of its recommended criteria for shale gas wastewater constituents and ensure that states expeditiously update their own criteria to provide equivalent protection. These criteria are needed to provide states with guidance on how to set limits on pollutants that are adequately protective of water quality. In the absence of national EPA-recommended criteria, states should develop their own improved criteria for pollutants in shale gas wastewater. In particular, Pennsylvania should complete the new standards it began developing for chlorides in $2010 .^{321}$

\section{Water bodies impaired by pollutants in shale gas wastewater, or with the reasonable potential to become impaired, should be identified, and pollution loads to those waters should be reduced.}

Under Section 303(d) of the Clean Water Act, states (and EPA, where states have not been delegated authority to implement the Act) must identify waters for which a water quality standard has not been met, even after required minimum levels of pollution control technology have been adopted. Such waters are considered "impaired waters." ${ }^{322}$ Under the Clean Water Act, no NPDES permit may be issued to a new discharger if the discharge will contribute to a violation of water quality standards, as when new discharges are made to waters that are already impaired. ${ }^{323}$ Further, existing discharges must be reduced so they no longer cause or contribute to the impairment. ${ }^{324}$ As a result, a determination that a water body is impaired affects whether new discharges may be allowed, as well as permissible pollutant loadings from existing dischargers. Moreover, even when there is no existing impairment in a receiving water body, a discharger that has the "reasonable potential" to cause or contribute to impairment must be assigned a permit limit strict enough to prevent that from happening. ${ }^{325}$

The states (and EPA) should formally designate water bodies that are impaired by pollutants found in shale gas wastewater. This is a key step toward protecting against new wastewater discharges that could further worsen water quality. Additionally, once a water body is designated as impaired, the state (or EPA) must develop a "total maximum daily load" (TMDL) for the pollutant(s) causing the impairment. ${ }^{326}$ A TMDL is a "pollution budget," which calculates the maximum amount of a pollutant that a water body can safely receive each day and divides it up among pollution sources. Clean Water Act permits must then be revised to ensure that no 
individual source exceeds its allocation under the TMDL. ${ }^{327}$ Further, even before a TMDL is developed, once a water body is identified as impaired, the permitting authority must begin imposing stricter limits in dischargers' permits. ${ }^{328}$

Pennsylvania, for example, has proposed that 68 miles of the Monongahela River be designated as impaired for sulfate, a constituent of shale gas wastewater. ${ }^{329}$ If EPA approves the proposal, a TMDL must be established for sulfate in the designated sections of the river. Existing pollution sources will have to reduce their discharges, and new sources will not be allowed unless and until assimilative capacity exists in the river.

\section{Water bodies not yet impaired by shale gas wastewater should be protected.}

When a water body is receiving discharges of shale gas wastewater but is not yet impacted by that wastewater, the state and EPA must take care to protect it. Clean Water Act regulations require states to develop "anti-degradation" policies and implementation procedures to protect water bodies in good condition. Among other things, the anti-degradation rules require that existing uses of a water body must always be protected and that, where a water body is currently cleaner than the minimum water quality standards to support fishing and swimming, any incremental decrease in water quality is permissible only under limited circumstances. ${ }^{330}$ These rules should be used to protect water bodies that have not yet been negatively impacted by shale gas wastewater. More specifically, state anti-degradation policies should be applied to prohibit or restrict shale gas wastewater discharges into water bodies that are in good condition.

\section{Handling, Storage, and Transport Prior to Disposal}

Improper handling, storage, or transport of shale gas wastewater can lead to spills and other releases of pollutants that contaminate nearby lands and waters with toxic or radioactive material. Yet in 1988, EPA decided that oil and gas wastewater should not be regulated as a hazardous waste, even when it in fact poses a hazard to human health and the environment. This regulatory exemption must be ended, either by Congress or by EPA. Even if both fail to act, states should use their authority to regulate waste more strictly than the federal government does and treat shale gas wastewater as hazardous.

\section{Congress or EPA should eliminate the RCRA exemption for shale gas wastewater.}

Because of the 1980 amendments to the Resource Conservation and Recovery Act (RCRA) and EPA's subsequent determination not to regulate oil and gas wastes under Subtitle C of the statute, shale gas wastewater is not controlled as stringently as hazardous waste, even though it may have hazardous characteristics. As described elsewhere in this paper, wastewaters from hydraulic fracturing contain many substances known to have harmful effects on human health and the environment. Many of these wastewaters would meet the RCRA definition of hazardous waste absent the regulatory exemption. ${ }^{331}$ For example, some produced waters would be classified as hazardous due to toxicity associated with barium. ${ }^{332}$ Were it not for the oil and gas exemption, any entity generating, transporting, recycling, treating, or disposing of such produced waters would be subject to rigorous standards and rules. ${ }^{333}$

Currently, however, shale gas wastewater is exempt from such federal RCRA hazardous waste regulation, and state regulations and enforcement are inadequate to ensure safe management of the waste. Numerous instances of spills and releases of oil and gas wastewater due to equipment 
failure, accidents, negligence, or intentional dumping have been documented; it is likely that these events could have been prevented through stricter regulation of waste handling. ${ }^{334}$

Consequently, Congress should amend RCRA to eliminate the exemption. Specifically, it should delete the section of the statute that exempts oil and gas wastes and instructs EPA to determine whether regulation of such wastes is warranted. ${ }^{335}$ If this section were struck from the statutory text, oil and gas wastes would have to be regulated according to their actual characteristics, as are other wastes.

In the interim, EPA should reverse its determination that regulation of oil and gas wastes under RCRA is not warranted, as NRDC petitioned the agency to do in $2010 .{ }^{336}$ The wastes generated now by the hydraulic fracturing process are very different from the wastes EPA considered when making its 1988 determination. These differences relate to the nature and number of chemicals used, waste management practices, proximity to populations and their drinking water sources, and amount of waste generated. The agency needs to address the impacts of 2012 hydraulic fracturing practices by revisiting its determination.

Nothing in RCRA prevents EPA from doing so. The exemption for oil and gas wastes in the 1980 RCRA amendments was for a limited period of time that has now expired. Courts have upheld EPA's authority to reconsider regulatory determinations made pursuant to the 1980 amendments. ${ }^{337}$ Moreover, statements made by EPA in its 1988 regulatory determination indicate that the agency never intended the determination to be its final word on oil and gas waste. Instead, EPA established a three-pronged plan and intended to take further action to fill in existing gaps in the regulations governing the disposal of such wastes. ${ }^{338}$ To date this threepronged plan - which included improving alternative federal regulatory programs, working with states to improve state regulatory programs, and working with Congress to develop new statutory authorities - has not been pursued. Gaps in the regulatory system governing oil and gas wastes have grown even wider, and evidence of the substantial harm these wastes can cause to human health and the environment has continued to accumulate. EPA must revisit its 1988 regulatory determination to fulfill its obligations and protect human health and the environment from the significant risks posed by shale gas wastewater.

2. States should classify shale gas wastewater as hazardous when it meets relevant technical criteria and regulate it accordingly.

RCRA establishes a cooperative federal-state scheme that allows states to manage wastes through regulations that are more protective than the federal government's. ${ }^{339}$ In California, wastes (such as oil and gas wastewater) that are exempted from federal RCRA regulations are subject to state hazardous waste requirements if they exhibit the physical and chemical characteristics of hazardous waste. ${ }^{340}$ Other states should follow California's lead in treating shale gas wastewater as hazardous when it is in fact hazardous. States (like Pennsylvania and New York) that define oil and gas wastewater as nonhazardous in their regulations should eliminate those definitions. In light of the federal RCRA exemption for shale gas wastewater, state hazardous waste regulation is needed to ensure that this waste is handled, stored, transported, and treated in such a way as to prevent harm to human health and the environment.

3. States should require regular testing of shale gas wastewater. 
States should require regular testing of shale gas wastewater. This is needed to assess whether wastewater from any given source, at any given time, possesses hazardous characteristics. The volume and chemical characteristics of flowback and production phase water change considerably over time. In effect, operators are not handling the same type of waste from day to day, so different handling, storage, and disposal methods may be appropriate. Only regular testing can reveal the variations in wastewater characteristics over time. Specific measurements are needed for produced water and post-treatment residuals to ascertain the presence and concentrations of potentially hazardous components. This information will assist in making decisions about how to manage the wastewater. EPA Region 2 has made the same recommendation, suggesting that regular testing be performed to determine whether shale gas wastewater poses a threat to health or the environment. ${ }^{341}$

Additionally, if the RCRA exemption for oil and gas wastewater is lifted, EPA regulations will require operators to determine whether their wastewater possesses hazardous characteristics, either by testing the wastewater or by applying knowledge of the wastewater's contents. ${ }^{342}$

\section{Underground Injection}

Shale gas wastewater should be disposed of in Class I hazardous waste disposal wells, which are subject to regulations that are more protective of health and the environment than the regulations for the Class II wells currently used for oil and gas waste disposal. Injecting wastewater into Class II wells instead of Class I hazardous waste wells may increase the risk of injection fluids' migrating into sources of drinking water. It may also increase the risk of earthquakes, such as the one in Ohio in January 2012, caused by a shale gas wastewater disposal well that intersected an unmapped fault. ${ }^{343}$ Other recent earthquakes in Texas, Arkansas, and West Virginia have also been linked to the injection of shale gas wastewater. ${ }^{344}$ These unnecessary risks could be minimized through the elimination of the RCRA exemption for oil and gas wastes or through an amendment to the Underground Injection Control (UIC) program regulations. States can also use their authority to more strictly regulate Class II oil and gas waste wells.

\section{EPA should require wastewater with hazardous characteristics to be injected into} Class I hazardous waste wells.

Because of the RCRA exemption for oil and gas wastewater, waste from hydraulic fracturing operations is currently injected into Class II disposal wells. If the exemption were eliminated, all wastewater with hazardous characteristics (defined in the RCRA regulations, as described above) would instead have to be injected into Class I hazardous waste wells. ${ }^{345}$ Alternatively, EPA could amend the UIC regulations to directly require that shale gas wastewater displaying specified hazardous characteristics be disposed of in Class I hazardous waste wells.

Class II wells are subject to regulations that are less stringent than those governing Class I hazardous waste wells. Class I hazardous waste wells must be sited such that they only inject below the lowest underground source of drinking water (USDW) in the area of the well, whereas Class II wells may inject above or below a USDW. ${ }^{346}$ Unlike Class II wells, Class I hazardous waste wells must submit more information demonstrating that the well will be sited in a location that is geologically suitable, taking into account earthquake risks. ${ }^{347}$ Class I hazardous waste well operators must consider an area within a two-mile radius of the well to determine if there may be pathways from the injection zone to USDWs; for Class II wells, the area of review is 
only the area within a quarter-mile radius. ${ }^{348}$ Well construction, operation, testing, and monitoring requirements are more stringent for Class I hazardous waste wells. ${ }^{349}$ Operators of such wells are required to continue monitoring the well and groundwater after the well is plugged, while Class II well operators are not. ${ }^{350}$

Finally, the criteria under which states can seek primacy for regulation of Class II wells are less stringent than the criteria for all other classes, including Class I. States seeking primacy over all other classes of wells must demonstrate that their regulations are as stringent as those of the federal program. States seeking primacy over Class II wells need only show that their regulations are "effective" in protecting USDWs. ${ }^{351}$ For all of these reasons, disposal of shale gas wastewater in Class I hazardous waste wells is preferable to disposal in Class II wells.

2. In the interim, states should use their authority to more strictly regulate Class II wells for oil and gas wastewater.

Under the UIC program, states have a significant amount of discretion regarding the development of regulations for Class II wells. ${ }^{352}$ At minimum, states with primacy over Class II wells must show that their programs are "effective" at protecting underground sources of drinking water, but there is no maximum stringency that their programs are prohibited from exceeding. Consequently, states are free to regulate Class II wells as strictly as they regulate Class I hazardous waste wells, or even more strictly if they so desire. All states with primacy over their Class II well injection programs can and should regulate Class II wells into which oil and gas wastewater is injected at least as strictly as Class I hazardous waste wells.

\section{Reuse for Additional Hydraulic Fracturing}

The hydraulic fracturing process itself should be federally regulated. However, when fracking occurs, reuse of wastewater for additional hydraulic fracturing can offer many benefits (although these benefits can in some cases be offset by energy use and the generation of concentrated residuals). Where appropriate, states should encourage or even require the reuse and recycling of shale gas wastewater.

\section{Congress should eliminate the Safe Drinking Water Act exemption for hydraulic fracturing.}

An amendment to the Safe Drinking Water Act in 2005 excluded hydraulic fracturing activities from the definition of "underground injection," except for fracturing fluid that contains diesel fuels. As a result, the underground injection of fluids other than diesel fuel for the purpose of fracturing is not federally regulated. While all of the major oil and gas producing states regulate oil and gas production to protect water resources to some degree, these regulations are uneven in their level of protectiveness. Not all states' regulations mention hydraulic fracturing specifically. Moreover, some states lack important provisions in their programs. For example, most states have well construction requirements that include provisions for cementing above oil or gas producing zones and across groundwater zones. These requirements may be very detailed, as they are in Alabama, or may simply be general mandates not to harm water resources, as they are in Arizona. ${ }^{353}$ 
Because of this uneven state regulation, federal regulation of hydraulic fracturing is needed to create a national baseline of groundwater protection. Congress must act to eliminate the SDWA exemption. If hydraulic fracturing activities were subject to regulation under the statute, EPA would have to ensure that injection of fracturing fluid would not endanger drinking water sources nationwide. ${ }^{354}$ In addition to this general standard, EPA would be able to enforce regulations governing the construction, operation, and monitoring of unconventional gas wells that are to be hydraulically fractured. EPA could choose to regulate hydraulic fracturing as a Class II activity, subject to the same requirements as wells used to inject oil and gas wastewater underground for disposal. It is also possible that EPA could classify oil and gas production wells that are hydraulically fractured under a different class, or develop an entirely new regulatory structure or subclass of wells. ${ }^{355}$ Either way, the end result would be improved regulation of shale gas wells.

In the current Congress, the proposed Fracturing Responsibility and Awareness of Chemicals Act of 2011 (the FRAC Act), H.R. 1084 and S. 587, would achieve this result. The bill contains two amendments to the SDWA: one that would amend the definition of underground injection to include hydraulic fracturing, and another that would create a new public disclosure requirement for the chemicals used in hydraulic fracturing. Congress should pass this bill or one similar to it. Conversely, Congress should not pass bills such as the Fracturing Regulations Are Effective in State Hands Act (the FRESH Act), S. 2248, which would eliminate all federal authority to regulate hydraulic fracturing activities. ${ }^{356}$

2. States should encourage or require reuse of shale gas wastewater in the hydraulic fracturing process where appropriate.

Greater reuse of shale gas wastewater for additional hydraulic fracturing would reduce the amount of wastewater disposed of by other methods that pose greater risks to health and the environment. It would have the added benefit of reducing the amount of freshwater withdrawn from other sources to use in the hydraulic fracturing process. In the Marcellus formation, wastewater reuse can often occur even without treatment. ${ }^{357}$ However, where treatment is necessary, wastewater recycling creates residual byproducts that are not well regulated (as discussed below), and the recycling process can be energy-intensive. When the benefits of recycling and reuse outweigh these disadvantages, states should encourage or require natural gas operators to reuse wastewater for additional hydraulic fracturing.

Policies encouraging recycling and reuse of wastewater are consistent with the federal Pollution Prevention Act (PPA), which aims to reduce pollution through changes in industrial production, operation, and raw materials use. While the PPA creates no binding obligations, it establishes a national policy of encouraging source reduction in the first instance, then recycling, and then treatment and release as a last resort. ${ }^{358}$ Reusing shale gas wastewater furthers the goal of source reduction by reducing the amount of new wastewater generated with the fracturing of each well.

Some states already encourage the reuse of flowback and production phase water. Pennsylvania requires well operators to develop a wastewater source reduction strategy that identifies methods and procedures to maximize recycling and reuse. ${ }^{359}$ The Susquehanna River Basin Commission (a regional governmental agency whose members are New York, Pennsylvania, Maryland, and the federal government) incentivizes reuse by relaxing review and approval requirements for interbasin diversions of flowback or produced water from one drilling site to another for use in further fracturing. ${ }^{360}$ Other states should follow suit and encourage or require shale gas 
wastewater recycling. (However, while evaluation of energy implications is beyond the scope of this paper, it is nonetheless important to note that the energy demands of on-site treatment technologies for reuse may be an important consideration when deciding to incentivize this practice.)

\section{Impoundments and Tanks}

Using open impoundments or tanks for the storage and disposal of shale gas wastewater creates a risk of spills or leakage of wastewater into the ground, potentially contaminating soil, surface water, or groundwater. Additionally, impoundments cause large land disturbances and generate hazardous air pollution. To eliminate the risk of these avoidable impacts, the use of impoundments should be prohibited, or at a minimum more strictly regulated; tanks should be more strictly regulated as well.

\section{States should not allow the storage or disposal of shale gas wastewater in open impoundments.}

Prohibiting impoundments is necessary to eliminate the impacts summarized above. Rather than collecting wastewater in centralized open impoundments either on or away from the drill site, flowback and production phase water should be collected at the well and either recycled or routed directly to disposal. EPA Region 2 has supported New York's proposal to ban the storage of flowback water in open pits on the well pad. ${ }^{361}$ New York and other states should also ban the use of centralized open impoundments away from the drill site. In the event that storage of wastewater is necessary, it should be done in closed tanks (which should be strictly regulated, as described below).

\section{If impoundments are not prohibited, they should be more strictly regulated. Storage tanks should be more strictly regulated as well.}

If states do not prohibit impoundments, at minimum they should more strictly regulate their location, construction, operation, and remediation. For example, states should require the maintenance of a sufficiently protective "freeboard" (the distance between the water level and the top edge of the impoundment) based on local conditions, such as the likelihood of flooding, and should require groundwater monitoring in the impoundment area. ${ }^{362}$

The U.S. Department of Energy recommends that all pits used for the long-term storage of wastewater be required to use a natural or artificial liner to protect groundwater. ${ }^{363} \mathrm{DOE}$ also recommends that impoundments not be excavated to a depth that extends below the seasonal high-water table, and that pits not be allowed within the boundaries of 100 -year floodplains without extra precautions. (However, these boundaries might not be adequately protective, given that many floodplain maps are out of date, and given that climate change is projected to increase the intensity and frequency of future flooding events. ${ }^{364}$ ) Finally, DOE recommends that states consider prohibiting the use of pits within the boundaries of public water supply and wellhead protection areas. ${ }^{365}$ States should incorporate these recommendations into their regulatory requirements for impoundments.

Additionally, states should not restrict the ability of local governments to regulate the siting and zoning of new impoundments, as Pennsylvania did in February 2012. Pennsylvania's new law 
requires local governments to authorize impoundments as a permitted use in all zoning districts. It also prevents local governments from establishing setbacks (the distance between an impoundment and an occupied structure) of more than 300 feet. ${ }^{366}$ Pennsylvania should repeal this law, and other states should not pass laws similar to it. Local governments should retain the authority to site and regulate impoundments as necessary to protect health and welfare.

States should also regulate the use of tanks for the storage of shale gas wastewater. Generally speaking, tanks should be maintained in a manner that prevents leakage. To that end, secondary containment should be required for all tanks. Secondary containment is a management practice wherein the tank sits within a traylike structure with raised sides such that materials released during a tank rupture would be contained and not released into the environment. The Department of Energy has recommended the use of secondary containment, suggesting requirements for containment dikes to meet a permeability standard, and suggesting that containment areas outside of tanks be kept free of fluids. DOE further recommends that regulations specify how long releases or other fluids inside a containment dike may remain before removal. ${ }^{367}$

Finally, if the RCRA exemption for oil and gas wastewater is lifted, EPA should strictly regulate surface impoundments for shale gas wastewater by enforcing the minimum technological and operational requirements for hazardous waste impoundments contained in the statute and regulations. $^{368}$

\section{Land Application}

Because application of shale gas wastewater to land and roadways can lead to environmental contamination through runoff of toxic pollutants into surface waters, it should be prohibited, or at minimum strictly regulated.

\section{States should not allow the land application or road spreading of shale gas} wastewater.

Applying shale gas wastewater to land and roads causes a serious runoff problem, sending contaminants into nearby surface water bodies. The Pennsylvania general permit for road spreading states that it does not authorize runoff into water bodies. In practice, however, some runoff can be expected to occur, as common management practices are inadequate to completely prevent it. One study found chloride concentrations up to five times greater than that allowed under EPA public drinking water standards in down-gradient wells from an oil field brine application on a gravel roadbed, despite 99 percent dilution of the solutes in the brine. ${ }^{369}$ These results indicate that even when precautions are taken, road spreading can still cause environmental contamination.

EPA Region 2, in its comments on New York's environmental review of hydraulic fracturing, warned that road spreading could lead to surface infiltration of wastewater and risk contamination of underlying aquifers. ${ }^{370}$ Consequently, the Region supported New York's decision to prohibit the road spreading of flowback and urged the state to consider extending that prohibition to production phase water as well. ${ }^{371}$

As discussed earlier in this paper, other substances are available for use on roads for dust suppression and deicing that are as effective as shale gas wastewater but have less environmental impact. For example, other dust suppression agents contain less chloride than shale gas 
wastewater. Other substances used for road spreading are also preferable because, unlike shale gas wastewater, they do not contain radioactive material. A study conducted by Argonne National Lab for the U.S. Department of the Interior concluded that land spreading of diluted NORM waste presented the highest potential dose of exposure to the general public of all waste disposal methods studied. ${ }^{372}$ Consequently, the use of shale gas wastewater for road spreading should be prohibited.

\section{If land application and road spreading are not prohibited, they should be more strictly regulated.}

If states do not ban land application and road spreading, these practices should only be authorized subject to strict limits on pollutant concentrations and required measures to prevent runoff. At minimum, permits should limit how often brine can be spread on lands and roads; application rates for brines; provisions for regular testing of brines; limits on application during rain, before rain, or while the road surface is saturated; limits on the maximum grade of the road to which brines may be applied; limits on how close to water bodies brines can be applied; provisions for additional study of the long-term effects of brine use on roads; provisions for testing for accumulations of contaminants; and limits on radionuclide levels in brine used on roads. $^{373}$

Additionally, EPA and states should enforce existing Clean Water Act requirements for controlling polluted runoff from municipal storm sewer systems, to ensure that any road spreading does not violate the requirements to the reduce polluted runoff to the "maximum extent practicable" and to avoid causing violations of water quality standards. EPA should also complete its ongoing development of new rules to strengthen the CWA stormwater regulatory program, including new standards specifically tailored to controlling polluted runoff from roadways and other transportation facilities. ${ }^{374}$

\section{Residual Waste}

Just as shale gas wastewater should not be categorically exempt from regulation under RCRA, residual waste derived from the treatment of that wastewater should not be exempt from regulation if it displays the characteristics of a hazardous waste. Any residual substance left over from the treatment of wastewater that displayed hazardous characteristics will most likely display hazardous characteristics as well, as chemicals are present at higher concentrations in the residuals than in the original wastewater. Further, given its higher pollutant concentrations, residual waste may, in some cases, meet the criteria for hazardous waste even where the untreated wastewater did not.

\section{Shale gas wastewater treatment residuals with hazardous characteristics should be regulated under RCRA Subtitle $C$.}

As discussed, shale gas wastewater is currently exempt from regulation under RCRA. However, under certain circumstances, residual waste streams generated by treatment and disposal methods may be subject to regulation as hazardous waste under RCRA Subtitle C. ${ }^{375}$

The issue of whether residual waste is exempt from regulation as a hazardous waste is an important one. Post-treatment residual wastes contain the same pollutants of concern as the 
original wastewater, but in much greater concentrations. Thus, careful management of residuals is needed to avoid releasing even small amounts of them into the environment. Congress or EPA should require that residual waste with hazardous characteristics be regulated as hazardous under RCRA. This result could be accomplished if Congress or EPA were to eliminate the RCRA exemption for shale gas wastewater.

\section{Public Disclosure}

Regardless of which treatment or disposal method an operator uses to manage its shale gas wastewater, it should be required to publicly disclose the final destination of the waste. For example, Pennsylvania requires every operator to submit information, which the state posts on its website, revealing the name and location of the specific destinations where the operator sends its wastewater. These include treatment facilities, injection wells, landfills, road spreading, and reuse for further hydraulic fracturing. ${ }^{376}$ However, the data sheets available from Pennsylvania DEP contain extensive errors, most notably due to inconsistent categorization of disposal methods. Consequently, Pennsylvania should review operator-submitted data for consistency. Pennsylvania should also post online the other forms and reports that operators submit to the state, such as the $26 \mathrm{R}$ forms that contain wastewater chemical analyses. These forms are not currently made available online and are difficult and expensive to obtain through state open records requests. Other states should develop their own public disclosure rules as well, so that citizens everywhere can learn about the composition and ultimate fate of the wastewater generated in their states.

\section{"Model" Regulations}

The federal Bureau of Land Management (BLM) is currently developing regulations for hydraulic fracturing activities on federal lands, including management of produced water. ${ }^{377}$ The content of the forthcoming regulations is presently unknown. However, given that the BLM's authority over development of federal oil and gas resources and activities on federal lands is expansive, the BLM rulemaking presents an opportunity to create a model that states can adopt. If the regulations set strict technology standards, they may also spur innovation in new and improved wastewater treatment technologies. Consequently, the BLM regulations should be set to be as protective of health and environment as possible, and should include at minimum (to the extent BLM has regulatory jurisdiction) all recommendations set forth in this paper. 


\section{ENDNOTES}

1 U.S. Government Accountability Office (GAO), Information on the Quantity, Quality, and Management of Water Produced During Oil and Gas Production, report to the Ranking Member, Committee on Science, Space, and Technology, House of Representatives, January 2012, 5, http://www.gao.gov/assets/590/587522.pdf.

2 U.S. Department of Energy (DOE), Modern Shale Gas Development in the United States: A Primer, April 2009, 17, http://www.netl.doe.gov/technologies/oil-gas/publications/epreports/shale_gas_primer_2009.pdf.

3 U.S. GAO, Information on the Quantity, Quality, and Management, 4.

4 U.S. DOE, Modern Shale Gas Development, 15.

5 Ibid., 8.

6 U.S. GAO, Information on the Quantity, Quality, and Management, 6.

7 U.S. DOE, Modern Shale Gas Development, 13.

8 Ibid., 21; Charles W. Abdalla et al., Penn State Extension, Marcellus Shale Wastewater Issues in PennsylvaniaCurrent and Emerging Treatment and Disposal Technologies, April 2011, 1,

http://www.ohioenvironmentallawblog.com/uploads/file/marcellus_wastewater_fact_sheet $\% 5 \mathrm{~B} 1 \% 5 \mathrm{D} \% 281 \% 29$.pdf 9 U.S. GAO, Information on the Quantity, Quality, and Management, 6.

10 Ibid., 12.

11 Notice of Final 2010 Effluent Guidelines Program Plan, 76 Fed. Reg. 66,286, 66,295-96 (October 26, 2011); James M. Silva et al., "Produced Water Pretreatment for Water Recovery and Salt Production," January 26, 2012, iii, http://www.netl.doe.gov/technologies/oil-gas/publications/EPact/08122-36-final-report.pdf.

12 Daniel J. Soeder, "Porosity and Permeability of Eastern Devonian Gas Shale," SPE Formation Evaluation, March 1988, 116, http://www.pe.tamu.edu/wattenbarger/public_html/Selected_papers/--

Shale\%20Gas/SPE15213.pdf.

13 Notice of Final 2010 Effluent Guidelines Program Plan, 66,296.

14 See, e.g., "3,400 Gallons of Frack Water Spilled in Accident," Lockhaven Express, February 22, 2011, http://www.lockhaven.com/page/content.detail/id/529606/3-400-gallons-of-frack-water-spilled-in-accident.html; see also New York State Water Resources Institute, Spills and Leaks Associated with Shale Gas Development (Ithaca, NY: Cornell University, April 26, 2011), 4, http://wri.eas.cornell.edu/gas_wells_20_690970228.pdf. 15 John A. Veil, Argonne National Laboratory, Final Report: Water Mañagement Technologies Used By Marcellus Shale Gas Producers, report prepared for U.S. Department of Energy, July 2010, 5 , http://www.evs.anl.gov/pub/doc/Water\%20Mgmt\%20in\%20Marcellus-final-jull0.pdf.

1633 U.S.C. $\$ 1342(1)(2)$.

17 Veil, Water Management Technologies, 10.

18 Mary Tiemann et al., Marcellus Shale Gas: Development Potential and Water Management Issues and Laws (Washington, DC: Congressional Research Service, 2012), 32-33, http://www.arcticgas.gov/sites/default/files/documents/12-1-27-crs-marcellus-shale-gas-development-potentialissues-laws.pdf.

19 lbid., 15.

20 Dominic C. DiGiulio et al., Investigation of Ground Water Contamination Near Pavillion, Wyoming (Draft) (Ada, OK: U.S. Environmental Protection Agency, December 2011), http://www.epa.gov/region8/superfund/wy/pavillion/EPA_ReportOnPavillion_Dec-8-2011.pdf. 21 See John A. Veil, Bruce G. Langhus, and Stan Belieu, Feasibility Evaluation of Downholed Oil/Water Separator (DOWS) Technology, report prepared for the U.S. Department of Energy, January 1999, http://www.evs.anl.gov/pub/doc/dows.pdf.

22 M.E. Blauch, "Developing Effective and Environmentally Suitable Fracturing Fluids Using Hydraulic Fracturing Flowback Waters" (paper presented at the Society of Petroleum Engineers Unconventional Gas Conference,

Pittsburgh, PA, February 2010), http://www.onepetro.org/mslib/servlet/onepetropreview?id=SPE-131784-MS; Dave Grottenthaler, "Cabot Gas Well Treated with 100\% Reused Frac Fluid" (lecture, Developing Unconventional Gas Conference, Pittsburgh, PA, November 2010); John Papso, Matt Blauch, and Dave Grottenthaler, Cabot Gas Well Treated with $100 \%$ Reused Frac Fluid, 2010, http://www.swsi.com/pdf/Cabot_SWSI_reuse.pdf.

23 Charles W. Abdalla et al., Penn State Extension, Marcellus Shale Wastewater Issues in Pennsylvania -- Current and Emerging Treatment and Disposal Technologies, April 2011, 
http://www.ohioenvironmentallawblog.com/uploads/file/marcellus_wastewater_fact_sheet $\% 5 \mathrm{~B} 1 \% 5 \mathrm{D} \% 281 \% 29$.pdf ; John A. Veil, Argonne National Laboratory, Final Report: Water Management Technologies Used By Marcellus Shale Gas Producers, report prepared for U.S. Department of Energy, July 2010,

http://www.evs.anl.gov/pub/doc/Water\%20Mgmt\%20in\%20Marcellus-final-jul10.pdf.

24 Veil, Water Management Technologies, 24, Appendix A.

25 lbid., 24-26.

26 Chad Knutson, Yaning Yang, and Seyed Dastgheib, "Use of Produced Water from the lllinois Basin by CoalBased Power Plants" (lecture, Water/Energy Sustainability Symposium, Pittsburgh, PA, September 2010), http://www.gwpc.org/meetings/forum/2010/proceedings/28Knutson_Chad.pdf.

27 A. Gene Collins, Geochemistry of Oilfield Waters (New York: Elsevier Scientific Publishing Company, 1975), Chapter 14.

28 A. Gene Collins, "Oil and Gas Wells - Potential Polluters of the Environment?", Water Pollution Control Federation 43, no. 12 (December 1971): 2383-2393, http://www.jstor.org/stable/25037252.

29 American Petroleum Institute, Overview of Exploration and Production Waste Volumes and Waste Management Practices in the United States, 2000; C.E. Clark and J.A. Veil, Argonne National Laboratory, Produced Water

Volumes and Management Practices in the United States, report prepared for the U.S. Department of Energy, 29, September 2009, http://www.ead.anl.gov/pub/doc/ANL_EVS_R09_produced_water_volume_report_2437.pdf. 30 State Review of Oil and Natural Gas Environmental Regulations, Inc. (STRONGER), Pennsylvania Hydraulic Fracturing State Review, September 2010, 11,

http://www.shalegas.energy.gov/resources/071311_stronger_pa_hf_review.pdf.

31 Don Hopey, "Quakes in Ohio Tied to Area Shale Operations," Pittsburgh Post-Gazette, March 10, 2012, http://www.post-gazette.com/pg/12070/1215767-503-0.stm?cmpid=news.xml.

32 Craig Nicholson and Robert L. Wesson, Earthquake Hazard Associated with Deep Well Injection - A Report to the U.S. Environmental Protection Agency, U.S. Geological Survey Bulletin, 1990,

$\mathrm{http}$ ://foodfreedom.files.wordpress.com/2011/1 1/earthquake-hazard-associated-with-deep-well-injection-report-toepa-nicholson-wesson-1990.pdf; U.S. EPA, Technical Program Overview: Underground Injection Control

Regulations, December 2002, revised July 2001, 3, http://www.epa.gov/safewater/uic/pdfs/uic_techovrview.pdf.

33 Clark and Veil, Produced Water Volumes, 8.

34 Veil, Water Management Technologies, 24-26.

35 See Consent Agreement and Final Order, in the Matter of CNX Gas Company LLC (No. SDWA-03-2009-0224, U.S. Environmental Protection Agency, Region III, September 24, 2010),

http://www.epa.gov/reg3wapd/pdf/public_notices/cnx_pa_8042010.pdf.

36 Ben Adducchio, "Mine Discharges Contributed in Dunkard Fish Kill," West Virginia Public Broadcasting,

October 16, 2009, http://www.wvpubcast.org/newsarticle.aspx?id=11684.

37 Jon M. Capacasa, Director, Water Protection Division, U.S. EPA Region III, to Al Lander, President, Tunnelton

Liquids Company, "Notice of Violation, Intent to lssue Administrative Order and Opportunity to Request a Hearing; Docket No. SDWA-03-2011-0190-DU," May 12, 2011,

http://www.epa.gov/region03/marcellus_shale/pdf/letter/tunnelton-violation5-1-11.pdf.

38 Jon M. Capacasa, Director, Water Protection Division, U.S. EPA Region III, to George Jugovic, Jr., Regional Director, Pennsylvania Department of Environmental Protection, "Re: Tunnelton Liquids Company: NPDES Permit \#PA 0091472," May 9, 2011, http:/www.epa.gov/region03/marcellus_shale/pdf/letter/tunnelton-letter5-9-11.pdf. 39 U.S. House of Representatives, Committee on Energy and Commerce, Minority Staff, Chemicals Used in Hydraulic Fracturing, April 2011, 8-9,

http://democrats.energycommerce.house.gov/sites/default/files/documents/Hydraulic\%20Fracturing $\% 20$ Report $\% 20$ 4.18.11.pdf.

40 Charles G. Groat and Thomas W. Grimshaw, Fact-Based Regulation for Environmental Protection in Shale Gas, report prepared for the Energy Institute, University of Texas at Austin, February 2012, 17,

http://energy.utexas.edu/images/ei_shale_gas_regulation 120215.pdf.

41 T. Hayes, Gas Technology Institute, Sampling and Analysis of Water Streams Associated with the Development of Marcellus Shale Gas, report prepared for Marcellus Shale Coalition, December 2009,

http://www.bucknell.edu/script/environmentalcenter/marcellus/default.aspx?articleid=14; U.S. House of Representatives, Chemicals Used in Hydraulic Fracturing, 8.

42 U.S. House of Representatives, Chemicals Used in Hydraulic Fracturing.

43 New York State Department of Environmental Conservation, An Investigation of Naturally Occurring

Radioactive Materials (NORM) in Oil and Gas Wells in New York State, April 1999, 
http://www.dec.ny.gov/docs/materials_minerals_pdf/normrpt.pdf; U.S. Geological Survey, Naturally Occurring Radioactive Materials (NORM) in Produced Water and Oil-Field Equipment - An Issue for the Energy Industry, September 1999, http://pubs.usgs.gov/fs/fs-0142-99/fs-0142-99.pdf.

44 Pennsylvania Department of Environmental Protection, NORM Survey Summary, September 1992, http://files.dep.state.pa.us/OilGas/BOGM/BOGMPortalFiles/RadiationProtection/NORM.pdf.

45 David G. Hill, Tracy E. Lombardi, and John P. Martin, Fractured Shale Gas Potential in New York, 2009, 8 , http://www.pe.tamu.edu/wattenbarger/public html/Selected papers/--

Shale $\% 20 \mathrm{Gas} /$ fractured\%20shale\%20gas\%20potential\%20in\%20new\%20york.pdf; John A. Harper, "The Marcellus Shale - An Old 'New' Gas Reservoir,” Pennsylvania Geology 38, no. 1 (Spring 2008): 2-13, http://www.denr.state.pa.us/topogeo/pub/pageolmag/pdfs/v38n1.pdf.

46 Marvin Resnikoff, Ekaterina Alexandrova, and Jackie Travers, Radioactivity in Marcellus Shale, report prepared for Residents for the Preservation of Lowman and Chemung (RFPLC), May 19, 2010,

http://www.rwma.com/Marcellus\%20Shale\%20Report\%205-18-2010.pdf.

47 E.J. Sullivan et al., "Water Treatment Technology for Oil and Gas Produced Water" (abstract presented at Identifying Technologies to Improve Regional Water Stewardship: A Conference Series Featuring Intersections of Technology and Water Management, North-Middle Rio Grande Corridor, Albuquerque, NM, April 2004), 216, http://www.unm.edu/ cstp/Reports/H2O_Session_4/4-5_Sullivan.pdf.

48 See D.F. Kincannon and A.F. Gaudy, Jr., "Some Effects of High Salt Concentrations on Activated Sludge," Journal of the Water Pollution Control Federation 38, no. 7 (July 1966): 1148-1159, http://www.jstor.org/stable/25035591; Fikret Kargi and Ali R. Dincer, "Effect of Salt Concentration on Biological Treatment of Saline Wastewater by Fed-Batch Operation," Enzyme and Microbial Technology 19, no. 7 (November 15, 1996): 529-537, http://www.sciencedirect.com/science/article/pii/S0141022996000701.

49 Sheng-Jie You, Yung-Pin Tsai, and Ru-Yi Huang, "Effect of Heavy Metals on Nitrification Performance in Different Activated Sludge Processes," Journal of Hazardous Materials 165, no. 1-3 (June 2009): 987-994, http://www.sciencedirect.com/science/article/pii/S030438940801604X.

50 Marta Eiroa, Christian Kennes, and Maria C. Veiga, "Formaldehyde Biodegradation and Its Inhibitory Effect on Nitrification," Chemical Technology and Biotechnology 79, no. 5 (May 2004): 499-504, http://onlinelibrary.wiley.com/doi/10.1002/jctb.1011/abstract.

51 Soondong Kwon et al., "Laboratory and Field Evaluation of a Pretreatment System for Removing Organics from Produced Water," Water Environment Research 83, no. 9 (September 2011): 843-854, http://www.ingentaconnect.com/content/wef/wer/2011/00000083/00000009/art00010.

52 Qian Yi, Wen Yibo, and Zhang Huiming, "Efficacy of Pre-Treatment Methods in the Activated Sludge Removal of Refractory Compounds in Coke-Plant Wastewater," Water Research 28, no. 3 (March 1994): 701-707, http://www.sciencedirect.com/science/article/pii/0043135494901503.

53 F. Pagnanelli et al., "Mechanisms of Heavy-Metal Removal by Activated Sludge," Chemosphere 75, no. 8 (May 2009): 1028-1034, http://www.sciencedirect.com/science/article/pii/S0045653509000824; Barry G. Oliver and Ernest G. Cosgrove, "The Efficiency of Heavy Metal Removal by a Conventional Activated Sludge Treatment Plant," Water Research 8, no. 11 (November 1974): 869-874, http://www.sciencedirect.com/science/article/pii/0043135474900992.

54 Y.V. Nancharaiah et al., "Biodegradation of Nitrilotriacetic Acid (NTA) and Ferric-NTA Complex by Aerobic Microbial Granules," Water Research 40, no. 8 (May 2006): 1539-1546, http://www.sciencedirect.com/science/article/pii/S0043135406000881.

55 Veil, Water Management Technologies, 24-26.

56 Letters from EPA to these facilities and facility responses are available at "Key Documents About Mid-Atlantic Oil and Gas Extraction," U.S. EPA Region III, last modified March 14, 2012, http://www.epa.gov/region3/marcellus shale/\#sewagecertif.

57 Michael L. Krancer, Secretary, Pennsylvania Department of Environmental Protection, to Shawn Garvin, Regional Administrator, U.S. EPA Region III, July 26, 2011, http://www.epa.gov/region3/marcellus_shale/pdf/letter-padep-to-epa7-26-11.pdf.

58 "PA DEP Oil \& Gas Reporting Website - Statewide Data Downloads By Reporting Period," Pennsylvania Department of Environmental Protection, last modified April 3, 2012, https://www.paoilandgasreporting.state.pa.us/publicreports/Modules/DataExports/DataExports.aspx. 59 Ibid. 60 Abdalla et al., Marcellus Shale Wastewater Issues in Pennsylvania, 6. 61 Veil, Water Management Technologies, 24-26. 
62 Capacasa to Lander, "Notice of Violation."

63 Oluwadamilare Adebambo, "Evaluation of the Beneficial Re-Use of Produced Water: A Review of Relevant Guidelines and Produced Water Toxicity" (master's degree project, Duke University, 2011), http://dukespace.lib.duke.edu/dspace/handle/10161/3709.

64 Michigan Department of Natural Resource, The Use of Oil Field Brine on Michigan Roadways, 1983, http://www.michigan.gov/documents/deq/Oil_Field_Brine_opt_306999_7.pdf.

65 Ibid., 6-13.

66 Interstate Oil and Gas Compact Commission and ALL Consulting, A Guide to Practical Management of Produced Water from Onshore Oil and Gas Operations in the United States, report prepared for the U.S. Department of Energy, October 2006, 62-63, http://www.all-llc.com/publicdownloads/ALL-PWGuide.pdf. 67 Pennsylvania Department of Environmental Protection, Approval of Brine Roadspreading Plans, October 31, 1998, http://www.elibrary.dep.state.pa.us/dsweb/Get/Version-48261/550-2100-007.pdf.

68 "Team 4 Investigation: Brine," WTAE Pittsburgh, November 15, 2005,

http://www.wtae.com/news/5334068/detail.html.

6940 C.F.R. Part 503.

70 Matthew Bruff, Ned Godshall, and Karen Evans, An Integrated Water Treatment Technology Solution for

Sustainable Water Resource Management in the Marcellus Shale, June 2011, http://www.netl.doe.gov/technologies/oil-gas/publications/ENVreports/fe0000833-final-report.pdf.

71 A. Gene Collins, "Finding Profits in Oil Well Wastewaters," Chemical Engineering 77 (1970): 165-168.

72 Marc A. Angulo, "Iodine," in 2010 Minerals Yearbook, U.S. Geological Survey (2011), 36.1,

http://minerals.usgs.gov/minerals/pubs/commodity/iodine/myb1-2010-iodin.pdf; U.S. Geological Survey, "Iodine," in Mineral Commodity Summaries 2012 (2012), http://minerals.usgs.gov/minerals/pubs/commodity/iodine/mcs-

2012-iodin.pdf.

73 Granville C. Egleson and Charles W. Querio, "Variation in the Composition of Brine from the Sylvania Formation Near Midland, Michigan," Environmental Science and Technology 3, no. 4 (1969): 367-371, http://pubs.acs.org/doi/abs/10.1021/es60027a003; A.B. Carpenter and M.L. Trout, "Geochemistry of Bromide-Rich Brines of the Dead Sea and Southern Arkansas," 12th Industrial Minerals Forum: Oklahoma Geological Survey Circular 79 (1978): 79-88; Joyce A. Ober, "Bromine," in 2010 Minerals Yearbook, U.S. Geological Survey (2011), http://minerals.usgs.gov/minerals/pubs/commodity/bromine/mybl-2010-bromi.pdf; U.S. Geological Survey, "Bromine," in Mineral Commodity Summaries 2012 (2012), http://minerals.usgs.gov/minerals/pubs/commodity/bromine/mcs-2012-bromi.pdf.

74 Brian W. Jaskula, "Lithium," in 2010 Minerals Yearbook, U.S. Geological Survey (2011),

http://minerals.usgs.gov/minerals/pubs/commodity/lithium/myb1-2010-lithi.pdf; U.S. Geological Survey, "Lithium," in Mineral Commodity Summaries 2012 (2012),

http://minerals.usgs.gov/minerals/pubs/commodity/lithium/mcs-2012-lithi.pdf.

75 M.E. Blauch et al., "Marcellus Shale Post-Frac Flowback Waters - Where Is All the Salt Coming From and What Are the Implications?" (paper presented at the Society of Petroleum Engineers Eastern Regional Meeting, Charleston, WV, September 2009), http://www.onepetro.org/mslib/servlet/onepetropreview?id=SPE-125740MS\&soc $=$ SPE.

76 T. Hayes, Gas Technology Institute, Sampling and Analysis of Water Streams Associated with the Development of Marcellus Shale Gas, report prepared for Marcellus Shale Coalition, December 2009,

http://www.bucknell.edu/script/environmentalcenter/marcellus/default.aspx?articleid=14; E.L. Rowan et al., Radium Content of Oil- and Gas-Field Produced Waters in the Northern Appalachian Basin (USA): Summary and Discussion of Data, 2011, 31, http://pubs.usgs.gov/sir/2011/5135/pdf/sir2011-5135.pdf.

77 National Petroleum Council, Management of Produced Water from Oil and Gas Wells, September 2011, http://www.npc.org/Prudent_Development-Topic_Papers/2-17_Management_of_Produced_Water_Paper.pdf. 78 ALL Consulting, Handbook on Coal Bed Methane Produced Water: Management and Beneficial Reuse Alternatives, report prepared for Ground Water Protection Research Foundation, U.S. Department of Energy, National Petroleum Technology Office, and U.S. Bureau of Land Management, July 2003, http://www.allIlc.com/publicdownloads/CBM_BU_Screen.pdf; John A. Veil, "Produced Water Management Options and Technologies," in Produced Water: Environmental Risks and Advances in Mitigation Technologies, eds. Kenneth Lee and Jerry Neff (New York: Springer, 2011), 537-571.

79 See "Produced Water Management Information System," National Energy Technology Laboratory, accessed April 4, 2012, http://www.netl.doe.gov/technologies/PWMIS/; see also the decision support diagram at "Produced 
Water Management Information System - Technology Identification Module - Process," National Energy Technology Laboratory, accessed April 4, 2012, http://pwmis.netl.doe.gov/tim/wizard/dsp_fulldiagram.cfm. 80 A. Mofarrah et al., "Decision-Making Tool for Produced Water Management," in Produced Water:

Environmental Risks and Advances in Mitigation Technologies, eds. Kenneth Lee and Jerry Neff (New York: Springer, 2011), 573-586.

81 Mehrdad Ebrahimi et al., "Investigations of the Use of Different Ceramic Membranes for Efficient Oil Field Produced Water Treatment," Desalination 250, no. 3 (January 2010): 991-996,

http://www.sciencedirect.com/science/article/pii/S0011916409011205.

82 C.R. Woolard and R. L. Irvine, "Treatment of Hypersaline Wastewater in the Sequencing Batch Reactor," Water Research 29, no. 4 (April 1995): 1159-1168,

http://www.ingentaconnect.com/content/els/00431354/1995/00000029/00000004/art00239; O. Lefebvre et al., "Treatment of Hypersaline Industrial Wastewater by a Microbial Consortium in a Sequencing Batch Reactor," Environmental Technology 25, no. 5 (May 2004): 543-553, http://www.ncbi.nlm.nih.gov/pubmed/15242230. 83 John W. Ely et al., "Game Changing Technology for Treating and Recycling Frac Water" (paper presented at Society of Petroleum Engineers Annual Technical Conference and Exhibition, Denver, CO, October-November 2011), http://www.spe.org/atce/2011/pages/schedule/tech_program/documents/spe 145454\%201.pdf. 84 Mushtaque Ahmed et al., "Use of Evaporation Ponds for Brine Disposal in Desalination Plants," Desalination 130, no. 2 (November 2000):155-168, http://www.sciencedirect.com/science/article/pii/S001 1916400000837; Mattheus F.A. Goosen et al., "Thermodynamic and Economic Considerations in Solar Desalination," Desalination 129, no. 1(June 2000): 63-89, http://www.sciencedirect.com/science/article/pii/S0011916400000527.

85 A.M.K. El-Ghonemy, "Water Desalination Systems Powered by Renewable Energy Sources: Review," Renewable and Sustainable Energy Reviews 16, no. 3(April 2012): 1537-1556, http://www.sciencedirect.com/science/article/pii/S1364032111005193. 86 John E. Boysen et al., Evaluation of the Freeze-Thaw/Evaporation Process for the Treatment of Produced Waters, report prepared for Gas Research Institute and U.S. Department of Energy, 1996, http://www.gastechnology.org/webroot/app/xn/xd.aspx?xd=10AbstractPage/10828.xml. 87 Heather Cooley, "The Energy Implications of Desalination," in The Water-Energy Nexus in the American West, eds. Douglas S. Kenney and Robert Wilkinson (Northampton, MA: Edward Elgar Publishing, 2011).

88 W.L. Bourcier et al., "A Preliminary Cost and Engineering Estimate for Desalinating Produced Formation Water Associated with Carbon Dioxide Capture and Storage," International Journal of Greenhouse Gas Control 5, no. 5 (September 2011): 1319-1328, http://www.sciencedirect.com/science/article/pii/S175058361 1001009. 89 Raphael Semiat, "Energy Issues in Desalination Processes," Environmental Science and Technology 42, no. 22(2008): 8913-8201, http://pubs.acs.org/doi/abs/10.1021/es801330u.

90 J. Daniel Arthur, "Prudent and Sustainable Water Management and Disposal Alternatives Applicable to Shale Gas Development" (presentation to the Ground Water Protection Council, San Antonio, TX, January 2009), http://www.energyindepth.org/PDF/ALL-Shale-Gas-Water.pdf.

91 Leon Y. Sadler and Oommen George, "Concentration of Saline Produced Water from Coalbed Methane Gas Wells in a Multiple-Effect Evaporator Using Waste Heat from the Gas Compressor and Compressor Drive Engine," Desalination 101, no. 2(April 1995): 169-176,

http://www.sciencedirect.com/science/article/pii/001191649500019X.

92 Altela, "An Integrated Water Treatment Technology Solution for Sustainable Water Resource Management in the Marcellus Shale" (National Energy Technology Laboratory Kick off Meeting, Morgantown, WV, 2010); Matthew Bruff, Ned Godshall, and Karen Evans, An Integrated Water Treatment Technology Solution for Sustainable Water Resource Management in the Marcellus Shale, June 2011, http://www.netl.doe.gov/technologies/oilgas/publications/ENVreports/fe0000833-final-report.pdf.

93 Semiat, "Energy Issues."

94 Bruff, Godshall, and Evans, An Integrated Water Treatment Technology Solution, 27-29; Matthew Bruff and Sinisha A. Jikich, "Field Demonstration of an Integrated Water Treatment Technology Solution in Marcellus Shale" (paper presented at the Society of Petroleum Engineers Eastern Regional Meeting, Columbus, Ohio, August 2011), http://www.onepetro.org/mslib/servlet/onepetropreview?id=SPE-149466-MS; Veil, "Produced Water Management Options."

95 Bruff, Godshall, and Evans, An Integrated Water Treatment Technology Solution, 17, 22.

96 Brent Halldorson, "Adaptive Solutions for Shale Gas Water Management" (presentation, Developing Unconventional Gas East (Marcellus) Conference, Pittsburgh, PA, November 2010),

http://www.fountainquail.com/news/presentations/assets/DUG-E-Final-AP-FQ.pdf; Jack Z. Smith, "Wastewater 
From Natural Gas Drilling Is Made Clean," Fort Worth Star-Telegram, October 23, 2010 ,

http://www.istockanalyst.com/article/viewiStockNews/articleid/4606083.

97 GE Power \& Water, Thermal Treatment for Unconventional Gas Frac Water and Produced Water, 2010, http://www.geunconventionalgas.com/images/GEA17907\%20Evaporative\%20Treatment_R2.pdf.

98 C. Visvanathan, P. Svenstrup, and P. Ariyamethee, "Volume Reduction of Produced Water Generated From Natural Gas Production Process Using Membrane Technology," Water Science and Technology 41, no. 10-11 (2000): 117-123, http://www.iwaponline.com/wst/04110/wst041100117.htm; Lilian Malaeb and George M. Ayoub, "Reverse Osmosis Technology for Water Treatment: State of the Art Review," Desalination 267, no. 1(February 2011): 1-8, http://www.sciencedirect.com/science/article/pii/S0011916410006351.

99 Arthur, "Prudent and Sustainable Water Management," 17.

100 Harish R. Acharya, "Cost Effective Recovery of Low-TDS Frac Flowback Water for Re-use" (presentation to Kick-Off Meeting for National Energy Technology Laboratory (NETL) Produced Water Projects, Morgantown, WV, September 27, 2010), http://www.gwpc.org/meetings/forum/2010/proceedings/3Acharya Haris.pdf.

$101 \mathrm{Kah}$ Peng Lee, Tom C. Arnot, and Davide Mattia, "A Review of Reverse Osmosis Membrane Materials for Desalination - Development to Date and Future Potential," Journal of Membrane Science 370, no. 1-2(March 2011): 1-22, http://www.sciencedirect.com/science/article/pii/S0376738810010045.

102 Tzahi Y. Cath, Amy E. Childress, and Menachem Elimelech, "Forward Osmosis: Principles, Applications, and Recent Developments,"Journal of Membrane Science 281, no. 1-2(2006): 70-87,

http://www.yale.edu/env/elimelech/publication-pdf/Cath-Childress-Elimelech-JMS-2006.pdf; Tai-Shung Chung et al., "Forward Osmosis Processes: Yesterday, Today, and Tomorrow," Desalination 287, no. 78-81 (February 2012), http://www.sciencedirect.com/science/article/pii/S0011916410009392.

103 Cecilia E. Nelson and Ashok Kumar Ghosh, Membrane Technology for Produced Water in Lea County, report prepared for the U.S. Department of Energy, September 2011, http://www.netl.doe.gov/technologies/oilgas/publications/ENVreports/nt0005227-final-report.pdf.

$104 \mathrm{Ke} \mathrm{He}$ et al., "Production of Drinking Water from Saline Water by Direct Contact Membrane Distillation (DCMD),"Journal of Industrial and Engineering Chemistry 17, no. 1(January 2011): 41-48, http://www.sciencedirect.com/science/article/pii/S1226086X10002595.

105 Kamalwah K. Sirkar and Liming Song, Pilot-Scale Studies for Direct Contact Membrane Distillation-Based Desalination Process, September 2009, http://www.usbr.gov/research/AWT/reportpdfs/report134.pdf; Dhananjay Singh and Kamalesh K. Sirkar, "Desalination of Brine and Produced Water by Direct Contact Membrane Distillation at High Temperatures and Pressures," Journal of Membrane Science 389 (February 2012): 380-388, http://www.sciencedirect.com/science/article/pii/S0376738811008106.

106 T. Sirivedhin, J. McCue, and L. Dallbauman, "Reclaiming Produced Water for Beneficial Use: Salt Removal by Electrodialysis," Journal of Membrane Science 243, no. 1-2 (November 2004): 335-343, http://www.sciencedirect.com/science/article/pii/S0376738804004806.

107 Tom Hayes, "The Electrodialysis Alternative for Produced Water Management," GasTIPS 10, no. 3 (Summer 2004): 15-20,

http://media.godashboard.com/gti/4ReportsPubs/4_7GasTips/Summer04/TheElectrodialysisAlternativeForProduced WaterManagement.pdf.

108 T.J. Welgemoed and C.F. Schutte, "Capacitive Deionization TechnologyTM: An Alternative Desalination Solution," Desalination 183 (2005): 327-340, http://www.desline.com/articoli/6724.pdf; Pei Xu et al., "Treatment of Brackish Produced Water Using Carbon Aerogel-Based Capacitive Deionization Technology," Water Research 42, no. 10-11(May 2008): 2605-2617, http://www.sciencedirect.com/science/article/pii/S0043135408000274.

109 Kris Christen, "Desalination Technology Could Clean Up Wastewater From Coal-Bed Methane Production," Environmental Science and Technology 40, no. 3 (February 2006): 639-639,

http://pubs.acs.org/doi/abs/10.1021/es062630s.

110 Robert Atlas, "Purification of Brackish Water using Hybrid CDI-EDI Technology" (presentation to International Desalination Conference, Aruba, 2007).

111 P.M. Biesheuvel and A. van der Wal, "Membrane Capacitive Deionization," Journal of Membrane Science 346 , no. 2(January 2010): 256-262, http://www.sciencedirect.com/science/article/pii/S0376738809007005; P.M.

Biesheuvel et al., "Theory of Membrane Capacitive Deionization Including the Effect of the Electrode Pore Space," Journal of Colloid and Interface Science 360, no. 1 (August 2011): 239-248,

http://www.ncbi.nlm.nih.gov/pubmed/21592485; Haibo Li and Linda Zou, "Ion Exchange Membrane Capacitive Deionization: A New Strategy for Brackish Water Desalination,” Desalination 275, no. 1-3 (July 2011): 62-66, http://www.sciencedirect.com/science/article/pii/S0011916411001536. 
112 Konstantinos Dermentzis and Konstantinos Ouzounis, "Continuous Capacitive Deionization-Electrodialysis Reversal Through Electrostatic Shielding for Desalination and Deionization of Water," Electrochimica Acta 53, no. 24 (October 2008): 7123-7138, http://www.sciencedirect.com/science/article/pii/S001346860800652X; Haibo Li et al., "Electrosorptive Desalination by Carbon Nanotubes and Nanofibres Electrodes and Ion-Exchange Membranes," Water Research 42, no. 20 (October 2008): 4923-4928, http://144.206.159.178/ft/1092/593790/12241160.pdf. 113 Emilio Gabbrielli, "A Tailored Process for Remineralization and Potabilization of Desalinated Water,"

Desalination 39 (December 1981): 503-520, http://www.sciencedirect.com/science/article/pii/S0011916400861548; Joseph Cotruvo, "Health Aspects of Calcium and Magnesium in Drinking Water," Water Conditioning and Purification (June 2006), http://www.wcponline.com/pdf/Cotruvo.pdf; Ori Lahav and Liat Birnhack, "Quality Criteria for Desalinated Water Following Post-Treatment," Desalination 207, no 1-3 (March 2007): 286-303, http://www.sciencedirect.com/science/article/pii/S0011916407000306.

114 Bruff, Godshall, and Evans, An Integrated Water Treatment Technology Solution; Hayes, "The Electrodialysis Alternative"; K. Bourouni, M. T. Chaibi, and L. Tadrist, "Water Desalination by Humidification and Dehumidification of Air: State of the Art," Desalination 137 (2001): 167-176, http://www.desline.com/articoli/4107.pdf.

115 A. Gene Collins, Geochemistry of Oilfield Waters (New York: Elsevier Scientific Publishing Company, 1975). 116 U.S. EPA, Report to Congress: Management of Wastes from the Exploration, Development, and Production of Crude Oil, Natural Gas, and Geothermal Energy, report number EPA-530-SW-88-003 (Washington, DC: United States Environmental Protection Agency, 1987).

117James P. Ray and F. Rainier Engelhardt, eds., Produced Water: Technological/Environmental Issues and Solutions (New York: Plenum Press, 1992).

118 Mark Reed and Stale Johnsen, eds., Produced Water 2: Environmental Issues and Mitigation Technologies (New York: Plenum Press, 1995).

119 Tom Hayes and Dan Arthur, "Overview of Emerging Produced Water Treatment Technologies" (paper presented at the 11th Annual International Petroleum Environmental Conference, Albuquerque, NM, October 2004), http://ipec.utulsa.edu/Conf2004/Papers/hayes arthur.pdf.

120 Interstate Oil and Gas Compact Commission and ALL Consulting, A Guide to Practical Management of

Produced Water from Onshore Oil and Gas Operations in the United States, report prepared for the U.S. Department of Energy, October 2006, http://www.all-llc.com/publicdownloads/ALL-PWGuide.pdf.

121 Colorado School of Mines, An Integrated Framework for Treatment and Management of Produced Water: Technical Assessment of Produced Water Treatment Technologies, 2009, http://aqwatec.mines.edu/produced_water/treat/docs/Tech_Assessment_PW_Treatment_Tech.pdf. 122 John A. Veil, Argonne National Laboratory, Final Report: Water Management Technologies Used By Marcellus Shale Gas Producers, report prepared for U.S. Department of Energy, July 2010, http://www.evs.anl.gov/pub/doc/Water\%20Mgmt\%20in\%20Marcellus-final-jul10.pdf.

123 National Petroleum Council, Management of Produced Water.

124 Kenneth Lee and Jerry Neff, Produced Water: Environmental Risks and Advances in Mitigation Technologies (New York: Springer, 2011).

125 State Review of Oil and Natural Gas Environmental Regulations, Inc. (STRONGER), Pennsylvania Hydraulic Fracturing State Review, September 2010, http://www.shalegas.energy.gov/resources/071311 stronger pa hf review.pdf.

126 Clean Water Action, Environmental Violations at Marcellus Shale Drilling Sites Jan. 1, 2010 - Dec. 31, 2010, accessed March 30, 2012, http://www.cleanwateraction.org/files/publications/pa/violation_summary_2010.pdf. 127 American Petroleum Institute, Environmental Guidance Document: Waste Management in Exploration and Production Operations, 2nd ed. (Washington, DC: American Petroleum Institute, 1997), www.pipetegrity.com/especialistas/item/download/294.html; American Petroleum Institute, Water Management Associated with Hydraulic Fracturing (Washington, DC: American Petroleum Institute, 2010), http://www.shalegas.energy.gov/resources/HF2_e1.pdf; American Petroleum Institute, Practices for Mitigating Surface Impacts Associated with Hydraulic Fracturing (Washington, DC: American Petroleum Institute, 2011), http://www.api.org/ /media/Files/Policy/Exploration/HF3_e 7.ashx.

128 Charles G. Groat and Thomas W. Grimshaw, Fact-Based Regulation for Environmental Protection in Shale Gas, report prepared for the Energy Institute, The University of Texas at Austin, February 2012, 25, http://energy.utexas.edu/images/ei_shale_gas_regulation120215.pdf. 129 Jonathan D. Silver, "State Charges Local Company for Dumping Wastewater and Sludge," Pittsburgh PostGazette, March 18, 2011, http://www.post-gazette.com/pg/11077/1132812-454.stm; Kaitlynn Riely, "Greene 
County Man Pleads Guilty to Illegally Dumping Liquid Waste," Pittsburgh Post-Gazette, February 11, 2012 , http://www.post-gazette.com/pg/12042/1209625-503.stm.

130 U.S. EPA, OSWER Comparative Risk Project: Executive Summary and Overview (Washington, DC: U.S. Environmental Protection Agency, 1989), http://www.ntis.gov/search/product.aspx?ABBR=PB90272501.

131 U.S. EPA, Class I Underground Injection Control Program: Study of the Risks Associated with Class I Underground Injection Wells (Washington, DC: U.S. Environmental Protection Agency, 2001),

http://www.epa.gov/ogwdw/uic/pdfs/study uic-class1_study_risks_class1.pdf; W.R. Rish, “A Probabilistic Risk Assessment of Class I Hazardous Waste Injection Wells," Developments in Water Science 52 (2005): 93-135, http://www.sciencedirect.com/science/article/pii/S0167564805520100; W.R. Rish, “A Probabilistic Risk Assessment of Class I Hazardous Waste Injection Wells," in Underground Injection: Science and Technology, eds. C.-F. Tsang and J. A. Apps (New York, NY: Elsevier, 2006), 93-135.

132 J.E. Clark, D.K. Bonura, and R.F. Vorhees, "An Overview of Injection Well History in the United States of America," in Underground Injection: Science and Technology, eds. C.-F. Tsang and J. A. Apps (New York, NY: Elsevier, 2006), 3-12.

133 Henry A. Schroeder, "Relation Between Mortality from Cardiovascular Disease and Treated Water Supplies," Journal of the American Medical Association 172, no. 17 (1960): 1902-1908, http://jama.ama-

assn.org/content/172/17/1902.short; Joseph Cotruvo, "Health Aspects of Calcium and Magnesium in Drinking Water," Water Conditioning and Purification (June 2006), http://www.wcponline.com/pdf/Cotruvo.pdf; Richard W. Morris et al., "Hard Drinking Water Does Not Protect Against Cardiovascular Disease: New Evidence From the British Regional Heart Study," European Journal of Preventive Cardiology 15, no. 2 (April 2008): 185-189, http://cpr.sagepub.com/content/15/2/185.short.

134For a discussion of how polluted runoff from roads and highways harms water bodies, see Natural Resources Defense Council, After the Storm: How Green Infrastructure Can Effectively Manage Stormwater Runoff from Roads and Highways, September 2011, http:/www.nrdc.org/water/afterthestorm.asp.

135 Thomas G. Sanders and Jonathan Q. Addo, Effectiveness and Environmental Impact of Road Dust Suppressants, December 1993, http://www.mountain-plains.org/pubs/pdf/MPC94-28.pdf; Thomas Piechota et al., eds., Potential Environmental Impacts of Dust Suppressants: “Avoiding Another Times Beach" (Washington, DC: U.S. Environmental Protection Agency, 2004), http://www.epa.gov/esd $/ \mathrm{cmb} / \mathrm{pdf} / \mathrm{dust}$.pdf.

136 A.P. Boresi et al., Physical and Chemical Stability of Admixtures in Unpaved Road Soils (Bismarck, ND: North Dakota State University, 1996), http://www.ntis.gov/search/product.aspx?ABBR=PB96164637; Kathy Heffner, "Water Quality Effects of Three Dust-Abatement Compounds," U.S. Forest Service Engineering Field Notes 29 (January-April 1997): 35-43, http://www.fs.fed.us/t-d/pubs/pdfpubs/pdf97713801/pdf97713801.pdf.

137 U.S. EPA, Quality Criteria for Water 1986 (Washington, DC: U.S. Environmental Protection Agency, 1986), http://water.epa.gov/scitech/swguidance/standards/criteria/aqlife/upload/2009_01_13_criteria_goldbook.pdf; lowa Department of Natural Resources, Water Quality Standards Review: Chloride, Sulfate and Total Dissolved Solids, 2009, 3-8, http://www.dnr.mo.gov/env/wpp/rules/rir/so4-cl-ws_review_idnr_so4-cl.pdf; William H. Eldridge, David B. Arscott, and John K. Jackson, Stroud Water Research Center Expert Report on the Proposed Rulemaking by the Pennsylvania Environmental Quality Board [25 PA. CODE CH. 93] for Ambient Water Quality Criterion; Chloride (Ch) [40 Pa.B. 2264] [Saturday, May 1 2010] (Avondale, PA: Stroud Water Research Center, 2010),

http://www.sierraclub.org/naturalgas/rulemaking/documents/PA.Chapter93/2010.6.14.StroudReport.pdf.

138 Heffner, "Water Quality Effects," 35.

139 Frank M. D'Itri, Chemical Deicers and the Environment (Boca Raton, FL: Lewis Publishers, 1992); Devikarani M. Ramakrishna and Thiruvenkatachari Viraraghavan, "Environmental Impact of Chemical Deicers - A Review,"

Water, Air, \& Soil Pollution 166, nos. 1-4 (2005): 49-63, http://www.springerlink.com/content/q67285192u757226/. 140 Charlotte L. Demers and Richard W. Sage, "Effects of Road Deicing Salt on Chloride Levels in Four Adirondack Streams," Water, Air, \& Soil Pollution 49, nos. 3-4 (1990): 369-373,

http://www.springerlink.com/content/m8089v71143x1516/; Steven R. Corsi et al., "A Fresh Look at Road Salt: Aquatic Toxicity and Water-Quality Impacts on Local, Regional, and National Scales," Environmental Science and Technology 44, no. 19 (2010): 7376-7382, http://pubs.acs.org/doi/abs/10.1021/es101333u.

141 Samanta Lax and Eric W. Peterson, "Characterization of Chloride Transport in the Unsaturated Zone Near Salted Road," Environmental Geology 58, no. 5 (2009): 1041-1049, http://www.springerlink.com/content/537074372k224647/.

142 Peter E. Church and Paul J. Friesz, Effectiveness of Highway Drainage Systems in Preventing Road-Salt Contamination of Groundwater: Preliminary Findings (Washington, DC: National Research Council,

Transportation Research Board, 1993), http://www.nap.edu/catalog.php?record id=9096; William Wegner and Marc 
Yaggi, "Environmental Impacts of Road Salt and Alternatives in the New York City Watershed," Stormwater 2, no. 4 (May-June 2001), http://www.newyorkwater.org/downloadedArticles/ENVIRONMENTANIMPACT.cfm. 143 Eberhard Werner and Richard S. diPretoro, "Rise and Fall of Road Salt Contamination of Water-Supply Springs," Environmental Geology 51, no. 4 (2006): 537-543, http://www.springerlink.com/content/56h88m7607524w12/fulltext.pdf; for Pennsylvania, see Pennsylvania Department of Environmental Protection, General Permit WMGR064, paragraph 12, http://www.portal.state.pa.us/portal/server.pt?open=18\&objID $=505511 \&$ mode $=2$..

144 See, e.g., Nancy E. Karraker, James P. Gibbs, and James R. Vonesh, "Impacts of Road Deicing Salt on the Demography of Vernal Pool-Breeding Amphibians,” Ecological Applications 18, no. 3 (April 2008): 724-734, http://www.esajournals.org/doi/abs/10.1890/07-1644.1?journalCode=ecap; Pamela Silver, Shannon M. Rupprecht, and Mark F. Stauffer, "Temperature-Dependent Effects of Road Deicing Salt on Chironomid Larvae," Wetlands 29, no. 3 (2009): 942-951, http://www.springerlink.com/content/5x41340452723106/.

145 U.S. EPA, Quality Criteria for Water 1986; Iowa Department of Natural Resources, Water Quality Standards Review, 3-8; Eldridge, Arscott, and Jackson, Expert Report on the Proposed Rulemaking.

146 Michigan Department of Natural Resources, The Use of Oil Field Brine on Michigan Roadways, 1983, 6-13, http://www.michigan.gov/documents/deq/Oil_Field_Brine_opt_306999_7.pdf.

147 Interstate Oil and Gas Compact Commission and ALL Consulting, $\bar{A}$ Guide to Practical Management of

Produced Water from Onshore Oil and Gas Operations in the United States, report prepared for the U.S.

Department of Energy, October 2006, 62-63, http://www.all-llc.com/publicdownloads/ALL-PWGuide.pdf.

148 Pennsylvania Department of Environmental Protection, Approval of Brine Roadspreading Plans, October 31, 1998, http://www.elibrary.dep.state.pa.us/dsweb/Get/Version-48261/550-2100-007.pdf.

149 Michigan Department of Natural Resources, The Use of Oil Field Brine, 27-32.

150 Ibid., 19.

151 E. Scott Bair and Robert K. Digel, "Subsurface Transport of Inorganic and Organic Solutes from Experimental Road Spreading of Oil-Field Brine," Ground Water Monitoring and Remediation 10, no. 3 (Summer 1990): 94-105, http://info.ngwa.org/gwol/pdf/901878009.PDF; Melinda J. Chapman and E. Scott Bair, "Mapping a Brine Plume Using Surface Geophysical Methods in Conjunction with Ground Water Quality Data," Ground Water Monitoring and Remediation 12, no. 3 (Summer 1992): 203-209, http://onlinelibrary.wiley.com/doi/10.1111/j.1745-

6592.1992.tb00061.x/abstract.

152 Bair and Digel, "Subsurface Transport."

153 Yoram Eckstein, "Is Use of Oil-Field Brine as a Dust-Abating Agent Really Benign? Tracing the Source and Flowpath of Contamination by Oil Brine in a Shallow Phreatic Aquifer," Environmental Earth Sciences 63, no. 1 (2011): 201-214, http://www.springerlink.com/content/x441t216136548r4/fulltext.pdf.

154 For mention of the use of brine from a permitted brine treatment facility, see, e.g., PADEP, General Permit WMGR064, paragraph 15 .

155 T. Hayes, Gas Technology Institute, Sampling and Analysis of Water Streams Associated with the Development of Marcellus Shale Gas, report prepared for Marcellus Shale Coalition, December 2009,

http://www.bucknell.edu/script/environmentalcenter/marcellus/default.aspx?articleid=14.

156 For information on priority chemicals, see "Priority Chemicals," U.S. EPA, last modified March 26, 2012, http://www.epa.gov/osw/hazard/wastemin/priority.htm

157 Ibid.

$158 \mathrm{Jim}$ Green, Maggie Passmore, and Hope Childers, A Survey of the Condition of Streams in the Primary Region of Mountaintop Mining/Valley Fill Coal Mining, report prepared for the U.S. Environmental Protection Agency Region III, November 2000, http://www.cet.edu/pdf/mtmvfbenthics.pdf; Rod Bodkin et al., "Limiting Total Dissolved Solids to Protect Aquatic Life," Journal of Soil and Water Conservation 62, no. 3 (May-June 2007): 57A61A, http://www.jswconline.org/content/62/3/57A.extract; Mark Wozniak, "Investigation of Total Dissolved Solids Regulation in the Appalachian Plateau Physiographic Province: A Case Study from Pennsylvania and Recommendations for the Future" (master's degree project, North Carolina State University, 2011), http://repository.lib.ncsu.edu/dr/bitstream/1840.4/4175/1/Wozniak,+Mark+project.pdf.

159 Robert B. Jackson and Esteban G. Jobbagy, "From Icy Roads to Salty Streams," Proceedings of the National Academy of Sciences 102, no. 41 (October 11, 2005): 14487-14488,

http://www.biology.duke.edu/jackson/pnas05.pdf; Sujay S. Kaushal et al., "Increased Salinization of Fresh Water in the Northeastern United States," Proceedings of the National Academy of Sciences 102, no. 38 (September 20,

2005): 13517-13520, http://www.pnas.org/content/102/38/13517.short; Philip R. Trowbridge et al., "Relating Road 
Salt to Exceedances of the Water Quality Standard for Chloride in New Hampshire Streams," Environmental Science and Technology 44, no. 13 (2010): 4903-4909.

160 See, e.g., D.L. Nielsen et al., "Effects of Increasing Salinity on Freshwater Ecosystems in Australia," Australian Journal of Botany 51, no. 6 (2003): 655-665, http://www.publish.csiro.au/paper/BT02115.htm; Stuart E.G. Findlay and Victoria R. Kelly, "Emerging Indirect and Long-Term Road Salt Effects on Ecosystems," Annals of the New York Academy of Sciences 1223 (March 2011): 58-68, http://onlinelibrary.wiley.com/doi/10.1111/j.1749-

6632.2010.05942.x/full; Achim Paetzold et al., "Environmental Impact Propagated by Cross-System Subsidy: Chronic Stream Pollution Controls Riparian Spider Populations,” Ecology 92, no. 9 (2011): 1711-1716, http://www.esajournals.org/doi/pdf/10.1890/10-2184.1.

161 M. Evans and C. Frick, The Effects of Road Salts on Aquatic Ecosystems (Saskatoon, Saskatchewan, Canada: National Water Research Institute, 2001), http://144.171.11.39/view/2001/M/643748.

162 M. Eric Benbow and Richard W. Merritt, "Road Salt Toxicity of Select Michigan Wetland Macroinvertebrates Under Different Testing Conditions," Wetlands 24, no. 1 (March 2004): 68-76,

http://www.geology.wmich.edu/Koretsky/EnvironmentalGeochemistry/Benbow2004.pdf.

163 Barry T. Hart et al., "A Review of the Salt Sensitivity of the Australian Freshwater Biota," Hydrobiologia 210, nos. 1-2 (1991): 105-144, http://www.springerlink.com/content/147557285416m880/.

164 Ben J. Kefford, "Is Salinity the Only Water Quality Parameter Affected When Saline Water Is Disposed in Rivers?", International Journal of Salt Lake Research 7, no. 4 (1998): 285-300,

http://www.springerlink.com/content/j0238r15q70p34q3/; Ben J. Kefford, "The Effect of Saline Water Disposal: Implications for Monitoring Programs and Management," Environmental Monitoring and Assessment 63, no. 2 (1999): 313-327, http://www.springerlink.com/content/v31068344571t21x/.

165 Jason W. Baker et al., "Growth and Toxicity of Prymnesium parvum (Haptophyta) as a Function of Salinity, Light, and Temperature," Journal of Phycology 43, no. 2 (April 2007): 219-227, http://onlinelibrary.wiley.com/doi/10.1111/j.1529-8817.2007.00323.x/abstract.

166 Rebecca Renner, "Salt-Loving Algae Wipe Out Fish in Appalachian Stream," Environmental Science and Technology 43, no. 24 (2009): 9046-9047, http://pubs.acs.org/doi/abs/10.1021/es903354w.

167 U.S. EPA, Ambient Water Quality Criteria for Chloride - 1988 (Washington, DC: U.S. Environmental Protection Agency, 1988), http://water.epa.gov/scitech/swguidance/standards/criteria/upload/chloride1988.pdf. 168 Ibid.; Evans and Frick, The Effects of Road Salts.

169 Iowa Department of Natural Resources, Water Quality Standards Review, 3-5.

170 N.K. Nagpal, D.A. Levy, and D.D. MacDonald, Water Quality: Ambient Water Quality Guidelines for Chloride - Overview Report, prepared for the British Columbia Ministry of Environment, 2003, http://www.env.gov.bc.ca/wat/wq/BCguidelines/chloride/chloride.html.

171 H.J.M. Bowen, Trace Elements in Biochemistry (New York: Academic Press, 1966); H.J.M. Bowen, Environmental Chemistry of the Elements (London: Academic Press, 1979).

172 Ibid.

173 World Health Organization, Bromide in Drinking Water: Background Document for Development of WHO Guidelines for Drinking-Water Quality (Geneva, Switzerland: World Health Organization, 2009).

174 Ibid.; Markus Flury and Andreas Papritz, "Bromide in the Natural Environment: Occurrence and Toxicity," Journal of Environmental Quality 22, no. 4 (October-December 1993): 747-758,

http://akasha.wsu.edu/ flury/theses articles/bromide.pdf.

175 Calculations of acceptable drinking water levels are from World Health Organization, Bromide in Drinking Water.

176 Flury and Papritz, "Bromide in the Natural Environment," 752-755.

177 J.H. Canton, P.W. Wester, and E.A.M. Mathijssen-Spiekman, "Study of Toxicity of Sodium Bromide to Different Freshwater Organisms," Food and Chemical Toxicology 21, no. 4 (August 1983): 369-378, http://www.sciencedirect.com/science/article/pii/027869158390090X.

178 Stuart W. Krasner et al., "The Occurrence of Disinfection By-Products in U.S. Drinking Water," Journal American Water Works Association 81, no. 8 (August 1989): 41-53,

http://apps.awwa.org/WaterLibrary/showabstract.aspx?an=JAW_0026141; L. Heller-Grossman et al., "Formation and Distribution of Haloacetic Acids, THM and TOX in Chlorination of Bromide-Rich Lake Water," Water Research 27, no. 8 (1993): 1323-1331, http://gwri-ic.technion.ac.il/pdf/RM1/522.pdf.

179 Susan D. Richardson et al., "Tribromopyrrole, Brominated Acids, and Other Disinfection Byproducts Produced by Disinfection of Drinking Water Rich in Bromide," Environmental Science \& Technology 37, no. 17 (2003): 3782-3793; Michael J. Plewa et al., "Chemical and Biological Characterization of Newly Discovered Iodoacid 
Drinking Water Disinfection Byproducts," Environmental Science \& Technology 38, no. 18 (2004): 4713-4722, http://pubs.acs.org/doi/abs/10.1021/es049971v; Susan D. Richardson et al., "Occurrence, Genotoxicity, and Carcinogenicity of Regulated and Emerging Disinfection By-Products in Drinking Water: A Review and Roadmap for Research," Mutation Research 636, nos. 1-3 (November-December 2007): 178-242; Susan D. Richardson et al., "Occurrence and Mammalian Cell Toxicity of Iodinated Disinfection Byproducts in Drinking Water," Environmental Science \& Technology 42, no. 22 (2008): 8330-8338, http://pubs.acs.org/doi/abs/10.1021/es801169k. 180 P. Westerhoff et al., "Nation-Wide Bromide Occurrence and Bromate Formation Potential in Drinking Water Supplies" (paper presented at the National Conference on Environmental Engineering, Boulder, CO, 1994), http://cedb.asce.org/cgi/WWWdisplay.cgi?89205.

181 Howard S. Weinberg et al., The Occurrence of Disinfection By-Products (DBPS) of Health Concern in Drinking Water: Results of a Nationwide DBP Occurrence Study, report prepared for U.S. Environmental Protection Agency, Office of Research and Development, September 2002, http://epa.gov/athens/publications/reports/EPA_600 R02_068.pdf.

182 Paul Handke, Trihalomethane Speciation and the Relationship to Elevated Total Dissolved Solid Concentrations Affecting Drinking Water Quality at Systems Utilizing the Monongahela River as a Primary Source During the 3rd and 4th Quarters of 2008 (Harrisburg, PA: Pennsylvania Department of Environmental Protection, 2009),

http://files.dep.state.pa.us/Water/Wastewater\%20Management/WastewaterPortalFiles/MarcellusShaleWastewaterPa rtnership/dbp_mon_report_dbp_correlation.pdf.

183 Jeanne M. VanBriesen and Jessica M. Wilson, "Monongahela River Bromide Issues" (presentation to the Pennsylvania Rural Water Association Meeting, State College, PA, March 29-April 1, 2011); Stanley States et al., "Bromide in the Allegheny River and THMs in Pittsburgh Drinking Water: A Link with Marcellus Shale Drilling" (paper presented at the American Water Works Association Water Quality Technology Conference, Phoenix, AZ, November 13-17, 2011), http://www.essentialpublicradio.org/sites/default/files/story/extras/2011-december/201112-02/state-studysmall.pdf.

184 Jeanne M. VanBriesen, "Bromide Levels in the Monongahela River" (presentation to the State of the Monongahela River Research Symposium, Carnegie Mellon University, Pittsburgh, PA, November 2011). 185 See, e.g., Wilkinsburg-Penn Joint Water Authority, "Water Treatment Process Change," last modified January 4, 2011, http://wpjwa.com/?p=11582.

186 New York State Department of Environmental Conservation, An Investigation of Naturally Occurring Radioactive Materials (NORM) in Oil and Gas Wells in New York State, April 1999,

http://www.dec.ny.gov/docs/materials_minerals_pdf/normrpt.pdf; U.S. Geological Survey, Naturally Occurring Radioactive Materials (NORM) in Produced Water and Oil-Field Equipment - An Issue for the Energy Industry, September 1999, http://pubs.usgs.gov/fs/fs-0142-99/fs-0142-99.pdf.

187 Pennsylvania Department of Environmental Protection, NORM Survey Summary, September 1992, http://files.dep.state.pa.us/OilGas/BOGM/BOGMPortalFiles/RadiationProtection/NORM.pdf.

188 Marvin Resnikoff, Ekaterina Alexandrova, and Jackie Travers, Radioactivity in Marcellus Shale, report prepared for Residents for the Preservation of Lowman and Chemung (RFPLC), May 19, 2010, http://www.rwma.com/Marcellus\%20Shale\%20Report\%205-18-2010.pdf.

189 Timothy Puko, "Public Water Safe From Radioactivity Throughout Region," Pittsburgh Tribune-Review, June 21, 2011, http://www.pittsburghlive.com/x/pittsburghtrib/news/pittsburgh/s 743117.html.

190 Robert Wolford, "Characterization of Organics in the Marcellus Shale Flowback and Produced Waters" (master's thesis, Penn State University, 2011), https://etda.libraries.psu.edu/paper/12343/7626.

191 See full analysis in Hayes, Sampling and Analysis.

192 Daniel J. Soeder, "Environmental Impacts of Shale-Gas Production," Physics Today 64, no. 11 (November 2011): 8, http://www.physicstoday.org/resource/1/phtoad/v64/i11/p8_sl.

193 Kaushal et al., "Increased Salinization."

19433 U.S.C. $\$ 1311$ (a). For a general overview of the Clean Water Act's regulatory regime, see Claudia Copeland, Clean Water Act: A Summary of the Law (Washington, DC: Congressional Research Service, 2010),

http://www.cnie.org/nle/crsreports/10May/RL30030.pdf.

19533 U.S.C. \$ 1342. Pennsylvania has been delegated authority to administer the NPDES program within the state. See 25 Pa. Code Ch. 92a.

196 For a summary of how the Clean Water Act's regulations apply to the discharge of shale gas wastewater, see Memorandum from James Hanlon, Director, U.S. EPA Office of Wastewater Management, to EPA Regional 
Offices, "Natural Gas Drilling in the Marcellus Shale - NPDES Program Frequently Asked Questions," March 16, 2011, http://www.epa.gov/npdes/pubs/hydrofracturing_faq.pdf.

19733 U.S.C. \$1311; 40 C.F.R. \$ 125.3(a).

19840 C.F.R. \$ $122.44(d)(1)$.

19933 U.S.C. \$ 1314(b); 40 C.F.R. Pts. 401-699.

20040 C.F.R. $\$ 435.32$ ("[T] 4 here shall be no discharge of waste water pollutants into navigable waters from any source associated with production, field exploration, drilling, well completion, or well treatment (i.e., produced water, drilling muds, drill cuttings, and produced sand)."); see also 40 C.F.R. $§ 435.30$ (defining onshore oil and gas facilities as a point source category subject to 40 C.F.R. $\S 435.32$ ).

20140 C.F.R. $\$ \$ 435.50,435.60$.

20240 C.F.R. \$ 403.3(i).

20333 U.S.C. $\$ 1370$.

20440 C.F.R. $\$ \$ 403.3(k),(p), 403.5(a)(1)$.

205 Hanlon to EPA Regional Offices, 10.

20633 U.S.C. $\$ 1317$ (b); 40 C.F.R. $\$ \$ 405-471$.

207 Notice of Final 2010 Effluent Guidelines Program Plan, 76 Fed. Reg. 66,286, 66,296 (Oct. 26, 2011).

20840 C.F.R. $\$ \$ 403.5(\mathrm{c}), 403.8(\mathrm{f})(4)$.

209 See U.S. EPA, Local Limits Development Guidance (2004),

http://www.epa.gov/npdes/pubs/final local limits guidance.pdf.

210 See "Overview of Pretreatment," Pennsylvania Department of Environmental Protection, accessed March 28, 2012, http://www.dep.state.pa.us/dep/deputate/waterops/redesign/pages/pretreament/Pretreatment $\% 20 \mathrm{Intro}$.htm. 211 Notice of Final 2010 Effluent Guidelines Program Plan, 76 Fed. Reg. at 66,297.

212 See John A. Veil, Argonne National Laboratory, Final Report: Water Management Technologies Used By Marcellus Shale Gas Producers, report prepared for U.S. Department of Energy, July 2010, 20, 45, 48, 53, http://www.evs.anl.gov/pub/doc/Water\%20Mgmt\%20in\%20Marcellus-final-jull0.pdf.

213 Emily Collins, University of Pittsburgh School of Law, e-mail message to author, April 9, 2012.

21440 C.F.R. $\$ 122.42($ b).

215 See David McGuigan, Associate Director, Office of NPDES Permits and Enforcement, Water Protection Division, EPA Region III, to Richard Chiavetta, Plant Manager, Allegheny Valley Joint Sewage Authority, July 13, 2011, 2, http://www.epa.gov/region03/marcellus_shale/pdf/potw7-13-11/pittsburgh.pdf.

21640 C.F.R. \$ 122.42 (b)(3).

217 Effluent Limitations Guidelines, Pretreatment Standards, and New Source Performance Standards for the Centralized Waste Treatment Point Source Category; Final Rule, 65 Fed. Reg. 81,241 (Dec. 22, 2000) (codified at 40 C.F.R. Pt. 437); Effluent Limitations Guidelines, Pretreatment Standards, and New Source Performance Standards for the Centralized Waste Treatment Point Source Category, 68 Fed. Reg. 71,014 (Dec. 22, 2003) (codified at 40 C.F.R. Pt. 437).

218 See 40 C.F.R. $\$ 125.3(\mathrm{c})(3)$.

21940 C.F.R. $\$ 125.3(\mathrm{~d})$.

22033 U.S.C. $\$ \$ 1311,1342 ; 40$ C.F.R. 122.44(d)(1)(i).

221 See 33 U.S.C. $\$ 1313 ; 40$ C.F.R. $\$ \$ 131.2,131.4$

222 See 40 C.F.R. $\$ 131.3$ (b).

223 See "National Recommended Water Quality Criteria," U.S. EPA, last modified March 7, 2012, http://water.epa.gov/scitech/swguidance/standards/current/index.cfm.

22440 C.F.R. \$ $122.44(d)(1)$.

225 See Pennsylvania Department of Environmental Protection, Coordinating National Pollutant Discharge

Elimination System (NPDES) Permitting in the Monongahela River Watershed, May 1, 2010,

http://www.elibrary.dep.state.pa.us/dsweb/Get/Document-79820/362-2100-001.pdf.

$22625 \mathrm{~Pa}$. Code Ch. 92a.

$22725 \mathrm{~Pa}$. Code $\$ 92 \mathrm{a} .48(\mathrm{a})$.

$22825 \mathrm{~Pa}$. Code Ch. 95.

$22925 \mathrm{~Pa}$. Code $\$ 95.10$.

$23025 \mathrm{~Pa}$. Code $\$ 95.10(\mathrm{~b})(2)$.

$23125 \mathrm{~Pa}$. Code $\$ 95.10$ (b)(3).

$23225 \mathrm{~Pa}$. Code $\$ 95.10$ (b)(3)(i)-(ii).

$23325 \mathrm{~Pa}$. Code $\$ 95.10$ (b)(3)(iv)-(vi). 
$23425 \mathrm{~Pa}$. Code $\S 95.10(\mathrm{a})(7)$.

235 Pennsylvania Department of Environmental Protection, "DEP Calls on Natural Gas Drillers to Stop Giving

Treatment Facilities Wastewater," news release, April 19, 2011.

236 Donald Gilliland, "DEP Says Marcellus Shale Drilling Waste No Longer Being Discharged into Streams,"

Central Pennsylvania Patriot-News, June 3, 2011 ,

http://www.pennlive.com/midstate/index.ssf/2011/06/dep_says_marcellus_drilling_wa.html.

237 See Chapter 1; reporting data is available at

http://www.paoilandgasreporting.state.pa.us/publicreports/Modules/DataExports/DataExports.aspx.

238 Ohio Revised Code $\$ 1509.22(\mathrm{C})(1)$; see also Scott J. Nally, Director of Ohio Environmental Protection

Agency, to David Mustine, Director of Ohio Department of Natural Resources, May 16, 2011,

http://www.epa.ohio.gov/portals/35/pretreatment/marcellus_shale/POTW_Brine_Disposal_Letter_may11.pdf. The options listed as legal disposal methods for oil and gas wastewater in Ohio are (1) injection, (2) road surface application (excluding flowback, drilling, and treatment fluids), (3) enhanced recovery, and (4) other methods approved by the state for testing or implementing a new technology or disposal method.

$23925 \mathrm{~Pa}$. Code Ch. 93.

$24025 \mathrm{~Pa}$. Code. $\$ 93.7$.

241 See "Proposed Rulemaking, Environmental Quality Board: Ambient Water Quality Criterion; Chloride (Ch)," Pennsylvania Bulletin 40, no. 18 (May 1, 2010): 2264, http://www.pabulletin.com/secure/data/vol40/40-

18/771.html.

242 Ibid.

243 See "Regulation Details: Regulation \#7-457," Independent Regulatory Review Commission, accessed March 28, 2012, http://www.irrc.state.pa.us/regulation_details.aspx?IRRCNo=2841.

244 Pennsylvania Department of Environmental Protection, "Chapter 93 Water Quality Standards (Draft),"

December 20, 2011,

http://files.dep.state.pa.us/PublicParticipation/Advisory\%20Committees/AdvCommPortalFiles/WRAC/DRAFTprTR13_Annex-Ch93-updated.pdf.

245 See Jon M. Capacasa, Director, Water Protection Division, U.S. EPA Region III, to Kelly Jean Heffner, Acting Deputy Secretary for Water Management, PADEP, May 12, 2011, 1-2,

http://www.epa.gov/region3/marcellus_shale/pdf/letter/heffner-letter5-12-11.pdf.

24642 U.S.C. $\$ 300$ h et seq.

24740 C.F.R. \$ 144.11 .

248 See 42 U.S.C. $\$ 300 \mathrm{~h}-4$. Pennsylvania has not obtained primacy, so its UIC program is administered by EPA.

24942 U.S.C. $\$ 300 \mathrm{~h}(\mathrm{~b})(3)(\mathrm{A})$.

25040 C.F.R. \$ 144.6.

251 See "Requirements for all Class I Wells and Class I Hazardous Waste Wells," U.S. EPA, accessed March 28, 2012, http://www.epa.gov/ogwdw/uic/pdfs/page_uic-class1_summary_class1_reqs.pdf.

25240 C.F.R. \$ 146.24.

25340 C.F.R. $\$ 146.22$ (a).

25440 C.F.R. $\$ 146.22$ (b)(1).

25540 C.F.R. $\$ \S 144.28$ (f)(6)(ii), 146.23(a).

25640 C.F.R. $\$ 144.28(f)(2)$.

$25725 \mathrm{~Pa}$. Code $\$ 78.18$.

258 Ibid.

259 See "1992 Findings Statement for Oil and Gas GEIS," New York Department of Environmental Conservation, September 24, 1992, http://www.dec.ny.gov/energy/47368.html.

26042 U.S.C. $\$ 300 \mathrm{~h}(\mathrm{~d})(1)(\mathrm{B})(\mathrm{ii})$.

261 Fracturing Responsibility and Awareness of Chemicals Act ("FRAC Act"), H.R. 1084 \& S. 587, 112th Cong. (2011).

$26225 \mathrm{~Pa}$. Code $\$ 287.601$.

263 Pennsylvania Department of Environmental Protection, "General Permit WMGR123: Processing and Beneficial Use of Oil and Gas Liquid Waste," March 14, 2012,

http://files.dep.state.pa.us/Waste/Bureau\%20of\%20Waste\%20Management/WasteMgtPortalFiles/SolidWaste/Resid ual_Waste/GP/WMGR123.pdf.

$26425 \mathrm{~Pa}$. Code Ch. 289; $25 \mathrm{~Pa}$. Code $\$ 78.57$ (c).

$26525 \mathrm{~Pa}$. Code $\S \S 289.152,289.251$. 
26625 Pa. Code § 287.1.

267 General Assembly of Pennsylvania, House Bill No. 1950, Printer's No. 3048 (signed into law Feb. 14, 2012 as Act No. 13); see also Daniel Raichel, "Home Rule Disaster: Pennsylvania Residents May Be Forced to Live Within 300 Feet of A Frack Well Pad," Switchboard (blog), Natural Resources Defense Council, February 9, 2012, http://switchboard.nrdc.org/blogs/draichel/home rule disaster pennsylvani.html.

268 Robinson Township v. Pennsylvania, No. 284 MD 2012 (Pa. Commw. Ct. filed March 29, 2012); see also Gayathri Vaidyanathan, "Lawsuit Challenges State Oil and Gas Zoning Scheme," EnergyWire, April 2, 2012. 269 EPA Region II, "EPA Comments on Revised Draft NYSDEC Revised dSGEIS for Horizontal Drilling and High-Volume Hydraulic Fracturing to Develop the Marcellus Shale and Other Low-Permeability Gas ReservoirsEnclosure," Jan. 11, 2012, 6,

http://www.epa.gov/region2/newsevents/pdf/EPA\%20R2\%20Comments\%20Revised\%20dSGEIS\%20Enclosure.pdf 270 This includes, for example, NPDES permitting requirements for municipal separate storm sewer systems ("MS4s"). See EPA, "Road-Related Municipal Separate Storm Sewer Systems (MS4s),"

http://cfpub.epa.gov/npdes/stormwater/municroads/home.cfm; 33 U.S.C. \$1342(p)(3)(B) (including the requirement to "reduce the discharge of pollutants to the maximum extent practicable"). It also includes water quality-based requirements applicable to NPDES permitted discharges. 33 U.S.C. $\$ \$ 1311,1342 ; 40$ C.F.R. 122.44(d)(1)(i). $27125 \mathrm{~Pa}$. Code \$ 78.57(a).

$27225 \mathrm{~Pa}$. Code $\$ 291.201$.

273 Pennsylvania DEP, General Permit WMGR064, http://www.portal.state.pa.us/portal/server.pt?open=18\&objID=505511\&mode=2.

274 See, e.g., New York State Department of Environmental Conservation, "Draft Generic Environmental Impact Statement on the Oil, Gas and Solution Mining Regulatory Program,” January 1988, 15-9, http://www.dec.ny.gov/docs/materials_minerals_pdf/dgeisv2ch15.pdf ("Brine may be spread on paved and unpaved roads ... [A] spreader bar or similar spray must be used with the proper application rate to eliminate runoff."). 275 See Ohio Department of Natural Resources, Spreading Oil-Field Brine for Dust and Ice Control in Ohio, created October 1993, revised September 2004, 23, http://www.ohiodnr.com/Portals/11/publications/pdf/Brine.pdf ("Surface water can be immediately contaminated in roadside ditches, and contaminated runoff may impact streams or ponds. Studies in Vermont have shown that 90 percent of the salt applied to road surfaces reaches streams when the ground is frozen. Dilution is somewhat greater when oil-field brine is applied ....").

276 See "Notices, Department of Environmental Protection: Applications, Actions and Special Notices," Pennsylvania Bulletin 41, no. 38 (September 17, 2011): 4987, http://www.pabulletin.com/secure/data/vol41/4138/1606.html.

277 See Pennsylvania Department of Environmental Protection, Road Spreading of Brine for Dust Control and Road Stabilization, April 2009,

http://www.mde.state.md.us/programs/Land/mining/marcellus/Documents/Brine_for_dust_control.pdf. 278 New York Department of Environmental Conservation, Revised Draft Supplemental Generic Environmental Impact Statement on the Oil, Gas and Solution Mining Regulatory Program: Well Permit Issuance for Horizontal Drilling and High-Volume Hydraulic Fracturing to Develop the Marcellus Shale and Other Low-Permeability Gas Reservoirs, September 7, 2011, 5-133, 7-60-7-61, Appendix 12, http://www.dec.ny.gov/energy/75370.html. 279 Ibid.; see also Steven Russo, New York Department of Environmental Conservation, e-mail message to Kate Sinding, Natural Resources Defense Council, March 13, 2012 (on file with author).

28042 U.S.C. $\$ 6921$ (b)(2)(A).

28142 U.S.C. $\$ 6921(\mathrm{~b})(2)(B)$.

282 Regulatory Determination for Oil and Gas and Geothermal Exploration, Development and Production Wastes, 53 Fed. Reg. 25446 (July 6, 1988).

283 lbid.

$284 \mathrm{lbid}$.

285 The RCRA exemption has no preemptive effect. This means that states are free to regulate, under their own hazardous waste programs, the storage and handling of oil and gas waste. See U.S. EPA, "Exemption of Oil and Gas Exploration and Production Wastes," 5.

28635 Pa. Stat. Ann. $\$ \$ 6018.103,6018.301$.

28735 Pa. Stat. Ann. \$ 6018.302(b), 6018.303(b).

$28825 \mathrm{~Pa}$. Code $\$ 287.51$.

$28925 \mathrm{~Pa}$. Code $\$ 287.53$. 
$29025 \mathrm{~Pa}$. Code $\$ \S 287.52,287.54$. Blank $26 \mathrm{R}$ forms are available for download at http://www.elibrary.dep.state.pa.us/dsweb/View/Collection-10502.

$29125 \mathrm{~Pa}$. Code $\$ 287.55$.

$29235 \mathrm{~Pa}$. Stat. Ann. $\$ 6018.303(\mathrm{a})(1)$.

$29325 \mathrm{~Pa}$. Code Ch. 299.

29435 Pa. Stat. Ann. \$ 6018.303(b)(2).

295 For a summary of regulations applying to waste residuals, see "Waste Residuals," U.S. EPA, last modified October 26, 2011, http://www.epa.gov/nrmrl/wswrd/dw/smallsystems/residuals.html.

296 See generally U.S. EPA, Exemption of Oil and Gas Exploration and Production Wastes from Federal

Hazardous Waste Regulations, October 2002, 5-6, 22-24,

http://www.epa.gov/epawaste/nonhaz/industrial/special/oil/oil-gas.pdf.

297 Pennsylvania Department of Environmental Protection, "DEP Calls on Natural Gas Drillers to Stop Giving

Treatment Facilities Wastewater," news release, April 19, 2011.

29840 C.F.R. $\$ \S 403.5$ (prohibiting pass through and interference), 403.3 (defining pass through and interference);

see, e.g., Ian Urbina, "Regulation Lax as Gas Wells' Tainted Water Hits Rivers," N.Y. Times, February 26, 2011, A1

(explaining that POTWs are not required to monitor or test for radioactive material contained in shale gas

wastewater).

299 Notice of Final 2010 Effluent Guidelines Program Plan, 76 Fed. Reg. 66,286, 66,297 (Oct. 26, 2011 ).

300 Ibid., $66,296$.

301 Natural Resources Defense Council et al., "Comments Re: Notice of Final 2010 Effluent Guidelines Program

Plan - Development of Pretreatment Standards for Discharges of Shale Gas Wastewater," Feb. 27, 2012,

http://www.regulations.gov/\#!documentDetail;D=EPA-HQ-OW-2008-0517-0849.

30233 U.S.C. $\$ \S 1317$ (b)(1), (c).

303 U.S. EPA, Introduction to the National Pretreatment Program, June 2011, 3-5,

http://www.epa.gov/npdes/pubs/pretreatment_program_intro_2011.pdf.

304 See ibid., Attachment 3-1; see also 40 C.F.R. 435.46-435.47.

305 See Notice of Final 2010 Effluent Guidelines Program Plan, 76 Fed. Reg. at 66,289.

306 Ibid., 66,288.

30733 U.S.C. $\$ \$ 1317$ (c) (requiring pretreatment standards for new sources to be promulgated simultaneously with the promulgation of performance standards for new sources under $\$ 1316$ ), $\$ 1316$ (a)(1) (requiring all new source performance standards to "reflect[] the greatest degree of effluent reduction which the Administrator determines to be achievable through application of the best available demonstrated control technology").

30825 Pa. Code $\$ 95.10$ (b)(3)(iv)-(vi).

309 See "Clean Water Act (CWA): Pretreatment Program," U.S. EPA, last modified November 30, 2011, http://www.epa.gov/agriculture/lcwa.html\#retreatment Program.

31040 C.F.R. Pt. 437.

311 Effluent Limitations Guidelines, Pretreatment Standards, and New Source Performance Standards for the Centralized Waste Treatment Point Source Category; Final Rule, 65 Fed. Reg. 81,241 (Dec. 22, 2000) (codified at 40 C.F.R. Pt. 437); Effluent Limitations Guidelines, Pretreatment Standards, and New Source Performance Standards for the Centralized Waste Treatment Point Source Category, 68 Fed. Reg. 71,014 (Dec. 22, 2003) (codified at 40 C.F.R. Pt. 437).

312 See generally U.S. Department of Energy, National Energy Technology Laboratory, Shale Gas: Applying Technology to Solve America's Energy Challenges, March 2011, 3, http://www.netl.doe.gov/technologies/oilgas/publications/brochures/Shale_Gas_March_2011.pdf (summarizing the history of shale gas development). 313 “PA DEP Oil \& Gas Reporting Website - Statewide Data Downloads By Reporting Period," Pennsylvania Department of Environmental Protection, last modified March 27, 2012, https://www.paoilandgasreporting.state.pa.us/publicreports/Modules/DataExports/DataExports.aspx. 314 U.S. Department of Energy, Secretary of Energy Advisory Board, Shale Gas Production Subcommittee 90-Day Report, August 18, 2011, 6, http://www.shalegas.energy.gov/resources/081811_90_day_report_final.pdf. 315 Natural Resources Defense Council et al., "Comments Re: Notice of Final $201 \overline{0}$ Effluent Guidelines Program Plan" (see n. 5).

316 Michael L. Krancer, Secretary, Pennsylvania Department of Environmental Protection, to Shawn Garvin, Regional Administrator, EPA Region III, July 26, 2011, 2, http://www.epa.gov/region03/marcellus_shale/pdf/letterpadep-to-epa7-26-11.pdf.

31733 U.S.C. $\$ 1313(\mathrm{c}) ; 40$ C.F.R. $\$ 131.5$. 
318 See "National Recommended Water Quality Criteria," U.S. EPA, last modified March 7, 2012, http://water.epa.gov/scitech/swguidance/standards/current/index.cfm.

319 See Jon M. Capacasa, Director, Water Protection Division, U.S. EPA Region III, to Kelly Jean Heffner, Acting Deputy Secretary for Water Management, PADEP, May 12, 2011, 1-2,

http://www.epa.gov/region3/marcellus shale/pdf/letter/heffner-letter5-12-11.pdf.

320 Bridget DiCosmo, "EPA Weighs Setting Possible First-Time Water Quality Criteria For Bromide," Inside EPA, January 4, 2012.

321 See "Proposed Rulemaking, Environmental Quality Board: Ambient Water Quality Criterion; Chloride (Ch)," Pennsylvania Bulletin 40, no. 18 (May 1, 2010): 2264, http://www.pabulletin.com/secure/data/vol40/40-

18/771.html.

32233 U.S.C. $\$ 1313(\mathrm{~d})$.

323 Friends of Pinto Creek v. EPA, 504 F.3d 1007 (9th Cir. 2007).

324 See 33 U.S.C. $\$ \$ 1311$ (b)(1)(C), 1342(a), 40 C.F.R. $\$ 122.4(d)$.

32540 C.F.R. $\$ 122.44(\mathrm{~d})(1)(\mathrm{i})$.

32633 U.S.C. $\$ 1313(d)(1)(C)$.

32740 C.F.R. $\$ 122.44(\mathrm{~d})(1)(\mathrm{vii})(\mathrm{B})$.

328 National Pollutant Discharge Elimination System, Surface Water Toxics Control Program, 54 Fed. Reg. 23,868, 23,879 (June 2, 1989) (interpreting the Clean Water Act as stating that a state's failure to complete TMDLs cannot be used as an excuse to defer the inclusion of water quality-based limitations in permits as required by CWA section $301(b)(1)(C))$.

329 Pennsylvania Department of Environmental Protection, "Pennsylvania Integrated Water Quality Report $2010, "$ http://www.portal.state.pa.us/portal/server.pt/community/water_quality_standards/10556/integrated_water_quality_r eport - 2010/682562.

33040 C.F.R. $\$ 131.12$. See also “Water Quality Handbook, Chapter 4: Antidegradation," U.S. EPA, last modified March 18, 2012, http://water.epa.gov/scitech/swguidance/standards/handbook/chapter04.cfm.

33142 U.S.C. \$ 6903(5) (defining hazardous waste as "[A] solid waste, or combination of solid wastes, which because of its quantity, concentration, or physical, chemical or infectious characteristic may- (A) cause, or significantly contribute to an increase in mortality or an increase in serious irreversible, or incapacitating reversible, illness; or (B) pose a substantial present or potential hazard to human health or the environment when improperly treated, stored, transported, or disposed of, or otherwise managed").

332 See Chapter 3 (describing the hazardous characteristics of Marcellus produced water).

333 For a detailed description of RCRA Subtitle C regulations, see U.S. EPA, RCRA Orientation Manual, October 2011, Section III, http://www.epa.gov/osw/inforesources/pubs/orientat/rom.pdf.

334 For a list of documented spills and releases, see Natural Resources Defense Council, "Petition for Rulemaking Pursuant to Section 6974(a) of the Resource Conservation and Recovery Act Concerning the Regulation of Wastes Associated with the Exploration, Development, or Production of Crude Oil or Natural Gas or Geothermal Energy," September 8, 2010, 28-30, http://docs.nrdc.org/energy/files/ene_10091301a.pdf.

33542 U.S.C. $\$ 6921(b)(2)$.

336 Natural Resources Defense Council, "Petition for Rulemaking Pursuant to Section 6974(a)" (see n. 38).

337 American Portland Cement Alliance v. EPA, 101 F.3d 772 (D.C. Cir. 1996).

338 Regulatory Determination for Oil and Gas and Geothermal Exploration, Development and Production Wastes, 53 Fed. Reg. 25,446, 25,447 (July 6, 1988).

33942 U.S.C. $\$ 6926$; see also U.S. EPA, RCRA Orientation Manual, Section III, Ch. 11 (see n. 37.).

34022 Cal. Admin. Code $\$ 66261.4($ b) (2).

341 EPA Region II, "EPA Comments on Revised Draft NYSDEC Revised dSGEIS for Horizontal Drilling and High-Volume Hydraulic Fracturing to Develop the Marcellus Shale and Other Low-Permeability Gas ReservoirsEnclosure," Jan. 11, 2012, 8, http://www.epa.gov/region2/newsevents/pdf/EPA\%20R2\%20Comments\%20Revised\%20dSGEIS\%20Enclosure.pdf 34240 C.F.R. $\$ 262.11$.

343 See Miranda Leitsinger, "Fracking Waste Led to Earthquakes, Ohio Says in Adding New Rules," MSNBC, March 9, 2012, http://usnews.msnbc.msn.com/_news/2012/03/09/10625517-fracking-waste-led-to-earthquakesohio-says-in-adding-new-rules.

344 Mike Soraghan, "Earthquakes: Drilling Waste Wells Exempt from Earthquake Testing Rules," EnergyWire, March 22, 2012. 
34540 C.F.R. $\$ 146.3$.

346 See 40 C.F.R. $\$ 146.5$.

34740 C.F.R. $\$ 146.62$; see also Soraghan, "Earthquakes."

34840 C.F.R. $\$ \$ 146.6,146.63$.

34940 C.F.R. $\S \S 146.22-.23,146.65-.69$.

35040 C.F.R. $\$ 146.72$.

35142 U.S.C. $\$ \$ 300 \mathrm{~h}-1,300 \mathrm{~h}-4$.

352 See U.S. EPA, Guidance for State Submissions Under Section 1425 of the Safe Drinking Water Act, 2,

http://www.epa.gov/ogwdw/uic/pdfs/guidance/guide_uic_guidance-19_primacy_app.pdf.

353 Mary Tiemann and Adam Vann, Hydraulic Fracturing and Safe Drinking Water Act Issues (Washington, DC:

Congressional Research Service, 2011), 27-30, http://www.arcticgas.gov/sites/default/files/documents/hydraulic-

fracturing-and-safe-drinking-water-act-issues.pdf.

35442 U.S.C. $\$ 300 \mathrm{~h}(\mathrm{~b})(1)$.

355 Tiemann and Vann, Hydraulic Fracturing, 11 (see n. 56).

356 Fracturing Regulations Are Effective in State Hands Act, S. 2248, 112th Cong. (2012),

http://www.eenews.net/assets/2012/03/29/document_daily_05.pdf; see also Hannah Northey, "GOP Bill Would

Cement State Oversight of Hydraulic Fracturing," Energywire, March 29, 2012.

357 Charles W. Abdalla et al., Penn State Extension, Marcellus Shale Wastewater Issues in Pennsylvania -- Current and Emerging Treatment and Disposal Technologies, April 2011,

http://www.ohioenvironmentallawblog.com/uploads/file/marcellus_wastewater_fact_sheet $\% 5 \mathrm{~B} 1 \% 5 \mathrm{D} \% 281 \% 29$.pdf

35842 U.S.C. $\$ 13101$.

35925 Pa. Code $\$ 95.10$.

36018 C.F.R. $\$ 806.4$.

361 EPA Region II, "EPA Comments on Revised Draft NYSDEC Revised dSGEIS," 1 (see n. 45).

362 For example, Pennsylvania regulations include both freeboard and groundwater monitoring requirements, although it was beyond the scope of this paper to evaluate the technical sufficiency of the state's particular regulatory standards. See $25 \mathrm{~Pa}$. Code $\$ \S 78.56-57,289.152$.

363 U.S. Department of Energy, State Oil and Natural Gas Regulations Designed to Protect Water Resources, May 2009, 38.

364 See U.S. Global Change Research Program, Global Climate Change Impacts in the United States (New York: Cambridge University Press, 2009), 41-44, http://downloads.globalchange.gov/usimpacts/pdfs/climate-impactsreport.pdf.

365 U.S. Department of Energy, State Oil and Natural Gas Regulations, 38-39.

366 General Assembly of Pennsylvania, House Bill No. 1950, Printer's No. 3048 (signed into law Feb. 14, 2012 as Act No. 13).

367 U.S. Department of Energy, State Oil and Natural Gas Regulations, 38 (see n. 65).

36842 U.S.C. $\$ 6924 ; 40$ C.F.R. Part 264, Subpart K.

369 E. Scott Bair and Robert K. Digel, "Subsurface Transport of Inorganic and Organic Solutes from Experimental Road Spreading of Oil-Field Brine," Ground Water Monitoring and Remediation 10, no. 3 (Summer 1990): 94-105, http://info.ngwa.org/gwol/pdf/901878009.PDF.

370 EPA Region II, "EPA Comments on Revised Draft NYSDEC Revised dSGEIS," 6 (see n. 45).

371 lbid.

372 K.P. Smith, D.L. Blunt, G.P. Williams, and C.L. Tebes, Argonne National Laboratory, Radiological Dose Assessment Related to Management of Naturally Occurring Radioactive Materials Generated by the Petroleum Industry, September 1996, http://www.ead.anl.gov/pub/doc/anlead2.pdf.

373 Harvard Law School Emmett Environmental Law \& Policy Clinic to Scott Walters, Pennsylvania Bureau of Waste Management, “Re: Proposed Modification of General Permit No. WGMR064,” Nov. 16, 2011, 2, http://www.law.harvard.edu/academics/clinical/elpc/publications/elpc-comments-on-wgmr064-final-no-appendices11.16.11.pdf.

374 See "Proposed National Rulemaking to Strengthen the Stormwater Program," U.S. EPA, last modified

December 27, 2011, http://cfpub.epa.gov/npdes/stormwater/rulemaking.cfm.

375 See generally U.S. EPA, Exemption of Oil and Gas Exploration, 5-6, 22-24.

376 “PA DEP Oil \& Gas Reporting Website,” Pennsylvania Department of Environmental Protection (see n. 17). 
377 Mark Drajem and Katarzyna Klimasinska, "Fracking Rules on U.S. Lands Seen by Interior as Model," Bloomberg, February 2, 2012, http://www.bloomberg.com/news/2012-02-02/fracking-rules-on-u-s-lands-seen-byinterior-as-state-model.html. 



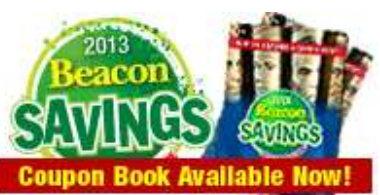

Coupon Book Avallable Nlow!
Thursday, January 24, 2013

Ohio.com > News $>$ Local News $>$

\section{Events Calendar

\begin{tabular}{|c|c|c|c|c|c|c|c|c|}
\hline \multicolumn{5}{|c|}{ January 2013 } & \multicolumn{2}{|c|}{ (2) } \\
\hline Su & Mo & Tu & We & Th & $F r$ & $S a$ \\
\hline 30 & 31 & 1 & 2 & 3 & 4 & 5 \\
\hline 6 & 7 & 8 & 9 & 10 & 11 & 12 \\
\hline 13 & 14 & 15 & 16 & 17 & 18 & 19 \\
\hline 20 & 21 & 22 & 23 & 24 & 25 & 26 \\
\hline 27 & 28 & 29 & 30 & 31 & 1 & 2 \\
\hline 3 & 4 & 5 & 6 & 7 & 8 & 9 \\
\hline
\end{tabular}

\section{EVENT SEARCH:} Go

$==>$ Submit an Event

\section{Most Read Stories}

\section{4 hrs 7 days}

Akron man charged in fatal shooting of son, 4

Akron attorney trying to stop demolition of vet's home

Postal service to hire hundreds of letter carriers in Ohio at \$15 an hour

Akron police say ringing cell phone burns pair planning to rob pizza delivery driver

Ohio man dies while diving in Florida Keys

Ohio judge to deadbeat dad: Have no more children

Marla Ridenour: Rob Chudzinski shows no fear in handing Browns' playcalling to Norv Turner

Diebold's Swidarski out as CEO as company stumbles over earnings

Buchtel middle school teacher faces potential firing for Facebook photo posting

Summa announces 54 layoffs

Read More >>

\section{MORE IN NEWS...}

Akron man charged in fatal shooting of son, 4 Thistledown Racino inches closer to opening

Marla Ridenour: Rob Chudzinski shows no

\section{Pennsylvania drilling wastes might overwhelm Ohio injection wells}

\section{By Bob Downing}

Beacon Journal staff writer

Published: January 22, 2013 - 10:30 PM | Updated: January 23, 2013 - 02:22 PM

The volume of drilling wastes from Pennsylvania's Marcellus shale is growing and threatening to overwhelm existing waste-handling infrastructure in Ohio and other states, according to a study released Tuesday.

Ohio's 179 injection wells for disposing of briny waste might not be sufficient for the Pennsylvania waste, plus wastes from Ohio's developing Utica shale, said Brian Lutz, assistant professor of biogeochemistry at Kent State University, who led the analysis while he was a postdoctoral research associate at Duke University.

The volume of Marcellus wastewater has grown 570 percent from 2004 to 2011 due to increased shale gas production in Pennsylvania, Lutz said.

"The overall volume of water that now has to be transported and treated is immense," he said. "It threatens to overwhelm the region's wastewater-disposal infrastructure capacity."

The wastes in play include flow-back water, produced immediately after hydraulic fracturing, or fracking, plus brine, or production water, generated after the fracking is done and the well goes into production. Such wastes generally are similar with a few key differences.

The liquid wastes can contain significant amounts of salts and total dissolved solids; low-level radiation and toxic heavy metals picked up from underground rocks; oils and grease; leftover toxic chemicals used in fracking; and certain volatile organic compounds, including benzene.

Pennsylvania has about 6,400 Marcellus shale wells that have been drilled and another 3,500 that have been permitted. In comparison, Ohio has about 500 wells permitted in the Utica shale, of which 200 have been drilled.

Lutz said Pennsylvania generated about 20 million barrels (each holding 42 gallons) of wastewater in 2011. About 7 million barrels were shipped to Ohio injection wells.

Ohio is projecting that its injection wells handled nearly 14 million barrels in 2012 up from 12.8 million barrels in 2011. (Final figures have not been compiled). More than half of that volume came from Pennsylvania and West Virginia.

Pennsylvania has five permitted and operating injection wells. Some of the state's wastewater is recycled; some goes to special plants for treatment.

Ohio cannot ban such wastes because they are interstate commerce protected under the U.S. Constitution. It is unknown exactly how much injection capacity the state can handle.

"This is the reality of increasing domestic natural gas production," said Martin Doyle, a professor of river science at Duke. "There are significant trade-offs and environmental impacts whether you rely on conventional gas or shale gas."

Lutz reported that Marcellus shale horizontal wells that have been fracked are producing less wastewater per unit of gas than conventional wells would produce.

Fracked natural gas wells in the Marcellus shale produce only about 35 percent
Search for: in All Go

Get Connected

Multimedia UPublish MyCommunities
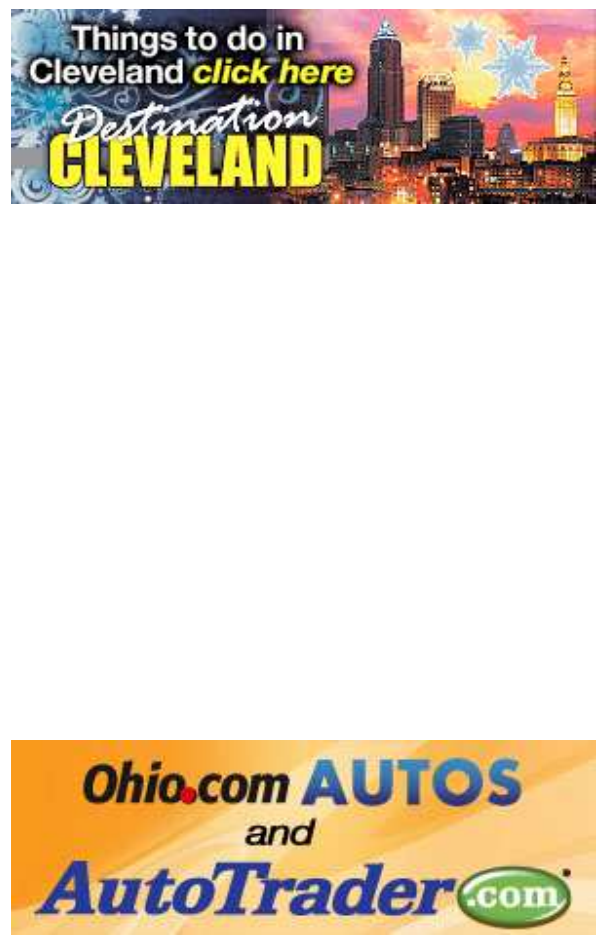
fear in handing Browns play-calling to Nory Turner

Ski patrol rewarding kids for doing the right thing

Cavaliers notebook: Tyler Zeller hoping to grow into starting role

Bob Dyer: Big KSU bust eventually shows its age

APS hosts update on

Litchfield-Firestone construction project

Akron attorney trying to stop demolition of vet's home

Judge weighs whether to keep Steubenville rape trial open

UA sculptors carve cool art at lce Fest

\section{Cleveland Browns}

Browns hire tight ends coach John Embree, outside linebackers coach Brian Baker - 12:00 PM

\section{Beer Blog}

Beer story sampler 10 -12:06 PM

\section{Cleveland Cavaliers}

Forbes: Cavs worth $\$ 434$ million $-8: 37 \mathrm{AM}$

\section{Heldenfiles}

Albee Lies in Tony Voting $-12: 20$ PM

\section{On Sports Media}

NBC made right call in moving Sunday Night Football 0

\section{Varsity Letters}

Grizzly Invitational Wrestling Tournament is Saturday - 1:06 PM

\section{University of Akron}

\section{Zips}

Zips basketball: The unspoken word is a possibility - 3:15 PM

\section{Ohio State Buckeye} Blogging

Buckeyes lose two players off football roster - 6:18 PM

\section{Tribe Matters}

Report: Travis Hafner, Jim

Thome, maybe Manny

Ramirez, among DH

possibilites with Indians

- 2:40 PM

\section{Pets}

Area pets news briefs

\section{Kent State Golden}

Flashes as much wastewater per unit of gas recovered as conventional wells, according to the analysis that appears in the journal Water Resources Research.

"We found that on average, shale gas wells produced about 10 times the amount of wastewater as conventional wells, but they also produced about 30 times more natural gas," said Lutz, who only recently came to Kent State. "That surprised us, given the popular perception that hydraulic fracturing creates disproportionate amounts of wastewater."

There have been proposals to ship the brine waste via barge down the Ohio and Mississippi rivers to injection wells on the Gulf Coast, he said.

The researchers at Kent State and Duke analyzed gas production and wastewater generation for 2,189 gas wells in Pennsylvania, using data reported by the industry to the state's Department of Environmental Protection.

Doyle said the researchers were surprised that drillers classified most of the wastewater as brine, not fracking flow-back water.

"A lot of attention, to date, has focused on chemicals in the flow-back that comes out of a well following hydraulic fracturing," he said. "However, the amount of brine produced - which contains high levels of salts and other natural pollutants from shale rock - has received less attention, even though it is no less important."

Studies have shown that brine can be as difficult to treat as many of the chemicals used in fracking fluids, he said.

What's needed are better ways to recycle and to treat wastewater, two options that are being developed, Doyle said.

Many of the challenges facing shale development also would occur if conventional vertical-only drilling were expanding, Lutz said.

"We have to accept the reality that any effort to substantially boost domestic energy production will present environmental costs," he said.

Bob Downing can be reached at 330-996-3745 or

bdowning@thebeaconjournal.com.

Click here to read or leave a comment on this story.

\section{Story tools}

Q

$$
\text { Email } 8 \text { Print Reprint host Fopular S Subscribe }
$$

Share this story

$$
\text { Tweet }\{30
$$

\section{Find us on Facebook}

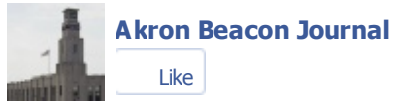

11,512 people like Akron Beacon Journal.

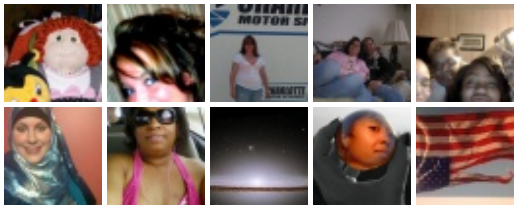

Facebook social plugin

Share this story on Facebook and Twitter 
Marla Ridenour on Sports

Cavs' Varejao hospitalized with blood clot, out for rest of season

\section{Sports Editor's Desk}

Morning express: Chris

Grant, Kyrie Irving star

moments

\section{Ohio politics}

Akron hosts Israeli official

\section{All Da King's Men}

Celebrating...What, Exactly?

\section{Mass Destruction}

The Entitled

\section{Akron Aeros}

Aeros fans treated to biggest scoreboard in Double-A by

Opening Day

Friends, food and fun in the kitchen

This does not make me feel safer

Ohio Utica Shale

Ohio hits 500 Utica shale permits with 212 wells drilled - 12:46 PM

\section{Sound Check}

Rock Hall announces tickets \& some

performers/presenters for

induction ceremony in April

\section{Close to Home}

Antibacterial products for flu prevention? Nope - 12:01 PM

\section{Government efficiency}

Check out Civic Commons

America Today - Civility

Series

Who passes the civility test?

\section{Inside Ohio.com}

LOCAL HISTORY

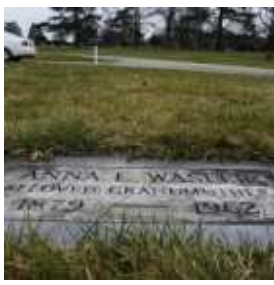

Akron woman's burial a grave concern in 1962

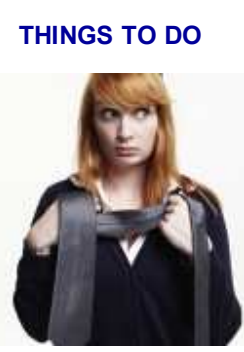

'SPANK!' is slap-happy humor

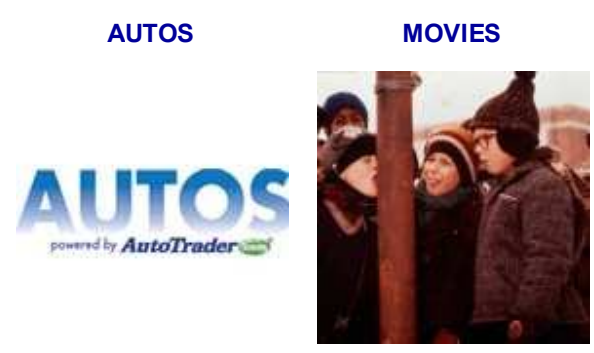

Find your car
Rich Heldenfels: Movie critics aren't always right
FOOD

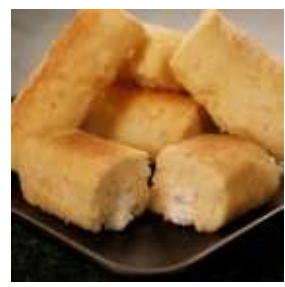

No need to miss the Twinkie - make your 


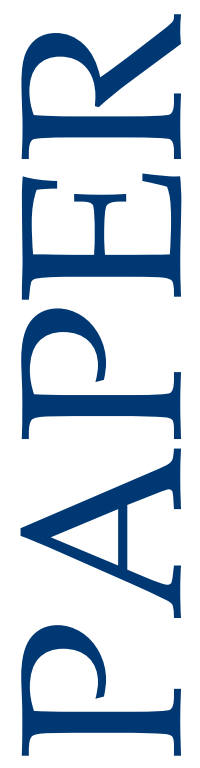

July 2012 RFF DP 12-40

\section{Shale Gas \\ Development and \\ Property Values}

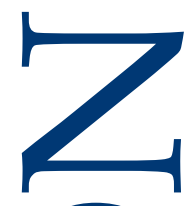

Differences across Drinking

Water Sources

Lucija Muehlenbachs, Elisheba Spiller, and Christopher Timmins

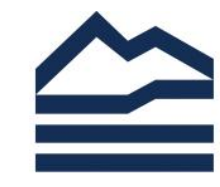

RESOURCES FOR THE FUTURE 


\title{
Shale Gas Development and Property Values: Differences across Drinking Water Sources
}

\author{
Lucija Muehlenbachs \\ Elisheba Spiller \\ Christopher Timmins*
}

\begin{abstract}
While shale gas development can result in rapid local economic development, negative externalities associated with the process may adversely affect the prices of nearby homes. We utilize a triple-difference estimator and exploit the public water service area boundary in Washington County, Pennsylvania to identify the housing capitalization of groundwater risk, differentiating it from other externalities, lease payments to homeowners, and local economic development. We find that proximity to wells increases housing values, though concern about the risk to groundwater fully offsets those gains. By itself, concern about groundwater contamination reduces property values by up to 24 percent.
\end{abstract}

JEL Classification Numbers: Q53

Keywords: shale gas, property values, hedonic models, groundwater

*Muehlenbachs: Resources for the Future, Washington, DC, muehlenbachs@rff.org. Spiller: Resources for the Future, Washington, DC, spiller@rff.org. Timmins: Department of Economics, Duke University, christopher.timmins@duke.edu. Acknowledgements: We thank Kelly Bishop, Jessica Chu, Carolyn Kousky, Alan Krupnick, Corey Lang, Joshua Linn, Lala Ma, Jan Mares, Ralph Mastromonaco, Stefan Staubli, Randy Walsh, and Jackie Willwerth. We thank the Bureau of Topographic and Geologic Survey in the PA Department of Conservation and Natural Resources for data on well completions. We gratefully acknowledge support from the Cynthia and George Mitchell Foundation. 


\section{Introduction}

A recent increase in the extraction of natural gas and oil using unconventional methods has transformed communities and landscapes. This paper focuses on shale gas extraction in Pennsylvania, which has grown rapidly in recent years thanks to recent developments in hydraulic fracturing and horizontal drilling. Natural gas provides an attractive source of energy. When burned, it emits fewer pollutants (e.g., carbon dioxide, sulfur dioxide, nitrogen oxides, carbon monoxide and particulate matter) than other fossil-fuel energy sources per unit of heat produced, and it comes from reliable domestic sources. The extraction of natural gas that had hitherto been economically unrecoverable has resulted in greatly expanded supply and in many landowners receiving high resource rents for the hydrocarbons beneath their land. There are, however, many potential risks that accompany the drilling and hydraulic fracturing process. The processes required to develop and produce natural gas from shale rock use a great deal of water and require the injection of chemicals into the ground at high pressure. Compared with conventional natural gas development, this may result in greater risk to air, water, and health. Important for housing markets and local tax revenues, the environmental impact of shale gas development and the perception of the risks associated with these processes, as well as increased truck traffic or the visual burden of a well pad, could depress property values.1

The risks associated with leasing one's land to gas exploration and production companies are especially important for homes that depend on groundwater as a source of drinking water. One risk associated with shale gas development is the potential for groundwater contamination caused by faulty well casings or cement [SEAB, 2011]. Another arises if hydraulic fracturing occurs too close to a drinking water aquifer [EPA, 2011] or if there are naturally occurring hydraulic pathways between the formation and the drinking water aquifer Warner et al. 2012. Osborn et al. 2011 find evidence of methane in drinking water wells near shale gas wells in Pennsylvania and New York, although they do not demonstrate

\footnotetext{
${ }^{1}$ The potential for reduction of property values is important given the current housing crisis, as, in severe cases, it could cause homeowners to fall "under water" in terms of mortgage repayment, potentially increasing the risk of loan default and foreclosure.
} 
causality. 2 Even if shale gas operations did not contaminate groundwater in the short run, the possibility of future groundwater contamination may be capitalized negatively into the property value, resulting in important long-term consequences for the homeowner.

However, there is also evidence that natural gas development creates jobs and generates income for local residents WWeber, 2011, Marchand, 2011. Upon signing their mineral rights to a gas company, landowners may receive two dollars to thousands of dollars per acre as an upfront "bonus" payment, and then a 12.5 percent to 21 percent royalty per unit of gas extracted $3^{3}$

Although it is likely that housing values will be affected by shale gas well proximity (both positively and negatively), there has been little research into how the presence of a natural gas well affects property values overall. 4 In this paper, we use a triple-difference, or difference-in-difference-in-differences (DDD) estimator, applied to houses that border the public water service area (PWSA), to measure the effect of groundwater water contamination concerns from shale gas development. Understanding both the positive and negative impacts of shale gas exploration can help the government make better decisions (such as implementing increased regulation to ensure groundwater integrity or extending the reach of the PWSA) that could protect homeowners from the negative effects of shale gas development while allowing for the benefits associated with increased local economic growth, lease payments, and a cleaner source of fossil-fuel energy. State regulators are currently debating such rules and regulations. In this paper we estimate the differential effect of shale gas development on properties that depend on groundwater and those that have access to piped water, giving us valuable insights into the capitalization of groundwater contamination risk. The key to estimating the concern for groundwater contamination is controlling for correlated unobservables that may bias estimates (e.g., unattractive attributes of properties and neighborhoods that may be correlated with exposure to drilling activity, and beneficial factors like lease payments and increased economic development). Even in the best data sets, these factors may be hard to measure, and can lead to

\footnotetext{
${ }^{2}$ Even if groundwater in Pennsylvania had been contaminated prior to drilling Swistock et al. 1993, our estimation strategy deals with this concern by using information on sales of the same property before and after drilling.

${ }^{3}$ Natural Gas Forum for Landowners: Natural Gas Lease Offer Tracker, Available on: http://www.naturalgasforums.com/natgasSubs/naturalGasLeaseOfferTracker.php.

${ }^{4}$ Two notable exceptions are Boxall et al. 2005, Klaiber and Gopalakrishnan 2012.
} 
omitted variables bias. We take several steps to overcome that bias. The intuition proceeds as follows. First, we use property fixed effects, comparing changes in the price of a particular property over time, controlling non-parametrically for anything about that property that remains the same. Next, we see how those price changes differ depending upon whether the property is located in a treatment or control area, defined according to well proximity. Finally, we observe how the differences in the change in price across proximity-based treatment and control groups differ depending upon water source (i.e., groundwater versus piped water). In addition to controlling for any time-invariant unobserved heterogeneity at the level of the property, our approach will therefore also control for two sources of potential time-varying unobservable heterogeneity-(i) anything common to our proximity-based treatment and control groups (e.g., lease payments); and (ii) anything within one of those groups that is common to both groundwater and PWSA households (e.g., increased local economic activity). Furthermore, we also geographically restrict some of the specifications in our analysis to the smallest available neighborhood that will allow us to observe differences in water source: a 1000 meter buffer drawn on both sides of the PWSA boundary. This reduces the burden on our differencing strategy to control for time varying unobservables, as homes located within a few blocks of each other presumably are affected similarly by these time varying unobservables. Using this identification strategy along with data on property sales in Washington County, Pennsylvania, from 2004 to 2009, we find that houses are positively affected by the drilling of a shale gas well unless the property depends on groundwater, in which case properties are negatively affected.

\section{Application of the Hedonic Model for Non- Market Valuation}

In the hedonic model (formalized by Rosen [1974|), the price of a differentiated product is a function of its attributes. In a market that offers a choice from amongst a continuous array of attributes, the marginal rate of substitution between the attribute level and the numeraire good (i.e., the willingness to pay for that attribute) is equal to the attribute's implicit (hedonic) price. The slope of the hedonic price function with respect to the attribute at the level of the at- 
tribute chosen by the individual is therefore equal to the individual's marginal willingness-to-pay for the attribute; thus, the hedonic price function is the envelope of the bid functions of all individuals in the market. This implies that we can estimate the average willingness-to-pay for an attribute (i.e., exposure to groundwater risk from hydraulic fracturing) by looking at how the price of the product (i.e., housing) varies with that attribute.

A vast body of research has examined the housing price effects of locally undesirable land uses, such as hog operations Palmquist et al., 1997, underground storage tanks Guignet, 2012, and power plants [Davis, 2011] to name a few. These estimates are then used to measure the disamenity value of the land use (or willingness-to-pay to avoid it). This paper similarly uses hedonic methods to model the effect of proximity to a shale gas well on property values $5^{5}$ In particular, we use variation in the market price of housing with respect to changes in the proximity of shale gas operations to measure the implicit value of a shale well to nearby home owners, depending upon water source. As such, it should be able to pick-up the direct effect of environmental risks - in particular, risk of water contamination and consequences of spills and other accidents - while differentiating those risks from other negative externalities (e.g., noise, lights, and increased truck traffic) and the beneficial effects of increased economic activity and lease payments. The latter is analogous to the effect of a wind turbine Heintzelman and Tuttle, 2012, where the undesirable land use is also accompanied by a payment to the property on which it is located. In this paper, we focus on the hedonic impact of groundwater contamination risk on housing values, as it is generally considered to be one of the most significant risks from shale gas development ${ }^{6}$

The academic literature describing the costs of proximity to oil and gas drilling operations is small. See, for example, Boxall et al. [2005], which examines the property value impacts of exposure to sour gas wells and flaring oil batteries in Central Alberta, Canada. The authors find significant evidence of substantial (i.e., 3-4 percent) reductions in housing price associated with proximity to a well.

\footnotetext{
${ }^{5}$ Assuming that the housing supply is fixed in the short-run, any addition of a shale gas well is assumed to be completely capitalized into price and not in the quantity of housing supplied. Given that the advent of shale gas drilling is relatively recent, we would expect to still be in the "short-run". As more time passes, researchers will be able to study whether shale gas development has had a discernable impact on new development.

${ }^{6}$ Krupnick et al, "What the Experts Say About Shale Gas: There's More Consensus Than You Think," RFF Discussion Paper, Forthcoming
} 
Klaiber and Gopalakrishnan 2012 also examine the effect of shale gas wells in Washington County, using data from 2008 to 2010. They examine the temporal dimension of capitalization due to exposure to wells, focusing on sales during a short window (e.g., 6 months) after well permitting and using school district fixed effects to control for unobserved heterogeneity. Like Boxall et al. [2005, Klaiber and Gopalakrishnan 2012 also find that wells have a small negative impact on housing values. We find evidence of much larger effects on housing values - a difference we ascribe to the rich set of controls for unobservables (both timeinvariant and time-varying) used in our DDD identification strategy described above.

Because the hedonic price function is the envelope of individual bid functions, it will depend upon the distributions of characteristics of both home buyers and the housing stock. This means that if few of the neighborhoods in our sample are affected by increased traffic and noise, then there will be a lower premium placed on quiet neighborhood location. However, if shale development is widespread and results in most neighborhoods being affected by heavy truck traffic, then the houses located in the relatively few quiet neighborhoods would receive a high premium. In the case of a widespread change in the distribution of a particular attribute in the housing stock, it is possible that the entire hedonic price function might change, so that even the price of properties far from shale wells will be affected. Furthermore, the hedonic price function is dependent on the distribution of tastes. If the mix of homebuyer attributes changes dramatically over time, that could also lead to a shift in the hedonic price function. Bartik 1988 shows that, if there is a discrete, non-marginal, change that affects a large area, the hedonic price function may shift, which can hinder one's ability to interpret hedonic estimates as measures of willingness to pay. Rather, the estimates may simply describe capitalization effects Kuminoff and Pope, 2012. This would be a conservative interpretation of our results. Whereas a willingness to pay interpretation is useful for the cost-benefit analysis of alternative regulations and standards that might be imposed on drillers, a focus on the capitalization effect is relevant for policy if we are interested in whether shale gas wells increase the risk of mortgage default. It is also important for local fiscal policy, as drilling may have important implications for property tax revenues. 


\section{Background on Risks Associated with Shale Gas}

Shale gas extraction has become viable because of advances in hydraulic fracturing and horizontal drilling. Hydraulic fracturing is a process in which large quantities of fracturing fluids (water, combined with chemical additives including friction reducers, surfactants, gelling agents, scale inhibitors, anti-bacterial agents, and clay stabilizers and proppants) are injected at high pressure so as to fracture and prop open the shale rock, allowing for the flow of natural gas contained therein. The multiple risks associated with fracking (including the contamination of groundwater) may have an impact on property values and are, hence, relevant for mortgage lenders.7 Knowing the perceived costs associated with these risks can also be of use to regulators considering different standards for drilling operations.

First, development can cause contamination of local water supply resulting from improper storage, treatment, and disposal of wastewater. Hydraulic fracturing also generates "flowback fluid" and produced water, the hydraulic fracturing fluids and formation water that return to the surface, often containing salts, metals, radionuclides, oil, grease, and VOC's. These fluids might be recycled for repeated use at considerable cost, treated at public or private waste water treatment facilities, or injected in deep underground injection wells. Mismanagement of flowback fluid can result in contamination of nearby ground and surface water supplies. Second, air pollution is a concern - escaped gases can include NOx and VOC's (which combine to produce ozone), other hazardous air pollutants (HAP's), methane and other greenhouse gases. Third, spills and other accidents can occur - unexpected pockets of high pressure gas can lead to blowouts that are accompanied by large releases of gas or polluted water, and improper wellcasings can allow contaminants to leak into nearby groundwater sources. Fourth, there may also be a risk of contamination from drill cuttings and mud. These substances are used to lubricate drill bits and to carry cuttings to the surface and often contain diesel, mineral oils or other synthetic alternatives, heavy metals (e.g., barium) and acids. These materials can leach into nearby groundwater

\footnotetext{
${ }^{7}$ For a risk matrix for shale gas development see: http://www.rff.org/centers/energy_economics_and_policy/Pages/Shale-Matricies.aspx.
} 
sources. Other negative externalities include deterioration of roads due to heavy truck traffic, minor earthquakes, and clearing of land to drill wells, which can also affect housing prices by reducing the aesthetic appeal of the region in general.

\section{Method}

Implementation of the hedonic method is complicated by the presence of house and neighborhood attributes that are unobserved by the researcher but correlated with the attribute of interest. The specifications we use in order to demonstrate and address this problem include a simple cross-section, a property fixed effects regression, and a triple-difference (DDD) estimator that uses detailed geographical information about well proximity and the placement of the piped water network to define several overlapping treatment and control groups. We briefly review the econometric theory behind each of these approaches below.

\subsection{Cross-Sectional Estimates}

The most naïve specification ignores any panel variation in the data and simply estimates the effect of exposure to a shale gas well by comparing the prices of houses in the vicinity of a well to those houses that are not exposed to a well. Considering the set of all houses in the study area, we run the following regression specification:

$$
P_{i}=\beta_{0}+\beta_{1} W E L L D I S T_{i}+X_{i}^{\prime} \delta+Y E A R_{i}^{\prime} \gamma+\varepsilon_{i}
$$

where

$P_{i} \quad$ natural $\log$ of transaction price of house $i$

$W E L L D I S T_{i}$ distance to nearest shale gas well at the time of transaction

$X_{i} \quad$ vector of attributes of house $i$

$Y E A R_{i} \quad$ vector of dummy variables indicating year house $i$ is sold

In this specification, the effect of exposure to a well is measured by $\beta_{1}$.

The problem here is that $W E L L D I S T_{i}$ is likely to be correlated with $\varepsilon_{i}$ (i.e., houses and neighborhoods that are near wells are likely to be different from those 
that are not near wells in unobservable ways that may also affect housing prices). For example, houses located in close proximity to wells may be of lower or better quality than those located elsewhere in the county. One way to check for this possibility is by comparing observable attributes of houses and neighborhoods, both located near and far from shale gas wells. Significant differences in observable attributes suggests a potential for differences in unobservables, which could lead to bias in the estimation of Equation (1) (see Table 5 in the Appendix). Therefore, it is important to control for these unobserved location attributes that lead to the location decisions by gas exploration and production companies.

Utilizing pooled ordinary least squares (OLS) can also be problematic since the error terms associated with homes sold multiple times will likely be correlated, given that unobserved attributes of the home may not change much over time. This creates correlation between the error terms, which violates the independent, identically distributionassumption necessary for consistent estimation of the parameters. Using property fixed effects allows us to control for these correlated unobservables by specifically accounting for the correlation within homes sold more than once.

\subsection{Property Fixed Effects}

Properties that are near shale wells might differ systematically in unobservable ways from those that are not near wells. If properties farther from wells are associated with more desirable unobserved characteristics, then this would create an elevated baseline to which the houses near wells would be compared, inflating the estimated negative effect of proximity to a well. Utilizing property-level fixed effects allows us to difference away the unobservable attributes associated with a particular house, or with the house's location.

In our second specification, we exploit the variation in panel data to control for time-invariant property attributes with property-level fixed effects. Suppose $P_{i t}$ measures the natural $\log$ of the price of house $i$ which transacts in year $t$. $X_{i}$ is a vector of attributes of that house ${ }^{8}$ and $W E L L D I S T_{i t}$ is the distance of house $i$ to the nearest well at the time of the transaction. $\mu_{i}$ is a time-invariant attribute associated with the property that may or may not be observable by the

\footnotetext{
${ }^{8}$ The house attributes do not change over time in our dataset, because the attributes of the house in the final transaction are the only attributes that are recorded in the data.
} 
researcher, and $\nu_{i t}$ is a time-varying unobservable attribute associated with the property. Importantly, $\mu_{i}$ may be correlated with $W E L L D I S T_{i t}$ in the following equation:

$$
P_{i, t}=\beta_{0}+\beta_{1} W E L L D I S T_{i t}+X_{i}^{\prime} \delta+\mu_{i}+\nu_{i t}
$$

We employ a fixed effects technique in order to remove $\mu_{i}$ from Equation 2

$$
\tilde{P}_{i t}=\beta_{1} W E \widetilde{E L D} I S T_{i t}+\tilde{X}_{i}^{\prime} \delta+\tilde{\nu}_{i t}
$$

where $\tilde{P}_{i t}, W E \widetilde{L L D} I S T_{i t}, \tilde{X}_{i}$, and $\tilde{\nu}_{i t}$ are mean differenced variables. Estimating this specification controls for any permanent unobservable differences between houses that have the shale well treatment and those that do not.

\subsection{Difference-in-Difference-in-Differences (DDD)}

While property-level fixed effects account for time-invariant unobserved house and location attributes, they are not able to control for time-varying sources of unobservable heterogeneity. This is a concern, as shale gas well extraction could be associated with a boom to the local economy and with valuable payments for mineral rights at the house level, both of which can be hard to quantify, yet may be correlated with well proximity. As Table 1 demonstrates, average distance to the nearest well decreases over time as more wells are drilled. In fact, the average distance to a well decreased by almost 50 percent over the time period. If the economic boom associated with increased in-migration and employment due to drilling activity increases housing values over time, then this increased capitalization will appear to be caused by closer proximity to shale gas wells. If we do not take this underlying trend into account, then we will underestimate the negative impact of the well. Failure to account for payments for mineral rights can have a similar effect. This warrants going beyond a simple fixed effects specification and conducting a quasi-experimental procedure that removes the underlying time trends and better estimates the impact of proximity to shale gas wells on housing values. We employ a linear DDD technique, which is described in more detail below. There, we define a pair of overlapping treatment and control group of houses by exploiting a house's proximity to wells and whether or not it is part of the public water service area (PWSA). 
Table 1: Shale Gas Activity Over Time in Washington County, PA

\begin{tabular}{ccccc}
\hline \hline Year & No. Wells & No. Permitted & Dist. To Nearest Well $(\mathrm{m})$ & Dist. to Nearest Permit $(\mathrm{m})$ \\
\hline 2005 & 5 & 9 & $11,952.9$ & $11,952.9$ \\
2006 & 25 & 32 & $11,879.4$ & $11,883.6$ \\
2007 & 80 & 116 & $9,370.8$ & $7,806.5$ \\
2008 & 188 & 221 & $7,336.6$ & $7,329.3$ \\
2009 & 188 & 268 & $6,326.3$ & $6,323.6$ \\
\hline \hline
\end{tabular}

Notes: Counts are of wellpads (there may be multiple wellbores on each wellpad).

\subsubsection{Treatment Group Well Proximity}

In order to identify the houses "treated" by exposure to groundwater contamination risk, we first exploit the fact that the effects of a well are localized, in that many of the disamenities associated with development (such as noise and truck traffic along with groundwater contamination) will not affect houses that are further from a well. At some distance far enough away from the well site, drilling may not influence property prices at all. This appears to be the case based on work by Boxall et al. 2005] on sour gas wells in Alberta, Canada. In order to identify the correct treatment distance from a well, we conduct an econometric test to see at which point the well no longer impacts housing values. The test we employ follows the strategy of Linden and Rockoff [2008]. This method compares properties sold after a well has been drilled (within certain distances) to properties sold prior to a well being drilled (within the same distance), and identifies at which distance wells stop impacting housing values. We then define our first treatment group as houses having a well within this distance. 


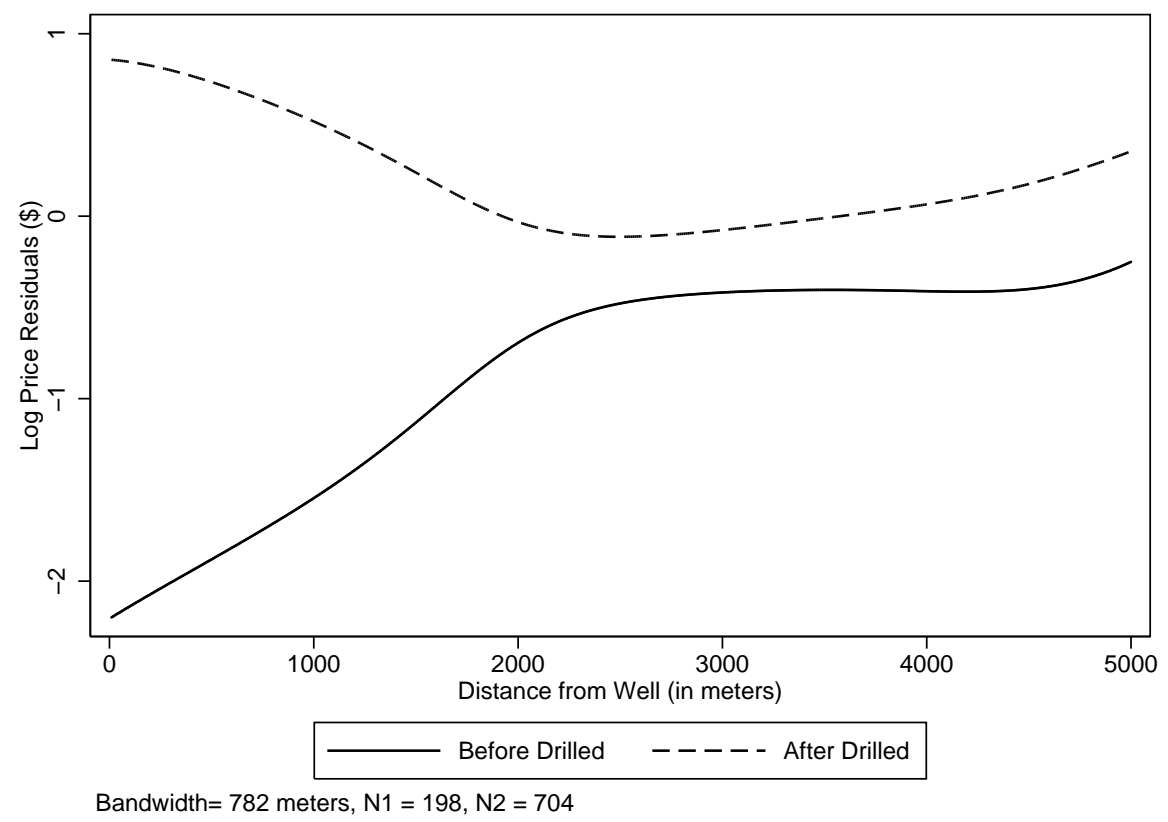

Figure 1: Sales Price Gradient of From Local Polynomial Regressions on Distance from Current/Future Well

In order to conduct the Linden and Rockoff 2008 test, we create a subsample of properties that have, at some point in time (either before the house is sold or after), only one well pad located within 5000 meters. We begin by estimating two price gradients based on distance to a well: one for property sales that occurred prior to a well being drilled and one for property sales after drilling began. The distance at which the difference in these two price gradients becomes insignificant is the distance at which we can define the first treatment group. Figure 1 shows these price gradients estimated by local polynomial regressions. For properties that are located more than 2000 meters from a well, the gradients are similar both before and after the well is drilled. However properties located closer than 2000 meters to a well are sold for more on average after the well is drilled than before the well is drilled, which would correspond to properties receiving, or expecting to receive, lease payments 9 The solid line in the graph demonstrates that properties sold prior to a well being drilled within 2000 meters receive lower

\footnotetext{
${ }^{9} \mathrm{~A}$ horizontal well might extend over a mile (1609 meters) and therefore it is possible for a property within 2000 meters of a well to be receiving payments.
} 
sale prices the closer they are to a well, implying that wells are being located in less desirable areas.10 Thus, we use a distance of 2000 meters from a well to measure the treatment, where any property located farther than 2000 meters is assumed to not be affected by well drilling. Importantly, we expect the effects of a boom to the local economy to be similar across that 2000 meter threshold. This defines our first treatment-control group: treated homes are those located within 2000 meters distance of a shale gas well, and the control homes are those located outside this 2000 meters band. This allows us to control for the unobserved time varying factors that are correlated with shale gas development by looking at homes sold inside and outside of a 2000 meter boundary of shale gas wells, as both these groups will likely be affected in similar ways by a regional economic boom. Finally, given evidence that wells are located in less desirable areas, we control for these unobserved area attributes with property fixed effects.

\subsubsection{Private Water Wells vs. Piped Water}

Much of the concern surrounding shale gas development arises from the risk of groundwater contamination. Houses that utilize water wells may be affected if the surface casing of a gas well cracks and methane or other contaminants migrate into the groundwater Osborn et al. 2011] or if fractures connecting the shale formation reach the aquifer [?]. Houses that receive drinking water from water service utilities, on the other hand, do not face this risk. ${ }^{11}$ We hypothesize that this risk may be capitalized into the value of the home; in particular, households using water wells may be more adversely affected by proximity to shale gas wells relative to households relying on piped water, and therefore would face a lower transaction value when "treated" by proximity to a well. In order to capture this difference across houses, we define an additional treatment group by designating houses depending upon whether they rely on groundwater or piped water. Specifically, we use GIS data on the location of the PWSA and map the houses

\footnotetext{
${ }^{10}$ Creating this figure after excluding properties that have permitted, but not drilled, wells nearby excludes only 11 observations and results in a figure similar to Figure 1 . This provides further evidence that the upward sloping portion of the "before drilled" line reflects negative unobservables correlated with proximity rather than expectations of future drilling.

${ }^{11}$ While hydraulic fracturing may cause contamination of the publicly available water supply, the city is tasked with providing clean water to its constituents, so the risk of receiving contaminated water through piped water lines is much lower than an unregulated well managed by a homeowner.
} 
into their respective groups. This allows us to interact distance with a groundwater indicator in our estimation in order to find the different impact of proximity to wells for groundwater versus piped water homes. Any differences between groundwater and piped water dependent houses that were present before the well is put in place are accounted for at a very detailed level by property fixed effects. While houses within 2000 meters of a shale gas well are equally likely to receive benefits from lease payments regardless of water source, those houses dependent upon groundwater are more likely to capitalize the negative consequences of increased contamination risk. This defines our second treatment-control group: by looking at the difference across groundwater dependence (and within $2000 \mathrm{~m}$ of a shale gas well), we are essentially controlling for the unobserved lease payments that are common to both these groups, while allowing the first treatment effect (proximity to shale gas wells) to vary by drinking water source.

As a preliminary examination of whether and how groundwater and PWSA homes differ in their impact from shale gas well proximity, we conduct a generalized propensity score (GPS) model, as detailed in Hirano and Imbens 2004. GPS allows the treatment of proximity to vary continuously, while regular matching models assume a binary treatment. For this test, we thus define the treatment as the distance to the nearest well, and estimate the impact on housing values as this distance is varied. We include as controls housing characteristics and census tract attributes ${ }^{12}$ Figure 2 demonstrates the impact of proximity to shale gas wells for the entire sample (including cities), and it appears that the treatment effect of proximity varies substantially with water service. For houses in a PWSA, being close to a well actually increases housing values. This implies that the local economic development and lease payments associated with shale development can boost the housing market substantially, but only if the house is protected in some way from the environmental impacts. However, for houses without piped water, being closer to a shale gas well decreases housing values. Thus, we find strong evidence of a contrasting impact across different water service areas. Figure 2 also shows that the impact of proximity to shale wells tapers off after approximately $6 \mathrm{~km}$, providing evidence that the impact of shale development are localized.

\footnotetext{
${ }^{12}$ Ideally, we would run the estimation on each year separately in order to eliminate the time-varying issues that can bias the outcome from the fixed effects model. Unfortunately, our sample size is not large enough to run it with each year separately, so we have to estimate the dose response aggregated from 2006-2009. However, to control for the unobserved attributes correlated with years, we include year dummies.
} 

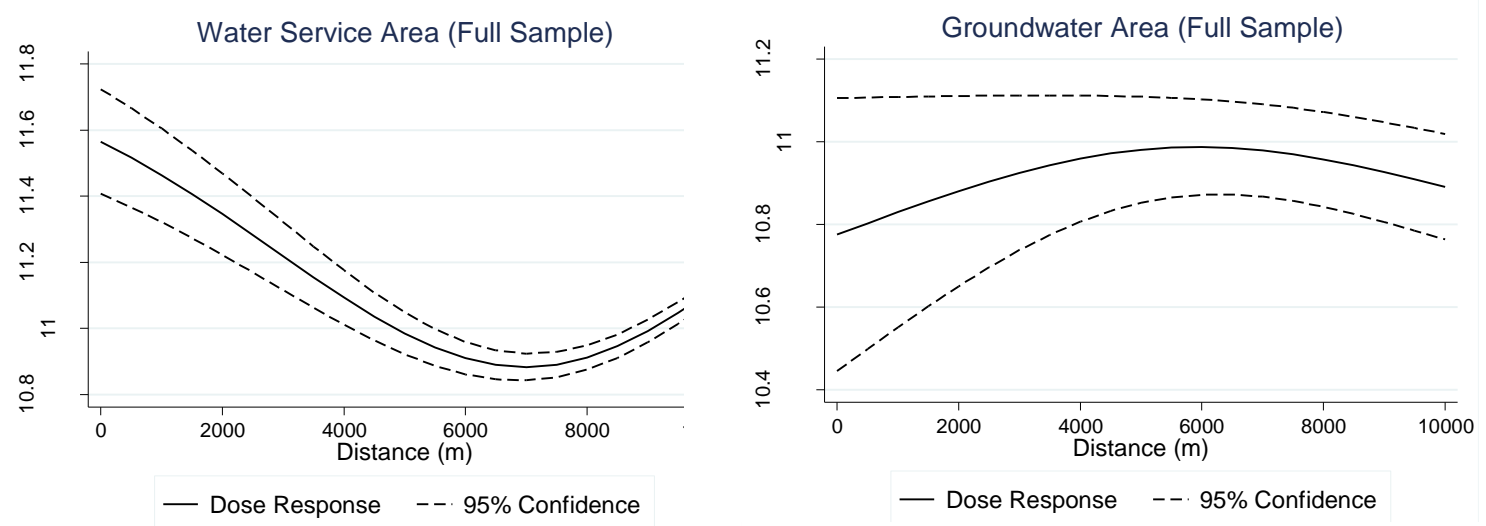

Figure 2: Impact on Housing Values from Proximity to the Nearest Shale Gas Well

\section{Data}

Our main dataset is used under an agreement between the Duke University Department of Economics and Dataquick Information Services, a national real estate data company. These property data include information on all properties sold in Washington County, Pennsylvania from 2004 to 2009. The buyers' and sellers' names are provided, along with the transaction price, exact street address, square footage, year built, lot size, number of rooms, number of bathrooms, number of units in building, and many other characteristics. We begin with 41,266 observations in Washington County, PA, and remove observations that do not list a transaction price, have a zero transaction price ${ }^{13}$ do not have a latitude/longitude coordinate, were sold prior to a "major improvement", 14 are described as only a land sale (a transaction without a house), or claim to be a zero square footage house. The final cleaned dataset has 19,055 observations. Summary statistics comparing the full sample and final sample show that they are similar in all respects except the transaction price (Table 2) - that difference being attributable

\footnotetext{
${ }^{13}$ Most observations are removed after deleting transactions with a price of zero $(12,327$ observations).

${ }^{14}$ We delete sales prior to major improvements because Dataquick data only report housing characteristics at the time of the last recorded sale. If the property was altered between the last sale and earlier sales, we would have no record of how it had changed. Nonetheless this only removes 4 observations.
} 
to dropping observations with a zero price.

Table 2: Summary Statistics

\begin{tabular}{lllll}
\hline & \multicolumn{3}{c}{ Final Sample } & \multicolumn{2}{c}{ Full Sample } \\
& Mean & Std. Dev. & Mean & Std. Dev. \\
\hline Property Characteristics: & & & & \\
Transaction Price (Dollars) & 127,233 & 135,002 & 103,462 & 181,573 \\
Ground Water & 0.09 & 0.286 & 0.1 & 0.3 \\
Age & 54.6 & 39.7 & 52.6 & 40 \\
Total Living Area (1000 sqft) & 1.8 & 0.877 & 1.79 & 0.88 \\
No. Bathrooms & 1.69 & 1.01 & 1.66 & 1.02 \\
No. Bedrooms & 2.73 & 1.12 & 2.65 & 1.15 \\
Sold in Year Built & 0.118 & 0.322 & 0.0954 & 0.294 \\
Lot Size (100,000 sqft) & 0.244 & 0.766 & 0.262 & 1.3 \\
Distance to Nearest MSA (km) & 35.8 & 7.04 & 35.8 & 7.1 \\
Census Tract Characteristics: & & & & \\
Mean Income & 65,655 & 23,778 & 66,132 & 23,474 \\
\% Under 19 Years Old & 23.9 & 4.19 & 23.8 & 4.14 \\
\% Black & 3.78 & 5.87 & 3.61 & 5.74 \\
\% Hispanic & 0.426 & 0.72 & 0.428 & 0.713 \\
\% Age 25 w/High School & 39.2 & 10.5 & 39.2 & 10.4 \\
\% Age 25 w Bachelors & 16.7 & 7.51 & 16.9 & 7.51 \\
\% Same House 1 Year & 88.6 & 6.75 & 88.8 & 6.64 \\
\% Unemployed & 6.19 & 2.84 & 6.11 & 2.82 \\
\% Poverty & 7.63 & 6.93 & 7.38 & 6.86 \\
\% Public Assistance & 2.21 & 2.13 & 2.11 & 2.1 \\
\% Over 65 Years Old & 17.7 & 4.92 & 17.8 & 4.89 \\
\% Female Household Head & 10 & 5.6 & 9.85 & 5.54 \\
Shale Well Proximity: & & & & \\
Distance to Closest Well (m) & 10,109 & 4,307 & & \\
Distance to Closest Permit (not Drilled) (m) & 10,239 & 4,675 & & \\
Number of Wellpads Drilled within 2km & .0306 & .489 & & 26.236 \\
\hline Observations & 19,055 & & \\
\hline
\end{tabular}

Notes: Transactions in Washington County, 2004-2009, of houses in sub-sample used, and all transactions. The number of observations varies depending

In order to control for neighborhood amenities, we match each house's location with census tract information, including demographics and other characteristics. The census tract data come from the American Community Survey, which provides a tract-level moving average of observations recorded between the years 2005 and 2009.

We also match geocoded housing transactions data to our second main data source - the location of wells in Washington County. We obtained data describing the permitted wells located on the Marcellus shale from the Pennsylvania Department of Environmental Protection. To determine whether the permit has been drilled, we rely on two different datasets. A well is classified as drilled if there was a "spud" date (i.e., date that drilling commenced) listed in the Pennsylvania Department of Environmental Protection Spud Data or if there was a completion date listed in the Department of Conservation and Natural Resources Well 


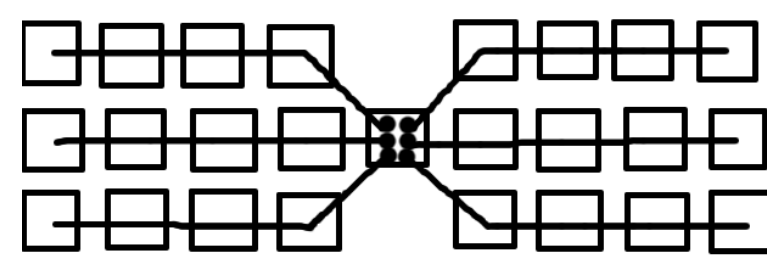

Figure 3: Well Pad with Multiple Wells

Information System (The Pennsylvania Internet Record Imaging System/Wells Information System [PA*IRIS/WIS]). As there were many wells listed in one but not both datasets, combining the two datasets provides us with a more complete picture of drilling activity in this part of Pennsylvania. The final dataset includes both vertical and horizontal wells, both of which produce similar disamenities, including risks of groundwater contamination 15

Many of these wells are in very close proximity to one another, yet the data do not identify whether these wells are on the same well pad. Well pads are areas where multiple wells are placed close to each other, allowing the gas companies to expand greatly the area of coverage while minimizing surface disturbance. As current shale gas extraction in Pennsylvania typically involves horizontal drilling, a well pad can include many wells in close proximity while maximizing access to shale gas below the surface. Figure 3 demonstrates how six horizontal wells can be placed on a small well pad, minimizing the footprint relative to vertical drilling (which would require 24 wells evenly spaced apart, as indicated by the squares in the figure).

Without identifying well pads, we might overstate the extent of drilling activity confronting a property. For example, a house near the well pad in Figure 2 would be identified as being treated by six wells, though presumably after the first well has been drilled, the additional impact from each additional wellbore would be less than the first. Thus, we create well pads using the distance between the wells, and treat each well pad as a single entity. In order to create well pads, we choose all wellbores that are within one acre (a 63 meter distance) of another

\footnotetext{
${ }^{15}$ Risk of improper well casing or cementing would be present in both vertical and horizontal wells.
} 
wellbore and assign them to the same well pad 16 our data, of the wellbores that are within one acre of another wellbore, 50 percent are within 11 meters and 75 percent are within 20 meters. Any wellbore within one acre is considered to be on the same well pad, so if more than two wellbores are included, our constructed well pads can cover an area larger than one acre. The average number of wellbores per well pad is 3.7 ( $\max$ of 12 ), where 25 percent of the well pads in our data have only 1 well.

We begin by matching house transactions to all wells located within $20 \mathrm{~km}$ of the house, including permitted but not drilled wells, drilled wells, and prepermitted wells (i.e., wells that are permitted and drilled after the time of the housing transaction). Once these wells are matched, we create variables that measure each house's Euclidean distance to the closest well pad that is either permitted or drilled at the time of the transaction, and variables describing the well count within 2000 meters. These are our main variables of interest, as they identify our "treatment": how proximity to wells affects housing values. We also calculate the inverse of the distance to the nearest well and use this variable as the treatment in the cross sectional and fixed effects specifications, allowing for an easier interpretation of the results - an increase in inverse distance implies a closer distance to a well, so a positive coefficient would imply a positive valuation of proximity. Furthermore, utilizing inverse distance places more emphasis on homes that are closer to wells; this is a reasonable functional form (relative to a linearly decreasing function), given that the marginal disutility of disamenities associated with drilling likely declines as one moves further from a well (i.e., visual aesthetic issues may not be present at 3-4 miles distance, though truck traffic may still affect those farther away).

In order to capture the water contamination risks that home owners may face from shale gas extraction, we utilize data on public water service areas in Washington County and identify houses that do not have access to public piped drinking water. We obtained the GIS boundaries of the public water supplier's service area from the Pennsylvania Department of Environmental Protection. Houses located outside of a PWSA most likely utilize private water wells, since the county does not provide much financial assistance to individuals who wish to

\footnotetext{
${ }^{16}$ During completion, a multi-well pad, access road, and infrastructure are estimated to encompass 7.4 acres in size, after completion and partial reclamation, a multi-well pad averages 4.5 acres in size [New York State Department of Environmental Conservation, 2011].
} 
extend the piped water area to their location ${ }^{17}$ This allows us to separate the analysis by water service area into PWSA and "groundwater" areas, and we use this distinction to identify the water contamination risk that may be capitalized into the transaction value. Figure 4 shows the map of Washington County, Pennsylvania, describing the locations of the permitted and drilled (spudded) wells, property transactions, and the water service area. This map describes all wells and transactions in the sample, so some of the wells shown there were not present at the time of a nearby transaction. The large clustering of transactions in the center part of the county corresponds to the two cities in the county: Washington and Canonsburg. These cities fall along the major highway that cuts through the county (I-79, which connects with I-70 in Washington City). We hypothesize that houses within these major cities may face significant changes due to the economic boom associated with shale gas development. Thus, we exclude these cities in certain specifications in order to help isolate the disamenity value associated with proximity to a well from the property value benefits associated with the economic boom.

\footnotetext{
${ }^{17}$ Personal communication with the Development Manager at the Washington County Planning Commission, April 24, 2012.
} 


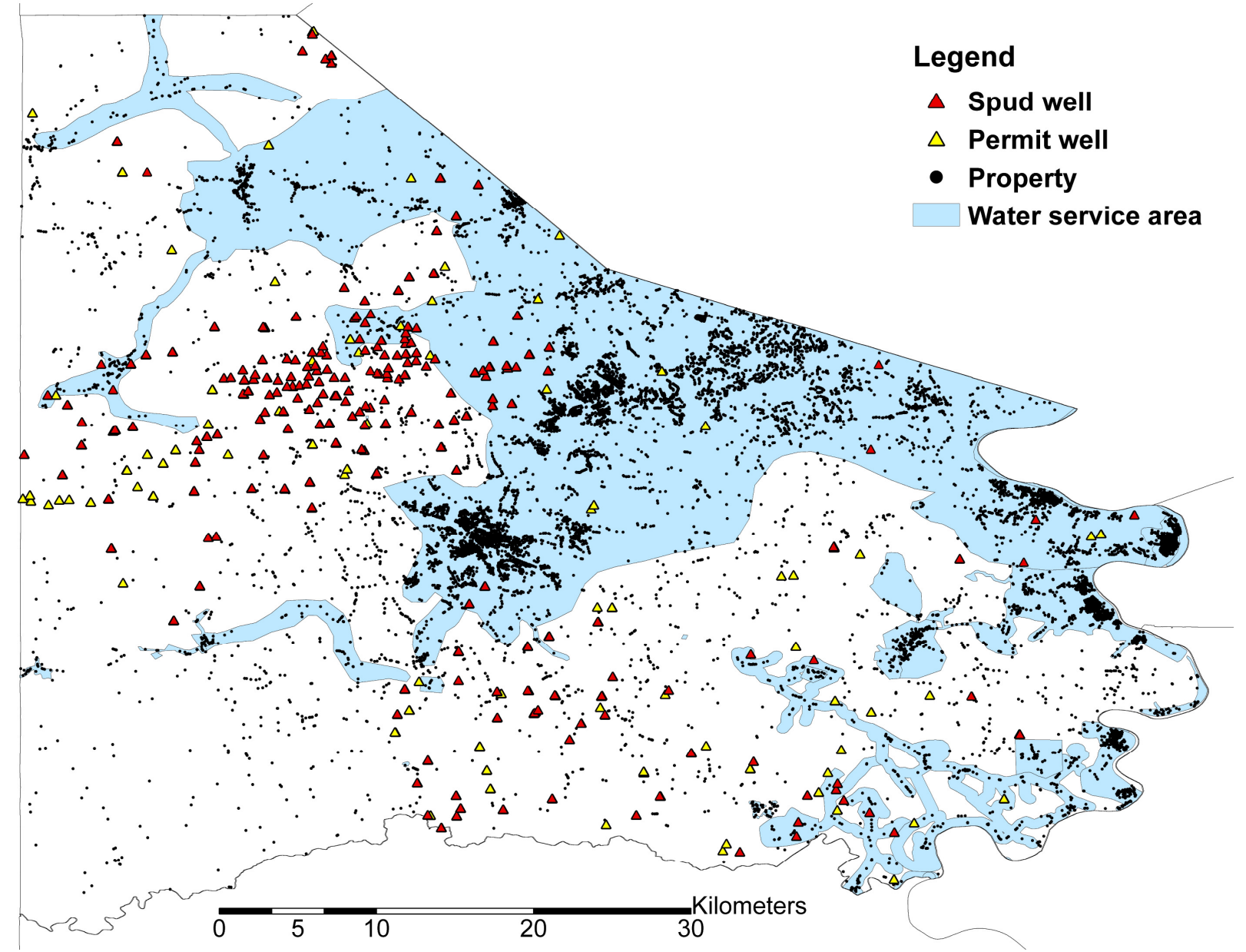

Figure 4: Property Sales in Washington County, 2004-2009. Includes Permitted Wells, Drilled Wells, and Water Service Areas 


\section{$6 \quad$ Results}

\subsection{Cross-Sectional Results}

We first report results for our cross-sectional specification, where we regress logged transaction prices on regression controls for house and census tract attributes, year dummies, and several treatment variables. These treatment variables include both inverse distance to the nearest drilled well and this variable interacted with a dummy for groundwater (which equals one if the house is located outside a PWSA). This allows us to separately identify the impact of proximity to a well for households living in groundwater areas. We expect this coefficient to be negative, as being closer to a well causes a greater risk to households living in groundwater areas. We also include inverse distance to the nearest permitted well in order to identify whether there is a different impact from permitted wells relative to drilled wells. This variable is also interacted with a groundwater dummy. We run the regression for the full sample as well as the subsample excluding the cities.

We find a positive and significant impact of proximity to a drilled well, though the interaction with groundwater is negative and insignificant. Inverse distance to a permitted well interacted with groundwater is positive but insignificant. The positive sign on the coefficient may be picking up the fact that proximity to a permitted well implies a likely lease payment 18 In fact, these lease payments increase with the amount of land leased, and lot sizes in groundwater areas are much larger than in the PWSA areas. Thus, the groundwater-dependent houses may positively capitalize on the permitting of the well before the negative amenities associated with drilling occur. However, given the insignificance of the coefficient on the interaction of groundwater with proximity, it is difficult to draw conclusions regarding the overall impact of proximity to wells for the groundwater area homes.

Since inverse distance is not a linear function of proximity, we cannot interpret

\footnotetext{
${ }^{18}$ Usually the mineral rights would be part of any property transfer, unless those rights were severed from the title to the property by being retained by the seller during the transfer, or sold to another party prior to the transfer. If mineral rights are sometimes severed, this would simply reduce the size of the price premium we estimate on well proximity. This should not, however, affect our estimates of the capitalization of groundwater contamination risk unless the probability of mineral right severance is correlated with water source in the area around the groundwater-PWSA boundary. We have no reason to suspect that this is the case.
} 
the magnitude of these coefficients directly. Instead, we take the derivative of the price with respect to distance (meters) in order to find the marginal effect of proximity on price. Thus, the derivative of the price function is:

$$
\partial(\ln p) / \partial(\text { distance })=-\beta /\left(\text { distance }^{2}\right)
$$

where $\beta$ is the coefficient and distance is in meters. For a PWSA house that is 1000 meters away from a well pad, the percent change in price from a one meter increase in distance is -0.03 percent $\left(-100 * 326.148 *\left(1 / 1000^{2}\right)\right)$, implying positive impacts on housing values from proximity to wells (Table 3 , column 1). The comparable result for groundwater-dependent houses is inconclusive given that the coefficient on the interaction term is insignificant. These results likely reflect the fact that the cross-sectional specification does not account for unobserved attributes of either the house or its location. These attributes may be correlated with proximity to a well and with water source, which can cause a bias in the cross-sectional coefficients. This leads us to employ a property fixed effects approach in order to remove these unobservable location attributes.

\subsection{Property Fixed Effect Results}

The signs of the coefficients from the FE specification are similar but larger and more significant than under the OLS specification.19 For the full sample (including cities), we find a positive impact of drilled shale gas well proximity on housing values, though it is negative (and larger) for those households living in groundwater areas. This implies that shale development causes an increase in housing values in general (perhaps due to lease payments, increased economic activity, or higher rental prices), though houses that do not have access to piped water have an overall negative impact due to shale gas development risks. When we exclude the cities, this effect is even more pronounced: the size of the coefficient on proximity to drilled wells decreases, suggesting that the effect of increased economic development is concentrated in the cities. The results imply that the marginal change in housing prices from moving one meter farther from a well is

\footnotetext{
${ }^{19}$ There are more observations in columns 2 and 4 relative to columns 1 and 3 because of missing values for property characteristics-the fixed effects specification does not require these variables to be complete for all homes, so we are able to make use of more observations in the fixed effect regressions than in the OLS regressions.
} 
Table 3: Cross Sectional and Property Fixed Effects Estimates of the Effect of Shale Gas Wells on Log Sale Price

\begin{tabular}{|c|c|c|c|c|}
\hline & $\begin{array}{l}1) \\
\text { OLS }\end{array}$ & $\begin{array}{l}(2) \\
\text { OLS }\end{array}$ & $\begin{array}{l}(3) \\
\mathrm{FE}\end{array}$ & $\begin{array}{l}(4) \\
\text { FE }\end{array}$ \\
\hline Inverse Distance to Well $\left(\right.$ meters $^{-1}$ ) & $\begin{array}{l}326.148^{* * *} \\
(121.106)\end{array}$ & $\begin{array}{l}263.962^{* *} \\
(125.322)\end{array}$ & $\begin{array}{l}1103.470^{* *} \\
(447.170)\end{array}$ & $\begin{array}{l}764.502^{* *} \\
(363.109)\end{array}$ \\
\hline Inv. Dist. to Well*Groundwater & $\begin{array}{l}-290.933 \\
(207.612)\end{array}$ & $\begin{array}{l}-411.179 \\
(250.482)\end{array}$ & $\begin{array}{l}-1458.178^{* * *} \\
(420.039)\end{array}$ & $\begin{array}{l}-1351.901 * * * \\
(370.750)\end{array}$ \\
\hline Inv. Dist. to Permitted (not Drilled) Well & $\begin{array}{l}21.767 \\
(121.548)\end{array}$ & $\begin{array}{l}-151.561 \\
(225.927)\end{array}$ & $\begin{array}{l}296.562 \\
(335.141)\end{array}$ & $\begin{array}{l}1470.929 \\
(994.679)\end{array}$ \\
\hline Inv. Dist. to Permitted* Groundwater & $\begin{array}{l}193.943 \\
(228.639)\end{array}$ & $\begin{array}{l}605.057 \\
(406.166)\end{array}$ & $\begin{array}{l}-333.022 \\
(516.627)\end{array}$ & $\begin{array}{l}-1560.450 \\
(1213.657)\end{array}$ \\
\hline Groundwater & $\begin{array}{l}-.108 \\
(.069)\end{array}$ & $\begin{array}{l}-.098 \\
(.086)\end{array}$ & & \\
\hline Age & $\begin{array}{l}-.014^{* * * *} \\
(.000)\end{array}$ & $\begin{array}{l}-.012^{* * *} \\
(.001)\end{array}$ & & \\
\hline Total Living Area (1000 sqft) & $\begin{array}{l}.283^{* * *} \\
(.019)\end{array}$ & $\begin{array}{l}.285^{* * *} \\
(.025)\end{array}$ & & \\
\hline No. Bathrooms & $\begin{array}{l}.070 * * * \\
(.021)\end{array}$ & $\begin{array}{l}.057^{*} \\
(.030)\end{array}$ & & \\
\hline No. Bedrooms & $\begin{array}{l}-.014 \\
(.018)\end{array}$ & $\begin{array}{l}-.026 \\
(.024)\end{array}$ & & \\
\hline Sold in Year Built & $\begin{array}{l}-.204^{* * *} \\
(.040)\end{array}$ & $\begin{array}{l}-.365^{* * *} \\
(.067)\end{array}$ & & \\
\hline Lot Size $(100,000 \mathrm{sqft})$ & $\begin{array}{l}.280 * * * \\
(.057)\end{array}$ & $\begin{array}{l}.301^{* * *} \\
(.064)\end{array}$ & & \\
\hline Lot Size Squared $(100,000 \mathrm{sqft})$ & $\begin{array}{r}-.025^{*} \\
(.013)\end{array}$ & $\begin{array}{l}-.022^{* *} \\
(.010)\end{array}$ & & \\
\hline Distance to Nearest MSA $(\mathrm{km})$ & $\begin{array}{l}.011^{* * *} \\
(.002)\end{array}$ & $\begin{array}{l}.003 \\
(.003)\end{array}$ & & \\
\hline Mean Income (1000 dlls) & $\begin{array}{l}.005 * * * \\
(.001)\end{array}$ & $\begin{array}{l}.007 * * * \\
(.002)\end{array}$ & & \\
\hline$\%$ Unemployed & $\begin{array}{l}-.030^{* * *} \\
(.007)\end{array}$ & $\begin{array}{l}-.034^{* * *} \\
(.010)\end{array}$ & & \\
\hline$\%$ Age $25 \mathrm{w} /$ Bachelors & $\begin{array}{l}.027^{* * *} \\
(.004)\end{array}$ & $\begin{array}{l}.026 * * * \\
(.006)\end{array}$ & & \\
\hline \% Female Household Head & $\begin{array}{l}.006 \\
(.004)\end{array}$ & $\begin{array}{l}.009 \\
(.007)\end{array}$ & & \\
\hline$\%$ Over 65 Years Old & $\begin{array}{l}.005^{*} \\
(.003)\end{array}$ & $\begin{array}{l}.014^{* *} \\
(.006)\end{array}$ & & \\
\hline$\%$ Black & $\begin{array}{l}-.007^{* *} \\
(.003)\end{array}$ & $\begin{array}{l}-.038^{* * *} \\
(.008)\end{array}$ & & \\
\hline$\%$ Hispanic & $\begin{array}{l}-.097 * * * \\
(.019)\end{array}$ & $\begin{array}{l}-.076^{* * *} \\
(.030)\end{array}$ & & \\
\hline 2006 & $\begin{array}{l}-.072^{*} \\
(.039)\end{array}$ & $\begin{array}{l}-.107^{*} \\
(.063)\end{array}$ & $\begin{array}{l}.345 \\
(.207)\end{array}$ & $\begin{array}{l}.325 \\
(.348)\end{array}$ \\
\hline 2007 & $\begin{array}{l}-.096^{* *} \\
(.040)\end{array}$ & $\begin{array}{l}-.076 \\
(.063)\end{array}$ & $\begin{array}{l}.704 * * * \\
(.197)\end{array}$ & $\begin{array}{l}.672^{* *} \\
(.325)\end{array}$ \\
\hline 2008 & $\begin{array}{l}-.248^{* * *} \\
(.042)\end{array}$ & $\begin{array}{l}-.259^{* * *} \\
(.065)\end{array}$ & $\begin{array}{l}.854^{* * *} \\
(.207)\end{array}$ & $\begin{array}{l}.859 * * * \\
(.321)\end{array}$ \\
\hline 2009 & $\begin{array}{l}-.493^{* * *} \\
(.059) \\
\end{array}$ & $\begin{array}{l}-.525^{* * * *} \\
(.084) \\
\end{array}$ & $\begin{array}{l}1.394^{* * *} \\
(.265)\end{array}$ & $\begin{array}{l}1.498^{* * *} \\
(.347) \\
\end{array}$ \\
\hline $\begin{array}{l}\mathrm{n} \\
\text { Mean of Dep. Var. }\end{array}$ & $\begin{array}{l}10,833 \\
11.09107\end{array}$ & $\begin{array}{l}5,847 \\
10.94342\end{array}$ & $\begin{array}{l}10,960 \\
11.07652\end{array}$ & $\begin{array}{l}5,945 \\
10.92134\end{array}$ \\
\hline
\end{tabular}

Notes: Robust standard errors clustered at the census tract (102 census tracts). Columns (3) and (4) include property fixed effects. Columns (2) and (4) do not include the two largest cities in Washington County (Washington and Canonsburg). *** Statistically significant at the $1 \%$ level; ** $5 \%$ level; * $10 \%$ level. 
-0.0764 percent for PWSA houses and 0.059 percent $(0.0764502 \%-0.1351901 \%)$ for groundwater-dependent houses (Table 3 , column 4) ${ }^{20}$ This presents some evidence that those living outside the PWSA, while attaining increased housing values from lease payments, are not able to offset the negative impacts associated with groundwater risks.

According to Table 3, the relative effect of proximity to shale gas wells on groundwater and PWSA homes is very different in the OLS and fixed effects specifications. In the fixed effects specification, homes overall are more positively affected by proximity, although the effect on groundwater homes is more negative. We test the difference between the coefficients on proximity and proximity interacted with groundwater across the two specifications, and find that the interaction term changes significantly, although the proximity term alone does not. This demonstrates that there is an unobservable correlated with proximity and groundwater that is being picked up by the fixed effect approach. Specifically, the change in coefficients suggests that shale gas wells are being located near homes in groundwater areas that are unobservably better. There is indeed evidence that these groundwater area homes are observably better and have larger lots (See Table 5 for differences across homes located close to shale gas wells). Properties with larger lots - which tend to be located in groundwater areas - would be preferred by gas exploration and production companies, as leasing the same quantity of land would require fewer transactions and potentially lower costs per well. Though we control for lot size in the OLS specification, lot size may be correlated with positive unobservable attributes in groundwater areas, which would explain the shift in the interaction coefficient. However, as evidenced by Figure 1. there appear to be negative unobservables correlated with proximity in PWSA homes, which could drive the increase in the proximity coefficient when moving from OLS to fixed effects.21

Unfortunately, relying on fixed effects can be problematic given time varying

\footnotetext{
${ }^{20}$ The t-statistic on the difference in these parameters is -1.73 , implying a statistically significant net gain in housing values from moving farther from the well.

${ }^{21}$ In order to create this figure we only included homes with one wellpad within 5000 meters, which excluded many of the groundwater dependent properties: the results from this figure are driven mostly by PWSA homes for which, given the upward sloping solid line, it would appear there are negative unobservables correlated with proximity. Creating a separate figure for groundwater and PWSA properties would have too few observations in each distance bin to be reliable. This does not affect our DDD estimation strategy, however, which relies on homes being located near one or more wells within 2000 meters.
} 
unobservables - e.g, the local economic boom and lease payments to individual homeowners. This warrants our use of a triple-difference estimator to remove these confounding effects.

\subsection{Difference-in-Difference-in-Differences}

Though we do not have information on gas lease payments to homeowners ${ }^{22}$ we assume that all properties (conditional upon proximity to a drilled well and other observables such as lot size) have an equal likelihood of receiving lease payments regardless of water service area. ${ }^{23}$ Moreover, while both may see their prices go up because of mineral rights and increased economic activity, properties that rely on groundwater may see their property values increase by less (or even decrease) given concerns of groundwater contamination from nearby shale gas development. Our overlapping treatment and control groups based on well proximity and water source provide us with a two-part quasi-experiment with which we can tease out the negative impact of groundwater contamination from the positive impact of the mineral lease payments and economic activity.

We estimate the following regression equation:

$$
\log \left(\text { price }_{i t}=N_{2000, i t}+\text { Groundwater }_{i} * N_{2000, i t}+\theta_{t}+\mu_{i}+\nu_{i t}\right.
$$

where $N_{2000, i t}$ is a count of the number of well pads within 2000 meters at the time $t$ of sale. It equals zero if $t$ is before drilling takes place, or if house $i$ is more than 2000 meters from the nearest well pad. In addition, Groundwater is an indicator for whether property $i$ relies on groundwater; $\theta_{t}$ is a year fixed effect

\footnotetext{
${ }^{22}$ Mineral leases are filed at the county courthouse however not in an electronic format. Some leases have been scanned and are available in pdf format at www.landex.com, however, this service is geared towards viewing a handful of leases; downloading all leases in a county would be expensive and matching the leases to properties via an address or tax parcel number would likely be an imprecise endeavor.

${ }^{23}$ It could be the case that, given groundwater safety concerns, individuals in groundwater areas are less likely to sign a mineral lease, in which case we would overestimate the negative impact of a well in a groundwater area if fewer groundwater dependent homes are receiving lease payments. Our results would thus be interpreted as an upper bound on the negative impact of proximity for groundwater dependent homes. However, gas companies will only drill after obtaining the mineral rights to a sufficiently large area to warrant drilling, implying that holdouts are the minority in areas where wells have been drilled. Furthermore, property owners unwilling to sign based on groundwater contamination concerns are likely rare; if others nearby have granted their mineral rights, groundwater contamination is not prevented by not signing.
} 
to capture trends over time; $\mu_{i}$ is a property fixed effect that absorbs the timeinvariant differences between properties that eventually have one or more wells within 2000 meters and those that do not, ${ }^{24}$ as well as time-invariant differences between groundwater and PWSA houses. The interaction Groundwater $_{i} * N_{2000, \text { it }}$ measures the treatment effect on groundwater homes relative to PWSA homes, accounting for any time-varying unobservables that similarly affect close and distant houses.

Finally, in order to reduce the burden on our differencing strategy to control for time-varying unobserved neighborhood attributes, our main specification only looks at houses located within 1000 meters of either side of the border of the PWSA. ${ }^{25}$ This represents the smallest (and most homogenous) geographic area we can use that still contains houses relying on groundwater along with houses in the PWSA.

In order to validate our assumption of common time trends across the two groups (PWSA and groundwater) and within the same neighborhood (1000 meters from the border), we regress transaction values on the housing characteristics and census tract attributes that are used in our cross-sectional specification, and then calculate the residuals, separately for groundwater-dependent and PWSA homes. We plot the residuals over time prior to any wells being drilled (the first well in Washington County was drilled in June 2005), once for a restricted sample of homes located within 1000 meters of either side of the PWSA border, and once for the entire sample of homes in Washington County. Figure 5 plots the time trend across the full sample of the two groups, while Figure 6 restricts the sample to homes located within 1000 meters of either side of the PWSA border. Both figures track quite well across the two samples prior to any house being treated by a well, although the restricted sample (which is our final DDD sample) tracks more closely. This demonstrates that focusing on homes that are closer together helps eliminate differing pre-trends across the control and treatment group, thereby validating our DDD approach with the restricted sample.

\footnotetext{
${ }^{24}$ While being located inside the PWSA or groundwater area may not be invariant over time, we only have data on the most recent layout of the PWSA; thus our data on water service are time invariant and we do not include a groundwater dummy in this specification.

${ }^{25}$ We also include a specification with the entire sample in Washington County to test how the assumption of common trends changes with a larger group.
} 


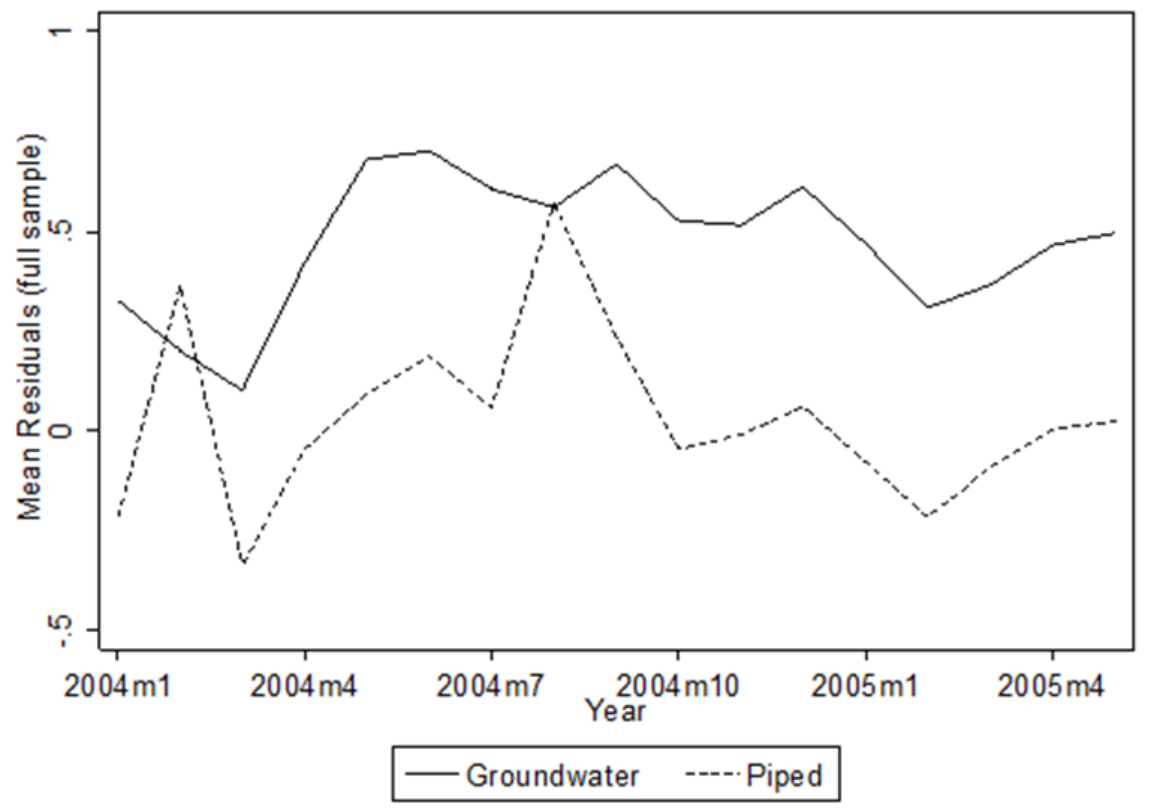

Figure 5: Mean Residuals of Log Transaction Price using the Full Sample

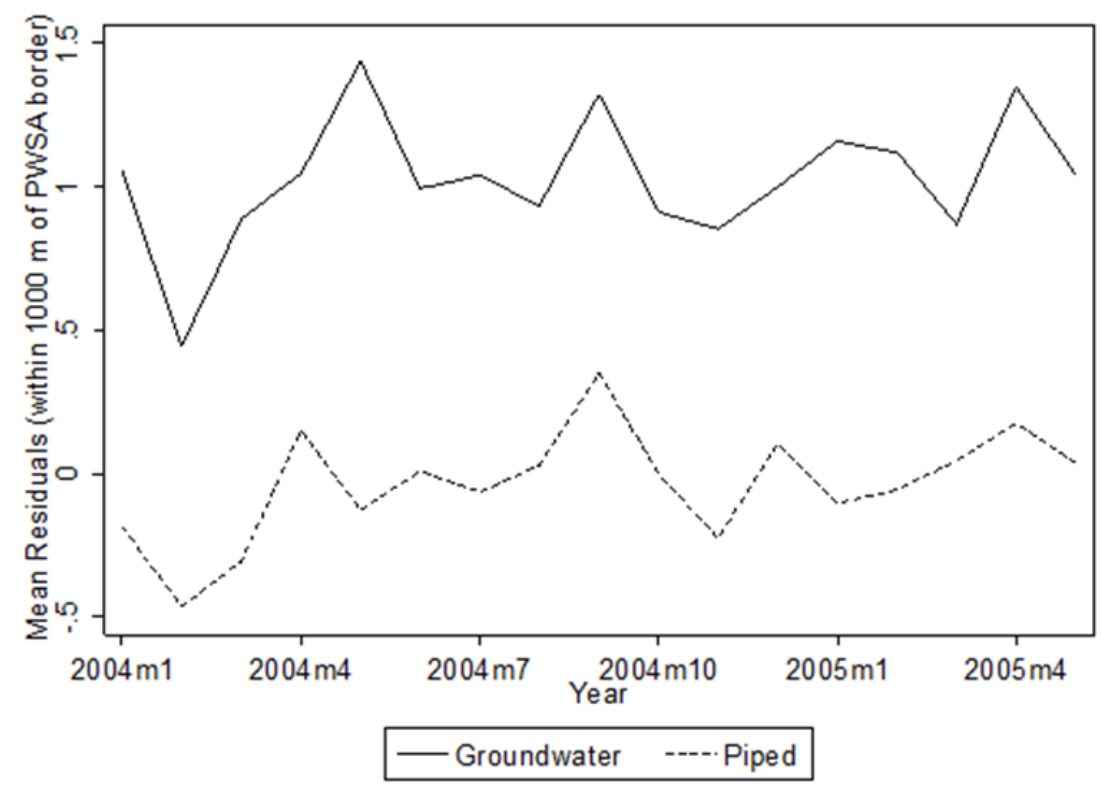

Figure 6: Mean Residuals of Log Transaction Price using the properties located $1000 \mathrm{~m}$ from the PWSA Border 
We provide additional evidence to validate our assumption that PWSA homes within 1000 meters of the PWSA border are a good control for the groundwaterdependent homes near the other side of the border, by inspecting aerial maps of the homes in this region. We find that, for nearly all of our sample, PWSA and groundwater areas are not divided in such a way as might cause neighborhood discontinuity (e.g., such as by a highway, railroad track, etc) ${ }^{26}$ This provides further justification for use of homes on the PWSA side of the border as controls for the groundwater-dependent homes in our DDD method.

We estimate our DDD specification using a number of different subsamples. In our first two regressions, we use a subsample that omits properties that were sold after they had permitted (but not yet drilled) wells within 2000 meters (columns 1 and 2 of Table 4). This subsample removes houses that may be receiving lease or bonus payments from a gas exploration and development company due to a permitted but not drilled well. The initial specification in column 1 looks at all properties in both the PWSA and groundwater areas (instead of only those located along the PWSA border), which allows us to test the importance of the assumption of common time trends close to the border. In the second regression (column 2) we restrict the sample to PWSA border homes. Since it is possible that the PWSA has been extended beyond the border designated in our data, we omit properties that are 300 meters on the groundwater side of a water service area in order to reduce the risk of including misclassified properties. Our third specification looks at all houses in Washington county, including the properties with permitted (but undrilled) wells, but controls for these with an indicator for having permitted wells nearby, as well as the interaction of this indicator with Groundwater (column 3).27. Finally, this third specification is also run using only the PWSA border home properties (column 4). Thus, only columns 2 and 4 allow for the assumption of common time trends.

\footnotetext{
${ }^{26}$ One exception is displayed in the Appendix (Figure 9), where highway 70 coincides with the PWSA boundary. Our results are robust to dropping homes located in this area.

${ }^{27}$ Including properties treated by permitted wells increases the sample size by 128 observations for the full sample, and by 46 for the band around the PWSA border.
} 
Table 4: DDD Estimates of the Effect of Shale Gas Wells on Log Sale Price by Drinking Water Source

\begin{tabular}{lllll}
\hline & $(1)$ & $(2)$ & $(3)$ & $(4)$ \\
& Full & Band & Full & Band \\
\hline Wellpads Drilled within $2 \mathrm{~km}$ & $.288^{* * *}$ & $.321^{* * *}$ & $.091^{*}$ & $.107^{* *}$ \\
& $(.068)$ & $(.082)$ & $(.053)$ & $(.040)$ \\
Wellpads Drilled within $2 \mathrm{~km}^{*}$ Groundwater & $-.901^{* *}$ & $-.433^{* * *}$ & .011 & $-.236^{*}$ \\
& $(.370)$ & $(.117)$ & $(.106)$ & $(.124)$ \\
Wellpads Permitted (not drilled) within 2km & & & .177 & -.036 \\
& & & $(.119)$ & $(.088)$ \\
Wellpads Permitted (not drilled) within $2 \mathrm{~km}^{*}$ Groundwater & & & .002 & -.749 \\
& & & $(.123)$ & $(.593)$ \\
Year Effects & Yes & Yes & Yes & Yes \\
Property Effects & Yes & Yes & Yes & Yes \\
\hline $\mathrm{n}$ & 17,779 & 3,229 & 17,907 & 3,275
\end{tabular}

Notes: Robust standard errors clustered at the census tract (102 census tracts). All specifications include year-of-sale and property fixed effects. Columns (1) and (2) are specifications that omit properties with wells permitted (but not drilled) within 2000 meters. Columns (3) and (4) include properties with wells permitted within 2000 meters. Columns (2) and (4) only examine properties within a 1000 meter band around the water service area. ${ }^{* * *}$ Statistically significant at the $1 \%$ level; ** $5 \%$ level; * $10 \%$ level.

Similar to the cross-sectional and FE results, we find that property values go up after a well pad has been drilled within 2000 meters, while properties that rely on groundwater are negatively affected by exposure. We find that permitted (but not drilled) wells do not have a significant effect on property values in our final specification, though controlling for these wells reduces the impacts (both positive and negative) of the treatment on housing values relative to column 2 (Table 4, column 4). Though insignificant, the parameter estimate on the interaction term of permitted wells with the groundwater indicator is large and negative, providing some evidence that permitting may be negatively capitalized into the housing value by groundwater homes. This could be due to the fact that the new home buyer is aware of the forthcoming drilling activity due to incoming lease payments or that construction has already begun to occur nearby.

The estimates in the final specification (column 4) demonstrate that houses in the PWSA positively capitalize proximity to a well pad by 10.7 percent, and this result is statistically significant. This is most likely due to lease payments, which allow houses in the PWSA to increase their values while avoiding the risks (or perceived risks) of contaminated groundwater. For houses that depend on groundwater, however, the point estimate of the effect of drilling a well pad within 
2000 meters implies a net decrease in property values. This net effect is made up of a statistically significant reduction in value of 23.6 percent attributable to groundwater contamination risk, partially offset by the 10.7 percent increase (likely) attributable to lease payments. Their difference (-12.9 percent) while not significant, ${ }^{28}$ suggests that, in contrast to PWSA homes, prices of groundwater dependent houses certainly do not rise as a result of nearby drilling, and may fall because of groundwater contamination risk.

The final estimation also demonstrates the importance of controlling for the fact that gas exploration and development companies have strategic location decisions. In the third specification, permitted wells significantly decrease values for groundwater dependent homes, though this significance disappears when we only look at homes near the PWSA border. Since gas wells near both sides of the border are located in relatively similar areas, they are less likely to be located in strategically different ways, and hence our final specification demonstrates that not controlling for these location decisions can cause groundwater dependent homes to appear more harmed by proximity to wells than they truly are.

\section{Conclusion}

Our study seeks to understand and quantify the positive and negative impacts of shale gas development on nearby housing values. Our goal is to distinguish who benefits and who loses from this unconventional form of natural gas extraction. Specifically, we focus on the potential for groundwater contamination, one of the most high-profile risks associated with drilling. We demonstrate that those risks lead to a large and significant reduction in house prices. These reductions offset any gains to the owners of groundwater-dependent properties from lease payments or improved local economic conditions, and may even lead to a net drop in prices. Unfortunately, due to limitations on lease payment data, we are not able to disentangle the positive effects of nearby drilling on property values from the effects of negative externalities that are not associated with groundwater risks (e.g., increased traffic; noise, air, and light pollution) - doing so is the subject of ongoing research. With our triple-difference strategy, we are, however, able to provide evidence that concern for groundwater contamination risk significantly

\footnotetext{
${ }^{28}$ The t-statistic on the difference in these parameters is -1.03 .
} 
decreases the value of nearby homes. Thus, being able to mitigate the potential for water contamination from shale gas development (such as through the extension of the piped water service area) allows houses to benefit from the lease payments and increased economic activity that accompanies drilling without having to bear the cost of the groundwater risks. This finding also provides added impetus for regulators to increase regulations to protect groundwater around hydraulic fracturing sites and for industry to increase transparency and voluntary action to reduce water contamination concerns.

To the extent that the net effect of drilling on groundwater-dependent houses might even be negative, we could see an increase in the likelihood of foreclosure in areas experiencing rapid growth of hydraulic fracturing. The U.S. government acknowledged the possible negative consequences of allowing leasing on mortgaged land in March 2012 when it began discussing a regulation requiring an environmental review of any property with an oil and gas lease before issuing a mortgage. ${ }^{29}$ However, this proposed regulation was rejected within a week. ${ }^{30}$ The overall lack of research regarding the impacts on housing values from proximity to shale gas wells hinders the ability of the government to regulate optimally, both at the national and local levels. This paper helps to fill that void.

29"Mortgages for Drilling Properties May Face Hurdle," New York Times, 18 March 2012.

30"U.S. Rejects Environmental Reviews on Mortgages Linked to Drilling," New York Times, 23 March 2012. 


\section{References}

T.J. Bartik. Measuring the benefits of amenity improvements in hedonic price models. Land Economics, 64(2):172-183, 1988.

P.C. Boxall, W.H. Chan, and M.L. McMillan. The impact of oil and natural gas facilities on rural residential property values: a spatial hedonic analysis. Resource and Energy Economics, 27(3):248-269, 2005.

L.W. Davis. The effect of power plants on local housing values and rents. Review of Economics and Statistics, 93(4):1391-1402, 2011.

EPA. EPA Releases Draft Findings of Pavillion, Wyoming Ground Water Investigation for Public Comment and Independent Scientific Review, Environmental Protection Agency News Release . 2011. URL http://yosemite.epa.gov/opa/admpress.nsf/ 0/EF35BD26A80D6CE3852579600065C94E.

D. Guignet. What do property values really tell us? a hedonic study of underground storage tanks. NCEE Working Paper Series, 2012.

M.D. Heintzelman and C.M. Tuttle. Values in the Wind: A Hedonic Analysis of Wind Power Facilities. Land Economics, 88(3):571-588, 2012.

K. Hirano and G.W. Imbens. The propensity score with continuous treatments. Applied Bayesian Modeling and Causal Inference from Incomplete-Data Perspectives, pages 73-84, 2004.

H. Allen Klaiber and Sathya Gopalakrishnan. The Impact of Shale Exploration on Housing Values in Pennsylvania, Working Paper. 2012.

Nicolai V. Kuminoff and Jaren Pope. Do "Capitalization Effects" for Public Goods Reveal the Public's Willingness to Pay? Working Paper. 2012.

L. Linden and J.E. Rockoff. Estimates of the impact of crime risk on property values from megan's laws. The American Economic Review, 98(3):1103-1127, 2008.

J. Marchand. Local labor market impacts of energy boom-bust-boom in western canada. Journal of Urban Economics, 2011.

New York State Department of Environmental Conservation. Revised Draft Supplemental Generic Environmental Impact Statement On The Oil, Gas and Solution Mining Regulatory Program, Well Permit Issuance for Horizontal Drilling and High-Volume Hydraulic Fracturing to Develop the Marcellus Shale and Other Low-Permeability Gas Reservoirs. 2011. URL http://www.dec.ny.gov/docs/materials_minerals_ pdf/rdsgeisexecsum0911.pdf.

Stephen G. Osborn, Avner Vengosh, Nathaniel R. Warner, and Robert B. Jackson. Methane contamination of drinking water accompanying gas-well drilling and hydraulic fracturing. Proceedings of the National Academy of Sciences, 108(20):8172$8176,2011$. 
RB Palmquist, FM Roka, and T. Vukina. Hog operations, environmental effects, and residential property values. Land Economics, 73(1):114-124, 1997.

S. Rosen. Hedonic prices and implicit markets: product differentiation in pure competition. The Journal of Political Economy, 82(1):34-55, 1974.

SEAB. Shale Gas Production Subcommittee Second Ninety Day Report, Secretary of Energy Advisory Board,U.S. Department of Energy. November 2011.

B.R. Swistock, W.E. Sharpe, and P.D. Robillard. A survey of lead, nitrate and radon contamination of private individual water systems in Pennsylvania. Journal of Environmental Health, 55(5):6-12, 1993.

N.R. Warner, R.B. Jackson, T.H. Darrah, S.G. Osborn, A. Down, K. Zhao, A. White, and A. Vengosh. Geochemical evidence for possible natural migration of Marcellus formation brine to shallow aquifers in Pennsylvania. Proceedings of the National Academy of Sciences, 109(30):11961-11966, 2012.

J.G. Weber. The effects of a natural gas boom on employment and income in Colorado, Texas, and Wyoming. Energy Economics, 2011. 


\section{A Appendix}

Table 5: Means (and Standard Deviations) of Property Characteristics by Distance to Nearest Current or Future Well

\begin{tabular}{|c|c|c|c|c|}
\hline & $<2 \mathrm{~km}$ & $2-4 \mathrm{~km}$ & $4-6 \mathrm{~km}$ & $6-8 \mathrm{~km}$ \\
\hline \multirow[t]{2}{*}{ Transaction Price (Dollars) } & 120,108 & 112,262 & 104,810 & 104,300 \\
\hline & $(107,633)$ & $(103,219)$ & $(116,334)$ & $(97,693)$ \\
\hline \multirow[t]{2}{*}{ Age } & 54.58 & 54.65 & 57.62 & 58.66 \\
\hline & $(39.19)$ & $(40.3)$ & $(40.01)$ & $(40.17)$ \\
\hline \multirow[t]{2}{*}{ Total Living Area (1000 sqft) } & 1.896 & 1.747 & 1.642 & 1.682 \\
\hline & $(1.004)$ & $(.8265)$ & $(.679)$ & $(.7133)$ \\
\hline \multirow[t]{2}{*}{ No. Bathrooms } & 1.612 & 1.48 & 1.482 & 1.521 \\
\hline & $(.9343)$ & $(.9562)$ & $(.9373)$ & $(.931)$ \\
\hline \multirow[t]{2}{*}{ No. Bedrooms } & 2.699 & 2.52 & 2.452 & 2.577 \\
\hline & $(1.067)$ & $(1.21)$ & $(1.164)$ & $(1.151)$ \\
\hline \multirow{2}{*}{ Sold in Year Built } & .06311 & .1222 & .1013 & .1162 \\
\hline & $(.2437)$ & $(.3278)$ & $(.3019)$ & $(.3206)$ \\
\hline \multirow[t]{2}{*}{ Lot Size $(100,000$ sqft $)$} & .4076 & .2238 & .2209 & .1864 \\
\hline & $(.5176)$ & $(.3906)$ & $(.4955)$ & $(.3763)$ \\
\hline \multirow[t]{2}{*}{ Distance to Nearest MSA $(\mathrm{km})$} & 34.81 & 34.99 & 35.74 & 37.77 \\
\hline & $(5.76)$ & $(6.184)$ & $(7.013)$ & $(5.631)$ \\
\hline \multirow[t]{2}{*}{ Mean Income } & 68,851 & 59,431 & 59,431 & 58,681 \\
\hline & $(11,678)$ & $(12,038)$ & $(12,749)$ & $(16,620)$ \\
\hline \multirow[t]{2}{*}{$\%$ Under 19 Years Old } & 24.67 & 23.66 & 23.01 & 23.67 \\
\hline & $(4.066)$ & $(4.523)$ & $(3.095)$ & $(4.566)$ \\
\hline \multirow[t]{2}{*}{$\%$ Black } & 1.846 & 4.277 & 3.393 & 5.518 \\
\hline & $(3.082)$ & $(4.529)$ & $(3.62)$ & $(7.88)$ \\
\hline \multirow[t]{2}{*}{$\%$ Hispanic } & .6519 & 681 & .2979 & .4773 \\
\hline & $(.9262)$ & $(1.026)$ & $(.4401)$ & $(.7651)$ \\
\hline \multirow[t]{2}{*}{$\%$ Age $25 \mathrm{w} /$ High School } & 43.52 & 43 & 41.26 & 41.82 \\
\hline & $(4.766)$ & $(5.573)$ & $(7.712)$ & $(7.977)$ \\
\hline \multirow[t]{2}{*}{$\%$ Age 25 w Bachelors } & 13.98 & 14.03 & 14.98 & 14.83 \\
\hline & $(3.421)$ & $(3.838)$ & $(5.9)$ & $(6.393)$ \\
\hline \multirow[t]{2}{*}{$\%$ Same House 1 Year } & 89.99 & 88.81 & 87.99 & 87.02 \\
\hline & $(3.055)$ & $(3.96)$ & $(4.838)$ & $(7.504)$ \\
\hline \multirow[t]{2}{*}{$\%$ Unemployed } & 6.243 & 7.028 & 5.979 & 6.859 \\
\hline & $(1.648)$ & $(2.269)$ & $(2.46)$ & $(3.09)$ \\
\hline \multirow[t]{2}{*}{$\%$ Poverty } & 4.764 & 6.286 & 7.019 & 8.53 \\
\hline & $(3.366)$ & $(4.513)$ & $(4.633)$ & $(7.882)$ \\
\hline \multirow[t]{2}{*}{$\%$ Public Assistance } & 1.991 & 1.962 & 2.126 & 2.526 \\
\hline & $(1.025)$ & $(1.574)$ & $(1.763)$ & $(2.576)$ \\
\hline \multirow[t]{2}{*}{$\%$ Over 65 Years Old } & 17.3 & 18.13 & 18.08 & 17.67 \\
\hline & $(3.711)$ & $(4.46)$ & $(4.674)$ & $(5.233)$ \\
\hline \multirow[t]{2}{*}{$\%$ Female Household Head } & 9.577 & 11.62 & 10.59 & 12.19 \\
\hline & $(3.349)$ & $(4.727)$ & $(4.205)$ & $(5.438)$ \\
\hline \multirow[t]{2}{*}{ Ground Water } & .4396 & .1639 & .09304 & .06808 \\
\hline & $(.4975)$ & $(.3704)$ & $(.2906)$ & $(.2519)$ \\
\hline Observations & 207 & 775 & 1623 & 2130 \\
\hline
\end{tabular}

Notes: Summary statistics based on the distance to the closest well drilled at time of sale or at some time in the future. 


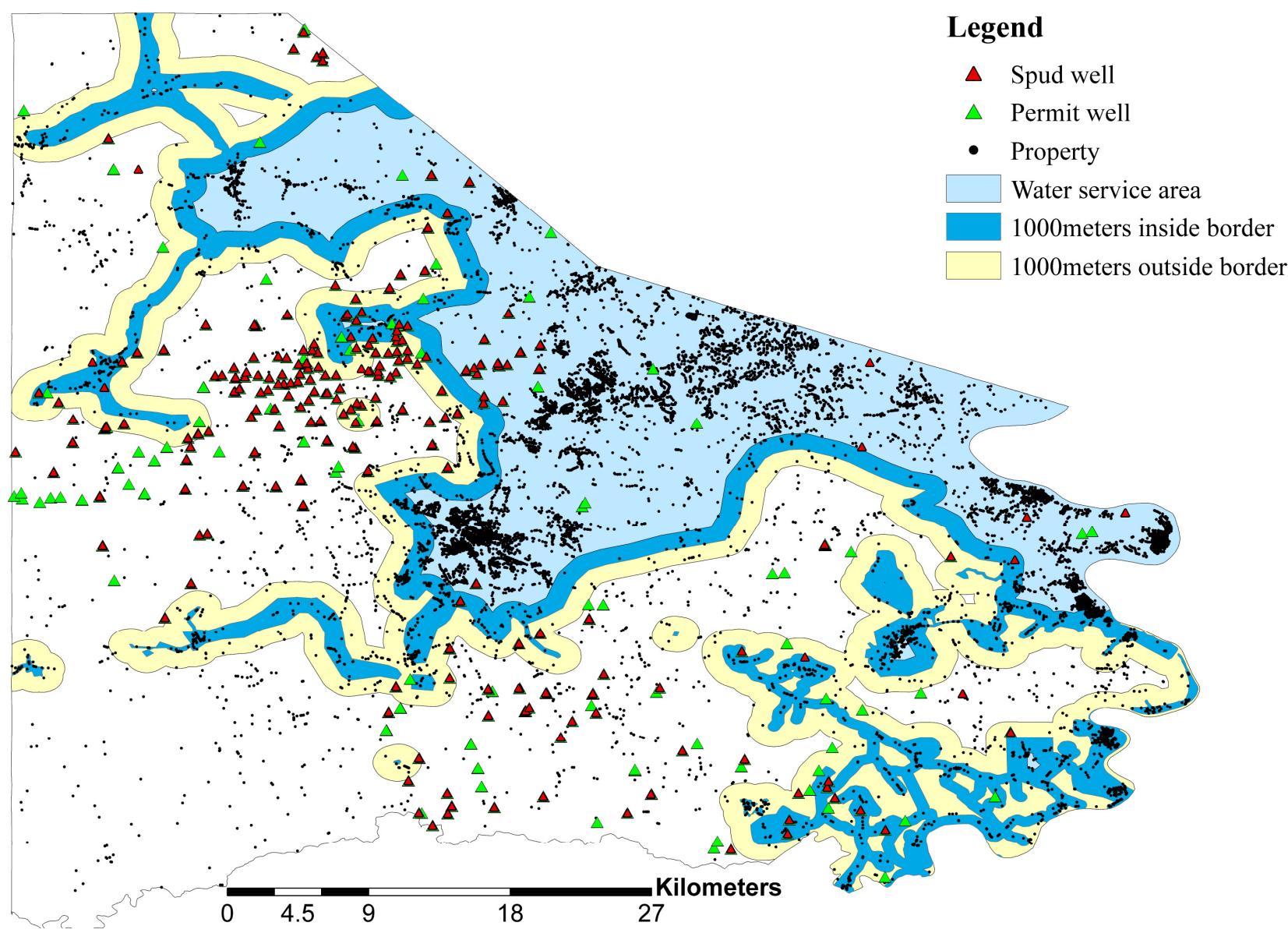

Figure 7: Property Sales and permitted and drilled wells in Washington County, 2004-2009. Indicates 1000 meter band inside and outside of public water service areas. 


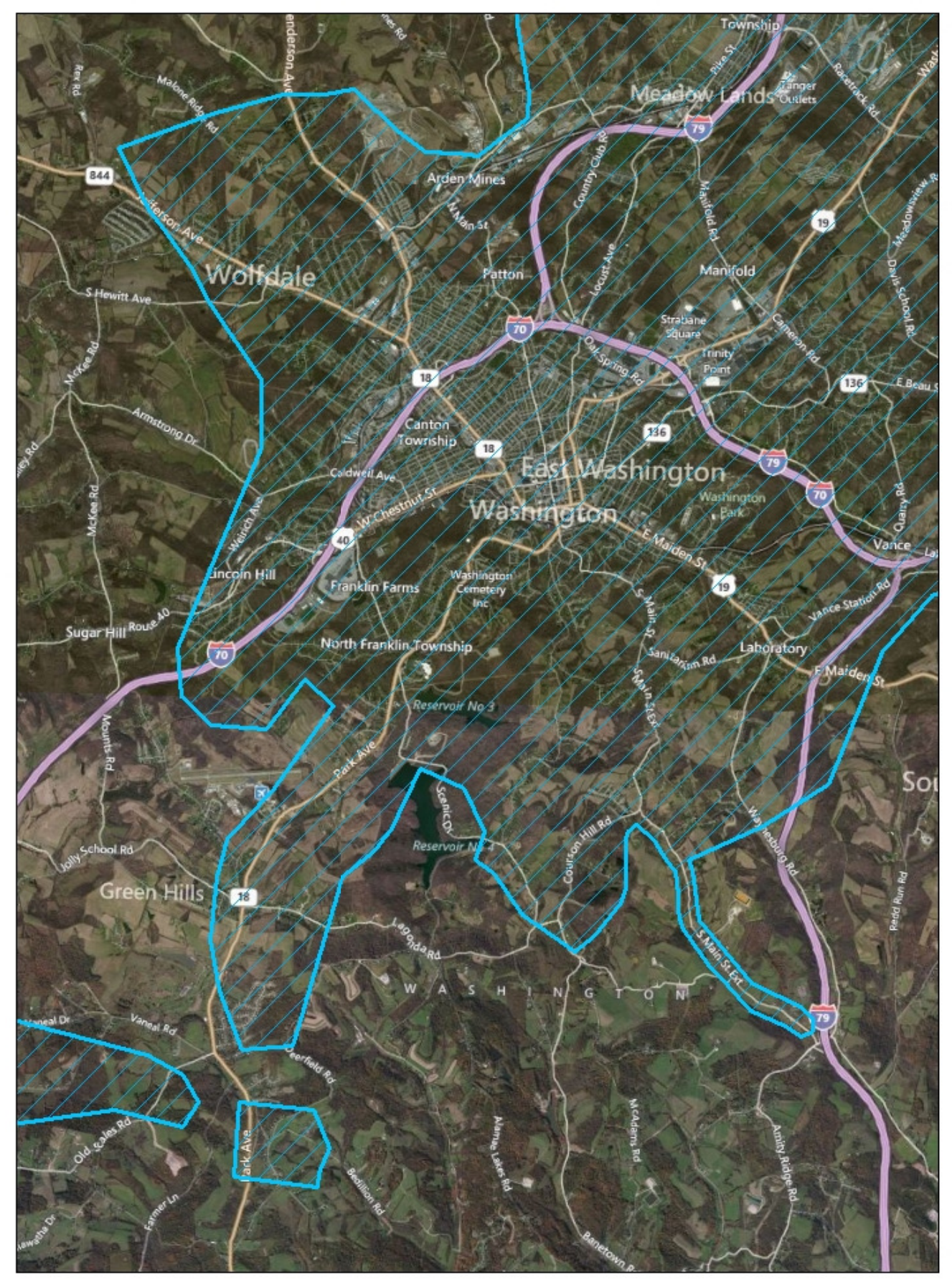

Figure 8: Example of no artificial boundaries: Close-up of Washington City. 


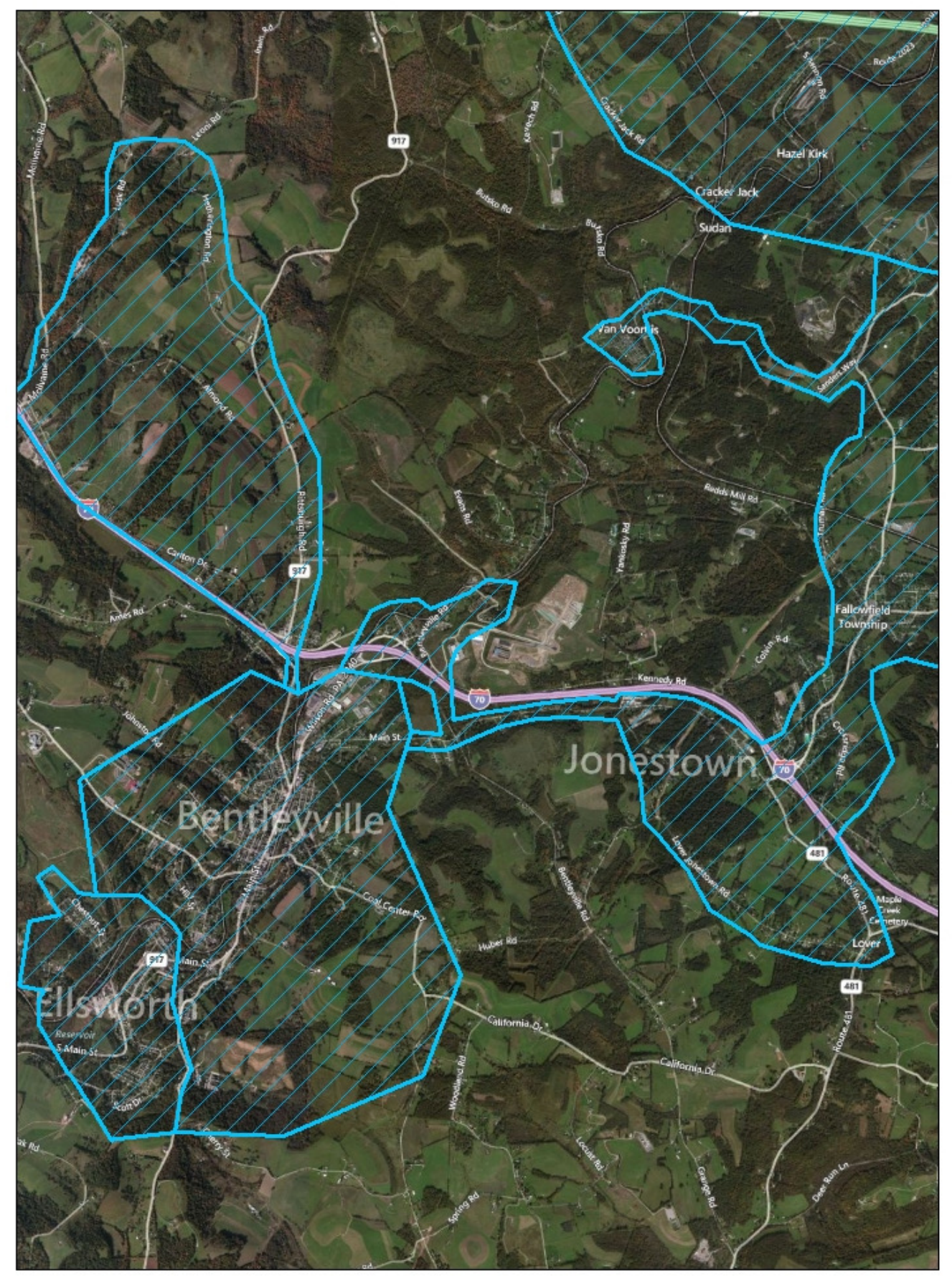

Figure 9: One exception where a highway coincides with the PWSA boundary; Our results are robust to dropping this area. 

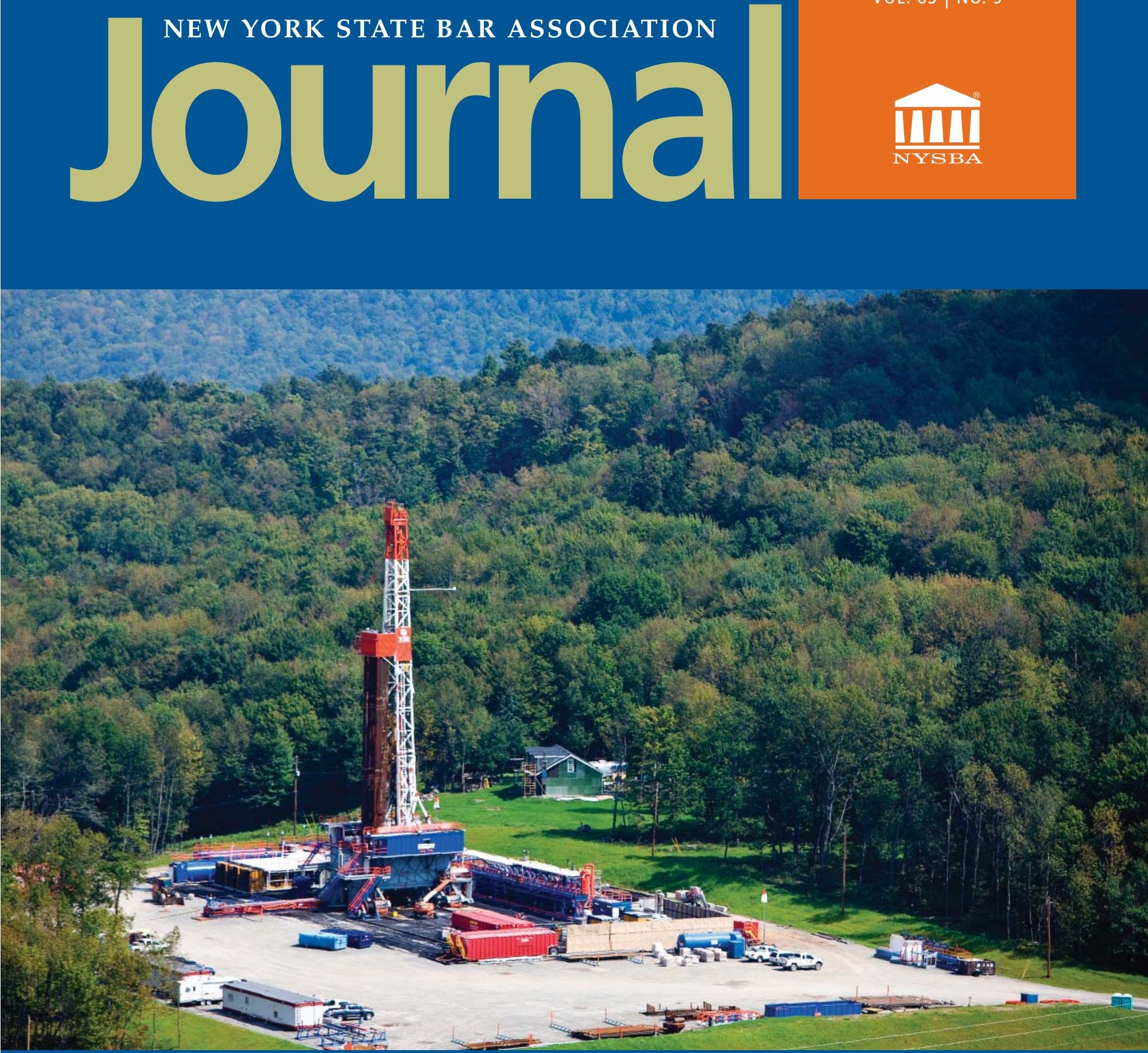

\section{Homeowners and Gas Drilling Leases: Boon or Bust?}

Also in this Issue Retaliation Claims Dismissal Motions

New Trust Laws

Did the Odds Change? Attorney Professionalism By Elisabeth N. Radow Forum 


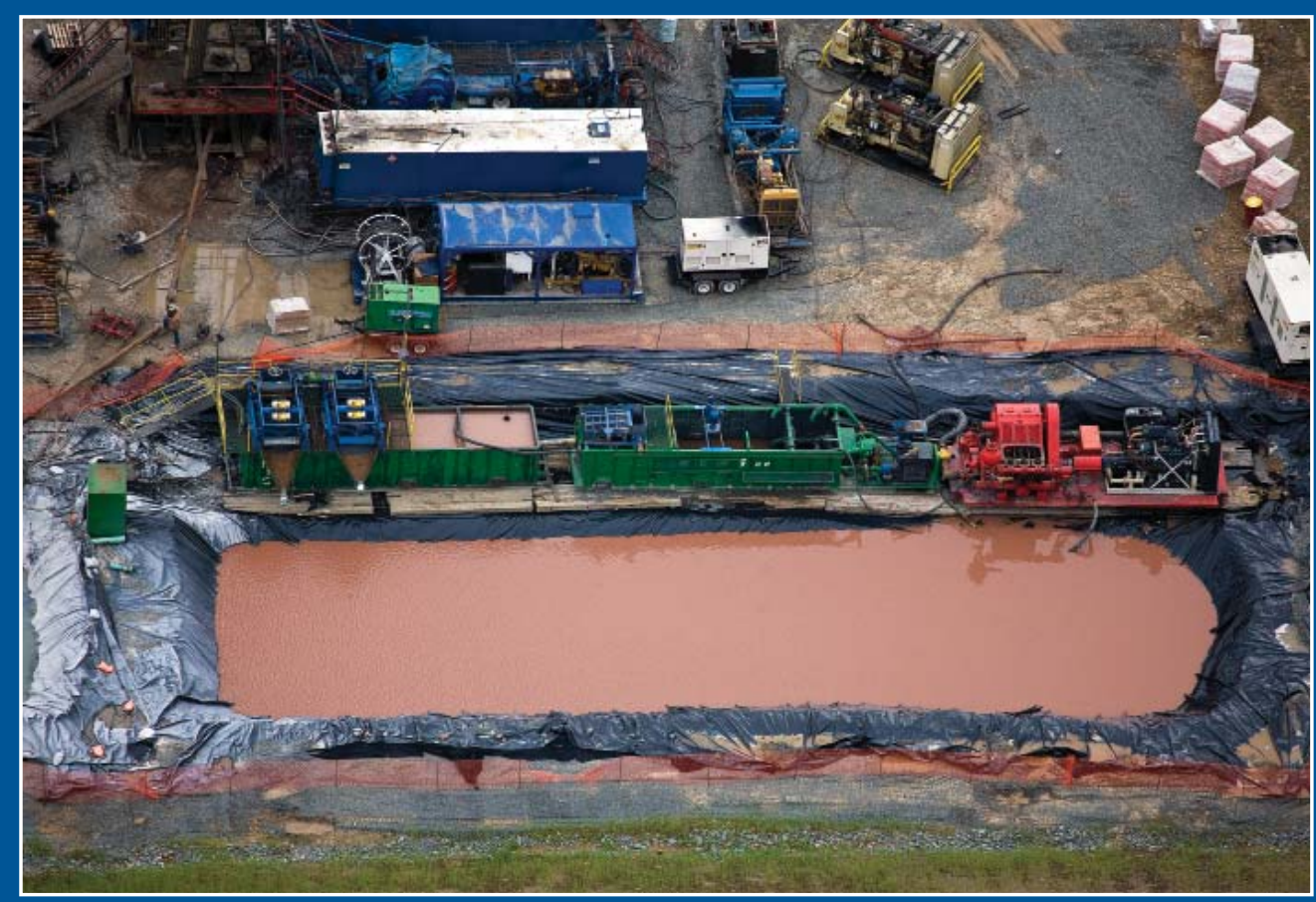

Waste pond at hydro-fracking drill site, Dimock, PA

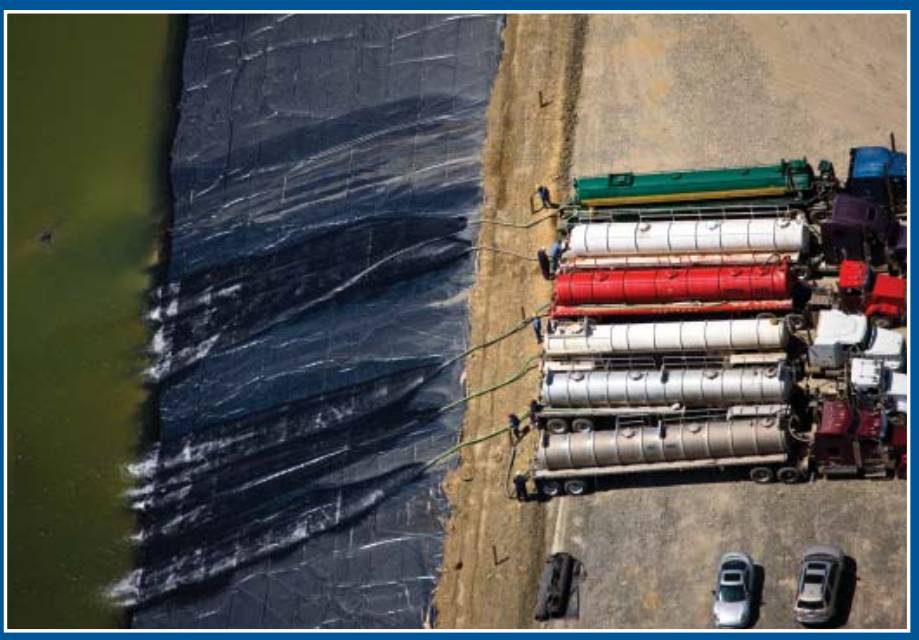

Tanker trucks filling water reservoir at hydo-fracking gas drilling operations near Sopertown, Columbia Township, PA
Elisabeth N. Radow (eradow@ cuddyfeder.com) is Special Counsel to the White Plains law firm of Cuddy \& Feder LLP. Ms. Radow chairs the Hydraulic Fracturing Committee for the League of Women Voters of New York State. Ms. Radow's Law Note, Citizen David Tames Gas Goliaths on the Marcellus Shale Stage, was published in the 2010 Spring issue of the Cardozo Journal of Conflict Resolution. This analysis and the assertions made in this article are attributable to the author alone.

Photographs courtesy of J Henry Fair Mr. Fair's work has appeared in the New York Times, Vanity Fair, Time and National Geographic. His new book, The Day After Tomorrow: Images of Our Earth In Crisis is a series of essays and startling images. www.industrialscars.com.

Flight services provided by LightHawk http://www.lighthawk.org.
Overspray of drilling slurry at hydro-fracking drill site, Dimock, PA

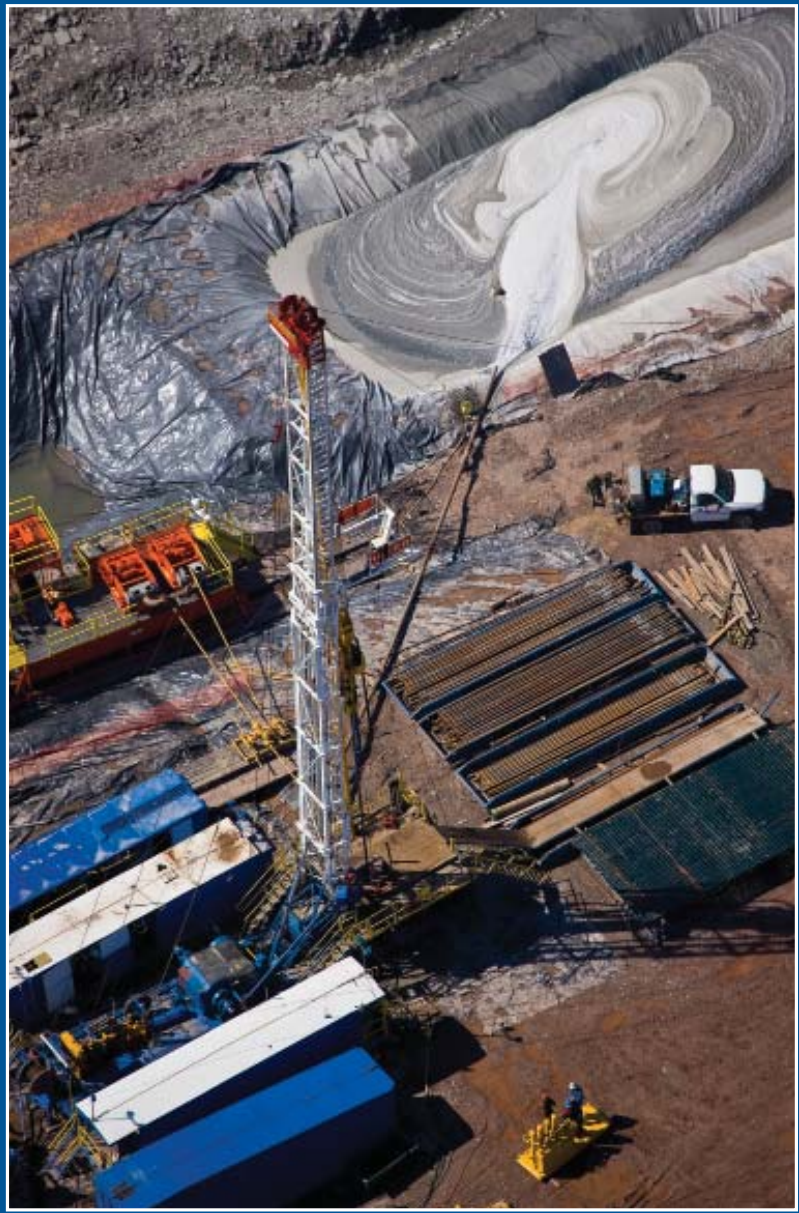


Residential fracking carries heavy industrial risks, and the ripple effects could be tremendous. Homeowners can be confronted with uninsurable property damage for activities that they cannot control. And now a growing number of banks won't give new mortgage loans on homes with gas leases because they don't meet secondary mortgage market guidelines. New construction starts, the bellwether of economic recovery, won't budge where residential fracking occurs since construction loans depend on risk-free property and a purchaser. This shift of drilling risks from the gas companies to the housing sector, homeowners and taxpayers creates a perfect storm begging for immediate attention.

\section{A home represents a family's most valuable asset, financially and otherwise.}

The introduction of fracking in homeowners' backyards presents a divergence from typical current land use practice, which separates residential living from heavy industrial activity, and the gas leases allocate rights and risks between the homeowner and gas company-lessee in uncharacteristic ways. Also, New York's compulsory integration law can force neighbors who do not want to lease their land into a drilling pool, which can affect their liability and mortgages as well.

\section{The Marcellus Shale Region}

The Marcellus Shale region, located across New York's Southern Tier, represents a portion of one of America's largest underground shale formations, with accessibility to gas deposits ranging from ground surface to more than a mile deep. The decade-old combined use of horizontal drilling and high-volume hydraulic fracturing is the current proposed means of extracting the trapped shale gas. Horizontal drilling, which dates back to 1929, became widely used in the 1980s, with the current technology providing lateral access to mile-deep shale in multiple directions from a single well pad.

To envision what this looks like, imagine one well pad that accommodates eight or more vertical wells with each well engineered to extend a mile or more in depth then turn and drill horizontally in its own direction, up to a mile through shale across residential properties and farms owned by a cluster of neighboring residents. High-volume hydraulic fracturing, first introduced by Halliburton in 1949, mixes millions of gallons of water with sand, brine and any of a number of undisclosed chemicals, which are injected into the well bore at pressure sufficient to rupture open the formation, prop open the mile-deep shale fractures with sand and release the trapped gas back into the well. Fracking-produced wastewater, with concentrated levels of these toxic chemicals, drilling mud, bore clippings and naturally occurring radioactive material, such as uranium, radium 226 and radon, is released from the well into mud pits and holding tanks, then trucked out for waste treatment or reused. Reuse of frack fluid, currently the favored practice because it spares the finite water supply, concentrates the waste toxicity. The Environmental Protection Agency estimates that $20 \%-40 \%$ of the fracking wastewater stays underground. The Marcellus Shale sits amid an intricate network of underground aquifers that supply drinking water in New York and surrounding states via municipal water supplies, private wells and springs. Shallow private wells constitute the primary source of drinking water for the upstate New York residences and farms where fracking for shale gas would take place, posing a cumulative threat to the state's complex matrix of aquifers that source our groundwater.

\section{The Risks}

The use of fracking expanded in 2005 when Congress exempted it through statutory amendments from complying with decades-old federal environmental laws governing safe drinking water and clean air. (This exemption is now commonly known as the Halliburton loophole.) Also in 2005, New York changed its compulsory integration law to pave the way for fracking.

According to the 2010 Form 10-Ks of Chesapeake Energy and Range Resources (both doing business in the Marcellus Shale region), natural gas operations are subject to many risks, including well blow-outs, craterings, explosions, pipe failures, fires, uncontrollable flows of natural gas or well fluids, formations with abnormal pressures and other environmental hazards and risks. Drilling operations, according to Chesapeake, involve risks from high pressure and mechanical difficulties such as stuck pipes, collapsed casings and separated cables. If any of these hazards occur it can result in injury or loss of life, severe damage or destruction of property, natural resources and equipment, pollution or other environmental damage and clean-up responsibilities, ${ }^{1}$ all in the homeowner's backyard.

American culture traditionally favors land use that keeps heavy industrial activity out of residential neighborhoods. The reasons range from safety to aesthetics. A home represents a family's most valuable asset, financially and otherwise. In legal terms, homeownership or "fee simple absolute title" means a bundle of rights encompassing the air space above and the ground below the land surface. It entitles homeowners to build up and out, pledge the house and land as collateral for a mortgage loan, and lease or sell the property. Part of a home's purchase price pays for this bundle of rights. Another bundle of rights attributable to homeownership

Continued on Page 14 


\section{Continued from Page 12}

consists of the actual roof over one's head; clean, running water; and access to utilities. A third bundle of rights is attributable to the intangibles that make a house a home, such as peaceful sanctuary, fresh air, and a safe, secure haven for budding children. Residential fracking challenges all of these attributes of home ownership.

\section{Shifting Risk}

Gas leases provide the bundle of rights from which gas companies generate financing and operate gas wells. Profitable gas extraction benefits from broad rights to access, extract, store and transport the gas, on the company's timetable. Gas leases contain these rights. Profitable gas investment benefits from latitude on timing of gas extraction and the latitude not to extract gas at all. Gas leases contain these rights too. The gas company has the sole discretion to drill, or not to drill. Leases provide the currency in trade. The longer the lease term, the more latitude a leaseholder has to manage market fluctuations. With its broad gas storage rights, a leaseholder can store gas from other sources, on-site and wait for the demand curve to peak before executing the most favorable transactions. In August 2011, the U.S. Geologic Survey estimated reserves of "technically recoverable" shale in the Marcellus Shale play at 84 trillion cubic feet, reflecting a significant reduction from DEC's long-standing website estimate of between 168 trillion and 516 trillion cubic feet. Shale gas projections have an inherent value, separate and apart from the extracted gas. People invest capital based on the anticipated reserves. Time will tell how the new estimates change if and where gas companies actually drill in New York. Some regions may be too difficult or expensive to access; others will be off-limits by law. The terms of the gas leases nevertheless entitle the gas lessee to maintain the leasehold, which can facilitate investor activity. The Form 10-K appended to the 2010 Chesapeake Energy Annual Report states,

Recognizing that better horizontal drilling and completion technologies, when applied to new unconventional plays, would likely create a unique opportunity to capture decades worth of drilling opportunities, we embarked on an aggressive lease acquisition program, which we have referred to as the "gas shale land grab" of 2006 through 2008 and the "unconventional oil land grab" of 2009 and 2010. We believed that the winner of these land grabs would enjoy competitive advantages for decades to come as other companies would be locked out of the best new unconventional resource plays in the U.S. We

Hydro-fracking drill sites, feeder pipelines, and access roads and gravel banks for road building (Dimock, PA)

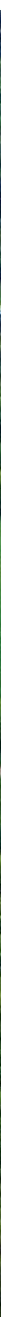


believe that we have executed our land acquisition strategy with particular distinction. At December 31, 2010, we held approximately 13.2 million net acres of onshore leasehold in the U.S. and have identified approximately 38,000 drilling opportunities on this leasehold. We believe this extensive backlog of drilling, more than ten years worth at current drilling levels, provides unmistakable evidence of our future growth capabilities. $^{2}$

The broad bundle of rights granted by gas leases enables gas companies to raise capital in the millions or billions of dollars once the up-front per-acre signing bonus is paid to the homeowner. This is beneficial for the drilling investment itself and for maintaining the company's competitive advantage. On the other hand, the effect of the lease encumbering the homeowner's residence can have repercussions for mortgage financing, as will be discussed below.

\section{Getting the Gas}

Drilling companies derive the right to drill underneath residential (and non-residential) property in three ways:

- deed to the subsurface rights below the fee estate (a practice not typically used in New York);

- lease agreement with the fee owner; and

- compulsory integration, which involves government action that forces a property owner who wishes no drilling activity below its property into a drilling pool if the lessee otherwise has control of a statutorily prescribed percentage of land (in New York it is $60 \%$ ).

A drilling application submitted to DEC must show the area (up to 640 aces), known as a spacing unit, assigned to the well. The spacing unit becomes officially established when DEC issues the well permit.

\section{Deed to Subsurface Rights}

A deed to the subsurface or mineral rights splits the fee estate between the surface property and the subsurface property, with separate deeds for each estate. Subsurface deeds are common in Western states where drilling is an established practice; it gives the deed holder the full range of rights to the subsurface. As with the surface deed, it is considered a real property interest and is also recorded in the land records against the section, block and lot for the surface property. The rights do not extend above the subsurface and should not, as a legal matter, interfere with the rights of the surface owner. As a practical matter, because of drilling lifecycle hazards, the surface owner may sacrifice some of the attributes of home ownership discussed in this article.

\section{Standard Lease Agreement With Fee Owner}

The standard space lease, between a building owner (landlord or lessor) and a tenant (or lessee) grants the right to occupy a specified space in the building for a finite time, in exchange for an agreed upon rent payable in regular installments. If the lease contains a percentage rent (a commercial lease concept based upon tenant revenue), it includes a formula for calculating the percentage rent and gives the landlord the right to inspect the tenant's books to verify that the landlord receives the agreed upon percentage. Except for the space leased to the tenant, the landlord retains all rights of ownership. When the lease expires, the tenant moves out, or the tenancy converts to a month-to-month tenancy. No duration of month-to-month holding over on the tenant's part converts the month-to-month arrangement into a lease for years. To end the relationship, either the landlord or tenant can give 30 days' written notice to the other. ${ }^{3}$ To extend beyond the month-to-month relationship, the parties must enter into a new written lease.

In contrast, gas leases function more like a deed with a homeowner indemnity than a space lease - revealed by an assessment of the cumulative impact of the broad bundle of rights granted to the gas company-lessee and the corresponding bundle of rights relinquished by the homeowner. Standard pre-printed gas leases presented to New York homeowners by landmen and signed, without negotiation, represent the typical practice (until recently) in our state, and will be used here to illustrate the impact this has on the of rights and responsibilities of the homeowner. Depending upon the DEC's ultimate regulatory framework, homeowners who negotiate gas leases can expect similar impacts given the industrial sized risks involved.

\section{The Use}

A gas lease grants the right to extract the gas and a litany of related gas-constituents; it also grants the right to explore, develop, produce, measure and market for production from the leasehold and adjoining lands using methods and techniques which are not restricted to current technology.

\section{The Space}

In a standard gas lease, the physical leased space consists of the subsurface area within the property boundaries and undesignated portions of the surface lands
to set up and store drilling equipment; create a surface right of way to use or install roads, electric power and telephone facilities, construct underground pipelines and so-called "appurtenant facilities," including data acquisition, compression and collection facilities for use in the production and transportation of gas products to, from and across the leased property; and store any kind of gas underground, regardless of the source, including the injecting of gas, protecting and removing gas, among other things.

The lessee's expansive, undesignated, reserved surface rights can result in acres going to support the operation, jeopardize a home mortgage and eliminate the homeowner's ability to build on the surface in 
areas the lessee determines would interfere with drilling operations. Without limiting the location, size and type of pipeline, the homeowner leaves open the chance of a high-pressure gas line running under the property.

\section{The Term}

The lease runs for a five-year primary term (a portion contain a five-year renewal term), which in a standard lease the lessee can unilaterally transform into an indefinite, extended term, without signing a new lease, for any of the following reasons:

exploration anywhere in the spacing unit, or a well in the spacing unit is deemed "capable of production," or gas from the spacing unit is produced, or the spacing unit is used for underground gas storage, or the prescribed payments are made.

The term "capable of production" is defined broadly enough to include off-site preparatory work. Regardless of the stated lease term, once a well is "capable of production," the rights continue for as long as operations continue, possibly decades.

\section{The Rent}

Homeowners receive a signing bonus ranging from dollars to thousands of dollars per acre of leased land. This single payment can potentially tie up the property, indefinitely. References in so-called "paid-up" leases (common in New York) to other potential additional payments (except for the royalty payment) are deemed satisfied by the signing bonus. Absent negotiation, royalties consist of a percentage (typically $1 / 8$ or $12.5 \%$ ), net of production-related expenses and any loss in gas volume that reduces the revenue received. Late payments or failure to make a royalty payment can "never" result in an automatic lease termination. Homeowners share the royalty with other members of the drilling pool on a pro-rated basis. This is known as correlative rights. The larger the drilling pool, the smaller the royalty. Unlike the percentage rent provision in a commercial lease, a gas lease contains no detailed formula for calculating the net royalty payment, no pro-rata share corollary to calculate the relative percent the homeowner bears to the pool of all other property owners entitled to divide the royalty pie and no right to review the lessee's books and records.

\section{Assignment}

Space leases require a tenant to obtain landlord consent for a third-party lease assignment. In contrast, a gas lessee can sell and assign to or finance the gas lease (or any interest) with any party it selects, without providing notice to the homeowner. This continuing right deprives homeowners of control over confirming consistency between the initial lease and the terms of the assigned document - who ends up with the lease, who gets hired and allowed onto the family's private property and the quality of the drilling activity performed in their backyard. As the record title holder, homeowners remain potentially liable for the activity that occurs on their property, if it is not effectively delegated.

\section{Hazardous Activity/Hazardous Substances}

Space leases expressly prohibit hazardous activity and the presence or storage of hazardous substances on the property, such as chemicals and flammable or toxic petroleum products. Gas leases permit both the drilling activity and the use of hazardous substances and flammable products, such as the methane gas itself. Gas leases reserve the right to store gas of any kind, indefinitely, underground, regardless of the source, which can create additional risk to the homeowner's personal safety and adversely impact, as will be discussed, a homeowner's responsibility to its lender.

\section{Easements}

Gas leases contain grants of easements, which is not typical for a lease. This grant includes the lessee's right, even after surrendering the leasehold, to "reasonable and convenient easements" for the existing wells, pipelines, pole-lines, roadways and other facilities on the surrendered lands. Assuming its enforceability, a driller can surrender a lease and still assert a range of potentially perpetual surface and subsurface rights as superior to those of the fee owner without any further payment and without the obligation for repair, maintenance or resulting damage. However, unless the actual lease containing the easement grant gets recorded against the residential property in the public records, which, apparently is often not the case, the lessee has no assurance the easements will be protected. Even so, leases reserving potentially perpetual, undesignated easements for roads and pipelines raise expensive, longterm liability concerns for homeowners, their lenders and, potentially, fellow taxpayers.

\section{Insurance/Indemnification-Risk Allocation to Homeowner}

Space leases typically require the tenant to post a security deposit to cover late rent or property damage. Gas leases do not contain a similar provision. Space leases also require tenants to purchase general liability insurance naming the landlord as an additional named insured with an indemnity covering costs for uninsured damage and other costs occasioned by the tenant and its invitees. Risks associated with typical leasehold property damage belong to tenants since they control the space. Drilling leases typically omit these points. Absent negotiation, gas leases contain no insurance and no indemnification. Even assuming the existence of an indemnification, federal protection via the Halliburton loophole can provide cover. Unless anticipated DEC rules change, New York intends to require disclosure only of fracking chemicals by gas companies. While this represents a step in the right 
direction, it also gives companies an "out" by merely requiring them to disclose which chemicals they use. It does not necessarily make companies liable for the damage those chemicals cause. Eliminating the right to frack with toxic and carcinogenic chemicals by reinstating the laws amended by the Halliburton loophole would eliminate the shift of financial responsibility away from the gas company as it relates to this aspect of the gas drilling lifecycle. Regulating use of benign fracking additives that can boost risk would be useful as well. For example, radioactivity, a known danger at elevated levels, poses greater risks when it interacts with frack-fluid additives that contain calcium. ${ }^{4}$ By not restoring liability to the companies that control drilling operations and coupling it with economic reasons to prevent casualties, role in the lease process. Contract law favors the rights of private parties to enter into arm's-length transactions without government intervention. Yet, when large numbers of complaining upstate homeowners recount consistent practices employed by the landmen that resulted in pre-printed standard gas leases signed without negotiation, it would be appropriate to involve the New York Attorney General, to examine the facts. In consumer protection contexts, the government (on its own or as a result of litigation) has seen fit to offer protection. Homeowners who signed gas leases do not constitute consumers per se, but the analogy supports Attorney General involvement to restore to the landowner the bulk of rights attributable to fee ownership and, by extension, the property's value. Paradoxically, for

\section{Assuming its enforceability, a driller can surrender a lease and still assert a range of potentially perpetual surface and subsurface rights as superior to those of the fee owner.}

a homeowner will have to first experience the property damage or personal injury, then successfully arbitrate or litigate against the gas lessee for reimbursement and remediation, a burden most homeowners can't afford or mentally handle. Even assuming a homeowner's fortitude to sue, focus on damages and remediation misses the fact that residential fracking introduces irreparable risks to homes and the families that live there.

\section{Gas Lease Mortgages}

New York law ${ }^{5}$ recognizes minerals (before extraction) as real property. In May 2011, a Chesapeake Energy subsidiary, Chesapeake Appalachia, pledged mineral rights on over 1,000 Bradford County, Pennsylvania, mineral leases as collateral for a $\$ 5$ billion line of credit mortgage loan with Union Bank of California, while in July, 2011, another Chesapeake Energy subsidiary, Appalachia Midstream Services, pledged pipeline rights-of-way on over 2,000 Bradford County properties to access an unspecified line of credit mortgage loan with Wells Fargo. Although the mortgage was properly recorded in the county recorder's office against the section, block and lot of the fee/surface property, the news of a $\$ 5$ billion loan linked to their property surprised mortgage-seeking homeowners. Legally, Chesapeake's mortgaged interests are distinguishable from the surface owner's, so that shouldn't interfere with a home loan, but residential fracking might. It is worth noting that Wells Fargo, one of Chesapeake's lenders, stands among national lenders that do not grant mortgage loans to homeowners with gas leases.

\section{Homeowner Predicament}

Despite DEC website warnings about the potential adverse impacts of gas leases, ${ }^{6}$ the government plays no example, gas leases reciting "good faith negotiations" between the parties lock in homeowners with lesseefavored termination clauses. Unlike space leases that terminate on a stated expiration date, gas leases give lessees latitude to extend a stated lease term, indefinitely, by asserting it is "capable of production" or "paid up" or otherwise, subject to "force majeure," asserting New York's de facto drilling moratorium as the event beyond their control. "Force majeure" litigation is now on the dockets across New York's Southern Tier.

\section{Municipal Backlash; Indefinite Leases}

Municipalities within the 28 counties sitting on top of New York's Marcellus Shale differ on the benefits of fracking. Municipalities in favor of fracking focus on local economic growth. ${ }^{7}$ Municipalities opposing fracking take into consideration competing established economies, such as agriculture and tourism. By asserting home rule, municipalities have enacted moratoria, amended master plans or codes to prohibit heavy industry, including gas drilling, and banned drilling on public land or altogether. ${ }^{8}$ In September 2011, Anschutz Exploration Corp. filed a lawsuit against the Town of Dryden asserting the supremacy of the state to issue a drilling permit over the right of the municipality to amend its zoning law to prohibit drilling or storage of natural gas. ${ }^{9}$ The outcome of this case will have significant ripple effects throughout the state.

When municipalities favor fracking, homeowners with questions or concerns are on their own. Residents who do not wish to renew and residents who are committed to leasing but want to renegotiate terms when their lease expires, as with an expired space lease, are meeting some resistance from the gas 
companies, who are using General Obligations Law $\S 15-304$ (GOL) to reinstate expired leases. That statute states that before a recorded drilling lease expires by its own terms, the owner "may" serve a cancellation notice to the lessee triggering a lessee right to file an affidavit affirming that the lease is in full force and effect. Then, more papers get filed to confirm and preserve that right. Unlike the space lease which terminates on a certain date, GOL § 15-304 gives drillers a second chance which (so long as the driller has recorded the full lease) can tie an unwilling homeowner indefinitely to a gas lease the homeowner no longer wants. Homeowners electing not to give the statutory notice live in limbo, uncertain as to where they stand.

If a lessee decides to drill for gas but lacks the total acreage it needs, the lease provides the statutorily required leverage to form a so-called "spacing unit" by forcing unwilling property owners surrounding the voluntarily leased property into a drilling pool, a process called compulsory integration.

\section{Compulsory Integration}

Involuntary compulsory integration represents the most controversial method drilling companies use to access gas. Compulsory integration (or forced pooling) exists by statute in 39 states. ${ }^{10}$ It replaced the common law rule of "capture" which allowed Person A to legitimately collect and own gas from Person B's supply if it flowed into Person A's well. To capture gas before a neighbor did, surface wells proliferated in close proximity to one another, causing the overall gas pressure to drop and making gas extraction inefficient for all involved. It also blighted the surface lands. Today, Environmental Conservation Law § 23-0901 (ECL) deputizes a driller, subject to a DEC hearing, to force an unwilling property owner into a spacing unit if the drilling company otherwise controls $60 \%$ or more of the acreage in the spacing unit either by lease, deed or voluntary integration, 11 which itself involves lease swaps among leaseholders to form the spacing unit.

Proponents assert that forced pooling makes the drilling infrastructure investment more cost efficient by maximizing access to gas while also maintaining the surface landscape and fairly compensating the noncontributing "integrated" homeowner with a shared net $12.5 \%$ royalty. Opponents consider it a form of eminent domain. The constitutionality of forced pooling under a predecessor statute was confirmed in dicta by the New York Court of Appeals in Sylvania v. Kilborne, itself citing the United States Supreme Court, which held that "a state has constitutional power to regulate production of oil and gas so as to prevent waste and to secure equitable apportionment among landholders of migratory gas and oil underlying their land fairly distributing among them the costs of production and the apportionment." 12
Yet, the updated statute's effect eliminates the homeowner's right to control the homestead, creates financial risk for the driller's acts by not expressly holding the driller responsible, and jeopardizes access to a mortgage or the ability to sell the property. The ECL permits objection by a homeowner to the forced pooling within prescribed guidelines (having a scientific basis) none of which includes asserting a conflict with other (existing or intended) contract obligations, such as a mortgage. ECL § 23-0503, empowers DEC to schedule an adjudicatory hearing if it determines that "substantial and significant issues have been raised in a timely manner." Whether a driller's rights of involuntary compulsory integration come after, or trump, sanctity of contract between a homeowner and its mortgage lender needs clarification.

\section{\$6.7 Trillion Secondary Mortgage Market}

The Federal Housing Finance Agency (FHFA) was created in July 2008 on the heels of the mortgage crisis, to provide supervision, regulation and housing mission oversight of Fannie Mae and Freddie Mac and the Federal Home Loan Banks (FHLB) and to support a stable and liquid mortgage market. As of September 2010, according to FHFA, the combined debt obligations of these government-sponsored entities totaled $\$ 6.7$ trillion, with Fannie Mae and Freddie Mac purchasing or guarantying $65 \%$ of new mortgage originations. FHFA, as conservator of the secondary mortgage market, has a fiduciary responsibility to promote the soundness and safety of the secondary mortgage market. It is in FHFA's interest to limit mortgage defaults.

Most American homeowners hold a mortgage loan and $90 \%$ of all residential mortgage loans are sold into the secondary mortgage market (exceptions exist for million dollar homes which do not get sold by the lending bank). It is assumed that most upstate New Yorkers who signed gas leases have a mortgage, will want one in the future or want that right for a future purchaser. Mortgage lending favors low-risk activity on its mortgaged properties. Fannie Mae, Freddie Mac and the FHLB establish lending guidelines for appraisers and underwriters that dictate whether a home is a worthy investment. This helps to facilitate their combined mission to attract investors, such as pension funds, who provide liquidity in the secondary mortgage market. Primary lenders, in turn, rely on their borrowers' compliance with mortgage covenants mirroring these lending guidelines for the life of the loan.

Assuming $10 \%$ of the existing secondary mortgage market portfolio includes residential properties subject to drilling activity, this amounts to $\$ 670$ billion of secondary mortgage market debt; assuming the number is only $1 \%$, this amounts to $\$ 67$ billion. Eventually, gas drilling may span up to 34 of the lower 48 states, including densely populated cities such as Fort Worth, 


\section{POINT OF VIFW}

Texas. If so, a substantial portion of the secondary residential mortgage market portfolio may be at risk from residential fracking.

\section{Loan Underwriting Reveals Collateral Flaws With Residential Fracking}

Home Appraisal

All mortgage loans require a property appraisal, title insurance covering the lender or its assignees and homeowner's insurance. Home and land appraisals are based upon like-properties, similarly situated, and are used to determine market value, the loan-to-value ratio and the maximum loan amount. Reliable appraisals of properties subject to gas leases are difficult to obtain and potentially prohibitively expensive; it would require a comprehensive title search of area properties encumbered by gas leases. Often a memorandum of the gas lease and not the lease itself is recorded, and a read-through of the entire gas lease is required to make a fair comparison between lease-encumbered properties. Underwriters need to evaluate the risks and know who pays for them; without the full lease in hand, they can't make such an evaluation. ${ }^{13}$

Evaluating the driller's identity can be another underwriting challenge; with unrecorded lease assignments, lenders don't know who is performing the heavy industrial activity on their residential collateral. Federal Housing Authority guidelines for federally insured mortgage loans, which make up a portion of the secondary mortgage market debt, require that a site be rejected "if property is subject to hazards, environmental contaminants, noxious odors, offensive sights or excessive noise to the point of endangering the physical improvements or affecting the livability of the property, its marketability or the health and safety of its occupants,"14 all of which are potential characteristics of residential fracking.

\section{Lender's Title Insurance}

A lender's title policy insures the mortgage lien, as of the date of the policy (up to the loan amount), against loss or damage if title is vested in someone other than the homeowner. Gas leases signed after the policy date are not covered by the policy. Gas leases in effect when the policy is issued will be listed as a title exception. Coverage won't include the gas lease or any claims arising out of it. Title endorsements don't eliminate this exception to coverage. Underwriters consider these exceptions a red flag, sufficient to jeopardize the loan. Lenders financing properties subject to compulsory integration won't discover the title encumbrance from a title search because ECL $\S 23-0901$ makes no apparent reference to recording the DEC determination of compulsory integration in the land records. New York title policies expressly exclude from coverage loss or claims relating to any permit regulating land use. It remains unclear

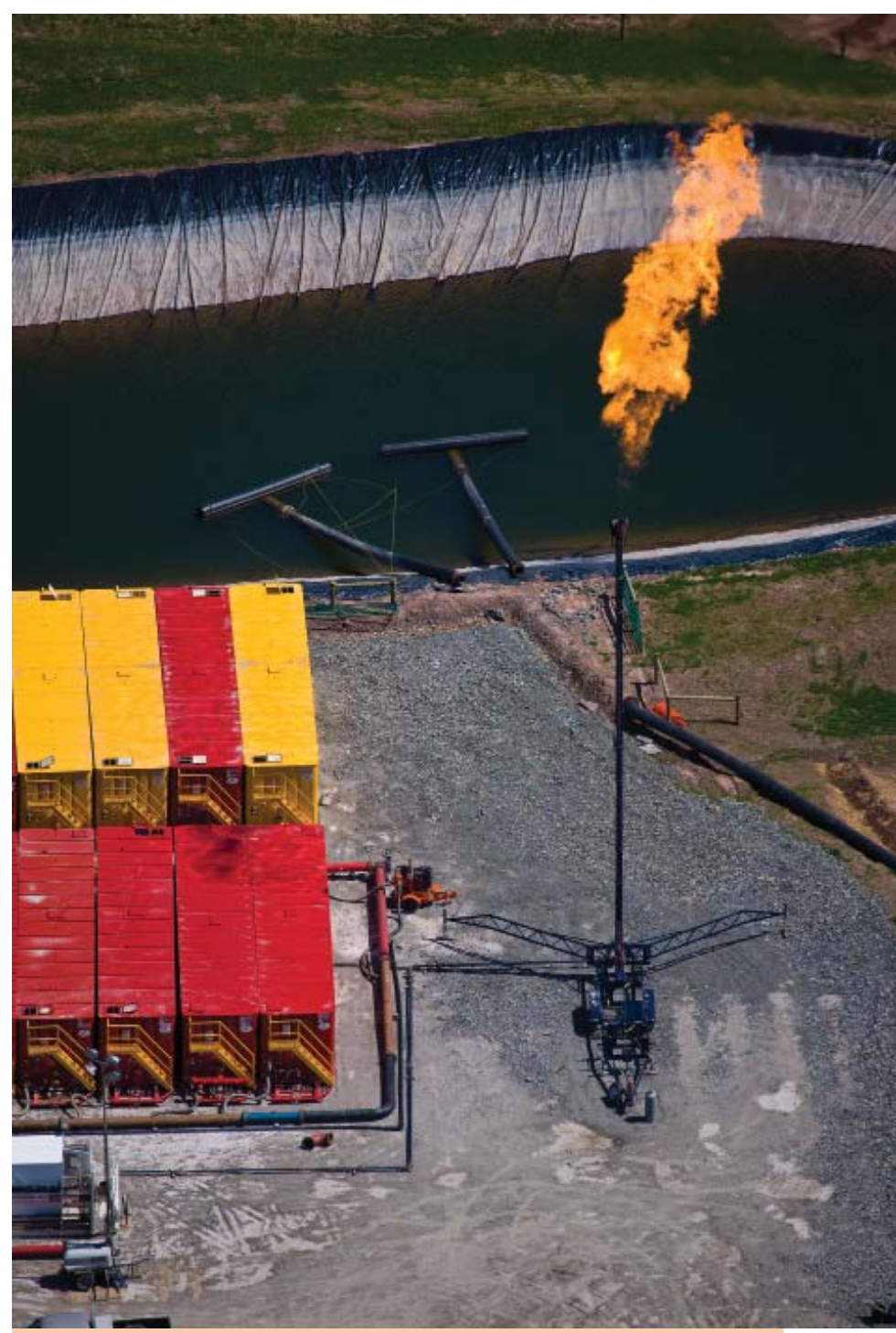

Flare at hydro-fracking gas drilling operations near Sopertown, Columbia Township, PA

whether a gas drilling permit which includes forced pooled property would fall within this exclusion. Either the Legislature will clarify the statute or the ambiguity will be a source of future litigation. Rating agencies and secondary mortgage market investors should be apprised if a loan portfolio which they have rated or in which they have invested, as the case may be, contains gas leases or forced pooled properties, since both add new risk.

\section{Homeowner's Insurance}

All residential mortgage lenders require homeowner's insurance from their borrowers. Even the most comprehensive homeowner's coverage, known as "broad risk form" or "special form" insurance excludes the types of property damage associated with the drilling lifecycle, such as air pollution, well-water contamination, earth movement and other risky commercial activity performed on residential property. 
The Mortgage: No Hazardous Activity/Substances, No Gas/Gas Storage, No Radioactive Material

Residential mortgages prohibit borrowers from committing waste, damage or destruction or causing substantial change to the mortgaged property or allowing a third party to do so. This includes operations for gas drilling. Standard residential mortgages prohibit borrowers from causing or permitting the presence, use, disposal, storage, or release of any "hazardous substances" on, under or about the mortgaged property. In mortgages, "hazardous substances" include gasoline, kerosene, other flammable or toxic petroleum products, volatile solvents, toxic pesticides and herbicides, materials containing asbestos or formaldehyde and radioactive materials. Borrowers are also prohibited from allowing anyone to do anything affecting the mortgaged property that violates any "environmental law." "Environmental law" means federal, state and local law that relates to health, safety and environmental protection. Mortgages obligate borrowers to give lenders written notice of any release, or threat of release, of any hazardous substances and any condition involving a hazardous substance which adversely affects the value of the mortgaged property.

Mortgages prohibit the activities gas leases permit to preserve the property's marketability. For example, shallow water wells and springs, typical in the northeast, represent the home's drinking water source; they become susceptible to contamination from drill site spills and leaks or flooding from frack wastewater. Frack fluid chemicals, pollutants and naturally occurring radioactivity in the waste have been reported to far exceed levels considered safe for drinking water. A contaminated well cannot be easily remediated, if at all. A home or a farm without on-site potable water may not sell. Migrating methane gas from the drilling process risks explosions both inside and outside of the home.

Because water and migrating methane gas each defy boundaries, following minimal underwriting setback requirements between the home and the drill site may prove inadequate to protect a water well from irreparable contamination or a home from explosion. A bank can consider these factors when approving a mortgage loan, and once financed, when declaring a mortgage loan in default.

\section{Homeowner and Lender Vulnerability}

The 2010 Form 10-K issued by Chesapeake states:

There is inherent risk of incurring significant environmental costs and liabilities in our operation due to our generation, handling and disposal of materials, including waste and petroleum hydrocarbons. We may incur joint and several liability, strict liability under applicable U.S. federal and state environmental laws in connection with releases of petroleum hydrocarbons and other hazardous substances at, on, under or from our leasehold or owned properties, some of which have been used for natural gas and oil exploration and production activities for a number of years, often by third parties not under our control. For our non-operated properties, we are dependent upon the operator for operational and regulatory compliance. While we maintain insurance against some, but not all risks described above, our insurance may not be adequate to cover casualty losses or liabilities, and our insurance does not cover penalties or fines that may be assessed by a governmental authority. Also, in the future we may not be able to obtain insurance at premium levels that justify the purchase. ${ }^{15}$

In the Form 10-K appended to its 2010 Annual Report, Range Resources adds:

We have experienced substantial increases in premiums, especially in areas affected by hurricanes and tropical storms. Insurers have imposed revised limits affecting how much the insurer will pay on actual storm claims plus the cost to re-drill wells where substantial damage has been incurred. Insurers are also requiring us to retain larger deductibles and reducing the scope of what insurable losses will include. ${ }^{16}$

Signing a gas lease without lender consent is likely to constitute a mortgage default. At any time before or after the drilling begins, a lender can demand the borrower to either terminate the lease or pay off the loan. Since the gas companies have pledged the gas leases as collateral for loans or brought in investors based upon the potential income the gas lease can produce, facilitating a lease termination may require protracted litigation. Further, it is not likely that most homeowner-borrowers will have the ready cash to repay the loan. This places the lender in an untenable position.

Residential fracking, perpetual unfunded easements and long-term gas storage beneath mortgaged homes create a cumulative threat to the repayment of mortgage loans tranched in secondary mortgage market portfolios. Homeowners suffering irreparable property damage, such as well water contamination, structural damage or casualty from a gas explosion, won't have coverage from homeowner's insurance and may have no recourse against the gas company holding the lease. This is so even if homeowners sue and succeed in court since the gas companies' own disclosure statements state they are underinsured. New York State Comptroller Thomas Di Napoli has proposed an up-front gas company-funded emergency fund to remediate those emergencies that can be fixed. As of yet, the gas industry, the Governor, the state Senate and the Assembly have not offered support for such a fund. The Form 10-K for Chesapeake Energy and Range Resources, for example, cite the risks attendant to gas drilling. They do not indicate the source of funding to support the numerous risks from the drilling activity. Unless this source of funding can be identified, the secondary mortgage market, as holder of $90 \%$ of the nation's home mortgages, may be left with the 
clean-up bill. Ultimately, financial responsibility could fall on the taxpayers.

New York homeowners who signed gas leases without the facts about this unconventional drilling claim they did not know the risks involved. These homeowners did not know that they violated their mortgage by entering into the gas lease or have potentially no insurance coverage in case of a drilling loss. Impacted homeowners can write to New York's Attorney General to (1) document their experience; (2) request a reprieve from a mortgage loan default; and (3) institute a "no gas drilling" policy until it is determined that the mortgaged collateral won't be at risk from the driller's plans. To achieve this, gas leases should be revised to modify or omit the risky clauses, such as gas storage, surface rights and undesignated, unfunded easements. In the alternative, the gas leases can be terminated. Homeowners need help before gas permitting begins, in order to spare the homestead and the home mortgage market too.

\section{New Mortgages for Homeowners With Gas Leases and New Construction 18}

Even before the drilling commences, many upstate New York homeowners with gas leases cannot obtain mortgages. Bank of America, Wells Fargo, Provident Funding, GMAC, FNCB, Fidelity and First Liberty, First Place Bank, Solvay Bank, Tompkins Trust Company, CFCU Community Credit Union and others ${ }^{17}$ are either imposing large buffer zones (too large for many borrowers) around the home as a condition to the loan or not granting a mortgage at all.

Once lenders connect the "no hazardous activity" clause in the mortgage with the mounting uptick in uninsurable events from residential fracking, this policy can be expected to expand. Originating lenders with gas industry business relationships may decide to assume the risk, make mortgage loans to homeowners with gas leases and keep the non-conforming loans in their own loan portfolio. However, there is a limit to what an originating bank can keep in its own loan portfolio. Eventually, cash infusions from the secondary mortgage market will become a necessity; and secondary mortgage market lending guidelines will be a reality. If homeowners with gas leases can't mortgage their property, they probably can't sell their property either (this assumes the purchaser will need mortgage financing to fund the purchase). The inability to sell one's home may represent the most pervasive adverse impact of residential fracking.

Real estate developers and contractors rely on construction financing and financeable homeowners to stimulate construction starts. New York's upstate construction future depends upon the ability to sell what one builds. Washington County, Pennsylvania, for example, reported improved home sales servicing the gas industry in 2010, but apparently not of properties built on drill sites.

\section{The Conundrum Revisited}

The energy and housing sectors both rely on investor dollars to fund their future. Pension funds and other money sources that still invest in housing but now consider natural gas the preferred investment raise a potential paradox: Will individuals' retirement funds expand as their homeownership rights fade away? The conundrum to consider: how can a nation with $\$ 6.7$ trillion in residential secondary mortgage market debt that measures economic recovery by construction starts and new mortgage loans also accommodate risky and underinsured residential fracking involving a stillunknown quantity of this residential mortgage collateral? Before New York embraces fracking as a new frontier, it would be wise for our corporate and government leaders focused on the vitality of our housing and energy sectors to address and resolve this conundrum.

1. Chesapeake Energy Corp., 10-K: Annual Report Pursuant to Section 13 and 15(d) 27 (2011) (Chesapeake Energy 10-K: Annual Report); Range Resources, Uncovering Tomorrow's Energy: 2010 Annual Report 13 (2010) (Range Resources 2010 Annual Report).

2. Chesapeake Energy 10-K: Annual Report 4.

3. N.Y. Real Property Law § 232-b.

4. Mark Greenblatt, Texas drinking water makes pipes and plumbing radioactive, KHOU.com (May 18, 2011) at http:/ / www.khou.com/home/-I-Team-Texasdrinking-water-makes-pipes-and-plumbing-radioactive-1221408194.html.

5. N.Y. Jurisprudence, Mines § 7; see N.Y. Uniform Commercial Code § 9-102.

6. Div. of Mineral Res., A Landowner's Guide to Oil \& Gas Leasing, Dep't of Envtl. Conservation (2008), http://www.dec.gov/docs/materials_ minerals_pdf/brochure.pdf.

7. Cornell University Professor Susan Christopherson cautions against boom-bust impacts. See Susan Christopherson, Marcellus Gas Drilling, Cornell Univ. 2011, http://www.greenchoices.cornell.edu/development/marcellus.

8. Joe Hoff, Moratoria, Bans, Resolutions Opposed to Hydrofracking: A Local and Global Sampling, R-Cause (Sept. 20, 2011) www.r-cause.net/bans-moratoria.

9. Anschutz Exploration Corp. v. Town of Dryden \& Town of Dryden Town Bd., Supreme Court, Tompkins County; N.Y. Environmental Conservation Law $\S$ 23-0303(2) (ECL)

10. ECL § 23-0901; Marie C. Baca, State Law Can Compel Landowners to Accept Gas and Oil Drilling, Pro Publica (May 19, 2011), http:/ / projects.propublica. org/tables/forced-pooling.

11. ECL $\S 23-0901$

12. Sylvania Corp. v. Kilborne, 28 N.Y.2d 427 (1971) (quoting Hunter Co. v. McHugh, 320 U.S. 222 (1943)).

13. See Greg May, VP, residential lending, Gas and Oil Leases Impact on Residential Lending,Tompkins Trust Co., White Paper,(Mar. 24, 2011), http:/ / www.tompkins-co.org/tccog/Gas_Drilling/Focus_Groups/Assessment\%20 Documents/White\%20Paper.pdf

14. Dep't of Hous. \& Urban Dev., Valuation Analysis for Single Family One-toFour Unit Dwellings (4150.2) (2011).

15. Chesapeake Energy 10-K: Annual Report 29, supra note 1.

16. Range Resources 2010 Annual Report 13, supra note 1.

17. Greg May, VP, residential lending Tompkins County Trust, telephonic update of white paper, supra note 13, and Joseph Heath, Esq.

18. See Ian Urbina, Rush to Drill for Natural Gas Creates Conflicts With Mortgages, N.Y. Times, Oct. 20, 2011, p. 1. Mr. Urbina's article used Elisabeth Radow's August 11, 2011, letter to Freddie Mac and the federal agency that oversees Freddie Mac, warning the agencies about potential conflicts in the mortgage market, as a documentary source for his piece. The letter may be viewed at http://www.nytimes.com/interactive/us/drilling-downdocuments-8.html\#document/p12/a33448. 


\section{Impacts of Leasing Additional State Forest for Natural Gas Development}


DCNR is entrusted to balance the uses and values of our state forests while protecting the integrity and health of the whole system.

There are proposals and public debate about the merits of a moratorium on natural gas drilling on state forest.

This mapping analysis demonstrates how any additional leasing involving surface disturbance upsets the sustainable balance DCNR is charged to maintain. 


\section{State Forest Land in North-Central Pennsylvania}

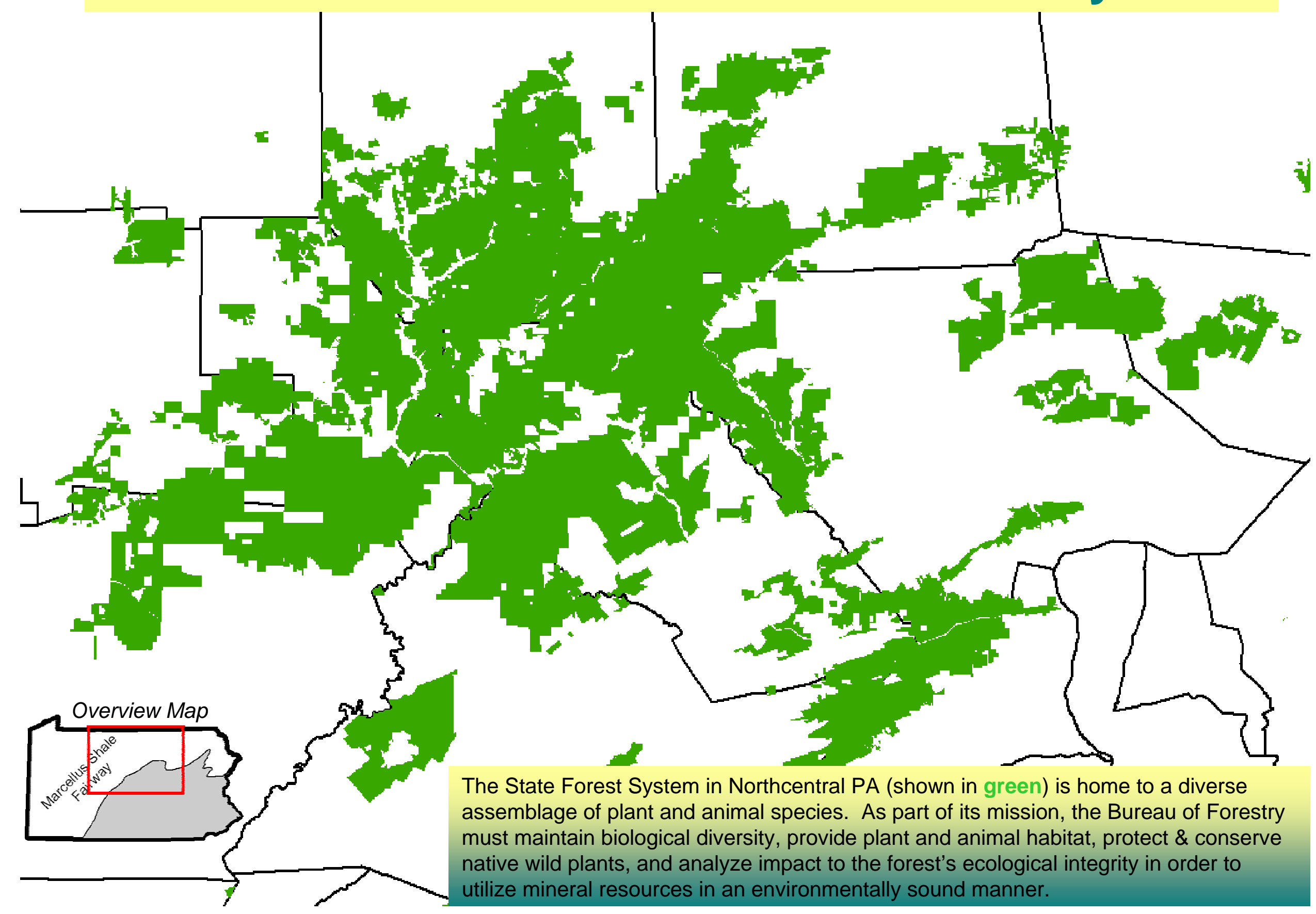




\section{State Forest Land in Northcentral Pennsylvania}

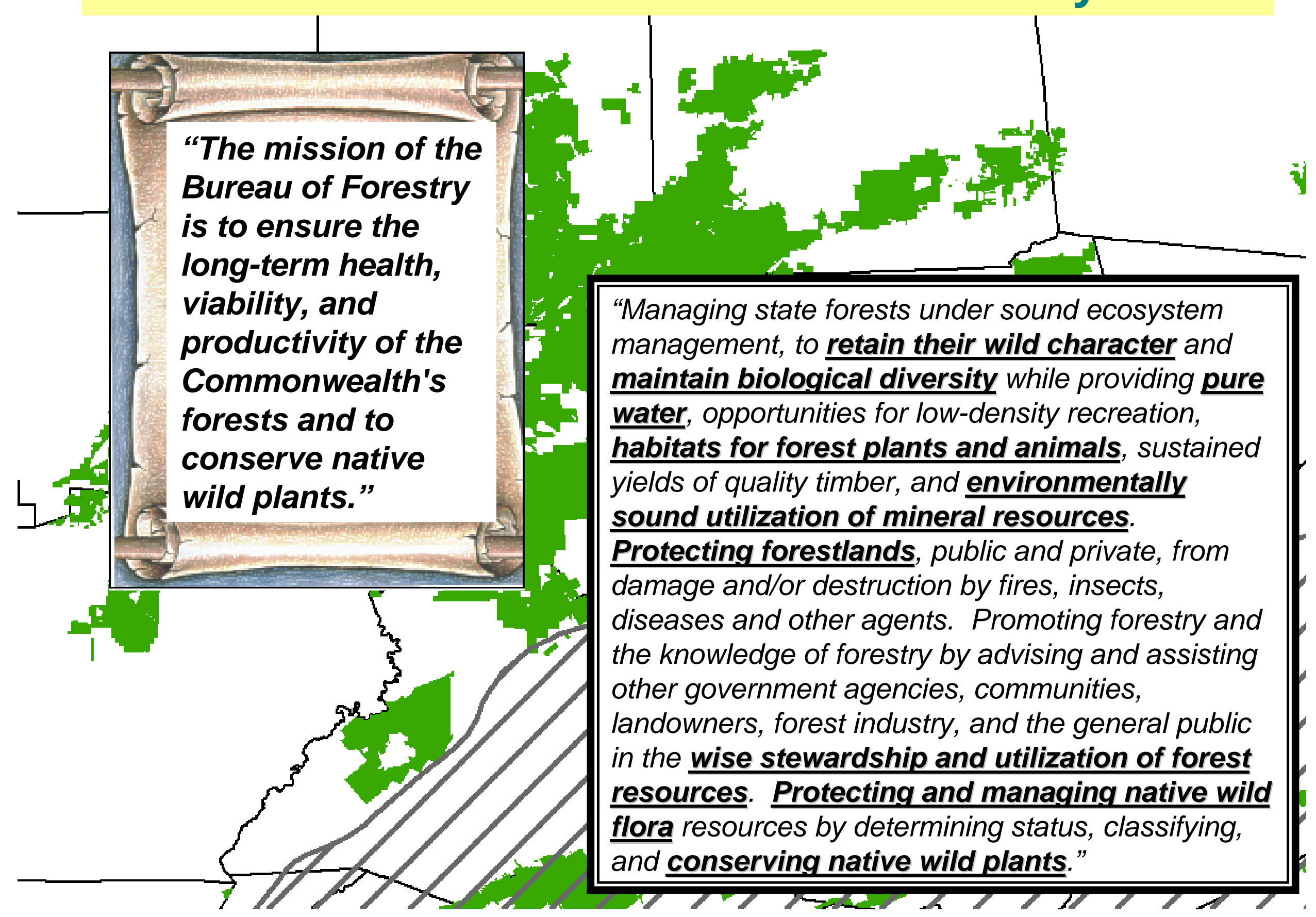




\section{Maintaining the Forest's Ecological Integrity}

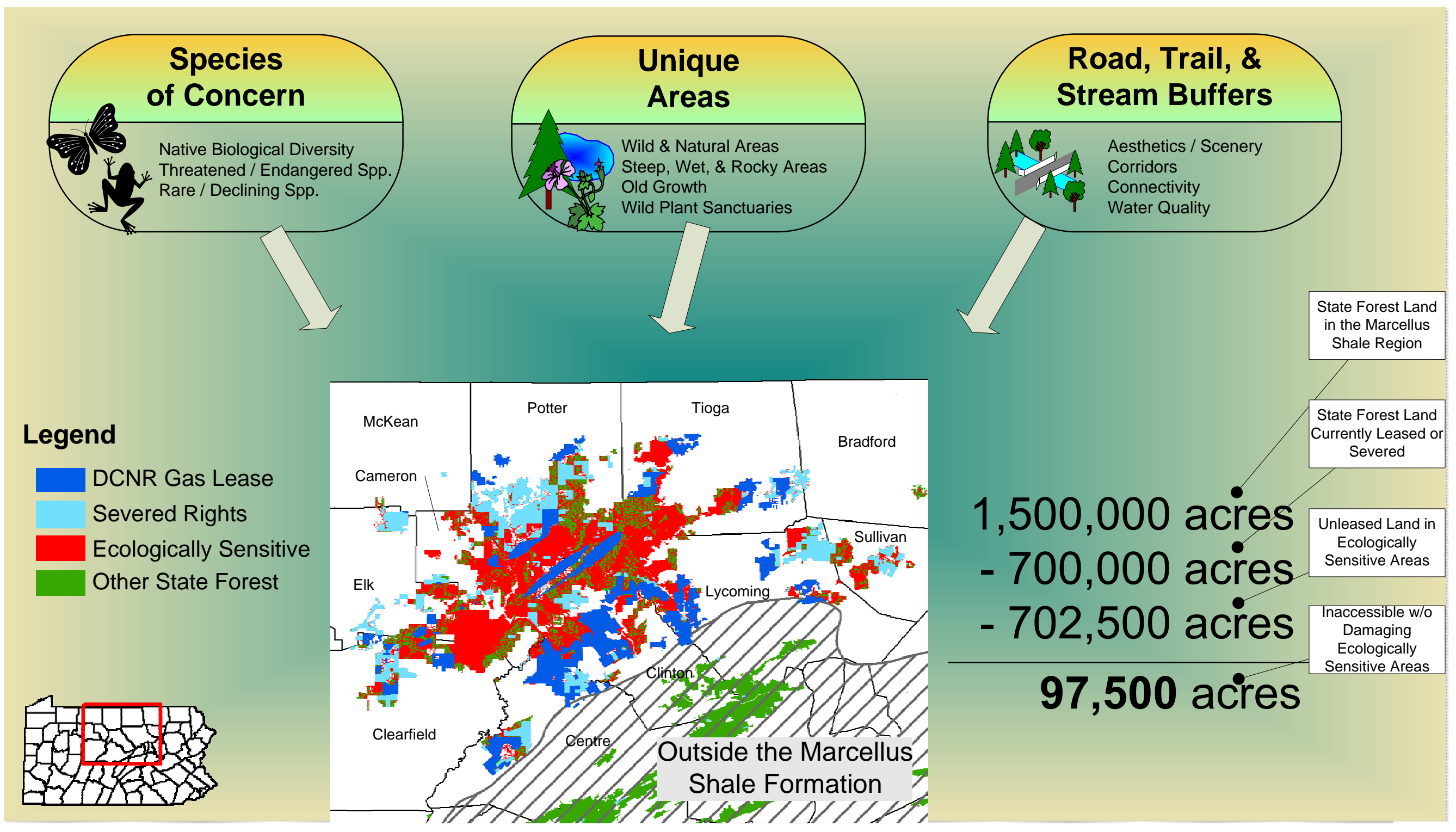




\section{Maintaining the Forest's Ecological Integrity}

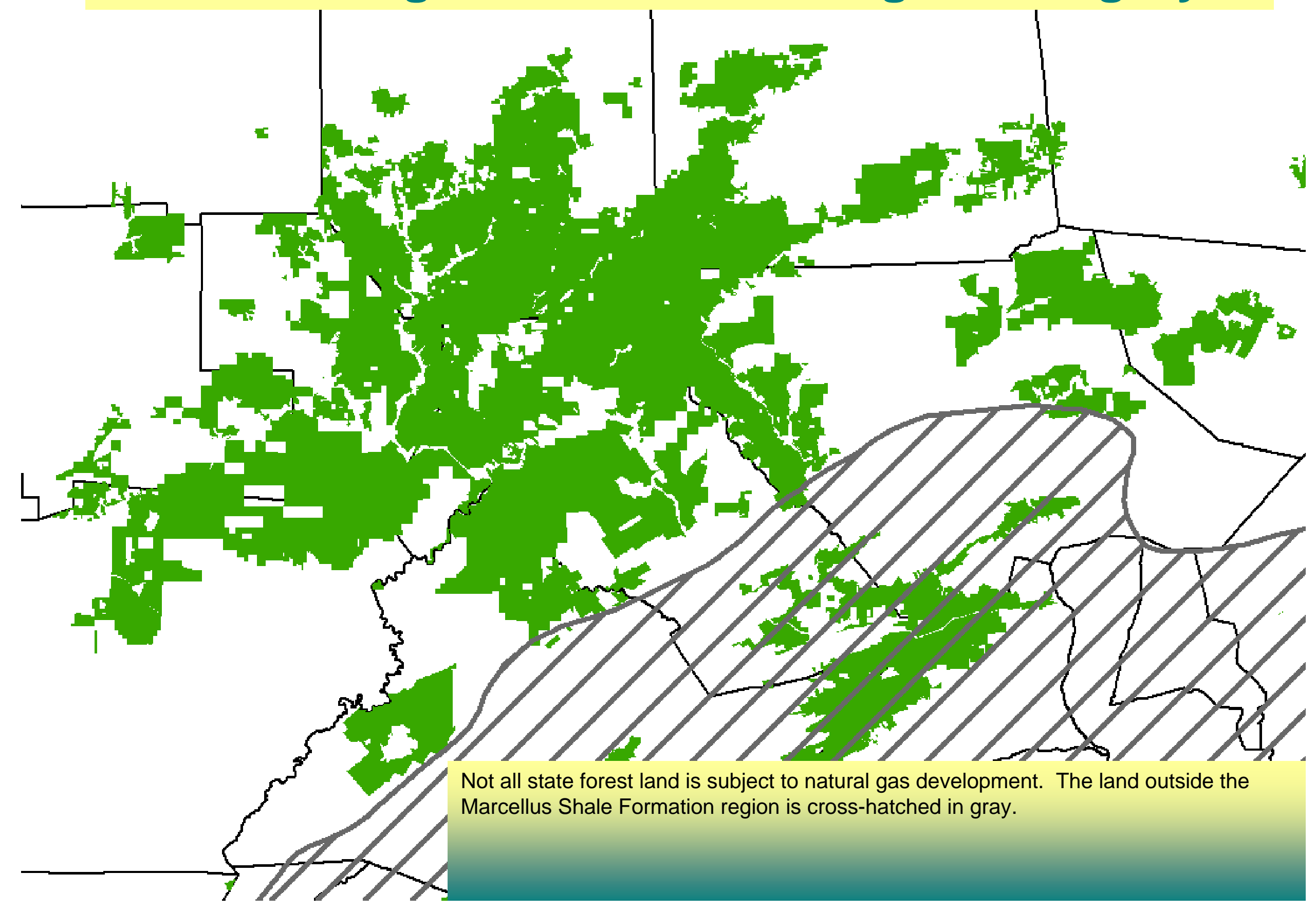




\section{Maintaining the Forest's Ecological Integrity}

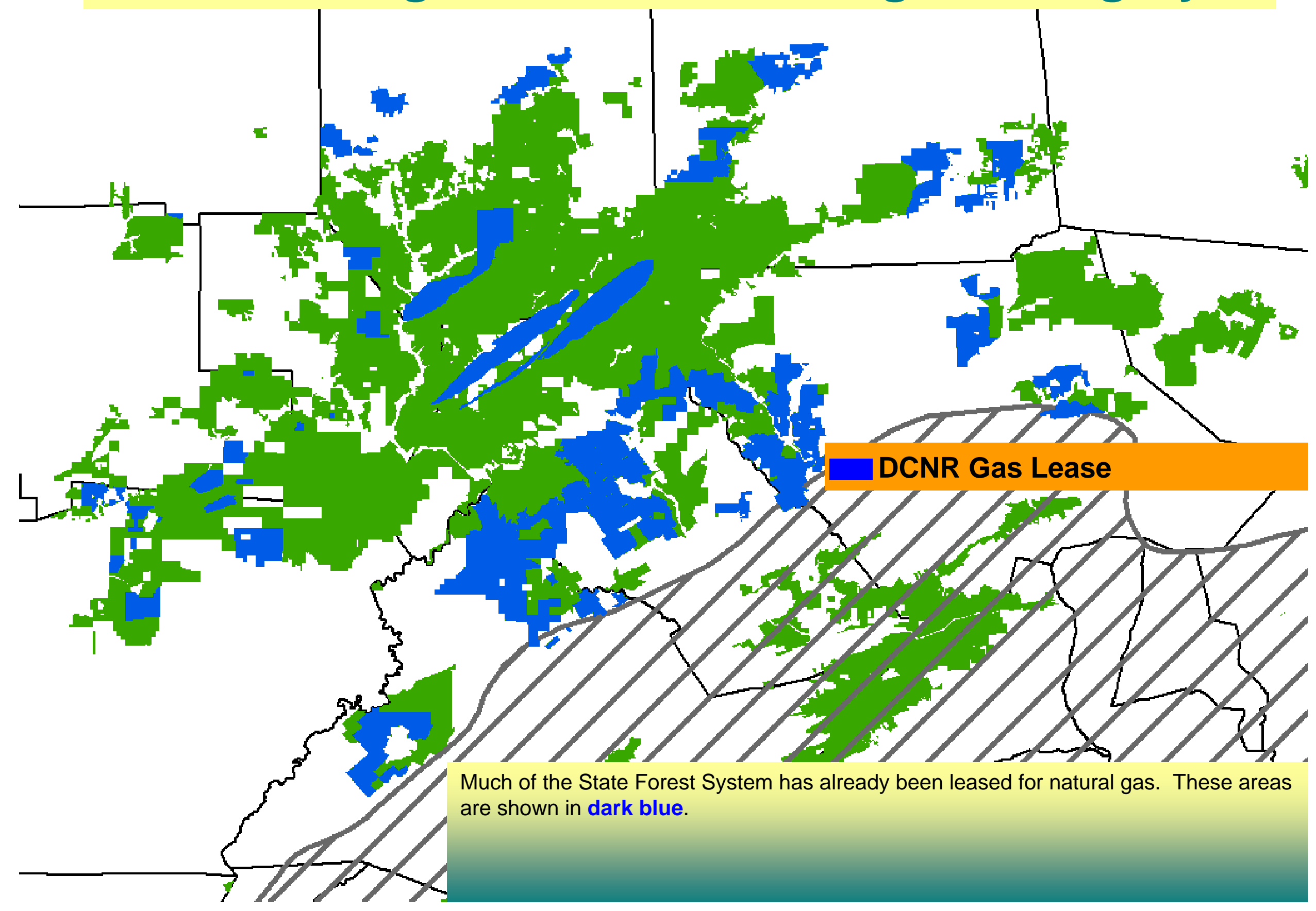




\section{Maintaining the Forest's Ecological Integrity}

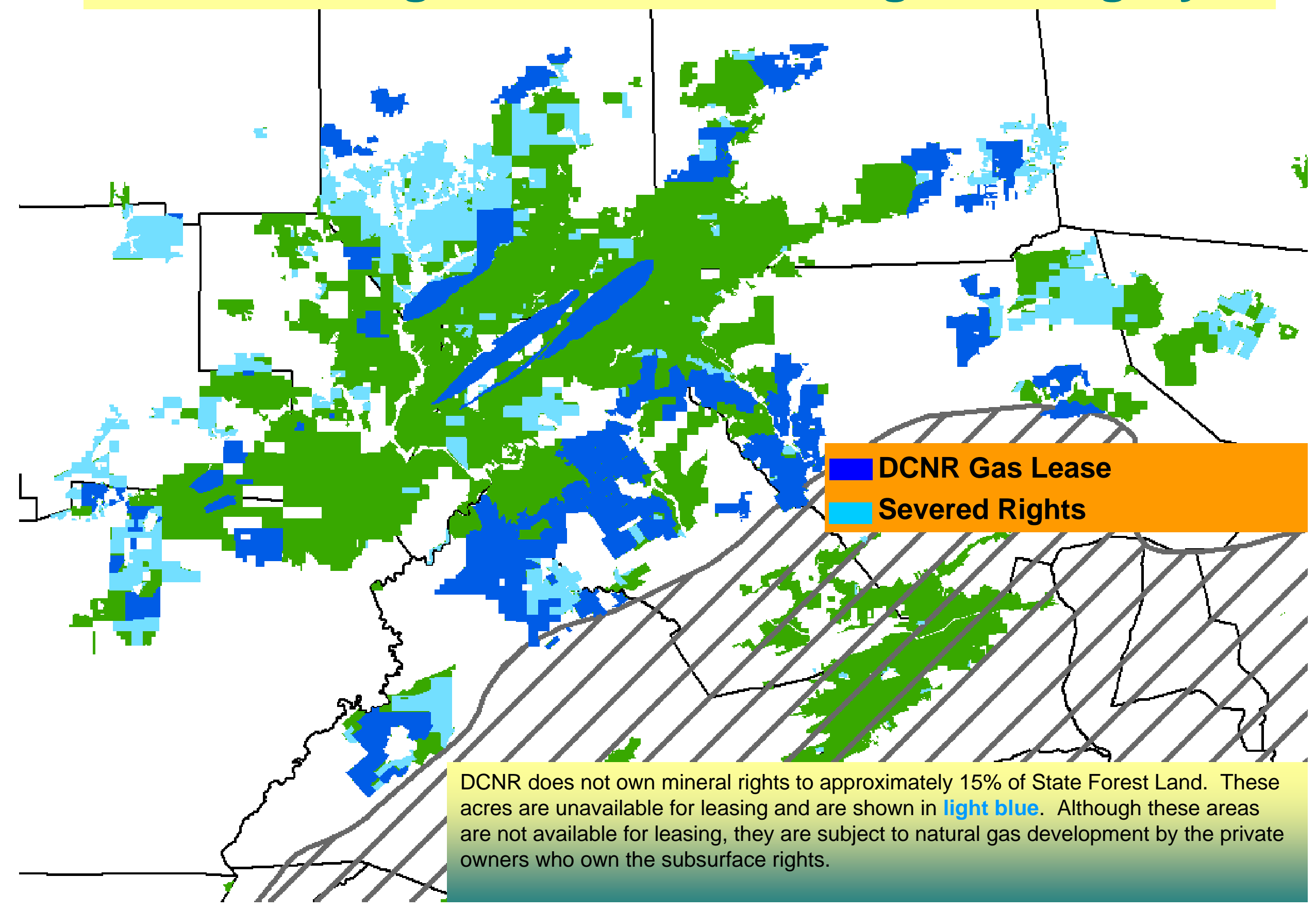




\section{Maintaining the Forest's Ecological Integrity}

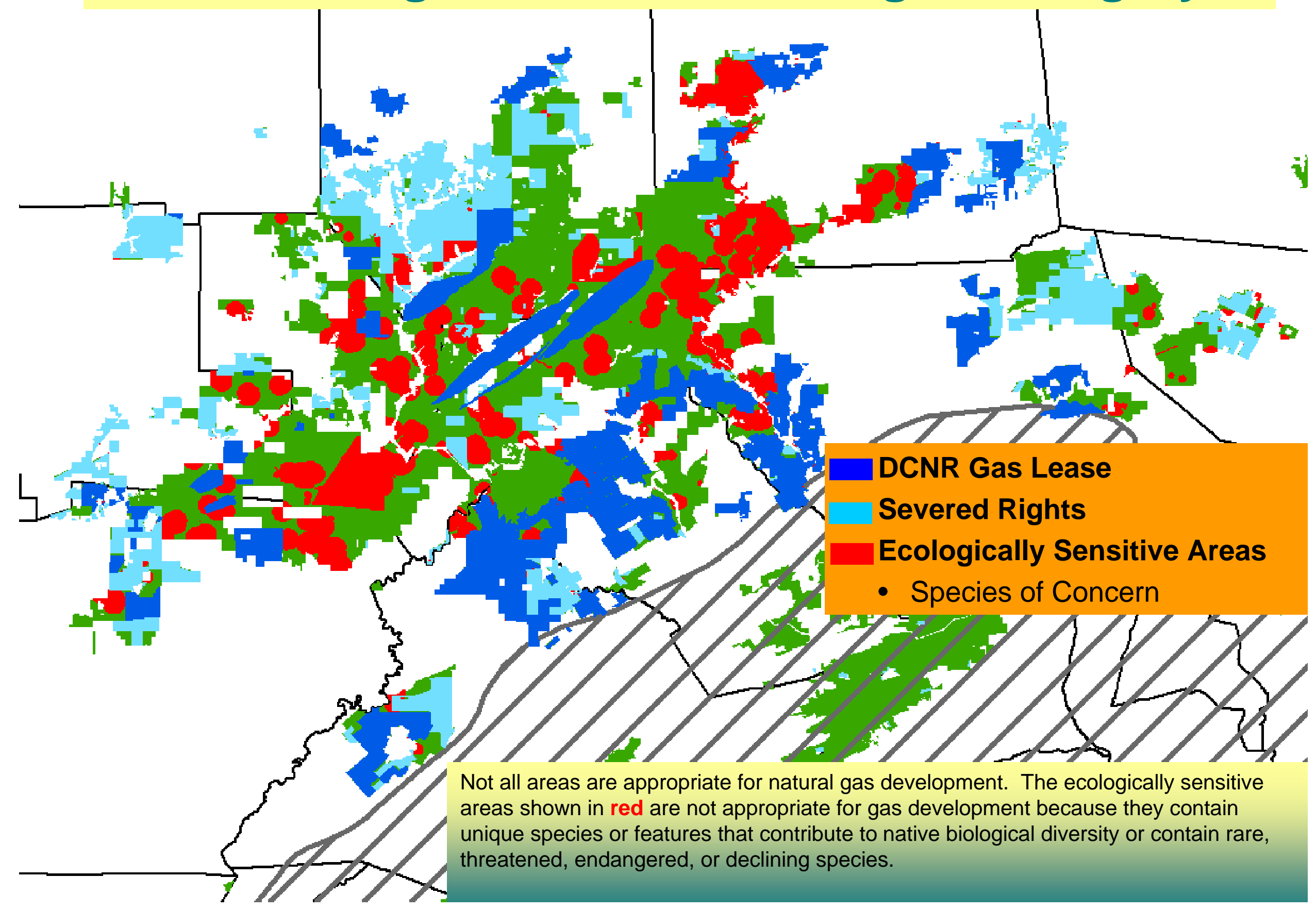




\section{Maintaining the Forest's Ecological Integrity}

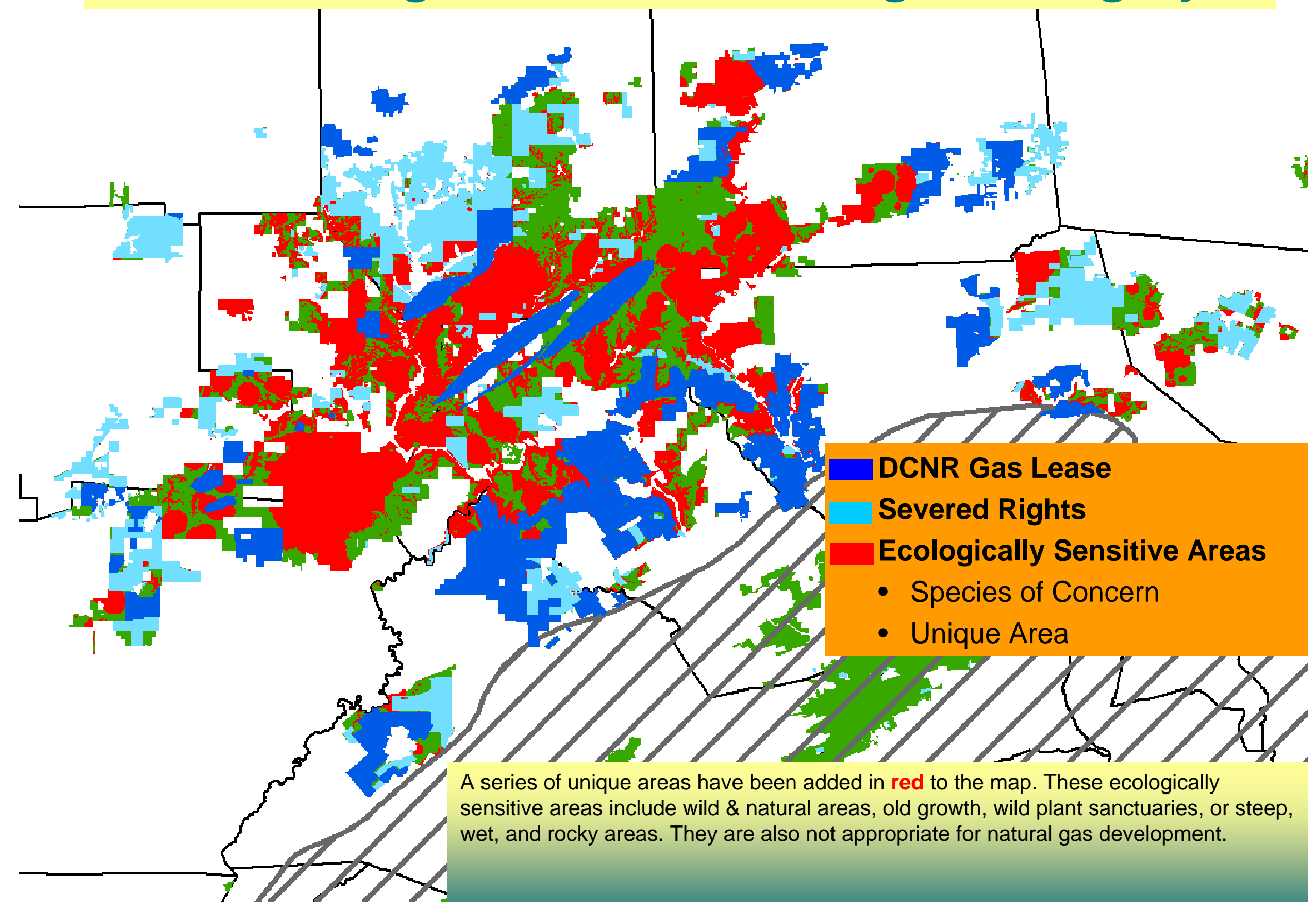




\section{Maintaining the Forest's Ecological Integrity}

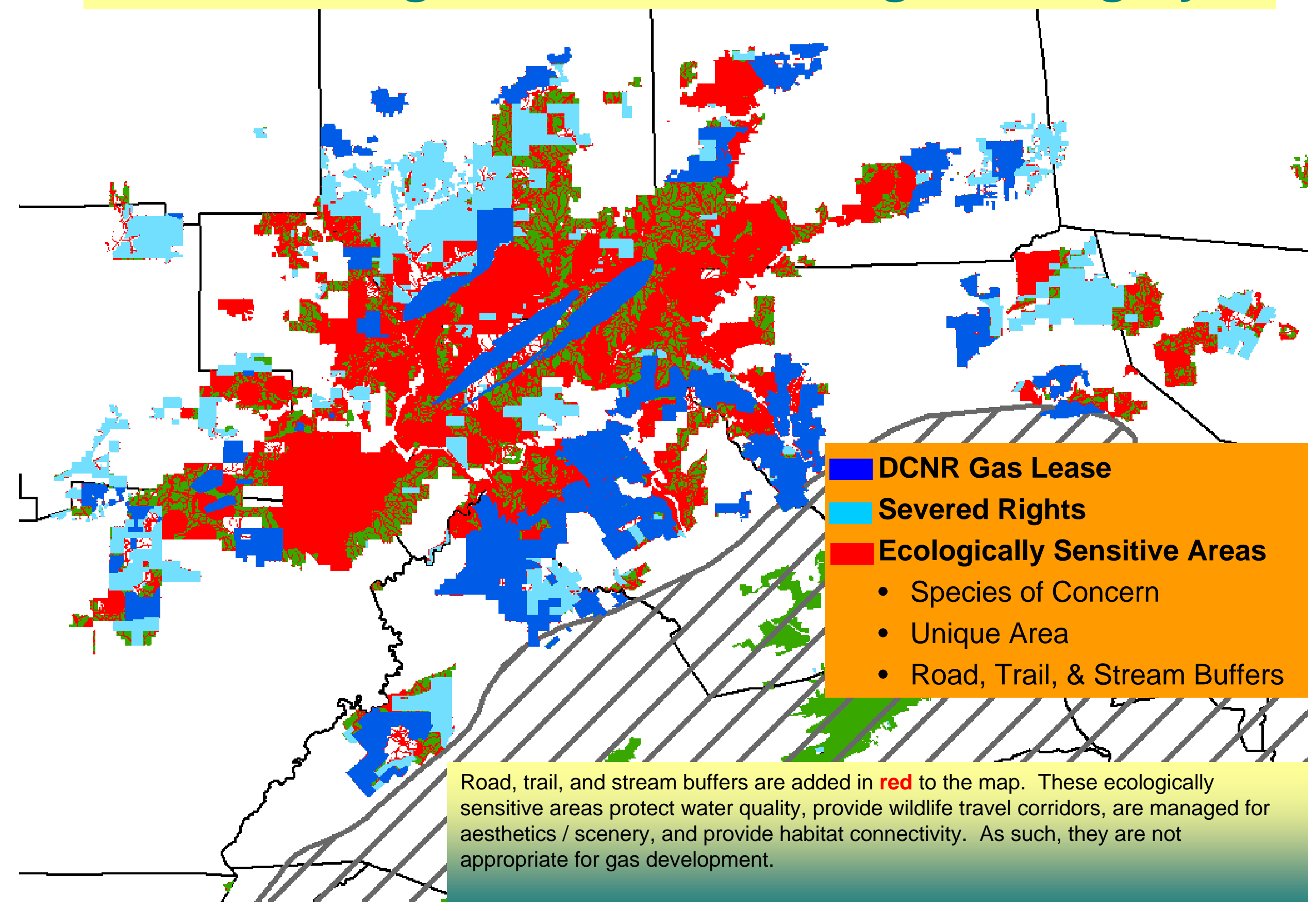




\section{Maintaining the Forest's Ecological Integrity}

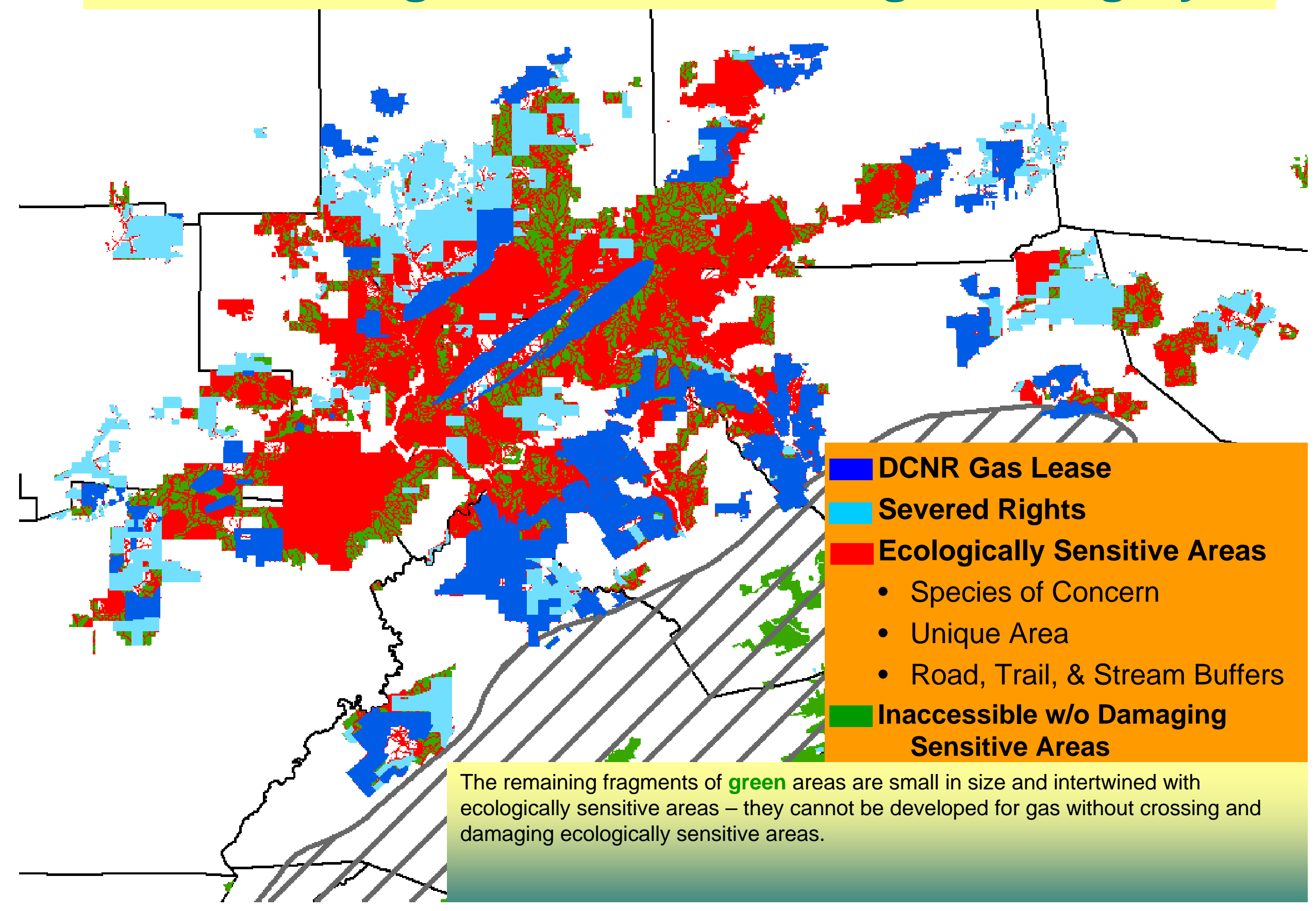




\section{Maintaining the Forest's Wild Character}

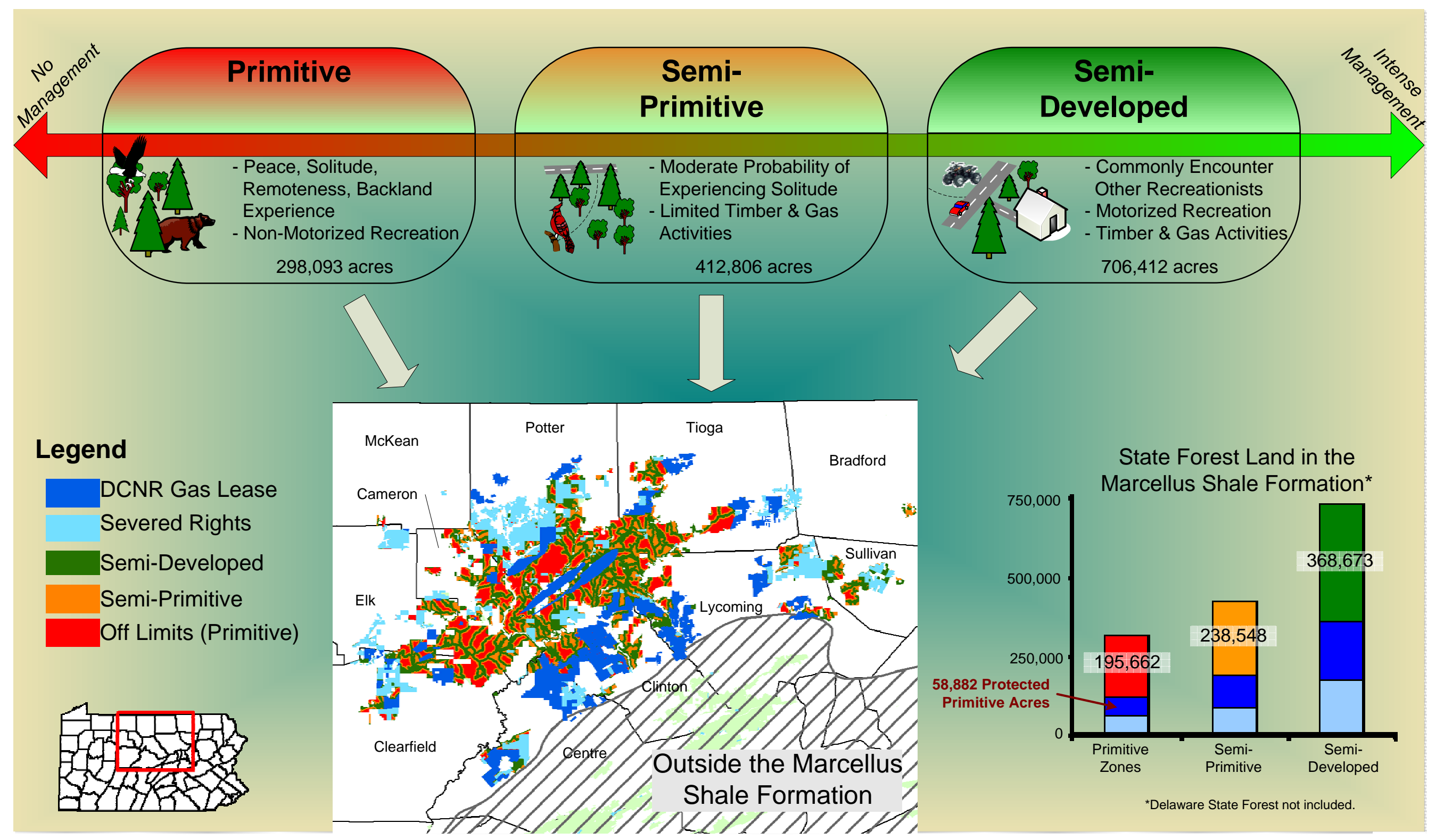




\section{Maintaining the Forest's Wild Character}

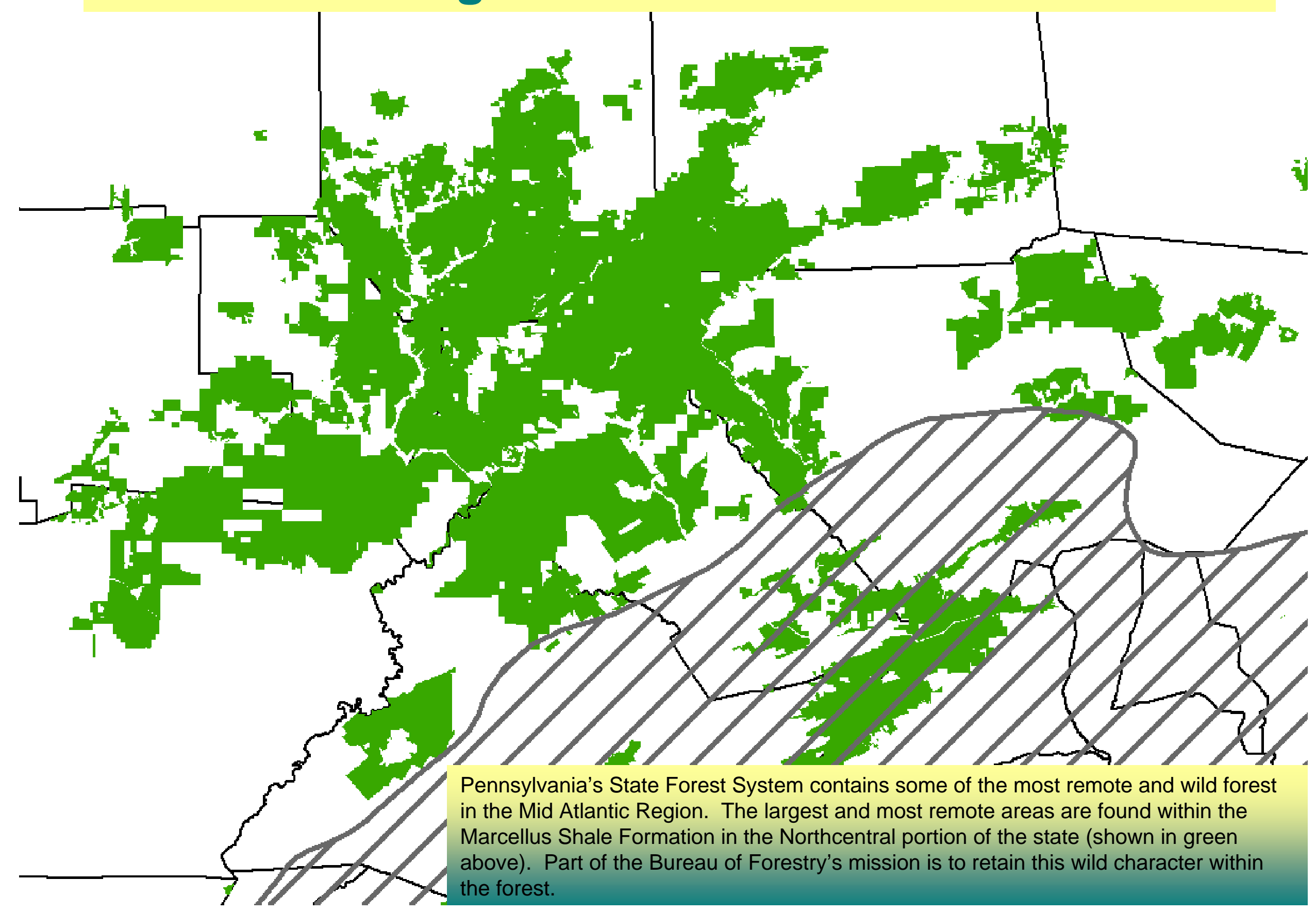




\section{Maintaining the Forest's Wild Character}

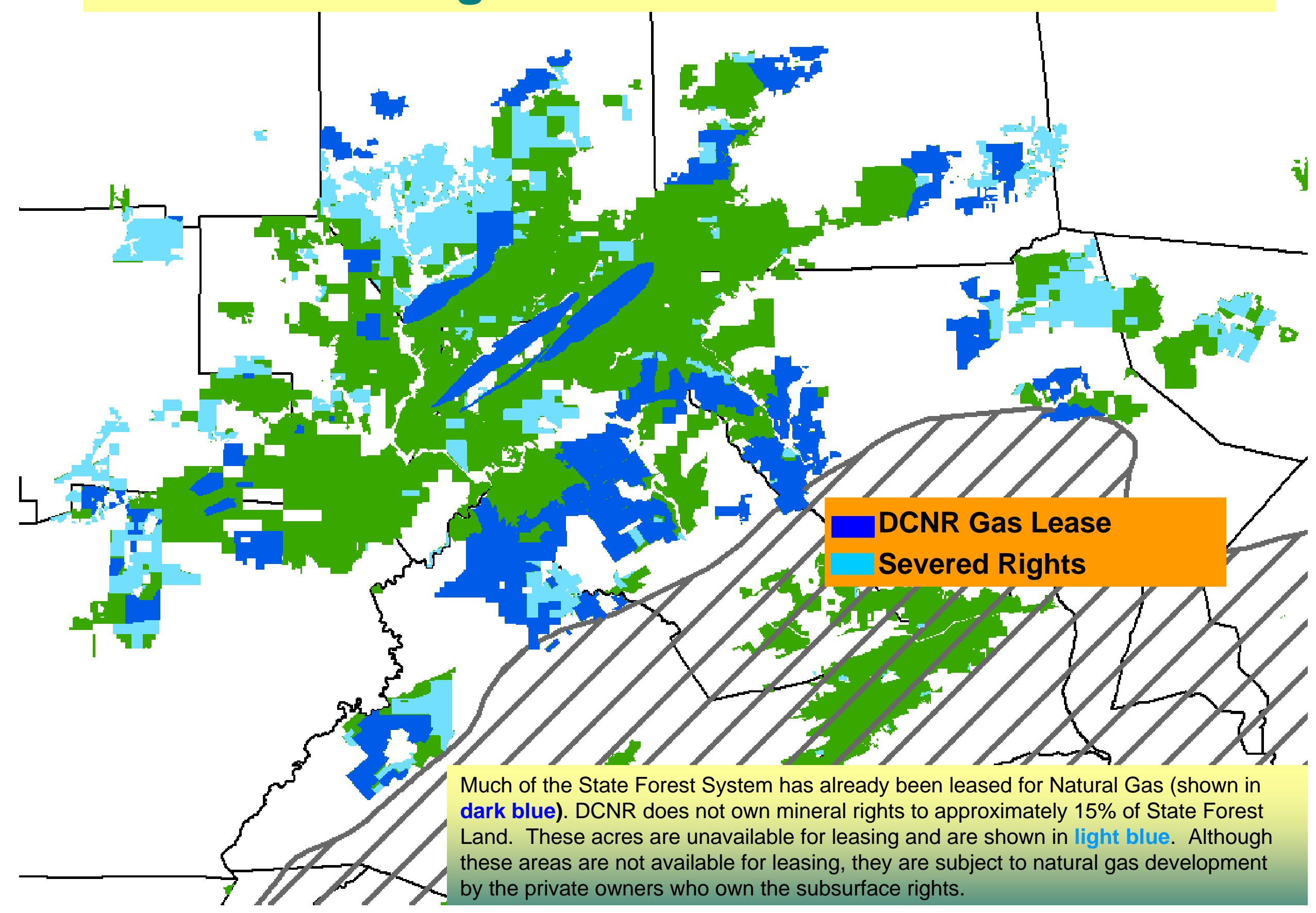




\section{Maintaining the Forest's Wild Character}

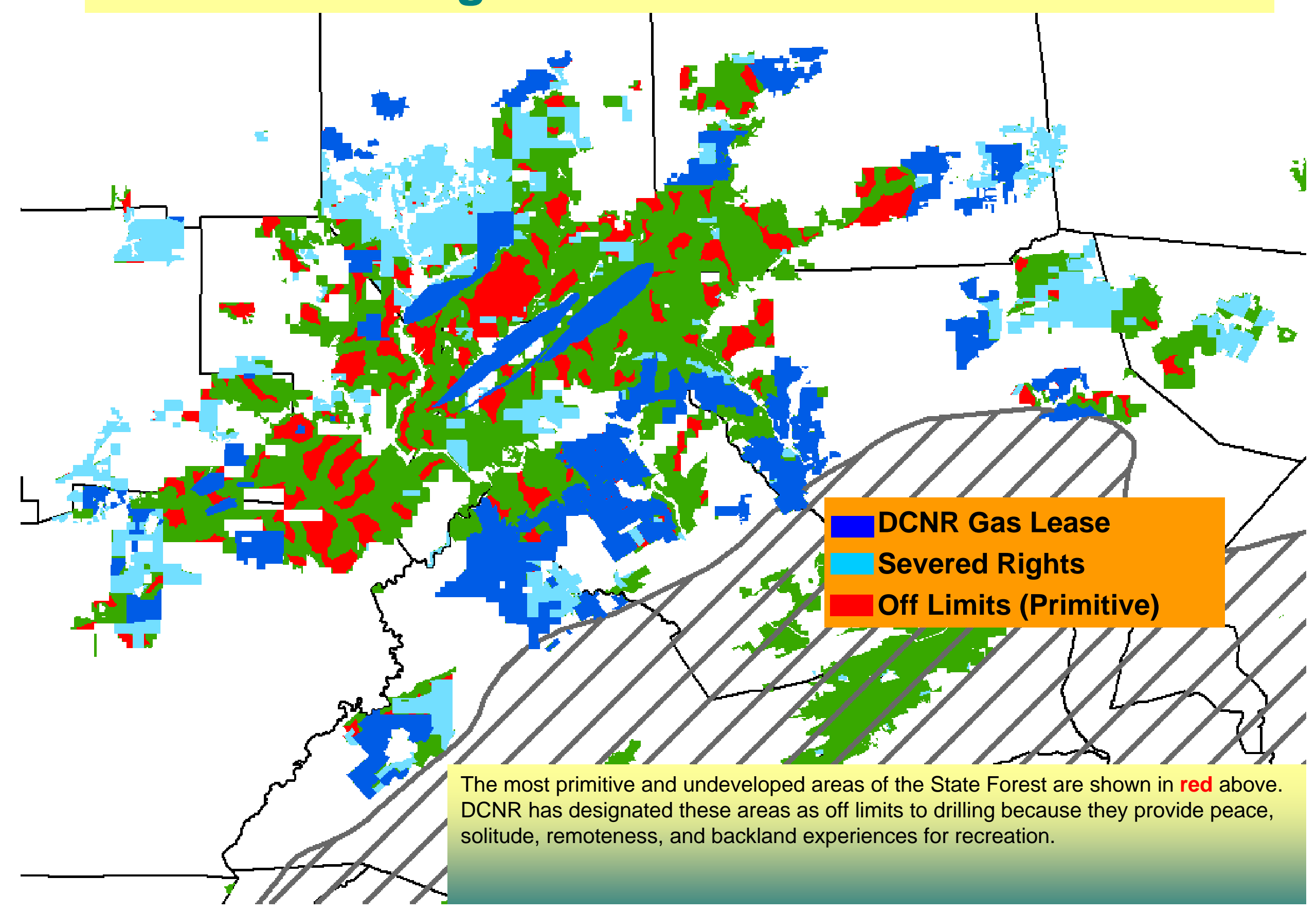




\section{Maintaining the Forest's Wild Character}

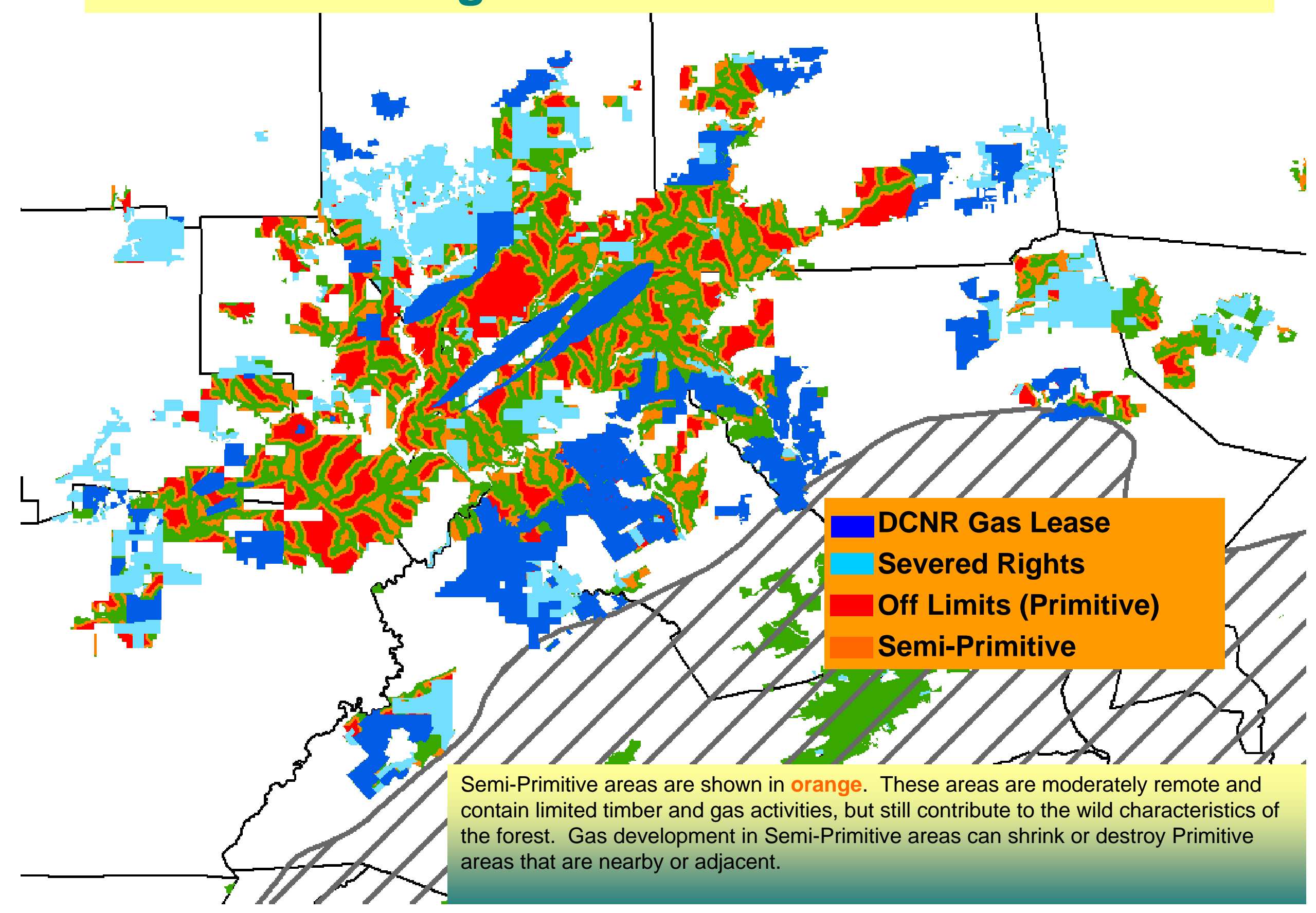




\section{Maintaining the Forest's Wild Character}

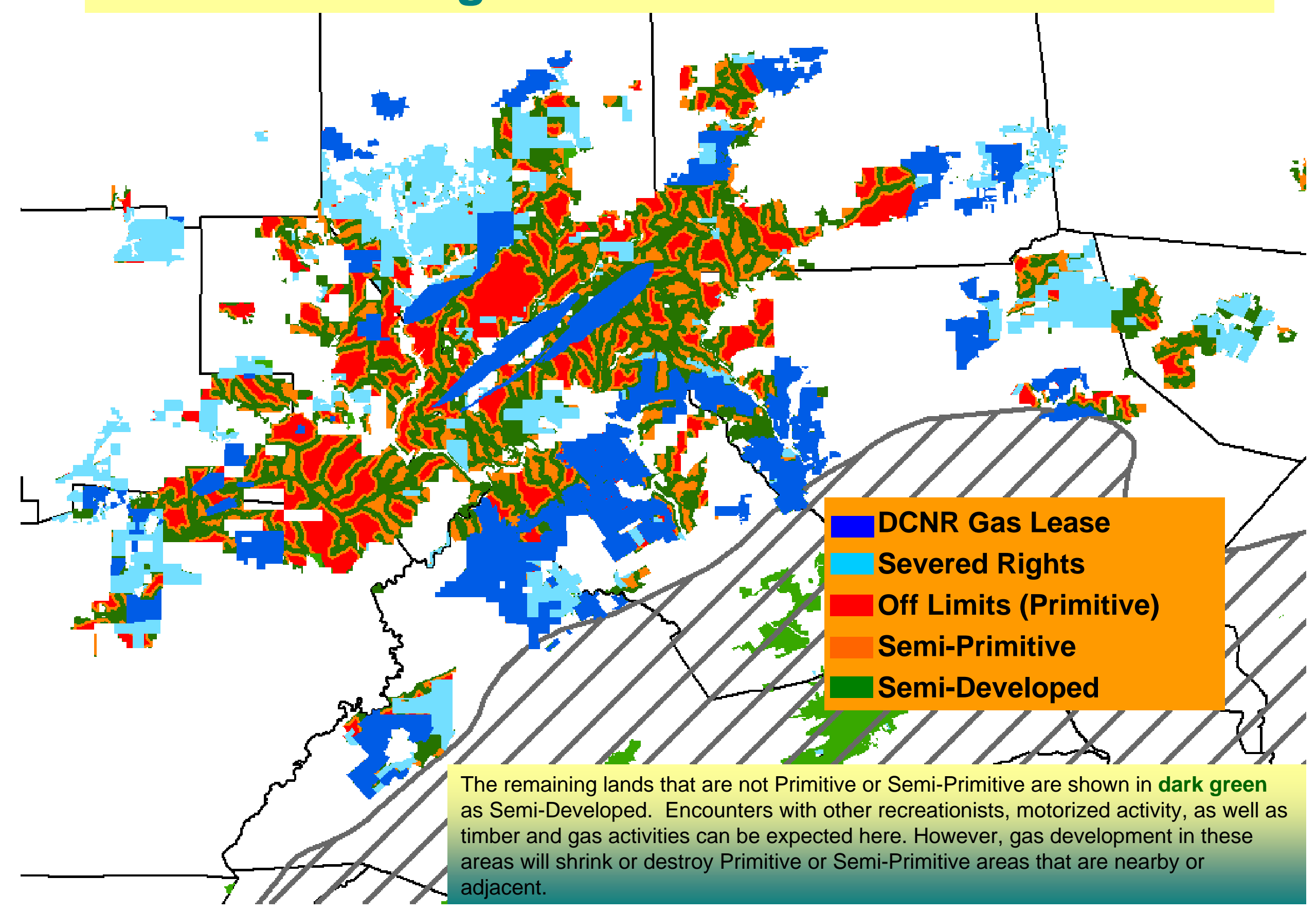




\section{Impacts on the Wild Character}

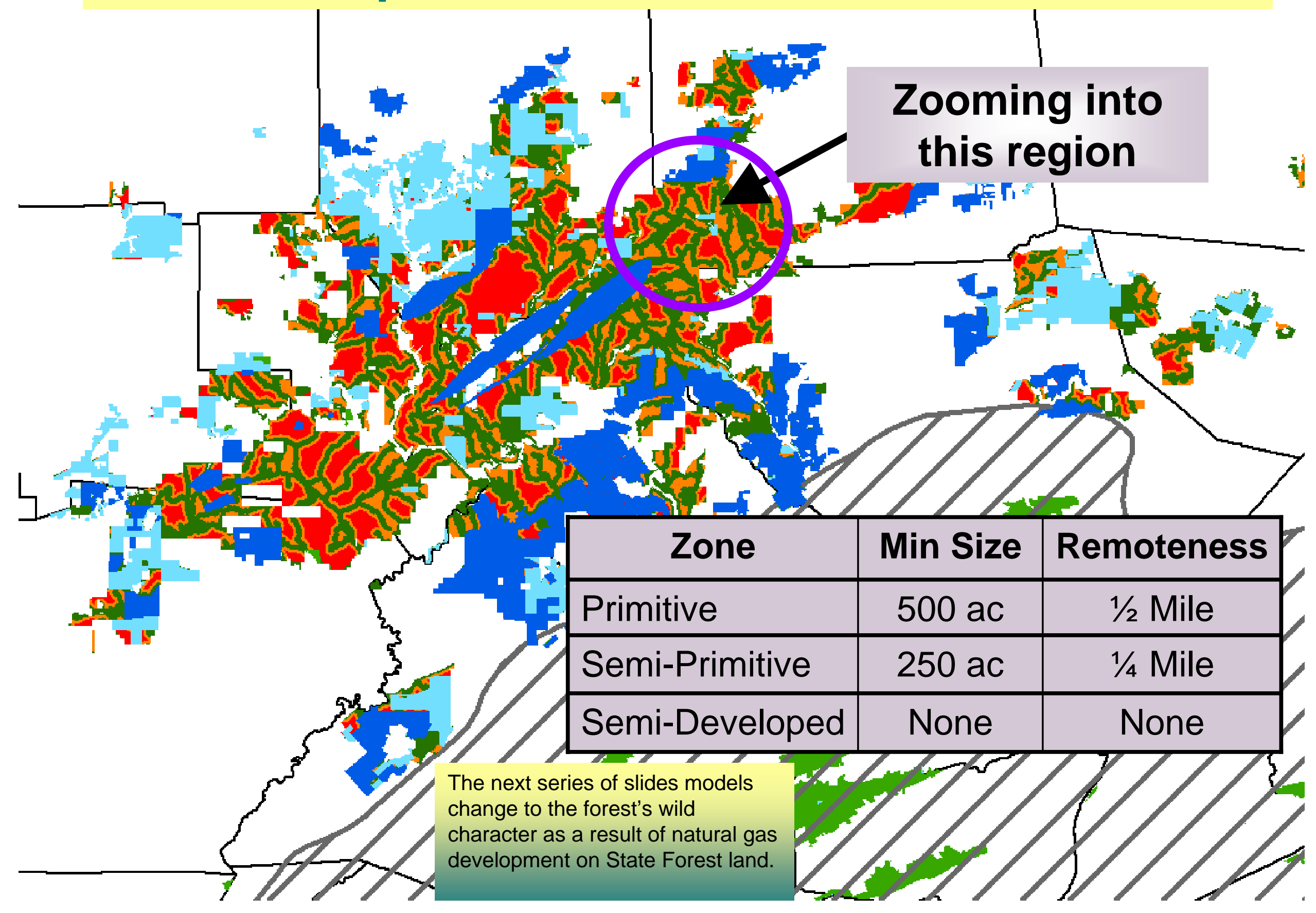




\section{Topography}

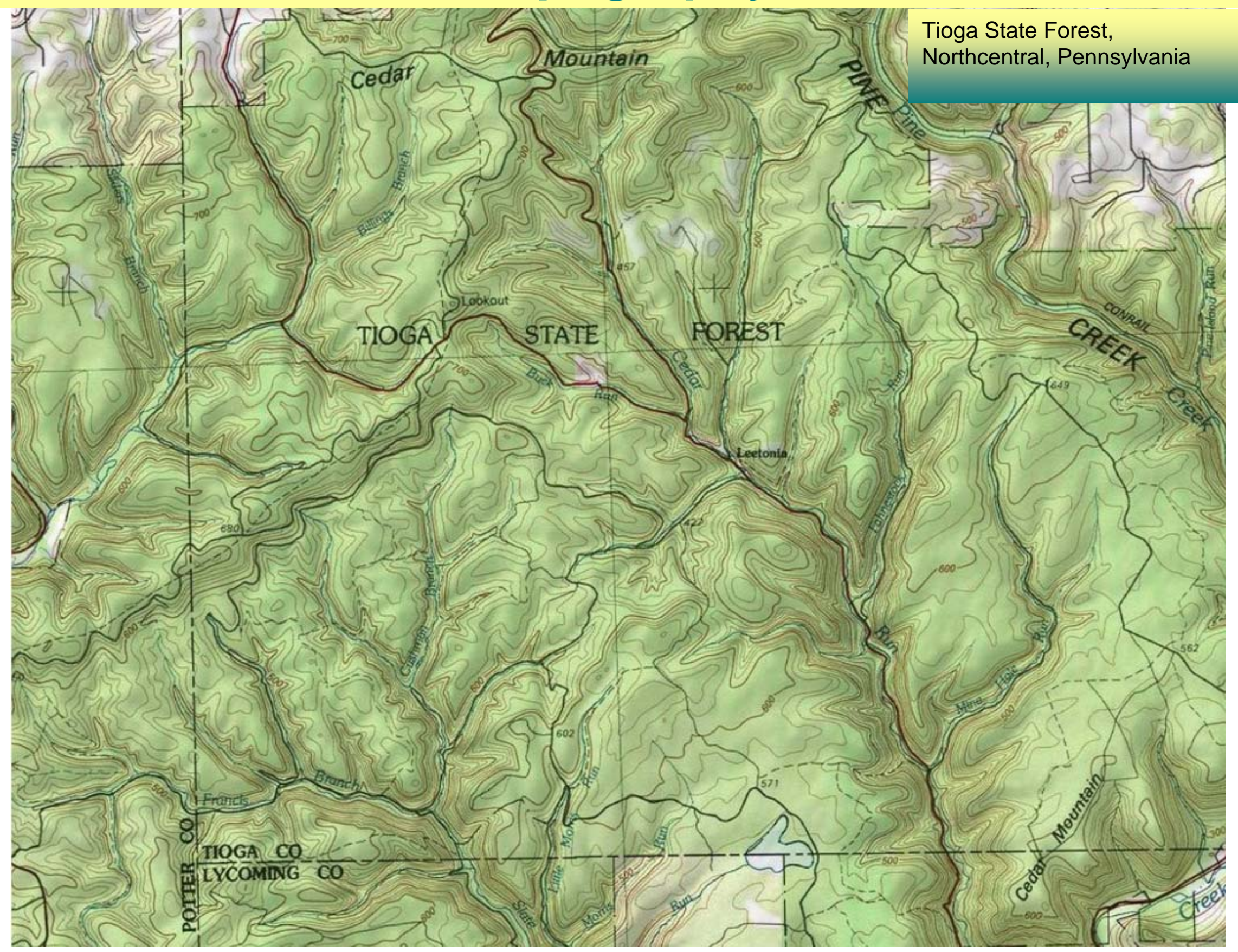




\section{New Well Pad Locations}

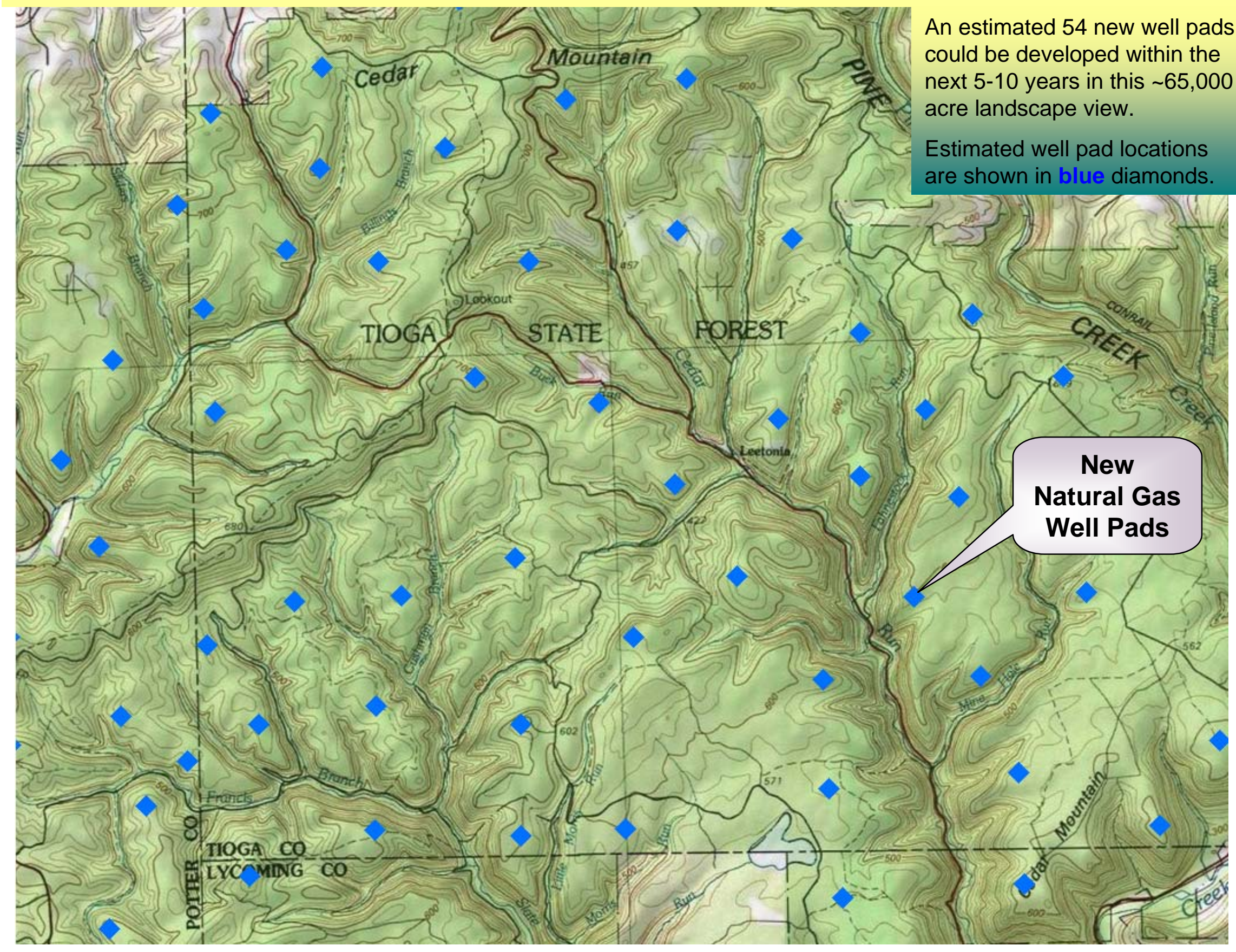




\section{Wild Character before Well Pads}

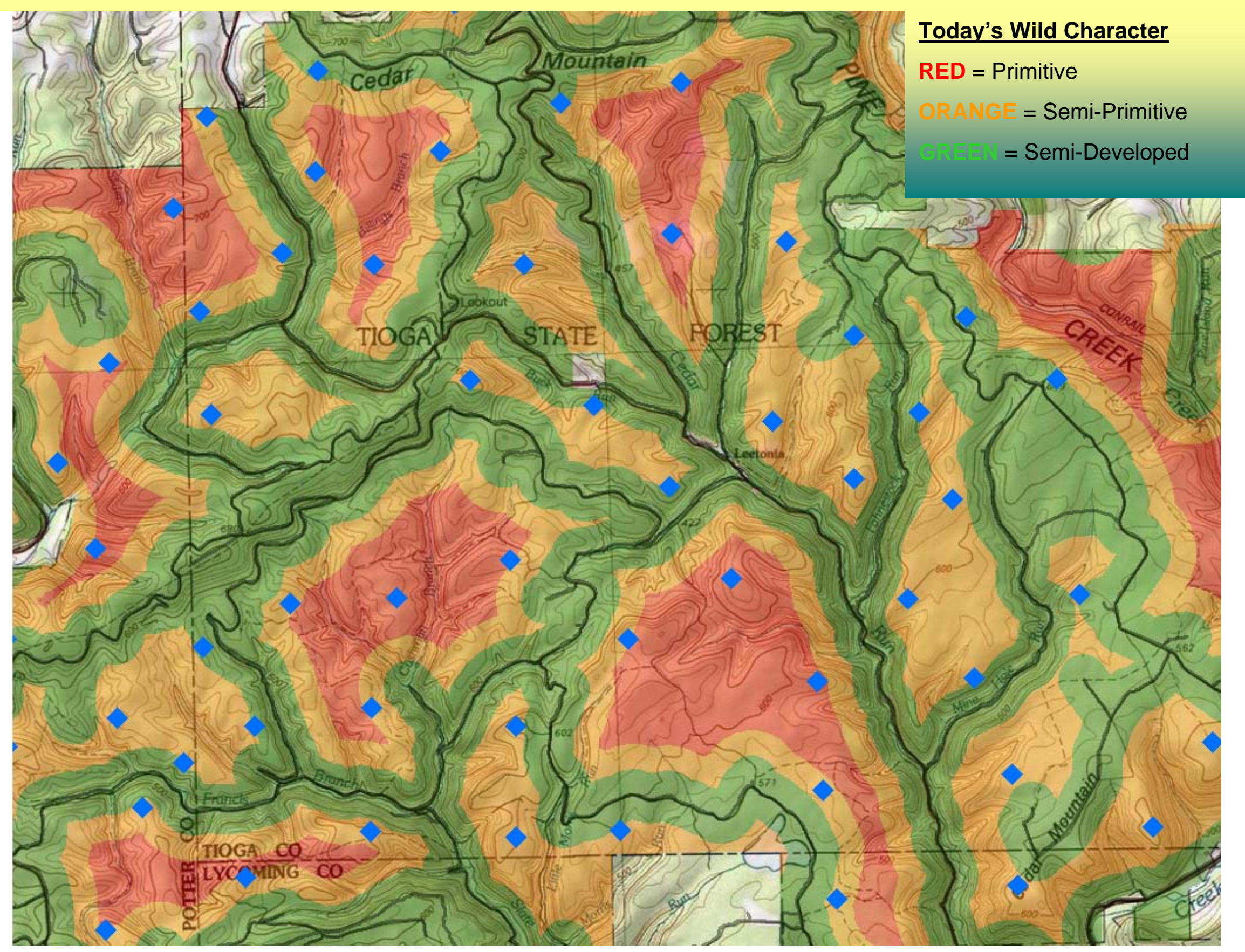




\section{New Access Roads Required}

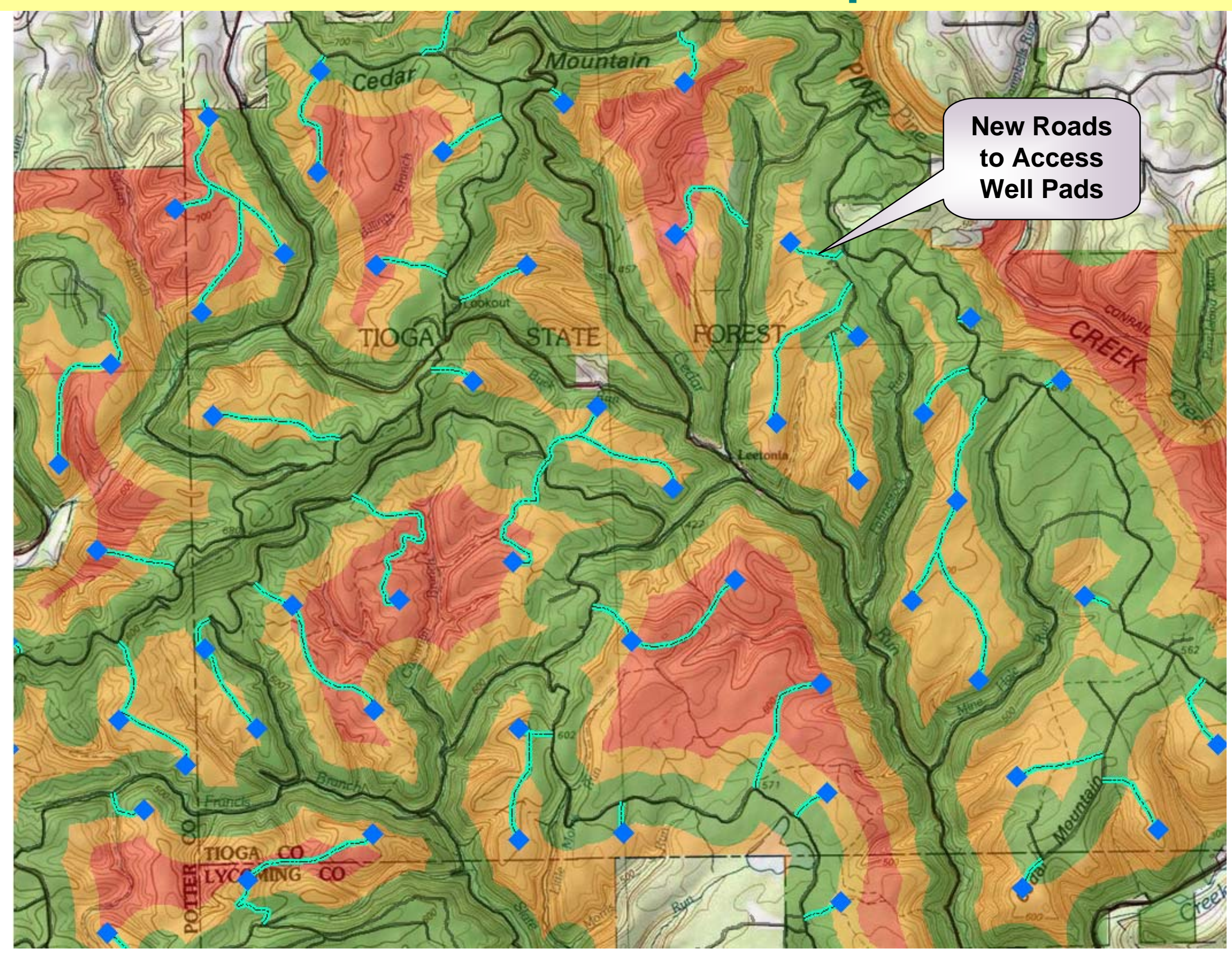


Forest's Wild Character with New Well Pads

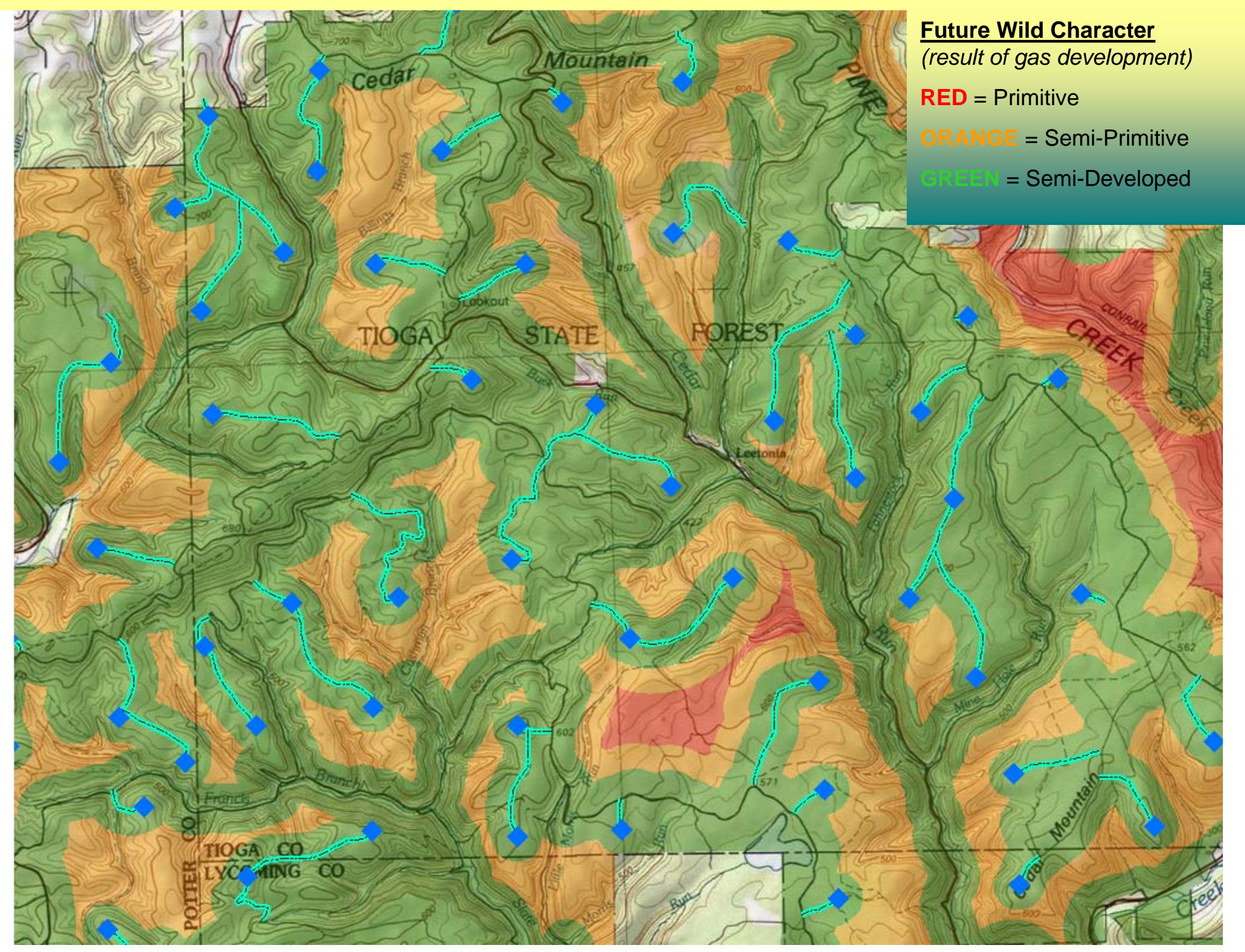




\section{Impact on the Forest's Wild Character}

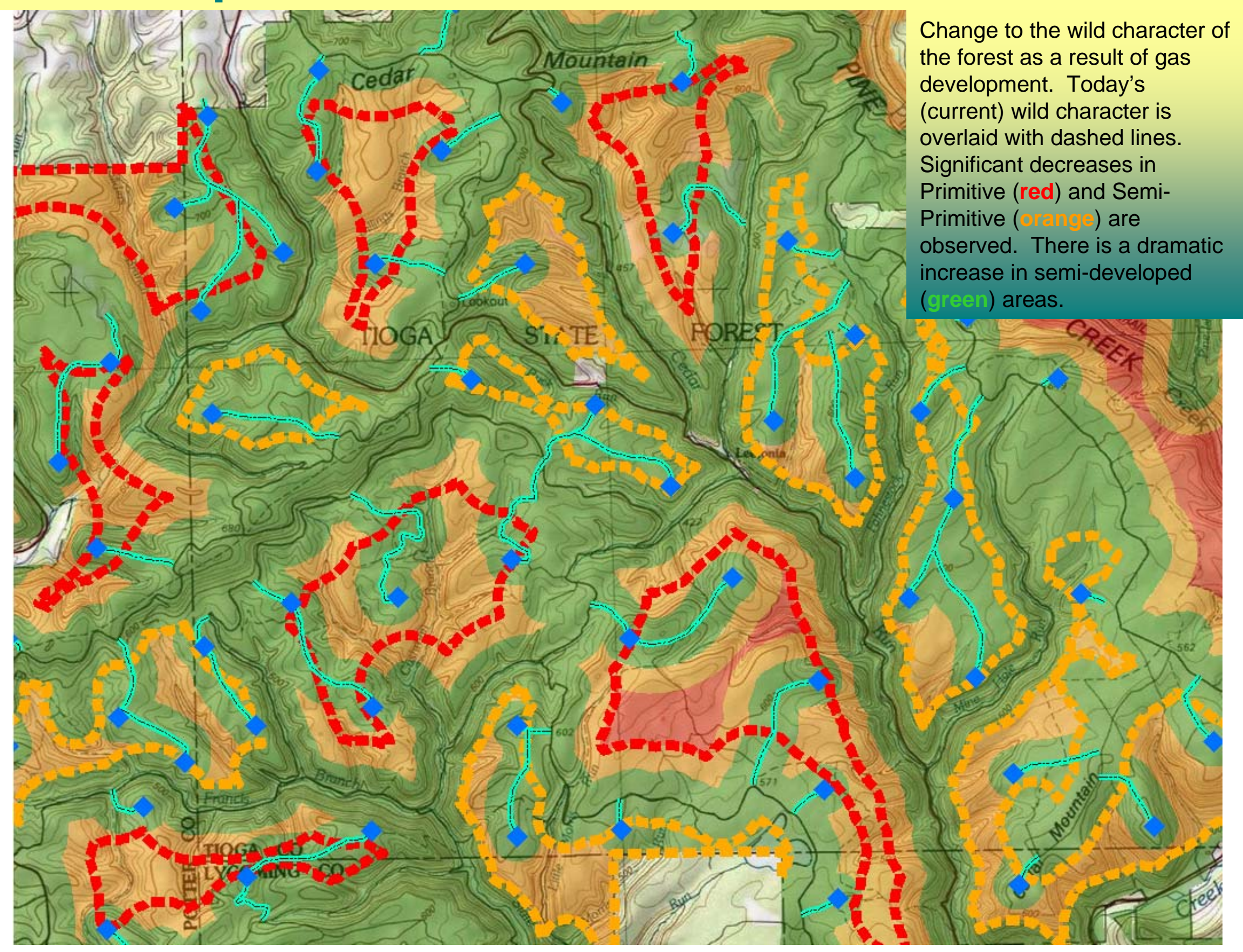




\section{Impact on the Forest's Wild Character}

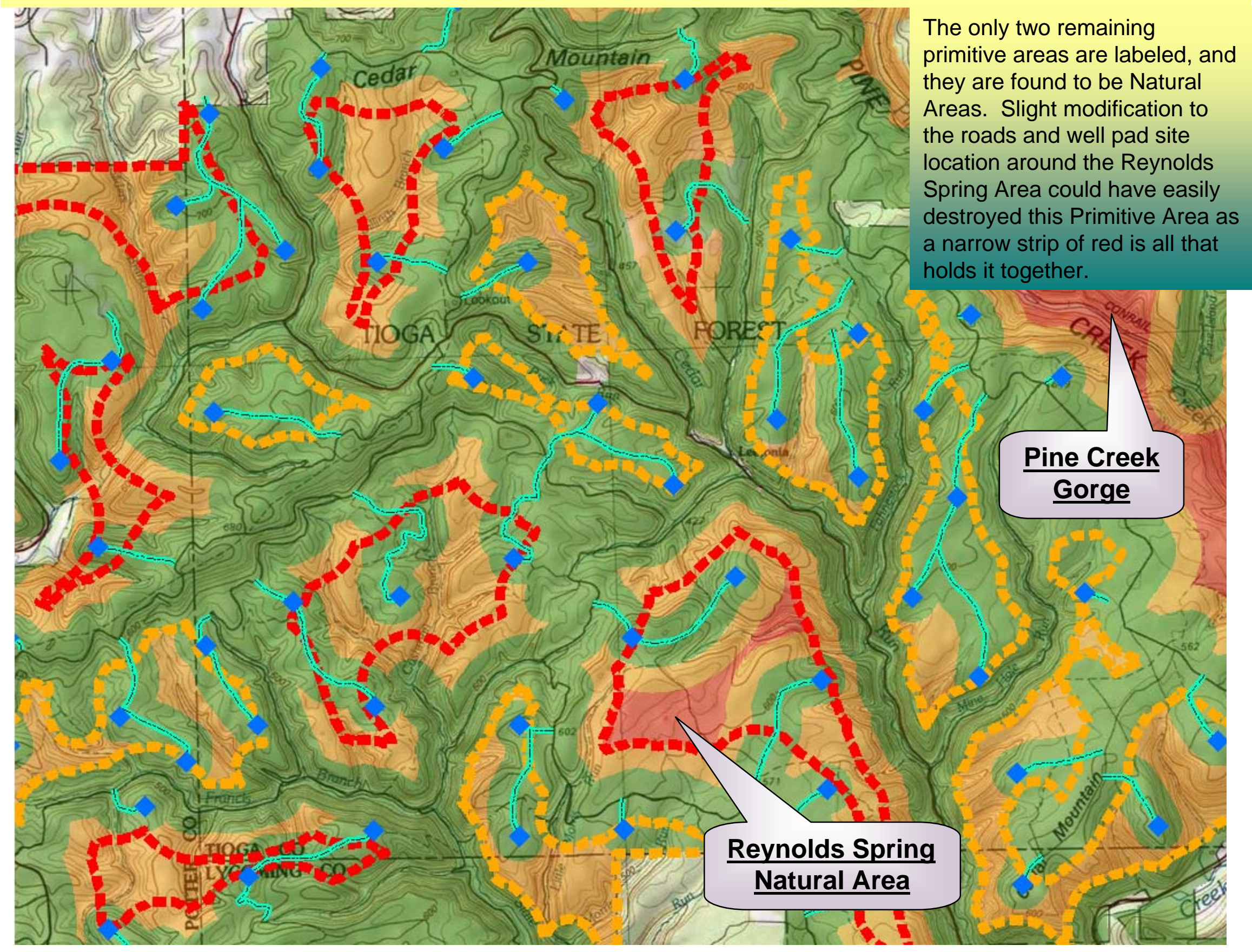




\section{Change in the Forest's Wild Character}

Before

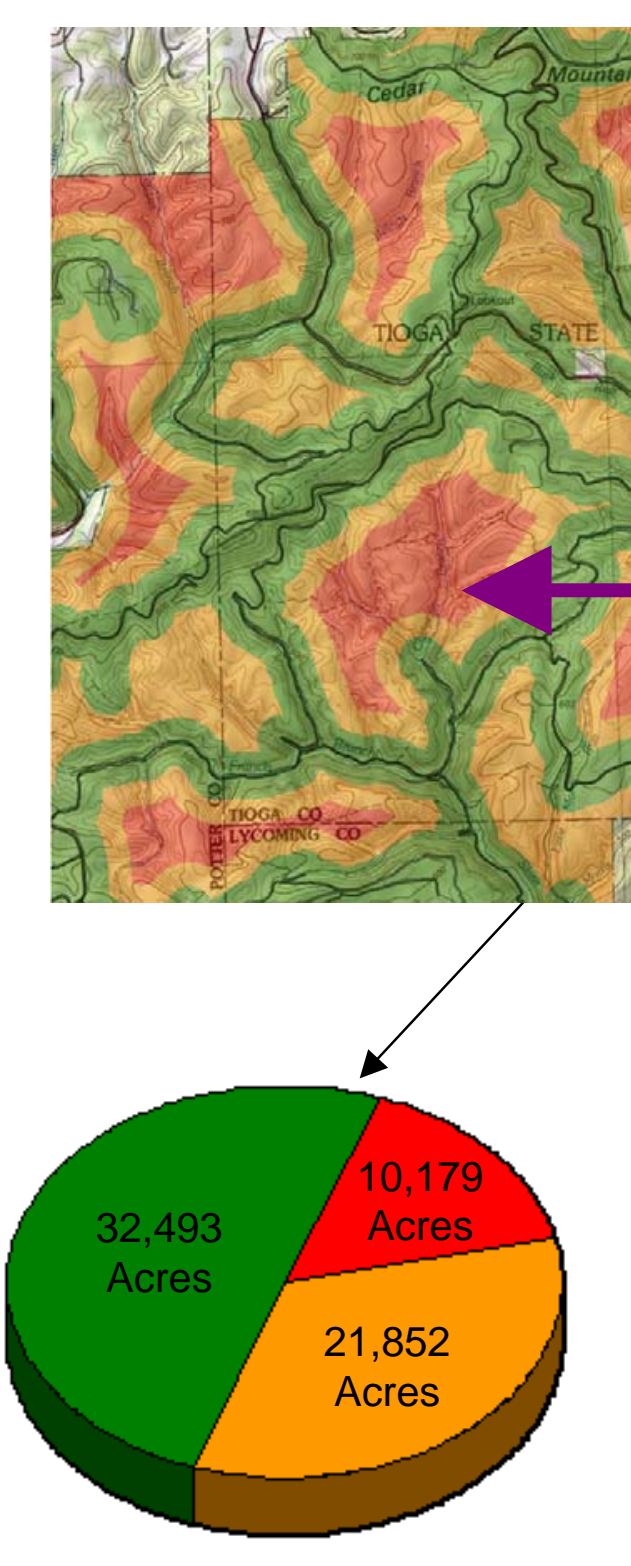

After

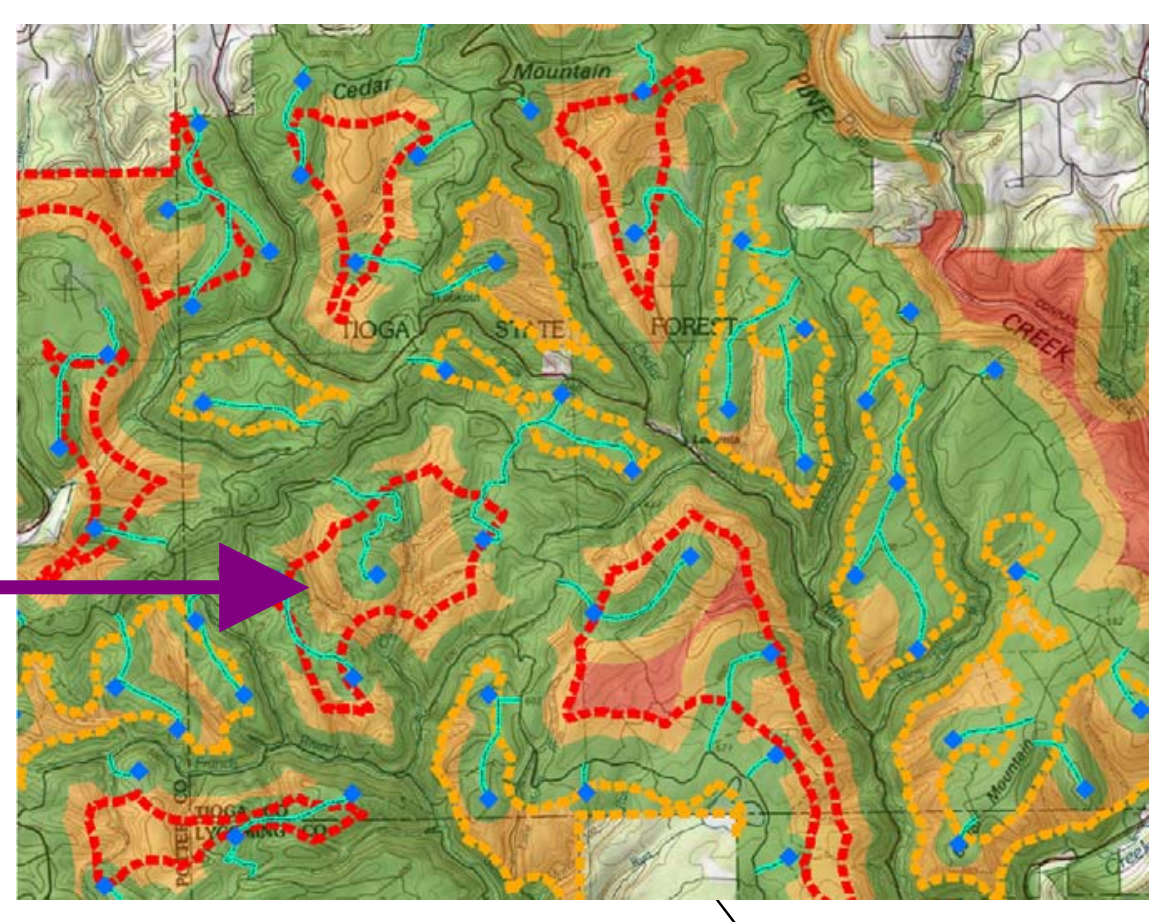

In this $~ 65,000$ acre landscape view, with 54 new well pads...

\begin{tabular}{|l|r|}
\hline \multicolumn{1}{|c|}{ Zone } & Net Gain/Loss \\
\hline$\square$ Primitive & $-8,171$ \\
\hline$\square$ Semi-Primitive & $-5,374$ \\
\hline$\square$ Semi-Developed & 13,545 \\
\hline
\end{tabular}

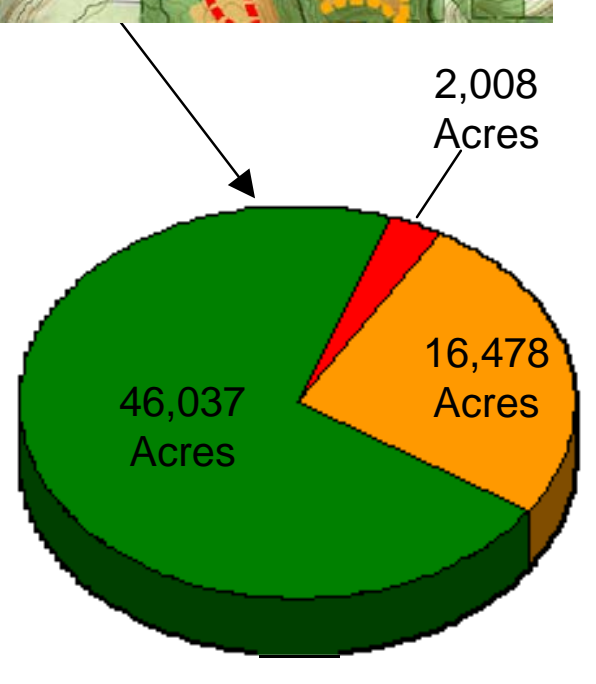




\section{Modeling Change in the Forest's Wild Character}

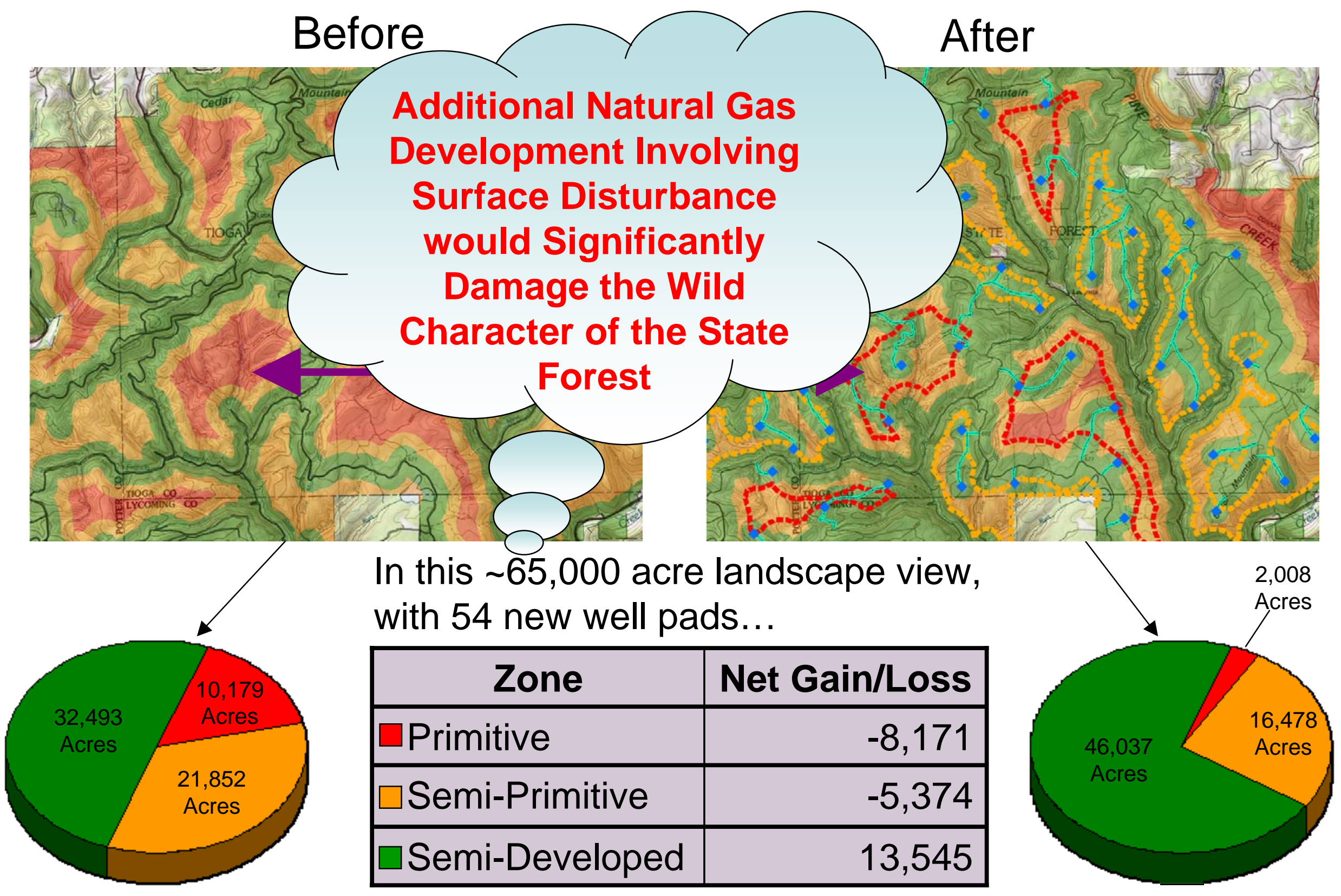




\section{Maintaining the Forest's Wild Character}

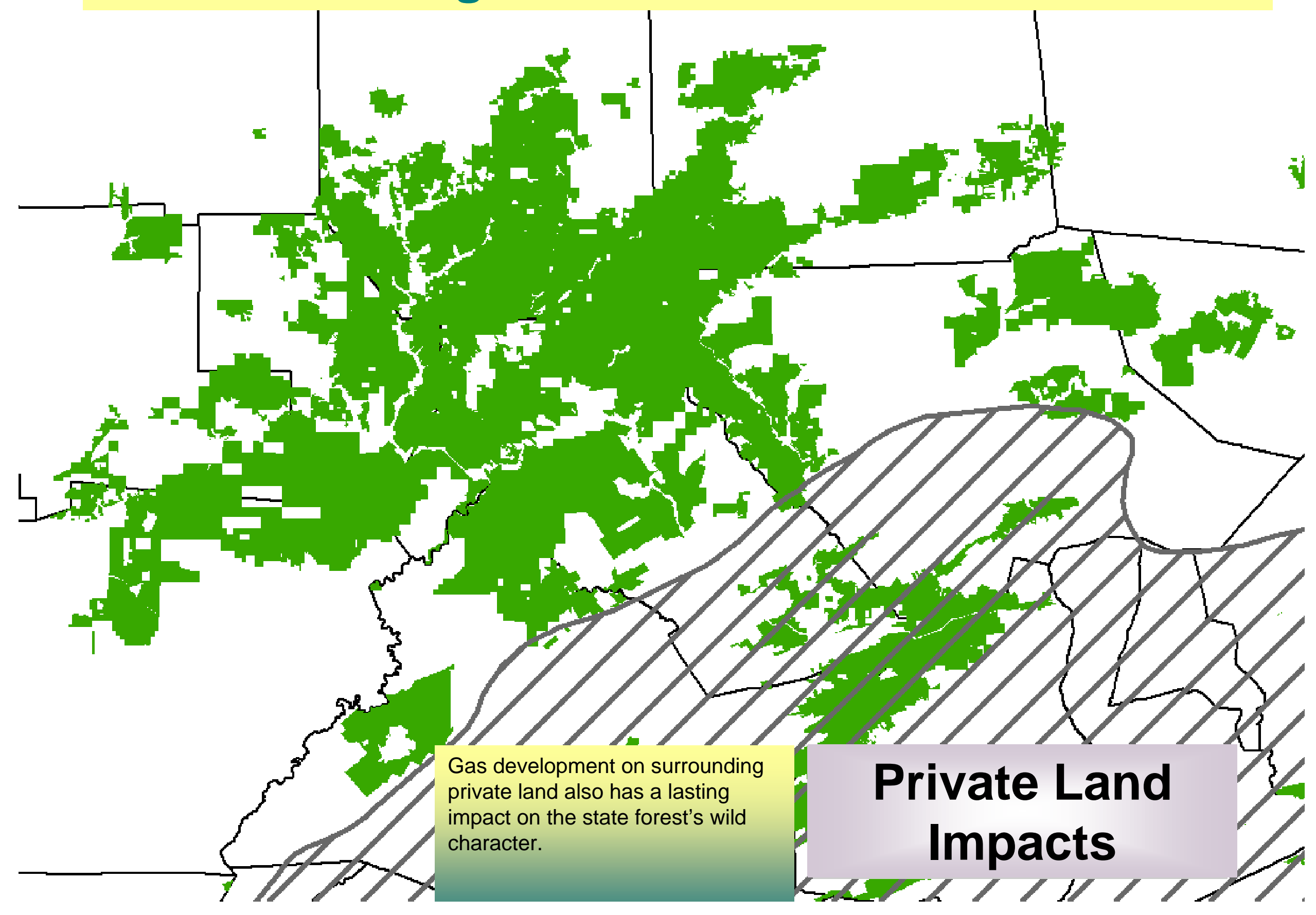




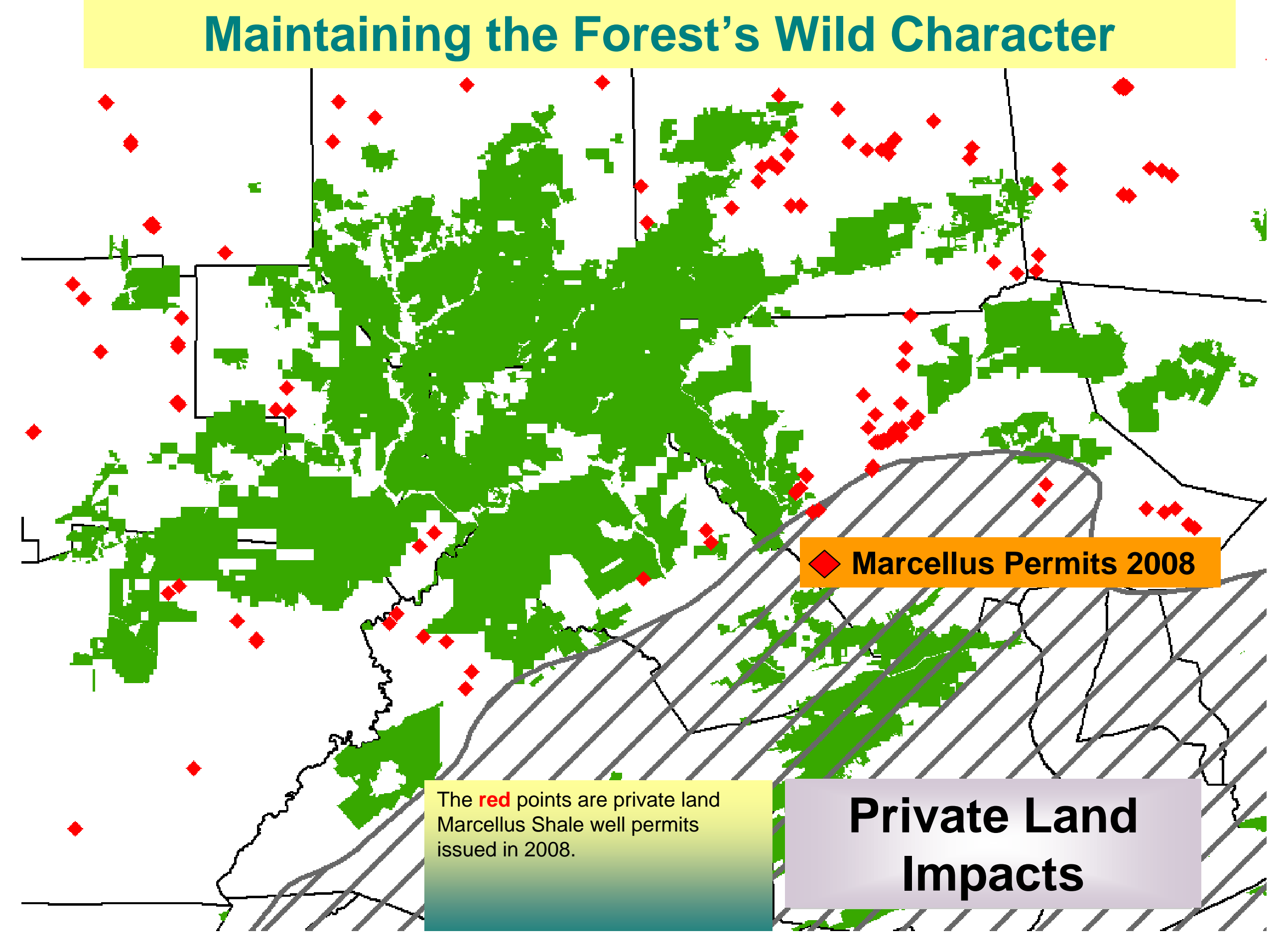




\section{Maintaining the Forest's Wild Character}

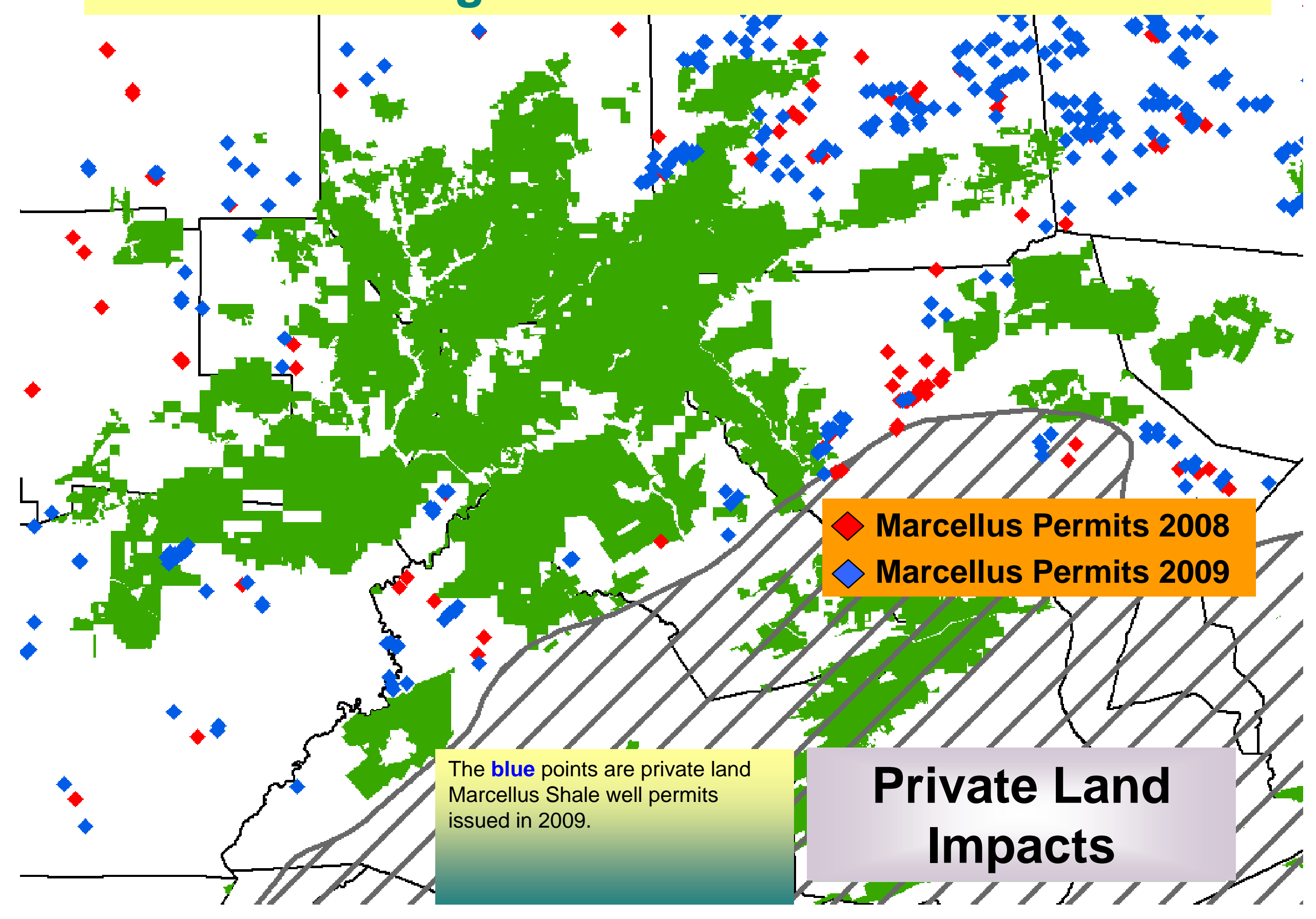




\section{Maintaining the Forest's Wild Character}

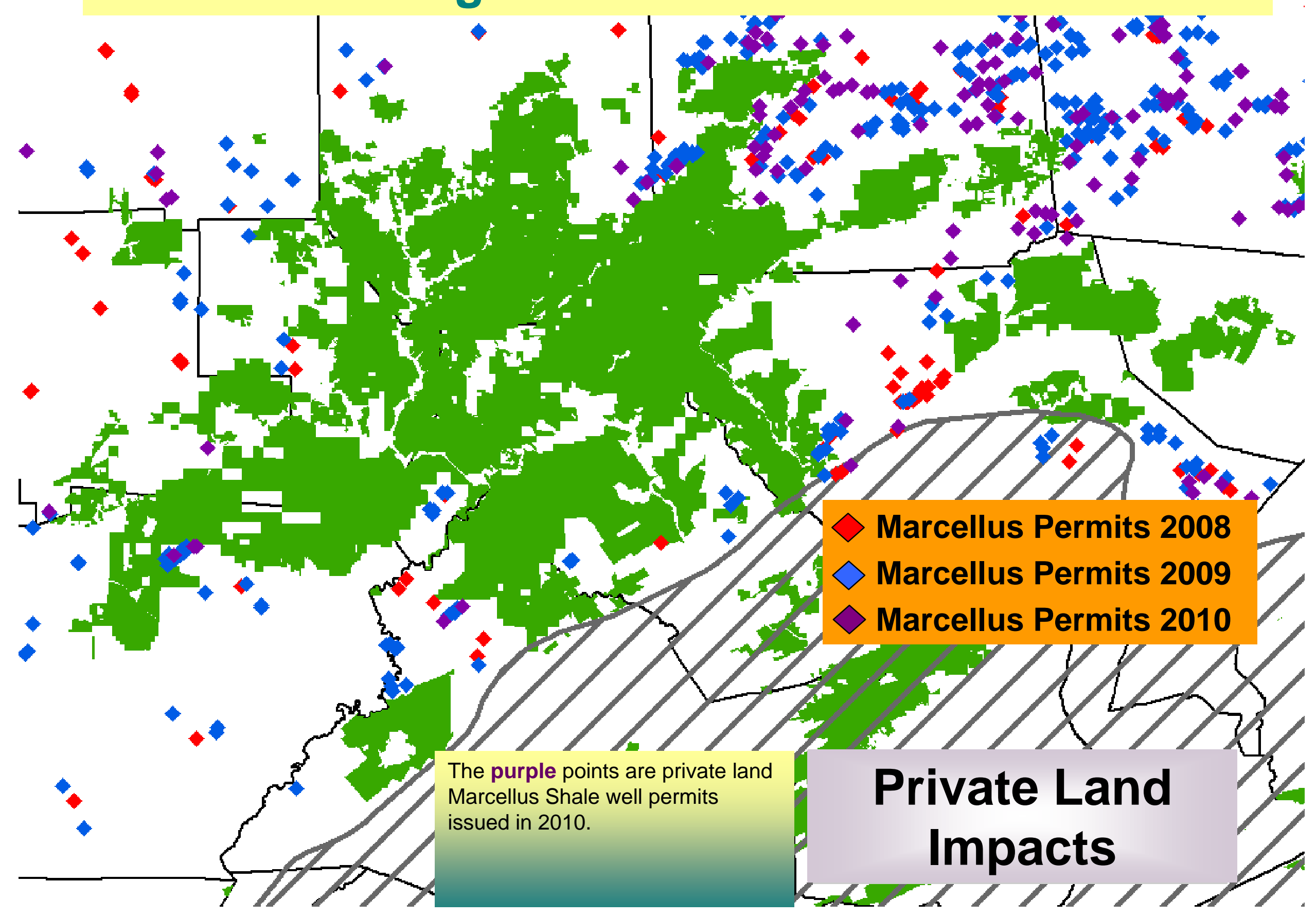




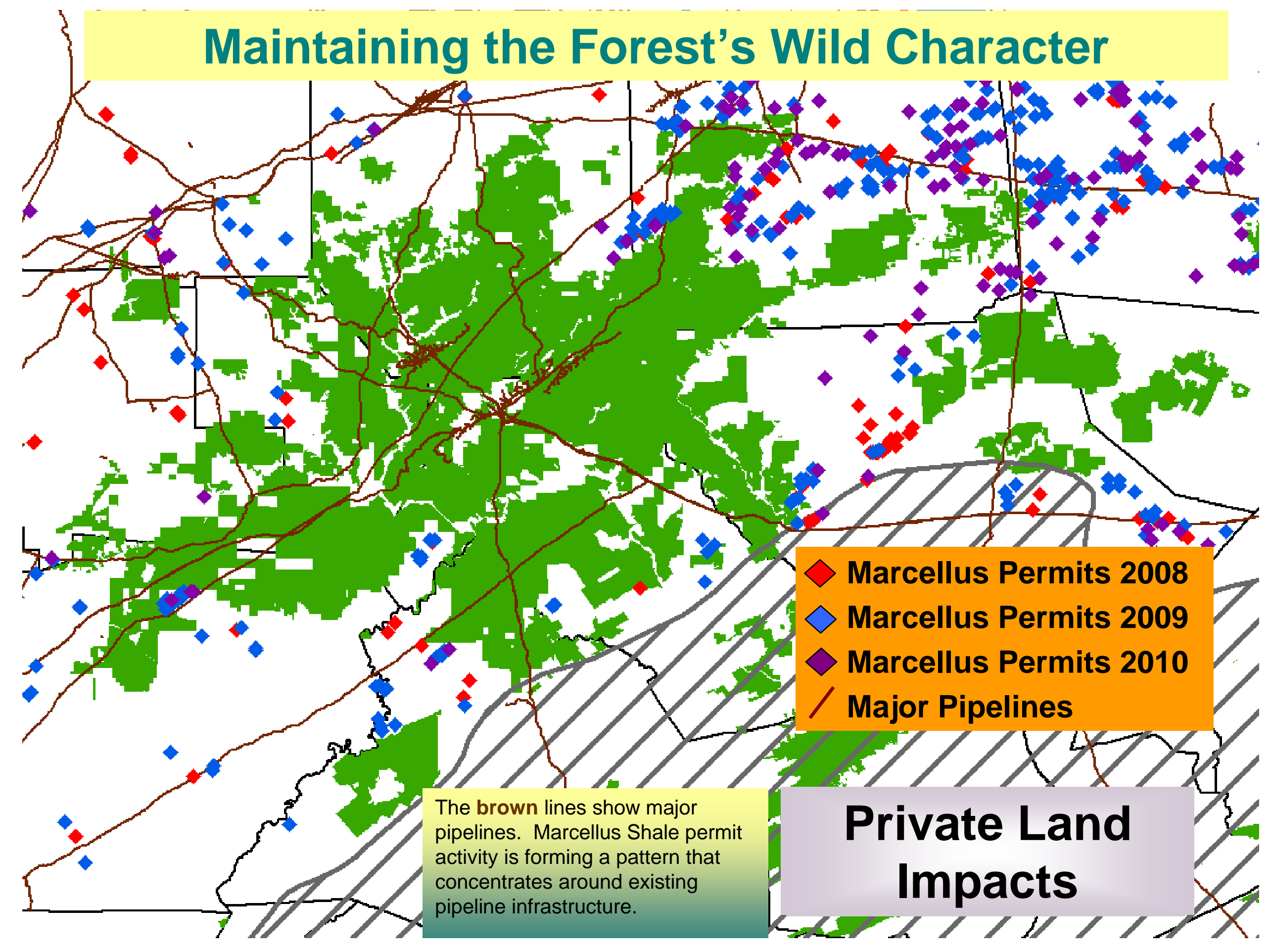




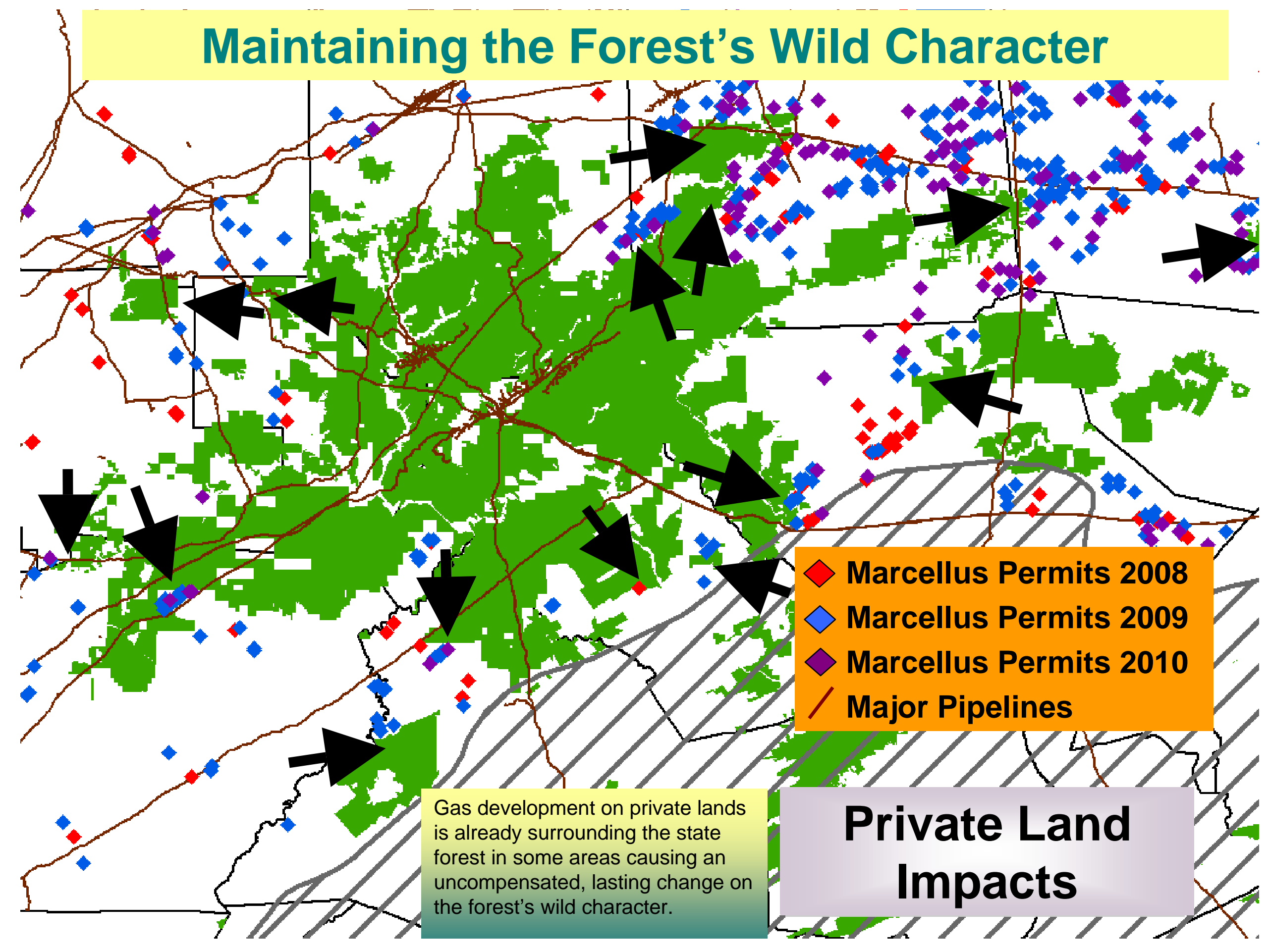




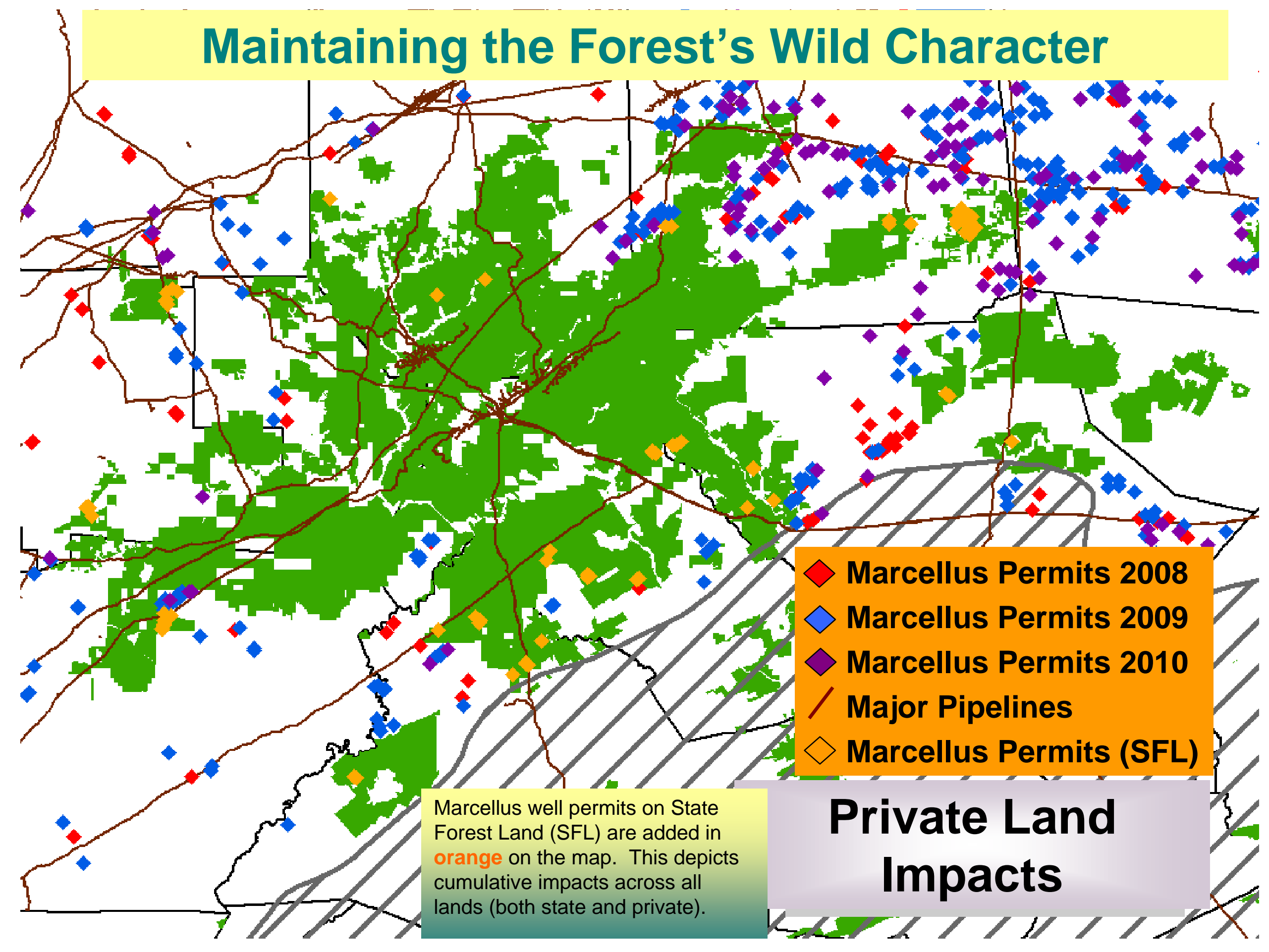




\section{TNC-WPC Priority Forest Patches}

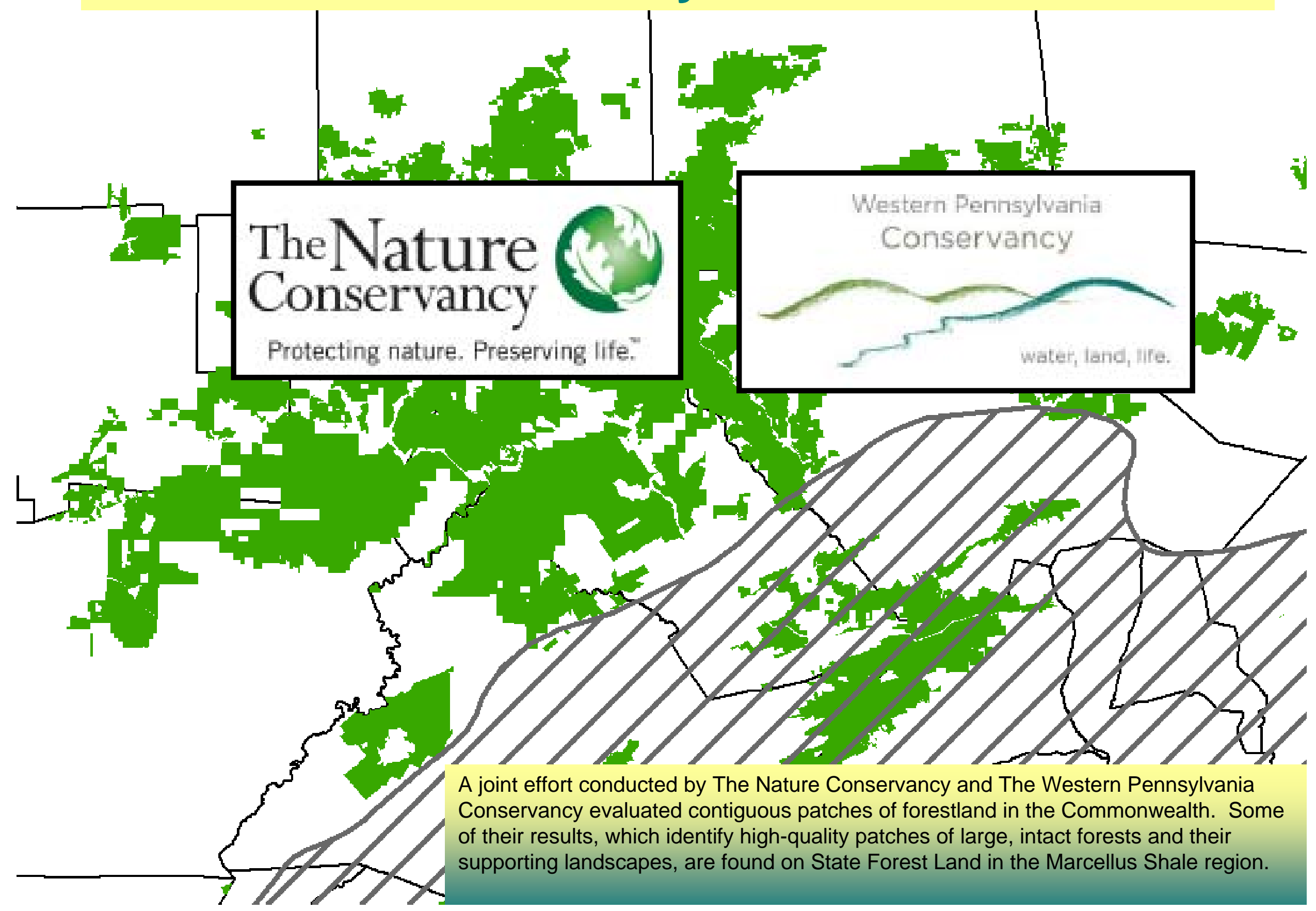




\section{TNC-WPC Priority Forest Patches}

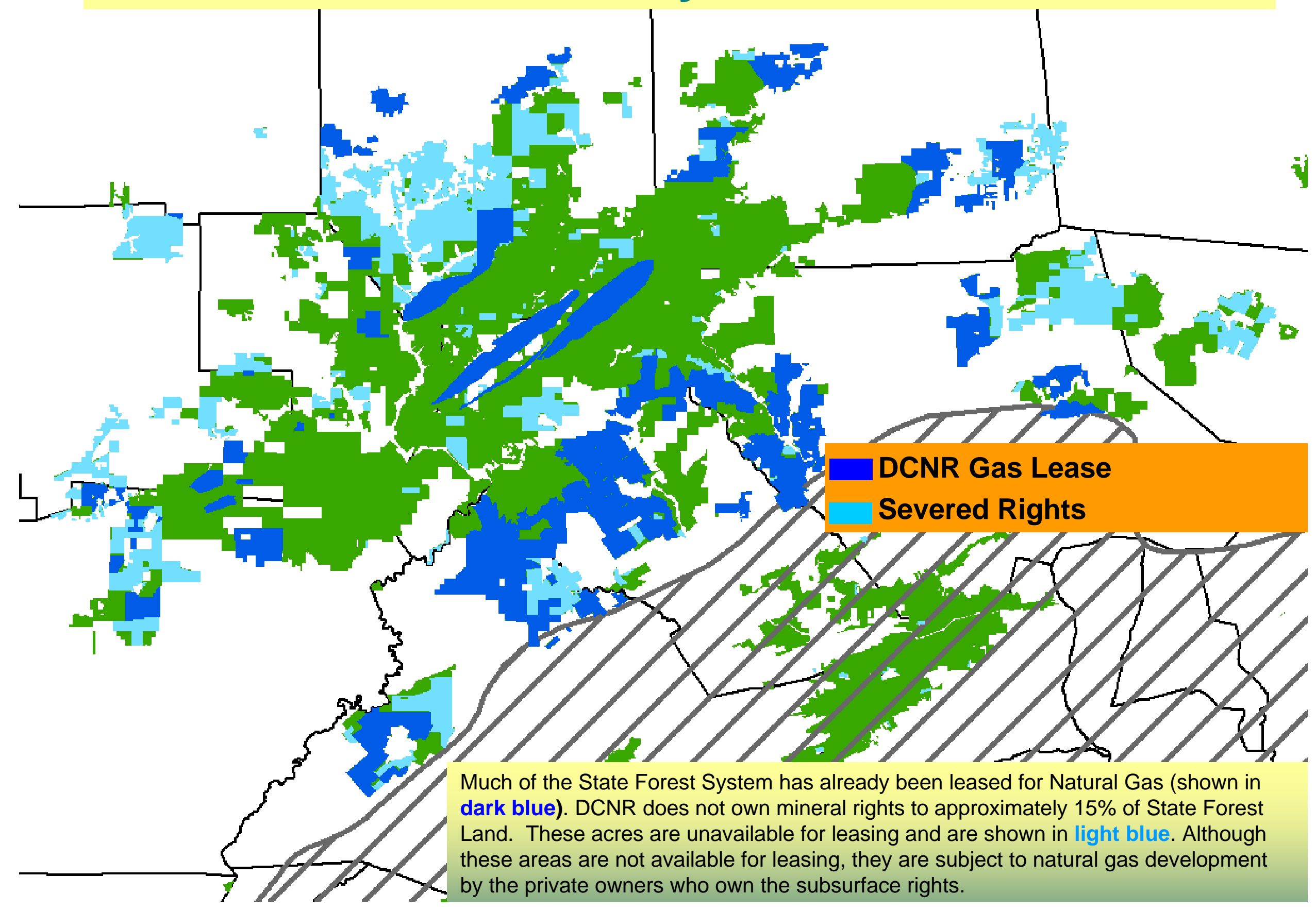




\section{TNC-WPC Priority Forest Patches}

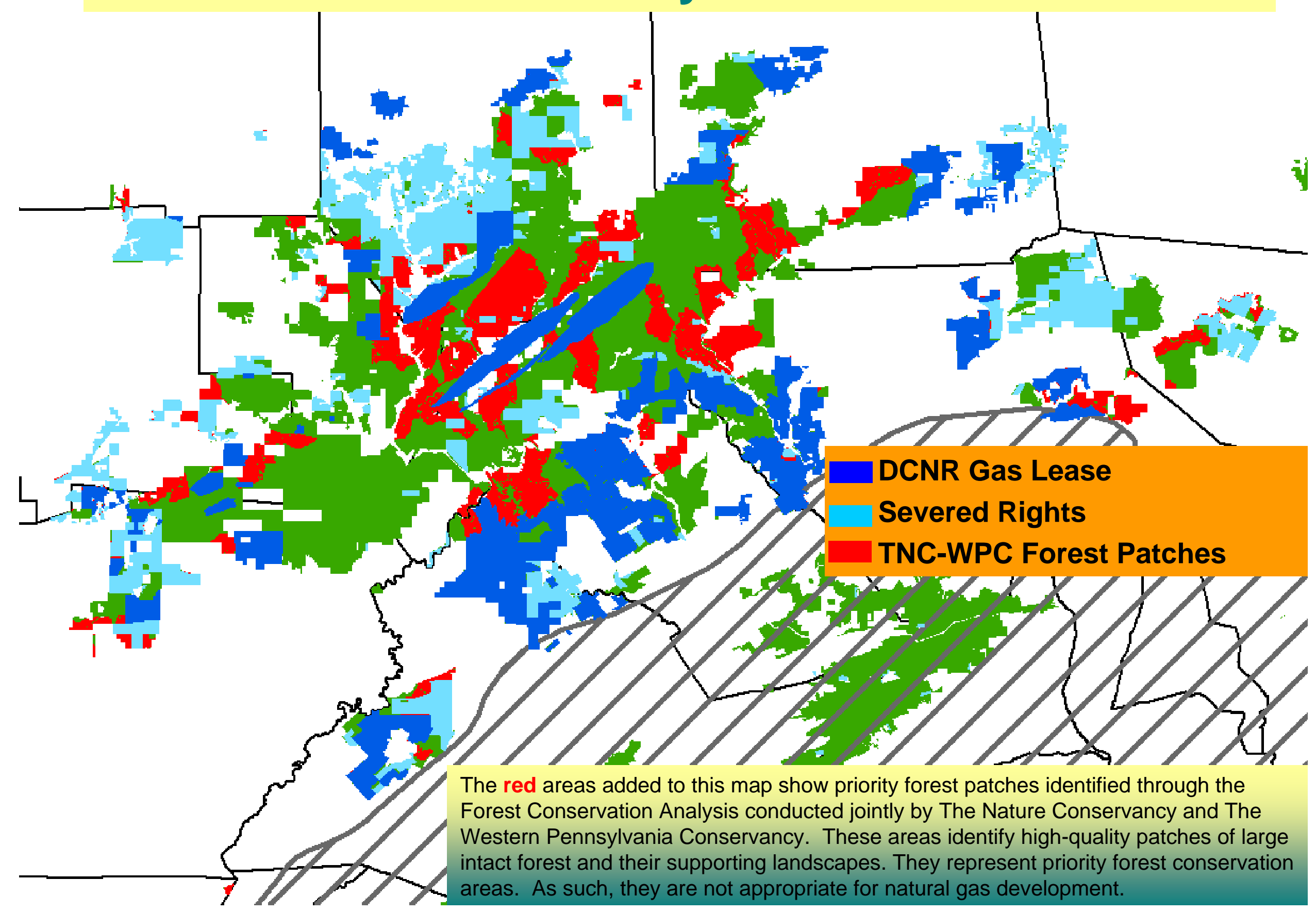




\section{Cumulative Assessment \& Impacts}

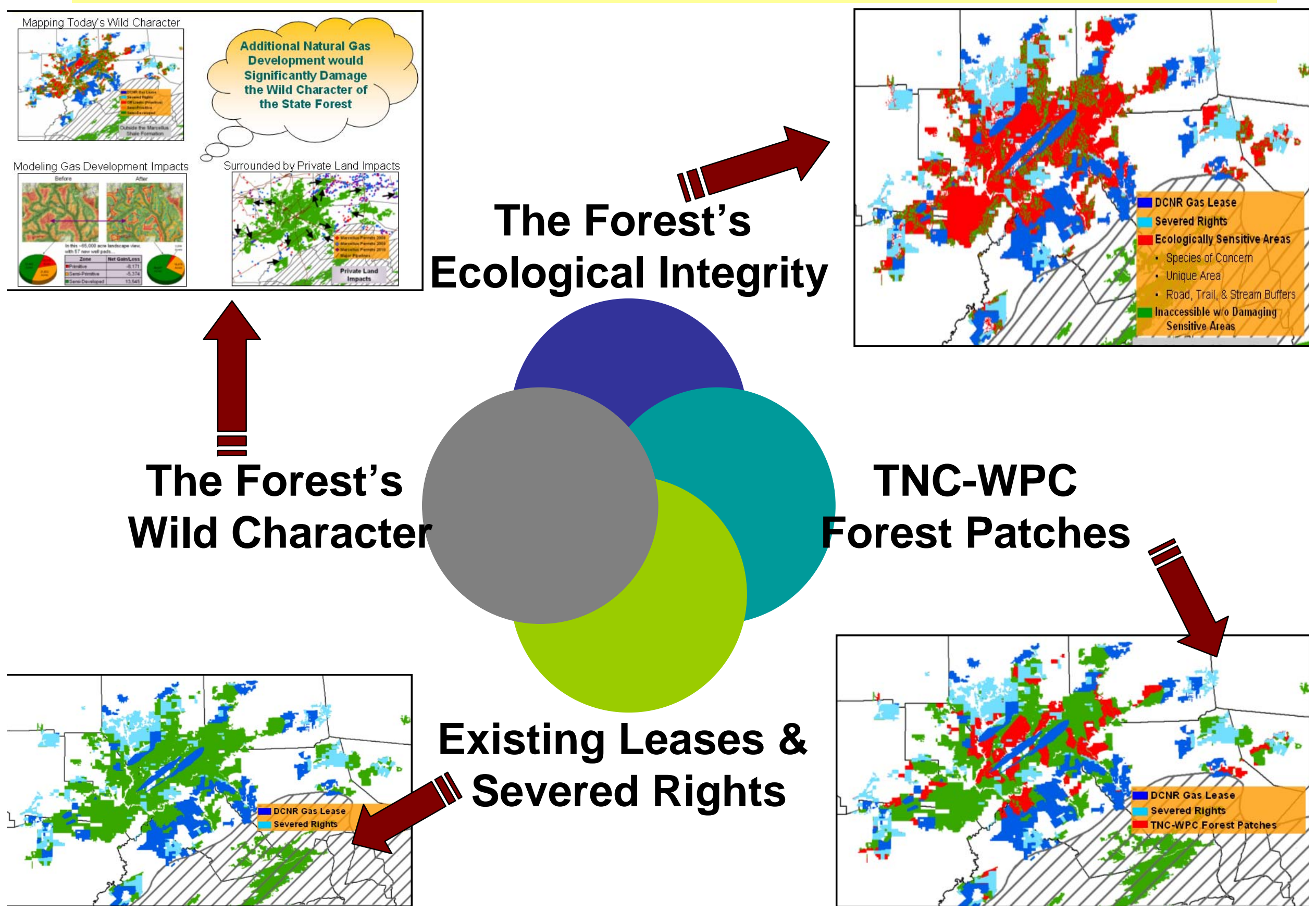




\section{Cumulative Assessment \& Impacts}

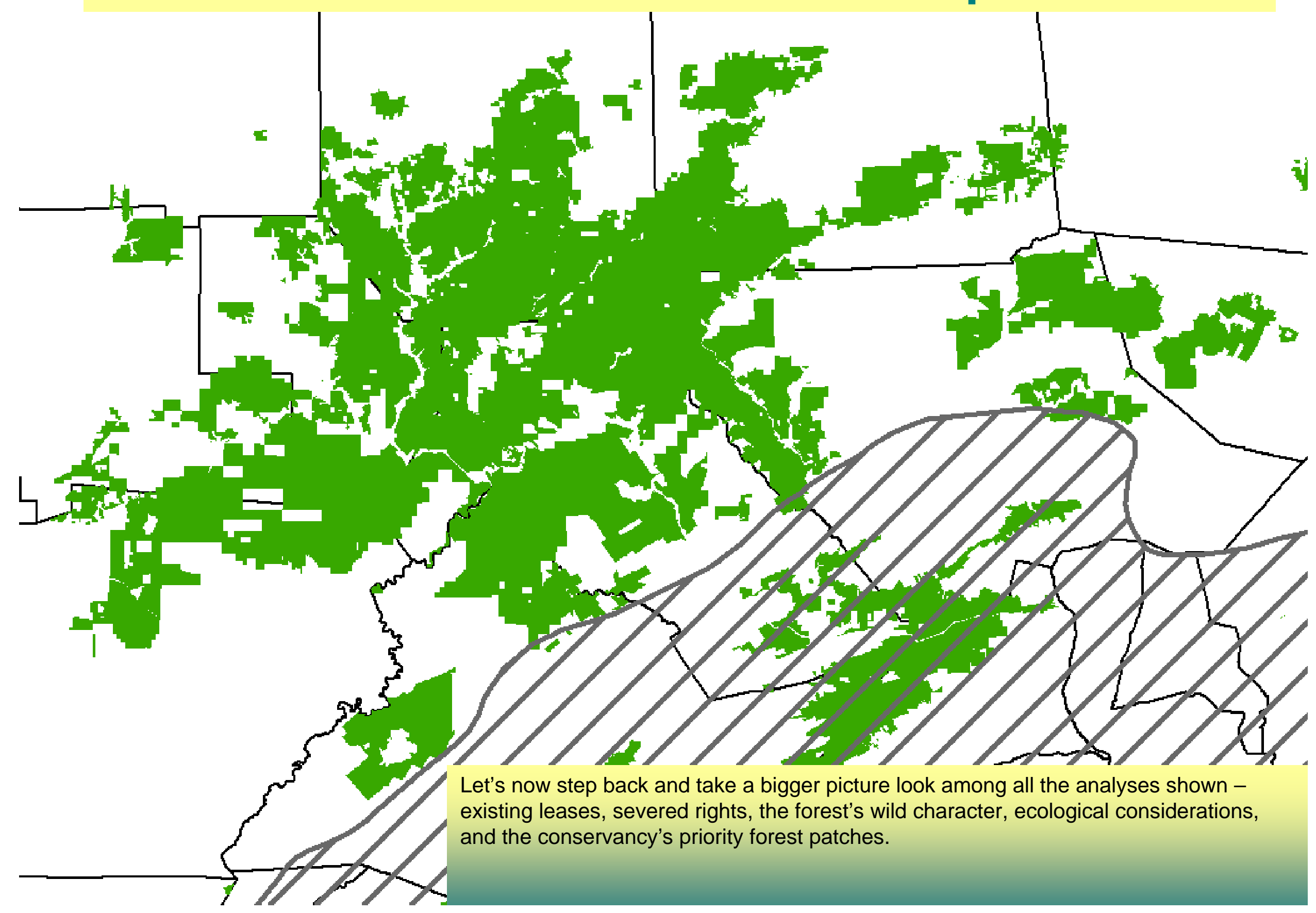




\section{Cumulative Assessment \& Impacts}

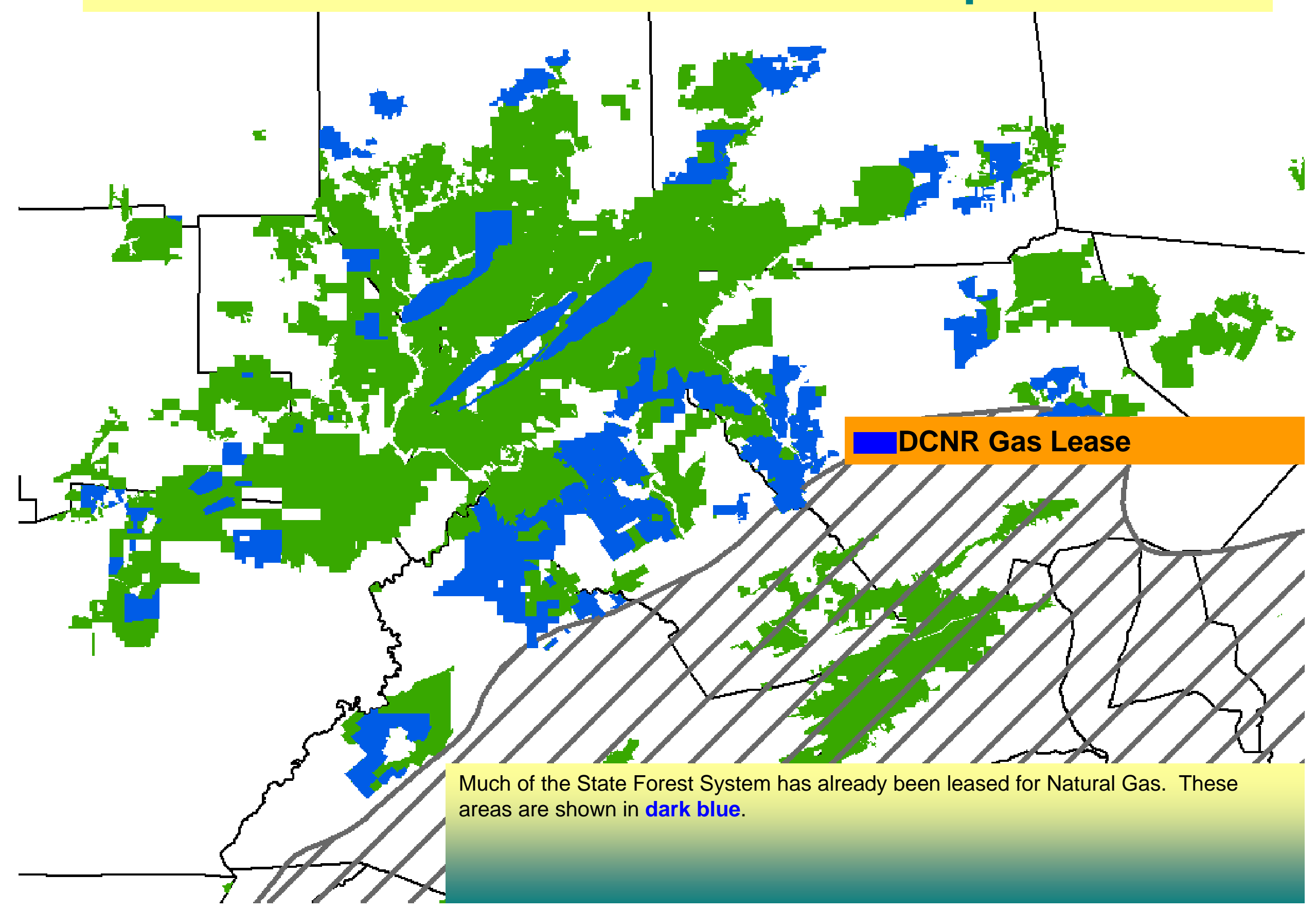




\section{Cumulative Assessment \& Impacts}

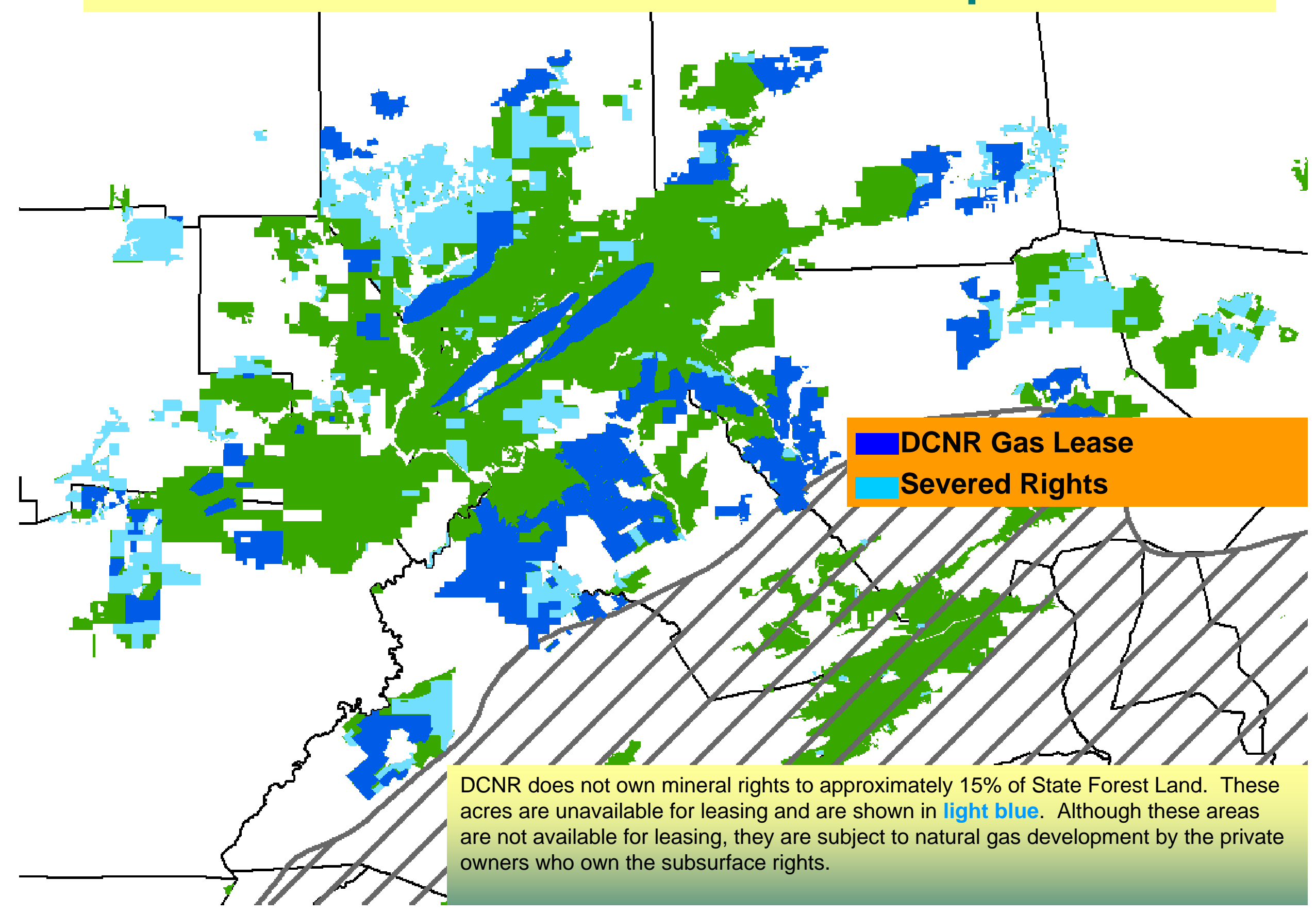




\section{Cumulative Assessment \& Impacts}

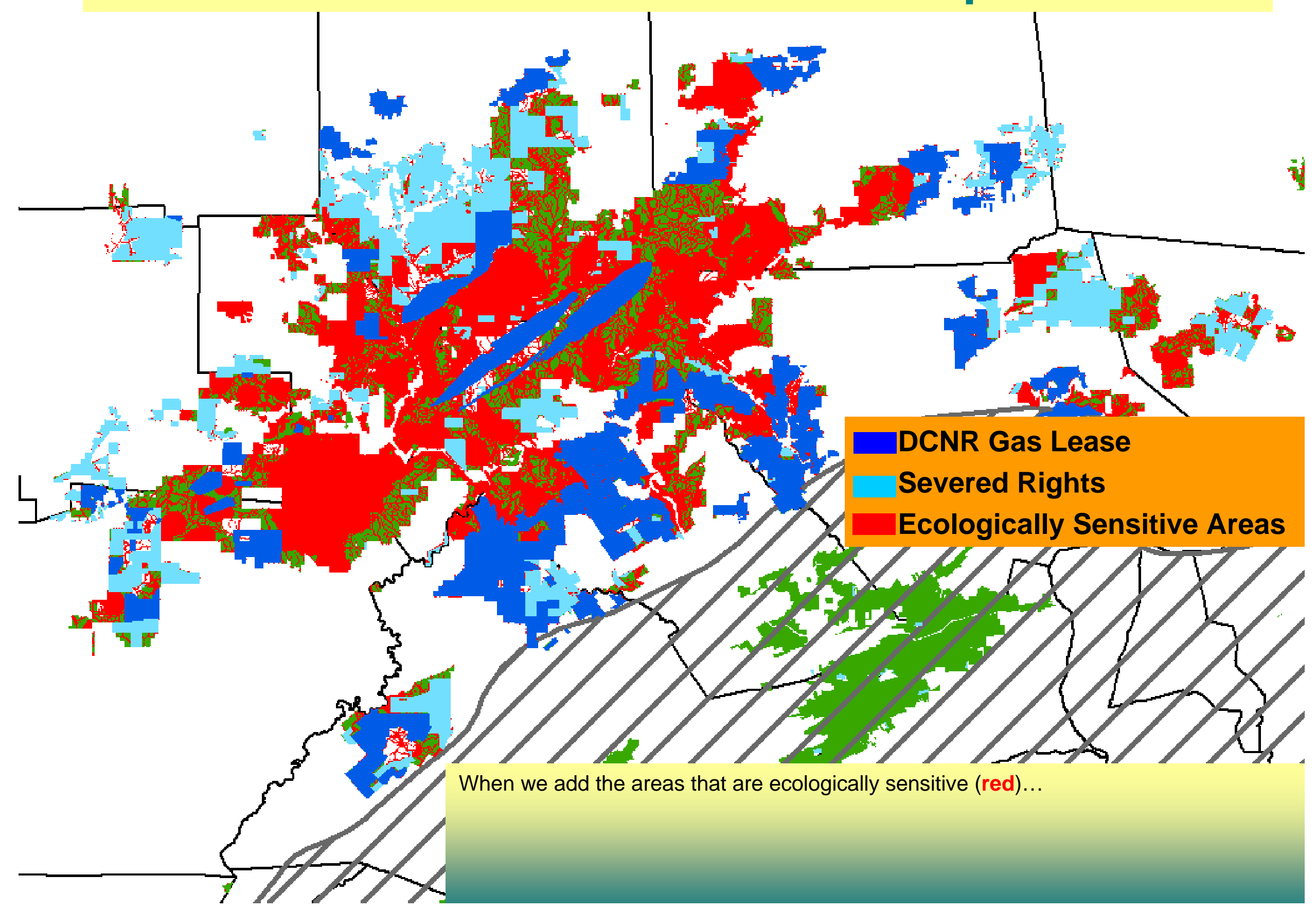




\section{Cumulative Assessment \& Impacts}

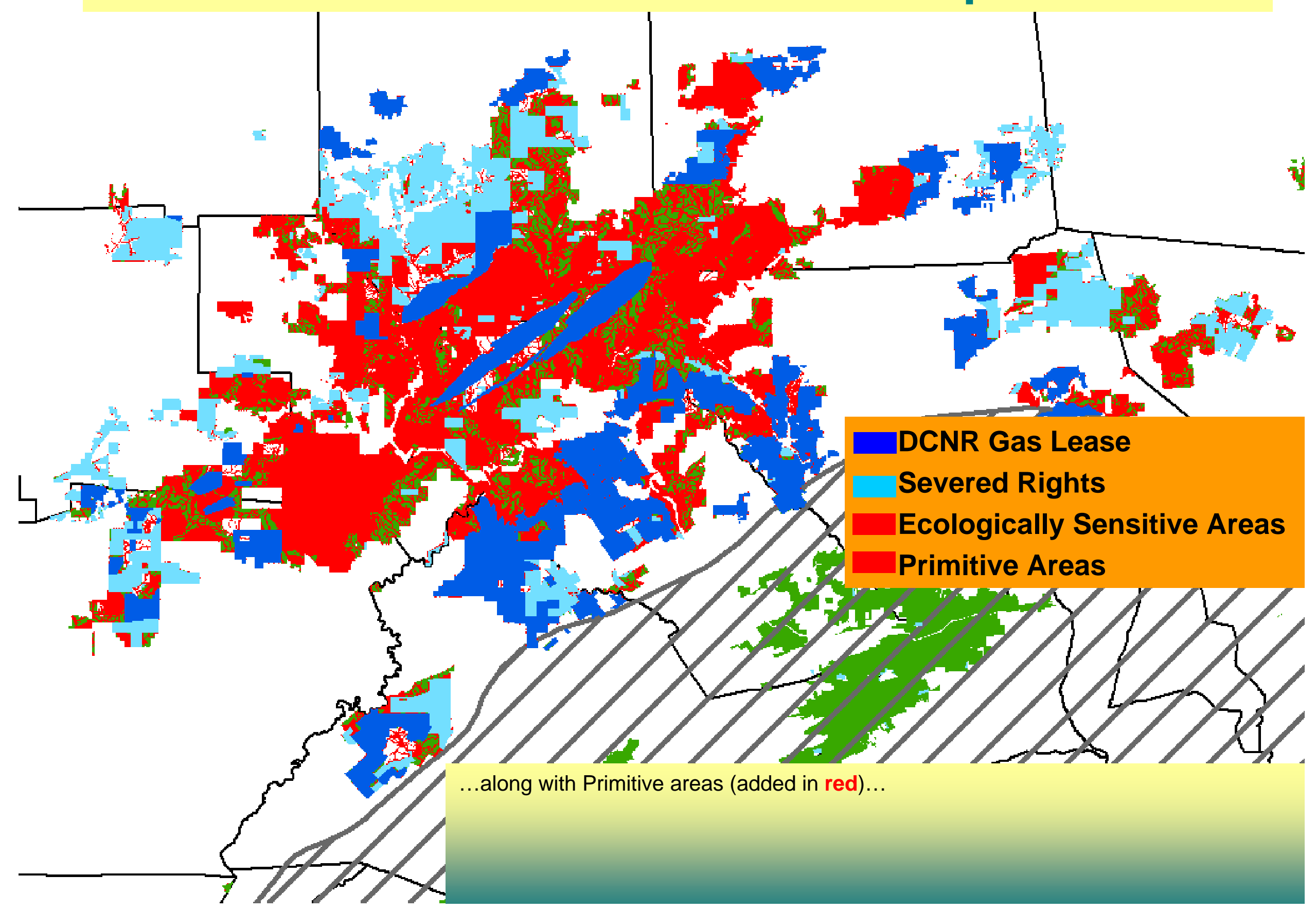




\section{Cumulative Assessment \& Impacts}

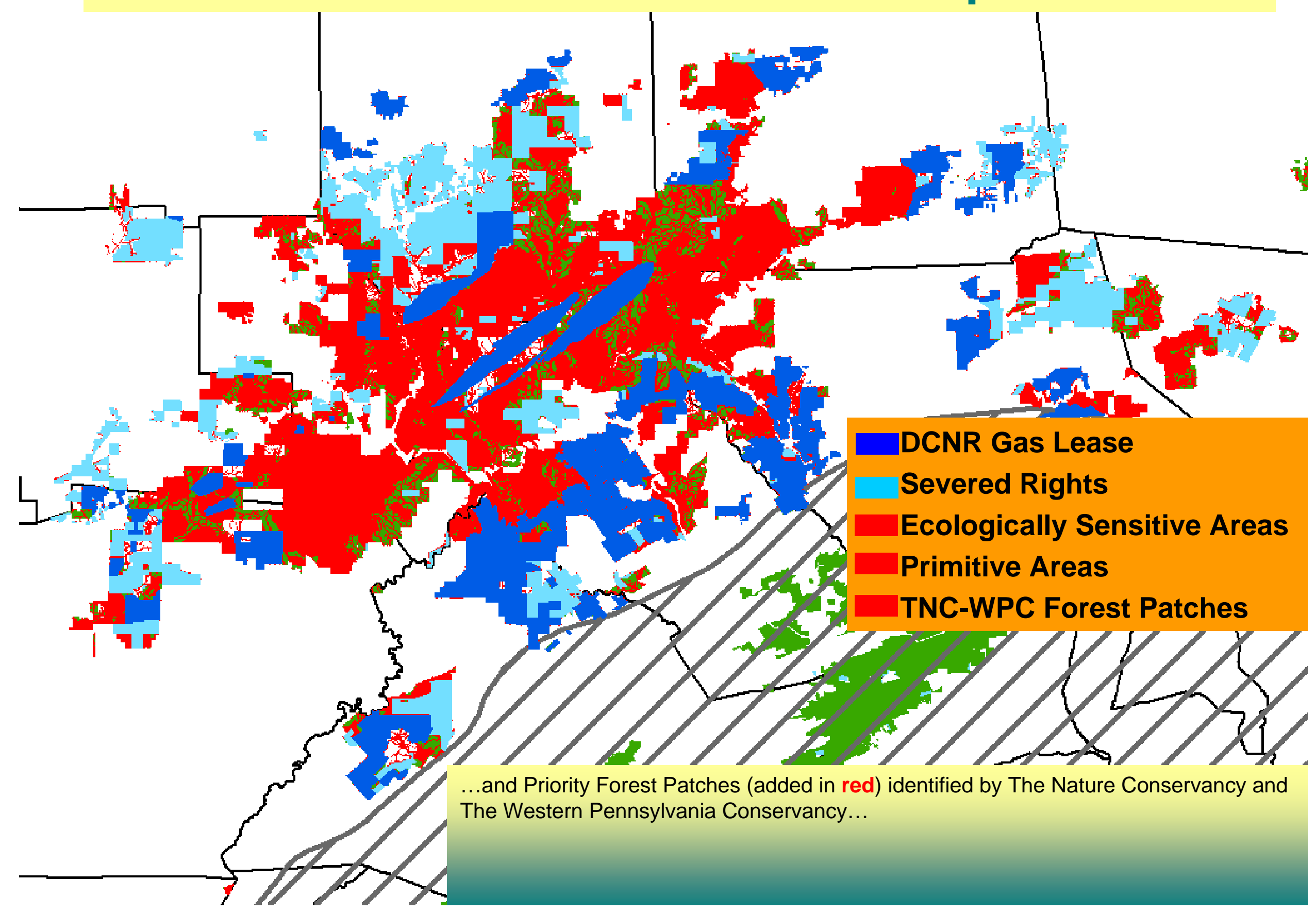




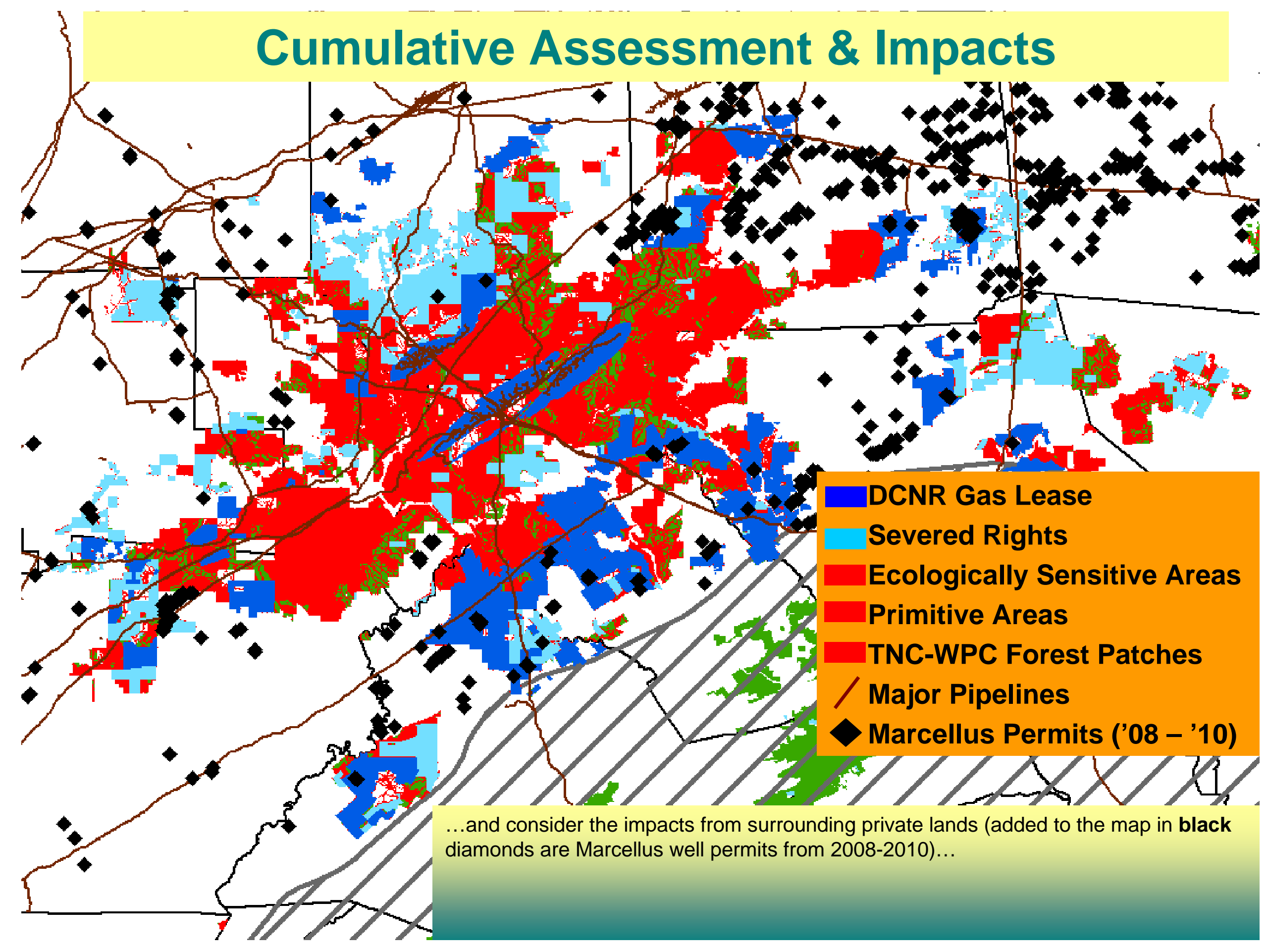




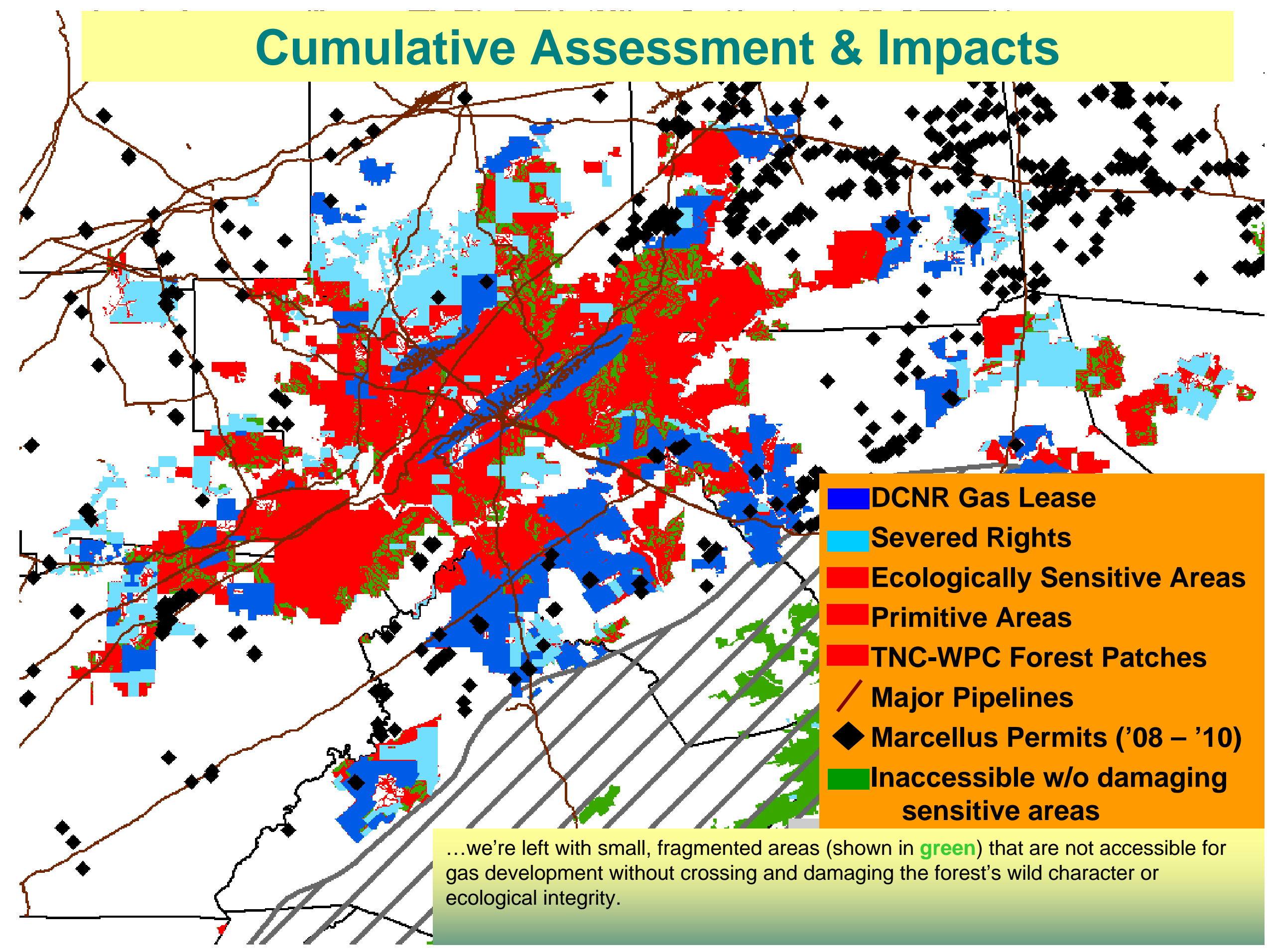




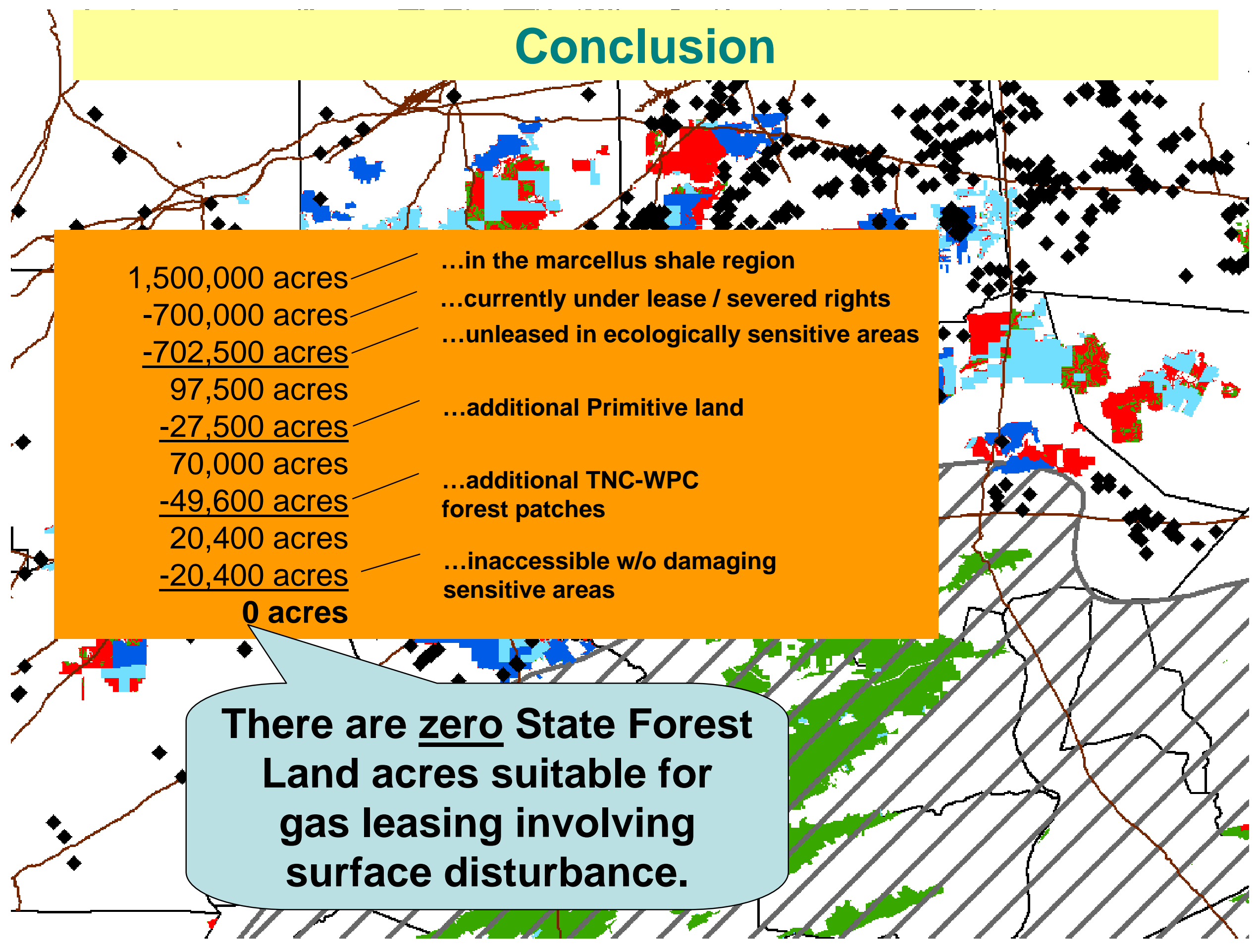




\section{An Economic Review of the Environmental Assessment of the MARC I Hub Line Project}

\section{ECONorthwest

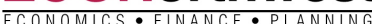

Eugene

99 W. $10^{\text {th }}$ Avenue, Suite 400

Eugene, OR 97401

541.687 .0051

Portland

222 SW Columbia, Suite 1600

Portland, OR 97201

503.222.6060

www.econw.com 


\section{CONTACT INFORMATION}

This report was prepared by Sarah Reich, Ann Hollingshead, Tom Souhlas, and Ed MacMullan of ECONorthwest, which is solely responsible for its content.

ECONorthwest specializes in economics, planning, and finance. Founded in 1974, we're one of the oldest independent economic consulting firms in the Pacific Northwest. ECONorthwest has extensive experience applying rigorous analytical methods to examine the benefits, costs, and other economic effects of environmental and natural resource topics for a diverse array of public and private clients throughout the United States and across the globe.

For more information about ECONorthwest, visit our website at www.econw.com.

For more information about this report, please contact:

Sarah Reich

ECONorthwest

99 W. 10th Ave., Suite 400

Eugene, OR 97401-3040

541-687-0051

reich@eugene.econw.com 


\section{INTRODUCTION AND SUMMARY}

Central New York Oil and Gas Company (CNYOG) proposes to build a natural gas pipeline and related facilities in Sullivan, Bradford, and Lycoming Counties in northeastern Pennsylvania. The MARC I Hub Line Project (the Project) would connect two existing natural-gas pipelines to provide access to interstate markets for natural gas produced from the Marcellus Shale formation. ${ }^{1}$

As part of its review of CNYOG's request for a Certificate of Public Convenience and Necessity to construct and operate the pipeline, the Federal Energy Regulatory Commission (FERC) conducted an Environmental Assessment (EA) of the Project, pursuant to the requirements of the National Environmental Policy Act (NEPA). FERC released the EA in May of 2011. The EA purports to describe the environmental effects of the Project, including the socioeconomic effects. It also includes a section intended to discuss the potential cumulative effects of the Project.

FERC's EA of the Project focuses on the impacts of constructing and operating the pipeline and associated compression facilities. FERC determined that it was inappropriate to include in its analysis the effects of facilities intended to connect to the pipeline, such as production wells and gathering pipelines related to developing the Marcellus Shale, because their locations are currently unknown and speculative. ${ }^{2}$ FERC purports to include these activities, however, within its assessment of the cumulative effects of the Project. ${ }^{3}$

Earthjustice asked ECONorthwest to review FERC's EA of the MARC I Hub Line Project and assess the completeness and accuracy of the socioeconomic and cumulative effects analyses. This report presents our findings. Our review assesses FERC's analysis of the direct and indirect effects on socioeconomic resources and its analysis of cumulative effects, including the environmental and socioeconomic effects of developing the Marcellus Shale in northeastern Pennsylvania.

To complete our assessment, we have reviewed information related to the potential impacts associated with development of the Marcellus Shale, and descriptions of impacts from other reasonably foreseeable pipeline projects in the region. We have also reviewed peer-reviewed, academic, and government publications on topics related to

- The socioeconomic effects of pipeline development, shale-gas extraction, and similar energy-development activities

- The socioeconomic dimensions of pipeline and natural-gas-development effects on the environment and related ecosystem services, such as the degradation of water quality and forest habitat

\footnotetext{
${ }^{1}$ Federal Energy Regulatory Commission (FERC). 2011. MARC I Hub Line Project, Environmental Assessment. Docket No. CP10-480-000. May. Pg. 1.

2 FERC 2011, Pg. 3.

${ }^{3}$ FERC 2011, Pg. 4.
} 
- The economic importance of natural, physical, social, and human capital in northeastern Pennsylvania, focusing on Sullivan, Bradford, and Lycoming Counties

In our review, we identify three major shortcomings in FERC's EA of the Project that arise because it fails to fully identify and consider the socioeconomic impacts of the Project itself, and the impacts of reasonably foreseeable projects that overlap in time and/or space with those of the Project, and together, produce cumulative impacts. Specifically, the EA:

1. Fails to fully describe and consider the direct and indirect socioeconomic effects of the Project.

2. Omits a discussion of cumulatively significant socioeconomic effects.

3. Fails to adequately describe the other cumulatively significant effects.

Because of these deficiencies, the EA does not fully describe the range of potential environmental consequences of the Project. As such, the EA provides decision makers and stakeholders with an incomplete and inaccurate assessment of the Project's potential impacts, and so fails to support the proposed finding that the Project will have no significant impact.

In the following sections, we outline the evidence for each of these shortcomings, and present information that FERC should have considered as it prepared its EA of the MARC I Hub Line Project. 


\section{DIRECT AND INDIRECT SOCIOECONOMIC EFFECTS}

The EA identifies these categories of socioeconomic impacts that would arise from the construction and operation of the pipeline:4

- Changes in population in the study area

- Expenditures on materials and labor within and outside the region

- Increased demand for temporary housing

- Increased demand for public services

- Revenues from property taxes assessed on the Project and other taxes on projectrelated expenditures

- Changes in property values

In other sections, the EA mentions the Project's potential impacts on other resources such as water resources, vegetation and wildlife, recreation, traffic and access, and air quality - that contribute to the social and economic well-being of nearby residents and communities. ${ }^{5}$ It does not discuss the socioeconomic implications of these impacts, however. Its failure to do so leaves its overall description and assessment of the Project's socioeconomic effects incomplete.

The failure to address thoroughly the socioeconomic effects of the Project's impacts on environmental resources contravenes widely accepted guidance for impact analysis. The U.S. Environmental Protection Agency (EPA), the Office of Management and Budget $(\mathrm{OMB})$, and the National Research Council (NRC) have each provided guidance toward the sound evaluation of the economic effects of regulatory and non-regulatory actions. This guidance reflects generally-recognized professional standards for conducting economic analyses. In its Guidelines for Preparing Economic Analysis, EPA sets forth recommendations that complete economic analyses should consider three separate, but equally important dimensions along which economic consequences may materialize: benefits and costs, economic impacts, and distribution of effects. The Guidelines further state that unless an analysis is broad in scope and embraces even impacts for which there are no monetary data, it cannot provide the public and decision-makers with the relevant economic information on which to make a decision. ${ }^{6}$ This guidance rests, in part, on recent reports from the EPA's Science Advisory Board and the NRC that underscore the importance of considering the value of impacts to ecosystem services in the context of environmental decisions. ${ }^{7}$ OMB offers similar guidance, directing analysts to provide quantitative and qualitative descriptions of the benefits and costs of actions that

\footnotetext{
4 FERC 2011, Pp. 67-69.

5 FERC 2011, Pgs. 29, 43, 63, 66, 72.

6 U.S. Environmental Protection Agency. 2010. Guidelines for Preparing Economic Analyses. Report No. EPA240-R-10-001. December.

7 U.S. Environmental Protection Agency, Science Advisory Board. 2009. Valuing the Protection of Ecological Systems and Services. Report No. EPA-SAB-09-012. May. and National Research Council. 2005. Valuing Ecosystem Services. National Academies Press: Washington D.C.
} 
transparently describe the nature, timing, likelihood, location, and distribution of benefits and costs. ${ }^{8}$

The EA fails to fully describe the direct and indirect effects of the Project consistent with this professional guidance. It does not include a thorough discussion of the positive and negative effects of the Project. For some categories of effects, such as employment and income effects, for example, the EA describes potential positive changes but omits any discussion of potential offsetting, negative changes. It focuses on the short-run economic consequences of the Project and fails to adequately address the long-run consequences, especially those indirect effects that arise as firms, individuals, and communities respond to the effects of constructing and maintaining the Project. It also fails to analyze the impacts at all potentially-affected scales of impact (e.g., an individual, a locality, a region, the nation), or consider distributional issues.

Here we illustrate of the types of information FERC should have considered as it described the direct and indirect socioeconomic effects of the Project.

Direct and Indirect Effects on Jobs and Income. FERC states that constructing and operating the Project would increase job opportunities and income, although it does not state the relevant geography across which these impacts would materialize. It emphasizes that the workforce of an estimated 300 to 500 workers would "largely be comprised" 9 of workers from outside the region for the short duration of construction, raising the possibility that an increase in employment locally might be offset by a reduction elsewhere. FERC further describes that the operation of the Project would require just 10 workers. FERC does not indicate if these would likely be local or nonlocal workers, nor if the positions would require new hires or draw on existing employees. ${ }^{10}$ FERC further ignores the potential impacts on jobs and incomes in sectors not directly linked to the Project. Evidence from other communities that have experienced natural-gas-related development suggests that, while construction and operation activities can increase job opportunities and incomes in the short-run, the long-run outcomes of such development are more mixed and persistent. ${ }^{11}$ Offsetting impacts on jobs and income, for example, may occur in industries that rely on resources that are otherwise consumed by the Project. Degradation of bird habitat resulting from a pipeline, for example might reduce related jobs and incomes in the recreation and tourism industry. These offsets may be temporary in nature, from tourists who avoid the area during construction or cannot find hotel or motel vacancies because they are taken up by non-local project workers. They may be permanent, to the extent that the pipeline

8 Office of Management and Budget. 2003. Circular A-4 to the Heads of Executive Agencies and Establishments Regarding Regulatory Analysis. September 17.

${ }_{9}^{9}$ FERC 2011, Pg. 68.

10 FERC 2011, Pg. 68.

11 Jacquet, J. 2009. “Energy Boomtowns \& Natural Gas: Implications for Marcellus Shale Local Governments \& Rural Communities." Pennsylvania State University, Northeast Regional Center for Rural Development. Report No. 43. Retrieved on July 7, 2011, from http:/ / nercrd.psu.edu/publications/rdppapers/rdp43.pdf; Kay, D. "The Economic Impact of Marcellus Shale Gas Drilling. What Have we Learned? What are the Limitations?" Cornell University. Working Paper Series: A Comprehensive Economic Impact Analysis of Natural Gas Extraction in the Marcellus Shale. April. 
facilitates more wide-spread development that changes the supply or character of recreational activities, causing people to recreate elsewhere. FERC ignores these indirect, long-term impacts on jobs and income that may arise as a result of the Project. FERC also fails to discuss the distributional consequences of the Project related to jobs and income, which are often unevenly spread across local populations.

Direct and Indirect Effects on Public Services. FERC provides an incomplete description and assessment of the Project's potential impacts on public services. It briefly discusses the short-term increase in demand for some local public services that would result from the influx of construction workers, but does not describe the impact on other services or the long-term effects. ${ }^{12}$ FERC focuses on just one type of services, emergency response services, claims that CNYOG would coordinate with local law enforcement agencies, fire departments, and emergency medical services, and states that the demand for these services would diminish when the temporary workforce leaves the area. ${ }^{13}$ FERC fails, however, to include any meaningful discussion of the potential effects of the influx of temporary workers and construction activities on local government services, such as law enforcement, medical care, road maintenance crews, social services, and waste management. The literature suggests that local governments are often unprepared for the short-term, rapid increases in out-of-town populations that can accompany largescale infrastructure projects. ${ }^{14}$ The increased demands can impose increased costs on local departments, increasing response times and reducing the level of services available for resident populations. ${ }^{15}$ The increased costs and impacts on infrastructure can leave service providers unable to sustain normal levels of service to existing residents not just during a project, but also after a project's workers have moved on. FERC's analysis does not adequately address these issues, leaving local governments vulnerable to increased and uncompensated costs, and potentially eroding social capital in the local communities. ${ }^{16}$

Direct and Indirect Effects on Property Values. Although FERC describes comments it received about the impact the Project would have on property values, it fails to include any meaningful discussion of what the Project's impact would be. ${ }^{17}$ In fact, FERC admits that the Project could affect property values when it says "this is not to say that the Project would not affect resale values." 18 Several studies have found that the presence of pipelines on or adjacent to residential property does not adversely affect their value: homes near pipelines sold for prices close to the prices for similar homes not near the

\footnotetext{
12 FERC 2011, Pg. 68.

13 FERC 2011, Pg. 68.

14 Jacquet 2009.

15 Pammer, W., J. Jaquet, R. Howe, and L. Sullivan. 2009. Impacts to Local Governments and Municipalities from Natural Gas Drilling. Cornell Cooperative Extension: Natural Gas Development Resource Center. Ithaca, NY. May $4^{\text {th }}, 2009$.

16 Sugarloaf Project Alliance. 2008. Sugarloaf Pipeline Project: Social Impact Assessment. February.

17 FERC 2011, Pg. 69.

18 FERC 2011, Pg. 69.
} 
pipeline. These studies provide no evidence, however, that the value of properties with easements and adjacent to the Project will not be affected during its expected life, especially in the event of a failure of the pipeline itself or another nearby pipeline.

Another group of studies looks at the effect of pipelines on property values following a rupture or spill. These studies, suggest, in fact, that they can affect residential property values, as residents and prospective buyers perceive an increased risk associated with living nearby the pipeline and capitalize that risk into the value of property. ${ }^{19}$ FERC's analysis fails to consider this evidence or to provide a complete discussion of the Project's potential impacts on property values.

Direct and Indirect Effects on Value of Ecosystem Services. "Ecosystem services are the direct and indirect contributions that ecosystems make to the well-being of human populations." 20 To the extent that the Project would affect ecosystems and their ability to make such contributions, it would have socioeconomic impacts. FERC acknowledges that the Project would affect ecosystems, describing its impacts to environmental resources, such as water quality, vegetation and wildlife, air quality, and other components that make up the region's ecosystem. It focuses on these impacts from a biophysical perspective, however, ignoring their potential socioeconomic dimensions. In doing so, it fails to provide a complete evaluation of the socioeconomic consequences of the Project.

In recent years, there has been growing attention toward investigating the impacts of industrial and commercial activities by studying their effects on ecosystem goods and services. ${ }^{21}$ Some ecosystem goods and services have economic value when they are extracted, as when water is diverted from a stream to irrigate crops. Others have value in situ within the ecosystem, as when people travel to the forest to watch birds or hike. The list of goods and services provided by the region's ecosystems, illustrated in Table 1, is long and growing as scientists learn more about the inner workings of ecosystems and people find new ways to derive benefits from them.

\footnotetext{
19 Hansen, J.L. E.D. Benson, and D.A. Hagen (2006) “Environmental Hazards and Residential Property Values: Evidence from a Major Pipeline Event." Land Economics 82(4): 529-541.; Simons, R.A. (1999) “The Effect of Pipeline Ruptures on Noncontaminated Residential Easement-Holding Property in Fairfax County." The Appraisal Journal 67(3): 255-63.; Simons, R.A., K. Winston-Geideman, B.A. Mikelbank (2001)

“The Effects of an Oil Pipeline Rupture on Single Family House Prices." The Appraisal Journal 69(4): 410-18.

20 EPA SAB 2009, p. 12.

21 Daily, G.C. 1997. Nature's Services: Societal Dependence on Natural Ecosystem. Washington, D.C.: Island Press;, EPA SAB 2009; NRC 2005.
} 
Table 1. Summary of Ecosystem Goods and Services ${ }^{22}$

\begin{tabular}{|c|c|c|c|c|c|}
\hline \multicolumn{6}{|c|}{ Examples of Ecosystem Goods and Services } \\
\hline 1 & $\begin{array}{l}\text { Production and } \\
\text { regulation of water }\end{array}$ & 7 & $\begin{array}{l}\text { Production of food for } \\
\text { humans }\end{array}$ & 12 & $\begin{array}{l}\text { Production of ornamental } \\
\text { resources }\end{array}$ \\
\hline 2 & $\begin{array}{l}\text { Formation and } \\
\text { retention of soil }\end{array}$ & 8 & $\begin{array}{l}\text { Production of raw } \\
\text { materials for industry }\end{array}$ & 13 & $\begin{array}{l}\text { Production of aesthetic } \\
\text { resources }\end{array}$ \\
\hline 3 & $\begin{array}{l}\text { Regulation of } \\
\text { atmosphere and climate }\end{array}$ & 9 & $\begin{array}{l}\text { Pollination of wild plants } \\
\text { and agricultural crops }\end{array}$ & 14 & $\begin{array}{l}\text { Production of recreational } \\
\text { resources }\end{array}$ \\
\hline 4 & $\begin{array}{l}\text { Regulation of floods and } \\
\text { other disturbances }\end{array}$ & 10 & $\begin{array}{l}\text { Biological control of pests } \\
\text { and diseases }\end{array}$ & 15 & $\begin{array}{l}\text { Production of spiritual and } \\
\text { cultural resources }\end{array}$ \\
\hline 5 & $\begin{array}{l}\text { Regulation of nutrients } \\
\text { and pollution }\end{array}$ & 11 & $\begin{array}{l}\text { Production of genetic and } \\
\text { medicinal resources }\end{array}$ & 16 & $\begin{array}{l}\text { Production of scientific and } \\
\text { educational resources }\end{array}$ \\
\hline 6 & $\begin{array}{l}\text { Provision of fish and } \\
\text { wildlife habitat }\end{array}$ & & & & \\
\hline
\end{tabular}

In most times and places, there are insufficient resources to satisfy all the demands for all of the ecosystem goods and services in Table 1 . Hence, there is competition for the resources and, when resources are used to produce one set of goods and services, the demands for others go unmet. This may occur, for instance, when trees are cleared for a right-of-way, compromising wildlife habitat and reducing the value people derive from viewing wildlife in their natural surroundings.

Some ecosystem goods and services, such as recreational opportunities and scenic vistas, contribute directly to the well-being of people who have access to them. Their contribution to consumers' well-being makes them economically important in their own right, but they have additional economic importance when they shape the quality of life people enjoy from a place, thereby influencing location decisions of households and firms. These so-called quality of life amenities are discussed in more detail in the next section.

Other ecosystem goods and services are important in that they fulfill demands that do not necessarily entail a conscious, explicit use of natural resources. These are called environmental values. There are two general categories: nonuse, or passive use values and values of goods and services that generally go unrecognized. Passive use values arise whenever people place a value on maintaining some aspect of the environment, even though they do not use it and have no intention to do so. Research has documented passive values for maintaining the existence of species threatened with extinction, for example, and for special natural areas, such as national parks. They also can materialize when people want to maintain a particular cultural or ecological characteristic of a resource, as when people want to maintain the existence of landscapes associated with traditional agriculture or native wilderness, for enjoyment by future generations.

22 Adapted by ECONorthwest from De Groot, R.S., M.A. Wilson, and R.M.J. Boumans. 2002. “A Typology for the Classification, Description and Valuation of Ecosystem Functions, Goods and Services." Ecological Economics 41 (3): 393-408; and Daily, G.C. 1997. Nature's Services: Societal Dependence on Natural Ecosystem. Washington, D.C.: Island Press. 
Environmental values also can be important when a water-related ecosystem provides valuable services that people generally consume without being aware of them. Some scientists and economists believe many services have great economic value, even though people generally are unaware of their importance. ${ }^{23}$ Environmental values typically increase as people learn more about the environment and the services it provides. ${ }^{24}$

By affecting the supply of environmental resources available in the region, the Project has the potential to produce impacts on the value people derive from the region's ecosystem services. By failing to describe these impacts, either quantitatively or qualitatively, FERC's analysis of the Project's socioeconomic impacts is incomplete.

Direct and Indirect Effects on Quality of Life. As mentioned in the previous section, FERC fails to describe the Project's potential impacts on the region's amenities that contribute to residents' quality of life. These impacts may have important socioeconomic consequences. The nearer people live to amenities, the lower their cost of using them. Thus, consumers can increase their economic well-being by living in a place that offers recreational opportunities, pleasant scenery, wildlife viewing, and other amenities making important contributions to their quality of life. Quality-of-life amenities can be powerful drivers of economic development. Differences in quality of life explain about half the interstate variation in job growth, 25 and the quality of life available in rural Pennsylvania is a major factor influencing why many households come to and stay in the region. Some residents in the Project area undoubtedly could enjoy higher earnings living elsewhere, such as Philadelphia or New York City, but choose not to do so because their overall economic welfare - the sum of their earnings plus quality of life - is higher here. ${ }^{26}$ FERC fails to examine the Project's potential impacts on the interrelationship among the region's amenities, quality of life, and economy.

Another, related impact that FERC fails to consider in its analysis of socioeconomic impacts is the potential for the Project to adversely affect the value residents derive from the amenities of their properties on or adjacent to the Project. Some of these amenities, which may include scenic views, solitude and quietude, sense of safety, and sense of privacy may be captured in the market price of individual properties. For example, many people are willing to pay more for a house with a view than for an equivalent house without a view. The market price, however, may not fully capture the value an existing property owner derives from these amenities. Economic studies have shown that people often demand a higher price to give up things they value than they would otherwise be willing to pay to acquire them. This effect, known as the endowment effect,

\footnotetext{
23 Daily, G.C. 1997.

24 Blomquist, G.C. and J.C. Whitehead. 1998. "Resource Quality Information and Validity of Willingness to Pay in Contingent Valuation." Resource and Energy Economics 20 (2): 179-196.

25 Partridge, M.D. and D.S. Rickman. 2003. “The Waxing and Waning of Regional Economies: the ChickenEgg Question of Jobs Versus People." Journal of Urban Economics 53: 76-97.

26 Power, T.M. 2005. "The Supply of and Demand for Natural Amenities: An Overview of Theory and Concepts." In Amenities and Rural Development: Theory, Methods, and Public Policy. G.P. Green, S.C. Deller, D.W. Marcouiller, eds. Cheltenham: Edward Elgar Publishing Limited; and Hand, M.S., J.A. Thacher, D.W. McCollum, and R.P. Berrens. 2008. "Intra-Regional Amenities, Wages, and Home Prices: The Role of Forests in the Southwest." Land Economics 84 (4): 635- 651.
} 
is a manifestation of another concept economists call loss aversion. Loss aversion means that an individual's willingness to accept payment to give something up is greater than their willingness to pay to acquire it. ${ }^{27}$ To fully describe and assess the Project's socioeconomic impacts on residents living nearby, FERC must explicitly examine its interactions with both the endowment effect and loss aversion.

${ }^{27}$ Kahneman, D. J.L. Knetsch, and R.H. Thaler. 1991. “Anomalies: The Endowment Effect, Loss Aversion, and Status Quo Bias.” The Journal of Economic Perspectives 5:1 (193-206). 


\section{Cumulative Impacts}

A cumulative impact, in the context of NEPA, is "the impact on the environment which results from the incremental impact of the action when added to other past, present, and reasonably foreseeable future actions regardless of what agency (Federal or non-Federal) or person undertakes such other actions. Cumulative impacts can result from individually minor but collectively significant actions taking place over a period of time." 28

Two projects need not be directly related to produce cumulative impacts, so long as the resources they impact are related in some way, either in time or in space, or both. ${ }^{29}$ Cumulative effects can occur in a variety of ways. They might be the result of additive effects of multiple projects that interact in a linear fashion, effectively "stacking" impacts. They might have opposite effects, offsetting each other. They may have synergistic effects, combining to exceed the additive effect alone. This may occur, for example, when a threshold for change is reached for a social, economic, or ecological variable, beyond which the impact becomes apparent, or increases in significance more quickly. ${ }^{30}$

In the EA, FERC identifies six potential impacts of the Project that it views as relevant to the cumulative impacts analysis. ${ }^{31}$ The EA entirely omits a discussion of the potential cumulative nature of impacts to socioeconomics, and it does not offer an explanation or justification for this omission. ${ }^{32}$ The resources it does include in the cumulative impact analysis are

- Water resources (groundwater, surface water, and wetlands)

- Vegetation

- Wildlife

- Land Use (including recreation, special interest areas, and visual resources)

- Air Quality

- $\quad$ Noise

In the context of this EA, FERC purports to identify past, present, and reasonably foreseeable future actions potentially relevant to the cumulative impact analysis. It singles out five that likely would actually produce impacts that, when combined with

2840 C.F.R. 1508.7.

${ }^{29}$ Council on Environmental Quality. 1997. Considering Cumulative Effects under the National Environmental Policy Act. Retrieved on July 6, 2011, from http:/ /ceq.hss.doe.gov/nepa/ccenepa/ccenepa.htm.

30 Contant, C.K. and L.L. Wiggins. 1993. "Toward Defining and Assessing Cumulative Impacts: Practical and Theoretical Considerations." In Environmental Analysis: The NEPA Experience. S.G. Hilderbrad and J.B. Cannon. Pp. 336-356.

31 FERC 2011, Pg. 103.

32 FERC 2011, Pg. 67. 
the incremental impacts of the Project, would produce potentially cumulativelysignificant impacts. The projects include: ${ }^{33}$

- TGP's Northeast Supply Diversification Project

- 300 Line Project

- Northeast Upgrade Project

- North-South Project

- Development of the Marcellus Shale Gas Reserves

Although FERC includes the development of the Marcellus Shale in its analysis of cumulative effects, its analysis is incomplete and inadequately supported. It fails to consider widely available information, from the project area itself and from other areas, about the actual impacts of shale-gas development at a scale that is likely to occur in the study area after pipeline conveyance becomes available. As a result, it does not describe the full range of cumulative effects that potentially could result if both the Project and the other reasonably foreseeable projects are implemented as currently anticipated.

In this section, we outline some of the readily available information available to characterize the potential impacts of the development of the Marcellus Shale Gas Reserves in Bradford, Sullivan, and Lycoming Counties (the three-county area). Based on this information, we describe the shortcomings of FERC's analysis of cumulative impacts in two areas: its omission of cumulative impacts of socioeconomic effects; and its incomplete discussion of the cumulative impacts related to the six resources it does describe. We begin by summarizing the available information on the development of the Marcellus Shale Gas Reserves in the three-county area, including the likely extent of development at full build-out and the processes that likely would be employed to extract the natural gas.

\section{A. Description of the Potential Development of the Marcellus Shale Gas Reserves}

The EA considers oil and gas wells, including Marcellus Shale natural gas development, under unrelated projects that have potential cumulative impacts. The EA notes "drilling has occurred and will continue to occur in the counties where the Project would be constructed" in Lycoming, Sullivan, and Bradford Counties. ${ }^{34}$ The EA does not, however, include the cumulative impacts of future gas wells and other facilities that would deliver gas from Marcellus Shale to the Project's pipeline, called upstream facilities, because "the exact location, scale, and timing of future Marcellus Shale upstream facilities...is unknown and, thus, outside the scope of our analysis." 35

This conclusion, however, contradicts the information on the location, scale, and timing of the development of future Marcellus Shale facilities that is widely available, and

33 FERC 2011, Pg. 103.

34 FERC 2011, Pg. 98.

35 FERC 2011, Pg. 102. 
sufficient to make a general estimate of the scale and magnitude of the potential impacts. There are currently 70 drilled Marcellus Shale natural gas wells within a 6-mile area around the proposed MARC I Gas Pipeline, including 42 wells in Bradford County, PA, 22 wells in Lycoming County, 4 wells in Sullivan County, and 2 in Wyoming County. ${ }^{36}$ In that 6-mile area, there are also 48 permitted wells that have not yet been drilled, including 23 permitted wells in Bradford County; 14 permitted wells in Lycoming County; 8 permitted wells in Sullivan County, and 3 permitted wells in Wyoming County. ${ }^{37}$ Clearly, the area is poised to see a rise in Marcellus shale development, particularly if the MARC I pipeline provides access to markets, encourages developers to drill new wells, and owners of wells to operate them. Overall assessments of the potential development are readily available. In one of these, Terry Engelder, Professor of Geosciences at Pennsylvania State University, estimates that Sullivan County will reach full gas development in 20 to 30 years, which "will result in the construction and operation of approximately 316-500 drill pads and approximately 2,528 wells." 38

Industry reports corroborate the likely expansion of well development in Sullivan, Bradford, and Lycoming counties after the MARC I pipeline goes online. The Project's sponsor has provided some of this corroboration, claiming in one statement that "The response to our proposed MARC I pipeline development was outstanding. Not only did we receive expected volume interest from local distribution companies seeking to enhance their supply portfolio and increase reliability, but we also confirmed strong interest from local producers with development rights in the high profile Marcellus shale that exists the length of the pipeline [italics added]." 39

The potential future natural-gas development related to the Project would have a nontrivial footprint across the landscape of the region, if it resembles development patterns and uses techniques that have occurred elsewhere in the Marcellus Shale and in similar shale-gas formations. In the Marcellus Shale, the average amount of forest cleared for a well pad and associated infrastructure is almost 9 acres. ${ }^{40}$ Well spacing occurs, on average, separated by 40 to 160 acres per well. ${ }^{41}$ A report by the U.S. Department of the

\footnotetext{
${ }^{36}$ Earthjustice. 2011. “Maps with 6-Mile Development Zone.” April. On file with ECONorthwest.

37 These numbers likely underestimate the number of gas wells that could potentially take advantage of the MARC I pipeline. Evidence from Bradford County shows gathering lines longer than the 6-mile diameter we used in our illustration above. Bradford County Natural Gas Information, http://www.bradfordcountypa.org/Natural-Gas.asp .
}

38 Engelder, T. 2011. “Statement of Professor Terry Engelder, Ph.D.” July 6. Exhibit B to Foregoing Comments of the Proposed Interveners.

39 Inergy. 2008. “Inergy Announces Successful MARC I Hub Line Open Season.” August 6. Retrieved on July 7, 2011, from http:/ / investor.inergypropane.com/phoenix.zhtml?c=132026\&p=irolnewsArticle\&ID=1184555\&highlight.

40 The Nature Conservancy, Audubon, and Western Pennsylvania Conservancy. 2010. Pennsylvania Energy Sprawl Impacts Assessment: Presentation to the Board of Directors, Audubon Pennsylvania. Draft Results. October 15.

41 Ground Water Protection Council and ALL Consulting. 2009. "Modern Shale Gas Development in the United States: A Primer." U.S. Department of Energy, Office of Fossil Energy and National Energy Technology Laboratory. DE-FG26-04NT5455. April. Pg. 21. 
Interior of the Fayetteville Shale in Arkansas showed a typical horizontal well pad and its related roads and utilities occupies a total of 6.9 acres. The analysis found 4 horizontal wells completed from a single well pad, with roads and utilities, would disturb 7.4 acres. ${ }^{42}$

The gas-well development potentially influenced by the Project also would have a nontrivial impact on the region's water resources. Current development practices in the Marcellus Shale involve the drilling of both horizontal and vertical wells. In this process, drillers use up to 300,000 gallons of water per day, per well. ${ }^{43}$ After completion of the drilling process, developers pump a site-specific mix of water, friction reducing additives, biocides, oxygen scavengers, and acids, into the well to widen the shale fractures and release natural gas. ${ }^{4}$ This is the hydraulic fracturing process. Some wells can be hydrofractured multiple times over their productive life. ${ }^{45}$ Water is also used during the fracturing process, which can use up to 9 million gallons per fracture (usually over about a week). ${ }^{46}$ Marcellus Shale development uses trucks to deliver water and liquid additives and to haul out wastewater, known as flowback. In the delivery of water alone, the process requires approximately 890 to 1340 truckloads of water per wellsite. ${ }^{47}$ Because of its weight, the delivery of 364 loads of water to one site is the equivalent of 3.5 million car trips. ${ }^{48}$ These increases in truck traffic usually occur in a short time period - often spanning only the length of the initial 20- to 30- day drilling and completion period. 49

The potential gas-well development would also directly affect the region's labor markets. The economic impacts of well development usually occur in two distinct phases: the development (or drilling) phase and the production phase. As Figure 1 shows, the development phase accounts for over 98 percent of the natural-gas industry workforce at a drilling site. ${ }^{50}$ Data from the U.S. Bureau of Labor and Statistics indicate that workers in the natural gas industry earn a mean hourly wage of $\$ 31$ per hour and

42 U.S. Department of the Interior. 2008. Reasonably Foreseeable Development Scenario for Fluid Minerals: Arkansas. Prepared for the Bureau of Land Management Easter States Jackson Field Office. March.

43 Penn State. 2011. "Water Withdrawals for Development of Marcellus Shale in Pennsylvania." Marcellus Education Fact Sheet. College of Agricultural Sciences: Agricultural Research and Cooperative Extension.

44 Randall, C.J. 2010. “Hammer Down: A Guide to Protecting Local Roads Impacted by Shale Gas Drilling." Working Paper Series: A Comprehensive Economic Impact Analysis of Natural Gas Extraction in the Marcellus Shale. December.

45 Penn State. 2011. Pg. 3.

46 Penn State. 2011. Pg. 3.

47 Randall, C.J. 2010.

48 Randall, C.J. 2010.

${ }^{49}$ Ground Water Protection Council and ALL Consulting. 2009.

50 Jacquet, J. 2011. 
benefits. ${ }^{51}$ The majority of these jobs, however, go to experienced workers from outside the region, and disappear when drilling is complete. ${ }^{52}$

Figure 1. Distribution of Direct Employment During Phases of Gas Development

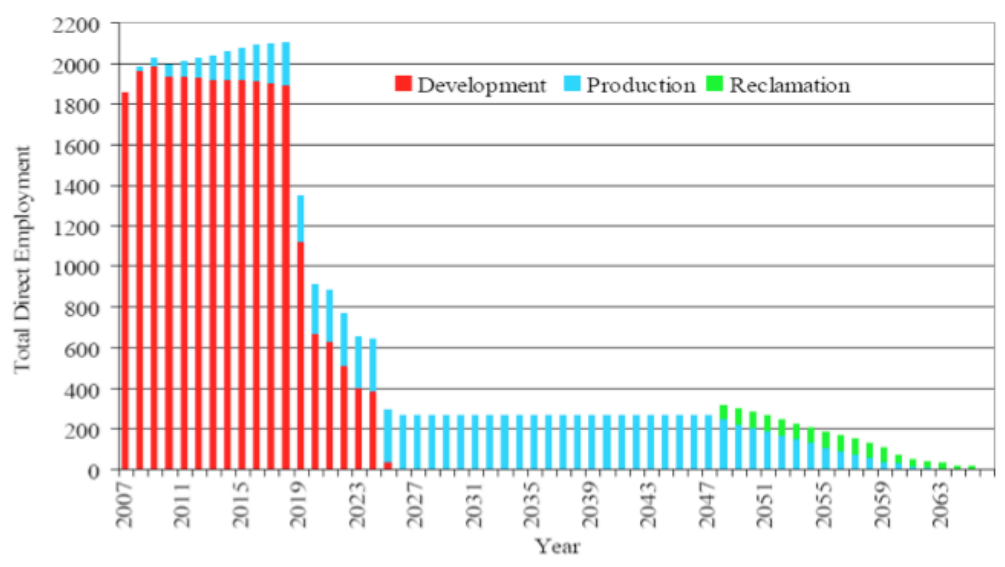

This description of the reasonably foreseeable development and production activities that might occur in the region, perhaps in response to influence from the Project, provides context for identifying the cumulative socioeconomic effects FERC could have and should have described and assessed in the EA. The following sections illustrate the types of effects and the information available to FERC for describing and assessing them.

\section{B. Potential Cumulative Socioeconomic Impacts}

Sufficient information exists for FERC to describe and assess cumulative socioeconomic effects associated with (1) jobs and incomes, (2) tax revenues, (3) property values, (4) public services, (5) quality of life, and (6) values derived from ecosystem services.

\section{Jobs and Income}

The information provided above indicates the Project's impacts on jobs and incomes would interact with those of foreseeable development and operation of gas wells in the region to have cumulative, short- and long-term effects on labor markets. FERC recognizes the Project would generate short-term increases in jobs and income from construction activities, mostly for non-local workers, at least at first. ${ }^{54}$ If anticipated welldevelopment activities ramp up concurrent with the pipeline construction, additional

\footnotetext{
51 U.S. Bureau of Labor Statistics. 2010. National Industry-Specific Occupational Employment and Wage Estimates. NAICS 221200 - Natural Gas Distribution.

52 Kay, D. 2011.

53 Jacquet, J. 2011.

54 Jacquet, J. 2011.
} 
increases in jobs and income associated with drilling (described above) would occur at the same time, and across the same region as the Project. This activity could result in additive, cumulative effects on the local market for labor and on the levels of income generated from development activities.

If impacts on jobs occur in a full-employment economy as industry officials and some economists predict, it could result in offsetting cumulative effects, by drawing labor away from other potential economic opportunities. Even in an economy that hasn't fully recovered from the Great Recession, the increase in jobs for gas development may draw employees with technical and regulatory expertise and other specialized skills away from other sectors of the economy, resulting in additional offsetting effects through increased competition for and cost of some types of labor at the local level, an effect that one researcher has documented in Bradford and Lycoming Counties:

[L]ocal businesses may compete with each other and the new extractive industry for skilled workers (e.g., mechanics, heavy equipment operators, truck drivers). This competition leads to a shortage of skilled workers and strains the ability of local businesses to provide commensurate wages and benefits. ${ }^{55}$

Price inflation and competition for workers were also reported in Bradford County. One key informant stated: "I have friends in the automobile dealership business. They are losing mechanics, because the gas companies are paying ... a much more lucrative wage. . " Rent, fuel, and food prices also rose as providers responded to increased demand. 56

Researchers point out that, even if overall positive effects on jobs and incomes materialize in the region, the distribution of effects from gas development are likely to be uneven across some populations and sectors of the economy, and the long-run effects are very likely to be mixed, with important consequences for a thorough assessment of cumulative effects:

Key informants in [Bradford, Lycoming, Washington, and Steuben Counties] worried that Marcellus Shale development might lead to a "gap between the haves and the have-nots." Participants saw clear divisions between who would benefit and who would bear the burden of development. 57

Mixed economic results are likely even in the short run. The rising tide is not likely to lift all boats: there will be losing constituencies among communities and individuals who are displaced or left behind. The experience of many economies based on extractive industries is a warning that their short-term gains frequently fail to translate into lasting, community-wide economic development. Most alarmingly, in recent decades credible research evidence has

\footnotetext{
55 Brasier, K., M. Filteau, D. McLauglin, J. Jacquet, R. Stedman, T. Kelsey, and S. Goetz. 2011. “Residents' Perceptions of Community and Environmental Impacts from Development of Natural Gas in the Marcellus Shale: A Comparison of Pennsylvania and New York Cases." Journal of Rural Social Sciences. 26(1): 32-61.

56 Brasier et al. 2011.

57 Brasier et al. 2011.
} 
grown showing that resource dependent communities can and often do end up worse off than they would have been without exploiting their extractive sector reserves. 58

The volatility of fossil fuel markets poses obstacles to the stability and long-term security of economic growth in energy-producing regions. Fossil fuel extraction, especially when prices are high, creates an enormous amount of wealth, most of which currently leaves the region. Employment in fossil fuel extraction also is driven by price, which changes rapidly.59

In reality, the economic impact may very well be negative. And the likelihood is that gas drilling would adversely affect other economic activities such as tourism and sport fishing and hunting. To some extent gas drilling and these other industries are likely to be mutually exclusive. The net effect is what must be considered. 60

Measuring or predicting this "net effect" is far from a straightforward task, especially since much of the economic boost related to drilling will come via short term boom/bust cycles in a region that has struggled long term with outmigration and disinvestment trends. ${ }^{61}$

\section{Tax Revenues}

It is important to note that the impacts on tax revenues, described as a significant benefit in many shale-gas developments in other parts of the United States, do not apply in Pennsylvania, because natural gas is not subject to property tax, leasing and royalty incomes are not subject to local earned income taxes, and most drilling equipment is exempt from the state sales tax. ${ }^{62}$ But gas-related expenditures do affect tax revenues. Many of the potential cumulative effects described in the preceding section will be accompanied by effects on tax revenues. Expenditures associated with the Project, plus expenditures on foreseeable development of and production from gas wells in the region likely will have a combined effect on state and local tax revenues.

Researchers have noted indirect increases in revenues related to sales tax and employee withholding taxes as drilling increases the number of jobs and overall economic activity in areas already experiencing development within the Marcellus Shale formation. One study finds, "counties with 150 or more Marcellus wells experienced an 11.36 percent increase in state sale tax collections between 2007 and 2011," which was significantly larger than increases to counties with fewer wells and counties with no wells. ${ }^{63}$

\footnotetext{
58 Kay, D. 2011.

${ }^{59}$ Headwaters Economics. 2011. "Fossil Fuel Extraction and Western Economies." April.

60 Brasier et al. 2011.

61 Kay, D. 2011.

6261 Pa. Code \$32.35 Mining; Hamill, S. 2010. “2002 court case proved windfall for shale drillers.” Pittsburgh Post Gazette. September 28; Brasier et al. 2011; Pennsylvania Budget and Policy Center. 2011.

"Representation without Taxation: How Natural Gas Producers Escape Taxes in Pennsylvania." April.

63 Penn State. 2011. "State Tax Implications of Marcellus Shale: What the Pennsylvania Data Say in 2010." Marcellus Education Fact Sheet. College of Agricultural Sciences: Agricultural Research and Cooperative Extension.
} 
Quantifying the impacts on tax revenues requires careful analysis. Many newly created, gas-related jobs are filled by non-permanent and transient workers, which means both income tax and retail tax revenue will be lower than anticipated, as earned income leaves the region with the workers, who spend less locally than local workers otherwise would. 64 Moreover, increased government spending on public services to meet the increased demands of the workforce and construction activities may partly or entirely offset increases in tax revenues. 65

\section{Property Values}

Assuming the Project is implemented and gas-well development accelerates in the threecounty region, property values likely will not remain unaffected. The changes may be positive for some properties, negative for others, and would, as FERC correctly points out, depend on a variety of different factors. ${ }^{66}$ While further investigation is required to determine the direction and magnitude of the Project's effect on property values the effects likely would materialize only for properties in close proximity to the pipeline and related facilities. The development of new wells, however, likely would have more widespread effects across the region. The cumulative effects may exhibit threshold characteristics, where values across the region remain largely unaffected until a critical point is reached and non-linear effects occur.

Several findings from the literature suggest the cumulative effects could be negative for many properties:

[T]he distance to an industrial site has a statistically significant negative effect on the value of residential properties. However, the effect is largely localized within a relatively short distance from the nearest industrial site. ${ }^{67}$

Single-family homes and small lots may decline in value. There have been reports that banks are reluctant to give mortgages for properties with a gas lease or even for properties nearby leased land. It would be very difficult to find a buyer for a home if mortgages are unavailable or if the home's drinking water is contaminated. In Wise County, Texas, in the Barnett Shale region, it has been reported that real estate appraisers have discounted valuations by as much as $75 \%$ if a property has a gas well. 68

[In Alberta, Canada] property values are negatively correlated with the number of sour gas wells and flaring oil batteries within $4 \mathrm{~km}$ of the property. Indices reflecting health hazards associated with potential rates of $H 2 S$ release (based on information from Emergency Response Plans and Zones) also have a significant negative association with property prices.

\footnotetext{
${ }^{64}$ Barth, J. 2010.

65 Brasier et al. 2011.

66 FERC 2011, Pg. 69.

67 de Vor, F. and H.LF. de Groot. 2009. “The Impact of Industrial Sites on Residential Property Values: A hedonic pricing analysis for the Netherlands." Annual International RSA Conference: Leuven, Belgium. April 6th-8th 2009.

68 Barth, J. 2010.
} 
The findings suggest that oil and sour gas facilities located within $4 \mathrm{~km}$ of rural residential properties significantly affect their sale price." 69

The value of some properties may increase - a result of increased demand for housing and the contribution to value of the potential royalty income from gas-well development:

Rental rates will probably increase due to the influx of transient workers, hotel occupancy rates may increase, and some parts of Pennsylvania have experienced this in the Marcellus play. The value of large tracts of land may increase if they are desirable for gas leases. ${ }^{70}$

An additional factor that FERC should consider within the context of cumulative effects on property values is the response of mortgage lenders to the increasing specter of widespread gas development in close proximity to residential properties. Evidence from $\mathrm{New}$ York suggests that some lenders are reluctant - and in some cases possibly legally prohibited - from authorizing mortgages on some residential properties with surface or subsurface rights to gas development. ${ }^{71}$

\section{Public Services}

The Project and foreseeable gas-well development likely would produce cumulative demands for public services and on the ability of local jurisdictions to provide them.

For local governments the population influx as a result of Marcellus construction "comes with added costs, both in the short run and in the long run. The consistent theme is that local governments - counties, cities, townships, villages - are subjected to a wide range of demands for new services or increased levels of service, and that the administrative capacity, staffing levels, equipment, and outside expertise needed to meet those demands are beyond anything that has been budgeted."72

Communities in Bradford County, where gas development in already underway, have experienced stresses on public services:

The lack of housing created problems for social service agencies trying to place low-income and homeless residents in temporary housing. State police in Bradford County were citing more traffic violations, and the correctional facility had detained three out-of-state natural gas workers on misdemeanors - one had a warrant for a felony charge in Texas. Bradford County key informants also believed that, unless a severance tax was enacted and revenues

\footnotetext{
69 Boxall, P. W. Chan, and M. McMillan. 2005. “The impact of oil and natural gas facilities on rural residential property values: a spatial hedonic analysis." Resource and Energy Economics. 27: 248-269.

70 Barth, J. 2010.

${ }^{71}$ May, G. 2011. "Gas and Oil Leases Impact on Residential Lending." Residential Mortgage Lending Tompkins Trust Company. March.

72 Christopherson, S. and N. Rightor. 2011. "How Should We Think About the Economic Consequences of Shale Gas Drilling?" Working Paper Series: A Comprehensive Economic Impact Analysis of Natural Gas Extraction in the Marcellus Shale. May.
} 
distributed back to local governments, county and municipal taxes would have to increase to meet the rise in demand for social services. ${ }^{73}$

\section{Quality of Life}

Many residents of the three-county area have chosen to live in the region because of its natural amenities, strong community, and attractive quality of life. In a previous section we describe the importance of these attributes to the economic strength of the region, and its continued ability to attract and retain people. In a study of the potential effects of well development on community and social values, one resident expressed exactly this sentiment:

"[It's] such a beautiful place to live. I've turned down many opportunities to go other places and work for bigger pay, but it's such a beautiful ... and a pleasant place to live that I hate to see those values be degraded."74

Attributes that affect quality of life may be especially sensitive to cumulative effects from the Project and accompanying gas-well development. The potential quality-of-life impacts are well-documented, stemming from rapid changes in the variables described above and in the region's stock of social capital and in its natural capital, described in the next section.

Rapid growth in boomtowns is also linked with mixed social impacts... rapid population growth associated with the development of industry can increase stress, change individuals' patterns of interactions within communities, decrease community cohesion, and change a community's character. 75

Individuals' quality of life, ties to community members, and mental and physical health can also be affected, leading to increases in social problems (e.g., crime, substance abuse) and overall disorganization. This increases stress on local organizations and community services, and creates a lower standard of living for persons detached from the extractive-related economy. ${ }^{76}$

\section{Values Derived from Ecosystem Services}

We introduce the importance of considering the Project's impacts on ecosystem services and the socioeconomic dimensions associated with those impacts in Section II. The Project and reasonably foreseeable gas-well development in the three-county region would cumulatively reduce the supply of valuable ecosystem services through their adverse impacts on water-quality, vegetation and wildlife, and other related resources. These impacts would produce adverse socioeconomic consequences to the extent that they decrease the value of goods and services available to Pennsylvanians and out-of-

\footnotetext{
73 Brasier et al. 2011.

74 Brasier et al. 2011.

75 Brasier et al. 2011.

76 Brasier et al. 2011.
} 
state visitors. This decrease would occur primarily by diminishing the supply of capital necessary to provide goods and services. ${ }^{77}$

The Project's cumulative impacts would affect, directly and indirectly, the region's stock of natural capital. Natural capital is a term used to describe the inventory of nature's physical building blocks (e.g., trees, water, fish, soil, etc.) and the functional interconnections between the building blocks, which together form ecosystems. ${ }^{78}$ Ecosystems are dynamic systems that support physical, chemical, and biological processes that influence flows, storage, and transformation of matter and energy. ${ }^{79}$ These "ecosystem processes" contribute to the maintenance and accumulation of the building blocks of natural capital, and in this way, are inextricably interrelated with the concept of natural capital. The Project and accompanying gas-well development would reduce the region's supply of natural capital and the associated ecosystem processes, for example, by clearing trees and creating fragmented forest habitat for sensitive bird species. 80

These changes in natural capital may be quantifiable in biophysical terms, but they do not produce economic costs directly (either quantifiable or unquantifiable). Instead, reductions in natural capital lead to changes in goods and services people value, which are called ecosystem services. Ecosystem services describe the ways in which humans derive value from what nature provides. The cumulative impacts on natural capital would change the types and quantities of ecosystem services people can derive from a particular area, and by doing so, produce economic or costs (or benefits, if the types or quantities of ecosystem services are enhanced).

The economic value of the ecosystem services impacted by the Project and other reasonably foreseeable actions is a measure of their contribution to individuals' quality of life, or to the productivity of businesses and communities. This value can materialize in different ways. Figure 2 demonstrates the major categories of economic value for ecosystem services. The left side of Figure 2 shows use value, perhaps the clearest type of economic value. Direct use value describes the value associated with the direct use of an ecosystem service, such as spending a day fishing. Indirect use value describes the ecosystem services that precede that direct service, such as the aquatic habitat that nurtures and provides refuge for the targeted fish.

The right side of Figure 2 shows passive use value, which represents nature's values that exist when there is no direct or indirect use of an ecosystem. Passive use values are less obvious than use values, but - in some instances - can represent a greater total value because they incorporate demands from a larger population. Figure 2 separates passive use value into two categories. One, called existence value, comes from people's desire

\footnotetext{
77 Economists use the term capital to describe resources commonly used to produce things people value (e.g., different types of goods and services).

78 Daily, G.C. 1997.

79 Campbell 2009.

80 See: Audubon. 2011. “Re: Docket No CP10-480-000, Environmental Assessment of MARC I Hub Line Project." July 8.
} 
for the continued existence of a species, landscape, or some other aspect of an ecosystem, or of the ecosystem as a whole. The other, called bequest value, arises because people desire to ensure that the ecosystem will be available for enjoyment by future generations.

Typically, these passive use values are described in terms of an individual's willingness to pay for an object's current or future existence. For example, if an individual is willing to pay a given sum to prevent the elimination of a tidal wetland, then this amount represents the existence value she places on the wetland. Similarly, if she is willing to donate a given sum to a conservation fund dedicated to maintaining healthy tidal wetlands into the future, this amount represents the bequest value she places on them.

The middle of Figure 2 shows another component of the total value, called option value. An option value refers to the benefit of maintaining an opportunity to derive services from an ecosystem in the future. It can originate from either side of Figure 2. Sometimes, market prices exist that provide information useful for quantifying option values, but not always.

\section{Figure 2. Components of Total Economic Value}

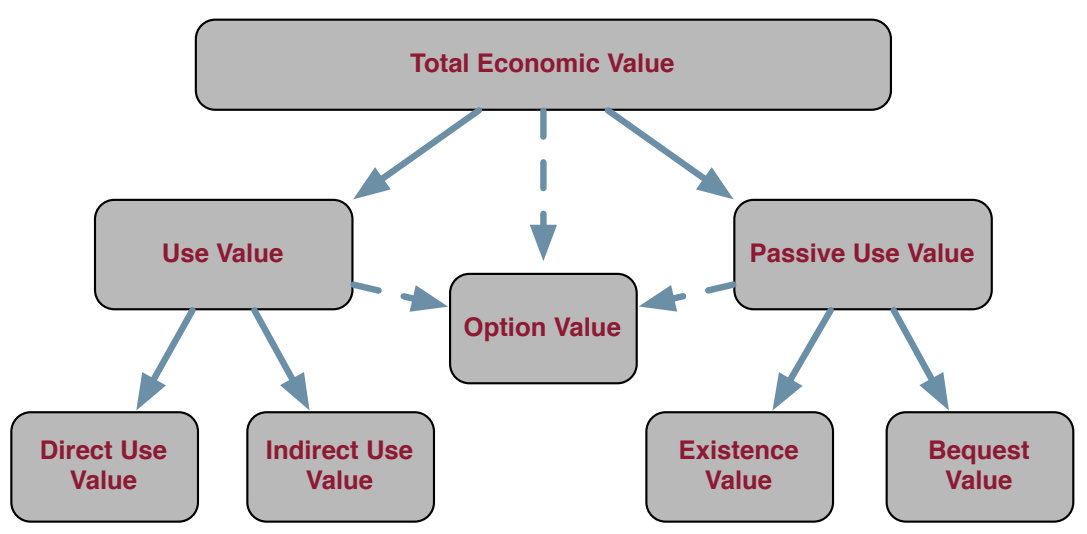

Below, we illustrate the values associated with the Project's cumulative impacts on three environmental resources: water quality, vegetation and wildlife, and recreation. Other cumulative impacts likely would diminish the supply and value of additional ecosystem services, including, but not limited to those related to air quality, other changes in land use (especially agricultural land uses), and soils. To provide a complete analysis of the Project's cumulative effects, FERC should conduct a thorough review of the Project's potential impacts on ecosystem services, referring back to Table 1 presented in Section II, and present a discussion of the socioeconomic dimensions of these impacts. FERC's analysis should include not just an assessment of the cumulative impacts across the region, but the distributional consequences of those cumulative impacts. Some individuals and communities may experience negative impacts without gaining any benefits from the Project; it is important to identify where these distributional inequities may occur, so decision-makers can respond appropriately.

Water Quality and Quantity. FERC acknowledges in the EA that both the Project and the development of the Marcellus Shale in the three-county area would have impacts to 
water quality. ${ }^{81}$ Any impacts the Project might have on water quality in the area would interact cumulatively with the impacts of gas wells. Voluminous evidence exists regarding these potential impacts and concern about their environmental and socioeconomic consequences:

- The Susquehanna River Basin Commission (SRBC) considers all water used in hydrofracturing to be consumptively lost to the system. ${ }^{82}$

- While the water volumes needed to drill and fracture wells are large, they generally represent a small percentage of total water resource use in a basin. This water, however, is generally used over a short period of time, and it is "consumed" rather than returned to its source, because it has to be hauled away and treated. When competing demands for this water from growing populations and increasing industrial and commercial purposes, the demands from gas-well development may be difficult to meet, especially in some locations. If there is low stream flow at the time water is required, this could negatively affect fish and other aquatic life, fishing, recreational activities, municipal water supplies, and industries such as power plants. ${ }^{83}$

- Other major concerns for water resources arising from pipeline and gas-well development include erosion and sedimentation and the treatment and safe disposal of produced water. ${ }^{84}$

- Gas-well development in the Marcellus Shale can directly compromise water quality during several stages of development. Construction creates erosion and siltation. Drilling through aquifers may contaminate drinking-water supplies. Chemicals added to fracking fluid may leak into the ground and contaminate aquifers and surface water supplies. ${ }^{85}$

- Despite increased regulation of well casings, fracking fluid, and wastewater disposal, risks persist: "direct contamination of groundwater as a result of fracturing procedures appears to be highly unlikely; however, subsurface impacts as a result of wellbore cementing practices and improper balancing of well pressures can and have occurred. While these events may be rare, they can result in significant contamination of local drinking water sources." 86 A recent review of proposed

\footnotetext{
81 FERC 2011, Pg. 104.

82 Penn State 2010.

83 The League of Women Voters of Pennsylvania. 2010. “Marcellus Shale Natural Gas: Environmental Impact." Marcellus Shale Natural Gas Extraction Study 2009-2010.

84 Soeder, D. and W.M. Kappel. 2009. "Water Resrouces and Natural Gas Production from the Marcellus Shale." U.S. Department of the Interior, Fact Sheet 2009-2032. U.S. Geological Survey (USGS). May.

85 LWVP 2009.

86 Riha, S. and B. Rahm. 2010. "Framework for Assessing Water Resource Impacts from Shale Drilling. Cornell University. Working Paper Series: A Comprehensive Economic Impact Analysis of Natural Gas Extraction in the Marcellus Shale. April.
} 
fracking wells in New York state concluded that migrating fracking fluids can contaminate surface aquifers. ${ }^{87}$

- "Gas drilling impacts on water resources can also be classified as arising from certain or uncertain events. Events that are certain include those integral to the drilling process such as water withdrawal and wastewater production and treatment. These events can be planned for and closely regulated, and their magnitude is directly related to the pace and scale of gas drilling development. Uncertain events can be considered accidents. While they can be anticipated, in the sense that they are likely to occur at some point, their occurrence and consequences are highly uncertain over time and space. Uncertain events include surface runoff, spills and leaks, as well as subsurface events related to well integrity." 88

- From 1992 to 2008 there were at least nine reported cases of gas migration at operating wells in Pennsylvania, resulting in three fatalities. In the last two years, there have been numerous instances of well blowouts and explosions, drinking water contamination and illegal discharges, surface water spills, and instances of improper wastewater treatment leading to high levels of TDS in rivers and streams. These accidents include a "catastrophic failure" of a blowout preventer in Clearfield County, PA that spewed 35,000 gallons of wastewater and natural gas into the air for 16 hours; leaks from improper well casings that contaminated at least nine drinking water wells with methane; a spill of approximately 250 barrels of diluted hydraulic fracturing fluids that killed at least 168 fish and other aquatic life; and an incident of gas migration that caused a house to explode in Jefferson County, resulting in three fatalities. Abandoned wells, many of which are in unknown locations, have also caused stray gas to migrate to the surface and contaminate the environment. Since 1998 there have been 38 investigations of stray gas migration from abandoned wells in homes, commercial buildings, private water wells and groundwater aquifers, in a church, a campground, and a senior care home that resulted in temporary evacuation. 89

- A Pennsylvanian resident whose water supply came from a natural artesian spring, reported that drilling conducted by a fracking company contaminated his water source. PA DEP brought him and his neighbors bottled drinking water and installed a 2,000 gallon tank for non-potable water. "A pristine, beautiful cold spring is now totally destroyed," Hilyer said, "Now I have a tank of junk water, and I'm living off creek and boiled water." The next door neighbors report that "having an endless supply of fresh, clean, cold water was the added plus in their decision to purchase the home." 90

\footnotetext{
87 Meyers, T. 2009. Comments of Natural Resources Defence Council, et al. on the Draft Supplemental Generic Environmental Impact Statement on the Oil, Gas and Solution Mining Regulatory Program, Attachment E (December 30).

88 Riha, S. and B. Rahm 2010.

89 Michaels, C., J. Simpson, and W. Wegner. 2010. “Fractured Communities: Case Studies of the Environmental Impacts of Industrial Gas Drilling." Riverkeeper. September.

90 Zemach, H. 2008. “Gibbs Hill homeowners lose water supply after fracking.” Ridgeway Record. August.
} 
- PA DEP fined Talisman Energy \$15,506 for a November 2009 spill that sent over 4,200 gallons of hydraulic fracturing flowback fluid into a wetland and a tributary of Webier Creek, which drains into the Tioga River, a coldwater fishery. ${ }^{91}$ This year, the PA DEP fined Chesapeake Energy more than $\$ 1$ million for water-quality violations in Bradford County related to hydraulic fracturing. ${ }^{92}$

Several studies demonstrate that the people of Pennsylvania value clean, unpolluted water:

- Households in the Susquehanna River Basin are willing to pay, on average, \$25 for remediation of acid mine drainage damage in the basin. Households outside the basin were willing to pay $\$ 34$, a result explained by higher levels of education and sensitivity to acid mine drainage among some populations outside the basin. ${ }^{93}$

- Residents in western Pennsylvania valued improvements in water quality in a stream that went from "moderately polluted" to "unpolluted," in terms of its ability to support fish species, from $\$ 27$ to $\$ 51$ per household per year for five years. Residents valued improvements that raised water quality from "severely polluted" to "unpolluted" at $\$ 76$ to $\$ 112$ per household per year for five years. ${ }^{94}$

These potential impacts on water quality have important implications for the assessment of cumulative socioeconomic effects that FERC should have included in the EA. Water irreversibly polluted by the pipeline or by gas-well development would no longer be available for other uses. Pollution of water supplies for households and communities leaves them exposed to hazards when they use the water, restricts their use of the water, causes them to incur costs to remove the pollutants or find substitute supplies, or all of the above. Even when water has not been polluted, households and communities experience a reduction in well-being from the uncertainty that results when gas-related activities create the potential that pollution may manifest itself in the future. These and related socioeconomic effects must be addressed if the EA is to provide a comprehensive, accurate assessment of the Project's cumulative socioeconomic effects.

Vegetation and Wildlife. The Project and gas-well development will each affect the natural landscape by displacing vegetation, wetlands, and other types of ecosystems. These ecosystems provide a valuable stream of goods and services, such as air purification including absorbing greenhouse gases, clean water (described previously), and recreation (described next). They are also valuable in their own right. Both temporary and permanent disturbance of these habitats, and the species that depend on them, are likely to accelerate as gas-well development increases. The Nature Conservancy estimates that each well pad could disturb up to 30 acres of forest habitat,

\footnotetext{
${ }^{91}$ Micheals et al. 2010.

92 Kusnetz, N. 2011. “PA Officials Issue Largest Fine Ever to Gas Driller.” ProPublica. May 17.

93 Hansen et al. 2008.

94 Farber, S. and B. Griner. 2000. "Valuing watershed quality improvements using conjoint analysis." Ecological Economics. 34: 63-76.
} 
directly and indirectly through edge effects. ${ }^{95}$ Overlaying potential well sites and remaining intact forest patches suggests that a considerable area of forested landscape in Bradford County, especially, may become fragmented and less suitable for providing certain types of habitat for sensitive wildlife populations, such as songbirds. ${ }^{96}$ The goods and services people derive from the acres the Project would directly affect may be limited, compared to the current supply available in the region, but as more acres of natural landscape are converted to well pads, roads, and commercial and industrial facilities to support gas-well development, these resources may become more scarce. When cumulative impacts lead to scarcity, the impacts may rapidly become non-linear: as things become scarce, they become more valuable. Thus, the values we present in the following paragraphs may actually underestimate the actual losses people experience in the long-run.

Forest Habitat. In 2009, researchers conducted several meta-analyses estimating various use and passive use values associated with forestland. In estimating the passive use value of forestland, the researchers compiled data from 23 relevant studies. ${ }^{97}$ Their results identify per-acre estimates for passive use values by geographic region and forest biome. They estimated the marginal, per-acre passiveuse value associated with forests in Pennsylvania at \$294 per year. This value estimates society's total willingness to pay for intact forest land. Insofar as this estimate considers only passive use values, it likely underestimates the total economic value people place on protecting these resources, because direct users of forest habitat likely are willing to pay more. It also likely underestimates the value because, as human populations and incomes grow in Pennsylvania and elsewhere, the marginal value of forest land probably will increase.

Wetland Habitat. Wetlands are a well-studied habitat type that provides welldocumented values for a wide array of ecosystem goods and services. Table 2 provides several estimated values for the ecosystem services provided by wetlands. The first set of rows estimates the values associated with several different wetlands that researchers assumed provide only a single type of service. In many cases, a wetland may provide multiple services, however. The range of values associated with single-service wetlands is about $\$ 5-\$ 9,200$ per acre per year depending on the ecosystem service. ${ }^{98}$ Another estimate, based on the net primary productivity of various landscapes in the U.S. National Wildlife Refuge System suggests that the ecosystem service values of wetlands, generally, may be about $\$ 2,400-\$ 12,400$ per acre per year. ${ }^{99}$ These estimates come from meta-analyses of many individual site-

\footnotetext{
95 The Nature Conservancy et al. 2010.

96 The Naturel Conservancy et al. 2010.

97 Chiabai, A., C.M. Travisi, H. Ding, A. Markandya, and P.A.L.D. Nunes. 2010. "Economic Valuation of Forest Ecosystem Services: Methodology and Monetary Estimates." Cost of Policy Inaction: The Case of Not Meeting the 2010 Biodiversity Target.

98 Woodward, R., and Y. Wui. 2001. "The Economic Value of Wetland Services: A Meta-Analysis". Ecological Economics. 37: 257-270.

99 Ingraham, M. and S. Foster. 2008. "The Value of Ecosystem Services Provided by the US National Wildlife Refuge System in the Contiguous US." Ecological Economics. 67:608-618.
} 
specific studies. The New Jersey Department of Environmental Protection calculated the value of ecosystem goods and services provided by freshwater wetlands within its borders at about $\$ 14,000$ per acre per year. ${ }^{100}$

\section{Table 2. Value of Ecosystem Services Associated with Wetland Habitat (\$/Acre/Year)}

\begin{tabular}{lrr}
\hline \multicolumn{3}{c}{ Single-Service Wetlands } \\
\hline Single-Service Wetland Type & Mean Value & Range of Values \\
\hline Flood Attenuation & $\$ 645$ & $\$ 146-\$ 2,865$ \\
Water Quality & $\$ 684$ & $\$ 207-\$ 2,260$ \\
\hline Water Quantity & $\$ 208$ & $\$ 10-\$ 4,216$ \\
\hline Recreational Fishing & $\$ 585$ & $\$ 156-\$ 2,201$ \\
\hline Commercial Fishing & $\$ 1,276$ & $\$ 177-\$ 9,214$ \\
\hline Bird Hunting & $\$ 115$ & $\$ 41-\$ 323$ \\
\hline Bird Watching & $\$ 1,988$ & $\$ 866-\$ 4,562$ \\
\hline Amenity & $\$ 5$ & $\$ 2-\$ 23$ \\
\hline Habitat & $\$ 502$ & $\$ 156-\$ 1,609$ \\
\hline Storm Protection & $\$ 389$ & $\$ 18-\$ 8,433$ \\
\hline \multicolumn{1}{c}{ General Wetlands from US National Wildlife Refuge System } \\
\hline
\end{tabular}

Base Value of Net Primary Productivity

$\$ 2,400-\$ 12,400$

Source: Woodward, R., and Y. Wui. 2001. "The Economic Value of Wetland Services: A Meta-Analysis". Ecological Economics. 37: 257-270; Ingraham, M. and S. Foster. 2008. "The Value of Ecosystem Services Provided by the US National Wildlife Refuge System in the Contiguous US." Ecological Economics. 67:608618.

Sensitive Species. Bradford County has six threatened, six endangered, and one candidate species, the Timber Rattlesnake at the state level. NatureServe, a nonprofit conservation organization, which independently analyzes and rates species health, classifies three of Bradford County's species globally vulnerable, and, at the state level, 24 as vulnerable, 22 as imperiled, and 13 as critically imperiled.101

Lycoming County has six threatened, 11 endangered, and one candidate species, the Timber Rattlesnake at the state level. NatureServe classifies six of Lycoming County's species as globally vulnerable, and one as globally imperiled. NatureServe rates 33 of Lycoming County's species as vulnerable, 23 as imperiled, and 25 as critically imperiled.

\footnotetext{
100 New Jersey Department of Environmental Protection. 2007. Valuing New Jersey's Natural Capital: An Assessment of the Economic Value of the State's Natural Resources. April.

101 NatureServe. 2011. Retrieved on July 8, 2011 from http:/ / www.natureserve.org/.
} 
Sullivan County has 13 threatened species, 17 endangered species, and one candidate species, the Timber Rattlesnake. NatureServe classifies four species in Sullivan County as globally vulnerable. At the state level, NatureServe classifies 34 species as vulnerable, 32 as imperiled, and 33 as critically imperiled.

In addition to the species listed above, the Myotis sodalis (Indiana Myotis), a bat listed as an endangered species by the U.S. Fish \& Wildlife Service, has habitat in and around the area of the Project. 102 There is little literature describing the benefits humans derive from bats. To the extent that the Project decreases bat populations in region, it could decrease economic well-being in two ways:

- The Project could decrease the pest-suppression benefits bats provide to agriculture

- The Project could decrease the benefits individuals derive from knowing the Indiana Myotis exist, despite potentially never interacting with the species directly.

Many bats, including the Indiana Myotis, prey on insects that are potentially harmful to agriculture. ${ }^{103} \mathrm{~A}$ recent study quantified the economic value associated with bat predation in terms of the resulting agricultural benefits, at the county level. The study extrapolated the results of a study focused on the benefits of bat predation in a cotton-dominated agricultural landscape in south-central Texas, which found that bats provided pest-suppression services worth $\$ 12$ to $\$ 173 /$ acre of agricultural land.104 Insofar as the Project reduces this service bats provide, it would decrease the economic well-being farmers derive from the pest suppression bats provide.

Wildlife contribute to people's economic well-being, either because they know they exist, have the option to enjoy them or see that their children enjoy them in the future, or engage in recreation, subsistence hunting, sightseeing, or some other direct use of the resources. The Indiana Myotis has received federal endangered status. Economic research has shown that people place a considerable value on the continued survival of sensitive species, such as those listed as threatened or endangered. Table 3 lists the results from several economic analyses examining household willingness to pay to protect sensitive species. The estimates included in the table are limited to birds valued by U.S. or New England households. Bats, of course, are mammals, and the species included in Table 3 are all birds. The data, however, serve to provide support for the notion of value attributable to sensitive species with habitat near the Project. Insofar as it threatens the health of Indiana Myotis populations, the Project also may impose higher costs for governments, firms, and households that engage in future activities that affect the species, and higher

\footnotetext{
102 U.S. Fish and Wildlife Service. “Species Profile.” Retrieved on 7 July 2011, from http://ecos.fws.gov/speciesProfile/profile/speciesProfile.action?spcode=A000.

103 Kunz, T., E. Braun de Torrez, D. Bauer, T. Lobova, and T. Fleming. 2011. “Ecosystem Services Provided by Bats." Annals of the New York Academy of Sciences. 1-38.

104 Boyles, J., P. Cryan, G. McCracken, T. Kunz. 2011. “Economic Importance of Bats in Agriculture.” Science. 332: $41-42$.
} 
costs for governments charged with monitoring species status and ensuring their protection. ${ }^{105}$

\section{Table 3. Household Willingness to Pay (WTP) to Protect Sensitive Species}

\begin{tabular}{|c|c|c|c|}
\hline Species & Survey Region & Willingness to Pay & $\begin{array}{c}\text { Annual or Lump- } \\
\text { sum }\end{array}$ \\
\hline Wild turkey & New England & $\$ 12.75-\$ 17.20$ & Annual Payment \\
\hline $\begin{array}{l}\text { Red-cockaded } \\
\text { woodpecker }\end{array}$ & U.S. & $\$ 14.72$ - \$22.92 & Annual Payment \\
\hline Peregrine falcon & Maine & $\$ 36.14$ & Lump-sum Payment \\
\hline Mexican spotted owl & U.S. & $\$ 77.10$ & Annual Payment \\
\hline
\end{tabular}

Source: Richardson, L. and J. Loomis. 2009. "The Total Economic Value of Threatened, Endangered and Rare Species: An Updated Meta-Analysis." Ecological Economics. 68: 1535-1548.

Recreation. The Project, in concert with gas-well development in northeast Pennsylvania, likely would produce cumulative impacts on recreational benefits derived from the natural resources in Sullivan, Bradford, and Lycoming Counties. These impacts would materialize insofar as they would negatively affect water quantity, water quality, air quality, wildlife habitat, visual aesthetics, archeological and historical sites, and peace and quiet.. Additional impacts might occur as they cumulatively affect traffic and congestion, and the demand for lodging.

The region that would experience cumulative impacts from the Project and gas-well development in northeast Pennsylvania, including Bradford, Lycoming, and Sullivan Counties, contains several different parcels of State Game Land, as well as Tamarack Run Natural Area, World's End State Park, Ricketts Glen State Park, Kettle Creek Wild Area, and Kettle Creek Gorge Natural Area. ${ }^{106}$ These designated spaces provide several recreation opportunities including hunting, fishing, hiking, and wildlife viewing. In addition to these areas, private lands throughout the region offer a wide variety of recreation opportunities:

- Lands, including county parks, a state park, State Game Land, and private lands in Bradford County provide residents and visitors with recreation opportunities such as hiking, picnicking, fishing, biking, wildlife viewing, and hunting. ${ }^{107}$

- Residents of Lycoming County say they participated in many types of recreation in the County's public parks and State Game Lands, including picnicking and enjoying open space, and exercising for fitness. Residents of Lycoming County alone visited five public recreation areas in 2003 at a rate of about 232,543 visits

\footnotetext{
105 Wilcove, D. and L. Chen. 1998. "Management Costs for Endangered Species." Conservation Biology. 12(6): 1405-1407.

106 Pennsylvania Game Commission. "State Game Land Maps." Retrieved on 7 July 2011, from http://www.portal.state.pa.us/portal/server.pt/community/state_game_lands/11363.

107 Bradford County, Pennsylvania. 2010. Bradford County Parks Master Plan. September.
} 
per year, or 2 visits per resident of the County per year (this does not include residents from elsewhere that participated in recreation activities in the County). ${ }^{108}$

- Lycoming's 2008 Recreation Plan identifies several key goals related to waterbased recreation in the county, including improving water quality, increasing the number of public facilities, and improving their quality. 109

- Sullivan County is home to many high-quality nature-based recreation opportunities. World's End State Park is known for its sightseeing, hunting, fishing, boating, hiking, camping, and various winter activities. ${ }^{110}$ In Ricketts Glen State Park, visitors boat, swim, hunt, camp, and use hiking and equestrian trails. ${ }^{111}$ Sullivan County also has two natural areas: Kettle Creek Gorge and Tamarack Run, which also provide water-based and land-based recreation opportunities. ${ }^{112}$

Outdoor recreation plays an important role in the economy. Across the state of Pennsylvania, in 2006, resident anglers spent about \$16 per person per day on triprelated, equipment, and other expenditures while non-resident anglers spent about \$26 per person per day for a total of about $\$ 1.4$ billion (in 2011 dollars). Resident hunters spent about $\$ 15$ per person per day on trip-related, equipment, and other expenditures while non-resident anglers spent about $\$ 17$ per person per day for a total of about $\$ 1.8$ billion. Resident wildlife watchers (away from their homes) spent about $\$ 25$ per person per day on trip-related, equipment, and other expenditures while non-resident wildlife watchers spent about $\$ 50$ per person per day for a total of about $\$ 1.6$ billion. ${ }^{113}$ There are insufficient data to breakdown these expenditures to the county level, but some of the statewide expenditures likely went to individuals providing goods and services and communities within Bradford, Lycoming, and Sullivan Counties. Table 4 shows that, in 1999, thousands of individuals purchased fishing licenses and boat registrations in the three counties, and many of those individuals likely spent time and additional money on fishing and boat-related recreation in the three counties. Furthermore, state park attendance in the three counties was over 400,000 in 1999.114 Some of the individuals visiting these parks likely were from the area, others may have travelled long distances.

\footnotetext{
108 County of Lycoming, Pennsylvania. 2003. Lycoming County Recreation Survey. March.

109 Lycoming County. 2008. Comprehensive Recreation, Parks, and Open Space/Greenway Plan. April.

110 Worlds End State Park. Retrieved on July 8, 2011, from http://www.dcnr.state.pa.us/stateparks/parks/worldsend.aspx.

111 Ricketts Glen State Park. Retrieved on July 8, 2011, from http:/ / www.dcnr.state.pa.us/stateparks/parks/rickettsglen.aspx.

112 County Natural Heritage Inventories. Retrieved on July 8, 2011, from http:/ / www.naturalheritage.state.pa.us/CNHI.aspx.

${ }^{113}$ U.S. Fish and Wildlife Service. 2008. 2006 National Survey of Fishing, Hunting, and Wildlife-Associated Recreation: Pennsylvania. FHW/06-PA.

114 Pennsylvania State Data Center. 2000. Research Brief: Recreational Licenses and State Park Attendance are Popular in Pennsylvania. September.
} 
In both cases, the individuals visiting the state parks likely spent money on goods and services related to their trips.

Table 4. Fishing Licenses, Boat Registrations, and State Park Attendance in 1999

\begin{tabular}{lrrr}
\multicolumn{1}{c}{ County } & Fishing Licenses & Boat Registrations & State Park Attendance \\
\hline Bradford County & 7,908 & 2,950 & 87,126 \\
Lycoming County & 15,280 & 6,114 & 119,239 \\
Sullivan County & 1,557 & 335 & 201,877 \\
\hline
\end{tabular}

Source: Pennsylvania State Data Center. 2000. Research Brief: Recreational Licenses and State Park Attendance are

Popular in Pennsylvania. September.

These data illustrate the importance of recreational activity for the residents of the threecounty area. The region's high-quality resources attract visitors from other parts of Pennsylvania and the United States as well. Insofar as the Project and the accompanying development of and production by gas wells in the counties would diminish the quality of quantity of recreational opportunities in the area, they would cumulatively reduce the number of or duration of recreation trips, recreation-based expenditures, and related jobs, incomes, and tax revenues in the three counties.

They also would have cumulative effects on the economic well-being of recreationists. Oftentimes, individuals participating in recreation activities derive benefits from their experience in excess of the money they spent to participate in the activity. The difference between what they would be willing to pay and what they actually pay to participate in a recreation activity represents the second component of value, called consumer surplus. Consumer surplus is important because it registers improvements in economic wellbeing: if someone can pay just a little to enjoy fishing, boating, or some other activity that is worth a lot, then he or she is economically better off.

Table 5 contains estimated values of the consumer surplus derived from several different types of recreation activities available in Bradford, Lycoming, and Sullivan Counties. The table contains the average value among Northeast studies, the average value from studies across the nation, as well as the full range of recorded values. The economic importance of recreation is increasing in importance overall: more people are recreating more often, and willing to pay greater amounts to do so. The study from which these values are drawn indicates that they are growing faster than inflation, with the value of an outdoor recreational activity-day growing by about $\$ 1$ per year. ${ }^{115}$

The analytical steps FERC must take to describe the potential cumulative impacts on recreational services are well understood. For example, to determine the impacts on hiking, it first must identify all hiking trails that the Project would affect directly. Current information indicates it would intersect the Loyalsock Hiking Trail. Then, it must identify gas-well developments that also would interfere with each trail, estimate

\footnotetext{
115 Rosenberger, R. and J. Loomis. 2001. Benefit Transfer of Outdoor Recreation Use Values: A Technical Document Supporting the Forest Service Strategic Plan (2000 Revision). U.S. Department of Agriculture, Forest Service, Rocky Mountain Research Station. General Technical Report No. RMRS-GTR-72.
} 
the cumulative, potential impact on the number of hiking trips, and calculate the socioeconomic changes that would result. Table 5 shows the average consumer surplus associated with a day of hiking is nearly $\$ 90$ per person in the Northeastern United States. Additional data would provide the basis for estimating the change in expenditures that would accompany the changes in hiking on each trail, and the likelihood that hikers would shift their focus to other trails or to other activities.

Table 5. Consumer Surplus per Recreation Day for Various Recreation Activities (\$/Person/Recreation Day)

\begin{tabular}{lrrr}
\hline Recreation Activity & Northeast Mean & National Mean & \multicolumn{1}{c}{ National Range } \\
\hline Birdwatching & $\$ 41.69$ & $\$ 35.40$ & $\$ 6.94-\$ 93.84$ \\
Camping & $\$ 39.60$ & $\$ 44.48$ & $\$ 2.43-\$ 268.54$ \\
\hline Fishing & $\$ 38.99$ & $\$ 56.40$ & $\$ 2.49-\$ 665.96$ \\
General Recreation & $\$ 20.18$ & $\$ 41.98$ & $\$ 1.70-\$ 307.98$ \\
\hline Hiking & $\$ 89.92$ & $\$ 36.88$ & $\$ 0.48-\$ 313.40$ \\
\hline Mountain biking & $\$ 48.95$ & $\$ 88.24$ & $\$ 24.95-\$ 353.65$ \\
\hline Picnicking & $\$ 67.51$ & $\$ 49.59$ & $\$ 10.69-\$ 170.72$ \\
\hline Sightseeing & $\$ 145.23$ & $\$ 44.06$ & $\$ 0.78-\$ 250.88$ \\
\hline Swimming & $\$ 26.56$ & $\$ 51.05$ & $\$ 2.63-\$ 160.67$ \\
Wildlife viewing & $\$ 37.43$ & $\$ 50.66$ & $\$ 2.87-\$ 416.06$ \\
\hline
\end{tabular}

Source: Loomis, J. 2005. Updated Outdoor Recreation Use Values on National Forests and Other Public Lands. U.S.

Department of Agriculture, Forest Service, Pacific Northwest Research Station. General Technical Report PNW-GTR-658. 